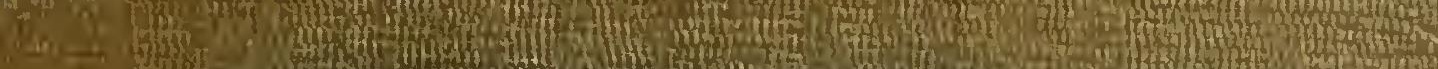

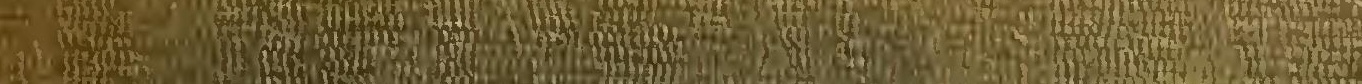
(2: ${ }^{2}$ of

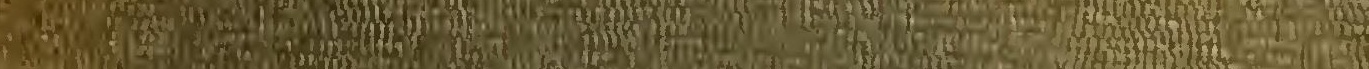

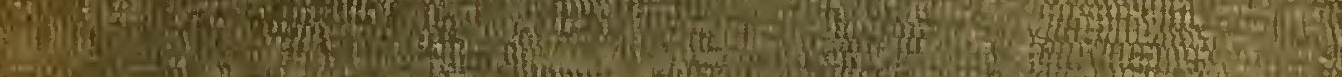

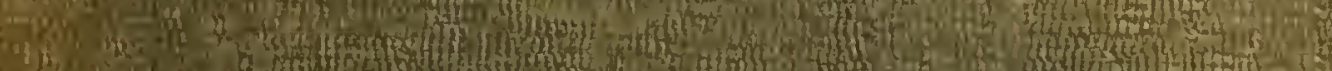

1) 5. 1.4.

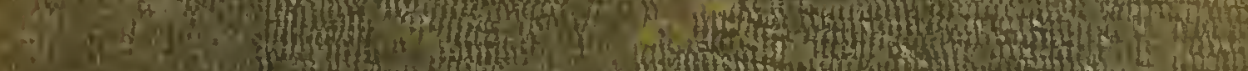

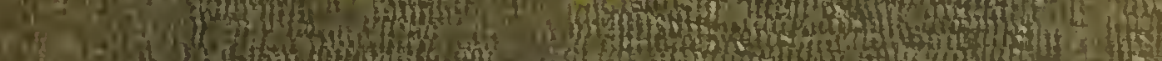

(1)

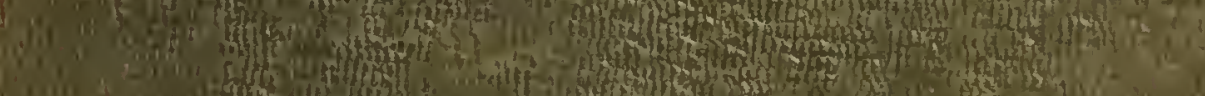

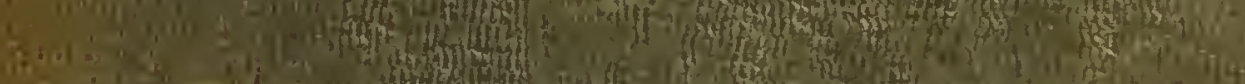

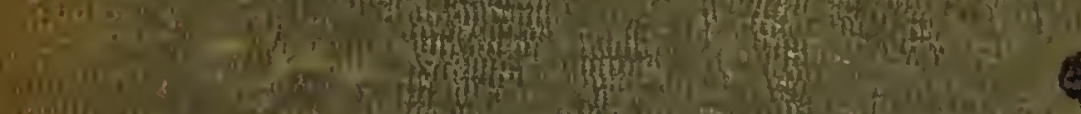

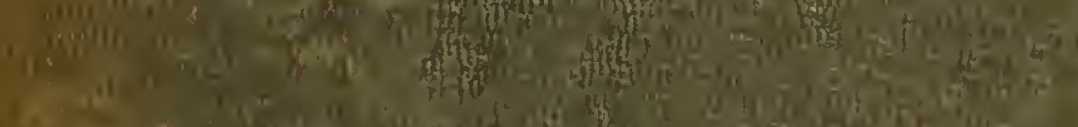

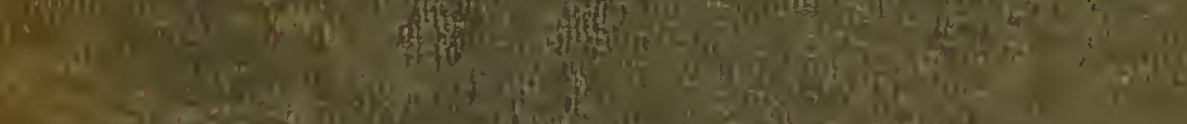
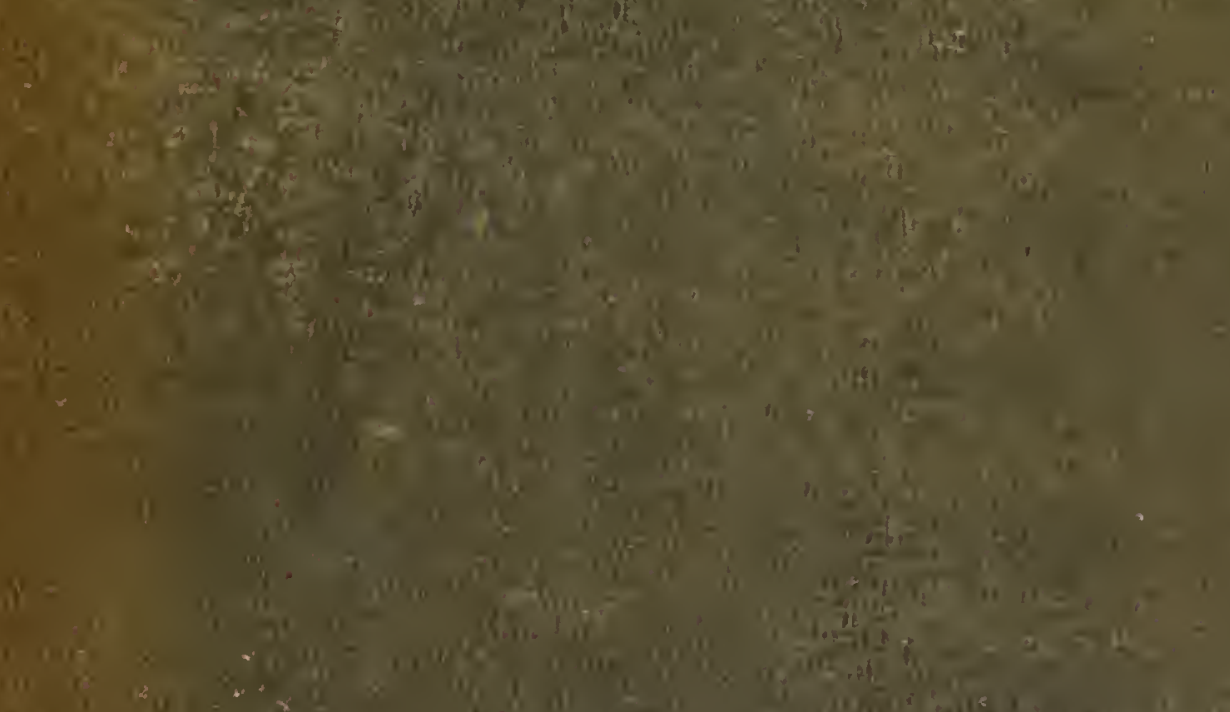

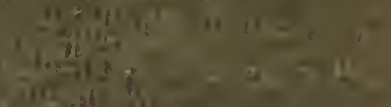

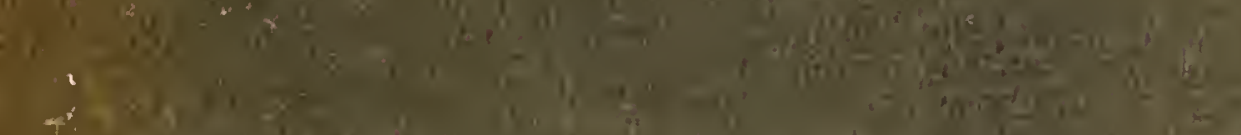

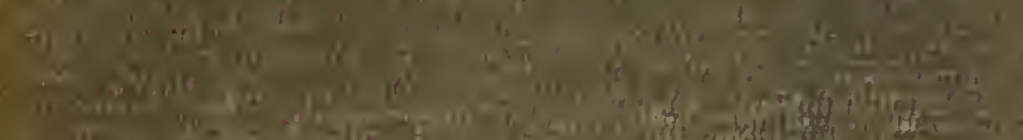

11.

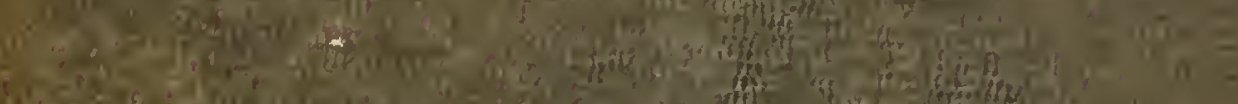

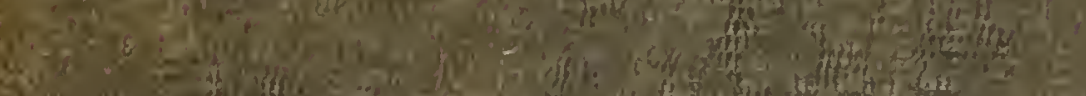

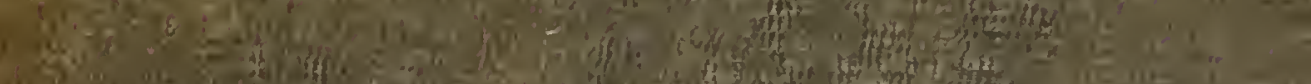

if 7 a

"n ${ }^{2}$ of

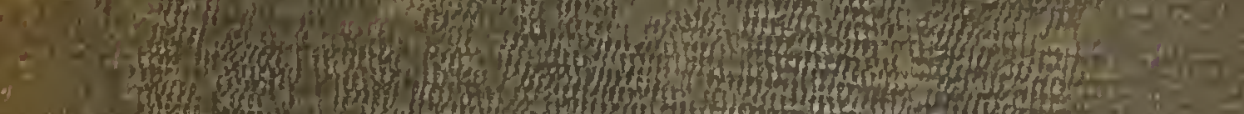

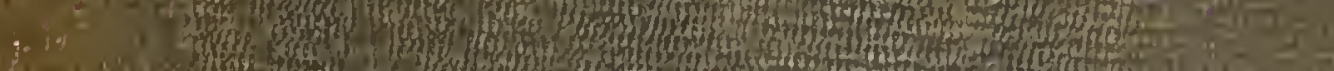

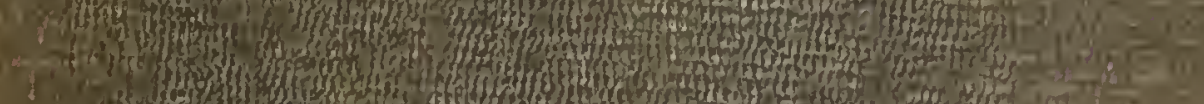

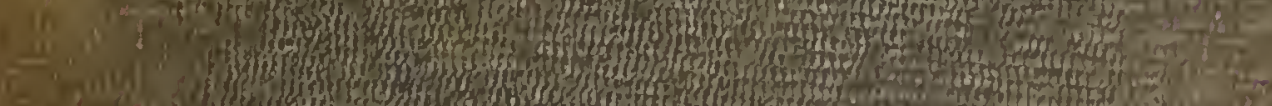

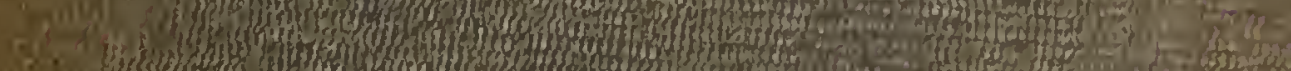

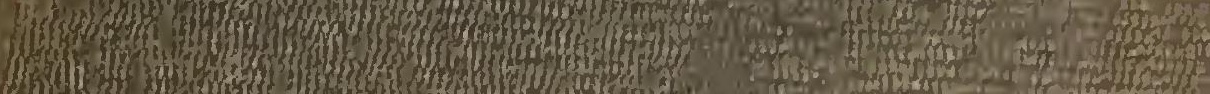
1.3. 11. (19) 

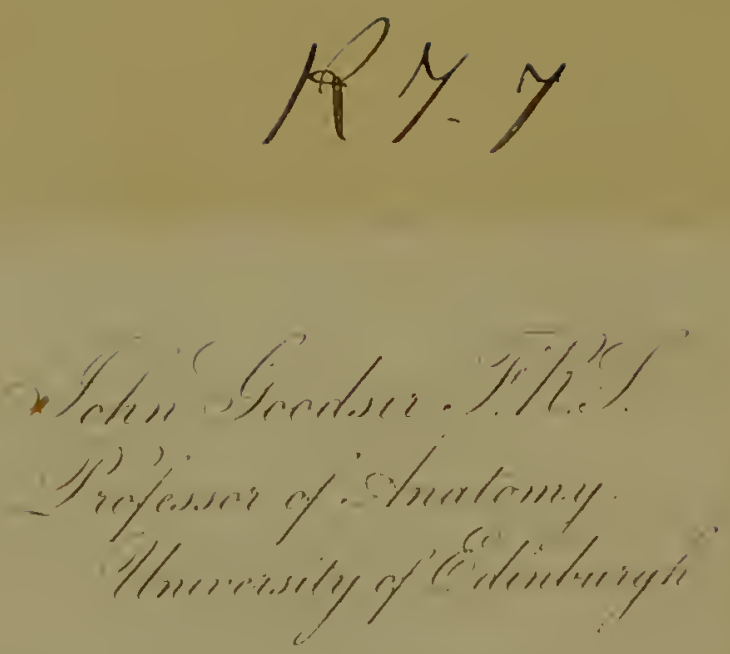

R.C.P. EDINBURGH LIBRARY

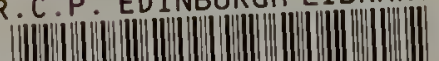

|. (n.

R27099P0236 





\section{$3+.2+2$}

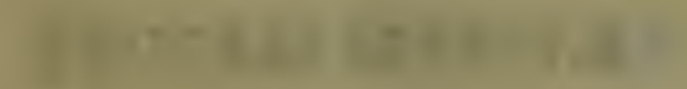

$$
1=
$$

alariad calmbialiss?

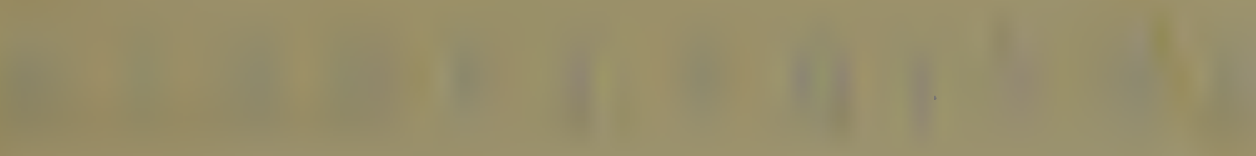

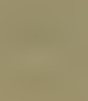

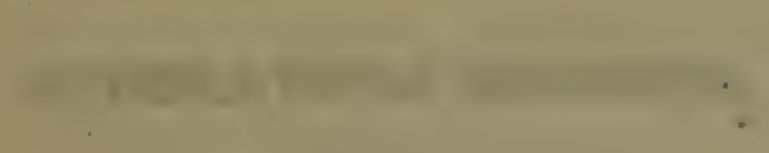

$$
\text { 1 } 1
$$

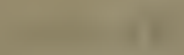

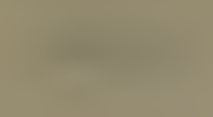




\title{
LEHR HCH
}

\author{
d e r \\ vergleichenden Anatomie.
}

Von

v. SIEBOLD und STANNIUS.

\author{
Zweiter Theil. \\ W i r b e $\mathrm{l} t \mathrm{~h}$ i e r e \\ H. Stannius.
}

Berlin.

Verlag von Veit \& Comp.

1846. 


\section{GEHIR UCH}

d e r

vergleichenden Anatomic

der

W I R B E L T II I E R E

von

H. S T A N N I U S,

Professor in Rostock.

\section{Berlin.}

Verlag von Veit \& Comp.

1846. 


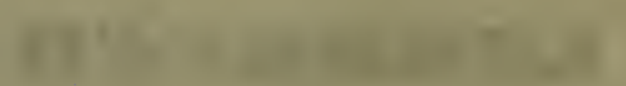

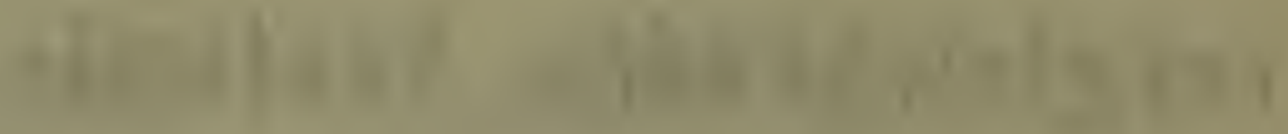

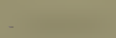

UIINAB THA HRIO

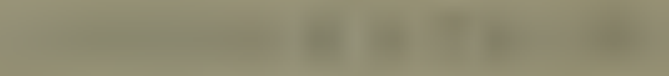

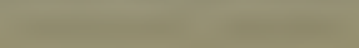

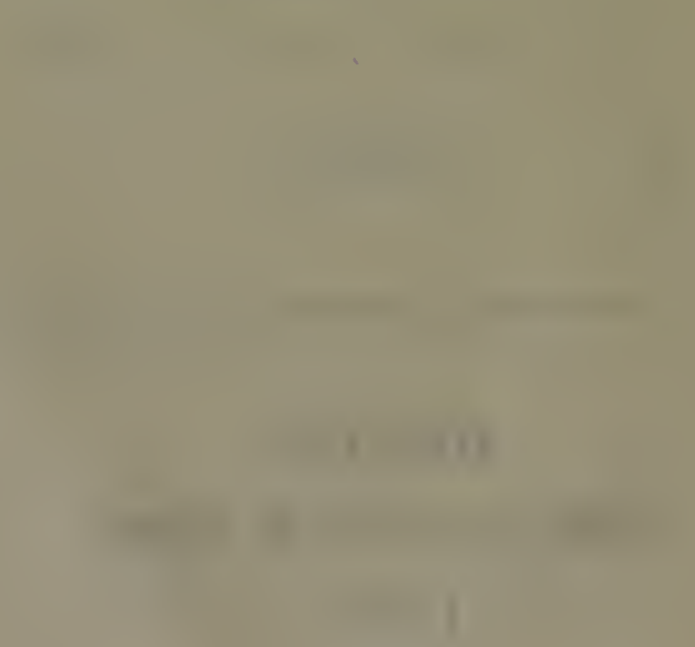




\section{Vorre d e.}

Vorliegendes Lehrbuch soll, durch kurze und gedrüingte Auffiihrung der wichtigsten Thatsachen und dureh Hinweisung auf die Literatur, Anfängern beim Studium der vergleichenden Anatomie der Wirbelthiere einen Stiitzpunkt geben, Lehrern aber einen mögliehst demonstrativen Vortrag - unter Ausschluss des leidigen Dictirens - erleichtern.

Es sehliesst sich an eine ähnliche Arbeit des Herrn Professor von Siebold über die wirbellosen Thiere. Ueber die getroffene Anordnung des Materials will der Verfasser mit Keinem, der sic anders gewïnscht läite, rechten; sie ward durch den Ansehluss an Herrn von 'Sicbold's Arbeit bedingt. An der Hand eines nach abweiehenden Prineipien entworfenen Inhaltsverzeichnisses wird leicht aueh ein anderer Weg bei der Benutzung des Buches für Studium oder Vortrag eingeselilagen werden können.

Entwickelnngsgesehichte und Histiologie mussten leider unberieksichtigt bleiben, dia sonst der Unfang des Buches die vom Verleger gesteckten Grenzen allzuweit übersehritten lïitte.

Gerne hätte der Verfasser Uebersichten und kurze Charakteristiken der Ordnungen und natïrliehen Familien der vier Wirbelthierelissen den anatomischen Darstellungen vorausgehen lissen, wïre es ihm, bei einem kü̈rglich zıgemessenen Materiale, ü̈̈glieh gewesen, in dieser Riehtung Besseres zu lieferı, als in ten meisten gangbaren Lehrbüchern der Zoologic zu finden ist. Wic 
Grosses in der grenimnten Beziehmug geleistet werden kann, beweisen J. Mäller's, naeh läigst hegonnenem Drucke dieses bereits in Jilue I\$44 abgefassten Buches, publicirte Arbeiten über die natïrlichen Fanilien der Fisehe.

Was den thatsaichlichen Inhalt des Buches anbelangrt, so hat der Verfusser nach Kräiften gestrebt, selbst zu priifen; bei dem immensen Unfange des Materiales kam er jedoeh immer unr in beschränktem Maasse der Antopsic sich rühmen. Gewöhulieh wurlen seine Quellen angeführt.

Der einflussreichen Erweiternngen unseres Wissens, welche uns im letzten Jahre, namentlich in Betreff der Anatomic der Fische, so reichlich zn Theil geworden sind, ist in den Nachträgen kırz gedacht worlen. Ansserdem sind für Seite 99 und 100 und für Seite 125 und 126 des ersten Heftes Cartons geliefert und anf diese Weise einige bedeutende Entdeckingen noeh benntzt und theilweise nuriehtige Angaben verbessert worken. Endlich hat der Verfasser hier der von ihm aufgefumdenen Thymus der Knochenfische (Teleostei Miill.) kurz Erwähnung gethan.

Mïge dies Buch seinen oben angedenteten $\mathrm{Z}$ weck nieht ganz verfehlen.

Rostock, im Januar 1846.

\section{H. Stannius.}




\section{Inhaltsverzeichniss}

nach den Systemen und Organen, unter Berucksichtigung der Zusätze.

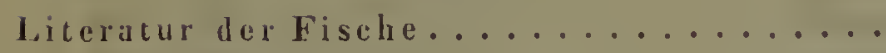

\begin{tabular}{rr}
\multicolumn{2}{r}{ Zusätze } \\
Seite- Seite \\
3 & 475 \\
129 & \\
248 & \\
339 & 481
\end{tabular}

\section{Vom Knochengerüste}

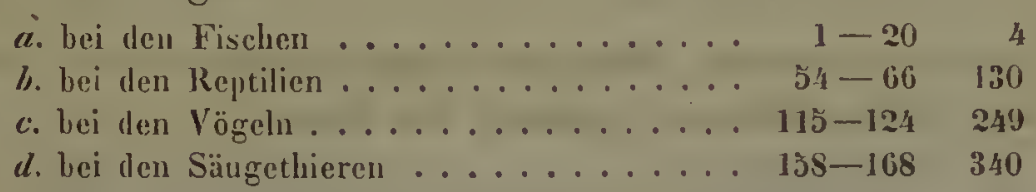

1. Vou der Wirbelsäule
a. bei den Fischen
$1-6$
$34 \quad 130$

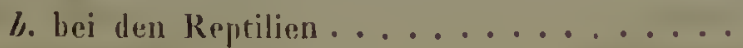
$116 \quad 250$

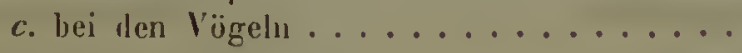
340

2. I onden Rippen
$\boldsymbol{a}$. bei den Fischen
l. bei den Reptilien...............
$7 \quad 13$
c. bei den $\mathbf{v o g e h n} \ldots \ldots \ldots \ldots \ldots$
รั5 135
$117 \quad 253$
$d$ bei deı Säugethieren............ $160 \quad 346$

3. Vour Scherle!

14. bei den Fischen .............8 8-15 14

Schleimrobrenknochen ihres Scheduls .

Kiefer.Gaumen-Apparat ........ 14-15 31

130

40


5. Vom Beckengeriuste

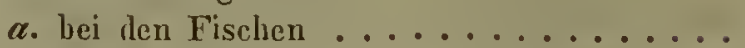

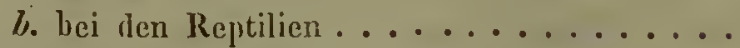

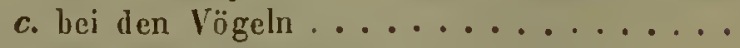

$d$. bei den Säugethieren .......... 163

140

$25 \%$

6. Vom Brustbeine

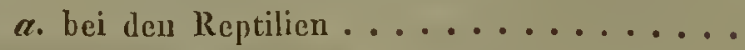

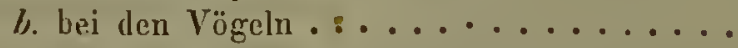

c. bei den Säugethieren .......... $161 \quad 349$

254

7. Von den Knochen der Extremitäten

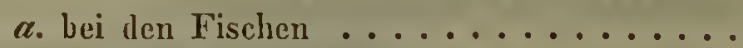

Unpaare Flossen der Fische .......

b. bei den Reptilien..............

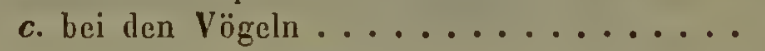

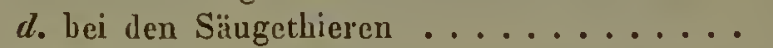

8. Vom Zungenbeine

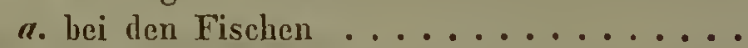

b. bei den Reptilien ...............

c. bei den Vögeln ...............

$16 \quad 38$

$6 ว-66 \quad 165$

$124 \quad 268$

d. bei den Säugethieren ...........

$168 \quad 367$

9. Vom Skelete des Respirations-Apparates

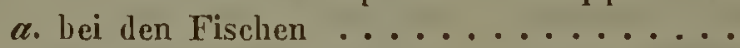

b. bei den Reptilien.

$17-18 \quad 39$

$65 \quad 165$

II. Von den iusseren Hautbedeckungen und dem Absonderungs-Apparate der Haut

$a$. bei den Fischen ........... Schleimröhrenknochen ihres Schedels ..

Z. bei deu Reptilien .............

c. bei den Vögeln ............

III. Von den Muskeln

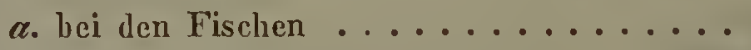

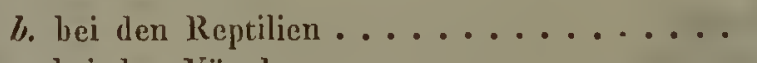

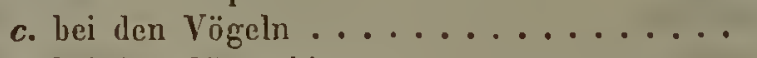
d. bei den Säugethieren
22
$68-76$

IV. Vom Nervensysteme und von den Simnes-

\section{Organen}

a. bei den Fischen ............. $\mathbf{2 3 - 3 3}$

๖. bei den Reptilien............. $77-86$

c. bei den Vögeln .............. 131-138

d. bei den Säugethieren .......... 179-185

1. Von den Centralorganen des Nervensystemes

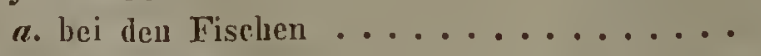

b. bei den Reptilien..............

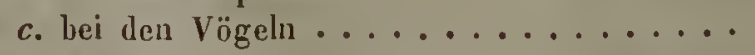

d. bei den Säugethieren 
2. Vom peripherisehen Nervensysteme
$a$. bei den Fischen ............ $26-28$
b. bei den Reptilien............ $79-83$
c. bei den Vögeln ............. 133-135
d. bei den Säugethieren ........... $182 \quad 393$

$\$ \quad$ Seite $\begin{array}{r}\text { Zuxätze } \\ \text { Scite }\end{array}$

3. Von den Geruehsorganen
$a$. bei den Fischen
b. bei den Reptilien ..............
$84 \quad 195$
c. bei den Vögeln ...............
$136 \quad 287$
d. bei den Säugethieren ...........
$183 \quad 396$

478

4. Von den Gesichtsorganen

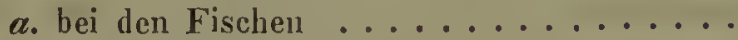

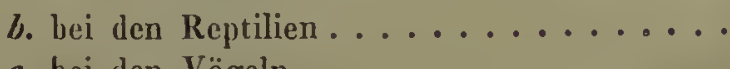

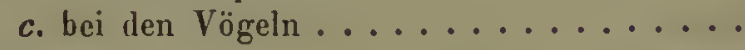
$137 \quad 289$
d. bei den Säugethieren
$184 \quad 400$

๖. Von den Gehörorganen

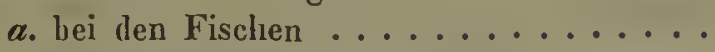
$31-32$
80
$86 \quad 200$
๖. bei den Reptilien.............
$138 \quad 293$
c. bei den Vögeln ..............
d. bei den Säugethieren ...........
185405

478

482

6. Von den electrischen 0 rganen

der Fische ...............

\section{Vom Verdauungs-Apparate}

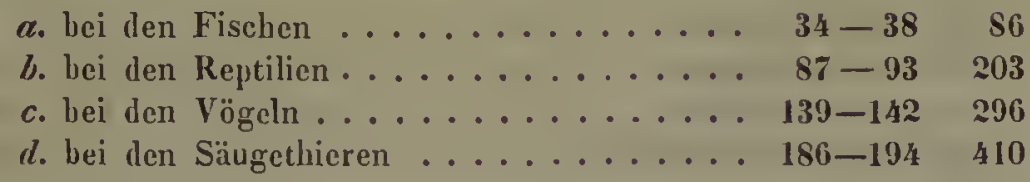

1. Vom Gebisse

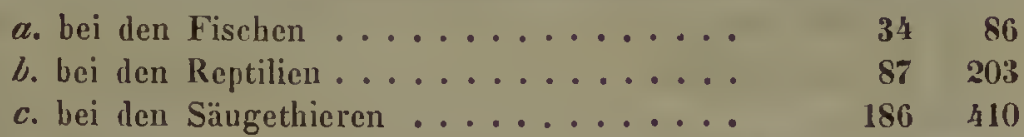

2. Von der Mund. und Rachenhöhle, von den in sie mündendeu Drüsen und $v 0 u$ der $\mathrm{Zunge}{ }^{\circ}$ )

$\boldsymbol{a}$. bei den Fischen ..............

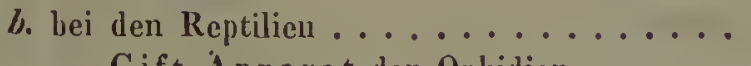

Gift-A pparat der 0phidier .....

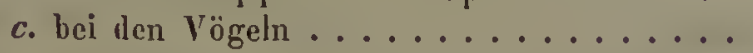

d. bei den Süugethieren $\ldots \ldots \ldots \ldots$

3. Voll der Speiserölre, dem Magen und lem Darmcanale

$a$. bei den Fisehen .............

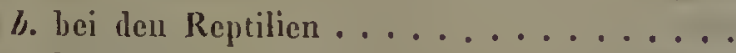

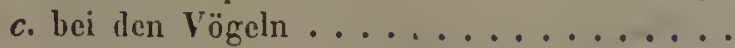

d. bei den Säugethiereı 
4. Von den Appeudices pyloricae und dem

\section{Paucreas}

der Fische ............... 37

Vour Pancreas

$a$. bei deu Reptilien ..............

乙. bei den Vögelı .............

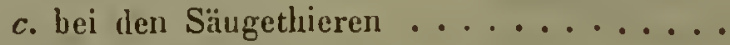

$92 \quad 212$

$142 \quad 305$

$194 \quad 432$

5. Von der Leber

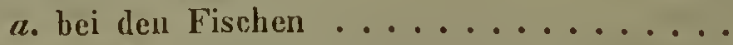

$83 \quad 96$

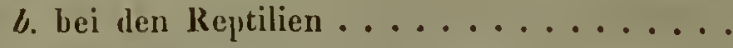

91211

c. bei den Vögelı ...............

$141 \quad 303$

d. bei den Säugethiereu $\ldots \ldots \ldots \ldots \ldots$

$193 \quad 430$

6. Vou der Milz

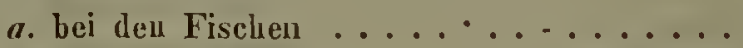
b. bei den Reptilien ..............
c. bei den Vügeln ...............
d. bei den Säugethieren $\ldots \ldots \ldots \ldots$
$142 \quad 305$
$194 \quad 433$
479

3

\section{Vom Gefässsysteme}

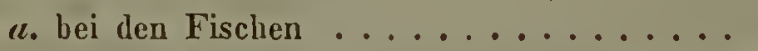
४. bei den Reptilien ..............
c. bei den Vögeln ...............
$39-45 \quad 98$
$94-101 \quad 213$
d. bei den Säugethieren
$143-147$
306
$195-202$
434

1. Vou Herzen

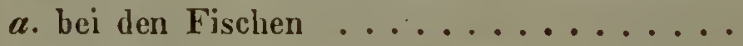
$\begin{array}{rr}40 & 99 \\ 95-97 & 214 \\ 143 & 306 \\ 195 & 434\end{array}$

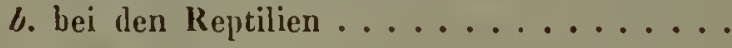
c. bei deu $V_{0 ̈ g e h n} \ldots \ldots \ldots \ldots \ldots \ldots$

2. Vour respiratorischen Gefässysteme

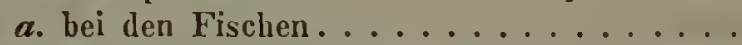

๖. bei den Reptilien..............

$41 \quad 10$

479

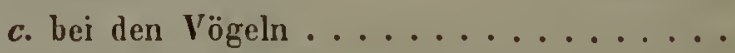

95 u. 100 214u.

222

$146 \quad 313$

d. bei den Säugethieren........... $201 \quad \mathbf{2 4 6}$

3. Von den Körperarterien

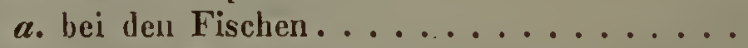

b. bei den Reptilien ..............

$42 \quad 102$ 
6. Vom lymphatisehen Gefäissysteme

a. bei den Fischen ............. $45 \quad 109$

I). bei den Reptilien............. 101223

c. bei den Vögeln ............... $147 \quad 313$

d. bei den Säugethieren........... $202 \quad 447$

VII. Von den pneumatischen Gebilden, dem Respirations-Apparate und den StimmOrganen

a. bei den Fischen ............. 51u.46- 119 u. 479

7. bei den Reptilien............ 102-105

c. bei den Vögeln .............. 148-152

d. bei den Säugethieren

$203-204$

1. Von der Schwimmblase

der Fische ...............

2. Von len Respirationsorganen

der Fische............. 46-48

3. Von den Kieınen

der Reptilien ...............

4. Von der Luftröhre, den Bronchien und Lungen

$a$. bei den Reptilien............. 103-104

b) bci den Vögeln ................

$c$. bei den Säugethieren

5. Vom oberen Keblkopfe

$a$. bei den Reptilien..............

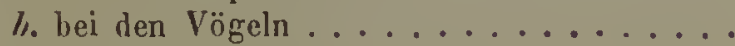

c. bei den Säugethieren ...........

$203 \quad 448$

6. Vom unteren Kehlkopfe

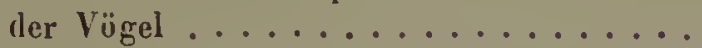

VIII. Von den Halnorganen
a. bei den Fischen ..............

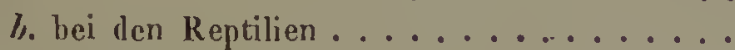
c. bei den Vögeln ...............
d. bei den Säugethieren

\section{Von den Blutgefïssilrïsen und Neben-}

153330

$206 \quad 456$ nieren

a. bei den Fischen

Thyinus

Nebennieren

b. bei den Reptilien ............. 108-109

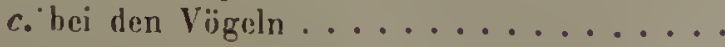


X. Von den Geschlechtsorganen

$$
\text { \$ Seite } \begin{aligned}
& \text { Zusätze } \\
& \text { Seite }
\end{aligned}
$$

a. bei den Fischen ............. $52-53 \quad 123 \quad 480$

b. bei den Reptilien............. 110-114 240

c. bei den Vögeln .............. 155-157 333

d. bei den Säugethieren .......... 207-215 459

Von lier Cloake

a. der Reptilien ............... $114 \quad 246$

b. der Vögel ............... $157 \quad 337$ 


\section{ZWEITER THEIL.}

\section{Vergleichende Anatomie der Wirbelthiere.}




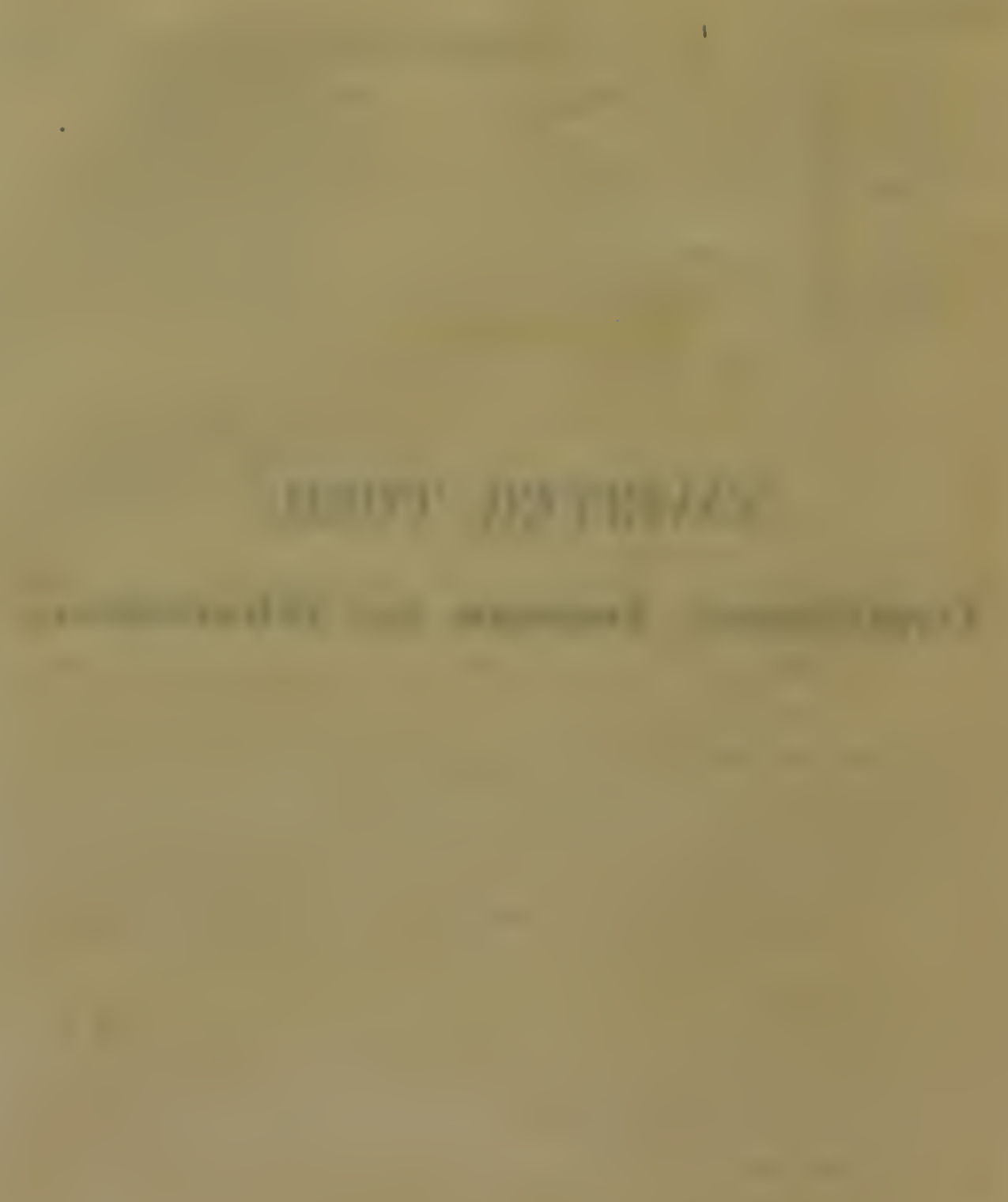




\section{Eistes Buch. D i e i s l e.}

L i t e r a t u r.

Curier et Valenciennes, Histoire naturelle des poissons. Paris 1828-1844. Noch nicht vollendet. Eine Uebersicht der Anatomic der Fische, mit treff. lichen Abbildungen zur Erläuterung des Baues von Perca fluviatilis, findet sich in ersten von G. Cuvier bearbeiteten Bande. Zahlreiche anatonische Notizen sind der Charakteristik der einzelnen Gattungen und Arten beigegeben. Johannes Müller, Vergleichende Anatomie der Myxinö̈len. Berlin 1835 ff. 4. Die wichtigste anatomische Monographie, Trelche wir besitzen. InI erstell Bande wird die Osteologie und Myologie der Myxinoïden nnter Vergleichung der Cyclostomen und der übrigen Ḱnorpelfische abgehandelt. Osteologische Nachträge sind in der vergleichenden Neurologie enthalten; die übrigen $A \mathrm{~b}$. theilungen behandeln das Gehörorgan. der Cyclostomen und das Gefässsystem aller Fische.

Müller's Vorgänger in der anatomischen Untersuchung der Cyclostomen war: Hein rich Rathke, Bemerkungen über den innern Bau der Pricke. Danzig 182j. 4. - Ueber den Bau des Querders (Ammocoetes) in seinen Beiträgen zur Geschichte der Thierwelt, Bd. 4. Halle 1827. 4. - Bemerkungen über den Bau des Amphioxus lanceolatus. Königsberg 1841. A.

Müller unil Retzius, Ueber die Anatomie des Branchiostona lubricum in den Monatsschriften der Berl. Akademie der Wissenschaften. Dec. 1841. 8. unil Muiller's Archiv, 1842. S. 218 des Jahresberichtes ${ }^{1}$ ).

Ueber die Plagiostomen ist zu vergleichen die Monographie von J. Henle, Ueler Narcine, eine neue Gattung electrischer Rochen. Berlin 1834. 4.

Ueber den Stör: Karl Ernst von Baer, Berichte von der königlichen anatomischen Anstalt zu Königsberg. Zweiter Bericht. Leipzig 1819. 8.

Ueber Lepidosiren: Bisch off, Lepidosiren paradoxa, anatonisch untersucht und beschrieben. Leipzig 1S40. A. und R. 0 wen, über Lepidosiren annectens in den Transactions of the Linnean Society. Lond. 1839.

Die Osteologie der Fische behandeln: Rosenthal's Ichthyotomische 'Tafeln. Berl. 1839. 4. - A gassiz, Recherches sur les poissons fossiles. Neuchatel 18331843. 4 .

Reich an Beobachtungen über die anatomischen Verhältnisse vicler Fische ist Alexander Monro, The structure and plysiology of Fishes explainel ant

1) Nachträglich Ist noeh Müller's ausführliche Arbcit ïber Branchiostoma zu rrwaiburu: Ueber den Bau und de Lebenserscheinungen des Brauchiostoma lubrieum. Berlin 18.4. 4. Mit 5 Kupfertafeln. 
compared with those of man and other animals. Edinb. 1785. fol. Uebersetzt von Schneider. Leijzig 1787. 4.

Retzius, Olsservationes in inatomian chondropterygiormn, praecipue Squali et Rajae generum. Lundae 1819. 4. - Stannius, Syubolac ad anatouriam piscium. Rostock 1839. 4. - Wellenbergh, Observationes anatomicar de Ortuagorisco Mola. Lugd. Bat. 1840. 4.

\section{Erster Abschnitt.}

\section{I om Ku ochengerïste.}

\section{Von der Wirbelsïinle.}

§. 1.

Die Wirbels iule der Fische besteht entweder aus einer ununterbrochenen, meist cylindrischen Rückensaite (Chorda dorsalis) von zelliger oder faseriger Textur l), die von fibrös-häutigen oder knorpeligen Hiillen umschlossen wird, oder aus einzelnen, gewöhnlich getrennten, nicht selten jedoch reihenweise unter einander verschmolzenen, bald knorpeligen, bald ossificirten Wirbeln. Aufwirts gerichtete. Fortsetzungen der äusseren fibrösen Scheide der Charda dorsalis oder auf Kosten der letzteren entstandene, bald knorpelige, bald ossificirte obere Wirbelbogen bilden in dem einen, wie in dem anderen Falle einen oberhalb der Chorda oder der Wirbelkörper gelegenen, zur Umschliessung des Ruickenmarkes bestimmten Canal. Abwärts gerichtete Fortsetzungen der äusseren fibrösen Scheide oder ausgebildetere solide untere Wirbelbogen sind wenigstens in der Caudalgegend stets deutlich nachweisbar, finden sich aber meistens 2 ) liings der ganzen

1) Dic Chorda dorsalis der Fische hat in der Regel ein gallertartiges Ansehn und besteht aus durchsichtigen an einander stossenden, gewöhulich gestreckten Zellen, welche Pflanzenzellen schr ähnlich sind. Nach den Beobachtungen von Goodsir und Mïller crmangelt jedoch die Chorda dorsalis von Branchiostoma Inbricun dieser Zellen und zeigt einen faserigen Ban. Die Faserulassen lösen sich leicht in blätteriger Form ab. Auch in der Mitte der gallertartigen Chorda dorsalis der Myxinoüden und Petromyzonten ist ein fuseriger Faden vorbanden. Bei Lepidosiren, den ich nach eigner Anschanung in Wiener Museun fiir cinen Fisch halten muss, scheint die Chorda ebenfalls mehr eine faserige, als zellige 'Textur zn besitzen. Die gallertartige Consistenz und der zellige Bau dïrfen also nicht mehr als charakteristische Merkmale der Chorde dorsalis gelten. - Nilr aus der Classe der Fische sind bis jetzt Thiere bekannt geworden, bei welchen die Chorda dorsalis während der ganzen Lebensdauer als continuirliches Rohr sich erhält, wie dies namentlich bei den Cyclostomen, Sturionen, Chimären und Lepidosiren der Fall ist. Sie ist dagegen voriibergehend bei den Embryonen aller höhereı Wirbelthicre bcobachtet worlen, wo sie als Vorläufer der Wirbelsäule erscheint, aber durch die sich entwickelnden Wirbelkörper allnälig verdrängt wird.

2) Nur die Classe der Fische besitzt auch läings der Rumplfhöhle vüllig ent- 
Wirbelsaiule. In der Caludalgegend bilden sie stets einen zur Linschliessung der Arteria und Vena crumlulis bestimmten Camal; sind sie lings der ganzen Wirbelsiule entwickelt, so tragen sie immer, und zwar gewöhnlich sammut den an ihne'n befestigten Rippen, zur Bildung und Unselıliessung der Bauchhöhle wesentlielı bei. Man hat daher die aufwiirts geriehteton, dins liuiekenurark unsschliessenden fibrösen oder soliden Thrile als Neurapophyses die alsteigenden, die Gefüsse umfarsenden als II ilematapophyses zwecknässig bezcichnet.

\section{\$. 2.}

Bei den einzelnen Fannilien der Fisclıe bietet die Wirbelsäule merkw ïrdige perennirende Entwickelungs-Verschiedenlıeiten dar, deren genauere Kenntniss von höchster Wichtigkeit ist.

1. Bei den am niedrigsten organisirten Fisehen, namentlich bei Branchiostoma, bei den Myxinoüden und bei Ammoeoetes, ist rine faserige odler gallertartige Chorda dorsmlis vorhanden, welehe ron eincr doppelten fibrös-hä̈utigen Hülte ungeben wird. Die äussere dieser beiden fibrösen lläıte verlängert sich nach oben und hildet oberlıalb der Chorda eine zur Aufnahme des Rückenmarkes bestimnite Röhre. Nichdem sie hicrauf einen zweiten Canal gebildet, tritt sie als einfaches fibröses Septum zwischen den Scitenmuskeln aufwärts. Eine abwärts steigende Fortsetzung der äusseren Haut, welche nur in der Candalgegend dentlich erkennbar ist, bildet einen Canal fiir die Areria und Vena caudalis und setzt sich gleichfalls in ein fibröses Septum fort. Die häutigen Ungelungen der Charilu dursalis ermangeln jeder Spü ron knorpel-oder knochenbildung und höehstens finden sich zarto ringförmige Streifungen an ihnen vor.

2. Auf einer höheren Bildungsstufe tritt an der fibrösen Seheide der Chorda dorsalis und inshesondere an der von ihr gebildeten zur Iufnahme des Riickenmarkes bestimmten Röhre die Entwickelung ron Knorjelsubstanz auf. Jieses Verhalten zeigt die Gattung Petromyzon. 1ls Rudimente der oberen Wirbethogen erscheinen hier an der Aussenfläche der Rückenmarkröhre paarige knorpelige Leisten. Die Anlagen unterer Winkelbogen erkennt man in zwei seitlichen, rom unteren Theile der Scheide der Chorila absteigenden, kantigen, ununterbrochenen Lïngsstreifen, welche einzclne eingesprengte Knorpelkörperchen "nthalten und in der Schwanzgegend sieh vereinigen, un cinen Canal zur Aufuahure der Arteriu und Verse caudalis zn bilden ${ }^{1}$ ).

wickelte, einen Canal einschliessende untere Wirbelbogensclienkel; bei den ineisten höhereı Wirbelthieren beschrïnkt sich das Vorkommen so entwickelter unterer Dornfortsütze auf die Schwanzrgegend.

1) Oberhalb des Rückemmarkrohres liegt bei den Myximölen nnd Petromyzonten eine ans schwärølichem Fettzellgewebe bestehende Masse, welche von einer fibrïsen Scheide, einer Fortsetzurıg derjenigen, die das Rïckennark einschliesst, ungeben wirl. - Richtung und Ausdehnnıg derjenignn Linornelstreifen, 
3. Eine weitere Entwickelung ist bei den Sturionen und bei Polyodon dadureh gegeben, dass aussen an der fibrösen Scheide der Chorda dorsalis knorpelige, aus melıren Stiueken bestehende obere und untere Wirbelbogen sich entwickelt haben. Beim Störe sind die oberen Wirbelbogen von den unteren - mit Ausnahme des vordersten Abschnittes der Wirbelsïule, wo sie confluiren und dadurch die zusammenhangende corticale Schicht der Wirbelkörper bilden, - durch einen zwischen beiden liegenden, häutig gebliebenen Abschnitt der fibrösen Scheide der Chorda getrennt. Die oberen Wirbelbogen bilden zuerst ein Dach für das Rückenmark, weiehen aber dann wieder aus einander zur Bildung eines Canales für ein fibröses Lüngsband. Die unteren Bogen besitzen in der Rumpfgegend nicht nur continuirliche rippentragende Querfortsätze, sondern bilden auch in Verbindung mit aeeessorisehen seitliehen und unteren Sehaltknorpeln einen unterhalb der Chorda gelegenen, zur Aufnahme der Aorta bestimmten Ganal. Erst in der Sehwanzgegend treten dann auch die Querfortsätze der unteren Wirbelbogen zur Bildung eines neuen die Fortsetzung der unterer Itohlader aufnehmenden Canales zusammen 2 ).

4. Die Bildung der Chimären ${ }^{3}$ ) unterseheidet sich von derjenigen der Sturionen hauptsäehlieh durch den Umstand, dass in der Dieke

welche die oberen Wirbelkörper reprïsentiren, sind in den rerschiedenen Regio. nen der Wirbelsänle von Petronyzon marinus etwas verschieden. Im vordersten Abschnitte der Wirbelsäule divergiren die einander entsprechenden Schenkel der rechten und der linken Seite zienlich bedeutend und besitzen daher eine schwache Aelınlichkeit mit Querfortsätzen, wähırend sie weiter hiuterwärts vermöge stär. kerer Convergenz mehr den Charakter oberer Bogenschenkel an sich tragen.

2) S. die genaueren Angaben bei Baer im zweiten Bericht von der anatom. Anstalt zu Königsberg, 1819, 8. B a e $r$ ist es iiberhaupt, der die Verlältnisse der Wirbelsäule zuerst klar aufgefasst hat, worin Müller ihu gefolgt ist. - Ein senk rechter Durchschnitt der Schwanzgegend der Wirbelsäule lässt daher fünf Canäle erkennen, ron denen der oberste für das fibröse Längsband, 'der zweite für das Rückenmark, der dritte für die Chorda dorsalis, der vierte für die Aorta unıl der fünfte für die Schwanzvene oder untere Hohlader bestimmt ist. Die letzten bleiben durch die zwischen ihneu sieh erhaltenden unpaaren unteren Schaltknorpel getrennt.

3) S. Müller, Vergl. Nenrol. d. Myxinoüden, S. 71. Die Zahl der in der frbrös-Läutigen Scheide ter Chorla liegenden ossificirten Ringe ist bei den Chimüren viel grösser als die ปler paarigen Bogenstïcke, und es koum etwa vier Ringe auf den einem einzigen Wirbel entsprechenden $A$ bschnitt des Rückgraths. - M ïller macht a. it. 0 . auf die Wichtigkeit dieser Thatsache aufnerksau. Sie bestätigt und erläutert die zusummengesetzte Eitstehungsweise des Wirbelkörpers, der eine innere und eine äıssere Schicht besitzt. Die corticale Schicht entsteht durch Verschurelzung der beiden Bogenschenkel einer Seite; die centrale durch eine eigene Ossification der Scheide der Chorda. Vgl. \$. 3. - Die oberen Wirbelbogen der Chimären bilden nur eine znr Aufnahme des Rückenunarkès bestimunte Röhre, ohne wie bei den Stören später wieder auseinander zul weiehen, un ein fibröses Längsband 211 unsehliessen. 
der Scheide der Chorda dorsitis zarte ossifieirte Ringe vorkommen, welehe bei den Stören mangeln. Uebrigens sind auch hier die oberen knorpeligen Wirbelbogen von den unteren, init Ausnahme des vordersten Absehnittes der Wirbelsäule, vollständig getrennt. Die unteren Wirbelbogen sind in der Rumpfgegend durch zwei von dem unteren Theile der Scheide der Chorda abgehende Knorpelleisten angedeutet, die durch Querfurehen so viele Abtheilungen erhalten, als Wirbelkörper vorhanden sind.

ร. Bei Lepidosiren 4 ist die Chorda dorsalis zunäehst von einen die Summe der Centraltheile der Wirbelkörper repräsentirenden eontinuirliehen Knorpelrohr umsehlossen. Dieses letztere wird wieder von einer fibrösen Seheide umgeben, und nur von dieser gehen die hier ossifieirten oberen und unteren Wirbelbogenschenkel aus, welehe von cinander völlig getrennt bleiben.

6. Bei mehren II aien, namentlich bei Hexanchus und Heptanchus, bildet dic fibrös-knorpelige Seheide der Chorda dorsalis ein Continuum, an welehem äusserlich keine Abtheilung in Wirbelkörper sieh erkennen lässt, deren Anzahl man nur naeh derjenigen der abgehenden paarigen Bogenstueke bestimmen kann. Die Chorda dorsalis selbst stellt aber kein gleiehmässiges Continuum mehr dar, vielmehr ist sie dureh quere membranöse, mit einer Centräöffnung versehene Septa 5), welehe im Inneren jener Seheide sieh entwiekelt haben, von Punkt zu Punkt beträchtlich eingesehniirt worden.

7. Bei den übrigen Plagiostomen und bei den $\mathrm{Kn}$ ochenfisehen ist die Chorda dorsalis dureh die vollständiger ausgebildeten, disereten, bald knorpeligen, bald völlig ossificirten Wirbelkörper grossentheils verdrängt und ihre Continuität ist oft gainzlich unterbroehen. Die einander correspondirenden Fläehen zweier Wirbelkörper besitzen fast immer eonische oder beeherförmige Vertiefungen, in welehen die Ueberreste der beim Embryo eortinuirlich gewesenen Chorda dorsalis als gallertartige Masse sich vorfinden. Häufig stehen indessen die in den entgegengesetzten Vertiefungen eines Wirhelkörpers eingeschlossenen Ueberreste der Chorda noeh mit einander

4) S. die Abbildu. bei Bischoff in d. a. Selır. Ich kann Bisehoff nielit beistimmen, wenn er die unteren rippenartig verlängerten Bogenschenkel als Rip. pen hezeichnet. Da diese sogenannten Rippen gegen die Schwanzgegend hin allmälig convergiren und an Schwanze in wirkliche Seitenstïcke des unteren Schwanzcanales siclt unwandeln, sind sie nieht blos als Rippen, sondern als rip. penartige untere Bogenschenkel zn betrachten. - Uebrigens finden sich, wie auch Bisch off angibt, an der Schlusslinie der oberen wie der nnteren Bogensehenkel getrennte Schlussstücke: Processus spinosi superiores und inferiores.

5) Jedes Septum entspricht der Mitte eines ansgebildeten Wirbelkörpers oder der Gegend des Centralcanales, welcher die eonischen Vertiefungen der rorderen und hinteren Fläche eirres Winkels verbindet. Vgl. Mïller bei A gassiz, Poiss. foss. Vol. 3. p. 360 sqq. tal. 40. b. 
in Verbindung mittelst eines Längscanales, welcher durch die Mitte.der Wirbelkörper sich hindurehzicht.

8. Vor allen bis jetzt untersuchten Fischen zeichnet sicli endlich die Gattung Lepidosteus (i) dureh den Umstand aus; dass jeder VVirbelkörper, statt der sonst vorn und hinten vorkommenden conischen Vertiefungen, vorn einen runden Gelenkkopf und hinten eine wirkliche Gelenkhöhle besitzt.

[Man vgl. über die in diesem Paragraphen enthaltenen Thatsachen die detaillirten Angaben von Müller, Vergl. Anatomie d. Myxinoïllen Th. 1. - S. auch Sehultze in Me ekel's Archiv f. Physiol. Bd. IV.]

§. 3.

Jeder Wirbel derjenigen Fische 1), bei welchen dic Scheide der Chorda dorsalis nebst ihren aufwärts und abwärts gerichteten Fortsetzungen nicht blos bäutig bleibt, besteht genetisch aus fünf Stiicken: 1) einem unparen centrale Stucke, dein Kerne des Wirbelkörpers, 2) dem aus zwei Schenkeln zusammengesetzten oberen Bogen und 3) dem gleichfalls aus zwei Stiucken bestehenden unteren Bogentheile 2 ). Jeder Wirbel besitzt also ausser seinem Körper einen oberen Bogen und eineu unteren Bogen, oder dessen nicht zur Schliessung gelangte paarige Schenkel. Verhältnissmässig selten erhalten sich die oberen und unteren Stücke im ausgewachsenen Thiere als gesonderte Theile ${ }^{3}$ ); meistentheils verschmelzen sie nämlich friihzeitig mit dem Centralstücke des Wirbclkörpers, das auf Kosten der urspriinglichen Scheide der Chorla dorsalis sich entwickelt hat. Geschieht diese Versehmelzung vollständig ${ }^{4}$ ), so wird das unpaare Centralstück

6) Blainville hat auf diese merkwürdige, bisher isolirt dastehende Thatsaehe zuerst aufinerksam gemaeht. S. die Abbild. bei Agassiz, Poissons foss. Vol. 2. part. 2. tab. 1.

1) In diese Categorie gehören besonders die Plagiostomen und Knochenfisehe.

2) Vgl. hierüber besonders J. Mïller, Vergl. Neurologie der Myxinoïden. Berlin 1840. S. 64 ff. und desselben Verfassers Abhandlung über die Wirbel der Haie in A gassiz, Poissons fossil., Vol. 3. 1) 360 sqq. S. auch Vogt, Embryologie des Salmones. Soleure 1841. 8. p. $107 \mathrm{sqq}$.

3) Bei den Cyprinen, den Cytharinen, den Characinen, den Salmonen, dem Hecht und Polypterus erhalten sich die unteren Stüeke während des ganzen Lebens als gesonderte Knoehen; die oberen Stücke anch beim Hecht und an den vorderen Wirbeln der Cyprinen, so wie bei Polypterus Bichir. Naeh $\Lambda$ gassiz Untersuchungen muss aueh bei allen fossilen Fischeu aus der Abtheilung der Ganoülles diese Trennung der unteren Bogen vorhanden gewesen sein.

4) Diese Versehmelzung hat oft nur sehr unvollständig Statt. So ist bei melıren Haien der innere Centraltheil der Wirbelkörper allein ossificirt, z. B. bei Scymnus, Acauthias, Centrina und in Unkreise dieser Centralossitieation liegt eine die Bogentheile verbindende Knorpelmasse. Naelı Miiller's Beobaehtumg ist bei Xiphias gladius der eeutrale, die hohlen Faecten begrenzende Theil des Wirbelkörpuers selbst im erwaelıseneu Zustande grossentheils vom cortiealen stärkeren Theile des Wirbelkörpers getrennt und steekt darin wie in einem Etuí. 
dureh eine den beiden Bogen angehörige linochenkruste unwaclsen und vereinigt sich mit letzterer auf das innigste, dann nimult also der peripherisehe Theil des Wirbelkörpers seinen Ursprung aus der Verwaclssung der paarigen oberen und unteren Wirbelstücke. Dic oberen Stiicke convergiren, indem sie aufsteigen, und bilden meistens allein, selten in Verbindung mit anderen accessorisclien Stücken (Ossibus oder Cartilaginilus intercalaribus. ${ }^{5}$ ), einen Canal zur Aufnahme des Rükkenmarkes. Bei den Stören und den meisten Knochenfischen sehliessen sie darauf gewöhnnlich noch ein fibröses Längenband ein 6). Die unteren Stücke bilden in der vorderen Hälfte der Wirbelsä̈ule die filschlich sogenannten Processus transversi, welche weiter hinterwärts zu unteren Bogen sich vereinigen, deren Reihe einen unterhallo der Wirbelkörper gelegenen, zur Aufnahme der Arteria und Vena caudalis bestimmten Canal darstellt.

\section{§. 4.}

Die Textur der Wirbelkörper bietet mancherlei Verschiedenheiten dar. Bei einigen Ilaien bleiben sie ganz knorpelig ${ }^{1}$ ); bei anderen beschränkt sich dic Ossification auf eine diinne Schicht des Centraltheiles 2), der unmittellar die conischen IIöhlen des Wirbelkörpers ungibt; selır selten bestehen sie aus alternirenden Schichten von Knorpel und Knochenmasse ${ }^{3}$ ). Bei den ineisten Knochenfischen sind sie durchaus verknöcliert 4). - An den Seiten der Wirbelkörper und an ihrer unteren Fläche finden sich sehr häufig, sowol bei Plagiostomen als bei Knochenfischen, nehr oder minder tiefe Gruben oder Rinnen ${ }^{5}$ ). - Die Gestalt und die verschiedenen Dimensionen der Wirbelkörper sind sehr grossen Versehiedenheiten unterworfen 6). Bc-

Dieselbe Beobachtung habe ich an den Wirbein eines Scomber gemacht. S. die Abbildd. bei M üller, Vergl. Neurol. d. Myxin. Tab. 4. Fig. 10.

5) Vgl. über diese \$. 5 .

6) Desselben geschah schon im vorigen \$. bei den Störeu Ervvähnung. Es ward frïher, z. B. vou Vogt, für einen Nerven angesehen.

1) Z. B. Echinorhimus, Hexanchns, Heptanchus.

2) Z. B. Acanthias, Centrini.

3) Diese anffallende Biłlungsweise ist ron Müller bei Sqnatina beobachtet worlen. Abbildıng, Vergl. Neurol. d. Myzinoülen. Tab. 4. Fig. 8.

4) Indessen erhält sich bei einigen Knocbenfischen eine urehr knor pelige Textur, z. B bei Cyclopterus, Orthagoniseus, Lophius. Eigenthünlich ist es, dass die Wirbel, gleich sämutlichen übrigen Kuochendes Körpers, nach dem Kochen bei Belone eine grasgriue Farbe anmehmen.

5) Unter den I'lagiostomen besonders anfallend bei Lamna. Hier finden sich an der Obertläche der Wirbelkörper mit Knorpelmasse ausgefülite Spalten. Bei deu Knochentischeu sind diese Gruben cine selır häufige Erscheinung.

(j) An stärksten und zugleich an wenigsten zahtreich sind die Wirbel bei den Plactognathen; an zahlreichsten bei den Ailen und Haien. Ueber die rerschirdens: Anzahl der Wirbel bei verschiedenen Fischeı funden sich Angiben in Cuvier's Vorlesungen ïber vergl. Auatouic Bil. 1. Bei den Plactognathen 
merkenswerth ist die häufig in einzelnen Abtheilungen der Wirbelsäule vorkonmende Versehmelzung der Wirbel\%. Bei den Chimären, den Roehen und Rhinobatus kömmt sie in dem dem Kopfe zunäehst gelegenen Abschnitte der Wirbelsäule vor. Aueh bei Knoehenfisehen (Siluroïden, Loriearien, Fistularia, Cyprinen) wird sie an den ersten Wirbeln beobaehtet. Ebenso entsteht, indem die Fortsätze und die Flossenträger des hintersten Sehwanzwirbels oder mehrer der letzten Schwanzwirlel unter einander verwaehsen, bei den meisten Knoehenfisehen eine vertieale Platte, an deren hinteren Rand die Sehwanzflosse sieh ansetzt ${ }^{8}$ ).

\section{§. ว.}

Gewöhnlich stossen die beiden Sehenkel jedes oberen Wirbelbogens oben zusammen zur Sehliessung des zur Aufnahme des Rükkenmarkes bestimmlen Canales, und versehnelzen, naehdem sie noeh das fibröse Längenband zwisehen sich eingcsehlossen haben, zu einem einfaehen Processus spiunsus superior, der seltener als getrenntes Stüek erscheint, wie bei Aeipenser, Lepidosiren u. A. 1) Diese als Regel anzuspreehende Bildungsweise unterliegt aber mancherlei Ausnabmen:

1. Bei vielen Knorpelfisehen liegt zwisehen den aufsteigenden Sehenkeln zweier auf einander folgender Wirbel jedesmal ein Knorpel. stüek eingesehaltet, das zur Vervollständigung des Canalis spinalis wesentlieh beitrïgt (Cartilago intercruralis) 2). Selten kommen

sehwankt die Zahl derselben zwisehen 15 und 18; bei Triehinrus sind 170, bei Gymnotus ungefähr 240 , bei Squalns vulpes nach Cuvier 365 vorhanden.

7) In Betreff der Chimären vgl, die von Müller, Osteologie d. Myxinoüden Tab. 5. Fig. 1. gegebene Abbildung. Bei den Roehen entsteht in dem vorderen Absehnitte der Wirbelsäule eine das Rückenmark einsehliessende Capsel mit dünnem Boden. Schon vor ibrer Bildung nehmen die Wirbelkörper in der Dimension der Dieke ab. Die dünne Basis jenes vorderen Stückes der Wirbelsäule, das ganz ans hyalinisehem Knorpel mit pflasterförmiger Kruste besteht, enthält keine Spur von Wirbelkörpern und nieht einmal einen Kiern von harter Iñoehen. substanz. Müller fand, dass selbst bei einem Rochenfötus von 2" Länge, die Säule der Wirbelkörper vor diesem Stüeke fadenförnig aufhörte. Myxinoiden 'Th. 1. S. 93. S. die näheren Augaben über die versehmolzenen Wirbel der Rochen bei Meekel System der vergl. Anat. Th. 2. Abth. 1. S. 195 ff. - Sebr auffallend ist die Versehmelzung der ersten Wirbel unter den Silıroïden, namentlieh bei Aspredo, Bagrus, Heterobranchus, Malapterurns, Sehilbe, Plotosus.

8) Deutlieh erkennt man den Beginn dieser Versehnelzung bei Esox. IIIdessen bildet der letzte Schwanzwirbel nicht inmer eine solehe Platte, die z. 13 . bei Muraena, bei Triehiurus, bei Fistnlaria fehlt.

1) Die Höhe der Processus spinosi ist ausserordentlieh versehieden; sehr niedrig bei den Muränoïlen; sehr hoeh bei Vomer, Plenronectes u. A. Die Vereinigung der oberen Bogenschenkel bleibt indessen am ersten Wirbel hisweilen ans, wie z. B. bei Cottns, wo also anels sin Dornfortsatz fehlt.

2) Solehe Cartilagines intercrurales kommen vor bei Petromyzon, Aeipenser, Chimaera, bei allen Haien und, wenigstens stellenweise, an der Wirbel. 
zwischen zwei obern Bogenschenkeln zwei oder drei solcher Schaltstücke vor. Man unterscheidet das Schaltstuck von den oft kleineren Bogenschenkel dadurch, dass letzterer auf dem Wirbelkörper selbst aufsitzt, während jenes mehr über der Verbindungsstelle zweier Wirbel liegt.

2. Gleichfalls kommen bei vielen knorpelfischen an denjenigen Stellen, wo die oberen Bogenschenkel convergiren, obere unpare Schlussstiicke vor ${ }^{3}$ ). Sie finden sich sowol zwischen einfachen oberen Bogenschenkeln, als auch bei Anwesenheit der Cartilagines intercrurales. In letzterem Falle entsprechen sie diesen und den Bogenschenkeln zugleich und alterniren mit ihnen.

3. Bei einzelnen Knorpelfischen 4) entspricht ein einziger Processus spinosus superior zugleich zwei oder drei. Wirbelkörpern.

4. Bei manchen Knochenfischen bilden die oberen Bogenschenkel nach vollständiger oder unvollständiger oberer Schliessung des Canalis spiualis keinen einfachen Dorn, sondern divergiren von neuem 5 ).

כ. Von der Basis der oberen Bogenschenkel gehen bei fast allen Knochenfischen noch eigene Gelenkfortsätze ab. Meist sind ihrer vier, zwei vordere und zwei hintere, vorhanden, seltener nur zwei, und dann erstrecken sich diese beiden zum nächst vorderen ${ }^{6}$ ) oder zum nächst hinteren Wirbelkörper, den sie bisweilen zangenförmig umfassen oder in dessen ihnen entsprechende Gelenkgruben sie eingreifen.

6. Selten treten von den oberen Bogenschenkeln noch eigenthümliche accessorische Fortsätze ab, welche cine Verbindung mit Hautschildern eingehen $\%$ ).

säule der Rochen. Oft übertreffen die Cartilagines intercrurales die eigent. lichen oberen Bogenschenkel an Höhe und Ausilehnung und schliessen allein den Canalis spinalis: z. B. bei Centrina und Heptanchus. - Bei den Pricken liegen zwischen ilen Austrittsstellen von zwei Spinalnerven zwei Bogenschenkel, vou denen der eine die Castilago intercruralis ist. Vgl. besonders Müller, Myxinoïlen 1. S. 91. und dessen Aufsatz über die Wirbel der Haic in Agassiz, Poissons fuss. Vol. 3. nit der dazu gehörigen Abbild. Tab. 40. b.

3) Sie finden sich bei den Cbimären und bei viclen Haien, namentlich den Gattungen Scyllium, Mustelus, Galeıs, Galeocerdo, Carcharias, Sphyrna, Squatina; deu übrigen Haien fehlen sic. Bei den Rochen sind sie die Schlusstücke der, uberen Bogensehenkel.

4) Namentlich bei Rhinobatus.

5) Diese Bildung komunt vor an den vorderen Wirbeln mehrer Loriearieı und Siluroïden und natuentlich der Gattungen Diorlon und Tetrorlon. Bei einigen Arten von Diorlon ist indessen die obere Decke des Canalis spinalis nur häutig.

6) Z. R. bei Thynnus vulgaris, Lophius u. A.

7) Dies ist der Fall bei Ien I,oricarien. Bei Hypostoma z. B. Geheu vou den oberen Bogenseheukeln der sieben vordersten Wirbel paarige Fortsïtze ab, welche aufwärts gerichtet siml und die knöebernen Seitenselilder des Hautske. letes stützeu. 
S. 6.

Die unteren Wrirbelbogen bestelen in rer Rogel an allen Wirbeln gleichfalls aus zwei Schenkeln, welshe im vorderen Theile der Wirḷelsäule gewöhnlich auswärts gerichtet sind und soģenannto Quelfortsätze von versehiolener Länge bilden, an denen meistens auch Rippen befestigt sind. In der Mitte der Wirbelsäule lucginnen aber diese Querfortsaitze zu convergiren und stossen endlich hinter dem Ende der Bauchhöhle unten zusammen zar Bildung rines Canales fiir dic Arleria und Veue cumbalis. Nach seiner Schliessung verschmelzen die beiden Schenkel gewöhnlich zu cinem einzigen mẹr oder nunder langen untcren Dornfortsatze l). Die wichtigsten Modificationen dieser Anordnung sind folgende:

1. An den vordern Wirbeln wehrer Knorpel- und Knochenfische fchlen diese den unteren Bogenschenkeln angeliörig('n Querfortsätze 2). Bisweilen bilden die Interen Bogenschenkel, sobald sie überhaupt iı den Wirbcln auftreten, sogleich, ohne erst als falsche Querfortsiitze zı erscheinen, den unteren Wirbelcanal 3).

2. Bei mehren Knorpelfischen liegen zwischen den unteren Bogenschenkeln eingekeilte Schaltknorpel 1 ).

3. Bei manchen Knochenfischen werden die Grundflächen zweior einander seitlich entsprechenden untern Bogenschenkel, schon bevor diese convergiren und sich vereinigen, durch einc quere Knochenbrïcke mit einander verbunden, welche dic Aorta einscluliesst 5 ).

4. Nicht selten treten von der Basis der unteren Bogenschenkel vordere und hintere oder blos vordere Gelenkfortsitze ab, wodurch die Verbindung zweicr Wirbel inniger wird.

כ. An die unterlalb des unteren Wirbelcanales liegenden Processus spinosi inferiores befestigen sich bisweilen noch Riple en ${ }^{6}$ ).

Die so eben beschriebenen Querfortsätze unterscheiden siclı also wesentlich von denjenigen aller höheren Wirbelthiere durch den Umstand, dass sie nichts anderes sind, als die an den vorderen Wirbeln aus einander gewichenen oder nicht zur Schliessung gelangten Schenkel des unteren Wirbelbogens, deren Vereinigung und Schliessung erst in der Schwanzgegend crfolgt.

1) Mehre dieser unteren Dornen sind bisweilen unter einander verwachsen. Beispiele liefern cinige Arten von Scarus und ron Chätodon.

2) So bei den Lophien und Plactognathen. - 3) Bei Lophius. - 4) Hei Raja, Rhinobatus, Accipenser. -- 5) Bei vielen Salmonen und Clupeen.

6) Z. B. bei Salıno Salar, Thynnıs vulgaris, Hypostoma, Zeus. Eine sehr merkwïrlige Bildung hat Müller bei Scomber seminudus beobachtet. Hier gehen die Rippen tragenden Fortsïtze der linteren Bauchwirbel vun iler unteren Mittellinic der Wirbelkörper mnparig ans, treten gerarle abrü̈rts, theilen siel dann, um cinen Canal zu bilden, und gehen diun erst seitlich abrvärts in zwei Schenkel aus, an derren die Rippen hangen. 
Verschieden von diesen falschen Querfortsätzen sind andere, welcle seltener an den Wirbcln ter Fische und zwar oft mit ihnen zugleich sowol an den Rumpf-als an den Schwanzwirbeln vorkommen. Sie gehen vom Wirbelkörper aus und tragen niemals Rippen $\%$.

§. $\tau$.

Die Rippen der Fische befestigen sich gewöhnlich an der Spitze dre ron drn unteren Bogenstücken ausgchenden Qucrfortsätze und umschliessen dann als gesonderte Knochenstuicke der letzteren und nicht, wie bei den höheren Wirbelthieren, als Anfinge der oberen Bogen erscheinend, mehr oder weniger vollständig dic Bauchhöhle. Seltencr

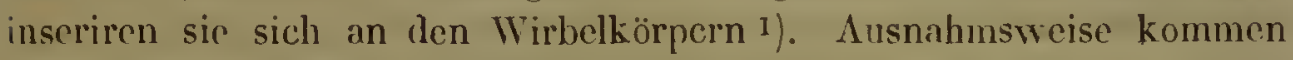
auch noch an den unteren Dornen ciniger Schwanzwirbel Rippen vor 2). Nieht ganz selten fehlen die Rippen gänzlich 3); häıfiger tragen einzclne Wirbel keine Rippen ). Sie sind bisweilen sehr starke Knochen, die manclımal durch straffe sehnige Bänder unter einander verbunden werden 5). Bisweilen, wie bein Stör, besteht jede Rippe aus mehren Segmenten; in anderen Fiillen sind sie aber nur ganz rudimentär $\left.{ }^{6}\right)$. Die Rippen sind vorn nicht an ein Brustbein befestigt, das den Fischen fehlt und höchstens dırch unpaarc untere Schuppen, welche schienenähnlich (ntwickelt sind, angedeutet wird 7). Mit den cigentlichen Rippen nicht

7) Sie kounnen z. B. ror bei den Pleurnnectes (z. B. bei flesus, maximus, platessa, rhombus, rlomboïles), bei Thentis hepatus, Trigla volitans, Mnraena conger, Muraenophis belena, Polypterus Bichir, Aspredo, an den Schwanzwirbeln von Thynnus vulgaris. Man kann sie den gleiehfalls voun Körper der Wirbel und nicht ron den oberen Bogenstiiclien ausgehenden Querfortsätzen der Schwanzund Lendenwirbel der Cetaeeen rergleichen.

1) Unter den Haien sind es z. B. die Gattungen Heptanehıs, Careharias und Alopias, hei welchen diese Befestigungsweise der Rippen naeh Müller vorkönmt.

2) Vgl. \$. 6. Anmerk. 7.

3) Z. B. bei den Cyelostomen, Lophius, Malthaea, Orthagoriscus, Diodon, Tetrodon, Ostrieion, Fistularia.

4) Z. B. die ersten Wirbel der Cyprinen, der Salnonen, der Cottıs und vieler andern Fische. Die zwei oder drei vordersten Wirbel sind überhaupt nieht selten etwas abweichend gebildet. Mit Unreeht bezeiehnen aber Einige diese Wirbel, wegen des Mangels von ibmen abgehender Rippen, als Halswirbel. Diese Auffassungsweise ist, ausser anderen dagegen spreehenden Grïnden, sehon deshalb falsch, weil es viele Fische gibt, welche gar keine Rippen besitzen und die sämuntliehen rippenlosen Wirbel der Lophien, der Ortlagorisens, Diodonten u.s.w. als Halswirbel zu bezeichnen, wirl sieherlich Niemandem einfallen. - Sogar fiir die Schwanzwirbul der Fisehe mangelt es an einem entschiedenen Criterinm, inden oftenbar Uebergangsstufen von den Bauehwirbelı zı deı Sehwanzwirbelı vorkommen. Diese sind gegeben 1) dureh die brückenartige Verbindıng zweier Processus trunsversi zur Bildung eines Canales für die Sclnvanzgefiisse und 2) durch das Vorkoumen von wirklichen Rippen an den dureh die Vereinigung zweinr unterer Bogenschenkel gebildeten Processus spinosi inferiores.

5) Diese B̈̈nder funden sieh \%. B. bei ten Cyprinen.

6) \%. B. bei Rlinolsatus.

7) Dies letztere ist dar Fall namentlich bei den Clupeen, den Vomer, den 
zu verwechseln sind die in den Intermuskularbändern der Seiten- und Riickenmuskeln liegenden Fleischgrathen. Sie sind lyald an den Querfortsätzen, bald an den Seiten der WVirbelkörper, bald an der Basis der oberen Dornen angelıeftet. Man kann sie un so loichter für rip)penartige Gebilde halten, als sie oft die wahren Ripjen an Stirke iilsertreffen ${ }^{8}$ ).

\section{Vom Schedel.}

§. 8 .

Das verlängerte Mark und (las Gehirn, nebst den sie umschliessenden Häuten und Fettmassen, sind von einer an das vorderste Ende der Wirbelsäule angefügten erweiterten Capsel umschlossen, wriche Erweiterung nur bei Branchiostoma fehlt. Die Wandungen dieser Capsel werden durch die ihr mehr oder minder eingeschobenen, zur Einschliessung und Unterstiitzung des Gehörlabyrinthes bestimmten, selten knorpeligen, in der Regel ossificirten Gehörcapseln oder Ossa petrosa vervollständigt. Continuirliche vordere Fortsetzungen der Hirncapsel dienen in der Regel den Gesichts - und Geruchsorganen zur Stuitze; sie bilden mit der gemeinsamen Gehirn- und Gehörcapsel den Schedel der Fische.

Knorpelige oder ossificirte Hartgelsilde, welche die Eingänge in den Digestions - und Respirationsapparat umgeben und weiche Theile dieser Apparate decken oder stiitzen - namentlich der Kieferapparat mit seinem Suspensorium, das Zungenbein, der Kiemendeckel-Apparat, clie Kiemenbogen und die Schlundkiefern - stehen in der Regel mit dem Schedel in mehr oder minder inniger Verbindung. - Bei der Mehrzahl der Fische lehnen dic obersten Stücke des Extremitätengürtels an ihn sich an. Bei anderen gewährt die Schedeldecke selbst noch den unpaaren Flossen Stützpunkte 1); bei einigen 2) kommen ganz eigenthümliche Schedelflossenknorpel vor. - Schleimabsondernde Gebilde, welche an der Oberfläche der Haut ihr Secret ergiessen und mit denen des Rumpfes in ununterbrochener Verbindung stehen, durchsetzen sehr häutig die soliden Schedeldecken oder lehnen mittelst ihrer eigenthumlichen, soliden, meist ossificirten Grundlagen an sie sich an.

Zeus. Bei Clupea stehen diese unpaaren Sebienen wirklieh mit den unteren Enden der Rippen in sehwaeher Verbindung.

8) Wirklich haben sich namentlich Meckel (System der vergl. Anatomie 2. S. 246), Cnvier in seiner Bescbreibung des Thunfischskeletes und $A$ gassiz in der des Polypterus Biehir irre leiten lassen. Müller hat sich ïber diesen Gegenstand sehr gründlich ausgesprochen. Myxinoïden 1. S. 98. Bein Thunfiseh naınentlich gelangt man, obne sorgfältige Berüeksiehtigung aller Verbältnisse dieser Fleischgräthen, leicht dahin, sic fiir Rippen zu halten, da sie stelleuweise dic eigentlichen Rippen an Stärke übertreffen.

1) Hierher gebören dic vordern Fortsetzungen der Riickenflosse bei manclien Sebollen; das Kopfsehild der Eeheneis; die eigenthümlichen Kopfknochenstrahlen bei Lophius u. s. w. - 2) Bei vielen Rochen. 
Durch diese höchst mannigfaclıcn Beziehungen des Fischschedels zu anderen Apparaten des Körpers gewinnt derselbe auf den ersten Anblick ein frcmdartiges Ansehen- und erschcint complicirter, als cr wirklich ist. -

Die Tcxtur des Schedcls ist schr verschieden; bald ist der grösste Theil seiner Wandungen blos faserhäutig und es kommen nur einzelne Verknorpelungen oder Verknöcherungen an ihm vor; bald ist cr mit Ausnahme häutiger Fontanellen vorwaltend oder ganz knorpclig; bald haben sich auf Kosten seines Knorpels einzelne Ossificationen gebildet und Liikken seiner knorpeligen Grundlage, so wie ein Theil dieser letzteren selbst sind von oberflächlichen Ossificationen bedeckt; bald endlich ist die knorpeligc Grundlage des Schedels verschwunden und seine Wandungen erscheinen durchgängig ossificirt. - Meistentheils finden sich bei den Knorpclfischen in der oberen Wand des sonst knorpeligen Schedels mehr oder minder beträchtliche, blos hả̉utig geschlossene Fontanellen. Aehnliche Fontanellen kehren bei den Sturionen und den meisten Knochenfischen in der knorpeligen Grundlage ihres Schedels wieder, sind aber hier nicht blos häutig geschlossen, sondern durch Knochenplatten, welche Aequivalente der Stirn- und Scheitelbeine bilden und auf Kosten einer ursprïnglich fibrösen Grundlage sich cntwikkelt haben, oberflächlich bedeckt.

An die Wirbelsäule sich anschliessend, dient der hintere Abschnitt des Schedels zur Einschliessung des verlängerten Markes und des Gehirnes. Das den grössten Theil des verlängerten Markes umschliessende hinterste Segment desselben stellt einen deutlichen Wirbel dar: den Occipitalwirbel. In ihm erhält sich bei vielen Knorpclfischen perennirend das vorderste Ende der Chorda dorsalis, welche letzterc nur bei Branchiostoma bis zur vordersten Spitze des Kopfes sich fortsetzt. Die vor dem Occipitalwirbel liegenden Schedelabschnitte sind freilich vielfich mit Wirbeln verglichen worden, ohne dass jedoch die Wirhelnatur derselben mit genügender Sicherheit nachgewiescn wäre.

\section{§. 9.}

Die wcsentlichsten Modificationcn der Schedelbildung sind bei den Knorpelfischen folgende:

1. Wo der vorderste Theil des centralen Nervensystemes in keiner Weisc rom Ruiekenmarke sich sondert, wie bei Branchiostoma, crmangelt auch das jenen Theil des centralen Nervensystemes umschliessende Rohr jeder Erweiterung und ist von dem Rückenmarkrohre nicht zu unterscheiden. Eine unmittelbare Fortsetzung des letzteren, hleibt es durchaus häutig und ist nur durch dic aufstrigende Vcrlängerung der äussercn Schcide der Chorda dorsalis gebildet1).

1) Nach den übereinstimmenden Beobachtungen von Rathke, Retzius, Müller, Goodsir. 
Dic Chorda sellst erstreckt sich unterhalb des Hirnrolires, und zwar weiter, als der Centraltheil des Nervensystemes nach vorn ${ }^{2}$ ).

2. Zur Bildung einer Erweiterung oder Schedelcapsel kömmt es erst da, wo eine bestimnte Sondrrung des vordersten Theiles des Centralnervensystemes, also eines Gehirnes rom Rückenmarke eintritt, wic dies bei den Cyclostomen zuerst der Fall ist. Die Chorla clorsalis setzt sich, vorn zugespitzt, cine kurze Strecke weit in die Basis der Hirncapsel fort. Die äussere Scheide dieser Chorda ist zu einer knorpeligen Basis cranii geworden; ihre aufstcigenden Fortsetzungen bilden das Schedelgewölbe, das entweder blos knorpelhäutig ${ }^{3}$ ), oder theilweise 4), oder grossentheils 5) verknorpelt ist. Die knorpelige oder knochenharte Basis crauii besteht bald aus zwei getrennten ${ }^{6}$ ), bald aus einem gespaltenen 7), bald aus einem unpaaren ${ }^{8}$ ) Stücke. Immer besitzt der harte Basilartheil (Os basilare) vorn zwei divergirende Fortsätze, welche einen vordern häutigen Theil der Schedelbasis zwischen sich nehmen. Die Seiten des Os Zasilare und zum Theil auch seine Schenkel tragen jederseits eine auswärts gerichtete Knochenblase, welche das Gchörorgan einschliesst. Eine blos häutige 9) oder knorpelige 10) Nasencapsél hangt bald innig mit dem vordersten Theile der Gehirncapsel zusammen 11 ), bald ist sie durch cine doppelte Scheidewand und Einschnürung von ihr getrennt 12).

3. Bei den Chimären und P lagi os tomen ist die Schedelcapsel gewöhnlich bis auf obere, bisweilen sehr beträchtliche Fontanellen verknorpelt. Eine Sonderung derselben in einzelne Stuicke findet nicht Statt 13 ). Schedel und Wirbelkörper gehen nicht mehr unmittelbar in einander über, indem dic Spitze der Chorda dorsalis in Basilartheile des Sche-

2) Nach Müller und Retzius. - 3) Bei Ammoeoetes und Myxine. 4) Bei Bdellostoma. - 5) Bei Petromyzon.

6) Bei Ammocoetes. Hier stehen die getrennten Leisten aber aueh unter und hinter der Nase in einem spitzen Bogen zusammen.

7) Bei Myxine. - 8) Bei Bdellostona und Petronyzon. - 9) Bei Ammoeoetes. - 10) Bei den Myxinö̈len und bei Petromyzon. - 11) Bei Petromyzon. - 12) Bei den Myxinoïlen.

13) Bei allen Chimären - aueh bei $\mathrm{Cb}$. aretica - bemerkt inan am hintern Theile des Schedelgewölbes eine kleine unpaare 0effnung. Bei den meisten Rochen, mit dusnahme ron Narcine, ist eine mehr oder ninder bedeutende Streeke der oberen Schedeldecke nieht knorpelig, sondern faserbäntig. Die Lage dieser Fontanelle und ihr Unfang sind sehr versehieden. Bisweilen ist sie durch eine Knorpelbrüeke getheilt. - Dieselbe Erscheinung kebrt bei den Haien wieder, und zwar in einem solchen Grade, dass bei Galens fast die ganze knorpelige Schedeldeeke fehlt und nur eine knorpelige Querbrïcke vorhanden ist. Diese Thatsachen sind zur Erläuterung der Schedelverbältnisse der Knoehenfisebe und der ungeschwänzten Batrachier von Wiehtigkeit; denn auch bei diesen finden wir - aber bedeekt von Schreitel- und Stirnbeinen - dieselben Lücken, oft in geringerer, oft in gleicher Ausdehnung, wie z. B. bei den Cyprinen, bei Cottus, bei den Fröschen. 
(lels fehitt 14 ). Das Gehörorgan liegt entweder theils innerhalb der Schedelhölle und theils in der Knorpelmasse des Schedels, oder ist ganz innerhalb der letzteren eingeschlossen 15). Die mehr oder "minder vollständig legrenzten und überwölbten Auggenhöhlen liegen immer seitlich an Schedel und vor den Schläfengruben und sind selten auffallend weit nach vorn vorgeschoben $\left.{ }^{16}\right)$. Vor ihnen liegen die Capseln oder Gruben zur Aufnahnie des Geruchsorganes, die bei den Plagiostomen unter: die Schnauzenfläche treten.

4. Bei den Stören ist der ganze Schedel bald vollständig, bald mil Ausnahme einer über dem verlängerten Marke in der Hinterhauptsgegend liegenden Liicke ${ }^{1 i}$ ) verknorpelt. Das knorpelige Schedeldach sainmt der Lücke werden von ossificirten, in einzelne Abtheilungen zerfallenen, den Schedelknochen der Knochenfische kaum vergleichbaren Hautschildern bedeckt. Unter der knorpeligen Schedelbasis findet sich eine dem hinteren Keilheinkörper der Gräthenfische vergleichbare, schon unterhalb der ersten Wirbelkörper beginnende Knochenplatte, welche nach vorn den Schedelknorpel durchbohrt und auf der unteren Fläche der Schnauze wieder zum Vorschein kömmnt 18). Der Schedel selbst ist fest mit der Wirbelsäule verbunden, indem die Spitze der CKarder dorsalis in seine knorpelige Basis sich verlängert. Das Gehörorgan liegt theils in der Schedellöhle, theils in der continuirlichen Knorpelmasse des Schedels. - Die Augenhöhlen finden sich vor der Schläfengrube seitwärts am Schedel und sind hinten durch einen Processus fromalis mosterior, vorlu durch einen ausgebildeteren Processus frontalis auterior begrenzt. - Vor den Augenhöhlen lie gen in der Basis der Schnanze die Gruben fiir das Geruchsorgan.

5. Der Schedet ron Lepidosiren ${ }^{19}$ ) ist, gleich demjenigen der Sturionen, fest mit der Wirbelsäule verbunden, indem die Spitze der Chorda dorsulis in seine Basis sich verlängert. Ucbrigens zeichnet er sich, obschon zum Theil knorpelig bleibend, durch bedeutend stärker und allgemeiner vorkommende Ossificationen aus. Im Hinterbauptswir bel sind die Seitenstijcke (Ossa occipitalia lateralia) verknöchert, werden aber oben durch einen die IIinterhauptsschuppe repräsentiren-

14) Dureh einen aus drei Flächen bestehenden Gelenktheil ist der Schedel bei den Chimären beweglich mil der Wirbelsäule verbunden. Aehnlich bei den Haien. S. das Nähere bei Meckel, System Th. 2. Abth. 1. S. 197.

15) Das Gehörorgan ist ganz van den Schedelknorpeln eingescblossen bei den Plagiostomen; theilweise bei den Chimären.

16) Bei einigen Plagiostomen.

17). Von Brandt und Müller wird die Verknorpelung des Schedeldaches bei Accipenser Ruthenus als vollständig gesclildert und abgebildet. Ich finde bei dem gewöhnlichen Accipenser Sturio der Ostsee die angegebene Lücke beständig.

18) Abgebildet bei Baer in Meckel's Archiv f. Anat. u. Phys. Jahrg. 1820 Tab. 5. Fig. ?.

19) Vgl. die Angaben von Bischoff I.c. 
den Knorpel verbunden. Der an der Schedelbasis gelegene Keilbein körper ist fast eben so weit ausgedehnt, wie bei den Sturionen. $\mathrm{Er}$ ist auswendig ossificirt, während seine der Schrdelhöhle zugewendete Oberfliche mit knorpel iiberzogen bleibt. Die obere Schedeldecke wird durch einen einzigen, die Scheitel - und Stirnbeine darstellenden Knochen gebildet. Die knorpeligen Felsenbeine sind seitlich vor den Hinterhauptsbeinen zwischen dem oberen Deckknochen und dem Keilbeinkörper, eingefiigt. Sie nehmen das Gehörorgan auf, das nicht in der eigentlichen Schedelhöhle liegt. Neben ihnen liegen die halb knorpeligen, halb ossificirten mit dem Schedelgeriiste zusammenhangenden Quadratknorpel. Dic vorderen Seitenwände des Schedels bilden zwei Knochenstücke, welche continuirlich in den Oberkiefer übergehen. Die vordere Gaumenflïche bleibt knorpclig. Ein dem Zwischenkiefer verglichener zahntragender knochen dient dem zusammengesetzten knorpeligen Nasengeriiste zur Stütze.

[Die Bildungsverhältnisse des Schedels der Cyclostnmen sind aun vollständigsten erläutert von Mïller in dem ersten Theile seiner vergl. Anatomie der Myxinoïden, in welchem ausgezeichneten Werke auch schöne Abbildungen von Myxine, Bilellostoma, Amunocoetes, Petromyzon, Callorhynchus, Myliobates, Rhinoptera und Accipenser sich finden. - Ueber Petroniyzon und Ainmocoetes sind Rathke's frühere Arbeiten zu vergleichen. - Ueber Accipenser hat v. Baer a. a. 0 . in Meckel's Archiv und im Königsberger Berichte an gründlichsten gehandelt. - Gute Abbildungen von Plagiostomen. Schedeln finden sich auch bei Henle, Ueber Narcine, Berl. 1834. 4.]

\section{§. 10.}

Dcr Schedel der Gräthcnfische unterscheidet sich von demjenigen der Störe wesentlich durch den Umstand, dass die Chorda dorsalis nicht mehr continuirlieh in seine Basis sich fortsetzt; vielmchr besitzt das Basilarstück ihres Hinterhauptsbeines an seiner Hinterläche die, allen Wirbelkörpern in der Regel zukommende, mit Gallertmasse gefüllte, conische Verliefung. - Nach der herkömmlichen Vorstellungsweise besteht der bedeutendste Unterschied zwischen dem Schedel der Knochenfische und demjenigen der Knorpelfische darin, dass er bei diesen letzteren eine continuirliche Knorpelcapsel bildet, während er hei jenen in zahlreiche einzelne, unmittelbar unter einander verbundene Knochen zerfallen soll. In der That ist diese Unterscheidung nur einer oberflächlichen Anschauung des Knochenfisch-Schedels entnommen. Bei sehr vielen Knochenfisehen erhält sich nämlich, zum Theil unter lose aufliegenden Ossificationen verborgen, perennirend eine zusammenhangende knorpelige Schedelcapsel. Auf Kosten dieser letzteren haben sich meistens nur partielle Ossificationen gebildet, welche einander häufig nicht unmittelbar berühren, sondern durch zwischenliegende Ueberreste der zusammenhangenden primitiven Knorpelcapsel getrcnnt erhalten werden. Hiervon uiberzeugt man sich am deutlichsten durch Unter- 
suchung von Schedeln der Salmonen, Esocinen, Cyclopoden u. A. Von der Persistenz einer wirklichen nur partiel ossificirten, aber theilweise durch aufliegende Knochen bedeckten Knorpelcapsel bis zur ausschliesslichen Bilclung des Schedels aus cinzelnen, einander dicht und innig beriihrenden Scliedelknochen, wie sie bei den meisten Plectognathen (mit Ausnahme von Orthagoriscus) und bei den eigentlichen Muränoïden angetroffen wird, findet dann ein ganz altmälicher Uebergang Statt 1). - Bei den meisten linochenfischen erhält sich namentlich ein Ueberrest der urspriinglichen Knorpelcapsel unter dem knöchernen Schedeldache. Die knochen, welche den Schedel oben bedecken und durch ihre Anzahl und gegenseitige Lagerung den Scheitelbeinen und Stirnbeinen der höheren Wirbelthiere entsprechen, liegen in der Regel oberflächlich auf dem continuirlichen oder durch Lücken unterbrochenen knorpeligen oberen Schedeldache. Unter geeigneter Behandlung gelingt die Entfernung dieser Knochen leiclit und ohne die mindeste Verletzung des unter ihnen liegenden Knorpelgeristes. Man findet nach ihrer Wegnahme, dass unter ihnen die Seitenwandungen der Schedelcapsel allseitig, oder blos brückenförmig, durch cin vollständiges oder lückenhaftes Knorpelclach mit einander und mit der Hinterhauptsschuppe verbunden sind. Die etwa vorhandenen, von diesen Knochen verdeckten Lücken oder Fontanellen bicten bei allen Individuen der gleichen Art durchaus constante Umrisse und Lagenverhältnisse dar. Die Ausdehnung und die Contouren dieser Lücken sind bei den verschiedenen Familien verschieden. Diese Fontanellen entsprechen denjenigen, welche an der

1) Als solche Uebergangsformen von dèn Esocinen und Salmoniden zu ten Aalen und den Plectognathen sind zu betrachten die Percoïlen, namentlich Perca, Lucioperca, Acerina; die Gattung Amuodytes, die Clupeen, die Cotti, die Cypri. noïllen, die Siluroïlen, Belone und Exncoetus, ferner die Schollen und die Gadoülen. [Beiläufig bemerke irh hier, dass Müller's Trennung der Gattungen Belone, Exocoetus, Heuliramphus' von den Esocinen in jeder Beziehung völlig gerechtfertigt erscheint. $\mathrm{Zu}$ den von $\mathrm{Müller}$ namhaft geluachten Charakteren kommen noch das ron Esox völlig abweichende Verhalten der knorpeligen Grundlage des Schedels, die Unvollständigkeit des knöchernen Infraorbitalringes und die Bildung eines grossen Ganglion Vagi an Magen - lauter auffallende Un. terscheilungsinerkmale von den Esocillen.] Bei den Gadoïden sind kaum noch schwache Ueberreste der ursprünglichen Knorpelcapsel zu erkennen. Bei den Aalen (Muraena, Muraenophis), so wie bei den meisten Plectognathen (Diodon, Tetrodon) ist das Knorpelskelet des Schedels, namentlich auch unterhalb der Scheitel- und Stimbeine, völlig verschwumden. Bemerkenswerth ist es, dass bei diesen Fischen zugleich das Skelet der Schleimröhren entweder ganz ausser Beziehung zum Schedel bleibt, wie bei den vorgenannten Plectognathen, oder ihm nur sehr locker und oberflächlich verbunden ist, wie bei den Aalen. - Der Schedel der Plagiostomen ist nur mit der knorpeligen Grundlage des Schedels der linochen. fische, einschliesslich der auf Kosten dieser knorpeligen Grundlage entstandenen Ossificationen zu vergleichen. Die auf Kosten fibröser Uäute entstandeneu Schedelknochen treten bei den Kunochenfischen als ganz neue Elemente hinzu. 
obern Schedeldecke der Knorpelfische, und namentlich der Plagiostoinen, vorkommen. Lirgen diese Fontinellen bei letzteren unter der Haut frei zu Tige, so werden sie hei den Kuochenfischen durch Knochenplatten verdeckt. Diese letztepen (dip Ossu puriefalia und fronIalie principaliu) entstehen also nieht auf Kosten des das obere Schedeldach bildenden Knorpels, sondern entwickeln sich iiber demselben aus einer fibrös-häiutigen Crundlage. - Es sind also am Fischschedeł selir häufig Ossificationen zwiofacher Art perennirend zu unterscheiden: 1) Knochen, welche auf Kostrn des primitiven Schedelknorpels und 2) Knochen, welche auf Kosten ciner fibrös-häıtigen Grundlage entstanden sind. Erstere können als integrirende Schedelknochen, letztere als Deckknochen bezeichnet werden. Elstere vordraingen den Knorpel, letztere bedecken ihn blos auswendig. Zu den integrirenden Schedelknochen gehören immer die sämmtlichen Knochen des Hinterhauptswirbels mit Einschluss der Hinterhauptsschuppe, ferner die Os\&a mastoiden, die Ossa petrosa, Cuvier's vorderer Keilbeinkörpor, die Alae magnae, die Ossa frontuliu pusteriora und auleriora; zu den blossen Deckknochen gehören diggegen, ausser den Ossa parietalia und frontalia principalia, das Os splienvideum basilure s. prosterius, der Vomer und das O.s ethmeicleum.

[Während die meisten Anatomen die knorpelige Grundlage des Schedels der Knochenfisebe fast gänzlich vernacllïissigten, hat C. E. vo Baer in einem wichtigen Anfsatze: Ueber das äussere und innere Skelet, in Meckel's Archiv fiir Anat. u. Physiol., Jahrgang 1826. S. 371 ff., sie in ilrem Gegensatze zu den blos oberfläehlieh auflicgenden Deckknochen zuerst gewürdigt, obschon blos andeutungsweise. Baer nimunt eiren gleichzeitig vorhandenen knöchernen und knorpeligen Schedel an. - Die von Baier entleckten Thatsachen sind bestäıgt und erweitert durch C. B. Reichert (Vergleichende Entwiekelungsgeselichte des Kopfes der nackten Reptilien, Königsb. 1838. 4. S. 212 ff.). Reicher.t gründet auf dieses Verhalten dèr Schedelknochen eine kritische Beleuchtung der bisher gangbaren Schedeltheorie, und kömmıt zu dem Resultate, dass die oberen Deckknochen des Fisehschedels nicht als typische Scheitel- und Stirnbeine, also njeht als solche Knochen, welche Aequivalente bei höleren Wirbelthieren tinden, sondern einzig als Hautknochen, als moliticirte Seluppenbildungen zu betrachten sinjl. Für ein Schleimhantgebilde erklärt er auch den Vomer der Fisehe. Während Köstlin in seiner Schrift ïber den Schedel der Wirbelthiere diese Thatsachen gänzlich rennachlässigt, sindl sie durch Vogt und Agassiz in den letzten Lieferungen des A gassiz'schen Werkes über die fossilen Fiselhe, mit Recht hervorgehoben. Jedoch finden sich die Verfasser nicht bervogen, der Rei. chert'schen Theorie beizntreten. - Meine oligen Angaben stïtzen sich auf zahlreiche eigene Untersuchungen, welche in einer besonileren Schrift näher mitgetheilt werden sollen. Noch ming hier bemerkt werden, dass das Perenniren der knorpeligen Schedelgrundlage nielit allein bei den Fisehen, sondern auch bei anderen Wirbelthieren, nanentlich bei den Batrachiern, beobachtet worlen ist. Auclk bei anderen Reptilien scheiden sich wäbrend des ganzen Lebens die Sehedelknochen in integrirende, auf Kosten der ursprünglichen knorpeleapsel entstan- 
dene, unl in Deckknochen, welche in einer oberflächlichen fibrös-häutigen Grmullage gebildet wurden. Diese Thatsalehen gewimen an luteresse, wenn man sie mit Jacolsson's Beobachtıngen iiber den Primordialschedel vergleicht. Jacob. sull fand bei Säugthier-Eubryonen an der Inuenfliche der meisten, späirer den pernaneuten Schedel bildenden Knochẹı ciu cigenthïmliches Kinvipelskelet. $\mathbf{E r}$ gibt ferner an, dass, seinen Beabachtungen zufolge, das ganze Os occipitis, las Corpus ossis sphenuïdei und das Os ethuö̈deum anf liosten der primitiven Finorpelcapsel des Sehedels entstünden, während alle ïbrigen Schedelknochen in Membranen sich entwicheln, ohne als Finorpel präformirt zu seiı. Wie bei den Säugthieren verhalte sich allch die Ossification lıcin Menschen. Man ersieht aus Jacobson's Nittheihngen, dass das generische Verlalten der Schedelknochen bei den Fischen und den nackten Rejtilien kein isolirtes Phänomen ist; sie lehren wieder, lass Theile, welehe bei den höleren Wirbelthieren in Laufe der Entwickelung sjurlus verschwinden, bei den niedriger organisirten Classen der Wirbelthiere perennirend sich erhalten können; sie beweisen endlich die. Unlaal tbark eit der Reichert'schen Deductionen, in so ferne diese auf deu rerschiedenen Entwickelnngsprocesse der Schedelknochen basirt sind. Int es einmal nachgewiesen, dass die Scheitelbeine und die Stimbeine der Sängthiere anf äluliche Weise, wie bei ilen Fischen, auf husten einer fibrösen Grundlage sich entwicheln, so fällt jeder Grund, diese Ḱnochen des Fisclikopfes als den eigentlichen Scheilel fremd zu betrachten, hinweg; viehuehr stellen sie sich auch in dieser Beziehung als die vollkommensten A\&quivalente der gleichunigen linarlıeı der höchsten Wirbelthiere heraus.]

\section{§. 11 .}

Der Schedel der Girälıentische ist zugleich Gelıürcapsel 1), indent nicht nur die Ossa petrosa integrirende Theite dessellen sind, sondern auch andere Schedelknochen: namentlich die Ilinterhauptsbeine und die Ossa mastürlea zur Aufnahme von Theilen des Gehörorganes mit verwendet werden. - Der vor den Ossa petrosa liegende Abschnitt des Schedels verschmälert sich in der Regel beträichtlich und verliert an Tiefe; seine Höhte nimmt die vordersten Anschwellungen des Gehirnes und meistens auch die Geruchsnerven auf. Da dieser Abschnitt mit dem von ihm absteigenden knöclıernen, knorpeligen oder fibrösen Septum interorbitale die beiden Augenhöhlen bildet, iiberwölbt und trennt, so wird er an passendsten als Orbitalsegment des Schedels bezeichnet. Dieses Orbitalsegment setzt sich nach vorn fort in den Schnauzentheil, der den Greruchsorganen nnd dem Kieferupiarate zur Grendlage und Stutze dient. - Die geraden Muskeln des Augapfels, und inter ihnen namentlich die Musculi recti ex/erui, befrstigen sich bei den ineisten Knochenfischen nicht an den nächsten knöchernen Ungebungen der Augenhölle, sondern es sind dic Muskeln beider Bulbi eine grosse Strecke weit von einem unter der hinteren IIälfte der Schedelhöhle

1) Bei den Kunclıentischen stossen, ähntich wie bei den Myxinoïlen, die Giehörcajıseln (Ossa pelrosa) vor dem Os hasilare occipitis zusammen. 
liegenden Canale umschlossen, der vorn in die eigentliehen Augenhöh len einmündet 2 ). -

In der Regel durchaus symmetrisch gebildet, zeichnet sich der Schedel nur in der Familie der Pleuronectiden dureh seitliehe Asyınmetrie aus.

\section{§. 12.}

Dic cinzelnen in die Zusammensetzung des Schedels der Gräthenfische eingehenden Knochen sind folgende:

1. Das hinterste Segment des Schedels, welches zur Umschliessung eines grossen Theiles der Medlulla oblougata dient, besteht, wie schon oben bemerkt ward, in einem wahren Wirbel, dem gesammten Hinterhauptsbeine $\left.{ }^{1}\right)$. Dieses wird aus nuehren einzelnen Knochen zusaminengesetzt, nämlich 1) dem Körperstüek $(\boldsymbol{O} \& \boldsymbol{b} \boldsymbol{a}$ silare), 2) und 3) zwei oberen Bogenstüeken (Ossa occipitalia lateralia), 4) einem oberen Schlusstuick (Os occipitale superius s. Squama occipitalis). In der Regel kömmt zu diesen Stücken noch jederseits ein zwischen der squama occipitalis und den Occipilalia laleralia eingekeiltes, bald mehr, bald minder vollständig ossificirtes Schaltstück hinzu: das Occipitale externum. Diese Stucke sind meistens unter allen Schedelknoehen am vollständigsten ossificirt, sind auf Kosten der ursprünglichen Knorpelcapsel des Schedels entstanden, und bald durch Nähte, bald dagegen durch zwischenliegende Knorpelstreifen: Ueberreste der primitiven Knorpelcapsel, von einander gesondert. - Der Körper des Hinterhauptsbeines ( $/ s$ basilare) besitzt hinten eine eonische Vertiefung, welche derjenigen des ersten Wirbels entspricht und die gewöhnlichen Uebèrreste der Gallertsäule enthält. Von der unteren Fläehe des Os basilarelsteigen oft Seitenfortsätze zur Vervollständigung des unter der Sehedelbasis liegenden, die Augenmuskeln aufnehmenden Canales, abwärts. Das Occipitale Lasilare und die Occipilalie lateralia werden dureh eine innere, quer vorspringende Leiste gewöhnlich in zwei unvollständig gesonderte, über einander liegende Fächer oder Abthei-

2) Diescr Canal ist an ausgebilletsten bei den Acanthopterygicrn und unter den Malacopterygiern bci den Clupcen und Salmoncn; er ist schwach angedeutet bei den Muränoïden und fehlt den Gadoülen, den meisten Plcctognathen und Sauroïden.

1) Die säınmtlichen Theile des Hintcrhauptsheines sind unter glcichen Benennungen abgebildet bei Cuvier und Valenciennes, Tab. 1. No. 5. 8. 9. und 10. - Hallmann beınühet sich in ilcr a. S. die Occipitalia externa als Ossa mastoïdea zu deutcn. - Wcil das Os occipitale superius läufig sehr beträchtlich ist, weil es sich ferncr häufig zwischen die Ossa parietalia vertängert (was namentlich bei vielen Acanthopterygiern, bci den Gadoïlcn u. A. der Fall ist), weil es cndlich of cinc wahre Crista sagittalis billet (Labroïlen), oder gar die Schcitclbeine verdrïngt (viele Siluroïlen) hat man lio Hintcrhauptsschuppe als Os interparietale gcieutet. 
lungen getheilt, von denen die untere zur Aufnalune der Gehörsteine mit verwendet wird, die obere oder höliere aber der Medlalla ollongata zur Stiitze dient. Jedes Occipilale laterale besitzt gewöhnlich einen Gelenkhöcker, der an einen entsprechenden Fortsatz des ersten Wirbels fest und unbeweglich sich anlegt. Durch seitliche Oeffnungen in den Ossa occipiralia lateralia ${ }^{2}$ ) treten beständig die Nervi vagi und glossopharyngei aus. - Das obere Schlussstuck oder das Occipitale superizss bildet häufig eine starke Crista occipicalis. - Die Jccipitalia exterule nehnen immer einen Theil des Gelörlabyrinthes auf, behalten meist inwendig eine schwache Knorpelschiclıt und dienen mit ihrer äusseren, gewölnnlich in eine Spitze ausgezogenen Fläche einem der oberen Schenkel des Extremitätengürtels zum Befestigungspunkte.

2. Das zweite Schedelsegment besteht aus dem unpaaren unteren $\boldsymbol{S}_{p}$ henvïleum basilare und aus mehren paarigen Knochen, von denen die bedeutendsten die Ossa petrosa sind.

Das unpaare Spkeroüleum Lasilare ${ }^{3}$ ) der Knochenfische bildet mit dem ihm vorn sich anschliessenden Vurner 4) eine knöcherne Längsbrücke, welche unterhalb des Schedels von dem Os basilare occipitis aus bis zum vordersten Ende des Schnauzentheiles sich erstreckt. Das lange Sphenoüleum Laxilare liegt mit seinem hinteren Rande oft schuppenartig unter dem vorderen Theile des (Jccipitale basilare ${ }^{5}$ ), oder greift mit oberflächlichen Zacken in dessen Rindensubstanz ein ${ }^{6}$ ), und setzt sich dann unterhalb des, durch die sich berührenden Osscs petruse gebildeten Bodens der Hirncapsel nach vorne, oft bis zum Schnauzentheile des Schedels fort. Bisweilen legt sich der Knochen dicht unter die eben genannten soliden Schlussstiucke der Hirncapsel; in andern Fällen bleibt er aber von ihnen entfernt. Meistens näınlich bildet die obere Fläche des Sphenoüdeum basilare den Boden eines unterhalb der allseitig geschlossenen Ilirncapsel gelegenen, zur Aufnalhme mehrer Augenmuskeln bestimmten Canales, dessen obere Wandungen von den unteren Schlussknochen der Itirncapsel (Ussa petrosa), und dessen Seitenwandungen von absteigenden Fortsätzen der letzteren allein, oder zugleich von aufsteigenden Seitenfortsiitzen des $S_{p}$ henoideum lasilare gebildet werden. Das Sphenoüleum basilare der Kno chenfische besitzt also im Allgemeinen die Eigenthiimlichkeit, dass es kein unteres Schlussstück der eigentlichen Hirncapsel bildet, welche vielmehr unten von den paarigen, in der unteren Mittellinie an einan-

2) Bisweilen dienen diese Kunnchen auch zum Durclıschnitte des als Nervus hypoglo,ssus Auct. bezeichneten ersten Spinalnerven.

3) Abgebildet bei Cuvier und Valencieunes, Pl. II. Fig. 3. No. 6.

4) Abgebildet eberrlaselbst No. 16. - 5) \%. B. bei Diodon. - 6) Z. B. bei Gadus, Silurıs. 
der stossenden Os\&z petrosa begrenzt wird. Nur bei wenigen Kinochenfischen kömint eine kleine Stelle der Oberfläche des Splienoüdeum basilare in unnittelbare Berührung mit der Mypopleysis cerelorit), welche durch cine vor dem vorderen hande uer Ossu petrosu liegende Lücke der Schädchnsis herabrigt. Iäulig ruhet auf dem Splıenoüleum basilare mit einem absteigenden Stachel der sogenannte vordere Keilbeinkörper $\left.{ }^{8}\right)$ (Os sphenoüllewm anterius Cuv., Sphemoüleum superius Iallm.).

Die beträchtlichsten Knochen dieses Schedelsegmentes, welche die eigentliche Schedelcapsel unten schlicssen und den grössten 'Theil ihrer soliden Scitenwand bilden, sind die $0 s s a$ petros a ${ }^{9}$ ). Sie verbinden sich abwärts der Länge nach unter einander und stossen mit ihren hinteren Rändern an den vorderen Rand des Occipitale basilare und zum Theil auch an die Vorderränder der Occipitalia lateralia. Der vorderc Rand des Basilartheiles der Ossa petrosa stösst nicht unmittelbar an andere Schlussknochen der Schedelbasis, sondern endet frei und bildet dic hinterc Begrenzung einer Liicke, welche vorn gewöhnlich durch eine knorpelige oder ossificirte Querbrücke (Os splicnoïlenm anterius Cuv.) umschrieben, abwärts aber mit durch den schuppenförmigen hinteren Keilbeinkörper verdeckt wird. In die so entstandene Lücke scnkt sich die /ypmplyysis cerelıri. - Die Innenwand der Ossa petrosa trägt wesentlich zur Aufnahme des Gehörorganes und namentlich der Gehörsteine mit bei. Ist ein Augenmuskelcanal vorhanden, so verläuft er unterhalb dieser Knoehen, die zur Bildung seiner Seitenwände oft durch absteigende Fortsätzc beitragen. Diese letzteren schliessen dann an correspondirende Fortsätze des $O_{s}$ splieuoideum Uasilare sich an. - Durch Oeffnungen oder Canäle der O.s.s petrosa, mindestens durch vordere Ausschnitte derselhen, treten gewöhnlich drei Hirnnervenpaare: die Ncrvi abulucentes, faciales und trigemiui. - Es ist also bei den Knochenfischen durch die eingeschalteten, parige untere Schlussstuicke darstellenden, unmittelbar an das Basilare occipitis sich anschliessenden Ossa petrosa der hintere Keilbeinkörper von der unmittelbaren Bcgrcnzung und Umgürtung der Hirncapsel ausgeschlossen worden.

Aufwärts und hinterwärts findet sich am oberen Rande der Seitenfläche jedes $O_{s}$ petrosum ein Knochen, der hinten an das Occipitale extermum, oben an den Schlussknochen der Schcdeldecke (1/ prarietale) anstösst. Dieser, durch Function, Lage und Verbindung als $O$.

7) Z. B. bei den Gadoïlen. - 8) Z. B. bei Perca, Clupea, Salmo.

9) Haltmann hat in der a. S. S. S5. diese schon frïher von Anderen adop. tirte Deutung der hier ahgrhandelten Kinochenstiicke gerechtfertigt. Cnvier bezeichnet sie als grosse Krilheinfliigel (Alne magnae s. Alae temporales). Vgl. seine Ablildung klieser Knochen von Perca l. c. Tal). 1. No. J1. 
mastö̈leum zu br\%eichnende Knochen kömmt deutlich an der OberUaiche des Scledels z.1 Tage und besitzt in der Regel einen stielförmigen, nach hinten gerichteten Fortsatz, walcher, gloich denjenigen des Uccipitale extermum zur Befestigung des Extrenititengiurtels und starker Sehnen der Soitenmuskeln des Rumpfes dient. Seine innere, der Schedelhöhle zugewendete Wand trägt zu Aufnahume des Gehörlabyrinthes und namentlich der halbcirkelförmigen Canäle bei. Häufig erstreckt sich die Ossification dieses linochens nicht bis an seine innere Oberfläche, welche nicht selten knorpelig bleibt. Bisweilen verlängert sich das Us mostüirleum schuppenförmig uiber einen grossen Theil des Is petrosum; bei anderen Knochenfischen zerfällt es in zwei Kinochenstiicke 10).

An die vordere IIälfte des oberen Randes des $1 / s$ petroxumn scliliesst sich dis Os frontale posterims 11 ), ein Knochen, der an der hinteren Grenze des oberen Randes der Augenhöhle einen inehr oder minder betrïchtlichen Vorsprung (Processus orbitalis prosterior) bildet. Sein hinteres Rand berïhrt meist den vorderen des $/ s$ morstoüleum.

Zwischen den oloeren Raindern der Ossn mastwïlen und zum Theil auch der Fruntalia posterioria sind die 0.8 a parietalin als häufig paarige, sehr oft aber nur durch einen umpaaren Knochen reprisentirte obere Schlussstiicke eingekeilt, die nicht selten durch die nach vorn verlängerte Iinterhautsschuppe aus cinander gedrängt werden 12).

An der Stelle, wo dis Os frumble posterins, das Ms mastü̈demm und os petrusum sich berühen, findet sich, bestimmt zur Aufnahme des Suspensoriums der Kiefes", entweder nur eine lange schmale Gelenkgrube, oder hinter dieser noch eine zweite rundliche 13).

Es ward schon friiher erwihnt, dass an der Uebergangsstelle dej. gemeinschaftlichen Grehirn - und Gehörcapsel in das Orbitalsegment des Schedels eine Verengerung der Schedelhöhle Statt findet. So weit die Osse petrusa Basilarsticke sind, endet ilır vorderer Rand frei; an denjenigen Theil ihres Vorderrandes aber, der die aufsteigende Seitenwand des Schedels bildet und zugleich an den Vorderrand jodes $\boldsymbol{U}_{\boldsymbol{s}}$ frontale posterius schliesst sich als besonderes Knochenstuick jederseits ein Keil-

10) Cuvier hat diese beiden Stiicke unit besonderen Namen belegt: Das be" ständig vorknumeude bezeichuet er als $n_{s}$ mastoideum; das accessorische, wel. ches, wie er selbst beutertit, häufig fehlt, wie dies z. B. bei Esox, Muraena, Cyprinus der Fall ist, nennt er Os petrnsum. Hall in ann sieht das Mastoideum Cuv. als Ala temporalis an. Zur eigentlichen Begrenzung des Hirnes trägt es in der Regel gar nicht bei; es bleiht weist in ler Tiefe knorpelig, wie z. B. bei Esox, Saluo u. A. sehr leutlich zu erkennen ist. Es legt sich schuppenartig über das Os petrosum bei den Gadoülen.

11) Unter gleicher Benennung abgebildet bei Cuvier und Valencienues I. r. Tal. 1. Nin. 4.

12) Vgl. das in der Anmerkung 1. S. 22. Gesagte.

13) Eine Gelenkgrube ist z. B. vorhaulen bei Salmo, zwei bei Esox u. $\Lambda$. 
beinflügel (Ala magna ${ }^{14}$ ). Er vervollständigt die Seitenwand des Schedels, bildet eine Art unvollstiindiger vorderer Querwand, und vermittelt so, durch häutige, zum Durchtritte der Augennerven bestimmte Theile ergänzt, den Uebergang der breiteren Schedelhöhle ir den verengten Orbitaltheil. Iläufig werden die beiden Keilbeinflitgel an Schedelgrunde unter einander verbunden durch eine unpaare Querbriicke, die, naeh Cuvier's Vorgange, als vorderer Keilbeinkörper (Os splienoüleum anterius) bezeichnet wird.

Dieser vordere Keilbeinkörper ${ }^{15}$ ) ist immer sehmal, bildet die vordere Begrenzung der zur Aufnahme der Mypoplyysis bestiminten Schedelliucke und setzt sich oft abwärts in einen diunnen Stiel fort, der auf dem unter ihm verlaufenden $\boldsymbol{O}_{\boldsymbol{s}}$ sphenvïlleum lasilare ruhet. $\mathrm{Er}$ liegt bei den Fischen also oberhalb des hinteren $\boldsymbol{S}$ phenoüleum basilare. Bisweilen setzt sich der Körper dieses Knochens fort in einen dünnen Knorpelstiel, der nach vorn in die Basis der Schnauze übergeht, das Septum iuterorbitale trägt und mehr oder minder vollständig von dem hinteren Keilbeinkörper und dem Vomer eingeschlossen wird. In an1dern Fällen ist seine Verbindung mit diesem von der Sclnauze nach hinten sich erstreckenden knorpelstiele nicht nachweisbar. Bei einzelnen Gattungen von Knochenfischen scheint dieser vordere Keilbeinkörper uberhaupt zu fehlen oder nur in fibrös-häutigem Zustande vorhanden zu sein.

14) Bei den Salıuonen sind diese Knochen sehr ausgebildet, bei den Gatloiden sehr unbeträchtlich. Cuvier nennt sie Alae parvae s. orbitales und bildet sie so alb l. c. No. 14. Hallma $\mathrm{n} n$ that sie, nach dem Vorgange von Meckel, richtiger als grosse Keilbeinflügel bezeichnet. Hüufig erscheinen sie als partielle Ossificationen einer zusamuenhangenden knorpeligen Grundlage, wie man leicht nach Weg. nahıne der oberen Deckstiicke erkennt. Unterhalb der letzteren werden sie meistens durch eine knorpelige Querbrücke verbunden.

15) Es ist hier für diesen Knochen vorlänfig Cuvier's Benennung: vorderer Keilbeinkörper, beibehalten worlen. Es mag bemerkt werilen; wie auffallend die Uebereinstimumng zwischen diesem Knochen und dem hinteren Keilbeinkörper der Schlangen-Embryonen ist, wie ihn Rathke in seiner Entwickelungsgeschichte der Natter Tab. VII. Fig. 17. d. abbildet. - H all man n schlägt für diesen Knochen, weil er bei vielen Fischen mit einen abwärts gerichteten Stiele auf dem sogenannten hinteren Keilbeinkörper ruhet, den Naınen Sphenoüdeum superius vor. Diesen Stiel finde ich z. B. bei Perca, Lucioperca, Acerina, Belone, Salıno, Clupea, Ammodytes. - Hall mann macht in ll. a. Schr. mit Recht auf einen Irrthum Cuvier's aufinerksam, der diesen Knochen mit den abwärts verschmolzenen Seitenst ücken des Orbitaltheiles des Scherlels der Cyprinö̈len und Siluroïlen (Alae orlitales) confundirt. - Bei den Cyprinen bleibt der Knochen permanent knorpelig und vermittelt die Verbindung der Ossa petrosa. Bei Muraena ist er flach und knöchern und erınangelt des abwärts gerichteten Stieles. Bei Esox ist er knorpelig und setzt sich nach vorn durch einen Knorpelstiel in den Knorpel der Schnauzenbasis continuirlich fort, der vom Sphenoïderm posterius und vom Vomer abwärts bedeckt wirl. Bei.Pleuronectes, Gadus, Cottus habe ich ihn verwisst. 
3. Die Höhle der Gehirncapsel verlängert sich nach vorn in den verengten und versehmälerten Orbitalabschnitt des Schedels, verliert aber lier, um den Augen Raum zu lassen, an 'Tiefe. Die Fortsetzungen der Scitenwäindc treten daher gewöhnlich, nachdem sie eine mehr oder minder tiefe obere Iöhle (wie bci den Cyprinen), die jedoch oft nur durch einen engen Canal repräscntirt ist, unsclrlossen haben, abw:ïrts zur Bildıng eines selten knöchernen, meist fibrösen Septum interorbifale zusammen. Dieser ruhet auf dcin vorhin beschriebenen, von der Schnauzenbasis nach hinten zu Cuvicr's vorderen Kcilbeinkörper siclı erstreckenden, Knorpelstiel. Die obercn Deckstücke des Orbitalabschnittes bilden die gewöhnlich paarigen eigentlichen Stirnbeine (Ossa frontalia principalia). Diese bilden, seitwärts vorragend, zuglcich das Dach der Augenhöhlen, das bei einigen Familien durch accessorische Supra orbitalknochen ${ }^{16}$ ) erweitert wird. Bestehen die Seitenwandungen des Orbitalsegmentes aus eigenen, eine tiefere Höhle seitlich unschliessenden Knochenstücken, so hat man diesc letzteren als Alae orlitiales ${ }^{15}$ ) zu deutcn. Durch die Höhle oder den engeren, oberen Canal des Orbitalsegmentes treten dic Geruchsnerven bis an die Grenze des Schnauzenthciles des Schedels. Dic Grenze beider vorderen Schedelibschnitte wird durch die hier seitlich und auswärts sich anschlicssenden $0 . s \&$ a froutalia auteriora ${ }^{18}$ ) bezeichnet. Jeder dieser knochen bildet an der vorderen Grenze der Angenhöhle einen gewöhnlich integrirend ossificirten, selten knorpelig bleibenden Processus orbitalis auterior. Durch eine gewöhnlich ziemlich weite Deffnung eines jeden $O_{8}$ froutale anterius tritt der Geruchsnerv der entsprechenden Seite hindurch. Sehr selten werden blos die Aussenwände beider Foramina pro nervis olfactoriis von den Ossa frontalia anteriora gebildet, während ein zwischen diesen beiden linochen liegendes unpaares Knochenstiuck den Innenrand beider Oeffnungen vervollständigen hilft. Dieses unpaare Zwischenstiuck 19) ist als erste Andeutung einer eigencn Lamina cribrosa ossis ethmö̈dei anzusehen.

Der Orbitaltheil des Schedels setzt sich in den Schnauzentheil desselben fort. Diescr Schnauzentheil (Cuvier's Os ethmö̈$\left(\{e u m){ }^{20}\right)$ ist bald oberflächlich, bald vollständig ossificirt; bald ist er solide, bald ausgehöhlt; bald kurz, bald sehr verlängert. Er bildet stets

16) Z. B. bei den Cyprinen, bei Cyclopterus, bei Esox u. A.

17) Z. B. bei den Cyprinoïlen, den Silurö̈den, wo die beiden Kunochen an der Basis zugleich ringformig verwachsen sind.

18) Abgebildet bei Cuvier und Valenciennes 1. c. No. 2. - Sie bleiben knorpelig bei den Muränoïden.

19) Dieses bisher ïbersehene Stück fand ich constant bei den Gadoïden.

20) Aligebildet bei Cuvier und Valenciennes I. c. No. 3. 
die sulide Grundlage der beiden Geruchsgruben. Sein vorderstes. Endr lient dem Oherkiefer-Apparate zur Stiitze.

Dic Basis der Schnauze und zum Theił auch schon de's Orbitalsegunentes wird abwärts durch den oberflächlich anliegenden Vomer 21 ) gebildet. Dieser schliesst sich an dis vordere Ende des Os sphenö̈. deum. lusilure, gewinnt vorn an Breite und leyt sich, nachden er den hinterwairts gerichteten Knorpelstiel der Schnauze unnschlossen hat, meist lose und schuppenförmig unter den Schnauzentheil des Schedels. In der Regel ist er mit Zaihnen besetzt. Gewölnlich gewïhrt er auch dem Oberkiefer-Apparate Stützpunkte.

[Die Grundlage der bisherigen Dentungen tos Fischschedels hat Cuvier geliefert. S. dessen Rigne animal, Tome 3. PI. X. (mit Albildmugen von Gadus Morrhua), und Hist. uat. Il. poissons, Vol. 1. p. 316 sqq. PI. 1-3. (Init Abbildun. gen von Perca fluriatilis). Zahlreiche Abbildungen von Fischschedeln und Skeleten unit oft verfehlten Dentungen und iiberhanpt sehr mangelhaftem Texte siehe bei Rosenthal, Ichthyotouische Tafeln, Berl. 1812-1822. 4. - Bessere, gleich. falls zahl reiche Abbildungen bei A gassiz, Poissons fossiles, an vielen Stellen iles Werkes; der Verf. hat allmälich mehre von den $C$ nvier'schen theilweise abwei. chende Dentungsversuche der Knochen des Fischsehedels publicirt. - Abbildun. gen von Fischschedehn mit zun Theil eigenthiimlichen Dentungen ihrer Theile in den Scbrifren von Oken, Spix, Bojanus, Geoffroy St Hilaire, Carus und Wagner. - An monographischen Arbeiten sind zu vergleichen: A reudt, Diss. de capitis ossei Esocis lucii structura, Regiom. 1824. 4. und eine mir erst kürzlich bekannt geworlene Dissertation von Zaeringer, Quaedaun de historia naturali atque descriptio sceleti Salmonis farionis, Friburg. 1829. 8. (unter Schultze's Leitung). - Ein wahrer Fortschritt geschah durch Hallmann's Vergleichende Osteologie des Schläfenbeines, Hannover 1837. 4. Mit Abbild., in so fern der Verf. nicht anf Beschreibung trockener, in ven Huseen vorgefun. dener Schedel sich beschränkt, sondern mehre Kinochen in Bezug auf die von ilnen umschlossenen. Weichtheile, die durchtretenden Nerven 11. s. w. vergleichend mitersuchte. - Fleissig, aber nicht in den eben genannten Sime bearbeitet, sondern nur anf Untersuchung trockener Scherlel gestiitzt, ist die Arbeit von Köst. lin: Der Bau des knöchernen Kopfes in den vier Klassen der Wirbelthiere. Stnttg. 1844. 8. - Die ältere Literatur findet man sehr vollstänlig und kritisch aufgeführt bei Cuvier und Valenciennes 1. c. T. 1. 1. 313 sqq.]

\section{Vou den Schleimröhrenknochen des Schedels.}

\section{§. 13.}

Aecessorische Knochen des Schedels, welche zwar bei den meisten, aber keinesweges $\left.{ }^{1}\right)$ bei allen Knochenfischen vorkommen, sind diejenigen, welche nach Cuvier als Ossa wasalia, iufraorlitalia und sapratemporalia bezeichnet werden. Das sogenannte $O_{s}$

21) Abgehildet ebendaselbst No. 16.

1) Sie fchlen z. B. hei den ueisten Lophien unl Plectognafhen. Sie sinl bei iudern Fischen unvollständig, wie z. B. bei Belone, Hemiramphus, Exococtus. 
"asale liegt als unehr oder minder schuppenförmige Knochenplatte oder als röhrenförmiges knöchelehen gewöhnlich einwiirts von der Nasengrube an oder auf dem Sclinauzentheile des Schedels. Der vorderste der sehr verschiedenartig gestalteten $\ln$ fraorbitalknochen ${ }^{2}$ ) ist meistens seitlich und auswïrts von der Nasengrulbe an den vorderen (gewöhnlich von dem Os fromtale asterins gebildeten) Augenhöhlenfortsatz befestigt und bildet eine vordere und äussere Begrenzung der Augenhöhle. An ilın schliesst sich hinten ein ähnlicher Knochen an, der in Verbindung mit zwei oder drei ilım folgenden einen unteren und äusseren Ring um die Augenhöhle bildet, indem der letzte der selben an den hinteren Augenhöhlenfortsatz (und namentlich an das Os fromtale posterius) befestigt zu sein pflegt. Bisweilen erlangen diese Knochen eine solche Ausdehnung, dass sie das Praeoperculum fast erreichen oder selbst mit ihur verwachsen und dann, auch unter einander schr innig verbunden, einen vollständigen äusseren Gesichtspanzer bilden, der den Gaumenapparat und das Unterkiefer-Suspensorium rerdęckt ${ }^{3}$ ). - Nicht selten 4) schliessen sich mehr oder minder unmittelbar an den hintersten Infraorbitalknochen mehre andere Knochenstücke an, welche den iusseren, zur Seite der oberen Ilinterhauptsgegend befindlichen Kopfknochen (dein Os froutule pusterius, mastoüdleum 11. s. w.) aufliegen, in ihrem Bauc jenen analog sind und bis zur Anhefungsstelle des Schulterguirtels am Schedel reichen oder iuber die Zinken des Os suprascapulare weggehen. Cuvier hat diese linochen, nach Bakker's Vorgange, Ossa supratemporalia genannt.

Die zahlreich und verschiedentlich angestellten Vergleichungen die ser Knochenstiicke mit typischen Kopfknochen höherer Wirbelthiere ermangeln iiberzeugender Begriindung ${ }^{5}$ ). Untersucht man diese Knochen nïher, und namentlich an frischen Köpfen, so findet man, dass sie entweder bald einfache, bald ramificirte Canäle cinschliessen 6), oder durch das Hinzutreten von aponeurotischen Theilen i) zur Bildung von Canälen oder von IIöhlen verwendet werden. Diesc Canäle oder Höhlen sind inwendig von einer schleimhautähnlichen Fortsetzung der äusseren Haut ausgekleidet und miinden durch mehr oder minder feine und

2) Die grösste Ausbildung erfahren diese Knochen bei den Sciänö̈len und hei Lepidoleprus. S. Abbildungen der Ersteren bei $\mathrm{Cuvier}$ und Valenciennes Tab. 140. Sie stellen weite Hölılen dar, die aussen theils durch zierliche Kno. chenbrücken, theils häıtig geschlossen werden. Der vorderste Infraorbitalknochen zeichnet sich häufig durch seinen betrïchtlichen Unfang vor den folgenden aus.

3) Am stärksten bei Trigla; mehr oder minder bei der ganzen Fannilie der Cataphractell.

4) Z. B. bei Gadus, Lepiloleprus.

5) Zusammengestellt in meineın Aufsatze. S. S. 31.

6) Einfache Canäle z. B. bei den Cyprinen, rauificirte bei den Clupeen, seb. fein vertheilte bei den Cataphracten.

·) Bei den Gadoïden, Lepidoleprus, Sciänoïlen u. s. w. 
zahlreiche Oeffnungen an die äussere Itautoberfläche. In die Höhle odcr den Canal jedes solchen Knochens treten durch eigene Oeffnungen $\mathrm{Ner}$ ven und Gefässe, und in der Nähe der letzteren findet man häurig einfache odler ramificirte kleine: Drïsensebläuche ${ }^{8}$ ), bestimmt zur Absonderung von Schleim, der die äussere Oberflïhe des Kopfes schlüpfrig erhält. Es sind also diese Knoehen die Träger oder Stiitzen eines schleimabsondernden Apparates der Kopfhaut.

Da aber andere Theilc dieses Schleim absondernden Apparatcs in eigenen Röhren odcr Canälen auch über die Oberfläche anderer Kopfknochen, welehe nieht als accessoriseh betrachtet werden diurfen, sich erstreeken ${ }^{9}$ ), so bedarf es des Bewcises, dass die hier abgehandelten Knochen wesentlich nur dem Schlcim absondernden Apparate angehören. Dies gcht aber aus folgenden Thatsachen hervor: 1) Bei vielen Knochenfischen stimmen Ossa nasalia, infraorbitalia und supratemporalia in ihrem wesentliehen Verhalten völlig überein mit denjenigen Trïgern jenes Absondcrungsapparates, welche anderen Schedclknoehen blos oberflächlich aufgesetzt sind oder welchc durch deren Substanz. hindurehdringen 10). 2) Bei Anderen finden sieh unter der Haut läng des ganzen Rumpfes riieksiehtlieh ihres Baues und ihrer Function ganz analoge Knochen wicder und erscheinen zugleich als Fortsetzungen dieser Kopfknochen 11). 3) Bei einigen Knoehenfisehen sind, statt jener Knochen, auch am Schedel, ähnlich wie an Rumpfe, verwachsene Sehuppen vorhanden, in denen der genannte Absonderungs -Apparat verläuft 12). 4) Bei andern werden die Knochen blos durch gegliederte Röhren vertreten ${ }^{13}$ ), wahren und unmittelbaren Fortsetzungen derjenigen Röhren, welehe hier auch am Rumpie den Schleim absondernden Apparat der Haut umschliessen. 5) Bei anderen fehlt am knöehernen Theile des Kopfes der Schleim absondernde Apparat mit seinen cigenthiimliehen Knoehen gänzlich 14). 6) Bei andern verläuft, bei Abwesenheit eigener Knochen, jener AbsonderungsApparat, innerhalb der meist sehr dicken IIaut und zwar nehmen die in dieser gelcgenen häutigen oder solideren Röhren denselben Verlauf, wie jene Knochen bei anderen Fischen ${ }^{15}$ ).

8) Am deutlichsten bei Gadus morrhua, eallarias; aueh Cyprinus Brama; die Nerven besonders stark bei Lepidoleprus, Corvina, Sciäna u. s. w.

9) S. §. 22. - 10) \%. B. bei Gadus, Lepirloleprus, den Sciänoïlen, Cottus, vielen Pereoïden. - 11) Gadus, Cottus, Pleuronectes u. s. w.

12) Z. B. bei Scomber, Thynnus mit Ausnahme des vordersten, ossificirten. Knochens.

13) Bei allen Muränoïden, den Siluroïden.

14) Bei den Plectognathen: Tetrodon, Diodon, Ostracion, bei den Lophien: Lophius, Malthaea u. A.

15) Bei mehren Tetrodon-Arten; auch Raja, Rhinobatus, Chimära könnten obwol Knorpelfische - als beweisent hier angeführt werden, indeu die Knorpel. röhren ihres Schleim absondernden Apparates ịn Wesentlichen einen ganz ana- 
[Diese Angaben beruhen auf Untersuchung von melir als 100 Fiscligattungen. Eine vorläufige Mittheilung derselben ward gegeben in Froriep's Notizen, April 1842, No. 469.]

\section{Vou Kiefer - Gaumenapparate.}

\section{ร. 14.}

Der Kïfer-Gaumenapparat der Knorpelfische bietet eine so ausserordentliche Mannichfaltigkrit der Bildungen dar, dass es erforderlich ist. soin Verhalten je naclı den einzelnen Familien kurz zu schildern.

1. Bei Branchiostoma findet sich nur ein den Mund umgebender, reifenförmiger, den Mundknorpeln vieler andern Knorpelfische entsprechender Knorpel. Er ist aus vielen Sticken zusammengesetzt, welche in die Knorpel der Mundcirren auslaufen 1).

2. Bei Ammocoetes treten zuerst knorpelige Gaumenleisten und eine von ihnen eingeschlossene knorpelige Gaumenplatte auf, welche durch ihr hinteres Ende mit der Scliedelbasis verwachsen ist, und auf welcher der Nasengaumengang ruhet, Ober- und Unterkiefer, so wie alle Lippenknorpel fehlen gänzlich 2 ).

3. Bei den Myxinoïden breiten sich die beiden Schenkel des Os basilare fliggelförmig aus und bilden einen Gaumen-Schlund-Rahmen, mit welchem dann noch mehre abgesonderte Knorpel und Knochen, namentlich eine lange Gaumenplatte mit Gaumenleisten, auf welcher ersteren der Nasengaumengang ruhet, ferner dic knöcherne Nasenstiitze, das Knorpelgerüst des Schlındsegels und eigenthiimlich gestaltete Mundknorpel verbunden sind. Der untere Mundrand wird, in Ermangelung eines Unterkiefers, vom Zungenbeine gebildet ${ }^{3}$ ).

4. Bei Petromyzon 4) tritt von den knorpeligen Seitenwänden des Schedels ein unter dem vorderen Theile der Basis cranii gelege nes kurzes, knorpeliges Gaumenstiick ab, auf welchem der Nasengaumengang liegt. Vorn und hinten, von der Seite dieses Gaumenknorpels ausgehend, bilden zwei sich vereinigende Fortsätze einen mit einer Membran ausgefiiltten Knorpelhogen, auf dem das Auge ruhet. Am vorderen Rande des Gaumenstückes befestigt sich ein gewölbtes hinteres Mundschild und weiter nach vorn liegen eigenthümliche Knorpelstiicke

logen Verlauf haben, wie seine knöchernen Grundlagen bei den useisten Knochenfischen. Ich werde in einer ausfülrliclien Arbeit, die von zahlreichen Abbildun. gen begleitet ist, auf diesen Gegenstand zurückkoinınen.

1) Ueber Branchiostoma vgl. die angeführten Schriften von $R$ athke und von Miiller und Retzius.

2) Abbildungen von Ammocoetes. Müller l. c. Tab. 4. Fig. 6-10.

3) Abbildungen von Bdellostoma. Müller 1. c. Tab. 3. Fig. $1-7$; von Myxine ibil. Fig. 8. 9. Tab. IV. Fig. 11.

4) Abbild. von Petromyzon marinus. Müller l. c. Tab. 4. Fig. 1-5. 
zur Deckung und Ungebung des Mundes. Dieser wird hier von cinem eigenthümlichen Lippenringe begrenzt.

5. Bei dell Chimären ${ }^{5}$ ) sind auffallend gesialtete Lippenknorpel vorhanden. Ein voun Schedel getrcnnter Oberkiefer-Gaumen-Apparat fellt gänzlich. Die continuirlich vorwairts sicl fortsetzende Schedelbasis bildet vorn cinen zahntrigenden Alveolarrand. Der Unterkiefer ist vom Schedel getrennt, hangt aber nicht an einem beweglichen Suspensorium, sondern articulirt mit cinem von der Knorpelmasse des Schedels ausgchenden unbewegliclien Fortsatzc.

6. An die Chimäron schliesst sich durch den Mangel eines vom Schedel getrennten Obcrkiefer-Gaumen-Apparates, durcl den Besitz cigenthümlicher Labialknorpel, und endlich durch dic nicht erfolgte Ablösung des das Suspensorium des Unterkicfers bildenden Quadratjocibeines die Gattung Lepidosiren $\left.{ }^{6}\right)$, entfernt sich aber wieder durch den Besitz. eino's eigenthiumlichen, dem ossificirten Deckstiicke des Schedels mittelst Bandmasse verbundenen zahntragenden Zwischenkicfers, so wie dureh die Ossification seines Quadratjochbcincs.

7. Bei den Plagiostomen ") finden sich, ausser lianfig rorkommenden accessorischen Labialknorpein, zahntragende olserc und untere Knorpelstücke, die durch cin Suspensorium am Schedel aufgychängt sind und die Kiefer hilden. Das Suspensorium bestelıt gewöhnlich aus aincm einzigen Knorpelstiick, zu welchem nur bei cin\%elnen Gattungen ein vorwärts gerichtr:tes Knorpelstiick linzutritt, das inan den Cuvierschen $O s$ jugale der Knochenfische verglichen hat. Ein bei viclen Rochen an der vorderen Wand des Spritzloches gelegener Knorpel ist als Aequivalent des Os pterygö̈leum $C u v$. der Gräthenfische angesehen worden. Nur bei einer Gattung von Rochen finden sich Knorpel, die den Gaumenbeinen (Ossa palatina Cuv.) der Grathenfische analog zu sein scheinen. - Die Mundthoile sind nur bei wenigen, zur Fanilie der Torpedines gehörigen Plagiostomen vorstreckbar.

8. Bei den Störon 8) liegt unter der langen knorpeligen Sclınauze,

5) Abhild. von Callorlyunchus antarctiens. Müller l. e. Tab. 5. Fig. 2.

6) S. die Abbildungen und die ausführlieheren Mittheilungen üher diesen Gegenstand bei $\mathbf{B}$ isehoff in d. a. Schr.

7) Abbild. von Nareine brasiliensis. Müller l. c. Tab. 5. Fig. 3. 4.; von Squatina laevis ibid. Fig. 5. u. 6.; von Rhinoptera brasiliensis und Myliohates aquila, T'ab. 9. Fig. 12. 13. - Die Labialknorpel sint am vollständigstẹn von Müller besehrieben worden. Sie finden sieh besonders bei den Haien; nnter den Rochen koınmen sie bei Nareine und Rhinoptera vor. Der den Gaumenbeinen verglichene Knorpel ist von Henle bei Nareine brasiliensis aufgefunden worden. - Der joshbeinähnliehe Knorpel an Suspensorium kömnt bei Rhinoptera und Myliobates vor. - Die Abbildungen, welche Rosenthal in seinen ichlyyotomischen Tafeln gegeben, sind oft ungenau und stehen den Miiller'sehen in jeder Bezichung nach.

8) Abbild. von Aecipenser Ruthenus, Müller l. ep Tab. 9. Fig. 10. u. 11. Die 
in dic ihr Schedel sich verlängert, ein sehr eigenthiimlich gebildeter vorstruckbarer Kiefer-Gaumenapparat, der an dem Schedel durch ein aus dre Stiicken bestchendes Suspensorium befestigt ist, das demjenigen vieler Knochenfische entspricht. Von diesen drei Stiicken ist nur das oberste ossificirt. Der Kiefer-Gaumenapparat selbst besteht theils aus knöchernen, theils aus knorpeligen Stïcken. Eine paarige Knochenplatte ist dem $\boldsymbol{O}_{\boldsymbol{s}}$ palafinum $C u v$. der Gräthenfische, eine paarige Knorpelplatte dem os pterygö̈leum derselben verglichen worden. Ausserdem kömmt noch am hinteren Theile des Gaumenapparates eine unpaare accessorische Gaumenplatte vor. Ein Paar Randstiicke sind als Oberkiefer und Zwischenkiefer gedeutet worden. Der Unterkiefer besteht aus zwei Seitenhälften.

9. Bei den Spatularien ${ }^{9}$ ) ist der Kiefer-Gaumenapparat gleichfalls mittelst eines aus drei Stucken bestehenden Suspensorium am Schedel befestigt, von welchen wieder das oberste ossificirt ist. Der Oberkicfer - und Gaumenapparat liegt mit scinem vorderen Ende unter dem Schedel, ist aber nicht vorstreckluar, wie bei den Sturionen. Eine aussere paarige Knochenlamelle repräsentirt den Oberkiefer; ein Zwischenkieferstuick fehlt. Zwvischen Oberkiefer und Gaumenbein liegt cine dem Os pterygoülcum Cur. der Knochenfische verghlichene parige, knorpelige Lamelle. Eine hinter dieser vorhandene paarige, knöcherne Lamelle betrachtet man als Aequivalent des Os pulatiuum $C_{u v}$. der Gräthenfische. Der Unterkiefer ist knöchern.

[Die sorgfältigsten anatomischen Untersuchungen über den Kïefer-Gaumenapparat der linorpelfische sind von Müller angestellt nnd in dem ersten Theile seiner Vergleichenden Anatonie der Myxinö̈len, erläutert durch treffliche Abbildungen, niedergelegt worden. Wïller hat zugleich die früheren Deutungen dieser Theile bei den verschiedenen Knorpelfischen kritisch gemustert und ist namentlich z.ı dem Resultate gelangt, dass den Cyclostomen ein wirklicher Oberund Unterkiefer fehlt, indem ihre nach röllig abweichenden Typen geformten Mund- und Lippenknorpel als solche Gebilde nicht zu betrachten sind; ebenso verwirft er, mit Recht, die Ansicht Cuvier's, dass die Labialknorpel der Haien, ver Chimären und einiger Rochen für Trieferstücke zul halten seien. Dagegen sucht er den Kiefer-Gaumenapparat der Störe, Spatularien und Plagiostomen auf denjenigen der Knochenfische zu reduciren und vergleicht ancls den zahntragenden Alveolarrand des Chimärenschedels dem Oberkiefer und Zwischenkiefer der Gräthenfische. Die Haltbarkeit der Mïller'schen Deutungen ist später von

Deutung der drei Bestandtheile des Kiefer-Suspensorium bei den Stören, welche Miiller zweifelhaft geblieben ist, scheint mir durch eine Vergleichung derselben mit den in gleicher Anzahl vorhandenen der Gattung Silurus erleichtert zu werden. Nachträglich bemertie ich, dass Müller selbst so eben diese Vergleichung angestellt hat. S. den eben erschienenen Jahresbericht im Gten Hefte des Archi. ves 1843.

9) Abbill. von Planirostra edentula Müller 1. c. Tab. V. Fig. 7. 
Reichert in Frage gestellt worlen. Sie scheinen in der That, bevor sie adop. tirt werlen, noch sorgfialtiger rergleichender Prïfung zu bedïrfen.]

$$
\text { §. 1\%. }
$$

Bei d'n Kuochenfischen ist der Kiefer-Gaumenapparat bei weitem zusamnengesetzter. Als Oberkicfer und Zwisehenkicfer betrach. tet man Knochenstiicke, wolche am oheren Rande des Einganges in dic Mundhöllle gelegen sind und incistentheils einen hohen Crad von Beweglichkeit besitzen, ibrigens jedoch riicksichtlich ihres Baues, ihrer Verbindung und der Anzahl der sic zusammenset\%enden Knochenstucke eine schr grosse Mannichfaltigkeit darbicten.

Bei den meisten Knochenfischen liegt der aus zwei paarigen und gewöhnlich symmetrischen Hälften gebildete Zwischenkiefer 1) vor dem Oberkicfer, ist umfänglicher als dieser, bildet den ganzen oberen Kieferrand odel einen grossen Theil dessclloen, zcichnet sich durch seine Freibeweglichkeit aus und ist in der Regel allein zahntragend. Er besteht meist aus zwei in der oberen Mittellinic durch Bandmasse, selten durch Naht vereinigten bogenförmigen Absehnitten. An der Verbindungsstelle besitat jeder cinen aufsteigenden $\Lambda$ st von sehr verschiedener Länge, welcher durch elastische Bänder und Gelenke mit dem vorderen Theile der Schnauze bald unmittelbar, bald durch Vermittelung zwischenliegender Knorpel-oder Knochenstiickchen verbunden zu sein pflegt. Dic Länge des aufsteigenden Astes und seine Lcichtbeweglichkeit gestatten vielen Fischen diesen Kiefertheil bedeutend vorzustrekken. Seltener ist dieser Zwischenkiefer frster mit dem iibrigen Schnauzengeriiste verbunden oder angewachsen. - Der Oberkiefer licgt bei der Mehrzahl der Knochenfische hinter dem Zwischenkiefer und ihm parallel und besteht dann aus zwei in der Mittellinie sich nicht fest verbindenden Seitensehenkeln. Das obere Ende jedes dieser Sehenkel pflegt mit dem Vomer, dem Intermaxillare und dem Gaumenbeine dureh Gelenke beweglich verbunden zu sein. Jeder Seitenschenkel besteht meistens aus cinem einzigen Stiicke, seltener aus zwei oder mehren

1) So verhält es sich bei den meisten Knochenfischen, besonders aber den Acanthopterygieru. Ein unpaares Intermaxillare besitzt Diodon; es kömut nach Müller auch bei Mormyrus vor. Durch Naht sind die beiden Schenkel des Zwischenkiefers verhunden, z. B. bei Tetrodon; in der ganzen Länge verbunden sind sie bei Belone. - Die aufsteigenden Aeste sind sehr stark entwikkelt bei Zeus, Vomer, Labrus, Anarrhichas u. A.; sie verbinden sich eng oder verschmelzen bei Cyprinus, Cyclopterus; sie werden unbedeutend bei Saluo, Clupea, und verschwinden bei Silurus, Muraena. Bei diesen letztgenannten Fischen, so wie auch bei Andern, z. B. Belone, Xiplias, hört die freie Bewreglichkeit des Zwischenkiefers auf. Bei vielen bildet er mit dem Oberkiefer einen gemeinschaftlichen Bogen, z. B. bei den Salmonen, den Characinen, Esocinen, den Clupeen u. A. - Bei den Plectognathen fiudet eine innige Verschunelzung des 0berkiefers mit dem Zwischenkiefer Statt. 
Stiicken \% - Bei viclen Knochenfischen liegt der Obcrkiefer nicht als ein zweiter Bogen binter dem Zwischenkiefer, sondern bildet mit dicsem letzteren, der mitten zwischen seine beiden Seitenschenkel geschoben ist, eimen zusimmenhangenden, meist beweglichen, selten unbeweğlich am Schedel befestigten Bogen oder selbst cinen Schnabel. In der Familic der Plectognathen sind Oberkiefer und Zwischenkiefer völlig verwachsen.

Der Unterkiefer der Knochenfische ist durch ein eigenthümliches, aus mehren Stuicken bestehendes Suspensorium am Schedel befestigt und an den Innenrand dieses Suspensorium, so wic namentlich an das Gelcnkstiick, das den Unterkiefer trägt, schliessen sich mehre bis zum Oberkiefer reichende Knochenplatten, welche unterhalb der Angenhöhle gelegen, als Gaumenstücke betrachtet werden. Meistens verbinden sich dieso Gaumenstiicke nur vorn durch Grelenk mit der als Vomer bezeichneten Schnauzenbasis, mit dem Oberkiefer und dem Frontale auterius; seltener lehnt sich der grösste Theil ihrer Innenränder mehr oder minder fest und unbeweglich an das Os sphenoüdeum posterius.

Das cigntliche Suspensorium des Unterkiefers besteht mindestens aus drei, gewöhnlich aber aus fünf Stuicken ${ }^{3}$ ). Das oberste diescr Stiicke greift in der Regel ein in eine lange, an der oberen Scitenwandung des Schedels iiber dem Felsenbeine gelegene einfache oder doppelte Gelenkgrube und ist nur selten unbeweglich mit dem Schedcl verwachsen 4). An dem obcren Theile scines Hinterrandes trägt dies Stuick einen gewöhnlich runden Gelenkhöcker zur Einlenkung des Operculum, des obersten Stiickes des Kiemendeckels. $-\Lambda \mathrm{b}$ wärts steigend wird dieser Knochen in der Regel stabförmig. Diese stabförmigc Verlängerung ist häufig theilweise knorpelig oder durch knorpelige Substanz unterbrochen und erscheint so als ein gesonderter Knochen, der sich einwärts vom Praeupereulum und vom eigentlichen Träger des Unterkiefergelenkes bis in die Nähe dieses Gelenkes erstreckt. Bisweilen erkennt man, dass er hier durch uniegelmässig gestaltete, schwer zu isolirende knorpelige Masse in das Gelenkstuck des Unterkiefers übergeht und auf diese Weise mit einem an der Innenseite des Unterkiefers gelegenen und in dessen Höhle nach vorn verlaufenden

2) Dic Zusammensetzung des Oberkiefers aus mehren Stücken findet sich z. B. bei Esox, bei den Salmonen, den Clupeen, einigen Scombernïlen, besonders aber bei Lepidosteus. Der Oberkiefer tritt gegen den Zwischenliefer bisweilen schr zurück, wie z. B. bei Belone, wo der lange Schnabel einzig durch die beiden der Länge nach verlundenen Zwischenkiefer gebildet wird. Ganz rudimentïr oder fehlend ist der Oberkiefer bei deu Siluroülen; vielen Aalen fehlt er ganz.

3) Drei Stücke sind vorhanden bei den Siluroülen; sie entsprechen Cuvier's Temporale, dem Praeonerculum und Cuvier's Os jugale. Eine Reduction dersethen findet auch Statt bei den Plectognatlien und den Murinoïden.

4) \%. B. bei Diodon. 
Knorpelstreifen (Meckel'scher Knorpel) locker zusammenhangt. Cuvier hat das mit dem Schedel durch Gelenk verbundene Stiuck 0 \& temporalc, die stabförmige Verlängerung von dem Punkte an, wo sie durch Knorpelmasse vom vorigen Knochen sich scheidet, os symple. cticum genannt. An dieses 0 s symplecticam oder an die Stelle, wo es vom $O_{s}$ iemporale abgeht, befestigt sich gewöhnlich das hinterste Stiuck des Zungenbeinbogens durch einen Fortsatz, den Cuvier $\boldsymbol{O}_{\text {\& }}$ stylö̈deum nennt.

Unterhalh des Gelenkhöckers für das Operculum lehnt sich an den hinteren Rand des Os temporale ein mehr oder minder bogenförmiger Knochen, Pracoperculum, der abwärts und vorn unter den eigentlichen Trüger des Unterkiefergelenkes tritt und dieses letztere fast immer erreicht. Es ist nur selten mit dem hinteren Rande des Os temnporale unbeweglich verbunden $\left.{ }^{5}\right)$. Bisweilen aber verwächst es mit denjenigen abwärts verlängerten Schleimcanal-Knochen (Ossa iufraorliialia), welche sonst einen einfachen Infraorbitalring bilden. Geschieht dies ${ }^{6}$ ), so wird das Unterkiefer-Suspensorium mit dem ihm verbundenen Gaumenapparate von einem Schilde mehr oder minder vollsłändig überwölbt. Bei den meisten Knochenfischen ") nimmt das Pracoperculum einen bogenförmigen, zum Unterkiefer hin sich verlängernden und in dessen Aussenwand sich fortsetzenden Arm des Schleimcanales der Haut in Knochenrinnen oder fest angewachsenen Knochenschuppen auf.

Ueber dem vorderen und unteren Ende des Praeopcrculum liegt das eigentliche Gelenkstück, das den Unterkiefer trägt, von Cuvier als $O s$ jugale bezeichnet. - Zwischen dem vorderen und unteren Rande des $O_{s}$ temporale, dem Praeoperculum und $O_{s} j u g a l e$ ist ein meist flacher Knochen gelegen, den Cuvier $O s t y m p a n i c u m$ nennt.

Von den vorderen und oberen Rändern dieses Os tymprnicum und des Os jugale aus erstreckt sich eine, meist aus drei Stiicken bestehende Knochenfläche zur Schnauzengegend des Schedels und zum Oberkiefer auf - und vorwärts, welche den Gaumenapparat bildet 8). Den obersten und vordersten dieser Knochen, welcher durch ein Gelenk

5) Bei den Plectognathen. Die Verhältnisse des Praenperculum bei dieser Familie, bei den Sihurö̈len und den Muränö̈den lassen keinen Zweifel darüber aufkoinmen, dass dieser Knoehen - wie dies auch sehon Meekel, Rathke, Reiehert u. A. angenommen - wirklich dem Kiefersuspensorium und nieht dem Kiemendeekel-Apparate angehört.

6) Bei der Familie der Cataphraeten, namentlicls der Gattung Trigla.

7) Ausnahmen von dieser Regel bilden die Plectognatien, die Lophien. Am entsehiedensten tritt jenes Verhältniss dagegen hervor bei den Aalen.

8) Bei einigen Familien verküınıert dieser Gaumenapparat, nanentlieh bei den Siluroiden, Erythrinen, Muränoïden; besonders bei Murïnophis Helena. Der Innenrand des Gaumenapparates stosst bisweiden an das Sphenoüdeum basilare, z. B. bei Diodon. 
mit dem Schnauzentheile des Schedels, meist aber auch mit dem vorderen Stirnbeine und dem Oberkiefer verbunden ist, betrachtet man nach Cuvier sehr allgemein als Gaumenbein, Os palatiuum. Es verläuft bisweilen dem Oberkiefer parallel und ist häufig mit Zähnen besetzt. Von den hinter ihın liegenden, die Verbindung mit dem Unterkiefer-Suspensorium bewirkenden beiden Knochen hat man den äusseren, an das Os jugule sich anlegenden Knoehen Os transversum, den inneren os pterygoülleu $\mathrm{m}$ genannt.

Der Unterkiefer besteht bei den meisten Knoehenfischen aus zwei vorn durch Bandmasse verbundenen Aesten, deren jeder häufig einen Processus coronoülleus besitzt. Meistens besteht jeder Unterkieferast aus drei bis vier Stileken: 1) dem vorderen $O s$ dentale, dessen oberer Rand gewöhnlich zahntragend ist; 2) dem $0 s$ articulare, das dem Os jugale eingelenkt. ist; 3) dem am hinteren Rande jedes Os articulare gelegenen, oft knorpelig bleibenden Eckstiucke: Os angulare ${ }^{9}$. Unbeständiger ist ein kleines am Innenrande des Os ariculare gelegenes Knochen- oder Knorpelstück, das Cuvier dem Os operculare der Reptilien vergleieht. Selten erseheint die Zahl dieser Knochenstücke so vermehrt, dass sie derjenigen der besehuppten Reptilien gleichkömmt 10 ). - Sehr beständig bildet das 0 s deutale inwendig eine mehr oder minder beträchtliche Höhle, in welcho der Meckel'sche Knorpel, ein Unterkieferınuskel und die Nerven und Gefässe sich hineinerstreeken.

[Wenn Cuvier's Benenuungen in obiger Darstellung unverändert beibehalten wurden, so geschah dies nur aus dem Grunde, weil sie die bekanntesten und geläufigsten sind, nicht aber, dass die damit belegten einzelnen Knoclienstüeke dadurch als Aequivalente der gleichnamigen Theile hölıerer Wirbelthiere bezeichnet würden. Kein anderer Theil des Fischskeletes hat so mannichfache Deutungel erfahren müssen, als die in diesem Paragraphen abgehandeltell Knochen. - Was zuerst das Os tęmporale mit seinen Verlängerungen: den Os symplecticum und dein Meckel'schen Kinorpel anbetrifft, so geliören dieselben dem ersten Visceralbogen an und möchten ihre Aequivalente in dell gleichnanigen Knorpel der Säugethiere und deın in den Hannner des Gehörorganes sich uuwandelnden Blastem finden. Das Praeoperculum halte ich mit Ge offroy und Reichert für das Os tympanicum s. quadratum. Auf die Analogie von Cuvier's Os jugale mit den Os quadratn-jugale der Batrachier hat $M$ üll e r bereits iiberzeugend aufmerksam gemacht. Sehr zweifelhaft bleibt iminer noch die,Deutung von Cuvier's Tympanicum. Gute Abbildungen des Kiefer-Gaumenapparates von Perca fluviatilis bei Cuvier und Valeneienues T. 1. Tab. 1-3. Die anomalen Fische Lepidostens und Polypterus s. bei Agassiz, Poiss. foss. Vol. 3. Tab. 40 sqq. - Bei einigen Knochenfischen konmen noch accessorische Lippenknorpel vor, wie Müller entdeckt hat. - I

9) Ich habe dieses Stück bei genauerer Untersuchung nie vermisst.

10) Bei Ostenglossum (nach Miiller) so wie auch bei Lepidnsteus osseus auf 6. 


\section{Vom Zungenbeine.}

§. 16.

Bci den Gyclostomen und namentlich bei den Myxinoïden und Petromyzonten zeigt der Zungenbein-Apparat so eigenthümliche und zusammengesetzle Verhältnisse, dass es vorläulig unmöglich seheint, sic auf diejenigen der höheren Fisehe zu reduciren. Bei den Myxinoïden bilden ihm angehörige Theile, bei Mangel eines Unterkiefers, den unteren Mundrand 1). - Einfacher und sehr iibereinstimmend gestaltet erseheint das Zungenbein bei den höheren Knorpelfisehen und Knoehenfischen. Es stellt einen hinter dem Unterkiefer und vor dem ersten Kiemenluggen gelegeneu, aus zwei, meist gegliederten und Inittclbar unter einander verbundenen Seitenschenkeln bestehenden Bogen dar. Jeder Seitenschenkel ist selten am Sehedel selbst ${ }^{2}$ ), gewöhnlich am Suspensorium des Unterkiefers beweglich eingelenkt. Bei den Knochenfisehen gesehieht diese Einlenkung durch einen knöchernen oder knorpeligen Stiel (Os styloüdeum), der bei den Gattungen, dic ein vollständig entwickeltes Suspensorium besitzen, an der Verbindungsstelle des $\boldsymbol{O}$ s temporale mit den $\boldsymbol{O} \boldsymbol{s}$ symplecticum befestigt ist. Die Zahl der Scgmente, aus welchen jeder Zungenbeinbogen zusammengesetzt ist, zeigt sieh verschieden; bei inehren Haien ist jeder Schenkel einfaeh, bei vielen Rochen besteht er aus zwei, bei den Chimären, Sturionen und Spatularien aus drei Stiieken; unter den Knochenfischen wechselt die Zahl der letzteren; doeh sind deren höehstens vier vorhanden. - Die Verbindung der Seitenbogen wird bei den Roehen und Sturionen dadurch bewirkt, dass ihre unteren Enden an die Bogen des vordersten Kiemenpaares sich anheften. Schon bei den Chimären und Haien sind sie durch cin eigenes unpares Mittelstück (Copula) verbunden; dies wird aueh bei den Knoehenfisehen nur sehr selten vermisst $\left.{ }^{3}\right)$. Bei den letzteren schliesst sieh gewöhnlich vorn an diese Copula noch ein meist einfaches, selten paariges Os linguale $s$. entoglossum, das der Zunge zur Stiitze dient 4$)$. - Unterhalb der

1) Den Zungenbeinapparat der Myxinoïden schildert ausführlich Müller, Myxin. Th. 1. S. 49., und gibt schöne Abbildungen nicht blos von Bdellostoma, sondern auch von Petronyzon, Chimaera und Planirostra. - Das Zungenbein fehlt bei Branchiostoma.

2) So bei den Chimären durch fibröse Membran an den Schedel und namentlich auch an seine Unterkiefer-Apophyse. Am Schedel, nach Rathke, bei Raja aquila und Rhinobatus rostratus; bei Torpedo und Narcine am Suspensorium des Unterkiefers; bei Rhinobatus Horkelii an der Grenze des letztern und des Schedels.

3) Nicht so häufig, als Rathke angiht; ich finde es z. B. bei Diodon, bei Cyclopterus u. A. Es fehlt bei Muraenophis helena.

4) Es fehlt bei Muraenophis und andern von Rathke namhaft gemachten Fischell. 
Vereinigung der Züngenbeinlıgen und mehr oder weniger innig, oft durch Sehuen an sie befestigt, erscheint bei den meisten Knochenfischen noch ein Zungenbeinkiel, der, von sehr verschiedener Grösse und Furm, denjenirgen Furtsetzungen der Seitenmuskehn des Rumpfes, welche min als M. stermohyoüllci bezeichnet, als Ansatzpunkt dient 5 \%. - An jeder Zungenlbeinbogen, und besonders an seinen mittleren. Theil, heften sich bei den uncisten Kurpelfischen und bei allen Knochenfischen knorpelige oder knöcherne Strahlen, Radii Lranchiostegri. Gewölnnlich durch eine doppelte Hint, zwischen welcher Muskelfasern verliufen, zusammengehalten (Hemlirana branchiostega), tragen sie zur Schliessung der kiemenhöhle mehr oder minder wesentlich bei und bilden also eigentlich einen Theil des Kiemendeckel-Apparates. Sie fehlen den Sturionen, werden bei Planirostra durch eine Knochenplatte repräsentirt, sind bei den Chimären, Haien und Rochen als knorpelige Strahlen vorhanden und meist mit ähnlichen vom Kiefersuspensoriun ausgehenden, hier den Kiemendeckel darstellenden Knorpelstrahlen verbunden. Bei den Knochenfischen bieten sie je nach Zahl und Forı bedeutende, auch als systematische Charaktere benutzte Terschie denheiten dar 6 ).

[Man vgl, besonders Rathke, Anat. philos. Untersuchungen ïher den Kicmenapparat und tas Zungenbein der Wirbelthiere, Riga 1832. 4.1

\section{Vom Skelet des Respirations-Apparates.}

\section{\$. 17.}

Fast allen Fischen konnmen knurpelige oder knücherne, meist mit der Wirbelsäule oder mit dem Schedel mehr orler minder innig verbundene Grebilde zu, welche theils zur Deckung des Kiemenapparates, theils zur unnittelbaren Unterstiitzung derjenigen gefässreichen Theile dienen, in welchen die Unwandlung venösen Blutes in arterielles geschicht.

Was zuerst die soliden Aussengebilde des Kiemenapparates anbetrifft, so kommen schon bei Branchiostoma Knorpelstäbchen in sehr grosser Zahl vor; welche clic Seitenwïnde des Respirations schlauches bilden. Bei Ammocoetes und bei Petromyzon ist ein knorpeliger, nit der Wirbelsäule und mit dem Schedel in Verbindung stehender, sehr zusanumengesetzter äusserer Ki cmenk orb vorhanden, an den die Constrictoren der Kiemensïcke sich befestigen. Nur noch bei den Plagiostomen finden sich ähnliche, wenn schon ininder zu-

5) Er fehlt bei Diodon, Tetrodon, Iophius; bietet ïbrigens sehr verschiedene Gestaltungsverhältnisse dar. Fr ist doppelt und paarig bei Polyłterus, wie Mïller gefunder.

6) Bei Diorlon und Tetrodon bildet der erste Kiemenhautstrahl eine breite Platte; die Strahlen sind von enormer Länge bei den Iophien; sie sind in grosser Zahl vorhanden und stark gekrïmmt bei den Aalen. 
sammengesetzte, die Rảnder der Kiemenspalten stützende, reihenförmig gestellte Knorpelstreifen, welche aber die Wirbelsäule nicht erreichen.

Zugleich erscheinen bei ihnen, und zwar namentlich bei den Haien, als erste Andeutungen des $\mathrm{Kiemendeckels} \mathrm{der} \mathrm{übrigen} \mathrm{Fische} \mathrm{mehre}$ vom Kiefersuspensorium ausgehende Knorpelstreifen. Aehnliche Streifen kommen bei den Chimären vor. Sie liegen theils frei, theils sind sie an einer mit den Zungenbeinbogen zusammenhangenden Knorpelplatte befestigt und schliessen sich an die eigentlichen Radii brauchiostegri an. Bei Planirostra wird der Kiemendeckel durch eine einfache Knochenplatte repräsentirt, welche am zweiten Stiick des KieferSuspensorium befestigt ist. Bei den Sturionen dagegen besteht er, obschon äusserlich einfach erscheinend, wie bei den Kn ochenffischen, aus drei Knochenstiicken. Diese sind das 0 perculum, das $\boldsymbol{S} u l o p e r$ culum und das Interoperculum. Ihr Verhalten bei den meisten Knochenfischen ist folgendes. Das beträchtlichste dieser Knochensiücke ist immer das am meisten nach hinten und oben gelegene Operculım. Es besitzt an seinemvordern und obern Winkel eine Gelenkgrube, welche in einen convexen Gelenkkopf des Os temporale passt. Es liegt hinter dem abstcigenden Aste des Praeoperculum, an dem es meistens durch Bandmasse lose so befestigt ist, dass es wie ein Thürflügel aufund zugeklappt werden kann. - An den unteren Rand des Operculum ist die zweite kleincre, nicht ganz sclten fibrös-häutig bleibende Platte des Kiemendeckel-Apparates: das $\boldsymbol{S} u \boldsymbol{L}$ operculum gewöhnlich der Länge nach angeheftet. Von den Vorderrändern der beiden vorigen Knochen aus, ihnen meist innig angeheftet, seltener von ihnen mehr getrennt, erstreckt sich das I u cerop ercul u un bogenförmig zum Unterkiefer hin und verbindet sich mit dessen unterein Winkelstück durch Bandmasse. An der Innenfläche des Interoperculum ist durch Ligament der Zungenbeinbogen gewöhnlich so befestigt, dass der KiemendeckelApparat ohne gleichzeitige Mitbervegung der Zungenbeinbogen weder geöffnet, noch geschlossen werden kann.

[Ueber Branchiostoma s. d. angef. Schriften von Rathke, von Müller und Retzius. - Ueber Amuocoetes und Petronyzon vgl. Rathke, Bemerkungen über den innern Bau von Petromyzon, Danzig 1826, und dessen Beiträge z. Geschichte d. Tlierwelt Abth. 4., Halle 1828. 4. Born in Heusinger's Zeitschrift f. organ. Physik Bd. 1. Mayer, Analekten f. vgl. Anatomie, Bonn 1835. 4. Tả. 1. - Ueber die Plagiostomen und Knochenfische Rathke's Unters. üb. d, Kiemenapparat. - Ueber Accipenser Baer, Bericht. - Ueber Planirostra und Chimaera Müller, Myxinoïd. Th. 1. - Rathke macht S. 76. der zuletzt genannten Schrift eine Menge von Knochenfischen namhaft, bei denen die Zahl der Stücke des Kiemendeckels auf 2 oder auf 1 reducirt sein soll. Ich finde jedoch z. B. bei Chaetodon, Muraena, Uranoscopus, Callionymus, Trichiurus, Lophius, Malthaea die gewöhnliche Zahl der Stücke; bei den Plectognathen aber, namentlich bei Diodon, zerfällt das lange stabförmige Interopierculum streng genomiven 
in zwei Stückio, so dass also eher eine Verinehrung, als eine Verminderung der Knochenstücke - bei übrigens sehr eigenthümlichem Verhalten des Kiemendekkels - anzunehmen ist. Enorm entwickelt ist er bei Malthaea und anderen Lophien. - Den Siluroïlen fehlt das Interoperculum.]

\section{§. 18.}

Bei den höheren Knorpelfischen und bei såmuntlichen Knochenfischen kommen vier knorpelige oder knöcherne Kiemenbogen ( $A$ rcus brauchiules) vor, welche der Reibe nach hinter dem Zungenbeinbogen gelegen sind. Sie dienen mit ihrem grösseren, mittleren $\mathrm{Ab}$ schritte, gewöhnlich sämmtlich, seltener nur zum Theil I) als solide Stiitzen der knorpeligen oder knöchernen Kiemenstrahlen und der diese letzteren ïberziehenden häutigen Kiemenblättchen. Auf sie folgt hinten ein unvollkommener gebildeter Bogen, welcher fast nie mehr als Kiementräger dienend, häıfig mit Zähnen besetzt, den Schlundkopf seitlich und abwärts unterstiitzt und darum als unterer Schlundknochen (Os pllaryugenm inferizs) bezeichnet wird. Nur die Gattung Lepidosiren liefert ein Beispicl rom Vorkommen von Kiemenblättchen an diesem fünften Bogen ${ }^{2}$ ). Er ist gewöhnlich vom hintersten Kiemenbogen getrennt, selten mit ihm verwachsen ${ }^{3}$ ).

Jeder Kiemenbogen besteht aus zwei Seitenschenkeln, deren untero Enden an der Bauchfläche convergiren und hier in der Regel mittelst einer Reihe kleiner unpaarer Knochen- oder Knorpelstiicke, selten durch grössere und breitere Knorpelplatten unter einander verbunden sind 1). Diese gewöhnlich vorhandenen ${ }^{5}$ ) Verbindungsstiicke entsprechen, ihrer Lage und Bedeutung nach, der Cupula der Zungenbeinbogen, an welche sie auch meistens hinten sich anschliessen. Was ihre Zahl anbelangt, so ist diese keinesweges immer derjenigen der Kiemenbogen gleich, indem zwei oder drei der letzteren sehr häufig eine gemein-

1) Vgl. über diesen Punkt den vom Respirationsorgane der Fische handelnden Abschnitt.

2) S. Bisclu off's Angaben a. a. 0. "An ihrer unteren, nach der Kiemen. höhe hinsehendeu Seite tragen die drei hintersten Kiemenbogen die Ceberresto der kleinen bïschelförnigen Kiemen; der erste und zweite Kiemenbogen tragen kcine solche."

3) Diescr Fall tritt bei Muraenophis He'ena ein. Rathke spricht dieseun Thiere besondere Schlumlkiefer ab. Mir scheint aber der dickere vierte Kiemen. bogen durch eine Verschmelzung von Schlundkiefer und Kiemenbogen entstanden zu sein.

4) Solclie breitere Knorpelplatten, hinterwärts verlängert, koumuen vor bei den Rochen. Bci Rhinobatus (rostratus und Horkelii) schliessen sich die Bogen des vordersten Kicınenpaares nicht an diese Platte, sonderu werden durch einen queren Kinorpelstab verbunden.

5) Sie fehlen bei Muraenophis, Lophius, Malthaea; nach Rathke aurh bei den Syngnathen und bei Uranoscopus. Rei Cyclopterus aber, denen Rathke sin gleichfalls abspricht, sind sie vorhanden. Selbst bei den Lophien ist wol nur eino Verwachsung des Schlundkiefers unit der plattenförmigen Copula anzunehuen. 
schaftliche Copula besitzen. Die beiden oberen Enden der Schenkel jedes Kiemenbogens vercinigen sieh nieht. Sie sind durch Zellgewelse oder fibröses Gcwebe an der Basis cranii oder unterhalb des vordersten Abschnittcs der Wirbelsäule 6) befestigt vder hier cingelenkt.

Jeder einzelne Kiemenbogen ist gewöhnlich aus mehren Gliedern zusammengesetzt, deren Grösse, Länge, Form und Anzahł mannichfaehen Verschiedenheiten unterworfen ist. In der Regel besteht jeder Seitenschenkel der drei vorderen Kienienbogen der Knochenfische aus vier Gliedern, währeud der des letzten Kiemenbogens meist eine geringere Anzahl derselben besitzt und der untere Sehlundknochen aus zwei Segmenten oder aus cinem einzigen besteht. Die beiden Seitenschenkel des letzteren können unten verwachsen 7) oder dureh ein einziges unpaares Stück ersetzt werden ${ }^{8}$ ).

Unter den einzelnen Gliedern der Kiemenbogensehenkel ist immer das zweite von unten das längste und beträchtlichste und nächst ihm das dritte. Dem vierten oder obersten Gliede, welches bei vielen Gräthenfischen anomale Formen darbietet und mit Zähnen besetzt ist, hat Inan, besonders in Berüeksiehtigung dieses letzteren Verhaltens, den Namen eines oberen Schlundknochens (Os pharyngeum superius) gegeben. Die einzclnen in ciner Reihe hinter einander liegenden oberen Schlundknochen sind sehr häufig unter sich verwaehsen 9). Bei Cuvier's Labyrinthfischen treten die oberen Schlundknochen noeh in eine schr wescntliche Beziehung zum RespirationsApparate, in so fern sie, wenigstens theilweisc, dureh das Zerfallen in Blätter siebbeinförinige Labyr inthe bilden, welehe, mit Schleimhaut überkleidet, die Grundlage cines respiratorischen Gefässnetzes abgeben $\left.{ }^{10}\right)$. Eigenthümliche Entwiekelungen anderer Art zu ähnlichem Zwceke finden sich am oberen Stücke des zweiten und vierten Kiemenbogens von Heterobranchus anguillarìs.

Eine andere auffallende Bildung bieten die meisten Pleetognathen 11) dar, indem hier, nicht von dem oberen Schlundkiefer, sondern von dem

6) Unter den Kunochenfischen köınut dies letztgenamnte Verhalten z. B. bei den Aalen: Anguilla, Muraenophis u. A., unter den Knorpelfischen z. B. bei den Haien vor.

7) Sie sind durch Naht mit einander verbunden bei Cluromis nach $\mathrm{Cuvier}$ 's Aligaben.

8) Diese Verwachsuug findet sich sowol bei Acanthopterygiern als bei Malacopterygiern. Miiller hat neuerlich ans den Knochenfischen mit unpaarem unterem Schlundkiefer die Gruppe der Pharyngognathi abgebildet. Er rechnet dahin: 1) die Scomber-Esoces (Exocoetus, Belone, Hemiramphus 1. s. w.), 2) die Chroniden, 3) die Labroïlei cycloïdei und 4) die Labroïdei ctenoïdei. S. Erich son's Archiv für Naturgeschichte, 1843, S. 305 .

9) Z. B. bei Uranoscopus, Cottus sehr deutlich.

10) S. die Abbildungen bei $\mathrm{Cuvier}$ und Valenciennes I. c. Tab. 20ว. แ. 206.

11) Ich finde diese Bildung namentlich bei Tetrodon, Diodon, Ostracion. 
Basilarstiicke eines jeden Schenkels des dritten Kiemenbogens aus, unterhalb der Copulae der Kiemenbogen, ein Knochenbogen nach vorn sich erstreckt, der durch ein Ligament an die vorderste Copula, welche mehr dem Zungenbein, als den Kiemenbogen angehört, sich befestigt.

Die convexe Flïclie der Kiemenbogen und ihr Innenrand sind gewöhnlich mit eigentlüunlichen, rauhen, oft ossificirten Oberhautgebilden, in Form von Plittchen, Tuberkeln, Zähnen, Zangen, Spitzen u. s. w. besetzt, welche das Eindringen von Speisen in die Kiemenhöhle hindern. - Dic Convexität der mit Kientenblättchen besetzten Segmente der Kiemenbogen bildet eine Rinne, in welcher die Nerven und Gefässstämme der Kiemen verlaufen.

[Man vgl. uiber den hier abgehandelten Gegenstand besonders die schon angefülurte Schrift von Rathke über den Zungenbein- und Kiemenapparat. Einzelne berichtigende Bemerkungen über Innorpelfische finden sich in Müllerer's Osteologie und Myologie der Myximoillen. Ueber Narcine und Torpedo vgl. Henle in seiner Schrift üher Narcine S. 22.; über Lepidosiren Bisclioff l. c. S. 15. Alle diese Schriften enthalten gute Abbildungen. I

\section{Von den Knochen der Extremitäten.}

\section{§. 19.}

Die Vorderextremitäten oder Brustflossen der Fische sind gewöhnlich an einem durch die Vereinigung oder Verschmelzung zweier Seitenschenkel gebildeten Schultergürtel befestigt. Das obere Ende jedes Schenkels ist bei den Sturionen und denjenigen Knochenfischen, leei welchen der Extremilätengürtel nicht blos rudimentär vorhanden ist 1), mit dem Schedel, bei den Rochen mit dem vorderen Alssclmitte der Wirbelsäule verbunden, während es bei den llaien und Chimären beide nicht untnittelbar berührt. - Bei den Haien besteht dieser Gürtel aus einem schräg vorwärts und abwärts gerichteten Knorpelbogen, dessen beide Seitensclienkel in der Mittellinie unter dem IJerzen continuirlich in einander übergehen. An seinem oberen Ende trägt jeder Scitenschenkel ein ihni durch Bandmasse angefügtes Knorpelstuick. An der Biegungsstelle jedes Schenkels ist ihm eine Reihe ossificirter, fast wie Wirbelkörper gestalteter, unter einander durch Ligamente verbundener kleiner Knochencylinder aufgesetzt. An scinem hinteren Rande besitzt er Gelenkflichen, bestiumt zur Aufnahme von zwei bis drei Knorpelstiucken, welche die Flossenknorpel tragen. Diese bestehen in mehren Reihen längliclıer Knorpelcylinder, welche aber nicht durch die ganze häutige Flosse sich hindureh erstrecken. Im grösseren hinteren Alschnitte der letzteren finden sich nümlich zwischen den Ilautbedekkıngen foine gelbe Faserstreifen, von hornartigem Ansehen, welche

1) Ilerher gehören namentlich die Murämoïden. Ihuen fehlt die Verbindung des Silultergïrtels unit den Hinterhaupte. 
auch in den Flossen der Chimären vorkommen, deren Brustflossen in Betreff ihrer Zusaminensetzung von denen der Haien überhaupt nicht bedeutend abweichen. - Bei den Rochen findet sich ein ähnlicher, aber oben mit der Wirbelsäule verwachsener oder ihr eng angehefteter Schulterguirtel. Er bildet bei Rhinobatus einen einfachen, nirgend unterbrochenen Knorpelring, zerfällt aber bei andern Rochen in mehre Glieder. Auch an ihm sind die Flossenstrahlen nicht unnittelbar, sondern durch Vernittelung dreier zwischenliegender, ihın beweglich einlenkter Knorpelstiicke $(0 s s a$ metacarqji und $c a r p i)$ befestigt. Gewöhnlich bilden die beiden äusseren Knorpelstücke einen vorwärts und einen hinterwärts gerichteten Bogen. Der vordere, aus zahlreichen an einander gefügten Gliedern bestehend, erstreckt sich zur Seite des Schedels vorwärts. Bisweilen erreicht die vordere Spitze dieses Bogens die hintere des den flochen eigenthünlichen, an den Processus orbitalis auterior befestigten Schedelflossenknorpels. - An diesen Knorpeln haften nun die cylindrischen Flossenknorpel, welche, in vielen Reihen auf einander folgend, die solide Grundlage der ganzen Flosse bilden. - Bei den Sturionen und Knochenfischen hat, mit Ausnahme mancher Aale, deren Extremitäten sehr abortiv werden, die Befestigung ihres in Wesentlichen übereinstimmend gebildeten Schultergürtels ain Schedel Statt. Derselbe besteht bei den Knochenfischen aus zwei Seitenschenkeln, welche rom Schedel aus, hinter und unter den Kiemenbogen vorwärts gerichtet absteigen und sich an der Bauchseite des Körpers durch Ligament, seltener durch Naht 2), zu einem einzigen Bogen vereinigen. Jeder Seitenschenkel ist in der Regel aus drei Knochenstücken zusammengesetzt. Der oberste Knochen befestigt sich gewöhnlich mit zwei Apophysen an das Os occipitale superius und an das Os mastoüdeum des Schedels ${ }^{3}$. Man bezeichnet ihn, nach $\mathrm{Cu}$ vier, gewöhnlich als Os suprascupulare. Der zweite kleinere, nicht ganz beständige Knochen ist der $\boldsymbol{S}$ capula zu vergleichen. Der dritte, beträchtlichste Knochen vernittelt durch seine Verbindung mi demjenigen der entgegengesetzten Seite die untere Schliessung des Bogens und besteht gewöhnlich aus zwei Lamellen, welche eine zur Aufnahme der Seitenmuskeln des Rumpfes bestinmte Furche oder Höhlung einschliessen. Cuvier nennt ihn fälschlich Humerus, während er als Clavicula zu deuten ist. An der Innenseite des oberen Endes dieses

2) Durch Naht gesehieht dic Verbindung bei der Familie der Loricarien. Der bei dieser Fanilie fast ganz unter dem Panzer verborgenen Extremitätengürtel bildet ein nur in der Mitte offenes knöchernes Septum zwischen Kiemenliöhlo und Bauehhöhle. In der voin Bauchtbeile des Schultergürtels gebildeten knö̈hernen Seheide liegt das Herz.

3) Bei Lophius, Malthaea u. A. besitzt er cine einfache mit dem Sehedel verbundene Spitze; bein Wels gesehieht die Verbindıng dureh zwei Zinken, ron denen die eine zur Seite des Basilare occipitis sich anlegt. 
Knochens ist ein gewöhnlich aus zwei Stücken bestehender, meistens nach hinten gerichteter Fortsatz befestigt, der mit dem Os coracö̈lcum verglichen ist 4 ). Die Clavicula trägt ausserdem gewöhnlich zwei bis drei Knochenstücke ${ }^{5}$ ), welche Cuvier als Vorderarmknochen bezeichnet. - An sie schliessen sich endlich - ausser einem Flossenstrabl - die eigentlichen Träger dieser Strahlen, die Ossa mecacarpi, meistens vier bis fünf in eine Reihe gestellter Knochenstiickchen, selten ausserordentlich verlängert, wie bei den Lophien, und in diesem Falle bisweilen in geringerer Zahl vorhanden $\left.{ }^{6}\right)$. Die Flossenstrahlen seibst sind länglich und mit ihrer Basis durch eine Gelenkvertiefung an dic Ossa carpi befestigt; jeder Strahl besteht aus zwei Hälften. Der erste Strahl ist häufig dicker als die übrigen und bei einigen Fischen, namentlich vielen Siluroïden, eigenthiimlich bewaffnet. Bemerkenswerth sind die sogenannten fingerförmigen Anhänge der Triglen, drei von den iubrigen getrennte Flossenstrahlen, welche wahrscheinlich als Tastorgane dienen. Sehr abweichend ist die Extremitätenbildung bei Lepidosiren, wo Statt zahlreicher Flossenstrahlen nur ein einziger Knorpelfaden jederseits vorhanden ist.

Die Knochen der Hinterextremitäten stehen bei den Fischen nie in unmittelbarer Verbindung mit der Wirhelsäule und sind minder zusammengesetzt, als die der Vorderextremiläten. Bei den Plagiostomen besteht das Beckengerüst aus zwei zu einer Querleiste verbundenen Knorpeln. Aussen und hinten befestigt sich an jeden derselben ein Knorpelbogen, welcher die Flossenknorpel trägt, und ausser diesem oft ein einzelner stärkerer Flossenstrahl. Bei den Männchen der Plagiostomen und Chimären trägt der Knorpelbogen mit seinem hinteren Ende die zangenförmigen äusseren Begattungsorgane. Bei den Chimären und Stören sind die beiden Knorpel des Beckengerüstes getrennt. Bei den Knochenfischen i) haften die Flossenstrahlen gewöhnlich unmit-

4) Er fehlt den ineisten Malacopterygii apodes Cuv. init Ausschluss der Ophidini Müll., den Silurö̈len. den Loricarinen, Anarrhichas u. A. Ueber seine abweichenden Formen s. Geoffroy in den Ann. d. Musée T. IX. p. 413. Der Herausgeber von Cuvier's Vorlesungen, Duvernoy, betrachtet diese Knochen wegen ibres Verhaltens bei Amphacanthus, Mugil, Argyreiosus, Seserinus u. A., wo sie sich zum After hin ausdehnen und sich zum Theil vereinigen, und bei einigen anderen Knochenfischen, wo sie in Bezichung stehen zu den Hinterextremitäten, als Beckenknochen: Ossa immominata - eine Deutung, welche sich gewiss nicht rechtfertigen lässt.

5) Bei den Lophieı sehr rudinentär; bei den Siluroïlen fehlend.

6) Bei Lophius und Malthaea finde ich 2 ; bei Chironectes 3 ; doch sind nach Meckel bei Batrachus 5 vorhanden. - Bei Polypterus finden sich nach $\mathrm{Cuvier} \mathbf{3}$.

7) Vielen Knochenfischen fehlen die Hinterextrenitäten gänzlich, z. B. den Muränoïlen, den Ophidini, den Syngnathen, Anarrhichas, vielen Plectognathen. Bei andern, z. B. bei Lepidopus, sind sie sehr rudimentär. Bei Cottus indisiator nach Meckel sehr entwickelt. Am eigentliümlichsten bei den Cyclopoden, na. 
telbar, selten mittelst Os.sa melalarsi (Polyptcrus), an einem paárigen Knoehen, dessen Seitentheile in der Regel mehr oder ininder vollständig dureh ihre Innenriinder verbunden und nur selten ganz von einander getrennt sind 8). Die Lage der IIinterextiemitaten ist - wenn sie uiberhaupt vorhanden sind - versehieden; bald nämlieh liegen sie vor den Brustflossen (P.jugulares), bald wenig hinter und unter denselben (P. thoracici), hald endlieh hinter ihnen und sind mehr nder weniger dem After genähert (P. abdominales).

[Ueber die Extremitäten der Fisehe haben an ausführlichsten gehandelt $\mathbf{C u}$. vier im ersten Theile der Histoire nat. l. poiss. und im ersten Theile der Leçons d'anat. comparée. Ge offroy Saint.Hilaire, Pbilos. anat. T. 1. Meckel, System d. vergl. A nat. Bd. 2. Abth. 1. - Abbildungen finden sieh in den Werken von Cuvier, Rosenthal, Agassiz in Carus' Erläuterungstafeln und Wagner's leones zootomicae; Abbill. von Plagiostomen bei Henle, über Nareine, und Müller, Myxinoïd. Th. 1. - Der Gattung Branehiostoma und den Cyclostomen fehlen die Extremitäten gänzlieh.]

\section{Von den unpaaren Flossen.}

\$. 20.

Die Rüeken-, Sehwanz- und Afterflossen der Fisehe enthalten als solide Grundlagen einzelne Strahlen, welehe reihenweise, bald sehr dieht an einander liegen, bald weiter von cinander entfernt, dureh mehr oder minder beträeltliehe häutige Zwisehenräume von einander getrennt sind. Bei den Cyelostomen sind die cinzelnen Flossenstrahlen in fibrös-häıtige mit der Wirbelsäule in Verbindung stehende Blätter cingesehlossen; bei Branehiostoma sitzen sie einem solehen fibrösen Blatte auf. Bei den meisten höheren Fisehen sind die cinzelnen Strahlen der Rüeken- und Afterflossen melir oder minder beweglieh eingelenkt auf den Spitzen eigenthümlicher knorpeliger oder knöeherner Stiitzen, der Flossenträger. Bei den Haien, den Chiinären und manehen Knoehenfisehen ${ }^{1}$ ) sind diese Flossenträger grossentheils zwisehen einem fibrösen rnit den Kanten der Wirbelsäule in Verbindung stehenden Blatte eingesehlossen; bei den meisten Knoehenfisehen dagegen tritt die Basis eines oder selbst mehrer 2) soleher Flossenträger zwischen je zwei Processus spinosi superiores oder inforiores, an welehe letzteren denn die Flossenträger meistens durelı eine fibröse senkreeht stehende Haut befestigt sind. Wegen dieser Beziehung zur Wirbelsäule haben einige Anatomen die Flossenträger mit Unreeht als Theile

mentlich bei Cyelopterus und Leparlogaster, wo sie durch ihre Versehmelzung das Brustsehild bilden.

8) Z. B. bei Belone, Exocoetus, Salno u. A.

1) Muränoïden, Ophicephalus u. A.

2) Z. B. bei Pleuronectes, Chaetodon, Zeus, Tetrodon an vielen Absehnitten der Wirbelsäule. 
dersetben betrachtet und als accessorische Dornen bezeiclınet. Gewöhnlich entspricht jedem Flossenstrahl ein Flossenträger; bei den Rochen aber bestrht letzterer meist ans ciner Reihe uber einander liegender Ciliedel: Schr häufig koummen auch Flossenträger ohne ihnen entsprechende Flossenstrahlen ror; oft dienen sic auch als Stutzen von Ilautschildern ${ }^{3}$. Eine sehr eigenthümliche Bildung zeigt bei viclen Knochenfischen 4) der crste unter den Trägern der Afterflosse, in so fern er ausserordentlich stark, lang, rorwärts gekrimmt, dem Processus spinosus inferiur innig verbunden, und oft aus der Verwachsung mehrer knochenstiicke entstanclen ist; er bildet dann eine scharfe hintere Grenze der Bauchhöhle 5). - Die Strahlen der Schwanzllosse sind bei den meisten Knochenfischen an dem letzten senkrecht stehenden Schwanzwirbel befestigt; beim Stör und den Haien hat dagegen ihre Befestigung an den unteren Dornen des aufwärts gehogenen Endes der Wirbelsäule Statt. Die Flossenstrahlen der Knochenfische sind zum Theil spitzige Knochen; in andern Fällen weich, gegliedert und meist auch ramificirt $6 \%$ In der Regel besteht jeder Flossenstrahl aus zwoci, der Länge nach verbundenen Seitenhälften. Diese weichen meistens an der Basis aus einander zur Bildıng zweier Gelenkköpfe, durch welche sie sehr heweglich mit den oheren Enden der Flossenträger verbunden zu sein pflegen; bisweilen wird diese Verbindung noch durch ein eigenes Gelenkknöchelchen vermitteht.

3) Z B. hei Trigla u. v.A. - 4) Besonders auffallend bei den Pleuronectes-Arten.

5) Sehr eigenthümlich sind kugelförnige Anschwellungen einzelner Flossenträgẹ bei einigen Arten ron Chactodon und Ephippus (s. Abbild. bei Cuvier u. Valenciennes Tab. 204.). - Bei einigen Knochenfischen verï̈ngert sich die Rückenflosse auf den Sclıedel, z. B. bei Pleuronectes; bei anderen kommen einzelne Flossenstrahlen daselbst vor, z. R. bei Lophius; bei Eclieneis hestelıt das Kopfschild aus eigenthümlich modificirten und verwachsenen Flossenstralılen und Trägeru derselben.

6) Auf diesen Verschiedenheiten in der Bildung der Flossenstrahlen beruhet dic Sonderung und Eintheilung der meisten Knochenfische in Acantlopterygier und Malacopterygier. Letztere besitzen weiche, verästelte und articulirte Rückenflossen, wälirend diesclben bei den Acanthopterygiern, wenigstens theilweise, spitze, ungegliederte und unverzweigte Knochenstïcke sind. - Dass dieses von Cuvier befolgte Eintheilungsprincip ler Knochenfische manche Inconvenienzen hat und namentlich nicht immer ganz naturgemäss ist, hat ncuerlich J. Müller auseinan. dergesetzt in seinen Aufsatze: Beiträge zur Kenntniss der natürlichen Familien der Fische in Erichson's Archiv f. d. Naturgeschichte, 1843. S. 292 ff. Müller bringt nicht nur eine Anzahl von Acanthopterygiern und Malacopterygiern, weil sie vereinigte untere Sclılundknochen haben, in die neue Orinung der Pharyngngnathen, sondern fasst auch den Begriff der Acanthopterygier schärfer, indem er nachweiset, dass sie, sobald sie vollstïndige Bauchflossen besitzen, durchgängig einen ungegliederten ersten Strahl dieser Bauchflossen haben. Müller rechnet daher auch die Discoboli zu den Acanthopterygiern - nach dem Vorgange ron Risso. 


\section{Zweiter Abschnitt. \\ Von den änsseren Hrutbedeckungen.}

§. 21.

Die äusseren Hautbedeckungen der Fische bieten eine ausserordent liche Mannichfaltigkeit der Bildungen dar, welche theils durch die verschiedene Dicke der Cutis, theils durch die Anwesenheit von Schuppen, von derbercn zusammenhangenden Ossificationen (Ostracion), von oberflächlichen Schmelzbildungen, von vertikalen Stachcln, die mit horizontalen Fortsätzen in der dicken Cutis haften (Diodon) u. s. w. bedingt wird. - Die Dicke der Cutis ist nicht nur bei verschiedenen Gattungen und Arten der Fische, sondern auch an verschiedenen Stellen der Hautoberlläche desselben Thieres sehr verschieden. Ihre Bildungselemente sind verschlungene Zellgewebsfasern, welche häufig Höhlungen einschliessen, die mit Fett angcfüllt sind. Sie entbält Blutgcfässe. Bedeckt wird sie von Pigmentzellen, welche bisweilen eine eigene Schicht bilden. Oberflächlich liegt endlich die aus Pnaster.Epithelialzellen gebildete Epidermis. Bei den meisten Fischen sind Schuppen vorhanden; bald liegen sie zerstreut, baId sind sie dachziegelförmig über einander gelagert. In beiden Fällen sind sie eingebettet in abgesonderten, geschlossenen Säcken, die von Fortsetzungen der Cutis gebildet werden. An der untcren Fläche der Schuppen haftet cine silberglänzende, aus mikroskopischen krystallinischen $\mathrm{S}$ äbchen bestehende Materie. An der Oberlläche jeder Schuppe liegt eine schr feine, von der Cutis gesondcrte Membran, welche concentrische Linicn besitzt, die den ebenso gerichteten Erhabenheiten der Schuppe selhst entsprechen. Mit Unrecht hat man die Schuppen als Oberhaut - oder Horngebilde betrachtet und angenommen, dass ih. Wachsthum nur schichtweise und blos durch Apposition Statt fände. Haben gleich die zahlrcich angestellten mikroskopischen Untersuchungen ihrcn feineren Bau noch nicht erschöpfend aufgeklärt und ist namentlich die Anwesenheit von Blutgefässen in ilırer Substanz noch nicht nachgewiesen: so ist doch an der unteren Fläche der meisten Schuppen eine weichere Substanz von der Textur des Faserknorpels nicht zu verkennen und es gibt ossificirte Schuppen, in welchen das Vorkommen von strahligen Knochenkörperchen sicher nachgewiesen ist. - Bei den Stören, den Loricarien, den Ostracion u. A. kommen statt ihrer stärker entwickelte Knochenplatten vor, welche oft eine obcrflichliche glasühnliche Schmelzschicht besitzen. - Bedeutenden Werth habcn einige neuere Systematiker auf die Bildung des freien Randes der Schuppen gelegt. Die Fische mit ganzrandigen Schuppen hat man Cycloïden, dicjenigen, deren Schuppen einen gczähnclten oder gervimperten freicn Rand besitzen, Cte- 
nö̈len genannt; eine Unterscheidung, welcho jedoch als allgemeines Classificationsprincip zu voreilig benutzt worden ist.

Sehr allgemein kommen im Hautgebilde oder unter der Cutis der Fisehe Apparate vor, welche den Schleim absondern, der die IIautoberfläche schliupfrig erhält. Diese Schlcim absondernden Apparate zeigen wieder cine grosse Mannichfaltigkeit der Bildungen. Bei den Myxinoüden sind es runde, platte Säcke, die zwischen den Muskeln liegen und deren jeder eine eigene äussere Oeffnung besitzt. Bei den Rochen finden sich, statt dieser Säcke, vielfach verzweigte, zusammenhängende Röhren oder Caniile, deren Wandungen theils fibro-cartilaginös sind, theils aus elastisehen Fasern bestehen und in den Stämmen viel dicker zul sein plìgen, als in den Zweigen. Während diese Röhren bei den Rochen gesehlossen sind und nur dic Enden ihror Zweige frei nach aussen miinden, finden sieh bei den Chimären theilweise zwar aueh solchc Röhren, deren kïrzere Zweige mit zahlreiehen, weiten, runden, sehr regelmässig gestellten Oeffnungen münden, thcilweise abcr, und namentlich am Kopfe, der Länge nach geöffnete Halbcanäle, wolche von Stelle zu Stclle durch sehr zicrlich gebildete auswärts geöffnete Knorpelrinnen gestiitzt werden. Bei den Knochenfischen kommen riicksiehtlieh der Beziehungen des absondernden Apparates zum Iautgebilde und zu den Schuppen beträchtliche Versehiedenheiten vor. Bei viclen mit kleinen Sehuppen versehenen Fischen liegt der Rumpftheil des Schleim absondernden Apparates unter der mit Schuppen bekleideten Cutis verborgen. Er stellt in diesem Falle gewöbnlich eine Längsröhre dar, welehe durch kurze Quercanäle nach aussen mündet. Die Röhre selbst wird theils von Häuten umschlossen, thcils erhält sic in kleineren oder grösseren Zwischenrïumen, soliderc Stiitzen und Unigcbungen. Diese letzteren bestehen bald in cylindrischen Knoelıenröhren 1), bald in knöchernen Rinnen oder Halbcanälen 2), also in wirklichen Knochen des Seitencanales. - Iäıfig liegen dergleichen Knochenreihen oberflächlicher und dabei viel dichter, so dass man sic auch ohne Entfernung der Cutis von aussen wahrnimmt ${ }^{3}$ ). Bei anderen Knochenfischen fehlen den Röhren die knöchernen Stützen 4 ). In allen denjenigen Fällen, wo dieser Absonderungs-Apparat, von geschlossenen Wandungen umgeben, cin röhrenartiges Continuum darstellt, belegt man ihn während seines Verlaufes an Rumpfe mit dem Namen des Seitencanales. - Bei der Mehrzahl der Knochenfische nchmen aber eigenthïmlich gestaltete Schuppen diesen AbsonderungsApparat auf. Die Reihe von Schuppen, welehe diese Bestimmung hat, ist unter dern Namen der Seitenlinic bckannt und dic systematische

1) Z. B. bei den Murïinoïlen. - 2) Z. B. bei Cottus, den Gadoïlen. 3) Bei len Pleuronectes. - 4) Bei den meisten Siluroülen; bei einigen Tetrodon u. $A$. 
Zoologie tiat die ausserordentlich grossen Verschiedenheiten, welche die Beschaffenheit, die Stellung und besonders die Richtung dieser eigenthümlich modificirten Schuppen darbieten, zur Charakteristik der Gattungen mannichfach benutzt. Bald liegt der Absonderungs-Apparat blos in einem der Schuppe aufgesetzten Cylinder, welcher mit jener, die die Grundlage bildet, eine übereinstimmende Textur besitzt; bald bilclet er Verzweigungen unter dem bäutigen Ueberzuge der Schuppe u. s. w. Bei Untersuchung grösserer Fische findet man, diss die solide Grundlige des absondernden Apparates, mag sie in eigenen Knochen oder in Schuppen bestehen, eine untere zum Durchitritt von Nerven und Gefisssen bestimmte Oeffnung besitzt, dass der Canal selbst von einer Schleimhaut ausgekleidet ist, diss endlich in der Nähe des Eintrittes der Nerven und Gefässe bisweilen zarte aus mikroskopischen Zellen gebildete Blinddïrmchen 5) - also wirkliche absondernde Drüsen - vorhanden sind. - In der Regel nimmt dieser absondernde Apparat bei den Fischen einen sehr beständigen Verlauf. An jeder Seite des Rumpfes erstreckt er sich rom Schwanze bis an die hintere Grenze des Kopfes bald einfach, bald unter Abgabe stärkerer Aeste vorwärts. Ausnahmsweise 6) stehen die Apparate beider Seiten durch einen schon hirier dem Schedel quer über den Rücken verlaufenden Canal in Verbindung. Gewöhnlich erstreckt sich der Apparat jeder Seite an oder uiber dem Os suprascamulare zum Schedel und theilt sich hier in drei Arme: 1) einen in der oberen Hinterhauptsgegend quer aufsteigenden, der die Verbindung der Apparate beider Seiten bewirkt; 2) einen oberen Längsarm, der über dem Os mastö̈lleum mehr oder minder gerade vorwärts verlïuft und an der hinteren Grenze der Augenhöhle in zwei Schenkel sich spaltet, von denen der eine oberhalb der Augenhöhle bis in die Gegend der Nasengrube sich erstreckt und in Cuvier's Os nasale zu enden pflegt, während der andere in eigenthümlichen Stiitzen: den sogenannten Ossa infra. orlitulia, ringförmig unterhalb der Augenhöhle vorwärts sich begibt; und 3) einen tiefen absteigenden Arm, der längs des Pracoperculum 7) abwärts und von hier aus gewöhnlich an der Aussenseite des Unterkiefers vorwärts sich erstreckt. Der ganze Kopftheil des Apparates pflegt in eigenen, von knöchernen Windungen umschlossenen, durch Oeffnungen unterbrochenen Canälen der verschiedenen Kopfknochen oder in ihnen aufgesetzten und mit ihnen verwachsenen knöchernen IIalbcanälen zu verlaufen. Doch erleidet diese Regel Ausnahmen, inden z. B. bei den meisten Knorpelfischen und unter den Knochenfischen bei mehren Plectognathen auch der Kopftheil des Seitencanales alusser Be-

5) Nach Untersuchungen an grösseren Gadus - Arten und an Cyprinus Brama.

6) Bei allen Muränoïden.

7) Bei den Muränoïden wird das Praeoperculum gauz ouler fast ganz durch eine Knochenröhre des Seitencanales ersetzt. 
riihrung mit den Kopfknochen bleiht ${ }^{8}$ ) und blos im Ilautgebilde eingeschlossen ist.

[Man vgl. über die Structur der Haut und besonders der Scliuppen folgende Arbeiten: Kuntzullan $\mathrm{n}$ in den Verliandl. d. Gesellsch. naturf. Freunde in Berlin, 1824. Tl. 1. S. 269 ff, mit Abbill. - Heusinger, Histologie II. 226. - A gas siz, Poissons foss. an mehren Stellen; Agassiz in den Ann. d. sc. natur. 1840. XIV. 10. 97. - Mandl in den Ann. d. sc. natur. 1839. XI. p. 347. und XIII. p. 62. - Besonders aber Peter's in Müller's Archir, 1841. S. CCIX. Meine Beobachtungen stimmen durclgängig mit denen von Peters überein. Die Tasche, welche die Schuppen umgibt, ist nicht blos Oberhautgebilde, wie Agassiz annimmt. Die Anwesenheit von strahligen Knochenkörperchen in Ilen Schuppeı von Polypterus und Lepillosteus hahen Peters, Müller, Agassiz u. A. constatirt; ich finde sie auch in denen von Thynnus rulgaris. - Ueber andere Knochenbildıngen der Haut vgl, Mïller's Myxinö̈len Th. 1. S. 63. - Die Schilderung der verschiedenen Formen der Sclupupenbildung gehört der Zoologie an; sie zunı ausschliesslichen systematischen Eintheilungsprincipe zu wählen, erscheint mehr als berlenklich. Vgl. über diesen Gegenstand die vortreffl. Bemerkungen v. J. Mïller in Wiegmann's Archiv 1843. S. 298. Abbildungen des Seitencanales s. bei Monro, Vergleichung des Baues der Fische, übers. von Schneider. Blaiıville, Princip. d'Anat. comp. lıat die knöchernen Röbren des Seitencanales beim Aale gekannt. Sie kommen bei allen Muränoïlden vor.]

\section{Dritter Abschnitt. Uebersicht der Muskeln.}

§. 22.

Jede Seitenhälfte des Rumpfes wird von einer starken Muskelmasse (dem Seitenmusk ol) eingenommen, welche von der Basis der Schwanzflossenstrahlen mit einzelnen Sehnen beginnt und dann nach vorn sich erstreckt, wo sie am Hinterhaupte und längs des ganzen Schultergürtels sich anheftet. Fortsetzungen dieses Muskels erstrecken sich bei den Knochenfischen von dem vordern Rande der Bauchseite des Schultergürtels zu den Zungenbeinbogen, als Musculi sternohyoüdei. An der Oberfläche des Seitenmuskels erscheinen zahlreiche mehr oder weniger parallele, im hinteren Theile des Rumpfes zickzackförmige, nach vorn mehr geschwungene, in der Querdimension verlaufende sehnige Streifen. Sie sind die Säume durchtretender Ligamente, welche den Seitenmuskel in eben so viele Abtheilungen theilen, als Wirbelkörper und Spinalnerven vorhanden sind. Die zwischen zwei solcher Querstreifen eingeschlossenen Muskelbuindel haben einen geraden ge-

8) Bei Raja und Rhinobatus geht nır eine ganz kurze Strecke durch den Scherlelknorpel. 
streckten Verlauf. Jedes einzelne Muskelsegment bildet in der Regel drei zusammenhangende Hollkegel oder IIohlkegel-Abschnitte; die Spitze des mittleren ist nach vorn, die der beiden anderen nach hinten gerichtet. Die IIohlkegel oder Ilohlkegel-Abschnitte aller cinzelnen Muskelseginente stecken successive in rinander. Eine mittlere Liingsfurche theilt den Rumpftheil des Seitenmuskels in eine Riicken- und Bauchlïilfte. Diese beiden Irilften entsprechen einander völlig und sind, was besonders deutlich bei Betrachtung der Schwanzgegend hervortritt, durchaus symmetrisch und gleichartig gcbildet. Dic Rückenhisilfte erstreckt sich von der Mitte der Wirbelkörper aus üher die oberen Wirhelbogenschenkel, die Bauchhälfte von derselben Gegend aus uiber dir unteren Wirbellogenschenkel und in der Bauchgegend zuggleich iiber deren Verlängerungen, die Rippen. Schon die ganze Region der Flossenträger wird oben sowol, als unten häufig von einem gesonderten Längsmuskel bedeckt. Die die Seitenwïnde der eigentlichen Bauchhöhle belegende Muskelnasse ist also nicht, wie bei den meisten höheren Wirbelthieren, ein eigenthümliches System von Muskeln, sondern eine unmittelbare Fortsetzung und ein Aequivalent derjenigen, welche über die unteren Wirbelbogenschenkel in dor Schwanzgegen! sich erstreckt. Eine vollständige Sonderung der Seitenmuskelmasse in einzelne, den Riickenmuskeln und den Interprocessualmuskeln der liöheren Wirbelthiere entsprechende Fascikel findet bei den Fischen noch nicht Statt. Nur bisweilen erscheinen parige gerade Bauchmuskeln ${ }^{1}$ ), welche einem eigenthüinlichen Systeme vorderer oder unterer gerader Schluss muskeln angehören.

Die Bewegungen der Flossenstrahlen werden durch Systeme kleiner Muskeln bewirkt, welche, in verschiedenen Richtungen über einander liegend, zum Theil in antagonistischem Verhältnisse zu einander stehen. Die der After- und Rijckenflosse bestehen aus einer Lage oberflächlicher Muskeln, welche von der Itaut zur Basis der Flossenstrahlen sich erstrecken. Die tieferen umfassen die Flossenträger und heften sich gleichfalls an die Wurzeln der Strahlen. Diese Muskeln bcwirken an den Riicken - und Afterflossen deren Hebung und Senkung. An der Schwanzflosse finden sich noch ausgebildetere Muskeln, welche die Flossenstrahlen einander nähern und von einander entfornen. Aehnliche Verhällnisse kehren an den Flossen der Extremitäten wieder. Eine oberfliichliche Lage kleiner, an ihrer Basis verschmolzener, vom Schultergiirtel absteigender Muskeln hebt z. B. die Brustflosse; eine tiefere Lage senkt sie. Wirken die Muskeln beider Lagen zusanmen, so ziehen sie die Flosse vorwärts. Aehnlich beschaffen, wie die Vorwärtszieher der Flossen, sind ihre Riickzieher, welche sie den Bauchwandungen nähern. - Bei den Plagiostomen, und namentlich bei den Rochen,

1) Z. B. bei Branchiostoma, Myxine U. A. 
erreichen die Muskeln der Extremititen einen ungeheuren Unfing und sincl, der horizontalen Lage der Flossen geniass, eigenthümlich modificirt.

Die 'Bewegung der Kiefer geschicht bei den Knochenfischen durch eine grosse Muskelmasse, welche meist mit mehren ausgebreiteten Schichten und Abtheilungen von der äusseren oder oberen Fläehe der das Kiefersuspensorium und den Gaumenapparat bildenden Knochen ausgeht, unterhalb der Augen, von einer fibrösen Membran bedeckt, sich vorwärts erstreekt und mit zwei durch Aponeurose verbundenen Sehnen von ungleicher Stärke an Oberkiefer und am Processus coronö̈«ens des Unterkiefers, sich befestigt. - Die beiden Bogen des Unterkicfer's werden einander genähert durch einen an der Innenfläehe eines jeden vorhandenen und in dessen Hölıle sich erstreckenden Muskel. Zwisehen den Unterkieferbogen und denen des Zungenbeines licgen etwas schräg die Musculi gewiolıyoüdei. - Zur Annäherung der den GalumenApparat und das Kiefersuspens orium zusammensetzenden Knochen an die Schedelbasis und zugleich zu ihrer Senkung dient ein von der Schedelbasis zum Innenrande und zur untern Fläche dieser Knochen sich erstreckender quer verlaufender Muskel. Gehoben wird derselbe Apparat durch einen von der Gegend des Processus orbitalis posterior zum Os temporale und pterygoüdenm absteigenden Muskel. Das Operculum besitzt gleichfalls einen mehr oder minder zusammengesetzten Hebemuskel und einen ihın entgegenwirkenden Senker. Die Constrictoren der Kiemenhöhle sind bei den Cyclostomen, den Chimären und Plagiostomen schr ausgebildet. Bei den Knochen fisehen sind sie dureh die zwisehen den Radii Urancliostegi des Zungenbeines gelegenen Muskeln reprüsentirt, deren Bildung dureh eigenthümliche Verhältnisse der Kiemenhöhle, wie sie z. B. bei den Lophien und bei den Muränoïden vorkommen, manniehfach modifieirt erscheint. Die hintere Wand der Kiemenhöhle besitzt in der Regel ein muskulöses Diaphragma. - Ein sehr complicirter Muskelapparat bedingt die Bowegungen der Kiemenbogen. Zilhlreiche kleine Muskeln steigen von der Schedelbasis zu den einzelnen Kiemenbogen abwärts und ziehen sie aufwärts. Ein stärkerer Muskel erstreckt sich von der untrren Fliiche der Wirbelsäule schicf zu den obersten Abschnitte eines der hinteren Kiemenbogen, hebt den ganzen Apparat und zieht ihn zuriick. - Ihm entgegen wirkt cin vom Zungenbein zu jedem Os pharyngeum inferius sich erstreckender Muskel. Zwei andere Muskeln liegen zwischen demselben Knoehen und dem Schultergiirtel; der eine zieht den Kiemenbogen-Apparat nach hinten; der andere zieht ihn zugloich abwïrts. - Durch obere und untere Quermuskeln werden die Kiemenbogen und Ossa pharyugea inferiora beider Seiten einander" geniihert. Kleine sehiefe Muskeln ziehen die unteren Segmente derselben an ihre Copmalue. 
[Zahlreiche nähere Angaben über das Verhalten der Muskeln bei den Cyclostomen s. in den angef. Schriften von Müller und $R$ athke; über die Muskeln der übrigen Fische aber in $\mathrm{Cuvier}$, Histoire nat. d. poiss. Vol. 1., mit vortreff-

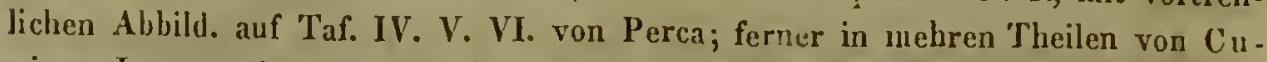
vier, Leçons d'anat. comparée, mit vielen Zusätzen von Duvernoy, und in Meckel's System der vergl. Anatomie; Abbildungen auch bei Carus, Erläuterungstafeln Heft 1. Tab. 2. - Kein Theil der vergleichenden Anatomie bedarf mehr einer durchgreifenden, über alle Wirbelthierclassen ausgedehnten Bearbeitung, als die verlıältnissmäissig noch sehr vernachlässigte Myologie.]

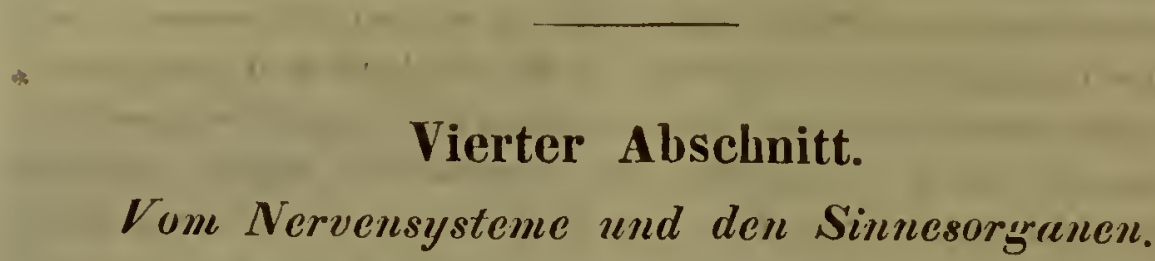

\section{Von den Centralorganen des Nervensystemes.}

§. 23.

Die Centralorgane des Nervensystemes bestehen bei den Fischen aus dem im Canale der oberen Wirbelbogenschenkel liegenden Rückeninarke und dem von der Schedelhöhle unschlossenen, aus mehren $\Lambda \mathrm{n}$ schwellungen bestehenden Gehirne, welche vermittelst des verlängerten Markes in einander übergehen. Nur der niedrigste bis jetzt bekannte Fisch (Branchiostoma lubricum) macht hiervon in so fern eine Ausnahme, als bei ihm der vordere Theil des centralen Nervensystemes vor dem Rückenmarke nicht durch eigene Anschwellungen ausgezeichnet ist, jenes vielınehr nach vorn allmälich sich verdünnt und dann als Hirn vorn abgerundet endet ${ }^{1}$ ).

Das Rückenmark der Cyclastomen ist bandartig, platt, elastisch und dehnbar und besteht aus bandartigen, platten, blassen Fäden mit zwischenliegenden feineren Fasern 2). Auch bei den Chimären bleibt es, unter Anwesenheit ähnlicher Bildungselemente, elastisch und zeigt sich im hintersten Theile bandartig ${ }^{3}$ ). Bei den ubrigen Fischen besitzt seine Textur diese Eigenthümlichkeiten nicht. Seine Form ist hier gewöhnlich cylindrisch; es hat eine hintere tiefere und eine vordere seichtere Lïngsfurche und einen engen Mediancanal. Es besteht aus vier Strängen, von denen die oberen, wenigstens im vorderen Theile des Riickenmarkes, entwickelter zu scin pflegen, als die unteren. Gewöhnlich ist das Rückenmark sehr lang und erstreckt sich durch die ganze Länge des Wirbelcanales; nur ausnahmsweise wird es sehr kurz, wie bei Lophius und Orthagoriscus 4). - Es endet bei den Knochenfischen

1) So nach Mïller, Monatsber. d. Acad. d. Wiss., Dec. 1841. - 2) Vgl. Mïller, Vgl. Neurol.d. Myxinoïd. - 3) S. Valentin in Müller's Arcliv, 1842.

4) Vgl. Arsaky, de piscium cerebro et medulla spinali, Hal. 1813. Bei Or. 
mit einer scharf hervortretenden rundlichen oder ovalen gangliösen $\Lambda$ nschwellung ${ }^{5}$ ), alus welcher bisweilen noch ein unpaarer Faden abgeht 6 ). - An der Ursprungsstelle einzelner stïrkerer Nervenwurzeln aus den hinteren Stringen besitzen diese bisweilen paarige knotige Anschwellungen $\vec{r}$.

\section{§. 24.}

Das vellingerte Mark und die vor ihn liegenden Hirntheile bieten eine grosse Mannichfaltigkeit der Bildungen dar. Im Allgeneinen hat das Gehirn der Fische - mit der cinzigen angegebenen Ausnahme - die Eigenthümlichkeit, dass es ans einer Reihe, theils paariger, theils unpaarer oberer Anschwellungen besteht, deren Zahl in den verschiedenen Ordnungen derselben sich nicht gleich bleibt und dass auch an seiner Basis hinter der meist sehr stark entwickelten Hypopllygsis gewöhnliclı noch untere Lappen vorkonmen $\left.{ }^{1}\right)$. Die Weise der Reduction dieser einzelnen Abtheilungen des Fischgehirnes auf die Hirntheile der höheren Wirbelthiere und ihre davon abhängige Benennung sind sehr verschiedenartig ausgefallen $\%$. Ain sichersten gelingt die Deutung der einzelnen oberen Abtheilungen des Fischgehirns, wenn man sie den primitiven Hirnabtheilungen der Embryonen der höheren Wirbelthiere vergleicht, deren Zahl anfangs drei beträgt, aus denen aber sehr·bald, fünf sich entwickeln. Das vorderste dieser Bläschen (dis Vorderhirn) ist die Grundlage der künftigen Hemisphären, das zweite (Zwischenhirn) repräsentirt die Umgebungen des dritten Ventrikels; aus dem dritten (Mittelhirn) entwickeln sich die Vierhügel; aus dem vierten (Hinterhirn) bildet sich das kleine Gehirn und das fünftc (Nachhirn) ist dic

thagoriscus ist das Rïckenmark kaum so lang als das Gehirn und besitzt gallglienartige Anschwellungen.

5) Z. B. bei Perea, Lueioperca, Gadus, Silurus, Pleuronectes.

6) Bei Cyprinus nach E. H. Weber, Me ekel's Archiv $182 \%$

7) Bei Trigla lange bekannt; nach Mïller auch bei Polynemus. Bei Beideı seheinen die sogenanuten fingerförınigen Anlänge der Brustflossen, zu welchen die aus diesen Ansehwellungen entspringenden Nerven sieh ljegeben, Tastorgaue zu sein. Bei T'rigla adriatica finden sieh drei verschnolzene und drei isolirte T'uberkeln; bei Trigla lyra kommen fünf vor. Vgl. die Abbildung von Tied eutuu in Meckel's deutsehem Arehir, Bd. 2.

1) Die vichtigsten frïheren Arbeiten ïber das Fisehgehirn sind naulaft ge. maeht in eiıem an Beobachtungen äusserst reichhaltigen Aufsatze von Gottsclıe: Vergl. Anatomie des Gehirns der Gräthenfisehe, in Müller's Arehiv f. Auat. u. Phys. Jahrg. 1835. Ieh kann die Angaben des Verf., gestïtzt auf rielfache Prü. fung derselben, fast durchweg bestätigen, ohne unit seinen Deutungen übereinzu. stimmen.

2) Eine kritische Zusammenstellung sämmntlicher üler das Gehirn ler Grïthenfisehe aufgestellten Ansichten hat geliefert Miiller ill seiner vergleichenden Neurologie der Myxinoïlen, Berlin 1840. 
Grundlage der Gegend des verlïngerten Markes ${ }^{3}$ ). Wird dieser Ausgangspmkt, unter Berüksiehtigung der Ursprungsstellen der Nerven und der Insertionsstelle der Iypophysis consequent festgehalten, so gelangt man zu einer einigermaassen befriedigenden Deutung der oberen Anschwellungen des Fisehgehirnes. Die Verminderung ihrer Anzahl in den Gehirnen vieler Fische erklärt sieh dureh Verschmelzung zweier Grundlagen zu einer, ihre Vermehrung aber durch Spaltung einer Grundlage in zwei besondere Gebilde.

Geht man bei Betraehtung der einzelnen Hirntheile der Fische von vorn aus, so findet man in der Mehrzahl derselben zuerst ein oder zwei Paare meist rundlicher Ansehwellungen (Tubercula olf actoria), welehe den Geruchsnerven angehören.

Abgesehen von den Ansehwellungen der Geruchsnerven sind bei den Myxino ïden 4) drei auf einander folgencle paarige Hirnabtheilungen vorhanden, welehe an der Basis kaum gesondert erscheinen. Das vorderste Paar entsprieht dem Vorderhirn oder den Ilemisphären; zwisehen dem binteren Theile der die beiden Hemisphären trennenden Furche liegt ein kleiner unpaarer Körper. Auf sie folgen die $\boldsymbol{L}_{0} \boldsymbol{L}_{\boldsymbol{i}}$ vestriculi tertii, von deren Basis die Sehnerven ihren Ursprung nehmen, hinter welehen die kleine Hypophysis liegt. Die letzte und kleinste der oberen paarigen Abtheilungen repräsentirt Mittelhirn und Nachhirn zugleich. Die Lobi inferiores werden dureh cine hinter der No/poplingsis liegende unpaare Erhabenheit angedeutet. Alle genannten Hirntheile sind durehaus solide; nur zwisehen der letzten paarigen Abtheilung des Gehirnes und der Medulla ablongata liegt ein Sinus rhomboüdalis. Das verlängerte Mark zeigt sich in Yergleich zum Rückenmarke in der Dicke und Breite angesehwollen. Es besitzt zwei divergirende Marksäulen, welehe zur Seite der hintersten Hirnabtheilungen vorn frei und stumpf enden (die Lobi medullae oly. long g ta $a$ ) , aus welchen die Mehrzahl der Nerven ihren Ursprung nimmt.

An Gehirne der Petromyzonten ${ }^{5}$ ) zeigen sich hinter den Tubercula olf actoria die vorn dureh eine Spalte getrennten, hinten verbundenen soliden $\mathrm{Hem}$ is phären. Auf sie folgt dis unpaare $Z$ wisehenhiı'n, welehes die Ilöhle des dritten Ventrikels enthält, die in die Höhle der /Yypophysis iibergeht. Vor dieser letzteren kommen die Schnerven hervor. Hierauf folgt dis gleiehfalls hohle paarige Mittelhirn. Das

3) Vgl. C. E. v. Baer, Ueber die Entwickelungsgeschichte der Thiere, liönigsluerg 1837. 4. S. $107 \mathrm{ff}$.

4) Vgl. Müller I. c. S. 8 ff. Abbildungen in Mïller's Schtift ïber den Bau des Gehörorganes bei den Cyclostomen Tab. 2 .

5) Abbildungen in Carns Zootomie, Tal. IX.; bei Ratlıe, üb. den Bau d. Pricke, Tab. 3.; bei d'Alton in Müller's Archiv 1840; bei Müller, Gehörorgan d. Cyclostomen Tab. 3. und copirt bei Waguer, Icones physiol. Tab. $\mathbf{2 3 .}$ 
Cerebellum erscheint als unbedeutende Querleiste, welche iber den vordersten Theil des Sinus rlomboülalis ausgespannt ist und nur eine Conmissur der seitlichen oberen Theile der Medulla oblongata darsteltt. Die Lobi inferiores werden durch eine hinter der IIJpopllysis am vorderen Theile der Basis des verlingerten Markes gelegene unpaare Vorragung vertreten. Die Medulla oblongata selbst gewinnt naelı dem Hirne zu an Breite und besitzt einen weiten $S_{i}$ us rloombö̈dalis, der unter dem Cerebellom in die Höhle des Mittelhirnes sich fortsetzt. Die den Myxinoïden eigenthümlichen Lobi medullae oblongatae fehlen.

Bei den Chimären ${ }^{6}$ ) scheinen die auf die unbedeutenden Riechtuberkeln folgenden grossen, hohlen Lappen die Hemisphären und den Lobus veutriculi tertiizugleich zu repräsentiren, denu unter ihnen liegt die zwei seitliche, den $\boldsymbol{L}_{0} \boldsymbol{b i}$ inferiores veryleichbare Erhabenheiten sich zeigen. Das Mittelhirn besitzt einen stark entwiekelten, länglich-runden, durch eine Liingsfurche paarigen, inwendig hohlen Lappen, der sowol den vor ihm liegenden Lobus, als auch nach hinten das $\boldsymbol{C e}_{\text {- }}$ rebellmm grossentheils überragt und mittelst eines dïnneren Stieles der Basis des Gehirnes aufsitzt. Das hinter ihm gelegene gleichfalls sehr entwickelte Cerebellum zeichnet sich dureh zierliche Windungen aus. Zur Seite des Simus rhomböillalis liegen beträchtliche, ihn grossentheils iiberwölbende, oben an einander stehende, aber durch eine Mittelfurche getrennte Lobi me liullae oblongatae und abwärts von diesen letzteren seitliehe $\boldsymbol{L} \circ \boldsymbol{b} i \boldsymbol{V a g} i$.

Bei A c cipense ${ }^{7}$ ) folgen auf die Riechtuberkeln die oben durch eine tiefe Spalte getrennten, an der Basis dureh Markmasse eng verbundenen Hemisphären. Jeder Lobus zeigt zwei dureh eine seichte Furche geschiedene, inwendig solide Massen. Auf sie folgt ein kleiner unpaarer Lolus ventricmli tertii, oben nur von Hirnläuten üherwölbt, daher, nach Wegnahme derselben, eine offene Höhle darbietend, welche seitlich von leichten, den Thalami optici veryleichbaren Erhabenleiten begrenzt, oben, nur unmittelbar vor den Lobi optici, durch eine schmale Commissur bedeckt wird. Diese Höhle communicirt mit der

6) Vgl. Valentin in Mïller's Archir 1842; mit Ablildung. Ich kaun der Deutung Jer Gehirntheile, wie sie Valentin gegeben, nicht beitreten; er bezeich. net die ersten Lappen als Henisphären, das Mittelhirn aber als Lohus ventriculi terlii. Auch rïcksichtlich des kleinen Gehirns möchte Einiges zu modifici. ren sein.

¡) Vgl. Stannius in Müller's Archiv 1843, mit Abbildungen. Der Stör hesitzt anch eine Epiphysis, der iu dem angef. Aufsatz keine Erwälnnung ge: schehen ist; weil dies Gebilde nur mit den Gefissen und gefässreichen Häuten des Hirnes in Verbindung zu stehen scheint. Diese Epriphysis erstreckt sich beim Stör aufwärts in die Knorpolsulıstanz des Sehedels linein. 
der verschmolzenen $L \circ b i$ inferiores, an deren Basis die starke so lide IIpopllysis ruhet. Die auf den Lobus veutriculi tertii folgenden Loli optici sind paarig und hohl; ron ihnen nehmen die Nervi optici ihren Ursprung. Das selır enlwickelte, hohe, oberllächlich theilweise gewundene Cerele $\ell_{n} m$, bildet nicht allein eine die vierte Hirnhöhle überwölbende Quercommissur, sondern ragt auch mit seinem unassigeran zapfenförmigen Körper frei hinein in die Höhle des Mittelliirns. Die nach dem Hirne zu beträchtlich an Breite gewinnende $\boldsymbol{M}_{e}$ lulla oblongata besitzt cinen weiten Siuus rhombö̈dalis, schmale, lange, säulenförmige Loli, die sich nicht berühren, und bildet zur Seite des Cerebellum stark entwickelte Lobi nervitrige$m i n i$. An der durch eine Längsfurche in zwei Seitentheile zerfallenen Basis findet sich eine brickenartige Quercommissur.

Bei den Plagiotomen ${ }^{8}$ ) zeichnen sich die mehr oder minder viereckig-rundlichen, vorzigglich in der Breitendimension entwickelten, meistens durch eine seichte obere Furche paarigen Hemisphärenmassen aus durch ihren beträchtlichen Unfang, durch Spuren von Windungen und durch den Besitz einer Höhle. Diese letztere communicirt bisweilen mit einer Höhle der Rieclınerven, welche nicht gleich bei ihrem Ursprunge, sondern erst viel weiter nach vorn ihre Anschwellungen bilden. In der Hemisphärenhöhle werden den Streifenhïgeln vergleichbare Erlabenheiten beobaclitet. Auf dies Vorderhirn folgt bei mehren Plagiostomen ein unparer kleiner Lobus veutriculi terti mit einer Höhle, unterhalb welcher die Iypopliysis liegt. Ilinter dieser finden sich zwei getrennte $L$ obi inferiores. Das viel bedeutender entwickelte Mittelhirn bestelt aus zwei durch eine Mittellinie oben getrennten ziemlich convexen Markmassen, welche eine Höhlung überwölben. Dis sehr beträichtliche Cerelellum uiberragt mit seiner mittleren oberen Masse, welche zuweilen deutliche IVindungen zeigt, häufig einen grossen Theil des Mittelhirns und bildet zugleich unten eine über die vierte Hirnhohle weggehende Quercommissur. An und neben der vierten Hirnhöhle finden sich starke Lobi nervi $t$ rige $\boldsymbol{m} i \boldsymbol{u} \boldsymbol{i}$. An der Ursprungsstelle des Nervus vagus zeigen sich bald schwache Erhabenheiten, bald mehre kleine Ganglien, bald sehr starke den $\boldsymbol{s}_{i-}$ uns rhomboülalis überwölbende in der Mitte zusammenstossende Massen, die sogenannten Lobi electrici der Zitterrochen.

8) Abbildungen von Plagiostomen-Gehimen finden sich bei Carus, Zootomie Tab. 1X. und Darstellung des Nerrensystemes Tab. II.; bei Kulı, Beitr. z. Zool. u. vergl. Anat. Frankf. 1820. Tab. 1.; bei We ber, de aure et auditu hom. et anim. Lips. 1820. 4. Tab. 10.; bei Swan, Illnstrations of the comp. anat. of the nerv. syst. Lond. 1836. 4. Tab. X.; bei Wagner, Icones physiol. Tab. 23.; bei Valentin in Neue Denkschr. d. schweiz. Gesellsch. f. Naturwiss. Neuchat. 1841. Bd. 6.; bei Mayer, Spicilegium observat, anatomicar. de Organo electrico in Rajis, Bonn. 1843. 4. u. a. a. 0. 
Bei den Knoclienfisehen ${ }^{9}$ ) licgen ineistens unmittelbar vor den II emisphärenlappen die den Riechncrven angehörigen Anschwellungen, die selten erst am vorderen Theile der Nervi ulfacturii sich bilden. Auf die IIemisphärenlappen folgen dann die sogenannten Lobi optici, welche zugleich das Zwischenhirn und Mittelhirn repräsentiren, denn die Hypophysis befestigt sich an der Basis des vorderen Theiles dieser Lappen und die Nervi trochleares entspringen zwischen ihnen und dem Cerebellum. Hinter der Mypoplaysis liegen an ihrer Basis die Loli inferiores. Oben folgt auf die $\boldsymbol{L}_{0} \boldsymbol{L}_{i}$ optici nach hinten das Cerelellum, an welches ferner noch häufig Anschwellungen der Medulla ollongata (Lobi posteriores auct.) sich anschliessen.

Dic parigen, soliden Hemisphärenlappen der Gräthenfische haben gewöhnlich eine bläulich-graue Farbe und zeigen häufig einige sehr schwache Erhabenheiten oder Windungen; sie bcstehen grossenthcils aus grauer Substanz, enthalten aber zugleich weisse Fasern, mit denen die Pyramidalstränge in sie ausstrahlen. Die beiden Lappen verbinden sieh durch eine Commissura iriterlobularis, deren Fasern aus den Pyramiden stammen. In der Regel sind sie kleiner als die Loli optici ${ }^{10}$ ), seltener gleich gross 11), noch seltener grösser als sie 12). Bei den Sehollen ist der aufwärts gelegene Lobus inmer grösscr und ausgebildeter, als der untere, ihm entsprechende.

Zwischen den Hemisphärenlappen und den Loli optici liegen seitlich auf dem Hirnstiele noch zwei klcine Tuberkeln (Tulercula intermedia), welche durch eine feinc Quercommissur (Contmissura temuissima) verbunden werden. Mit ihnen steht durch Gefässe oder häutige Theile in Verbindung die, wie es scheint, allen Fischen zukommende Epiphysis, ein vielleicht durchaus vasculöses Gebilde, das oft bedeutend höher, als dic cigentlichen Hirntheile, in der Schedelhöhle sieh erhebt ${ }^{13}$ ).

Die gleichfalls paarigen $L_{0} b_{i}$ optici sind gewöhnlich länglichrund oder cylindrisch und bestehen aus grauer, init wcissen Fasern untermengter Substanz. Ihre Grösse stcht anscheinend in einem geraden Verhältnisse zur Grösse der Augen ${ }^{14}$ ). Stets besitzen sie in ihrem In-

9) Vgl. besonders den Aufsatz von Gottsehe, dem zahlreiehe Abbillungen beigegeben sind.

10) Sehr klein fand sie Gottsehe bei Zens faber.

11) Z. 13. bei Gobins niger und Crenilabrus norwegicus naeh Gottsehe.

12) Bei Muraena. Hier kommen auch Spuren von Theilung jedes Hemisphärenlappens in zwei Abtheilungen vor, die aneh Valentin angibt.

13) Ich habe sie nie veruilsst; sehr entwickelt ist sie z. B. bei Salmo.

14) Von Gottsehe nach Beobachtungen an den Pleuronectes.Arten geschlos. sen. Klein sind sie aueh bei Sihrus, wo die Sehnerven unt Augen schwach und klein sinul. 
nern eine umfangreiche Ilöhle und enthalten zahlreiche kleine Gebilde, welche sehr verschiedenartig gedeutet worden sind ${ }^{15}$ ).

Unter den Lobi optici inserirt sich mit cinem bald kurzen, lsald langen 16) Trichter (I ufundilulum) dic Mypopleysis. Der Trichter hangt zusammen unit einem grauen dreieckigen Theile (Tri gou um fissum), in welchem ein von zwei wulstigen Lippen begrenzter; in den Ventrikel der Sehlappen führender Spalt sich findet. Yor dieseu grauen Dreieck liegt eine, die Ursprïnge der beiden Sehnerven verbindende Commissur (Commissura transversa Ialleri). Die röthlich-grau'gefärbte, gefässreiche, anscheinend immer solide /Iypuphluys is ist bei allen Knochenfischen gross, bei einigen aber wieder hervorstechend entwickelt ${ }^{17}$ ). Sie ruhet in einer vorn von den brückenförmigen vorderen Keillocinkörper, hinten von dem Vorderrande dèr Ossa petrosa geschlossenen Luicke der unteren Schedelwand.

Gleichfalls unter den Lobi optici liegen, die Loli inferiores, incist zwei ovale Lappen von graulich-weisser Farbe, hinten gewöhnlich eng verbunden, vorn durch das Trigronum fissum weiter aus einander gedrängt. Sie sind, anscheinend immer, hohl und ihre Ilöhle communicirt mittelst des Trichters mit dem Ventrikel der LoLi optici. Zwischen und unter ihnen liegt häufig ein membranöser, gefässreicher, oft weiter Sack (S accus vasculosus), der eine ciweissartige Fliissigkeit enthält. Dic hinteren Grenzen der Loli iuferiores verdecken eine weisse, dicht an der Ursprungsstelle der $\boldsymbol{N}$. $\boldsymbol{N}$. oculorum motorii befindliche Quercommissur.

Das bald sehr kleine ${ }^{18}$ ), bald auffallend grosse und stark entwikkelte 19) Cerebellum ist gewöhnlich oberflichlich glatt, besitzt aber hisweilen Furchen ${ }^{20}$ ). Obgleich es unpaar erscheint, erkennt man doch unehr oder minder deutliche Spuren einer mittlern Läingsfurche. Inwendig besitzt es eine mit den übrigen Ventricularräumen communicirende

15) Mit besonderer Sorgfalt von Gotts che beschrieben.

16) Sehr lang bei Lophius und Clupea Alosa nach Gottsehe.

17) Z. B. Cyelopterus, Pleuronectes; ich habe mich nie von Anwesenheit einer Höhle in diesem Gebilde überzengen können.

18) Bei Gobius niger, Julis, Lophius nach Gottsche; selır klein find ich es auch bei Cottus unl Cyclopterus.

19) Bei Thymus nach Cuvier, bei Echeneis nach Gottsclıe, bei Gyunotus nach Valentin, bei verwandten Nuränö̈len nach Mïller; bei Sconber scomber, Salnı salar fand ich es ebenfalls sehı stark entwickelt. - Es iiberragt bei den genannten Fischen bald emen grossen Theil der Lolii optici, bald reicht es rnoch weiter nach vorn, wie bei Thynnus. S. die Abbildung bei Müller, Gehörorg. 1. Cyclostomen Tab. 3.

20) Bei Seomber beobachtet; auch bei Thynnus und Echeneis nach Cuvier und Gottsiche. 
IIöhle. In die Markmasse des Cerebellum gehen dic scitlich aufsteigenden Corpora restiformia über.

Hinter dem kleinen Gehirn liegen häufig paarige Anschwcllungen der Medulles oblongate, die sogenannten Lobi posteriores, welche oft oberhall) des vierten Ventrikels sich verbinden. Sie scheinen die stark entwickelten Uisprungsstellen des Nervus trigeminus zil sein. llinter ilmen. liegen noch seitliche Anschwellungen an der Ursprungsstelle des Nervars vagus (Loli Vagi).

Von dem Boden der vierten Hirnhöhle erhebt sich biswcilen noch eino unpalare Anschwellung ${ }^{21}$ ) oder es kommen deren sogar mehre ${ }^{22}$ ) bor. - Der Sinus rhombö̈lalis, dessen Boden von den vorderen Psramiden und dessen Seitenwände von den Corpora restiformia und den hinteren Pyramiden gehildet werden, hat eine verschiedene Auslehning und communicirt nach hinten mit dem Mediancanale des Riikkenuriarkes. An scinem Boden finden sich mehre Commissuren. Voin Riickenmarke aus nach dem IIirne zu gewinnt die Medulla oblongata immer an Breite.

\section{§. 25.}

Das Gehirn der Fische ist nicht nur im Verhiiltnisse zur ganzen Kürpermasse, sondern auch zur Masse der aus ihm hervortretenden Nerven sehr klein; am betrïchtlichsten ist es bei den Plagiostomen. Mcistentheils fiillt es die Schedelhöhle hei weitem nicht aus und ist oft in Vergleich zu dem Unfange der letzteren sehr unbetrichtlich zu nennen. Eine harte Hirnhant ist fast immer dentlich nachweisbar. Die das Gehirn unmittelhar umkleidende gefässreiche Piø mater wird meistentheils von einer fettreichen, sulzigen Masse, die bald in grössercr; balle in geringerer Menge vorhanden ist, umgeben; durch diese Masse wird die Schedelhöhle oft zum grössten Theile ausgefüllt 1 \%

\section{Von den Spinalnerven.}

§. 26.

Díe Spinalnerven der meisten Fische cntspringen mit zwoi Wurzeln, einer vorderen und einer hinteren - ein Gesetz, von welchem nur sehr wenige Ausnahmen bekannt sind, indem nur bei einigen Gadus-Arten, statt einer hinteren Wurzel, deren zwei an der Mehrzahl der Spinalnerven vorkommen ${ }^{1}$ ). Bci einigen Knochenfischen besitzt

21) Z. B. hei den Cyprinen. - 22) Z. B. bei Silurus.

1) Sehr eigenthümlich sind die Umhïllungen des Gehirnes bei Petromyzon und Aceipenser durch Anwesenheit ron härteren Scheibchen und gefïssreichen fircherförmigen Platten. - Reichert lat die Existenz der harten Hirnhaut der Knochenfischr mit Uurecht in Abrede gestellt.

1) Iies Verhalten hat $S$ wan bei Gadus Morrhua entuleckt; ich beobachtete rs an 31 Spinalnerven von Gadus Callarias, der freilich nach K röyer von erstgenannter Art niclit specifisch verschiedelı sein soll. Die eine dieser beilen hinte- 
ausschliesslich der erste Spinalnerv eine hintere und zwei vordere Wurzeln 2) und bei anderen werden die beiden ersten Spinalnerven aus zwei hinteren und einer vorderen Wurzel gebildet $3 \%$ - Von der Regel, wonach die hinteren Wurzeln der spinalnerven zu einem Ganglion anschwellen, kennt man dagegen keine bestimmte $\Lambda$ usnalıme 4). Diese gangliöse $\Lambda$ nschwellung wird gewöhnlich gleich nach dem Austritte der hinteren Wurzel aus dem von den oberen Bogenschenkeln der Wirbel gebilcleten Canale beobachtet 5). Die Austrittsstelle der Wurzeln ist in der Regel der Zwischenraum zwischen zwei oberen Bogenschenkeln der Wirbel; selten treten sic durch dic Knochensubstanz der obcren Bogenschenkel 6). Sogleich nach der Ganglicnbildung der hintcren Wurzel verflicht sich die vordere mit ihr und alsbald treten die einzelnen Zweige aus dieser verbundenen Nervenmasse hervor. In der Regel sind $\boldsymbol{R} a m i$ dorsales s. posterioresi) und Rami ventrales s. anteriures vorhanden; meistens geht zwischen beiden noch ein Ramus medius 8 ) ab.

Rami dorsales sind meistens zwei vorhanden: ein vorderer (R. spinosus), der längs dem hinteren Rande des ihm entsprechenden Processus spinosus zum Riucken aufsteigt und ein hinterer (R. communicans), der schräg nach hinten sich erstreckt und dann mit dem $\boldsymbol{R}$. spingosus des nächst binteren Spinalnerven sich verbindet 9). Durch die Vereinigung beider entsteht dann häufig ein $\boldsymbol{R}$. communicans für den $\boldsymbol{R}$. Interalis trigemini $\left.{ }^{10}\right)$. Bisweilen gehen neben den genannten beiden Hauptästen noch untergeordnete Zweige ab, die sich sogleich in die Rückenmuskeln begeben. Mitunter gibt der $\boldsymbol{R}$. clorsalis $\mathrm{n}$ ur einen solchen Rückenmuskelzweig ab und seine Fortsetzung bildet einen $\boldsymbol{R}$. communicans. Durch dic Vereinigung diescr $\boldsymbol{R}$. communicontes entsteht in diesem Falle ein Längsnervenstamm, der an der Basis der Dornfortsätze nach hinten sich erstreckt. Aus diesem letzteren gehen dann $\boldsymbol{R}$. dorsales ab, die theils unmittelbar in dic oberste Schicht der Rückenmuskeln sich vertheilen, theils an den $\boldsymbol{R}$. Lateralis $\boldsymbol{N}$. trigemini treten $\left.{ }^{11}\right)$.

Der $R a m u s$ medius geht mcistens unmittelbar aus dem

ren Wurzeln ist für den Rückenast, die andere für den Bauchast der Spinalnerren bestimut.

2) Z. B. bei Belone vulgaris.

3) Ihr Verhalten bietet bedeutende, selbst indiriduelle Versehiedenlieiten dar. S. meine Abhandlung über den Dorsch in Müller's Archiv 1842.

4) Swan's Angabe, dass bei Gadus die hinteren Wurzeln keine Ganglien besitzen sollen, ist unriebtig. Aber die für den Rïckenast bestimmte hintere Wurzel schwillt erst in beträchtlicher. Entfernung von ihrer Austrittsstelle zu einem Ganglion an.

5) Z. B. bei Cyelopterus, Salmo, Belone, Cottus. - 6) Z. B. bei Lophius. - 7) Müller vermisste sie bei den Myxinoïden. - 8) \%. B. bei Cottus, besonders stark aber bei Cyelopterus. - 9) Z. B. hei Sahmo, Cyclopterus. 10) Bei Cyelopterus, Silurus. - 11) \%. B. liei Belone, Cottus. 
durch die Vercinigung beider Wurzeln gebildeten sehr kurzen Stamm hervor; seltener ist er ein Zweig des $\boldsymbol{R}$. anterior und ist dann untergeordnet ${ }^{12}$ \% Wo or sehr stark entwickelt ist, tritt er in der seitlichen Mittollinie des Rumpfmuskels nach aussen und theilt sich unter der llaut in zwei Zweige, von denen der eine zum Rücken aufsteigt, während der andere zum Banchc abwärts sich begibt. Diese Hautzweige gehen zum 'Theil in die Bahn des $\boldsymbol{R}$. lateralis $\boldsymbol{N}$. vagi über $\left.{ }^{13}\right)$. In andern Fällen scheint er grossentheils in die Rumpfmuskeln sich zu verthcilen 14 ).

Der Ramus anterior pllegt meistens einfach zu scin und ïbertrifft die beiden anderen Aeste bedeutend an. Stärke. Er erstreckt sich abwiirts zum Bauche; wo Rippen vorhanden sind, liegt er gewöhnlich an deren vorderem Rande, dicht ïber dem Bauchfelle; sobald die unteren Bogenschenkel der Wirbel zu unteren Bogen sich vereinigen, wird es zu einem $\boldsymbol{R}$. interspinosus inferior. Bisweilen spaltet er sich unten am Bauche in zwei Aeste, von denen der eine vorwärts, der andere hinterwärts gerichtet ist ${ }^{15}$ ).

Von den Rami anteriores werden die Extremitäten mit Nerven versorgt; dic für die Extremitätcn bestimmten vorderen Aeste sind meistens bedeutend stärker als die übrigen. An die Brustflosse begeben sich bei den Knochenfischen in der Regel Elemente der Rami anteriores der zwei bis vicr ersten Spinalnerven. Immer legt sich der $\boldsymbol{R}$. auterior des ersten Spinalnerven an den des zweiten an und gibt ausser Fasern für die Brustflosse einen Ast für den M. sternoliyö̈(leus ab 16). Bei den Rochen vereinigt sich eine grosse Zahl der vordersten Spinalnerven sogleich nach ihrer Entstehung aus den beiden Wurzeln zu einem gemeinschaftlichen Stamme, aus wclchem die Nerven fïr die Brustflosse abgehen.

Dic Kehllfosse vieler Knochenfische wird von den vorderen $\Lambda$ esten des vierten bis siebenten Spinalnerven mit Nerven versorgt; bei den Bauchflossern treten die $\boldsymbol{R}$. anteriores weiter hintcrwärts gclegener Spinalnerven an die Bauchflosse.

In der Schwanzgegend vereinigen sich die einzelnen hinteren und vorderen Aeste der Spinalnerven oft geflechtartig zur Bildung von zwei Längstämmen, aus welchen denn wieder die cinzelnen Nerven abtreten. In das Geflecht der Riickenäste geht auch die hinterste Fortsctzung des R. lateralis trigemini oft ein.

[Diese Darstellung beruhet durchgängig anf cigenen Untersuchungen an Knochenfischen.]

12) \%. 13. bei Salmo, Gadus. - 13) \%. B. bei Cyclopterus. - 14) Bei Cottus, Salmo, Bclone. - 15) Z. B. bei Cycloptcrus.

16) Diesen Ast des ersten Spinalnerven bezeichnet man gewöhnliclı als N. hypoglossus. 


\section{Von den Hirnnerven.}

§. 27.

In der Anordnung der IIirnnerven ") der meisten bis jetzt genan untersuchten Fische herrscht eine sehr wesentliche Uebercinstiminung. Nur bei Branchiostoma2) sind auch die von dein vordersten Theile des Central-Nervensystemes entspringenden Nerven sämmtlich nach dem Typus der Spinalnerven gebildet und eigene Sinnesnerven, deren Existenz jedoch bei der Anwesenlieit von Sinnesorganen unbedingt angenommen werden darf, wurden bisher nicht beobachtet.

1. Der $\boldsymbol{N}$. olfactorius entspringt aus den Hemisphärenlappen des Gehirnes mit mehr oder minder zahlreichen Buindeln oder stellt mehr eine Fortsetzung dieser Hirntheile dar, wie bei den Plagiostomen. Bei den Cyclostomen, den Stören und vielen Gräthenfischen bildet jeder $\boldsymbol{N}$. olfuctorius sogleich bei seinem Hervortreten aus dem vorderen Hirnlappen eine unmittelbar vor diesem gelegene Anschwellung ${ }^{3}$ ) ( $\boldsymbol{T} u$ berculum olfactorium) 4). Mitunter liegen auch zwei solcher Anschwellungen hinter einander $\left.{ }^{5}\right)$. Bei Vorhandensein derselhen hat der

1) Specielle Untersuchungen über das Verhalten der Hirnnerven der Fische sind vielfach angestellt worden. Ausser den Schriften von Carus, Serres und Desmoulins, welche letzteren indess selten zuverlässig sind, müssen rerglichen werden die Untersuchungen von $\mathbf{M}$ üller und $\mathbf{G}$ o o ll sir über Branchiostoma ( $M$ ülle r's Archiv 1842, Jahresb.), ron Müller über die Myxinö̈len (Vergl. Nemrol. d. Myxin.), von Schlemm uud d'Alton über Petromyzon (Müller's Archiv 1838), von Scarpa und Swan über einzelne Nerveu der Plagiostomen (Scarpa, Anat. Unters. d. Gehörs u. ll. Geruchs, Nïrnb. 1800; Swan, Illustrations, Lond. 1835 sqq), vou mir über Accipenser (Symholae ad anatomiam piscium, Rostocls. 1838. 4.) nnd ïber die Knochenfische die von E. H. Weber (De anre et anditu 'hom. et aninal., Lips. 1820. 4. und Meckel's Archiv 182\%), von Cuvier (in Cuvier et Valenciennes, Poissous Tome J.), von Büchner (Mém. de la soe. d'hist. nat. de Strasbourg, Toune 2.), von Schlemm und d'Alton (Müller's Archiv 1837, Jaluresb.), von Swan (l. c.), ron mir (Mïller's Archiv 1842). Meine neneren Untersuchungen, welclie hald ansfiihrlich mitgetheilt werden sol. len, erstrecken sich besonders über die Gattungen: Cottus, Scomber, Cyclopterus, Belone, Salmo, Coregonus, Pleuronectes, Clupea und Muraena.

2) Vgl. Rathke, Müller und Goodsir. "Der vorlerste Nerv ist etwas dicker, als die folgenden. Er gleicht nicht ganz ilem Trigeminus, sondern nur einem Theile desselben, da die Seiten des Mumles und der grössere Theil des Kopfes nicht inchr von ihm, soudern bereits von den fünf folgenden Nerveu versorgt werden."

3) Abbildungen hei Gottsche 1. c.

4) Vgl. über das Thhercalum olf. besonders Gottsche in Mïller's Archiv 183.. Es findet sich unter den einheimischen Fischen, z. B. bei Accipenser, Perca, Scounber, Cottus, Trigla, Esox, Belone, Cyclopterus, Salmo, Coregonus, Clupea, Pleuronectes; nach Gottsche auch bei Ammodytes, Gasterostens, Gobius u.v. A.

5) Am dentlichsten beim Aal und überhaupt hei den Muränoïden. S. Alubildungen bei Valentin in den neueu Denksclı. d. schwciz. Gesellsch. für d. ges. Naturwiss. Th. 6., Neuchatel $18 \pi 3$. 
eigentliche Geruchsnerv immer eine beträchtliche Dicke. Fehlt das Tuberculum unmittelbar vor dem Hemisphärenlappen, so bildet der Geruchsnerv ein solches unmittelbar vor seinem Eintritte in das Geruchsorgan 6). Die aus diesen Tulerculum austretende Nervenmasse ist beträchtlicher als die eintretende. - Der Geruchsnerv verlänft durch den Orbitalabschnitt der Hirncapsel vorwïrts und tritt durch ein Foramen des Os froutale anterius oder eines ihm entsprechenden knorpeligen Fortsatzes ") in das Geruchsorgan. Bei den Schollen ist der obere Nerv viel stärker als der untere ${ }^{8}$ ).

2. Der bei Myxine 9) ganz rudimentäre $\boldsymbol{N}$. opticus hat bei den meisten übrigen Fischen eine betrïchtliche Stärke $\left.{ }^{10}\right)$. Er entspringt aus dem unteren Theile der Loli optici, scheint indessen auch Fasern aus anderen Ifirntheilen zu empfangen 11 . Bei Bdellostoma ermangeln die beiden Sehnerven jeder Verbindung und Kreuzung. Bei Petrom y zon, den Plagiostomen und Stören stehen sie nur durch eine Commissur in Verbindung. Bei den Knochenfischen findet, nachdem die beiden Sehnerven an ihrem Ursprunge durch eine Commissur sich verbunden haben, eine vollständige Krenzung derselben ohne wechselseitigen Austausch von Fasern an der Kreuzungsstelle Statt. Bald geht der für das rechte Auge bestimmte Nerv uber, bald geht er unter dem Nerven des linken Auges weg 12); selten durchbohrt der eine Nerv die auseinanderweichenden Bündel des anderen ${ }^{13}$ ). Bei den Plagiostomen, Stören und Knochenfischen besteht der Sehnerv in ciner gefalteten Membran ${ }^{14}$ ). Bei den Knochenfischen verlässt er die Schedelhöhle gewöhnlich durch eine unterhalb der Alae magruae und zwischen die sen Knochenstiicken gelegene Oeffnung des membranösen Theiles dẹr vorderen Schedelwand $15 \%$.

Dic Augenmuskelnerven fehlen den Myxinoïden 16). Bei Petromyzon sind ihrer zwei vorhanden, welehe Elementen des $\boldsymbol{N}$.

6) Z. B. bei Cyprinus, Cobitis, Gadus unter den Knochenfischen und bei den Rochen und IIaien. S. die Abbill. von Swan und Scarpa.

7) Bei Galus wird das Foramen durch das Os ethmoïdeum und das Fron. tale anterius gebildet.

8) Schon von Gottsche richtig bemerkt. - 9) Vgl. Müller a. a. O.

10) Bisweilen ist er jedoch schwach und dünn, z. B. bei Silurus.

11) Vgl. Gottsche. - Naunentich wurden Ursprünge von den Loli infe. riores und voin Trignnmm fissum beobachtet.

12) Beide Fälle scheinen nach meinen Beobachtungen gleich häufig zu sein.

13) Ist Regel beim Häring; doch gibt es hier individuelle Ausnahmen.

14) Schon den älteren Anatomen bekannt, z. B. bei Xiphias, Scounber, Pleuronectes, Clupea, Salmo, Silurus, Cyprinus, Esox, Perca, Lucioperca, Sparus; naeb Soem merring auch bei Raja und Squalus.

15) Dies Verhalten darf bei den Knochenfischen als Regel angenommen werden; es findet Statt z. B. bei Cottus, Scounber, Gadus u. A.

16) Nach Müller l. e. 
oculorrm motorius und dem $N$. trochlearis entsprcchen. Sie verbinden sich gleich nach ihrem Austritte aus der llirncapsel zu einem Stamme, welcher in die M. M. rectus superior, rectus interms und abligums superior sich vertheilt 17). Dic ubrigen drei Augenmuskeln werden durch zwei Zweige des $\boldsymbol{N}$. trigeminns versorgt. Bei allen übrigen rischen liegt keine Beobnchtung von Mangel eines der drei Augenmuskelnerven vor.

3. Der $N$. ocubor um motorius nimmt scinen Ursprung von der Basis encephali hinter den Lobi inferiores. Er tritt bei den Knochenfischen durch den grossen Keillocinfliigel is) oder (lurch dic unterhall dessclben ausgespannte fibröse Yembran in die Augenhöhle 19). Er vertheilt sich immer in die $\boldsymbol{H}$. M. rectus superior, internus, inferior und obliguns inferior. Ausserdem gibt or bei den Knochenfischen cine kurze Wurzel zu dem Ciliarknoten ${ }^{20}$ ); mindestens verbindet sich einer sciner Zweige mit einem Zweige des $\boldsymbol{N}$. trigeminus zur Bildung eines neben dem $\boldsymbol{N}$. opricus in den Bullus tretenden Ciliarnerven 21).

4. Der N. trochlearis entspringt an der oberen Fläche des Gehirnes zwischen den Lulri optici und dem Cerelvellum. Er tritt bei den Knochenfischen bald durch den grossen Keilbeinflügel ${ }^{22}$ ), bald durch den fibrös-häutigen Theil der Schedelcapsel in die Augenhöhle 23). Eir vertheilt sich stets ausschliesslich in den M. obliqums superior.

5. Der N. abuluceus entspringt, gewöhnlich nit zwei Wurzeln 24), aus den unteren Pyramiden der Medulla oblangater. Bisweilen steht er mit dem Ganglion des $\boldsymbol{N}$. trigemimus ${ }^{2 \mathfrak{j}}$ ) oder mit cinem Fädchen des $\boldsymbol{N}$. sympothricus in Yerbindung $\left.{ }^{26}\right)$. Scine Austrittsstelle findet sich gewöhnlich an der Schedelbasis ${ }^{2 i}$ ); bei vielen Knochenfischen tritt er durch das Os petrosum 28 ). Er verzweigt sich ausschliesslich in den $M$. rectus extermus ${ }^{29}$ ).

6. Der $\boldsymbol{N}$. trigeminus ist bei allen Fischen cin Nerv von bedeutender Stärke. Er entspringt inmer aus den Scitentheilen der Meclulla oblongata, abwärts von den Lolii optici und Lobi posteriores. Das Verhalten sciner Wurzeln bietet grosse Verschiedenheiten dar. Bei Pe-

17) Nach Schlemm und d'Alton l. c. - 18) Z. B. bci Cyprinus, Saluro.

19) \%. B. bei Galus, Cottus.

20) Ein deutliches Ganglion ciliare mit Ganglienkörpern fand ich bei Scom. ber, Cottus, Cyclopterus, Belone. Bei anderen Knochentischen, wie bei Gadus, Salıno, habe ich mich nicht bestimut von seiner Anwesenheit überzeugt. B üchner fand das Ganglion auch bei Cyprinus.

21) \%. B. bei Accipenser, Salmo, Gadus. - 22) \%. B. bei Cyprinus. 23) Z. B. hei Gadus, Cottus. - 24) Bei fast allen von mir untersuchten Knochenfischen. - 25) Von mir bei Gadus beobachtet. - 26) Bei Cyclopterus von mir, bei Cyprinus von Büchner beobachtet. - 27) Z. B. bei Accipenser.

28) Z. B. bei Salmo, Esox.

29) Wo ein die Augenmuskelu aufuehuender Knochencanal unterhalb der Schedelhöhle vorhanden ist, tritt er sogleich in diesen hinein, z. B. bei Salmo. 
tronyzon besitzt er eine obere und eine untere Wurzel; bei Accipenser vermehrt sich die Zahl der Wurzeln bedeutend. Diese Vermehrung der Wurzeln, welche auch bei einigen Gräthenfischen ${ }^{30}$ ) beobachtet wird, erklïrt sich nur theilweise aus dem Umstande, dass die neben dem $N$. acusticus austretende Wurzel des $\boldsymbol{N}$. focialis init zu den Wurzeln des $\boldsymbol{N}$. trigeminus gezählt worden ist. Niemals nehmen alle Wurzeln des N. rrigemimus gleichınässig Antheil an der Bildung seines Ganglion; namentlich ist die dem $\boldsymbol{N}$. facialis entsprechende Wurzel stets davon ausgesclilossen ${ }^{31}$ ). Bisweilen finden sich an einzelnen Wurzeln isolirte Ganglien 32). Bei den Grïthenfischen tritt der grössere Theil seiner Aeste durch Canäle des Os petrosum; selten durch einen am Vorderrande dieses Knochens befindlichen Ausschnitt. Die einzelnen Aeste dieses Nerven verhalten sich bei den rerschiedenen Abtheilungen der Fische verschieden. Bei den Myxinö̈den vertheilen sich seine zahlreichen Aeste sowol unter häutigen Ausbreitungen, als in Muskeln, enthalten also sämmtlich zugleich centripetale und centrifugale Fasern ${ }^{33}$ ). Der Bereich des Nerven erstreckt sich hicr ïber die Haut des Gesichtes und der Oberfläche des Kopfes, die Tentakeln, das Nasenrohr, die Schleimhaut der Zunge, der Mundhöhle, des Rachens, des Schlundsegels und die Zungenzähne, ferner iiber die Muskeln der Nase, der Mundknorpel, des Schnauzenknorpels, des Mundes, der Zunge und des Zungenheines. Bei Petromyzon verzweigt sich der in eine geringere Zahl ron Aesten zerfallende. Nerr in diesellsen Organe, gibt aber zugleich noch Augenmuskelnerven ab 34). Bei den minder sorgfältig untersuchten Pligiostomen hat er drei Hauptäste ${ }^{3 \tilde{3}}$ ), von denen der erste dem R. primus der höheren Wirbelthiere entspricht; der zweite vertheilt sich an Kiefermuskeln, Lippen und Schnauze; der drilte gibt den Kiefermuskeln und der in der Umgebung des Mundes liegenden Haut Zweige. Bei den Chimären ${ }^{36}$ ) finden sich ein dem $\boldsymbol{R}$. ophthalmicus entspre chender Ast, ein Ast fuir die häutigen Theile der Schnauze und die hier befindlichen Schleimcanäle, ferner cin Ast für Schnauze, äussere Haut, Muskeln der Lippenknorpel, Lippen und Schleimhaut der Mundhöhle, und ein sturker, die Elẹmente des $\boldsymbol{N}$. facialis einschliessender Ast, dessen Zweige für Muskeln des Kimmensackes, für Muskeln und Haut der Unterlippe, fiur Zunge und Schlcinbant der Mundhöhle, für Gaumen und Zäline bestimmt sind. Bei den Stören ${ }^{3 \pi}$ ) sind die Aeste gleichfalls zahlreich: 1) cin R. ophthalmicus für dio Orbita und deren Ungebungen (der cinen Ciliarnerven abgibt) und auch für das Ge-

30) Ich fand vier bei Gadus und Cottus; nur drei bei Belone, Salmo, Cyclopterus. - 31) Nach zahlleichen Untersuchungen an Knochenfischen.

32) Namentlich bei Cottus, bei Cyclopterus an der zweicen Wurzel beobachtet.

3.3) Nach Miller. - 34) Nach Schlemu und ('Alton. - 35) Nach Swan. - 36) Nach cigener Untersuchung. - 37) Vgl, meine Symbolae ad
anat. pisc. 
ruchsorgan und dessen Umgebvingen bestimmt ist; 2) zwei Aeste für Schnauze und Bartfäden; 3 ) ein $\boldsymbol{R}$. maxillaris superior; 4) ein R. maxillaris inferior, der auch fiir die Muskeln des Unterkiefers Zweige abgibt; 5) cin $\boldsymbol{R}$. palatinus; 6) R. R. temporales und $\boldsymbol{T}$ ) der zum Theil dem $\boldsymbol{N}$. facialis entsprechende $\boldsymbol{R}$. oper cularis, in Verlauf und Vertheilungsweise demselben Nerven der Gräthenfisehe analog. Bei den noch sorgfältiger untersuehten Gräthenfischen sind gewöhnlich folgende Aeste vorhanden: 1) ein $\boldsymbol{R}$. op/ thalmicus für die Orlita, die Stirn, das Ceruchsorgan; gewöhnlich gehen von ihm, seltener unmittelbar aus dem gangliösen Plexus des Trigemiuus, zwei Ciliarnerven ab, von welehen der eine isolirt in den Bullus tritt ${ }^{38}$ ), während der andere mit einem Zweige des $\boldsymbol{\Lambda}$. oculorum motorius und oft auch des $\boldsymbol{S}_{y}$ mpathicus sich verbindet; 2) ein Ast für die häutigen Umgebungen des Oberkiefers und $\mathrm{Z}$ wisehenkiefers; 3) ein Unter-Augenhöhlenast für die Wangenhaut und die unter dem Auge liegenden Schleimcanäle 39); 4) ein $\boldsymbol{R}$. palatinus für das Gewölbe der Mundhöhle, unter der Sehleimhaut sich verbreitend; 5) ein $\boldsymbol{R}$. maxillaris inferior fü die Kaumuskeln und laäutige und musculöse Theile des Unterkiefers bestimmt, neben welchem seltener noch abgesonderte $\boldsymbol{N}$. N. temporales aus dem Hauptplexus der Wurzeln hervortreten $\left.{ }^{00}\right)$.

Bei vielen Gräthenfischen geht aus dem Wurzelgeflechte des $\boldsymbol{N}$. trigemimus noch ein Stamm ab (R. lateralis) 41 ), weleher gewölnnlich das Schedelgewölbe durehbohrt, oberhalb des Sehedels naeh hinten verläıft, neben die Spitze der Dornfortsätze der Wirbel tritt und unter Aufnahme von Verbindungsfäden, die mehren Hirnnerven 42) und den Dorsalästen aller Spinalnerven angehören, bis zum Schwanze sich erstreckt. Der $\boldsymbol{R}$. lateralis trigemini vor seiner Verbindıng mit andern Nerven entsprieht einem $\boldsymbol{R}$. communicans der Rückenäste der

38) $R$. ciliaris longus. Schlemin salı beim Zander diesen Zweig mit einem Faden aus dem Ganglion ciliare des Sympathicus sich verbinden. Er tritt in der Nähe der Befestigung des M. rectus superior in den Bulbus and scheint nie zu fehlen; ich fand ihn bei allen oben genannten Fischen.

39) Er ist um so stärker, je bedeutender der Schleincanal entwickelt ist; sehr stark sah ich ihn bei Lepidoleprus und bei den Sciänoïden; auch bei Gadus; sehr schwach bei Cyclopterus, Belone, bei welchem letzteren Thiere der Infraorbital - Canal ganz abortiv ist.

40) Z. B. hei Gadus.

41) Von E. H. Weber entieckt. Ich sah ihn bei Perca, Cottus, Cyclopterus, Gadus, Silurus, Belone, Muraena. Bei Cyprinus und Salmo fehlt er. Er gibt in der Regel feine in der Schellelhöhle sich vertheilende Zweige ab.

42) Verbindungszweige vom Vagas wurden von mir beobachtet bei Cottus, bei Gadus, bei Belone, bei Muraena. Bisweilen treten sie -innerhalb der Schedel. höhle hinzu, geben von den Wurzeln des Vagus alb und haben eigene Ganglien. 
Spinalnerven ${ }^{43}$ ); seine Fortsetzung ist ein Collector von Primitivfasern verschiedenen Ursprunges, wie der Grenzstrang des $\boldsymbol{s}_{y j m p \text { pathicus. Aus }}$ diesem so viele und heterogene Elemente enthaltenden Längsstamme nehnen Zweige für dic Rückenflossen und deren Muskeln ihren Ursprung. Bisweilen gehen Aeste dieses $\boldsymbol{R}$. Lateralis zu den Extremitäten und zur Baucligegend 4 ); mitunter ist er nur rudimentär; oft fehlt er ganz.

7. Als dem N. trigeminus angehörig, sieht man endlich noch den bei den Gräthenfischen, dem Störe und den Plagiostomen, beständig vorhandenen $\boldsymbol{R}$. opercularis an, einen Nervenstamm, welcher theils Elemente des $\boldsymbol{N}$. trigeminus, theils Elemente des $\boldsymbol{N}$. facialis enthält. Gebildet wird er aus einer dicht neben dem $N$. acusticus hervortretenden, keine Ganglienkörper enthaltenden Wurzel ( $\boldsymbol{N}$. facia (is), an welche schr bald, oft aber erst nachdem sie schon Zweige für die den Kiemendeckel-Apparat bewegenden Muskeln abgegeben hat, mit Ganglienkörpern belegte Elemente des $\boldsymbol{N}$.trigeminus sich anlegen. So entsteht ein gemischter, gewöhnlich starker Nervenstamm, der in zwei Ilauptäste zerfällt, von welchem der eine, am Suspensorium des Unterkiefers absteigend, zu diesem letztern sich begibt, während der andere zum Zungenbein und zu den Radii branchiostegi tritt. Beide Aeste verzweigen sich sowol in häutigen Theilen, als an Muskeln.

Ein gesonderter $\boldsymbol{N}$. facialis ist bei den Cyclostomen beobachtet worden ${ }^{45}$ ); er enthält hier dem $\boldsymbol{N}$. acusticus angehörige Fasern (N. acusticus accessorius). Er verbreitet sich in Nuskeln und gibt auch Hautzweige für Gesicht und Kopf ab. Bei Petromyzon geht aus der Verbindung des $\boldsymbol{N}$. facialis mit dem $\boldsymbol{N}$. vagus der $\boldsymbol{R}$. lateralis hervor.

8. Der $\boldsymbol{N}$. acusticus ist bei allen Fischen ein sehr beträchtlicher Nerv, der mit drei bis fünf sehr weichen Wurzelstämmen hinter dem $\boldsymbol{N}$. trigeminus und vor dem $\boldsymbol{N}$. vagus aus dem Seitentheile des ver-

43) Ueberhaupt lässt sich eine grosse Analogie zwischen mehren Hirnnerven der Fische und den Spiulnerven nicht verkennen. Der sogenannte $\boldsymbol{N}$. hypoglossus ist ein Spinalnerv. Der $\boldsymbol{N}$. vagus hat Rami anteriores (die säınntlichen $\boldsymbol{R}$. R. Iranchiales und pharyngei) und Rami posteriores (die R. R. supratemporalis und opercularis, so wie auch die von seinen Wurzeln und seinem Stamme abgehenden $\boldsymbol{R}$. $\boldsymbol{R}$. communicantes ad $\boldsymbol{R}$. lateralem trigemini; diese entsprechel den $\boldsymbol{R}$. dorsales comınunicantes an den Spinalnerven der Gräthen. fische). Der $N$. glossopharyngeus hat cinen $\boldsymbol{R}$. anterior in seinem $\boldsymbol{R}$. branclialis. Die Rami maxillaris inferior, maxill. superior und $R$. infraorbitalis sind $\boldsymbol{R}$. anteriores des $\boldsymbol{N}$. trigeminus, während sein $\boldsymbol{R}$. lateralis ein $\boldsymbol{R}$. posterior oder dorsalis ist.

44) A.n ausgebildetsten ist er bei Gadus; sehr entwickelt auch bei Muraena. Bei beiden hat er auch einen Bauchast, der sich dem Rückenast analog verhält.

45) Von Mïller bei Myxine; von Born und Schlentn u. d'Alton bei Petrolsiyzon. 
längerten Markes hervortritt und sogleich in die rerschiedenen Theile: des Gehör -Apparates siclı begibt 46).

9. Der Nervus ghlossopharyngeus fehlt bei den Cyclostomen als gesonderter Nerv ${ }^{4}$ ). Bei den übrigen Fischen scheint er ohne Ausnahme vorhanden zu scin und entspringt vor dem N. vagus, an dessen Wurzeln er oft sehr dicht anliegt, von den Seitentheilen der Medulla oblougatre. Er tritt durch die inneren theile des Gohörorganes hindurch. Gewöhnlich verlässt er den Schedel durch ein eigenes, bei den Gräthenfischen in Os occipilale lulercale liegendes Locli und gelangt so in die Kienenhöhle. Hier bildet er sogleich ein Ganglion, in welches jedoch nicht inmer seine sümmtlichen Fasern eingehen. Dann theilt er sich in zwei Aeste: einen $\boldsymbol{R}$. anteriar, der unter der Schleimhaut des Gaumens sich verbreitet und bei den Knochenfischen Fädchen zur Nebenkieme schickt $\$$ s). Bei den Cyprinen begeben sich Zweige von ihm in das erectile Geschmacksorgan ${ }^{49}$ ). Selten fehlt dieser Zweig $\left.{ }^{50}\right)$. Der zweite Ast des Nerven ist der ungleich stärkere $\boldsymbol{R}$. Lranchialis, der fiur den ersten Kiemenbogen bestimmt ist und dessen Endzweige in der Zunge oder unter der Schleimhaut der unpaaren Zungenbein-Copula sich verbreiten.

10. Der. $\boldsymbol{N}$. vagres ist bei allen Fischen sehr beträchtlich, häufig stärker, als der $\boldsymbol{N}$. trigemisus. Er entspringt stets von dem Seitentheile der Medulla oblongata, neben dem Cerebellum und dern vierten Ventrikel, hinter dem $\boldsymbol{N}$. acusticus. Ist er sehr stark, so findet sich hier eine eigene Anschwellung (Lobus vagi) an seinem Ursprunge $\tilde{s}$ ). Seine Vertheilung an den Kiemenapparat, clen Schlund, die Speiseröhre und den Magen unter Abgabe von Muskel - und Schleimhautzweigen ist durchaus beständig. Von ihın ausgehende, zum Herzen sich begebende Nervenfaden sind bei mehren Fischen sicher nachgewiesen 52). Er sendet den Schlundkiefern Zweige. Wo eine Schwimmblase vorhanden ist, wird auch diese mit $Z$ weigen von ihm versorgt. Bei allen Fischen, mit Ausnahme des Branchiostoma, wo er spinalartig ist, und der Myxinoïden ${ }^{53}$ ), bildet er allein oder in Verbindung mit anderen Nerven ${ }^{54}$ )

46) Vgl. über die Vertheilung dieses Nerven die Seluriften von Scarya, We her und Bresehet über das Gehörorgan der Fische.

47) Nach Mïller und Sehlemu u. d'Alton.

4\$) Von mir sehr beständig beobachtet, während Müll er den Nebenkiemeu Zweige aus dem $N$. trigeminus zukommen lässt.

49) Nach Weber's, Bü ehuer's und neinen übereinstimmenden Beobaelıtungen. - כ0) Ich vermisste ihu bei Esox und Belone. - 51) Z. B. hei den Cyprinen. - 52) Von Büehner bei Cyprinus, von uir bei Gadus, bei Belone.

53) Naeh Miiller.

54) Bei Petromyzon in Verbindung mit dem N. facialis und hypoglossus nach Schlemm und d'Alton; bei Cyprinus nach Weber und B ü ehner in Verbindung mit dem $N$.trigreminus. Ein soleler Verbindungszweig kann aneh danı vorkommen, wenn ein eigener $\boldsymbol{k}$. lateralis trigemini vorhanden ist, wie bei 
den R. Luteralis vag̈i, einen an der Seite des Rumpfes nach hinten siclı erstreckenden Nervenstamm $\left.55^{5}\right)$. Gewölınliclı gelıen Aeste von ihm zur Haut des liopfes und des Kientendrckels (R. R. sup ratemporalis Ind opercu(aris) 56). Bei den Myxinoïden erweitert sich der Bereich des $N$. "rö" dadurch, dass ein aus seinen beiden Magenaisten geluildeter unpaarer Stamm an Darme his zmm After sich erstreckt $5 \%$ ). - Die Zinhl der Wurzoln des $\boldsymbol{N}$. "ağs beläuft sich bei den Gräthenfischen in ler Rexel auf zwoi. Die beiden Wurzeln legen sich zwar dicht an cinander und treten durch ein gemeinschaftiches for umen des $/$ s occiprirale laterale, verschuclzen aber nic rollstindig und scheinen höchstens einige Fäden auszutausclien 38). Aus der stärkeren Wurzel, welche regelinässig wenigstens ein sehr beträclitliches Ganglion bildet ${ }^{39}$ ), in welches jedoch nicht alle Elemente eingehen, stammen die Kiemen-, die Schlund-, die Speiserölren - und Magenäste $\left.{ }^{60}\right)$. Der crste K i e men Nervenstamm bildet beständig noch ein ihm eigenthümliches Ganglion. Die zweite Ilauptwurzel, welche gewöhnlich kein Ganglion zu besitzen scheint ${ }^{61}$ ), ist die Quelle des Systemes der Seitemnerven, wohin namentlich der $\boldsymbol{R}$. Lateralis, der $\boldsymbol{R}$. opercularis und der $\boldsymbol{R}$. supratemproralis zu rechnen sind. Der R. istestiuulis $N$. vugi steht bei

Cottus; er kaun fellen, obgleich der $\boldsymbol{R}$. lateralis trigemini mangelt, wie bei Salmo. Die Anwesenheit von Elementen des $N$. trigrmimus ist also nicht notlwendig; eine Verbindung mit dem, dem $N$. fircialis theilweise entsprechenden $k$. opercularis trigemini ist bei deu Knochenfischen nirgend nachgewiesen.

5 J) Der $R$. lateralis vari liegt bald in der Tiefe zwischen den beiden Hauptmassen der Seitenmuskeln, wie bei Raja, Chimaera, Clupea, Belone, bald ganz obertlachlich unter der Haut, wie bei Accipensel, Salmo und vielen anderen Fi. schen, bald hat er einen $R$. profundus und $k$. superficialis, wie bei Pleuronectes, Cottus. Selten ist er liurz, wie bei Petromyzon, wo er mur längs des ersten Dritttheils des Rumpfes zu verfolgen ist; oft gibt er starke Aeste ab, wie bei Cyprinus und Clupea zum Rücken (den Lateralis trigemini vertretend); bei Belone iu die Gegend del Brustflosse; bei Gallus u. s. w. Meistens folgt der Hauptstanm des Nerven der Richtung der seitlichen Schleimröhren, unter welchen er liegth Fehlen diese am Rumpfe, wie bei Cyclopterus, so ist er sehr dünn. Er gibt sehr deutlich Zweige für die Schleimröhren und für die Haut ab. Letztere bilden bisweilen Schlingen nit feinen Zweigen der Spinalnerven, wie bei Cyclopterus, Gadus.

5(i) Diese schon Schlemm und 13 ï chner zum Theil bekannten Zweige habe ich bei allen von mir untersuchten Grïthenfischen: Perca, Trigla, Cottus, Cyclo. pterus, Gadus, Salno, Coregouus, Clupea, Pleuronectes, constant angetroffen.

5̃) Nich Müller.

58) Nach Beobachtungen von mir an vielen Grïthenfischen. Bei Cyclopterus und bei Belone tritt ein gangliöses Fädchen aus der stärkern Wurzel zur zweiten.

50) Mitunter bildeu einzelne Wurzelstränge vor Entstehung des Hauptgangliou eigene gangliöse Anschwellungen.

60) Bei Belone besitzt jeder $\boldsymbol{R}$. intestinalis vagi an der speiseröhre eiı starkes Gangliou.

(i) Bei Cyclopterus, Cottus, Clupea, Salmo vermisste ich es, fand es dagegen bei Belone. 
den Knochenfischen stets in inniger Verbindung mit dem $\boldsymbol{N}$. sympathicus.

Dem $\boldsymbol{N}$. hypoglossus analog betrachtet man einen bei vielen Fischen vorhandenen, stets aus dem Rürkenmarke mit einer oder mit zwei Wurzeln entspringenden, nach Ursprung und Vertheilungsweise den Ruickenmarksnerven zuzuzïhlenden Nerven, der meist zwischen denı Schedel und dem ersten Wirbelbogen austritt und dann einen oder zwei Rami clorsales und einen stärkeren $\boldsymbol{R}$. anterior abgibt. Letzterer legt sich an den $\boldsymbol{R}$. anterior des nächst folgenden Spinalnerven an, gibt ihm Fasern ab, die vereint mit jenem zur Brustflosse treten, und setzt sich dann abwärts fort, um in den $\boldsymbol{M}$. sternoliyoüdeus sich zu vertheilen.

Bisweilen ${ }^{62}$ ) kommen hinter dem $\boldsymbol{N}$. vagus noch cinzelne isolirte sehr feine Nervenwurzeln aus der Grenze der Medulla oblongata und der M. spinalis hervor, die in die Umgebungen des Gehirnes innerhalb der Schedelhöhle sich vertheilen, oder auch in die Schultermuskeln eintreten.

\section{Vom Nervus sympatlicius.}

§. 28.

Bei den Cyclostomen scheint kein gesonderter $\boldsymbol{N}$. sympathicus vorzukommen 1); die Störe und Plagiostomen besitzen ihn, doch fehlen hier noch exacte Untersuchungen über seinen Verlauf und seine Verbindungen 2). - Bei den Knochenfischen ist sein Verhalten Folgendes ${ }^{3}$ ): Der Grenzstrang bildet ein Continuum, das von der Austrittsstelle des $\boldsymbol{N}$. trigemimes bis in den hintersten Theil des Canales der unteren Wirbelbogenschenkel sich erstreckt. Der Kopftheil des Grenzstranges liegt ausserhalb der Schedelhöhle, an beiden Seiten der Schedelbasis. Hier verläuft er unterhalb der Austrittstellen des $\boldsymbol{N}$. trigeminus, des $N$. facialis s. opercularis trigemini, des N. glossopharyngeus, des $\boldsymbol{N}$. vagus und $\boldsymbol{N}$. hypogglossus nach hinten, um dann unmittelbar unter die Anfïnge der Rami anteriores der Spinalnerven zu treten und so in den Rumpftheil sich fortzusetzen. Mit allen genann-

62) Z. bei Salmo, Accipenser u. A.

1) Nach Müller's, Schlemu's, d'Alton's und meinen Untersuchungen.

2) Vgl. Giltay (Dissert. de nervo sympathico, Lugd. Bat. 1834. 8.), Re mack (Froriep's Neue Notizen 52. S. 153.), Swan (Illustrations) und Stannius (Symbolae ad anat. piscium).

3) Vgl. E. H. W eb er, Anatomia eomparata Nerri sympathici, Lips. 1817. 8., und die Arbeiten von Cuvier, Giltay, Sehlemu d'Alton, Büchner und Stannius über die Gräthenfische. Meine Untersuchungen erstrecken sich über die Gattungen Cottus, Cyclopterus, Gadus, Pleuronectes, Salmo, Coregonus, Belone und Muraena. Giltay muss sich getäuscht liaben, wenn er die Anwesenheit zahlreicher sympathischer Füden in Muskeln der Fische, namentlich in ihren Kiemenmuskeln behauptet. 
ten llịnnerven und nit den Rami anteriores sämnntlicher Spinalnerven steht er durclı feine, bald einfache, bald doppelte oder mehrfache Fïden in Verbindung. In der Regel findet sich an jeder Verbindungsstelle des Grenzstranges init einem der genannten Ilirnnerven und mit jedem R. anterior eines Spinalnerven ein Ganglion. Es kann aber anch durch Verschmelzung die Zahl der Ganglien reducirt sein, wie dies manentlich am Kopftheile des Grenzstranges beobachtet wird 4). Die in dem Grenzstrange verlaufenden, seine Ganglien verbindenden Stränge llaben im Kopftheile meistens eine etwas graue, im Rumpftheile in der Regel eine weisse Farbe. Die Ganglien des Kopftheiles übertreffen diejenigen des Rumpfthelles meistens an Stärke. Aus dem vordersten Ganglion des Kopftheiles geht, wie es scheint regelınässig, ein für das Ciliarnervensystem bestimmter Zweig ab; eine Verluindung mit dem N. aluducers ist gleichfalls beobachtet worden ${ }^{5}$ ). Aus dem zweiten oder dritten Ganglion treten Zweige für die Gefässe des Circulus ce. phalicus, für die Nebenkieme und auch feine Rami branchiales ab. Die beiden letzlen Ganglien des Kopftheiles und die ersten Ganglien des Rumpftheiles senden starke und kurze Zweige einwärts, welche ein vor oder unter dem Körper eines der ersten Wirbel liegendes grosses Ganglion splanchnicum bilden. Bald ist jederseits ein solches vorhanden; dann ist das rechte an stärksten und erhält aus dem linken sehr bedeutende quere Verbindungsstränge 6 ); bald fehlt linkerseits ein eigenes Ganglion und die linkerseits abgetretenen $Z$ weige senken sich in das beträchtliche Ganglion splaschnicum der rechten Seite 7 ). Aus diesem letztern gehen immer die, die Arteria coeliaco-mesenterica begleitenden graden Rami splanchurici hervor, welche später immer mehr oder minder zahlreiche Verflechtungen mit den Rami intestinales Nervi vagi bilden. Bisweilen werden an ihnen noch untergeordnete Ganglien beobachtet; stets treten ihre Zweige in Begleitung der Gefässstämme zun Darmcanale, der Leber und Milz und, sobald sie vorhanden ist, auch zur Schiwimmblase. Aus dem Ganglion splanclinicum hervorgehende Zweige begeben sich auch in die Nieren und zur Aorta.

Aus dem Grenzstrange des Rumpfes nehmen mehr oder minder zahlreiche, bald paarige, bald unpaare, stärkere und schwächere Rrmi renales, Rami oarici und spermatici ihren Ursprung. Sie sind bald

4) Die Zahl der Ganglien an Kopftheile unterliegt oft individuellen Verschie. denheiten, die ich bei allen von inir untersuchten Fischen angetroffen babe; an den Austrittsstellen des $\boldsymbol{N}$. trigeminus und des $\boldsymbol{K}$. opercularis finden sich bald zwei, bald nur eins; das unter deu Glossopharyngens liegende ist nicht ganz constant. Unter der Austrittsstelle des Vagus liegen oft zwei Ganglien. Sehr vielen Abweichungen sind die unter den Iypoglossus und den beiden ersten Sppinalnerven liegenden Ganglien unterworfen.

5) Vgl. \$. 27. - 6) Z. B. bei Gadus, Belone, Cyclopterus. - 7) Z. B. hei Cyprinus, Cottus, Salmo. 
von weisser Farles ${ }^{8}$ ), bald grau; namentlich in dem letzten Falle üluertreffen sic, wegen der Masse in sie cingehender sogenaunter Selicidenfortsätze, den ganzen Grenzstrang sehr bedeutend an Stärke 9) und lsositzen bisweilen eingestreute kleine Ganglien. Aueh dic Harnblase çlaält ihre Nerven vom Sympathicus. Die Arteria dorta wird von Füilen beider Grenzsträige oft umsponnen. In Canale der unteren Rogenschenkel stehen die beiden Grenzstränge dureh quere Conmissuren vielfach in Verbindung und verselinelzen auch stellenweisc oder gänzlich zu einem unpaaren Strange $\left.{ }^{0}\right)$.

\section{Vom Geruchsorgaure.}

§. 29.

Das Geruchsorgan der Fische besteht in eincr meh. oder minder faltenreichen, von einem Flimmer-Epithelium ausgekleideten Sehleimhaut, an welcher der Geruchsnerv sich ausbreitet. Diese SchleimbautAusbreitung liegt bald in knorpeligen oder häutigan Capseln, bald in Gruben an der Vorderfäche des Kopfes. Nur sehr selten communiciren dieselben mit der Mundlıölıle.

Das Geruchsorgan der Gyclostomen ist unpaar oder einfach. Bei Branchiostoma besteht es in einer iber dem linken Auge befindlichen ziemlich flachen, becherförmigen Vertiefung, die mit ihrem unteren spitzeren Theile dem eentralen Nervensysteme unmittelbar aufsitzt. Die Concavität des Becherchens ist mit Flimmerorganen besetzt und steht nihit der Mundhöhle in keiner Verbindung ${ }^{1}$ ). - Bei den Myxinoïden führt eine dicht über deın Munde geöffnete, luftröhrenartig von Knorpelringen gestützte lange Nasenröhre in die unınittelbar vor der Hirncapsel gelegene Nasencapsel, innerhalb welcher dic Schleimhaut Lïngsfalten bildet ${ }^{2}$ ). Vom Grunde des Nasensackes fiilırt cin unter der Hirneapsel verlaufender Nasengaumengang durel eine Oeffnung in die Mundhöhle. Hinter der Nasengaumenöffnung liegt eine segelartige, rückwärts gerichtete Klappe, welehe zur Bewegung und Erneuerung des in der Nasenhöhle enthaltenen IVassers zu dienen seheint. - Bei den Pe tromyzonten führt ein an der Oberfäelıe des Kopfes muindendes, der Knorpelringe ermangelndes Nasenrohr in eine einfache, bald knorpelige, bald häutige Nasencapsel, deren innere Häute in eine lange, am Ende blind geschlossene Röhre sich verlängern, welche den harten Gaumen durehbohrt, aber durch die undurchbolırte Schleimhaut der Mundhölle von dieser alogeschlossen ist ${ }^{3}$ ).

8) Z. B. bei Cyclopterus. - 9) Z. B. bei Gadus. - 10) \%. B. bei Gadus, Cyclopterus, bei Cottus.

1) S. Kölliker in Müller's Archiv 1843. S. 32. Mit Abbill.

2) Abbild. bei Miiller, Vergl. Anatomie d. Myxinoïl. Th. 1. Tab. 2. Fig. 10.

3) Abbild. bei Mïller l. c. Tab. 4. Fig. 1. Die. Nasencapsel ist bei Petro- 
Bei den Plagiostomen, Chimären und Sturionen ist die knorpelige Grundlage der Nasengruben unit der Knorpelmasse des Schedels verwachsen. Bei den Plagiotomen liegen die grossen Nasengruben an der unteren Fläche der Schnauze, und zwar bei den Roehen neben den Nundwinkeln. Sie sind durch häutige, von Knorpeln gestiitzte, unter Einfluss kleiner Muskeln stehende Klappen verschliessbar. Der in diesen vorlıandene Nasenfliügcl-Knorpel ist xneist mit dem Rande der Nasengrube an mehren Stellen verwachsen 4) und nur selten völlig gesondert $5 j$. Mitunter kömmit in der Mitte einer gemeinsamen Nasenklappe noch ein unpaares knorpelstück vor 6 ). - Bei den Chimären liegen die weiten, ticfen Nasengruben unmittelbar über der Oberlippe. Ihr Eingang wird durch eine häutige von einem Knorpel gestiitzte Klappe verdeekt. Andere zusanmengesetzte Nasenflügelknorpel kominen an der Innenseite (les Einganges in dic Nasengruben vor \%).

Bei Lepidosiren findet sieh ïber jeder Seite der Schnauze ein merkwürliges helmartiges Knorpclgerüst, inwendig von der Nasenschleinlıaut ausgeklcidet, deren Falten kammförnig nach beiden Seiten sich erstrecken. Es ist, wenigstens bei Lepidosiren paradoxa, eine vordere und cine hintere Nasenöffnung vorhanden, welehe letztere in dem Mundwinkel gelegen ist 8 ) und in die Mundhöhle mündet.

Bei den Sturionen und Knochenfischen liegen die Nasengruben an dem Seitentheile der Schnauze. Bei den Knochenfischen ist jede Nasengrube von der äussern Ilaut bedeckt und besitzt - mit Ausnalıme der Labroïdei ctenoïdei und der meisten Chromides (Miill.), denen nur eine einzige Oeffnung jederseits zukömmnt - zwei hinter einander gelegene äussere Oeffnungen, welche indessen bisweilen ziemlich weit von einander entfernt sind. Die vordere Oeffnung licgt häufig in einer röhrenförmigen, durch Iruskelfasern contractilen Verlängerung oder besitzt einen klappenartigen Iautvorsprung. Selten bestehen die Nisengruben in gestielten Glöckchen, an deren Grunde die Schleimhautfalten liegen 9). Die Schleimhaut-Ausbrcitung sclbst besitzt mchr oder minder zalılreiche Faltungen. Sie ist befestigt auf einer fibrösen oder knorpelartigen Grundlage, welche bald rund, bald lïnglich ist. Von clieser ge-

uyzon knorpelig, bei Amınocoetes blos häitig und besitzt hier keine Längsfalteı der Sehleimliaut.

4) Vgl. über dic Nasenflïgelknorpel Müller l. c. S. 172. Mit Abbild.

5) Z. B. bei Narcine, Seyllium.

6) \%. B. bei Myliobates und Rhinoptera. S. Müller l. c. Tab. 9. Fig. 12.13. und S. 172.

7) Abbild. bei Müller l. c. 'Tab. 5. Fig. 2.

8) Vgl. Biseh off's angef. Sehrift S. 10. u. 14., so wie dessen Abbildungen, bes. Tab. 4. Bei Lepidosiren adneetens soll dagegen naeh 0 wen die hinten nit. der Mundhöhle communicirende Nasenöfnung fehlen.

ग) Bei Lophius. 
hen zarte Leisten aus, die zur Stütze der Schleimhlautfalten dicnen und eine unvcrkennbarc Aehnlichkeit mit den Stützen der Kiemenblättchen besitzen. Ist dic Nasengrube rund, so gehen sie radienförmig von cincm gemeinsamen Centrum oder von einer kurzen Mittclleiste aus; bei lïnglicher Form der Nasengrube gchen ineistens von cincr Axe zwei Rei hen von Falten kammförinig ab. Bisweilen theilen sich die Falten wif: der in Zweige. Am zusamuengcsetztesten schicint die Nasenbildung bei Polypterus zu sein ${ }^{10}$ \%. Die Schleinhaut der Nasengruben ist inner sehr gefissreich und ausser den Ausbreitungen des Nervus olfactorius vertheilen sich an ilır feinc Zweige, die aus dem vordersten Astc des $\boldsymbol{N}$. trigemiıus stammen. Beirn Stör ist über jedc Nisengrube eine briickenförmige schrägc Leiste ausgcspannt, wclche eine knorpelige, knochenharte solide Grundlage besitzt.

[Man vgl. über das Geruchsorgan folgende Schriften: $\mathrm{H}$ arwo od, System d. vergl. Anatomie, übers. von Wie de in an n, Berl. 1799. 4. - Scarpa, Anatow. Untersuchungen des Gehörs u. Géruchs, Nürnb. 1800. 4. - Blainville, Princ. d'Anat. comp. T. 1.]

\section{Vom Gesichtsorgane.}

§. 30 .

Das Auge der Fische stcht auf sehr verschiedenen Stufen der Ausbildung. Bei Branchiostoma scheinen zwei seitlich an Vorderende des centralen Nervensystemcs befindliche Pigmentflecke, zu wclchen anscheinend ein kurzer Nerv tritt, als Augen gedeutet werden zu müssen ${ }^{1}$. Noch bei den parasitischen Myxinoüden bleiben die Gesichtsorgane höchst unentwickelt. Bei Myxine findet sich jederseits, von Muskeln und Haut bedeckt, ein sehr klcincs, als Auge zu betrachtendes Körperchen, zu welchem ein Nerv sich begibt 2). Bei Brellostoma liegt das hinsichtlich seiner inneren Organisation gleichfalls noch nicht hinlänglich untersuchte Auge oberhalb der Muskeln und wird von ciner dünnen Fortsetzung der äusseren Haut bedeckt. Die Augenmuskeln scheinen durchaus zu fehlen. - Ausserordentlich klein sind auch die Augen bei Lepidosircn, wo jedoch die Hautdecken durchsichtig über diese Organe, in denen man Sclerotica, Linse, Chorioïdea unterschieden hat, wcggehen. Auch hier sind keinc Augenmuskeln aufgefunden worden ${ }^{3}$ ). - Sclbst bei einigen Knochenfischen könmt es vor, dass die äusserc Haut, ohne sich beträchtlich zu verdünnen oder durchsichtig zu werden, die unter ihr liegenden sehr. kleinen Augen über-

10) Nach Müller.

1) Vgl. die Abhandlungen von Müller und Retzius und die von Kölliker in Mïller's Archiv 1843.

2) S. Mïller, Ueber den eigenthümlichen Bau des Gehörorganes der Cy. clostomen, Berl. 1838. 4. S. $23 \mathrm{ff}$.

3) Nach den Augaben von Bisch off und 0 wen. 
zieht, so dass die Existenz dieser Organe selbst, mit Unrecht, bei ihnen friher geläugnet worden ist 4 ).

Bei den meisten Fischen sind die Augen verhïltnissmässig gross; bei einigen durch ihren Umfang amsgezeichnet ${ }^{5}$ ); nur bei einzelnen Familien, wie namentlich den Silıroïden und den Aalen sind sie klein. Sie liegen gewöhulich an beiden Seiten des Orbitalsegmentes des Schedels, sind selten, dicht neben einander gestellt, aufwärts gerichtet 6 ) und liegen noch seltener, wie bei den Schollen, asymmetrisch beide an derselben Seite des Kopfes.

Der in der Orbita gelegene Theil des Bulbus pflegt von Fett, von gelatinösem Zellgewebe und selbst von Lymphräumen reichlich umgeben zu sein. Bisweilen ist der Bulbus auf eigenthimliche Weise an die Wände der Orbita befestigt. So besitzt bei den Plagiostomen die Sclerotica hinten, neben der Eintrittsstelle des Sehnerven, eine knorpelige äussere Anschwellıng mit rundlicher Gelenkfläche, welche auf einem aus dem Grunde der Augenhöhle vorragenden, auf einem diinneren Stiele sitzenden, am Ende keulenförmig verbreiterten Knorpel sehr frei beweglich, nur durch Zellgewebe locker angeheftet, ruhet. Bei den Stören und mehren Knochenfischen tritt an die Sclerotica, von der Orbitalwand aus, ein neben dem Nervus opticus gelegenes fibröses Tenaculum \%). Die Bewegungen des Bulbus werden sehr allgemein durch vier gerade und zwei schiefe $A$ ugenmuskeln vermittelt, welche letztere von der vorderen Wand der Angenhöhle ihren Ursprung nehmen. Der eigenthümlichen Lage der geraden Augenmuskeln vieler Knochenfische in einem unterhalb der Schedelbasis verlaufenden, vorn mit den Augenhöhlen communicirenden Canale, geschah schon früher (\$. 12.) Erwähnung. Die Muskeln beider Bullbi gehen divergirend aus ihm hervor. Am weitesten nach hinten erstrecken sich in ihm die M. M. recti externi. - Thränenorgane fehlen den Fischen allgemein.

Der Bulbus ist bei den meisten Fischen vorn ziemlich flach, hinten dagegen gewöhnlich kugelrund. Meistens geht die äussere Haut, nach Bildung einer ringförmigen Einstiilpung im Umkreise des Bulbus, durchsichtig werdend, einfach über das Auge weg; seltener kommen erst Augenlidbildungen zu Stande, entweder in Gestalt eines am Auge angewachsenen oberen Hautfortsatzes, wie bei den Rochen und Schollen, oder mit freien Rändern 8); in diesem letztern Falle erscheinen sie bei Knochenfischen als vordere und hintere durchsichtige Falte 9), oder kreisförmig

4) Z. B. bei Apterichthus coecus (s. de la Roche in den Ann. du Musée T. XIII. p. 326.); bei Silurus coecutiens (s. Rudolphi, Grundr. d. Physiologic
Th. 2. Abth. 1. S. 155 .

§) Z. B. bei Priacanthus, Ponatomus, Myripristis u. A. - 6) Z. B. bei Uranoscopus. - 7) Dies finde ich z. B. bei den Salmonen und bei den Esocinen. 8) So bei allen Haien. - 9) Bei Scomber, Caranx, vielen Clupeen. 
mit mittler Oeffnung ${ }^{10}$ ), oder angeschwollen und mit einem, eigenen Sphincter verschen 11 ). Nur bei einigen Ifaien kömunt auch eine wirkliche Nickhaut vor 12 ).

Die fibröse Sclerotica unschliesst hei den Knochenfischen ge wölınlich zwei starke Knorpelscheiben, welche oft verknöchern. Bei einigen Fischen findet sich statt ihrer eine wirkliche Knochencipsel, welche vorn zur Insertion der Cornea und hinten zum Durchtritte des Schnerven geöffnet ist 13). Bei den Plagiostomen ist dic Sclcrotica einfach knorpelig.

Dic in der Mitte dünnere, nach rlem Rande zu dickere Cornca ist gewöhnlich sehr flach convex. Sclten zerfillt sic durch cinen dunkelen Streifen in zwei Abtheilungen 14).

Die bei vielen Knochenfischen durch ein fetthaltiges Zcl!gewebe von der Sclerotica getrennte Choriöidea besteht aus drei Blättern: 1) der äusseren, durch nadelförmige mikroskopische Krystalle silber - oder goldfarbenen eigentlichen Chorioüdea, welche die Iris bildet; 2) der inneren, mit sechseckigen Pigmentzellen bedeckten, auch als Uvea sich fortsetzenden Membraua Ruysclicaua, und 3) der mittleren Gefässhaut (Membrana vasculosa Ifalleri). Die gewöhnlich sehr dicht an dic Ilornhaut anstossende Iris scheint bei den Knochenfischen nur eine sehr geringe Beweglichkeit zu besitzen. Bei den Rochen geht vom oberen Rande derselben ein in mohre Zweige gespaltener, schleierartiger Fortsatz (Operculum pupillare) abwärts, welcher die Pupille vor. hangartig verschliessen kann. Eine ähnliche Einrichtung könmt auch bei den Pleuronectiden vor. Offenbar steht sie nit der platten Körperform und der Art des Schwimmens dieser Thiere in Verbindung und dient zur Abhaltung zu grellen Lichtes. Dic Pupille selbst ist bei den meistcn Fischen rund, seltener und zwar namentlich bei vielen Plagiostomen länglich oval oder in die Quere verlängert. Ciliarfortsätze sind bei, Accipenser und bei mehren Plagiostomen, namentlich den Inien, so wie bei cinzelnen Knochenfischen bcohachtet worden 15); der Mehrzahl der letzteren scheincn sie jedoch zu fehlen.

Der Sehnerv durchlohrt die Augenhïute bald in schräger Richtung, entfernt von der Augenaxe, bald tritt er in den Mittelpunkt des Bulbus cin. Da er eine gefaltete Haut darstellt, deren Ränder kein Continuum bilden, so entsteht auch in der Retina einc von der Eintrittsstelle des Sclinerven bis zu ihrem vorderen Rande sich erstreckende Spalte, deren Ränder, denjenigen der gefalteten Haut des eigentlichen

10) Bei Butirinus. - 11) Bei Orthagoriscus Mola nach Cuvier.

12) Z. B. bei den Familien der Carchariae, Triaenodontes, Galei, Scylliodon. tes, Musteli. - 13) Z. B. bei Xiphias.

14) Bei Anableps tetrophthaluus. S. das Nähere über den Bau seines Auges bei Soemmerring l. c. p. 68. - 15) Beobachtet bei Thynnus vulgaris. 
Sehnerven entsprechen. Durch diese Spalte der Retina dringt bei vielen Knochenfischen eine von der Mcmlrana Ruyschiana gebildete pigment - und gefïssreiche Falte (Irocessus falciformis), welche von der Hyaloïde a umfasst, durch den Glaskörper zur Linse tritt und meistens vermittelst eines anscheinend knorpelartigen Kinötchens, der $\boldsymbol{C a}_{\boldsymbol{m}}$. panula Halleri, an den Rand der Linse sich befestigt.

Die Retina 16) selhst besteht bei den Knochenfischen deutlich aus mehren Blättern oder Iliuten, von denen die innerste blos durch die fïcherförmig aus einander strahlenden Primitivfasern des Selunerven gebildet wird. Die stabförmigen Körperchen der Retina und die Zwillingszapfen sind bei den Fischen besonders dentlich erkennbar. - Die von emer dünnen Capsel umgebene Linse ${ }^{17}$ ) ist kugelrund, sehr gross und derb, besitzt einen besonders harten Kern, liegt in einer Grube des Glaskörpers, wo sie durch Ligamente, welche von der Memlurana hyaluïllea gebildet werden, befestigt wird und ragt mit ihrem vorderen Abschnitte durch die Pupille in die vordere Augenkammer, welche durch sie fast vollständig ausgefiillt wird, so diss der Humor aqueus nur in sehr geringer Menge vorhanden ist. Das von der aus Fasern und Zellen gebildeten Membrana hyalö̈lea umschlossene Corpus vitreum hat die Consistenz von fliissigen Eiweiss.

Zwischen del Membrana Ruyschiana und der eigentlichen Chorioïdea liegen bei der Mehrzalll der Fische, un den eintretenden Sehnerven die von den Arterien und Venen der Chorioïdea gebildeten Wundernetze, welche unter dem Namen der Choroïdealdriuse bekannt ist ${ }^{18}$ ).

[ Nan rglo über das Auge der Fische besonders folgende Abhandlungen: Ha]. ler, Opera minora, T. III. p. 250 sqq. - Rosenthal, Zergliederung des Fisehauges, in Reil's Archiv f. Physiol. Th. X. S. 393. - Blainville, Principes d’anatomie comparée, T. 1. Paris 1822. 8. - W. Soemunerring, De oculorum hominis animaliumque seetione horizontali, Gött. 1818. fol. p. 62 sqq. - Jurine in den Mémoires de la société physique de Genève, Tome J. - Albers in den

16) Vgl. Gottsehe in Mïller's Arebiv 1834, S. 457 ff. und besonders den Aufsatz von Hannover, Ueber die Netzhaut und die Gehirnsubstanz bei den Wirbelthieren, in Müller's Arehiv 1840, S. 322.

17) Die Uebereinstimmung der Fischlinse mit derjenigen der übrigen Wirbelthiere hinsichtich ibres feineren Banes ist naehgewiesen worden von Werneck in Am mon's Zeitschr. f. Ophthalmologie Bd. V.

18) Vgl. über diesen Gegenstand \$.49. - S Erdl, Disquisitiones de piscium glandula ehoroïlleali. Monach. 1839, 4. - J. Müller, Vergl. Anatomie des Gefässsyst. l. Myxinoïleı, S. 82 ff. Nach Müller's umfassenden Untersugbungen seheint dies Organ bei allen Knochenfischen vorzukommen, welehe Pseudobranchien besitzen, dagegen viclen der Fische zu fehlen, denen auch die Nebenkiemen fehlen. Daher feblt es bei Silurus, Pimelodus, Synodontis, bei den Aalen, bei Cobitis. Trotz des Mangels der Pseudobranchien kömmt es vor bei Erythrinus und Osteoglossun. Es fehlt dagegen bei den init Pseudobranchien versehenen Stören und Plagiostomen. 
Denkschriften d. Acad. der Wissensch. zu Mïnchen, 1808. (Sehr unbedeutend.) Cuvier u. Valeneiennes, hist. nat. d. poiss. I. 446.]

\section{Vom Gehörorgane.}

§. 31 .

Das Gehörorgan der verschiedenen Ordnungen der Fische, von welchem indessen bei Branchiostoma noch keine Spur nachgewiesen ist, steht auf sehr verschiedenen Stufen der Ausbildung, behält aber stets die Eigenthiimlichkeit, dass ihm die Schnecke und eine eigentliche Paukenhöhle fehlen. Selten nur kömmt eine Verbindung des knorpeligen oder selbst des häutigen Labyrinthes mit der äusseren Hautoberfläche zu Stande. Das Labyrinth liegt entweder ausserhalb der eigentlichen Schedelhöhle, bald in mit ihr communicirenden Gehörcapseln (Cyclostomen), bald innerhalb der Knorpelsubstanz des Schedels (Plagiostomen, Lepidosiren) oder es liegt theils in letzterer und theilweise auch in der Schedelhöhle selbst (Chimären, Sturionen, Knoehenfische).

Bei den Cyclostomen ist das Labyrinth in einer eigenen mit dem Schedel in unmittelbarer Verbindung stehenden seitlichen Knorpelcapsel eingeschlossen. Bei den Myxinoïden liegt das blos in einem ringförmigen, in sich selbst zurücklaufenden Rohre bestehende häutige Labyrinth, an dessen oberer Wand der Nervus acusticus sich ausbreitet, in einer ihm entsprechend gestalteten Möhle jener Capssel. Es enthält keine den Gehörsteinen anderer Fisclie analoge Concretionen. - Das häutige Labyrinth der Petromyzonten ${ }^{1}$ ) wird noch durch eine eigenthümliche membranöse Umhüllung an seine umschliessende Knorpelcapsel befestigt. Es besteht 1) aus einem Vestibulum, das drei Ab theilungen besitzt: zwei grössere paarige, welche auswendig durch eine Furche, inwendig durch einen faltigen Vorsprung getrennt sind. Mit ihnen ist eine dritte unpare, saekförmige Abtheilung durch einen Stiel verbunden. Hierzu kommen 2) zwei halbcirkelförmige Canäle, deren jeder bei seinem Ursprunge aus dem Vestibulum eine Ampulle besitzt, in welche faltenförmige Vorsprünge hineinragen. Beide Canäle steigen an der Oberfläche des häutigen Vestibulum, welcher sie angewachsen sind, auf, um sich knieförnig mit einander zu verbinden. An ihrer Verbindungsstelle communiciren sie abermals mit deın Vestibulum durch eine Oeffnung. Das häutige Labyrinth enthält nur helle Flüssigkeit und keine feste Concretionen. Die beide Aeste des Nervus acusticus umfassen die Ampullen.

Bei den Plagiostomen ist das Labyrinth ganz von der Knorpelsubstanz des Schedels umschlossen. Das häutige Labyrinth wird von einem eigenen, durch derbere Textur ausgezeiclneten knorpeligen Labyrinthe zunächst umgeben; zwischen beiden befindet sich

1) Ammocoetes verhält sich ganz wie Petrumyzon. 
eine Flüssigheit. Die innere Oberfläche des knorpeligen Labyrinthes ist von einem Perichondrimu überzogen, von welchem aus fadenförmige Fortsiitze an die äussere Oberfläche des häutigen Labyrinthes sich erstrecken, unn es zu befestigen. Die Wandung des engeren häutigen Labyrinthes ist sehr spröde. Das Vestibulum membranacemu bildet einen in drei Abtheilungen zerfallenen Sack; welcher einen kleineren sack.artigen Anhang besitzt. Es enthält zwei weiche, kreideartige Concremente. Drei weite halbcirkelförmige Canäle stehen mit dem Vestibulum bald durch weite Oeffnungen, bald dureh zwei enge Güinge in Verbindung. Bei den IIaien erstreekt sieh blos ein Canal vom Vestilulum crrtilagineum aus bis in eine von Haut verschlossene Oeffnung in oberen Ilinterlıauptstheile des Schedels, während hei den Rocirn sowol das knöcherne, als das häıtige Vestibulum einen solchen Verbindungsgang hesitzt. In der Mitte der Oecipitalgegend ihres Schedels zeigt sieh nämlich eine blos von Haut überzogene Grube, welche vier sehr kleine Oeffnungen besitzt, von denen zwei zum rechten und zwei zum linken Labyrinthe fuihren. Die beiden vorderen communiciren mit dem Vestibulun curtilagineum; die beiden hinteren mit dem Vestibulum membranaceum. Zwischen der hinteren Oeffnung und der ausseren Ilaut liegt ein membranöser Saek (Sinus audiforius exteruus), der mittelst cines durch die Schedelöffnung alssteigenden Cilnales in das membranöse Vestibulum seiner Seite sich üffnet. Der durch einen kleinen Muskel zu verengende Saek enthält, gleich seinem Canale, kohlensaure Kalkerde in einem flüssigen Vehikel und steht durch einen bis drei sehr feine Canälehen mit der äusseren Itautoherfläehe in Verbindung.

Das Gehörorgan der Chimären und Störe zeigt mit demjenigen der Knoehenfische grosse Uebereinstimmung. Bei allen diesen Fisehen liegt nämlich das häutige Labyrinth theils innerhalb der Schedelhöhle, theils in der knorpeligen oder knöchernen Substanz der Schedelwandungen. Bei den linochenfischen tragen zu seiner Auf. nalume und Unterstiitzung zahlreiche Knochen des Schedels hei: das Os basilare occipitis, das Occipritale laterale, das Occipitale superius, das "s mastoüdeum und das Os petrosum 2!. - Das häutige Labyrinth besteht 1) aus dem Vorhofe (Vestiluulum s. Alveus communis canalium semicircularium), einem der inneren Schedelwand locker angehefteten Sacke von verschiedener Form und Grösse; 2) aus einem von dem Vorhofe bald durch eine schwache Einschnürung unvollkommen getrennten, bald mit ihm durch einen engen Canal verbundenen Săckchen (Saccus vestiluli s. Saccus lnpillo$r u m)$. Die Ilöhle dieses Säckchens wird durch eine membranöse

2) S. die näheren Angaben darüber bei Hallmann, Vergl. Osteologie des Schläfenbeines, S. $38 \pi$. 
Scheidewand in zwei mit einander zusammenhangende Kammern ge theilt. - Der vordere Theil des Vestibulum enthält einen weissen, sehr harten, rundlichen oder ovalen, glatten Stein ( $L$ a pillus). Zwei ähnliche Steine finden sich in den beiden Kammiern des Säckchens. Der grössere derselben $(S a$ gitta) ist meist rundlich oder länglich, streifig und gezäbnelt und an seiner Innenfläche mit einem Grübehen versehen, das zu seiner Befestigung dient. Der andere (Asteriseus) ist von verschiedener Gestalt und in der Regel viel kleiner $\left.{ }^{3}\right)$. - 3) Die letzten und wesentlichsten Theile des membranösen Labyrinthes sind die drei halhcirkelförmigen Canäle mit den Ampullen. Jeder Canal besitzt zwei Sehenkel, von welehen der eine immer mit einer Ampulle aus dem Alveus commusis hervorkömmt, während der zweite entwe(ler mit dem Schenkel eines anderen Bogenganges verbunden 4 ), oder getrennt ${ }^{5}$ ), immer aber ohne Ampulle in den Alveus communis sieh einsenkt. Der vordere und hintere halbcirkelförmige Canal stehen senkrecht; der äussere steht horizontal. Wo der Gehörnerv an die Ampulle tritt, findet man an dieser eine quere Vertiefung. Von ihr erhebt sieh im Innern der Ampulle eine Seheidewand, Septum transversum, welehe die Höhle der Ampulle in zwei Theile theilt. Der dureh dic Ampullenwand in das Septum eintretende Nerv dringt, in feine Zweige aufgelöset, durch dieses hindurch und verbreitet sich an der Oberfläche des Septum und der zunächst gelegenen Ampullenwand. - Der Nervus acusticus tritt nicht allein in die Ampullen der halbcirkelförmigen Canäle, sondern bildet auch im Umkreise der Otolithen äusserst feine Ramificationen und Geflechte. Nur ausnahmsweise kömmt bei den Knoehenfisehen eine Communication des Labyrinthes mit häutig verschlossenen Oeffnungen am Schedel vor $\left.{ }^{6}\right)$.

[Die wichtigsten Schriften über das Gehörorgan der Fische sind folgende: J. Müller, Ueber den eigenthüml. Bau d. Gehörorganes b. d. Cyclostomen, Berl.

3) Nach Krieger's schätzbaren Untersuchungen bestehen die Gehörsteine aus Kirystillen kohlensauręr Kalkerde, von denen jeder in einer eigenen Zelle eingeschlossen ist.

4) Z. B. beim Hecht, bei Belone u. A. - 5) Z. B. bei den Cy]rinen.

6) Hierher gehört zunächst eine unpaare, blos häutig bedeekte unpaare Oeffnung im Schedeldache von Cobitis fossilis. Abgeb. bei Weber, Tab. VI. Fig. 44. - Bei Lepidoleprus trachyrhynchus und coelorhynchus findet sich in der Hinterhauptsgegend des Schedels jederseits eine länglicb-runde Oeffnung in eine durch zarte Haut ausgekleidete und in der Tiefe häutig verschlossene Grube fübrend, welche inwendig an einen Recessus des zur Aufnahme des Gehörorganes bestimuten Abschnittes der Schedelhöhle grenzt. Vgl. 0 t to in Tiedemann u. Treviranus Zeitschrift Bd.2. - Bei Lepidoleprus norwegieus vermisse ich mit Müller diese Bildung, die aber bei allen Mormyri und bei der Gattıng Notopterus, nach den Beobachtungen von Heusinger und Müller, wiederkehrt. S. Heusinger in Meckel's Archiv f. Anat. u. Physiol. 1826, S. 324. Müller in Wiegmann's Archiv 1843, S. 324 . 


\section{Vierter Abschnitt. Vom Nervensysteme u. den Sinnesorganen. S3}

1sas. - Monro, Vergleichung d. Baues n. d. Physiologie der Fische. Uebers. v. Sclineider. Leipz. 178\%. 4. - Scarpa, De auditu et olfactu. Ticin. 1789. 4. Huschke, Beiträge znr Physinlogie u. Naturgeschichte. 1r Bd. Weimar 1824. 4. - Besonders reichhaltig: L. H. Weber, De aure et auditu hominis et animaliun. Lips. 1820. 4. - Breschet, Recherches anat. et physiologiques sur l'organe de l'ouie des poissons. Paris 1838. 4. - Upber die Gehörsteine vgl. Ed. Kirieger, Diss. de Otolithis. Berol. 1840. 4. - Ueber die Ampulien der halbcirkelförmigen Canäle: Steifensand in Müller's Archiv 1835, S. 174.]

§. 32.

Bei inehren Knoehenfischen kömmt eine Verbindung des Labyrinthes mit der Schwimmblase zu Stande. Die Weisen derselben sind rersehieden :

1. Bei einigen Fischen findet blos eine Verbindung der, vorn blind endenden Schwimmblase mit häutig gesehlossenen Stellen des Schedels Statt, welehe die Höhlung, in der der grosse Grehörstein liegt, begrenzen 1 ).

2. Bei anderen wird das häutige Labyrinth dureh eine Reihe von Knöchelehen mit der Schwinmblase verbunden ${ }^{2}$ ). Bei allen wahren Cyprinoïden, bei allen mit einer Schwimmblase versebenen Siluroïden, bei den Erythrinen und Characinen verlängert sieh jeder Vorhof dureh cinen Canal naeh hinten. Die eonvergirenden Canïle beider Seiten vereinigen sich in cinem häutigen Behälter, welcher im Basilartheile des Hinterhauptsbeines gelegen ist (Sinas impar). Zwei kleine I.öcher führen aus diesem Sinus impor in zwei runde noeh mit Labyrinthwasser gefüllte Säckehen (Sinus spliaerici s. Atria sinsı imparis), welche, an der Oberfläche des ersten Wirbels neben dem Foramen mugmun gelegen, zum Theil von einem eigenthïmliehen Knöehelchen (Claustrum) umfasst werden. Dureh drei mit den drei vordersten Wirbeln beweglich zusammenhangende Knöchelchen kömmt nun eine mittelbare Verbindung zwiselien der hinteren Fortsetzung des häutigen Labyrinthes und der Sehwimmblase zu Stande.

3. Bri einigen Clupeen ${ }^{3}$ ) kommen vordere geschlossene Enden

1) 7. B. bei Holocentrum ( $\mathrm{Cuvier}$ u. Valenciennes T. 3. p. 196.), Myripristis (ibid. p. 167.). Von Weber b'ei Sparus Salpa und Sargus entdeckt (1. c. p. 71.$)$.

2) Bei Cyprinus, Cobitis und Silurus von W eber entdeckt (l. c. p. \$6. Tab. IV. V. VI.). Von Miiller auf die oben genannten Familien ausgedehnt. S. Archiv 1842 , S. 323 ff. - E. H. Weber verglich früber die die Verbindung des inneren Labyrinthes unit der Schwimmblase veruittelnden Knochen mit den drei Gehörkuöchelchen der Säugthiere. Näher liegt es, mit Ge offroy und Meckel, diese Knochen als abgelösete Stïcke der ersten Wirbel zu betrachten.

3) Bei Clupea, Engraulis, Notopterus. Das vordere Ende der Schwimmblaso tritt canalförnig zur Basis des Hinterhauptsbeines. Durch gabelförmige Theilung dieses verengten Fortsatzes entstehen zwei häutige Canäle, welche in cinen linochengang des Hinterhauptsbeines treteu. Hier schwellen sie sogleich an und je. 
der Schwimmblase in unınittelbare Berührung mit Anhängen des hiiu tigen Vestibulum.

[ Diese Beziehungen des Gehörorganes zur Schwimmblase sind ron E. H. Weber entleckt, von Heusinger, Cnvier und Müller weiter verfolgt worden.]

\section{Vou den electrischen Organen.}

§. 33.

Sowol bei einigen Plagiostomen, als bei einigen Knochen fischen kömmt ein merkwürdiger Apparat vor, der unter Einfluss des Nervensystemes Electricität frei werden lüsst. Genauere anatomische Untersuchungen über das Verhalten dieses Apparates sind an den Torpedines, dem Gymnotus electricus und dem Malapterurus electricus angestellt worden. Die electrischen Apparate bestehen in nerven- und gefässreichen häutigen Gelilden. Diese zerfallen durch vertical 1) oder durch horizontal 2) gestellte Scheidewände in eine bedeutende Anzahl säulenartig neben einander stehender oder horizontal über einander liegender Abtheilungen. Jede solche Abtheilung wird durch zahlreiche, in dem ersten Falle horizontal, in dem anderen vertical stehende Septa in eine Menge von kleinen geschlossenen Räumen getheilt, deren jeder mit einer gallert-oder eiweissartigen Flüssigkeit gefüllt ist. Die häutige Grundlage dieser Apparate besteht aus Fasern, welche denen des elastischen Gewebes rïcksichtlich ihres Baues sehr nahe kommen. Diese Fasern sind nicht blos in den die grösseren Abtheilungen bildenden Häuten, sondern auch in den diunneren Septa nachweisbar. Die Wände der mit Flüssigkeit gefüllten Räume sind von einem aus kernhaltigen Zellen gebildeten Epithelium ausgekleidet. Zwischen dieser Epithelialschicht und dem eigentlichen Septum befindet sich eine durchsichtige Substanzlage, welche den capillaren Gefässnetzen und den Nervenausbreitungen zur Grundlage dient. - Im Ucbrigen bieten diese Organe, je nach Verschiedenheit der Thiere, rücksichtlich ihrer Lage, ihrer Ausdehnung, der Ursprungsstätte ihrer Nerven u. s. w. beträchtliche Verschiedenheiten dar.

Bei den Torpedines liegen sie zu beiden Seiten des Kopfes zwischen diesem und den vorwärts sich erstreckenden Brustflossenknorpeln, als platte Organe unmittelbar unter dęr äussern Haut. Nach Entfernung der letzteren gelangt man auf eine anscheinend selnige Membran mit polygonalen, zellenartigen Figuren, den Endbegrenzungen eben

der zerfällt abermals in zwei von Knochen unschlossene häutige Röhrchen, deren jedes in einer blinden Blase endet. Eine dieser ron einer Knochenblase uinschlossenen häutigen Blasen berührt einen Anhang des häutigen Vestibulırn. Vgl. Weber a. a. 0 .

1) Bei den Torpedines. - 2) Bei Gymnotus. 
so vieler ähnlich gestalteter, vertical oder etwas schräg gestellter Säulen. - Jedes Organ erhält vier Nervenstänıne, von denen der vorderstc: aus dem dritten Aste des Nervus trigeminus stammt, während dio drei anderen den Kiemenästen des $N$. vaguzs angehören.

Der Zittcraal (Grymnotus electricus) besitzt zwei grössere obere und ein kleineres unteres, áber paariges electrisches Organ. Jedes grössere obcre Organ liegt unmittelbar unter der äusseren IIaut und erstreckt sich lïngs des ganzen Schwanzes, über der Afterflosse und den Muskeln derselben gelegen, nach hinten. Das untere kleinere wird von den Muskeln der Schwanzflosse bedeckt. Beide zerfallen in horizontal iiber einander liegende Abtheilungen. Die Nerven dieser Gebilde (jederseits ïber 200) sind Fortsetzungen der Rami anteriores der Spinalnerven.

Bei dem Zitterwels (Malapterurus electricus) erstrecken sich zwei äussere Organe jederseits vom Kopfe bis hinter die Bauchflosse und liegen unmittelbar unter der äusseren Haut. Ihre Nerven erhalten sic aus dem N. vagus. Die inneren, von jenen durch eine Aponeurose getrennten Organe erhalten ihre Nerven aus den Rami anteriores der Spinalnerven. Das äussere Organ besteht aus sehr kleinen rautenförmigen Zellen.

[Die Zahl der electrischen Fische wird gewöbnlich grösser angegeben; indess bleibt es höchst zweifellaft, ob Trichiurus indicus und Tetrodon electricus wirklich mit diesen Apparaten versehen sind. Zu den electrischen Rochen gehö. ren aber ausser den eigentlichen Torpedines (' $T$. vulgaris, Inarmorata und Galvani) auchı noch Arten der Gattung Narcine. - Ueber die anatomischen Verhältnisse dieser Thiere vgl. vorzüglich die Abhandlungen von J. Hunter, Philos. Transact. 1763, P.2. p. 4S1. und 1775, P. 2. p. 395. - Rudolphi in d. Abhandl. d. Berl. Acad. d. W issensch. 1820-21, S. 220. und 1824, S. 187. - V alentin in den Neuen Denkschr. d. allg. Schweiz. Gesellsch. f. d. ges. Naturwiss. Bd. 6. Neufchat. 1841, wo die histologischen Verhältnisse ausführlich erörtert sind und auch eine Beschreibung des electrischen Apparates der Gattung Narcine gegeben ist. - Ueber das Physikalisch. Physiologische vgl. Matteucci, Traité des phénomènes electro-physiologiques; suivi de recherches anatoniques sur le système nerreux et sur l'organe électrique de la torpille par Savi. Paris 1844. 8. Mayer (Spicilegium observationum anatomic. de organo electrico in Rajis etr. Boun. 1843. 4.) will auch bei nicht electrischen Rochen ein Analogon dieser Organe gefunden haben.] 


\section{Fünfter Abschnitt. \\ Vom Verdauunge-Apparate.}

I. Vom Gebisse.

§. 34.

Die $Z a ̈ h n$ e der Fische bieten die grösste Mannichfaltigkeit dar hiısichtlich ihres Baues, ihrer Form, ihrer Zahl und ihrer Insertionsstellen. Während es cinerseits Fische gibt, welche der Zähne gänzlich ermangeln 1) oder dieselben nur in sebr geringer Menge besitzen 2), kommen andere vor, bei denen eine grosse Anzahl von Zähnen und zwar an den verschiedensten Knochen sich findet. Zahntragend können folgende Knochen werden: der Unterkiefer, der Oberkiefer, die Gaumenbeine, der Vomer, der hintere Keilbeinkörper, das Zungenbein, die Kieunenbogen, die unteren Schlundknochen. Bei der Gattung Pristis ist die Schnauze sägenförmig mit Zähnen besetzt. Zïlne kommen ausserdem in blos häutigen Gebilden vor. Selten sind fast alle genannten Theile gleichzeitig zahntragend; meistens finden sich blos an einigen oder mehren derselben Zähne ${ }^{3}$ ).

Die Form dieser Zähne ist höchst verschiedenartig. Oft sind sie von einer ausserordentlichen Duinne und Feinheit und dabei so kurz, dass sie eher durch den Tastsinn, als durch das Gesicht wahrgenommen werden. Dies sind Cuvier's Dents en velours $\left.{ }^{4}\right)$. Sind sie etwas länger, so ähnelt eine damit besetzte Fläche einer Raspel (Deuts en ripe) 5). Verlängern sie sich noch mehr, so erscheinen sie borstenförınig. - Die Zähne mancher Fische ähneln den Reisszähnen der Säugthiere $\left.{ }^{6}\right)$; bei anderen sind sie plattenförmig; bei anderen erscheinen sie als starke, stumpfe und ziemlich lange Kegel ${ }^{7}$ ); oder sie sind kurz und cylindrisch; in diesem Falle sind sie an ihrem freien Ende bald eben, bald abgerundet 8 ); oft sind diese Zähne so klcin und so zahl-

1) 7. B. Anmocoetes, Accipenser, Planirostra und die Familie der Lophobranchii.

2) Z. B. die Myxinö̈den, die Chimären, die Cyprinen.

3) Bei den Cyprinen nur an den Schlundkiefern; bei den Plagiostomen nur an den Kieferknorpeln; bei Labrus und Scarus an Unterkiefer, Zwischenkiefer und den Schlundkopfknochen; bei Esox an den meisten, bei Salmo an fast allen überhaupt zahntragenden Knochen. Bei Sndis, Notopterus und Osteoglossum ist auch der hintere Keilbeinkörper zahntragend. - Nur an häutigen Gebilden (Lippen) kommen die Zähne vor bei Petromyzon; auch Helostomus unter den fínochenfischen besitzt Lippenzähne.

4) \%. B. bei den meisten Percoïden. - 5) Z. B. die Vomerzähne bei Esox, hei Silurus. - 6) Z. B. die Vorderzähne von Dentex, Esox u. A. - 7) Z. B. bei Anarrhichas. - 8) Ersteres bei Labrus, letzteres bei Sargus. 
reich, dass die damit besetztc Fläche ein granulirtes $A$ nschn erhält 9 \%. Das freic Eunde der conischen Zähne kann in zwei oder drei Spitzeu getheilt 10), oder kann ungebogen sein ${ }^{11}$ ), oder es ist mit Widerhaken versehon 12). Die Zähne können an Ende zweilappig ${ }^{13}$ ), oder dreilappig 14), oder eingekerbt ${ }^{15}$ ), oder mit sägenförınigen Rändern, oder mit Spitzen 16) versehen sein - kurz es zeigt sich in der Form der Fischzithe eine Mannichfaltigkeit, wie sie in keincr anderen Thierclasse wieder angetrolfen wird. Dic Forı der Zähne wechselt bisweilen mit deu Alter oder bietet sexuelle Verschiedenheiten dar ${ }^{1} \bar{i}$ ).

Was die Befestigungsweise dieser Gebilde anbelangt, so ist diese nicht ininder mannichfach. Sie haften blos in den ungebenden Weichtheilen 18), oder sind in Alveolen eingekeilt; in diesem letzteren Falle baften sie in dem sie aufnehmenden Knochen unbeweglieh und sind selbst fest mit ihm verwachsen ${ }^{19}$ ), oder sind ihon im Gegentheil nach einer Richtung hin berweglich verbunden $20 \%$. Bei einigen Fischen müssen sich näulich die Zähne bei Schliessung des Mundes immer nach linten umlegen. Bei anderen rayt ein von der untercn Fläche der Zahnlıöhle ausgeliender Knochenfortsatz in die hohle Basis seines Zahnes liillein ${ }^{21}$ ). Selten liegen die Zähne in ciner Längsgrube und die an einander stossenden Zähne sind durck wahre sägenförmige oder wellenförmige Nähte ihrer Seiten unter sich verbunden ${ }^{22}$ ).

Die Textur der Zähne ist gleichfalls sehr verschiedenartig. Au häufigsten bestehen sie aus Knochensubstanz, welche dichter ist als die derjenigen Knochen, an welchen sie befestigt sind. In diesem Falle kann ihre ganze Masse gleichförmig sein ${ }^{23}$ ), oder sie sind auswendig von festerer Knochenmasse überzogen ${ }^{24}$ ); einige besitzen eine wirkliche Sehmelzschicht ${ }^{25}$ ). An den Zähnen von Balistes ist noch eine dem Cämentum der Säugthierzähne entsprechende Substınz beobachtet worden und an den Gaumenzälınen von Scarus soll durch Ossification der Pulpa noch eine vierte härtere, elfenbeinartige Substanz hinzukonmen. Die Zähne der Cyclostomen bestehen aber nicht aus knochenmasse, sondern aus Hornsubstanz. In ihrer Zusammensetzung ihnen ähnlich scheinen die clastisclien und biegsamen Zähne der Chätodonten, der Trichodonten und der Loricarien zu sein. - Die Zähne erncuern sich häufigg und während der ganzen Lebensdauer, indem die alten beständig durch ncue, sich vorschiebende, verdrüngt werden.

9) Z. B. bei Labrus. - 10) Zweispitzig bei Citharina, Ireizackig bei Platax. - 11) Z. B. bei Pimelepterus. - 12) Z. B. bei Trichiurus. - 13) \%. B. Sargus unimaculatus. - 14) Z. B. Aplodactylus. - 15) Z. B. Boops. 16) \%. B. Notilanus u. A. - 17) Nach Angaben von Müller u. Henle l. c. - 18) \%. B. Peitrouyzon, Mugil, Salarias. - 19) Z. B. Esox, Salmo. 20) Z. B. Clıauliodus, - 21) Z. B. Balistes. - 22) Z. B. Myliobates. 23) Z. B. Exococtus, Echeneis. - 24) Z. B. Spliyraena. - 23) Z. B. Sal-
gus, Balistes. 
[Die ausführlichste Arbeit über den Zabnbau der Fische ist R. 0 wen's Odontography, Part. 1. u. 2. Lond. 1840 u. 41. S., mit selır zahlreichen Abbildun. gen, welche sowol die Formeurerhïltnisse, als den feineren Bau der Zähne erläutern. Vgl. ferner Born in Heusinger"s Zeitscbr. fïr organ. Pbysik, Th. 1. S. 152. - Cuvier ill ersten Theile seiner Histoire nat. d. poissons und in den Leçons d'anatomie comparée. - Ketzius in Mïller's Archiv f. Anat. u. Phys. Jabrg. 1837. (besonters über den mikroskopisclıen Bau der Zäbne.) - A gassiz an vielen Stellen seiner Poissons fossiles. - Müller und Henle, Systematische Beschreibung ver Rochen und Haien, Berlin 1838. fol., mit zahlreichen Abbildungeu von Zähnen der Plagiostomen.]

\section{Vom Tractus intestinalis.}

§. 35.

Die Mund- und Rachenhöhle der Fische sind voñ höchst ver sehiedener Länge und Weite. Am eigenthïmlichsten verhält sieh die Mundhöhle bei Branehiostoma dureh den Besitz fingerförınig gestellter Wimpern oder Flimmerorgane, deren Sehwingungen das Phänomen einer Räderbewegung zu Stande bringen 1). - Bei allen Fischen stehen Mund - und Rachenhöhle in Coummunieation mit den Athmungswerkzeugen. Bei vielen Knochenfisehen verhindern hinter den Kiefern gelegene Schleimhautfalten den Ruiektritt des verschluckten Wassers aus der Mundhöhle, und die Zähnchen und mannichfach gestalteten Fortsätze, mit denen der coneave Rand ihrer Kiemenbogen besetzt ist, verhiitet den Eintritt der Speisen in die Kiemenspalten. Wo der Kiemensehlaueh sehr lang ist, wie bei Branchiostoma, beginnt dic Speiseröhre erst weit hinter der Mundhöhle. - Speieheldrüsen fehlen anscheinend beständig 2). - Das gewöhnlich derbe, harte, oft mit Zähnen besetzte Zungenrudiment scheint zur Vermittelung von Gesehmacksempfindung nieht geeignet. Indessen kommen bci einigen Fischen eigenthümliehe Gebilde vor, welche vielleieht die Geschmacksempfindung vermitteln künnten. Als solches erscheint z. B. ein sehr contractiles, vom Nervus glossopharyngeus mit zahlreichen Fäden versorgtes, am Gewölbe der Raehenhöllle gelegenes Organ der Cyprinen ${ }^{3}$ ).

1) S. das Nähere in Mïller's Abhandiung.

2) Sie werdeu vou Rathke und Meckel bei einzelnen Fischen erwähnt; ich habe mich indessen ron ihrer Anwesenheit hisher nie überzeugen können. Eine bei den Chimären und allen Plagiostomen vorkommende eigenthümliche, gewölnnlich unterbalb des $\boldsymbol{M}$. greniohyoüdeus gelegene, röthliche, gefässreiche Drïse, welche schon ron Retzius beschrieben ist, darf gewiss nicht für eine Speichel. drüse angesehen werlen. Sie besitzt bei den eben genannten Fauilien eben so wenig, als bei Accipenser, wo sie an vorleren Ende des Küemen-Arterienstanınes liegt, einen Ausfihlıungsgang und scheint deı vor dem Herzen in Unkreise der grossen Gefiissstïmme fast bei allen beschuppten Reptiliei vorkommenden, der Thymus rergliclsenen, Blutgefüssd rïsen zu entspreclıen.

3) Vgl. uber diesen Apparat die Bemerk. vou E. H. Weber in Meckel's Archiv f. Anat. u. Phy's. Bd. 2. S. 309. 
Der Tractus intestinalis liegt, mit seltenen Ausnahmen ganz innerhalls der Bauchlıölle 4). Diese ist bei vielen Knorpelfischen hinten nieht vollständig gesehlossen, sondern miindet oft durch zwei ${ }^{5}$ ), selten durch einen einzigen 6) Porers abulominalis nach aussen. Auch steht sie bei vielen Knorpelfischen mit der Ilöhle des Pericardium in offener Verbindung $\%$.

Der eigentliclie Darmcanal bestelit bei den Fischen meistens aus drei verschiedenen Abtheilungen, von welchen die beiden letzten nur selten völlig zusammenfallen 8). Die erste oder der Munddarm entspricht dem Schlundkopfe, der Speiseröhre und dem Magen; die zweite oder der Mitteldarm repräsentirt den gesammten Dünndarm, die dritte oder der Afterdarm ist das Intestinum rectmm der höheren Wirbelthiere. Ihre Grenze ist nicht immer scharf zu bezeiehnen. Veränderte Dimensionsverhältnisse, Abweiehungen in der Textur ihrer Schleimhaut, in der Dicke und Faserlage ihrer Muskelhaut, die Insertionsstellen der Ausführungsgänge der verschiedenen Drüsen geben häufig Haltpunkte ab für ihre Unterscheidung. Sehr oft aber sind ihre Grenzen noch schärfer bezeichnet durch das Vorhandensein einer Pförtnerklappe und einer Diekdarmklappe oder eines ihre Stelle vertretenden Wulstes. Die der Speiseröhre entsprechende Region des Munddarmes steht sehr oft mit pneumatischen Apparaten in Höhlenverbindung. Dahin gehören die Schwimmblase, von deren Verhalten später die Rede sein soll, und ein von der vorderen Wand der Speiseröhre bei vielen Plectognathen ausgehender Sack. Dieser Sack, der von der vorderen Wand der Speiseröhre ausgeht, setzt sowol nach vorn bis unter den Unterkiefer, als aueh nach hinten bis zum Ende der Bauchgegend sich fort, nimmt Luft auf und dient zum Aufblasen dieser Thiere. In der Regel eine einfache Ilöhle bildend, soll er bisweilen getheilt und mit zelligen Wanden verselien scin. Dass er als ein respiratorisehes Organ zu betrachten sei, dagegen spricht der Ursprung seiner Gefässe.

In Munddarme, der bei den liöheren Fischen mit einem gewöhnlich sehr muskulösen, durch die Ossa phary"gea infcriora unterstützten

4) Bei der Gattung Solea liegt jedoch, gleich den Gesehleehtstheilen, fast der ganze Mittellarn und ein Theil des Afterdarmes ausserhalb der Bauchhöhle zwi. schen den Fulera der Afterflosse und den Musticln der reehten Seitenhälfte des Schwanzes.

3) Bci deu Plagiostomen, wo sie nieht zur Ausfülırung des Sperma und der Eicr dienen, und bei vielen anderen Fischen, wo sic diese letztere Bestimnung haben.

6) Er ist cinfaelı und unpaar bei Branehiostoma uud bei Lepidosirell, - Bei Branchiostoma, wo dieser Porus zu dem Respirations-Apparate in Beziehung steht und aueh zur Ausführung des Samens und der Eier dient, liegt er wcit vor der Afteröfnung.

7) Bei den Myxinoïlen, Ammoeoetes, Aceipenser, Chimacra, den Plagiostomen.

8) Z. B. bei den Cyprinen, bei einigen Pleuroneetes; nach $R$ a thke aueh bei Saluno, Labrax und Clupea Pilchardus. 
Schlundkopfe beginut, wird liäufigg eine Selıeidung von Speiseröhre und Magen vermisst. Die hintere Hälfte desselben, welche der Magengegend entspricht, zeichnet sich nimlieh oft weder durch eine Erweiterung, noch durch Eigenthiimlichkeiten ihrer Texturverhältnisse vor der vorderen aus 9 ). Ein llagen ist zuerst da zu unterscheiden. wo die hintere Hälfte des Munddarmes allnälich sich erweitert und wo gleichzeitig nnit dieser Erwveiterung Veränderungen in der Dicke und Textur seiner Häute eintreten 10). Seine Sonderung wird deutlicher, wo er, bei veränderter Textur, schlauchartig oder sackartig sich erweitert 11). Selten wird der Magen zugleich durch eine Einschniurung von dem kurzen Oesophagus getrennt 12). - Die Bildung des Nagens bietet übrigens grosse Versehiedenheiten dar. Bei den meisten Fischen zerfillt el in eine Purlio carliaca und pylorica, die unter mehr oder minder spitzem Winkel in einander übergehen. Sehr häufig liegt vor der Uebergangsstelle in den Pförtnertheil ein Blindsack, der in Betreff seinel Gestalt, Ausdehnung, Lage und Richtung sehr verschiedenartig sich verhalten kann, bei einzelnen Fisehen aber von sehr beträchtlicher Ausdehnung ist ${ }^{13}$ ). Meistens ist die Portio pylorica des Magens darmartig, selten wieder sackförmig erweitert, wie z. B. bei cinigen Sargus. Bisweilen bildet sie an der Uebergangsstelle in den Mitteldar'm einen spitzen Winkel 14).

llinter der meistens vorhandenen Pförtnerklappe ist die Insertionsstelle der Appendices pyloricac oder des Ausführungsganges eines driisigen Pancreas und des Gallenganges. Der bald enge, bald weite Mitteldarm ist häufig in der Pförtnergegend am weitesten und bisweilen selbst weiter als der in ihn übergehende Magen. Gewöhnlich verengt er sieh allmälich nach hinten. - An der Grenze von Mitteldarm und Afterdarm fehlt mit seltenen Ausnalumen jede Spur von Blinddarm ${ }^{15}$ ). Bald bietet der Durchnnesser dieser beiden Abtheilungen des

9) Bei den Cyclostomen, den Cyprinell, den Cobitis, manchen Pleuronectes, vielen Pharyngognathen: Exocoetus, Hemirauphus, Beloue, den Labroïden, den Lophobranchii; unter den Plectognathen bei Balistes und Ostracion, unter den Aalen bei Symbranchus; ferner bei unehren Blennius, Gohius u. s. w.

10) Z. B. bei Gasterosteus und bei mehren Schollen, z. B. Flesus, Limanda, Passer, Platessa.

11) Z. B. bei den Siluroïlen, bei Esox.

12) Selhr stark bei einigen Piuclodus-Arten, schwach bei cinigen Pleuronoctes, Cottus u. A.

13) An längsten ist wol dieser Blindsack bei Ammodytes, sehr weit bei Chironectes. - Ein Blindsack kömmt schon bei Branchiostoma vor, wird aber hier von Müller als Leher gedeutet, während Rathke ilın als Magen betrachtet.

14) Z. B. bei Esox.

15) Andeutungen davon finden sich nach Curier und Valencienles (V. 6. p. 3วั4. U. 361.) bei der Gattung Box; bei Box vulgaris einer; bei B. Salpa zwei. 
Darucanales keine Verschiedenheiten dar ${ }^{16}$ ), bald ist der Afterdarm enger ${ }^{17}$ ), als der Mitteldarm, bald endlich ist er weiter, als dieser ${ }^{18}$ ). In Vergleich zum Mitteldarm ist der $\Lambda$ fterdarm immer selır kurz und verläuft in der Regel ganz gerade.

Viele Fisclie, und unter ihnen besonders die gefrüssigen Raubfische, besitzen einen sehr kurzen Tractus intestinalis, der oft ganz gerade oder fast gerade vom Schlunde zum After verläuft ${ }^{19}$ ); bei anderen $F_{1}$ schen ist er länger und bildet mehre, oft selbst sehr zahlreiche Krümmungen und Windungen 20 ).

Sehr selten ist der Darmcanal mit der Rückenwand des Leibes fest verwachsen 21); meistens wird er durch Fäden, Bänder, oder durch ein wirkliches häutiges Gekröse, d. h. durch Peritonnal-Duplicaturen befestigt 22 ).

Die Anordnung der Häute des Darmcanales stimmt im Wesentlichen mit der bei den höheren Wirbelthieren vorkommenden überein. Der Schlundkopf ist bei den höheren Fischen gewöhnlich von einem starken, ringförmigen Muskel umgeben, der von vorn nach hinten an Dicke abnimmt. Bisweilen ist die Speiseröhre durch Muskeln, welche von der Riickenseite des Rumpfes ihren Ursprung nehmen, erweiterungsfähig ${ }^{23}$ ). Die Muskelhaut des Magens ist von sehr verschiedener Dicke, gewöhnlich aber schwächer, als die des Oesophagus. In der Regel ist sie in der Portio pylorica am stärksten und bildet oft an der Uebergangsstelle des Magens in den Mitteldarm einen dicken Wulst 24). Im Mittel - und Afterdarm verhält sich ihre Dicke gleichfalls sehr verschieden; nicht selten ist sie im Afterdarme schwächer, als im Mitteldarme 25 .

Während die Muskel-Primitivbindel des Tractus intestinalis in der Regel keine Querstreifen besitzen, sind die letzteren in der ganzen Nuskelhaut des Darmes von Cyprinus tinca beobachtet worden ${ }^{26}$ ).

16) Z. B. bei Tetrodon, Diodon, Anarrhichas, Scorpaena, Anableps, Clupea, Saluo, Esox, Anguilla u. A.

17) Z. B. bei Gasterosteus, Centriscus, Ostracion, Balistes, Syngnathus.

18) Z. B. bei Perca, Diacnpe, Percis, Trigla, Sciaena, Sparus, Scomber, Cottus, Labrus, Pleuronectes, Gadus, Cyclopterus, Echeneis, Silurus u. A.

19) Z. B. bei Petromyzon, den Plagiostomen, Cobitis, Belone, Anarrhichas, den Saluonen. - 20) \%. B. bei den Cyprinen, vielen Squamipennen u. A.

21) Bei Branchiostoma, Petromyzon, Ammocoetes.

22) Nach den Beobachtungen von Rathke ist das Gekröse ursprünglich stets vorhanden, kann jedoch später durch Resorption fast ganz verschwinden, wie bei den Syngnathen und mehren Cyprinen.

23) Wie bei meliren Cottus-Arten. S. Rathke's nähere Angaben 1. c. S. 15.

24) Sehr stark z. B. bei Mugil; auch bei Johnius, Scomber u. A.

23) \%. 13. bei dien Plagiostomen, den Plectognathen.

2(i) Von Reichert, s. Med. Zeitung 1. Vereines für Heilkunde in Preussen, 1841, Nu. 10. 
Die meisten Verschiedenheiten bietet die Anordnung der Sehleimhaut des Tractus intestiualis dar. Nur bei Branchiostoma ist sie überall mit einem Flimmerepithelium versehen. - Die Schleimhaut der Speiseröhre, welche bei den ineisten Fisehen von einer verdiekten Epithelialschieht ausgekleidet ist, bildet sehr hïufig Längsfalten, die nicht selten unter einander sich verbinden und deren freier Rand oft init zottenartigen Vorsprüngen oder mit Sehleim absonderuden $C$ ryptae besetzt ist. Bisweilen finden sieh an seiner Innenfläehe stärkere fleisehige Papillen oder Warzen ${ }^{27}$ ); sehr selten kommen an derselben zahnartige Bildungen vor 28). Bei Anwesenheit eines wirkliehen Magens verändert sich die Textur der Sehleimhaut an dessen Grenze meist allmälieh, seltener plötzlieh. Sie ist im Magen häufig glatt, seltener bildet sie feine netzförmige Verdoppelungen und noeh seltener besitzt sic Papillen odel Zotten. Die netzförnigen Falten werden, wenn sie überhaupt vorkommen, im Grunde des Blindsackes sehwächer und sehwinden aueh zuweilen in der Portio pylorica ganz. - Oft sind die Magendrüsehen sehr deutlieh $\mathbf{2 9}$ ). -

Die Fläehenverğrösserung der Sehleimhaut des Mitteldarmes ist auf die manniehfaehste Weise realisirt. Am häufigsten findet sieh ein Netzwerk, gebildet dureh mehr oder minder stark vorragende, nicht selten gezaekte Falten der Sehleimhaut. Oft verlaufen die grösseren Sehleimhautfalten ziekzackförmig oder wellenförmig der Länge naeh und werden dureh sehwäehere transverselle Falten verbunden, wodurch polygonale Zellen entstehen. Oft enthalten grössere Zellen kleinere und diese wieder Zellen dritter und vierter Ordnung eingesehlossen ${ }^{30}$ ). Aber aueh wahre Zotten können allein oder, von den stärkeren Falten ausgehend, gleiehzeitig mit diesen vorkommen. Selten erseheinen st:̈irkere Querfalten unter Gestalt vollständiger oder unvollständiger vorspringendèr Ringe im Mitteldarme 31 ). - Auch im Afterdarme der Fische kömmt eine Vergrösserung der Schleimhautfläehe auf ähnliehe Weise, wie im Mitteldarme, zu Stande, obschon die Bildung hier meist einfacher ist.

Eigenthümlieh verhält sieh der Mitteldarm einiger Cyclostomen ${ }^{32}$ ), der Chimären, der Störe, des Lepidosiren, der Plagiostomen und des Poly-

27) Z. B, sehr stark bei Accipenser, Acanthias, Box, Caesio; schwach hei Clupea, Gadus u. A.

28) Bei Rhombus xanthurus, Stromateus fiatola, T'etragomurus.

29) Z. B. bei Trigla, Uranoscopus, Blenuius, Gasterosteus, Cyclopterus.

30) So wird beim Stör ein Theil des Darmcanales zu einem sehr complicirten Secretionsorgan und gewinnt nicht geringe Aehnlichkeit mit der Imenwand der Lunge mancher Schlangen, z. B. derjenigen von Pythou.

31) Z. B. bei Clupea; auch in Afterdarme mehrer Salınonen.

32) Die Spiralklappe fehlt bei Branchiostomi, wie auch bei Ammocoetes und den Myxinoïlen, köumt dagegen der Gattung Petromyzon zu. 
pterus durch die Anwesenheit der sogenannten Spiralklappe. Diesc ist gewühnlich in der Art schraubenförmig gewunden, dass sowol ihr an der Darmwand befestigter, als auch ihr frcier Rand cine Spiralc bildct. Seltener ist sie in einer longitudinalen Linie befestigt und dabei spiralförm'g gerollt 33). Bisweilen, wie z. B. bei den Stören, finden sich an dieser Spiralklappe noch zahlreiche Darmdrüschen. - Bei den Chimären und Stören erstreckt sich die Spiralklappe bis zum After; bei Pe tromyzon und bei den Plagiostomen folgt dagegen auf den Spiraldarm noch ein ziemlich weitcr, kurzer, mit einfacher Schleimhaut ausgekleideter Afterdarm. In den Anfang des letzteren, und zwar an seiner Ruickseite, mündet bei den Plagiostomen ein längliches, fingerförmiges, lohles, druisiges, am Mesenterium angeheftetes Organ mit weiter Oeffnung. Da bei den Plagiostomen auch die am Ende verbundenen Harnleiter und die Ausfiihrungsgänge der Geschlechtstheile die hintere Wand des Endes des Afterdarmes durchbohren, um in ihn einzumünden, findet hier schon eine wirkliche Cloakbildung Statt.

[Ueber den Traclus intestinalis der einheimischen Fische rglo besonders: H. Rathke, in der zweiten Abtheilung seiner Beiträge zur Geschichte der Thierwelt, Halle 1824. 4. - Rathke in Müller's Archiv 1837, S. 335 ff. - Ausserdem siehe die grösseren Werke von Cuvier und Meckel.]

\section{Von der Milz.}

\section{§. 36 .}

Dieses den Wirbelthieren ausschliesslich eigenthümliche und zuerst bei den Fischen auftrctende Organ ist bei fast allen Ordnungen und Gattungen der letztgenannten Thierclasse sicher nachgewiesen. Nur bei Branchiostoma und bei Lepidosiren scheint sie durchaus zu fehlen und bei den Cyclostomen bleibt es zweifelhaft, ob die bisweilen paarig vorhandenen, eines Ausführungsganges ermangelnden drüsigen, in der Nähe der Cardia gelegenen Organe wirklich der Milz entsprechen. Bei mehren Ilaien besteht sie aus zahlreichen kleinen, durch Blutgefässe verbundenen Körperchen und bei Accipenser werden Nebenmilzen beständig beobachtet. Bei den meisten Fischen stellt sie jedoch eine einzige bräunlich-rothe, selten hellrothe, weiche, sehr blutreiche Masse dar, deren äussere Form sehr verschicdenartig sein kann. Sie liegt bei allen Fischen in der Nähe des Magens oder der ersten IIailfte des Darmcanales, meist rechterseits, befcstigt durch Gefässe und Bauchfellfalten oder häıfiger clurch zellgewebsartigc Bänder.

[Vgl. die speciellen Angaben über ihr Verhalten bei den einzelnen Fisch. arten in Cuvier und Valenciennes, Hist. nat. d. poiss. - Nach Schrvager Bardeleben, Observat. microscop. de glandularum ductu excretorio carentium

3.3) Diese letatere Bildung kömmt nach Meckel, Duvernoy und Müller vor bei den Gattungen Carcharias, Zygaena, Galeocerdo, Thalassorhinus. 
structura etc., Berol. 1841, besteht die Pulpa der Milz bei den Fisehen, gleichwie bei den übrigen Wirbelthieren, aus zellenartigen Höhlen, welche mit runden, den Zellenkermen gleichenden Körperchen angefült sind. - Bei den Myxinoïden kommen jelerseits an fler Cardia driisige Organe olne Ausfiihrungsgang vor, und bei Petromyzon findet sich gleichfalls ein solches Organ, das von Mayer zuerst besehrieben ist und nach $\mathrm{Schwager-Bardeleben} \mathrm{einen} \mathrm{ähnliehen} \mathrm{Bau} \mathrm{besitzt,}$ wie die Milz der übrigen Wirbelthiere. - Rathk e rermisst die Milz bei J.epadogaster. Aul grössten fand er sie bei Clupea Pilcharilus. - In eine Menge kleiner runder Läppehen zerfallen ist sie z. B. bei Lamna cornubica, wie Retzius zuerst beobachtete. Ein ähnliehes Verhalten bemerkten $\mathrm{Cu}$ vier und Blainville bei mehren anderen Haien. - Bẹi Lepidosiren soll, nach 0 wen's Angaben, die Milz fehlen. - Nebenmilzen sah ich bei Pleuronectes maximus.]

\section{Von den Appendices pyloricae und dem Pancreas.}

\section{§. 37.}

Mehren Ordnungen der Fische, nämlich allen Cyclostomen und auch vielen Knochenfischen, mangelt jede Spur sowol einer Bauchspeicheldrise, als auch der sogenannten Appendices pyloricae. Diese letzte ren, die bei sehr vielen Knochenfischen vorkommen, sind röliren-oder blinddarmförnige Ausstiilpungen des Darmes, welche äicht hinter dem Pförtner in die Darmhöhle übergehen. Mlan bat lange Zeit angenommen, dass sie die Stelle des eigentlichen drisigen Pancreas verträten, und in der That liegt nur eine, bisher noch nicht sicher bestätigte Beobachtung von der Coexistenz eines drüsigen Pancreas und dieser Appendices vor 1). Diese Appendices pyloricae besitzen dieselben Häute, wie der Darm selbst, und die sie inwendig auskleidende Schleimhaut stimmt auch in ihren Texturverhältnissen überein mit der Schleimhaut desjevigen Darmtheiles, in welchen sie einmünden. Die Zahl dieser blinddarmförmigen Ausstülpungen, welche in der Regel eine grosse Menge Schleim absondern, ist je nach den einzelnen Familien, Gattun-

1) Müller hat eine von ihın ausgegangene Behauptıng, betreffend die $\mathrm{Co}_{0}$. existenz eines wahren drüsigen Pancreas und der Appendices pyloricae bei der Gattung Lota später wieder zurüekgenommen. So bleibt nur die Beobachtung von Alessandrini, welcher bein Störe die Anwesenheit eines driisigen Pancreas beobachtet hat, als Einwurf gegen die bisher übliche Anschauungsweise übrig. „Viseus dextrum latus tenet cavitatis abdominalis, aliquantmu vero sequitur exitum primae portionis descendentis intestini eique strictim adhaeret prope pylorum atque hoe modo insitionem proprii duetus excretorii penitus celat." Bisher habe ich mich nicht sicher von der Anwesenheit dieses Organes überzeugen und habe namentlich keinen in den Darm mündenden Ausführungsgang entdekken können. Alessandrini hat aber eine so ausführliche, von Abbildungen begleitete Beschreibung gegeben, dass kaum eine Täuschung von seiner Seite anzunehmen steht. Ich muss diesen Gegenstand daher der wiederholten Untersuchung anderer empfehlen und werde auch selbst jede Gelegenheit, die zu seiner A ufklärung sich mir bieten sollte, gewissenhaft benutzen. 
gen und Arten sehr verschieden; selten sind nur ein 2), zwei ${ }^{3}$ ) oder (drei 4) solcher Blinddärmchen vorhanden, häufiger kounmen sie in beIriichtlicher Anzahl vor ${ }^{5}$ ). Bald, und zwar namentlich dann, wenn ihre Zahl gering ist, erscheinen sie als einfache kiirzere oder längere Ausstiilpungen, deren jedle abgesondert in den Darm mündet; bald vereinen sich mehre zu einem gemeinsamen, in den Darm führenden Gang, und diese gemeinschaftlichen Mündungsgänge sind bald sehr zahlreich, bald in geringer Anzahl vorhanden 6). Oft treten die Blinddärmehen nicht Innmittelbar in die in den Darm übergehenden Gänge, sondern vereinigen sich erst zu Zweiggängen, welche dann wieder zu Aesten eines (llauptganges zusammentreten $\%$. In anderen Fällen sind die Blinddärmchen selbst an ihrem Ende gespalten oder verzweigt 8). Bisweilen liegen die peripherischen Blinddärmchen büschel - oder garbenförmig neben einander und werden durch zwischenliegendes Zellgewebe zusammengehalten 9 ). - Ein solches Convolut von Blinddärmchen erhält schon mehr das Ansehen einer conglomerirten Drüse, wenn mehre Zweige des Ausführungsganges und die in sie übergehenden Blinddärmchen nicht nur durch Zellgewebe verbunden, sondern auch von einer gemeinsamen Iülle umschlossen werden 10). Endlich können in einen Darmgang, anstatt längerer, gestreckter Blinddärmchen, grössere zellenartige Ausstiilpungen übergehen, deren jede wieder in Zellen zweiter und dritter Ordnung zerfällt, wie bei Accipenser 11 ). Jeder dieser Gänge und jede einzelne Zelle besitzt die sämmtlichen Häute des Darmcanales; die Schleimhaut zeigt dieselben netzförmigen, complicirten Vertiefungen, wie in Darmcanale, und die dicken Muskelwandungen sind durch Bindegewebe zusammengehalten. Die ganze Masse endlich wird hier von einer gemeinsamen Membran umschlossen.

2) Z. B. bei Aumodytes tobianus.

3) Z. B. bei vielen Arten von Pleuronectes, bei der Mehrzahl der zu Cu vie r's Pharyngii labyrinthiformes gehörigen Fische, bei mehren Arten der Gattung Aulphiprion u. A.

4) Z. B. bei Perca fluviatilis, Diploprion, Aspro, Acerina.

כ) Bei den Arten der Gattung Trigla schwankt dic Zahl zwischen 5-9, bei Cottus zwischen 4-9, bei Uranoscopus zwischen $11-13$; sehr zahlreich sind sie bei vielen Scomberoïden, bei inehren Squamipennen, bei vielen Gadoïden, Clupeen und Salmoniden, auch bei Cyclopterus und Lepidosteus.

6) Z. B. haben bei Clupea Pilchardus $48-\check{0} 0$ Anhänge, nach Rathke 33 Mündungen; dagegen kommen nur 2 vor bei Xiphias, 5 bei Thynnus vulgaris.

7) S. dic Abbillung von Thynnus vulgaris bei Müller, de str. gland. Tab. VII. Fig. 4.

-8) Z. B. bei Cyclopterus, Fiatola, Gyınnotus, und bei Derınatopterus und Istiophorus nach Ehrenberg. - $\quad$ 9) Z. B. bei Thynnus rulgaris.

10) So bei Xiphias nach Rosenthal; bei Seriola und Temnodon nach Cu vier.

11) Vgl. die Abbildung bei Monro, Vergleichung des Baues der Fische ete. Tab. VIII. Ich kann die Bacr'sche Darstellung in Königsberger Berichte nicht ganz treffend nennell. 
Bei einigen Knochenfischen ${ }^{12}$ ), so wic auch bei den Chimären und Plagiostomen erscheint cine, ganz wic das Pancreas der höheren Wirbelthiere gebildetc, gelappte drüsige Bauchspcicheldrüse, deren Canälchen zu einem gemeinschaftlichen Ausführungsgange zusammentreten, der in den Anfang des Spiraldarmes einmüindet 13 ).

[Beide Gebilde, Pancreas und Appendices pyloricne, fehlen besonders denjenigen Fischen, welche gar keinen gesonderten Magen besitzen oder durch eine sehr einfache Magenbildung sich auszeichnen, namentich den meisten La. broïden, den Cyprinoïlen, den Esocinen (init Ausnahme der Mormyri), den Lophobranchien und Plectognathen. Auch den Siluroïlen und Loricarien mangeln die Appendices pyloricae, jedoch scheint bei einigen derselben ein kleines drüsiges Pancreas vorzukominen. Beide Gebilde können auch einzelnen Gattungen solcher Familien abgehen, deren übrige Genera Appendices pyloricae besitzen. So fehlen sie z. B. nach Cuvier bei Ambassus Commersonii, bei Agriopus verrucosus, bei Anarrhichas lupus, ferner den Gattungen Chironectes, Malthaea, Batrachus u. A. in.]

\section{Von der Leber.}

\$. 38 .

Die hinsichtlich ihres feineren anatomischen Baucs noch nicht hinlänglich untersuchte Leber der Fische, bestebt bei allen, mit einziger Ausnahme von Branchiostoma lubricum, wo sie, ähnlich wic bci den Anneliden, noch nicht von den Darmwänden gesondert ist, aus einem mehr oder minder beträchtlichen drüsigen Organe von ziemlich weicher Consistenz und gelblicher oder gclber, gelbbrauner, rothbrauner, oder rother oder selbst schwärzlicher Färbung 1). Mcist zeichnet sic sich durch einen grossen Fettgehalt aus. Sic liegt in der Regel im Anfange der Bauchböhle, oft sehr weit in derselben hinterwärts sich erstrekkend $\left.{ }^{2}\right)$, bisweilen den grössten Theil des Darmes umgebend ${ }^{3}$ ). Ihre Form ist unendlich vielen Verschiedenheiten unterworfen und oft bedingt durch die verschiedene Gestalt und die Dimensionen der Bauchhöhle.

12) Z. B. bei Anguilla vulgaris; anscheinend auch bei Silurus glanis und bei Esox.

13) Bei Raja batis z. B. besteht das derbe Pancreas aus zwei dreieckigen, durch eine schmale Brücke verbundenen Lappen. Der Ausführungsgang uüudet, bis zu seinem Ende von Drüsensubstanz mmgeben, in den Anfang des Spiraldarmes an der der Einmündungsstelle des Gallenganges gegenüber liegenden Seite. - Bei Lepidosiren soll, nach 0 wen, das Paucreas fehlen.

1) Roth soll die Farbe der Leber sein bei Holocentrum orientale. - Uebri. gens ist die Färbung bei verschiedenen Individuen derselben Art oft nicht ganz gleich.

2) Z. B. unter den einheimischen Fischen bei Clupea, Gadus, Gasterosteus.

3) Bei fast allen $C_{y}$ prinen. 
Bald liegt ilıre IIauptmasse melı' rechts $\left.{ }^{4}\right)$, bald links $\left.{ }^{5}\right)$. Biswcilen bildet sie eine rinzige ungethcilte Masse 6 ), welche vielfach cingcschnitten sein kann, ohne in mehre gesondterte grüssere Lappen zu zerfallen. Häufiger zerfillt sie in zwei seitliche Itauptlappen, welche sclten ganz. getrennt bleiben, wie bei den Myxinoülen, und gewölınlich durch cin of betriichıliches Querstïck verbunden werden 7 ); in andercn Fällen hat sic drei Lappen ${ }^{8}$ ) und bestcht scltcn aus zahlreichen, durch die Gallencanälchen żiemlich eng verbundenen Läppehen 9). Ist sic zweilappig, so ist schr häufig der linke Lappen der beträchtlichcre. - Mit selır wenigen Ausnahmen ${ }^{10}$ ) kömmt den Fischen eine Gallenblase zu, wclche gewöhnlich dicht unter der Lebcr oberflächlich liegt, seltener in ihrc Substanz eingebettet 11), bisweilen ilber ganz von der Leber gctrennt ist 12) und dann in der Regel zwischen ihr und dem Magen oder dem Darme liegt. Meistens steht die Grössc dieser Gallenblase in directem Verhältnisse zum Umfange der Lcber. Ihre Gestalı ist sehr verschieden; sie ist bald kugelförmig ${ }^{13}$ ), bald oval, bald cylindrisch, bald gefässartig in die Länge gezogen 14) und dann bisweilen durch den grösstcn Theil der Bauchhöhle sich crstreckend. - Die Gallencanälchen der Leber vercinigen sich meistens zu mchren Stämmchen, welche letz tere bald zu einem Ductus hepaticus zusammentreten, bald nach und nach einzeln, und zwar meist unter rechtem oder stumpfem Winkel in den Ductus cysticus ${ }^{15}$ ) oder in die Gallenblase sclbst oder in boide einmünden ${ }^{16}$ ). Der bisweilen dicke und mit muskulöscn Wandungen

4) Z. B. bei Gasterosteus, Cyprinus Carpio.

5) Z. B. Esox, Muraena, Sahmo, Cottns, Cyclopterus 11. A.

6) Z. B. die kleine Leber von Petromyzon; ferner bei Cobitis, Cottns, Salmo, Osmerus, Thymallns, Muraena, Esox, Belone, Lophins, S5ngnathus, Ortha. goriscus, Tetrodon, Mugil, Blepharis, Seriola u. v. A.

б) \%. B. bei den Haien, bei Gymnotus, Sphagebranchus, den meisten Gadus, Polypterus, Silurus, Loricaria, Anarrhichas, Vouner, Coryphaena, Caranx, Lepillopus, Chorinemus, Anxis, Ophicephalus, Chactorlon, Glyphisodon, Uranosco. pus u. v. A.

8) Z. B. bei mehren Rochen, bei nehren Clupeen, bei den uneisten Cyprinen, bei Thynnus, bei Corvina u. A. - 9) Z. B. bei Ammodytes tobianus.

10) Sie fehlt bei Petronzyzon und Amınocoetes; nach Rathke bei Scomber leuciscus; nach $\mathrm{Cuvier}$ auch bei Labrus turdus. Mit Unrecht aber spricht $\mathbf{D}$ u . vernoy den Labroïlen überhaupt die Gallemblase ab. Auch bei Cyclopterns, dem Cnvier und, ihın folgend, Wagner sie abspricht, ist sie rorhanden.

11) Wie bei einigen Cyprinen, Accipenser, mehren Rochen.

12) Z. B. bei vielen Squanipennen, bei Salmo Salar, Lopluius piscatorius, Voner Brownii u. A. - 13) Z. B. bei Sebastes, Synanceia, Mugil.

14) An auffallendsten bei den Scomberö̈len: Thynnus vulgaris, Th. pelauis, Scomber, Auxis, Thyrsites, Lepidopus; anch bei Upeneus Merula, Sciaena, Otolithus u. A.

15) 7. B. hei Lophins, Labrus viridis, Cyprinus, Gadıs Morrhı, Muraena Anarrhichas, Accipenser. - 16) Bri meliren Rochen. 
versehene ${ }^{1 *}$ ) Darmgallengang senkt sich in der Regel dicht hinter dem Pylorus in den Anfang des Darmcanales; sobald Appendices Myloricue vorhanden sind, dicht über, unter oder zwischen der Einmündungsstelle dieser letzteren. Bei den Plagiostomen senkt er sich in den Anfang des Klappendarmes 18). Oft findet sich, entsprechend seiner Einmündungsstelle, im Innern des Darmes eine kleine Papille 19).

[Man vergl. über die Leber der Fische besonders Cuvier, Leçons d'Anat. comp. T. 1V. p. 1., revu par G. L. Duvernoy, Paris 1835; die zahlreichen Angaben über das Verlaalten derselben bei einzelnen Species in Cuvier und $\mathrm{Va}$ lenciennes, Hist. nat. d. poiss., und über die Leber der inländischen Fische einen Aufsatz von Rathke in Meckel's Archiv, Jahrg. 1826. - Ueber Branchiostoma s. die Notiz bei Müller in Jahresbericlit der Acalemie, Dec. 1841.]

\section{Sechster Abschnitt. \\ $V$ o m Gefüsssysteme.}

§. 39.

Bei den Fischen tritt das Körpervenenblut in das Herz und von diesem aus, mittelst eines dickwandigen Aortenstieles $(B u l$ bus arteriosus) in Kiemenarterien, deren feinste Verzweigungen innerhalb der Kiemenblättchen oder anderer Athmungsorgane es in Kiemenvenen überführen. Diese letzteren setzen in die Stämme der Körperarterien sich forl, deren feinste capillare Verzweigungen in die Körpervenen übergehen. Das venöse Blut sammelt sich theils unmittelbar in den zum Ilerzen führeuden Körpervenenstämmen, theils gelangt es in diese, nachdem es ein Pfortadersystem durchlaufen hat. - Bei den meisten Fischen ist also das Herz nur ein venöses Kiemenherz; bei anderen aber mehr als dies, in so fern Fische bekannt sind, deren Kiemenarterienstamm oder deren IIerz Aortenbogen abgibt, welche unmittelbar in den Körperarterienstamm oder die Aorta libergehen ${ }^{1}$.

17) Bei mehren Haiell.

18) Beim Stör inserirt er sich unnittelbar hinter der Magenerweiterung, also weit entfernt roin Spiraldarın.

19) Z. B. Labrax lupus, Accipenser, Raja, Rhinobatus.

1) Diese Anordnung ist bis jetzt nur bei einigen aalartigen Fischen, bei Lepidosiren nud bei Branchiostoma, perennirend angetroffen worden. Bei Amphipnous Cuchia theilt sich nach Taylor die Kiemenarterie in Irei Zwveige. Einer derselben tritt jetlerseits zwischen den vierten kiemenlosen Kiemenbogen und den Schlundknocben ind dann vor dein zehnten Wirbel lirect zur Aorta, welehe ausserlem durch Kiiemen. und Lungentenen gebildet wird (Ediuburgh Journ, of sc. 


\section{Vom Herzen.}

S. 40 .

Die Bildung dos Hormens I) bei Brancliostuma zeigt bedeutende Aehnlichkeit mit derjenigen der gefaissförmigen Herzen der Anneliden. Es ist doppelt: ein Kiemenarterien - und ein Hohlvenenherz. Jenes ist eine von keinem Ilerzbeutel umschlossene, gleichförmig dicke, ziemlich lange, contractile Röhre, die, unter dem Kiementhorax gelegen, am Ende der Speiseröhre mit dem gleichfalls röhrenförmigen contractilen Hohlvenenherzen zusammenhangt 2 ). - Das Herz der übrigen Fische liegt mit dem Bulbus arteriosus in einem bald nit der Bauchhöble communicirenden ${ }^{3}$ ), bald geschlossenen 4) Herzbeutel. Dieser erhält bei einigen Cyclostomen ${ }^{5}$ ) eine knorpelige Decke, welche mit dem knorpeligen Kiemengeriiste zusammenhangt, und besitzt bei anderen Knorpelfischen eine äussere fibröse Capsel 6). - Der Herzbeutel vieler Fische steht mit der Oberfläche der Iterzkammer durch anschei nend tendinöse Fäden in Verbindung, die indessen bei genauerer Un tersuchung als Blutgefässe sich zu erkennen geben ${ }^{\top}$ ).

1831). - Auch bei Monopterus liegt, nach Müller, jederseits an dem keine Spur von Kieme besitzenden vierten Kiemenbogen, ein von der Kiemenarterie direct zur Aorta verlaufender Aortenbogen. - Bei Lepidosiren setzen sich, nach 0 we n und Bischoff, Aeste der Kiemenarterie nach Abgabe ron Kiemen - und Lungen. zweigen direct in die Aorta fort. - Bei Branchiostoma geht, nach Retzius und Müller, jederseits ron dem Mittelherzen ein herzartiger, contractiler Aortenbogen ab, der ror der vorlersten Kieme liegt und direct in die Aorta führt. - Bei den Myxinoïden hat Müller aus dem vorlersten Kiemenarterienaste hervorgehende obliterirte Ductus arteriosi angetroffen, worans sich ergibt, dass eine analoge Bildung bei den Myxinoïlen wenigstens temporär vorkömmt. Vgl. Mül. le r, Vergl. Anat. des Gefisssystenes der Myxinnïden, Berlin 1841, S. 27 u. 19.

1) Ueber das Herz der Fisclie in Allgemeinen rgl. Tiedemann, Anatomie des Fischherzens, Landshut 1808, 4.; Meckel, System d. vergl. Anat. Bd. 5 .

2) S. Müller und Retzius a. a. 0 .

3) Bei den Myxinoïden, bei Ammocoetes, Accipenser, Chimaera, den Plagio. stomen. Bei letzteren bildet der einfache Canal in der Bauchliöhle zwei Seitencanäle, wclche sich vor dem Anfange des Magens öffnell. Bein Stör geschicht die Communication durch einen unpaaren, an der Bauchseite der Speiseröhre rerlaufenden, mehre Zoll langen Canal. Flimmerbewegung liabe ich weder in dem Canal, noch in dem Herzbeutel beobachtet.

4) Bei Petromyzon und bei den Knochenfischen. - Eine Fortsetzung des Herzbeutels überzicht auch unmittelbar dic Substanz des Herzens.

5) Bei Petromyzon. - 6) Bei Accipenser, den Plagiostomen.

7) Sie koumen constant vor bei Muraena, Muraenophis, Anarrhichas, Cobi. tis, Accipenser, Petromyzon. Beim Stör unl bei Cobitis habe ich mich daron üljerzeugt, dass diese anscheinend tendinösen Fäden wirklich Blutgefässe sind. Beim Stör sind es zum Theil Arterien, welche aus der Arteria mammaria in. terna an die das Herz umkleidenden drüsenähnlichen Lymphräume treten. Siehe über diese \$. 4ว. Anın. 3 . 
Das II er'z sellost bestelıt aus einer gewölınlich dickwandigen, sehr muskulösen 8) Kammer nelst dem aus dieser hervortretenden $B$ u $/$ ( $\boldsymbol{u} \boldsymbol{s}$ arteriosus und einer weiten, meist mit duinneren Wandungen versehenen Vorkammer, wolche die Kammer gewölınlich seitwairts etwas uberragt. Kammer und Vorkammer hesitzen in der Regel eine einfache Itöhle. Indess gibt es Fische, deren Vorkammer durch eine unvollkommene Scheidewand in zwei Höhlen zerfällt 9). An der Eintriltsstelle des Körpervenen-Sinus in die Vorkammer fehlen gewöhnlich Klappen und nur selten kömmt eine häutige Doppelklappe vor 10 ) - Zwischen der Vorkammer und der Kammer sind sehr regelmässig halbmondrörmige Klappen vorhanden 11). - Die Kammer 12) sellost, in Form und Umfang beträchtliché Verschiedenheiten darbietend, geht mit ihrem vorderen Ende über in den nur bei den Cyclostomen häutigen, bei den ïbrigen Fisch en sehr verdickten, oft muskulösen und contractilen länglichen $B$ ullus arteriosus. Nur bei $\mathrm{Br}$ a n chios to $\mathrm{m}$ a ist das Kiemen-ArterienherzBeides: Ilerzkammer und Bullus arteriosus zugleich; doch gehen von ilım seitlich sehr zahlreiche kleine contractile Bullilli am Ursprunge der Kiemenarterien ab. In der arteriösen Mündung der Ilerzkammer finden sich bei den Cyclostomen, bei Lepidosiren und den Knochenfischen nur zwei einfache, halbmondförmige Klappen. Bei den Chimären, Stören und Plagiostom en, so wie auch bei Polypterus, kommen aber in dem sehr musculösen Bullus arteriosus zwrei bis fïnf Querreihen dicht neben einander stehender halbmondförmiger Klappen vor $\left.{ }^{13}\right)^{3}$ -

8) Die Primitivbündel der Muskelfasern des Herzens fand ich immer quergestreift, eine Regel, die, nach Müller, anch für die Myxinoïden Gültigkeit hat.

9) Dies ist wol sicher der Fall bei Lepidosiren paradoxa. Bisch off fand hier eine netzförmig durchbrochene Scheidewand. S. dessen Schrift: Lepidosiren paradoxa, Leipzig 1840, 4. S. 17. Nach Treviranus (Beobachtungen a. d. Zootumie u. Physiologie, 1. Heft, Bremen 1839, 4.) sollen auch bei Trigla und Anarrhichas zwei Vorkammern vorhanden sein, zwischen welchen eine durchbohrte Scheidewand sich findet. Ich babe mich von der Richtigkeit dieser Angaben nieht überzeugen können. - 10) Bei Myxine.

11) Sie fehlen bei Lepilosiren nach Bisch off. Bei den meisten Fischen kommen zwei freie Klappen ror; bei Orthagoriscus Mola vier.

12) Die Muskelsubstanz der Kammer ist bei beginnender Fäulniss leicht in eine äusșere und innere Schicht zı trennen, von denen jene eine Art Sack 111 diese bildet. Dies rührt daher, dass die äussere Muskulatur der Herzkammer, bei verschiedenem Verlinfe der Muskelbündel, derber wnd dichter ist, als die in. nere, weichere Muskelmasse, welche mit der ersteren nur locker verbunden zn sein pflegt. Vgl. Rathke in Meckel's Archiv, 1826.

13) In jeder Querreihe stehen drei, seltener vier Klappen. - Zwei Querreihen kommen vor bei Chimaera, Carcharias, Scylliun, Galeus; Irei bei Sphyma, Mustelıs, Acanthias, Alopias, Lamna, Rhinobatıs, Torjedo; drei bis vier bei Accipenser; vier bei Hexanchus, Hejstanchus, Centrophorus, Trygon; vier bis fïnf bei Raja; fiinf bei Scymnis, Myliobatis, Pteroplatea und Squatina. Nach Anga. ben von Müller, Archiv 1842. Müller hat, wie ich nachträglich bemerke, anch 
Dis Arterien des Iferzens entspringen gewöhnlich aus dem zweiten oder dem dritten kiemen-Venenstamme if), seltener auch aus einem als Arteria mamuaria zu bezeichnenden Aste der Arteria axillaris. - Die Nerven stammen aus dem Nervus vagus, und zwar meistens aus scinen Rami pharymgei, welche mit sympathischen Fäden in Verbindung zu stehen pflegen.

\section{Von den Kiemengefässen.}

\section{§. 41 .}

Während bei Branchiostoma die Bulbillen der Kiemenarterien seitlich aus dem Arterienherzen abtreten, setzt sich bei den übrigen Fischen das vordere Ende des Bullus arteriosus fort in den ausserhalb des Herzbeutels liegenden, nie mehr contractilen Kicmen-Arterienstamm, aus welchem jedersoits die Kiemenarterien hervorgehen. Bei den Myxino ïden hat jeder Kiemensack seine besondere Arterie 1); bei den übrigen Fischen 2) tritt an die vordere Kiemenblattreihe eines jeden Sackes oder einer jeden Spalte eine andere Arterie, als an die hintere, indem eine Arteric für tic beiden an demselben Kiemenbogen befestigten Kiemenblattreihen bestimmt ist. Jede Kiemenarterie tritt in einen durch die Furche der Kiemenbogen gebildeten und durch die in zwoi verbundenen Reihen aufsitzenden Kiemenblattelien vervollständigten Canal. Jedes Kiemenblättehen ${ }^{3}$ ) erhäill seinen eigenen Gefässstamm, dessen feinste capillare Netze sich in den Falten der Blättchen finden. Sie gehen ununterbrochen in die Anfïnge der Kiemenvenen über. Bei den Myxinoïden geht von jerlem Kiemensack eine Kiemenvene ab; bei den Petromyzonten gehört jede Kienenvene den an einander stossenden Flächen zweier Kiemensäcke an. Bei den Rochen bilden die Kiemenvenen um jede innere Kiemenspalte einen Cirkel, aus welchem cine Kiemenvene abyeht; diese Cirkel anastomisiren unter einauter durch Quergeässe. - Die Kiemenvenen haben bei den Knorpelfischen sowol, als bei den Knochenfischen, nicht nur dorsale, sondern auch ventrale Verlïngerungen.

bei Polypterns drei Reihen Klappen gefunden; jede Reihe enthält acht bis zelın Klappen.

14) Alıs der zweiten Kiemenvene nacl Hyrtl bei Salmo, Perca und Lucio. perca; aus der dritten Kienenveur nach meinen Beobachtungen bein Stör, wozu aber noch die aus der Arteria mummuria stammenden Zweige hiuzukommen.

1) Nach $M$ iiller l. c.

2) Auch bei Petrouyzou.

3) Sehr schöne Beobachtungen über die feinsten Kiemengefïsse finden sich bei Hyrtl in den Mel. Jahrb. d. Oesterr. Staates, Bd. 24., 1838, S. 235 ก. 


\section{Von den Körperarterien.}

ร. 42.

Bei allen Fischen entstehen durch unmittclbare Fortsetzung, Verzweigung oder Verbindung der Kiemen-Venenstämme die Arterienstämme des Körpers, zu deren Bildung nur selten direct aus dern Herzen stammende, also venöses Blut führende Aortenbogen beitragen. Sehon unmittelbar aus einzelnen Kiemenvenen, und zwar theils als Aeste, theils als ventrale Verlängerungen derselben, treten sowol bei Knochenfischen, als bei Stören und Plagiostomen $\Lambda$ rterien für das Herz, die Zungenbeinmuskeln, die Membrana branchiostega und feine nutritive Zweige für das Knoehengeriist und die Sehleimhaut der Kiemenbogen ab 1). Zum Theil nach Abgabe von Aesten bilden die sämmtlichen dorsalen Fortsetzungen der Kiemenvenen dureh ihre Vereinigung zu unpaaren oder paarigen Stämmen die Ausgangspunkte der Arterienäste des Körpers. Die Entstehungsweise dieser Stänıme aus den Kie menvenen bietet bei den verschiedenen Ordnungen der Fische Verschiedenheiten dar. Bei den Myxinoïden treten die meisten Kiemenvenen sogleich, nachdem sie die Kiemen verlassen, zur Bildung einer unter der Wirbelsäule gelegenen Aorta zusammen, welche nieht blos hinterwärts als Aorta descendens, sondern aueh rorwärts als Arteria ver. tebralis impar sieh fortsetzt. Ausserdem hangen alle oder die meisten Kiemenvenen jeder Seile durch eine der Aorta parallele Lüingsanastomose zusammen, die naeh vorn als Arteria carotis communis sich fortsetzt. Diese beiden Carotiden begleiten die Speiseröhre nach vorn, unter Abgabe von Speiseröhren - und Zungenmuskelzweigen. Hinter dem Kopfe theilt sieh jede Carotis commusis in zwei Aeste: eine A. carotis exterza, welehe in Kopfmuskeln und Zunge sieh verzweigt, und eine $\boldsymbol{A}$. carotis interna. Die beiden Carotides internae verbinden sieh bogenförmig unter dem Anfange der Wirbelsäule. Dieser Bogen nimmt das Ende der $A$. vertebralis impar auf. Aus ihm entsteht eine unpaare Kopfarterie, welehe vorwärts verläuft und Zweige für Nase, Nasengaunnengang u. s. w. abgilbt.

Bei Petromyzon entsteht die Aorta auf ähnliehø Weise. Die Carotides communes werden aber gebildet dureh die Vereinigung der ersten Kiemenvene mit einem vorderen seitliehen Aste der Aorta. Die Arteria vertelralis impar und die unpaare Kopfarterie fehlen.

Bei den Chimären, Stören - und Plagiostonnen treten die meisten oder sämmtliche Kiemenvenen zur Bildung der Aorta descendens zusammen 1). Aber die Entstehung der Carotiden ist abweiehend 2).

1) S. die Abbild. bei Monro, Tab. 1.

2) Bei den Chimären dringt die erste Kiemenvene jeder Seite in die Sche. delhöhle als Carotis posterior und dio zweitc Kiemenvene, welche übrigens, 
Bei den Knochenfischen treten sämmtliche Kiemenvenen s) einer Seite successive zu einem unter dem Anfange der Wirbelsäule und unter der Brsis crauii gelegenen Lärgsbogen zusammen. Dio hinteren Schenkel dieser beiden panrigen Bogen vereinigen sich zur Bildung einer Aorta desceudess und die vorderen Schenkel fliessen transversel zusammen. So entsteht cin ausserhalb der Schedelhöhle gelegener Gefässkreis (Circulus ceplialicus), der nach hinten in die unpaare Aorta sich fortsetzt, aus dessen rorderem Abschnitte Zweige abtreten, die für das Gehirn, die Orbita und die Nase bestinmt sind, und aus dessen Seiten die Carotides posteriores entstehen. - Aus der Aorta ${ }^{4}$ ), welche selten von der Bauchfläche der Wirbel völlig zu isoliren ist, entspringen drt. intercostales und an verschiedenen Punkten untergeordnete Zweige für die Nieren, die Platten des Mesenterium und die Geschlechtstheile. Ihre Hauptäste sind aber 1) eine Art. cocliaco-mesenterica, wolche, sclten unmittelbar aus dem hinteren Abschnitte des Circulus cephali. cus hervorkommend $\left.{ }^{5}\right)$, die $A$. coeliaca und mesenterica superior zugleich vertritl 6); 2) die für die Extremitäten bestimmten Art. axillares und 3) eine eigene $A$. mesenterica posterior, die gewöhnlich vorkömmt $\overline{7}$. - Das Ende der Aorta setzt sich als $A$. caudalis in dem

gleich den folgenden, zur Bildung der Aorta heiträgt, gibt eine in die Augenhöhle tretende A. carotis anterior al. Beim Stör und bei den Plagiostonen bildet sieh aus den vorderen Kienenvenen jeler Seite eine Carotis posterior, die bei den Rochen in clas Rückgrath, bei den Stören in die Kínorpelmasse des Schedelgrundes eintritt. Die beiden Caralides posteriores vereinigen sich bei den meisten dieser Fische eben so wenig, als bei den Chimïren; nur bei den Haien fliessen dic beiden Carntides posteriores in einem mittleren Loche der Sehedelbasis zusammen, wo denn die Hirnarterie entspringt. Die Carotis anterior entsteht aher beim Stör mnd den Plagiostomen aus den Gefässen der Pseudobranchie des Spritzloches.

3) Bei vielen Knochenfischen entspringt aus dem Bauchende der ersten Kie. uncnvene jederseits eine $A$. lyjö̈deo-opercularis, welche den obereu Rande des Zungenbeinbogens folgt, Zweige an das Zungenbein mnd die Kiemendeeken abgebent. Sie titt dann, nachdem sie das Suspensorium des Unterkiefers durchbohrt, an die innere Seite des Kiemendeeliels und gelangt naeh Abgabe ciniger Hautzweige zur Nebenkieme. - Iyrtl sah bei Lmeioperca und bei Aspro Zingel aus den ventralen Theile der hicmenrenen einen unpaaren Stamm zusammentreten, der zwischen die Mnskelı der Brustflossen abwärts verläuft und hier sieh vertheilt. Beim Herlıt entspringt, nach Mïller, die $A$. suliclavia aus dem gemeinschaftlichen Stamm der beiden vorderen Kiemenvenen jeder Seite. Die $d$. sub. clavia gibt eine A. mammarin interna ab, lie an Bauehe rïekwärts verläuft und vordere Intercostalzweige abscliekt. S. ilarüber auch Monro S. 6. U. 7.

4) In der Aorta des Störes, des Laelises, des Welses liegt ein von der Sehedelbasis ausgehendes fibröses Band. - Bei mehren Cyprinen bildet die Aorta innerhatb aler Bauchhöhle unter jedem Wirbelkörper einen Sinns.

5) Bei Lota nach Hyrtl. - 6) Z. B. bei Aecipenser, Perca, Cyprinus. Bei Raja sind, nach Monro, diese beiden Arterien getrennt.

7) Ich finde sic z. B. bei Accipenser, Salmo. 
Canale der unteren Wirbelbogenschenkel verlaufend, fort. - Vie für rlie starken Vorderevtremitiiin'n bestimmten Ar\% axillares schwellen durch partielle Erweiterung und Belegung mil Mushelfasern bei Torpedo und bei den Chimären zu aceessorischen IIerzen an 8 ).

[Die wichtigsten dieser Darstellung zu Grunde liegenden Arbeiteu über das arterielle Gefässsystem der Fische sinıl ein an Beobachtungen sehr reicher Aufsatz von Hyrtl in den Met. Jahrbiuchern d. Oesterr. Staates, XV. S. 70 u. 232. unl Mïller's vergl. Anatom. des Gefässsystemes d. Myxinoïden. - Zu vgl. ist auch die Schrift von Monro, üb. den Ban u. die Physiol. der Fische. - Rücksichtlich aller sjecielleren Data muss auf diese Arbeiten verwiesen werden.]

\section{Von den Venen.}

§. 43.

Die Venen der Fische zeichnen sich sowol dureh die Dünne ihrer Wandungen, als auch dureh ihre Weite und die häufige Bildung ein. zelner sinusartiger Erweiterungen aus ${ }^{1}$ ). Klappen seheinen nur selten in ihnen vorzukommen 2). Die das venöse Blut aus den versehiedenen Körpertheilen aufnehmenden Stïmme treten theils unmittelbar zum Iferzen, theils bilden sie zuvor Pfortadersysteme. Die grösseren Venenstämme verhalten sich folgendermaassen: 1) Zwei Venae cardinales anceriores $\left.{ }^{3}\right)$ s. jugulaves nehmen das Blut aus dem Hirne, dem Schedel, der Augenhöhle, dem Schlunde und zum Theil auch von den Kie menbogen auf. Selten erweitert sich der Bereich einer dieser Venen, wodurch sie dann asymmetrisch wird 4). 2) Ihnen entsprechen zwei hintere Cardinalvenen (Venae cavae posteriores Auctor.) ${ }^{5}$ ). Die Ent-

8) Bei den Chimären von Durernoy entdeckt. Vgl. Ann. d. sc. nat,, 1837, T. 8. p. 33. - Später anch von Valentin beschrieben. Ich finle sie bei Chimacra arctica und monstrosa. - Bei Torpedo vou Davy aufgefunden. Auch an den äusseren Hülfsorganen der männlicheı Geschlechtsılıeile lıat $\mathrm{D}$ avy bei l'la. giostomen ein pulsirendes Organ beobachtet, das jedoch noch nicht uäher untersucht ist.

1) Dic Venen sind oft mehr Rinnen in dem Parenchym der Organe, z. B. der Nieren, als mit selbstständigen Häuten verschene Canäle. Stark erweitert sind z. B. die Jugularvenen der Kinochenfische, die Lebervenen der Rochen; bei Petromyzon findet sich ein von Ratlıc uäher beschriebener Blutbelıälter, der das Blut der Nieren und Geschlechtstheile aufnimmt. Aclndiclıe, mit den hinte. ren Cardinalvenen commumicirende, finden siclı bei den Rochen.

2) Monro erwähnt ihrer, als bei Raja vorkommend, S. 8.

3) Sie liegen gewöhnlich mnter den unteren Wirbelbogen, nur bei Petromy. zon oberhalb derselben, wic $R$ athke angibt.

4) Bei den Myxinö̈ilen nach Retzius und Mïller.

5) Sic werlen häufig unit Unreclıt als hintere Holılvenen bezcichnet, wie $\mathrm{B}$ a er nachgewiesen. Sie sind aber auch nicht bloss Aeqnivialente des Systemes der Venae vertelirales posteriores, wie Baer meinte. Ihre Analoga finden sich vielmehr nur bei den Embryonen höherer Wirbeltliere, wie Rathke (drit. 
stohungsweise derselhen ist folgende: die Venen der Schwanzflosse sanmolı sicl in rifren Stamm, der in der Rrgel rinfaclı gefissförmig ist, hei Arguilla und Muraenophis aher ein pulsirendes Caudalherz besitzt. Der Stanmu der Caudalvene verläuft unterhalb der Art. caurlalis im Canale der untern Dornen der Schwanzwirbel und nimmt in dieser Strecke siimmtliche Venen des Schwanzes auf. Nachdem die Vena caudalis den genannten Canal verlassen, treten in sie in der Regel mehre Aeste aus der einen (6) (meist der linken) Nicre. Sie steht gewöhnlich auch mit Venen des Afterdarmes in Verbindung ${ }^{\circ}$ ). Hierauf erstreckt sie sich, zwischen den Nieren, oder durch das Parenchym einer derselben (meist der rechten) verlaufend, als Vena cardiualis posterior dextra vorwärts, nimmt allmälich die Venen der Niere ihrer Seite, Venen der Rumpfwandıngen, welche durch die Nicrensubstanz treten, Venen der keimbereitenden Geschlechtstheilc und auch wol der Schwimnblase ${ }^{8}$ ) auf. Die Venen der entgegengesetzten Niere sanumeln sich allmälich in einen der vorigen parallelen Stanım, welcher durch Aufnalıne von Gefiissen gleicher Art verstärkt wird, gewöhnlich aber schwächer bleibt, als der vorige, und stcllt so eine $\boldsymbol{V}$. cardinalis posterior sinistra dar. Immer steht sie nit der ihr entgegengesetzlen eigentlichen Fortsctzung der Schwanzvene durch zahlreiche Qucr-Anastomosen in Verbindung. Zulctzt nehmen beide Stämme gewöhnlich noch die Venen der Extremitäten auf. - 3) Die bald nichrfachen, bald zu einem Stamme verbundenen Venae hepaticae (die rinzigen Repräsentanten der unteren Iohlvene der höheren Wirbelthiere) cmpfangen das venösc Blut aus der Leber.

Durch die Vereinigung aller dieser Venenstämme entsteht ein gemeinsamer Siuus venarum. Die Art seiner Entstehung ist verschieden. Bei den Myxinö̈den ${ }^{9}$ ) verbindet sich der aus der Vereinigung der beiden hinteren Cardinalvenen entstandene hintere Körperrenenstamm mit der $\boldsymbol{V}$. jugularis sinistra zu seiner Bildung und dann erst senken in ihn zwci Lebervenen und die asymmetrische, durch Aufnahne von Venen des Rumpfes verstärkte $\boldsymbol{V}$. jugularis dextra sich ein. Bci den Plagiostomen ${ }^{10}$ ) vereinigt sich je eine hintere und cinc vordere Cardinalvene mit Venen der Vorderextremitit und einer oberflichlichen Kopfvene zur Bildung cines Quervenenstammes (Ductus Cuvieri) und durch die Vereinigung der beiden Ductus Cuvieri entsteht der Siuns commonis, in den dann die Lebervenen cintreten.

ter Bericht üb. d. naturw. Semin. zu Königsb., 1838. 4.) sehr überzeugend ge. zeigt hat.

6) Nach eigenen Untersuchungen an Knochenfischen. Nach Retzius und Mïller ist bei den Myxinö̈den die linke Cardinalvene au stïrksten.

7) Nanentlich schr deutlich bein Wels, wo diese Zwreige Wurzeh des Leber-Pfortadersystemes billen. - 8) Z. B. bei Esox, Giulus.

9) Vgl. dariber bes. Müller a. a. 0. - 10) S. Molro l. c. Tab. II. 
Bei den Knochenfischen entstehen gleichfalls, durch die Vereinigung jeder vordern Cardinalvene mit der ihr entsprechenden hinteren, zwei quere Ductns Cuvieri. In den durch ibre Verbindung entstandenen Sinus communis senken sich dann die Lehervenen, entweder mit einem gemeinsamen Stamme ${ }^{11}$ ), oder int zwei 12), ja selhst mit mehren Aesten 13). Dieser Sinus nimmt auch die $\boldsymbol{V}$. jugularis inferior auf, wenn sie unpaar ist ${ }^{1 /}$ ).

Dic zuführenden Gefässe des Leber-Pfortadersystemes ${ }^{15}$ ) sind bei den Fischen in der Regel nicht bloss die Tenen des Magens, des Darmkanals, der Milz, der Appendices pyloricre, sondern meistens gesellen sich zu ihnen auch Venen der Schwinmblase, der Rumpfwandungen ${ }^{16}$ ) und der Genitalien ${ }^{17}$ ). Bei viclen Fischen vereinigen sich diese - bisweilen theilweise durch eigenthümliche Lage ausgezeichneten 18) - Gefässe zu einem Pfortaderstanme ${ }^{19}$ ), ehe sie ihr Blut in die Leber ergiessen. Selten ist dieser Stamm herzartig contractil, so dass er cin wahres Pfortaderherz darstellt 20 ). - In anderen Fällen, und zwar bei der Mehrzahl der Knochenfische, Ireten die zur Bildung des Pfortadersystemes beitragenden Venen einzeln oder in einige Stänme gesammelt ${ }^{21}$ ) zur Leber. Selten bilden sie vor ihrem Eintritte in dieselbe Wundernetze 22 ).

11) So mach Rathke bei Belone, Cyclopterus, Anguilla, Ammodytes, Salıno, Silurus, Accipenser. - 12) Z. B. bei Gadhs, Esox, Pleuronectes, Thyunns u. A.

13) Z. B. bei Clupea, Cottus, einigen Cyprinen u. A.

14) Z. B. bei Thymus mach Müller.

15) S. hicrüber vorzüglich einen Aufsatz ron Rathke in II eckel's Archiv f. Anat. u. Physiol, 1826, S. 126 ff. - 16) Bei den Myxinoülen nach Miiller.

17) Bei den Myxinoïlen, den Cyprinen, Cobitis, Blennius, Perea, Osmerus nach Rathke.

18) Bei Petromyzon liegt der Stamm der Intestinalrenen, nach Rathke, im Inneren des Darmes in der denselben durchziehenden Falte. Duvernoy und Meckel beobachteten hei Galeocerlo, Zygaena unl einigen anderen Haien einen ähnlichen Verlauf dieses Gefässes im freien Raudle der hier eigenthümlich gestalteten Längsklappe des Darmes. Duvern oy glaubt hier sogar eine Belegung der Vene mit Muskelfasern erkanut zu haben. Siehe Anı. I. sc. nat. T. 3. 1835. p. 27 4.

19) Bei Petromyzon, den Plagiostomen, Anguilla, Acerina, Lota n. A.

20) Von Retzius und Mïller bei Branchiostoma und Myxine entrleckt.

21) An weitesten ist die Isolirung gediehen bei den meisten Cyprinen; we. niger bei Pleuronectes maximus, Lophius, Xiphias; drei Stämue sind rorhanden bei Cottus; zwei Hauptstämme und neben ihnen isolirte Gefässe z. B. bei Gadıs, Belone, Clıpea; zwei getrennte Hauptstämme hei Esox, Osmerus, Blennius; einzelne Gefässe nehen einem Hauptstanme bei Perca, Ammodytes, Cyclopterus, bein Wels, bei Orthagoriscus mola. - Meist nach Ratlike's Angaben.

22) Nach Eschricht's und Müller's Entleckung gehen bei 'Thy'nnus vul. garis und Th. brachypterus die vom Magen, von der Milz, vom Damue, vou den Appendices pyloricae kommenden Venen einzehn über in ein grosses Wundernetz, bevor sie in die Leber treten. S. deren Aufsatz in den Abhandl. d. Berl. Acad. d. Wissensch., 1835. 
Da bei den Fischen die Venen der -Rumpfwandungen durch die Nierensubstanz hindurch in die Venae carlinales treten, haben einige Physiologen eine pfortaderähnliche Vertheilung derselben innerhalb der Nieren angenommen, ohne dass jedoch eine solche bei den Fischen mit Sicherheit nachgewiesen wäre ${ }^{23}$ ).

\section{§. 44.}

Yon besonderem Interesse ist noch das Verhalten der Gefässe in den Pseudobranchien oder Nebenkiemen und in der sogenannten Chorö̈dealdrüse der Fische. Es sind dies zwei Gebilde, welche meistens, obschon nicht immer, gleichzeitig vorkommen und deren Bau besonders durch Müller aufgeklärt ist.

Die Pseudobranchien kommen den meisten Fischen zu, fehlen aber anderen, wie es scheint, gänzlich 1). Sie erscheinen unter zwei verschiedenen Formen.

1. Als blutreiche, den wahren Kiemen ähnliche, aber viel kleinere, unbedeckt liegende Organe, welche einen Kamm von Blättchen mit Knorpelstrahlen und fedriger Vertheilung der Blutgefässe darstellen. Die Federchen sind schmal und sehr regelmässig zu einem Kamm oder Fächer geordnet 2).

2. Als blutreiche, anscheinend drüsige ${ }^{3}$ ), aus mehren Läppchen bestehende Gebilde 4 ), welche von der Haut der Kiemenhöhle, bisweilen auch von Fett und Uuskeln oder sogar von Knochen 5 ) bedeckt werden. Die feineren Elemente sind die nïmlichen, wie bei der vorigen Form; die Läppchen sind dicke, breite und gewöhnlich kurze Federchen mit einem mikroskopisch erkennbaren Kiel von zelligem Knorpel. Dieser Kiel ist beiderseits nit häutigen, hohen und breiten Blättchen besetzt.

23) S. darüber Jacobson, de systemate venoso peeul., Hafn. 1821; Isis 1822, S. 114. und Nicolai, 1sis 1826 , S. 404. Ich habe mich bisher nieht sicher von der Existenz der jfortadermässigen Vertheilung der Rumpfvenen und der $\mathbf{Z}$ weige der Schwanzvene in den Nieren von Gadus, Cyprinus und andern untersuchten Knochenfischen überzengen können und theile daher vorläufig die ron Meekel und Cuvier gegen Jaeobs on vorgebrachten Bedenken.

1) Miiller vernisste sie unter den Plagiostomen bei Seymnus, Lamna, My. linbates, Trygon; unter den Knoehenfisehen bei den Muränoölen, vielen Silurö̈den, einigen Clupeen, bei Cobitis, Mormyrus, Polypterus.

2) Diese Form ist bei den Knochenfisehen die häufigste.

3) Nach M ïller bei Gasterosteus, Coryphaena, Lichia, Gerres, Chromis, Cychla, Ophicephalus, Anabas, Cyprinus, Cyprinodon, Esox, Belone, Exocoetus, Hemiramphus, Echeneis, bei allen Gadoïlen (ich finde sie so auch mol zwar sehr gross bei den verwaniten Lepidoleprus), bei vielen Salmonilen, bei Tetrodon.

4) Bei Esox unter einer Hautfalte versteekt, nach aussen von der oberen Insertion der Kiemenbogen.

5) Bei Cyprinus. Man fundet sie hier, nach Weguahne des eontractileu Gaumenorganes, zwischen dem hinteren Ende des queren Gaumenmuskels und den oberen Schlundknochen, welche sie zum Theil bedecken. 
Meistens licgen die Läppehen neben cinander in Einer Keilhe; in ande ren Fïllen liegen sie haufenweise und gekrümmt auf cinander.

Bei den ineisten Kunoehenfisehen liegen die Nebenkiemen am Gaumentheile der Kiemenhöhle, hinter dem queren Gaumenmuskel, vor oder auswärts von dem oberen Ende der Kiemeı. Abweichende Lágenverhältnisse kommen bei vielen Knorpelfischen vor. Bei den Stören und bei den meisten Plagiostomen liegt sie an der vorderen Wand des Spritzloches. Die Sehleimhaut der Spritzlochhöhle lildet hier eine Reihe senkrechter kammartiger Falten $\%$. Bei den Carcharias liegt sie in einem blinden Gange versteckt in Munde, vor und auf dem Kiefersuspensorium.

Ihr Verhältniss zur Choloidealdrise ist folgendes: 1) Viele Fische, denen die Pseudohranchie fehlt, besitzen auch letatere nicht 7 . 2) Dic Choroïdealdrüse könmnt selten spurweise ohne Vorhandensein ciner Pscudobranehic vor s). 3) Bei den Knochenfischen ist kein Beispiel von Mangel der Chorö̈dealdrüse bei Anwesenheit einer Pseudobranehie bekannt. 4) Nur bei Stören und Plagiostomen ist letztere ohne gleiehzeitige Anwesenheit einer eigentliehen Choroüdealdriise vorhanden.

Pseudoloranchien und Chorö̈dealdruise sind nur cigenthümliche Wundernetzhildungen 9). Die Arterien der Pseudobranchisn entspringen bei verschiedenen Fischen aus versehierlenen Stämmen: Jald aus dem Circulus cephalicus ${ }^{10}$ ), bald ans der A. lyoüdeo-opercularis 11 ), bald ans Kienenvenen ${ }^{12}$ ); sic anastomosiren auch mit andern Mrterien. Dic Arterie der Pseudobranchic zerfïllt nun in Zweige und jedes Blättchen des Organes erhält ein feines zuführendes Gefässehen, das durch einen Bogen in ein abführendes Gefäss ïbergeht. Diese Vasa revehentiu vereinigen sich zu einem Stanm, der zur Arteria ophthalmica magur 13) wird. Diese letatere bildet sodann den arteriellen Theil eines Wundernetzes, das unter dem Namen der Choroïdealdrise bekannt ist. Die Arteria ophthalmicn magur löset sich nämlich bïschelförnig auf und aus diesem Gefässconvolute entspringen arteriöse Gefässstämme für die Chorioüdea des Auges. Venen führen dies Blut in die Choroïdealdrüse

6) Bei den Embryonen von Mustelus, Aeanthias, Spinax gehen von ihnen die von Ratlıke und Le uckart beobachteten äusseren Kiemenfiden der Spritz. löcher ab. Vgl. Leuckart, Untersuchungen über die äusseren Kiemen der Em. bryonen vou Kochen und Haien, Stuttg. 1836. 8. S. 17 11. 34.

7) Beile fehlen den Welsen, z. B. Silurus, Pimelodus, Synodontis, den Aaleu, flen Cobitis. - 8) Z. B. bei Erythrinus, Osteoglossum, Notopterus.

9) Der membranöse Theil der Pseudobranchie erhält aber aus den Kopfgefässen noch seine eigeuen mutritiven Gefisschen. - 10) Z. B. bei Esox.

11) Z. B. bei Lucioperca, Perea, Gadus, Lota u. A. - 12) Bei den Haien.

13) Die Arteriae ophlhalmicae magnme beiler Seiten stehen, nitch 11 ïl. ler, dureh eine über dem Os sphenö̈denm basilare verlanfende Anastomose in Verbindung. Sie empfangen auch bisweilen, z. B. bei Lucioperca, Gadus Verbilldungszweige von Gefïssen, die aus dew Circulus cephalicus entspringen. 
zuriick und zerfallon hier elsenfalls wundernetzartig in Röhren, aus welchen das Blut in dir Veno ophthrolmica magna sich sammelt, welche dasselbe dann in die grossen Körpervenen iiberfiuhrt 1f). - Dic Störe und Plagiostomen bilden ron dieser $\Lambda$ nordnungsweise in so ferne eine Ausnahme, als boi ihnen aus den Crefissen der Pscudobranchie die fuir das Auge und das Gehirn bestimute A. carotis anterior hervorgeht. -

Andere Wundernetzbildungen sind die der Lehervenen und der Arteria coeliaca bei Lamna cornubica, die der Magen- und Darmgefïsse bei Squalus vulpes, die der Pfortader und der Arterin coeliaca der. 'Thunfische ${ }^{15}$ ).

[Die rollstïndigste Zusammenstellung der lierher gehörigen, meist von Mïl. ler zuerst beobachteten und successive bekaunt geulachten Thatsachen findet sieh in seiner vergl. Auatomie des Gefässsystemes der Myxinoüden. - Ueber die Choroïleaidrïse vergl. auch Erdl, disquisitiones de glandula ehoroüleali, Monach. 1839. 4.1

\section{Vom Lyinph-Gefuisssysteme.}

\section{\$. 45.}

Mit Ausnahme des durch helles farbloses Blut ausgezeichncten Branchiostomil sind bei allen bisher untersuehten Fischen Lymphgefisse aufgefunden worden 1), und es scheint sogar, als ob das Lymph-Gefässsystem in dieser Thierclasse vorzïglich ausgebildet sei. Sehr starke Saugadernetze und Säcke finden sich an den Verdauungsorganen, besonders dem Magen, so wie auch an der Milz; kaun minder reichlich kommen sie an den Geschlechtstlıeilen, in der Augenhöhle, an der Basis der Brustflossen und an den Muskeln des Stammes der Wirbelsäulc vor. Bisweilen umgeben Lymphgefässe die.grösseren oder kleineren Blutgefiissstiimme scheidenartig ${ }^{2}$ ); ja sellst das Ilerz kann von solchen Lymphsïcken umgeben sein 3). - Freie Mündungen der Saugadern kom-

14) Diese Angaben stützen sich auf MïHler's Beobachtungen an Gadus, Cy. prinus, Silıno, Esox, Lophius, Scomber, Lucioperca, Perca. Wemn die Pseudo. branchic und die Choroidealdriise fehlen, wie bein Wels, so sind die in das Innere des Auges tretenden Gefässe klein ınd entspringen aus den Kopfaweigen des Circulus cephalicus.

15) S. hierïber die Abhandlung ron Müller und Eschricht, nit vortreff. lichelı Abbildungen. - Vergl. ïber Wuuderuetzbildungeı der Schwimublase das betrefrende Capitel.

1) S. ̈̈ber die Lymphgefisse der Myxinö̈len Müller, vergl. Anat. d. Ge. fässsyst. d. Myxin. S. 18. - 2) Sowol von Fohmann, als ron mir mehr. fach besbachtet, namentlich bein Stör und bei den Rochen.

3) Wie es scheint bei Petromyzon. Noch deutlicher bein Stör. Hier sind die IIerzkamuer und der Bulbus arterinsus ron einer auf deu ersten Aubliek Urïsig erscleinenden, schwammigen Substanz unkleidet. Zalılreiche Blutgefisse, welehe mit den Gefissen, die man irriger Weise fïr tendinöse roun Herzbeutel zun IJerzen sich erstreckende Fäden hielt, iu Verbiudıng stehen, verbreiten sich daran auf sebr cigenthiimliche Weise. Bei Untersuchung des Contentum dieser 
men bei den Fischen eben so wenig vor, als bej den höheren Wirbel. thieren 4); sie beginnen, so weit man dies hat verfolgen können, als geschlossenc Bläschen oder zellenartige Erweiterungen, dic von einer innern glatten Mcmbran ausgekleidet werden. Die Lymphgefässstämmc bilden gleichfalls nicht selten sinusartige Erweiterungen, in welchen häufig zellige oder klappenartige Vorsprünge rorkommıen. Wirkliche Klappen aber finden sieh, wie es scheint, nur an den Stcllen, wo grössere Saugaderstïmme in das Venensystem einmünden. - Was die Lagc dieser grösseren Stämme anbetrifft, so erstreeken sich sehr allgemcin zwei paarige starke Lymphgefüsse oder ein unpaares, vorn in zwci Schenkel ausgehendes, durch die ganze Länge der Bauchhöhle unrnittelbar unter der Wirbelsäule, über oder nelsen den Blutgefässstämmen gelegen 5 ). Diesc Stämme münden in Venen ein, welche den Schlüsselbeinvenen oder Jugularvenen der höheren Wirbelthiere entsprechen. Anderc Stämme verlaufen unterhalb der Seitenlinie in der Rinne zwischen den Seitenmuskeln des Rumpfes, sind jederseits einfach bis dreifach vorhanden, vereinigen sieh aber im letzteren Fallc zu einem Stamme, nehmen eine Menge von Nebenästen aus der Bauch - und Rük. kenseite der Körperperipheric auf und communiciren an zwei Stellen mit dem Venensysteme. Die e ine Verbindung ist die mit der Caudalvene, und geschieht dadurch, dass jeder Saugaderstamm in einen lymphatischen Caudalsinus uibergeht. Die beiden Caudalsinus verbin densich dureh einen Quercanal, der die Basis des mittleren knöchernen Strahles des letzten Schwanzwirlels durchbohrt und treten convergirend in den Canalis vertebralis inferior, wo sic in den Anfang der Vena caudalis inforior zusammenfliessen. Die zweite Verbindung geschieht durch einen vielleicht contractilen, zu beiden Seiten der Schedelhöhle gelegenen Kopfsinus, der in die Jugularvene oder in den Ifohlvenensinus mündet. Eine Klappe hindert den Riiektritt der Lymphe in die Saugaderstämme 6). Vielleicht finden sieh ausser diesen Uebergangspunkten der Lymphgefässe in das Venensystem noch zahlreiehere, und es scheint, als ob namentlich auch kleine Lymphgefässe in kleinere Venen ubergehen $\left.{ }^{7}\right)$.

scheinbaren Drüsen erkannte ich sie als Lymphsäcke, indem ich, ausser spärlich vorhandenen Blutkörperchen, unendlich viele, kleine runde Lymphkörnchen, etwa fünf - bis sechsmal kleiner, als die Blutkörperchen des Störs, von der Grösse der menschlichen Blutkörperchen darin antraf. Einige hatten eine granulirte Oberfläche, andere waren von einer blassen kreisrunden Schale ungeben.

4) Monro's Annahme solcher freien Mündungen beruhete offenbar auf Injection der feineren und dünnhäutigeren Scbleimkanäle der Rochen.

5) S. die Abbildung bei Fohmann Tab. 4. vom Aal. Ich habe bei vielen Knochenfischen zwei solcher Bauchstämme angetroffen.

6) S. hierüber die interessante Abhandlung von Hyrtl in Miiller's Archir 1843, S. 224 ff. mit Abbild.

7) Namentlich nach den Untersuchungen ron Fohmann. Eill zwischen deth Magenhäuten des Störs gelegener Sinus lymphaticus communicirt an dieser 


\section{Siebenter Abschnitt. Vom Respirations-Apparate. 111}

Lyınphefässkn:iuel (lymphatische Drüsen) sind bei den Fischen mit Sicherheit noch nicht nachgewiesen worden. Doch kommen in der Bauchhöhle vieler Fische in mehr oder minder beträchtlicher Zahl, gewöhnlich in der Nähe der Milz und des Pförtners gelegen, weissliche Körper vor, welche ein" milchweisses Contentum besitzen, in welchem die mikroskopische Untersuchung feine Körnchen nachweisct ${ }^{8}$ ).

[Nan rgl, über das Lymphsystem der Fische, das von Alex. Monro und IV. Hewson entdeckt ist, besonders: Monro, Vergleichung d. Baues d. Fische, Leipz. 1787, 4. und Fohmann, das Saugadersystem der Wirbelthiere, 1. Heft, Heidelb. 182i, mit Abbild.]

\section{Siebenter Abschnitt.}

\section{Vom Respirations-Apparate.}

§. 46.

Die eigentlichen Respirationsorgane der Fische bestehen aus gefässreichen häutigen Theilen (Kiemenblattlchen), welche gewöhnlich mittelbar an Kismenbogen bcfestigt sind. Ein verschiedenartig ein gerichteter Apparat beweglichor Theile hat den Zweck, dem Wasser Zutritt und Abfluss zu und von der Höhle oder den Höhlen, in wclchen die Respirationsorgane eingeschlossen sind, zu verschaffen. Sie communiciren stets mil dem Anfange der Verdauungshöhle und besitzen wenigstens cinen äusseren Ausgang; in der Regel sind deren jedoch zwei, oft auch mehre vorhanden.

Bei Branchiostoma gelangt das Wasser durch den Mund sogleich in cinen von der Bauchhöhle umschlossenen, nach hinten in die Speiseröhre übergehenden Kiemenschlauch, dessen mit Flimmer-Epithelium ausgeklcidete Seitenwände durch Knorpelstäbchen gebildet werden. Je zwei der letzteren begrcnzen cine durch Querleistcn unterbrochene contractile Spalte, durch welche das Wasser aus dem Kicmenschlauche

Stelle mit zạhlreichen Venenzweigen. - Irrthümlich scheinen Fobmann's Ansichten über die zufilırenden und rïekfihrenden lymplıatisclıen Gefässe der Kiemen zu sein. Vgl. darüber Nüll er's Bemerk. in seiner angef. Sehrift S. 29.

8) Es sind dies diejenigen Körperehen, welche ieh früher (s. meine Symbolae ad antat. piscinm, Rost. 1839) beselrieben und als Residuen des Dottersackes hetrachtet hatte und welehe ron $M$ iiller als Panereas angesehen waren. Sic kommen bei den uneisten Knochenfischen, z. B. bei Cottıs, Trigla, Scomber, Gadus, Belone, Cobitis, Cyelopterus u. A. an der oben angegebenen Stelle vor. 0 b. sehon ich niclit im Stande war, eine directe Verbindung derselben mit Lymph. gefässen nachzuweisen, sah ich doch öfter starke Lyuplıräume in ihrer unmittel. baren Nähe und spreche die Verınuthung aus, dass sie Mescnteriald rïsen sein mögen. 
in die Bauehhöhle tritt. Diese letztere verliisst es dureh einen ziemlieh weit-vor dem After gelegenen einfiehen Porus Uranchialis abdominalis, der zugleich als Ausmündungsstelle des Gesehlechts-Apparates dient.

Bei den Myxinoüden führen jederseits seehs bis siehen Duclus Uranchiales externi, die bald cine gemeinsame, bald getrennte äusser'e Oeffnungen besitzen, in sechs bis sieben Kiemenbeutel und jeder dieser letzteren communicirt dureh einen am Ausgange contractilen Gang mit der Speiseröhre. Jeder Kiemenbeutel ist inwendig von Sehleimhaut ausgekleidet und erhält dureh eine seröse Membran nicht blos einen unmittelbaren äusseren Ueberzug, sondern aucl eine beutelartige lose Unbiullung, in welche die Kiemenarterie cintritt. Ein schr complicirter M. constrictor Uranchiarum entleert das in die Kiemenbeutel aufgenommene Wasser in die Speiseröhre. Aus dieser tritt es dureh einen unpaaren linken Ductns oesophageo-cutaneus, der in das Stigma exterroum oder in das lezte dieser Stigmata mündet, nach aussen.

Bei den Pricken sind jederseits sicben, in eigenen serösen Beuteln liegende Kiemensäcke vorhanden, denen eben so viele Sligmata externa entsprechen. Jeder dieser Säcke communicirt durch einen kurzen Gang mit einem unpaaren, unter der Speiseröhre liegenden, hinten blind endenden, vorn in die Yrundhöhle führenden Canale, an dessen Ostium eine häutige Doppelklappe befindlich ist. Jeder scröse Beutel kann dureh eine eigene Muskelsehieht verengt werden und die Kiemensäcke werden von aussen dureh einen starken Muskelapparat zusammengedrückt, der an dem knorpeligen äussern Kiemenkorbe befestigt ist.

Bei den Plagiostomen findet sich eine Reihe getrennter Kicmensäcke. Jeder mündet sowol nach innen, als auch nach aussen dureh eine eigenc Spalte. Die äusseren Oeffnungen liegen frei und unbedeckt, bei den Haien seitlieh,' bei den Rochen an der Bauchfläche unter den Brustflossen; sie erseheinen daher bei jenen vertieal, bei den Rochen transversel gestellt. Ihre Zahl beläuft sich - mit Ausnahme der Gattungen Hexanchus und Heptanchus, wo sie auf seehs und sieben stcigt - jederseits auf fiinf. - Die Kiemensäeke selbst entstehen dadurch, dass von der Mittellinie jedes Kiemenbogens, zwischen dessen vorderer und hinterer Kiemenblattreihe ein doppeltes häutiges Diaphragina sich erhelt, dessen eine Lamelle die Ifälfte eines vorderen, und dessen zweite Lamelle die Ilälftc eines hinteren Kiemensaekes auskleidet. An der vorderen Wand des ersten Sackes haftet cine halbe Kieme 1) und der letzte Sack besitzt überhaupt nur eine halbe Kieme. - Bei den meisten Plagiostomen - jedoch init Ausnahme der Carchariac und Triaenodontes geschieht der Austritt des den Kiemensïeken zugefülrten Wassers zum Theil durch Spritzlöcher. Dies sind Gïnge, welehe, vor dem Kiefer-

1) Diese halbe Kieme ist an Zungenbeine befestigt. 
suspensorium liegend, aus der Mundhöhle an die Oberfläche des Kopfes führen. Ihre äussere Oeffnung pflegt durch eine Klappe verschliessbar zu sein.

Bei den Stören und Knochenfischen tritt das Wasser durch den Mund in die Zwisehenräune der mit Schleimhaut überzogenen Kiemenbogen. Diese sind durch cinen bewegliehen Kiemendeckel, der bei den Sturionen noch eine accessorische Kieme trïgt, geschützt. Der Ausgang aus der Kiemenhöhle bildet in der Regel eine schräg von oben und hinten nach unten und vorn sich erstreckende Spalte 2 ), ausser welcher bei den Stören und bei Polypterus noch ein Spritzloch vorhanden ist. Selten ist diese Spalte selır verengt, wie z. B. bei den Lophien. Noch seltener sind die Kiemenspalten beider Seiten einander unten sehr genähert oder zu einer einzigen verschmolzen. - An der hinteren Wand der Kiemenhölle finden sich gewöhnlieh zahlreiche Schleim absondernde Drüsen (Folliculi tranchiales) ${ }^{3}$ ). - Alle Kiemenbogen sind von einer Fortsetzung der Schleimhaut der Rachenhöhle bekleidet. Der der Raehenhöhle zugekehrte concave Rand derselben ist mit mannichfach gestalteten, zum Theil derben Fortsätzen: Stacheln, Tuberkeln, Platten u. s. w. besetzt, die das Eindringen von Speisen und fremden Körpern in die Zwischenräune der Kienenbogen hindern ${ }^{4}$ ). In einer Rinne des convexen Randes der Kiemenbogen verlaufen die Gefäss - und Nervenstämme der Kicmen. Zwischen je zwei Kiemenbogen findet sich ein mehr oder weniger weite und lange Spalte. Bei vielen Knochenfischen werden diese Spalten dadurch verkleinert, dass die einzelnen Bogen in einer mehr oder minder beträclttlichen Streeke durch Fortsätze der inneren Hautbedeckungen sieh verbinden $\left.{ }^{5}\right)$. Gewöhnlich nehmen dic Spalten von vorn nach hinten an Ausdehnung allmälich ab. Häufig fehlt die letzte, zwischen dem vierten Kiemenbogen und dem unteren Schlundknochen liegende Kiernenspalte, indem die Hautbedeckung ununterbrochen von jenem auf diesen Knochen sich fortsetzt ${ }^{6}$ ).

2) Dic Grösse der äusseren Oeffnung zeigt bedeutende Verschiedenheiten; ain beträchtlichsten ist sie bei den Clupeen, selır klein bei den Aalen und besonders hei den Lophien. Bei der letztgenannten Familie ist aber die Kiemenliöhle selbst von ansserordentlicher Weite. Die beiden äısseren 0effnungen nähern sich schon bei Sphragebranchus und verschmelzen bei Symbranchus.

3) S. darüber meine Symbol. arl anat. pisc., Rost. 1S39, und Müler, Gefässsyst. 1. Myxinö̈len, S. $4 \mathrm{~S}$.

4) Diese mannichfachen Billungen werlen von der systematischen Zoologie als Unterscheidungscharaktere manuichfach benutzt.

5) Dies Verhalten kömmt z. B. vor hei den Cyprinen, wehr noch bei den Plectngnathen uml den Lophobranchii. Bei Muraenophis werden aus den Spalten kleine I ïcher.

6) Dieser Mangel ler letzten KRiemenspalte hangt mit der Anwesenlıcit von einer cinzigen Kicuenblattreilıe auf leun letzten Kiemenbogen eng znsimmen. Rathke führt init Lnrecht die Gidlus als solche Fische auf, denen die letate 
[Man vgl. über den Kiemenbogen - und den Opercular-Apparat \$. 17. u. 18., wo auch die wiclitigstcu Schriften über die Respirationsorgane der Fische angeführt sind. Hinzuzufigcu sind noch: Lcrcboullet, Anatomie comparée de l'appareil respiratoirc dans les animaux vertébrćs, Strasb. 1838, 4. und $\mathrm{H}$ rtl in den Medic. Jahrbücliern des Oesterr. Staatcs, Bd. 2's, 1838, S. 232.]

\$. 47.

Das respiratorische Gefissnetz findet sich in den Kiemenblättchen, welche aber ausser den respiratorischen Gefässen eigene ernährende, den Branehialgefässen vergleichbare Gefässe erhalten. Die Kiemenblattehen sind bei den höheren Knorpelfisehen und bei den Knochenfischen in zwei parallelen Reifen auf jeden Kiernenbogen so gestellt, dass sie die Rinne seines convrxen Randes in einen Canal verwandeln. Kleine Muskelbiindel, welehe zwisehen den beiden Reihen der Kiemenblättehen an deren Basis liegen, ziehen sie aneinander 1). Bei dén meisten Knochenfisehen trägt also jeder ver vier Kiemenbogen zwei Reihen von Kiemenblättchen, so dass sie also gewöhnlielı vier ganze Kiemen besitzon. Von dieser Regel kommen manniehfache Ausnahmen vor, deren die häufigste die ist; dass der letzte Kieinenbogen nur eine Blätterreihe trägt 2 ). Die Kiemenblätter nehmen inmer nur den mittleren Theil der convexen Seite der Kiemenbogen ein. Dic Kiemenblätchen schbst sind gewöhnlich länglich, platt, lanzettförmig oder sichelförmig; sie besitzen meist äusserst zahlreiche feine Querfalten, dureh welehe eine sehr beträchtliche Flächenvergrösserung derselben bewerkstelligt wird ${ }^{3}$ ). Bei der Familie der Lophobranchii zeigen die Kiemenblätter in so ferne einen eigenthümliehen Bau, als auf del verduinnten kurzen Basis derselben ein erweitertes Ende sitzt, woraus ihre keulenförmige Gestalt resultirt.

Jedes häutige Kiemenbliittehen besitzt eine solide Grundlage in einem bald knorpeligen, bald knöehernen 1) Strahl, dessen Basis

Kicmenspalte inangcln soll. Sie ist bci allen Gadoïlcn: Gadus, Raniceps, Phycis u. s. w., vorhanden, wenn auch ihre Ausilchnung unbeträchtlich ist.

1) Von Alcssandrini und von Duvernoy beschricben. S. dic Annal. d. scienc. natur., 1839, und Cuvier, Lcçons d'anat. comp., ed. Durernoy.

2) Mehre Familien der Knochenfische haben nur drci ganze und eine halbe Kieme; dies ist der Fall bei den Labroïlen (nnit Ausschluss der Chronniden), bei vielen Cataphrarten, naucntlich den Gattungen Cottus, Scorpaena, Sebastes, Syn-, anccia, Agonus, Apistes; bci meliren Cycloporlen, namentlich bei Cyclopterus Liparis, Lcparlogaster, Gobiesox; ferner bci Zcus, bei Chironectes, bei Polypterus. - Nur Irei Kiemen besitzen: Lophius, Batrachus, Diollon, Tctrodon, Monoptcrus, Cotylis, Sicyases und unter den Kunrpelfischen auch Lepidlosiren; zwei und cine halbe Kiemen besitzt Malthaea; zwei Auphipnous Cuchia. Vgl. Müller in Ericlis on's Archir S. 302.

3) Hyrtl zählte bei Saluı Hucho an den längsten Kicnenblättchen 800 bis 1000 solcher Falten; bei Accipenser Huso 1400 bis 1600. - 4) Knorpelig z. B. bei Perca, Cottus, Trigla, Cyclopterus; ossificirt bei Salmo, Alosa u. A. 


\section{Siebenter Abschnitt. Vom Respirations-Apparate. 115}

dem Rande des Kicmenbogens, seitlich von- der Furche aufsitzt. Dieser Strahl liegt immer an innern Rande des Blättchens; er nimmt bald die ganze Länge des letzleren ein, bald ist er kürzer als dieses ${ }^{5}$. - In der Regel sind die beiden Blaitterreihen desselben Kiemenbogens von gleicher Länge; bisweilen ist jedoch die vordere Blätterreihe kiirzer, als die hintere 6 \%. Die einzelnen Blättchen derselben Reihe sind gewöhnlich von einander getrennt, seltener parweise oder durchgängig durch Querlamellen mit einander verbunden $\%$. - Die beiden Blätterreihen eines Kiemenbogens können völlig von einander gesondert 8), oder in kürzerer oder längerer Strecke, mehr oder minder innig durch ein häutiges Diaphragma verbunden scin $\%$. Nicht selten alterniren aber auch die Blättehen der beiden Reihen ${ }^{10}$ ).

Bemerkenswerth sind die äusseren Kiemen bei den Embryonen der Plagiostomen; es sind dies freie fadenförmige Verlängerungen, welche meist von beiden Reihen der Kiemenblätter ausgehen. Sie sehwinden frühzeitig $\left.{ }^{11}\right)$. Auch aus den Spritzlöchern gehen häufig solche Kiemenfäden hervor.

\section{§. 48.}

Von besonderem Interesse sind noch die accessorischen Athemorgane mehrer Fisehe. Dahin gehören die mit Schleimhaut ausgekleideten siebbeinförmigen Labyrinthe der obersten Glieder der Kiemenbogen (Ossa pharyngea superiora) bei einer Familie von Knochenfischen (Pharyngii labyrintliformes Cuv.) und die baumförmigen Organe an denselben Theilen bei Ileterobranchus. Die zuführenden Gefüsse dieser Organe sind nach Taylor Fortsetzungen der Kiemenarterien; die aus dem intermediaren Capillargefässnetze hervorgehenden Gefässe treten in die Kiemenvenen über. - Von gleicher Bedeutung sind, bei analogem Verhalten der Gefässe, die Kiemenhöhlenlungen bei Saccobranchus singio und bei Amphipnous Cuchia. Endlich kommen wirkliche Bauchhöhlenlungen vor, welehe mit einer Glottis in die untere Wand des Schlundes münden, bei Lepidosiren.

[Man vgl. über den interessantesten Punkt, nämlich über das Verhalten der Gefässe in diesen Theilen den Aufsatz von Taylor im Edinb. Journal of scienc, 1831. - Ueber die siebbeinföruigen Labyrinthe s. Curier, Hist. nat. d. poiss., Vol. VII. p. 323. und die Abbildungen Tab. 20ว. u. 206. - Ueber Heterobranchus s. Ge offroy im Bulletin philomatique, anı. X. n. 62. \%. 105.; Heusinger im Berichte von der zoot. Anstalt zu Würzburg S. 42.; Valenciennes, Hist. nat.

5) Z. B. bei Cottus, Cyclopterus. - 6) Nanentlich am ersten Kiemenbogen bei den Cyprinen, bei Salmo u. A. - 7) Bei Xiphias. - 8) Z. B. hei Cottus, Trigla, Esox, Cyclopterus. - 9) Theilweise bei Cyprinus, Silurus, Salmo, Accipenser. - 10) Z. B. bei Cyclopterus, Tetrolon u. A.

11) Vgl. darüber besonders: F. S. Leuckart, Untersuchungen über die äusseren Kiemen der Embryonen voll Rochen und Haien, Stuttg. 1836, 8. (mit Abbildungen). 
d. poiss., Vol. XV. p. 353 sqq. - Bei Saccobranchus geht von der Kiemenhöhle ein in den Seitenunuskeln über den Rippen liegender langer Luftsack aus. Siehe darüber, ausser Taylor, Valenciennes 1. c. p. 402. - Amphipnous Cuchia hat nur am zweiten Kiemenbogen wenige langfädige Ǩiemenblättchen. Der dritte. Kiemenbogen trägt, statt der Kiemenblättchen, eine dicke, halbdurclıscheinende, häutige Kieme mit gefranztem Rande. In die Kiemenhöhle mündet aber eine jederseits hiriter deın Kopfe liegende sehr gefässreiche Blase. In diese vertheilen sich Kiemenarterien; die Venen vereinigen sich zur Bildung der Aorta. S. darüber Taylor a. a. 0. - Ueber Lepidosiren vgl. die Abhandlungen von 0 wen und Bischoff.]

\section{Achter Abschnitt. \\ Von den Harnorganen.}

$\S .49$.

Dic Nieren licgen bei Branchiostoma in der Nähc des Porus abdominalis in Gestalt mehrer, von cinander getrcnnter, drüsiger Körperchen 1). - Bei den Myxinoïden 2) bilden sie isolirte, zarte, gefässreiche Läppchen. Mit jedem derselben hangt ein klcines Säckchen zusammen, das durch eine Verergerung in ein zweites, in den langen. Harnleiter mündendes Säckchen übergeht. - Bci den Petromyzonten erstreckt sich die durch das Bauchfell bedeckte Gesammtmassc der Nicren von der Mitte der Bauchhöhle bis zu deren Ende. Die blind geschlossenen Harnkanälchen verlaufen theils quer und wenig geschlängelt, theils sehr gewunden. Einc Harnblase fehlt; die Ureteren öffnen sich in eine vor dem After gelegene Papille, in welche auch die Bauchöffnungen übergehen. - Bei den Plagiostomen erstrecken sich die Nieren gewöhnlich nicht längs der ganzen Bauchhöhle, hintcr welcher sie, vom Bauchfell bedeckt, liegen, sondern sind kurz, dick, lappig und an der Oberflaiche gleichsam himartig gewunden. Der am inneren Rande jeder Niere verlaufende Harnleiter nimmt die zu grösscren Stämmen zusammengetretenen Harnleiter allmälich auf. Dic beiden Harnleitcr münden, nachdem sie am Ende sich blasenartig erwcitert und bei den Männchen die Saamenleiter aufgenommen haben, bald vereinigt, bald getrennt in dic Rückenfläche des Afterdarmes $\left.{ }^{3}\right)$. An der Mündungsstelle findet sich gewöhnlich eine kleine Papille, dic mit einer Klappe versehen ist. - Bci den Stören crstrceken sich dic sclır langen

1) Nach Retzius und Müller.

2) Nach Müller, Gefässsytem der Myxinoïden, S. 13.

3) Eine wirkliclıe Harnblase, wie sie Mayer, Toussaint u. A. besclurei. ben, habe ich bei mehren ron mir untersuchten Rochen veruisst. 
Nieren von der Kiemenhöhle bis zum Ende der Bauchhöhle, äusserlich vom Bauchfelle und über diesem noch von einer tendinösen Membran bekleidet, welche zahlreiche derbere Querbänder bildet. Der Harnlciter läuft als weiter contractiler Canal am äusseren Rande jeder Niere abwärts. Etwa im zweiten Dritttheile der Bauchhöhle mündet der kurze, weite Saamen- oder Eileiter in den Harnleiter seiner Seitc und die gemeinschaftlichen Harn- und Eileiter bcider Seiten fliessen zuletzt in cinen kurzen unpaaren Gang zusammen, der hinter dem After sich öffnet. - Bei den Knochenfischen nehmen die Nieren, dicht an die untére oder vordere Fläche der Wirbelsäule geschmiegt, zunächst von einer eigenthümtichen fibrösen IIaut und darauf vom Bauchfelle iiberzogen, ausserhalb oder oberhalb welchem sic also liegen, gewöhnlich die ganze Länge der Bauchliöhle ein ${ }^{4}$ ). Sie beginnen vorn an der hinteren Grenze des Schedels, oberhalb und hinter der Kiemenhöhle, als zwei durch den Schlundkopf getrennte dicke, lappige, gefässreiche, weiche Massen und erstrecken sich, flacher werdend, in der Mittellinie dicht an einander liegend und oft verschmelzend, hinterwärts. Sie erreichen gewöhnlich das hinterste Ende der Rumpfhöhle und treten, sehr verschmälert, bisweilen noch eine kurze Strecke weit in den Canal der unteren Wirbelbogenschenkel. Ihre röthlich-braune, in der Regel weiche, schwammige Masse ist vorn, in der Nähe des Kopfes meist derber als in dem weiter hinterwärts gelegenen Abschnitte. Sie bestehen aus kleinen, gefässreichen, platten Lappen. Die in die Nieren tretenden Arterien bilden zum Theil die, unter dem Namen der Malpighi'schen Körperchen bekannten Gefässknäuel, welche bei den Fischen klein und minder häufig und dicht, als bei den höheren Wirbelthieren zu sein pflegen ${ }^{5}$ ). - Die Ductus uriniferi sind lange, blind geendete Canäle von überall gleichem Durchmesser, welche bald gewunden, bald gestreckt, bei einigen unmittelbar, bei anderen nachdem sie zu grösseren Aesten sich vereinigt, in die Ilarnleiter übergehen. Selten theilen sich die Harncanälchen gabelförmig innerhalb der Nierensubstanz. Der Stamm eines jeden Ureter beginnt als solcher entweder schon im vordersten Theile seiner Niere, oder dic durch Sammlung der Harncanälchen gebildeten einzelnen Rami ureterici vereinigen sich erst weiter hinterwärts zu einem gemeinsamen Stamme. Meistens verbinden sich die beiden Harnleiter zu einem gemeinsamen Canale, welcher, allmälich sich erweiternd, in die Harnblase übergeht. Seltener treten sie gesondert in die Blase und noclı seltener senken sich in dic letztere, neben den Stämmen der Harnleitern mehre einzelne Rami ureterici ein, wic dies bei Gasterostcus der

4) Eine Ausnahme bildet z. B. Thynnus, wo die Nieren nicht bis zur Mitte der Bauchhöhle reichen.

5) Vgl. darüber Hyrtl in den Medic. Jahrb, des Oesterr. Staates, Bd, 23\%., 1838, S. 83. 
Fall ist. Gewöhnlieh gesehieht die Einsenkung in den Körper der Harnblase zwisehen den Seitenhörnern derselben, seltener in den Blasenhals. Eine Harnblăse seheint den Knochenfisehen nur selten zu fehlen ${ }^{6}$ ). Sie ist gewöhnlich sehr dinnwandig, selten dieksvandig ${ }^{7}$ ). Ihre Form ist sehr vielen Abweiehungen unterworfen; bald ist sie rund, bald oval, bald schlauchförmig, häulig zweihörnig oder gabelförmig gespalten. Ebenso verschieden ist ihr Unfang; besonders gross scheint sie bei denjenigen Fischen zu sein, denen die Schwirmblase fehlt 8). Sie liegt jmmer über dem Afterdarm. Sie öfnet sich hinter dem After dureh eine kirze Verengerung, welehe man als Urethra betrachten kann. Selten fällt ihre Miindung mit derjenigen der Geschlechtstheile zusammen, was namentlich bei den Männehen der Fall ist, während bei den Weibehen die Eileiter gewöhnlieh abgesondert zwischen After und Urethra ausmüinden.

[Man vgl. über die Harnorgane der Fisclic Stecnstra-Toussaint, ComJnentatio de systemate uropoctico pisciun, Iugd. Bat. 1835, 4. und Gottsche in Froriep's Notizen No. 838. - Ueber den feineren Bau der Nieren s. Mïller, de glandularuı secernentiuın struetura penitiori, Tab. XIII.]

\section{Von den Nebennieren.}

\section{§. 50.}

Sie sind sowol bei den höheren Knorpelfisehen als bei den Gräthenfischen beobaehtet worden. An der Rückenseite der Nieren bilden sie bei den Haien einen schmalen Streifen von okergelber Farbe 1); bei den Roehen findet sieh bald ein ähnlicher langer Körper hinter jeder Niere an den IIarnleitern, oder es sind vier bis fiinf kleinere Körperchen 2) dieser Art, von gleicher Farbe, ziemlich weieher Consistenz, und aus mikroskopiseh wahrnehmbarèn runden Körnchen bestehend, vorhanden. Aehnliehe, aus Körnehen bestehende, gelblich-weisse, die nämliehen Körnehen enthaltenden Körperchen finden sich in grosserZahl an den Nieren des Störs ${ }^{3}$ ). - Bei den Knochenfisehen haben die Nebennieren eine abweichende Form. Sie stellen rundliche oder runde, weissliehe oder weisslich-graue Körperehen dar, welche bald doppelt. bald dreifaeh vorhanden 'sind, von einer eigenen Membran umsehlossen werden und einen feinkörnigen Inhalt besitzen. Sie liegen entweder

6) Eine wirkliche Blase fehlt bei Cobitis fossilis, wo dic beiden Harnleiteraun äussersten Ende der Bauchlı̈ble zu eineın sehr kurzen unpaaren Gang zusammentreten. Ausserten soll sic angeblich fehlen bei Sillago acuta, Platycephalus insidiator, Pogonias fasciatus, Clupea Pilehardus u. $A$.

7) Z. B. bei Sebastus norwegicus. - 8) Sehr gross ist sic z. B. bei Cyclopterus, Pleuronectes, I.oplius, Orthagoriseus.

1) So wenigstens bei Acanthias. - 2) So bei Raja Batis.

3) Sic sind hier weit zahlreicher und stehen nux selten mit einader is Verbiadung. 
am hintersten Ende der Nierenniasse an der vorderen Grenze des Gefässcanales der unteren Wirbelschenkel d) oder weiter vorwärts, etwa in der Mitte der Nieren, bald frui, bald in deren Substanz eingesenkt 5 ).

[Vergl. über diese Gebilde Retzius, Observat. in anat. ehondropterygiorum, Land 1819, 4. (Plagiostomen) und Stannils in Miller's Archiv 1839, S. 97.]

\section{Neunter Abschnitt. \\ Von den besonderen Absonderungsorgrenen.}

Die Schwimmblase.

$\S .5 \% 1$.

Mit dieser Benennung belegt man ein von mehren übereinanderliegenden Häuten urnschlossenes, meist unpaares, doch in der Regel symmetrisches, selten völlig paariges 1), immer hohles, pneumatisches Organ vicler Fische, das zum grössten Theil oder ganz in ihrer Bauchhöhle gelegen ist. Dasselbe kömmt nicht allen Fischen zu; unter den Knorpelfischen wird es nur bei den Fanilien der $A$ ccipenseres und Spatulariac angetroffen; einzelnen Familien der Knoclienfische fehit es gänzlich 2); in anderen Familien fehlt es einzclnen Grattungen, während es bei anderen vorkömmt 3 ), ja es kann unter mehren Arten derselben Gattung einigen rigen sein, anderen mangeln 4 ).

Die Höhle der Schwimmblase wird zunächst unschlossen von einer mit Pflaster-Epithelium ausgekleideten Schleimhaut, auf welche sodann nach aussen eine bald dünnere, bald dickere, weisse, glänzende, oft deutlich aus zwei Schichten bestehende fitöose Haut folgt, die ihrerseits wieder zum theil vom Bauchfelle überzogen zu werden pllegt. Selten finden sich an ilırer Innenwand zellige Vorspriinge $\left.{ }^{5}\right)$. Sie bildet meist

4) Dic häufigste Bildung; bei Perca, Lueioperca, Cottus, Trigla, Cyprinus, Gadus, Pleuroneetes und vielen anderen Fisehen von mir beobachtet.

§) Bei Anguilla, Esox, Belone, Salıno.

1) Bei Polypterus Bichir sind zwei lange cylindrisehe Sehwimmblasensäcke vorhanden, welche zu einer kurzen unpaaren Höhle zusammentreten, die dureh eine Glottis ventralis in den Schlund miindet.

2) Unter deu Weiehflossern der Familic der Pleuronectes, den Loriearien.

3) Fehlend z. H. bei Lophius, Pereis, Percophis, Eleginus, Auxis, Tracliyptesus, Gymnetrus u. vielen $A$.

4) Beispiele bieten dar die Gattungen Polynemus, Scomber u. A.

5) Bei Auia naelı $\mathrm{Cuvier}$; in der vorderen Hälfte der linteren Altheilung der Sehvimunblase von Erythrinus taeniatus und salvus naeh Miiller und $\mathrm{Ja}$ cobi. Bei Platystoma faseiatmm fand Müller einen eigentlümlichen zelligen Saum an den Seiten und am linteren Unfange der Selıvimmblase. Bei Bagrus filamentosus sind zwei linter einander liegende, inwendig aus kleinen luftbaltigen 
einc einfache Ilöhle, welche biswcilen durch unvollkommcne Scheidewände in mchre mit cinander communicirende grösserc Kammern zer. fällt 6 ). Häulig bestcht sie auch aus zwei hinter einander liegenden Abtheilungen 7 ), welche nur selten ausser Cominunication stehen ${ }^{8}$ ). Mituntcr kommen durch eine Längseinsehnïrung zwci seitliche Abtheilungen zu Stande 9), oder es findet eine Längs - und cine Querabtheilung zugleich Statt $10 \%$. Ziemlich oft bildet sie Ausstulpungen, ist an beiden Enden zweihörnig ${ }^{11}$ ), oder hat blos am vorderen Ende zwei Ausstiilpungen 12), oder am hinteren ${ }^{13}$ ), oder besitzt seitliche Ausstülpungen 14), meist in grössercr $\Lambda$ nzahll; welche bisweilen wieder fingerförmig gcthcilt sind ${ }^{15}$ ); es kommen selbst baumförmige Verzweigungen einzclner Ausstiilpungen vor $\left.{ }^{16}\right)$. - In der Regel hat sie eine längliche Form und ist nur selten mehr in der Breitendimension entwiekelt. Sie wird gewöhnlich unmittelbar, seltencr mittelbar von der Bauehhöhle unschlossen und liegt in der Regel vor der Vorderfläche der Nieren uiber dem Tractus intestinalis und den drüsigen Anhängen desselben, zwischen den keimbereitenden Geschlechtsthcilen, beginnt häufig in der Nähe des Schlundes, setzt sich bisweilen durch $\Lambda$ nhängc in die Sche-

Zellen bestehende Schwimmblasen vorhanden. Auch Lepidosteus sollte nach $\mathbf{C u}$ vier, Agassiz und van der Hoeven eine zellige Schwinmblase besitzen, während Valentin (Repertorium f. Anat. u. Physiol., Jahrg. 1840) bei Lepidosteus spatula, statt der angeblichen Zellen, quergestreifte muskulöse Trabeculae carneae gefunden hat, durch welche die Luft der Schwimmblase offenbar rasch entleert werden kanı.

6) Bęi Bagrus, Arius und mehren Arten vor Platystomil.

7) Z. B. bei den Cyprinö̈len und Characinen. Bei beiden Familien ist, nach Müller's Untersucliungen, die vordere Abtheilung durch den Bau ihrer Häute in hohem Grade elastisch, die hintere nicht. Beide sind mit Muskeln verselien.

8) Z. B. bei Gymmotıs aequilabiatıs nach $\mathbf{H u m b}$ oldt, Bagrus filanentosus nach Miiller.

9) Z. B. Tetrodon oblongus, Diodon rirularis, Prionotus punctatıs, einigen Arten von Dactylopterus u. s. w.

10) Z. B. Cobitis fossilis, Pinelodus biscutatus, P. occidentalis, Auchenipterus furcatus.

11) \%. B. Dules maculatus, Pimelepterus altipenuis, Lactarius delicatulus.

12) Z. B. Sphyraena vulgaris, Trigla cuculıs, einige Arten Otolithus, Conodon antillanus, einige Micropogon 11. A. Das vordere Ende ist dreihörnig bei Holocentrum longipinue, Pristipoma robrum, P. fasciatum, Butirinus.

13) Z. B. bei mehren Sillago, Heliases insolatus, Letlırinus atlanticıs, Cantharis vulgaris, Miena, Sunaris u. A.

14) Z. B. bei Unbrina vulgaris jederseits drei; bei Cheilodactylus carponemus ans jedem Ende zwei und von jeder Seite vier. Biei vielen Gallus - Arten.

15) So bei Sciaena aquila und hololepidota; bei vielen Arten ron Corrina. Abbildungen von Schwimmblasen der Sciänö̈den bei $\mathrm{Cuvier}$ und Valenciennes, Hist. nat. d. poiss., Tab. 138. 139.

16) So bei Corvina lobata, wo ans zwei vorderen abgeschnürten Abtheilun. gen zwei baumformig verzweigte Stiele hervorgehen. 
delbasis fort $\left.{ }^{17}\right)$, liegt in anderen Fällen weiter linten und erreicht bald das äusserste Ende der Bauchlöhle 18), bald erstreckt sie sich nicht so weit hinterwïrts. Selten wird sie vollständig von Knochen eingeschlos. sen 19), häufiger treten einzelne ihrer Fortsetzungen in Höhlungen, welche bald von Schedelknochen 20 ), bald von Wirbelfortsïtzen 21) gebildet werden, oder ihr linteres Ende wird von einer Ilöhlung der knöchernen Flossentrïiger aufgenommen 22 ). - Bei einigen Fisehen kommen in ihrer äusseren Haut, oder zwischen dieser und der inneren, Muskelfasern vor, bei anderen erstrecken sich von der Wirbelsäule ausgehende Muskeln ${ }^{23}$ ) an dieselbe, bisweilen bewirkt ein aus Knochen und Muskeln bestehender Apparat willkuihrliche Verdünnung und Verdichtung der in der Schwimmblase enthaltenen Luft 2i). Sie steht entweder durch einen $\boldsymbol{D} u$ ctus pneumaticus mit dem Tractus intestinalis, und zwar meist mit der Speiseröhre, in Höhlenverbindung, wie bei den Sturionen und den Malacopterygii abdominales, oder sie ist gesehlossen, wie bei allen Acanthopterygiern, bei den Malacopterygii subbrachii, bei den Plectognathen, den Lophobranchii und bei den Pharyngognathi (Miill.) der Fall ist 25). Der $\boldsymbol{D}_{u-}$ ctus pneumaticns besitzt die nämlichen Häute, wic der Körper der Schwimmblase, nur sind sie meist dünner. An seinem Ostium oesophageum erweitert er sich bisweilen und besitzt mitunter einen eigenen Splitrecter; er ist bald kurz und weit, bald lang, eng, selbst gewunden und senkt sieh meist in die Dorsalwand des Tractus intestinalis; sehr selten tritt er seitwärts in den Desophagrus ${ }^{20}$ ) oder hat sogar ein Orificium oesophageum ventrale ${ }^{27}$ ). - Bei vielen Knochenfischen berührt die Wandung der Schwimmblase eine Ausstülpung des membranö-

17) Z. B. bei vielen Clupeen: Clupea, Engraulis, Notopterus.

18) Z. B. bei Clupea.

19) Z. B. bei Cobitis (s. die Abbild. bei $W$ eber, de aure et auditu, Tab. VI.), ferner bei Clarias, Heterobranchus, Heteropneustes und Ageneiosus nach Müller.

20) Bei den Clupeen. - 21) Z. B. bei Gadus navavaga naeh Baer.

22) Z. B. bei Pagellus calamins. - 23) Z. B. bei Gadus.

24) Bei den Gattungen Auchenipterus, Synodontis, Doras, Malupterurus und Euanemus findet sich, naach Müller, an ersten Wirbel jederseits ein anfangs dünner, schualer Fortsatz, der zuletzt in eine grosse runde Platte sich ausilehnt, welche die Schivinmblase eindrüekt. Die Platte kann dureh einen vom Schedel entspringenden Muskel gehoben werden, wobei denn die Luft aus dem Ductus oesophageus der Schwimublase austritt. Eine ähnliche Einriehtung besteht beí manchen Artelt der Gattung Ophidium.

25) Für den Systematiker wichtige Bemerkungen über diesen Gegenstand finden sich mitgetheilt von Müller in Wieg mann's Archiv, 1843, S. 343. Der Luftgang der Selıwimmblase ist vorhanden bei den Fanilien der Cyp̧rinö̈den, Siluroïden, Sauroïden, Esoees, Salmones, den Characinen, Clupeen, Mormyri, den Stırionen. Unter Cnvier's Malacopterygii apodes kommen Gattungen mit und andere ohne Luftgang der Schwimublase vor. Erstere simd von Müller vereinigt worden zur Familie der Anguillares; letztere bilden seine Ophidini.

26) Bei Erythrius. - 2i) Bei Polypterus Bichir. 
sen Labyrinthes des Gehörorganes oder steht mit demselben in einer durch einc Reihe von Knöchelchen verınittelten Verbindung ${ }^{28}$ ). - Die Arterien der Schwimmblase entspringen aus dem Aortensysteme und nehmen bald aus der letzten Kiemenvene, bald aus dem Stamme der Aorta, bald ans der Arteria coeliaca ihren Ursprung; ihre Venen münden bald in die Pfortader, bald in die Cardinalvenen, oder auch in dic Lebervenen. Die Art der Verthcilung dieser Gefässe ${ }^{29}$ ) bietet bei vielen Fischen in so ferne eine Eigenthümlichkeit dar, als sic Wundernetze bilden, in welche sowol Arterien, als Venen sich auflöscn. Das Verhalten dieser Wundernctze kann schr verschieden sein. Bei vielen Fischen lösen sich die Gcfässstämme strahlenförmig, schweifförmig, wedelförınig, quastförmig in viele feine Röhren auf, welche sich zuletzt in baumförmig sich vertheilende kleine Zweige fortsetzen. Wenn dieses Zerfallen der cinzelnen Arterienstämmehen über den ganzen Zwischenraum der fibrösen Ilaut und der Schleinhaut sich fortsetzt, so kömmt es zu keiner localen Anhäufung der feinen Gefässröhren. Diese diffusen Wundernetze können aber auch blos an bestimmten Stellen der Schwimmblasc vorkommen und bilden dann die sogenannten rothen Körper. In diesem Falle verzweigen sich die Capillargefässe entweder sogleich, nachdem sie die Masse eines Wundernetzes verlassen haben, in dessen nïchster Ungebung, oder sic sammeln sich in viele kleine Zweige, wclche sich baunförnig in einem eigenen Saume oder Hofe der einzelnen Wundernetzmassen verzweigen, während die iibrige Fläche der Schwimmblase ihr Blut nicht aus den Wundernetzen, sondern aus einfach verzweigten Gefässen erhält. Endlich kommen locale amphicentrische Wundernetzc vor. Die Arterienstämme zerfallen in uncndlich zahlreiche Röhrchen, welche wieder zu grossen Arterienstämmen zusammentreten, die dann baunförmig an der innern Haut der ganzen Schwimmblase sich vertheilen. Aus den so vertheilten Reisern gehen Venen hervor, welche, zu grossen Venenstämmen verbunden, zu den Wundernetzen zurückkehren, hier wicder in unendlich viele Röhrchen zerfallen, um eincn neuen Venenstanm zu bilden, der das Blut dem Pfortadersysteme oder Körpcrvenensysteme zuführt. - Bei denjenigen Fischen, deren cinzclne Schwimmblasenarterien in eben so viele einzclne von cinander getrennte Wundcrnetze zerfallen, sind dicse lctztcren hïufig von blassen oder gclblichen, mässig dicken, von der ungebenden Schleinhaut scharf ahgegrenzten Säumen ungeben, in welche: dic haumartige Verzweigung der aus dein Wundernetze kommenden arteriellen Reiser Stalt hat. Dicse Säune sind zellig und drüsig und scheiden wahrschcinlich vorzugsweise dic in der Schwimmblase ent-

28) Vgl. \$. 32. Bei den Cyprinoiden, Siluroïlen und Characinen.

29) S. besonders Müller's vergleichende Anatomic des Gefisssystemes der Myxinoïden. 
haltene Luft aus. Bei anderen Fischen kommen zerstreute Gribchen auf der ganzen Innenfläclıe der Schwimmblase vor, waihrend dieselben bei wieder anderen nicht nachweishar sind. Hier geschieht also die Luftabscheidung von deın grössern Theile der Innenfläche der Schwimmblase. - Die Nerven der Schwimmblase stammen aus den Intestinalästen des Neruws vagus, welche vor ihreu Herantreten schon sympathische Fäden aufgenommen haben und an welche häufig noch einzelne Zweige vom Sympathicus sich anlegen.

[Die Schriften ïber die Schwimmblase der Fische sind ausserorlentlich zahlreich. Zul vergleichen siud besonders: G. Fischer, Versuch über die Schwinnnblase der Fische, Leipzig 1795, 8. - de la Roelue in den Annales du Musée d'hist. nat., XIV. 1809. - Rathke in den Neuesten Schriften d. naturf. Gesellschaft in Danzig, Halle 1825, Bd. 1. Heft 4. - v. Baer, Untersuchmgen über die Entwickelungsgeschichte d. Fisclıe, Leipz. 1835, 4. - Rathke in Müller's Archiv, 1838, S. 413. - Ja cobi, Diss. de vesica aërea piscium, Berol. 1840, 4. - Müller, Vergl. Anatomie des Gefässsystemes d. Myxinoïlen, Berlin 1841, 4. und in Archiv f. Anat. u. Physiol., 1841 11. 1842. Ein sehr vollständiges Material zur Geschichte der Schwinumblase hei den einzelnen Arten und Gattungen enthält Cuvier und Valenciennes, Mist. nat. dl. poissons. - Gegen die lange herrschent gewesene Ansicht, als ob die Schwimmblase den Lungen der höheren Wirbelthiere vergleichbar wäre, haben anı schärfsten, mit vollen Rechte, v. Baer und Mïller sich ausgesprochen. Physiologischer Charakter der Lungen ist es, dass ihnen venöses Blut zugefïhrt wird, welches in arterielles ungewandelt, in den Körper zurückkehrt. Allen Schwimmblasen fehlt dieser Charakter anscheinend durchaus. Dagegen liegt es nicht fern, die Schwimmblasen deun Bronchialgerïste der höheren Wirbelthiere zu vergleichen. Namentlich ist ihre Aehnliclkeit mit den oft sehr beträchtlichen zellenlosen hinteren Abschnitten der $0_{p}$ hidierlungen, welche kein respiratorisches Gefässnetz mehr besitzen, unverkennbar.]

\section{Zehnter Abschnitt.}

\section{Vom Geschlechts-Apprerete.}

\section{§. 52.}

Die keimbereitenden weiblichen Geschlechtstheile der Fische liegen gewöhnlich innerhalb der Bauchhöhle; selten grösstentheils oder ganz ausserhalb derselben, wie bei den Schollen $\left.{ }^{1}\right)$. Sie sind in der Regel an gekrösartigen Bauchfellfalten befestigt. Ein Flimmer-Epithelium scheint, namentlich in den Eileiteru, immer vorhanden zu sein. Die Ovarien sind meist paarig vorhanden; indess kommen in den meisten Ordnungen einzelne Gittungen und Arten vor, welche durch unpare

1) Die Eiersäcke liegen hier gewöhnlich ganz ausserhalb der Bauchlıöhle auf den Trägern der Afterflosse. 
Anordnung dieser Gebilde sieh auszeiehnen 2). Rüeksiehtlieh des Baues der Eierstöcke und ihres Verhaltens zu den Eileitern sind vier verschiedene Typen zu unterscheiden:

1. Das auswendig gewöhnlieh vom Bauehfelle bekleidete, aus ciner Muskelhaut und einer von dieser umschlussenen Schleimhaut bestehende Ovarium bildet cine gesehlossene Iöble, welehe ununterbroehen in einen sehr kurzen Eileiter übergeht. In diesem Falle, der sich bei den ineisten Knoehenfisehen realisirt findet, zeigen sich im Innern der Eierstoekshöhle bald blattartig vorspringende Längs - 3) oder Querfalten von versehiedener IIöhe und Dicke, bald kolbrnförmige, kegelförmige oder warzenförmige Erhabenheiten, an denen die Ausbildung der unbefruchteten Eier vor sieh geht und die zum Theil dureh die reifenden Eier hervorgezogen werden. Sind die Eierstöcke paarig, so geht bald jeder in einen eigenen, kurzen Eileiter über und die beiden Eileiter vercinigen 4) sieh später zu einem einzigen Eiergang oder dieser letztere entsteht sogleich dadureh, dass die hinteren, von Vorsprüngen freien Enden der beiden Eierstoekshöhlen zu einer einzigen unpaaren, weiteren ${ }^{5}$ ) oder engeren Höhlung zusammenfliessen. Ein unpaarer Eierstock verlängert sich dagegen, bei Vorhandensein des hier abgehandelten Bildungstypus, in einen einzigen röhrenförmigen Eierleiter. - Die Ausmündungsstelle der Oviducte ist eine hinter dem After, vor der Oeffnung der Urethra liegende Grube oder Papille \%). Fast alle Fisehe, denen diese Anordnung der weiblichen Geschleehtstheile zukömmt, sind eierlegend, wenige lebendig gebärend 7 ). In diesem letzteren Falle übernimmt der hinterste Absehnitt des Eierstockes, weleher dann auch eine eiweissartige Flüssigkeit absondert, die Function eines Uterus.

2. Das Ovarium besteht in einer einerseits glatten, andererseits mil blattartıgen Vorsprüngen versehenen, an einer Bauchfellfalte befestigten Platte, neben weleher kein Eileiter vorhanden ist 8). Die an

2) Unpaar sind die innern weiblichen Geschlechtstheile z. B. unter den Cyclostomen bei Petromyzon, unter den Plagiostomen bei mehren Haien, namentlich den Gattungen: Seyllium, Mustelus, Galeus, Carcharias, Sphyrna; unter den einheimisehen Knocheufischen bei Perca fluviatilis, Blennius viviparus, Ammody. tes tobianus, wo der reehts gelegene Eierstoek dureh eine Scheidewand in zwei Seitenhälften zerfallen ist und bei Cobitis taenia und barbatula.

3) Z. B. bei Gadus, Pleuronectes, Belone u. A. Bisweilen sind Längs • und Querfalten zugleich vorhanden, wie bei Cyprinus; die einzelnen Falten verbinden sich häufig unter einander. Bei Anwesenheit warzenartiger Vorsprünge befindet sich am Ende eines jeden derselben nur ein $\mathrm{Ei}$, das also in einem, durch einen Stiel gehaltenen Kielche liegt, wie bei den Vögelı. So verhält es sieh z. B. bei Acerina, Blennius u. A.

4) Z. B. bei Clupea. - 5) Sehr weit bei Pleuroneetes, Cyelopterus, Cot-' tus, Gadus u. A. - 6) Z. B. bei Gasterosteus.

7) Z. B. bei Blennius viviparus, Anableps, mehren Silurus u. A.

8) Diese von Rathke entdeckte Anorinung findet sich bei meluren Aalen und 
den blattartigen Vorsprüngen gebildeten Eier fallen in die Bauchhöhle und werden dann dureh einen einfachen, zwisehen dem After und der Mündung der Harnwerkzeuge gelegenen Porus abdominalis ausgeführt.

3. Ausser dem plattenförmigen Ovarium ist ein von diesem völlig getrennter aber sehr kurzer Eileiter vorhanden. Die Eier fallen zuerst in die Bauchliölle und gelangen dann erst in den Eileiter. Hierher gehört Petromyzon 9), wegen des Besitzes einer den Eileiter repräsentirendell kurzen häutigen Röhre, welehe in das Ende des Darmcanales hincinragt. Ferner auch Aceipenser 10). Die Eier treten hier, nachdem sie frei in die Bauchhöhle gefallen, in einen kurzen, weiten, vom Bauchfelle gebildeten, inwendig mit Flimmer-Epithelium ausgekleideten Trichter, und aus diesem in den Harnleiter. An der Einmündungsstelle des Triehters in den Harnleiter findet siel. eine verschliessbare Klappe.

4. An die Stelle des kurzen Eileiters tritt bei den Chimären und Plagiostomen eine wirkliehe Tuba, entweder paarig, wie die Eierstöcke, oder unpaar, wenn das Ovarium es ist. Sind die weibliehen Geschlechtstheile paarig, so liegen die inneren Mündungen der beiden Tuben dicht neben einander, fast zu einer einzigen versehmolzen. Die Eier erhalten in dem Eileiter entweder blos eine feste Sehaalenhaut oder es geschieht innerhalb desselben zugleieh die Entwickelung der Jungen. Jede Tuba zerfällt in mehre Abtheilungen. Die erste, engere ist dureh den Besitz von Längsfalten ihrer Sehleimhaut ausgezeichnet. An ihrem Ende befinden sieh zwei Hervorragungen, bedingt dureh die Anwesenheit zweier, aus zahlreiehen blind geendeten Röhren bestehenden $\mathrm{E} i$ leiterdrüsen ${ }^{11}$ ), welehe in die Höhle des Eileiters münden. Dieser geht hierauf entweder sogleieh, oder mittelst eines zwisehenliegenden

allen Laehsen. - Bei Osınerus entstelıt durclı ein von jedem Eierstneke ausgehendes Band eine Höhle, deren Aussenseite von der Seitenwand desBauches, de. ren Innenwand von jenem Bande gebildet wird.

9) Bei Petromyzon hangt der unpaare Eierstoek nieht mehr an einem gekrösartigen Mesoarium, sondern ist mit den Bauchwandungen nur durch Zell. gewebe verbunden.

10) Zur Seite der Ovarien ist bein Stör die Banchhaut mit Flimmer-Epithelium ausgekleilet. Dies setzt sieh fort in die trichterförmigen Eileiter; die Bewegungen der Cilien erfolgen so, dass Substanzen, z. B. aufgestreutes Kohlen. pulver, aus der Bauchhöhle dem Harnleiter zugefillirt werden. Im Harnleiter selbst und nach dem Uebergange der Eileiter in seine Hölle hört alle Flimmerbewegung auf. - Analog scheint, nach Müller's Beobachtungen, Polypterus Bichir sich zu verhalten. Die Eierstöeke sind ohne Ausfïhrungsgänge; dagegen sind zwei ausführende Eileiter von einigen Zoll Länge vorhanden, die mit dem Ende des Ureters sich vereinigen.

11) Nach Mïller besitzen die Haien mit Nickhaut eine eigene Form der Eileiterilü̈sen. Diese bilden zwei sclmeckenartig gekrümmte lohle Schläuche, walche sich gegenüber liegen. Die Wände sind drüsig. Als drüsige Elcuente erscheinen immer Rölurchen. 
engeren Absehnittes ïber in cine beträchtliehe Erweiterung, den Uterus, dessen lnnenwand dureh eigenthünliche Längsfalten, die mit blatt. artigen Vorsprïngen versehen sind, ausgezeiehnet ist. Die bciden Uteri münden bei den Plagiostomen mittelst einer Art Scheide in die Rückenfläche des Afterdarınes. - In welchen Brziehungen ein paariges, aus kleinen Zellen bestehendes drüsiges Organ ohne Ausführungsgang, das in Falten des Bauehfelles 'gelegen ist, zu den Geschlechtstheilen steht, ist noch unbekannt.

[ Ueber den Geschlechts - Apparat der Knochenfische ist besonders zu vergl. eine sehr ausfïhrliche Abhandlung von H. Rathke in dessen Beiträgen zur Geschichte der Thierwelt, Th. 3. S. 117 ff.; ferner ein Aufsatz von ihm in Meckel's deutschem Archiv, Th. 6. S. 589. - Ueber Accipenser vgl. Brandt und Ratze. burg, Medic. Zoologie Th. 2. Tah. IV. - Ueber die Plagiostomen Treviranus in Tiedemann und Treviranus, Zeitschr. f. Physiol. Th. 3.; von besonderem Interesse ist - vorzïglich in Betreff der hier nicht zu erläuternden Placenta. Bildung - ein Aufsatz von Müller, über den glatten Hai des Aristoteles, in den Schriften der Berliner Academie der Wissenschaften, 1842.]

\section{§. 53.}

Sind gleich die IIo den der meisten Fische paarig, so fehlt es doch nicht an Bcispielen von unpaarer Anordnung derselben 1). Auch sind sie in ersteren Falle nicht immer ganz symmetrisch, inden nicht selten der eine den andern an Grösse übertrifft. Rücksichtlich ihres inneren Baues und ihrer Verhältnisse zum Saamenleiter zeigen sie folgende wesentliche Verschiedenhciten:

1. Die Iloden mehrcr Knorpel - und Knochenfisehe sind, ihrem äusseren Verhalten nach, von den Eicrstöeken derselben Thiere nicht zu untcrscheiden 2). Ihre Substanz besteht nur aus schr kleinen, mehr oder minder runden Körnern von gleicher Grösse, welehe meist an dieht neben einander liegenden blattartigen Vorsprüngen der IIodenplatte sich entwickeln. Bei den Cyclostomen und den Aalen, denen ein körniger Hode zukömmt, fehlt ein eigener Saamenleiter und der Saame wird frei in die Bauchhöhle ergossen, aus welcher ein hinter deın After gelegener Porus abulominalis ihn ausfuhrt. Bei Accipenser gelangt dagegen der Saame durch Quergefässe, welche durch das Band des Hodens verlaufen, in den Harnleiter. - Die Hoden erstrccken sich in diesem Falle durch die ganze Lünge der Bauchhöhle oder durch den grössten Theil derselben.

1) Z. B. bei Petromyzon, Perca fluviatilis, Blennius viviparus, Ammodytes tobianus, Cobitis u. A. Der Hode liegt bald links, wie bei Perca, bald rechts, wie bei Ammodytes, bald in der Mittellinie, wie bei Blennins.

2) Diese Bildung ist beobachtet bei Branchiostoma, Myxine, Petromyzon, Accipenser, Muraena. Ralhke vindicirt sie auch den Cottus und Pleuronectes. Nach demselben Beobachter kömunt die körnige Structur zugheich mit der Anwesenheit von Saamencanälchen vor bei Cyclopterus. 
2. Wesentlich verschieden ist der Bau der Hoden bei den meisten Knochenfisehen. Sie sind sackirtig oder stellen eine geschlängelte und geknäuelte ${ }^{3}$ ), bisweilen durch Einschnitle lappige 4) Masse dar, welche mit einem von vorn nach hinten herablaufenden Saanenleiter in Verbindung steht. Sind die Hoden paarig, so treten die beiden Saamenleiter sogleich oder später ${ }^{5}$ ) zu einem längeren oder kürzeren ein. fachen röhren- oder saekförmigen ${ }^{6}$ ) Canale zusammen, dem Saamengange, der zuletzt, init der Urethra verbunden, in eine dicht linter dem After gelegene kleine Warze 7 ) oder Grube ausgeht. In den Saamenleiter münden nun zahlreiehe blindgeendete Saanıencanälchen ${ }^{8}$ ), welche ïberall einen gleichen Durchmesser behaupten, an ihrem Ende oft gabelförmig. gespalten, bisweilen durch zahlreiche netzförmige Anastomosen mit einander verbunden sind 9) und dureh Bindegewebe zusammengehalten, die eigentliche Iodensubstanz ausmachen. Diese wird von einer eigenthümlichen diinnen Membran und sodann vom Bauchfelle umgeben, das, eine Falte bildend, den Hoden zugleich befestigt. Bald erstreeken sich die an der Rückenseite der Bauehböhle gelegenen Hoden durch die ganze Länge derselben, bald sind sie kürzer.

3. Ein anderer Typus wird bei den Plagi ostomen beobachtet $10 \%$. Im vordersten Theile der Bauchhöhle liegt jederseits ein breiter platter Hode. Scine Substanz ist durclı zahlreiche Scheidewände in Fächer oder Capseln getheilt. Jedes dieser Fächer wird durch eine rundliche erbsengrosse Blase ausgefültt, welehe wiederum zahlreiche kleine Bläschen oder Zellen enthält, in denen die Spermatozoen sieh entwickeln. Dieser Hode steht durch Vras efferentia in Verbindung mit dem mehr einw:irts gelegenen langgestreckten, ans vielfach geschlïngelten Canälen bestehenden Nebenhoden, der in einen anfangs gleiehfalls geschlängelten, später geraden Saamenleiter uibergeht. Dieser mündet, an Ende erweitert, in die blasenartige Erweiterung der Ureteren.

Aecessorische drüsige Organe sind bei einigen Knochenfisehen und den Plagiostomen beobachtet 1 ). Bei den Chimären und

3) Z. B. bei Gadus. - 4) Bei Cyclopterus. - 5) Z. B. bei Clupea, Gasterosteus, Cottus, Salmo, Pleuronectes. - 6) Sehr weit bei Cottus, Gadus; sackförmig bei Pleuronectes.

7) Diese einem Penis verglichene Warze oder Papille findet sich z. B. bei Cyclopterus, Cottus, Blennius, Pleuronectes, Silurus, Gasterosteus u. A. Sehr weit linter dem After liegt sie bei Anableps.

8) Vgl. über den feineren Bau des Hodens Rathke in seinen Beiträgen z. Gesch. d. Thierwelt, Heft 3. S. 183.; Treviranus in Tiedemann und Treviranus, Zeitschr. f. Physiol. Th. 2. S. 12.; J. Müller, De gland. secern. str. p. 10ङ., mit Abbild. - 9) Bei Clupea Alosa nach Müller.

10) Vgl. ausser den angefïhrten Schriften von Müller und Treriranus, Stannius in Müller's Archiv 1840, S. 41. und Hallinan n ebendas. S. 467.

11) Rathke beschreibt bei Blennius eine Drüsenschicht, welche sich un das Ende des Saamenganges und der Urethra herumlegt. Derselbe Beobachter 
Plagiostomen, bei welehen eine wirkliehe Begattung Statt findet, sind eigene äussere, zangenförmige, an den Trïgern der Flossenstrahlen der Hinterextremitit befestigte Begattungsorgane oder Haftorgane vorhanden, an deren Basis seitlich zwei drüsige, absondernde, nach aussen mündende Gebilde liegen 12).

Bemerkenswerth ist es, dass bei der Familie der Lophobranehier ${ }^{13}$ ) die Fier am Körper der männlichen Individuen zur Entwickelung kommen. Die Männehen der Gattung Seyphius tragen die Eier hart an der unteren Fläche des Rumpfes, an welcher sie dureh eine feste weissliche Substanz ankleben. Bei anderen Syngnathen und den Hippocampen besitzen die Männehen eine förmliche Bruttasehe hinter dem After, gebildet durch zwei einander entgegen gewachsene Hautfalten der Schwanzgegend.

fand bei Gobius niger sehr zusammengesetzte accessorische innere Geschlechtstheile, 1. c. S. 201. Bei den Plagiostomen findet sich ein paariges drüsiges; aus kleinen Zellen gebildetes Organ ohne Ausführungsgang, analog deınjenigen der Weibchen.

12) An der dem Schwanze zugewendeten Seite jedes Haftorganes befindet sich eine ziemlich weite 0effnung, welche in eine unter der Haut und den Muskeln verborgene, auf den Flossenknorpeln gelegene Höhle führt. Diese ist ziemlich weit und enthält einen rücksichtlich seines feineren Baues noch nicht näher untersuchten drïsigen, absondernden Apparat.

13) Vgl. Eckström, die Fische in den Scheeren ron Mörkö, übers. von Creplin, S. 133.; Retzius in 0ken's Isis, 1835; Rapp in der Isis, 1834; Siebold in Wiegmann's Archiv für Naturgesch., 1842, S. 292 ff. - Die Frage, ob es wirklich die Mämmchen und nicht etwa die Weibchen sind, welche das Brütorgan besitzen, muss meiner Ueberzeugung nach zu Gunsten der ersteren entschieden werlen. Ich kann dasjenige, was Siebold a. a. 0 . rücksichtlich der inneren Geschlechtstheile anführt, so weit Weingeistexemplare eine Entscheidung zulassen, vollkonmen bestätigen. Siebold hat die Güte gehabt, zu diesen Untersuchungen eine grosse Anzahl von Syngnathen mir zu übersendell. - Abbildungen dieser Bruttasche, so wie der Geschlechtstheile der Fische ïberhaupt, finden sich in Carus und 0 tt 0 , Erläuterungstafeln fo vergl. Anatomie, Heft 5 . Taf. VI. 


\section{Zweites Buch.}

\section{l) i e e p t i i e n.}

\section{L i t e r a $t$ u r.}

Duméril und Bibron, Erpétologic générale ou histoire naturelle complète des Reptiles. Paris 1834 sqq. Mit Ablilu. - Noch unvollendet. Mit Beriicksich. tigung der in den Einleitungen crörterten anatomischen VerhäItnisse álsgearbeitete systematische Schrift.

Schlegel, Essai sur la physiognomie des serpens. 2 Vol. Amsterd. 1837. 8. u. fol. - Enthält eine anatomische Cliarakteristik der 0phidier.

Cuvier, Recherches snr les reptiles douteux, in Humboldt und Bonpland, Recueil d'observations de zoologie et d'anatomie comparée, Vol. 1.

Rusconi und Configliachi, Del proteo angnino di Laurenti monografia. Pavia 1818. 4. - Rusconi, Observations anatomiques sur la Sirène, mise en parallèle avec le protée et la tétard d. 1. Salaniandre aquatique. Pavie 1837. 4.

A. F. Funk, De Salamandrae terrestris vita, evolutione, formatione tractatus. Berol. 1827. fol. c. tab.

E. F. C. Siebold, Observationes de salamandris et tritonibus. Berol. 1828. 4. c. $f$.

Ant. D Ingès, Recherches sur l'ostéologie et la myologie des Batraciens à leurs différens âges. Paris 1834. 4. Nit Abbilı. - Sehr reichhaltig.

Bojanus, Anatome testudinis Europaeae. Vilu. 1819-1821. fol. c. tab. - Dic vollständigste ikonographische Dartellıng, welche wir über irgend ein Wirbelthier besitzen. Der Text beschränkt sich leider nur anf Erklärung der trefflichen Abbildungen.

Die Osteologie der Reptilien findet sich (mit Ausschluss derjenigen der Ophidier) am rollständigsten kritisch abgehandelt bei $\mathrm{Cu}$ vier, Recherches sur les osseinens fossiles. Tome 9 et 10 . Mit schönen Abbildungen.

J. G. Schneider, Historia Amphibiormm naturalis et litteraria. Fasc. 1 et 2. Jen. 1799-1801. - J. Müller, Beiträge z. Anat. d. Amphibien, in Tiedemann und Treviranus, Zeitschr. f. Physiologie, Bd. IV. - C. F. A. Mayer, Ana. lecten zur rergleiclienden Anatomie. Bonn 1835-183\%. 4. - Panizza, Sopra il sistema linfatico dei rettili ricerche zootomiclie. Paria 1833. fol. Mit prachtvollen Abbillungerı, welche, auclı abgesehen rom Lymph.Gefässsystem, instructiv sind. 


\section{Frster Abschnitt. \\ Vom Knochenger üste.}

I. Von der Wirbelisiule.

§. 54.

Dic Wirbcl der Reptilien zerfallen inindestens in Rumpfwirbel und Schwanzwirbcl. Die Unterscheidung der ersteren in Halswirbel, Rückenwirbel und Lcndenwirbel beruhet häufig auf der Anwe. senheit oder dem Mangel von Rippen an den Wirbeln verschiedener Rcgionen des Rumpfes; bei einigen Gruppen jedoch, wo sämmtliche oder dic mcisten Rumpfwirbel rippentragend sind, ändert sich die Bezeichnung der Wirbel je nach der verschiedenen Dimension der Rippen in den einzclnen Gegenden der Wirbelsäulc. So bezeichnet man z. B. bei den Crocodilen diejenigen Wirbel als Halswirbel, deren Rippenrudimente nicht verlängert sind und zählt zu den Lendenwirbeln auch diejenigen, welche sehr schwache Andeutungen von Rippen besitzen. Kreuzbeinwirbel heissen endlich diejenigen Wirbel, mit denen die Darmbeine verbunden sind.

Die Rumpfwirbel der Reptilien ermangeln ausgebildeter, einen Canal umschliessender unterer Bogenschenkcl, welche dagegen - mit wenigen Ausnahınen, zu denen namentlich die ungeschwänzten Batrachier gehören - an den Schwanzwirbeln vorkommen. Sic sind aber nie unter dem Körper eines cinzigen Wirbels, sondern zwischen jc zwei Wirbelkörpern befestigl.

Dic'Zahl der Wirbel unterliegt den grössten Verschicdenheiten; am geringsten ist sic bei den ungeschwänzten Batrachiern 1), sehr bedeutend dagegen bei den Proteïdcen, den Salamandrinen und besonders den Cöcilien; schr beträchtlich ist die Wirbelzahl auch bei allen beschuppten Reptilien; unter ihnen wieder am beträchtlichsten bei den schlangenähnlichen Sauriern und bei den Ophidiern.

Bci allen nackten Reptilien besitzt der Atlas zwci Gelenkflächen und crinangelt gewöhnlich 2) aller Querfortsätze, besitzt auch

1) Bei den ungeschwänzten Batrachiern sind ausser dem langen Steissbeine sehr regehnässig neun Wirbel vorhanden, welche Zahl jedoch bei einigen Gattungen durch Verschmelzung von Wirbeln vermindert wird. Bei Ceratophrys dorsata verschmelzen der erste und zweite Halswirbel. Bei Systoma und Pipa sinkt, in Folge von Verschmelzung einerseits des Atlas mit dem nächstfolgenden Halswirbel und andererseits des Kreuzbeines mit dem Steissbeine die Zahl der Wirbel auf sieben. Letztere Verschmelzung kömmt auch bei Xenopus (Dactylethra). vor. - Bei Proteus finden sich etwa 60, bei Siren über 80, bei Ainphiuma mehr als 100 Wirbel; über 200 sind bei Coecilia vorhandell. Noch beträchtlicher ist die Wirbelzahl bei Schlangen; d'Alton zählte bei Python 323 Wirbel.

2) Z. B. bei Pipa vorhanden. 
nie Rippenanhänge. - Die Körper der Uhrigen Wirbel sind bei den Proteiden, dem Axolotl und den Cöcilicn, wie bei den Fischen, an ihrer vorderen und hinteren Fläche conisch vertieft oder ausgehöhlt \$). Die Wirbelkörper der Salamandrinen sind an ihrer Vorderseite convex, an ihrer Hinterseite concav, während bei den ungeschwänzten $\mathrm{Ba}$ trachiern meistens - obschon nicht inmer 4) - die Hinterseite querconvex und die vordere concav zu sein pflegt. An dem querconvexen. Gelenkkopfe finden sich meistens Spuren einer mittleren Furche. Die Dornen der oberen Wirbelbogen sind nie beträchtlich, meist flach, hinterwärts gerichtet. In der Regel besitzt jeder obere Bogen vier Gelenkfortsätze, von denen die beiden hinteren auf den beiden vorderen des nächstfolgenden Wirbels ruhen. - Querfortsätze sind bei den geschwänzten Gattungen ziemlich ausgebildet vorhanden; an ihren Enden befestigen sich häufig Rippen, welche jedoch immer unbedeutend sind, das Brustbein niemals erreichen, dagegen meistens den Ligamenta intermuscularia zu Ansitzpunkten dienen. Die Querfortsätze der ungeschwänzten Batrachier ${ }^{5}$ ) sind in der Regel lang und die meisten tragen keine Rippen. Mehr oder minder beträchtliche Andeutungen der letzteren finden sich nur an den Querfortsätzen des dritten und vierten Wirbels durch Anwesenheit knorpeliger Apophysen, welche bei den Aglossa besonders stark entwickelt sind. Der einzige Kreuzbeinwirbel der ungeschwänzten Batrachier zeichnet durch seine langen und breiten Processus transversi sich aus ${ }^{6}$ ) und besitzt an der Hinterseite seines Körpers gewöhnlich zwei Tubercula, welche in zwei entsprechende Gelenkhöhlen der Vorderseite des sehr verlängerten, dünnen, schwertförmigen Schwanzwirbels eingreifen, der nur bei wenigen Grattungen 7) mit dem vorigen Wirbel verwachsen ist.

3) In diesen oft tiefen Höhlen (Proteus) findet sich, ganz wie bei den Fischen, als Ueberrest der Chorda dorsalis eine gallertartige Masse. Interessant ist es, dass diese konischen Vertiefungen auch den Larren vieler Batrachier zukominen. - Uebrigens bieten, den Beobachtungen von Dugès und Müller zufolge, die Wirbelkörper der Batrachier inerkwürdige Entwickelungs-Verschieden. heiten dar. Bei Einigen entstehen die Wirbelkörper allein durch die oberen Wirbelbogensehenkel; die Scheide der $\boldsymbol{C h}$. dorsalis bleibt unterhalb derselben liegen unil hat gar keinen Antheil an ihrer Bildung. Hierher gehören Cultripes, Pelobates und Pseudis paraloxa. - Bei den meisten ungeschwänzten Batrachiern und bei Salanandra terrestris entstehen dagegen die Wirbelkörper als ossificirte Ringe in der äusseren Scheide der Ch. dorsalis, die in den Zwischenstellen handartig wird. S. die Bennerk. von Müller in seiner rergl. Neurologie d. Myxinö̈den.

4) Bei Pipa finde ich die Convexität an der Vorderfläche der Wirbelkörper.

ऽ) Ausserordentlich verlängert an zweiten und dritten Wirbel von Pipa, am dritten und vierten von Xenopus; bei Pipa an zweiten und dritten Wirbel mit knorpeligen Rippenrudinenten versehen. Ich finde die knorpeligen Rippenrudimente bei den einheimischen Fröschen sehr beständig an dritten und vierten Wirbel; aber nur sehr schwach angeleutet.

6) Enorm ausgebildet bei Pipa u. Xenopus.

7) Pipa, Xenopus, Systoma. 
Bei den Ophidiern ${ }^{8}$ ) geschicht die Verbindnng der Wirbelkörper dadurch, dass ein an der linteren Fläche des Wirbelkörpers befindlicher kugclrunder'Gelcnkkopf in eine entsprechende Gelenkhöhle der Vorderscite des nächstfolgenden Wirbelkörpers eingreift. Dic oberen Bogen zwcier Wirbel verbinden sich durch je vicr Gelenkflächen, welche so angeordnet sind, dass die des vorderen Wirbels diejenigen des nächst hinteren decken. Indem die freien Enden der äusseren Gelenkfortsützc sich kreuzen, entstchen oft falsche Querfortsätze. Wahre Querfortsätze fehlen an den Rumpfwirbcln oder werden nur durch ein Paar an der Basis der oberen Bogenschenkel vorragende Tubera repräsentirt. An diese befestigen sich die Rippen, welche an allen Rumpfwirbeln, mit Ausnalime der vordersten, vorkommen. Die letzte oder die letzten Rippen sind oft gabelförmig gespalten. Jede knöcherne Rippe trïgt an ihrem freien Ende oft eine knorpelige Spitzc. Kreuzbeinwirbel sind, bei dem gewöhnlich vorhandenen Mangcl eines Beckens, nur selten zu unterscheiden. An den Schwan zwirb eIn kommen, Statt der Rippen, zicmlich beträchtliche Querfortsätze vor, welche an den ersten dieser Wirbel oft getheilt oder doppelt sind. - Die oberen Dornen sind bei den grossmäuligen Schlangen höher, als bei den Mlicrostomata, wo sie niedrig: sind oder fehlen. Einfache untere Dornen finden sich an den meisten Rumpfwirbeln; paarige unterc Bogenschenkel, welche aber häufig getrennt bleiben und dann keinen einfachen unteren Dorn bilden, unter allen Schwanzwirbeln. - Abweichend von den übrigen Wirbeln gestaltet sind die beiden ersten Ilalswirbel. Der $\Lambda$ tlas ist gewöhnlicli ringförmig und besteht aus dem Körper und den bald paarigen, bald zu cinem Stiicke verschmolzenen oberen Bogenschenkeln. Der Epistro. pheus besitzt einen Zahnfortsatz.

Die Wirbel der Chelonier 9) haben das Eigenthünliche, dass ihr oberer Bogen fast immer durch Naht mit dem Körper verbunden ist. Der Atlas besteht aus dem Körper und zwei unverschmolzenen oberen Bogenschenkeln. Vor dem Körper des Epistropheus und von ihm noch durch cin Os sesamoüdeum getrennt, licgt, als abgesondertcs Stück, der Processus adontoüđleus. Eigenthiimlich verhiilt sich die Articulation der Halswirbel. Die Körper ciniger derselben sind an der Vorderfläche convex, an der hinteren concav; bei anderen findet die umgckehrte Anordnung Statt; was dadurch inöglich wird, dass den eben geschilderten Wirbelkörpern biconvexc oder biconcave eingeschoben sind. Die Processus spinosi superiores, und inferiores der Halswirbel sind nie schr stark ausgebildet; deutliche Querfortsätze fehlen. Von

8) Vgl. die sehr genaue Abhandlung von d'Alton, De pythonis ac boarum ossibus, Hal. 1S36, 4., mit Abbill.

9) Vergl. über die Verhältnisse der Wirbelsäule bei den Cheloniern Peters, Observationes ad anatomiam Cheloniorum, Berol. 1838, h., mit Abbild. 
dem oberen Bogen eines jeden Wirbcls treten zwei hintere und zweí vordere Gelenkfortsätze ab; dic vorderen werden von den hinteren des näehst vorderen Wirbels bedeckt. An der Bauchseite des Hinterrandes der letzten IIalswirbel finden sich bisweilen klcine accessorische Knöchelchen. Der, erste Riiekenwirbel ist durch seinen oberen Dornfortsatz mit dem Hautskelet verhunden; dic folgenden Rückenwirbel verschinelzen durch ihrc obercn Bogenstücke auf das Innigste mit diesen Knochensehildern des Hautskeletcs. Vom ersten Ruickenwirbel an bis zum Ende des Schwanzes kommen anfangs Rippen, später aber ihnen analoge Querfortsätze vor, welche letzteren immer als abgesonderte, mit den Wirbeln nicht verwachsene Knochenstücke sich erhalten. Dic Rippen der Rückenwirbel sind fast beständig nicht an einem einzelnen Wirbel befcstigt, sondern treten von der Verbindungsstelle je zweier Wirbel ab, ohne dass ihre Articulation mit diesen durch besondere Querfortsätze vermittelt würde. Die dcr Schwanzwirbel treten zwar nur von einem Wirbel ab, tragen jedoch mit ihrer Basis zur Vervollständigung der an der Vorderfläche der Wirbelkörper befindlichen Gelenkgrube bci. - Untere und oberc Dornfortsätze sind an den Schwanzwirbeln nirgend deutlich vorhanden.

Bei den Sauriern besitzt der $\mathrm{Atlas}$ ausser seincm Körper ein Paar getrennter oberer Bogenstiicke. Der Epistropheus hat einen vor seineın Körper licgenden, gesonderten Processus odoutoüdeus. Die Hinterseite jedes Wirbelkörpers ist querconvex, die Vorderseite ist entsprechend ausgehöhlt; cine Regel von welcher nur die mit hohlen Facetten versehenen Schwanzwirbel einiger Gattungen Ausnahmęn bilden ${ }^{10} \%$. Die beiden verschmolzenen oberen Bogensebenkel besitzen immer obere Dorncn, deren Länge freilich bedeutenden Verschiedenheiten unterworfen ist. Die oberen Bogenschenkel besitzen an ihrer Basis zwei vordere und zwei hintere Gelenkfortsätze, von denen die hinteren die vorderen des näehstfolgenden Wirbels decken. Sowol an den Hals-, als an cinem Theile der Rückenwirbel kommen häufig einfache untere Dornen vor, welche gewöhnlich zwischen je zwei Wirbelkörpern gelegen und meist getrennte Knochenstücke sind 11). An den letzten Ifalswirbeln zeigen sich rippenähnliche, doch nicht mit dem Brusthcine articulirende Knochen. All e Rü ckenw ir bel bis zum Becken, allenfalls mit Ausnahme des letzten, tragen Rippen, welche an einem zwischen Wirbel und oberem Bogenschenkel liegenden Tuberculum befcstigt zu sein pllegen. Es sind gewöhnlich zwei Kreuzbeinwirbel vorhanden, an deren starken Querfortsätzen das Darmbein befestigt ist. An den Schwanzwirbeln kommen gewöhnlich Querfortsätze vor, welche

10) Z. B. Anguis, einige Geckones.

11) Z. B. Varanus, Iguana, Chamaeleo, Psamunosaurus, Uromastix u. A. 
bisweilen, wie z. B. bei Uromastix, durch ihre Breite sich auszeichnen. Zwischer je zwei Sehwanzwirbelkörpern sind, bisweilen mittelst kleiner Tuberkeln, die unteren Bogensehenkel befestigt, welche in eine Spitze. auslaufend; die Processnes spinosi inferiures bilden. Gewöhnlich fehlen diese unteren Wirbelbogen zwischen den vordersten Schwanzwirbeln und werden auch an den letzten abortiv.

Die Wirbel der Crocodile bieten manche Eigenthürnliebkeiten dar. Sämmtliche Ilalswirbel besitzen Rippenrudimente, von denen bald weiter die Rede sein soll. Der Atlas besteht aus vier Stiucken: einem Basilarstiłcke zwei oberen Bogensehenkeln und einem abgesonderten bogenförmigen oberen Sehlusstuicke. Der Epistrophe us hat einen mil seinem Basilarstucke durch Naht verbundenen Proc. odontoüdeus; uibrigens stimmt er darin mit. allen anderen Wirbeln überein, dass seine unter einander verwachsenen, in einen oberen Dorn auslaufenden oberen Bogenschenkel durch Naht mit dem Wirbelkörper verbunden sind. Jeder Wirbelkörper besitzt eine vordere vertiefte und eine hintere convexe Fläche. Der obere Bogen jedes Wirbels hat vier Gelenkfortsälze: zwei vordere und zwei hintere; die letzteren decken die vorderen des nächstfolgenden Wirbels. Seitwärts geht von jedem Bogenschenkel der Halswirbel (nnit Ausnahme der beiden vordersten) ein kleiner Processus transversus ab. Viel beträchtlicher sind diese mit gleichem Ausgangspunkte versehenen Querfortsätze an sämmtlichen Riucken - und Lendenwirbeln. Die noch stärkeren Querfortsätze der Kreuzheinwirbel und der vorderen. Schwanzwirbel zciehnen sich dadurch aus, dass sie an der Grenze der Wirbelkörper und der oberen Bogensehenkel liegen und von beiden: dureh Nalit getrennt bleiben. Die Körper der meisten Halswirbel und der vier vordersten Rückenwirbel besitzen einen einfachen mit dem. Körper verschmolzenen unteren Dorn. Die meisten Schwanzwirbel. (mit Ausnahme der vordersten) sind mit unteren Bogenschenkeln versehen, welche imıner zwischen je zwei Wirbelkörpern inserirt sind und am Ende zu einem einfachen unteren Dorn versehmelzen. Dieser kann jedoch auch ein abgesondertes Stuick sein. - Sämmtliche sogenannten Halswirbel und die Rumpfwirbel sind rippentragend. Die Rippen der beiden ersten Halswirbel sind einfache, hinterwärts geriehtete, an dem Körper des Atlas und von der Verbindungsstelle des Proc. odlontoüdezs mit dem Körperstiicke des zweiten Halswirbels befestigte Knochengriffel. Die übrigen Halsrippen sind an ihrer Wurzelhälfte gabelförmig. gespalten und befestigen sich mit dem einen Schenkel an den Processus transversus des oberen Bogenschenkels, mit dem anderen aber an den Wirbelkörper. Dasselbe gilt von den ersten Rippen der Rückenwirbel, welche aber, von der dritlen, an ausschliesslich an Querforlsiilzen, jedoch incist mil zwei Köpfehen sielı befestigen. Auch an den Enden der Processus transversi mehrer sogenannter Lendenwirbel sieht man bei 
jungen Thieren sehr klcine sclbstständige als Rippenrudimcnte zu betrachtende Ossificationen ${ }^{12}$ ).

[Man vgl. über die Wirbelsïule der Reptilien, ausser den Handbüchern von Curier und Meckel, besonders Curier's Recherches sur les ossemens fossile, Tome IX. u. X. unit den dazı gehörigen Abhild. Ueber die Wirbel der Ratrachier, und besonders über ihre Entwickelungsgeschichte, Dug ès, Recherches sur l’o. stéologie et la myologie des Batraciens, Paris 183\%. 4.]

\section{§. 55.}

Die Rippen sind bci allen nackten Reptilicn nur rudimentär 1) und erreichen weder das Brustbein, noch verbinden sich die sich seitlich entyegengesctzten unter einander. Eben so wcnig finden solche Verbindungen Statt bei den starken, gewölbten, am Ende meist knorpeltragenden Rippen der Ophidicr und einiger schlangenähnlichen Saurier. Bei den meisten Sauriern enden cinige der vordersten Rippen frci, während ein Theil der folgenden mit den Knorpeln an das Brustbein sich befestigt. Bei vielen Sauriern ${ }^{2}$ ) kommen eigcnthümliche Verbindungsweisen der Rippen vor. Im zweiten Dritttheile des Rumpfes vereinigen sich nämlich bisweilen je zwei einander entsprcchende Rippen rechter und linker Seite durch cinen convex nach vorn gerichtcten Knorpclbogen, der unter spitzcm Winkel von ihren Knorpclenden abtritt. Bisweilen gehen noch von dcr Mitte dieses Bogens vorwärts gerichtete Spitzen oder Fortsätze ab 3). Dicse als Bauchrippen bezeichneten Bogen entsprechen den $\mathbf{I n b}_{\mathbf{b}}$ scriptiones tendineae der Bauchmuskeln, wclche auch bci anderen Sauriern ihre Stelle vertreten. - Bei Draco ist ein grosser Theil der Rippen sehr verlängert und trägt nicht zur Umschliessung der Rumpfhöhle, sondern zur Unterstiitzung (der Flughaut bei ${ }^{4}$ ). - Viel Eigenthümliches besitzen die Rippen der Crocodile. Schon die mcisten Halsrippen, mit Ausnahme der bciden crsten, sind dadurch ausgezeichnet, dass sic an ihrcm frcicn Ende nicht zugespitzt crscheinen, sondern in einen horizontalcn, nach vorn und hinten sich erstreckenden Fortsatz auslaufen, mittelst desscn sie einander bcrühren und decken ${ }^{5}$ ). Die verlängerte, mit einem einfachen Knorpcl versehcne Rippe des ersten Rückenwirbels erreicht das Sternun nicht. Jeder Knorpcl der folgenden acht Brustbcin-

12) Ich habe sie bei jungen Exemplaren der Champza und Crocodilus an den meisten Ruupfwirbeln angetroffen.

1) Sie finden sich bei den Cöcilien an den meisten Rumpfwirbeln; an vielen Wirbeln von Triton und Salamandra; nur an einigen bei den Proteïden und Derotremata.

2) Bei Clıamaeleo, Polychrus, Gecko fimbriatus nach Meckel; ferner bei Ano. lis, Seps, Acontias. - 3) Gecko fiubriatus nach Meckel.

4) Ablildung bei Tiedemann, Anatomie und Naturgeschichte des Drachens, Jieidelb. $18 ! 0,4$.

5) Eine Einrichtung, wodurch die Seitenbewegung des Halses sebr beschränkt wird. 
Rippen besteht aus zwei Segmenten. An der Verbindungsstelle jeder dieser Rippen mit ihrem Knorpel findet sich, analog dem Processus uncimatus der Vögel, ein dureh Ligament ihr verbundener, hinterwärts gerichteter, platter, ziemlich brciter Fortsatz, der dic nächst folgende Rippe errcicht und deekt. Diese Fortsïtze bleiben lange knorpelig, ossificiren aber später ziemlich vollständig \%) - Die Rippen der beiden letzten Riickenwirbel und die Rippenandeutungen an den sogenannten Lendenwirbeln erreichen das Sternum und dessen hintere gabelige Fortsetzungen nicht. Aber entsprechend diesen sieben Wirbeln finden sich an der Bauchfläche sieben Paar unter einander durch eine fibro-cartilaginöse Membran verbunderer Bauchrippen. Jede der letzteren besteht aus zwei, eine kurze Strecke mit einander parallel liegenden Segmenten. Das hinterste Paar ist am lïngsten und lehnt sich hinten an eine von den Schaambeinen ausgehende fibro - cartilaginöse Membran. Dies System der Bauchrippen, das unter dem Namen des Sternum abulominale bekannt ist, gehört in die Kategorie der Inscriptiones tendineac.

Bei den Chcloniern ") hat man den im Bereiche des Hautschildes liegenden verlïngerten Rippen der eigentlich sogenannten Rückenwirbel eine ausserordentliche Breite zugeschricben und die Entstchung des Hautschildes selbst durch Verwachsung dieser verbreiterten Rippen erklärt. Bei Untersuchung von Schildkröten-Fötus überzcugt man sich jedoeh leicht, dass diese Anschauungsweise auf Confusion zweier ganz verschiedenen Ossifications-Elemente beruhet, nämlich der eigentlichen Rippen und der sie bedeckenden und umwachsenden Ilautknochen. Erstere selbst besitzen die gewöhnliche Breite, die sic auch bei er wachsenen Seeschildkröten an ihren Enden noch in späteren Lebenszeiten darbieten; die Ilautknochen legen sich über dic Rippen, umwachsen sie und vercinigen sich unter einander durch Nähte. Die mit einander der Reihe nach durch Naht verbundenen, die Seitentheile des Rückensehildes bildenden Knochenstueke sind also - mit Ausnahme des ersten und des letzten, welche blos Ilautknochen zu sein pllegen - Producte der Verwachsung von IIautknoehenstucken mit den eigentlichen Rippen. Die Enden der Rippen inseriren sich nicht am Brustbeinc. - Uebrigens werden dic urspriinglichen unter den Hautschildern liegenden Rippen häufig inchr oder minder vollständig resorbirt $\left.{ }^{8}\right)$.

6) Ich fand diese bisher übersehenen und sonst nur den Vögeln eigenthïmliehen Fortsätze zulerst bei Champza lueius, später aher bei allen von uir untersueliten Crocodilen und beim Gavial. Sie sind grossentheils linorpelig; jeder knorpelige Fortsatz enthält aber einen Kuochentern. Der Fortsatz selbst erreicht die nächst hintere Rippe und ist lem ler straussartigen Vögel an ähnlichsten.

7) Vgl. \$. 5\%. unl die eitirte Abhandlung von Peters. Eubryonen von Seeschildkröten sind besonders iiberzengend; ieh untersuchte die ron $\mathrm{Ch}$. mydas und imbrieata und kann die Angaben ron Peters durchaus bestätigen.

8) Z. B. bei Lmys, besonders aber bei Cryptopus und Testudo. 


\section{Vom Schultergerüst und Brustbein.}

§. 56.

Bei allen Reptilien ist das $\mathrm{S} c h u l$ tergeriist, sobald es überhaupt vorhanden, vom Schedel getrennt. Bei den Perennibranchiaten und den Salamandrinen bildet das Schultergerüst jeder Seite ein grossentheils kuorpeliges und nur stellenweise ossificirtes Continuum, das aber in Gestalt verschiedenartig gerichteter und geformter Fortsätze die Elemente dreier verschiedenen Theile darzubieten pllegt. Diese sind 1) das Scapular'stück, das gewöhnlich halb knorpelig, halb verknöchert vom Rücken auswärts und abwärts steigt; 2) ein Clavicularfortsatz 1) und 3) ein hinter ihm liegender Coracoïdalfortsatz. Dieser letzte steigt hinter dem vorigen von aussen nach innen zur Brustseite ab. Der eine Processus coracuäileus pllegt an der Brustfläche den anderen zu berïhren oder zu bedecken 2). Bisweilen kömmt hinter dem Berührungspunkte beider noch eine isolirte unpaare $B r$ ustbeinplatte ${ }^{3}$ ) von faserknorpeliger Textur vor. - An dem Winkel, den der $\boldsymbol{P}$. coracoüdeus mit der Scapula bildet, liegt, meist von Knochensubstanz umgeben, seltener im Knorpel, die Gelenkgrube für den Humerus. - Das Schulter gerüst der ungeschwänzten Batrachier stellt einen hinten offenen, vorn geschlossenen und mit Brustbeinstiicken verbundenen Halbgürtel dar. Jede Seitenłı̈̈lfte besteht in der Regel aus vier Stücken: 1) einer die Querfortsätze der Wirbelsäule und deren Muskeln bedeckenden flachen, gewöhnlich knorpeligen, selten grossentheils ossificirten Platte (Cartilago suprascapularis) 4); 2) einem an deren äusseres Ende sich anschliessenden, gewöhnlich etwas gebogenen Knochen, dessen freies Ende cartilaginös wird und zum Theil den grösseren Abschnitt der Gelenkgrube für den Humerus bildet (Scapula); 3) vervollständigt wird diese Grelenkgrube durch einen von ihr aus bald schräg, bald quer zur Mittellinie der Brust gerichteten Knoehen (Os coracö̈lleum); 4) der letzte meist schmale Knochen erstreckt sich, olıne zur Bildung der Gelenkgrube beizutragen, von dem freien Ende der Scapula zur Mittellinie der Brust. Er entspricht der Claviculı und liegt vor dem Os coracü̈lenum, Ineistens ihm parallel, indem beide Knochen nur selten divergiren 5) und einen Winkel bilden. Der Zwisehenraum welcher beide trennt, wird gewölnnlich durch meinbranöse. Theile ausgefiillt ${ }^{6}$ ). Meist stossen die Ossa curacoülea und die Claviculae beider Seiten in der Mittellinie der Brust unmittellsar oder inittelst eines zwischenliegenden Knorpelstreifens zusammen; seltener schiebt sich der Innenrand eines Os coracoülderm über den anderen \%. Auf diese Weise ent-

1) Er ist sehr schwach bei Triton. - 2) 7. B. bei P'roteus, bei Siredon, bei Triton. -- 3) Bcim Axolotl. - 4) Bei Pipa grossentheils verknüchert.

5) Bci Pipa. - $\quad$ 6) Bei Pipa durch eine 'f́brös-knorpelige Meubran.

7) Bufo, Calamita. 
steht ein Brustkorb, der immer noch durch das Hinzutreten anderer unpaarcr Knochen oder Knorpclplatten vervollständigt wird. An den Hinterrand der vereinigten O\$sa coracoüdea schliesst sich ein unpaarer, am Ende verbreiterter Knochen, der dem Schwertfortsatze des Brustbcines verglichen ist. Seine Stelle wird bisweilen durch eine fibro-cartilaginöse Platte vertrcten ${ }^{8}$ ). An den Vorderrand der vereinigten Claviculae befestigt- sich, wenigstens bei Rana, ein âhnliches, nach vorn gerichtetes schmalcs Stuck, das ein Manubrium stern $i$ darstellt 9 ).

Das Schultergerüst der Saurier bietct ähnliche Beziehungen zum Brustbeine dar. Es besteht in der Regel aus denselben vicr Stücken, wie bei den Batrachiern. An eine mcist breite fibröse Platte scbliesst sich dic ossificirte Scapula, welche in Verbindung mit dem zur Brust gerichteten, durch einen halbmondförmigen Rand an das Brustbein befestigten 1 s corncoüdew m die Gelenkgrube für den Ifumerus bildet. Die Bildung des Os coracoüdeurn ist in so fcrn eigenthïmlich, als es nach vorn und innen in zwei oder drei Zacken oder Zinken ausläuft, welche durch Zwischenräume von einander getrennt werden ${ }^{10}$ ). Diese Zwischenräume werden dadurch zu allscitig urnschlossenen Löchern, dass an den freien Rand der einzelnen Zacken cine continuirliche bogenförmige Knorpelplatte sich anschliesst. Das vordere verbreiterte Ende dicser Knorpelplatte des rechten Os coracoüdeum pflegt die des linken in der Mittellinie der Brust, oberhalb des Sternum zu bedecken. Die Clavicula endlich wird durch eine von dem Vorderrande der Scapula zum Manubrizm sterni quer und unterhalb des Os coracoüdeum sich erstreckende Knochenleiste repräsentirt. Sie trägt zur Bildung der Ge lenkgrube für den Ilumerus nicht bei. - Die Ossa cor acoü dea beider Seiten lehnen sich mit ihren halbmondförmigen Ausschniten an die vorderen Ränder des Hauptstückes des Brustbeines. Das Sternum der Saurier besteht gewöhnlich aus zwei unpaaren hinter cinander gelegenen Stücken. Das hintere, von dem so eben die Rede war, ist am beträchtlichsten und stellt eine mehr oder ininder deutlich rhomboidale, bisweilcı aus zwei paarigen Seitenhälften 11) zusammengesetzte Knorpelplatte dar. An seine hinteren Scitenränder befestigen sich Rippenknorpel, an die vorderen die O.ssa coracoüdea. An die vordere Spitze diescr Brustbcinplatte heftet sich ein langes unpaares nach vorn gerichtetes Manubrium, das durch zwei bald von seiner Mitte, bald von scinem Vorderrande abgehende transversale Scitenäste bald dic Form eines Kreuzes 12 ), bald dic eines $\mathrm{T}^{13}$ ) annimmt. Mit der vorderen Spitze dieses Manubrium sind die Claviculac verbunden.

\footnotetext{
8) Pipa. - 9) Es fehlt bei Bufo. - 10) Zwei z. B. bei Lacerta; drei bei Varanus. - 11) Z. B. bei Varanus. - 12) Z. B. bei Lacerta, Scincus, Platydactylus. - 13) Z. B. bei Varanus, Iguana.
} 
Von der eben beschriebenen Anordnung des Sehultergerustes und des Brustbeines machen die Chamäleonten und die Crocodile eine Ausnahme. Bei beiden ist die Knorpelplatte oberhalb der ossificirten Scapula unbedentend und eine Clavieula fehlt gänzlich. Die beiden assa coracoïlea, denen die eigenthïmlichen Zacken und Knorpelplatten der meisten Saurier mangeln, lehnen sieh an das einfache rhomboidale Hauptstiick des Brustbeines, das beim Chamäle on ossificirt ist, aber kein Manubrium besitzt, während es bei den Croeodilen knorpelig bleibt und ein knöehernes, theils dem Knorpel aufliegendes, theils nach vorn verlängertes ossifieirtes einfaches Manubrium ohne transverselle Aeste hat. Bei beiden Familien heftet sich an den hinteren Rand des Brustbeines ein einfacher oder zusammengesetzter Längsknorpelstreif, der bei den Crocodilen nach hinten gabelförmig gespalten ist. An diese Verlängerung inseriren sich, gleichwie an die hinteren Seitenränder des Hauptstiickes, Rippenknorpel.

Bei den schlangenähnliehen Sauriern 14) verkimmern Sehultergerüst und Brustbein und sehwinden zum 'Theil völlig, wie bei Acontias. Bei den Ophidiern endlich fehlen sie, gleich den Vorderextremitäten, durehalls.

Sehr einfach ist das Schultergeriust der Chelonier, das von dem theils durch verwachsene Rippen und IIautknoehen, theils durch das Brustbein gebildeten Panzer umsehlossen wird. Es besteht aus zwei Knocken, welehe beide zur Bildung der Gelenkgrube für den Hunerus beitragen. Der eine dieser Knochen repräsentirt die Scapula und Cla. vieula, welche letztere in Gestalt eines einfachen, oberlalb des Brustschildes einwirts gerichteten Fortsatzes erseheint. Das freic Schulterblattende dieses Knochens ist dureh Ligament über dem Rippenrudimente des ersten Rückenwirbels befestigt. Der zweite am Brustsehilde hinter wärts gerichtete Knochen ist das / $/ s$ coracoüdeam. Ein streifenför miges Band verbindet sein freies Ende nit demjenigen der Clavicula.

Das Brustbein der Chelonier besteht in der Summe derjenigen Knochenstuicke, welehe die Grundlage ihres Brustschildes (P/cestron) bilden. Die Zahl dieser Brustbeinstücke beläuft sich gewölınlieh auf neun, von welehen je vier parig, eines jedoeh unpaarig ist. Das letz. tere ist meistens zwischen den beiden obersten Paaren der Brustbeinstuieke eingeschlossen. Gestalt und Verbindungsweise dieser Stiieke sind

14) Vgl. über diesen Gegenstand besonders Hellsinger in seiner Zeitsehr. für organ. Physik, BH. 3. S. 489. Ind Müller in Tiellemann und Trevira. mus, Zeitschr. Bd. 4. - Ein Brustbein fehlt bei Anguis und Ophisaurus. Anguis, obschon ohne äusserliche Rudimente von Extremitäten, besitzt doch ein Seluultergerüst auf jeder Seite. Es sind Scremula, Clavicula und Os corncoïderum vorhanden. Vollstindiger ausgebildet sind Schultergerüst und Brustbein bei Psendo. pus unil bei Chirotes. - Lepidosternon, Cephalopeltis und Acontias besitzen keine Spur von Schultergerüst. 
bei den versehiedenen Gattungen der Schildkröten grossen Versehiedenheiten unterworfen 15) Während bei den Seesehildkröten niemals eine vollständige Vorsehmelzung aller dieser Stücke eintritt, sind sie bei den Landschildkröten nur in früher Jugendperiode getrennt, und vereinigen sich durch Nähte allmälich sowol allseitig unter einander, als auch seitwärts, in mehr oder minder betrïchtlieher Ausdehnung, mit dem Rüekensehilde. Das aus der Verwaelısung dieser Brustbeinknoehen mit dem Hautskelete entstandene Plastron bedeckt das Sehulter - und Beckengerüst von der Bauehseite.

[Vgl. besonders Cuvier, Recherehes, T. IX. u. X., Tab. 232. 233. 240. 245. 252. 253. 25๊5.]

\section{Vom Beckengerüste.}

§. 57.

Die Mehrzahl der Reptilien besitzt ein mehr oder weniger ausgebildetes Beekengerüst, das selbst häufig solchen Gattungen zukörumt, bei denen ein Sehultergerist mangelt. Ohne Spur eines Beckens sind unter den unbeschuppten Reptilien die Cöcilien und die Gattung Siren, und unter den beschuppten viele Ophidier. - Bei Proteus bleibt das Becken knorpelig und besteht aus zwei panrigen schräg absteigenden leistenförmigen Darmbeinen, Ossa ileum, welche an den Kreuzbeinwirbeln vermittelst Bänder befestigt sind und aus ciner horizontalen Knorpelplatte, welehe kaum eine Spur einer Medianfurehe darbietet. Diese Platte entsprieht den Sitz- und Sehaambeinen. - Beim Axo lotl und bei den Salamandrinen gesehieht die Verbindung der Hüftheine mit dem Querfortsatze des Kreuzbeinwirbels dureh Vermittelung cines rippenartigen Fortsatzes. An diesen lehnt sieh jedes absteigende IIüftbein mit einer knorpeligen Epiphyse. Statt der einfaehen horizontalen Knorpelplatte des Proteus findet sieh hier eine hinten knöcherne, vorn knorpelige, aus paarigen Seitenhälften gebildete Platte. Der hintere knöcherne Abschnitt dieser Platte reprisentirt die Sitzbeine; der vordere knorpelige wird als Analogon der Sehaambeine betraehtet. Beim Axolotl verlängert sich der vordere knorpelige Abschnitt in einen mittleren unpaaren Knorpelstiel, der sieh aber bei den Salamandern alsbald spaltet und so die Form eines Y annimint ${ }^{1}$. Das Becken der ungesehwänzten Batrachier hat eine sehr anomale Form. Die beiden langen Ossa ileum werden durch den starken Querfortsatz des Krenzbeinwirbels gestützt.

15) Vgl. bierüber besonders die nähern Angaben und Abbildungen von $\mathbf{C u}$ vier l. c. 'T. IX. p. 401. Bei dell Interesse, das das Plastron für die systematisehe Znologie hat, sind anch $\mathrm{D}$ unéril und Bibron auf nälıere Lrörıerungen über seine lbildungsverhältnisse eingegangen. L. c. T. I. p. 370 sqq.

1) Allgemein wirl dieser Kñorpel der Salanandrinen als nicht znm Beeken gehörig betrachtet und für eine an die Beutelknoehen maneber Säugthiere crinnernde Bildung erklärt. 
Jedes llüftbein verbindet sich, unten verbreitert, mit dem Os ischii und Os pulis seiner Seite. Indem diese letztgenannten beiden Knochen und zum Theil auch die Ossa ileum mit den gleichnamigen Knochen der entgegengesetzten Seite verschmelzen, nimmt das Becken die Form ciner Scheibe an. Alle drei Beckenstiicke, von denen die mehr unten und vorn gclegenen Ossa mulis stets knorpelig bleiben, tragen zur Bildung der für das Femuir bestimmten Gelenkpfanne bei. Zwischen den beiden Gelenkpfannen erhält sich eine in der Mitte durch Knorpel ausgefiillte Liicke.

Die ineisten Saurier besitzen ein vollständig ausgebildetes Becken, das jederseits aus drei Knochen gehildet wird, die sämmtlich zur Bildung der Gelenkpfanne beitragen. Das Hüftbein ist gewöhnlich länglich, fast horizontal gestellt, und von hinten nach vorn etwas abwïrts gerichtet. Bei den Chamäleonten steht es dagegen fast perpendiculär, besitzt auch oben, glcich dem Schulterblatt, eine platte cartilaginöse Epiphyse, welche oberhalb der Querfortsätze der Kreuzbeinwirbel liegt. Die Schaambeine vereinigen sich bei den Sauriern mit den Sitzbeinen nicht mehr zur einer gemeinschaftlichen Platte, wie bei den Salamandern, vielmehr bilden die beiden Schaambeine und die beiden Sitzbcine, indem sie sich je mit einander zu einer besonderen Schaambein- und Sitzbein fuge verbinden, zwei hinter cinander gelegene, durch eine weite Oeffnung getrennte Bogen. Diese die beiden Bogen trennende Oeffnung zerfällt oft durch einen von der Sitzbeinfuge ausgehenden, vorwärts gerichteten Fortsatz in zwei mehr oder minder vollständig getrennte Seitenhälften; bisweilen ist statt dieses Fortsatzes nur ein mittlerer ligamentöser Strang vorhanden. Beim Chamäleon trägt jedes Sitzbein nahe an der Symphyse cinen kleinen accessorischen Knochen; auch bei vielen anderen Sauriern: Iguana, Varanus, Polychrus 11. A. geht von der Symphyse der Sitzbeine ein nach hinten gerichteter, ihr beweglich ver. bundener Knorpel ab, der selten theilweise ossificirt. Bei den schlan genähnlichen Sauriern: Pseudopus, Bipes, Ophisaurus, Anguis sind nur Rudimente des Beckens vorhanden. Sie bestehen in einem jederseits an derr Querfortsatze eines Wirbels oder am Ende der Rippen befestigten verschieden gestalteten Knöchelchen, das dem Darmbeine entspricht und nur selten noch andere rudimentäre Extremitätenknochen trägt.

Interessant ist es, dass dergleichen Beckenrudimente auch bei manchen Ophidiern angetroffen werden; sie liegen hier aber in der Regel, mit Ausnalıme von Acontias und Amphisbaena, wo sie an den Enden von Rippen befestigt sind, ganz frei, ohne mit der Wirbelsäule verbunden zu sein und erscheinen bald ohne Spur von Extremitaten, bald tragen sie nit Sporen besetzte Rudimente derselben.

Die Beckenknochen der Schildkrüten werden von deın Bauchschilde umgeben, hangen aber init denselben gewöhnlich nur durch Li gamente zusaınmen - eine Regel, von welcher die Gattung Chelys in 
so ferne eine bedeutende Ausnahme macht, als die Beckenknoehen hier nieht nur mit dem Bauehsehilde, sondern aueh mit dem Rüekensehilde eine festere Verbindung eingehen. - Ihre Anzahl und Anordnung bleibt bei den Cheloniern dieselbe wie bei den Sauriern und sie tragen sämmtlieh zur Bildung der Gelenkpfanne bei. Bestaindig ist die Lage des Beckens so, dass die Hüftbeine von der Wirbelsäule sehräg naeh vorn absteigen und dass die gemeinsame Oberfliiehe der Sitz - und Sehaambeine dem Bauehsehilde parallel liegt. Stets vereinigen sieh sowol die beiden Sitzbeine, als aueh die beiden Sehaambeine in der Mittellinie. Bei den Seeschildkröten wird die Sitzbeinfuge mit der Sehaambeinfuge nur durch liganent verbunden. Sitzbeine und Sehaambeine sind hier also, abgesehen von dem Ligamente, dureh eine einzige weite Oeff. nung getrennt. Bei den Land- und Sisswassersehildkröten stossen aber die vereinigten Sitzbeine in der Mitte hinten an die beiden Sehaambeine; es finden sieh hier zwisehen den unverbundenen Seitenästen der Sitz- und Sehambeine also zwei Oeffnungen.

Abweiehend von der allen übrigen besehuppten Reptilien zukommenden Anordnung zeigt sieh das Beeken der Croeodile. Die sogenannten 2) Sehaambeine tragen hier nieht zur Bildung der Gelenkpfanne für den Obersehenkel bei und vereinigen sich nieht unter einander. Jedes Schaambein ist mit einer Apophyse des Sitzbeines seiner Seite verbunden und erstreekt sieh rippenartig sehräg abwärts und vorwärts. Beide Sehaambeine werden dureh die zwisehen den Bauehrippen gelegene Aponeurose verbunden.

[ Sehr gute Abbildungen rom Beekengerüste der Reptilien finden sich bei $\mathrm{Cu}$ vier, Recherehes ete. - Ueber die abortiven Beekenknochen vieler Saurier und Ophidier haben gehandelt Ma ye r, Nov. Act. phys. med. Aead. Caes. Leop. Carol. 1. 12. p. 2. 1825, und noeh gründlicher, He u singer in seiner Zeitschr. fo organ. Physik, 13l. 3. S. 481. Vgl. auch Müller in Tiedemann und Treviranus, Zeitsehr. Bd. IV. Unter den Ophidiern sind es die Gattungen Python, Boa, Eryx, Tortrix, Typhlops, Acontias, Ainphisbaena, bei denen man bisher Beckeurudimente aufgefunden hat. Rhinophis besitzt nach Müller keine Spur von Beckenrudiment. Mayer hielt die Beekenrudimente mit Unrecht fïr Knochen der Extremitäten. Gegen diese Annahme spricht, ausser dem von Heusinger gründlich erörterten Verhalten der Muskehn, aueh noeh der Unstand, dass zu diesen Knoehen bei Pseudopus und bei Bipes lepidopus abortive Extremititenknochen hinzukommen. Bei Acontias und Amphisbaena findet sieh an der innern Seite der letzten Rippen ein s-förmig gekrümmtes Knöchelehen, hei Acontias durch Bandfasern befestigt; bei Amphisbaena frei und an Ende einen Knorpel tragend; bei Anguis ist der etwas versebieden gestaltete Knoehen an der Spitze des Querfortsatzes eines Wirbels befestigt. Bei Pseudopus trägt der ähnlich befestigte Kno-

2) Diese sogenannten Schaambeine erinnern an die oben erwähuten accessorischen Bauehdeekenknochen der Salainandrinen, denen sie mehr ähneln, als den Sehaambeinen der übrigen Reptilien. 
chen die aus zwei Gliedern bestehenden Extremitätenknochen; das zweite Glied der letzteren ist mit einem hornigen Nagel überzogen. Bei Bipes lepidopus finden sicb, nach Cuvier, in einem ähnlichen warzigen Stummel Rudimente eines Femur, einer Tibia und vier äussere Glieder; bei andern Bipes.Arten sind die Extremitäten noch weiter ausgebildet und bilden den Uebergang zu Seps. Bei Typhlops sind wieder blos Beckenrudimente vorhanden, die sich von beiden Seiten unter spitzem Winkel vereinigen und wahrscheinlich meist den Schaambeinen entsprechen. Bei Tortrix koinmen zu den Beckenrudimenten in deın Ende der Klaue Extreınitätenknochen binzu. Bei Boa uul Python besteht das Becken- und Extremitätenrudiment jeder Seite aus füf Knochen und Knorpeln: drei Beckenknochen und zwei Extreınitätenknochen, von denen das äusserste einen Nagel trägt. Noch vollkommener ist die Bildung bei Eryx. - S. die Abbild. bei Heusinger.]

\section{Von den Knochen der Extremitäten.}

\section{§. 58.}

Die Knochen der Extremitäten der Reptilien nähern sich rücksichtlich ihrer allgemeinen Anordnung, selbst bei den im Wasser lebenden Gattungen, welchen sie als Ruder dienen, weit mehr denen der Säugethiere, als denen der Fische. Die Knochen der Vorderextremitäten bestehen - sobald sie nicht verkümmern - aus einem einfachen Oberarmknochen (Humerus) 1), aus zwei gewöhnlich getrennten, nur bei den ungeschwänzten Batrachiern verschmolzenen Vorderarmknochen (Radius und $\boldsymbol{U}(\boldsymbol{n} \boldsymbol{a}){ }^{2}$ ), aus einer unbeständigen Zahl von

1) Der Kopf des Humerus hleibt bei den Batrachiern fast immer knorpelig. Bei den Salainandrinen hat der Oberarmknochen wegen seiner halsartigen Einschnürung unterhalb des Gelenkkopfes und wegen seiner heiden trochanterartigen Knorren, so wie auch wegen der beiden zur Einlenkung der Vorlerarıknochen bestimmten Conlyli, grosse Aehnlichkeit mit einem Femur. - Bei den meisten ungeschwänzten Batrachiern ist er fast gerade, bei den Kröten mehr gekrüınınt. Er besitzt in der Regel nur eine Leiste. Bei Cystignatlus pachypus ist er eigenthümlich in die Breite entwickelt und wird so zu einem fast flachen Knochen. Der Oberarın ist bei fast allen ungeschwänzten Batrachiern beträchtlich länger, als der Vorderarm. - Bei den meisten Sauriern kï̈rzer, als der Vorderarm, besitzt der Hunerus, namentlich bei den Eidechsen, grosse Aehnlichkeit mit dem der Vögel; unten zeigt er zwei rundliche Erhabenheiten zur Articulation mit den Vorderarınknochen. - Das Oberarmbein der Crocodile ist länger als die Vorderarmknochen und besitzt eine starke Leiste. - Unter den Cheloniern ist es bei den Seeschildkröten aı kürzesten, ziemlich gerade, sehr platt, oben mit starken Fortsätzen versehen; bei den Landschildkröten ist es länger, stark gekrümmt, rundlich, besitzt einen dentlich abgesetzten Hals und scliwächer entwickelte Fortsätze. Bei allen Schildkröten ist der Oberarın so um seine Axe gedrehet, dass seine Streckfläche nach vorn, seine Beugefläche nach hinten liegt.

2) Die beiden Vorderarmknochen der ungeschwänzten Batraclier sind, wie es scheint beständig, verschınolzen und bilden einen einzigen ziemlich breiten Knochen. Er besitzt eine besonders an seinen beiden Enden deutlich hervortretende Längsfurche und hat inwendig, wenigstens in seinem unteren, an deutlichsten gefurchten Abschnitte auch zwei getrenute Markröbren. Er bat einen deutlichen Ellenbogeuknorren. An der unteren Gelenkfläche finden sich stets zwei 
Handwurzclknochen (Ossa carpi) ${ }^{3}$ ), aus der Reihe der Ossa metacarpi ${ }^{4}$ ) und endlich aus den Phalangen der Finger ${ }^{5}$ ). Selten kommt als eigenthümliche Bildung zn diesen Knochicn noch eine oberhalb des Ellenbogenknorrens kniescheibenähnlich gelegene Ossification hinzu, der man den Namen Elle nbogenscheibc (Patella brachialis) gegeben hat 6). - Der Plan der Anordnung dicser Knochen ist im Allgemeinen ganz derselbe, wie bci den Säugethicren.

überknorpelte Erhabenheiten. Bei den übrigen Reptilien sind beide Knochen getrennt und in der Regel ist die Ulua länger, als der Radius; nur bei Chelonia und Trionyx findet das ungekehrte Verhalten Statt. Bei den Schildkröten sind überhaupt die Vorderarminochen oben und unten (besonders bei Chelonia) in grösserer Strecke unberveglich mit einander verbunden. Bei allen Schildkröten bildet ferner die Ulna den Aussenrand, der Radius den Innenrand des Arues, cine Eigenthümlichkeit, welche am meisten bei den Landschildkröten hervortritt und init dem oben erörterten Verhalten des Humerus zusammenhangt.

3) Sie bleiben bei Sirell und Proteus cartilaginös. Bei den Salauandrinen sind sie kurz und rundlich; es finden sich ihrer in drei Reihen sicbeu bis acht; bei den ungeschwänzten Batrachiern stehen sie in zwvei Reihen und sind in der Zahl von sieben vorhandell; bei den Sauriern bilden die in verschiedener Anzahl vorhandenen Knochen zwei Reihen. Bei den Crocodilen finden sich zwei Reihen; in der hinteren liegen drei Knochen, ein kleinerer und zwei grössere, welche den Mittehandknochen sehr ähnlich gebildet sind. In der vorderen Reihe finde ich, wie Meckel, vier sehr kleine, allerdings sehr spät ossificirende Knochen. Bei den Landschillkröten liegen in der ersten Reihe vier, in der zweiten fünf Handwurzelknochen; ihre Zahl wächst bei den Eınyden und den Seeschildkröten auf zchn, welche in zwei Ordnungen liegen. Sie sild bei den letzteren eigenthüınlich abgeplattet, wodurch dic Hand dieser Thiere cine unverkennbare Aehnlichkeit mit derjenigen der Cetaceen erhält.

4) Die Mittelhandknochen sind gewöhnlich längliche Knochen und glcichen ihrem Baue nach in der Regel denen der Phalaugen. Kurz und dick sind sie bei den Chanäleonten. Bei den Landschildkröten hat unan sic häufig als Phalanges digitorun bezeichnet und darun auch wol gauz geläugnet.

5) Die Zahl der Finger, so wic die Anzahl der e in en Finger zusammensetzenden Glieder sind sehr verschieden. Bei Proteus sind nur drei Finger vorhanden; bei den ungeschwänzten Batrachiern nur vier ausgebildete Finger, indeu der Daumen rudimentär bleibt. Unter den Sauriern kehrt die Verminderung der Fingerzahl wiedler bei Seps, Chalcides und Anderen mit verkümmerten Extremitäten versehenen Gattungeı. Die häıfigste Zahl der Finger ist fünf. Gewöhnlich stehen sic in Einer Reihe; bei den Chanäleouten sind aber die beiden äussern Fingrer abgesondert und nach hinten gerichtet. - Die Fingerglieder sind gewölnnlich länglich; nur bei den Landschildkröten auffallend kurz. Dic Zahl der Glieder ist an den verschiedeneu Fingern versehieden. Bei einigen Suuriern (Iguana, Basiliscus, Lacerta) bestehen die beiden äusseren Finger aus vier oder fïnf Phalangen.

- 6) Es ist dieser Knochen nur eine Sehnenossification in deın Streckinuskel des Oberarmbeines; er kömınt vor bei Pipa, Rana, vielen Sauriern, z. B. Lacerta, Iguana, Polychrus, ferner bei einigen Cheloniern, nanentlich bei der Gattung Testudo. Vgl. dariber R. Wagner in Heusinger's Zeitsclir. f. organ. Physik, Bd. 1. S. 592. 
Die Knochen der Hinterextremitaten bestehen da, wo sie nicht bles rudimentiar sind, aus einem einfachen Oberschenkelbeine (Femur) ${ }^{7}$ ), ans der Tibia und Fibula $\boldsymbol{F}^{8}$ ), die nur bei den ungeschwänzten Batrachiern verwachsen, aus einer unbestaindigen Zabl von Fusswurzelknochen (Ossa tarsi) 9), ans der Reihe der Ossa metatarsi ${ }^{10}$ ) und aus

7) Dieser Knochen bietet wenig Eigenthïmlichkeiten lar. Bei Proteus ist er rerhältnissınässig lang; bei den Salamandern besitzt er einen sehr starken hopf und hat bei ihnen und bei den Tritonen eine sehr starke untere Iseiste; bei den ungeschwänzten Batrachiern zeichnet er sich durch seine Länge aus. Bei den Sauriern und bei den Crocodilen ist sein Kopf nicht rund und wenig abgesetzt. Auch der Trochanter ist schwach. Bei den Cheloniern ist das Oberschenkelbein durch die Stärke seines Kopfes ausgezeichnet, der unter rechtem Winkel mit dem eigentlichen Knochen sich verbindet. Dieser besitzt gewölnnlich 2wei Rollhiigel, die besonders bei Euys sehr entwickelt sind. Der Knochen selbst ist bei den Seeschildkröten melır gerade, bei den Emylen und Cheloniae stark vorwärts gekrümmt.

8) Rücksichtlich der Verwachsung ron Tibia und Fibula finden sicls bei den ungeschwänzten Batrachiern ähnliche Verbältnisse, wie in Betreff ihrer Vorderarmknochen. Am deutlichsten tritt die Neigung zum Zerfallen in zwei Knochen bei Pipa hervor; bei Rana am wenigsten. Bei den Salamandern ist die Fibula stärker, als die Tibia; bei allen übrigen Ordnungen findet das entgegengesetzte Verhältniss Statt.

9) Die Fusswurzelknochen bleiben bei Proteus, Siredon und Salamandra knorpelig, während sie bei Triton verknöchern. Sie sind klein und liegen mindestens in zwei Reihen hinter einander. Schr eigenthümlich ist das Verhalten der Fusswurzelknochen bei den ungeschwänzten Batrachiern. Sie bestehen aus sieben Knochen, wenn unan voll einer Verknorpelung, welche hinter den langen Knochen liegt, absieht. An die verschuolzene Tibia und Filıula schliessen sich zwei lange parallele Kinoclien, welche auf den ersten Anblick für accessorische Tibia und Fibula gelialten werden könnten. Sie sind balıl vollständig von einander getrennt (Bufo), bald am oberen Ende verwachsen (Rana), bald endlich ist ihre Verwachsung vollständig (bei Obstetricans punctatus nach Dıgès). Bei Pija sind sie kurz und dick. Der innere entspricht dem Astragalus, der äussere dem Calcaneus. Theils zwischen diesen Knochen und dem Metatarsus, theils aber am Daumenrande des Fingers finden sich fünf andere ossificirte orler knorpelige Knöchelchen. (S. die Abbild. bei Dugès Tab. IV.) - Bei den Saurieru sind die Fusswurzelknocben in zwei Reihen gestellt; ihre Zahl ist geringer als bei irgend einer anderen Ordnung und scliwankt zwischen vier und fünf. Auch wei den Crocodilen sind nur fünf kleine, zwei Reihen bildende Fusswurzelknoclien vorlianden, von welchen der Calcitueus und Astragalus die beträchtlichsten sind. - Bei den Cheloniern liegen die in grösserer Anzalıl (sechs bis sieben) vorhandenen Ossa tarsi in zwei Reilıen. Bei Testulo liegt in der ersten Reihe nur ein einziger sehr grosser Knochels; statt seiner sind bei Chelonia zwei vorhanden; in der Vorderreihe liegen stets fünf bei Testudo, grossentheils kleine, bei Chelonia grössere, platte Knoclien.

10) Die Mittelfussknochen sind bei den ungeschwänzten Batrachiern, den meisten Sauriern und Cheloniern und den Crocodilen lange Röhrenknoclıeı. 
den Phalangen der Zchicn $\left.{ }^{11}\right)$. Eine Knicscheibe (Patella) $\left.{ }^{12}\right)$ ist bei einigen Sauriern und Chelonicrn beobachtet worden.

\section{Vom Schedel.}

ร. 5.?.

Der Schedel der Reptilicn lıat keine Bezielıng melı' zu einem Apparate von Schleimröhren-Knochen, wie dies bei den meisten Gräthenfischen der Fall ist und dient auch dem Schultergerust nicht mehr qum Stitzpunktc. Niemals bleibt cr ganz knorpelig, wis bei den Cyclostomen, den Plagiostomen und bei den Chimärcn, sondern ist immer von mehr oder uninder ausgebildeten Knochen unschlossen.

Indessen erhält sich nelsen diesen letzteren hiäufig die ursprüngliche knorpelige Grundlage des Schedels peremnirend; am vollständigsten bei den ungeschwänten Batrachiein y), abortiver bcim Axolotl. Bei crsteren verharrt gewöhnlich nicht nur die eigentliche knorpelige Schedelcapsel init einzclnen integrirenden Ossificationen, sondern auch cin Theil des Kiefer-Apparates zeigt danernd eine knorpelige Grundlage. In der oberen knorpeligen Schedeldecke finden sich, wie dies auch bei den Fischen unter gleichen Bedingungen der Fall ist, gewöhnlich hetrïchtliche Fontanellen oder Liicken. Das weiche Schedcldach nit seinen Lücken, der grösstc Theil der weichen Schedelbasis, die knorpelige Bedeckung der Nascnlöhlengegend und dic knorpelige Grundlage der Oberkiefergegend werden auch hier durch lose aufliegende Knochenplatten und Knochenstäbe bedeckt und gestützt; die zusanmenhangenden knorpclig häutigen Theile kommen also erst nach Entfernung dieser Ossificationen zu Tage. - Noch bei einigen Sauricrn erhalten sich einzclne Ueberreste der primitiven Knorpelcapsel. Am deutlichsten ist dics Verhältniss bei den Chanäleonten, wo die ganze Schilddecke der Scheitelbein - und Stirnbeingegend zwei verschiedene Elemente enthält, nämlich 1) eine tiefere, diinne, knorpelähnliche Schicht, welche in die fibrös-häutigen Seitenwände des Schedels'uninittelbar ibergeht und 2) die obcrflichlichen Ossificationen. Auch bei den übrigen Sauriern ist ein zwischen dem oberen Bogen des Ilinterhauptsgürtels und dem Hinterrande des Scheitclbeines knorpclbäutig bleibender Abschnitt der Schedeldecke als Ucberrest der primitiven Schedelcapsel zı betrachten. In die gleiche Categorie gehören ferner die fibrös-häutigen Scitcnwändle des Saurier-Schedels mit ilırcn rudimen-

11) Die Zahl der Glieder, aus welchen die einzehen Zehen bestehen, ist sehr verschieden. Sie sehwankt zwischen 1 und 5 .

12) Sie ist von Wagner beobaehtet bei mehren Monitor, Lacerta, Scincus und bei Terrapene elausa und erschient hier als eine ziemlich beträchtliche Ossification in der Sehne der Streckinuskeln des Unterschenkels.

1) S. die meistens sehr treuen Abbildungen in der Schrift von $\mathbf{D}$ ug ès übe: die Batrachier, Tab. 1. - Vgl. auch \$. 10. 
tären Verknorpelungen und Verknöcherungen, der vom Kcilbcinkürper aus nach vorn sich erstreckende Knorpelstiel, welcher bei den Sauricrn, Grocodilen und Cheloniern vorkönmit u. s. w. Nur bei den Ophidiern ${ }^{2}$ ) erhïlt sich als Ucherrest der primitiven knorpeligen Grundlage des Schedels, gleichwie bei fast allen höheren Wirbelthieren, blos das innere hnorpelgerüst der Nasenhöhlen.

Bemerkenswerth ist fcrner die unvollständige Ossification des Scheitelbeines vieler Saurier, in welchen oft frei zu Tage liegende häutige Fontanellen ${ }^{3}$ ) sich erhalten, die gcwöhnlich auf ein schr kleines Loch in der Mitte des Scheitelbcines ${ }^{4}$ ) reducirt sind, in anderen Fällen aber dadurch verdeckt werden, dass eine innige Verschmelzung und Verwachsung der unvollständig ossificirten Stirn- und Scheitelbeine mit den starken Schuppenknochen der Haut Statt findet 5).

s. 60.

Der Schedel aller unbeschuppten Reptilien zcichnct sich dadurch aus, dass das Hinterhauptsbein wesentlich aus zwci Scitcnstuicken (den Ossa occipitalia lateralia) gebildet wird und dass das Dccipitale basilare und superins entweler nicht einmal als gesonderte Anlagen vorhanden, oder nur durch inchr oder minder schmale, jenc Seitenstiicke trennende Knorpelstrcifen angedeutet sind. Nur äusserst sclten ist das Occipitale basilare durch einen gesonderten Knoohenkern repräsentirt. Mit dieser vorwaltenden Ausbildung der Seitenstücke des Hinterhauptsbeines hangt der constanteste osteologische Charakter des Schedels der nackten Reptilien: das Vorkommen zweier seitlichen, völlig von cinander getrennten Coudyli occipitales zusammen. - Mit Ausnahme der Occipitalia lateralia und der Ossa petrosa sind die hnochen des Schedels nur diinne Platten. Beständig fchlt eine Sella turcica.

Der Schedel der geschwänzten nackten Reptilien besitzt, so abweichend seine Formuverhältnisse eincrseits bci den Proteïdeen, andererscits bei den Cöcilien und endlich wieder bei den Salamandrinen immer scin mögen, manche fast bestïndig wicderkehrende Eigenthümlichkeiten.

Der Ilinterhauptsgürtcl wird gebildet durch zwei Ossa occipitalia lateralia, deren jedes mit dem ilm seitlich und aussen sich

2) Bei ihnen sind sämmtliche Seitenwandungen des Schedels, mit Einschluss derjenigen seines Orbitalsegmentes, vollständig verknöchert. Auch die beiden Orbitae sind hier nicht durch einfaches weicheres Septum, sondern durch die allseitig verknöcherte vordere Fortsetzung des Schedelcanales getrennt.

3) Solche häutige Fontanellen erhalten sich z. B. bei Stellio, Phrynocephalus, Euprepes, Sceleporus u. A.

4) Er findet sich bei sehr vielen Sauriern, z. B. der ganzen Familie der Mo. nitores, den meisten Iguaneu, den Chamäleonten u. s. w. das ganze Leben hindurch unil verschwindet nie.

5) Z. B. bei Pscudopus, Scincus u. A. 
anschliessenden Os petrosum gewöhnlich so innig verschmolzen ist, dass beide nur cinen einzigen Knochen darzustellen scheinen. Eine Trennung heider Knochen wird gewöhnlich auch nur durch einen knorpeligen Streifen bewirkt. In der Regel stossen die beiden Occipitalia lateralia, deren Gelenkhöcker sehr wcit von einander entfernt sind, so dicht zusammen, dass kcinc Spur eines Occipitale basilare und $s u$ perius vorhanden ist; nur bcim Axolotl sieht inan nach Wegnahme der Scheitclbeine und des Keilbeins, dass die beiden völlig ossificirten seitlichen Hinterhauptsbeine unten und oben durch Zwischenknorpcl verbunden werden.

Die ganze Schedclbasis, von der Grenze des Itinterhauptsloches an, bis zum Grunde der Nasencapsel, wird gebildet durch das breite, völlig platte $O_{s}$ sphenoüdeum basilare ${ }^{1}$ ).

Die Seitenwandungen der Schedelhöhlc werden vor den Felsenbeinen, bis zur hinteren Grenzc dcr Nasenhöhlen hin, durch ossificirte Keilbeinflügel gebildet 2). Nur beim Axolotl bleibt die hintcre Hälftc jeder Seitenwandung perennirend knorpelig, während die vordere, dem Stirnbeine seitwärts entsprechende, integrirend ossificirt ist.

Die obcren Schedeldecken entstehen immer durch zwei paarige Scheitelbeine und zwei paarige Stirnbeine. Nur bei ninigen Cöcilien kömmt ausser ihnen noch ein unpaarcs $\boldsymbol{O} s$ ethmoüdeum an der Schcdeldecke zu Tagc ${ }^{3}$ ).

Zwei Nascnknochen sind - mit Ausnahme mehrer Cöcilicn vorhanden. Gcwöhnlich zeigen sich auch am vorderen Augenhöhlenrande eigene Ossa frontalia anteriora, die aber namentlich den Proteïdeen und anscheinend auch den Cöcilicn fehlen.

Die Oberkicferbeine sind gewöhnlich unbeweglich mit dem Schedel verbunden und ermangeln der durch vollstïndige Jochbogen 4) vermittelten Verbindung mit den Quadratbeinen. Nur die Cöcilicn machen von dieser Regel eine Ausnahme und bei der Breite der ihren Jochbogen bildenden Knochen entsteht über der Augen - und Schläfenböhle ein durch ein klcincs Augenloch perforirtcs Schild. - Bei Siren

1) Es ist am längsten bei Proteus und Siren; am kürzesten bei den Cöcilien.

2) 0 b sie auch bei den Cöcilien vorkommen, muss ich unentschieden lassen; ich habe mich von ibrer Anwesenheit nicht überzeugen können.

3) Bei Coecilia albiventris beobaclitet und früher als Frontale medium, durch Dugès aber als Os ethmö̈deum geleutet, weil es unter die Ossa frontalia absteigt und zum Durchgange der Nervi olfactorii dient. Es erscheint aber nicht bei allen Cöcilien an der Oberfläche des Schedels. Bei den Salamandern, besonders aber beim Axolotl, bleibt die den $O s$ ethmoïdeum entsprechende Region des Schedels knorpelig. Beim Axolotl besteht die ganze Grundlage der Schnauze in einem mit dem Schedel innig zusammenhangenden Knorpel, der grossentlieils durch aufliegende Knochenstücke gedeckt wird.

4) Bei den Salamandrinen wird die hintere Hälfte des Jochbogens dnrch ein. zum Quadratbeine sich erstreckendes Ligament ersetzt. 
sind die Oberkieferbeine ganz abortirt und fehlen sogar bei Proteus; beträehtlieh sind sie dagegen bei den Cöcilien ${ }^{5}$ / und Salamandrinen. Der meist paarige $Z$ wi sehenkiefer besitzt gewöhnlich starke oberhalb der Nasenhöhlen aufsteigende Aeste. Er ist bei mehren Cöeilien mit den Nasenbeinen zu einem Knoehen versehmolzen ${ }^{6}$.

Der Gaumenapparat besteht meistens in kleinen zahntragenden Platten, welehe gewöhnlieh dem Sphenoïdeum Lasilare lose aufsitzen. Dieselben sind nur bei einigen Gattungen, z. B. bei Proteus, dureh ein eigenes 0\& pterygoöideum mit dem Quadratbeine verbunden. Bei Siren sind jederseits zwei soleher Platten vorhanden, von welehen die hintere einem Gaumenheine, die vordere dem paarigen Vomer der Batraehier, Saurier und Ophidier zu vergleiehen ist. Bei Proteus bilden beide ein einziges Stuiek. Bei den Coecilien findet sieh jederseits ein grosser zahntragender Gaumenknoehen vor dem Sphenö̈leum ljasilare. Bei den Salamandern ist jederseits ein einziger, hinten sehr sehmaler, vorn plattenartig verhreiterter Knoehen vorhanden, der zum Theil unter dem sphenoïdeum basilare liegt und vorn den Boden der Nasenhöble bildet. Die Untersuehung junger Salamander lehrt, dass derselbe aus der Verwaehsung zweier ursprïnglieh getrennt gewesener Knoehenstüeke entstanden ist, also dem Vomer und dem Gaumenbeine zugleieh entspricht. Aueh beim Axolotl liegen perennirend jederseits zwei zahntragende Platten hinter einander, von welehen die hintere mit dem knorpeligen Processus pterygö̈leus des Quadratbeines in Verbindung steht. - Ein gesondertes 0 s pterygoïdeum, welehes Gaumenbein und Quadratbein verbindet, kömmt bei Proteus, bei Menobranehus und bei Coeeilia vor.

Das den Unterkiefer tragende Quadratbe in bietet grosse Versehiedenheiten dar. Bei Siren und bei Proteus besteht es in einem läng:liehen, ziemlieh beträehtliehen, vorwärts geriehteten Knoehen, der oben an das Felsenbein geheftet ist und mit seinem unteren vorderen Ende das Unterkiefergelenk trägt. Bei Proteus und bei Menobranehus besteht es aus zwei Elementen, dem eigentliehen Quadratbeine und dem das Unterkiefergelenk tragenden Quadratjoehbeine, und ist bei beiden von dem ossifieirten Os pterygoüdeum getrennt. - Bei den Salamandrinen besteht das Kiefer-Suspensorium wesentlieh aus drei Elementen: 1) dem etwas sehrigg hinterwärts zum Unterkiefer absteigenden Processus tympanicus, 2) dem Proc. pterygoïdeus und 3) dem kleinen Quadratjoehbein. Letzteres bleibt beim Axolotl i) permanent knorpelig, während es

5) Bei denjenigen Cöeilien, welehe einen sehildförmigen Joehbogen besitzen, findet sieh eine eigenthümliehe Oeffnung zwischen dein Oberkiefer und Zwisehenkiefer; sie fuhrt in einen Canal, der unter dem Oberkieferbeine liegt und ein Tentakel enthält.

6) Bei Coec. hypoeyanea sind, nach Müller, beide Knoehen getrennt.

7) Beim Axolotl erhält sieh das gesanmte Kiefersuspensorium zum grossen Theile in knorpeligem Zustande; nur das eigentliche Quadratbein ist ossificirt. 
bei den Salamandern ossificirt; der beim Axolotl knorpelige, hreite Pro. cessus pterygö̈lleus erreicht das Gatumenbein, wihhend derselbe Fortsatz bei den Salamandern, wo er verknöchert ist, trei nach vorn und anssen ragt und ausser aller Verbindung mit dem Grumenbeine und dem Oberkiefer blcibt.

Dic beiden Unterkieferiiste sind bei den gesehwänzten nackten Reptilien fest mit einander verbunden, ohne jedoch verwachsen zu sein. Jeder Ast besteht aus zwei bis vier einzelnen Knochenstiicken. Die wesentlichsten derselben sind 1) das zahntragende Os dentale und 2) das Os articulare, das bein Salamander mit dem dritten innern Deckstücke oder dem $\boldsymbol{O}$ s operculare verschmilzt. Gewöhnlich befindet sich die Gelenkfliache an hinteren Ende des Unterkiefers; von dieser Regel machen die Coecilien in so ferne eine Ausnahme, als bei ihnen hinter der Gelenkläche noch cin langer krummer Fortsatz vorkömmt.

[Man vergl. über Protens und Siren Cuvier, Recherches T. X. Tab. 255.; über Coecilia Dugès I. c. Tab. XIV., Müller in. Tiedemann und Trevira. nu s, Zeitschr. Tal. XVIII. Fig. 3. u. 5.; über die Salamander und T'ritonen $\mathbf{C u}$. vier l. c. T. X. Tab. 253-25ว., Funk l. c. Tab. III. und Du gès I. c. Tab. XIV.; ïber Amphiuma Cuvier in den Mém. d. Musée d"hist. nat, Tome XIV. Tab. 2.; über Menobranchus und Menopoma Mayer in den Analekten f. vergl. Anatomo, Tab. VIf. Fig. 1. u. 2.1

\section{ร.. 61.}

Dic Schedel der ungeschwänzten Batrachier besteht gewöhnlich in ciner länglichen, cylindrischen, grossentheils knorpeligen Röhre, in deren hintercm Abschnitte bestiindig integrirendr, durch cartilaginöse Zwvischenräume verbundenc Ossificationen vorkommen, deren miltJeres Segment meistens fibro-cartilaginös bleibt und die vorn durch einen ossificirten Ring crgänzt wird. ZII den integrirenden Ossificationen kommen zahlreiche Knochenstücke hinzu, welche der knorpeligen Grundlage oberlächlich lose aufliegen. Seltencr bildet, wie bei P'ipa, die ganze auffallend plattgedrückte Hirncapsel, mit Ausnahme der, isolirte Knochen enthaltenden, Occipitalgegend, einen einzigen ununterbrochenen Knochengürtel, dessen oberc Platte seitwärts vorspringt. - In der IIin terha u p t sgegend finden sich bei allen ungeschwänzten Batrachiern gewöhnlieh nun zwej ossificirte, unten sowol, als oben durch einen sebmalen knorpeligen Zwischenraum von einander getrennte Scitenstucke (Occipitalia later alia), deren jedes einen Gelenkhöcker trägt und cine Oeffnnng für den Durchtritt des $\boldsymbol{N}$. vagues und des in seiner Bahn verlaufenden $\boldsymbol{N}$. glossopharyngeus besitzt. Nur ausnahmsweise wird bisweilen ein klcines glcichfalls integrirend ossificirtes Occipitale basilare beobachtet 1). - An jedes seitliche Hinterhauptsbein schliesst sich seitlich und zum Theil auch vorn ein betrüchtliches, grösstentheils oder ganz ussiff-

1) Bei Bufo marinns. 
cirtes 0 s pelrosum, das, quer nach inssen vorspringend, dem KieferSuspensoriurr zur Stiitze dient. Es vervollstiindigt hinten in der Regel die Seitenwand der Schedelhölle, nimurt das Gehörorgan auf und lässt den $\boldsymbol{N}$. trigeminass durchtreten. Gewöhnlich werden die beiden Ossa petrusa durch eineı breiten Zwischenraum, der der Schedelhasis angehört, von einander getrennt. Dieser Zwischenraum bleibt dann, gleich dem ganzen folgenden Schedelsegment, fibro-cartilaginös. Das Dach der knorpeligen Grundlige des inittleren Schedelabschnittes entlıält in der Scheitel - und Stirngegend vier kleinere oder zwei grössere, durch fibro-cartilaginöse Briicken von cinander getrennte Oeffnungen, welche auswärts von den knorpelig-häutigen Seitenwandungen begrenzt werden. Die Fontanellen kommen aber oberflächlich nicht zu Tage, weil zwei, gewöhnlich der ganzen Länge nach an einander sich anschliessende, selten wie bei den Hylae getrennte, meist an ilren Aussenrändern etwas umgebogene knochenplatten, die von der Hinterhauptsgegend his zum vorderen Ende der Orbitalregion sich erstrecken, die knorpelig-häutigen Theile, sammt den Liicken, lose aufliegend, bedecken. Diese aufliegenden Knocheuplatten entsprechen den Scheitelbeinen oder den verschmolzenen Stirn- und Scheitelbeinen. Auch die Basis der knorpeligen Schedelcapsel wird von einer liinglichen mit zwei Querschenkeln versehenen Knochenplatte, welche gleichfalls von der Hinterhaurtsgegend bis zur vorderen Grenze der Hirncapsel sich erstreckt, bedeckt. Dir Querschenkel dieser Platte legen sich unter die durch die Ossa petrusa gebildeten Querfortsatze. Die ganze Platte stellt das Os splcenö̈leum lasilare dar. Die hiintigen Seitenwandungen des Seliedels besitzen gewöhnlich keine integrirende oder aufliegende Ossifieationen, sind jedoch selten ausnahmsweise ossificirt 2) und lassen immer die Nerven der Gesichtsorgane durchtreten. - Der vorderste Abschnitt der llirncapsel stellt einen vollstindig geschlossenen Knochenring dar (Cuvier's Os en ceinture), dessen Höhle vorn gegen die Nasenhöhle hin, his auf zwei zun Durchtritt der Geruchsnerven bestimmte Oeffnungen oder Canäle geschlossen ist. Dieser muf Kosten der knorpeligen Grundlage gebildete Knochenring wird gewöhnlich oben grossentheils von den oberen Schedelplatten oder Scheitel-Stirnbeinen hedeckt, so dass er erst nach deren Entferning frei zu Tage liegt. Vorn schliessen sich an diesen knochenring die heiden breiten, durch ein Sepum geschiedenen knorpeligen oder knorpel-häutigen Nasenhöhlen an. An der vorderen Grenze der Augenhöhle geht, den Vorderrand derselben bildend, von der Vereinigungsstelle des Knochenringes init der fibro-cartilaginösen Ungebung der Nasenhöhle ein mehr oder minder schmaler Querknorpel nach aussen in einen Knorpelbogen iil.er, der dem kieferbogen parallel laufend, oder mit ihm verschmolzen in den

2) Bei Ceratophrys cormuta, Xenopus Bojei, Pipa. 
Processus pterygö́dens des Quadratbeines sieh fortsetzt. Das fibröse Dach jeder Nasenhöhle, sammt dem Querknorpel, wird von einer Knochenplatte, die nach aussen stielförnig sich versehmälert, bedeckt. Diese Knochenplatte ist Cuvier's Frontale snterius. Ihre Ausdehnung ist nach dem Altersstadium und ic nach der Artverschiedenheit weehselnd; bisweilen bedeckt sie noch einen Theil des Knochenringes der Hirneipsel. Selten kommen noeh isolirte ïussere Nasenbeine hinzu ${ }^{3}$ ). In jeder Nasenhöhle findet sich bei vielen Frösehen noch eine schr kleine Ossifieation, welehe, eine Nasenhöhlentasche bildend, als Coneha zu bezeiehnen ist.

Das Kiefer-Suspensorium oder das Quadratbein ist ein sehr zusammengesetztes Hartgebilde, das nie vollständig zu verknöehern scheint. Es articulirt beweglieh durch zwei knöeherne, oft vermittelst zwischenliegender Knorpelsubstanz verbundene $\Lambda$ pophysen init dem $\boldsymbol{O}_{\text {s }}$ petrosum. Von der äusseren Apophyse erstreckt sich ein frei endender Processus mastoideus schräg vorwäts und abwïrts zur Augenhöhle; sehräg hinterwärts und abwärts begibt sich ein, seiner Gestalt nach, den Os tympanicum vieler Saurier entsprechender Fortsalz, Processus tympanicus, der in Gemeinsehaft mit dem Quadratjoehbein das Unterkiefergelenk bildet. Ein dritter vorwärts gerichteter Fortsatz ist der tiefer liegende Processus pterygö̈leus, der einwärts vom Quadratjochbeine und vom Oberkiefer in die knorpelige Grundlage des vorderen Augenhöhlenbogens übergeht und an einer Stelle eng an den Oberkieferbogen sieh ansehliesst. - Das den Unterkiefer tragende Gelenk wird nicht blos von dem Ende des Processus tympanicus des Quadratbeines, sondern wesentlich auch von einem Gelenkende des an jenes sieh anschliessenden os quadrato-jugale gebildet, welches als eine dünne Knoehenleiste, vom Quadratbein nach vorn geriehtet, an den eigentlichen ossificirten Oberkiefer sich anschliesst und init diesem einen $\mathrm{zu}$ sammenhangenden Bogen bildet - eine Regel, von welcher jedoch die Gattung Pipa eine Ausnahme bildet. Das Os maxillare superius selbst erstreekt sich bogenförmig, den grössten Theil des oberen Mundrandes bildend, nach vorn und sehliesst sich hier an den vor und. zwisehen den beiden Nasenhöhlen gelegenen gleiehfalls ossifieirten $Z$ wischenkiefer seiner Seite. Jeder der beiden lose verbundenen Zwischenkiefer besitzt einen Alveolarrand und einen zum Nasenhöhlendaeh aufsteigenden Fortsatz. - An der hinteren Grenze des Nasenhöhlenbodens oder des Gaumendaches findet sich jederseits gewöhnlich mit Ausnahme der Gattung Pipa - eine lose aufliegende, bei den Fröschen zahntragende Knochenplatte, welehe die hintere Nasenöffnung begrenzt. Sie entspricht dem paarigen Vomer der übrigen Reptilien. -

3) Ich finde sie neben den aufsteigenden Zwischenkiefer-Aesten bei Cystignathus pachypus. 
Endlich erstreekt sich an der Unterseite des Schedels von dein vorderen Ende des ringförmigen Knoehens ein stabförmiger Knochen nach aussen zum Oberkiefer, weleher den den vorderen Augenhöhlenrand bildenden Knorpel bedeekt. Man hat ihn Gaumenbein genannt. - Der Unterkiefer besteht gleiehfalls gewöhnlich aus knorpeligen und ossificirten Theilen zugleich. Seine Gelenkflïehe (Os articulare) ist knorpelig und setzt sich in einen von Knoehen belegten Stiel nach vorne fort. Der grösste Theil dieses Knorpels liegt in einer Rinne, die von dem Hauptknochen, Os operculo-angulare $\mathrm{D} u g \mathrm{ès}$, gebildet und aussen von dem Supraangulare Dug. vervollständigt wird. Der von diesen Knoehen umsehlossene Knorpel hangt vorn zusimmen mit dem paarigen Schlussstiiek der beiden Unterkieferbogen: Os dentale.

[Ueber den Schedel der ungeschwänzten Batrachier vergl. Inan, ausser dema 10ten Bande von Cuvier's Recherches, besonders die angef. Schrift von Dug ès, der zuerst die Aufinerksankeit auf die Coexistenz eines knorpeligen und knöcher. nen Schedels bei dieser Ordnung gelenkt hat. Bei zahlreichen von mir untersuchten Schedeln in - und ausländischer Arten der Gattuıgen Rana, Hyla, Bufo, Bombinator u. A. habe ich wesentlich dieselhen Theile gefunden, welche Dugès beschreibt. Pelobates weicht durch ein Schläfenhöhlendach ab und Pipa ist ausgezeichnet wegen der bis zur Hinterhauptsgegend sich erstreckenden ringförmigen Ossification. Die bisher aufgestellten Deutungen des Batrachierschedels sind nicht ganz befriedigend zu nennen. Cuvier's Frontalia anteriora sind mehr Nasenbeine, als vorlere Stirnbeine. Das Os en ceinture wird meistens dem Siebbein verglichen. Das passt allerdings auf einige Arten, wo die Ossification ganz unbeträchtlich und beschränkt ist, aber nicht auf andere, wo diese ringförmige Verknöcherung die halbe Schedellänge einnimnt, wie z. B. bei Hyla lactea, und noch weniger auf Pipa, bei der anscheinend die ganze Hirncapsel, mit Ausnahıne der 0 ccipitalgegend, von einem ununterbrochenen Knochengürtel umgeben ist. Diese ringförmige Ossification erinnert an weisten an die Kingbildungen der Schedelknochen bei den ächten 0phidiern. Zur Uutersuchung wälle man frische, nicht aher getrocknete Schedel, indem nur hei ersteren die knorpeligen Theile zu erkennen sind.]

\section{§. 62.}

Alle besehuppten Reptilien lesitzen ein durchaus wirbelähnliches Hinterhauptsbein, das einen vollständig geschlossenen. Ring darstellt. Seine einzelnen Bestandtheile sind gewöhnlich: ein unpaares Os basilare, ein gleichfalls unpaares Occipitale superius s. Squama occipitalis und zwei seitliche, beide verbindende Occipitalia lateralir. Selten sind die letztgenannten beiden Knochen mit der Squama zu einem Knoehen verschmolzen 1). Jedes Occipitale laterale verlingert sieh bei den Ophidiern in einen schwachen, bei den Sauriern, Gheloniern und Crocodilen aber in einen starken Querfortsatz. Dieser letztere wird bei dem Chamäleon und den Cheloniern nicht blos durch das Occipitale laterale, sondern unter

1) Bei Anphisbaena. 
Hinzutreten eines accessorisehen Knochens, des Occipilale exter$n \mathrm{um}^{2}$ ), der jenein dureh Naht verbunden bleibt, gebildet. Das Occipitale lacerale besitzt Foramina zum Durehtritt der Nervi glossopharyngeus und vagurs.

Beständig ist nur ein mittlerer Condylus occipitalis vorhanden. Seine Formation nähert sieh am meisten derjenigen dor unbeschuppten Reptilien da, wo er nur dureh die beiden Occipitalia lateralia gebildet wird und aus zwei einander beriuhrenden Gelenkköpfen besteht, wie bei mehren Chamäleonten; am fernsten stelıt dagegen jener Bildung die der Crocodile, wo er, einfach und rund, fast ganz auf Kosten des Os basilare entsteht. Bei den meisten Sauriern, den Ophidiern und Cheloniern besitzt er drei an einander stossende Höekerchen und wird dureh das Os basilare und die beiden Occipitalia lateralia gebildet. - Auch rüeksiehtlieh des Antlıeiles, den die einzelrien Hinterhauptsknoehen an der Begrenzung des Forumen magnum haben, kommen Versehiedenheiten vor. Bei den meisten Sauriern und Cheloniern tragen dazu sämmtliehe Theile des Hinterhauptsbeines bei; bei Chamäleo ist das $O s$ basilare und bei den meisten Ophidiem ${ }^{3}$ ), den Crocodilen und einigen Schildkröten f) das Occipitale superius ganz davon ausgesehlossen. - Bei den meisten Cheloniern bildet das Occipitale superius eine beträchtliehe naeh hinten verlängerte Hinterhauptsleiste. Theile des Hinterhauptsbeines werden bei allen besehuppten Reptilien zur Aufnahme des Gehörlabyrinthes mit verwendet: bei den Sauriern und Ophidiern das Occipitale laterale; bei den Cheloniern das Occipitale externum und bei den Crocodilen, ausser den Occipitalia lateralia, aueh das Occipitale superius ${ }^{5}$.

Vor dem Basilare occipitis wird die Sehedelbasis vervollstindigt durch einen ihm dureh Naht verbundenen Keilbeinkörper ( $\boldsymbol{S}_{\mu}$ he sьӥ deum lasilare). Seine untere Fläehe liegt bei den Ophidiern und Sauriern völlig frei, ist aber bei vielen Cheloniern und besonders bei den Crocodilen dureh die Ossa pterygö̈dea zum Theil verdeekt 6 ). Die obere der Schedelhöhle zugewendete Fläehe des Keilbeinkörpers bildet iminer eine Sella turcica. Vorn ist er bei den Sauriern, Gheloniern und Crocodilen ${ }^{\top}$ ) in einen dünnen Knorpelstiel ausgezogen, welcher meist bis in die Nasenhöhle sich verlängert und nieht nur das fibrös knorpelige septum interorbitale, sondern auch das Septum

2) Abweichende Ansichten über diesen Knochen s. bei Hallmann.

3) Bei Rhinophis trägt, nach Müller, auch die Squama occipitalis zur Umschliessung des Foramen magnum bei. - 4) Bei Hydromedusa nach Peters.

5) Vgl. den Abschnitt über das Gehörorgan \$. 86.

6) Bei den Crocodilen besitzt das Sph. llasilare an seiner unteren Fläche ein Locb, das den Eingang zu einem in die Sellu turcica führenden Canal bildet.

7) Bei den Crocodilen bildet es, elie es in den Knorpelstiel übergelit, eine kurze verticale Knochenleiste. 
werum stütat. Bei den meisten Oplidiern verliingert er sicl in einen duinmen Knoehenstiel, der aber bei einigen Gattungen, wo das Keilbein anch rorn breit bleibt ${ }^{8}$ ), fehlt. Bei den Sanriern besitzl der Keilbeinkörper starke seitliche Gelenkfortsiitze zur Articulation mit den Ossa pterygö̈dea; bei den Ophidiern statt ilırer hleine Seitenfortsaitze; solche Fortsiitze fehlen bei den Cheloniern und Crocodilen. - Ossificirte aufsteigende Keilbeinfliigel sind bei den Sauriern, den Ophidiern und auch bei den meisten Cheloniern nicht vorhanden; nur bei den Landschildkröten komınen sehr niedrige aufsteigende Fortsätze der Keilbeinkörper vor und bei den Crocodilen finden sich, als bẹsondere Knochenstucke, von dem Keilbeinkörper und der vorderen abgestutzten vertiealen Leiste desselhen, so wie von den Ossa pterygoüulea anfsteigende hintere Keilbeinflügel, welche die Scitenwand der Schedelhöhle vervollständigen.

Derjenige Schedelabschnitt, welcher das Grehirn umgibt, wird oben fast ganz von dem bald paarigen, bald unparen Scheilelbeine überwölbt, indem das Stimbein, auf das Orbitalsegment des Schedels beschräinkt, fast nur die zum Durehtritt der Geruchsnerven bestimmte canalförmige vordere Fortselzung der Schedelhöhle bedeckt. Nur bei einigen Sauriern und bei den Crocudilen hat das Stirnbein noch etwas mehr Antheil an der Bedachung der eigentlichen Schedelhöhle. Unpaar ist das Scheitelbein bei den Ophidiern, bei den Crocodilen und bej den meisten Sauriern, mit Ausnahme der Geckonen ${ }^{9}$ ); parige Scheitelbeine von beträchtlicher Ausdehnung finden sich bei allen Cheloniern. Zu den Seiten des Scheitelbeines liegt immer die Schlafengrube. Uebrigens bietet es bei ciuzelnen Ordnungen sehr charakteristische Eigenthiimlichkeiten dar. Bei den meisten Sauriern geht rom Scheitelbeine jederseits eine starke Leiste bogenförmig nach hinten und atssen und legt sich mit ihrem hinteren Ende auf den Processus transversus des Hinterhauptsbeines. Bei den Ophidiern stellt das Scheitelbein einen nur an der Schedelbasis offenen, hier aber durch den Keilbeinkörper und dessen Stiel geschlossenen Ring oder Gürtel dar, bildet also die Seitenwandungen der eigentlichen Schedelcapsel 10). Bei (len Clieloniern

8) Z. B. bei Trigonoeephalus, Naja.

9) Paarig ist es auch bei Bipes nach Müller.

10) Dies ist eine lex aun meisten characteristiseben Eigenthümlichkeiten der Ophidier. Indess bilden die Amplisbänen, Chirotes, Lepidosternon und andererseits Acontias, ja selbst eimige Scincö̈den Uebergangsstufen zwischen Ophidiern und Sauriern. Bei den Scineö̈len sind absteigende schmale Fortsätze des Seheitelbeines vorhanden, welebe indess nur die Columellae erreiehen; bei Acontias biegt sich das Scheitelbein seitlich un und umschliesst den oberen Seitentheil der übrigens seitwärts häutig begrenzten Schedelhöhle. Hier fehlen schon die Columellae. Bei Amphisbaena endlich bleibt awischen dein Scheitelbein und dem Keil. bein jederseits nur eine schmale Lï̈che. 
besitzt jedes Scheitelbein eine zur Sehedelbasis absteigende Leiste, welehe einen grossen Theil der Sehedelhöhle seitlieh begrenzt ${ }^{11}$ ).

- Den Orbitalabschnitt des Schedels bedeckt bei den Sauriern, den Ophidiern und den Crocodilen ganz, bei den Cheloniern grösstentheils das Stirnbein ${ }^{12}$ ), Frontale medium s: principale. Dasselbe ist unpaar bei den meisten Sauriern und den Croeodilen, paarig bei Laeerta, Varanus ${ }^{13}$ ), den Ophidiern und den Cheloniern. Es bildet bei vielen Sauriern ${ }^{14}$ ), bei den Cheloniern und Groeodilen dureh schmale absteigende Leisten an seiner unteren Fläche gewöhnlieh einen Halbcanal, der dureh fibrös-cartilaginöse Theile zu einem Canal für die Geruehsnerven vervollstïndigt wird. Bei den Ophidiern bilden aber die beiden Stirnbeine einen unten vollständig gesehlossenen Gürtel, der eine weitere Höhle einsehliesst.

Bei den meisten besehuppten Reptilien lehnen sich an den vorderen Rand des Stirnbeines zwei mehr oder minder beträehtliche $\mathrm{Na}$ senbeine, welehe die Nasenhöhle bedeeken. Von dieser Regel maehen zunäehst mehre Saurier mit offenen Nasenhöhlen ${ }^{15}$ ) eine Ausnahme, indem bei ihnen nur ein unpaares rudimentäres Nasenbein vorhanden ist, das die beiden Nasenlabyrinthe in Gestalt einer dureh einen aufsteigenden Fortsatz des Zwisehenkiefers vervollständigten mittleren Leiste trennt. Bei einigen Sauriern fehlt sogar dieses Nasenbeinrudiment ${ }^{16}$ ). Eine andere Ausnahme bilden die Chelonier, bei denen an den Vorderrand der Frontalia media die in der Mittellinie durch Naht verbundenen Frontalia anteriora anstossen, welehe, bei der Abwesenheit von Nasenbeinen, die Nasenhöhle zum grossen Theile überwölben. Nur bei der Gattung Hydromedusa sind Nasenbeine angetroffen worden ${ }^{17}$ ), deren Stelle bei Trionyx und Chelys dureh eine knorpelige, rüsselartig verlängerte Nasendeeke vertreten wird. Bei den Ophidiern vereinigen sieh absteigende Fortsätze der Nasenbeine zur Bildung eines einfaehen knöchernen Septum der beiden Nasenhölılen.

Bei den ineisten Sauriern und Ophidiern findet sieh am Boden der Nasenhöhle zur Seite des Septum ein das vorderste Horn des knorpepeligen Nasenlabyrinthes stuitzendes und theilweise umsehliessendes Musehelbein, Concha anterior ${ }^{18}$ ). Aehnliehe Knochen kommen

11) Von einigen anderen Eigentbümlichkeiten des Scheitelbeines ist schon \$. 59. die Rede gewesen.

12) Die beiden Stirnbeine rücken bei den Aıphisbänen weiter nach vorn und bedecken den 0 rbitaltheil fast nicht mehr.

13) Auch bei Anguis, Ophisaurus, Acontias.

14) Am auffallendsten bei Acontias und Gecko, aber auch, obschon minder stark, bei Scincus, Iguana u. A.

15) Z. B. Varanus. - 16) Z. B. bei Pseudopus.

17) S. darüber die angeführte Schrift von Peters.

18) Unter den Sauriern am deutlichsten bei denen mit offenen Nasenböblen, 
auch bei den Crocodilen sehr ausgebildet vor, sind aber hier von den Oberkieferbeinen und Nasenbeinen bedeckt und werden erst nach deren Entfernung deutlicl siehtbar.

Die Seitenwände der Schedelhöhle werden bei allen beschuppten Reptilien hinten gebildet durch das Occipitale laterale und durch das an dessen vorderen Rand stossende Os petrosum. Dieser bei den Ophidiern und den meisten Sauriern ziemlich betrïehtliche Knoehen kömmt bei den Cheloniern und namentlieh bei den Crocodilen äusserlieh wenig zu Tage. Er nimmt immer einen Theil des Gehörlabyrinthes auf und ist ausserdem zum Durchtritte des Nervus facialis bestimmt, wie denn aueh der zweite und dritte Ast des $\boldsymbol{N}$. trigeminus dureh einen vorderen Ausschnitt dieses Knochens hindurehtreten.

Die weitere Bildung der Seitenwandungen der Sehedelhöhle unterliegt, je naeh den einzelnen Ordnungen beträehtlichen Verschiedenheiten. Die Seitenwandungen der eigentliehen Hirneapsel sind ganz ossifieirt und werden dureh das gürtelförmige Seheitelbein gebildet bei den Ophidiern. Die gürtelförmigen Stirnbeine umsehliessen bei ihnen die Höhle des Orbitalabsehnittes des Sehedels. Die Seitenwandungen bestehen dagegen bei allen Sauriern nur in einer fibrösen Haut, welehe blos einzelne Verknorpelungen enthält. Bei den Cheloniern werden sie grossentheils dureh absteigende Fortsätze der Scheitelbeine und bei den Croeodilen theilweise durch die als gesonderte Knoehenstüeke erscheinenden hinteren Keilbeinflügel gebildet. Ergänzt werden diese knöehernen Theile bei den Cheloniern und Crocodilen dureh fibröse Häute, welehe nieht nur den vordersten Theil der eigentlichen Hirneapsel seitlieh umsehliessen, sondern aueh, gleich wie bei den Sauriern, die im Orbitaltheile des Sehedels vorhandene Rinne für die Geruehsnerven zu einem Canale vervollständigen, abwärts aber zu einem häutigen, auf dem Knorpelstiel des Keilbeinkörpers ruhenden Septum interorbitale versehmelzen. Dies setzt sich gewöhnlich als Septum der Nasenhöhlen nach vorn fort.

$$
\text { §. } 63 .
$$

Durch Nähte mit den Sehedelknoehen verbunden sind bei den meisten beschuppten Reptilien eigene Knochen, welehe die Augenhöhlen begrenzen. Es sind dies die Frontalia anterioral) und poste-

z. B. den Varanen, bei Pseudopus; aber auch bei den übrigen vorhanden, obschon durch die Nasenbeine verdeckt.

1) Das Os frontale anterius ist beständiger, als das Os frontale poste. rius; jenes fehlt bei wenigen Schlangen, z. B. bei Tortrix, während allen engmäuligen Schlangen und einigen ibnen nahestehenden Sauriem, so wie auch mebren weitmäuligen Schlangen die Frontalia posteriora fehlen, in welchem Falle denn die Augengrube hinten ganz offen ist und ohne alle Grenzen in die Schläfengrube übergeht. Der Mangel der Frontalia posteriora ist beobachtet bei 
riora, die weniger beständigen Thranenbeine (1ssa lacrymalia), welehe den Thräneneanal bilden und die seltener vorhandenen $0_{8} \& \alpha$ supraorlitalia.

Dic Ossa frontalia auteriora ungehen den vorderen Rand der Augenhöhlen und grenzen diese durcil absteigende Sehenkel von den Nasenhöhlen ab. Diese absteigenden Schenkel berithren sich in der Mittellinie nie, sondern werden dureh membranöse oder cartilaginöse Theile getrennt, welche den Geruchsnerven Durchtritt gestatten, also die Stelle des, als besonderes Knochenstück mangelnden, Siebbeines vertreten. Die Frontalia anteriora liegen gewöhnlich seitlich von dem vordersten Theile des Frovtale principale und vom Nasenbeine und sind bei den Sauriern, den Croeodilen und den meisten Ophidiern auch oben und aussen vollständig von einander getrennt; bei einigen Ophidiern berühren sie sieh indess hinten und oben mit selmmalen Fortsätzen, die sieh über die Nasenbeine legen \%. Bei den meisten Cheloniern dagegen, denen, wie sehon erwähnt ward, die Nasenbeine fehlen, liegen sie vor den Frontalia media, sind in der oberen Mittellinie dureh Naht mit einander verbunden ${ }^{3}$ ) und bedecken aneh grossentheils dic Nasenhöhle.

Thränenbeine kommen bei den meisten Saurien und bei den Croeodilen vor und liegen auswiirts und abwiirts von den vorderen Stirnbeinen, an der vorderen Grenze der Augenhöhlen, vorn an den Oberkiefer, unten und hinten gewöhnlich an das Jochbein anstossend. Ossa supracorlitalia, welehe den oberen Augenhöhlenrand erweitern, oder dessen häutige Erweiterungen stützen, sind nur bei cinigen Sauriern und Ophidiern angetroffen worden; bald einfach, wie bei Varanus und Python, bald mehrfach, wie bei Lacerta.

Jedes $O$ s froutale posterius bildet einen hinteren Augenhöhlenvorsprung und bezeiehnet die Grenze zwisehen Augenhöhle und Schliifengrube. Es liegt gewöhnlieh auswärts von einem Theile des Os frontale medium und Os parietale. Bei der Gattung Chelonia verlängert es sich nach hinten, indern es den ganzen Aussenrand des Scheitelbeines begrenzt und bildet auf diese Weise einen grossen Theil des die Schläfengrube überwölbenden Daches.

Bei vielen besehuppten Reptilien, namentlieh bei den Ophidiern und bei einigen Sauriern 4), bildet das Frontale posterias nur einen einfachen Processus orlitalis posterior, ohne mit einem hinteren Augenbogen oder mit Sehläfenknoehen sich zu verbinden. Bei den meisten

Elaps, Duberrial, Brachyorrhos; ferner hei Tortrix, Uropeltis, Rhinophis, Typhlops, Alanus, Cephalopeltis, so wie auch bei Amphisbacna und Chirotes. Bei einem Python-Schedel finde ich einen griffelförmigen, nach hinten gerichteten Knochen an Fiontale posterius befestigt.

2) Z. B. bei Python.

3) Getrennt bleiben sie indessen bei Chelys durch die Frontexlia media.

4) Z. B. bei den Geckonen. 
ubrigen Ordnungen und Familien tritt es sowol mit deu $U_{s} \approx y / g o m a-$ ticum als aueh naeh hinten mit dem $/ \boldsymbol{s}_{s}$ quadrato-jugale in Verbindung; ausnalımsweise mangelt bei vielen Cheloniern die Verbindung mit dem os quadrato-jugale und bei cinigen Sauriern die unmittel-

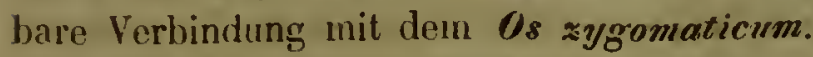

Dis O.s sygomaticzm fehlt ganz bei den Ophidiern, eben so bei einigen Sauriern 5), und erscheint bei einigen anderen nur als unbedeutender Fortsatz des Oberkieferbeines. Bei den meisten Sauriern, bei allen Clieloniern und bei den Croeodilen bildet es, vom Oberkiefer ausgehend und das Frontale posterius erreichend, einen Augenhöhlen bogen, der indess bei den Varanen dureh ein zwisehen beiden kno clien liegendes Band ergänzt wird.

Dureh ein bei vielen Cheloniern, den meisten Sauriern und den Crocodilen an das $O_{s}$ zygomaticum und an das Frontale posterius stossendes, bei anderen Cheloniern 6) blos mit dem Os zygomaticum. verbundenes os $\left.q u a d r a t o-j u g a l e^{7}\right)$ wird ein Schläfenbogen gebildet oder vervollständigt. Dieser Knochen erreicht beständig das, das Unterkiefer-Suspensorium bildende Os tympanicum s. quadratum. Sein Befestigungspunkt an diesem unterliegt jedoeh bedeutenden Verschiedenheiten. Bei einigen Cheloniern, namentlich den Seesehildkröten und bei den Crocodilen erstreckt er sieh abwärts zu dem für den Unterkiefer bestimmten Gelenkfortsatze des Quadratbeines; bei anderen Cheloniern erreieht er diesen letzteren nieht mehr und bei allen Sauriern trägt er nur zur Befestigung des an den Sehedel sich anlegenden Endes des Quadratbeines bei. Bei den Ophidiern, bei denjenigen Sauriern, die kein Jochbein besitzen ${ }^{8}$ ) und bei Chelys fehlt er ganz.

Ein im hintersten Absehnitte der Sehläfengegend gelegener Knochen ist das $0 s$ mastö̈deqm. Es stellt bei den meisten Ophidiern eine oberhalb des Os petrosum liegende, dureh Ligamente beweglich an det hinteren Grenze des Scheitelbeines und an dem Occipitale laterale befestigte, dann aber frei hinterwärts gerichtete Leiste dar, deren hinteres Ende ein Gelenk fuir das Quadratbein bildet. Bei anderen Ophi. diern fehlt es oder ist ganz rudimentär ${ }^{9}$ ). Bei den meisten Sauriern ist es gleiehfalls rudimentär ${ }^{10}$ ); bei anderen erseheint es als eine zwisehen dem Quadratjochbein und dem hinteren Fortsatze des Seheitel-

5) Bipes, Acontias, mehre Geckonen; bei einigen Geckonen ist es indessen ganz rudimentär vorhanden.

6) Z. B. Euys, Trionyx.

7) Cuvier bezeichnet diesen Knochen als Schlafbeinschuppe, Syuama tem. poralis. - S) Z. B. bei deu Geckonen.

9) Es fehlt bei Typhlops, Rhinophis und den ıneisten übrigen engınäuligen Schlangen oder ist ganz rudinentär und dient dem Quadratbeine nicht zur Stütze.

10) Z. B. Iguana, Scincus, wo es als ein kleines rundliches Kinochenstück über dem Processus transversus des Hinterhauptsbeines liegt. 
beines eingekeilte Leiste 11\}, die die Schedel-Articulation des Quadratbeines hinten vervollstïndigt. Die auffallendste Bildung zeigen die Chamäleonten. Die beiden Mastoïlea stellen zwei nach hinten und oben gerichtete Bogen dar, die weit hinter dem Schedel mit einander in Berührung treten und an ihrer Vereinigungsctcile durch das hinterwärts gerichtete, die Gestalt einer Crista occipitalis annehmende Scheitelbein erreicht werden. Bei den Landschildkröten legt sich das Os mastö̈deum schuppenartig uiber den lintersten Theil des Quadratbeines; bei Chelonia und den Crocodilen bildet es ein Dach iber dem Quadratbeine, dient ihm mit zur Befestigung und stitzt sich selbst auf den Querfortsatz des Hinterhauptsbeines.

Das Os tympanicum s. quadratum endlich bildet bei allen beschuppten Reptilien einen Gelenkfortsatz, der den Unterkiefer trïgt. Die Befestigungsweise dieses Knochens am Schedel ist verschieden. Bei den Ophidiern und Sauriern ist es beweglich, bei den Cheloniern und Crocodilen durch Naht fest und unbeweglich mit ihm verbunden. Bei den grossmäuligen Ophidiern articulirt es mit dem hintersten freien Ende des Os mustoïdeum; bei den Ophidia microstomata ist es an der Grenze des Occipitale laterale und Petrosum aufgehängt; bei den Sauriern haben an der Bildung des zu seiner Aufnahme bestimmte Gelenkes der Querfortsatz des Hinterhauptsbeines, der hintere Fortsatz des Scheitelbeines, das Os mastö̈deum und das Os quadrato-jugale Antheil. Bei den Schildkröten und Crocodilen ist es zwischen dem Quadrato-jugale, Mastoïdeum, Occipitale laterale, Petrosum, Sphenoüdeum und Pterygoüdeum fest eingekeilt. Bei den Ophidiern bildet es blos cine abwärts gerichtete Leiste; bei vielen Sauriern verhält es sich ïhnlich; bei Anderen bildet es hinten eine Rinne oder Längsgrube, die bei einigen Tejus schon zu einer weiteren und tieferen rundlichen Höhle wird. Weiter ausgebildet erscheint diese Höhle bei den Schildkröten und Crocodilen. Es gewährt dem Paukenfelle, sobald dasselbe äberhaupt vorhanden ist, einen Stiitzpunkt.

[Die ausfuihrlichsten Untersuchungen über den Schedel der Saurier, Chelonier and Crocodile finden sich in 9ten und 10ten Bande von Cuvier's Rechereles sur les nssemens fossiles. Ueber sämntliehe heschuppte Reptilien vgl. Meekel, System d. vergl. Anatomie Th. 2., und Köstlin, Bau des knöehernen Kopfes. Ueber einzelne ihrer Knoehen: Hall mann, Vergl. Ostenlogie d. Sehläfenbeines. - Ueber viele Saurier unl 0phidier: J. Mïller in Tiedemann und Treviranus, Zeitsehr. 13d. 4. - Ueber die Ophidier: d'Alt on, De Pythonis et Boarum ossibus, und $\mathrm{Cuvier}$, Leçons d'anat. eomp. T. 2. - Ueber die Chelonier, ausser Bojanus, besonders Peters in der angef. Sehrift. Die iltere Literatur kann hier nieht ausfülılieh gegeben werden. Die meisten oben angef. Schriften sind mit Abbildungen versehen.]

11) Z, B. bei Varanus, Gecko. 


\section{\$. 64.}

Der Kiefer-Gaumen-Appirat der beschuppten Reptilien bietet in so ferne grosse Verschiedenheiten dar, als er bei den Sauriern und besonders bei den Ophidiern schr frei beweglich, bei den Cheloniern und Crocodilen aber - mit Ausnahme des Unterkiefers fest und unbeweglich mit dem Schedel verbunden ist. - Die Saurier und Oplidier haben das Gemeinsame, dass ihr Quadrathein, welches nicht nur den Unterkiefer träigt, sondern welchem gewöhnlich anch das Os prerygoüdeum eingelenkt ist, frei beweglich mit dem Schedel articulirt. Bei den Ophidiern dient dem lose mit dern Schedel verbundenen Kiefer-Gaumen Apparate die ganz solid knöcherne Schedelcapsel als fester Stiitzpunkt, withrend ein solcher fester Stiitzpunkt ihm bei den Sauriern eigentlich nur dureh den Processus transversus des Hinterhauptsheines gewährt wird. Bei den Sauriern ist übrigens der Oberkiefer-Gaumen-Apparat, abgeseben von den dem $\boldsymbol{S}_{\text {phlenoüdeum }}$ uasilare stets beweglich eingelenkten Ossa pterygoidlea, mit dem vorderen Schedelabschnitte und den Gesichtsknochen fest verbunden. Der Kiefer-Gaumen-Apparat kann bei ihnen niemals allein, sondern nur mit dem ganzen vorderen Schedelabschnitte, welchem er angefügt ist. gehohen werden. Die Bewegung des letzteren wird dadurch möglich, dass das Scleitelbein einerseits mit dem Vorderrande des Ifinterhauptsbeines und andererseits mit der continuirlichen soliden Schedelbasis (dern $\boldsymbol{S}$ phenoüdeum lasilare) nur durch fibrös -häutige Theile zusammenhangt. Bei den ächten Ophidiern bietet dagegen die ganze völlig unbewegliche und allseitig ossificirte Schedelcapsel dem nur mit dem Frontale asterius beweglich verbundenen oberkiefer-Apparate einen durchaus festen Stiitzpunkt dar und die Freiheweglichkeit kömmt nur dem Kiefer-Gaumen-Apparate und seinem Suspensorium zu. Die Ophidia microstomata bilden in dieser Beziehung allınäliche Uebergänge zu den Sauriern.

Die Zusainmensetzung des Oberkiefer-Gaumen-Apparates zeigt iibrigens bei allen beschuppten Reptilien eine gewisse Uebereinstimmung. Die constant vorkommenden Knochen sind: e in einfaches oder paariges Zwisehenkieferbein, zwei Oberkieferbeine, zwei Gaumenbeine, zwei Ossa pterygö̈dea. Zu ihnen koinmen, als nicht so beständige Knochen, zwei Ossa transversa, ein einfacher oder pariger Vomer und, als Copulae mit dem Schedeldache, dic nur den meisten Sauriern eigenthiurnlichen Columellae.

Der Zwischenkiefer ist bei den Sauriern, Cheloniern und Crocodilen fest eingekeilt zwischen den beiden Oberkieferbeinen; eben so verhält er sich bei den Amphislöinen und mehren verwandten Gattungen, wihrend er bei den ïchten grossmäuligen Schlangen auf dem, durch die beiden Nasenbeine gelildeten, Septum der Nasenhöhlen aufsitzt und nit den Oberkieferbeinen unverbunden bleibt. Er ist einfach 
bei den meisten Sauriern, bei den Ophidiern und bei Chelys, paarig bei den Scincoïlen, den übrigen Cheloniern und den Crocodilen. Bei. den Sauriern trennt cin aufsteigender Fortsatz die beiden Nasenhöhlen und verbindet sieh oft mit den Nasenbeinen. Sein (nicht immer vorhandener) horizontaler Theil trägt bei cinigen Sauriern, bei den Cheloniern und besonders bei den Croeodilen zur Vervollstiindigung des Bodens der Nasenhöhle und des Daches der Mundhöhle,bei.

Das Oberkieferbein stellt bei den ächten Ophidiern nur eine zahntragende Leiste dar, die, mit dem Froutale anterius articulirend, bei den unschaidliehen und einigen giftigen Schlangen, z. B. Hydrophis, Bungarus, Sepedon, Naja, lang, bei inanchen giftigen, wie namentlich dei Crotalus, Trigonocephalus, Vipera, dagegen sehr kurz ist. - Bei den Amphisbänen, den ächten Sauriern, den Cheloniern und Crocodilen ist es fest und unbeweglich mit dem Schedel verbunden. Während sein Gesiehtstheil bei allen Cheloniern und vielen Sauriern zur Begrenzung der Augenhöhle und Nasenhöhle beiträgt, ist es bei den Ampbisbänen, Lacerten, Varanen u. $\Lambda$. von ersterer, bei den Crocodilen von beiden ausgeschlossen. Der Antheil, welchen es an der Bildung des knöchernen Gaumengewölbes hat, ist sehr verschieden. Noeh bei vielen Sauriern bildet es kaum mehr als ein Alveolarstïck 1); bei anderen einen schmalen Gaumenrand 2); breiter wird dieser bei den meisten Cheloniern, während bei den Crocodilen der grösste Theil des knöchernen Gaumens durch die beiden fast in ihrer ganzen Länge mittelst Naht verbundenen Gaumenplatten der Oberkieferbeine gebildet wird.

Die Gaumenbeine bestehen bei den ächten Ophidiern in zwei kurzen, weit von einander getrennten, zahntragenden Leisten, welche hinten mit den Ossa pterygö̈dea verbunden sind. Schon bei mehren Ophidia microstomata verlieren sie ihre Freibewegliehkeit. Bei den Amphisbänen, den Sauriern, Chelonicrn und Crocodilen sind sie sowol mit den Oberkieferbeinen, als mit den Ossa pterygoülea unbeweglich verbunden und tragen bei allen ächten Sauriern und den Crocodilen zur Umschliessung seitlicher Oeffnungen bei, wolche eine Lücke im Augenhöhlenboden bilden und in deren hinterem Umkreise der $\boldsymbol{M}$. $\boldsymbol{p} \boldsymbol{c} \boldsymbol{c}$ rygoüdeus sich befestigt. Bei den moisten Sauriern bildet jedes Gaumenbein eine einfacho Knochenplatte, das cinerseits den Boden der Augenhöhle und andererseits das Gaumengewölbe vervollständigt; sclion bei den Scineoïlon, so wie auch bei den meisten Cheloniern entsteht durch zwei Platten eine Rinne für den hinteren Nasengang jeder Seite, welche Rinne bei den Crocodilen z.ı einer allseitig begrenzten Höhle wird. Bei den meisten Sauriern ${ }^{3}$ ) und bei vielen Cheloniern sind die beiden Gaumenbeine in der Mitte mehr oder weniger weit von einan-

1) Z. B. bei Iguana. - 2) Z. B. hei Scincus, Gecko, Chamacleo, Varanus.

3) Namentlich bei den Geckonen, Chamäleonten, Scincoïten. 
der, bei jenen dırch eine Lüicke, bei diesen dırch den zwischen sie gcschobenen Vomer, von einander getrennt; bei einigen Cheloniern und bei der Crocodilen sind sie in der Mittcllinie durch Naht mit einander verbunden.

Die Ossa pterygoüdea sind bei den ächten Ophidiern schmale gebogene Lcisten, welche stets vorn an die Gaumenbeine, hinten aber durch je eine stielförmige Verlängerung gewöhnlich an das Untcrkiefer. gelenk des Quadratbcines stossen und aussen durch ein cigenes knochenstiick (Os transversum s. pteryguädenm externum) mit dem Obcrkieferbeine verbunden werden. Bei einigen engmiiuligen Schlangen und bci den Chamäleonten fällt dic Verbindung mit dem Quadratbeine weg. Bei den meisten Sauriern kömmt zu den genannten Verbindungen noch eine bewegliche Einlenkung an Querfortsätzen des Sphenoiileum. Uasilare. Bei den Amphisbänen und den Sauriern vervollstän. digen die Ossa pterygoüdea mit ihren Gaumenplatten das knöcherne Gaumengewölbe, gewöhnlich ohne einander in der Mittellinic zu berïhren. Bei den Cheloniern sind sie stets in der Mittellinic durch Naht verbunden, bilden den grössten Theil des knöchernen Gaumengewölbes 4), stehen gewöhnlich mit dem Oberkiefer nicht in Verbindung, legen sich an den ganzen hinteren Rand der Gaumcnbcine, liegen stets unter einem Theile des Sphenö̈leum basilare und unter scinem Knorpelstiel, verbinden sich scitwärts durch Naht mit den Quadratbeinen und stützen endlich in der Regel die absteigenden Aeste der Scheitelbeine. Bei den Crocodilen berühren sie sich in der Mittellinie, schliessen sich mit ihren Vorderrändern an die hinteren Ränder der schmaleren Gaumenbeine, tragen, auswärts frei, noch zur Umgürtung der seitlichen Oeffnungen bei, welche am Boden der Augenhöhle sich finden, verbinden sich aussen durch die Ossa transuersa init den Oberkiefern, den Jochbeinen und den Ossa frontalia posteriora, liegen unterhalb eines grossen Theiles des Sphenoüdeum Lasilare und treten durch selır kurze aufsteigende Aeste mit den Ossa petrosa, tympanica und den Keilbeinfliigeln in Verbindung. Sie sind ausgehöhlt; ihre beiden, durch ein knöchernes Septum geschiedenen, Höhlen sind Verlängerungen derjenigen der Gaumcnbeine und enthaltcn die hinteren Nasengänge, welche durch zwei Oeffnungen an ihrer Grundlliiche nach aussen muinden.

Das nur den Sauriern, fast allen Ophidiern und den Crocodilen eigenthümliche, den Cheloniern fehlende Os transversum 5) s. pterygö̈deum externum vermittelt die Verbindung des Os pterygö̈deum und bisweilen auch des Gaumenbeines ${ }^{6}$ ) mit dem Ende des Alveolartheilcs des Obcrkiefers und häufig zuglcich mit dem Jochbcine odcr

4) Besonders bei Chelys.

5) Es fehlt bei Typhlops, ist aber bei Rhinophis vorhanden.

6) Z. B. bei Scincus. 
auçh noch mit dem Frontale posterius \%). Es ergänzt nur selten das Gaumengewölbe ${ }^{8}$ ).

Den meisten Sauriern ${ }^{9}$ ) eigenthümlich ist ein an der oberen Fläche des Os plerygoülleum, über seiner Articulation mii dem Keillseinkörper befestigter, aufwärts zu der Grenze des Scheitelbeines und des llinterhauptsbeines sich erhebender Knochensticl, C'olumella, der allen übrisen Reptilien felıtt.

Bei allen beschuppten Reptilien endlich, mit Ausnalime der Crocodile, findet sich ein bald paariger, bald unpaarer Vomer, der vor den Gaumenbeinen, oder, wie bei cinigen Schildkröten, zunn Theil auch zwischen ihnen gelcgen, in Verbindung mit ilınen nicht nur die bciden linteren Nasenöînnungen umschliesst, sondern sie ạuch trennt. Unpaar ist dieser Vomer bei allen Cheloniern; parig bei den Ophidiern und Sauriern; hier berihhen sich die beiden Knochen in der Mittellinie. Zwischen Gaumenbeinen und Zwischenkiefer eingekeilt, vervollständigt der Vomer bei den Schildkröten und namentlich bei vielen Sauriern den vorrleren Abschnitt des Gaumengewölbes, bildet bei den Sauriern und Ophidiern den grössten Theil des Bodens der Nasenhöhle und dient den Nasenmuscheln zur Stiitze. Bei einigen Sauriern, namentlich bei den Yaranen kömmt ganz vorn zwischen dem Vomer und dem Zwischenkiefer noch ein kleines längliches unpaares Knöchelchen vor.

Der Unterkicfer der beschuppten Reptilien bietet sowol rücksichtlich der Verbindungsweise seiner beiden Seitenäste, als auch rücksichtlich der Anzalll der ihn zusammensetzenden einzelnen Knochenstücke grosse Verschiedenheiten dar. Die beiden Unterkieferbogen verbinden sich bei den Sauriern und den Crocodilen fest und innig mit einander durch eine zwischen den Ossa dentulia liegende Naht. Bei den moi sten Cheloniern - mit Ausnahme der Gattıngen Chelys und Ilydromedusa - ist sogar für beide Aeste des Unterkiefers nur ein cinziges mittleres unparics $O s$ destale vorhanden. Ganz entgegengesetzte Verhältnisse finden dagegen bei den Schlangen Statt, indem, wenigstens bei den Ophidia nlacrostomata, die beiden Unterkiefcräste weit auseinander stelien und nur durch dehnbare Bandmasse init einander verbunden sind. Von ihnen unterscheiden sich die engmäuligen Schlangen durch eine innigere Verbindung beider Aeste und bilden so den Uebergang zu den Sauricrn.

Die geringste $A$ nzabl von Knochenstücken in Unterkicfer wird bei den Giftschlingen, namentlich bei Crotalus und Trigonocephalus angetroffen, wo ihrer nur vier jederseits vorhanden sind; ihre Zahl steigt bei der Mehrzahl der Ophidicr auf fünf; bei den meisten Sauriern und

7) Bei den Crocodilen. - 8) Z. B. hei Scincus.

9) Sie fehlt den Chamäleonten und vielen schlangenähnlichen Sauriern: Acontias, Anguis, Seps, Pseudopus, Bipes, Ophisaurus. 
bei den Crocodilen sind sogar sechs vorhanden; eben so viele wirden bei den Cheloniern geziilılt werden, wiirde bei den meistenderselben nicht, bei Anwesenheit eines unpaaren $\boldsymbol{O S}_{\text {s dentale }}{ }^{10}$ ), die Zahl simmtlichel Knochenstiicke des Unterkiefer's auf eilf reducirt. - Die einzelnen Knochen, welehe den Unterkiefer deı höhheren Saurier, der Crocodile und der Schildkröten zusammensetzen, sind folgende: 1) Das Os ilentale, unter allen (lias betrüchtlichste, welches zugleich allein die Zähne träigt; 2) das die lumenfliche des Unterkiefers vervollstïndigende $O_{*}$ operculare, bei den Crocodilen an weitesten nach vorn geriickt, bei den Cheloniern mehr hinterwäits gelegen; 3) das den unteren Winkel bildende Os angulare; 4) das ülser ilım, an hinteren und oberen Theile des Unterkiefers liegende $\boldsymbol{O} s$ supraungulare; 5) das bei den Crocodilen kleine, die Innenflache vervollständigende, bei den Cheloniern und den Sauriern den Kronenfortsatz bildende 0 s complementare; 6) das Gelenkstück, Os arrticulare, welches in den in die Unterkieferhöhle sich erstreckenden Meckel'schen Knorpel sich forlsetzt.

Ein Processus cormü̈deus fehlt dem Unterkiefer der Crocodile, ist dagegén bei den meisten Ophidiern, so wie auch bei den Cheloniern vorhanden und bei den Sauriern gewöhnlich sehr stark entwickelt. Bei den Ophidiern, Cheloniern und einigen Sauriern, z. B. den Chamäleonten, befindet sich das Gelenk am hintersten Ende jedes Unterkieferastes, während sich letzterer bei den meisten Sauriern und bei den Crocodilen noch mehr oder minder bedeutend hinter dem Gelenke verlängert.

Die Gattung Rhamphostoma besitzt endlich die Eigenthüinlichkeit, dass die Symphyse der beiden Unterkieferäste, welche schon bei mehren ächten Crocodilen nach hinten sich ausdehnt, von vorn bis zu den vorletzten Zähnen reicht, indem die beiden Ossa dentalia sich in dem grössten Theile ibrer Länge verbintlen und im letzten Viertel ilırer Ausdehnung noch die Ossa opercularia beider Seiten, gleichfalls durch Symplyyse verbunden, zwischen sie treten.

[S. über den Kiefer - Gaumen - Apparat die früher \$. 62. angeführten Schriften.]

\section{Vom Zungenbein - und Kiemenbogen-Apparate.}

§. 6 อั.

Das Zungenbein der Perennibranchiaten ${ }^{1}$ ) besteht aus zwei Zungenbeinbogen nebst deren Copula und dem Kiemenbogen$\Lambda$ pparate und entspricht mit einigen Modificationen den gleiclinamigeı

10) Es ist jeloch parig bei Chelys und Hydromedusa.

1) Siehe Cuvier, Recherches sur les ossem. foss., T. X. Tab. 255. (Siren u. Proteus). Rusconi l. c. Tab. IV.V. VI. Achnlich ist das Verhalten bei Menopoun nach Mayer. 
Apparaten der Fische. Von jeder Seite des Os petrosum steigt ein an ihm durclı Liganent hefestigter Zungenbeinbogen (vorderes Horn des Zungenbeincs) abwärts. Beide Bogen convergiren und stossen zusammen an einer mittleren, unpaaren, schmalen Copula (Zungenbeinkörper), welche vorn eine der Zunge zur Grundlige dienende Knorpclplatte (Cartilago entogglossa) trägt, nach hinten aber stabförmig verlängert ist ${ }^{2}$ ). Von dem hinteren Endc dieses Knochens gehen jederseits zwei ${ }^{3}$ ) einfache oder aus zwci Abschnitten bestehende, den Zungenbeinbogen parallele Knochen ab, an deren Enden drei oder vicr bald knöehcrne, bald knorpelige Kiemenbogen theils unmittelbar, theils mittelbar befestigt sin( 4). - Bei den Cöcilien ${ }^{5}$ ) ist, ausser den Zungenbcinbogen, nur das erstc Paar der folgenden vier Bogen mit der Copula verbunden; die beiden nächsten Paare stehen weder unter einander, noch mit der Copula in Verbindung und dem fünften Paare dient las vierte zur Stiitzc. - Der Zungenbein Apparat der Salamandrinen bietet während ihres Larvenzustandes ${ }^{6}$ ) eine auffallende Aehnlichkeit mit dem der Perennibranchiaten dar, erfährt aber später, bcsonders durch das Schwin den der Kiemenbogen, bedeutende Veränderungen. Bei den ausgebil deten Thieren sind zwei vorn bald unverbundene, bald dic Spitze der die folgenden Bogen verbindenden Copula erreichende Zungenbeinbogen *) vorhanden. Anstatt des Kiemenbogen-Apparates zeigen sieh aber zwei scitliche, mittelst einer knorpeligen Copula vereinigtc Knorpelbogen und ein hinter ihnen liegendes Paar verknöcherter Bogen (Columellae), die dureh eine hintere ossificirte Copula verbunden sind. Die hintere Copula grenzt an die vordere. Jede Columella artieulirt an ihrem hinteren Ende mit dem vor ihr liegenden Bogen. - Bei den ungeschwänztcn Batraehiern ist das eigenthümlich gcformte Zungenbein durch Reduction der ursprünglichen Kiemenbogen und ihrer Copula und durch Verschmelzung dieser Theile mit den eigentlichen Zun-

2) Bei Siren setzt sich an das hintere Ende der Copula noch ein unpaares, gleichfalls in der Längsrichtung nach binten sich erstreckendes Knochenstück, das an seinem freien Ende vielfach ausgezackt ist.

3) Bei Proteus ist das zweite nur rudimentär. Aus zwei Segmenten bestelit jeder dieser Knochen, nach Cuvier, bei Siren.

4) Vier knorpelige Kiemenhogen finden sich bei Siren (auch beim Axolotl und bei den Salamanderlarxen); drei ossificirte bei Protens. Die letzten beiden befestigen sich durch Knorpel an den ersten.

5) Vgl. Henle, Vergleichend anat. Beschreib. des Kehlkopfs, Leipz. 1839, 4., Tab. 1. Fig. 1.

6) Siehe Rusconi, Descrizione anatomica degli organi della circolazione delle larve delle Salamandre, Pavia 1817. 4. - C. Siebold, Observat. de SalaInandris et Tritonibus, Berol. 1828. 4. Fig. 15-17. - Martin St. Ange in Ann. d. sc. nat., T. XXIV.

7) Bei Triton ensatus nach Rathke. Hier findet sich auch eine zweilappige Cartilago entoglossa, welche sonst den Tritonen felilt. 
genbeinstiicken entstanden 8 ). Der einfache Zungenbeiıkörper $\left.{ }^{9}\right)$ stellt gewölnlich eine mehr oder ninder breite, nur sehr selten ${ }^{10}$ ) theilweise ossifieirte Knorpelplatte dar, von deren vorderem Theile die grossen Iö̈rner als ein Paar langer Knorpelbogen alggehen und in der Regel ${ }^{11}$ ) nit dem Schedel intieuliren. An den Seiten des Zungenbeinkörpers zeigen sich noch zwei Parar viel kiirzere Fortsätze, welelıe bei Versehmälerung des Zungenbeinkörpers auch als untergeordnete Aeste der grossen Hörner erseheinen können 12). Das vierte Bogenpaar endlich, das stets voin hintersten Theile des Körpers abgeht, besteht in zwci beständig verknöcherten, stabförmigen, an ihrem Ende cine knorpelige Epiphyse tragenden Stücken: Columsellaxe.

§. 66.

Ber den Oplidiern fehlt entweder jede Spur eines Zungenbeines 1) oder es ist rudimentïr und nur durch zwei lange Knorpelfäden repräsentirt, welelıe, zur Seite der Zungenseheide liegend, vorn in einem Bogen sich vereinigen. - Bei den Sauriern 2) besitzt das Zungenbein einen sehr unbedeutenden Körper, der vorn in eine für die Zunge bestimmte Spitze ausläuft. IIinten ist es mehr oder minder tief gabelförmig getheilt und setzt sich auch nicht selten auf diese Wcise in ein Paar accessoriseher binterer Hörner fort ${ }^{3}$ ). Ausser diesen aber kommen regelmässig jederseits zwei schmale Ilörner vor. Das vordere dieser IIörner besteht gewöhnlich aus zwei, seltener aus drei meistens knorpeligen oder selbst bandartigen Segmenten, welche häufig unter spitzen Winkeln zusammentreten 4). Es umfasst gewöhnlich seitlich den Hals und artieulirt selten mit dem Schedel 5). Das zweite Ilorn besteht bald aus einem, bald aus zwei Segmenten, ist gewölnnlich grossentheils ossi-

8) S. die Abbildungen vou Batrachierlarven bei Rathke, Kiemenapparat u. Zungenbein d. Wirbelthiere, Tab. IV. Fig. 3-8.

9) Zahlreielıe und vortreffliche Abbildungen hat Henle gegeben a. a. 0. Tab. 1. 11. 2. - 10) Bei Alytes und bei Xenopus nach Henle.

11) Mit Ausnalume von Pipa. Siche Henle a. a. O. Bei den Aglossa divergiren die grossen Höruer zuerst, eonvergiren dlann und versehmelzen. Auf diese Weise schliessen sie eine Oeffnung ein, durch welche die Musc. hyoglossi treten. Bei Pipa endell sie in dieser Verschmelzung. - Statt des zweiten und dritten Hornes finilet sich bei den Aglossa ein Paar breiter Fortsätze. Auch versehmilat bei ihnen der Zungenbeinkörper mit deın Stiumnladenknorpel.

12) Bei Hyla venulosa nach Henle.

1) Miiller vermisste es bei 'Tortrix, Typhlops, Rhinophis.

2) Zahlıeiche Abbildungen bei Cuvier, Ossell. foss., Tab. 2ł5. Fig. 1-8. Vou Zungenbein der schlangenälnnlichen Saurier gab Müller Abbildıngeu iı Tiedeuann und Treviranus, Zeitsehr. f. Phys., Bd. 5. Tab. 19. Fig. 4-10.

3) Bei Lacerta, Scincus, Iguana. Bei letzterer Gattung und auch bei aulern Sauriern dienen sie den Hautlappen der Kehle zur Stiitze.

4) Bei Gecko wird das erste Segment an seinem Ende breiter, bei Lacerta und Scincus das zweite an Anfange; beide Bedingungen treffen zusammen bei Varanus. - 5) Dies ist der Fall bei Iacerta und Scineus. 
ficirt und oft nur an der Spitze knorpelig ${ }^{6}$. Bei den Crocodilen ;) bildet der Zungenbeinkörper eine nach der Bauchseite convexe Knorpelplatte, welche ein Paar Hörner trägt. Jedes derselben besteht aus einem ossificirten und einem knorpeligen Segmente. Sie articuliren nicht nit dem Schedel. - Unter den Cheloniern 8) herrscht grosse Verschiedenheit rücksichtlich der Bildung des Zungenbeines. Der breite Kö̈rper ist bald einfach, bald besteht er aus zahlreichen Stücken \%). Bei Einigen ist er solide, bei Anderen besitzt er eine 10) oder selbst zwei ${ }^{11}$ ) Oeffnungen. Gewöhnlich trägt er drei Paar kurzer IIörner; nur bei den Landschildkröten ist das vorderste Paar mit dem Körper verschmolzen. Beständig erstreckt sich eine schmalere oder sehr breite Cartilagro entoglossa 12), welche mit ihrem hinteren Ende Jose durch Zellgewebe an die untere Fläche des Zungenbeinkörpers befestigt ist, nach vorn zur Zunge.

\section{Zweiter Abschnitt. \\ $V$ o $u \quad I I a u t o r g a n e$.}

§. 67.

Das Hautorgan der Reptilien bietet rücksichtlich seiner Zusammensetzung, seiner Verhältnisse zu den von ihm unschlossenen Theilen und der an ihm vorkommenden absondernden Drüsen mannichfache Verschiedenheiten dar. Bei den nackten Reptilien ist die Haut am einfachsten gebildet. Sic besteht aus der meist dünnen Cutis, deren Elennente verschlungene Zellgewebsfasern sind, aus einer diese bedeckenden Pigmentschicht ${ }^{1}$ ) und aus (ler, mehrfache Lagen von Zellen bildenden, Epidermis, welche in steter Erneuung begriffen ist. Bald haftet die Haut innig an den Muskeln, bald ist sie sehr locker durch Zellgewebsbruicken, welche namentlich bei den ungeschwänzten Batrachiern häufig subcutane Lymphräume einschliessen 2), mit ihnen verbunden. Bei den beschuppten Reptilien zeichnet sich die Haut meistens durch

6) Bci Varanus endet das hintere Horn über dem Schulterblatt.

7) Abbill. bci Cuvicr 1. c. Tab. 233. Fig. 3. - 8) Abbild. bci Cuvicr Tab. 240. Fig. 40-43. Bojanus Tab. Xml. Fig. 42. - 9) Bei Trionyx.

10) Bci Emys. S. auch dic Abhildung des schr eigenthümlich zusaminengc. setzten und gestalteten Zungenbcins ron Chclys bei Cuvier 1. c. Tab. 240. Fig. 41.

11) Bci Testudo radiata und $T$. indica nach $C$ uvier.

12) Schmal bei Chelonia, sehr breit und aus zwci Scitenlälften bestchend bci Chelys.

1) Dic ramificirten Pigmentzcllen der Frösche sind hinlänglich bekannt. Eine sorgfältige Beschreibung des Hantapparates der Frösche liefert Ascherson in Müllcr's Archiv, 1840, S. 15. mit Abbild.

2) Abgebilldet bei Dugc̀s, Rccherchics Tab. 5. 1. 122. 
grüssere Dicke aus; anI dïnnsten ist sie bei vielen Sauricrn, nanentlich den Geckonen und den Chamäleonten, welehe keine cinander deckenden Sehuppen besitzen, sondern wo die Ilaut durch kleine Erhabenhei ten, dic vorzugsweise reichlich ligment enthalten, sich auszeichnet. Sehr viel dicker ist die Cutis bei den mit deutlichen Schuppen versehenen Ophidiern und Sauriern. Die aus verschlungenen Zellgewelssfisern bestehende Cutis ist hier nicht gleichmässig eben, sondern bildet von Stelle zu Stelle Verdoppelıngen, welche nach ihrem freicn Ende hin allmälich sich verdiinnen. Indem jede solche freie Duplicatur die zunäehst liegende Ausloreitung der Cutis dachziegelförmig deckt, erhält die ganze Cutis ein schuppenförmiges Ansehen. Ueber der die Cutis unmittelbar bedeckenden Pigmentschicht liegt sodann die aus mehren Lagen bestehende continuirliehe Epidermis. Diese ist, so weit jede Schuppe der Cutis frei zu Tage liegt, verdiekt, verdiinnt sich aber, wenn sie unter den freien Rand derselben über den bedeckten Abschnitt der Cutis sich fortsetzt, um da wo sie oberflächlich zu Tage körnmt wieder hornartig sich zu verdicken. An den verdünnten Stellen und ununittelbar iilser der Pigmentsehicht erkennt man deutlich die polyedrischen, oft kernhaltigen Zellen der Epidermis, während diese an den hornartig verdickten Stellen nicht nachweisbar sind. Bei vielen anderen Sauriern, z. B. den Scincoïden ${ }^{3}$, Pseudopus, kommen Ossificationen in den von Epidermistaschen unschlossenen und oberflikehlich unınittelbar von einer Pignmentschicht bedeekten Cutisschuppen vor. Jede ossificirte Schuppe; an deren Basis die Cutis haftet, besteht, namentlich bei vielen Scincoïden, aus zahlıcichen, sehr regelmässigen, mosaikartig durch dliinne Bindegewehsstreifen unter einander verlundenen Knochenstückchen, welehe oberflïchlich bisweilen zierliche Rinnen und Furchen zur Aufnahıne der Pigmentschicht besitzen. Bei Pseudopus sind die Ossificationen noch dicker. - Bei den Crocodilen besitzt die Cưtis nicht sowol Schuppen, als sie viehnehr in grösscre, sehr regelmässig gestiltete, dureh festeres Gewebe ausgezcichnete Abtheilungen oder Schilder zerfällt, welche von biegsameren schlafferen Falten oder Einscnkungen der Cutis allseitig umschlossen und von cinander abgegrenzt werden. Auf Kiosten der Cutis bilden sich mit vorschreitendem Alter in der Substanz jener derberen Schilder Ossifieationen. Dic Epidermis ist auch bei ihnen, so weit sie die Oberflïche jener Schilder bedeckt, dicker, als in ihren Zwischenrïumen, wo sie siclı verdünnt. - Bei den Cheloniern zcigt die Cutis im Allgemeinen eine ähnliche Bildung, wie bei den Crocodilen, inden sie im Bereiche des Kopfes, des IIalses, der Extremitäten und des

3) Ich habe hier sowol, als bei Pseudopus deutliche Knochenkörperchen beobachtet. Ich untersuchte mehre Lygosoma (Tiliqua Gray). Die Structur der Schuppen verliente bei den Scincoïlen ron ler systematischen Zoologie mehr berïcksichtigt $2 u$ werlen, als bisher geschehen ist. 
Schwanzes in ähnliche, durch laxere faltige Siume getrennte Schilder zerfïlt. In der Rückengegend des Rumpfes entstehen aber auf Kosten der Cutis die merkwürdigen, mit den oberen Wirbelbogenschenkeln und mit den Rippen verwaclisenden Ossificationen, deren Summe das sogenannte Rückenschild der Chelonier bildet, das nach Entfernung der, unter dem Namen Schildpatt bekannten, hornartig verdickten Epidermis zu Tage kömmt. Diese auf Kosten der Cutis gebildeten Ossificationen, welche gewöhnlich durch Nähte mit einander verbunden sind, bestehen aus einer Reihe von Medianplatten des Riickens, aus grösseren paarigen die Rippen deckenden Seitenplatten und aus den umgürtenden Marginalplatten 1 ).

Eine interessante, aber rücksichtlich ihrer anatomischen und plysiologischen Bedingungen noch nicht hinreichend aufgeklärte Erscheinung ist der Farbenwechsel vieler Saurier, namentlich der Chamäleonten ${ }^{5}$ ).

Der absondernde Apparat des Hautsystemes ist bei den Reptilien höchst verschieden entwickelt; er scheint nur den Cheloniern und den Ophidiern gänzlich zu mangeln. Bei den Salamandern ${ }^{6}$ ) und einigen Tritonen finden sich zahlreiche Hautdrüsen, theils zerstreut, theils regelmässig gestellt; die letzteren erstrecken sich, zu jeder Seite der Wirbelsäule eine Lünğsreihe bildend, von der Schwanzspitze bis zum Kopfe und bilden hier, zu Haufen dicht an einander gedrängt, die fälschlich osogenannten Parotiden. Bei den Fröschen und Kröten finden sich, namentlich in den äusserlich warzig erscheinenden Regionen der Haut reichliche contractile Drüsen und die Bufonen sind, gleich den Salamandern, durch eine jederseits am Kopfe befindliche Anhäufung grösserer Drüsen, der Parotiden der meisten Schriftsteller, ausgezeichnet. Bei einigen Fröschen ") kommen auch Reihen grösserer Drüsen am Oberarme vor. Bei den Sauriern finden sich die in Gestalt blinder Säckchen erscheinenden Ilautdrüsen vorzugsweise in gewissen Regionen des Körpers; bei vielen erstrecken sie sich in Gestalt kleiner Tuberkeln von der Inguinalgegend bis zur Kniebeuge an der Innenseite des Schenkels abwärts und sind dann unter dem Namen Papillae femorales bekannt ${ }^{8}$; bei anderen kommen in der Oberarmbeuge ähnliche Drüsen

4) S. die Abbild. bei Cuvier, Recherehes Tah. 241. und bei Bojanus l.c. Tab. 11 .

5) Vgl. van der Hoeven, Ieones ad illustrandas coloris mutationes in Clamaeleonte, Lugd. Bat. 1831. 4. - Milne Edwards in Müller's Archiv 1834, S. 474. - 6) Abbild. bei Funk Tab. II.

7) Bei Pelobates eultripes nach Müller.

8) Vgl. larüber die sorgfältigen Untersuehungen von C. F. Me iss ner, De Amplibiorum quorundam papillis glandulisque femoralibus, Basil. 1832. 4 . Er fand sie bei Crocodilurus, Monitor, Ameiva, Tejus, Pseudoameiva, bei allen Laeertoïden, Algyra, Corlylus, Uromastix, Agama, Leiolepis, Braehylophus, Physignathus, Istiurus, Iguana, Polychrus. Vgl. die Abbild. bei Meissner. 
vor 9 ); bei den Amphisbänen, mehren Geckonen und Scincoïden finden sie sich in der Nähc des Afters ${ }^{10} \%$. - Bei den Crocodilen ist cinmal vor dem Iinterrande eines jeden Ilautschildes cine kleine Drüsenölfnung vorhanden und ausscrdem finden sich cinige grössere flautdrüsen, deren Secret einen mosclusartigen Gerueh besitzt. Von den letzteren liegt eine jedcrseits einwärts vom Schenkel des Unterkiefers.

\section{Dritter Abschnitt. Vom $M u s k e l s y s t e m e$.}

ร. 68.

Rücksichtlich der Anordnung der Muskeln des Stammes der Wirbelsäule schliessen sich unter den nackten Reptilien die Perennibranchjaten, die Derotremata und die Cöcilien auf das engste an die Fische an, indem der grösste Theil ihrer Muskelmasse durch den grossen Seitenmuskel (M. lateralis) gebildet ist 1). Dieser Muskel erhält sich bei ihnen nicht nur an den beiden Hälften des Schwanzes und an der oberen des Rumpfes, sondern erstreckt sich an letzlerem noch bis zur vorderen Mittellinie des Bauches. Er zerfällt bei ihnen, ganz wie bei den Fischen, durch eine rom Schwanzende bis zum Kopfe jederseits sich erstreckende Lïngsfurche in einen Rückentheil und einen Bauchtheil. und nimmt vom Rücken nach dem Bauche zu an Dicke ab. Schief von hinten und oben nach vorn und unten durchgehende Ligamenta intermuscularia, zwischen welchen die Muskelbündel einen geraden Verlauf haben, theilen die Seitenmuskelmasse in so viele einzelne: Abtheilungen, als Wirbel vorhanden sind. Der Ruickentheil des Seitenmuskels befestigt sich an den hinteren Theil des Schedels; sein Bauchtheil setzt sich nach vorne bis zum Zungenbeine fort, nur durch die an das Becken sich befestigenden Muskeln unterbrochen. Umhüllt von dem Bauchtheile des Seitenmuskels sind, mit Ausnahme eines fehlenden M. rectus abdomiwis, dic übrigen, gewöhnlich noch unvollzählig vorhandenen Bauchmuskeln. - Dasselbe Verhalten zeigt sich im Allgemeinen bei den Larven der Salamandrinen und ungeschwänzten Batrachier.

Bei den vollständig entwickelten Individuen dieser letztgenannten Ordnungen failt aber, gleichwie bei allen beschuppten Reptilien und den höheren Wirbelthieren überhaupt, der Bauchtheil des Seitenmuskels am Rumpfe völlig wcg, während er dagegen an der unteren odcr vorderen

9) Hier finde ich einige bei Iguana. - 10) So auch bei Tachydromus Daud.

1) Dies hat Müller nachgewiesen durch Untersuchung von Menobranchus und Amphimma; ich finde dasselbe Verhalten bei Proteus, Siredon und Coecilia. Siehe Müller's vergl. Anat. d. Myxinoïlen, I. S. 230. 
Flïche des Schwanzes vollstündig sich erhält. Die eigentlichen Rücken inuskeln der höheren Reptilien - gleichwie aller höheren Virbelthiere entsprechen aber dem Riickentheile des Seitenmuskels. Bei den Salamandrinen sind nicht nur an der Ober- und Unterseite des Schwanzes, sondern auch längs des ganzen Rumpftheiles des Ruickennuskels Ligumeata intermuscularia vorhanden, welche so viele Ablheilungen bilden, als Wirbel dia sind. Noch bei den Sauricrn zeigen sich in den zahlreichen Sehnen der Rückenmuskeln deutliche Ueberreste dieser $\boldsymbol{L}_{i}$ gamenta iutermuscularia. Sie gehen, wie man auf Querdurchschnitten erkennt, schief von oben und hinten nach unten und vorn und theilweise dann wieder nach hinten hindurch.

[Ueber las Muskelsystem der Reptilien sind vorzüglich folgendle Schriften zu vergleichen: Cuvier, Leçons d'anat. comp., T'. 1. und 4. a. - Meckel, Systeu d. vergl. Anat., Th. 3. unl 4. - Von der Mluskulatur der nackten Reptilien handeln ausser Townson, Funk, Siebold, Carus und Mayer: Zenker, Batrachomyologia, Jen. 1825. 4. c. fig. und Dug ès, Recherches etc. - Die Muskeln der Schildkröte bildet trefflich ab Bojanus 1. c. - Die Muskeln der Ophidier schildern durch Wort und Abbildung Hübner, De organis motoriis Boae caninae, Berol. 1815 4. und besonders ausführlich d'Alton in Müller's Archiv 1834.]

§. 69.

Eigene Hautmuskeln hahen sich bei den Perennibranchiaten von der Seitenmuskelmasse noch nicht gesondert. Bei den ungeschwänzten Batrachiern kommen mehre eigene, vom hinteren Theile der Beckengegend aus, an die Haut tretende Muskeln 1) vor. Bei den Salamandrinen ist ein Theil der zwischen Unterkiefer und Zungenbein gelegenen Muskeln innig an die Haut geheftet. Während bei den Schildkröten an ganzen Rumpfe keine Spur solcher Mluskeln vorhanden ist, vertritt ihr Latissimns colli ${ }^{2}$ ) die Function eines Hautmuskels am Halse. Unter den übrigen beschuppten Reptilien sind sie bei der Mehrzahı der Saurier weniger, als bei den Crocodilen und ganz besonders den Ophidiern entwickelt. Bei der letztgenannten Ordnung ${ }^{3}$ ) erstrecken sich nicht nur die beiden oberflächlichen schiefen Biruchmuskeln, von den Rippen aus mit zahlreichen Fascikeln an die Ilaut des Bauches, sondern es finden sich in der ganzen Bauchgegend noch mehre Systeme eigcner Schuppenmuskcln, welche, nur an Schuppen sich befestigend, mit dem Knochengerüste in kciner Verbindung stehen.

§. 70.

Hinsichtlich des Verhaltens der Rü ckenmuskeln kommen bei den einzelnen Ordnungen der Reptilien beträchtliche Verschiedenheiten vor. Es ist nicht blos dic Anordnung der Muskeln der gesammten Riicken-

1) Siehe Dugès, No. 56. Pubio-dorso-cutané und No. 57. Coccy-dorso-cutanés. - 2) Siche Bojanus Tab. XV. Fig. 5ั6. No. 21.

3) Diese Hautmuskeln sind sehr ausfïhrlich von d'Alton I. c. geschildert. 
fliche ubberhaupt, sondern auch die ihrer einzelnen Gegenden bei Reptilien verschiedener Ordnungen höchst manniehfiltig und namentlich ron der grösseren oder besehränkteren Freibeweglichkeit der Wirbel, von dem Verhalten der cinzelnen Wirbelfortsätze, von der Anwesenheit und Ausdehnung der Rippen, so wie von den Beziehungen der Wirbel zı den llautbedeckungen abhängig.

Bei den Salamandrinen 1) und ungeschwänzten Batrachiern 2) findet noch keine Sonderung der Ruickenmuskelmasse in eine innere und ïussere Portion Statt. Bei der ersten Familie zeigt sieh blos in der Nackengegend ein eigenthümlicher paariger Muskel, welcher von den Dornfortsätzen der vorderen Wirbel zum IIinterhaupte sich begibt ${ }^{3}$ ). Bei den ungesehwänzten Batrachiern theilen stärkere Sehnen die Riickenmuskclmasse in einzelne, successive hinter einander liegende grössere Abtheilungen. - Bei den Cheloniern sind wegen der eigenthïmliehen Verhältnisse des Hautskeletes zur Wirbelsäule, namentlich also wegen der Verwachst.ng der Hautknochensehilder mit den oberen Wirbelbogen und der dadurch bedingten Unbeweglichkeit der letzteren, gerade die eigentliehen Riickenmuskeln der Rumpfgegend auf ein Minimum der Ausbildung redueirt oder ganz versehwunden 4). Entwickelter sind dagegen bei ihnen die Rüiekenmuskeln der Sehwanzgegend, am meisten aber die des so beweglichen Halses ${ }^{5}$ ). - Bci den Sauriern und Crocodilen sondert sieh die Rijekenmuskelmasse längs des Rumpfes in eine innere und eine äussere Portion. Jene entsprieht den Musculi spiunlis, semispiualis, multifulus etc. der höheren Wirbelthiere, diese den $\boldsymbol{N u}$ (usculi sncrolumbalis und longrissimus dorsi. Letztere Portion befestigt sich mit aufsteigenden Bündeln theils an die Wirbel-Querfortsïtze, theils an die Rippen. - Noch deutlieher, als bei den Sauriern, ist bei den Ophidiern 6) die Trennung der Rückenmuskelmasse in eine innere und cine äussere Portion. Beide trennen sich schon am Schwanze. Dic äıssere, den Lougissimus dorsi und sucrolumbalis entsprechende Portion spaltet sich in Zipfel, welehe am Schwanze zu den Spitzen der Querfortsätze gehen; an Rumpfe aber bildet sie zwei Ifauntmassen, deren Bündel aufsteigend an die einzelnen Rippen sieh befestigen. Die

1) Abbild. bei Dugès Tab. XVII. und hei Funk Tab. II. Fig. 11.

2) Ablild. bei Zenker Tab. 1. und liei Dugès Tab. VI.

3) M. trachelomastoïdens Funk. Sus-occipito-spinal bei Dugès.

4) Sie fehlen ganz nach Meckel bei Cliclonia; sie sind von Emys abgebil. det hei Bojanus Tab. XVII. Fig. 67. No. 39. und liegen zwisehen dem nicht angewachsenen T'lıeile der Kippen und dem Sehilde zur Seite der Wirbel. Stark sind sie bei Cryptopus.

5) Siche Bojanus Tab. XVI__IIX. Sie entsprechen den Splenii, Biven. ter cervicis, Spinalis eervicis u. s. w.

6) d'Alton bezeichnet die innere Portion der Rüekenuuskeln als zwei. bäuchigen Rüekwärtszieher der Rippen, und trennt sie mit Unrecht von den eigentlichen Rüekenmuskeln. 
innere Portion sondert sicls in melire einzelne Abtheilungen, welche den M. M. spinalis, semispinalis und multifidhs entsprechen 7). - Gesondert von den eigentlichen Rückenmuskeln sind bei der Melırzahl der Reptilien die zwischen den Dornfortsiitzen der Wirbel liegenden $\boldsymbol{M}$. interspinales und die zwiselien ilıren Querfortsätzen befindlichen M. intertransversarii, so wie die, ilnnen ihrer Bedeutung nach verwandten hinteren Kopfmuskeln Recti et obligui capitis posteriores.

\section{§. 71.}

Eigene Muskeln, welche von der Wirbelsäule zu den Rippen sich begeben, kommen wenigstens bei den bescluppten Reptilien vor. Unter den Sehildkrölen besitzt Chelonia einen vom ersten Halswirbel zurn Rüekenschilde sich begebenden Rippenheber (M. scaleurs). Ein analoger Muskel erstreckt sieh bei anderen Schildkröten von einem der letzten Halswirbel zur zweiten Rippe. Sonst fehlt den Cheloniern das System der M. levatores costarum am Rumpfe gänzlich. Bei den Sauriern finden sieh schwaehe äussere und, bei einigen wenigstens, z. B. bei den Chamäleonten, auch innere Rippenheber. Letztere erstrecken sich von dem Processus spiusosus inferior oder von der Vorderfläche eines Wirbelkörpers zu der näclıst hinteren Rippe. Auch innere Rückwärtszieher der Rippen kominen vor. - Bei den Ophidiern sind die von der Wirbelsäule zu den Rippen sich begebenden Muskeln mehrfaelıer Art: 1) von der äusseren Portion des Rückenmuskels unvollständig gesondert ist eine eontinuirliche und zum Theil noch verschmolzene Reihe von Gelenkfortsatz-Rippenmuskeln oder langen äusseren Rippenhebern; 2) bedeekt von ilınen sind die eigentlichen $\boldsymbol{M}$. levatores costarum exterui; 3) diesen letzteren entspreehen an der Vorderfläche der Wirbelsäule die vom Processus spiisosus iuferior oder von der Vorderfläche zweier Wirbelkörper entspringenden und an die oberen Enden der Rippen sich befestigenden M. levalures costarnm iuterui oder inneren Vorwärtszieher der Rippen; 4) Antagonisten der vorigen Muskeln sind innere Rückwärtszieher der Rippen, welche, bei gleichem Ursprunge, den entgegengesetzten Verlauf haben. Es sind M. retrahentes costarum superficiales und profundi zu unterscheiden.

Die eigentlichen $Z$ wischenrippenmuskeln ( $\boldsymbol{M}$. intercostales) sind, mit einziger Ansnahıne der Chelonier, bei allen denjenigen Ordnungen vorhanden, welche wirkliche Rippen besitzen. Ausser ihnen kommen bei den Ophidiern noch schräg verlaufende lange Zwischen-

7) d'Alton unterscheidet vier Muskeln: den langen absteigenden Muskel zwischen den Gelenk - und Dornfortsätzen; den aufsteigenden Muskel zwischen den Dorn - und Gelenkfortsïtzen, den kurzen absteigenden Muskel zwischen Gelenk - und Dornfortsïtzen und dic Muskeln zwisclien den Wirbelbogen und Dorn. fortsätzen. 
rippenmuskeln vor, zwischen deren beiden Insertionspunkten eine grös. sere Inzahl von Rippen inne liegt.

[Man rgl. uiber das eigenthümliche Verhalten der abgehandelten Muskeln bei den Ophiliern besonders d'Alton l. c. und Everard Home in den Philos. Transact. 1812.]

\section{§. T2.}

Die Bauchmuskeln sind bei den Reptilien gewöhnlich nicht auf die Bauchgegend beschränkt, sondern erstrecken sich meistens auch iiber die Brustgegend, sind also wirkliche vordere Rumpfmuskeln. Der den Perennibranchiaten fehlende oder bei ihnen mit dem Bauchtheile des $\boldsymbol{M}$. Iateralis verschmolzene gerade Bauchmuskel erstreckt sich bei den Silamandrinen und bei den ungeschwänzten Batrachiern weit vorwärts und ist von dem M. sternohyoüdeus nur unvollständig geschieden 1). Er besitzt gewöhnlich starke Inscriptiones tendineae, deren Anzahl derjenigen der Rippen entspricht. Auch bei den Sauriern finden sich zum Theil solche sehnige Querstreifen. Bei den schlangenähnlichen Sauriern und bei den Ophidiern erscheint er noch bestimmter als vorderer Zwischenrippenmuskel, indem er zwischen den einzelnen Rippenknorpeln gerade vorwärts sich erstreckt. Beim Crocodil liegen die Bauchrippen zwischen seinen Bäuchen. Den Cheloniern scheint er gänzlich zu fehlen.

Während von den schiefen Bauchmuskeln bei den Perennibranchiaten und Batrachiern der eine häufig fehlt und auch bei den Cheloniern nur der innere derselben vorhanden ist, zeigt sich bei den Sauriern und besonders auch bei den Ophidiern eine Zunalime ihrer Zahl. Bei letzteren heften sich die cinzelnen Fascikel der beiden iuusseren ihrer vier Bauchmuskeln, nachdern sie von der äusseren Fläche und dem linteren Rande oder von den Spitzen der Rippen entsprungen sind, an die Haut und sind daher auch wol als eigenthümliche Rippen-Hautmuskeln betrachtet worden 2). Die dritte Schicht liegt ébenfalls an der äusseren Fläche der Rippen und geht am Bauche in eine Aponeurose über. Die vierte Schicht endlich, scheint dem M. obliquns internus zu entsprechen. Bei den meisten Sauriern und den Crocodilen sind statt dieser vier schiefen Bauchmuskeln nur drei vorhanden, von denen der oberflächlichste gleichfalls Fascikel an die Haut abgibt. - Der Musculus transversus abdominis ist bei den Cheloniern, Sauriern und Crocodilen vorhanden, fehlt dagegen den Ophidiern.

Ein accessorischer Bauchuuskel ist noch bei den Salamandrinen und den Crocodilen der M. pyramidalis ${ }^{3}$ ).

1) S. Abbild. bei Siebold Fig. 12.; bei Dugès Tab. XVIL. No. 24. Salamandra; Tab. VII. No. 52. 53. Rana. Die Inscriptiones tendinease fehlen bei Pipa. - 2) So namentlich von d'Alton.

3) Bei ersteren wegen der accessorischen am Becken baftenden Kinorpel; bei letzteren wegen des eigenthümlichen Verhaltens der Schaambeine. 
Zwerchfellartige Muskelausbreitungen kommen sowol bei unbesehuppten, als bei beschuppten Reptilien vor. Die eigentliumlichsten Bildungen dieser Art, wirkliche Peritonealmuskeln, sind unter den Batraehiern bei den Aglossi angetroffen worden 1). Ein vorderer Muskel entspringt jederseits breit von der Röhrr des Obersehenkelknoehens, erstreckt sich, ähnlieh einem Bauchmuskel, einwïrts von dem eigentlichen sehiefen Bauchmuskel vorwärts zur Brust, schlägt sich am Brustbein nach innen und tritt am Bauchfelle angeheftet zum Oesophagus. Jedem dieser Muskeln entspricht ein hinterer Peritonenlmuskel, der gleiehfalls voin Oberschenkel entsprungen, auswärts von den Nieren die ganze hintere Wand des Bauchfelles bis zur Speiseröhre und zum Pharynx bekleidet. Diesen Peritonealmuskeln vergleichbare $\Lambda$ pparate konmen bei den ibbrigen Batraeliern nur sehr schwach angedeutet vor. Sehr ausgebildet sind sie dagegen bei den Crocodilen. - Ein dem Zwerehfelle der höheren Wirbelthiere völlig analoger Muskel ist bei den Cheloniern vorhanden ${ }^{5}$. Er beginnt fleischig mit mehren Bündeln von den Körpern des dritten und vierten Rüekenwirbels und einer entsprechenden Rippe. Einige seiner Fascikel heften sich an den Rand der Lungen, während ein anderer unterhalb der Lunge auf das Bauchfell iblbergeht. Musculi sternomustö̈dei finden sieh unter den be schuppten Reptilien bei Cheloniern, Sauriern und Crocodilen.

§. 73.

Yon den Muskeln der Vorderfläe he der Wirbelsäule sind die unteren oder vorderen Schwanzmuskeln fast immer nur Wiederholıngen der an der Rückenseite des Sehwanzes vorhandenen. -

Bei den Salanandrinen und der Mehrzahl der ungeschwänzten Baltrachier findet sich an Kopftheil der Wirbelsäule ein kleiner gerader Kopfbeuger, Rectus capitis auterior, zu dem bei den Salamandern noch ein Rectus capitis Iateralis hinzukömmt ${ }^{1}$ ). Auch bei den Ophidiern sind zwei Paar von den unteren Dornen der Wirbel zum os 6 asilure sich erstreckende Kopfbeuger vorhanden, die beide, besonders aber der unterste, durch ihre Länge ausgezeiehnet sind, indem sie über eine grosse Anzahl von Wirbeln verlaufen. Dic dem M. longas colli und dem Rectus copitis auticus entsprechenden Muskeln finden sieh bei allen übrigen beschuppten Reptilien wieler. Sehr ausgebildet sind sie bei den Cheloniern ${ }^{2}$ ).

Bei allen Batrachiern und allen beschuppten Reptilien, mit Ausnahme der Ophidier, ist endlich ein dem M. quadratus lumborum ver-

4) Siehe Mayer, Ueber Pipa, in den Nov. act. Acad. Leop. Carol. T. XII. p. 2. 1825. Tab. XLIX. Ueber Xenopus vgl. Mayer, Analekten Heft 1. S. 31.

5) Abbild. bei Bojanus J. c. Tab. XVII-XX. No. 42.

1) Abbild. bei $D$ ugès Tab. XVH. Fig. 12S. (Salamandra).

2) Abhild. bei Bojanus 'Tab. XVII. XX. 
gleichbarer Muskel vorlanden, der von den Querfortsitzen der hinteren Rückenwirbel oder auch von den letzten lippen entspringend selten blos zum Querfortsatze des Kreuzbeines ${ }^{3}$ ), meistens vielınehr zum Iliftbein sich begibt.

\section{§. 74.}

Der allgemeine Plan der Anordnung der Schultermuskeln ist bei den Reptilien der nämliclıe, wie bei den hölıeren Wirbelthieren. Die Muskeln ilrès Schultergerüstes bestehen mindestens in Vorwärtsziohern und Hebern und in Rückwärtsziehırn, die jenen entgegenwirken. $Z_{11}$ ihnen kömmt sehr allgemein ein zwischen der Schulter und dem Zungenbeine gelegner $\boldsymbol{M}$. umolyyö̈leus. Die Schulterheber und Vorwärtszieher erstrecken sich von der Gegend der obersten Wirbel und meistens vom Kopfe abwärts und entsprechen den Musculi cucullares, rhombö̈lë̈, levatores scapulae, wälırend die Rückwärtszieher dem M. serratus auticus und dem pectoralis minor zu vergleichen sind.

Die Muskeln der Extremitäten bieten, wie sich beji der Verschiedenartigkeit der Bewegungen, welche zu vermitteln sie bestimmt sind, erwarten lässt, ausserordentlich mannichfache Anordnungsweisen dar, welche auch nur andeutungsweise zu schildern ausser dom Plane dieses Lehrbuches liegt. Zu den beständigsten Muskeln des Oberarmes gehören der dem Delioülleus vergleichbare Heber, der den Schulterblattmuskeln (M. M. supraspinatus und infruspinatus) vergleichbare Auswärtszieher, ein grosser Brustmuskel (Pectoralis major), ein M. Latissimus dorsi und ein M. coracolrachialis. Der Vorderarm besitzt stets Beuger und Streeker, welche theils vom Oberarm, theils von Knochen des Sehultergerüstes ihren Ursprung nehmen. Die Muskeln der Handwurzel und der Mittelhand bestehen in Streckern und Beugern, welche meistens vom Oberarmbein absteigen. Die Finger besitzen ausser gemeinschaftliehen Streckern und Beugern kleinere Muskeln dieser Art, so wie auch Adductoren und Abductoren. - Die Muskeln der hinteren Extremität lassen sich, gleich denen der vorderen, auf den Typus der höheren Wirbelthiere zurückfuihren.

[Es muss in Betreff dieses $\$$. auf die angeführten speciellen Schriften rerwiesen werden. Ueber die Muskeln der rudimentären Extremitäten vieler Saurier und Ophidier hat gehandelt $\mathbf{H}$ e using er, Zeitschrift f. organ. Physik, 3ter Bd. 1833. S. 481 ff. mit Abbild.]

\section{§. 75.}

Die A ntlitzmuske eln sind unbedeutend und beschränken sich auf die zur Erweilerung und Verengerung der Nasenlöcher bestimmten Muskeln ${ }^{1}$ ).

3) Sn bei einigen exotischen Fröschen, wo dieser Muskel als Analogon der Rippenheber sich zeigt.

1) Vgl. über dliese Muskeln den das Geruchsorgan der Reptilien behandelnden \$. 84 . 
Die Kiefermuskcln sind bci allen Ordnungen im Allgcmeinen nach glciehem Plane angeordnet. Nur bei den Ophidiern, und namentlich den weitmäuligen, tritt zu den gewöhnlichen Kieferınuskeln noch ein höchst eigenthümliches, durch die Freibeweglichkeit des gesanmten KieferGaumenapparates erforderlich gewordenes System ron Muskeln hinzu.

Die Muskeln, welche den Unterkiefer beben und anziehen, befestigen sich immer vor dem Unterkiefergelenke. Dicse Muskeln zerfallen schr beständig in zwci Jauptmassen: rinc äusscrc und cine inncre. Erstere entspricht dem $\boldsymbol{M}$. tempormlis und masseter, letztere den Musculi pterygoüdsi. Der äusscre Kaumuskel ist bei allen Reptilien von sebr bcdeutendem Umfange und besteht stets aus mehrcn Bäuchen oder selbst vollständiger getrennten Portioncn, welche häufig als vcrschicdene Muskeln beschrieben sind. Dicjenigc Portion, welche an den Processus coronoüdeus des Untcrkiefers sich befcstigt, entspricht dem M. tempuralis, die an die ganze Aussenfläche und den unteren Rand dieses Knochens öfter sich ansetzendc ist melır dem $\boldsymbol{M}$. masseter analog. Schr entwickelt ist diese Kaumuskelmassc bei vielen Schlangen, wo sie grösstentheils von der Median-Crista des-Schcitelbeines entspringt, bei den Chamäleonten, wo sie den Raum zwischen der mittlercn, nach binten verlängerten Schedeleiste und der äusseren Leiste ausfüllt, bei den Sauriern, wo die Fossa temporalis eine so grosse Weite erlangt. Die innere Kaumuskclmasse zerfällt gleichfalls öfter in mehre Portionen, so dass - namentlich bei den Sauriern - cin $\boldsymbol{M}$. pterygö̈leas externus und internus zu unterschciden sind.

Die zur Scnkung und Abziehung des Unterkiefers bestimmte Muskelmasse, welche hinter dem Gelenkende desselben sich befestigt, entspricht dem M. digastricus. Bci den unbeschuppten Reptilien und den Sauriern erstreckt er sich von der Nackengegend zum Unterkiefer; bei den Cheloniern dagegen nimmt er seinen Ursprung vom Processus mastoïdeus des Sehedels. Bei den Ophidiern wird seine Stelle durcl zwei Muskeln vertletcn. Der eine derselben bat seinen Stiitzpunkt am Hinterhauptsbeine und am Quadratbeinc, während der andere ron den Dornfortsätzen mehrer Wirbel absteigt.

Bei den weitmäuligen Schlangen ${ }^{2}$ ) treten zu den genannten Muskeln des Kiefer-Gaumcnapparates noch folgende hinzu: 1) das Kiefersuspensorium oder Quadratbein kann durch einen hinten in Hautmuskcln übergehenden Muskel zurückgczogen werden; 2) und 3) zwei hinter cinander zwischen der unteren Fläche des Sphenoüdeum basilare einerscits und den Ossu pterygoüdea und palatiua andererseits gelegene Muskeln zichen jenc Knochen an die Schedelbasis heran und nähern sie sich gegenscitig; 4) ein Muskelpaar erstreckt sich vom Scheitelbeine zu jedem os pterygö̈deum und hebt letzteres; 5 ) ein Muskelpaar

2) Abbildungen dieses Muskelapparates finden sich bei d'Alton l. c. Tab. VII. 
erstreckt sich vom heillbeinkörper zum Vomer, dessen Anziehung und so zugleich eine Beugung des Schnauzentheiles des Schedels bewirkend; 6) ein Muskelpaar zielt die beiden Untcrkicferhïlften an einander. Beide Muskeln durchkreuzen sieh; jeder entspringt vom Gelenkfortsatze des einen Unterkieferastes und erstreckt sich zum anderen Ende des entgegengesetzten Astcs.

\section{s. 76 .}

Das Zungenbein der Reptilien ist der Insertionspunkt einer grossen Anzahl von Ifuskeln, durch die es nach verschiedenen Richtungen hin bewegt wird, oder denen es als fester Stützpunkt dient. Die Zungenbeinmuskeln lassen sich ohne Schwierigkeit auf die der höheren Wirbelthiere zurückfuilhren; sie sind bei den meisten Reptilien ziemlich übereinstimmend gebildet, am eigenthümlichsten bei den Ophidiern, was einerseits durch die rudimentäre Bildung ihres Zungenbeines selbst, andererseits aber durch den Mangel eines Brustbeines und eincs Schulter-s gerüstes bedingt wird.

Vom Brustbeine aus wird das Zungenbein abwïrts gezogen durch zwei M. sternoliyoülei, welche bei der Mehrzahl der nackten Reptilien noch unmittelbarc Fortsctzungen der geraden Bauchmuskeln sind.

Yon der Schulter aus wird es seitwärts und abwärts gezogen durch zwei M. omolyyoüldei. Bei den Cheloniern werden die M. sterno- und omolıyoüdei durch ein einziges Muskelpaar repräsentirt, das von den Claviculae seinen Ursprung nimmt. Bei den Ophidiern aber werden diese Muskeln durch zwei Paar Nacken-Zungenbeinmuskeln vertreten, welche von der Aponeurose der Dornfortsätze der Wirbel ihren Ursprung nehmen.

Vom Unterkiefer aus wird das Zungenbein vorwärts gezogen durch zwei $\boldsymbol{M}$. mylolıyoüdei, welche aber bei den ungeschwänzten Batrachiern fast ganz ausser Verbindung mit dem Zungenbeinc stehend, die Aeste des Unterkicfers an einander zu ziehen bestimmt sind und ihrer Funktion nach M: intermandilulares . heissen könnten. Diese Muskeln, welche eincn Boden der Mundhöhle bilden, sind auch bei den Ophidiern vorhanden, hier aber gewöhnlich mit anderen Muskeln, nainentlich solchen, die zur Haut gehen, verschmolzen.

Die M. geniohyoüdei werden niemals vcrmisst. Bisweilen sind sie in mehre Portionen zerfallen.

Zu den bisher genannten Muskcln kommen noch Muskeln, welche bei den Salamandrinen vom Quadratbeine, bei den Fröschen theilweise vom Schedel, bei den Cheloniern, Sauriern und Crocodilen vom Seitentheile des Unterkiefers oder von dessen hinterem Ende cntspringen und das Zungenbein bald heben, bald es seitwärts ziehen.

Zur Zunge endlich erstrecken sich vom Zungenbeine aus beständig die M. hyoglossi, welche die Zunge zurückziehen und Antagonisten der sie vorwärts ziehenden $\boldsymbol{M}$. M. genioglossi sind. 
[Rücksichtlich des Details muss auf die oben namhaft gemachten Schriften verwiesen werden.]

\section{Vierter Abschnitt.}

\section{Vom Nervensysteme und eon den Sinnesorgrnen.}

\section{Von den Centralorganen des Nervensystemes.}

\section{§. 77.}

Das Rückenmark der Reptilien übertrifft das Gehirn an Masse nicht mehr so bedeutend, wie dies bei den Fisehen der Fall ist. Anscheinend erstreckt es sieh immer durch die ganze Länge des Wirbelacanales und ist bei langgestrecktem Körperbaue lang und diinn, bei gedrungenem Körperbaue, wie z. B. bei dlen ungeschwänzten Batrachiern, verhältnissmässig breiter, so dass es dann auch vom Gehirne an Breite weniger übertroffen wird, als unter der zuerst genanntrn Bedingung. Es schwillt bei den mit ausgebildeten Extremitäten begabten Reptilien in den Regionen, wo die für die Extremitäten bestimmten Nerven von ihm abtreten, ziemlich bedeutend an $1 \%$. Auch an den Ursprungsstellen der übrigen Nerven sind, namentlich bei den Ophidiern, unbedeutendere Anschwellungen bemerkt worden $\left.{ }^{2}\right)$. Die innere graue Substanz des Ruickenmarkes bildet, auf Querdurchschnitten sichthare, vordere und hintere Hörner ${ }^{3}$ ). Es besitzt immer eine vordere, gewöhnlich tiefere und eine hintere, meist oberflächlichere Längsfurche und einen Centralcanal, der, an der Medulla oblongata sich erweiternd und in die hintere Längsfurche iibergehend, den offenen, bei den unbeschuppten Reptilien längeren, bei den Sauriern und Crocodilen kiirzeren und breiteren Sinus medullae oblongatae bildet. Dieser letztere wird häufig von einer dicht an dem Cerebellum haftenden, dureh dię Gefässhaut gebildefen Quercommissur überwölbt ${ }^{4}$ ).

[Vortreffliche Abbildungen vom Rückenmarke der Schildkröte gibt Bojanus 1. c. Tab. XXI.]

1) Die Stärke dieser Anschwellungen entspricht deın Umfange des austretenden Nerven. Bei den ungeschwänzten Batrachiern ist die vordere Anschwellung sehr unbedeutend, die hintere dagegen sehr beträclitlich. Bei den Cheloniern sind beide stark und treten un so melı herror, als das Riickenmark zwischen ihnen - wegen der geringen Stärke der Rumpfnerven - selır dünne ist. Sicho Bo janus Fig. 83. 1. 84.

2) Carus beinerkte bei den Ophidiern, entsprechend der Abgangsstelle eines jeden Spinalnerven, eine leichte Anschwellung des Rückenmarkes.

3) Abgebildet bei Bojanus Fig. $95-100$.

4) S. Abbild. bei Bojanus Fig. 85. $\$ 7-89$. 
\$. 78.

Das Geli irn der Reptilien bietet zwar, was seinen Unfang anbetrift, bei den einzelnen Ordnungen nicht unbeträchtliehe Verschiedenleiten dar, zeigt abel riicksichtlieh der Zahl seiner einzelnen Anschwellungen eine wesentlielıe Uelbereinstiumung. Auf das verliingerte Mark folgt das Cerebellun; an dieses schliesst sich nach vorn die stets paarige Vierhügelmasse, worauf weiter nach vorn die Hémisphïen und endlielı ganz vorn liäug noch die kleinen Rieclınervenganglien folgen. Das ganze Gehirn zeichnet sich noch, verghichen mit dem der höheren Wirbelthiere, durch seine langgestreckte Form aus. D as verlänger te Hark gelıt bei den unbeschuppten Reptilien flach und fast gerade, bei den übrigen aber mittelst einer ziemlich beträchtlichen unteren Wölluung in das Gehirn iiber 1). Ueber den vierten Ventrikel, in welchem bei den Cheloniern und den Crocodilen Erhabenheiten vorkonmen, die zu den Iörnerven in Beziehung stehen, erstreckt sich das oberflächlich grauo Cerebellum. Es stellt bei den unbeschuppten Reptilien nur eine dünne, blattröruige Comınissur der Seitenwände des vierten Ventrikels dar, bleibt bei den Ophidiern noch sehr unbeträchtlich, gewinnt bedeutend an Masse bei den Sauriern und Cheloniern, besitzt bei letzteren sehon eine seichte Längsfurehe und wird noch beträchtlicher hei den Crocodilen, wo es, gleich wie bei cinigen Sauriern, durch zwei seitliche Anhänge ausgezciehnet ist und dureh cine Querfurche in cine vordere und hintere Alstbeilung zerfällt. Yor dem Cerebellum liegt, meist ganz frei, nur bei cinigen Siuriern theilweise von ihm bedeckt, die Vierhügeluasse, Lubi optici Auct. Sie stellt zwei rundliche Erhabenheiten dar, welche durch eine Längsfurche von einander getrennt werden und bei den unbeschuppten Reptilien im Verhältniss zu den Ilemisphären noch am umfänglichsten sind. Neben ihnen kommen bei einigen Sauriern noch eigenthiimliche seitliche und untere kleinere Anschwellungen vor. Die gewölbten Virrhügelganglien ljilden dic Decke einer einfachen, weiten Höhle, die den zur dritten Ilirnhöhle sich erstreckenden Aquaeducius Sylvii darstellt. Von dem Boden dieser Höllle erheben sich gewölınlich noch ziemlich lueträchtliche Anschwel. lungen 2). Vor den Vierhigeln, zwischen ilhnen und den Hemisphären, liegt an der Oberflaiche des Gehirnes frei die Zirbel, deren zwei Schenkel bei den höheren Reptilien von den Thalumi optici und der hinter diesen liegenden Cummissura posterior der Hemisphären ausgehen. Die vordersten Hirnmassen sind die Hemisphären, welche, besonders bei allen beschuppten Reptilien, die ibrigen Abtheilungen des Gehirnes an Masse und Unfang betrichtlich überwiegen. Sic gewinnen nanent-

1) Abgebildet bei Bojanus Fig. $88-\$ 9$.

2) Voin Frosche und Crocodile aligabildet bei Miiller I. r. Tab. 1V. Fig. 1. und 2. 
lich bei den Ophidiern, Sauriern und Crocodilen an Breite. Oberflächlich erscheinen sie grau, glatt und windıngslos. Sic sind allgemein paarig uud besitzen wenigstens eine vordere, bei den höheren Ordnungen jedoch eine vordere und eine lintere Commissur. Die nur einigen Ordnungen zukommenden Anschwellungen für die Geruchsnerven, welche immer viel unbeträichtlicher sind, als bei den Fischen, sind bald mehr oder minder vollstiindig von ilnen getrenut, bald verschmelzen sie Inehr mit ihnen ${ }^{3}$ ) und erscheinen bei den ungeschwänzten Batrachiern sogar unter einander verschnolzen. Die IIelnis phärenganglien bedecken immer die Seitenventrikel, deren Höhle gewöhnlich in die der Lobi offoctarii sich fortsetzt. Vom Boden der Seitenventrikel erheben sich die Corpurn striutu, in welche die Crura cerelıri übergehen. Nach innen von den gestreiften Körpern findet sich in jedem Scitenventrikel bei Cheloniern, Ophidiern und Crocodilen noch eine gangliöse Erhabenheit, bedeckt vom Plexus churivideus lateralis i). Mit ihrem hinteren Theile iulerwölben die Hemisphärenlappen vollstïndig oder grossentheils auch den dritten Ventrikel und die zu seinen Seiten, als zwei kleine, solide, seichte Erhabenheiten gelegenen Thalami uptici, welche auch bei den geschwänzten Batrachiern, obwol von selır geringen Umfange, vorhanden sind. Die Hölle des dritten Ventrikels setzt sich abwärts fort in das Infundibulum und durch dieses in die bei den ungeschwänzten Batrachiern zweilappige, bei den Ophidiern sehr beträchtliche, bei den Cheloniern längliche IIypaphlyssis. Vor dem Infundiunlum und hinter dem Chiasma des Sehnerven sieht man oft noch eine dem Tuler cinerum entsprechende schwache Erhabenheit. Sonst ist die Basis des Gehirnes, besonders bei den nackten Reptilien, sehr einfach und fast eben. - Die häutigen Uniliullungen des Ilirnes mid Rükkenmarkes entsprechen denen der höheren Wirbelthiere 5); bemerkenswertlı sind indessen die bei den nackten Reptilien sehr allgemein vorkommenden weissen Massen, welclie die Gefässhaut bedecken und bei mikroskopischer Untersuchung als Crystalle sich zu erkennen geben. Sie funden sich schon bei den Larren der Batrachier und zeigen sich auch an den Austrittsstellen der einzelnen Nerven, besonders der vom Rücke'nmarke stammenden, reichlich angehäuft.

3) Linvollkommen verschmolzen z. B. bei den Cheloniern; deutlich getrennt leei den Ophidiern. Mïller bildet diese Anschwellungen fïr die Geruchsnervelı auch an dem Gehirn der Crocollile ab; ich vermisse sie hier gänzlich, finde viel. mehr, dass jeder Geruchsnerv unmittelbar vor seinem Eintritte in das fieruchsorgan, gleichwie bei vielen Sauriern eine starke, längliche, inwendig nit einer Höhle versehene Anschwellung bildet.

4) Die Plexus chorioïdei laterales setzen sich einfach in den dritten Ventrikel fort.

5) S. die Abbill. des Ligrmentum denticulalum der Doura mater des Rühkemuarkes bei Bojanus l. c. Fig. 102. 
Vierter Abschnitt. Vom Nervensysteme u. v. d. Sinnesorgamen. 183

[Man vgl. ïber das Gehirn der Reptilien: Carus, Darstellung des Nervensystemes S. 174 fi. mit den Abbild. auf Tab. 3. - Serres, Anatomie comj. du corveau Tab. V., nit selur mangell. Abbildungen. - Vortreffich sind die Dar. stellungen ron Bojanus 1. c. Tab. XXI. - Das Ilim des Crocodils bildet ab Müller, Verg!. Nemrologie d. Myxinö̈den Taf. III. - Eine zusam!̣tenhangende Schilderung gibt Valentin in sciner Ausgabe der Sömmering'schen Nervenlelire, Leipzig 1841, 8., S. 110 ff. - Abbildungen des Gehirnes von Chelonia und Hoa s. bei Swan, lllustrations of the nervous Systen, Tab. XII. XVII. XVIII.J

\section{Von den Spinaluerven.}

§. 79.

Die Spinalnerven der Reptilien entspringen ganz allgemein unit zwei Wurzeln: einer vorderen und einer hinteren, ein Gesetz, von welchein ansclieinend nur der erste oder die beiden ersten Cervicalnerven sowol bei den nackten Reptilien, wo sie den fehlenden Nervus hypoglossus rertieten, als auch bei cinigen beschuppten Reptilien 1) eine Ausnahme machen. Die beiden Wurzeln rerlassen den Wirbelcanal in der Regel in dem Zwischenraume deı oberen Bogenschenkel zweier Wirbel; nur bei den Cheloniern liegt die Austrittstelle der Rumpfnerven oberhalb der Mitte jedes Wirloelkörpers. Imıner bildet dic hintere Wurzel nach ihrein Austritte aus dem IVirbelcanale oder während desselben cin Ganglion, worauf die Verbindung unit del" vorderen Wurzel Statt hat. Hierauf theilt sich der Stamm jedes Spinalnerven in einen schwiicheren $\boldsymbol{R}$. dorsalis s. pnsterior und einen staikeren R. vemralis s. aulerior. Die Rami anteriores des oder der crsten Rückenmarksnerven vertieten bei den nackten Reptilien den $\boldsymbol{N}$. lyypoglossus; bei den meisten höheren Reptilien verbinden sie sich mit diesem Nerven, oder nit dem $\boldsymbol{\Lambda}$. accessorius oder selbst ınit dem $\boldsymbol{N}$. facialis. Die füı die Extrenitaten bestimmten Nerven zeichnen sich durch bedeutendere Stärke vor den übrigen aus. Durch die Rami anteriores der letzten Cervicalnerven wird ein Plexus brachialis gebildet, aus welchem cin Ramus radialis, ulmaris und mediamms hervorgeht. Eben so entsteht durch diesolben Aeste der vorletzten Dorsalnerven cin Plexus cruralis, aus welchem Aeste für die Beckenmuskeln, so wie auch Stämme, welche dem $\boldsymbol{\Lambda}$. obturatorizs und cruralis entsplechen, abgehen; durch den letzten Dorsalnerven und die Sacralnerven wird aber ein mit jenem Geflechte in Verbindung stehender Plexus ischiadicus gebildet, aus welchem, ausser untergeordneteren Nerven, ein starker $N$ : ischiodicus entsteht, der über dem Unterschenkel in einen $\boldsymbol{N}$. peronens, popliteus und tibialis sich spaltet.

1) Bei den Cheloniern besitzen die beiden ersten Cervicalnervell nur eino vorilere Wurzel. - Man sehe üher das Verhalten der Spinalnerven bei den Clie. loniern die vortrefflichen Abbildungen von Bojanns. 


\title{
III. Von den Hirnnerven.
}

\author{
§. 80 .
}

Sümmtliche Hirnnerven der Reptilien zeigen rücksichtlich ihrer Ulsprungsstellen aus den Centralorganen des Nervensystemes sehr constante, dencn der lïsehe durchaus entsprechendc Verhältnisse.

Der bei den meisten Reptilien starke $\boldsymbol{N}$. olfuctorius entspringt inner aus den Hemisphährenlappen. Er besitzt bei den Batrachiern und Cheloniern ęin eigenes, dicht vor den Iremisphären liegendes Tulerculume olfactorium, das bald durch eine Einsehnürung deutlich gctrennt, bald mit dem entsprechenden Hemisphärcnlappen inniger verschmolzen ist. Bei den Sauriern und Crocodilen 1) fehlt ein solehes Tulierculum alfacturium vor den Ilemisphären und der Nerv bildet erst uninittelbar vor seinem Eintritte in das Geruchsorgan eine längliche, mit einer inneren Höhle versehene Anschwellung. - Der N. opticus entspringt aus dem Thalamus opticus und aus der Unterfläche der Vierhügelmassen. Die beiden Nervi optici bilden vor dem Infundilulum ein Chiresma 2). - Der $\boldsymbol{N}$. oculorum motorius entspringt an der Grundfläche des Gehirnes hinter dem Infusdilulum von den vorderen Pyramiden. Die Ursprungsstellen beider Nerven liegen immer nahe bei einander. Der $\boldsymbol{N}$. trochleuris entspringt, wenn er, wie dies der häufigste Fall ist, als gesonderter Nerv erseheint, an der obern Fläche des Gehirns, von dem hinteren Rande der Vierhügelmasse, zwischen dieser und dem $\boldsymbol{C}_{\boldsymbol{e}}$ reluellum. - Der gleichfalls in der Regel selbstständige $\boldsymbol{N}$. alulucens entspringt gewöhnlich mit zwei Wurzeln von der Basis des verlïngerten Markes, dicht neben dessen vorderer Furehe. - Der starke $\boldsymbol{N}$. trigeminus kömmt nit mebren Faseikeln zur Seite der Medulla oblangata zum Vorschein. - Der schwache $\boldsymbol{N}$. facialis entspringt zur Seite des vierten Ventrikels, dein hier gleichfalls austretenden $\boldsymbol{N}$. acusticus sehr dicht anliegend. - Der durelı grosse Weiehe ausgezeichnete $\boldsymbol{N}$. ucusticus entspringt vom Boden der vierten Hirnhöble und theilt sieh in zwei Hauptzwejge, von denen bei den naekten Reptilien der eine in den Sack des Labyrinthes, der andere in die Ampullen der halbcirkelförmigen Canäle sich begiltt; bei den beschuppten Reptilien ist gleichfills der eine Ast für diese Ampullen hestimmt, der andere aber für die Schnecke, und der Sack des Labyrinthes wird von bciden Aesten mit Zweigen versorgt. - Der $\boldsymbol{N}$. glossopharyngeus entspringt seitwärts vom yerlängerten Marke, bald dein $\boldsymbol{N}$. acusticus näher gerüukt, bald dicht neben dem hier gleichfalls, gewöhnlieh mit mehren Wurzeln, hervortretenden stärkeren $\boldsymbol{N}$. vagus. - Dcr $\boldsymbol{N}$. accessorius entspringt zwischen der vorderen und hinteren Wurzel der vordersten Cervicalner-

1) Dies Verhalten finde ich bei Lacerta, Varanus, Monitor und Champza lucius.

2) VGl. $\S .85$ 


\section{Vierter Abschnitt. Vom Nervensysteme u. v. d. Sinnesorganen. 185}

ren ${ }^{3}$, erstreckt sich, suceessive feine Zweige aus dein Rückenmarke aufnehmend, vorwirts und verschmilzt mit dem $\boldsymbol{N}$. vagus. - Der $\boldsymbol{N}$. Improglossns entspringt mit einer Wurzel von der Seitenflache der Mcclurlar oblongata unter den Wur\%eln des $N$. vagus. Er tritt durch ein eigenes Loch des Ilinterhauptslseines.

[In Betreff der nackten Reptilien s. die Abbild. hei Fischer, Amphibiormm mudormm neurologiae specimen, Berol. 1843, 4. Die Nervenurspringe der Schildkröte sind vortrefflich ilargestellt von Boj in us 1. c. Tall. XXI.]

\section{§. 81.}

Wïlırend die höheren Sinnesnerven bei den naekten Reptilien durch keinen Unstand besonders sich auszeichnen, besitzen andere Hirnnerven bei ihnen nerkwürdige Eigenthümlichkeiten.

1. Die A ugenmuskelnerven kommen häufig theilwerse aus der Bahn des $\boldsymbol{N}$. trigeminus. Am selbststiandigsten erhält sich der $\boldsymbol{N}$ erv. oculorum motorius; der, nachden er zuvor in zwei Aeste sich gespalten, gewöhnlich in die M.M. recti superior, inferior und iutermus, so wie in den $\boldsymbol{M}$. abligmus inferior sich vertheilt. Indess mangelt bei den Salamandern und Tritonen ein von dem $\boldsymbol{M}$. rectus superior abgehender Zweig, der vieluehr aus der Bahn des $\boldsymbol{R}$. primus $\boldsymbol{N}$. trigemini herrorkömınt. - Der $\boldsymbol{N}$. trochlearis ist zwar bei den ungesehwänzten Batraehiern selbstständig und verbreitet sich in den $\boldsymbol{M}$. obliquus superior, scheint dagegen bei den Salamandern und Tritonen ginz in der Bahn des $\boldsymbol{N}$. trigemirus zu verlaufen, aus dessen erstem Aste jener Muskel unit Nervenfäden versorgt wird. - Der $\boldsymbol{N}$. aldu cens ist mur bei den Salamandern und Tritonen, so wie bei den Gattungen Bufo 1) und Pipa selbststindig, wo er in den M. rectus interuns und suspeusurius oculi sich vertheilt; bei den übrigen Fröschen ist er in den ersten Ast des N. trigemimus übergegangen. Doch ist dies nur bei den ausgebildeten Thieren, nieht alser bei den Larven der Fall 2). - Bei Pipa endlieh erhalten sämintliche Augenmuskeln nieht blos von ihren eigenthiimlichen Nerven, sondern auch aus dem ersten Aste des $\boldsymbol{N}$. trigemiuns Zweige.

2. Der $\boldsymbol{N}$. trigemiuns ${ }^{3}$ ) zeichnet sich nieht blos durch die eben erwïhnten eigenthümliehen Beziehungen zu den Augenuuskel-

3) Bei den Sclillkköten abwärts his zum vierten Cerricalnerven. S. dic Ablild. bei Bojanus. Andere Abbildungen gab Bisch off, N. accessorii Willi. sii anatnuia et pliysiolngia, Darmst. 1832, 4. Tab. V.

1) Bei Bufo pantherinus salı Vogt ein Fälchell desselben in dis Ganglion des $N$. trigemimus übergehen; Fischer vernisste dasselbe bei Bufo pahmarmu.

2) Nach Fischer's Angaben 1. c. p. 53.

3) Das Ganglion dieses Nerven zerfält nach Fischer, bei Pelobates und Bombinator als erste Andeutung der Theilung bei den Salamandrinen, durch eine Einschuiirung in zwei Segmente. 
Nerven ${ }^{4}$ ), sondern auch durch scin Verhiilniss zum $\boldsymbol{N}$. facialis aus. Dies kann verschiedener Ait sein: 1) die in der Balın des $\boldsymbol{N}$. acusticus entspringenden Elemente des $\boldsymbol{N}$. facialis gelıen in den $\boldsymbol{N}$. trigeminus iiber und verlassen diesen wieder in Gestalt eines gemischten Nerven (R. jugularis Auct.), wie dics bei den ungeschwänzten Batrachiern der Fall ist; oder 2) Elemente des $\boldsymbol{N}$. crigemiuns treten in die Balin des voin $\boldsymbol{N}$. acusticus nehr isolirten $\boldsymbol{N}$. facialis, der in diesem Fille nicht nur cin cigenes Ganglion bildet ${ }^{5}$ ), sondern auch Zweige, welche sonst dem $\boldsymbol{N}$. trigemiuus angeliören, entsendet (Proteus, Triton, Salamandra). - Der erste Ast des $\boldsymbol{N}$. trigemiuns (R. ophthalmicus) vertheilt sich besonders in das obere Angenlid, an die Schleimlanut der Nase und an die Muskeln der Nasenlöcher. Bei den Fröschen besitzt er cinen $\boldsymbol{R}$. ciliaris; bei den Cöcilien tritt cin Zweig von ihm in das Tentakel. Die beiden Rami maxillares verlassen, wie bei vielen Fischen, das Ganglion des $\boldsymbol{N}$. trigemiuus oft ${ }^{6}$ ) in Gestalt eines einfachen Stammes, der, nach Abgabe untergeordncter Kaunuskelzweige, in einen R. maxillaris superior und inferior sich spaltet. Jener versorgt besonders das untere Augenlid und dic Haut der Jochbeingegend mit käden; dieser, stärker als der vorige, verbreitet sich nicht nur in der Haut der Kicfergegend und in Kaumuskeln, sondern setzt sich längs der Innenfläche des Unterkiefers oder in cinera Canale desselben fort als $\boldsymbol{R}$. alveularis und endet vorn in $\boldsymbol{M}$. mylohyoüleus. Bei allen nackten Reptilien (viclleicht init Ausnahıne von Coecilia) ist ferner ein R.plalatiuns vorhanden, der, in der Schleimhaut des Gaumens sich verbreitend, bald aus dem Ganglion des $\boldsymbol{N}$. trigeminus liervorkömınt, wie bei den ungeschwänzten Batrachiern, bald als $\Lambda$ st des $\boldsymbol{N}$. faciorlis erscheint, wie bei den Salamandrinen und bei Proteus. Eine andere Eigenthïmlichkeit der Fische wiederholt sich bei den nackten Reptilien dadurch, dass ihr dem $\boldsymbol{R}$. opercularis der Fische grösstentheils entsprechender $\boldsymbol{N}$. faciolis $\left.{ }^{2}\right)$ ( $\boldsymbol{R}$. jugularis Trigemini Auct.) cinen Unterkiefernerven absendet, der mit den $\boldsymbol{R}$. alveolaris inferior des Trigeminus verläuft und mit ihm durch Schlingen sich verlsindet. Dieser aus Elcmenten des $\boldsymbol{N}$, trigemimus und facialis bestchende $\boldsymbol{R}$. jugularis erhält bei allen ungeschwänzten Batrachicrn einen Verbindungsast aus dem ersten, dem Glossopliaryngeus entsprechenden Aste

4) Hierher gehört auch, dass er, nach Fischer, bei Rana und Hyla einen Muskelzweig für Ilen $\boldsymbol{M}$. suspensorizes oculi abgibt.

5) Das gleiche Verhalten beobachtete $\mathbf{F}$ is cher bei den Larven der Frösche. - Fischer gilt eine abweichende Dentung ler Beziehungen zwischen dem $\boldsymbol{N}$. trigeminus und $\boldsymbol{N}$. facinlis.

6) Bei den ungeschwänzten Batrachiern, den Salamandrinen.

7) Bei den Tritonen tritt, nach $F$ ischer, von der Wurzel des $\boldsymbol{N}$. facialis ein Zweig in das Ganglion des $N$. trigeminus, welchen ter genannte Forscher durch dieses hindurch bis in die Musheln ter Nase rerfolgt haben will. 
des. Vagu.s. Meistens ist sein erster Zweig bestimut für die zwischen der Membrana tympani und dem Nundwinkel gelegene Haut (R. anricularis) ${ }^{8}$ ); der zweite ist der schon erwähnte $\boldsymbol{R}$. alveoluris inferior und der dritte ein theils in den M. stermolnyoürleus, theils in die Ilaut der Brustgegend sich verbreitender $\boldsymbol{R}$. guluris. Bei den Salamandrinen verbindet sieh von den drei Aesten des $\boldsymbol{N}$. facialis nur der erste nit einen Aste des $\boldsymbol{N}$. glossopharyngeus, un dinn in die Helser des Uuterkiefers, des Zungenbeines und die ungebenden häutigen Theile sich zu rerbreiten. Die beiden andern Aeste sind der R..palatinus und alvenlaris iuferior.

3. Der N. vagus enthält bei den nackten Reptilien zugleich die Elemente des $\boldsymbol{N}$. glossopharyngeus, der aus dem Ganglion des $\boldsymbol{N}$. nagus als erster Ast abtritt und häufig noch ein eigenes Ganglion 9) bildet. Ausser denı schon erwähnten Verbindungsaste zum $\boldsymbol{N}$. facialis tritt von ihm ein Schlundzweig und ein ausschliesslich oder hauptsächlich in die Substan\% der Zunge sich begebender $\boldsymbol{R}$. lingualis ab, welcher bei Pipa in die Schleimhaut der Mundhöhle sich verbreitet. Das System der vonr $\boldsymbol{N}$. vagus abtretenden Seitennerven erscheint ntehr oder minder vollständig wieder, ohne dass anscheinend jemals Elemente des $\boldsymbol{N}$. trigeminus an ihrer Bildung Antheil nähınen. Bei allen Perenniloranchiaten, den Derotremata, bei Triton und bei Pipa ist wenigstens ein aus Elenienten des $\boldsymbol{N}$. vagus gebildeter Seitennerv 10) vorhanden. Bei Proteus kommen sogar zwei solcher Nerven vor, von denen der eine aus dem.Ganglion des $\boldsymbol{N}$. vagues abtritt, während der andere ein Ast des $\boldsymbol{R}$. intestinalis ist. Bei den Salunandern und Fröschen sind wenigstens während ihres Larvenzustandes ahnliche Seitennerven vorhanden und als letzte Andeutung des Systemes dieser Nerven, wenn auch nicht gerade als Ueberbleibsel des Ifauptstammes, köunnt bei allen ungeschwïnzten Batrachiern ein am Sehedel aufsteigender und hier unter der Ilaut des Nackens und der Sehulter oder in IIautdrisen sich verbreitender $\boldsymbol{R}$, cutaneus s. auricularis Vagi vor. Ausnihnsweise erseheint endlich bei Coecilia der $\boldsymbol{R}$. lateralis profundus nicht als Ast des Vugus, sondern des dritten Spinalnerven, wobei aber zu be-

8) Dieser Ast ist von Fischer bei Pelobates und Bombinator vermisst worden. - 9) Bei Bufo, Rana.

10) S. ïber den Seitennersen der nackten Reptilien Van Deen in Müller's Archir 1834, S. 4iz. - Vogt l. c. S. 57. - Krolin in Froriep's Notizen No. 1043. S. 136. - Fischer I. c. p. 36. - Der Ramus cutaneus s. auricularis der Frösche, der, namentlich von Müller, als Ueberbleilisel des $N$. Lateralis angesehen ist, entspricht älınlichen aufsteigenden Nerven, welche silir allgemein bei den Fischen neben dem $N$. lateralis vorkommen (s. \$. 27.). Dieser Ast ist bei den Froschlarven, ganz, wie bei den Fischen, zugleicl init dem eigentlichen $N$. lateralis vorlanden. Bei-Pipa endlich erhält er sich, wie Fischer gezeigt hat, neben den $\boldsymbol{N}$. lateralis perennirend. 
merken, dass der $\boldsymbol{N}$. vagus mittelst des $\boldsymbol{N}$. sijmpat/ricus gerade mit diesem Spinalnerven bei den Cöeilien sehr innig sich verbindet 11). Die Seitennerven verbreiten sich theils an der Ilaut, theils, wie dies bei Triton besonders deutlich hervortritt, an den Hautúrüsen. - Sowol bei geschwänzten, als bei ungeschwänzten Batrachicrn sind Zweige des'N. vagus in Aufhebenuskeln der Schulter verfolgt worden, ohne dass bis jetzt - etwa mit Ausnahme von Pipa - cin in scinen Wurzelelementen abgesonderter $\boldsymbol{N}$. accessorius nachgewiesen wäre. - Feinere Zweige zu einzelnen Zungenbeinınuskeln treten gewöhnlich aus der Bahn des Vagus aus. - Bei den Perennibranchiaten gehen von dem Ganglion dieses Nerven mehre Rami lrauchiales ab; als bestïndiger Ast erseheint ferner stets ein für die Stimmlade und ilıren BewegungsApparat bestimmter $\boldsymbol{R}$. larygeus s. recurrens. - Der $\boldsymbol{R}$. intestimalis besitzt, wenigstens bei den Batrachiern, noch eine gangliöse Anschwellung, ehe er sieh an Speiseröhre, Lerz, Lungen und Magen vertheilt.

4. Der $\boldsymbol{N}$. lıypoglos8us erscheint bei den nackten Reptilien noch nieht als Ilirnnerv. Bei den neisten ungeschwänzten Batrachicrn wird er vertreten dureh den ersten, nur mit einer vorderen Wurzel entspringenden Spinalnerven; bei Pipa entsteht er, ihnlich wie bei den Ineisten Fischen, aus Aesten des Plexus Grachialis; bei den Salamandrinen wird er durch die beiden ersten verbundenen Spinalnerven repräsentirt; bei den Cöcilien geht er aus den Ganglion hervor, zu dessen Bildung, ausser dem $\boldsymbol{N}$. vagus, die drei ersten Spinalnerven beitragen; bei Proteus sind seine Elemente theilweise im $N$. vagus, zum Theil aber im ersten Spinalnerven eingesehlossen. Die dem $\boldsymbol{N}$. hippoglossus entspreeheinden Aeste, welehe in der Regel Verbindungen mit Zweigen des $\boldsymbol{N}$. vagus eingehen, verbreiten sich in die meisten Zungenbein- und Zungenmuskeln, namentlich in dic M. M. stermoluyoüdens, gemiohyoüdeus, lyyoglossus, so wie auch in die Substanz der Zunge.

[Man vergl. über die Hirnnerven der nackten Reptilien besonders die sehr reichlialtige Schrift von J. G. Fiseher: Amphibiorun nudorun neurologia. Speciminis primi pars 1 et 2. Berol. 1843. 4. e. tab. - Ueber die Nerven von Rana s. aueh Volkmann in Müller's Archiv 1838, p. 70. und über mehre niekte Reptilien Vogt, in den neuen Denksehriften der Sehweiz. naturf. Gesellsehaft, Neuehatel 1840. A. Bd. 4.]

\section{§. 82.}

Die beschuppten Reptilien nähern sich rïcksichtlich der Anordnung ihrer Hirnnerven melır den höheren Wirbelthieren; insbesondere zeigen sich die Crocodile in dieser Bezichung den Vögeln verwandt. Die Augenmuskelnerven sind, anseheinend immer, von dem $\boldsymbol{N}$. irigeminus gesondert; der $\boldsymbol{N}$. glossopharyıgeus ist durch Ursprung und Austrittsstelle vom $\boldsymbol{N}$. vagus getrennt; zu den Elementen des $\boldsymbol{N}$.

11) Siehe Fiseher I. c. p. 43. 
ougus treten, anscheinend beständig, Wurzeln, welche, ihren Ursprungsverhältnissen nach, dem $\boldsymbol{N}$. accessurius entsprechen; ein ausgebildeter Seitennerv kömmt bei ihnen nicht mehr vor; dagegen erscheint bei ihnen der $\boldsymbol{N}$. hypoglossus als selbststindiger Hirnnerv. Bemerkenswerth ist die Neigung zur Verschmelzung, welche die letzten IIirnnerven bald nach ihrem $\Lambda$ ustritte aus der Schedelhöhle zeigen.

Der $\boldsymbol{N}$. oculorum motorius versorgt, nachdem cr sich meistens in zwei Aeste gcspalten, mit seinen Zweigen dic M. M. recti superior, inferior und intermens und den M.obligmes inferior, so wie auch endlich den meist vorhandencn M. Levator palpelırae superioris. Bestän$\operatorname{dig}$ gibt $\mathrm{cr}$ eincn $\boldsymbol{R}$. ciliaris ab, der mit cinem $\boldsymbol{R}$. ciliaris voin ersten Aste des $\boldsymbol{N}$. trigemimus verbunden, wenigstens bei cinigen Cheloniern, bci den Sauriern und Crocodilen ein Ciliaryanglion $\left.{ }^{1}\right)$ bildet. Der N. trochlearis ${ }^{2}$ ) vertheilt sich ausschliesslich in den $M$. obliquns superior. - Der N. alducem.s ${ }^{3}$ ) gibt, anscheinend bestandig, einen Verbindungszweig für den vorderen Kopfstamm des $N$. sympathicus ab und tritt mit seinem anderen Aste in den M. rectus externus und in den M. suspensorius lulli, versorgt auch dic Muskeln der Nickhaut.

Der N. trig emiu us ist immer der stärkste Hirnnerv. Von seinen Wurzelelementen tritt noch in der Schedelhöhle ein $\boldsymbol{R}$. primus ab, der, wie bei viclen Fischen, gewölnnlich - wenigstens bci Chelonia, Python, Varanus, Lacerta u. A. - rin gcsondertes Ganglion bildet. Seine übrigen Elemente schwellen daraul zil eincm mehr oder minder beträchtlichen Ganglion Gasseri an; ob die Portio minor von demselben ausgeschlossen ist, wie sich dies vermuthen lässt, ist thatsächlich noch nicht sicher ermittelt. Scin erster Ast (R. ophthalmicus) dringt in die $\Lambda u g e n h o ̈ h l e$, entlässt einen $\boldsymbol{R}$. ciliaris, gibt Zweige an die oberen häutigen Bedeckungen des Auges, an die Thränenorganc und an die Stirnhaut ab, gelangt in die Nase, an deren Schleimhaut er Rami ethmö̈däles schickt und endet mit zarten Zweigen in den äusseren Umgebungen der Nisenlöcher. Der zweite Ast (R. maxillaris superior) $\left.{ }^{4}\right)$ gibt

1) Abgebildet bei Bojanus Tab. XXVI. Fig. 132. 133. Ieh finde es auch bei Lacerta, Varanus und beim Kaïman. Bei letzterem gibt der $\boldsymbol{N}$. trigeminas, ausser der Wurzel zum Ganglion, noeh einen eigenen starken Ciliarnerven ab. lch vermisse dagegen das Ciliarganglion bei Chelonia, ein Mangel, der mit einer andern Eigenthümlichkeit correspondirt. Es nimnt nämlich hier der Stamm des $\boldsymbol{N}$. oculorum motorius starke Fäden aus dem crsten, mit einem eigenen Gauglion versebenen Aste des $\boldsymbol{N}$. trigeminus auf.

2) Siehe Bojanus Fig. 131. - 3) Bojanus Fig. 131-133.

4) Auch Muskeläste scheinen voin zweiten Aste des Trigeminus abzugchen. Bojanus macht bei der Schildkrötc folgende Zweige nambaft: 1) einen $\boldsymbol{R}$. $x y$ gomaticus, der als sulicutaneus malae endet; 2) eincn $R$. lacrymalis; 3) cinen in Muskel sich verbreitenden $\boldsymbol{R}$. pterygoïdeus; 4) einen $\boldsymbol{R}$. palatinus posterior; 5) einen $\boldsymbol{R}$. palatimus anterior; 6) cinen $\boldsymbol{R}$. infraorbitalis; 7 ) cinen $\boldsymbol{R}$. elveolaris superior. 
ausser den Fäden zum Ganglion oder Plexus sphenopalatinus des vorderen Kopfstanmes des $N$. sympathicus, Zweige al, welche in den häutigen Bedeckungen des Kaumuskels, an der Thräinendriise, an deın unteren Augenlide, in der Schleimhaut des Gaumens, in den Canal des Oberkiefers und an dessen häutigen Bedeekungen sich vertheilen. Der dritte und stärkste Ast ( $\boldsymbol{R}$. maxillaris inferior) verzweigt sieh hauptsächlich in die Kaunuskeln; seine eigentliche Fortsetzung ist der $\boldsymbol{R}$. alveoluris inferior, der in dem' Unterkiefereanale verläuft, Rami dentales und Hautzweige, so wie auch Fäden für die Schleimhaut der Mund. höhle abgebend. Er endet sehr regelmässig mit Zweigen, welche in dem M. mylohyoüdeus sich vertheilen ${ }^{5}$ ).

Der $N$. facialis ist immer nur ein sehr unbetriehtlieher Nerv. Noeh bei einigen Ophidiern $\left.{ }^{6}\right)$ geht er in das Ganglioys Gasseri des $N$. trigemimus ein und verlässt, vereint mit dem dritten Aste des $N$. trigemiuus die Schedelhöhle. Dann theilt or sieh in einen Muskelast und einen sympathischen Ast, der mit den $N$. N. vagus, hypoglossus und glossophary" geus einen gomeinsehaftlichen Stamin bildet. Bei dert Cheloniern besitzt er sehr wenige selbstständige peripherisclie Endigungen ${ }^{7}$ ), geht vielmehr fast gañz in den Kopftheil des $N$. symprathicus über. Bei allen Sauriern besitzt er ausser seinen Verbindungszweigen fuir den $N$. symprathicus einen an das Paukenfell sich verbreitenden $N$. tymparicas ${ }^{8}$ ) und einen in den Hautmuskeln des IInlses und dem M. digastricus sieh vertheilenden Ast.

Der $N$. glossopharyngeus geht immer innige Verbindungen mit dem N. sympathicus ein, namentlieh mit dessen aus der Bahn des $F a$ cialis stammenden Elementen. In der Regel communicirt er auch sehr bald mit dem $N$. vagus und später mit dem $N$. Impruglossus. Häufig tritt er, verbunden mit dem $N$. facialis in ein grosses sympathisches Ganglion. Bei der Mehrzahl der beschuppten Reptilien besitzt er nur zwei Ilauptzweige, von denen der eine an den Pharynx, an die Úmgebungen der Gluttis und an den Kehlkopf als R. Laryngeus superior sich begibt, wälırend der andere, mehr oder minder stark mit Zweigen des $N$. laypoglossus communicirend, in die Substanz der Zunge

5) Ein Zungenast vom dritten Aste des $N$. trigeminus fehlt beständig.

6) Nach Vogt's Angaben 1. c. S. 48. Indessen ist die Verschmelzung des Facialis mit dem Ganglion Gasseri bei den Ophidiern keinesweges beständig; ich vermisse sie z. B. bei Crotalus. Der Muskelast verbreitet sich。in Kaumuskeln.

7) Bojanus erwähnt blos eines in $\boldsymbol{M}$. digastricus endenden Zweiges; Swan sah bei Chelonia, ausser diesen, noch Verzweigungen in Hantmuskel des Halses; Vogt leugnet dagegen, ebenfalls bei Chelonia, alle selbstständigen peripherischen Verzweigungen und lässt den Nerren ganz in den Sympathicus übergehen.

8) Bei Monitor, Varanus, Lacerta, Platydactylus, Gecko, Iguana, Chamaeleo ron $V$ ogt beobachtet. 
tritt. Bei den Crocodilen verlizilt sich der $N$. glossophlaxymgeus fast ganz, wie bei den rögeln. Ein sehr starker, aber kurzer Verbindurigszwrig vom $N$. cragus tritl an den $N$. glossopharyngens und verlässt diesen als ein zwischen Luftrölre und Speiseröhre bis in den $\Lambda$ nfang der Brusthöhle absteigender Ramus descemderss, der an den Kehlkopf, die Speiseröhre, die Luftröhre sich verzweigt und tief unten durch feine Fïdn mit dem Plexus pulmonalis des $N$. vagus sich verbindet 9 ).

Der Nervus wagus wird vom $N$. rrigemimus imıner an Stärke iibertroffen; $\mathrm{Cl}^{\circ}$ ist bei den Cheloniern beträchtlicher, als. bei den iibrigen beschuppten Reptilien. Zn seinen Elementen gesellt sich; anscheinend beständig, eine mehr oder minder tief abwärts reichende, durch ihre Ursprungsverhältnisse als $N$. accessorins charakterisirte Wurzel. Die Ganglienbildung an der Austrittsstelle des Nervon bedarf noch näherer Untersuchung. Bei einigen Gattungen findet sich hald nach seinem Austritte aus dęr Schedolhöhle eine beträchtliche Anschwel. lung, an deren Bildung namentlich auch der Kopfstamm des $N$. sympathicus nebst dem $N$. glossopharyugęus Antheil hat. Gewöhnlich findet eine sehr innige Verbindung der Stämme des N. vagus, glossupharyngrens und lyypoglossus Statt ${ }^{10}$ ). Der Stamm des Nerven steigt am Halse abwiirts, gibt den Ramus recurreus ab und gelangt.in die Brusthölıle. Ilier bildet or bei den Sauriern und den Crocodilen "1) ein starkes Ganglion, das den übrigen Ordnungen zu fehlen scheint. Im Anfange der Brusthöhle entstht ein starker Plexus cardiacus und milmosalis, zu wolchem gewöhnlich beträchtliche Elemente des $N$. sympathicus beitragen. Unter Abgabe von Zweigen an die Speiseröhre tritt der $N$. vagus zum Magen, an welchem er gewöhnlich endet. Nur bei den Ophidiern erstreckt sich der Eingeweideast sehr weit abwärts am Darm 12) und ist bisweilen bis in dic Nähe der Cloake zu verfolgen.

9) Dieser Ast ist von Vogt 1. c. S. 38. als Sympathicus superficialis beschrieben. Ich habe den Verbindungsast vom $N$. vagus in diesen Nerven ubergehen sehen und dasselbe Verhalten, wie bei den Vögeln gefunden. Auch der $\boldsymbol{N}$. lay yngeus superios tritt aus der Bahn des Glossopharyageus bei vielen be. schuppten Reptilien, ein Verhalten, was durch die Innigkeit der Verbindungen, welche zwischen diesem Nerven und dein $N$. vagus Statt findet, sich leicht erklärt.

10) Vgl. über die Ganglienbildung und die Verschmelzung der hinteren Hirn. nerven besonders die Angaben von Vogt.

11) Während Vogt das genannte Ganglion bei allen Sauriern, mit Ausnahme ron Draco, gefunden hat, leugnet er es mit Unrecht bei den Crocodilen. Es ist hier sogar durch seinen Unfang ausgezeichnet. Verbindungen des Plexus pul. monalis und cardiacus mit Elementen des $N$. sympathicus, welche aus der Gegend des Plexus brachialis kommen, habe ich ebenfalls bein Crocodile be-
obachtet.

12) Wahrscheinlich treten zahlreiche Elemente des $\boldsymbol{N}$. sympatlicus in der Bahn des $\boldsymbol{N}$. vagus abwärts, der daher den oberflüchlichen Halsstamm des $\boldsymbol{N}$. 
Der $N$. "lypogrlossus tritt durch cine Oeffnung des Occipilale laterale, legt sich meist gleich nach seinem Austreten an den Stamm des $N$. vagus, coinmunicirt hier gleichfalls mit den $N$. symputhicus und vertheilt sich, diese Nerven verlassend, nach Aufnahme mehr oder ulinder betrïchtlicher Zwoige aus den vorrensten IIalsnerven, die ihn bedeutend verstiirken, an die Muskeln des Zungenbeines und der Zunge ${ }^{13}$ ). Gewöhnlich schickt er einen bedeutenden, durch Cervicalnerven verstärkten $\boldsymbol{R}$. descendeus in den $\boldsymbol{M}$. sternolıyoüdeus und omolıyö̈leus.

[Die ausfïhrlichsten Untersuchungen über das Verhalten der Hirnnerren bei den beschuppten Reptilien finden sich in den schon mehrfach genannten Schrifteu von Bojanus, Swan und Vogt. Ueber die Nerven von Python s. auch Vogt in Mïller's Archiv 1839, und die dazu gehörigen Berichtigungen in Vogt's späterer Arbeit.]

\section{\$. 83.}

Der $N$. sympathicus der Reptilien bietet im Ganzen complicirtcre und mannichfachere Verhajltnisse dar, als bei den Fischen, indem einerseits die Elemente seines Kopftheiles häufig innerhall eigencr Canäle der Schedelknochen oder in der Bahn der Hirnnervenstämme selbst verlaufen und andererseits sein Halstheil höchst verschieden entwickelt ist. Sein liopthel geht, wie es scheint beständig, Verbindungen ein mit den N. N. trigemiuns, alulucens, facialis, giossopliaryngens, vagus und lıypoglossus; ob er auch mit dem Ciliarganglion communicirt, ist mit Sicherheit noch nicht ermittelt. Rücksichtlich seiner Anordnung bietet der Nerv bei den einzelnen Ordnungen der Reptilien mannichfache Eigenthümlichkeiten dar. In Betreff der meisten nackten Reptilicn fehlen noch genauere Untersuchungen. Bei den am sorgfältigsten untersuchten ungeschwïnzten Batrachicrn beginnt der Kopftheil in Gestalt eincs feincn Geflechtes an dem Ganglion des $N$. trigemisus, in welches hier auch die $N$. $N$. ablucess und facialis eingehen, und tritt durch die Schedelhöhle, welche er mit dem die Elemente des $N$. glossophuryrogeus enthaltenden $N$. vagrus verlässt. Von dem Ganglion des letzteren, mit welchem er innig verbunden ist, setzt er sich als Grenzstrang unter die Austrittsstellen der Rami auteriores der einzelnen Spinalnerven fort und scndet, in Begleitung der Gefässstämme, beträchtliche, zum Theil mit Ganglien versehene Aeste zu den Eingeweiden. Bei den Cheloniern beginnt er geflechtartig (Plexus sphenü̈dalis) am zweiten Astc des $N$. trigeminus, verläuft als einfaclier Stamm unter Abgabe von Rami nasules posteriores, nach hinten, nimmt Elemente

sympathicus unit zu repräsentiren scheint. - Bei Monitor beobachtete $V$ ogt einen $Z$ weig des $V$ agus für die oberflächlichen Nackenunuskeln; bei Lacerta ocellata einen Zweig für die liaumuskeln.

13) Bei den Crocodilen vereinigen sich die vorderen Aeste der beiden Nervi hypoglossi in der Mittellinie und trennen sich dann wieder, wic Vogt richtig bemerkt. 


\section{Vierter Abschnitt. Vom Nervensysteme u. v. d. Sinnesorganen. 193}

des $N$. abducers und cles $N$, facialis auf, tritt als $N$. Vidianus in einen Canal des Felsenbeines, nimmt abermals Aeste des $N$. facialis und des $N$. glossopharyngess, die loald getrennt, bald vereinigt sind, in seine Bahn auf, geht hierauf sogleich Verbindungen mit den $N$. $N$. vagus und hypoglossus ein, und setzt sich als oberflächlicher IIalsstamm, der neben den $\boldsymbol{R}$. intestiualis $N$. vagi verläuft und mit den meisten Halsnerven durch zarte $Z$ weige verbunden ist, bis an den Thorax fort. Nachdem er noch Elemente des $N$. vorgus aufgenommen, bildet er mit denselben das Ganglion thoracicum primum, aus welchem zahlreiche für den Plexus cardiacus und pulmonalis bestimmte Fäden hervorgehen. Aus diesem Ganglion setzt sich der Grenzstrang, mehre, dicht hinter einander liegende grauröthliehe, schlingenartige Anschwellungen bildend, welche mit den Nerven des Armgeflechtes Verbindungen eingehen, nach hinten fort unid communicirt, meist doppelte Schlingen und Bogen bildend, die durch Ganglien unterbrochen werden, mit den vorderen Aesten aller Spinalnerven. Ausser kleineren, die Intercostalarterien begleitenden $Z$ weigen hommen zwei verwickelte, unter einander durch Fäden verbundene Geflechte vor; aus dem oberen schwicheren gehen Aeste mit del Arteria coeliaca zum Magen; aus denı unteren stärkeren entstehen Zweige, die mit der Art, mesenterica zum Darme treten und andere, die zu den Nieren und den Geschlechtstheilen sich begeben. - Der N. sympathicus der Ophidier ist dureh die schwache Ausbildung seines Hals - und Rumpftheiles ausgezcichnet, so dass man letzteren, obschon mit Unreeht, bisweilen gainzlich geläugnet hat. Bei der weiten Ausdehnung des Ramus intestiualis N. vagi am Darmcanale wird es wahrscheinlich, dass ein grosser 'Theil seiner Elemente in diesem enthatten ist, und dass dieser daher zugleich den oberflächlichen Halstheil des $N$. sympathicus repräsentirt. Der Kopftheil beginnt am zweiten Aste des $\boldsymbol{N}$. trigeminus bald geflechtartig, bald mit einem Ganglion splienoïlale, aus welchem dann Zweige zur Nasenschleimhaut und zur Thränendrüse abgehen. Der Stamm nimmt Verbindungsäste vom $N$. abducens und $N$. facialis auf, tritt durch den Canalis Vidianus zum N. glossopharyugeus und bildet hier das Ganglion cervicale supremum, welches wiederum mit dem $N$. facialis in Verbindung steht, und aus welchem ein Fädchen zur Kopfarterie und ein in eine Oeffnung des Unterkiefers tretender Zweig hervorgehen. Aus dem Ganglion cervicale supremum verläuft er in der Bahn des Stammes des $N$. glossopliaryngens zur Austrittsstelle des $N$. vagus und von hier weiter zuin $\boldsymbol{N}$. Iyppoglossus, wo er eine kleine Ansehwellung bildet, Dann setzt er sich als mittlerer Halsstamm an der WVurzel der unteren Dornen der Wirbel gelegen, längs der austretenden Nerveustiinme fort, wird bald unkenntlich, lisst sieh aber weiterhin, von der Ilerzgegend an, wieder wahrnehmen in Geslalt eines ron jedein vorderen Spinalnervenaste abtretenden $\boldsymbol{R}$. visceralis. Zarte Schlingen, welche: 
diese äusserst feinen, mit kleinen Ganglien verschene Rami viscerales unter einander verbinden, repräsentiren den Grenzstrang. - Bei den Sauriern. stcllcn ein Paar Verbindungszweigc vom zweiten Aste des $N$. trigeminus, welche bisweilen deutliche Ganglien bilden, das Sphenoïlalgeflecht dar. In den vordcren Kopfstamm des $N$. sympathicus; der am Boden der Augenhöhle auf dem Gaumenbeinc nach hinten verläuft, um in den Canalis Vidianus zu trcten, mündet einfach ein 7weig des $N$. abducens oder auch noeh ein vorderer Ast des $N$. facialis. Das Verhalten des Kopftheiles an den übrigen Hirnnerven gestaltet sich verschiedenartig. Häufig tritt el ganz in die Bahn dieser Ncrven über. So bei Varanus in die gemeinschaftliche Bahn der $N$. N. facialis und glossopharyngeus, worauf cr später vermittelst des Ganglion supremum mit dem Ganglion Vagi, das mit Fäden des Iypoglossus in Vcrbindung steht, communicirt; so bei Iguana zunächst in die Bahn des $N$. fucialis, später in die der vereinigten $N$. N. glossopharyngreus, vagus und Kypoglossus; so bei Chamaeleo in ein Ganglion, welches sümmtlichen hinteren Hirnnerven und dem ersten Halsnerven gemeinschaftlich angehört. Nachdem er diese auf verschiedene Wcise vermittelten Verbindungen eingegangen ist, setzt er sich als obcrflächlicher Halsstamm, bald eine Strecke weit mit dem Stamme des Vagus verschmolzen, bald fruiher von ihm sich trennend, abwärts fort, bildet in der Gegend des Armgeflechtes einen Plexus, häufig auch ein stärkeres Ganglion, das mit dem Ganglion thoracicum des Vagus durch Schlingen in Verbindung steht und setzt sich später in der Rumpfhöhle als Grenzstrang längs den vorderen Aesten sämmtlicher Spinalnerven unter Abgabe der für die Eingeweide bestimmten Stämme fort. - Der $N$. sympathicus der Crocodile zeigt rücksichtlich seines Verhaltens bedeutende Aehnliehkeit nit demjenigen der Vögel. Der aus dem Sphenoïdalgeflechte des zweiten Astes des $N$. trigemimus entstehende vordere Kopfstamm tritt naeh Aufnahme des Verbindungszweiges vom $N$. abulucens an das Ganglion Gasseri des N. trigemimus oder in dasselbe, verbindet sich mit dem $N$. facialis und glossopharyngens, tritt in der Bahn des Stammes des $N$. glossophliaryngeus zu dem Ganglion des $N$. vagus und hypoglossus und bildet hier ein mit dieser Ansehwellung sehr eng vcrbundenes Ganglion. Aus diesem Ganglion gehen zwei sympathische Halsstämme hcrvor; der eine oder äussere Stamm (Ramus profundus) tritt, wie bci den Vögeln in den Canalis vertebralis colli abwärts, während der andere innere (Sympathicus medius) an den unteren Dornfortsätzen der Halswirbel abwärts verläuft. Die $\boldsymbol{S}_{y j m p a t h i c i}$ medii bcider Seiten verschmelzen hier, an den beiden Carotiden oder der unpaaren Carotis liegend, stellenweisc zu einem gemeinschaftlichen unpaaren Stammc, trennen sich aber wieder, um abermals zu verschmelzen. Der Sympathicus medius steht durch Querschlingen mit dem ảusseren im Canale der Halsrippen verlaufenden $\boldsymbol{R}$. profundus in Ver- 


\section{Vierter Abschnitt. Vom Nervensysteme u. v. d. Sinnesorganen. 195}

bindung und verschwindet am Ende des Halses als selbstständiger Stamm. Der Sympathicus profunchus schickt, nachdem er aus dem Cunalis vertebralis in die Brusthöhle getreten, Verbindungszweige für den Plexus pulmonalis des N. vagus ab und setzt sich dann an der Austrittsstelle der vorderen Aeste der Spinalnerven, zweischlingig verlaufend, als Grenzstrang fort, der die gewöhnlichen Eingeweidenerven bildet.

[Das sympath. Nerrensystem der Reptilien behandeln, ausser E. H. Weber, Anatomia compar. N. sympathici, Lips. 1817, 8.: B o jan us, Gil tay, Swan, Müller und Vogt. Bojanus gibt auf der XXII., und besonders auf der XXIII. Taf. ausgezeiclmete Darstellungen seines Verhaltens bei der Schildkröte (Enys); Swan lat die XV. und XVI. Taf. dem Sympathicus von Chelonia, die XVIII. u. XIX. dem der Boa constrictor gewiduet. Vogt beschreibt das Verhalten desselben bei Chelonia, vielen Sauriern und Ophidiern. Müller gibt in seiner vergleichenden Neurologie der Myxinoïden, Tab. IV. Fig. 3-5., Darstellungen desselben von Python, Crotalus und Tejus. - Ueber den N. sympathicus der Cöcilien finden sich einige Bemerkungen bei Fischer 1.c. p. 43. Er beginnt hier am N. facialis, tritt zun Glossopharyngeus, mit dein er sich verbindet, und bildet unter den $\boldsymbol{R}$. intestinalis $\boldsymbol{N}$. vay $i$ wegtretend, ein beträchtliches Ganglion, das mit Zweigen des $N$. vagus in Verbindung steht. Von hier aus erstreckt er sich zum dritten Spinalnerven, der den $\boldsymbol{k}$. laleralis abgibt. - Auf einen Irrthum $V_{0} g \mathrm{t}$ 's, der den $\boldsymbol{R}$. descendens Nervi glossopharyngei bei den Crocodilen als Sympathicus superficialis beschreibt, warl schon imı vorigen §. aufmerksan gemacht.]

\section{Von den Geruchsorganen.}

\$. 84.

Das Geruchsorgan der Reptilien liegt in Höhlen, deren innerer gewöhnlich pigmentreicher und stets von einem Flimmerepithelium ausgekleideter Schleimhautüberzug die Ausbreitungen des Geruchsnerven aufnimmt. Jede dieser paarigen Höhlen besitzt stets eine äussere und eine innere in die Mund- oder Rachenhöhle fuihrende Oeffnung. Letztere durchbohrt nur bei den Proteïdeen die Lippen, wird aber bei allen übrigen Reptilien umschlossen von Knochen des Gaumens. Am meisten fischähnlich ist das Geruchsorgan bei Proteus ${ }^{1}$ ); auf seinem Boden finden sich zwei Reihen paralleler Streifen oder Plättchen, welche durch einen Mittelstreifen getrennt werden, eine Bildung, welche sonst nicht wiederkehrt. Der Axolotl und der Salamander besitzen eine weite cinfaclıe Nasenhöhle, ohne Sinus, mit theilweise knorpeliger, von Schleimhaut überzogener Grundlage. Die hintere Nasenöffnung ist der vorderen sehr genähert. Dieser letztere Umstand kehrt auch bei den ungeschwänzten Batrachiern wieder; hier geschieht die Oeffnung und Schliessung des Uusseren Nasenloches, welches bei Pipa etwas röhrig verlängert ist, durch Muskeln, die vom Zwischenkiefer entspringen. Die Na-

1) S. die Abbild. bci Rusconi, Monografia Tab. IV. fig. 9. 
senhöhle selbst besitzt einen, durch ein vorspringendes cartilaginöses Muschelbein -in zwei Gänge getheilten vorderen und einen weiteren einfachen hinteren Sinus. Die hintere Nasenöffnung ist durch ilhre Weite ausgezeichnet. Die vorderen oder äusseren Nasenöffnungen der beschuppten Reptilien stehen häufig untrr K̇influss besonderer Muskeln, welche z. B. bei den Crocodilen sehr ausgebildet sich finden, sind selten röhrig vorlängert, wie bei Chelys und Trionyx unter den Cheloniern, und füluren bald in das vorderste Ende der Nasenhöhle, wie bei den Crocodilen, bald in deren vorderen Abschnitt, wie bei den Chelo. niern, Ophidiern und manchen Sauriern, bald etwa in die Mitte der Nasenhöhle, wie bei den Varanen. Alle beschuppten Reptilien besitzen eine knorpelige Grundlage der Nasenhöhle, an deren Boden bei einigen, namentlich den Sauriern, Ophidiern und Crocodilen, noch ein einfach gestaltetes knöchernes Muschelbein sich findet. Die Flächenvergrösserung der Nasenhöhle geschieht durch grubenförmige Einstülpungen der auskleidenden Schleimbaut oder zugleich durch Duplicaturen del von ihr überzogenen knorpeligen Grundlage oder durch Bildung grösserer Höhlen, welche mit der eigentlichen Nasenhöhle oft nur durch enge Oeffnungen in Verbindung stehen $2 \%$. Während bei den Sauriern und Ophidiern, so wie auch bei den Cheloniern ${ }^{3}$ ) der hintere Nasengang etwa von der Mitte des Bodens der Nasenhöhle ausgeht, verlängert sich bei den Crocodilen die Nase canalförmig nach hinten und verläuft in den röhrig gerollten $\boldsymbol{O} s$ pterygoüdeum und Sphenoüdeum basilare. Diese weit nach hinten gerückten, dem Eingang in den Kehlkopf genäherten, sehr dicht neben einander, gelegenen hinteren Nasenöffnungen können hier durch ein contractiles Velum palatinum verschlossen werden. Die Schleimhaut der Nase ist immer sehr reich an Cryptae. Eine eigene Nasendrüse 4), deren Ausfuhrungsgang jedoch in den Rachen mündet, ist mit Sicherheit bisher nur bei den Ophidiern und den Varanen angetroffen worden.

2) Z. B. beim Crocodil, der Klapperschlange u. A, - An zusammengesetztesten ist die Nasenhöhle durch Inuschelförmige Bildungen des Knorpels bei den Crocodilen und Cheloniern, am einfachsten bei den Sauriern; die Schlangen icli untersuchte Python - stehen zwischen diesen beiden Extremen.

3) Bei den Cheloniern ist die hintere Nasenöffnung znit zottenförmigen Pa. pillen besetzt.

4) Die Nasendrüse der Schlangen, welche sehr allgemein vorzukommen scheint und von Müller entdeckt ist (s. Meckel's Archiv f. Anatom. u. Physiol., 1829, Bd. 4. S. 70.) liegt zwischen dem Oberkieferbeine und der Seite der Nasenliöhle, bisweilen, wie bei Python, unschlossen von einer in die Nasenhöhle vorragenden Einstülpung des Nasenknorpels. Die von unir aufgefundene Drüse der Varaneı liegt unter der Schleimhaut an der hinteren Grenze der hinteren Nasenöffnung. Auch beim Crocodile glaube ich eine lappige Drüse in der Oberkieferhöhle auswärts von einem inuschelartigen Vorsprunge des Nasenknorpels beobachtet zu haben, deren Ausführungsgang aber zu finden mir niclit gelang. 
Vierter Abschnitt. Vom Nervensysteme u. v. d. Sinnesorganen. 197

\section{Von den Gesichtsorganen.}

§. 85 .

Die A ugen der Reptilien sind fast nie von schr beträchtlicher Grösse; am umfänglichsten sind sie verhältnissmässig noch bei einigen Batraehicrn und bei den Geckonen; selten sind sie durch ungewöhnliche Kleinhcit ausgezcichnet, wie z. B. bei Pipa, Coccilia, Typhlops, oder selbst ganz, rudimentär, wie bei den Proteïdeen, bei Acontias coceus und einigen Scincoïden 1). Sie liegen besländig an den Seiten des Kopfes. Der Bewegungs-Apparat des Bulbus erseheint häufig complicirter, als bei den Fischen, indem bei den meisten Reptilien zu den sonst gewöhnlich vorhandenen vier geraden und zwei schiefen Augenmuskeln noch ein im Umkreise des $N$. opticus liegender, den Bulbus in die Augenhöhle zurückziehender $M$. choanoüdes $s$. suspensorius oculi ${ }^{2}$ ) hinzukömmt.

Hinsichtlich der Augenlider zeigen sich beträchtliche Verschiedenheiten. Bei allen Perennibranchiaten, den Derotremata und Cöcilien setzt sich die äussere Haut ununterbrochen über die Augen fort, bei den Proteïdeen - so wie auch bei Acontias coecus und wenigen Sauriern - ohne sich merklich zu verdünnen, hei den übrigen dagegen dünn und durchsichtig. Es fehlen also hier, gleich wie bei Pipa unter den Batrachiern, die Augenlider gänzlich. Diese letzteren mangeln auch den Ophidiern und unter den Sauriern der Familic der Geckonen, deren Augen von einer durchsichtigen, die Thränen aufnehmenden Capsel brdeckt werden. Diese Capsel besitzt drei Lamellen, von denen die beiden äusseren verdünnte und durehsichtige Fortsetzungen der Epidernais und Cutis sind, während die innerste in die den Bulbus unmittelbar überziehende Conjunctiva übergeht. Gegen den inneren Augenwinkel lin, steht diese Capsel durch einen weiten Gang mit der Nasenhöhle in Verbindung, in welehe die Thränen abgeleitet werden. Die übrigen Ordnungen besitzen, ausser einem wenig beweglichen oberen Augenlide, ein beweglicheres unteres, das gewöhnlich, gleich dem oberen, von der unverdünnten äusseren Haut iuberzogen, bei den Fröschen jedoch sehr gross, dünn und durchsichtig ist. Bei den Sauriern ist dies untere Augenlid durch den Besilz einer rundlichen Knorpelplatte gervöhnlich ausgezeichnet; bei einigen Scineoïden durch eine der Cornea entsprechende durchsichtige brillenartige Stelle, dic das Sehen nicht hindert, eigenthümlich characterisirt. Nur die Ghimäleonten haben cin rundes Augenlid, das dem Bulbus eine Strecke weit sehr eng anliegt. Zu den genannten beiden $A$ ugenlidern kömmt meistens noch ein drittes,

1) Namentlich bei den Gattungen Dibamus und Typhline.

2) Er scheint den Ophidien allgemein zu fehlen, ist bei den Chelonicrn und Sauriern vollkommener, als bei den Crocodilen. 
mehr oder minder durchsichtiges, am vorderen oder inneren Augenwinkel gelegenes: die Nickhaut, Membrana sictitans. Sie ist bei den Batrachiern höchstens durch eine schwache Ilautfalte angedeutet, bei den meisten Sauriern, den Cheloniern und Crocodilen aber sehr entwickelt und enthält hier ebenfalls eine Knorpelplatle. Diese Membran kann hald nur über eine kurze Strecke des Bulbus vorgezogen werden, wie bei den Cheloniern, bald fast den ganzen Augapfel bedecken, wie bei den Crócodilen. Ihre Bewegungen geschehen unter Einfluss cines eigenthümlichen Muskelapparates, dessen Einrichtung bei den einzelnen Ordnungen zwar Verschiedenheiten darbietet, der aber im Ganzen mit dem den Vögeln zukommenden und später näher zu beschreibenden Bervegungsapparale grosse Aehnlichkeit besitzt. Sobald ein ausgebildetes drittes Augenlid vorhanden ist, erscheint auch eine eigenthümliche, am inneren Augenwinkel gelegene, gelapnte, meist von einer derben fibrösen Haut umgebene Drüse: die Harder'sche Drüse, deren Ausführungsgang unter' der Nickhaut mündet. Eine eigene, gleichfalls gelappte Thränendrüse ist wenigstens bei allen beschuppten Reptilien 3) vorhanden, und namentlich bei den Cheloniern und Ophidiern, im Verhältnisse zum Umfange des Auges durch bedeutende Grösse ausgezcichnet. Vom äusseren Augenwinkel aus umgibt sie den Bulbus halbringförmig. Ein beträchtlicher Theil derselben liegt bei vielen Opnidiern mehr in der Schläfengrube, als in der Orbita, ist also, vom M. temporalis theilweise bedeckt, den Einwirkungen desselben ausgesetzt. Bei den Cheloniern kann sie durch einen eigenen flachen Muskel, der über einen grossen Theil der Orhita sich ausbreitet und in eine Schnenhaut iibergeht, zusammengedrückt werden. Bei den Cheloniern ist ein Duchus nasalis, der den Thrïnen Abfluss in die Nasenhöhle verschaffen könnte, noch nicht nacligewiesen, während derselbe dagegen bei den Sauriern und Crocodilen, so wie bei den Ophidiern vorkommt.

Die bei den Batrachiern knorpelharte, hei den iibrigen Reptilien fibröse Sclerotica zeichnet sich hei den Cheloniern und Sauriern durch den Besitz eines aus dachziegelförmig über einander liegenden Knochenschuppen gebildeten Ringes aus, der um den Rand der Cornea sich herumzieht 4). Im hinteren Theile der Sclerotica findet sich bei den Cheloniern häufig noch cine Knorpelplatte.

Die Cornea bietet in Betreff ihres Umfanges und ihrer stärkeren oder geringeren Convexität bei den einzelnen Ordnungen und Familien mancherlei Verschiedenheiten dar. Bei den Ophidierı nimmt sio fast

3) Auch den ungeschwänzten Batrachieln scheint sie zuzukommen; Petit hat sie vor langer Zeit beschrieben. Ich tinde sie bei Hyla.

々) Ich vermisse indessen, gleich Tied c ma nu, den Knochenring bei den Cro. codilen, denen er von Sömmerring mit Unrecht zugeschricben wird. 
die Hälfte des Bulbus ein; bei den Batrachiern und Crocodilen ist siß sehr beträchtlich, bei den meisten Sauricrn weniger umfänglich und bei den Schildkröten endlich sehr klein in Verhältniss zum Umfange des Augapfels. Sie ist sehr convex bei den Crocodilen und Ophidiern, weniger bei den Batrachiern, Sauriern und Cheloniern.

Die Choriö̈dea zcichnet sich gewöhnlich durch ihre Dicke aus und besteht aus den schon den Fischen eigenthümlichen drei Blättern. Allgemein ist das Corpus ciliare mit seinen Processus ciliares; kurz bei den Batrachiern, den Ophidiern und Sauriern; diese sind etwas mehr entwickelt bei den Cheloniern und endlich lang und zahlreich bei den Crocodilen. Die Iris ist bei den Fröschen und mehren Ophidiern durch einen goldfarbenen Pupillarsaum ausgezeichnet. Die Pupille bietet manche Formverschiedenheiten dar; gewöhnlich kreisrund, erscheint sic bei den Crocodilen rhomboïdal und bildet bei den Fröschen im Zustande der Contraclion ein stumpfwinkliges Dreieck, während sie, erweitert, kreisrund erscheint.

Der Sehnerv bietet sehr abweichende Verhältnissc von demjenigen der Fische dar. 'Die Tractus optici werden bei mehren beschuppten Reptilien durch eine partielle bandartige Commissur der Fasern verbunden und bilden dann ein Chiasma, neben welchem eine blätterförmige Kreuzung der innersten Portion der Sehnerven Statt hat $\left.{ }^{6}\right)$. Jeder Sehnerv tritt gewöhnlich etwas auswärts von der Axe des Bulbus in diesen ein.

Bei vielen Sauriern erstreckt sich von der Eintrittsstelle des $N$. opticus aus durch den Glaskörper, keilförmig bis zum unteren Theilc der Linsencapscl dringend, der mit schwarzem Pigmente iberzogene gefässreiche Kamm, Pecte zo s. Marsupium, welcher dem gleichnamigen Gebilde des Vogelauges entspricht, aber durch den Mangel der Falten oder durch cine sehr geringe Zahl derselben 7 ) sich auszeichnet. Bei den Crocodilen findet sich blos eine schwache Andeutung dieses Gebildes ${ }^{8}$ ), das den iibrigen Reptilien fehlt.

An der Retina der Reptilien ist die Stäbchenschicht, der Choroïdea zugewandt (Membrana Jacobi), sehr deutlich. Die Stähe erscheinen als durchsichtige, dicke scchseckige Säulen 9 ).

3) Z. B. bei Iguana.

6) Vgl. darüber besonders Carus, Versuch einer Darstell. des Ner-vensystemes, S. 18s. Tab. 3. Fig. XIX. und J. Müller, Vergl. Physiol. d. Gesichtssinnes, S. 132. Tab. III. Fig. 17. 18.

7) Der Kamu ist gefunden bei Lacerta, Anguis, Iguana, Monitor. Bei Iguana bildet er zwei Falten und ist sonst einfach.

8) Nach Sömmerring's Angabe 1. c. 1\%. 59.

9) Vgl. die ausfihhrlicheren Angaben von Hannover in Müller's Archiv 1840, S. 320. und 1843, S. 314. (Schildkröte.) - L Lersch, De retinae structura inicroscopica, Berol. 1840. (Frosch.) 
Gestalt und Dimension der in ihrer Capsel eingesehlossenen Linse sind bei den versehiedenen Ordnungen versehieden. Sie ist sehr gross bei den Batrachiern, verhältnissmässig unbelı̈ichtlicher bei den übrigen Ordnungen und sehr klein bei den Cheloniern. In der Regel ist sie nicht mehr kugelrund, sondern vorn etwas flacher als hinten, was besonders bei den Sauriern deutlich ist. Die vordere Augenkammer und die Masse des Humor aqueus ist immer unbeträchtlich. Auch der Glaskörper ist - mit Ausnahme der Chelonier, bei welehen er durch seinen Umfing sich auszeichnel - unbedeutend. Dic Membrana lyy. alö̈lea ist bei vielen Reptilien, namentlich bei den Batrachiern und Ophidiern, dureh ein reiches Gefässnetz, dem das Blut durch eine Ciliararteric zugefuhrt wird, eigenthüinlich charakterisirt ${ }^{10}$ ).

[Man vgl. über las Gesichtsorgan der Reptilien: Blainville, Princ. d'anat. romp., p. 411. sqq. D. W. S o emm erring, De ocul. sect. horizcilt., Gött. 1818, fol. 1). $56 \mathrm{sqq}$. Ueber das Auge der Frösche: Petit in den Mém. de l'académie d. scienc., Paris 1737; über las Auge von Testudo mydas: Albers, Münchener Denkschr. 1808, S. 81. Ueher Emys europaea die schönen Abbiltungen leei Bo. janus l. c. Tab. XXVI.; über das Ange des Chamäleon: Treviranus, Beob. achtungen a. d. Zootom. W. Physiol., S. 95 ff.]

\section{Von den Gehörorganen.}

§. 86 .

Das Gehörorgan bietel je nach den verschiedenen Ordnungen der Reptilien merkwuirdige Verschiedenheiten dar. Schliesst sich seine Organisation bei den niedrigsten Ordnungen dieser Classe eng an die den Fischen, und namentlich den Plagiostomen, eigenthiimliche an, so lindet andererseits zwisehen dem Gehörorgane der Crocodile und denıjenigen der Vögel kaum cin irgend bedeutender Unterschied mehr Stàtt. - Das Labyrinth der nackten Reptilien wird stets von dem $O s$ petrosum unschlossen. Es besteht aus drei halbeirkelförmigen Canälon, welehe riicksichtlich ilırer Verbindung und ilhrer Ampullen bei den einzelnen Gattungen mancherlei besondere Eigenthiimlichkeiten darbieten, stets aber in don Sack (Saccus vestibuli) einmiinden. Dicser letztcre enthält ein ims kohlensaurer Kalkerde bestehendes Conerement und liegt in der hinteren Grube des Vestibulum, dessen ganze Höhle unil einer anscheinend milchigen, aus mikroskopiseḷen Krystallen bestehenden Fliissigkeil angefiullt ist. Dasselbe besitzt stets cine $F \boldsymbol{e}$ nestra ovalis, welche bald nur durch ein ovales eartilaginöses Deckelchen (Operculum) 1 ), bald durch dieses und ein stielförmiges Knöchelehen 2), lald auch noch, ausser dem Operculum, durch eine dünne

10) Vgl. Hy r'tl in den Med. Jahrb. lles Oesterr. Staates, Bu. 15. Jahrg. 1838.

1) Coecilia, Amphiuma, Menoponia, Proteïleen. - 2) Siredon. 


\section{Vierter Abschnitt. Vom Nervensysteme u. v. d. Sinnesorganen. 201}

Membran verschlossen wird 3). Bei vielen nackten Reptilien, namentlich bei den Cöcilien, den Derotremata, den Proteïdeen, den Salamandrinen und ciner Familie der ungeschwänzten Batrachier 4 ), wird dies ovale Fenster mit seinem Deckelchen, in Ermangelung einer Trommelhöhle, Innmittelbar von Muskeln und Haut bedeckt. Aber schon bei der Mehrzalıl der ungeschwänzten Batrachier geselt sich eine hinter dem $\boldsymbol{O}_{\boldsymbol{s}}$ quatratums gelegene Trommelhöhle mit Eustachischer Tuba und weiter ausgebildeten Gehörknöchelchen hinzu. Bei den meisten 5) ist die Trommelhöhle noch zun Theil knorpelig, und das hier häutige, bald frei, bald unter der Haut verborgen liegende Trommelfell ist über einem oben an dem Os quadratum befestigten Knorpelringe ausgespannt. In diesem Falle sind, mit Einschluss des Operculum, drei Gehörknöchel ehen vorhanden und die Paukenhöhle dringt auch noch nicht bis zur Fenestra ovalis vor, sondern ihre Membran befestigt sich, nachdem sie das mittlere Gehörknöchelchen überzogen, an das Os petrusum. Die Tula Eustachii bildet cinen kurzen Canal und beide Tuben öffnen sich von einander getrennt im Schlunde. Bei einer anderen Familie der ungeschwänzten Batrachier ${ }^{6}$ ) ist dagegen die Trommelhöhle schon ganz von knöehernen Wänden umschlossen und statt des Trommelfelles findet sich ein knorpeliger Deckel auf dem Eingange der Trommelhöhle. Ausser diesen ist nur noch ein langes krummes Knöchelchen vorhanden, das mittelst eines kleinen Scheibchens die Fenestra ovalis schliesst. Zugleich öffnen sich die beiden Tuben mit einer einfachen Mündung imı Rachen. - Bei den bescliuppten Reptilien erlangt das Labyrinth durch das Auftreten einer Schnecke nit einer Fenestra rotunda, welche hier noch zu dem ein oder mehre Steinchen enthaltenden Saccus vestibuli und zu den drei hallocirkelförmigen Canïlen sich hinzugesellt, eine höhere Ausbildung. Trotz dicser weiteren Entwickelung des Geliörlahyrinthes kann aber die Trommelhöhle nebst dem Trommelfelle wieder gänzlich mangeln, wie bei allen Ophidiern und vielen schlangenähnlichen Sauriern, wïhrend sie den Cheloniern und Grocodilen ohne A ısnahme zukönımt. Zur Umschliessung des Labyrinthes tragen bei den beschuppten Reptilien stets melire Knochen bei: bei den Ophidiern und Sauriern das Us petrosum und occipitale laterale, bei den Crocodilen ausser diesen Knochen nuch noch das Occipitale superius, bei den Cheloniern aber das Os petrosum und occipitale externum. - Am einfachsten ist die Bildung der Schnecke bei den Cheloniern. Sie zeigt sich in Gestalt eines rundlichen memloranösen Sackes, der in einer ähnlich gestalteten grossentheils von Knochensubstanz gebildeten IIöhle enthalten ist. Diese Schnecke besitzt eine durch cine Membrana tympani secundaria verschlossenc Fenestra rotunda und cornmunicirt ausserden

3) Salamandra maculata: - 4) Bombinator, Pelobates, Telmatobius, Phryniscus. - 5) Rana, Hyla, Bufo. - 6) Pipa, Xenopus. 
durch einen engen häutigen Canal mit dem Saccus vestiluuli. - Weiter ausgebildet und fast vollkommen mit der der Vögel übereinstimmend zeigt sich die Schnecke bei den Ophidiern, den Sauriern und besonders den Crocodilen. Ein kurzer am Ende etwas srweiterter Canal mil einer durch eine Membrana tympani secumblaria verschlossenen $\boldsymbol{F e}$ nestra rotunda stellt die Schnecke dar. Ein Knorpelring im Innern diescs Knochencanales bietct den häutigen Theilcn eine feste Stitze dar und theilt die Schnecke in zwei Abthcilungen: eine Scalre tympanis. externa und eine Scala vestilnuli s. interna, welche letztere in die Höhle des Vestibulum sich öffnet. Zwischen den Schenkeln des Knorpelringes, die am vordcren Ende vereinigt sich schlauchförmig umbiegen, ist eine Membran gelegen, auf welcher der $N$. cochlearis, wie auf einer Spirallamelle sich ausbreitet. Ausser einer Gefässhaut findet sich im Innern der knöchernen Schnecke noch eine oberflächlicho Membran, welche nach vorn mit dem schlauchförmigen Theile des Rahmens die Flasche, Lageua, bildet, welche Krystalle von kohlensaurer Kalk. erde enthält. - In Betreff der Paukcnhöhle kommen bei den beschuppten Reptiliẹn grosse Verschiedcnheiten vor. Den Ophidiern fehlt sie ganz. Das ovale Fenster wird bei den Ophidia macrostomata durch cin langes zwischen den äussercn Muskeln liegendes Gehörknöchelchen (Columella) geschlossen; bei den Ophidia microstomata ist letzteres sehr kurz, stellt bisweilen nur eine unregelmässige Platte dar und scheint bei cinigen selbst ganz zu fehlen. - Bei den Cheloniern wird dic Fenestra ovalis durch ein Operculum verschlossen; an dieses stösst die lange Columella. Die Paukenhöhle ist durch ein knöchernes Septum in zwei Abtheilungen zerfallen, welche nur durch den Canal, der die Coluınella aufnimmt, verbunden sind. Die äusscre Abtheilung wird nach aussen durch ein ausschlicsslich am Quadratbeine befestigtcs Trommelfell, zwischen dessen Lamellen ein scheibenförmiges Knorpelstiick liegt, an das die Columella angeheftet ist, verschlossen. Diese äussere Abtheilung setzt in die kurze Tuba sich fort. In die innere Abtheilung, das Antivestibulum nach Bojanus, mündet eine weite im Os mostoüdeum enthaltene Höhle. - Bei den Sauriern wird die Paukenhöhle nur zum Theil vom Quadratbeine gebildet, zum Theil aber ist sic von Haut oder von dẹ Muskeln des Unterkiefers und des Zungenbcines umgeben. Sclten fehlt das sonst gewöhnlich, wie bci den mcisten übrigen Reptilien, nach aussen etwas convexe Trommelfell ganz ${ }^{7}$ ); in der Regel ist es vorhanden, aber nur vorn am äusseren Rande des Quadratbeines, hinten und unten dagegen mit cinem knorpcligen Ringe an der Membran der Paukenhöhle befestigt. Das 'Trommelfell licgt bald frei, bald ist cs auswärts von Muskeln und Haut bedcckt. Die Tuba Eustrachii ist kurz und weit und stellt eigentlich nur eincn verengten Abschnitt der Mundhöhle dar.

7) Z. B. Chamaeleo, Anguis u. A. 


\section{Fünfter Abschnitt. Von den Verdauungs-Organen. 203}

Es sind drei Gehörknöchelchen vorhanden: das das ovale Fenster schliessende Operculum, dic Columella und cin klcines Knorpelstück, das, mit der Columella verbunden, an das Trommelfell sich befestigt. Bci den Crocodilen steht dic knöchernc Paukenhöhle in Verbindung mit zahlreichen Zellen, welche in allen benachbarten Knochen sich finden. Der Crehörknochen besitzt ein dreieckiges Operculum und läuft gegen das Trommelfell hin in drei Spitzen aus. Vorn und unten mündet die Tuba ein, deren Canal theils knöchern, theils häutig ist. Das grosse ovale Trommelfell ist theils am Quadratbeine, thcils am 0 \& mastoïleum befestigt. Eine das Trommelfell bedeckende muskulöse doppelte Klappe erscheint als erstc Andeutung eines äussercn Ohres ${ }^{8}$ ).

[Man vgl. über das Gehörorgan der Reptilien vorzüglich C. J. H. Wind is ch. mann; De penitiori auris in amphibiis structura, Lips. 1831, 4., mit Abbild. Ausserdem die schon \$. 31. angef. Schriften von Scarpa, Huschke, Steifensaud und Krieger, die Abbildungen von Bojanus Tab. XXVI. und besonders den reichbaltigen Aufsatz von Miiller in Tiedemann u. Treviranus, Zeit. schrift Bd. V. - S. auch Mayer's Analekten f. vergl. Anat, an mehren Stellen.]

\section{Fünfter Abschnitt. \\ Von den Verdauung-Organen.}

I. Vom Gebisse.

\$. 87.

Nicht allen Reptilien kommen Zähnc zu, welche einigen Batrachiern 1) und sämmtlichen Cheloniern fehlen. Die zur letztgenannten Ordnung gehörigen Thiere besitzen, statt der Zähne, Hornscheiden an den Kiefern, welche bei den fleischfressenden Gattungen mit scharfschneidenden Kanten versehen, bei den Pflanzenfressern dagegen stumpfer sind. Bei der Gattung Siren allcin kommen solche Hornscheiden gleichzcitig mit Zähnen vor. Die Zähne der ibrigen Reptilien dienen fast nur zum Ergrcifen und Halten der Speiscn, nicht aber zu ihrer Zerkleincrung. - Dic Zahlenverhältnissc der Zähne bicten bei den verschiedenen Gattungen keine so beträchtlichen Schwankungen dar, als

8) Das schon bei den Fiśchen vorhandene Septun der Ampullen der halbcirkelförmigen Canäle findet sich, wie Steifens and l. c. gezeigt hat, bei den beschuppten Reptilien wieder und dient, wie dort, den Nervenausbreitungen zur Grundlage. Bemerkenswerth ist es, dass bei den beschuppten Reptilien das Septum der äusseren Aupulle eiufacher construirt ist, als das der vorderen und der hiuteren. Bei den Schildkröten hat das Septum in der Mitte nur einen erhabenen Umbo; in ter äusseren Ampulle ist nur die Hälfte des Septum vorhanden. Bei den Crocodilen und Sauriern ist die äussere Ampulle, wie bei den Schildkrö. ten; die anderen haben eine kreuzförnige Bildung. - 1) Zabulos ist Pipa. 
dies bei den Fischen und den Säugthieren der Fall ist. Zähnetragend sind oft allein dic Kiefer, bald mit Einschlıss der Zwischenkiefer, wio bei den Crocodilen und vielen Sauriern, bald mit Ausschluss derselben. Oft aber sind auch Kiefer und Knochen des Gaumens mit Zähnen besetzt; bald die Ossa pterygoüdea allein, wie bei Iguana, bald die Ossa pterygö̈lea und palatina, wie bei den meisten Ophidiern und vielen Sauriern, bald die Vomer, wie bei den meisten Batrachiern 2). Selten ist, ausser den beiden Vomer, auch der Keilbeinkörper mit Zähnen besetzt, wic bei Salanandra glutinosa, - Der Intermaxillarknochen fast aller Ophidier - init Ausnahme von Tortrix und Python - erniangelt der Zähne; bei den meisten ungeschwänzten Batrachiern fehlen sie im Unterkiefer. - Als seltene Ausnahme durchdringen bei Deirodon scaber die verlängerten und von Dentine überzogenen Processus spinusi inferiores mchrer Rückenwirbel die Wandungen des Oesophagus zahnartig ${ }^{3}$ ). - Die Zähne der Kiefer stehen, mit einziger Ausnahme von Coecilia, in einer Reihe. In mehren Reihen stehen die Zähne der Ossa pterygoülea der Saurier, so wie die des Vomer, der Gaumenknochen, des Opercularstückes des Unterkiefers und des Keilbeines bei den verschiedenen Gattungen der nackten Reptilien. - Gewöhnlich sind die Zühne conisch; sie sind häufig mehr oder minder hakenartig gekrümml, nit mehr oder weniger scharfer Spitze versehen. Rücksichtlich ihrer Länge und Dicke bieten sie grosse Verschiedenheiten dar. Auf Querdurchschnitten erscheinen sie kreisrund, elliptisch oder oval. Bisweilen sind sie seitlich fein gezähnelt oder gegen die Spitze hin mehrfach eingekerbt 4). Aln längsten und am spitzigsten, und zugleich bis in die Nähe (ler Spitze von einer häutigen Scheide umgeben, ist die Zahnkrone bei den meisten Schlangen; die Aussentläche der Zahnkrone ist meist glatt; sie ist mit einer Längsfurche versehen bei vielen Ophidiern, von deren Giftzähnen später gehandelt werden soll 5). Die Hinterzähne der Crocodile tragen am Ende eine war'zenförmige Erhabenheit, die durch eine halsartige Einschnürung abgegrenzt ist. - Gewöhnlich sind die Zähne der Reptilien durch Anchylose mit den sie tragenden Knochen verbunden. Schr viele Saurier besitzen die Eigenthümlichkeit, dass nur die Aussenfläche ihrer Zähne an der äusseren Alveolarplatte der Kiefer befestigt ist, die Innenfläche derselben, bei dem Mangel einer inneren Alveolarplatte dagegen frei liegt 6 ). Man nennt diese Familie daher Pleu-

2) Hier fehlen die Zähne bei Xenopus.

3) Von Jourdan entleckt. S. die Abbild. bei Bächtold (Rapp), Untersuchungen über die Giftwerkzeuge der Schlangen, Tübing. 1843, 4.

4) Bei einigen Varanen, bei Iguana, Dicrodon, Acrantes, Cuemidophorus u. A.

5) §. 10\%. Gefurchte Zähne nicht giftiger Schlangen sind angetroffen bei Homalopsis, Dispholidus, Psammophis, Coronella rhombeata, Coluber plumbeus und einigen Arten von Herpetodryas, Dryiophis und Dipsas.

6) Bei den meisten Scincoïden, Iguanoïden, vielen Lacerten, den Chamäleonten. 
rodonten. Andere, bei denen dic Zähnc dem Kicfcrrande glcichsam angelöthet erscheinen 7 , heissen Acrodonten. Bei anderen nackten und beschuppten Reptilien ruhet die Basis der Zähne in einer seichten Alveole $\left.{ }^{8}\right)$. - - In die Reihe der Zahnbildungen gchört noch cine lange, platte, gekrümmte Bewaffnung des Zwischenkiefers bei reifen Schlangenund Eidechsen -Embryonen, welche später verschwindet und wahrscheinlich zum Durclıbrechen der Eischale dient $\%$.

[ Man vgl. über die Zähne der Reptilien $\mathrm{C} u$ vier in den Recherches sur les ossem. foss. nud 0 wen, Odontography Part. 2.]

\section{Von der Zunge.}

\section{§. 88.}

Nur wenige Batrachier sind durch völligen Mangel der Zunge ausgezeichnet und hesitzen am Boden der Mundhöhle nur flache Runzeln 1). Bei den Proteïdeen, den Cöcilien und den Salamandrinen ist die Zunge mehr oder minder klein und am Boden der Mundhöhle angewachsen. Bei den meisten ungeschwänzten Batrachiern ist sie hinten ganz frei, so dass sie umgeschlagen werden kann ${ }^{2}$ ), eine Regcl, von welchel jedoch mehrere Hylae eine Ausnahme bilden. Bei den Ophidiern ist sie lang, schmal, glatt, vorn in zwei tief getheilte Spitzen ausgezogen und in einer durch Verlängerung der Mundhaut gebildeten Scheide eingeschlossen, die am Eingange der Mundhöhle eine zu ihrem Durchtritte bestimmte Oeffnung besitzt ${ }^{3}$ ). Diese Scheide kömmt unter den Sauriern den Varanen zu und findet sich auch unbedeutend und weit nach hinten gerückt bei den Chamäleonten. Die Zunge ist bei den Sauriern (nit Ausnahme der Chamäleonten, wo die lange cylindrische, eigenthümlich vorstreckbare Zunge vorn knopfförmig endet) vorn und häufig auch hinten gespalten. Der Grad der vorderen Spaltung ist höchst verschieden, sehr unbeträchtlich bei den Geckonen, den Iguanidae und den Scincoïden, bedeutender bei den Lacertoïden und am bedeutendsten bei den Varanen (Fissilingues), deren Zunge auch durch ihre Länge und Schmalhcit völlig schlangenähnlich sich verhält. Bei der Mehrzahl der übrigen Saurier ist sie breit, kurz, dick oder flach und mehr oder weniger frei beweglich. Bald ist sie ganz glatt 4), bald vorn glatt und hinten warzig oder schuppig, bald halb mit Schüppchen, halb mit Fädchen besetzt ${ }^{5}$ ), bald nur mit kleinen Schüppchen pflasterartig besetzt 6 ),

7) Istiurus, einige Iguanoïden. - 8) Cöcilien, Batrachier, Geckonen, Ophidier u. s. w. - 9) Siehe Miiller in seinem Archiv 1841, S. 329.

1) Die Aglossa: Pipa, Xenopus.

2) Die Zungenform ist bei den Thieren dieser Orunung zn systematischer Unterscheidung der einzelnen Gattnngen vielfach benutzt worden.

3) So verhält sie sich anch bei den anomalen Microstomata: Typhlops, Rhin. ophis, Tortrix.

4) Varanel. - 5) Pseudopus, - 6) Bei vieleu Scincoïden, Seps. 
bald endlich gewinnt sie durch feine, weiche, lange dichtstehende $\mathrm{Pa}$ pillen oder Zotten ein sammtartiges Ansehen 7). - Bei den Cheloniern ist die Zunge kurz, flach und breit; bei den See- und SüsswasserSchildkröten von einem harten, dicken Epithelium überzogen, bei den Landschildkröten dagegen mit dichten, langen, weichen Zotten hesetzt. - Bei den Crocodilen ist die flache, breite, fast ganz am Boden der Mundhöhle angewachsene und durchaus nicht vorstreckbare Zunge, mit Ausnahme einzeln stehender Cryptae, glatt 8 \%.

\section{Von den drüsigen Organen der Mund- und Rachenhöhle.}

\section{§. 89.}

Lippendrüsen oder Kieferdrüsen, von einfachem Baue und mit zahlreichen Oeffnungen vor den Kieferzähnen mündend, komimen bei vielen Ophidiern und Sauriern 1) liangs des Ober - und Unterkieferrandes vor. Bei den giftigen Schlangen sind sie bei oft geringer Ausdehnung des Oberkiefers klein oder ganz fehlend, bei den übrigen dagegen gewöhnlich sehr lang. Mit der Glaudula Labialis superior hangt bei vielen nicht giftigen Schlangen 2) eine rücksichtlich ihrer Lage mit der Giftdrüse, rücksichtlich ihres Baues mit den Lippendruisen übereinkommende grosse Speicheldrüse ziemlich innig zusammen, deren Ausführungsgang in die Furche eines Zahnes übergeht. - Eine auf dem Boden der Mundhöhle, unter der Zunge liegende Masse einfacher Drüschen (Glandula sullingualis) ${ }^{3}$ ), deren zahlreiche Ausführungsgänge das Secret in die Mundhöhle führen, kömmt bei vielen Ophidiern und Sauriern vor und ist auch bei Landschildkröten beobachtet. - Auch das Secret der Nasen - und Thränendrüse gelangt meistens in die Mundhöhle.

Tonsillen sind bisher nur bei den Crocodilen angetroffen worden 1).

[Man vgl. über diese Drüsen besonders J. F. Meckel in seinem Archiv f. Anat. u. Phys., 1826, S. 1. mit Abb.; Mülle r, Gland. secern., p. 57. Tab. VI. fig. 4. 5.]

7) Iguana. - 8) Vergl. Carus und 0 tt 0 , Heft 4. Tab. 5. (Chanaeleo); Duvernoy, Mém. de la soc. d'hist. nat. de Strasbourg, T. 2.

1) Bei den Ophidiern selır allgemein vorhanden; auch bei vielen Sauriern, namentlich bei den Monitores, Iguanidae, Lacertoïdeae, Scincoïdeae, Anguis, Pseudopus.

2) Hierüber haben gelandelt $S c h l$ egel in den Nov. Act. Acad. Leop. Carol., T. XIV. P. 1. p. 143. Tab. XVI. und Duvernoy in den Ann. d. sc. nat., T. XXX. 1833. p. 26. Hierher gehören die Gattungen Dipsas, Homalopsis, Dryophis, Den. drophis. - 3) S. die Abbild. bei Meckel l. c. Fig. 8.

4) Ich finde sie sehr stark bei allen Crocodilen. Sie liegen linter den hinteren Nasenöffnungen zur Seite der Rückenwand des Pharynx und erscheinen an jeder Seite als fünf bis sechs sehr weite, quer gestellte, durch starke Schleinhautfalten unterbrochene Einstülpungen der Schleimhaut, an deren Boden Zellen sich finden. 


\section{V. Vom Tractus intestinalis.}

§. 00.

Der Verdauungscanal der Reptilien liegt immer innerhalb der Bauchhöhle, welche, mit einziger Ausnahme der Crocodile, bei denen. die Peritonealcanäle frei und offen durch eine an der Basis des Penis oder der Clitoris jederseits befindliche Oeffnung in die Cloake ausmünden, gesehlossen zu sein pflegt. - Fettansammlungen finden sich zwischen den Bauclifellplatten bei den Salamandrinen und den ungeschwänzten Batrachiern längs des Innenrandes der Gesehleehtstheile, bei den Ophidiern und den Sauriern an der unteren oder Bauchwand des Peritoneum. Dies Bauehfell ist sehr oft mit schwarzem Pigmente überzogen und umhüllt, ausser dem Tractus intestinalis und seinen druisigen Anhängen, auch die Lungen und die keimbereitenden Geschleehtstheile nebst deren Ausfiuhrungsgängen. Nachdem das Bauchfell die Lungen überzogen, bildet es dureh die Vereinigung seiner Platten die sogenannten Ligamenta pulmonum, welehe häufig in die serösen Ueberzïge der Gesehleehtstheile sich fortsetzen; von der Leber, die es sackförmig einhiillt, pllegt es - mit Ausnahme der Ophidier - als Ligamentum hepatico-gastricum zum Magen zu treten, diesen einzuhüllen und das die Milz umsehliessende Mesogastrium zu bilden, welehes ein Theil des eigentliehen Mesenterium ist. Dieses letztere folgt gewöhnlieh den Windungen des Darmcanales - eine Regel, von welcher jedoch diejenigen Ophidier eine Ausnahme maehen, bei denen der Darm aus sehr kurzen fast spiralförmigen Windungen besteht, welche letzteren nur dureh diehtes Zellgewebe zusammengehalten, und mit dem Darmcanale von einer weiteren Bauchfelltasche umschlossen werden 1).

Die Bildung des Tractus intestinalis ist am einfachsten bei den nackten Reptilien, wo die ziemlich lange, in der Regel noch mit einem Flimmerepithelium ausgekleidete Speiseröhre in den einfaehen, anfangs erweiterten, später sich verengenden Magen trichterförmig übergeht. Dieser verläuft ineistens gerade, ist jedoch bisweilen quer gestellt 2) und bildet nur bei wenigen Batraehiern einen kleinen Blindsaek ${ }^{3}$ ). Er ist beil einigen Gattungen durch einen Pförtnervorsprung vom Mitteldarme getrennt 4). Speiseröhre und Magen zeichnen sich gewöhnlich vor den übrigen Absehnitten des Darmcanales durch beträchtlichere Dicke ihrer Muskelhiut und dureh die Längsfalten, welche ihre

1) Die Verhältnisse des Bauchfelles können hier nicht specieller erörtert wer. den. Ich verweise auf $\mathrm{Robert}$, De liganentis ventriculi liberis peritonaei plicis etc., Marb. 1840, 4., und in Betreff der Crocodile auf: 0 wen, Proceed. of the zool. society, Part. 1. 1831. p. 139. und Martin, ibid. 1835. p. 129.

2) Bei Pipa. Hier ist der Pharynx sehr weit und runzelig. Die mit Längs. falten versehene Speiseröhre geht durch eine leichte Krümmung in den dickwan. digen, eigentlichen, quergestellten Magensack über.

3) Bei cinigen Bufonen. - 4) Bufo. 
Schleimhaut bildet, aus. Die Magenschleimhaut besitzt gewöhnlich kleine verzweigte Driischen. - Der verhältnissmässig kurze, nur bei den Lar. ven der Batrachier lange Darmcanal, welcher bei Pipa mit einem glok. kenförmig crweiterten Duodenum beginnt, zerfïllt bei den Proteïdeen und einigen anderen Gattungen noeh nicht in einen Mittel- und Afterdarm. Diese unterseheiden sich dagegen bei den Salannandern und ungeschwänzten Batrachiern, bald dureh versehiedene Weite, bald dureh eine blindsaekartige Erweiterung am Anfange des Afterdarmes ${ }^{5}$, bald dureh das Vorkommen einer Klappe an ihrer Grenze "), so wie dureh abweichende Texturvèrhältnisse ihrer Sehleimhaut. Die, Fläehenvergrösserung der Schleimhaut ist, namentlieh im Mitteldarme, durch diehte, gewöhnlieh wellenförmige oder ziekzackförmige, oft sieh verbindende Längsfalten, selten durch Zottenbildung ${ }^{\top}$ ) bewerkstelligt.

Bci den Ophidiern bilden Speiseröhre und Magen einen unun terbrochenen Lïngseanal, denn nur selten findet sicḷ an der Cardia eine blindsaekartige Erweiterung ${ }^{8}$. Die verhältnissmässig lange und weite Speiseröhre unterseheidet sich von dem Magen nur dureh dünnere Wandungen und minder zahlreiche Faltungen der Sehleimhaut, welche letzteren sehr beständig der Länge nach verlaufen. Der sehr erweiterungsfähige, nur ausnahmsweise zwei dureh eine Klappe geschiedene Säcke ${ }^{9}$ ) besitzende, gleich der Speiseröhre, mit kleinen Selıleirnhautdrüschen dicht besetzte Magen zerfällt in den eigentlichen gerade abwärts steigenden diekwandigen Magensack und den kurzen, engeren, darmförmigen, dünnhäutigeren, bald geraden, bald gebogenen oder selbst gewundenen Pförtnertheil. Dieser ist mehr oder weniger deutlich vom Mitteldarme gesondert; bald durch eine kreisrunde Klappe ${ }^{10}$ ), bald durch einen unbeträchtlichen blinden Vorsprung bei gleiehzeitiger Verdickung der Wandungen $\left.{ }^{11}\right)$. Der häufig durch dünnere Wände ausgezeiehnete Dünndarm verläuft selten ganz gerade $\mathbf{1 2}$ ), bildet vielmehr meistens zahlreiche kurze, dureh Zellgewebsbrüeken an einander geheftete Windungen 13). Bald ist er anfangs erweitert, um später sieh zu verengen ${ }^{4}$ ), bald bleibt er durchgängig ziemlich weit 15). Bei einigen Ophidiern ist er durch den Besilz von spiralförmig gewundenen Klappen, welche inwendig starke Vorsprünge, ja Septa bilden, ausgezeichnet ${ }^{16}$ ), bei andern bleibt er einfaeh. Die Schleimhaut des Dünndarmes besitzt meistens zahlreiehe Lïngsfalten, wclehe biswcilen durch Querfalten verbunden

5) Sehr deutlich namentlich bei Pipa zu Anfang des sehr kurzen und weiten Dickdarmes. Auch bei einigen Bufonen.

6) Rana, Hyla.

7) Bei Salamandra in Anfange des Mitteldarmes. - 8) Trigonoceplualus.

9) Bei Acrochordus javanicus nach Fohmann (Froriep's Notizen 958.).

10) Crotalus, Trigonocephalus, Vipera, Bungarus, Pelanis. - 11) Python.

12) Python, wo der Darın überlıaupt sehr kurz ist; auch Bua.

13) Vipera, Hydrophis, Elaps, Coluber natrix, C. variabilis u. v. A.

14) Boa. - 15) Hydrophis. - 16) Python. 
sind, wodurch denn bald grössere länglichc, bald kleinere viereckige Maschen cnistehen. In anderen Fïllen ${ }^{17}$ ) sind blattförmige Vorsprünge oder Zotten vorhanden. Vom Afterdarme ist der Mitteldarm gcwöhnlich deutlich gesondert, bald durch einen kreisrunden Wulst 18), bald durch eine häutige Klappe 19\%. Der Afterdarm zeichnet sich häufig durch beträchtlichere Weitc aus und beginnt bisweilen mit einem Blindsack ${ }^{20}$ ). Gewöhnlieh ist der Aftcrdarm durch einc ${ }^{21}$ ), seltener durch zwei ${ }^{22}$ ) innere Scheidewände in zwei oder drei Abtheilungen zerfallen, wclche durch mehr oder minder enge Oeffnungen jener Klappen oder Septa nit einander communiciren. Was die innere Textur des Afterdarmes anbetrifft, so ist seine Schleimhaut bald glatt, bald bildet sie Längsfalten; endlich kommen bisweilen in seinem Ictzten Abschnitte Querfalten oder wirkliche Valvulae conuiventes vor.

Bci den Cheloniern besitzt die gewöhnlich muskulöse und dickwandige Speiseröhre inwendig mcistens einfache Längsfalten, zwischen welchen zahlreiche Cryptae vorkommen, ist aber bei den Seeschildkröten mit zahlzeichen, langen, conischen, abwärts gerichteten Papillen besetzt. Der dickwandige Magen ist länglich, cylindrisch gewunden oder mehr quer gestellt. Seine. Schlcimbant bildet gewöhnlich Längsfalten und besitzt zahlreiche Drüsenöffnungen. Seine Portio pylorica ist durch einen krcisrunden Wulst oder durch eine Schleimhautfalte vom Darme abgegrenzt, welcher letztere bei den pllanzenfressenden Gattungen durch grössere Länge vor dem der Carnivoren sich auszeichnet. Der Darm zerfällt häufig, obschon nicht immer, in einen Mittel - und Afterdarm, welche bald durch verschiedene Weite sich unterscheiden, bald durch eine wirkliche Klappe ${ }^{23}$ ) oder selbst durch einen an dem Anfange des Afterdarmes vorbandenen Blindsack gesondert sind. Selten ist der Afterdarm länger, als der Mitteldarm 24). Die Schleimhaut des Mitteldarmes besitzt oft einfache oder verbundene Längsfalten oder bildet Zellen, die häufig wiederum kleinere Zellen einschliessen. Im After. darme kommen meist schwache Längsfalten vor.

Bci den Sauriern ist der Oesophagus verhältnissmässig weit. Inwendig besitzt er gewöhnlich Längsfalten. Er geht ohne inncren Vorsprung über in den mehr oder minder, oft nur unbedeutend erweiterten, cylindrischen oder conischen, gewöhnlich gerade von vorne nach hinten gcrichtcten Magen. Der Pförtnerthcil des Magens verengt sich

17) Python, Eryx. - 18) \%. B. bei Tortrix. - 19) Coluber.

20) Dryophis, Dipsas, Homalopsis, Tortrix. Andere Gattungen und Arten s. verzeichnet bei M e ckel Th. 4. S.369. S. auch D u vernoy, Ann. d. sc.nat., 1833, T.XXX.

21) 'Tortrix, Coluber. - 22) Nach Duvernoy bei Dispholidns Lalandii.

23) Bei vielen Arten der Gattung Testudo, namentlich tabulata, graeca, clausa, finden sich, nach Meckel, Klappen und Blinilsack zugleich. Bei Euyss scripta ist eine Klappo olme Blindsack vorhanden, bei Enys europaea eine Art Coecum. (Bojanus, Fig. 179.) - 24) Testudo, Chelonil. 
gewöhnlich, ist meist dickwandiger und etwas nach rechts gebogen. An seiner Uebergangsstelle in den Mitteldarn findet sich eine wulstige Vorragung oder eine häutige Pförtnerklappe ${ }^{25}$ \%. Der Darmkanal ist bei den Pflanzenfressern länger, als bei den Insertivoren. Der Mitteldarm bildet gewöhnlich einige Windungen; seinu Schleimhaut besitzt meistens zickzackförmige Längsfalten. Bei einigen Souriern ist der erste, dem Duodenum entsprechende Abschnitt sehr weit 26 ). Fast nie geht der Mitteldarm ohne deutliche Grenze in den Afterdarm über; gewöhnlich findet sich zwischen beiden eine Dickdarmklappe $2 \pi$ ). In der Regel ist auch am Anfange des Afterdarmes ein Blinddarm vorhanden 28) oder der allmälich verengte Mitteldarm geht plötzlich in den anfangs sehr weiten Afterdarm über ${ }^{29}$ ). Letzterer ist bei einigen Sauriern cinfach und kurz ${ }^{30}$ ), bei anderen durch eine Klappe in zwei Abtheilungen geschieden ${ }^{31}$ ) welche bald einfach, bald durch zahlreiche tief cindringende Querfalten oder unvollstïndige Septa wieder in mehre Zellen oder Taschen zerfallen können ${ }^{32}$ ). Diese Querfalten (Valvulae connivertes) finden sich dann ineist unmittelbar hinter dem Blindsack und der hinterste Abschnitt des Afterdarmes - das eigentliche Bectum erscheint wieder einfach.

Bei den Crocodilen ist der Schlundkopf durch kurze starke Muskeln an die Basis des Schedels und an den Anfang der Wirbelsäule angeheftet. Die Speiseröhre ist inuskulös und weit. Der gleichfalls dickwandige Magen, in den sich rechts die Speiseröhre üffnel, bildet nach der linken Seite einen länglich runden Sack. Scine Portio pylorica stellt cine durch eine starke Einschnürung gesonderte kleincre engere Abtheilung dar, welche vom Mitteldarme durch eine Pförtnerklappe wieder geschieden ist. An der Bauch- und Rückenfläche des Magens findet sich auswendig eine scheibenförnige Schncnausbreitung, wie bei den Vögeln. Der ziemlich lange, mehrfach gewundene, an einem breiten Mesenterium befestigte, anfangs mit viereckigen sehr flachen Zellen, später mit wellenförmigen oder zickzackförmigen Lïngsfalten, zuletzt mit geraden Längsfalten besetzte Mitteldarm wird durch einc Klappe von dem sehr kurzen, wcitcren Afterdarm getrennt ${ }^{33}$ ).

25) Lacerta, Varanus, Iguana, Stellio, Agama, Calotes, Scincus, Seps, Gecko, Ascalabotes, Chamacleo 11. A. Nach Meckel's Angaben.

26) Varanus elegans. - 2i) Z. B. bei Ignana, Varanus.

28) Z. B. Chanacleo, Seps, Scincus, Bipes, Lepidopus, Pygopus, Chirotes, Acontias, Stellio, Calotes, Draco, Polyclirıs, Agama, Jguama, Lyriocephalus, He. midactylus tuberculosus.

20) Bei vielen Geckonen, z. B. Platydactylus guttatus; bei Lacerta.

30) Platydlactyhis. - 31) Varamus.

32) Stark und zahlreich bei Ignana, Chamaeleo; sie fehlen dagegen vielen anderen: den Varmen, Geckonen, Scincoïlen.

33) Abbild. der Verdaungs-Organe der Reptilien s, bei Carus u. 0 tto, Er. läuterungstafeln Heft 4. Tab. V. 


\title{
V. Von der Leber, dem Pancreas und der Milz.
}

\author{
§. 91.
}

Die Leber der Reptilien liegt im vorderen Theile der Bauchhöhle, oft einen selsr betrïchtlichen Raum in derselben cinnehmend, den Matgen und einen Theil des Darmeanales bedeckend. Nur bei vielen weitmäuligen Schlangen liegt sie vor dem Magen neben dem Oesophagus 1 . Sie wird sehr allgemein durch rine zu ibrer Vorderflïche gehende l'erilonealfalte befestigt, welche, sich entfaltend, sie umhuillt und dann als Ligamentum hepatico-gastricum den Magen umgibt, um später in das Nesogastrium überzugehen 2). Naich vorn oder oben erstreckt sich selır häufig ein ligamentöser Strang von der Aussenfläche des Lebersackes zum Herzbeutel. Die Gestalt der Leber bietet beträchtliche Verschiedenheiten dar und hangt wesentlich von der ganzen Körperform ab, so dass sie im Allgemeinen in Reptilien von gestrecklem Baue in die Länge gezogen ${ }^{3}$ ), in Thirren mit breiterem Körper breiter ist 4$)$. Bald bildet sie cine einfache, ungetrennte Masse, welche nur kleine und untergeordnete Einschnittc besitzt ${ }^{5}$ ), bald zerfällt sie in zwei ${ }^{6}$ ) oder selbst drei mehr oder minder vollständig getrennte Lappen $\overline{7}$ ). Ist sic zweilappig, so iiberwiegt bald der rechte ${ }^{8}$ ), bald der linke Lappen den Anderen an Grösse. - Der Uinfang der Leber ist gleichfalls verschieden und sehr schwankend ist auch ihr Gervicht in Verhältniss zum Gewichte des ganzen Körpers 9). Eine bald runde, bald längliche, bald birnför-

1) Z. B. bei Python, Dryophis, Dendrophis u. A.

2) Bei vielen Ophidiern liegt sie innerhalb eines serösen Sackes und statt eines Ligamentum hepatico-gastricum findet sich nur dichteres Zellgewebe, z. B. bei Python, Coluber.

3) Namentlich bei den Ophidiern; auch bei den schlangenähnlichen Sauriern: Ophisaurus, Seps u. A.

4) Bei den Cheloniern und ungeschwvänzten Batrachiern.

5) Z. B. bei den Proteïleen, den Salanandrinen, den meisten Ophidiern u. A. - Sehr eigenthüınlich, nierenähnlich, aus dachziegelförmig sich deckenden Läppchen bestehend, längs welchen der Ausfillungsgang absteigt, ist sic nach $\mathrm{M}$ ï $\mathrm{l}$. ler bei Coecilia hypocyanea. Siehc Tiedemann und Treviranns, Zeitschrift Bi. 4. S. 220. Tab. XVIII.

6) Bei den ungeschwänzten Batrachiern; hier sind die beiden Lappen bald vollständig von cinander getrennt und nur durch eine Duplicatur des Bauchfelles verbunden, lald findet sich ein verbindendles Querstück. Ersteres bei Rana, letz. teres bei Bombinator, Hyla, Bufo. Zwei verbundene Lappen besitzen auch sehr regehnässig die Schildkröten. Abbild. bei Brotz u. Wagenmann und bei $B_{0}$ janus I. c. Tab. XVI. XVII. XIX.

7) Die getrennten Lappen bei Pipa. S. die Abbill. bei Mayer, Nor. Act. Acad. Lcop. Carol., T. XII. 11. 2. Talb. XLIX.

8) In der Regel bei den Schillkröten; der linke diagegen gervöhnlich bei deı ungeschwänzten Batrachierı.

9) S. darübcr die Gewichtsbestimmungen bei Brotz u. Wagenmanı. 
mige Gallenhlase ist sehr allgemein vorhanden ${ }^{10}$ ). Sie liegt bald frei, bald in der Leber versteekt "I). In der Regel ganz in der Nähe der Leber, meist an ihrer eoncaven Fläehe oder zwisehen ihren Lappen gelegen, entfernt sie sieh von der höher liegenden Leber bedeutend bei den grossmäuligen Sehlangen und findet sich hier neben dem Anfange des Darmcanales. Bald geht der Ductus cysticus vom Ductus hepaticus ab, bald sind eigene Ductus hepatico-cystici vorhanden. Bei vielen Ophidiern zeiehnet sich der Duchus hepaticus durch seine Länge aus. Gewöhnlieh ist ein gemeinschaflieher Ductus choledochus vorhanden; seltener mündet der Lebergang getrennt von dem Blasengange in den Darm 12). Ziemlich häufig tritt der Ductus choleclochus durch das Pancreas ${ }^{13}$ ), bisweilen mit dem Ductus pancreaticus vereinigt, zum Darme. Die Einmündungsstelle liegt in der Regel ziemlich dicht unterhalb des Pylorus.

[Am ausführlichsten und genauesten haben nach eigenen und fremden Beob. achtungen über die Lebcr der Reptilien gehandelt: J. Brotz ct C. A. Wagen . mann, Dc Ampbibiorun hepate, liene ac paricrcatc observat. zootom., Friburg. 1838, 4., mit Abbild. Vgl. auch Duvern oy in den Anu. d. sc. nat. T'. XXX.]

\section{§. 92.}

Ein Pancreas von drüsigem Baue kömmt den Reptilien durehgehend zu. Es liegt am Ende des Magens und am Anfange des Mitteldarmes. Seine Form ist mehr oder minder länglieh und es besteht nieht selten aus einzelnen Läppchen I), deren Ausführıngsgänge in einen Canal zusammenmünden. Der gewöhnlieh einfache, selten doppelte Ductus Wirsungiauns mündet neben dem Ductus choledochus in den Anfang des Mitteldarmes.

[Brotz und Wagenmann fandcn cs bei allen nackten Rcptilien verbält. nissinässig gross; unter den Sauricrn besouders gross bei den Pflanzen fressendcn. Zwei getrennt in den Darm unündendc Ductus pancreatici sind vorhanden bei Crotalus horridus und beim Nilcrocodil nach Duvcrnoy; in grösserer Zahl sollen sie bei Hydrophis doliatus vorkommen.]

\section{§. 93.}

Die stets vorhandene Milz verhält sieh rücksichtlich ihrer Form und ihres Umfanges versehieden. Bei den gesehwänzten nackten Reptilien liegt sie links in der Bauchhöhle, an der grossen Curvatur des Magens,

10) Sic soll, nach Müller, fchlen bci Testudo nigra. Bci manchen Eidech. sen, z. B. Lacerta agilis und vivipara, fehlt sie einzelnen Individucn, während andere sie bcsitzen.

11) Z. B. bei Lacerta ocellata, agilis, bci Chelone cauana, bicarinata, bei Te. studo livida nach Kuhl. - 12) Z. B. bei Boa constrictor nach Cuvier.

13) Z. B. bei Pscudes, den meisten Ophidiern, Anguis, Seps, Basiliscus.

1) Sehr auffallend ist die Lappenbildung bci Python, wo ron jedcm Lappen ein Ausführungsgang schräg zum Darm tritt. Diesc Gänge vcreinigen sich all. mälich zu Aesten und Stämmen. 
zwischen den Platten des Mesogastrium. Bei den ungeschwänzten Batrachiern findet sie sich gleichfalls zwischen den Blättern des Peritoneum eingeschlossen in der Mitte zwischen Mittel- und Afterdarm. Bei den Ophidiern liegt sie unmittelbar vor dem Pancreas, bei den Sauriern und Cheloniern am Magen oder am Anfangc des Mittcldarmes neben dem Pancreas.

[Vgl. die Abhandlungen von Brotz U. Wagenmann und von Duvernoy. - Letzterer fand bei Boa cenchris eine kleine Nebenmilz in einer Schlinge des Pancreas. - Bei Crocodilus sclerops liegt sie, nach Brotz, tiefer abwärts am Darme.]

\section{Sechster Abschnitt. \\ Vom Gef ̈̈ss-Systeme.}

§. 94.

Das Gefässsystem der Reptilien bietet eine grosse Mannichfaltigkeit der Anordnungsweisen dar, besitzt aber stets die Eigenthümlichkeit, dass seine Einrichtung eine bald weniger, bald mehr beschränkte Vermischung arteriellen und venösen Blutes, entweder innerhalb des Herzens oder innerhalb der grossen Gcfässstämme gestattet. - Während die niedrigsten Reptilien durch die Anordnung ihres Gefässsystemes auf das innigste an die Fische sich anschliessen, bilden die Crocodile in dieser Hinsicht einen Uebergang zu den Vögeln. Das rücksichtlich seines Umfanges und seines relativen Gewichtes sehr verschiedenartig sich verhaltende Herz ist stets von einem Herzbeutel lose umgeben, dessen Fortsetzung auch einen unmittelbaren Ueberzug des Herzens bildet. Bei den Salamandern, den Tritonen und den ungeschwänzten Batrachiern besitzt der Herzbeutel ein Flimmerepithelium. Der Herzbeutel ist nicht selten mit einer über die Leber sich schlagenden Bauchfellfalte verwachsen. Häufig treten von der Innenfläche des Pericardium ein oder. mchre anscheinend sehnige Fäden zum Herzen, welche bei genauerer Untcrsuchung wenigstens thcilweise als Gefässe sich zu erkennen geben ${ }^{1}$ ).

[Ueber die Anordnung des Gefäss - Systemes bei den Reptilien vgl, besonders folgende Schriften: Cuvier, Leçons d'anat. comp. T. 6. - J. F. Meckel, System d. vergl. Anatomie Th. J. - Martin S aint.Ange, der Kreislauf des Blutes beim Fötus des Menschen und bei den Wirbelthieren, Berlin 1838. - M. J. Weber, Beiträge zur Anatomie u. Physiologie, Bonn 1832, 4. - Mayer, Analekten für vergl. Anatomie, Boun $1835,4 .-0$ t to in Carus u. 0tto, Erläuterungstafeln Heft 6. Taf. 5. - Ueber die nackten Reptilien s. Kusconi u. Con-

1) Salamandra, Triton, Rana, Chelonier, Saurier, Crocodile. 
figliachi, Del proteo anguino di Laurenti Monographia, Pavia 1819, 4. Hyrtl in den medic. Jahrb. des Oesterr. Stantes, Brl.48. 18 $\$$. (Proteus.) - Cuvier in II umboldt u. Boupland, Recueil d'observat. de Zool. et d'Anat. comp., Paris 1811, 4., und in den Mém. du Musée d'hist. nat., T. XIV. 1817. (Amphiuma.) - 0 wen in Transact. of the zool. society of London, Vol. 1. 1835. (Siren.) Hyrtl in den medic. Jahrb. des Oesterr. Stantes, Bd. 15̆. 1838. (Triton, Salamandra.) - Burow, De vasis sangniferis Ranarum, Region. 1834., 4. - Gruby in den Ann. d. sc. nat, 1842. - Ueber die Ophidier vergl. Retzius in der Isis 1832, Heft ว. - Schlemm in Tiedemann u. Treviranus, Zeitschrift Bd. 2. Heft 1. - Vogt, Zur Anatomie d. Amphibien, Bern 1839, 4. (Pytlon tigris.) Ueber die Chelonier: Bojanus, Anatome testudinis, Tab. XXIV. XXV. XXIX. - G. R. Treviranus, Beobachtungen aus der Zootomie u. Plysiologie, Bremen 1839. - Ueber die Crocodile: Panizza, Sopra il sistema linfatico dei rettili, Pavia 1833, 1. 11. - Bischoff in Müller's Archiv 1830.]

\section{Vom Herzen und den arteriellen Gefässen der nackten Reptilien.}

\section{§. 95 .}

Das Herz der nackten Reptilien besteht stets aus zwei durch ein zartes dünnwandiges Septum, selten unvollkommen 1), gewöhnlieh vollkonmen getrennten Vorkammern und aus einer einfachen Kammer. Der reehte Vorhof enmpängt das Körpervenenblut, der linke das Lungenvenenblut. Aus der Herzkammer, in welehe sowol das Körpervenenals aueh das Lungenvenenblut eintritt, nimmt ein gemeinsehafticher Truncus arteriosus, der dureh Erweiterungen, durch Belegung mit Muskelfasern und bisweilen selbst durch innere Klappenreihen noeh sehr deutlich als Bulbus arteriosus sieh zu erkennen gibt, sowol das für das respiratorisehe Capillargefässsystem der Atbemwerkzeuge bestimmte, als aueh dis nittelst der Arterien im Körper zı vertheilende Blut auf. Die Vorhöfe, welehe bisweilen deutliehe Auriculac besitzen, sind stets dünnwandiger, als die Kammer, welche stark muskulös ist und dureh ihre Trabeculae carneae inwendig ein gitterförmiges Aussehen erhält. An den Ostia veussu der Kammer kommen bei Einigen kleine halbmondförmige Klappen vor. Aueh an dem Ursprunge des Truncus arteriosus linden sich sehr regelmässig zwei Valvulae semilunares.

Bei den Batraehicrlarven und den Perennibranehiaten liegt das Herz linter dern Zungenbeine, in der Mitte der Kehlgegend, oberhalb der Leber. Der Truncus arteriosus bildet bei den Perennibuanchiaten einen bisweilen mil doppelter $\left.{ }^{2}\right)$ Erweiterung versehenen muskulösen

1) Unvollkommen ist die Scheidewand nach Hylotl bei Protens; auscheinend auch bei Coecilia.

2) Nach Hyrtl l, c. 
Bulbus und enthält, wenigstens bei den Proteïdeen ${ }^{3}$ ), zwei Klappenreihen. Aus diesem Bulbus gehen jederseits, bald unnittell ar, bald mittelbar, drei bis vier Gefässbogen hervor. Diese sind die Aortenbogen, Nach Abgabe von Kiemenarterion f), von arteriellen Gefässen für den Kopf und die Vorderextremitäten und nach Entsendung der Lungenarterien, so wie naeh Aufnahme der aus den Kiennen zuriickkehrenden Gefässe treten sie jederseits in einen Stamın oder eine Aortenwurzel zusammen. Diese beiden Stümme vereinigen sieh an der Vorderfliehe der Wirbelsäule zur absteigenden Aorta. Zarte Zweige der letzteren bilden bei Proteus jederseits einen in den durchbohrten Querfortsätzen der Wirbel liegenden Längsstamm: die seitliehe Wirbelarterie, welehe Zweige an die Dorsalmuskeln und das Riiekeninark schickt. - Noeh Menopoma besitzt jederseits vier aus dem mit zwei Reihen halbmondförmiger Klappen versehenen Bulbus arteriosus entspringende Aortenbogen, welche nach Abgabe von Arterien für den Kopf und den vordersten Theil des Run1pfes und nach Entsendung von untergeordneten zu den beiden Lungenarterien sich verbindenden Zweigen zu zwei Stämmen zusammentreten, dureh deren Verbindung die absteigende Aorta entsteht.

Bei den Salamandrinen nimmt an der Bauehfliche der Herzkammer ein zwiefaeh erweiterter Truncus arleriosus seinen Ursprung, welcher zwischen den Vorkammern vorwïts verläuft ${ }^{5}$ ). Bei den Tritonen und mit wenigen Modificationen ist dies auch das Verhalten bei den Salamandern - entspringen aus ihm jederseits vier dureh Anastomosen mit einander zusammenhangende Stämme. Der vorderste zerfällt in zwei Ilauptzweige, deren einer fiir die Zungenbeingegend, den Ilals und den Boden der Mundhöhle bestimmt ist, wailirend der andere die $\boldsymbol{A}$. curotis cerebralis und die Iinterhauptsarterie bildet. Aus dem zweiten Stamme nimmt die Art. ophthalmica ihren Ursprung. Dann aber bildet das zweite Arterienpaar, naehdem es mit dem ersten in Verbindung getreten ist und das dritte völlig, das vierte aber erst naeh dem Abgange der aus ihm hervorgehenden Art. pulmonalis aufgenommen hat, eine Aortenwurzel. Die hinter dem Schlunde liegende absteigende Aorta wird aber fast ganz dureh die rechte Aortenwurzel gebildet, indem auf Kosten der linken fast nur die gemeinsehaftliche Eingeweidearterie entsteht und dann erst ihre Vereinigung mit der recliten erfolgt.

Bei den ungeschwiinzten Batrachiern ist der noch mit Muskelfasern belegte und so als Bulbus charakterisirte Truncus arteriosus communis

3) Bei Proteus finden sich, nach Hyrtl, zwei Reilıen halhmondförmiger Klappen, jerle zwei Klappen enthaltend. Achnlich bei Siren nach 0 wen.

4) Hyrtl lïugnet die Bildung eines capillaren Gefässnetzes in den Kienen. biattchen des Proteus, berïcksichtigt labei aber vielleicht nicht die ausserordentliche, von Rudolphi und Rusconi beschriehene, von Wagner bildlich darge. stellte Grösse der Blutkörperclien.

5) Er enthïlt, nach Hyrtl, bei Triton eine Klappenreihe. 
inwendig in zwei Halbeanälc zerfallen. Aus ilım entspringen nur zwei Stämme. Jeder derselben ist durch häutige Septa inwendig in drci Lumina getheilt und hat, ausser ciner $A r t$. pulmoualis, drei Aeste: eine Art. lingualis, eine $A$. carotis 0$)$ und eine abstcigende Aortenwurzel. Nach Entstehung der Artcriae subclaviae auc beiden Aortenwurzeln veleinigen sich dicse weit hinterwiirts zur absteigenden Aorta, nachdcm aus der linken kurz zuror noch die Art. coeliaco-mesentericu abgetreten ist. Die Aorte descendens gibt nur Zweige als fiir deu Stamin des Körpers, für dic Nieren ') und die Geschlcchtstheile, so wie für den Afterdarm und theilt sich auf dem $O_{s}$ coccygis in die bciden Art. iliacae.

\section{Vom Herzen der beschuppten Reptilien.}

\section{§. 96.}

Bei den beschuppten Reptilien finden riicksichtlich der Lage des Herzens Verschiedenheiten Statt. Am meisten dem Kopfe genähert ist es bei den Sauriern; weiter hinterwärts, und gewöhnlich etwas nach links liegt es bei den Ophidiern, den Cheloniern und den Crocodilen. - Bei den Ophidiern zeichnet cs sich durch seinc länglichc Form aus, bei den Chelonicrn dagegen durch seine Brcite; bei den Sauriern ist es bald länger, bald breiter und bei den Crocodilen immer ziemlich breit.

Das Herz der Ophidier, Saurier und Chelonier besitzt zwei - gewöhnlich durch ein vollständiges Septum geschiedene Torhöfe 1), deren Trennung in der Regel schon äusserlich, bald mehr, bald minder deutlich, durch einc an der Bauchscite vorbandenc Furche, innerhalb welcher die Arterien verlaufen, ausgesprochen ist.

Im Inneren der Vorböfe zeigen sich deutliche Trabeculae carneae. An der Einmündungsstelle der Körpervenen in den beständig weiteren rechten Vorhof sind zwei Klappen vorhanden; in den linken Vorhof mündet der einfache oder doppelte Lungenvenenstamm ohne Klappe. - An dic Vorhöfe schlicssen siclı - angeblich mit einzelnen bei mehren Chelo-

6) Eine eigenthümliche Bildung ist die schon lange bekannte Carotidendrüse der Batrachier: eine kleine kugelige, spongiöse Anschwellung, durch deren Arse der Stamu der Carotis einfach hindurchtritt. Huschke ('Tiedemann's Zeitschrift f. Physiologie, Bd. IV. S. 113.) erklärt sie für ein Wundernetz und bält sie für einen Ueberrest des Capillargefäss - Systems des ersten Kiemenbogens. Ich möchte sie den an der Carotis der Vögel gehefteten Körperchen, die man der Schilddrüse verglichen hat, an die Seite stellen, da sie mir in del That keine Wundernetze zu sein scheinen.

7) Auffallend ist die grosse Anzahl der zu den Niereu sich begebenden Arterienstämmchen. Nach $\mathrm{Hy} \cdot \mathrm{tl}$ finden sich bei den meisten ungescliwäuzten $\mathrm{Ba}$ trachiern 5, bei den Salanandern 10, bei den Tritoneu 12, bei Protens 18.

1) Nach Munnicks (Observat. variae, Groning. 1805, 1) 43.) besitzt bei Chersine scorpioides das Septum zwei dickwandige 0effnungen. Treviranus

1. c. fand auch bei Terrapene clausa ein Foramen ovale. 
niern vorkommenden Ausnalımen 2) - zwei stark muskulöse Kammern, deren Trennung äusserlich wenig oder gar nicht angedeutet ist, inwendig aber nur unvollkommen erfolgt, durch ein meist von der Spitze gegen die Basis vortretendes Septum. Zwischen diesem und dem freien Rande des Seplum atriorum bleibt nämlich eine ovale Oeffnung, durch welche eine Communication zwischen der viel weiteren rechten und der schr engen, aber zugleich dickwandigen linken Kammerhöhle möglich gemacht wird. Das Ostium veroosum jerler Kanmer kann durch rine, miltelst Faden an die Kammerwand befestigte, halbınondförınige Klappe, eine Fortsetzung des Septum atriorum, verschlossen werden. Durch diese Klappen, und namentlich durch die ausgebildeteren des rechten Ostinm venosum, vermag auch das Septum ventriculorum in dem Momente, wo durch die Zusammenziehung der beiden Yorkammern das Blut in die Ventrikel cinströmt, geschlossen zu werden. - Aus der linken Kammer entspringt - mit Ausnahme einiger höheren Saurier, bei denen aus ihr der rechte Aortenbogen seinen Ursprung nimmt ${ }^{3}$ ) gewöhnlich kein Gefässstamm. -

Aus der rechten Kammer entspringen sowol die Aortenbogen, als die Lungenarterien.

Bei vielen Sauriern, bei den Ophidiern und Cheloniern entsteht jedoch in ihr durch eine vorragende Yuskelleiste ein theilweise abgeschiedener Raum für das der Art. pulmonalis bestimmte Blut: der sogenannte Comus arteriosus. Aus ihm entwickelt sich die gesonderte Lungenarterie, an deren Miindung zwei halbmondförmige Klappen sich finden. Aus der eigentlichen Kammerhöhle nehmen mit einfacher Oeffnung oder mit getrennten Ostia, an deren jeder zwei halbmondförmige Lilappen vorkommen, der Truncus Aortae oder die beiden Aortenbogen ihren Ursprung ${ }^{4}$ ). Bei der Zusanmenziehung der Ventrikel tritt in diesem Falle das venöse Blut der rechten Herzkammer durch die Höhle des Conus arteriosus mehr oder minder ausschliesslich in die Lungenarterie; das arterielle Blut des linken Ventrikels strömt aber in die dann dem Foramen septi ventriculorum genäherten Ostia des Aortensystemes.

\section{§. 97.}

Das Herz der Crocodile unterscheidet sich wesentlich von dem der ubrigen beschuppten Reptilien durch den Besitz cines vollstïndigen $\boldsymbol{S} e-$ prum ventriculorum. Aus dem Conns arteriosus der sehr geräumi-

2) Treviranus fand bei Emys reticulata, serrata, centrata und bei Terra. pene clausa nur einen Ventrikel ohne Scheidervand.

3) Iguana nach Duvernoy und Otto.

4) Interessant ist es, dass, nach Bojanus Entdeckung, bei Emys eine kleine Ossification (Herzknochen) vorkömınt, welcher von den Tralieculae carneae der rechten Kammer aus zwischen die austretenden Arterieustämme sich erstreckt.
S. Tab. XXIX. Fig. 170-172. 
gen rechten Herzkammer entwickeln sich die Aorta sinistra und die Arteria pulmoualis, deren jede an ihren Ursprunge zwei Klappen besitzt. Aus der engeren, aber mit dickeren Wandungen versehenen linken Herzkanmer tritt die starke Aorta dextra hervor, an deren Ursprunge ebenfalls \%wei Klappen vorhanden sind, jenseits welcher sie sich zu einem Sinus erweitert. Alle aus den llerzkammern entspringenden Gefässstïmme sind an ilurem Ursprunge äusserlich eng verbunden und in dieser Gegend communiciren die beiden Aortell, von denen die rechte rein arterielles, die linke aber venöses Blut führt, durch eine Oeffnung mil cinander.

III. Von den Arterien der beschuppten Reptilien.

§. 98 .

Bei den beschuppten Reptilien ist die Zahl der bald aus einem Truncus arteriosus communis, bald unmittelbar aus den Herzkammern entspringenden Arterienbogen entschieden vermindert.

Bei den Sauriern entspringen aus einem kurzen Truncus arterio. sus conımunis, zusammen init den beiden Lungenarterien, jederseits zwei Arterienbogen, welche zu einer Aortenwurzel sich vereinigen, nachdem aus jedem inneren Bogen die Artt. carotides abgetreten sind. Die beiden Aortenwurzeln verbinden sich vor der Wirbelsüule zur absteigenden Aorta. Die Arterine subclavine entstehen entweder aus beiden Aortenwurzeln ${ }^{1}$ ) oder nur aus der rechten $2 \%$. Aus dem Stanne der absteigenden Aorta nehmen Rami oesophagei, eine Art. hepatica, die Art. coeliaco-mesenterica, Artt. intercostales, spermaticae, rena. les und die A. mesenterica posterior ihren Ursprung. Endlich gibt sie die Artt. iliacae ab und setzt sich als weite Art. sacra media in. nerhalb des Canales der unteren Dornen des Schwanzes fort.

Bei den Cheloniern ist bald ein kurzer Truncus communis vorhanden ${ }^{3}$ ), bald entspringt unmittelbar aus der IIerzkanmer für jede Seite ein eigener Arterienbogen. Beide Bogen sind bei ihren Ursprunge äusserlich eng verbunden mit der A\%t. pulmonalis, deren Ductus Botalli friihzeitig obliteriren. Aus dem rechten stärkeren Arterienbogen nehmen mittelst eines einfachen Truncus anonymus die Kopf- und Arm-Pulsadern und später auch mehre Arteriae intercostales ihren Ursprung. Beide Arterienbogen bilden einen weiten Ring um die Speiseröhre und der rechte gibt die starke Art. coeliaco-mesenterica ab, ehe er als schwacher Ramus communicans ungefähr auf der Mitte der Wirbelsäule nit dem linken zur absteigenden Aorta sich vereinigt.

Aehnlich ist das Verhalten der Arterien bei den Ophidiern. Auch hier kommen zwei Arterienbogen aus dem Merzen. Aus dem rechten

1) \%. B. bei Lacerta oeellata nach Müller. ich bestätigen kann. - 3) Z. B. Emys, 'T'estudo.

2) \%. B. bei Iguana, wie 
dieser Bogen entspringen dic beiden Art. coronariae cordis, die Ar\%. anouyma s. carotis communis 4), eine Art. collaris $\left.{ }^{5}\right)$ und Artt. illtercostales. Er vercinigt sich erst nach Abgabe diescr Aeste mit dem linken Arterienstamme zur absteigenden Aorta, aus wclcher mit unpaaren Stämmen parige Artt. intercostales und mit sehr zahlreichen, getrennten Aesten die Arterien für die Eingeweide hervorgehen. Die Aorta enclet als Art. sacra media oder condalis.

Bei den Crocodilen sind zwei Arterienbogen vorhanden; aus den rechten, der aus der linken Kammer sich entwickelt, also unvermischtes arterielles Blut führt, entspringt eine Arl. anouyura sinistra, welche in die einfache oder doppelte Carotis commauis i) und in die Subclavia sinistra sich theilt und eine Art. subclavia dextra. - Der linke, gemischtes Blut führende Bogen gibt melre starke Aeste zum Magen, zur Leber, zur Milz, zum Pancreas und zum Duodcnum ab und senkt sich dann als schwacher Ramus communicaus in die Fortsetzung des rechten Arterienbogens. So entsteht die Aorta desceudeus, welche, ausser den Trunci intercostales, eine Art. mesenterica superior, Artt. suprarenales, renales, lumbales, feinorales profundae, crurales und eine Art. mesenteria posterior abgibt und als Art. caulalis s. sacrn media sich fortsetzt.

Wundernetzbildungen sind bisher nur in geringer Zilhl beobachtet worden i): bei Vipera Redi unter und hinter der Giftdrüse, bein Crocodil an dem äusseren Ohre, gebildet durch die Art. maxillaris exterua, am Sehnerven, gebildet durch die Art. ophthalunica posterior, in der Nasenhöhle durch die Art. ethmö̈lalis und in den Knochenzellen des Oberkiefcrs durclı die Art. maxillaris interna.

\section{Vou den Venen.}

$$
\text { §. } 99 .
$$

Die Venen der Reptilien sind viel diinnhäutiger und zugleich umfänglicher und zahlreicher, als die Arterien. Bei den Cheloniern und Crocodilen sind Klappen in ihnen beobachtet worden. Säimıntliche Venenstämme treten in einen gemeinschaftlichen venösen, mit Muskelfasern belegten und darum contractilen Sinus ${ }^{1}$ ) zusammen, der in den

4) Schlemm l. c. nennt diesen Stamm, welcher die beilen Carolides, die beiden Art. verlelnrales und die Art. thyreoüdea inferior abgibt, Art. cepha. lica. Cuvier belegt ihn mit dem Nimen Carotis commmenis und schreibt daher den Ophiliern cine einfache Carotis zu.

5) Sic gibt vorlere Arlt. intercoslales, oesophugerne u. Nackenmuskcläste ab.

6) Das Nilcrocorlil hat, naeh Cuvier, zwei Trunci anonymi und zwei Ca. rotiden (Vorles. üb. vgl. Inat., Th. JV. S. 127.); van der Hoeven (Tijdschrift, Th. (j) fand bei Crocodilus biporcatus zwei Carotiden; Champza lncius und sclerops haben nur eine linke Carotis comm, primaria. - 7) Von H y rtl enteckt.

1) Auch die in ilın mündenden Stämme, namentich die Vena cava inferior, 
rechten Vorhof dcs Herzcns iibergeht. - Dic Hauptvenenstämme sind folgende:

1. Die Veuae jugulares. Sic nchmen hoi den ungeschwänz. ten Batrachicrn nur das Blut aus der Zungen-, Unterkiefer- und Stimmladengegend auf. - Bei den beschuppten Reptilien crweitert sich ihr Bercich bedcutend, indem, ausser den genannten Venen und denen der Luft - und Speiseröhre, auch die Venenstämme des Gesichtes und des Gehirnes grösstentheils odcr süimmtlich in sie übergehen.

2. Die Veuae vertebrales superiores, welche noch boi den ungeschwänzten Batrachicrn das venöse Blut aus dem Gehirnc vollstündig aufnehmen, bei den Ophidiern aber nur noch an ihrem Ursprunge mit den Venae jugulares verbunden sind, geben bei den Sauricrn und den Cheloniern die Verbindung mit den Hirnvenen ganz auf und werden nur aus den Venae intervertebrales, intertransversuriae und intercostales des vor dem Herzen liegenden Körperabschnittes, welche sie auch schon bei den Batrachiern aufnahmen, gcbildet 2 ).

3. Ihnen entsprechen in dem hinter dem Herzen und vor dem After liegenden Körpcrabschnitte die Venue vertebrales inferio. res s. posteriores. Sie entstchen aus den Venae intercostales und lumbales, welche jederseits zu eincm Längsstamme zusammentrcten, der bald unter den Querfortsätzen der Wirbel, bald über den Rippenköpfchen ${ }^{3}$ ) liegt und stehen unter einander, wie bei den Fischen, noch bisweilen in Verbindung. - Dicse Venenstämme, wclche bei den Proteíden und Salamandrinen sehr entwickelt sind und hicr in die Veuce cava sich ergiessen, stchen bei den Fröschen noch ausser Communication mit dem Systeme der oberen Hohlvenen, indem jeder nit einem innern queren Stammc als Venu aulvehens in die Niere seiner Seite tritt. $\Lambda$ uch bei den Cheloniern sind sie in deın den Nieren zunächst gelegenen Abschnitte am weitesten. Doch findet bei den Schildkröten eine deutliche vordere Communication dieser Stämme mit den Jugularvenen Statt, welche noch bestimmter bei den Ophidiern hervortritt.

Durch dic Vereinigung der Vena jugularis, der V. vertebralis superior, der vorderen Fortsetzung der $\boldsymbol{V}$. vertebralis inferior und bei Vorhandensein von Vordercxtremitäten - auch der $\boldsymbol{V}$. axillaris

sind bei ihrem Uebergange in ihn mit Muskelfasern belegt und zeigen daher bei lebenden Thieren leutliche Pulsationen, worauf Haller, Bojanus, Wede. meyer, Barkow u. A. längst anfmerksam gemacht haben.

2) In sie, gleich wie in die Venae vertelnales inferiores, gehen auch die Venae spinales über.

3) So bei den Cheloniern. S. Bojanus 1. c. Tab. XXV. - Bei den Batrachiern und Ophidiern liegen sie unter oder vor len Querfortsätzen und Rippen. S. die Abbild. bei Gruby 1. c. Tab. 9. Fig. 3. - Diese hinteren Vertebralvenen entsprechen dem Systeme der Venae arygos und hemiazygea der höheren Wir. belthiere. 
jeder Seite entstehen zwei obere oder vordere Ilohlvenen, welche in den gemeinsehaftlichen Sirus vesossus sich einsenken.

4. Das System der Vena cava inferior wird gebildet durch die Venae renales reveheutes, die Venenstämme der keimbereitenden Geschlechtstheile und die Lebervenen. Bisweilen nimmt sie auch Lumbarvenen und bei Proteus sogar von den Lungen kommende Bronehialrenen auf. Bei den Schildkröten ist dic untere Hohlvene am wenigsten concentrirt. Hier entsteht aus der Vena renalis revehens und den Venen der keimbereitenden Geschlechtstheile cin Stamm, der nur untergeordncte und kleinere Lebervenen aufnimml. Er ergiesst sich, abgesondert von den beiden grösseren Lebervenen, gleich diesen, in den gemënschaftlichen venösen Sinus. - Bei den Fröschen, den Ophidiern und Crocodilen entsteht durch das Zusammentreten der Venae renales revelientes und der Venen der keimbereitenden Gesehlechtstheile ein einfacher Stamm, der auch vorn die Lebervenen aufnimmt und dann in den Simus venosus sich einsenkt. Bei den Crocodilen tritt zu den Wurzcln der unteren Hohlvene noch eine zwischen den Nieren verlaufende vorwärts steigende Fortsetzung der Veua caudalis.

Dem Systeme der Vena cava inferior untergeordnet sind die Pfortader-Systeme der Nieren und der Leber. Beide bieten bei den Reptilien sehr eigenthümliche und im Einzelnen wieder abweichende Verhältnisse dar. Die Venae renales allvelientes der nackten Reptilien sind Venenstämme der Extremitäten, der Oviducte und der Saamenleiter und dic nach innen abtretenden Zweige der Venae vertelrales inferiores. Diese Venenstämme, welehe am äusseren Nierenrande verlaufen, lösen sich, in die obere Fläche der Niere tretend, pfortadermässig in ein intermediäres Capillargefäss - System auf, aus welchem die Anfänge der Veuae renales reveheutes entstehehen. - Bei den Ophidiern sind die sogenannten Vence renales adveliertes Fortsetzungen der beiden von der Schwanzspitze nach vorn verlaufenden Veuae caurlales. Bei den Schildkröten tritt, ausser den Zweigen der Vena vertebralis inferior, ein starker Ast eines aus der Verbindung der Schwanzvene mit den Venen der Hinterextremitäten entstandenen Gefässstammes in jede Niere. Aehnlich ist das Verhalten beim Crocodile; nur dass hier eine Fortsetzung der Sehwanzvene zwischen den Nieren verläuft, um später mit den Venae renales revelientes zur unteren Itohlader sich zu verbinden. Schon bei den Schlangen, und noch mehr bei den Sehildkröten, schwindet die pfortarlerähnliche Verästelung der sogenannten zuführenden Nierenvenen, und sic setzen sich allmälich innerhalb der Nieren einfach und unverzweigt fort in die Venae renales revelientes.

Das Pfortader-System der Leber wird bei den Reptilien nie ausschliesslich gebildet dureh die Venen des Darmeanales und der mit ihrn verbundenen drüsigen Organe, erhält vielmehr inmer noch Blut 
aus anderen Quellen. Bei den Ophidiern beginnt die Pfortader der Le. her mit cinem Aste der aus den Venen des Schwanzes zusammengesetzten rechten Vena renalis advehens. Sie nimnit in ihrem Verlaufe zur Leber, ausser den Venen der sogenannten chylopoietischen Organe, auch Intercostalvenen und Venen aus dem nicht mehr respiratorischen Abschnitte der Lunge auf. Bei den unbeschuppten Reptilien, den Cheloniern, Sauriern und Crocodilen entsteht aus den vereinigten Venen der Hinterextremitäten und der Aftergegend cine bald einfache, bald paarige Vena abdominalis anterior, welche, durch Aufnahme von venösen Gefässen aus den vorderen Bauchwandungen verstärkt, in die Leber tritt und hier, gewöhnlich nach eingetretener Verbindung mit den aus den Baucheingeweiden stammenden Venen, sich pfortadermässig verzweigt. Bei den Batrachicen ${ }^{4}$ ) und den Cheloniern wird sie noeh durch einen aus denı Zusammentreten der Venen des Herzens gebildeten, den Herzbeutel durchbohrenden Ast verstärkt ${ }^{5}$ ).

[Man vgl. über das Veneisystem der Reptilien die \$. 94. angeführten Schrif. tell von Mayer, Burow, Gruby, Hyrtl, Schlemm, Bojanus und Panizza; ausser ihnen aber die früher (\$. 43.) citirten Schriften von Jacobson, Nicolai und Rathke.]

\section{Von den Lungengefässeu.}

§. 100.

Die Lungen-Arterien bieten, ausser ihren schon angegebenen Ursprungsverhältnissen und dem Umstande, dass aus ihren Stämmen bei den nackten Reptilien 1) meistens Körperarterien abgehen, wenig Eigenthümliches dar. Bei denjenigen Ophidiern, welche nur eine Lunge besitzen, ist auch nur cine Lungenarterie vorhanden $\left.{ }^{2}\right)$. Die Lungenvenen ergiessen sich stets in das linke Atrium ${ }^{3}$ ), gewöhnlich getrennt, aber dicht neben cinander, seltener nach geschehener Vercinigung zu Einem Stamme, wie bei den Fröschen.

4) Bei den Fröschen. Vgl. die Abbill. bei Gruby l. c. Tab. 9. Fig. 1. u. 2.

5) Bei den Fröschen ist durch $\mathrm{Hyrtl}$ auch eine Verbindung des P'fortaderSystemes mit Venen der Augen- und Schedelhöhle, so wie auch eine der Pfort. ader angehörige Wundernetzbildung an Pharynx nachgewiesen.

1) Bei Proteus, Siren, Menopoma, Amphiuma, allen Fröschen.

2) Z. B. bei Coluber natrix.

3) $\mathrm{H}$ y rt, der die eigentlichen Lungenvenen bei Proteus entdeckt hat, welche, wie gewöhnlich, unmittelbar in das Herz treten, unterscheidet gleich seinen Vorgängern, noch hintere, auch bei Siren vorhandene, Iungenvenen, welche in die Venen der Geschlechtstlıeile und die Hohlvene einmünden. Sie dürften wol richtiger als Bronchialvenen zu betrachten scin. - Treviranus scliildert bei Caretta imbricata eine höchst abweichende Insertion der Lungenrenen. Ich finde bei sorgfilliger Untersuchung zweier Exenıplare, dass dic beiden Lungenvenen, wie gewölnlich, in die linke Vorkammer olne Kilappen einuündell. 


\section{Vom lymphatischen Systeme.}

\section{§. 101.}

Das Ly inphgefias-Systein ist bei allen Reptilien sohr ausgebildet. Die Lymphgefisse sind grossentheils durch ihren betrichtlichen Durchmesser und an cinzelnen Stcllen durch sackartige Erweiterung ausgezeichnet. Miiufig umgeben sie grössere und kleinere arterielle und renösc Gefiasse scheidenartig, so dass die Röhren dieser Gefässe von dere Lymphe uinspült werden. Bisweilen erstrecken sich Fädehen von der iiusseren Blutgefässwand zur inneren Lymphgefisswand. In anderen Fällen finden sich an der Innenwand der Lymphgefïsse Längsfalten oder durchbrochene Scheidewäinde. Beim Salamander sind die Lymphnetze und Lymphbehälter an der Cloake, am Afterdarme, an den Seiten des Kopfes ausserordentlich ausgebildet. Es ist ein einfacher, weiter Ductus thoracicus vorhanden, der in zwei Plexus axillores sich spaltet, welche die Lyınpgefässe der Forderextremitäten und des Kopfes aufnehmen und dic Veune suliclaviae umhüllend, in sic sich ergiessen. Bei den Fröschen sind die Plexus des Merzens, der Lungen, der Cloake äusserst stark. Eine grosse Cysterne chyli nimmt einen beträchtlichen Theil der Bauchhöhle cin und steht mit Lymphräumen der Regio ilirea in Verbindung. Dic gleichfalls schr entwickelten Lymphgefïsse der Schlangen, welche zwei Ductus thoracici besitzen, sammeln sich in einen grossen Plexus in der IIcrzgegend, der an mehren Stellen in die rorderen Venenstäinme mïndet. Bei den Schildkröten hiillen die Lymphgefässe uiberall dic Arterienstämme cin. Eine schr grosse Cysterna liegt zwischen den beiden Lingen und geht in dic beiden Ductus thoracici ubler, wolche in die Venae sulsclavine sich orgiessen. Bein Crocodil theilt sich der die Aorta umhüllende Plexus gleichfalls in zwei Ductus thoracici.

Von besonderer Wichtigkeit sind die bei Reptilien aller Ordnungen gefundenen Lymphherzen, welche - wenigstens bei den Fröschen und Schilkkröten - in rhythmischer Contraction begriffen, ihr durch grössere Lỵmphgefiss-Stämme ihnen zugeführtes Contentum in Venen, mit denen sie in Verbinduny stehen, entlecren. Bei den Fröschen sind vier, bei den übrigen Reptilien zwei solcher Lymphherzen beobachtet worden. Dic vorderen Lymphherzen der Frösche liegen jederseits auf den Querfortsätzen des dritten Wirbels unter dem hinteren Ende der Scroulne und communiciren mit Venen, welche in dic Veuae jugulares übrrgehen. Die hinteren Lymphherzen, welche bei Salaniandern, Fröschen, Eidechsen, Schlangen, Schildkröten und Crocodilen angetroffen sind, liegen meistens in del Regio ischiarlica hinter den Darmbeinen unter der Haut. Bei den mit rudimentiiren Extremiliten versehenen Sellangen liegen sic in eigenen kleinen Höhlen jreder Seite des Kreuzbeines und der luciden naichstvorderen Wirbel. Bei den Chelo- 
niern liegen sie unter dein hintersten grossen Medianschilde der Rükkensehaale, in einiger Entfernung vom oberen Ende des Darmbeines. Sie münden bei den Frösehen in Zweige der Verue isclinadicre, sonst in Venen, welche mit den Venae renales advehentes in Verbindung stehen. Diese eontraetilen Lymphherzen besitzen einen entschieden muskulösen Bau und zeiehnen sieh namentlieh dureh quergestrejfte Muskel-Primitivbündel aus. An den Eingängen der Lymphgefässe und an dem Ausgange in die Vene finden sich Klappen, welche so gestelit sind, dass sie den Rüektritt der Lymphe und den Eintritt des Blutes hindern. - Eine Mesenterialdrüse ist nur bei Crocodilen beobachtet.

[Man rglo über das Lyuphgefäss - System der Reptilien, ausser den vortreffliehen Abbildungen von Bojanns, das Praehtwerk von Panizza, Sopra il sistema linfatieo dei rettili, Pavia 1833, fol. mit ausgezeichneten \&ibbildungen. Ueber die Lymphberzen der Batrachier s. Müller in seinem Archiv 1834, S. 206.; über die der Brtrachier, Saurier und Ophidier: Panizza l. c.; ïber die der Ophidier: Ed. Weber in Müller's Arehiv 1835, S. 535., mit sehr sorgfältigen Abbildungen und Bemerkungen über das Lymphsystem des Python iiberhaupt; $V_{a}$ lentin in Müller's Archiv 1839, S. 176., worin darauf aufnerksän gemacht wird, dass die Lymphherzen bei Embryonen der Schlangen verlälmissmässig gross sind; über die der Chelonier s. Müller in den Physit. Abhandl. der Berl. Akallemie d. Wissensch., Jahr 1839, S. 31., mit schönen Abbild.]

\section{Siebenter Abschnitt. \\ Von den Stimm - und Athmungs-Organon.}

\section{Von der Stimmlade und dem Kehlkopfe.}

§. 102.

Bei allen Reptilien liegt am Eingange zum inneren oder LungenRespirations-Apparate das Stimmorgan. In dasselbe fiuhrt bei den gesehwänzten nackten Reptilien eine weit nach hinten in Sehlunde gelegene sehr feine Längsspalte. Diese ist bei den ungeschwänzten Batraehiern weiter und liegt meist dieht hinter der Zungenwurzel. Dieselbe Lage hat sie gewöhnlich bei den besehuppten Reptilien, eine Regel, von welcher jedoch die Ophidier, bei denen sie auf der Zungenseheide, und die Siuriergattung Phrynosoma, wo sie in der Substanz der Zunge liegt, Ausnahmen bilden. Bei den meisten Ophidiern, vielen Sauriern und einigen Schildkröten ${ }^{3}$ ) findet sieh vor der den Eingang zum Kehlkopfe bildenden Längsspalte keine Falte. Bei den Croeodilen ist der Kehlkopf durch ein unpaares longitudinales Frenulum, das in zwei den Eingang begrenzende Falten sieh theilt, an den Boden der

1) Namentlich bei den Geckonen, bei Lacertil, Ameiva, Hydrosaurus, Testudo. 


\section{Siebenter Abschuitt. Von den Stimm - u. Athmungs - Organen. 225̌}

Mundhöhle gchcftet. Bei Andercn erhebt sich an der Zungenwurzel eine Schleimhautfalte, welche quer über dem Eingange zum Kehlkopfe lirgend, denselben, wie eine Klappe, mehr oder minder vollständig verschliesst, also eine häutige Epiglottis darstellt 2). In diese Klappe tritt endlich häufig ein knorpeliger Fortsatz, der die vordere Spitze des Schildknorpels bildet, ein ${ }^{3}$ ). -

Der Eingang in die Lungen erscheint bei den meisten nackten Rcptilien als eine verschiedenartig gestaltete, grossentheils häutige Höhle oder Blase, welche bei den langgestreckten und geschwänzten Gattungen 4) mehr in der Dimension der Länge, bei den ungeschwänzten Batrachiern dagegen mehr in der der Quere entwickelt ist, bei jenen also mehr einer Luftröhre, bei diesem mehr einem Kehlkopfe zu entsprechen scheint. In der That aber findet bei den nackten Reptilien noch kcine Sonderung dieses Gebildes in Kehlkopf und Lụftröhre Statt, weshalb es zweckmässig erscheint, dasselbe mit Henle als Stimmlade zu bezeichnen. Diese Stimmlade enthält zwischen ihrer äusseren Haut und der sie inwendig auskleidenden, mit einem Flimmerepitlelium versehenen Schleimhaut stets Knorpelstiuckchen. Bei Proteus ist nur ein Paar seitlicher Knorpel vorhanden; bei den Derolremata, den Salamandrinen und den Cöcilien kommen schon zwei Paare vor, von denen das Eine die Cartilagines arytaenoüdeae, das Andere die Cart. Laryngotracheales repräsentirt. Diese letzteren Knorpelstreifen zcigen bei mehren Gattungen der geschwänzten nackten Reptilien seitliche Einkerbungen 5) oder Ausschnitte 6) und schicken bei anderen quere Aeste 5 ), namentlich nach innen und hinten ab. Auf diese Weise ist schon eine Tendenz zur Bildung von Ringen gegeben, welche unter einander aber noch durch den gemeinsamen longitudinalen Knorpelstreifer verbunden werden. Bei Cöcilia ist dieser letztere jedoch gegen die Lungen hin auch schon verschwunden und die entsprechenden isolirten Halbringe beider Seiten berühren sich und verschmelzen selbst an der hinteren Wand der Stimmlade. - Bei den ungeschwänzten Batrachiern sind die Cartilngines aryfaenoüdleae in der Regel von beträchtlicher Grösse und von drcicckiger Form ${ }^{8}$ ) und bci mehren Fröschen erscheinen an ihrer

2) Bei den Sehildkröten mit Ausnahme von Testudo, bei Ophisaurus, Pseu. dopus, Coluber flavescens.

3) Bei Crotalus, Lachesis, Vipera, Bungarus, Naja, Eryx, Boa; ferner bei Trapelus, Polychrus, Sceloporus, Phrynocephalus, Anolis, Iguana, Draco, Calotes, Chamaelen, Cyclura.

4) Namentlich bei Amphiuma, Menopoma und besonders bei Coecilia.

5) \%. B. bei Triton marmoratus u. cristatus; Salanandra maculata, Siredon.

6) Z. B. bei Triton igneus, Salamandra atra.

7) 'L. B. hei Menopoua, besonders aber bei Coecilia. Hier versehwinlen gegen die Lungen hin schon die longitudinalen Verbindungsstreifen zwischen deu queren Halbringen.

8) S. die näheren Angaben über die Gestalt derselben bei Henle S. 11 . 
Spitze kleine, den Cartilagines Suntorinianne ${ }^{9}$ ) vergleichbare Knorpelchen. Die Basis der Giessbeckenknorpel articulirt meist mit dem oberen Rande der beiden Cartilagines laryngn-tracheales 10). Diese letzteren sind selten vorn oder hinten von einander getrennt ${ }^{11}$ ), vielmehr meist dadurch mit einander verbunden, dass ihre oberen Querfortsätze einen hinten und rorn geschlossenen Ring bilden, von dem jederseits ein Seitenfortsatz der Länge nach abwärts steigt, welcher bisweilen noch quere, selten unter einander zu Ringen verbundene Knorpelleisten (rudimentitre Tracheal - und Bronchialringe) abschickt 12). Selten nur ist die Längenverbindung dieser auf einander folgenden Querleisten durch Schwinden des Längsstreifes stellenweise aufgehoben ${ }^{13}$ ).

Nur bei wenigen ungeschwänzten Batrachiern zeigt sich eine Verbindung des hintersten Zungenbeinhornes mit der Cartilugo laryngotrachealis 14), und noch seltener erscheint der untere Theil des Zungenbeinkörpers sanmt der Colunella als integrirender Theil der Stimmlade ${ }^{15}$ ).

Stimmbänder fehlen den geschwänzten nackten Reptilien; dage. gen kommen dünne, hïutige, selten ein kleines Knorpelchen enthaltende ${ }^{16}$ ), vorn und hinten an die Cartilagines arytaenoüileae befestigte Stimmbänder bei den meisten ungeschwänzten Batrachiern vor, welche den Ligamenta vocalia inferiora der Säugethiere entsprechen. Ausser ihnen sind bei den meisten ungeschwänzten Batrachiern noch durch eine einfache schmale Duplicatur der Schleimhaut gebildete Ligamenta vocalice infima vorhanden. - Bei den meisten geschwänzten nackten Reptilien besitzt die Stimmlade zwei Muskeln: einen Erweiterer und einen Verengerer. Bei den ungeschwänzten Batrachiern erhält sie ihre Muskeln nur vom Zungenbeine; es sind in der Regel drei Paare vorhanden $\mathbf{1 7}$ ).

Bei den beschuppten Reptilien findet eine entscliedenere Sonderung von Kehlkopf und Luftröhre Statt. Diese letztere, welche den Kehl.

9) Bei Rana temporaria und esculenta.

10) Nur bei der weiblichen Pipa mit einer rulinentären gesonderten Cartilago cricö̈dea. Siche Henle S. 10.

11) Bei Discoglossus unverbunden; bei Pelobates vorn, bei Ceratophrys hinten verbunden. Bei allen übrigen Batrachiern ist der Ring vollständig geschlos. seu. Er repräsentirt, wie Heule mit Recht hervorhebt, Schild -, Ring-und Tra. chealknorpel und entspricht zugleich theilweise den Bronchialknorpeln.

12) Bei Ceratophrys, Rama esculenta, Engystoma, Bufo; besoniers aber bei Pipa. - 13) Bei Pipa haben sich Bronchialringe isolirt.

14) Bei Alytes obstetricans, Bufo cinereus, Rana esculenta und temporaria.

15) Bei Pipa und Xenopus. Bei diesen beiden Gattungen kommen sexuelle Verschiedeuheiten in der Bildung der Stimmlade vor. Vergl. darüber Henle S. 18. u. 19.

16) Bei Microps Bonaparti uach Henle; bei Bufo Lazarus nach Mayex.

17) Vgl. darïber Honle S. 21. ff. 
kopf an Lïinge allmälich sehr überwiegt, wird durch diejenigen offenen oder geschlossenen Knorpelringe des Eingangscanales in die Lungen gebildet, welche miltelst keiner Läingsleisten mehr unter einander verbunden sind. Zum Kelilkopfe gehört dagegen derjenige vorderste $A$ bsclnitt dieses Canales, dessen Ringe noch durch vertieale Knorpelleisten zusanmenhangen. Die Zahl der in Verbindung bleibenden, also zum hehlkopfe gehörigen Querknorpel ist, je nael den einzelnen Gattungen und Arten, selir versehieden 18). Die queren Knorpelstieke des Kehlkopfes bilden bald unvollständige 19) und dann meist hinten offene, bald aber vollstïndige ${ }^{20}$ ) Ringe. Häufig sind die vorderen Abschnitte dieser Ringe zwar innig mit einander verselımolzen, dennoch aber bleiben noclı Spuren querer Zwischenriume zwischen ihnen erkennbar. In anderen Fïllen sind diese häutigen Interstitien verschwunden und dann ist statt einzelner Ringe eine solide, oft aueh hinten geschlossene Knorpelplatte vorhanden 21). Dirse zusarnmenhangende bald noch durchbroeliene, bald solide Knorpelplatte ist die Cartilago laryngea. Sie besteht häufig aus zwei, bald nur vorne, bald nur hinten, bald aber vorn und hinten mit einander verbundenen Seitenknorpeln (Cartilago thyreo-cricuädca), welche olserwärts in zwei continuirliche Fortsätze (Processus arytaenö̈lei) ${ }^{22}$ ) ausgehen, die die Ränder des Aditus laryngis stitzen. Bei anderen Gattungen und Arten sind aber die Giessbeckenknorpel nicht mehr Fortsätze der gemeinsamen knorpeligen Grundlage, sondern selbstständige getrennte Stüeke. Die Cartilago laryrgoren geht oft in eine hintere Spitze aus, welche bei einigen Gattungen vom oberen Theile der hinteren Wand abgelöst ist und dann, die Gelenkflijchen fiir die Cartilugines arytaenoüdeae bildend, eine gesonderte Cartilago cricoüdea darstellt. - Bei meliren beschuppten Reptilien treten die unverschmolzenen oder plattenförmig vereinigten Kehlkopfsbogen in einem vorderen Winkel zusammen ${ }^{23}$ ), der sich oft in einen kürzeren oder längeren oberen Fortsatz auszieht 24) (Processus epi-

18) Es fiuden sich 16 bei Crotalus, 8 bei Boa, 6 bci Scincus, Testudo, Tri. onyx, 3 bei Anguis, Calotes, Einys, 2 bci Gecko, Draco.

19) Bei Typhlops, Lachesis, Dipsas, Iguana. - 20) Bei Cylindrophis, Scytalc. - 21) Z. B. Plırynosoma, Alligator, Crocodilus, Chamaelco, Anolis.

22) Es gibt, nach Henlc's Untcrsuchungen, kaum cine Fainilie der beschuppten Reptilicn, in wclcher die Cartt. arytaenoïdene constaut verwachsen und constant getrcnnt sind. Sie sind verwachsen bei Cylindrophis und Eryx, getrennt bei llysia, Boa, Python. Bisweilen sind sic bei ciner von zwei nahe vcrwandtcu Arten getrennt, bei der andern vcrwacbsen; ja selbst individucllc Verschiedenheiten koinmen vor.

23) Z. B. hci Polychrus, Rhamphost na.

24) Bei vielen Ophidiern und cinigen Sauricrn. Der Processus epiglotti. cus fehlt den Crocodilen und Schildkröten, den Eidccbsen, Geckonen, Scinlien, Amphisbäneu. Er findet sich bei den Agauten, unit Ausmahnc von Phrynosoua und bci Chamacleo. 
glotticus), an dessen Basis bisweilen seitliche Einschnitte sich finden 25 ).

Stimmbänder werden bei den Ophidiern, den Cheloniern und vielen Sauriern gänzlich vermisst; bei einigen Sauriern wird ihre Stelle vertreten durch einen inneren Vorsprung, welchen die unteren Ränder der Cartilagiues arytacnoïdeae bilden; bei anderen findet sich jederseits, entsprechend dem unteren Rande dieser Knorpel, eine sehr schmale und dünne Falte. Bei den Crocodilen ragen die sehnalen Giessbeckenknorpel mit ihrem unteren Rande in die Kehlkopfshöhle hincin und unter ihnen bildet dic Schleimhant cine Art Tasehe. Die vollkommensten Stimunbänder besitzen die Geckonen und Chamaeleonten. Bei der letzteren Gattung kömmt zwischen dem Kehlkopfe und dem ersten Luftröhrenringe ein eigenthümlieher blasenförmiger häıtiger Sack vor, der von der Luftröhre aus mit Luft gefuillt werden kann.

Die Kehlkopfmuskeln der beschuppten Reptilien 26) bcstehen in der Regel nur in einem $\boldsymbol{M}$. compressor und einem $\boldsymbol{M}$. dilatator laryngis. Neben $\mathrm{dcm}$ einen oder dem anderen dieser Muskeln oder ohne dieselben sind bei den Ophidiern zwei Paar langer, platter, sehmaler Kellkopfsmuskeln vorhanden, welche sich zum Theil noch an die Trachea befestigen und nach ihrer Function am besten als Vorsirecker und Zurückzieher des Kehlkopfes bezeichnet werden.

Accessorische Stimmorgane finden sich bei viclen Batrachiern. Es sind häutigc, ausdehnbare Blasen, welehe jederseits am Unterkiefer liegen und in dic Mundhöhle, seitlich von der Zunge sich öffnen. Sie kommen nur den männlichen Individuen zu, finden sich aber nicht bei allen Gattungen und selbst nicht bei allen-Arten Einer Gattung ${ }^{2 i}$ ). Sel. ten ist nur cine unpaare Blase dieser Art vorhanden.

[Man vergl. über das Stimmorgan der Reptilien die vortrefliche Schrift von Henle, Vergl. anatom. Beschreibung des Kehllkopfes, Leipzig 1839, A., welche obiger Darstellung zu Grunte gelegt ist.]

\section{Von der Luftröhre und den Bronchien.}

\section{§. 103.}

Bei den meisten nackten Reptilien, namentlich bei den Salamandrinen 1), und der Mehrzahl der ungeschwänzten Batrachier geht die Ilöhle der Stimmlade mit ihrem unteren Rande in die Höhlen der beiden Lungen unmittelbar über. Die Cartilagrines laryngo-trachcales hören

25) Iguana, Chamaeleo u. A. - 26) Vgl. Heule S. $45 \mathrm{fr}$.

27) Sic fehlen z. B. bei Rana temporaria, während sie bei R. esculenta vor. handeu sint. Sehr ausgebildet sind sie bei Hyla. Sie sind vergleichbar deus Sacke, der bei den Chamäleonten zwischen dem ersten Luftröhrenringe und dem Kehlkopfe liegt.

1) Auch bei Siredon und Ampliuma. S. die Abbild. bei Henle, Kehlkopf Tab. 1. 
bald vor dem U'sprunge der Lungen auf, ohne iiber die urpanre Eingangshöhle des Respirations-Apparates hinaus sich zu erstrecken 2), bald setzen sie siclı an den selır kurzen, etwas verengten Ilals jeder Lunge ${ }^{3}$ ), bald noch weiter abwitits an dieser fort 4). - Bei den Proteïdeen gelıt clie Stimmlade nach unten in zwej lange, häutige Bronchi ülser, deren Ende zu Lungensïcken sich erweitert 5); schon bei Menopoma kommen an diesen Bronchi Fortsetzungen der Knorpel vor $\left.{ }^{6}\right)$. - Ling ausgezogen und selbst zuín Theil init discreten Knorpelbogen versehen sind die Bronchi bei Xenopus und Pipa i).

Indem bei den beschuppten Reptilien nicht nur an den paarigen Eingangscanälen der Lungen, sondern aucl schon in eineın kürzeren oder längeren Abschnitte des unpaaren Eingangscanales in den Respirations-Apparat discrete Knorpelbogen sich vorfinden: sind hier gewöhnlich Bronchi, Luftröhre und Kehlkopf als verschiedene Gebilde zu unterscheiden. Als Luftröhre ist nämlich, im Gegensatze zur Stimnlade, derjenige $\Lambda$ bschnitt des unpauren Eingangscanales zu bezeichnen, dessen Kinorpelgeruste aus solchen offenen oder geschlossenen queren Bogen besteht, die durch keine verticale Leiste mehr unter einander verbunden sind. Schwerer hält es, namentlich bei vielen Ophidiern, scharfe Grenzen zwischen Luftröbre, Bronchien und Lungen zu ziehen, indem oft derjenige Theil des Respirations-Apparates, welcher nach seiner Lage, seinem einfachen Zusainmenhange mit dem Kelılkopfe und der Bildung seiner Knorpelringe als Luftröhre zu bezeichnen ist, durch in. nern zelligen Bau und Art der in seinen Zellen sich verzweigenden Gefässe schon als Theil der Junge sich zu erkennen gibt ${ }^{8}$.

Die Luftröhre der Ophidier zeichnet sich durch ihre Länge aus, ist häufig auch verhältnissmässig weit ${ }^{9}$ ) und besitzt sehr zahlreiche Knorpelbogen ${ }^{10}$ ), von denen die obersten oder vordersten gewöhnlich

2) Bei Pelobates, Bombinator, Rana, Hyla nach Henle.

3) Bei Bufo palmarum, B. cinereus, Pseudes.

4) Bei Engystoma bis über die Mitte des Lungensackes. Abbild. bei Henle.

כ) Abbillung bei Configliachi und Rusconi, del proteo anguino, Tab. 3. fig. 1. 1. 4. - 6) Siche Henle Tab. 1. Fig. 10. u. 11.

7) Sielıc Henle Tab. 2. Die Bronchien sind bei der männlichen Pipa be. deutend kürzer, als bei der weiblichen.

8) Mit Maschen oder Zellen, welche ein respiratorisches Gefässnetz besitzen, ist die Luftrölre besetzt bei Crotalus, Vipera, Coluber, Trigonocephalus, Hydro. plis, Pelamis; ganz glatt ist dagegen die Luftröhre inwendig bei Naja, Acantho. phis, Elaps, Eryx, Python, Boa. Bei Crotalus horridus und Vipera berus sind die Luftröhrenzellen sehr dicht und tief, so dass sie bedeutender sind, als in der eigentlicheı Lunge. Gleichzeitig ist bei ihnen die Luftröhre sehr erweitert. Ueber den zelligeu Bau der Luftröhre von Typhlops crocotatus s. Meckel in seinem deutschen Archiv f. Physiol., Bd. 4. S. 72.

9) Z. B. bei Vipera, Naji, Tortrix u. A.

10) S. genauere Zahlenangaben bei Meckel, System der vergl. Anatomic, 
geschlossene Ringe bilden, während andere, und namentlich die tieferen, hinten nur durch ausfüllende Membran geschlossen $z u$ werden pflegen $\left.{ }^{11}\right)$. IIat die Luftröhre inwendig einen zelligen Bau, so zeichnet sie sich bisweilen zugleich durch ihre Weite ans. Bei vielen Ophidiern tritt die Luftröhre sofort in die einfache Lunge; bei anderen theilt sie sich dagegen in zwei, für die beiden Lungen bestimmte, sehr kurze Bronchi 12), welche eine geringe Zalıl von hinten offenen knorpelringen besitzen.

Unter den Cheloniern kömmt bei den Landschildkröten die kürzeste Luftröhre vor, die bei Emys und Chelonia in Verhältniss zu den Bronchien bedeutend länger ${ }^{13}$ ), nie aber so lang, wie bei den Ophidiern ist. Die Knorpelringe der Luftröhre sind bald sämmtlich vollständig geschlossen ${ }^{14}$ ), bald sind die vordersten liinten membranös. Sie sind derber und zugleich näher an einander gerückt bei den Landschiidkröten, als bei den Seeschildkröten. Die bei den Landschildkröten langen, bei den Seeschildkröten kürzeren Bronchi besitzen vollständig geschlossenc Ringe ${ }^{15}$ ), die erst innerhalb der Lungen unvollständig und unregelmäs sig werden.

Bei den Sauriern besitzt die Luftröhre in Verbältniss zu den Bron. chicn meist eine beträchtliche Länge ${ }^{16}$ ); ihre Ringe sind gewöhnlich vollständig, seltener unvollständig ${ }^{17}$ ); namentlich ist der erste Ring hinten oft nicht geschlossen ${ }^{18}$ ). In der Regel behält die Trachea überall einen gleichen Durchmesscr 19), doch kömmt wenigstens ein Beispiel von beträchtlicher Erweiterung derselben vor 20). Die gewöhnlich sehr

Th. 6. S. 256. Die Zahl der Ringe schwankt zwischen 100 (Coluber natrix) und 350 (Python tigris).

11) Bei den Coluber-Arten sind nur wenige der obersten Ringe geschlossen; bei Python das oberste Viertheil; bei Elaps etwa ein Drittheil u. s. w. Nach Retzius Angabe findet sich, namentlich bei Python bivittatus zwischen den ein. zelnen Luftröhrenringen eine deutliche Muskelfaserschicht (Isis 1832, S. 522.).

12) Z. B. bei Python, Heterodon, Acanthophis. Die Zahl der Knorpelringe in ihnen ist unbeträchtlich; z. B. bei Python tigris, nach Meckel, rechts zwölf, links rier.

13) Die Zahl der Luftröhrenringe schwankt, ,nach Meckel, zwischen 20 (Testudo graeca) und mehr als 60 (Emys serrata). Das Verhältniss des Stammes zu den Aesten ist bei Testudo graeca gleich 1:7; bei Einys europraea wie 2:1, bei Caretta inbricata wie $3: 1$. - 14) Nur bei Testudo, Sphargis, Chelonia.

15) Jeder besteht bei Chelonia aus ungefähr 25 Ringen; bei Emys aus mehr als 30 ; bei Testudo aus 50 bis 80 .

10) Die Luftrölıre ist bei Jguana etwa zehnmal, bei Monitor nngefähr zweiınal so lang, als die Bronchi.

17) Bei Iguana, Gecko, Chamaeleo, Ascalobotes u. A.

18) El ist offen bei Cephalopeltis, Anguis, Pseudopus, Zonarus, Iguana, Chamaeleo u. A. - 19) Sie ist sehr weit bei Ascalobotes.

20) Bei Ptyodactylus funbriatus köınmt eine von Tiedemann näher beschriebene Erweiterung an ler Trachea vor; über und unter derselben sind dio Trachealringe geschlossen, längs der Erweiterung hinten offen. 


\section{Siebenter Abschnitt. Von den Stimın - u. Athmungs - Organen. 231}

k!rrzen Bronchi sind bisweilen ganz rudimentir 21). - Auch bei den Crocodilen besitzt die verhältnissmaissig kurze Luftröhre ${ }^{22}$ f theils geschlossene, theils offene Ringe ${ }^{23}$ ).

\section{Von den Lungen.}

§. $10 \%$.

Bald mnittchar an die Stiminlade, bald an die Luftröhre, bald an häutige oder knorpelige Bronchi schliessen sich bei den Reptilien die Lungen. Gewöhnlich sind sie von den genannten Eingangscanälen deutlich abgesetzt; seltener beginnt die Ausbreitung des respiratorischen Gefissnetzes und die Maschenbildung schon innerhalb des Cannales der Luftröhre, wie dies namentlich bei vielen Ophidiern der Fall ist 1). Die Lungen erscheinen als Säcke von rundlich-ovaler 2), länglicher ${ }^{3}$ ) oder sehr gestreckter 4) Gestalt, welche fast nie frei liegen, sondern meistentheils rom Bauclifelle iiberzogen und dann durch Bauchfellfalten mit benachbarten Gliedern verbunden werden. Bei den meisten nackten Reptilien, den ineisten Sauriern, den Cheloniern und Crocodilen sind zwci Lungen von gleicher Länge und Ausdehnung vorhanden, bei den Cöcilien 5), mehren Sauriern 6) und Ophidiern i) übertrifft dagegen die eine Lunge die andere beträchtlich an Ausdehnung und viele Ophidier $\left.{ }^{8}\right)$ zeichnen sich durch das Vorhandensein einer einzigen Lunge aus oder besitzen als zweite nur ein sehr unbedeutendes Rudiment. Das Gerüst der Lunge wird durch Fortsetzungen der verschiedenen

21) $\%$. B. bei Scincus, Gecko.

22) Ihre Länge ist bei verschiedenen Arten verschicrlen. Bei Crocodilus acutus bildet sie, ̈̈hulich wie bei vielen Vögeln, eine Windung.

23) Offene Ringe finden sich iun oberen oder vorderen Theile der Luftröhre.

1) S. hierïber ven vorigen \$. Anmerk. 8.

2) Bei den ungeschwänzten Batrachierı, viclen Sauricın, Cheloniern, Crocodileı. - 3) Bei den Salamaudrineı, bei Anguis u. A.

4) Bei den Cöcilien, namentlich aber bei den 0phidiern. Bei ersteren gehen die Lungen an Eulle plötzlich in einen schulen Zipfel über; ähnlich - bei sonst abweichender Gestalt - bei einigen Chamälconten.

5) Bei Coecilia lypocyanea ist $\mathrm{z}$. B. die rechte Lunge viel länger, als die linke.

6) Schon bei den Iguanae ist die Länge beider Lnngen nicht gleich. Die Asymunetrie wird viel beträchtlicher bei den schlangenähnlichen Sauriern: Chirotes, Acoutias, Psendopus, Bipes, Ophisaurus, Auguis, Seps.

7) Doppelt, olsschon ungleich entwickelt sind dic Limgen bei Crotalus, Naja, Trigonoceplialıs, Acantlıphlis, Platurus, Tortrix, Eryx, Heterolon, Boa, Python, Amphishaena. In der Regel ist die liuke Lunge unberleutender, als die reclite; aber bei Eryx turcicus und vielen Coluber-Arten ist die rechte Lnnge rudinentär. Dè Grad dw. Ungleichheit beider Lungen ist verschieden; bei Boa ist die rechte Lunge wenig, bei Python bedentend länger, als die linke; gan\% ludimentïl. ist die zweite Lunge hei Heterodon, Acanthophis, Trigonocephulus, Coluber untrix. Dirse rudimentären Lungen siud auch innerlich murollkomnener entwickelt.

8) Eine einfache Lunge findet sich bei Vipera, Hydrophis, bei mehren Colı. ber, bei 'Typhlops $11 . \AA$. 
Membranen ihres Eingangscanales gebildet. Ihre Schleimbaut ist von einem Flimmerepithelium ausgekleidet.

Bei einigen nackten Reptilien erscheinen dic Lungen als einfache, inwendig glattwandige blasenförmige odor darmförmige Hohlsäcke ${ }^{\%}$, an deren Schleimhaut die Gefässe des kleinen Kreislaufes polygonale Interstitien umschreiben. Die der Gefässausbreitung bestimmte Fläche vergrössert sich bei Anderen 10) durch das Auftreten von inneren zellenartigen Vorsprïngen, welche bald sparsam vorhanden sind, bald zahlreicher, dichter und zusimmengesetzter erscheinen. Knorpelstreifen, von der Stimmlade ansgehend, erstrecken sich bisweilen zwischen den Häuten des Lungensackes ịn seinem Innenrande abwärts ${ }^{11}$ ).

Bei den Ophidiern stellt die Lunge gewöhnlich einen sehr gestreckten canallörmigen, inwendig mehr oder minder zelligen Sack dar, dessen Ausdehnung verschieden ist, der aler bei einigen Gattungen fast bis zum After hin reicht ${ }^{12}$ ). Bald erscheint die einfache Lunge nur als Erweiterung der an ihrer Riickwand schon zelligen Trachea 13), bald inserirt sich der Bronchus etwas unterhalb der Spitze jeder Lunge 11). Von der die Knorpelringe der Trachea oder der Bronchi hinien verbin. denden fibrösen Haut geht gewöhnlich ein derberer anscheinend elastischer Längsstrang aus ${ }^{15}$ ), von welchem quere Stränge in grosser Zahl abtreten, die die Grundlage der an der Innenwand der Lungen vorspringenden grösseren Maschen oder Zellenwandungen abgeben. Diese Zellen, welche zahlreiche kleinere Zellen verschiedener Ordnung einschliessen, erscheinen fast nie ${ }^{16}$ ) über die ganze Lunge gleichmässig verbreitet, sondern werden in der hinteren Hälfte derselben sparsamer, flacher; einfacher und minder gefässreich. Bisweilen schwinden sie hinten ganz, so dass die Lunge in diesem hinteren Theile eigentlich nur als Bronchialgerüst zu betrachten ist. Auch die Arteria mulmonalis vertheilt sich vorzugsweise oder ausschliesslich im vorderen, am entschiedensten durch zellige Structur ausgezeichneten Abschnitte der Lunge, während diese weiter abwärts Gefässe aus der Aorta und de-

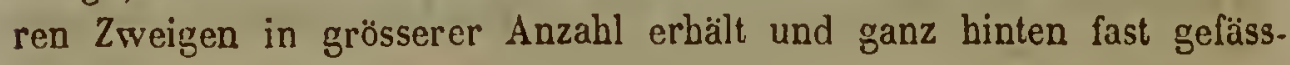
los ist ${ }^{17}$ ).

9) Bei Proteus, Triton.

10) Bei Siredon und bei Siren nach $\mathrm{Cu}$ vier, und dann in allıälicher Folgo bei Salamandra, Bufo, Rana, Pipa. - 11) Z. B. bei Engystoma nach Henle.

12) 7 . B. bei Hydrophis schistosus; nach mehren Angaben auch bei Pela. mis, bei Acrochordus. - 13) So bei Hydrophis schistosus.

14) 7. B. bei Python; hei Heterodon.

15) Z. B. bei Python. - Nur bei Acrochordus jaranicus finden sich auf der Oberfläche der einfachen Lunge, nach Fohınann, zablreiche Knorplel.

10) Sie schwinden 2. B. im hinteren Abschnitte der Lunge ron Coluber natrix, von Python, Vipera, Naja tripudians.

17) Vergl. Hyrtl, Strena anatomica de novis pulınonum vasis in ophidiis 


\section{Siebenter Abschnitt. Von den Stimm- u. Athmungs-Organen. 233}

Unter den Sauriern kommen gradweise Verschicdenheiten in der Ausbildung der Lungen vor. Bei vielen ${ }^{18}$ ) zeigen sie sich als einfache zellige Säcke; die Zellen sind im Allgemeinen etwas stärker vorspringend, als bei den Ophidiern, werden aber im hinteren Theile der Lunge oft flacher, oder verschwinden hier und anderswo in Anhängen der Lunge fast ganz 19). Bei einigen 20) setzt sich von dem Bronchus aus ein cartilaginöser oder fibröser Längsstreifen von vorne nach hinten fort, von dessen Sciten die derberen Stränge, welche den grösseren Zellen zur Grundlage dienen, abgehen. Bei anderen 21) finden sich zur Seite eines solchcn Längsstreifens reihenweise gestellte grössere Oeffnungen, welche in tiefere Höhlen oder Säcke mit zelligem Baue führen, die durch sie in den grossen mit flacheren Zellen besetzten Lungensack einmünden. Bei mehren Anderen 22) thcilt sich der Lungensack durch eine mittlere Scheidewand in zwei ungleiche Hälften, welche nur an der gemeinschaftlichen Einıündungsstelle des Bronchus zusammenhangen; in diesem Falle erheben sich, namentlich von den Wandungen der grösseren Hälfte, unvollkommene Septa, welche secundäre Säcke bilden. Bei einigen Varanen ${ }^{23}$ ) endlich theilt sich der Bronchus ziemlich weit vor seinem Fintritte in die Lunge in zwci Aeste von ungleicher Stärke. Jeder dieser Bronchialäste tritt in dic Lunge und besitzt hier mehre Oeffnungen, von welchen Gänge ausgehen, die zu Säcken sich erweitern; jcder Ast geht am Ende in zwei grosse Säcke iibcr. Alle dicse Säcke sind mit Maschen und Zellen an ihren Wandungen reichlich besetzt.

Bci den Crocodilen setzt sich der cinfache Bronchus canalformig und mit Knorpelringen versehen, weit in die Lunge fort und ist mit mehr odcr minder zahlreichen seitlichen, durch Knorpel gestützten Oeffnungen von verschiedener Grössé versehen, welchc in eben so viele Säcke oder Taschen führen. Tiefer abwärts entspringen von dem sich erweiternden Bronchus elastische Fasern, welche Oeffnungen einschliessen, die den Eingang in ähnliche Säcke bilden. Secundäre elastische Stränge, welche mit den grösseren zusammenhangen, schliessen kleinere Zellen ein, welche abermals Zellen mchrer Ordnungen enthalten. Aehnlich ist die Bildung der Schildkrötenlungen, wo die einzelnen Säcke von einander abgeschlossen sind und wo von ihren Wänden Maschen oder Zellenwände verschiedener Ordnung vorragen. Die hierdurch gegebene

nup. observat., Pragae 1837, 4. Die Venen münden in die $\boldsymbol{V}$.hepaticae und ga. stricae und gehen mit diesen in die Pfortader über.

18) Z. B. bei Platydactylus. - 19) Z. B. bei Chamaeleo, bei Polychrus inarinoratus u. A. - 20) Z. B. bei Lacerta ocellata.

21) Hei Gecko aegyptiacus, Scincus officinalis u. A. nach Meckel l.c. S. 75.

22) \%. B. bei Iguana, Stellio. galensis.

23) So finde ich es, wie auch schon Meckel angegeben, bei Varanus ben- 
Andeutung des Entstehens secundärer Bronchi erscheint am deutlichsten bei den Seeschildkröten, wo die von dem fast bis zum hinteren Ende der Lunge reichenden Bronchialstamme sehr zahlreich abgehenden, in die einzelnen Säcke tretenden kurzen Canäle eine knorpelige Grundlage besitzen.

[Man vgl. uiber die Lungen der Reptilien besonders Meckel in seinem deut. schen Archir f. Physiol., Bd. IV. S. 60., mit Abbild., und die früher citirte Schrift von Lereboullet. Abbildungen der Lungen von Einys gibt Bojanus I. c. Tab. XXIX. Fig. 174. 175.]

\section{Von den Kiemen.}

§. 105.

Während des ersten Lebensstadium sind bei allen Batrachierlarven aussere Kiemen vorlianden. An ihre Stelle treten bei den Larven der ungeschwänzten Batrachier später innere kiemen in Gestalt kleiner Quisstchen 1), die in einer oder in zwei Reihen an der Convexität der Kiemenbogen befestigt sind. Bei den Larven der Tritonen und Salamander erhalten sich die äusseren Kiemen bis zur Entwickelung der Lungenathmung und verschwinden dann mit den Kiemenspalten ganz, während bei den Derotremata 2) jederseits eine Kiemenspalte bleibt. Bei den Perennibranchiaten ${ }^{3}$ ) dagegen finden sich wïhrend der ganzen Lebensdauer äussere Kiemen neben den Lungen. Sie erscheinen hier als quastförmige oder federbuschartige Hautanhängsel, welche am äussersten Ende der sonst freien, an ihrer concaven Seite mit kleinen Wärzchen oder Zähnchen besetzten Kiemenbogen liegend, mit der äusseren Haut unmittelbar zusammenhangen. Jeder Kiemenbüschel besteht aus ästigen Füden, an deren unterer Fläche zahlreiche Blättchen mit gekerbten Rändern haften.

1) Jedes dieser Quästchen besteht aus zahlreichen Fäden von ungleicher Länge. Die beiden inittleren Kiemenbogen der Froscblarven tragell eine doppelte Reihe solcher Quäste; der vorderste Bogen besitzt eine einfache Reihe derselben und am vierten Bogen sind sie nur rudimentär.

2) Es erhält sich bei Amphiuma und Menopoma jederséits ein Kiemenloclı zwischen den beirlen hinteren Kiemenbogen. Auch bei einer jungen Coecilia ty. pocyanea hat Müller an jeder Seite des Halses ein wit der Mundböhle communicirendes Kiemenloch angetroffen, in welchen schwarze Franzen enthalten waren, die aber nicht hervorragten. Bei jungen Menopomen fand Mayer an Ende der drei ersten Kiemenbogen Zotten, als Leberbleibsel äusserer Kiemen (Analecterr I. S. 94.).

3) Proteus, Siren, Siredon, Menobranchus; Proteus lrat jederseits zwei, Siren drei und der Axolotl vier Kiemenspalten. 


\section{Achter Abschnitt.}

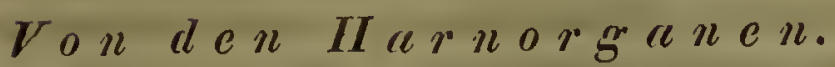

§. 106.

Die Nieren der nackten Reptilien liegen ausserhalb des Bauchfelles in hinteren Theile der Rumpflöhle, meist bis zu deren Ende sich erstreckend. Ihr Unfang ist je nach den Gattungen sehr verschie den 1) und eben so grosse Verschiedenheiten bietet ihre äussere Gestalt dar. Sie sind mehr oder minder lang gestreckt, bald bandförmig ${ }^{2}$ ), bald spindelförmig ${ }^{3}$ ), bald oblong; meist mit ihren inneren Rändern einander beruihrend, selten an ihren hinteren Enden in eine Masse zusamnenfliessend 4 ); bisweilen an den Rändern eingeschnitten oder gelappt. - Bei den Ophidiern sind die grossen Nieren durch eine Verlängerung des Bauchfelles an die Wirbclsäule geheftet, haben eine mehr oder minder längliche Form und stellen platte, deprinirte Yassen dar. Sie bestehen hier gewöhnlich aus zahlreichen rundlichen oder queren, durch Zellgewebe zusammenhangenden und durch den an ihrer convexeren Innenseite verlaufenden Harnleiter verbundenen Lappen. Nur selten besitzen die compacteren Nieren seichtere Querfurchen ${ }^{5}$ ). Sehr allgenein liegt die längere rechte Niere bedeutend weiter nach vorn, als die linke; das hintere Ende der Nieren findet sich mehr oder minder entfernt vom After. - Bei den Sauriern liegen sie, sehr weit nach hinten geriuckt und bis zum After reichend, in der Beckengegend. Beide Nieren sind bisweilen 6 ), wenigstens in ihrer hinteren Hälfte, dicht an einander gedrängt und fast verschmolzen. Sic sind meist länglich und bandförmig; bisweilen vorn dicker und hinten verschmälert, wie bei Varanus, oder dick und compact, wie bei Iguana. Meistens bestehen sie aus ziemlich zahlrẹichen, durch quere Einschnitte oder Furchen getrennten Lilppen. - Bei den Crocodilen sind sie oblong, vorn stumpf, in der Mitte verbreitert, hinten verschmälert. Die Lappenbildung ist nicht durchdringend und überhaupt, je nach der Artverschiedenheit, mehr oder minder deutlich. - Bei den Cheloniern bilden sie compactere, dickere, mehr rundliche Massen mit oberflächlichen hirnartigen

1) Acusserst klein beim Axoloti; abgebildet bei Mïller l. c. Tah. XII. Fig. 1h.; leträclıtlich bei den Salanandern, wo sie sich fast durclı die Hälfte der Rumpflıöhle erstrecken; viel voluminöser, obschon kürzes; bei den ungesclıwänz. ten Batrachicrn. - 2) Bei Coecilia, Proteus.

3) 7. B. bei Triton, Salamandra; bei beiden zugleiclı lang mul schmal.

4) Z. B. bei Proteus.

5) Z. B. bei Acrochordus. Auch bei Hydrophis bilden die Nieren kurze compactere Massen und sind ungefälır ven gleiclıer Länge.

6) L. B. bei mehren Arten von Lacerti, Iguana. 
Windungen und schwächercn oder stärkeren Einschnitten. Sie liegen im hintersten Tlieile der Rumpfliöhle. - Was den feineren Bau der Nieren anbetriff, so bestehen sie selten i) aus gestreckten, meist aus vielfach gewundenen Harncanälchen ${ }^{8}$ ). Diese unverzweigten, gestreck. ten und fast parallel verlaufenden Canälchen treten bei den ungeschwänzten Reptilien allmälich einzeln in den scitlich von der Niere licgenden Harnleiter ein. Bei den Ophidiern sammeln sich die stark gewundenen Harncanälchen biischelförmig in einen jedem einzelnen Nierenlappen zukommenden Ast des Harnleiters 9). Bei den Cheloniern und Crocodilen 10) erstreckt sich ein Ast des Ilarnleiters ticf in die Substanz eines jeden Nierenlappens und in ilın senken sich von der Oberfläche aus nach innen ctwas convergirend die Harncanälchen, wic in eine gcmeinsame Axe, successive ein. - Die einzelncn Harncanälchen bcsitzen eine derbere Turica propria, welche inwendig von einer Epithelialschicht ausgekleidet ist. Bei den Fröschen findet sich innerhalb eines klcinen Abschnittes der Harncanälchen ein lebhaft schwingendes Flinmcrepithelium "1). Die Malpighi'schen Körperchen (Gcfässknäuel) sind immer vorhanden und namentlich bei delı nackten Reptilien durch ihre Grössc ausgezeichnet. Die Länge der Ilarnleiter richtet sich nach der Entfernung der Nieren von der Cloake und nach der Länge der Nieren selbst. Sie sind daher bei den Ophidiern verhältnissmässig am längsten. Sie münden gewöhnlich, bald von den Ausführungsgängen der inneren Geschlechtstheile getrennt, bald mit ihnen vereinigt, in die Cloake. Bei cinigen Ophidicrn und bei den Varanen erwcitert sich jeder Harnleiter vor scinem Eintrittc in die letztere ziem. lich bedeutend.

Eine Harnblase, welche in die vordere Wand der Cloake mündet, kömmt allen nackten Reptilien 12) und unter den beschuppten den Sauriern und Chcloniern zu ${ }^{13}$ ). Sie ist bei den ineisten nackten Reptilien, so wie bei den Sauriern sehr dünnwandig und gefässreich, be-

7) Beim Arolotl nach Müller, Tab. XlI. Fig. 14. Achnlich bei den Em. bryonen anderer Reptilien.

8) Sie sind bei Protells durch ihre Grösse ausgezeichnet. S. Müller l. c.

9) Ahgebildet bei Mülller Tab. XII. Fig. 16. - 10) Abbild. bei Müller Tab. XII. Fig. 18.

11) S. hierïber die sehr schönen Abbildungen bei Bow man. - Die Malpighi'sclen Köpperchen kommen in den Nieren aller Reptilien vor. Bei Schlangen-Embryonen liegen sie anfangs in einfaclıer Reihe oberflächlich längs des Innenrandes der Nieren. Siehe Rathke l. c. p. 158.

12) Beobachtet bei Coecilia, Proteus, Siren, Siredon, Menobranchus, Am. pliuma, Menopoma, den Salamandrinen und den ungeschwänzten Batrachiern. lhre Mündung ist meistens sehr weit.

13) Z. B. bei Acontias, Anguis, Pseudopus, Seps, Scincus, Lygosoma, Chamaeleo, Gecko, Iguana, Draco, Stellio, Lacerta u. A.; auch bei Ainphisbaena und Chirotes nach Müller. 


\section{Neunter Abschn. Von den besond. Absonderungs - Organen etc. 237}

sitzt dagcgen bei Pipa und namentich bci vielen Cheloniern dickere Wandungen. Niemals münden die IIarnleiter in sie direct ein, höchstens inseriren sie sich, wie dies nannentlich bei den Schildkröten der Fall ist, an der Uebergangsstelle des Blasenhalses in die Cloake. Die Blase selbst enthält häufig, wenigstens bei Fröschen und Schildkröten, eine wässerige, klare Flüssigkeit und kann, wenn sie von dieser erfült und ausgedehnt ist, einen beträchtlichen Raum in der Bauchliöhle einnehmen. Ihre Form ist verschieden; bald ist sie rundlich oder oblong, und dabei einfach, bald in zwei seitliche, nicht immer symmetrische Abtheilungen mehr oder minder tiel gespatten ${ }^{14}$ ).

[Ueber die Harnwerkzenge der Amphibien vgl. Fink, De amphibiornun sy. stemate uropoëtico, Hal. 1817; s. auch Davy in Philos. transact., 1818, und Meekel's deutsches Arehiv 6. 345. - Einzelne Bemerkungen bei Müller in Tiedemann u. Treviranus Zeitschr. Bd. IV. - Ueber den feineren Bau der Nieren: Husehke in 0 ken's Isis 1828, p. 565 ff.; Müller, De struct. glandul, p. 86. Tab. XII.; Bowm an in Philos. transact. 1832, P. 1. 13. 57 sqq.; aneh in den Aum. d. sc. nat, 1843, 'T. 19. - Ueber die Entwiekelungsgesehiehte der Nieren: Rathke, Entwickelungsgesch. der Natter, Königsb. 1839, 4. - Gute Abbildungen der Nieren von Emys europaea bei Bojanus, Anatome testudinis, Tab. 28. Fig. 158. und Tab. 30. Fig. 186.]

\section{Neunter Abschnitt.}

\section{Von den besonderen Absonderungs - Organen ') und den Gefüssdrïsen.}

\section{Voin Giftapparate.}

\$. 107.

Das Gift, wodurch viele Ophidier schädlich werden, wird von einer eigenthümlichen Drüse secernirt. Diese Giftdrüse liegt gewöhnlich hinter und zum Theil noch unter dem Auge, über deın Oberkiefer und dem Os transversum. Sie verlängert sich nur bei Nija rhombeata ausserordentlich weit nach hinten, so dass sie die Rippen und deren Muskeln zum Theil noch bedeckt 2). Sie besitzt gewöhnlich eine bald einfache, bald doppelte fibröse Scheide, in welche beständig Muskel

14) Man vgl. über dies Gebilde auch noch Robert Townson, Observatio. nes physiologicae de Amphibiis, P. 1. u. 2., Gött. 1794. 1795, 4. e. fig.

1) Ueber die auf der äusseren Hautoberfläche, die in the Cloake mündenden, so wie über die zu den Gesehlechtstheilen in Bezichung stehenden Absonderungsorgane vgl. die entspreehenden $\$ \S$.

2) Naeh Reiuhardt (Isis 1843, S. 220.) und Rapl 1. c. Tab. 2. Fig. 7. Sie erstreckt sich bandförmig an der Rumpfseite der Schlange nach hiıten, wirl 
bündel eingehen, und kann theils durch diese, theils durch den sie bedeckenden $\boldsymbol{M}$. temporalis zusammengedrückt werden. Ist eine doppelte fibröse Scheide vorbanden, wie bei Trigonocephalus, so erstrecken sich, von der inneren aus, überall fibröse Lamellon in die eigentliche Drüse hinein und dann umbüllt diese Scheide auch den Ausfithrungsgang. Dieser Ausfuhrungsgang, in den die verschieden sich verhaltenden Drüsenröhren und Drïsenzellen ${ }^{3}$ ) sich sammeln, stellt meist einen cylindrischen Canal dar, erweitert sich jedoch bisweilen sackförmig, ehe er, wieder verengt, in den Giftzahn cinmündet 4). Der Giftzahn selbst zeichnet sich immer durch scine Länge vor den anderen Zähnen aus, gleich welchen er übrigens in einer häutigen Scheide steckt. Er haftet stets durch Anchylose am Oberkieferbeine. Bei den eigentlich sogenannten Giftschlangen ${ }^{5}$ ) ist er der einzige in dem hier selır kurzen Oberkieferbeine haftende Zahn; bei den giftigen Colubriformes ${ }^{6}$ ), so wie auch bei den Wasserschlangen, deren Oberkieferbein nach hinten sich verlängert, finden sich hinter dem Giftzahne, welcher der vorderste ist, noch mehre undurchbohrte Zähne. Bei den eigentlichen Giftschlangen enthält der Giftzahn einen mit zwei Oeffnungen verschenen und sonst allseitig geschlossenen Canal. Eingang und Ausgang desselben befinden sich an seiner convexen Seite und der Ausgang liegt in der Nähe sei. ner Spitze. Eine feine Rinne oder Naht erstreckt sich äusserlich längs der Convexität dieses Zahnes. Bei den giftigen Colubriformes ist er an der Wurzel und in der Nähe seiner Spitze mit je einer weiteren Oeffnung versehen, zwischen welchen Oeffnungen ein aussen gespaltener Längscanal verläuft. Ersetzt und erneuet wird der Giftzalın immer durch das Vorrucken eines der hinter ihm liegenden, in der Schleimhaut oder im Zahnfleische entstandenen Ersatzzähne.

[Man vergl, über den Giftapparat der Ophidier: Meckel in seinem Arehiv 1826, S. 1., mit Abbild. Tab. I. - Sehlegel, Nov. Act. Acad. Leop. Carol., T. XIV. P. 1. 1. 143., mit trefflichen Abbild. Tab. XVI. - H. O. Lenz, Schlangenkunde, Gotha 1832, 8. - J. J. B ä chtold (praes. W. v. Rapp), Untersuchungen über die Giftwerkzeuge Jer Schlangen, Tüb. 1843, 4., mit Abbild.]

\section{Von den Gefüssdrüsen.}

\section{§. 108.}

Bei den meisten Reptilien kommen in der Nähe des Herzens und der grösseren Gefässstämme drüsige, gefässreiche, eines Ausführungsganges ermangelnde Gebilde vor, in welchen man Analoga der Thymus

von einem ihr innig anhaftenden Muskel belleckt und besitzt einen röhrigen Bau. - Am wenigsten entwickelt ist die Giftlrüse bei Hydrophis.

3) S. über den rerschieden sich verhaltenden feineren Bau besonders Mül. ler, De gland. secern. struet, p. 54 sqq. T'ab. VI.

4) Bei Crotalus. S. die Abbild. bei Schlegel I. c. Fig. IX.

5) Trigonocephalus, Crotalus, Vipera. - 6) Elaps, Bungarus, Naja. 


\section{Neunter Abschn. Von den besond. Absonderungs - Organen etc. 239}

und der Sehilddrüse zu finden glaubl. Dahin gehören bei den ungeschwänzten Batrachiern zwei kleine Gehilde in der Ungebung der Aortenbogen 1) und weiter nach vorn die sogenannten Carotidendrüsen 2); bei den Ophirliern eine runde gelappte Drüse vor dem Ilerzen, unter den grossen Gefässstämmen und zwei längliche ähnliche Gebilde neben den Jugularvenen; bei den Cheloniern und Crocodilen ein vor der Luftröhre, zwischen den grossen Gefässstämmen gelegenes, bei den Seesehildkröten hesonders ausgebildetes und umfängliches, gelapptes und sehr gefiissreiches Organ ${ }^{3}$ ); bei denselben Thieren kleinere Gebilde in der Umgehung der Ilalsgefässe.

\section{Von den Nebennieren.}

§. 109.

Nebennieren scheinen den meisten und vielleicht allen Reptilien zuzukommen, nur bei den Perennibranehiaten, den Derotremata und den Cöcilien sind sie bisher nicht aufgefunden worden. Bei den Salamandrinen bestehen sie aus kleinen zerstreuten goldgelben Körnerhäufchen an der unteren Fläche der Nieren ${ }^{1}$ ). Bei den ungeschwänzten Batrachiern stellen sie mehre grössere, ebendaselbst liegende Streifen oder Bogen dar, welche besonders den Wandungen der Nierenvenen dicht anliegen 2). Bei den Ophidiern erscheinen sie als enge, schmale, gelbe Körperchen, welche neben den Stämmen der Vence renales revehentes oder neben der Aorta liegen. Bei den Sauriern liegen sie seitlich an Vas de. ferens und bei den Cheloniern am Innenrande der Nieren 3).

1) Abgebildet bei Mayer, Analecten Heft 1. Tab. 3. Fig. \&.

2) Abgebillet bei Inseble in Tiedemann und Treviranus Zeitschrift, Bd. IV.

3) Abbild. bei Bojanus Tab. XVI. Fig. 66., 'Tab. XXVII. Fig. I56., Tab. XXIX. Fig. 173. - Ueber analoge Gebilde bei Knorpelfischen rg\}. \$. 37. Anın. 2.

1) Hier sind sic längst von Rathke beschrieben und gedeutet worden.

2) Es sind Swaminerdam's Corpora heterogenea; von Rathke, vicl später von Retzius, Nagel, Gruby als Nebennieren angesprochen. Abgebildet bei Gruby, Anu. d. sc. nat., T. 17. 1842. Tab. 10. fig. 8. 9. - Vgl. Nagel in Müller's Archiv 1836, S. 37t.

3) Bnjanus Tab. XXX. Fig. 186.p. - Ueber die Entwickelungsgeschichte dieser Organe rgl. Rathke, Entwickelungsgesch. der Natter, S. 158. 


\section{Zelinter Abschnitt.}

\section{Vom Geschlechts-Appratate.}

\section{Von den weiblichen Geschlechtstheilen.}

§. 110.

Bei allen Reptilien sind die Ovarien von den Eileitern ge trennt, so dass nie ein ununterbrochencr Zusammenhang zwischen beiden Statt findet. Die Eicrstöcke aller nackten Reptilien bestehen in verschieden gestalteten weit ausgedehnten hohlen Säckcn, welche durch ein mittleres, aus Bauchfellplatten gebildetcs Mesoarium befestigt sind. Indem diese beiden Bauchfclllamellen am Rande des Eierstockes auseinander wcichen und ihn umhüllen, bilden sie seine äussere Ilaut. Beide Eierstöcke licgen zur Scite der Wirbelsäulc und nchmen, je nach der Reife der Eier, einen mehr oder minder beträchtlichen Raum ein. Einwärts von ihnen erstrecken sich die beträchtlichen Fettkörper. Die: Ovarien sind in der Regel symmetrisch und von gleicher Länge. Bei den geschwänzten Gattungen entstehen die Eier an der Innenwand der ungetheilten Höhlc, welchc sie durch cine an dem vorderen Ende des Eierstockes bcfindliche Oeffnung verlassen. Diese Oeffnung sieht man im Frühlinge ziemlich weil und bei den Salamandern durch ein spitz zulaufendes Röhrchen, bei den Tritonen durch einen schmalen Ring in die Höhlc des Ovarium sich fortsetzen. Bei den ungeschwänzten Batrachicrn besteht jeder Eierstock in einer grösseren Anzahl von transversellen Zellen, welche durclı vollständige Scheidewände von einander getrennt werden und dercn jede, vom äusseren Rande des Ovarium aus, nach innen sich werschmälert. Jede Zelle besitzt ihre eigene Oeffnung. In dic freie Höble dieser Zcllen fallen die an der Eierstockswand gereiften Eier nach ihrer Ablösung und verlassen sie durch die erwähnten Oeffnungen.

Die Eileiter 1) bestehen in langen, darmartig vielfach gewundenen Röhren, wclche durch Peritoneallamellen gekrösartig bcfestigt sind. An seinem freien Ostium abrluminale, das hoch aufwärts, meist zwischen Herzbeutel und Leber liegt, bildet jeder Eilciter eincn häutigen Trichter. Die Eileiter sind, mit Ausnahme ihres vordersten Abschnittcs, dickwandig und muskulös und pflegen sich gewöhnlich hinten etwas zu erweitern. Sie münden in die Rückwand der Cloake, bald dicht neben einander, bald weiter aus einander gcrückt. Ihrc Mündungen sind durch ein klappenartiges Würzchen verschliessbar oder bilden kurzc röhrenförmigc Verlängcrungen in die Cloakc, wie z. B. heim Axolotl.

1) Abbild. von Menobranchus bei Carus und 0 tto, Erläuterungstaf. Heft V. Tab. 6. Fig. 1. 
Bci dcr weiblichen Pipa sind noch äussere Ausbildungsor: gane vorhanden. Die Eier werden dem Wcibchen vom Männchen auf den Rücken gestrichen und dann bilden sich auf der Rückenhaut Zellen, in dencn die ferncre Entwickelung der Eier geschicht.

\section{§. 111.}

Die Ovaricn der Sauricr und Ophidier sind Schläuche, welche innere Vorspriinge besitzen und an deren Wand die Eier entstehcn, während sie bci den Cheloniern und Crocodilen Platten darstellen, auf deren Bauchscitc die Eier sich entwickeln. Sie liegen gewöhnlich oberhalb der Nieren, befestigt an Peritonealduplicaturen. Während sie sonst symmetrisch sind, ist bei den Ophidiern der rechte Eierstock grösser und licgt weiter nach vorn, als der linke. An die Ovarien sind die auswärts von ihnen gelegenen Eileitcr durch Bauchfellverdoppelungen befestigt. Die Eileiter, wclche gewöhnlich weit nach vorn sich erstrccken, liegen mit ihrem vorderen Ende bogenförmig vor oder ijber den Ovarien. Ihr Ostium abdominale ist immer trichterförmig erweitert und oft gefranzt. Sie erstrecken sich als mehr oder minder weite, muskulöse Röhren, bald ziemlich geradc, bald vielfach gewunden verlaufend, hinterwärts zur Cloake. Der grösste Theil ihrer Innenwand besitzt Längsfaltcn. Sie münden gewöhnlich mit zwei getrcnnten Ostia in die hintere Wand der Cloake; bei den Cheloniern 1) in den Hals der Harnblase. Bei vielen Sauriern und Ophidiern erweitern sie sich etwas vor ihrer Mündung; bei einigen Schlangen ist der blindgeschlossene, an der Dorsalseite des Rectum bedeutend vorwärts verlängerte und erwciterte grösste Abschnitt der Cloake, in den die beiden Eileiter münden, einem Uterus zu vergleichen 2 .

Die Begattungsorgane der weiblichen Sauricr und Ophidier sind, ganz nach dem Typus der männlichen gebildet, doppelt vorhanden; in der Regel sind die beiden eingestuilpten Clitorides kürzer, als die Penes. Bei den weiblichen Ophidiern kommen auch die im folgenden $\S$. zu bc. schreibenden accessorischen schlauchförmigen, mit weissern Smegma angefüllten Secretionsorgane vor. - Die weiblichen Crocodile und Schildkröten besitzen eine einfache, an der Vorderwand der Cloake be. festigte Clitoris.

\section{Von den münnlichen Geschlechtstheilen.}

\section{§. 112.}

Dic Hoden der nackten Reptilien besitzen einen röhrigen Bau I) und liegen innerhalb des hinteren Abschnittes der Bauchhöhlo.

1) S. die Abbild. bei Bojanus Tab. 30. Fig. 188. - 2) So bei Coluber Korros; vgl. §. 114. Anın. 2.

1) Siehe $S$ w a mulucrda in, Bibl. natur, Leyd. 1738, T. 2. p. 794. Tab. XLVII. fig. 1.; copirt bei Müllcr, De gland. secern. struct., Tab. XV. fig. 9. 
Sic werden befestigt durch eine Duplicalur des Bauchfelles, deren Platten auseinander weichen, um ihre äussere Bekleidung zu bilden. Sie sind bei den Perennibranchiaten und Derotremen platt, einfach und langgestreckt; bei den Salamandrinen zerfallt jeder Hode in zwei oder mehre hinter einander liegende Abtheilungen ${ }^{2}$ ), welche durch feine Canäle mit einander in Zusammenhang zu stehen scheinen. Bei den ungeschwänzten Batrachiern sind die IIoden einfach und ungetheilt. - Die Snamenleiter sind cỵlindrische geschlängelte Canälchen, welche, mehr oder minder weit, vor oder uber den Iloden, anscheinend blind geschlossen, beginnen, an dem äusseren Rande der Nieren zur Cloake absteigen und durch ein Bauchfolligament befestigl werden. Die Snamenleiter besitzen häufig nicht iberall gleiche Weite, sind vichmehr meist vorn enger, hinten weiter, verengen sich iber dann wieder kurz vor ihrem-Eintritte in die Cloake. In diese Saanenleiter scheint der Saame durch feine Quergefiisse zu trelen. Ausserdem aber mündet in das hintere Ende jedes Samenleiters bei den Salamandrinen und beim Axolotl ein Bündel zienlich langer, am Ende blind geschlossener Röhren, welche auch, obschon viel kürzer, bei den ungeschwänzten Batrachiern vorkommen ${ }^{3}$ ). Sie verlaufen zwischen den Bauchfelllamellen vom Aussenrande der Nieren aus abwärts. Begattungsorgane, welche dem Penis verglichen werden könnten, sind bei der Mehrzahl der nackten Reptilien nicht vorhanden ${ }^{4}$; bei den Tritonen und Salamandern jedoch findet sich innerhalb der Cloake, besonders deutlich während der Begaltungszeit erkennbar, eine einfache penisartige Papille ${ }^{5}$, welche aber undurchbohrt ist.

Bei den männlichen Individuen von Protcus, Siredon, Menopoma, Menobranchus und den Salamandrinen münden noch zahlreiche einfache Drüsenschläuche in die Cloake. Es sind dies dic Becken- und Af. tersen, welche, namentlich bei den Tritonen, vorzugsweise um dic Begaltungszeit entwịckelt sind \%).

2) Dies Zerfallen in eine grössere oder geringere Anzahl ron Abtheilungen ist nicht constant, sondern individuel weehselnd, wie die Beobaehtungen von Rathke, Funk, Finger lehren.

3) Diese den Saamenbläschen verglichenen Gefässe, welche Rathlie zuerst beschrieben hat, sind abgelildet leẹi Mü̈llẹr: De glaud. strustt., Tab. II. fig. 16. u. 17. und beschrieben 1). 45 .

4) Das angebliche Vorkommen eines doppelten Penis bei Coesilia beruhet, wie Bisehoff (Müller's Archiv 1839, S. 354.) aus einander gesetzt hat, auf eineıI Irrthume, wovon ich jetzt durch eigene Untersuchung mich überzeugt habe.

5) Bei den Tritonen von Ratlıe, bei den Salamandern ron Carus be. schrieben; abgebildet und sehr genau beschrieben bei Finger l. c.

6) Sie sind der Prostata oder den Cowper'schen Drïsen zu vergloichen und von Rathke, Mayer u. A. beschrieben worlen. - Interessante Erscheinungen sind die Ausbildung des Rückenkannes des Triton niger zur Begattungszeit, welcher später fast spurlos verschwindet, und die um dieselbe Zeit Statt 
[Man vgl. über dio Geschlechtstbeile der nackten Reptilien besonders Rathke in den Schriften der naturf. Geselisschaft zu Danzig, Th. 1. 1820. - Ueber die der Tritonen: J.H. Finger, De Tritonum genitalibus eorumque functione, Marb. 1841, 4., c. fig.]

\section{§. 113.}

Die Iloden der beschuppten Reptilien erhalten eine ähnliche Umkleidung und Befefestigung vom Bauchfelle, wie die der nackten. Sie liegen immer über oder yor den Nieren. Bei den Ophidiern sind sic, gleieh diesen letzteren, unsymmetriseh gelagert und meist auch von ungleieher Långe. Ihre äussere Gestalt ist wechsclnd; bald sind sie sehr länglich, platt, vorn zugespitzt, wie bei den meisten Ophidiern, bald mchr oval, wie bei den Crocodilen, einigen Sauriern und Chclonicrn. Unter dem Bauchfelluberzuge liegt ihre Tunica propria, welche naeh innen feine Septa abschiekt, die die Saamengefässe von einander sondern. Die Röhren, aus welchen der secernirende Apparat besteht, liegen bei den Ophidiern quer und sind ziemlich gestreckt, während sie bei den Cheloniern gewunden erseheinen. Sie sammeln sieh bei den Ophidiern in einen am inneren Rande des Hodens gelegenen, diesem letzteren innig verbundenen Nebenhoden. Auch bci den Cheloniern vereinigen sie sieh zu einer geringeren Anzahl von Stämmen, welche seitlich in den Sa amenleiter übergehen. Dieser letztere scheint an seinem oberen oder vorderen Ende, das häufig weit iber die vordere Grenze des Hodens hinaus sieh erstreckt, blind geschlossen zu sein und verläuft als ein ziemlich enger Canal, bisweilen stark gewunden, an der Vorderfläehe der Nicre abwärts zur Cloake. Bei den Ophidiern verengt er sich am Ende und mündet mit einer feinen Papille in das äusserste Ende des Harnleiters seiner Seite. Die so vereinigten Harn - und Saamenleiter jeder Seite senken sich dann dicht neben einander in die hintere Wand der Cloakc, welche an der Mündungsstelle häufig eine starke Papille besitzt. Bei den Sauriern tritt der Saamenleiter seitwärts unmittelbar in die Cloake. Bei den Cheloniern und Grocodilen münden die Saamenleiter in den Anfang der Rinne der Ruthe.

Bei den Cheloniern senkt sich in jeden Saamenlciter vor seinem Eintritte in die Cloake ein vielfach gewundener Canal, der den Saa. menbläschen verglichen worden ist.

Hinsichtlich der eigentlichen Begattungsorgane finden in so ferne wesentliche Verschiedenheiten Statt, als die Ophidier und Saurier zwei Ruthen besitzen, wclche ausserhalb der Cloake liegen, während den Cheloniern und Crocodilen ein einfaeher, an der Vorderwand der Cloake befestigter Penis zukömmt. Bei den Ophidiern und Sauriern

findende Anschwellung des Daumens vieler inännlichen Frösche, welche selbst eine eigene Daumendrüse besitzen. 
besteht jede Ruthe in einer von der Cloake ausgehenden und mit ihr zusammenhangenden, schlauchartigen Einstiulpung der Haut, welche, nach hinten gerichtet, und von den oberflächlichen Muskelschichten des Schwanzes bedeckt, in jeder Seite des letzteren den zwischen den Querfortsätzen und den unteren Dornfortsätzen der Wirbel gelegenen Raum ausfiullt. IVird diese schlauchförmige Einstülpung von aussen nach innen untersucht, so bietet sie folgende Zusammenselzung dar: 1) Auswärts ruhet sie in einer sie locker umgebenden aponeurotischen Scheide, welche sie scharf von den oberflächlichen Muskeln der Schwanzgegend trennt. An den vorderen, der Cloake zunäichst liegenden, Theil dieser Scheide inserirt sich ein ziemlich langer, an die Basis der Processus spinosi inferiores befestigter Muskel, der sic abzuziehen vermag. 2) Nach Entfernung dieser Scheide kommen im vorderen Theile der Einstuilpung fibröse Häule zu Tage, welche ein cavernöses Gewebe zwischen sich schliessen, das die innere Haut scheidenförmig umgibt. Es hangt dies cavernöse Gewebe zusammen mit weitmaschigeren Venennetzen, welche an reichlichsten seitlich und vor der Cloakalmuindung des Ruthencanales angetroffen werden. Diese vorderen Venennetze beider Ruthen stehen durch einen starken venösen Quersinus, der in del vorderen Afterlefze verläuft, mit einander in Verbindung. Vordere Muskeln, welche ron der Seitenwand des Beckens oder des Rumpfes blos an die, das cavernöse Gewebe unschliessende fibröse Haut treten, vermögen diese sammt der inneren Haut vorzuziehen. 3) Der hintere Theil der Einstulpung, in welchem das cavernöse Gewebe schwächer ist, wird von Längsfascikeln eines Muskels trichterö̈rmig umfasst, der endlich an die untere Seitenllïche der Wirbelsäule sich inserirt. Er zieht den ausgestülpten Penis zurück. Die Innenwand des Schlauches - dessen Länge sehr bedeutenden Verschiedenheiten unterliegt - ist eine schleimhautartige Einstülpung der äusseren Haut, welche hinten blindgeschlossen endet. Ihre Epithelialschicht ist dick und sie ist inwendig, namentlich bei den Ophidiern, in der Regel mit dichtstehenden Stacheln oder mit Häkchen eine Strecke weit ausgekleidet. Eine canalförmige Vertiefung, welche als unmittelbare Fortsetzung einer ähnlichen von der Mündungsstelle des Saamenleiters in die Cloake durch diese letztere sich erstrekkenden Rinne erscheint, verläuft in dem vorderen Theile dieser Einsackung. Durch die Wirkung der vorderen Muskeln und die Turgescenz der Corpora cavernosa wird diese innere Haut theilweise oder ganz ausgestiilpt und erscheint dann als äusserer Penis. Ihre innere canalförmige Vertiefung wird dann zu einer äusseren Rinne und dient zum Abflusse des Saamens 1).

1) Jeder Penis der Schlangen ist oft wieder gabelförmig getheilt, wo denn die Rinne sich gleichfalls theilt. So bei Crotalus, Vipera, Python. Auch ron 0 tto abgebildet bei Scytale, J. c. Fig. 4. 
Bei den Ophidiern findet sich unter jeder Rutheneinstülpung noch ein ziemlich weiter Schlauch, dessen äussere Wand gleichfalls durch Muskelbiindel an die Vorderseite der ersten Schwanzwirbel befestigt ist. Dieser Schlauch, dessen äussere Mündung auswärts von dem Eingange in die Rutheneinstulpung sich findet, ist ein accessorisches Secretionsorgan, in welchem meist eine weisse, fettige Masse angetroffen wird 2 ).

Die Chelonier und Crocodile besitzen an der Vorderwand der Cloake einen einfaclien, gekrümmten, vorne mit einer, cavernöses Gewebe enthaltenden, Eichel versehenen Penis. Dieser ist nicht durchbolırt, sondern blos mit einer zum Abflusse des Saamens dienenden Rinne versehen, welche mit cavernösem Gewebe ausgekleidet ist. Die Grundlage der Ruthe bilden, sehnige Fasern enthaltende, fibröse Körper ${ }^{3}$ ).

Von besonderem Interesse sind die Peritonealcanäle 1$)$. Bei den Cheloniern erstreckt sich eine canalförmige Fortsetzung oder Ausstiilpung des Bauchfelles in den Penis bis gegen die Eichel hin, wo sie blind endigt. Bei den Crocodilen verlängert sich das Bauchfell jederseits trichterförmig vor und neben der Cloake und geht so in zwei kurze Canäle über, deren jeder seitlich an der. Wurzel des Penis (oder der Clitoris) nach aussen sich öffnet. Diese Oeffnung ist durch eine kleine häutige Klappe verschliessbar.

[Man vgl. über die inännlichen Geschlechtstheile der beschuppten Reptilien: Bojanus l. c. p. 168. Tab. XXX. fig. 184-187. - Treviranus in Tiede. mann u. Treviranus, Zeitschr. f. Phys., Bd. 2. Tab. XIII. -0 t to in Carus u. Otto, Erläuterungstaf. Heft V. Tab. VI. - Schlegel, Phys. d. serp., p. 45. - Müller, Ueber zwei verschied. Typen in dem Bau der erectilen männl. Geschlechts-Organe u. s. w. Aus d. Schriften der Berl. Acarl. d. Wissensch., 1838. - Otto schreibt (l. c. Fig. 6.) den Sauriern Nebenhoden zu; ich habe mich bisher auch bei Varanus nicht iiberzeugen können, dass das von ihı dargestellte

2) Die hier beschriebene Einrichtung fand ich bei mehren Coluber-Arten, z. B. Coluber variabilis, C. Korros u. A.; nach Schlegel sollen diese Aftertaschen bei einigen Schlangen in die Cloake mïnden.

3) Die genaueren Angaben über den Bau des Penis s. bei Müller l. c。 p. 28. u. 29.

4) Der Erste, welcher dieser Peritonealcanäle Erwähnung gethan bat, ist Plunier. Siehe Schneider, Histor. amphib., II. p. 102. Sie sind später von Isidor e Geoffroy und Martin beschrieben worden. Siehe Ann. d. sc. nat., Xill. p. 153. und Heusinger's Zeitschrift für organ. Phys., Th. 2. S. 439. Cuvier, Leçons, éd. Duvernoy p. 430. - Die Angabe, wonach diese Peritonealcanäle bei den Cheloniern frei und offen nach aussen münden, beruhet, wie schon Mayer (Analecten S. 44.) und MüHer (l. c.) auseinandergesetzt, sicherlich auf einem Irrthume. Bei zwei männlichen Crocodilen (weibliche frisch $\mathbf{2 u}$ untersuchen fehlte die Gelegenheit) finde ich jedoch, gleich den früheren Beobachtern, zu denen noch 0 we $n$ hinzuköinmt ( $s$. Proceedings of the committee of science and correspondence of the zoological society of London, P. 1. 1841. p. 141.), die oben erwähnten offenen Mündungen auf das deutlichste. 
goldgelbe Gebilde mit den Hoden und Saamenleiter in Verbindung steht. Ich vermuthe eine Verwechselung mit ilen Nebennieren.]

\section{Von der Cloake.}

\section{§. 114}

Mit dem Namen der Clo ake wird die unmittelbar vor dem After befindliche und in diesen ausgehende Höhle belegt, welche die Miindungen des Afterdarmes, der Harnleiter, der Harnblase, so wie der Ausführungsgänge der inneren Geschlechtstheile aufnimmt. In sie öffnen sich häufig noch accessorische Drüsen, welche, bald nur bei einem Geschlechte vor handen, zu den Sexualfunctionen in Beziehung stehen, bald grössere secernirende Blasen oder Schläuche, welche bei beiden Geschlechtern vorkommen. Bei den Cheloniern und Crocodilen sind Clitoris oder Penis an ihrer Vorderwand befestigt, während die Begattungsorgane der Saurier und Ophidier und die, beiden Geschlechtern der letzteren zukommenden, Analsäcke zwar ausserhalb ihrer Höhle liegen, aber doch mit ihr in Verbindung stehen. - Gestalt und Länge der Cloake verhalten sich sebr verschieden. Sie ist kegelförmig und über dem Afterdarme verlängert bei den Tritonen; bei den Cöcilien 1), dem Axolotl und den ungeschrvänz. ten Batrachiern ist sie eine, fast nur durch abweichende Diunension und Texturverhältnisse ausgezeichnete Verlängerung des Afterdarmes, in deren Bauchwand mit weiter Oeffnung die Harnblase, in deren Riickwand die Eileiter und Harnleiter münden. - Bei den Ophidiern und Sauriern erscheint sie als eine ibber der Insertion des Afterdarmes hinaus verlängerte und hier blind geschlossene, ausserhalb des Bauchfelles gelegene Höhle, die bei einigen weiblichen Ophidiern ungeheuer gross und weit, einem Uterus ähnlich, an ihrem blinden Ende die beiden Eileiter aufnimmt 2). Bei Iguana ist sie an ihrem blinden. Ende in zwei Säcke gespalten, in welche die erweiterten Eileiter und die Harnleiter münden. Eine Längsfalte scheidet sie, der Spaltung zunächst, in

1) Ich fand sie bei Coecilia annulata sehr lang; ihre innere Haut bildete starke Längsfalten.

2) Diese merkwürdige Bildung traf ich bei Coluber Korros Reinw, an. Dic Cloake bildet einen 4 Zoll langen, sehr weiten, dickwandigen, fast $3 \frac{1}{2}$ Zoll hinter der Mastlarmöffnung verlängerten, mit dickem Epithelium ausgekleideten Blindsack. An seinem äusseren Ende nimmt er jedlerseits einen, mit kreisrunder, etwas wulstig in seine Höhle vortretender Oeffnung mündenden Eileiter auf. An dem zwischen beiden 0stia der Eileiter liegenden Theile des Blindsackes verlängert sich dieser zweihörnig noch sehr wenig vorwärts. Zwischen der Insertion der Eileiter und der auf einer gemeinsamen starken, harnröhrenartigen Papille erfolgenden Insertion der beiden am Ende stark erweiterten Harnleiter findet sich ein Zwischenraum von fast $3 \frac{1}{2}$ Zoll, da diese Papille der Mastdarmöffnung gerade gegenüber liegt. Von der Harnröhre aus erstreckt sich eine Lüngsscheiderrand fast bis zum Ausgange der Cloake, wo sie siclr verliert. Zwei Clitorides, zwei weite, mit Smegma gefüllte Drüsenschläuche unter ihnen. 
2.wei seitliche Irïlften. Bei den Ophidiern (Python) muinden Harnleiter und Samenleiter jeder Seite verbunden in eine Papille, welche, an der Riickseite befindlich, dein an der Bauchseite gelegenen Ostium des Afterdarmes gegeniiber sich findet und die Iölıle der Cloake zerfiullt durch cine von der genannten Papille absteigende Lïngsfalte in zwei seitliche Abtheilungen. Bei den Clieloniern, wo der Afterdarm wieder in die Riickseite des iunsseren Absclinitles der langen Cloake tritt, münden die Ilarnleiter getrennt von den Saamenleiterm; jene inseriren sich neben dem IIalse der IIarnblase. Bci den Crocodilen erscheint die gleichfalls lange Cloake wieder als unmittelbare Fortsetzung der Hölle des Rectum, das, durch abweichende Tevturverhältnisse seiner Itiute ausgezeichnet und durch eine bisweilen etwas spirale, meist kreisrunde Klappe geschiitzt, in sie iubergeht. Tiefer inseriren sich an der Rückwand die Harnleiter oberhalb cincl Klappe, welche die Cloake in zwei Abtheilungen sondert. - In die vordere Wand der Cloake miindet bei allen nackten Reptilien, so wie bei den Sauriern und Cheloniern, die Harnblase. Seitwärts öffnen sich in sie die, einigen Familien der Chelonier eigenthümlichen, beiden Geschlechtern zukommenden, beträchtlichen Bursae anales ${ }^{3}$ ). Aehnliche kleincre Driisenschläuche münden bei den Crocodilen kurz vor der Afterspalte. Die Cloake besitzt eigene Muskeln; bestänclig wenigstens cinen Sphincter.

[Die Cloake der Tritonen ist näher beschrieben von Rathke und Finger; die der Chelonier abgebildet bei Bojanus Tab. XXVI. u. XXVIII.]

3) Von Bojanus bei Enys entileckt; nach Duvernoy auch bei Chelydra serpentina und lacertina vorhanien; ebenso, nur kleiner bei Cistudo Carolinae. Abgehildet bei Bojanus Tab. XXVII. 156. $15 \%$. 


\section{Drittes Buch.}

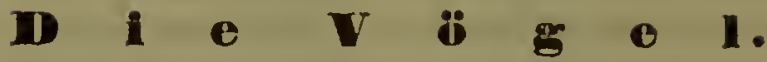

\section{L i t e r a t u r.}

'Tiedemann, Anatomie und Naturgeschichte der Vögel. Landsh. 1810-1814. 8. Licfert die ältere Literatur sehr vollständig.

Naumann, Naturgeschichte der Vögel Deutschlands. Leipzig 1822-1844. 8. Mit vortrcfflichen anatomischen Bemerkungen von $\mathrm{Nitzsch}$, so wie in den letzten Bänden auch von R. Wagncr.

Todd's Cyclopaedia of Anatomy and Physiology. London 1836. 8. Vol. 1. Artikel "Aves" von 0 wen, p. 265-35S. Mit eingedruckten Holzschnitten.

J. F. Meckel's Anatomie des indischen Casuars in seinem Archiv für Anatomie u. Physiologie, Bd. V. VI. 1825 u. 1820.

Owcn's Anatomie des Apteryx australis in Transactions of the zoological so. ciety of Louldon. Vol. 2. p. $25 \%$ sqq. Mit Abbild.

H. Barkow, Anatomisch-physiologische Untersuchungen, rorzüglich über das Sthlagalcr-Systein der Vögel. Leipzig 1830. 8. (Aus J. F. Meckel's Ar. chiv f. Anat. u. Physiol. 1829 u. 1830 besondlers abgedruckt. Enthält ausgezcichnctc Untcrsuchungen über das Gefässsystem, dic Geschlechtsthcile und andere Organe der Vögel.

Iconographische Darstellungen der Skelete der Struthionen und Raubvögel : E. d'A l . ton, Die Skelete der straussartigen Vögel. Bunn 1827. fol. und d'Alton (Vatcr und Sohn), Die Skelete der Raubvögel. Bonn 1838. fol.

Reichhaltige osteologischc Bemerkungen bei Nitzsch: Osteographische Beiträge zur Naturgeschichte der Vögel. Halle 1811. 8.

Ueber Entwickclungsgeschichtc der Vögel: Carl Ernst von Baer, Ueber Ent. wickelungsgeschichte der Thierc. 1stcr Thl. Königsb. 1828. 4. 2ter Thl. Königsb. 1837. 4. 


\section{Erster Absclınitt.}

\section{Vom Knochongerüste.}

\section{§. 115.}

Eine auffallende Eigenthümlichkeit einer melır oder minder beträchtlichen Anzahl von Knochen des Vogelskeletes ist ihre Pneumaticität d. h. die Anwesenheit markloser Diploë oder markloser Röhren und die durch Oeffnungen bewirkte Communication der zelligen Diploë und der hollen Röhren mit Luft aufnehmenden Gebilden. Die Luft dringt in die Schedelknochen auf zwei Wegen: von der Tula Eustachii und von den Nasenhöhlen aus; in die Knochen des Rumpfes und der Extremitäten gelangt sie besonders durch die den Vögeln eigenthümlichen mittelst weiter Oeffnungen mit den Bronchien an den Lungenoberfächen communicirenden Luftsäcke oder Luftzellen, welche den grössten Theil der Eingeweidehöhle einnehmen und meist noch über dieselbe hinaus sich erstrecken 1). - Die Pneumaticität der Knochen entwickelt sich erst nach dem Auskriechen der Vögel aus dem Eie allmälich unter Statt habender Resorption des ursprünglich vorhandenen Markes und unter Auflockerung der Zellen der Diploë. - Sie kömmt den Vögeln allgemein, ohne irgend eine bekannte Ausnahme zu, ist aber keinesweges bei allen Ordnungen und Gattungen gleich vollständig. Eben so wenig sind alle Knochen gleich häufig, einzelne vielmehr nur höchst selten luftruihrend.

[Man rgl. über diesen Gegenstand besonders Nitzsch in seinen osteog. Beiträgen; ferner dessen Aufsatz über die Pneunaticität des Kalao in J. Meckel's Archiv 1826, Thl. 1. S. 61S. und $0 \mathrm{wen}, \mathrm{On}$ the anatomy of the concave Horn. bill, Buceros cavatus in len Transact. of the zoolog. society of London, Vol. 1. p. 117. Bei Apteryx, bei vielen kleinen Singvögeln, bei inehren Fulicarien, $C_{0}$. lyıbus, Sterna, Rallus sind nur Theile des knöchernen Kopfes luftführend; bei Buceros dagegen fanden Nitzsch und 0 wen, mit Ausschluss aller andern sonst luftüührenden Knochen, nicht nur den Schedel, die Halswirbel, die letzten Schwanzwirbel, das Becken, sondern auch alle Knochen der Extremitäten, mit Einschluss der Phalangen der Finger und Zehen pneumatisch. Aehnliche Verhältnisse sind nur noch bei Palamedea angetroffen. Unter den einheimischen Vögeln besitzen die Störche, die Pelicane und Tölpel die grösste Ausbreitung der Pneumaticität. - Es gibt nur wenige kleine diinne Knochen des Kopfes, wie namentlich die Joch. heine, welche niemals pneminatisch gefunden sind. Nächst dem Schedel ist der Humerus am häufigsten luftführend; sehr viel seltener das Oberschenkelbein.]

1) Bei dẹn Pelicanen z. B., wie 0 wen mit Recht bemerkt, bis zu den Enden des Oberschenkels und der Flügel. 


\section{Von der Wirbelsäile und den Rippen.}

§. 116.

Die Wirbel1) zerfallen in IIals-, Rüken-, Kreuzbein- und Steisswirbel; eigentliche Lendenwirbel sind gewöhnlich nicht zu unterscheirlen, da häufig schon die letzten rippentragenden Wirhel, immer aber die unmittelbar auf sie folgenden mit den lliiftbeinen fest verbunden oder verwachsen sind. - Allgemeine Eigenthiimlichkeiten der Wirbelsíule ler Vögel sind Lünge des Malses und grosse Freibeweglichkeit seiner Wirbel in beschränkter Richtung, sehr verminderte Beweglichkeit odler völlige Unbeweglichkeit der in geringer Anzahl vorhandenen Rückenwirbel, vollständige Verschmelzung einer betriichtlichen Zahl von breiten Kreuzbeinwirbeh und endlich freiere Beweglichkeit der Schwanzwirbel. - Die Länge des IIalses ist grossen Verschiedenheiten unterworfen; sie wird nicht blos durch Verlïngerung der einzelnen, in constantem Zahlenverhiiltnisse sich erhaltenden Wirbel bedingt, wie dies bei den Sïugethieren Regel ist; vielmehr besitzen dic langhalsigen Vögel zugleich eine grössere Anzahl von Wirbseln 2\% Vor den übrigen Halswirbeln sind die beiden ersten ${ }^{3}$ ) durch einige Eigenthitmlichkeiten ausgezeichnet. Der Allas ist ein schmaler, ringförmiger Knochen, der ursprïnglich aus einem einfachen, die tief ausgehöhlte, den Condylus occipitalis aufuehmende Gelenkgrube fast ganz bildenden Körper und parigen oberen Bogenschenkeln besteht. Oberhalb der Gelenkgrube finclet sich ein schmaler Ring, durch den die Spitze des Processus odontoüdens des hreiteren Epistropheus durchtritt. Dieser Zahnfortsatz des zweiten Halswirbels ist beim jungen Vogel ein getrenntes Knochenstiick. - Die Körper aller Halswirbel besitzen einen hinteren, sehr flach convexen, jederseits seicht ausgeschweiften Gelenkkopf, dessen unterer Rand am meisten hinterwärts vorspringt; ihm entspricht eine an der Vorderseite der Wirbelkörper und selhst an Vordertheile ihrer unteren Fläche befindliche, oft durch die abwärts gebogenen Querfortsätze seitlich vervollstïndigte Concavität. - Der hintere stark: ausgeschnittene Rand des oberen Wirbelbogens beribrt den vorderen

1) Sümmutliche Wirbel können pneumatisch sein; die Oeffnungen liegetı gewöhnlich seitlich an den Wurzeln der Querfortsätze oder am Körper; seltener, wie bei manchen Raubrögeln und Enten, an den Dornen.

2) Die Zahl der Halswirbel beläuft sich z. B. bei Strix, bei Alcedo auf 11; bei den meisten Singrögeln, Picariae und Tauben anf 12; bei den Möven, Sturn. vögehn, Hühnern auf 13 ; bei Upupa, den T'rappen, manchen Enten auf 14; bein Storch und Ibis auf 15; beim Pelican und Casuar auf 16; bei Grus, Sula, Carbo auf 17; bein Flaningo auf 18 ; bei den Schwänen auf 23 bis $24 .-A m$ schmal. sten und längsten sind die Halswirbel bei Phoenicopterus und Ardea; an kürzesten bei Alca, Aptenodytes.

3) Ein isolirt dastehendes Beispiel von Verschmelzung derselben liefert, nach Nitzsch, Buceros erythorbynchus. 
Rand des nächst folgenden oberen Wirbelbogens mcistens nicht unmittelbar, vielmehr bleibt zwischen den oberen Bogen zwcier auf einander folgender Halswirbel gerwöhnlich - und besonders an den tieferen Halswirbcln - eine oft beträchtliche Lücke. Von den Seiten des hinteren Theiles jedes obcren Bogens erstrecken sich hintere Gelenkfortsätze zum näclist hinteren Wirbel, dessen vordere Gelenkfortsätze durch sie gedeckt werden. Die Gelenkflächen der hinteren Gelenkfortsätze sind sehr flach conrex; die der vorderen sehr seicht concav. - Als Processus transversi sind die absteigenden Theile der vorderen Gelenkfortsätze zu betrachten. Greht man von den mit deutlichen Querfortsätzen versehenen Rückenwirbeln aus und verfolgt jene nach vorn, so erkennt man, dass sie rm so mehr verkümmern und mit den vorderen. Gelenkfortsätzen verschmelzen, je mehr man dem vorderen Theile des Halses sich nähert. Diese abortiven Querfortsätze der Halswirbel enden aber auswärts nicht frei, sondern zwischen jeden derselben und den Rand seines Wirbelkörpers schicht sich cin eigenes - sehr häufig griffelförmig nach hinten verlängertes - Knochenstiick, welches also - ganz rippenähnlich - durch den, dem Capitulum entsprechenden Rand mit dem Wirbelkörper und durch den, dem Tuberculum analogen Rand mit dem Querfortsatze verbunden ist. Hierron ubberzeugt man sich leicht bei Untersuchung junger Vögel, wo die abortive Rippe ein eigenes Knochenstiick bildet. Indem aber dies Rippenrudiment sehr bald mit seinen beiden Ansatzpunkten verwächst, cntsteht auf jedcr Seite des Wirbels, in Gestalt cines IIöckers oder einer Längsleistc, eine mehr oder weniger slarke Vorragung, welche durch ein Loch oder einen Canal von dem Scitentheile des Wirbels getrennt bleibt 4 ). - Mehre der mittleren Halswirbel besitzen.noch darin eine Eigenthümlichkeit, dass von ihren Querfortsätzen aus ein Fortsatz nach der vorderen oder unteren Fläche der Wirbelkörper sich umbicgt, wodurch ein zur Aufnahme der Carotiden bestimmter Halbcanal oder Canal entsteht. - Die Processus spinosi superiores kommen häufig, mehr oder minder stark entwickclt, an den vordersten Halswirbeln (mit Ausschluss des Atlas), weniger ausgebildet an einigen der hintersten vor, fehlen den mittleren aber gewöhnlich ganz. - Unpaare untere Dornfortsätze, deren jeder nur von einem einzigen Wirbelkörper ausgeht, kommen gleichfalls nur an den vordersten und an den hintersten Halswirbeln vor. - Die Rückenwirbel machen, der Zahl 5) nach, selten mehr als ein Viertheil

4) Diese an den Halswirbeln entstandenen Foramina entsprechen genau den an den Rückenwirheln gleiclıfalls vorhandenen, die hier theils durch Capitulum und 'Tuberculum der Rippen, theils durch den Wirbelkörper und den Raerfortsatz. hegrenzt werden. - Der durch die einzelnen, auf cinander folgenden Foramina gebildete Canal der Halswirbel dient zur Umschliessung der Arteria und Vena verteliralis und des tiefen Halstheiles des Nervus sympathicus.

5) Beim Pelican finden sich nur 6 Rückenvirbel; bei den Hühnern, Störchen, 
der gesammten Wirbelsäule aus. In Vergleich mit den Halswirbeln haben sie gewöhnlich eine bedeutende Kürze. Ihre Körper sind schmal, seitlich comprimirt, verbinden sich ähnlich, wie die der Halswirbel, sind aber bisweilen völlig mit einander verwachsen \%). Die Ränder zweier auf einander folgender oberen Bogen sind dicht an einander gerúckt. Die Processus transversi sind sehr entwickelt, breit, flach, horizontal, mit ihrem freien Ende oft vorwärts und hinterwärts etwas verlängert und so oft confluircnd; an jeden Querfortsatz hcftet sich das Tubercu. lum einer Rippe. Ebenso sind dic Processus spinosi superiores in Gestalt seitlich comprimirtcr, breiter, gewöhnlich die ganze Länge der Wirbel einnehmender, meist dicht an einander gerüickter ${ }^{\overline{7}}$ ), bisweilcn sogar, der Länge nach, zu einem Kamme unter einander verwachsener Leisten sehr ausgebildet. Die Körper der vordercn - seltener fast aller - Rückenwirbel besitzen gewöhnlich einfache oder gabelförmig gespaltene Processus spinosi inferiores ${ }^{8}$, welche selten fehlen, dagegen bei fast allen Hühnern, mit einander verwachserd, zu einer langen durchbrochenen Knochenleiste sich entwickeln. Die zwci bis drei letzten Rückenwirbel sind sehr häufig mit dem Kreuzbeine verwachsen. Die Anzahl der Kreuzbeinwirbcl 9) ist immer sehr beträchtlich, lässt sich aber bei älteren Vögeln nur aus der Anzahl der Fortsätze erkcnnen. Denn die Körper dieser Wirbel, welche beim Fötus getrennt sind, verwachsen in der Regel zu einem langen Knochenkegel, der gewölınlich in seinem vorderen Segmente, unter Reduction der Querfortsätze, am breitesten, in scinem hinteren Segmente, bei Verbreiterung der Fortsätze, verschmälert ist. Der Spinalcanal der oberen Bogen wird durch eine einfache, zusammenhangende Knochenbrücke gedeckt, an der keine gesonderten Dornfortsätze entwickelt sind. Die Querfortsätze sind, namentlich in dem hinteren Abschnitte des Kreuzbeines, an ihrem Ur. sprunge mittelst zwischenliegender Oeffnungen von einander getrennt,

Tauben, Kukuken 7; bei den Eulen, Singrögeln, den Trappen, Mören, Sturmvö. geln, Connoranen 8; bei Tringa, Ardea, Grus, den Enten, Gänsen, dem Strauss 9; bei Rallus, Cygnus, einigen Colymbus, dem Casuar 10.

6) Beständig gilt dies, wenigstens von den mittleren, bei allen Hühnern; von einigen bei den Tauben, dem Pelican, bei Phoenicopterus, bei Colymbus, bei Faleo nisus.

7) Diese Charaktere fallen bei allen straussartigen Vögeln weg, indem die Dornfortsätze, minder verlängert, sich niclıt berühren. Das letztere gilt aueh von ihren Querfortsätzen. Daraus resultirt grössere Freibeweglichkeit der Wirbel. säule bei Unvermögen zum Fluge.

8) Sie sind wol an stärksten entwiekelt bei Cypselus; sehr schwach oder fehlend bei vielen langhalsigen Sumpfrügeln.

9) Am beträehtliehsten bei den Struthionen: beim Strauss 18; beim Casuar 20; bei den Möven 12; bei den Singvögeln 9 bis 13. - Bei mehren Straussen bleiben sie unverwaelisen. Bein Pinguin sind die drei vordersten nur durch Bandmasse mit den Hüftbeinen verbunden. 
in der Gegend ihrer äusseren Enden aber durch knöcherne Längs briicken mit einander verwachsen. Ausser diesen Querfortsätzen treten von dem Körperstïck des Kreuzbeines einzelne, rippenähnliche tiefere Fortsätze zum Iluftbeine. Sie stellen in Gemeinschaft mit den eigentlichen Querfortsätzen oft durchlöcherte Scheidewände dar, welche zu beiden Seiten des Kreuzbeinkegels die Regio sacro-iliaca in mehre Ilöhlen abtheilen. - Die Schwanzwirhel 10) sind beweglich unter einander verbunden. Sie besitzen gewöhnlich starke Querfortsätze, sehr schwache Gelenkfortsätze und ziemlich entwickelte obere und untere Dornen, welche letztere aber häufig fehlen. Der letzte Schwanzwirbel hat gewöhnlich eine ausgezcichnete Form, ähnelt einer Pflugschaar, ist seitlich zusammengedrickt und - namentlich bei bedeutender Ent wickelung der Stcuerfedern des Schwanzes ${ }^{11}$ ) sehr gross.

\section{§. 117.}

Unmittelbar auf die schon oben erwähnten, init den Körpern und mit den abortiven Querfortsätzen der Halswirbel vollständig verwachsenden Rippenrudimente folgen gewöhnlich einige verlängerte und unverwachsene Rippen 1), welche das Brustbein nicht erreichen. Eine oder zwei derselben plegen nur an den hier längeren Querfortsätzen der oberen Bogenschenkel zu haften, ohne immer auch durch Capitula mit den Wirbelkörpern verbunden zu sein. Den Rippen der eigentlichen Rückenwirbel, so weit diese letzteren nicht mit den Hüftbeinen verwachsen sind, kommen dagegen Verbindungen, sowol mit den Querfortsätzen als auch mit den Körpern der Wirbel zu, während die letzte oder die letzten Rippen, welche von den Ilïftbeinen an ihrem Ursprunge bedeckt werden, häufig wieder nur eine Verhindung besitzen. Die ge wöhnlich deprimirten wahren oder Brustbeinrippen stehen mit dem Sternum nicht durch Knorpel, sondern durch Knochen in Verbindung. Diese Knochen, die sogenannten Sternalrippen, Ossa ster. nocostalia ${ }^{2}$ ), welche unter mehr oder minder spitzen, ab-oder rückwärts gerichteten, von vorn nach hinten successive weiter werdenden Winkeln von ihnen abgehen, sind sowol mit ihnen, als auch mit

10) Bei den Hühnern 5 bis 6 ; bei Otis, Certhia, Upupa 6 ; bei den meisten Singrögeln, den Tauben, Störchen, Kranichen, Flaningo, Möven, Pelican, Gänsen, vielen Enten, dem Casuar 7; bei Bombycilla, Tringa, Rallıs, Sula 8; bei Cygnus, Struthio, Rhausphastos $\mathbf{9}$.

11) Z. B. bei Upupa, melı bei Certhia, noch mehr bei Picus entwickelt. Beim Toucan sind, nach 0 we $n$, die drei hintersten Schwanzwirbel unbeweglich mit einander verbunden, so dass der Sclıwanz auf den Rücken gelegt werden kann. - Bei Rhea ist lagegen der verlängerte letzte Sclıwanzwirbel kegelförmig.

1) Häıfig sind die Kippen pneumatisch, wie bei den Raubvögeln, vielen Sunpfrögeln und Schwimmvögelı, so wie bei Otis und Tetrao. Die Luftlöcher liegen gewöhnlich in der Nähe der Wirbelsänle und namentlich an Tuberculum.

2) Sie haben, wenn sie pueunatisch sind, ihre eigenen Luftlöcher, welche dicht bei ihrem Stentalende liegen. 
dem Brustbein beweglich verbunden. An scinem Brustbeinende verbreitert sich jeder Sternocostalknochen und spaltet sich in zwei kleine Gelenkköpfe. Jeder der letzteren articulirt heweglich mit einer der beiden, durch eine mittlere Längsgrube getrennten Kanten des Seitenrandes des Brustheines. Dic Sternocostalknochen nehmen successive von vorn nach hinten an Länge zu; der hinterste erreicht lisweilen das Brustbein nicht; mitunter findet sich auch hinten ein falscher Sternocostalknochen ohne entsprechende Rippe. - Eigenthümlich sind den wahren Rippen noch kleine, rückwärts und gewöhnlich aufwärts gerichtete, anfangs als getrennte Knochen vorhandcne, später mit ihnen verwachsende Fortsätze (Processus uncinati) ${ }^{3}$ ). Sie erstrecken sich etwa von der Mitte 'des Hinterrandes jeder Rippe iiber die Aussenfläche der nächstfolgenden hinteren, die sie also decken und mit der sie durch Ligamente verbunden sind. Sie verleihen der Riickenhälfte des Brustkorbes grössere Fcstigkeit.

\section{Vom Brustbeine.}

\section{§. 118 .}

Das Brustbein ist ein meistens sehr bcträchtlicher, im Ganzen vicr. eckiger, verhältnissmässig breiter, immer nach vorn oder unten convexer, nach hinten oder innen mehr oder weniger stark ausgehöhlter Knochen, welcher gewöhnlich ïber die eigentliche Brustgegend nach hinten hinausreicht. Es besitzt meistens einen mittleren, mehr oder minder stark vorspringenden Längskamm, den sogenannten Brustbeinkiel, welcher, der Länge nach verlaufend, das Brustbein aussen in zwei Scitenhälften scheidet, den bei den fliegenden Vögeln so ausserordentlich stark entwickelten $\boldsymbol{M}$. M. pectorales Ansatzflächen gewährt und dic Muskeln der beiden Seiten scheidct. Dieser Brustbeinkiel fehlt nur den straussartigen Vögeln, deren mehr oder minder schildförmiges wenig convexes Sternum überhaupt am schwächsten entwickelt ist 1). Am Vorderrande des Sternum finden sich scitlich zwei längliche Gelenkgruben zur Aufnahme der unteren Enden der Ossa coracö̈dca. Zwischen beiden erstreekt sich sehr häufig ein als Manubrium zu bezeichnender Fortsatz nach vorn. An die Seitenränder, deren jeder durch eine Längsfurche zweikantig ist, befestigen sich die den Rippenknorpeln entsprechenden Ossa sternocostalia. Zwischen dem Seitenrandc und dem vorderen Rande findet sich oft ein platter, mehr oder minder stark entwickelter, etwas vorwärts gerichteter Fortsatz (Processus costalis). -

3) Sie scheinen bei einigen Struthionen, namentliels beim indischen Casuar, nie vollständig mit den Rippen zu verwachsen. - Sind sie pneumatisch, so werden sie von den Rippen aus mit Luft gefüllt.

1) Fast noeh unvollkoinmener, als bei den bekannteren straussartigen Vö. geln, ist es bei Apteryx; ohue Kiel, mit Fontanellen und Ausschnitten. Vgl. die Abbild. von 0 wen l. c. 
Der hintere Rand ist bald abgerundet, bald hesitzt er Einschnitte von verschicdener Tiefe, welehe durch leistenförmige Verlängerungen des Knochens (die sogenannten Abdominalforlsätze) begrenzt werden. Sonst ist das Sternum bald vollständig in seiner ganzen Ausdehnung ossificirt, bald besitzt es membranös geschlossene Inseln in seinem hintersten Abschnilte.

[Eine ausführliche Ablıandlıng über das Brustbein der Vögel, mit zahl reichen Abbildungen, lıat geliefert A. A. Berthold in seinen Beiträgen zur Anatomie, Zootonie und Physiologie, Gött. 1831, \&., S. 105 sqq. - Ueber die Ossifications. geschichte des Brustbeines s. Ge offroy St. Hilaire, Plilosophie anatomique T. 1., Paris 1818, mit Abbild. und L'Herminier in den Aın. d. sc. nat. 'T. 6., 1836. - Das Brustbein zeigt bei den Vögeh Verschiedenlıeiten, welehe nit der Ausbildung ihres Flugvermögens in directer Bezichung stehen. Am meisten ent, wichelt durch Unfang, Stärke des Kammes und Solidität ist es bei Trochilus, Nectarinia, Cypselus. Hier ist es zugleich durchaus solide, ohne häntig gesehlos. sene Lïcken und Ablominalfortsätze. Diese letzteren feblen anch sonst häufig, wie bei viclen Tagraubvögeln, lei Thalassilroma, Psophia. - Bei anderen Tagraubvögeln, namentlich bei mehren Geiern und Falken, so wie bei den meisten Papageien, fchlen zwar die Abrlominalfortsätze, aber es sind häutig geschlossene Foutanellen vorlıanden. - Am häıfigsten besitzt der hintere Rand des soliden Brustbeines jellerseits einen Ausschnitt. Dieser ist sehr seicht bei Capriuulgus und Hirundo, ungeheuer tief z. B. bei Crypturus, vorn sehr zugespitzt bei Rallus. Einen Anssehnitt jederseits besitzen die Passerinen, Cuculus, die Fulicarien, Mö. ven, Phoenicopterts, Ciconia, Ibis, Pelieanus, Haliaeus, Nitzseh's Dermorhynchi und Pygopoden. - Eine Fontanelle und einen Ausschnitt besitzen z. B. Columba, V'anellus (sonst ist bei Colımba und Pterocles der Kamm besonders stark). Jerlerseits zwei Ausselnitte besitzen die meisten Eulen, sehr viele Picariac, die meisten Sclmepfen und Hühner; bei letzteren ist der imnere Aussclnitt an stïrk. sten. Bisweilen sind diese Einsehnitte ungeheuer tief, so dass der grösste Theil des Brıstbeinkörpers nur durch einen sehnalen línochenstreifen repräsentirt wird. - Sehr schmal ist das ganze Sternum bei Rallus und den Fulicarien. - Bei Cu. culus und Caprimulgns ist ler hinterste Theil des Stemum anffallend stark ab. wärts gcneigt. - Häıfig ist das Brustbein pmeumatisch. Die Luft dringt in dasselhe ein durch mehre Löcher, welche an seiner inneren Fläche, hinter dem vorderen Rande und in der Mittellinie liegen. Andere Luftlöcher finden sich, obschon uninder beständig; an den Seitenrändern.]

\section{II. Vom Schulter - und Beckengeriiste.}

§. 119.

Das Schultergerüst der meisten Vögel besteht urspriinglich jederseits aus drei Hauptknochen: der Scrpula, dem Os coracoüldeum und der Clavicula. Indem aber die Claviculac beider Sciten meistens init ihren unteren, vor dem Brustbeine gelegenen Enden unter einander verwachsen, bilden sie gewöhnlich cinen initteren einfachen, gabelförmigen Knochen, dic sogenannte Furcula. Zu den genannten Knochen 
kömmt bäufig noch ein klciner accessorischer Knochen: das sogenannte Nebenschulterblatt (Os linumero-scapulare s. Scapula accessoria).

Die Scapula ") ist gewöhnlich ein schmaler, säbellörmiger, vorn dikkerer, hinten flacherer, hier bisweilen verbrciterter oder erweiterter ${ }^{2}$, länglichcr, an der Rückenseite der Rippen, parallel der Wirbelsäule gele. gener, fast bis zum Becken nach hinten sich erstreckender Knochen. Durch sein vorderes dickeres Ende ist er nach innen mit der Clavicula, nach aussen mit dem Os coracö̈leum vcrbunden. Dịes bildet in Gemeinschaft mit der Scapula die Gclenkgrube für den Oberarm.

Das Os corrcoidleum ${ }^{3}$ ), der beträchtlichste unter den Knochen der Schulter, ist länglich, gcrade, steigt vom vorderen Ende der Scapula und vom oberen der Clavicula abwärts zum Brustbeinc, an dessen vorderen Rand es, verbreitert, sich befestigt, mit dem der anderen Seite mehr oder minder stark convergirend 4 ).

Jedc Clavicula ${ }^{5}$ ) ist oben sowol mit der Scapula, als mit dem Os coracoüdeum verbunden. Sie ist gewöhnlich nach vorn oder nach aussen convex. Abwärts steigend convergircn dic beiden Claviculae in der Regel und verschmelzen vor dem Vorderrande des Brustbeines zu einem v-förmigen Knochen (Furcula), der oft, wie z. B. bci den Singvögeln und allen Hühnern, in einen unteren unpaaren Fortsatz ${ }^{6}$ ) ausgeht. Das untere Ende der Furcula liegt bald frei, bald ist sie an die Spitze des Brustbcinkieles oder mit dem Manubrium mittelst eines Bandes oder einer Knorpclbaut befestigt, oder selbst danit verwachsen 7 ). - Die Stärke der Gabel und ihre Convexität bietcn, der Entwickelung des Flugvermögens parallcl gehende Verschiedenheiten dar 8). Selten sind die beiden Claviculac unten nur knorpelig ${ }^{9}$ ) oder blciben unvereinigt, oder fchlen ganz.

1) Wenn sie pneumatisch ist, liegen die Oeffnıngen der Luftlöcher gewöhn. lich in der Nähe des vorderen Endes. - 2) Z. B. bei Tetrao.

3) Er ist unter sämmtlichen Schulterknochen am bäufigsten pnemmatisch. Die Oeffnungen liegen gewöhnlich am oberen Ende; seltener unten am Brustbeinende, wie bei Ḧ̈hnern, Spechten, Grus.

4) Am stärksten ist die Convergenz wol bei den Tagraulvögeln.

5) Die pneumatischen Oeffnıngen liegen gewöhnlich mebrfach an der äusse. ren Seite der Knochen.

6) Er fehlt den Tauben. Bei Ardea steigt vom Vereinigungswinkel beiler Schenkel ein länglicher kleiner Fortsatz aufwärts.

7) Verwachsen oder lurch Kuorpel verhunden mit der Crista des Brustbeines z. B. bei Tantalus, Ciconia, Ardea, Grus, Pelecanus, Haliens, Colymbus.

8) Die Furcula ist am stärksten und am meisten convex bei den Tagraub. vögeln; schwach bei den Hühnern, Enten, Tauchern, Pinguinen, Psittacinen, Bu. ceros u. s. w.

9) Sie bleiben unten knorpelig bei Strix ulula nach Meckel; bei Strix flamulea sah sie Nitzsch constant in ein seitliches linochenpaar zerfallen; ebenso Meckel bei Buceros nasutus (während 0 wen bei 3 . cavatus sie verbunder fand); ich bei meliren Rhamphastos spec. dub.; vielen Papageien fehlt die Fur. 
Die Ossa la umeroscapularia ${ }^{10}$ ) sind kleine dreieckige, nur einzelnen Ordnungen eigenthiimliche, nach aussen vom vorderen oder oberen Gelenkfortsatze der Scapula und über dem Kopfe des Humerus liegende, das Oberarmgelenk vervollständigende Knochen.

[Die Sehulter der Struthionen zeigt sieh dadureh eigenthümlich, dass die drei Elemente des Schultergerüstes jeder Seite mit einander zu einem einzigen Kno. ehen versclmelzen und dass die Claviculae bei Apteryx, beim indischen Casuar und bei Rhea americana kiuın, bei Struthio eamelus und beim neuholländischen Casuar dagegen sehr bestimmt als starke, vorzüglich bei letzteren convergirende - wellu anch unvereinigt bleibende - Fortsätze angedentet sind. Beim neulıol. ländischen Casuar bleiben die das Brnstbein nieht erreichenden Claviculae wälırend der grössten Zeit des Lebens eigene Knoeben, während das Os coracö̈deum frïhzeitig mit der Scapula verwächst. Beim jnngen africanischen Strauss finde ieh Seapula und 0 s coracoüdeum als getrennte Knochenstïcke;-die nach innen vor dem Os coracoüıleum gelegene Clavieula, welche von jeneın später nur dureh eine Oeffnung theilweise getrennt bleibt (s. d'Alton Tab. VII. fig. g.), ist noeh ganz ligamentös, ohne Spur von V'erhmöclierung und erstreckt sich zum Brustbeine. Vgl, die Abbild. bei d'Alton, Skelete d. straussart. Vögel, Tab. VI. fig. f. und i., 'Tab. VII. fig. d. und g. Vgl. aueh de Fremery, Speeimen zool. sistens observ. de Casuar. Nov. Holland., Traject. ad Rhen. 1819, 8., und über Apteryx: 0wen l. c. Tab. ว̌วั. fig. 2. u. 4.]

\section{§. 120 .}

Das Becken der Vögel ist im Allgemeinen dadurch ausgezeichnet, dass es unten offen ist, indem die entsprechenden Knochen beider Seiten unvereinigt bleiben. Es ist dies eine Regel, von welcher nur der afrikanische Strauss 1) eine Ausnahme macht. - Jede Seitenhälfte des

enla gänzliclı; so, naclı Vigors in Taylor's Plillos. Mlagaz. 1831, No. 51. p. 232., bei Ps. mitratus, eximins und galgulus; nach Nitzseh (System der Pterylographie S. 145.) bei allen Platyeerci und bei Ps. pullarius; ich vermisste sie ausserdem auch bei Psittacula passerina. S. auch Kuhlmann, De absentia furculae in Psittac. pullario, Kil. $1841,8$.

10) Vgl. über diese Ḱnoehen Nitzsch, 0steog. Beitr. S. 83. Sie sind vorhanden bei den Tagraubvögeln, bei den Eulen, delı Passerinen, den Speehten. Sehr stark entwickelt z. B. bei Lanius. Sie fehlen z. B. bei Cuculus, Coracias, den Papageien, den Hühnern, Sumpf-, Schwimmvögeln und Straussen.

1) Ueberhaupt zeigt das Beeken der Struthionen manehe Eigenthümliehteiten; es ist verhältnissmässig lang, aber sehmal, und erstreekt sich über das ganze Kreuzbein, ein vollständiges Dach über demselben bildend. - Beim afrikanisehen Strauss entsteht nun dadureh, dass die beiden convergirenden und etwas vorwärts gewendeten Schaambeine mit einander sich verbinden und vorn in eine schild. artige Knorpelplatte übergehen, eine Sehaambeinfuge oder ein geschlossenes Bek. ken. d'Alton hemerkte jederseits noclı einen kleinen, länglichen, platten Kinoclien, der an die ähnliehen Knochen der Salimander und Bentelthierc erinnert. Bei Rhea americana nähern und vereinigen sich die beiden Sitzbeine dicht unterhalb des Kreuzbeines in einer langen Streeke, so dass das Krenzbein von den Beckenknochen völlig ungürtet wirl. Bei den übrigen Strutbionen werden diese unter den Vögeln isolirt dastehenden Bildungen gänzlich vermisst. Vgl. die Ab. 
Beckens wird aus drei Knochen gebildet, welche sämmtlich zur Einschliessung der eines festen Bodens ermangelnden, also in nen offenen Pfanne für den Kopf des Femur beitragen.

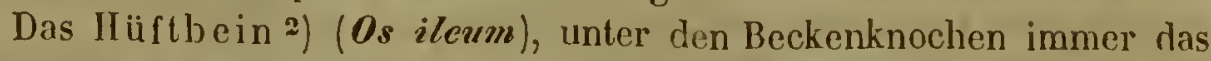
bei weitem beträchtlichere, ist breit, durch seinen Innenrand bald grossentheils, bald ganz mit den letzten Rückenwirbeln und dem Kreuzbeine verwachsen. Vorn bedeckt es meistens die Querfortsütze der Wirbel oder stösst mit dem gleichnamigen Knochen der entgegengesetzten Seite an oder über den mit beiden verschmolzenen Dornfortsätzen zusammen; hinten befestigt es sich gewöhnlich nur an den Aussenrändern der unter einander brückenförmig verbundenen Querfortsätze. Es zerfällt selır allgemein in zwei Abschnitte, von denen der vordere oberflächlich concav, der hintere aussen convex und inwendig sehr ausgehöhlt ist.

Das Sitzbein ( $\mathrm{s}_{\mathrm{s}}$ iscliii), viel unbeträchtlicher, als das Hüftbein, steigt von der Pfanne aus nach hinten, bildet sofort die äussere Begrenzung eines Hüftbeinloches, das von innen durch das $O_{s}$ ileum begrenzt wird und legt sich darauf verbreitert unter einem Winkel an diesen letzteren Knochen an, mit welchem es gewöhnlich rollständig verwächst.

Das $\mathrm{Schaambein}\left(O_{s}\right.$ mulis) ist ein dünner rippenförmiger, bisweilen nach hinten verbreiterter Knochen, der von der Pfanne aus, dem Sitzbeine fast parallel, nach hinten steigt und dasselbe hier iiberragt. Es begrenzt in Gemeinschaft mit dem Sitzbeine das kleine, dicht hinter der Pfanne gelegene Foramen obturatorium. Darauf legt es sich mehr oder minder dicht an das Sitzbein an. - Die Schaambeinenden beider Seiten convergiren oft ziemlich bedeutend und nähern sich da durch stark.

\section{Von den Kuochen iler Extremitäten.}

§. 121.

Die Knochen der Vorderextremitäten zerfallen bei den Vögeln allgemein in fünf Abtheilungen von verschiedener Länge. Der Oberarm ist bald kürzer, bald länger als der Vorderarm, bald ungefähr von gleicher Länge mit ihm. Die Handwurzel ist immer sehr kurz. Die Hand

bildungen bei d'Alton, Skelete d. straussart. Vögel, Tab. VII. fig. h. k. i. I. und hei 0 wen, Transact. of the zool. soc., Vol. 2. Tab. 54. u. 55. von Apteryx. Beim Pinguin ist das Hüftbein schmal, schulterblattähulich, vor der Grelenkhöhle verlängert, hinter derselben verkürzt. Die vier ersten, obschon verschmolzenen Kreuzbeinwirbel liegen frei und hangen mit dem über die Rippen etwas verlällgerten Hüftbeine nur durch Bandmasse schwach zusammen.

2) Es ist häufig pneumatisch. Die Luftöffnungen liegen gewöhnlich an dem Innenrande, den Wirbeln zugekehrt. Auch die übrigen Beckenknochen sind bisweilen lufthaltig durch Oeffnungen, welche in der Nähe der Pfanno liegen. 
- mit Einschluss des beträchtlichen Metacarpus - ist im Allgemeinen um so länger, je schneller der Flug der Vögel ist 1).

Der II merus ${ }^{2}$ ) ermangelt eines rundlichen Kopfes, ist vielmehr mit einer länglichen sehr wenig abgesetzten Gelenkfläche versehen. Sein oberes Ende ist sehr allgemein verbreitert und mit zwei Leisten: einer vorderen und einer hinteren, versehen ${ }^{3}$ ). An seinem unteren Ende besitzt er zwei durch eine Vertiefung getrennte Gelenkerhabenheiten und ein Paar Knorren 4). An seinem Ulnarrande kömmt häufig eine kleine patellaartige Verknöcherung vor 5 ).

Die Vorderarmgegend wird immer durch zwei Knochen: den vorderen, schwächeren Radius und die hintere, viel stärkere, bisweilen, wie bei den Tauben und Hühnern, durch eine starke Kriimmung vom Radius sich entfernende Ulna gebildet, welche letztere gewöhnlich ein Olecranon besitzt. Am unteren Ende des Radius kömmt häufig ein kleiner länglicher accessorischer Knochen vor, über welchen die Sehne des Flughautspanners weggeht 6 ).

Die sehr kurze Handwurzel wird aus zwei Knochen gebildet ${ }^{7}$ ), der eine liegt vorn, ist vorzugsweise an der Gelenkfläche des Radius eingelenkt und nimmt den grössten Theil des Gelenkes des Metacarpus auf; der zweite, gewöhnlich stärkere und hintere liegt in der Buge zwischen Ulna und Metacarpus.

Die beträchtliche Mittelhand besteht immer aus zwei länglichen, neben einander liegenden, an ihren beiden Enden verwachsenen, in der Mitte durch eine, meist einfache, längliche Luicke getrennten Knochen, von denen der dem Radius durch seine Lage entsprechende den zweiten an Dicke und Länge stets überırifft. Am Ende des Metacarpus liegt oft ein accessorisches Knöchelchen. Ein hoch oben an der Radialseite des Metacarpus befindlicher Vorsprung trägt den Daumen, der, mehr oder minder lang, bald aus einem einzigen, bald aus zwei Phalangen.

1) Am längsten ist sie bei Trochilus und Cypselus. Länger als der Vorder. arm aueh z. B. bei den Tauben.

2) Er ist sehr häufig pmeunatiseh. Die Oeffnungen liegen sehr constant am oberen Ende unterhalb der vorderen Leiste.

3) Mit starken Fortsätzen versehen und sehr kurz bei Cyjpelus (Nitzsch, 0steog. Beitr. Tab. 2. Fig. g.).

4) Bei den Sclnepfen und Möven, Puffinus, Sula einen starken Seitenfortsatz zum Ursprunge des Extensor melacarpi longus.

5) In der Regel bei len Passerinen; von Cypselus abgebildet bei Nitzsch, Osteog. Beitr. Tab. II. Fig. g. l.

6) Bei den Passerinen, den Sturmvögeln, den Eulen; bei letzteren durch Heusinger sehr genau beschrieben und abgeb. Meckel's Archiv 1822, B. VII. S. 179. Zavei an der Handwurzel vieler Vögel vorkommende Sesambeinclien bezeichnet $\mathrm{Nitzseh}$ als Epicarpium und Hypocarpiam.

7) Bei $\Lambda$ pteryx, nach 0 wen, aus einem Knochen; sie ist beim neuholländ. Casuar vorhanden; Meckel fant sie an der einen Seite aus einem Knoehen, an der anderen aus zwei bestehend; ich finde überall nur einen. 
besteht ${ }^{3}$ ). - Der zweite Finger ist unten an dem grössten Theile des Endes des Metacarpus befestigt. Er ist immer am längsten und besteht gewöhnlich aus zwei, seltener aus drei Gliedern. Das erste ist gewöhnlich breit, flach, solide, an seinem Vorderıande dicker, als am hinteren; das zweite ist nach unten zugespitzt und kürzer; noch mehr gilt beides von dem dritten, sobald es überhaupt vorhanden ist. - Der dritte Finger ist gewöhnlich klein. Er sitzt auf dem Ulnartheile des Metacarpus, liegt meist dicht an dem zweiten Finger und besteht aus einem einzigen Gliede ${ }^{9}$ ).

\section{§. 122.}

Die Knochen der Hinterextremitäten der Vögel sind: ein Oberschenkelbein, eine Kniescheibe, die 'Tibia und Fibula, ein, je nach der Zahl der Zehen, einfach oder zweifach vorhandenes Os metatarsi, und die Phalangen der Zehen. - Fusswurzelknochen fehlen fast immer ${ }^{1}$ ).

Das Oberschenkelbein 2) ist ein starker, cylindrischer, gewöhnlich schwach vorwärts gebogener Knochen, der beständig von der 'Tibia an Länge übertroffen wird 3 ). Sein kleiner hemisphärischer Gelenkkopf geht unter rechtem Winkel von ihm ab; eine Grube am oberen Theile desselben ist zur Aufnahme des Ligamentum teres ijestimmt. Sein Trochanter ist einfach, stark, nach aussen und vorn gelegen. An seinem unteren Ende besitzt er zwei, vorn durch eine Vertiefung getrennte Condyli; der innere, schwächere entspricht ausschliesslich der Tibia; der äussere, stärkere besonders ihr, zugleich aber auch der Fibula.

Die Kniescheibe liegt gewöhnlich als eine einfache Ossification vorn in der zwischen den beiden Condyli des Femur befindlichen Vertiefing 4 ).

Der Unterschenkel wird fast ausschliesslich durch die lange und starke Tibia gebildet, indem die nie ganz fehlende Fibula nur als ein

8) Vgl. darüber die Bemerkungen ron Nitzscb, 0steog. Beitr. S. 89.

9) Die stärkste Verküınınerung der Finger köınıt vor bei Apteryx u. beim indischen Casuar, die nur den mittleren Finger besitzen, der bei ersterem aus einer einzigen Phalange besteht. Der Daunen ist sehr lang bei vielen Schwimm. vögeln: Pelecanus, Uria, Alca, Colymbus, Diomerlea, Procellaria; kürzer bei den Schwalıen, Raubvögeln, Klettervögelı und Ḧ̈hnern; noch kürzer bei den meisten Passerinen und Sumpfögeln; ganz rudimentär bei Aptenodytes, bei dem da. gegen der dritte Finger durch seine Länge ausgezeiclnet ist.

1) Nur bei Apteryx kommt, nach 0 wen, ein kleiner Fusswurzelknochen ror.

2) Es ist häufig pnemuatisch, loch seltener als der Humerıs. Die Oeffnung liegt gewöhnlich vorn beim Trochanter; selten hinten, wie beim Strauss, bei Oriolus und einigen anderen.

3) Bisweilen ist er in Vergleich zum Unterschentel sehr kurz, wie bei $\mathrm{Hy}$. psibates, Phoenicopterus.

4) Die Kniescheibe ist doppelt beim zweizehigen Strausse und scheint nur einigen Colymbus.Arten mit sebr starkem Tibialfortsatze zu fellen. Vgl. Wag. ner in Heusinger's Zeitschr. Bd. 1. S. 587. 
schwacher, griffelförmiger, an der Aussenseite der Tibia, eine Strecke weit von ihr durch eine Lücke getrennter, dann sich an sie anlegender, nie bis zum Metatarsus reichender Knochen erscheint. Die Tibia ist oben am dicksten und bildet hier gewöhnlich zwei bis drei leistenartige Vorsprünge, die bei einigen Schwimmvögeln, namentlich den Colymbi, zu einem sehr hohen Fortsatze sich erheben. An ihrem unteren Ende besitzt sie zwei durch eine Vertiefung getrennte Gelenkköpfe (Rolle). Die die letzteren trennende Vertiefung wird gewöhnlich durch eine knöcherne Querbrücke theilweise überwölbt, unter welcher die Sehne des langen gerneinschaftlichen Zehenstreckers verläuft.

Die Mittelfussgegend wird gewöhnlich aus zwei Knochen: einem Hauptknochen und einem kleinen blos für den Daumen bestimmten Nebenknochen gebildet. Der Hauptknochen ${ }^{5}$ ) schliesst sich unmittelbar an die Tibia an, ist länglich, von verschiedener Dicke ${ }^{6}$ ), immer fast gerade und an seinen beiden Enden angeschwollen. An seinem oberen Ende besitzt er zwei, durch einen mittleren Vorsprung getrennte Gelenkflächen, von denen die äussere in einen hinteren und äusseren Höcker sich fortzusetzen pflegt. An seinem unteren Ende spaltet er sich, bisweilen ziemlich tief, in drei schmale Gelenkfortsätze für die Zehen, von denen der mittlere, eine Rolle bildend, meist am längsten und breitesten ist. An seiner Vorder - und Hinterfläche bildet er eine Längsfurche ') zur Aufnahme der Zehenstrecker und Beuger. Der kleine Mittelfussknochen des Daumens liegt an der Innenseite des Hauptknochens, mehr oder minder tief abwärts und bildet an seinem unteren Ende oft eine Rolle. Er fehlt bei Abwesenheit des Daumens.

Die gewöhnlichste Zahl der Zehen beträgt vier 8). Gewöhnlich ist der Daumen nach hinten, nur bei den Palmipeden mehr nach vorn gerichtet. Bei den Scansores und Papageien ist auch die äussere Zehe hinterwärts gewendet. - Jede Zehe bestelit aus mehren Phalangen; gewöhnlich nimmt die Zahl der letzteren an den einzelnen Zehen von innen nach aussen so $\mathrm{zu}$, dass sie successive yon zwei auf fünf steigt 9 \%

5) Nach Baer's Beobachtung entsteht dieser Knochen ursprünglich nicht durch einen einzigen Knorpel, vielmehr bilden sich so viele Knorpel, als Zehen vorhanten sind (C. E. v. Baer, Ueber Entwickelungsgeschichte der Thiere, Kö. nigsb. 1828, Th. 1. S. 94.).

6) Lang und dünn bei den Sumpfrögeln, Straussen, Raubvögeln; kleiner bei den Hühnern und Schwimmvögeln; sehr kurz und dick bei den Papageien und Pinguinen.

7) Am stärksten bei den Raubvögeln und Schwalben; meist ist die vordere viel stärker, als die hintere; bei den Papageien fehlt die vordere, die lintere ist schwacl.

8) Sie sinkt bei Struthio auf zwei; bei den Casuaren, bei Rhea, bei der Trappe, bei Calidris, beim dreizeligen Specht u. s. w. auf drei; bisweilen ist der Daumen ganz rudimentär, z. B. bei Procellaria, bei Pterocles.

9) Indessen kommen einige Ausnahmen von diesem Gesetze ror; bei Ptero. 
[Vgl. ausser den grösseren osteologischen Schriften: Kessler, Osteologie der Vogelfüsse; aus d. Bülletin d. naturf. Gesellschaft zu Moskau bes. abgedruekt. Belandelt besonders die relativen Längenverhältnisse der cinzelnen Abtheilungen der Hinterextremitäten.]

\section{Voin Schedel.}

§. 123.

Eine Eigenthümlichkeit des Vogelschedels, die derselbe mil den Yo. notrcmen gemein hat, besteht darin, dass die cinzelnen ihn zusammensetzcnden Knochen frühzcitig mit einander verschmelzen und dass zwischen den meisten dcrselben, namentlich zwischen denen der eigentlichen Hirncapsel, auch nicht einmal Spuren von Nähten zurückblciben. Dies gilt vol'zugsweise von den cigentlichen Schedelknochen; weniger und theilweisc gar nicht von den Knochen des Gesichtes und denen des Kiefergaumenapparates. - An den Schcdel der beschuppten Reptilien schliesst er sich durch seine Verbindungsweise mit der Wirbelsäule, welche auch durch einen einfachen Coudylus occipitalis geschieht, wodurch eine bedeutendere Freibeweglichkeit des Kopfes gestattet wird, als sie den Säugethieren zukömmt. - Den Sauriern nähern sich die Vögel durch die betvegliche Verbindung, welche zwischen ihrem Oberkiefer - Gaumenapparat und dem Schedel Statt hat und welche wesentlich durch das dem Schedel beweglich verbundene Quadratbein vermittelt wird. - Der Vogelschedel ist, wegen stärkerer Ausbildung des Gchirnes und Uebergewichts seiner Masse viel grösser und rundlicher, als bei allen Reptilicn, erscheint aber oft wegen starker Entwickelung der Zellen seiner Diploc̈, von aussen bcdeutend umfänglichcr, als seine Höhle es wirklich ist $\left.{ }^{1}\right)$. - Bei der innigen Verschmclzung der einzclnen Schedelknochen zu einem durch Nähte ununterbrochenen Ganzen, wird Behufs ihrer Unterscheidung die Untersuchung des Schedels sehr junger Vögel erforderlich. - Eine solche Untersuchung lehrt, dass die Anzahl der ihn zusammensetzenden einzelnen Knochen geringer ist, als bei den bcschuppten Reptilien. - Die Hinterhauptsgegend wird beim jungen Vogel durch vicr Knochen gebildet: durch das einfache, untere Occipitale lasilare, durch zwei Occipitalia lateralia und durch das einfache Occipitale superius (Squama). Sämmtliche Hinterhauptsknochen - untcr ihnen jedoch am wenigsten das Basilarstück - tragen zur Unschliessung des Foramen magnum bei 2). Der beim ausgewachsenen Vogel einfache, hemisphärische Gc-

eles und bei Caprimulgus hat die äussere Vorderzehe nur vier Glieder; bei Cypselus besitzt der Daumen zwei, die drei übrigen Zehen je drei Glieder.

1) Wie dies namentlieh bei Untersuchung des spongiösen Eulenschedels sieh zeigt, so wie einiger Enten, z. B. Anas clangula, A. fusea, wo weite holle Räume zwischeu den Lamellen der Diploë liegen.

2) Auf eigenthümliche Weise rückt bei der Gattung Scolopax das Foramen 
lenkkopf (Conlylus occipitalis) besteht bei jungen Individuen aller Ordnungen aus drei innig an einander liegenden Ilöckerchen, indem, ausser dem Occipirale basilare, auel die scitliehen IInterhauptsbeine zı seiner Bildung beitrigen. - Die Occipitalia lateralia besitzen Oeffnnngen zum Durehtritte der letzten Hirnnerven, nehmen einen Theil des Grhörlabyrinthes mit auf, bilden die hintere Wand der Paukenhöhle und erstrecken sich, bei der geringen Breitenausdehnung des Occipitale busilare, mit an die Schedelbasis. - Das Occipitale superius ist gewölnnlich umfänglieh, bildet die hintere Wand des Schedels, besitzt bisweilen permanente, iber dem IIinterhauptsloehe gelegene Fontanellen ${ }^{3}$ ) und wird zur Aufnahme des Gehörlabyrinthes mit verwendet 4). - Die kleinen, neben den Occipiulia lateralia eingekeilten Felsenbeine (Ossa petrosa) verwachsen frühzeitig mit den Sehlïfensehuppen. Zwisehen dem Vorderrande des Felsenbeines und dem grossen Keillbeinflügel liegt die zum Durehtritte des zweiten und dritten Astes des $\boldsymbol{N}$. trigeminus bestimmte Oeffnung. - $Z n$ den Seiten des Sehedels, vor den Occipitalia luteralia liegen die beträehtlichen Sehläfensehuppen (Squamae temporules), welche gewöhnlieh bis an die hintere Grenze der Augenhöhlen sich erstrecken. Die Schläfensehuppe bildet immer, bald allein, bald in Verbindung mit dem grossen Keillbeinfluggel, die Gelenkgrube für das dem Sehedel beweglich eingelenkte Quadratbein. Sie bildet immer einen mehr oder weniger ausgebildeten hinteren, und bisweilen, jedoch dann in Gemeinsehaft mit anderen Knoehen, einen vorderen Fortsatz; beide begrenzen die Sehläfengrube $\left.{ }^{5}\right) .-A n$ den Vorderrand des Occipilale basilure und des Basitartheiles der Occipitalia lateralia schliesst sieh mit seinem hinteren breiten Rande der sehr beträchtliehe Keilbeinkörper (Os sphenvïleum busilare), ein gewöhnlieh mehr oder minder dreieckiger, hinten breiter, vorn in einen schmalen spitzen Stiel

maynum weit nach rorn und kömmt hier horizontal zu liegen. Vgl. Nitzsch, 0steog. Beitr. S. 63. Tab. 1. Fig. 5.

3) Bei der Familie der Schnepfen, Grus, Platalea, Phoenicopterus, Anas, An. ser, Mergus, Mormon, Alca.

A) Eigenthümlich ist den Cormoranen ein mit der Hinterhauptsschuppe articulirender, seitlich comprimirter, dreieckiger, senkrecht hinterwärts gerichteter accessorischer Knochen, welcher die Ansatzflächen der len Unterkiefer bewegen(len Muskeln vergrössert.

5) Der hintere Fortsatz. (Jochfortsatz) ist sehr ausgebildet bei den Straussen, Hühnern, Papageien, wo er z. B. bei Psittacus amazonicus sowol den UnterAugenhöhlenring, als auch den Jochbogen erreicht; er ist schwach entwickelt bei deı Sumpf- und Wasservögeh (Larus) oder fehlt ganz (Anas). Der vordere Fortsatz $(\boldsymbol{P} \%$ orbitalis poslevior), zu dessen Bildung die Schläfenschnpe nur schr selten beitrïgt, wie z. 13. bei den Gänsen (nicht bej den Straussen, Hiihnern, Pingninen), ist bei Anas und Psittacus ausserordentlich stark entwickelt. Beide Fortsätze verbinden sich bisweilen zur Schliessung einer Schlïengrube, wie beim Ianshuhn, bei Tetrao und vielen Gallinaceen, bei l's. amazonicns 1. . A. 
ausgezogener Knochen, der nicht selten scitlich mit den Ossa ptery goüdea eine Gelenkvcrbindung eingeht. Die Innenfläche scines breiteren Abschnittes stiutzt die Hirnbasis und bildet eine Sella turcica. In ihm vcrlaufen die Carrotidencanäle, deren Eingang an der Schedel. basis neben den seitlichen Iinterhauptsheinen sich findet. Vor ihnen tritt die Tula Euslachii durch den Knochen. Dic beiden Tubac öffnen sich gemeinsam an der Ucbergangsstellc des Körpers in den Stiel. Die vordere Spitze des Keilbeinkörpers trägt zur Bildung der Schcdelhöhle nicht bei, sondern erstreckt sich gerade untcr dem Orbitalse. gmente vorwärts und dient oben dem Sepfum interorlitule und namentlich der Lamina perpendicularis ossis etlimö̈dë̈ zur Stutzc, während an ihre untere Seite der hintcre Theil des Vomer sich anlegt. - Die grossen Kcilbeinflügel (Alae temporales) sind gewöhnlich bedeutende Knochen, welche abwärts auf dem Keilbeinkörper ruhen, weiter aufwärts an die Schläferıschuppen, oben an die Stirnbeine sich anschliessen. Jeder diescr Knochen bildet einen mchr order minder beträchtlichen Theil der hinteren Augenhöhlenwand, vervollständigt aber auch oft die Schläfenhöhle, wie z. B. bei den Hühnern, Straussen, und trägt immer wesentlich zur Bildung des Processus orlitalis posterior bei. - Die vorderen oder kleincn Keilbeinfligel (Alae orbitules) sind unbeträchtliche und anscheinend unbeständige Ossificationen, welche in der Ungebung des Schnervenlochcs auf Kosten der hier anfangs vorhandenen fibrösen Haut, verhältnissmässig spät sich entwickeln. - Zwischen den beiden Schläfenschuppen liegen an dcr Schedeldecke die wenig umfänglichen Scheitelbeine (Ossa parietralia), die in der Mittellinie sich berühren und hinten von der Hinterhauptsschuppe, vorn von den Stirnbeinen begrenzt werden. Sie sind mehr in der Breite, als in dcr Längendimension entwickelt. - Die stcts paarigen, in der Mittellinie sich berihrenden Stirnbeine (Ossa froutalia) sind die umfänglichsten Knochen des Vogelschedels. Indem jedes Stirnbein 1) einen beträchtlichen Theil der oberen Schedeldecke, 2) nach vorn und abwärts sich umbiegend einen grossen Theil der hinteren Augenhöhlenwand und 3) nach vorn verschmälert und bis in die Nasengegend verlängert, die Decke des Orbitalsegmentes $\left.{ }^{6}\right)$ bildet, zerfällt es 1) in einen breiten oberen Schedelabschnitt, 2) in einen absteigenden hintercn Augenhöhlentheil und 3 ) in einen schmalen Nasenfortsatz. - Sebr ausgebildet ist das Siebbcin (Os ethmö̈deum); am meisten bei Struthio und Apteryx. Es besteht aus eincm obcren horizontalen und einem senkrecht absteigenden Theile. Jencr liegt zwischen den beiden Spitzen der Nasenfortsätze del Stirnbeinc, wird von ihnen umfasst und trägt immer zur Vervollständigung des Schcdeldaches an der

6) Eigenthümlich sind vielen Vögeln starke Gruben an der Oberfläche des Orbitalsegmentes; es liegen in denselben die starken Nasendrüsen. Vgl. \$.130. 


\section{Erster Abschnitt. Vom Knochengerüste.}

Grenze des Orbital- und Schnatuzensegmentes des Schedels bei. Der senkrechte Thcil, dessen Platten beim Strauss eine Höhle einschliessen, tritt abwiirts und vervollstänligt das Septum interorbitale. An der Grenze beider Fortsätze liegt eine Furche oder ein Canal, bestimmt zum Durchtritt des $\boldsymbol{N}$. olfuctorius, der nur bei Apteryx durch eine Art Lamina cribrosa hindurchtritt. Unter dieser Furche findet sich oft ein starker Seitenfortsatz 7 ), der häufig mit dem Thränenbeine verbunden, die Vorderwand der Augenhöhle vervollständigt. - An das Stirnbein schliesst sich vorn noch ein Thränenbein und cin Nasenbein an. Das Thränenbein ${ }^{8}$ ) stellt einen gewöhnlich sehr beträchtlichen, selten ganz abortiven, am vorderen und ausseren Theile der Augenhöhle gelegenen, stets durchbolırten Randknochen der Stirnbeine dar, der hinsichtlich seiner Ausdehnung und seiner Verbindungen sehr bedeutende Verschiedenheiten darbietet. Bei einigen Vögeln verbindet es sich mit dem abund vorwärts verlängerten Processus orlitalis posterior zu einem unteren Augenhöhlenringe 9). Bei anderen steht es mit accessorischen Knochen in Verbindung. Dies sind entweder Ossa supraorbitalia ${ }^{10}$ ), welche den oberen Augenhöhlenrand vervollständigen oder Ossa infraorbitalia 11), welche, dem Jochbogen parallel laufend, die Augenhöhle unten umgeben. - Die beiden, gewöhnlich länglichen Nasenbeine schliessen sich an die vorderen Enden der Stirnbeine und werden von einander durch die aufsteigenden Aeste des Zwischenkiefers und weiter hinterwiirts durch den Schedeldeckentheil des Siebbeines gctrennt.

Der Oberkiefer-Gaumenapparat ist beweglich mit dem Schedel verbundon. Den Mittelpunkt, von welchem die Hebung und Senkung des Kieferapparates geschieht, bildet das mit dem Schedel beweglich eingelenkte Quadratbein. Dasselbe besitzt gewöhnlich zwei neben einander liegende Gelenkhöcker, die mit den Schläfenschuppen articu-

7) Stark bei den Sehnepfen, Möven, Platalea, den Tauben, den Papageien; hier meistens auch mit deıı Thränenbeine verbunden.

8) Er ist rudimentär bei einigen Spechten: Picus, Upupa; sehr klein bei Cypselus. Er verbreitert die Stirn über den Augen bei den Tagraubrögeln, den Schnepfen, den Fuliearien, bei Tetrao, bei Cuculus u. s. w.

9) Die Verbindung zu einem vollständigen Ringe kömmnt zu Stande bei einigen Papageien, z. B. Ps. annazonicus, Ps. sulphuricus, bei einigen Seolopax-Arten und wenigen Enten. - Sowol bei andern Psittacus, als bei vielen Enten-Arten, koınmen alluiliche Annäherungen des verlängerten Thränenbeines an den hinteren Augenhöhlenfortsatz vor. Am schwächsten ist sie bei Ps. erithacus, stark schon bei Ps. Tuipana.

10) Bei den ineisten, jedoclı niclit allen, Tagraubrögeln findet sich ein einziges; bei Struthio canelıs, Psophia crepitans, Perdix javanica koımen drei bis vier solcher Knoclien vor.

11) Bei Sterna; ihnlielıe Knoeben hat Brandt bei Halieus, Puffinus, Diomedea, Tachypetes beobachtet. 
liren. An seinem unteren Ende hat es abwärts zwei bis vier Gelenkhöeker für den Unterkiefer; vorwärts eine Gelenkvertiefung zur Aufnahme des Quadratjochbeines; weit mehr einwärts, vorn und etwas nach oben eine Gelenkerhabenheit für das Os pterygüideum. Von dem vorderen Rande des Quadratbeines erstreekt. sich ein freier Muskelfortsatz 12) vorwärts mehr oder minder weit zur Augenhöhle hin. - Die Verbindung des Quadratbeines mit deın Oberkieferbeine gesehieht dureh den beständig dünnen, stielfürmigen Joehbogen, weleher nicht, wie bei den ineisten Säugthieren, den unteren Augenhöhlenrand bildet und auf den sieh nuch nur selten das - niemals mit ihm verschmolzene - Thränenlsein herabsenkt 13). Der Jochbogen ist beständig aus zwei Knoehen zusnmmengesetzt: 1) aus dem am Unterkiefergelenke des Quadratbeines sieh inserirenden Quadratjochbeine (Os quadrato-jugale) und 2) aus dem längeren, die Verbindung mit dem Oberkieferbeine vermittelnden Os zygomaticum s. jugale. - Das eigentliehe Oberkieferbein 14) (Os maxillare superius) ist ein meist unbeträehtlicher, mit dem Nasenbeine, dem Jochbeine, dem Gaumenbeine und dem beträchtlichen Zwischenkiefer verbundener, oft musehelförıniger Knoclıen, der den Boden der Nasenhöhle und den Gaumen vervollständigt. - Das immer beträehtliehe, riicksiehtlich seiner Gestalt manniehfaeh variirende, unpaare Os intermaxillave bildet den grössten Theil des Schnabels und bestimint dessen Form. Immer besitzt es zwei parallele, dicht neben einander nach hinten aufsteigende, die beiden Nasenbeine trennende Nasenfortsätze, welche sieh auf die liorizontale Platte des $\boldsymbol{O}_{\boldsymbol{s}}$ ethmö̈leum legen und mit ihnen verwachsen. Unmittelbar zuvor, ehe sie diese Unterlage erreiehen, sind die mit einander verwachsenden Nasenfortsätze gewöhnlich mehr oder minder biegsam und elastiseh, Daher rührt es, dass der Oberkiefer der Vögel, sobald das Quadratbein vorwärts gezogen wird, sich hebt 15). - Der Gaumenapparat besteht aus den beiden Gaumenljeinen, Ossa palatina, den beiden Flügelbeinen, Ossa pterygoülea, und dem Vomer. - Die Ossa palatiu

12) Er fehlt bei Caprimulgus. - Vier Gelenkhöcker für den Unterkiefer besitzt Ardea. - Das Luftloeh des fast inmer pneumatisehen Quadratbeines liegt gewöhnlieh der Pankenhöhle zugewendet. - Man sehe über diesen Knochen: F. Platmer, Benerkungen über das Quadratbein 1. die Paukenhöhte der Vögel, Leipz. 1839, 8 .

13) Bei den Raubvögelı, Alcedo, einigeu Papageien, Sula, IIalietıs, Pelecanus.

14) Sehr klein namentlich bei den meisten Hiihnern.

15) Vergl. die Mittheilungen von Nitzseh über die Bewegung des Oberkie. fers der Vögel in J. F. Meckel's Arehiv 1816, Bd.2. S. 377. Gewöhnlieh liegt der Biegungspunkt hinter den Nasenlöehern vor der Stirn; dam ist der ganze Obersehnabel beweglich. Bei vielen Vögeh der Schnepfenfanilie uvd bei den Kolibri's liegt dagegen der Biegepmnkt des Schnabelrückens weit vor den Naselöchern und damn ist nur die Spitze des Oberkiefers beweglieh. Bei Charadrius endlich finden sieh beide Biegungspunkte zugleich. 
sind betrichtliche, nach dem Gaumen lin unchr oder minder ausgehöhlte, voln inmore von einander getrennte, höchstens hinten in der Mittellinie sich beruilırende, den grössten Tbeil der Gaunenfläche bildende, die hintroren Nasenlöcher atswärts umgrenzende Knochen, welche dic Oberkicfribeine unit den (1ssa prerygoürlea verbinden 16). - Die

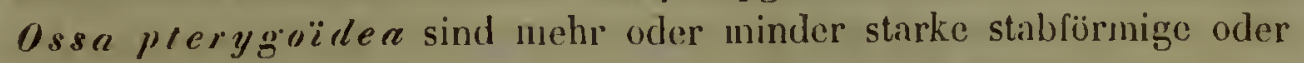
voru verbreiterte, stets von vorn nach hinten divergirende Knochen, welche rorn, unter oder neben dem Keilbeiukörper, beweglich init den Gaumenbeinen und hinten gleichfalls beweglich init den Quadratbeinen, oft auch mit dem Keilbeinkörper verbunden sind 16). - Der Vomer ist ein unparer, linglicher, zwischen den Gaumenbeinen liegender, den hinteı"en 'Theil der Nasenhöhle mit theilender Knochen 18).

Der Unterkiefer besteht, wie bei den Cheloniern, urspriinglich aus eilf einzelnen Knochenstiicken. Es sind: die einfache, unpaare, betrichtliche P'ars dentalis, ferner jederseits sin Os articulare, romplementare, angulare, suprangulare und operculare. Der Meckel'sche Knorpel erhält sich lange Zeit. - Die Gestalt des Unterkiefers variirt ausserordentlich; bald ist er sehr niedrig, bald bedentend höher ${ }^{19}$ ). Der Processus coromoüdeus ist nur schwach angedeutet. Häufig setzt sich der Unterkiefer hinter der mit dem Quadratbeine articulirenden zusammengesetzten Gelenkfliche fort nnd bildet einen mehr oder minler starkon Eckfortsatz 20). - Dic Ausdehnung, in welcher die boiden Unterkieferiste vorn nit einander verwachsen, ist sehr verschirden 21 ). - Iraiufig bildet jede Seitenhälfte. des Unterkiefers eine vollstiindig ossificirte Plattr. 2: $)$; in anderen Fällen bleibt eine Naht jederseits zwischen der vorderen und der linteren IÜilftr ${ }^{23}$ ); äusserst selten findet sich jederseits zwischen dem Zahnstïck und den hinteren Seitenstiicken eine beweglich gelenkartige Verbindung ${ }^{2-1}$ ); häufig köunnt jederseits hinter

16) Hinten sich berührend bei Larus, Carbo, Psittacus; bei letztgenannter Gattung sehr eigenthïmlich, breit, senkrecht, weit über die Ossa pterygrö̈den ntach hinten frei verlängert. Aehulich bei Loxia. - Bei Struthio and Casuarius verwachsen mit den Ossa pterygrö̈dea.

17) Sie besitzen eine Uritte Articulation mit dem Keilbeinkörper bei den Enlen, den Tamben, dem Haushulue, den Schnepfen (uit Ausnahme von Oedicneıms), den Enten, bei Caprimulgus, Hemijodius.

18) Er ist sehr scliwach bei den Hülımern und Papageien. Dass er bei den Straussen palarig sei, gilt wenigstens nicht rom Struthio camelus und voun neuholländischen Casuar, leren, von mir selbst an jungen Thieren getremute, Schedel. knochen ieh vor mir habe. - 19) Sehr hoch z. B. bei den Papageien.

20) Stark bei den mreisten Hiihnern, Enten, Schnepfen, deın Flaningo.

21) Bei Grus und Ciconia etwa $\frac{1}{3}$ der Länge; bei Phoenicopterus und Apteryx fast die Hälfte; bei Khamphastos unl Buceros gegen zwei Drittheile. Bei Numrnins liegeu die beiden Aeste gegen zwei Dritttheil ihrer Länge an einander, sind alier nicht anchylosirt.

22) \%. B. bei den Pạageien, den Tagraubvögeln, len meisteu Ilïlmeru, Reihern, Schwïnen. - 23) \%. B. bei den Enteu.

24) Vou Nitzseh bei Caprimulgus wahrgenommen. 
der Mitte eine längliche horizontale Lücke vor 25 ) und dann weiter hinten oft noch eine zweite kleinere Luicke. - Beinerkenswerth ist ein den Fulicarien cigenthümlicher, auf dem oberen Rande der Hitte des Unterkiefers sitzcnder, klappenartig berveglicher Knochen-oder Knorpelflügel 20). - Der Unterkiefer ist fast immer pncumatisch und erhält seine Luft gewöhnlich aus der Paukenhöhle, bald durch eine membranöse Röhre, welche in das cinwärts vom Kiefergelenke liegende Loch führt, bald durch ein röhrenförmiges Knöchelchen (Siphonium), das vom unteren Rande des Gehörganges ausgeht und oft zwischen Quadratbein und Occipitale laterale eingekeilt ist ${ }^{27}$ ). Selten tritt die Luft aus Halszellen in den Unterkiefer ${ }^{28}$ ).

[Man vergl. über den Sehedel der Vögel, ausser Curier's und Meekel's Handbüeliern, besonders den Aufsatz von Geoffroy St. Milaire in den Ann. d. Mus. T. X. p. 348. Tab. 27. und Bojanus, Parergon ad anatomen testudinis, Fig. 196-198., so wie auch die neue dureh Erdl besorgte Ausgabe von Spix Cephalogenesis: Tafeln zur vergleiehenden Anatomie des Schedels, Miinchen 1842, Fol. S. auch d'Alton, Skelete der straussartigen Vögel. Mit Abbildungen von Sehedeln junger Struthionen.]

\section{Vom Zungenbeine.}

§. 124.

Das Zungenbein ist im Ganzen ziemlich einförmig gebildet. Es besteht aus dem $\mathrm{Körper}$, aus den an diesen vorn sich anschliessenden Ossa lingualia s. entoglossa, aus dem den Körper nach hinten verlängernden $\mathrm{Kiel}$, und aus den beiden, gewöhnlich sehr langen, mit dem Schedel nicht verbundenen sogenannten hinteren oder grossen Hörncrn. Dicse letzteren entsprechen den oberen oder vorderen Hörncrn der Säugethiere, also den sogenannten kleinen Hörnern des mensch lichen Zungenbcines nebst den zu diesen gehörigen Ligamenta styloIyyoüdea und dem Processus styloüders des Schläfenbeines. - Der Zungenbeinkörper der Vögel (Geoffroy's Busi-lıyal) stellt gewöhnlich einen länglichen, seltener verbreiterten, platten Knochen dar. An seinen Vorderrand befestigen sich die bald ossificirten, bald knorpeligen, meistens beweglichen, selten mit ihm verwachsenen 1) ossa lingualia s. entoglossa. In der Regel parig, werden sie selten theilweise oder ganz verschmolzen und cinfach angetroffen 2). - Nach hinten verlängert sich der Zungenbeinkörper in einen selten fehlenden ${ }^{3}$,

25) Bei den Eulen, den meisten Singrögeln, den Selnepfen, Möven, Fuliearien, Alea, Uria. - 26) Von Nitzseh bei Fuliea atra beschrieben und abgebildet. Aueh bei Porphyrio vorhanden. Bei Gallinula elıloropus fiude ieh iln deutlieh, obsehon nur knorpelig.

27) Von Nitzseh entdeckt und abgebildet; es findet sich bei allen Singvögeln, bei den Papageien, bei Charadrius. - Die vom Jochbegen zum Unterkiefer sich begebendeu Bänder enthalten oft Ossificationen, die Nitzsel Metagnathium nennt. S. über dieselben aueh R e tzius in 'T'i de mann's Zeitsehr. II. 97.

28) So nach Oweı beim Pelikan. - 1) Beim afrikanisehen Strauss.

2) Z. B. bei den Enten. - 3) Z. B. bei den Speehten. 
gewöhnlich beweglieh, oft aber auch unbeweglich 4) mit ihm verbundenen Stiel oder Kiel (Geoffroy's Uro-/hyal), der unter oder vor den oberen Kehlkopf und dic ersten Luftröhrenringe tritt. - Jedes der beiden gewöhnlich sehr langen grossen oder hinteren IIörner, welche rom hörper in der Nähe seines hinteren Endes seitwärts abtreten, besteht in der Regcl aus zwei, seltener aus drei Gliedern und bildet nur ausnahmsweise ein einziges Scgment. Bei Anwesenheit mehrer Glicder bleibt das letzte gewöhnlich knorpelig. Diese grossen Hörner sind bei einigen Vögeln, namentlich den Spechten ${ }^{5}$ ), ausscrordentlich verlängert und sehr dünn, krümmen sich von hinten in einem vorwärts gerichteten Bogen um den ganzen Sehedel herum bis an den Oberkiefer, wo ihre Enden gewöhnlich rcchterseits, in einer Rinne oder einem Canale liegen.

[Vergl. Ge offroy, Philosoplie anatomique T. I. Pl. 4. p. 36-45. Duvernoy in den Mém. de la soc. d'hist. nat. de Strasbourg T. I. - Ueber die bewegliche Zunge des Spechtes und ihren muskulösen Apparat s. Huber, de lingua et osse hyö̈deo pici viridis, Stuttg. 1821, 4. und Henle, Kehlkopf S. 64.]

\section{Zweiter Abschnitt. \\ Von den äusseren Hautbedeckungen.}

\section{§. 125.}

Die äussere IIaut der Vögel ist verhältnissmässig dünner, als die der Säugethiere und besteht aus der Cutis und verschiedenen Oberhautund Hornbildungen. $\mathrm{Zu}$ den letzteren gehören: die eigentliche, feine in steter Abschuppung begriffenc - biswcilen an einzelnen nackten Stellen schwielig verdickte - Epidermis, welche die zwischen den Federn gelegenen Hautstellen überzieht; dann die Federn; die die Hinterextremitäten theilweise bekleidenden, den Schuppen vieler Reptilien analog gebildeten Schienen; die Schnabelscheiden; dic Nägel der Fusszehen und des Daumens, so wie endlich die Sporen. - Die Federn, welehe eine sehr grosse Mannichfaltigkeit der Bildungen zeigen, stecken mit ihren Kielen zunächst in häutigen oder hornartig verdickten Epithelialscheiden. Diese Scheiden - die Ueberbleibsel der anfangs oben geschlosscnen Bälge, in welehen die Federn sich bilden - liegen in canalformigen, etwas hervorgezogenen Taschen oder Einsenkungen der Cutis, welehe an der Innenwand der letzteren mit jungen Epithelialzellen ausgekleidet ist. In den offenen Grund einer solchen Tasche ragt cin kleines gefässreiches Wärzchen der Cutis hinein, auf welehem die Feder init ihrem Grübchen aufsitzt. An die Seheide selbst befestigen sich die kleinen zur Bewegung der Contourfedern bestimmten Mus-

4) \%. B. bei den Eulen, bei Cinclus, Ciconia, Anas u. A.

5) Achulich bei $Y u n x$, Trochilus. 
keln, welche besonders deutlich bei den Schwimmvögıln erkennbar sind. - Die Federn lassen sich in vier Gruppen bringen, welche alser nicht durch scliarfe Charaktere von einander gesondert werden können. Es sind: 1) die Contour-oder Lichtfedern (I'esunre); 2) die Dunen (Plumulne); 3) die Ilalbdunen (Penuoplumae) und 4) die Fadenfedern (Filoplumne). -

Bisweilen erstrecken sich Luftzellen unter die Haut, welche bald von den Nasenhöhlen mil Luft gefüllt werden, wic die des Kopfes und Ilalses bei Coracias, bald Fortsetzungen der Luftzellen der Eingeweidehöhle sind, wie z. B. die des Pelikans 1 \%. -

Von driisigen Organen, welche an der Oberflïche des Ilautgebildes münden, kömmt bei den Vögchn nur ein einziges vor, das einzelnen sogar fehlt 2). Es ist dies die sogenannte Bürzeldriise (Glmudula uropygii), bestimmt zur Absonderung der Schmere, welche die Federn einölt und selten nur durch einen specilischen Geruch ausgezeichnet ist, wie bei Upupa und Anas moschata. Sie liegt ïber den letzten Schwanzwirbeln, zwischen d'n Spulen der Steuerfedern, ineist nur von der äusscren Iaut, selten von dın Sehnen der Hebemuskeln des Schwanzes bedeckt. Sie besteht aus zwei, immer an ihrem Hinterende, bisweilen auch in weiterer Ausdehnung mit einander verlundenen Lappen, welche gewöhnlich einen gemeinschaftliehen, bald deutlich abgesetzten, bald wenig abgegrenzten Ausfiihrungscanal mit doppelter oder mehrfacher ${ }^{3}$ ) äusserer Oeffnung haben. Am grössten ist sie bei vielen Wasservögeln.

[Man vergl. über dlas Hautorgan der Vögel besonders Heusinger, System der Histologie, Eisen. 1822, 4. S. 204 ff. und C. L. Nitzseh, System der Pterylographie, herausgegeben von H. Burmeister, Halle 1840, 4. In beiden Werken finden sich zahlreiehe literarische Nacliweisungen, in letzterem Beobachtungen über die Entwiekelungsgeschichte der Federn vom Herausgeber. - Ueber die Bürzeldrüse s. Nitzseh l. e. S. 54. - Ueber ibren feineren Bau, ausser Nitzsch, noch J. Miiller, Gland. seeern. p. 41. Tab. II. S. 1. Sie bestelit aus eylindrischen, parallelen," blind endenden Tubuli, die nach und nach in mebre saekförmige Erweiterungen übergehen, welche elttwellor in zwoi gemeinschaft. liehe Hölılen, oder getrennt dureh mehre Oeffnungen miinden.]

1) Vgl. 0 wen in d. Proeeed. of the zool. soc. of Lond. Part. 3. 1835. 1. 9.

2) Nitzseh vermisste sie bei 0 tis, bei allen Struthionen, bei mehren amerikaniseheu Papageien, bei einigen Tamben, bei Algus giganteus. Er fand sie verhältnissuässig am grössten bei Pandion, Sula, Sterna, Procellaria; alı kleinsten bei Caprimulgus. - Bald ist der verlïngerte Ausfïhrungsgang der Driise an Ende mit cinem Federkranze versehen, ball fehlt ein solcher. Letzteres ist der Fall bei den Nuehtraubvögeln, Passerinen, Macrochiren, den meisten Cuculinen und den Tauben. Er findet sielı bei den Tagraubvögeln (mit Ausnalume von Cathartes), bei den Specliten, Amplibolen, Psittaeinen, Lipoglussen, Gallinacecu und allen Wasservögeln.

3) Bei allen Wasservögeln, mit Ausnahme der Unguirostres N., wo nur zwei vorhanden sind. 


\section{Dritter Abschnitt. \\ Vom Muskelsysteme.}

§. 126.

Die Muskulatur der Vögel ist im Allgemeinen ausgezeichnet durch starke Röthung der eigentlichen Muskelsubstanz und durch scharfe Sonderung derselben von den glänzenden, theilweise leicht und oft verknöchernden Sehnen, - Die mechanische Anordnung der Muskeln zeigt bei allen Vögeln grosse Uebereinstimmung. Wegen der eigenthümlichen Locomotivität der Vögel sind ihre Ilauptmassen am Brustbeine, am Becken und am oberen Theile der Schenkel vertheilt, während die leichten und schlanken Extremitäten nur lange und dünne Sehnen besitzen.

[Ueber die Anordnung der Muskeln im Allgemeinen vgl. man Cuvier's Vorlesungen Bd. 1.; Tiedemann's Zool. Bd. 2. S. 2.7 ff.; besonders aber Meckel's System Bd. 3. S. 289 und 13d. 4. S. 408; über die Muskeln der Stru. thionen s. Meckel's Aufs. Archiv Bd. Э.; über die Muskeln der Eule Ed. d'Al. ton de Strigun musculis commentatio, Hal. 1837, 4. mit Abb.; ferner Carus, Erläuterungstafeln Heft 1. Tab. IV. u. V.; über die Muskeln der Vorderextremitäten die treffliche Abhandlung ron Schoeps in Meckel's Archiv Bd. 4. S. 72. - Ueber die Hautmuskeln des Apteryx s. Owen in Froriep's N. Notiz. Bd. XXV. No. 548. - Einzelne Notizen gibt Nitzsch in s. Anuerkungen zu Nau. ul ann's Naturgesch. d. d. Vögel. - Ueber die Muskeln des Pinguins s. J. Reid in den Proceedings of the zool. society of London Part. 3. 1835. p. 132.]

\section{§. 127.}

Das System der Hautmuskeln ist im Ganzen sehr entwickelt. An dem hinteren Theile des Kopfes, am ganzen Halse, in der Nackengegend, unterhalb der Brust und am Bauche finden sich grössere flache Muskelausbreitungen; von ihnen gesonderte kleinere Portionen sind zum Theil dic kleinen Muskcln der Contourfedern, welche zu vier oder fünf an die Scheide jeder Federspule treten. Hautmuskeln anderer Art sind die rom Rumpfe zu den Flughautfalten sich begebenden Muskeln und Sehnen ( $\boldsymbol{M}$. M. patagii), so wie die zur Bewegung der $\Lambda$ runschwingen und der Steuerfedern des Schwanzes dienenden Mursculi remigum et rectricum.

Die Muskulatur der Wirbelsäule ist in deren einzelnen Regionen, entsprechend dem verschiedenen Grade ihrer Beweglichkeit, von sehr verschiedener Stïrke. Während die Muskeln in der Gegend der wenig oder gar nicht ljeweglichen Rücken- oder Kreuzbeinwirbel verhialtnissmässig sehr schwach entwickelt sind, erscheinen sie ausgebildeter an Schwarize und ganz besonders an dem so mannichfacher Bewegungen fähigen, meist langen Halse. In der Rückengegend finden sich die Mus- 
keln nur an der hinteren Wirbelfäche; am Schwanze und besonders am Halse sind sie auch an der Vorderläche mehr oder minder stark aus. gebildet. - $\Lambda$ n der Rückseite des Schwanzes Jient der M. spinalis caulue 1) zur Hebung des Schwanzes. Thn unterstitzt meistens ein durch ihn bedeckter von der $\boldsymbol{S}_{y m p h l y}$ sis sacro-iliaca und von den Querfortsätzen der Schwanzwirbel entspringender, für dic inncren Stenerfedern bestimmter M. levator rectricum. Ganz in der Tiefe der Rückengegend, den zwischen den Dornfortsälzen und den Gelenk fortsätzen befindlichen Rauin ausfüllend, liegt hinten der schwache $\boldsymbol{M}$. multifulus spinae. Er wird wenig bedeckt durch den gleichfalls schwachen, mit seinen dïnnen, von den Dornfortsätzen der Rücken. wirbel ausgehenden Sehnen bis zur Mitte des Ilalses reichenden $\boldsymbol{M}$. spinalis dorsi. Stärker ist der auf den $\boldsymbol{M}$. multifulus liegende, hinten mit ihm und mit dein Spinalis innig verbundene, vom vorderen Darmbeinrande und von der Oberläche dẹr letzten Rippe entspringende, nur selten, wie bei den Pinguinen, wegen aufrechter Stcllung des Körpers, bedeutend cntwickelte $\boldsymbol{M}$. opisthotenar, der sehr bald in cine inncro und eine äussere Portion (Longissimus dorsi und Sacrolumbalis) zcrfällt. Der Sacrolumbalis inserirt sich an einen grossen Theil der Vertebralenden der Rippen, so wie auch an die Querfortsätze der Rückenwirbcl. - Zusammengesetzter sind die Verhältnisse der an der Rückenseite des Halses liegenden Muskeln. Sie beschränken sich thcils auf die Halswirbel selbst, zwischen deren verschiedenen Fortsätzen sic sich erstrecken, wie der den M. spinalis dorsi widerholende M. spinalis colli s. cervicalis allscendens, der M. semispinalis, die M. M. splenii colli, der M. transversalis cervicis (als Halstheil der Sacrolumbalis), oder sie befestigen sich an das Hinterhaupt, wie der M. complexus, der von ihm zum Theil bedeckte $\boldsymbol{M}$. Liventer und der seitliche $\boldsymbol{M}$. trachelomastoüileus.

Von den Interprocessualmuskcln sind die M. M. interspina. les sehr schwach entwickelt, etwas stärker die M. M. intertransversarii, bedeutend mehr die wedelförmig am Hinterhaupte ausgebreiteten $M$. recti capitis postici und Recti copitis latcrales. - Den Rippenhebcrn analoge Muskeln finden sich schon am Ialsc in Fascikcln, welche von den Querfortsätzen zu tiefer abwärts liegenden Ripnenrudi menten sich begeben; sie werden stärker an den letzten Halswirbeln (M. M. scaleni Auct.) und treten am Rumpfe, als schwache Levatores costarum, von den Querfortsätzen der Riickenwirbel zu den vorderen Flächen der nächsthinteren Rippen. - Die Zwischenrippenmuskeln, deren abortive Repräsentanten ebenfalls schon zum Theil am Halse nachweisbar sind, zerfallen am Rumpfe in äussere und innere und finden sich sowol zwischen den eigentlichen Rippen, als auch noch stärker zwischen den

1) Levator coccygis; Coccygeus superior Auct. 


\section{Dritter Abschnitt. Vom Muskelsysteme.}

Sternocostalknochen. Auch die Processus uncinati der fippen sind durch kleine Muskelbündel unter einander verbunden.

An der Vorderfläche des Schwanzes ist ein $\boldsymbol{M}$. caudalis azbterior s. depressar caulue entwickelt. Ein zweiter kleinerer Depressor ist zugleich für die Senkung der Steuerfedern bestimut. - Seitwärts werden die Schwanzwirbel gezogen durch einen vom Sitzbeine kommenden Wuskel, M. pubo-coccygeus, der auch für die äussere Steuerfeder bestimmt ist. Ausserdern findet sich ein Aluluctor der eben genannten Federn. - Die Vorderfläche des Halses nimmt besonders ein der M. Lusgus culli Auct., ein System von Muskelbïndeln, welche zwischen den Processus spinosi inferiores der Rijcken. und Halswirbel einerseits und den Rippenrudimenten der Halswirbel andererseits sich finden und besonders im hintersten und vordersten 2) Theile des Halses ausgebildet sind. - Ausser ihm ist der $\boldsymbol{M}$. rectus capitis a $u$ ticus major, der, von den Körpern der fiinf bis sechs ersten Halswirbel entspringend, an die Basis des Keilbeinkörpers sich erstreckt, sehr entwickelt. Mehr seitwairts entspringt von den ersten Ilalswirbeln der Rectus capilis anticus minor.

Was die Bauchmuskeln anbetrifft, so sind sie, bei der grossen Ausdehnung des Brustbeines schwach entwickelt. Sie sind gewöhnlich in gleicher Anzahl, wie bei den Säugthieren vorhanden; nur der innere schiefe Bauchmuskel scheint bisweilen zu fehlen. Am stärksten sind in der Regel die in der Mittellinie durch eine Aponeurose verschmolzenen geraden Bauchmuskeln. Bei einigen Vögeln, z. B. den Struthionen, kömınt noch cin $\boldsymbol{M}$. pyramidalis hinzu. - Ein Zwerchfell ist, in geringem Grade ausgebildet, anscheinend bei allen Vögeln vorhanden; meistens ist es grossentheils aponeurotisch und besitzt nur wenige, von den Rippen und Sternocostalknochen stammende fleischige Köpfe, welche sich in der Mittellinie nicht vereinigen. Die aponeurotische Ausbreitung des Zwerchfelles schlägt sich, von der Pleura bedeckt, iiber die Bauchfläche der Lungen, bildet aber kein queres Septum zwischen Brust - und Bauchhöhle und scheint, seiner Function nach, ausschliesslich zur Erweiterung der Lungen und Bronchien bestimmt zu sein. Bei allen Vögeln ${ }^{3}$ ) besitzt es auch cinen Vertebraltheil, indem tendinöse Schenkel an die letzten Rückenwirbel sich befestigen, ermangelt aber eines mittleren vereinigenden Tlıeiles und lässt gewöhnlich die Luftsäcke durchtreten.

§. 128.

Die Muskeln der Schulter erstrecken sich vorzugsweise an die

2) Hier auch als M. breves colli anteriores bezeichnet.

3) Am meisten säugethierähnlich ist es entwickelt bei Apteryx, wo die Ven. trikel des Herzens indessen noch durch eine Apertur dieses Muskels hindurch zwischen die Leberlappen treten. 0 wen l. c. Tab. LII. fig. 1. - Abbildung des Zwerchfells vom Strauss, Catalogue of Hunter's collection. Vol. II. Tab. XXVI. 
ain meisten bewegliche Scapula. Die beiden Schulterblistter werden einander genähert und gegen die Wirbelsäule gezogen durch die oberflächlicheren $\boldsymbol{M}$. $\boldsymbol{M}$. cucullares, welche auch theilweise an das obere Eude der Gabel sich befestigen, und die ticíeren M. M. rhombö̈lei, welche von den Dornfortsätzen der Riiekenwirbel an sie herantreten. Aufwärts gezogen wird das Schulterblatt dureh die von den Querfortsätzen des letzten Halswirbels und der ersten Rückenwirbel entspringenden, in mehre Bündel zerfallenen Levatores scapulae. Sie wird gegen das Brustbein niedergezogen durch die mit mehren Köpfen von den Rippen entspringenden M. M. serrati artici (major und minor). Das Os coracö̈deum wird nach aussen und hinten gezogen durch den von den Sternocostalknochen und zum Theil vom Brustbeine stammenden $\boldsymbol{M}$. subclavius.

Unter den Muskeln des Oberarınes sind bei den Vögeln diejenigen, welche diesen Knochen an das Brustbein ziehen, ausserordentlieh entwickelt. Dies gilt, besonders bei den stark fliegenden Vögeln, von dem grossen Brustmuskel (Pectoralis major), der indessen, gleieh dem Brustbeine selbst, bei den Straussen ganz verkümmert ist. Dieser Muskel zicht nebst dem grossentheils vom Os coracoüleum und nur wenig vom Brustbeine entspringenden $\boldsymbol{M}$. corcocobrachialis inferior ${ }^{1}$ ), so wie mit einem dritten Muskel, dem Coracolrachialis superior, der einen ähnlichen Ursprung, wie der vorige hat, den Oberarm gegen die Brust. Gegen die Wirbelsäule und gegen das Schulterblatt wird der Oberarm gezogen durch'drei Muskeln: durch den oberflächlichen Latissimus dorsi, der häufig doppelt von den Dornen der Rückenwirbel entspringt und durch die tieferen, vom Schulterblatt ausgehenden $\boldsymbol{M}$. M. infraspinatus und supraspinatus. - An den Rumpf gezogen wird der Oberarm durch den von der inneren Schulterblattfläche entspringenden M. sulscapularis. - Gehoben wird er durch drei $\boldsymbol{M}$. M. deltoüdei, welche im Unkreise des Oberarmgelenkes und namentlieh vom Ds coracö̈deunn entspringen, so wie dureh den starken vom Brustbeine ausgehenden $\boldsymbol{M}$. pectoralis tertius.

Die Muskeln des Vorderarmes bestehen blos in Streckern und Beugern 2) und sind durch die Länge ihrer Sehnen ausgezeichnet. Es ist nur ein, deın M. triceps entsprechender, aber gewöhnlich nur zweiköpfiger, Strecker vorhanden, der vom Schulterblatt und von der hinteren Fläche des Oberarmes an die Ulna sich begibt. Zahlreicher sind die vom Oberarm theils an den Radius ${ }^{3}$, theils an ihn und an die

\section{1) Pectorulis tertius Auct.}

2) Bemerkungen über die Bewegungen der Vorderarmknochen finden sich bei Bergmann in Müller's Archiv 1839. S. 296.

3) Es sind dies die beiden sogenannten Pronatores, ller $\boldsymbol{P}$. brevis und $\boldsymbol{P}$. longus, so wie der Supinator. 
Ulna tretenden Beuger 4$)$. - An die II andw urzel befestigen sich zwei, vom inneren Oberarmknorren ausgehende Beuger 5) - Die Mittelhand wird gestreckt durch die vom äusseren Oberarmknorren ausgehenden Extensoren: E. metacarpi ralialis longus und E. metacarpi uluaris, so wie durch die vom Vorderarm zu ihr tretenden Exxtensores metcecarpi radialis brevis und metacarpi ulwaris; sic wirl gebogen durch zwei Flexores metacarpi radiales, von denen der cine von iusseren Oberarmknorren, der andere aber von der Innenfläche der Ulna entspringt, so wie durch einen gleichfalls ron hier ausgehenden Flexor sotacarpi lrevis. Ausserdem ist cin vom Oberarm entspringender Abductor und, als dessen Antagonist, ein von der Ulna ausgehender Adluctor metacarpi vorhanden. - Die Finger besitzen, ausser langen und.kurzen Streckern ${ }^{6}$ ) und Beugern 7 ), noch Addictoren und Abductoren $\left.{ }^{8}\right)$. -

Ganz eigenthïmlich sind den Vögeln endlich die in den, durch den Besitz clastischen Gewebes ausgezeichneten, Flug hautfalten endenden Muskeln (M. M. patugii s. Plicae alaris). Die eine dieser Falten (die hintere Flughaut) findet sich zwischen dem Rumpfe und der inneren Flïche des Oberarmes. Die zweite (oder vordere) Flughaut liegt zwischen dem Oberarm und Vorderarm. In dic hintere Flughaut inserirt sich ein von den mittleren Rippen kommender Muskel, der diesolbe anspannt; in die vordere Flughaut begeben sich zwei Muskeln: der von der Schultergegend kommende, in seinem Ursprunge sehr variirende $\boldsymbol{M}$. plicae alar. anter. longus.s und der zweiköpfig von verschiedenen Punkten entspringende M. plic. alar. anter. Greois. Endlich werden dic Kiele der Arm- und Handschwingen (Remiges secundi et primi ordinis) durch eigene Muskeln (Rectoves remignum), welche von der Fascia des Fllenbogengelenkes entspringen und durch tiefere Bündel verstärkt werden, aufgerichtet.

4) Der starke M. Liceps.

5) M. flexor carpi longus und Flexor carpi ulnaris.

6) Die langen Strecker sind: 1) der Extensor digitorum communis longus, der, vom äusseren Oberarmknolren entspringend, all den Daumen und an das ersts Glied les zweiten Fingers tritt, und 2) der ron der Ulna entspringende, an dae zweite Glied des zweiten Fingers trețende Extensor indicis proprius longus. - Die kurzen Strecker des Daumens sind: der Extensor pollicis extermus und E. p. internus.

7) Die langen Beuger sind: 1) der oberflächliche Flexor diriti superficialis, der von der Fiscia des Vorderarmes an das erste oder zweite Glied des langen zweiten Fingers tritt, und 2) der gleichfalls lier endende, von der imeren Fläche der Ulna kommende Flexor digiti monfundus. Ausserdem ist fïr jeden Finger ein kurzer Beuger vorhanden. - Die Nuskeln der Hand sind bei den Struthionen und besonders dem Casuar sehr verkümmert.

8) Der Daumen besitzt blos einen Adductor; der zweite Finger eineu Adductor und einen Abductor. 


\section{§. 129.}

Die Muskeln der Hinterextreinitäten ${ }^{1)}$ sind im Allgemeinen dem Typus der Säugthiere und des Menschen entsprechend gebildet. Von der äusseren Fläche und von den Rändern dos Hüftbeines entspringen gewöhnlich zwei, seltener drei an oder un den grossen Rollhügel des Oberschenkelbeines sich inserirende Muskeln, wclche den $\boldsymbol{M}$. M. glutrei entsprechen und als Ileber des Oberschenkels wirken. Zu ilınen kömmt gewöhnlich noch ein vierter schwächerer, dem $\boldsymbol{M}$. Uliucus externus entsprechender Muskel hinzu, der bei ähnlichem Ursprunge, nach innen vom Rollhügel sich inserirt. - Auswärts gezogen wird der Oberschenkel nur durch den kleinen, vom Hiiftbeine ausgehenden, an das hintere Ende des Trochanter sich befestigenden $\boldsymbol{M}$. gemellus superior 2 ). Als Nicdcrzieher wirken zwci Muskeln. Von den vorderen Dornen der letzten Schwanzwirbel erstreckt sich hinten an den Oberschenkel del M. femorococcygeus s. pyriformis. Von ihm ganz oder theilweise be deckt verläuft von der äusseren Fläche des Sitzbeines zur unteren oder hinteren Fläche des Oberschenkels der stärkere M. obturatorins interrous $^{3}$ ). - Als Adductoren wirken drei Muskeln ${ }^{4}$, die vom Becken aus tiefer abwärts an den Oberschenkel treten. - Die Muskeln des Unter schenkels nehmen theils rom Becken, theils vom Oberschenkel ihren Ursprung und sind Strecker oder Beuger. Der $\boldsymbol{M}$. sartorins entspringt vom vorderen Ende des Hüftbeines und befestigt sich an das obere Ende der Tibia. Ein anderer Strecker nimmt vou den Kreuzbeindornen und vom hinteren Ende des Hüft- und Sitzbeines seinen Ursprung, verschmilzt meist mit dem, dem Vastus und Cruralis entsprechenden tiefen Strecker und befestigt sich oben an die Fibula. Der Rectus femoris Meckel5) erstreckt sich yom Schaambeine an der inneren Fläche des Oberschenkels herab und geht in eine lange dünne Sehne über, die vor der Vorderfläche des Kniegelenkes nach aussen an den Unterschenkel tritt und mit dem durchbohrten Beuger der Zehen sich verbindet. In Folge dieses Mechanismus werden bei jeder Beugung des Kniegelenkes zugleich die Zeben gebeugt, wodurch denn die Vögel im Stande sind, im Schlafe bei gebogenem Knie ohne weitere willkührliche Intention mit gebogenen Zehen an den Zweigen sich festzuhalten. - Dem $\boldsymbol{M}$. gracilis $\left.{ }^{6}\right)$ entspricht ein vọn inneren Rande des Oberschenkelbeines zum inneren Theile des oberen Tibialrandes sich begebender Muskel. Ein stärkerer, dem Vastus und $\boldsymbol{C r}$ uralis entsprechender tiefer Strecker

1) Muskeln, welche dem Psons und lliacus internus zu vergleichen wären, fehlen den Vögeln allgemein.

2) Pyriformis Tiedeu. - 3) Quadratus femoris Cuv.

A) Meckel's Adductor externns, internus und tertins s. pectineus.

5) Meckel vermisste ihn bei mehren Wasservögeln: Colymbus cristatus, Uria, Morinon, Halieus. - Tiedemann und 0 wen bezeichnen diesen Muskel als Gracilis. - 6) Tiedemann's Rectus. 
geht vom Oberschenkel zur Kniescheibe und zur Tibia. - Die Beugung des Unterschenkels geschicht durch drei Nuskeln: 1) durch den vom unteren Theile des hinteren Hüftlocinrandes zun oberen Theile der Fibula absteigenden M. flexor filutaris; 2) durch den gewölınlich mit zwei Köpfen, sowol vom hinteren Ende des Sitzbeines und den Querfortsätzen der ersten Schwanzwirbel, als auch von der hinteren Oberschenkclfläche cntspringenden M. flexor tiliulis, dessen Schne mit dem Anfange der Schne des Fussstreckers verschmilzt; 3) durch den mehr einwärts liegenden, vom oberen Ende des Schaam- und Sitzbcines zur inneren Fläche der Tibia tretenden Flexor tibialis secundus. - Ein schwacher M. popliteus verläuft oben von der Fibula quer zur Tibia. Die Muskeln des Fusses sind bei der gewöhnlich vorhandenen bedeutenden Längc des Metatarsus meist sehr lang. Der dreiköpfig von den beiden Gelenkknorren des Oberschenkelbeines, so wie von der Patella und der vorderen Leiste der Tibia entspringende $\boldsymbol{M}$. gastrocnemius befestigt sich hinten an das obcre Ende des Metatarsus und streckt den Fuss; der M. peroneus und tilialis asticus, welche gewöhnlich hoch oben an das $U_{s}$ metatarsi sich ansctzen, heben ihn. - Die Zehen bcsitzen einen gemeinschaftlichen langen Strecker, welchcr, von der vorderen Schienheinfläche éntstehend, durch dic am untersten Ende der Tibia befindliche Knochenbriicke hindurchtritt und dessen Sehne unten auf $\mathrm{dem} O_{s}$ metatarsi gewöhnlich in drei für sämmtliche Glicder der drei äusseren Zchen bestimmte Zipfel sich spaltet. Die innerc Zehe erhält cinen eigenen, von dem obcren Theile des Os metatarsi entspringenden Strecker. Das erste Glied jeder der drei vorderen Zehen empfängt ausserdem noch einen eigenen Extensor von der Vorderfläche des Metatarsus. - Die Zehen besitzen mehre gemeinschaftliche oder langc Beuger, welche in so ferne cigenthünlich sich verhatten, als sie vorzugsweise vom unteren Ende des Femur, theilweise aber auch von den Knochen des Unterschenkels entspringen. Es sind der Flexor digiti secundi et tertii ${ }^{7}$ ); der M. Alexor communis quatuor digitorum s. perforatus und der M. Alexor profundus s. perforans, der gleichfalls für alle Zehen bestimınt ist. Ausserdem erhält die innere Zehe einen eigenen, vom Mittelfussknochen entspringenden Beuger. Endlich hesitzt diese Zehe noch einen eigenen Abductor und Adductor, wie auch der äussercn Zche cin Abductor zukömmt.

\section{§. 130 .}

Die Kiefermuskeln der Vögcl sind bei der Anwesenheit eines beweglichen Quadratbeines zahlreicher und complicirter, als die der Säugethiere. Das Flügclbein und das Quadratbein werden gehoben und vorwärts gezogen durch einen aus zwei Portionen bestehenden Muskel (Kevator oss. pterygö̈l. et quadrati). Es nimmt scinen Ur-

7) Der sogenannte durchbohrte und durchbohrende Beuger. 
sprung von der Augenhöhlenscheidewand und inserirt sich, von vorn hinterwärts gerichtet, mit seiner stärkeren vorderen Portion an das Flügelbein, mit der hinteren an die Innenfläche des Quadratbeines. Scin Antagonist ist ein von der Schedelbasis zum Us pterygoüdeum vorwärts und auswärts tretender $\boldsymbol{M}$. retraliens oss. pterygoüdei. - Der Unterkiefer wird gehoben durch mchre, den M. M. temporalis, mas. seter und pterygoüllei analoge Muskeln; häufig werden noch mehre unterschieden, indem der Schläfenmuskel gewöhnlich in drei bis vicr durch ihren Ursprung und ihre Ansatzpunkte distincte Portionen zerfailt. - Der Senker des Unterkiefers, M. digastricus, der an den hinteren Fortsatz dieses Knochens sich befestigt, nimmt mit einer Portion voun flinterhauptc und mit einer anderen von der untercn und hinteren Begrcnzung der äusseren Gehöröffnung seinen Ursprung. - Der Raum zwischen den beiden Aesten des Unterkicfers wird ausgefüllt durch den mit einer mittleren Sehne versehenen $\boldsymbol{M}$. transversus mandilulae. Die vom Unterkiefer zum Zungenbeine sich begebenden Muskeln entsprechen dem $\boldsymbol{M}$. stylohyoüleus, dem $\boldsymbol{M}$. mylohyoüdeus und dem $\boldsymbol{M}$. geniohyoülleus. Zwischen den beiden Scitenhörnern des Zungenbeines ist ein querer Muskel ausgespannt. Zur Zunge treten gewöhnlich die M. M. cerutoglossi s. M. M. linguae laterales, die M. M. hyoglossi recti und hyoglossi transversi.

\section{Vierter Abschnitt. \\ Vom Nervensysteme und von den Sinnesorganen.}

\section{Von den Centraltheilen des Nervensystemes.}

\section{§. 131.}

Das Rückenmark der Vögel erstreckt sich durch die ganze Länge des Canales der oberen Bogensehenkel, ist von cylindrischer Gestalt, verdünnt sich abcr schr bedeutend im oberen Wirbelcanale der Schwanzwirbcl, indem cs fadenförmig endet. Es besitzt eine hinterc und eine vordere Längsfurche und einen sehr engen Mediancanal. Auf Querdurehschnitten erscheinen die Hörner sciner inneren grauen Substanz. Entsprechend dem Ursprunge der zur Bildung der Extremitätenncrven bestimmten Wurzeln besitzt es zwei Anschwcllungen: eine vordcre und eine binterc, deren Stärke je nach der verschicdenen Ausbildung der Extremitäten wechselt. Bemerkenswerth ist das Verhalten des Rückenmarkes an der hinteren Anschwellung. ITier weichen nämlieh die hinteren Stränge eine kurze Strceke weit aus einander, um weiter vorwärts sich wieder an einander zı legen. So entstcht eine wcitere Spalte, welche den Namen des Siuus rhomboüdalis führt. 


\section{Vierter Abschnitt. Vom Nervensysteme u. v. d. Sinnesorganen. 279}

TAbbildungen des Rückenmarkes der Vögel finden sich in den Schriften von Carus, 0 wen und $S$ wan. In der leicht gerinnenden lymphatischen Flüssigkeit, welche in der rautenförmige Grube sich findet, erkannte Valentin grosse, zarte, keruhaltige Zellen.]

\section{\$. 132.}

Das von den gewöhnlichen drei Häuten ungebene, die geräumige r'undliehe Sehedelhöhle vollständig ansfüllende Gehirn überwiegt nieht nur an Masse das Ruiekenmark, sondern ist auch durch stärkere Wölhung und Breite bedeutend höher entwickelt, als das der kaltbliitigen Wirbelthiere. Statt dass bei diesen letzteren die Ansehwellungen, welche seine drei Hauptabtheilungen bilden, der Reihe naeh gerade hinter einander liegen, sind bei den Vögeln, unter grösserer Ausbildung der Hemisphären, die den Vierhügelmassen entsprechenden Ansehwellungen an die Seiten und abwärts getreten. Daher erseheinen bei Betrachtung des Gehirnes von oben nur zwei auf einander folgende Hauptmassen: die Hemisphären und das kleine Gehirn.

Der Uebergang des Rückenmarkes in clas dureh vicl bedeutendere Breitendimension ausgezeichnete verlängerle Mark gesehieht unter einem ziemlich starken Winkel. An der Basis der Mellulla oblongata erseheinen bei genauerer Untersuehung jederseits neben der Medianfurehe die unteren Pyramiden, welehe schmal hervorkommen und dann, allmälieh verbreitert, in die Hirnsehenkel sieh fortsetzen; ihnen zunäehst, auswärts, die in die Vierhiigel ausstrahlenden Yarkbiindel und noch weiter auswärts die Sehleifen, so wie endlieh an der äusseren Grenze Längsstränge, aus welehen die $\boldsymbol{N}$. $\boldsymbol{N}$. trigemini ihren Ursprung nehinen. - An der oberen Fläehe entsteht, indem die beiden oberen Stränge des Rückenmarkes auseinander weiehen, als Vertiefung die vierte Hirnhöhle, deren Dach durch die untere Fläehe des Mittelstückes des Cerebellum gebildet wird. Die deutlieh angeschwollenen Ursprünge der -beiden Gehörnerven theilen den Grund des Veutriculus quartus in einen hinteren und einen vorderen Raum ab. In dem hinteren Raume finden sich seitliche graue Hügel, dureh eine Quercommissur unter einander verbunden, und in der Mitte sieht man die oberen oder hinteren Pyramiden, so wie einige Querfaiden, welehe vielleieht als erste Andeutungen der Brüeke betraehtet werden könnten.

Das kleine Gehirn der Vögel hat in Vergleieh zu dem der kaltblütigen Wirbelthicre an Masse schr bedeutend gewonnen. Es besteht aus einem sehr beträchtlichen mittleren Theile und kleinen scitlichen Anhängen. Zahlreiche Querfurchen theilen namentlich das Mittelstüek in einzelne Blälter, welehe, ähnlieh wie bei den Säugthieren, den $\boldsymbol{A r}$ bor vilae bilden. Auf der Durehsehnittsfäehe der Zweige oder Blätter sieht man diese inwendig aus weisser Substinz bestehen, deren ganzer äusserer Umfang aber von einer starken Lage grauer Misse umzogen ist. Die weisse Substanz geht mittelst einer gelblichen oder röthlichen 
Masse iiber in diese graue. Die vierte Mirnhöhle verlängert sich aufwärts in die Substanz des kleinen Gehirns. Die seitlichen Anhänge scheinen nur den Flocken des Cerebellum der Säugthiere zu entsprechen und ruhen, gleich diesen, in einer Höhlıng, die von dem oberen halbcirkelförmigen Canale überwölbt wird.

Die den Vierhïgeln entsprechenden Massen erscheinen als runde Erhabenheiten, welche ganz seitwärts und abwärts getreten sind, ein Umstand, der das Vogelgehirn besonders charakterisirt. Jede seitlicbe Erhabenheit ist durchans einfach und noch nicht, wie bei den Säugthieren, in eine vordere und eine hintere Anschwellung grsondert. Jeder Körper besitzt noch eine Höhlung, welche init dem Aquacductus Sylvii communicirt. Sie werden unter cinander verbunden durch die sehr breite Sylvi'sche Brücke, oder die Decke des Aquaeductus. Die Thalami optici sind schwach, bestehen aus grauer Substanz und liegen vor der Sylvi'schen Bricke und der mit ilı zusammenhangenden Commis. sure posterior, hinter der Commissura amerior, zur Seite des Ventriculus tertias. Der dritte Ventrikel selbst communicirt durch einen kurzen Trichter mit der Ilypophysis, welche gewöhnlich eine längliche Gestalt hat und in Verhältniss zum Gehirne von geringerem Umfange ist, als bei den kaltbliitigen Wirbelthieren.

Zwischen den Hemisphären und den Cerebellum liegt die gefässreiche $Z i r b e l$, welche fest mit den Hirnhäuten zusammenhängt.

Die Hemisphären, welche in Betreff ihrer Gestalt bei den verschiedenen Ordnıngen der Vögel mancherlei Eigenthïmlichkeiten zeigen, sind glatt und windungslos. Seitlich: und abwärts besitzt jeder Hemisphärenlappen eine seichte Vertiefung, welche als Analogon der Fossa Sylvii betrachtet werden kann. Die Verbindung der beiden Hemisphären geschicht besonders durch dic Commissura anterior, welche dicht vor den Trualami oplici von einer Hemisphäre in die andere ïbergeht. Dicht über und etwas hinter ihr und mit ihr parallel kömmt aber noch ein kleines fadenförmiges diinnes Markblättchen vor, das von A. Meckel als erste Spur des Balkens angeschen wird. Die Höhlen der Hemisphären oder die Seitenventrikel liegen sehr oberflächlich und sind von bedentendem Umfange. Von ihrem Boden und von ihrer Vorder- und Aussenwand erheben sich die sehr beträchtlichen, den gestreiften Körpern entsprechenden Anschwellungen. Auch eine sehr schwache $\Lambda$ ndeutung des Gewölbes ist bemerkbar. Indessen fehlen die Ammonshörner. Die einander entsprechenden inneren Wandungen der beiden Hemisphären sind sehr diunn und durch eine zarte strahlige Markhaut ausgezeichnet. Die Plexus chorioidei sind immer vorhanden.

Vorn haften an den Hemisphären die grauen $B$ ulbi olfactorii oder Corpora manmillarin, deren Höhlung mittelst eines schmalen Verbindungstheiles mit derjenigen der Scitenventrikel communicirt. 
[Man rergleiche über die Organisation des Vogelgehirnes besonders den vortrefflichen Aufsatz von A. Meekel "Anatomie des Gehimes der Vögel" in J. F. Meckel's deutschen Arehiv für Physiologie. Bil. 2. S. 25 ff. Mit ausgezeich. neten Abbildungen. Andere Darstellungen in den friher eitirten Sehriften von Cuvier, Series, Carus, Owen und Swan; ineistens gleichfalls mit Abb.]

\section{Von den Spinalnerven.}

\$. 133.

Sänmtliche Spinalnerven - mit Einschluss des ersten - entspringen mit einer vorderen und einer hinteren Wurzel. Während ihres Austrittes aus den Furnmina interverteluralia sehwillt die hintere Wurzel zum Spinalganglion an. Jeder Spinalnerv besitzt einen sehwäeheren $\boldsymbol{R}$. posterior und einen starken $\boldsymbol{R}$. asterior; jeder dieser Aeste gibt starke Hautzweige ab. Die Bildung des Armgeflechtes gesehieht meistens dureh 4 Nerven: dureh die letzten Halsnerven und den ersten Rüekennerven; seltener wird es blos durch 3 oder durch 2 Nerven gebildet, wie bei einigen straussartigen Vögeln. Aus dem Armgefleehte entstehen gewohnlieh vier $\boldsymbol{N}$. N. thoracici anteriores für die Brustuluskeln, zwei $\boldsymbol{N}$. N. thoracici pusteriores, mehre Schulterblattnerven, ein $\boldsymbol{N}$. cutaucus internus, ein $\boldsymbol{N}$. medianus und ein starker $\boldsymbol{N}$. radialis, so wie aneh der erste $\Lambda$. intercostalis. - Die für die Hinterextremitäten bestimmten Nerven gehen aus zwei Geflechten ab. Das obere (Plexws lumlalis) entsteht gewöhnlieh aus drei Nerven: dem letzten Rückennerven und den ersten beiden Kreuzbeinnerven, seltener und, wie es scheint nur bei überwiegender Ausbildung der Hinterextremititäten, wie bei den Struthionen aus 4 oder 5 Nerven. Aus ihm nehmen, aussel einigen Hautnerven, ihren Ursprung der $\boldsymbol{N}$. obturatorius und der $\mathbf{N}$. curculis. Der zweite hintere Plexus ischialicus, del von dem vorigen häıfig noeh einen Verstärkungsast erhält, wird gebildet dureh vier Saeralnerven, zu welehen oft noch ein Zweig von einem fiinften hinzutritt. Sein Hauptstamm ist der durch das $\boldsymbol{F O}_{0}$ ramese ischiadicum tretende $\boldsymbol{N}$. ischiadicus. - Die Schwanznerven bilden einen schwachen Plexus coccygeus.

[Vergleiche besoulders Cuvier, Vorlesungen übersetzt von Meekel und T'iedemanu, Zoologie 2. S. 38. - W. Marbaeh, de nervis spinalibus avium nounullaruı, Vratisl. 1841, 8. Ueber die Struthionen Meekel in s. Arehiv. 1832. Ueber die Papageie s. M. J. Thuet, Disquis. anatom. Psittacorum, Turie. 1838, 4. 1. 32. Marbach hat die peripherischen Ausbreitungen der Spinalnerven be. sonilers genau verfolgt.]

\section{Von den Hirnnerven.}

§. 134.

Der N. olfuctorius nimmt seinen Ursprung von der Basis der Hemisphären, liegt im unteren Unfange des Bulbus olfactorius, tritt 
durch einen Schedelkanal in den oberen und inneren Theil der Augenhöhle und gelangt von ihr aus in die Nasenhöhle. Er vertheilt sich hier unter der Schleimhaut des Septum und der oberen Musehel.

Der $\boldsymbol{N}$. opticus entspringt blätlerig aus der Vierhügelmasse. Indem die beiden Tractus optici convergiren und mit einander in Berührung kommen, spalten sie sich in eine verschiedene Anzahl von Blättern. Die Blätter des einen Sehnerven sehieben sich zwisehen denen des anderen kreuzweise dureh, gleieh den sich kreuzenden Fingern beider Hände 1). Die beiden Sehnerven gelangen dureh die grossen Foramina opticr in die Augenhöhlen und treten nach aussen von dern Axenpunkte des Bulbus in denselben ein.

Die $\boldsymbol{N}$. N. oculorum uotorii kommen an der Basis des Gehirns, hinter der Hypophysis dicht neben einander hervor. Sie entstehen aus der grauen Substanz, welche hier zwischen den Hirnschenkeln liegt. Jeder Nerv tritt dureh ein besonderes Loeh neben dem Foramen opticum in die Augenhöhle. Er verzweigt sich in die $\boldsymbol{M}$. M. recti superior, inferior, interuus und in den M. obliquns inferior. Ausser diesen Zweigen gibt er stets einen Ramus ciliaris ab, welcher bald ohne vorgängige Verbindung mit einen $\boldsymbol{R}$. ciliaris $\boldsymbol{N}$. trigemiui, hald erst nach derselben ein Ganglion bildet 2 \%. Aus dem Ganglion oder erst von der späteren Verbindungsstelle der beiden Ciliarnerven entstehen Fäden in verschiedener Anzahl, welche zusammen unter dem Sehnerven in den Bulbus treten.

Der $\boldsymbol{N}$. quartus kömmt an der hinteren Grenze der Vierhügel, zwischen ihnen und dem Cerebellum hervor. Er tritt neben dem Sehnervenloche durch eine feine Oeffnung in die $\Lambda$ ugenhöhle und begibt sich ausschliesslich in clen $\boldsymbol{M}$. obliquns superior.

Der verhältnissmässig starke $\boldsymbol{A}$ : abduceus kömmt, von den vorderen Pyramidalsträngen entspringend, an der Basis des verlängerten Markes zum Vorschein. Nachdem er durch einen Ganal des Keilbeines in die Augenhöhle getreten, gibt er zwei feine Zweige für die Muskeln der Nickhaut ab und setzt sich fort in den $\boldsymbol{M}$. rectus externus ${ }^{3}$ ).

Der N. trigeuiuus, ausser dem $\boldsymbol{N}$. opticus gewöhnlich der stärkste Hirnnerv, entspringt nit zwei Portionen. Längs des Ursprunges der ungleich beträehtlicheren Portio major zeigt sich seillich am verlängerten Marke eine eigene längliche, strangförmige Anschwellung; die Portio minor aber entspringt aus den in die Medulla oblougata fortgesetzten vorderen Rückenmarksträngen. Nur die grössere Portion bildet das röthliche oblonge Ganglion Gasseri; die kleinere Portion

1) S. d. Abb. b. A. Meckel, I. c. 'l'ab. J. Fig. 3. und bei Miiller, Vergl. Physiol. d. Gesichts. Tab. III. Fig. 1-14.

2) Vgl. Muck, de ganglio ophthalmico et nerv, ciliarib. animal., Landish. 1815, 4. - 3) Abb. bei Schlemm, 1. c. Tab. III. Fig. 2. 
trägt, gemeinschaftlieh mit Elementen, welehe aus dem Ganglion kommen. zur Bildung des dritten Astes bei. Die drei Aeste des Trigeminus sind bei den Vögeln von ungefäır gleieher Stärke. Der erste Ast tritt durch einen engen Canal der Sehedelbasis unterhalb des $\boldsymbol{N}$. quartus in die Augenhöhle. Innerhalb derselhen gibt er, ausser einer Wurzel zum Ciliarknoten oder einem Verbindungsaste zum $\boldsymbol{R}$. ciliuris des $\boldsymbol{N}$. oculorum motorins, bisweilen noeh einige feinere Rrumi ciliares ab, schickt Fäden zur Conjunetiva, zur Niekhaut, zur Harder'schen Drüse und zur Stirn, welehe letzteren aueh in Kämme und in Hautverlängerungen der Stirngegend sieh verbreiten. Er steht dureh einen innerhallb der Augenhöhle von ihm abgehenden, später zum $\boldsymbol{N}$. facialis stossenden Zweig mit dem $\boldsymbol{N}$. sympathicus in Verbindung. Der Stamm des ersten Astes verlässt neben dem $\boldsymbol{N}$. olfructorins die Augenhöhle und gelangt in die Nasenhöhle, innerhalb weleher er Zweige abgibt, die besonders an dem Septun und den unteren Museheln sich verbreiten. Eigenthümlich ist es endlieh, dass der Nerv in den Schnabel naeh vorne sieh fortsetzt 4). Er tritt nämlieh in die zellige Knoehensubstanz des Zwisehenkiefers, sendet alsbald einen stärkeren oder mehre feinere Zweige zur Graumenhaut und erstreckt sieh, unter Abgabe von Fäden zur Wachshaut, his zur Spitze des Schnabels.

Der zweite und dritte Ast des $\boldsymbol{N}$. trigeminus verlassen die Sehedelhöhle zusammen dureh ein zwisehen dem Os petrosum, dem Keilbeinkörper und der Ala magna gelegenes Loch. Der Ramus maxillaris superior tritt in die Orbita, verläuft unterhalb des Augapfels, steht dureh einen $\boldsymbol{R}$. Vidianus in Verbindung mit dem $\boldsymbol{\Lambda}$. sympathicus, gibt Zweige zur Thrïnendrïse und zur Bindehaut ab; entsendet einen für die Haut unterhalb des Auges bestimmten $\boldsymbol{R}$. sulcutanens malae, setzt sieh fort in einen Canal des Zwisehenkiefers, gibt starke Rami palatini posteriores ab, welehe zum Theil in den Warzen der Gaumenhaut enden und erstreekt sich endlich bis zur Spitze des Schnabels.

Der dritte Ast, $\boldsymbol{R}$. maxillaris inferior, tritt in die Sehläfenhöhle und giht Zweige ab für den Muskelapparat des Gaumens, des Unterkiefers und des Quadratbeines. Nach Entsendung eines Fädchens für die Parotis tritt er in den Unterkiefereanal, nimmt die Chorda tympani auf, gibt zahlreiehe Zweige ab fuir die häutigen Umgebungen des Unterkiefers, entlïsst namentlich einen $\boldsymbol{R}$. inframaxillaris externus und cinen $\boldsymbol{R}$. mylolıyoidlens und endet an der Spitze des Unterkiefers. Ein Zungenast dieses Nerven ist niemals vorhanden.

4) Besonders stark sind diese Schnabelwweige bei den Schnepfen, bei welchen der Schnabel durch eine eigenthümlich zellige Bildung z: einem nocl cour. plicirteren Tastorgane ausgebildet ist, als selbst bei den Dermorhynchi. - Ba m. berg l. c. hat bei Meleagris Gallopavo und beim Haushuhne einen Knoten des ersten Astes in Z Zwisehenkiefer beobachtet. 
Der N. facialis, rin verhältnissmässig unbeträchtlicher Stamm, kömmt zur Seite des verlängerten Markes, dieht vor dem N. reusticus zum Vorsehein. Seine Wurzeln lassen sich in dic Fortsetzung der vorderen Rückenmarksstränge verfolgen. Er trit! mil dem $\boldsymbol{N}$. acusticus in das Felsenbein, gelangt in den Fallopii sehen Canal, gibt hier eine zum $\boldsymbol{R}$. alveolaris inferior des $\boldsymbol{N}$. trigeminus verlaufende Chorda tympari 5) ab, geht Verbindungen ein mit dem N. sympathicus und verlässt die Paukenliohle durch eine hinter dem Quadratbeine liegende Oeffnung. Dann gibt er Zweige ab an den $\boldsymbol{M}$. digrestricus und den dem Stylohyoideus entsprechenden Heber des 'zungenbeines, geht häufig Verbindungen ein mit Zweigen der $\boldsymbol{N}$. N. glossophrryngeus, ungus und hypoglossus und verbreitet sich, nachdem er heständig mit dem zweiten und gewöhnlich auch init cinigen der folgenden Cervicalnerven Verbindungen eingegangen ist, in den Hautmuskeln des Nackens und Halses.

Die Wurzeln des neben dem $\boldsymbol{N}$. fucialis austretenden $\boldsymbol{N}$. acus $\mathbf{i}$ cus $\left.{ }^{6}\right)$ lassen sich deutlieh in den Boden der vierten Hirnhöhle verfolgen. Der Nerv tritt init vier Aesten in das Labyrinth des Gehörorganes; drei dieser Aeste ( $\boldsymbol{N}$. vestibuli) sind für die Ampullen der halbeirkelförmigen Canaile, der vierte $(\boldsymbol{N}$. cochleae) ist für die Schnccke bestimmt.

Der $\boldsymbol{N}$. glossopharyngeus entspringt mit einer doppelten Reihe von Wurzeln, welche denen des $\boldsymbol{N}$. vogus eng verbunden sind, aus den Seitensträngen des verlängerten Markes. Seine WTurzeln bilden noch innerhalb der Schedelhöhle ein Ganglion, das init demjenigen des $\boldsymbol{N}$. vagus innig verbunden ist. Aus diesem Ganglion hervorgetreten, verlässt der Nerv, neben dem Vagus, und zwar gewöhnlich durch ein eigenes Foramen des Occipicale laterale dic Schedelhöhle, liegt den Ganglion supremum. $\boldsymbol{N}$. sympathici, mit dem or verbunden ist, eng an und bildet selbst sogleich aufs Neue eine gangliöse Ansehwellung. Zugleich empfängt er jetzt cinen - oft schr starken - Verbindungszweig vom $\boldsymbol{N}$. vagras. Aus dem so gemischten Stamme entstehen wonigstens zwei Hauptäste: ein $\boldsymbol{R}$. liugurlis und ein $\boldsymbol{R}$. descendens. Ersterer erstreckt sich zwischen den Muskeln des Unterkicfers und des Zungenbeines mit Elementen des $\boldsymbol{N}$. facialis und häufig auch mit einem Aste des $\boldsymbol{N}$. hypoglossus verbunden, unter Abgabe einzelner Zweige für die Zungenbeinmuskeln und für die Schlcimhaut und die Wärzchen der Fauces, zur Zunge. Er verläuft bei den mit ausgebilde-

5) S. d. Abb. bei Platner, Ueber d. Quadratbein, T'ab. II. Fig. 8. (Vor der Krähe.)

6) Nach Treviranus Beobachtungen verläuft bei vielen Vögeln der $\boldsymbol{N}$. ve. stibuli in der Bahn des $N$. facialis. Bei Arlea cinerea findet noch eine Verbindung Statt zwischen dem $\boldsymbol{N}$. coclileae und dem auf die genannte Weise zu. sammengesetzten Facialis. Tiedeın. u. Trevir. Zeits. f. Phys. Bd. V. Heft 1. 


\section{Vierter Abschuitt. Vom Nervensysteme u. v. d. Sinnesorganen. 285}

terel Zunge versehenen Vögeln unter Entsendung zahlreicher unter der Haut und in den Wärzchen der Zunge sich verbreitender Zweige, bis zur Zungenspitze. Der Ramus descendens, in den vorzugsweise oder ausschliesslich in Folge der oben erwïhnten Verbindung die Elemente des $\boldsymbol{A}$. vagus übergegangen sind, zerfïlt in melure Rami pharyngei, einen beträehtlichen $\boldsymbol{R}$. oesophageus und cinen für den oberen Kehlkopf bestimuten R. Iaryngens superior.

Die zahlreichen Wurzeln des $N$. va gus haben einen ganz ähnlichen Ursprung, wie diejenigen des $\boldsymbol{N}$. glossopharymgeus. Sie werden verstärkt durch den oberhall des dritten Cerviealnerven von dem Rückenmarke entspringenden und dann allmälieh noch feine Wurzeln aufnehmenden $\boldsymbol{N}$. accessurius. Nachdem der $\boldsymbol{N}$. vagus noch innerhalb des Schedelcanales sein Ganglion gehildet, tritt er aus dem Foramen jugulare, steht in Verbindung mit dem Ganglion des $\boldsymbol{N}$. sympaIhicus und schickt einen bedeutenden Verstärkungsast zum $\boldsymbol{N}$. glossopharyngeus, durch dessen Empfang dieser Nerv oft beträchtlicher wird, als der Stamm des N. vagus. Dieser letzterc gibt bisweilen einen Zweig in Muskeln der Nackengegend, bei einigen Papagcien auch einen Zungenzweig $a b \%$. Dann verläuft er an der Aussenseitc des Halses abwärts, gibt cinen $\boldsymbol{R}$. recurress ab, der an dem unteren Kehlkopfe und an seinen Muskeln, so wic auch an der Speiseröhre sich verzweigt. Innerhalb der Brusthöhle giht der $\boldsymbol{N}$. vagus Zweige zur Lunge, zum Herzen, zur Speiseröhre, zum Magen. Diese zum Theil in Gefleehte sieh auflösenden Zweige stehen mit Sehlingen des $\boldsymbol{N}$. sympatlicus in vielfacher Verbindung.

Der $\boldsymbol{N}$. / $y$ yoglossus entspringt, wie ein Spinalnerv, mit zwei Wurzeln an der Grenze der Medlulla ablongata und des Rüekenmarkes. Naehdem er durch das Foramen condyloideum des Schedels getreten ist und mit dein $\boldsymbol{N}$. sympattricus, so wie bisweilen auch mit dem $\boldsymbol{N}$. vagus durch feine Fädchen sich verbunden hat, theilt er sieh in zwei Aeste, von denen der eine in die Zungenmuskeln und an die Unterfläche der Zunge sich begibt, während der andere als Ramus descenderss zur Seite der Luftröhre absteigt, dem $\boldsymbol{R}$. recurrens Vagi entgegengeht und an der Speiseröhre, so wie in die Muskeln der Luftröhre (namentlich den $\boldsymbol{M}$. sternotrnchealis und furculo-(rachealis) sich vertheilt.

[ Man vgl. über die Hirmnerven der Vögel ausser den schon früher angeführten Schriften von Tiedemann, A. Meckel, E. H. Weber, Bischoff, Swan, Thuet, auch noch Schlemin, Observationes neurologicae, Berol. 1834, 4. mit Abbild. - Ritzel, Conmentatio de nervo trigemino et glossopharyngeo avium, Febr. 1843, 8. Bauberg, De avium nervis rostri atq. linguae, Hal. $1842,8$.

7) Nach den Beobachtungen von W. Rapp, Die Verrichtungen des fünften Hirnnervenpaares, Leipz. 1832, 4. S. 10. - S. darüber auch Thuet, p. 31 . 


\section{Vom Nervus sympathicus.}

§. 135.

Behufs der Verfolgung des sympathischen Nerven der Vögel wird am besten das Grnglious cervicale supremum zum Ausgangspunkt gewählt. Dasselbe liegt in der Austrittsstelle des $N$. glossophiaryugeus und $\boldsymbol{N}$. vregys, und ist inniger mit jenem, als mit diesem Nerven ver. bunden. Von diesem Ganglion aus erstrecken sich zwei Zweige vor wärts, um Verbindungen mit dem $\boldsymbol{N}$. facialis und $\boldsymbol{N}$. trigemiuus einzugehen 1). Der eine dieser Zweige begibt sich in den Fallopi'schen Canal, erscheint in inniger Verbindung mit den $\boldsymbol{N}$. facialis und bildet ein Geflecht, dessen Fäden theils mit dem zweiten Aste des $N$. trige $\boldsymbol{c}$ minus ${ }^{2}$ ) sich verbinden ${ }^{3}$, theils zur Thränendrüse sich begeben. - Der zweite Zweig erstreckt sich in den Canalis caroticus, tritt in Verbindung mit Fäden des $\boldsymbol{N}$. glossopharyugeus und $\boldsymbol{N}$. facialis und verlässt den genannten Canal, um als $\boldsymbol{N}$. Vidlimuıs an der Innenwand der Augenhöhle vorwärts sich zu begeben. Er gibt Rami palatini, R. nasales posteriores und Fädchen zur Harder'schen Drüse ab, nm endlich da mit dem ersten Aste des $\boldsymbol{N}$. trigemiuns sich zu verbinden, wo dieser die Augenhöhle vorn verlässt. In der Regel wvird an dieser Verbindungsstelle ein Ganglion vermisst.

Der vom Ganglion cervicale supremum ansgehende Halstheil des sympathischen Nervensystemes besteht 1) in Zweigen, welche die Carotiden begleiten und 2) in der eigentlichen Fortsetzung des Grenzstranges, welche im Wirbelcanale verläuft. - Die zu den Carotiden tretenden Zweige stehen unter einander durch mittlere Schlingen in Verbindung, oder treten, wie namentlich beim Vorhandensein einer einfachen Carotis cummunis 4), zur Bildung eines einfachen Stammes zusammen, der dann ganz ähnlich sich verhält, wie bei den Crocodilen. - Die Fortsetzung des Grenzstranges begibt sich, nachdem sie zuvor unter Bildung kleiner Ganglien sowol mit dem $\boldsymbol{N}$. hypoglossus, als mit dem ersten oder den beiden ersten Cervicalnarven in Verbindung getreten ist, in den Wirbelcanal. Innerhalb desselben verläuft sie

1) Verbindungen mit dem $N$. abducens und dem $N$. oculorum motorius sind bisher nicht allgemein und mit Sicherheit nachgewieseen; indess erwähnt Cuvier der ersteren Verbindung und Swan beobachtete beim Pelican eine Verbindung mit dem Zweige des Oculorum motorius, der zum M. obliquus inferior. tritt. - 2) So namentlich bei der Gans.

3) Bei der Eule ist von Treviranus ein Ganglion sphenopalatinum beobachtet.

4) Z. B. beim Pelican nach Swan. Hier verbinden sich die Enden dieser Carotidenzweige unten wieder mit den ersten Ganglia thoracica. Aehnliche Beobachtungen hatte früher schon Emmert mitgetheilt in Reil's Archiv fiir Phys. Bd. XI. S. 120. 


\section{Vierter Abschnitt. Vom Nervensysteme u. v. d. Sinnesorganen. 287}

einfach abwärts und gelıt mit den $\boldsymbol{R}$. anteriores aller Cervicalnerven unter Bildung ron, ilınen fest aufsitzenden, Ganglien sehr innige Verbindungen ein. Die den letzten Cervinalnerven und sämmtlichen Dorsalnerven entspreclıenden Ganglien des Grenzstranges stehen dagegen, wie bei den Clicloniern, durch zwei Lüngsschlingen unter einander in Verbindung, die durcl die Capitula der Rippen von einander so getrennt werden, diss die cine innerhalb des zwischen Capitulum und Tuberculurı der Rippen liegenden Canales, die andere aber ausserhalb desselben verläuft. In Sacraltheile der Wirbelsäule wird der Grenzstrang wieder einfacl. Unterhalb der Steissbeinwirbel rücken die Ganglien beider Grenzstränge an einander und verschmelzen endlich. - Aus dem Ganglion thoracicum primum treten Zweige ab, welche init Zweigen des $\boldsymbol{N}$. vagrus verbunclen, zum Ilerzen und zu den Lungen sich begehen. - Die Elemente des $\boldsymbol{N}$. splanchinicus bestehen aus Zweigen, welche von allen oder wenigstens ron den meisten Gauglia thoracica abtreten. Obere Zweige sammeln sich zu einen absteigenden, untere zu einem aufsteigenden Aste. Diesc beiden Aeste vereinigen sich bald unter Bildung einer Anschwellung, bald ohne eine solche jedcrseits zu cinem Stamme, der zur Arteria coeliaca tritt. Dic Aestc des so gebildeten $\boldsymbol{N}$. splanchmicus begeben sich in Begleitung der Gefässstärnme zu den Eingeweiden; die Magenäste gehen Verbindungen ein mit Zweigen des $\boldsymbol{N}$. vagurs. Tiefer abwärts entsteht aus den unteren Riickenganglien ein zweiter Stamm, der zur Nebenniere tritt und Zweige zum Dünndarm und zu den inneren Geschlechtstheilen sendet. Andere Zweige aus den Ganglien des Grenzstranges sind für die Nieren und für den Dickdarm bestimmt. Die letzteren bilden ein Geflecht an der A,\% mesenterica prosterior.

[Man vgl. über das sympath. Nervensystem die Schriften ron E. H. W eber 1. c. p. 24, Swan p. 103, Schlemm p.18. - S. auch noch Einmert in Reil's Arehiv Bd. XI. p. 117.]

\section{Von den Geruchsorganen.}

s. 136.

Die äusseren Nasenöffnungen sind einfache Löcher, ohne bewegenden Muskelapparat, welche häufig, wie z. B. bei den Krähen, durch straffe Ferlerchen oder durch knorpelige fligelartige Theile geschïtzt werden und bei den Sturmvögeln röhrig verlängert sind. Bald sind sie weit, bald äusserst eng ${ }^{1}$ ) oder gar fehlend. Ihre Lage bietet beträchtliche Verschicdenheiten dar. Wiilırend sie bei der Mehrzahl der Vögel seitwärts mehr oder minder gegen die Mitte des Schnabels hin

1) Sehr eng bei mehren Wasservögeln, z. B. Ardea, Pelecanus, Plotus, be. sonders bei Halieus und auch bei Sula alba und melaurara; wo die Oeffnungen erst neuerlich durch Schlegel nachgewiesen sind. Derselbe vermisste sie jedoch bei Sula piscatrix und parva völlig. 
liegen, finden sie sieh bei Apteryx fast an der äussersten Spitze dieses hier so sehr verlängerten Grebildes ${ }^{2}$ ), zeigen sich dagegen bei den Rhamphastiden oben an der Sehnabelwurzel. Da die die beiden äusseren Nasenöffnungen inwendig trennende Seheidervand nieht iminer vollständig ist, so unterseheidet man Nares imperviae und perviae, welehe letzteren am häufigsten bei Wasservögeln vorkommen. Weiterhin ist die durch den Vomer gestützte Seheidewand der eigentliehen Nisenhöhlen grösstentheils knorpelig; der hinterste knöeherne Theil wird dureh das Siebbein gebildet. - Die sehmalen, engen hinteren Nasenöffnungen liegen dicht an einander oder fliessen zuletzt zu ciner einzigen zusammen; dieht hinter ihnen-liegt die einfaehe Oeffnung der Eustachisehen Tuben; seitlich und namentlieh hinten sind sie of von Epithelialpapillen umgeben, zwisehen welehen Schleimfollikel sieh öffnen. Die Entfernung der hinteren Nasenöffnungen von den vorderen ist selır versehieden; ungewöhnlieh gross bei Apteryx, am geringsten bei Bueeros, wo jene fast gerade unter diesen liegen. Die Fläehenvergrösserung innerhalb jeder der weiten Nasenhöhlen gesehieht meistens dureh blosse Einbiegungen oder Einstülpungen ihrer knorpeligen Grundlage, die sogenannten Museheln. Immer sind, mehr oder minder bestimmt, drei Museheln zu unterseheiden, welehe, wie überhaupt, so auch namentlieh rüeksiehtlich ihrer relativen Ausbildung maneherlei Verseliedenheiten zeigen. Bei den Raubvögeln, namentlieh den Eulen, so wie bei vielen Wasservögeln ist die oberste Musehel - welehe, nebst dem Septum, der Ausbreitung des Geruehsnerven zur Grundlage dient - am meisten entwickelt, während bei den Iühnern, den Störehen die deutlich gerollte mittlere Musehel vor jener bedeutend prävalirt. Die untere Muschel endlich, welche bei den Hühnern, den Störehen, den Schwimmvögeln u. A. unbedeutend ist, zeigt bei den Passerinen und namentlich bei den Casuaren sehr zusammengesetzte labyrinthartige Bildıngen. Die Rhamphastiden zeiehnen sich dureh den Besitz knöeherner Museheln aus. - Die ganze Nasenhöhle ist von einer zarten, weiehen, sehr gefässı'eiehen, flimmernden Sehleimhaut iusgekleidet. Sic communicirt oft mit subeutanen Luftzellen, so wie aueh bei Anas elangula dureh eine weite obere Oeffnung mit den grossen Höhlen in der oberen Schedelwand ${ }^{3}$ ).

Eine in die Nasenhöhle mittelst eines einfachen Ausführungsganges mündende, gewöhnlieh derbe, harte, braunroth oder sehwärzlich gefärbte. Nasendrüse kömmt den Vögeln sehr allgemein - und vielleieht

2) S. 0 wen 1. e. Tab. XLVII. Fig. 1. Bei diesem merkwürdigen, durch die Kleinheit seiner Gesieltsorgane ausgezeichneten nächtlichen Vogel ist, nach 0 wen, überhaupt das Geruchsorgan sehr ausgebildet. Er liefert das einzige Beispiel von Existenz einer wirklichen Lamina cribrosa des Siebbeines.

3) Unrichtig ist Meckel's Angabe über den Mangel dieser Communieation (Arehiv 1832); Nitzsch hat sie richtig beobachtet.

4) Am meisten entwickelt ist sie bei viclen Wasservögeln; namentlich bei 


\section{Vierter Abschnitt. Voin Nervensysteme u. v. d. Sinnesorganen. 289}

ohne Ausnahme - zu. Fs bietet dies Gebilde rücksichtlich seiner Lage und seines Unfanges beträchtliche Verschiedenheiten dar. Am häufigsten liegt sie oben auf den Stirnbeinen und zwar entweder in mehr oder minder beträchtlichen, an der Oberfläche des Orbitalsegmentes befindlichen bogenförmigen Gruben dieser Knochen ${ }^{5}$ ) oder nur längs des Randes der Orbitae, den sie dann oben begrenzt 6$)$. Seltener liegt sie unter den Nasenbeinen i) oder vorn in der Angenhöhle am inneren oder vorderen Augenwinkel ${ }^{8}$ ), oder unter den Augen, über den Graumenbeinen, bedeckt von der den Boden der Angenhöhle bildenden fibrösen Membran 9 ).

[Man vgl. über das Geruchsorgan der Vögel die schon früher citirten Schriften von Scarpa nnd Harwood; ïber die Rhauphastiden, ansser Cuvier und Meckel (Archiv 1832), besonders 0 wen in 'Toddl's Cyclop. p. 310; über Apteryx 0 wen l. c. - Ueber die Nasendrüse den vortrefflichen, in das kleinste Detail eindringenden Aufsatz von Nitzsch in Meckel's Archiv f. Phys., Jahrgang 1820, Thl. 6. S. 234., in welchem anch die älteren Beobachtungen, namentlich die von Jacobson kritisch mitgetheilt werden. - Ueber den feineren Ban dieser Drïse s. Müller, d. glinul. struct., p. 53.]

\section{Von den Gesichtsorganen.}

\section{\$. 137.}

Die Angen der Vögel 1) sind in der Regel ansgezeichnet durch ihren, in Verhältnisse zum Gehirne sowol, als zum Schedel beträchtlichen Unfang, sind auch nie blos rudimentiir vorhanden oder gan\%

vielen Enten, bei Cygnins, Aptenodytes, Alca, Mormon, Larus, Haematopus, Nuinenius, Recurvirostra, Totanus, Tringa. Bei inehren Tringae so stark, dass die beiden Drüsen in der Mitte an einander stossen und die Stirn ganz bedecken. Bei den Passerinen ist sie in Ganzen klein; hier noch an stärksten bei Cinclus; wenig entwickelt bei den Reihern, Störchen, Hühnern, bei Caprinulgus. Bei allen Struthionen und anch bei Apteryx vorhanden. Bisher vermisst bei den Tauben, Coracias, Cuculus, Halieus, Steatornis.

5) Bald ist die Grube des Stirnbeines, in welcher die Driise liegt, vollstän. dig begrenzt (wie bei Charadrius, Oedicnemus, Hypsibates, Himantopus, Alca), wo sie denn vorn von dem in die Nase sich begebenden Ausfïbrungsgange durch. bohrt wird; - balı ist sie nur hinten nnd innen alogeschlossen nnd läuft nach vorn frei in den Orbitalrand aus (wie bei einigen Striges, bei Glareola, Cursor, Actitis, Haematopus, Larus, Sterna, einigen Enten [A. fusca]).

6) Bei den Passerinen, mit Einscliluss der Kräherı, bei welchen letzteren sie sich aber noch etwas in die Augenhöhle erstreckt; ferner bei Upuja, Alcedo, Yunx, Caprimulgus, Cypselıs, den meisten Hühnern, den meisten Scolopax.Arten, den Fulicarien, Grus, Anser, Cygnus, vielen Enten, Colymbus, Strothio.

i) Bei den Edeffalken, len Trappeu, der Waldschnepfe.

8) Bei den Tagraubvögeln, einigen Eulen (Strix alnco), ılen Papageien, bei Ardea, Ciconia. - 9) Bei den Spechten.

1) Die breiten Augenböhlen sind durch ein nicht immer ganz vollst:indiges Septum von einander getrennt.

Vergl. Anatomle von Siebold u. Stanvius. 
fehlend 2). Bei der verhältnissmässig bedeutenden Grösse des Bulbus ist seine Freibewegliehkeit ziemlich beschränkt. Fr besitzt drei A ugenlider, indem zu dem oberen und dem unteren regelnässig noch die Nickhaut hinzukömmt. Das olsere und unterc Augenlid sind inwendig von der Bindehaut ausgekleidet; das untere ist bei der Mehrzahl der Vögel dureh den Besitz einer zwiseben seinen Hiuuten liegenden Knorpelscheibe ausgezeiehnet ${ }^{3}$ ). Die Muskeln der beiden horizontalen Augenlider sind oft ganz abortiv; wo sie ausgebildet sind, unterscheidet man einen $\boldsymbol{M}$. levator palpebrae superioris, einen Depressor palpebrae inferioris, so wie einen M. orbicularis palpebrarum. Das untere Augenlid ist beweglicher als das obere. - Die Niekhaut ist eine meist durchsiehtige, bisweilen perlweisse Hembran, welehe von der inneren Seite des Auges über dessen vorderen Umfang gezogeŕ werden kann. Thre Bewegungen stehen unter Einfluss eines sehr eigenthümliehen Muskelapparates, der erst naeh Entfernung der $\boldsymbol{M}$. M. recti völlig deutlieh wird. Der eine dieser Muskeln: M. quadratus s. Lursalis besitzt nur einen festen Ansatzpunkt oben an der Sclerotica, naeh dem hinteren Augenwinkel hin. Von hier aus steigt er abwärts bis dieht oberhalb des Sehnerven, wo er frei endend dureh das Auseinanderweichen seiner Bündel eine Tasche oder eine Scineide bildet, bestimmt zur Aufnahme der Sehne des zweiten Muskels. Dieser Muskel, M. Myramidalis bildet einen Bogen un den Sehnerven; er entspringt fleisehig unten von der Selerotiea naeh dem vorderen Augenwinkel zu, geht dann in eine Sehne ïber, welehe durch die beiden Laminae des M. quadratus hindurehtritt und kehrt darauf zum inneren Augenwinkel zurüek, wo seine Sehne in die Niekhaut iibergeht ${ }^{4}$ ). Der Verlauf der Sehne dieses Muskels innerhalb der Scheide des M. quadratus verhütet allen Druck auf den Sehnerven, bei Anspannung des $\boldsymbol{M}$. $\boldsymbol{\eta} \boldsymbol{y}$ ramidalis, welcher, in Verbindung mit jenem, die Niekhaut vor das Auge zieht. - Die Harder'sche Drüse - von einfaehen Baue, ans traubenförmigen Bläsehen oder Zellen - bestehend 5) - ist meist von weisser Farbe, gross und liegt immer am inneren Augenwinkel. Sie öffnet sich mit einem weiten Ausfübrungsgange unter der Nickhaut. -

2) Nach 0 wen's Bemerkung ist bei dem näehtlichen Apteryx der Augapfel verhältnissmässig kleiner, als bei irgend einem andern Vogel; relativ am grössten sind die Augen dagegen bei den Eulen.

3) Diese Knorpelplatte fehlt z. B. bei den Eulell, bei Ciconia, Ardea, Cygnus, Anas, Mergus u. a.

4) Uin das Ausgleiten dieser Sehne zu verhüten, bildet bei manehen Vögeln die Selerotiea einen kleinen Vorsprung; so z. B. beim Schwan; bei den Eulen aber findet sieh zu ähnlichem Zwecke ein eigenes, an den unteren Theil des Knochenringes der Sclerotica befestigtes Knöchelehen (Os tuberculare). Vergl. Nitzs ch, Osteog. Beitr., S. 78. Taf. 1. Fig. 6. u. 7.

5) Ueber ihren Bau s. Müller, de gl, sec. struct, p. 51. Tab. V. fig. 6. 7. 


\section{Vierter Abschnitt. Vom Nervensysteme u. v. d. Sinnesorganen. 291}

Die eigentliche Thränendrüse ist gewölnnlich verhältnissmässig klein und liegt am :iusseren Angenwink(c) 6). Der" weite hiutige Thränencannal, der in die Nasenhühle miindet, beginnt mit zwoi Oeffnungen an inneren Augenwinkel. - Zur Bewegung des Bulbus dienen vier $\boldsymbol{M}$. $\boldsymbol{M}$. recti und zwei $\boldsymbol{M}$. $\boldsymbol{M}$. olliqui; sie sind sämmtlich durch ihre Kiirze ausgezeichnet; die schiefen Nuskeln entspringen von der vorderen Wand der Orbita; die geraden nehnen ihren Ursprung im Unkreise des Sehnervenloches und befestigen sich flach aponeurotisch an der Ilinterfläche der Sclerotica ausserhalb ihres Knochenringes.

Der Bulbusi) der meisten Vögel ist durch die Stärke des Vorsprunges, den sein vorderes Seginent vor dom hinteren macht, ausgezeichnet. Das hintere Segunent bildet eine beträchtliche Halbkugel, die durch einen verengten, bisweilen fast cylindrischen Theil in das vordere Segment, das den Abschnitt eines weit kleineren Kreises bildet, übergeht. An wenigsten tritl dies Verhältniss bei den Wasservögeln, am schärfsten bei den Eulen hervor. Bei den meisten Landvögeln ist die Axe des Auges eben so gross oder wenig geringer, als der Querdurchmesser, während bei den Wasservögeln dieser jene bedeutender iibertriff. - Die Sclerotica besteht aus drei Schichten, von denen die innerste durchsichtig und briichig ist. Sie ist hinten diinn, biegsam, elastisch; vorn im Umkreise der Cornea wird sie durch einen Knochenring unterstitzl, welcher dem Auge eine bestimmte Form sichert. Dieser Scleroticalring, der bei den Eulen anı grössten ist, besteht aus dachziegelförmig über einander liegenden Platten. Ihre Zahl 8) schwankt zwischen 12 und 30 ; sie sind gewöhnlich von oblong-viereckiger Form, bisweilen aber auch unregelmässiger gestaltet; in der Mitte sind sie ge wölnnlich am dicksten und auch einwärts gebogen; die Ränder, besonders der vordere und hintere, sind etwas zugeschärft. Sehr dick sind sie bei den Eulen. Dicht hinter den Hornhantrande theilt sich die Sclerotica in zwei Platten: eine innere und eine äussere, zwischen welchen dieser Knochenring hineingeschoben ist; die äussere setzt sich gleichmässig über seine Aussenfläche fort. Die innere ist an der vorderen und hinteren Grenze der Knochenplatlen dicker, in seiner Mitte diunner. - Die Gornea ist durch die Stärke ihrer Wölbung ausgezeichnet, welche aber bei den Schwimmvögeln schon weniger hervor-

6) Bei einigen hühnerartigen Vögeln übertrifft sie indessen die Harderscbe Drüse an Unfang.

7) Abbild. bei Soein un erring, de sect. horizont., Tab. 3.

8) Ueber ihre Zahlenverhältnisse s. besonders A lbers, Beitrige z. Anat. u. Physiol., Bremen 1802, mit r. Abbild. Der Casuar hat z. B. 12; Rudolphi fand bei Alca arctica 30, 15 kleinere vordere und eben so viele hintere grössere. Wenn Allis angibt, es werle bei Podargus die Zusammensetzung aus einzelnen Knochenplatten vermisst, so ist er in Irrthume; sio sind, wie ich mich bei P. femo. ralis überzeugt, vorhanden, nur dünn, knorpelartig und sehr schwer zu treunen. 
tritt. - Dic innere Fläche der Chorioïdea ist reichlich mit schwarzem Pigmentc überzogen. Das ringförmige Li gamentum ciliare ${ }^{9}$ ) ist bei den Vögeln sehr breit und zeigt eine zusarnmengesctzte Bildung. Anscheinend sind Muskelfasern in dem Theile desselben (dem sogenannten Crampton'schen Muskel, dem Fuserkranze von Treviranus) ent. halten, welcher die äussere Wand des Canalis Fontanae mit der inneren des Knochenringes verbindet. Der Ca ualis Foutanae sclbst liegt zwischen dem Rande der Sclerotica und Cornea cinerseits und dem Ligamentum ciliare andererscits. Das Corpus ciliure ist breit, sehr faltig ${ }^{10}$ ) und geht in zahlreiche Ciliarfortsätze iiber, deren Enden an der Linscnkapsel haften. - Eigenthïmlich ist dem Vogelauge wieder der, schon bei einigen Sauriern vorhandene, Kamm oder Fächer, der nur der Gattung Apteryx fehlt ${ }^{11}$ ). Es ist dies eine der Chorioïdea angehörige, von der Eintrittsstelle des Nervus opticus aus schräg und keilförmig durch den Glaskörper tretende, gegen den Rand der Linsencapsel gerichtete und oft mit ihm verbundene 12), gefaltete, pigmentund gefïssreiche Membran, welche bald breiter, bald schmäler ist. Die Zahl der Fächerfalten ist, je nach den Gattungen und Familien, sehr verschieden: am geringsten bei Caprimulgus und den Eulen ( 5 bis 7); am grössten bei den Passerinen (bis 30 ; obwol gewöhnlich nur 1620). Seine Artericn erhält der Fächcr aus eincm an der Eintrittsstelle des Schnerven in den Bulbus unter der Sehne des $\boldsymbol{M}$. myramidalis liegenden Rete mirabile pectinis; nachdem die aus ihm kommenden Arterien in den Augapfel gedrungen sind, verbinden sie sich zu einem Stamme, aus welchem die Zweige zu den einzelnen Falten des Kammes gehen. - Die Iris ist ausgezeichnet durch die Lebhaftigkeit ihrer Bewegungen, welche anscheinend auch unabhängig von der Menge des einfallenden Lichtes und willkürlich eintreten. Ihre Breite ist sehr verschieden; am beträchtlichsten bei den in der Dämmerung fliegenden Eulen und Ziegenmelkern. Die eigentliche Iris besitzt vorn eine Pigmentschicht ${ }^{13}$ ), von deren mannichfacher Beschaffenheit die verschie-

9) Der feinere Bau dieses Gebildes ist noch nicht hinreichend aufgeklärt. Selır sorgfältige Angaben über sein Verhalten finden sich bei Huek, die Bewe. gung der Krystallinse, Dorpat 1839, 4. S. 91 ff., der seine einzelnen Theile strenge scheidet und die Existenz von Muskelfasern läugnet, welche, nach Crampton, durch Treviranus und namentlich durch Krohn vertheidigt ward und von der ich, bei früheren Untersuchungen, gleichfalls inich überzeugt zu haben glaube.

10) Die Faltell sehr fein, die Fortsätze sehr lang bei den Eulen.

11) Nach Owen. - Ueber die Zahl der Fächerfalten s. besonders die An. gaben von Socinmerring, von Huschke und von Wagner (Münch. Denkschriften 1832. S. 295.). Ueber die Gefässe Barkow, in Meckel's Archiv 1829. 1830. - 12) Z. B. bei der Gans, lem Schwan, dem Storch u. v. a.

13) Interessant ist Wagner's Bemerkung, dass die gelbe Färbung der Iris bei den Eulen durch ein in traubigen Bälgen und Zellen enthaltenes flüssiges Fett zu Stande kömmt. Aehnlich verhält es sich, nach Krohn, beim Hubne. 
denc Färbung derselben abhängt, und dann cine Faserschicht, deren concentrisch verlaufende, wenig sich kreuzende Primitivbiindel wenigstens muskelähnlich sind. Hinten ist sie von dem Pigmente der Uvea übcrzogen. - Die Pupillc ist gcwöhnlich rund, selten transverscl verlängert odcr vertical-oval. - Die Netzhaut bietct im Ganzen nichts Eigenthümliches dar. - Bei der beträchtlichen Convexität dẹ Cornea und der bedeutenden Ausdehnung der vorderen Augenkammer ist die von der Membrana humoris aynei umschlossenc wässerige Feuchtigkeit gewöhnlich sehr reichlich vorhanden. - Die Linse zeichnct sich bei den stark und hoch fliegenden Vögeln durch mangclnde oder wenig hervortretende Convexität ihrer Vorderfläche aus, die dagegen bei den nächtlichen Vögeln, wie bei den Eulen, bei Caprimulgus, $\Lambda$ ptcryx sehr bedeutend ist, während die Schwimmvögel zwvischen diesen beiden Extremen die Mitte halten. Die Capsel, in welcher sie eingeschlossen ist, erhält ihre Gefässe vom Kamme aus. - Der Glaskörper, in seiner Membrana hyaloülea eingeschlossen, ist in Vergleich zum Humor. aqueus in nicht gerade bedeutender Menge vorhanden.

[Die ältere Literatur über las Vogelauge findet sich zusammengestellt bei Ticdemann l. c. - S. Soemmerring, de oculor. sect. horizo, Gött. I818, fol. - G. K. Treviranus, Beiträge z. Anat. u. Physiol. der Sinneswerkzeuge, Heft 1. Bremen 1828. Fol. S. 83. - Huschke, Comm. de pectinis in oculo avium potestate, Jen. 1827, 4. - A. Krohn, Ueber die Structur der Iris der Vögel, in Müller's Archiv 1837. S. 357. - Ueber den feineren Bau der Retina; Hannover l. c.l

VII. Von den Gehörorganell.

§. 138.

Durch den Bau ihres Gehörorganes schliessen sich die Vögel auf das engste an die Crocodile an. Es fehlt ihnen noch ein äusseres Ohr, dessen Mangel bci Einigen durch ein eigenthümliches Vcrhalten der Federn im Umkreise des äusseren Gehörganges, bei anderen aber, und zwar namentlich bei den Eulen, durch eine bewegliche, halbmondförmigc, häutige Klappe ersctzt wvird. Der äussere Gehörgang selbst ist kurz, weit, häutig und von einer schwach gefalteten Fortsetzung der äusseren Haut ausgckleidet. Eine verdünnte Fortsetzung der letzteren ibcrzieht auch das im Grunde des äusseren Gehörganges ausgespannte, etwas convex nach aussen vorragende Trommelfell. Dicse Membrana tymı)ani befestigt sich an einem unvollständigen Knochenringe, welcher aber nicht durch einen eigenen Knochen, wie bei den Säugthicr'n, sondern durch die zunächst gelegenen Knochen, närnlich das Splienö̈lcum basilure, das Occipitale laterale und die Squame. comparalis gebildet, nach vorn jedoch gewöhnlich durch einen fibrocartilaginösen Strcifen ergänzt wird, so dass dic Bewcgungen des zunächst gelegenen Quadratbeines keinen Einfluss auf das Trommelfell 
ausuiben 1). Das letztere ist schief abwärts gerichtet ınd von'mehr oder minder ovaler Gestalt. Dic dureh dasselhe aussen verschlossene Pau-

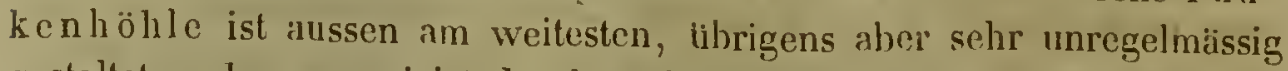
gestaltet und communieirt dureh mehre Oeffnungen mit den Zellen der Sehedelknochen, so wie namentlich auch mil dem gewöhnlich pneumatischen Paukenbeine. Sic steht mit der Rachenhöhle dureh die im Ganzen weite Tula Eustachii in Verbindung. Diese verläuft zum grossen Theile innerhalb des sphenoüleum Gusilure als knöcherne Röhre. An der Schedelbasis, da wo der breitere Abschnitt des genannten Knochens unter einem Vorsprunge in den schmäleren übergeht, verlassen beide Tuben den Knochen, werden cartilaginös, und verschmelzen zu einer einzigen Röhre, welche mit einer länglichen, in der Längsaxe des Schedels befindlichen Oeffnung, die häufig seitwärts mit kleinen Wärzehen besetzt ist, hinter der hinteren Nasenöffnung in den Rachen mündet.

Der cinzig vorhandene wirkliche Gehörknochen (die Colunella) entsprieht dem Steigbiigel; cr besitzt einen langen Stiel, der an seinem Ende cine ovale oder seheibenförmige Platte trägt, die das in das Vestibulum führende cirunde Fenster verschliesst; sehr selten ist der Sticl vor seiner Befestigung an der Platte zweisehenkelig ${ }^{2}$ ). An scinem anren Ende hat der Sticl zwei oder drei cartilaginöse Fortsätze, welehe in einem Dreiecke an dic Membrana tympani sich befestigen und als Andeutungen des Hammer und Amboss betrachtet worden sind. Ein einziger Muskel, weleher fleisehig von dem Ilinterhauptsbcine entspringt, heftet sich sehnig an die eartilaginösen Fortsätze der Columella und an dic Membrana tympani, welche er nach innen zicht; seinen Antagonisten bildet eine kleine Sehne, welche rom Paukenhöhlengelenke des Quadratbeines an den knorpeligen Fortsatz der Columella tritt.

Das von mehren Sehedelknoehen umschlossene Labyrinth besteht in dem Vorhofe (Vestibulum), drei halbcirkelförmigen Canälen und der Schnecke. Das knöeherne Labyrinth schliesst ein entspreehendes nicinbranös-knorpeliges ein. Zwisehen den knöchernen und den häutigen Theilen befindet sich eine wässcrige Feuchtigkeit. Der Vorhof stellt cine verhältnissmässig kleine, unregelmässige, gleich den halbcirkelförmigen Canälen, eine Flüssigkeit enthaltende, Höhle dar. In der Flüssigkeit des Vorhofes sind ein Paar unbedeutende flockige, aus kohlensaurer Kalkerde bestehende Concretionen enthalten. Die halbcir-

1) Bei den Hühnern findet sich ein völlig gesehlossener solider Paukenring, worauf Platner zuerst aufmerksam gemacht hat, indem die Lücke zwischen der Sehläfenschuppe und dem Sphenö̈deum Lasilare durch Knochensubstanz aus. gefüllt ist.

2) So finde ich ihn sehr steigbügelähnlich z. B. beim neuholländischen $\mathbf{C a}$. suar; eben so, gleich Meckel, beim Pelican. 


\section{Vierter Abschnitt. Vom Nerrensystome u. v. d. Sinnesorganen. 295}

kelförmigen Can ïlr 3) liegen so, dass der äussere und der hintere Canal sich kreuzen, indeu dieser iiber jenen weggeht. Es sind drei Ampullen rorhanden, welclie, gleichwie bei den iibrigen Wirbelthieren, cinen zusammengesetzten innerin Bill besitzen. Auf dem inneren Septum, an welchen die pulpöse Ausbreitung des Gehörnerven stattfindet, befindet sich in der vorderen und hinteren Ampulle ein knopfförmig nach olon und nach unten vorragender freier Schenkel, so dass dis ganze Septum hier ein Kireuz darstellt, dessen Querschenkel angewachsen und dessen senkrechte Schenkel frei sind 4). -

Die knöcherne Schnecke hat die Gestalt einer kurzen, stumpfen, conischen, etwas gekrimmten Röhre 5). Die innere Schnecke ist knorpelig-häutig. Ausser ihrer äusseren, mit dem Knochencanale durch Fasern verbundenen Ilaut besteht sie aus knorpeligen Theilen. Dies sind zwei, oft mit zahnartigen Fortsätzen 6) versehene Knorpelschenkel, welche einen Rahmen bilden, der an seinem einen Ende kolben-oder retortenförmig sich umbiegt und so eine Ampulle: die sogenannte Flasche, Lagena, bilden hilft. In deı länglichen Zwischenraume, der wwischen den beiden Schenkeln des Rahmens bleiht, ist ein sehr zartes, straffes Häutchen, als Lamina spiralis ausgespannt. So zerfällt die Schnecke in eine Scala tympreni und $\mathbf{S}$. vestibuli. Ueberwölbt wird die Spirallamelle durch eine Querfalten bildende Memlrane vasculosa ${ }^{7}$ ). Auf dem Spiralblättchen und in der Flasche geschicht die Ausbreitung des Schneckennerven. Innerhalb der Flasche finden sich Krystalle von kohlensaurer Kalkerde in einem fliissigen Vehikel.

[Man vgl. über das Gehörorgan der Vögel ausser den schon früher angefiibrten Schriften von Scarpa, Windischmann und Steifensand, die Ab. handlung von Treviranus, in Tiede mann und Treviranus Zeitsch., Bd. 1. Heft 2. S. 185. 1825. - Breschet, Recherches anat. et physiol. sur l'organe de l'audition chez les oiseallx, Paris 1836, 8. Mit Abb. in Fol. - Huschke in Müller's Archiv 1835. S. 335̃. - F. Platner, Bemerkungen über d. Quadratbeilı u. d. Paukenhöhle d. Vögel, Leipz. 1839, 8.]

3) S. d. Abb. bei Treviranus 1. c. Tab. IX. fig. 1. u. 2.

4) Die äussere Ampulle verhält sich verschieden. S. d. Abb. bei Steifeu. sand, in Müller's Archiv 1835, Tab. II. fig. 17-23.

5) S. d. Albb. bei Treviranus 1. c. fig. 1. u. 2.

6) Abl. b. Huschke (Müller's Archiv 1835.) Tab. VIr. fig. 1-9.

7) Abb. b. Windischmann Tab. II. fig. 6. Diese Haut betrachtete Tre. viranus mit Unrecht als Gehörblätter. 


\section{Fünfter Abschnitt. \\ Vom Verduuungs - Appurute.}

\section{Vom Munde und Rachen.}

§. 139.

Die Kiefer der Vögel sind nicht, wie die der meisten übrigen Wirbelthiere, mit Zähnen bewaffnet; der von eirer Hornscheide ïberzogene, bisweilen, wie z. B. bei Mergus, mit scharfen Randvorsprüngen besetzte, Schnabel vertritt ihre Stelle; er ist am härtesten bei den ihre Beute zerreissenden Raubvögeln, so wie bei einigen von Fischen lebenden Vögeln (Sturmvögel); ferner bei in die Rinde der Bäume hackenden Spechten und bei den Papageien und anderen Vögeln, welche harte Saamencapseln und Früchte knacken. Je weicher die Nahrungsmittel der Vögel sind, um so weicher wird ihr als Ergreifungsorgan dienender und oft zum Tastorgane entwiekelter Schnabel. Als ein durch grossen Nervenreichthum ausgezeichnetes, mit starken Zweigen vom.N. trigeminus versorgtes Tastorgan erscheint er namentlieh unter den liasservögeln bei Enten und Gänsen, so wiґ aueh bei den mit eigenthümlichen zelligen Bildungen dieses Theiles begabten Schnepfen. Eine nähere Beschreibung seiner unendlich mannichfachen, durch die verschiedene Lebensweise bedingten Formverhältnisse gehört in das Gebiet der Zoologie. Eben so verschiedenartige Bildungen, wie der Schnabel, bietet die Zunge dar. Ganz rudimentär bei den Pelicanen, wo sie fast nur in einem Epithelialüberzuge der knorpeligen Grundlage besteht, wenig entwickelt beim afrikanischen Strausse, zeigt sie einen bedeutenden Umfang nebell eigenthümlicher Bildung beim Flamingo und erseheint bei den Papageien vorzugsweise alusgebildet. Als eigentliches Geschmacksorgan ist sie hier meist mit zahlreichen langen und weichen Papillen besetzt, während sie bei der Mehrzahl der Vögel mehr oder minder starr, steif, hart und wenigstens im Vordertheile mit dickem, hornartigem Epithelium überzogen, oder mit Warzen, Widerhaken (Spechte) u. s. w. versehen, als Ergreifungsorgan entwickelt ist. Bei den Kolibris ist sie, an der Spitze pinselförmig, geeignet, den süssen Saft der Blumen in den Mund zu führen, bei den Toukans seitwärlts bis zur Spitze kamm- oder bürstenartig mit haarförmigen Fortsätzen versehen, bei den Spechten sowol, als bei den Colibris eigenthümlich vorstreckbar. - Die Mundhöhle ist an ihrer oberen Flïche selten glatt, gewöhnlich mit verschiedenartig entwickelten hinterwärts gerichteten Warzen besetzt; sie ist weit bei den Raubvögeln, bei Cypselus und besonders bei Caprimulgus; bei den Pelicanen bildet sie nach unten eine enorme saekfồrmige Erweiterung und bei der männlichen Trappe öffnet sich unter der Zunge ein häu- 
tiger Sack, der vor der Iuftröhre nnter der Haut des Ilalses bis zur Furcula absteigt 1 ).

Die drisigen Organe, welche in dic Mundhöhle und in die Gaumengegend der Vögel ihr Secret ergiessen, sind manniehfaeh und zahlreich, wenngleich keinesweges alle diese Gebilde auch allen Vögeln zukommen. Ihrem Baue nach zerfallen sie 1) in einfaehe, bald vereinzelt, bald aggregirt stehende Follikel; 2) in eonglomerirte Drisen mit mehren Ausführungsgängen und 3 ) in conglomerirte Drüsen mit einem gemeinsehaftliehen Ausführungsgange. - Ihrer Lage nach verhaiten sieh diese Drüsen folgendermaassen: 1) Folliculi liuguales kommen bei vielen Vögeln längs der Seiten der Zunge vor; sie bestehen aus cinfachen Blindsäeken 2). 2) Glandulne sulmaxillares s. gulares, unter der Sehleimhaut der Mundhöhle gelegen, den Zwisehenraum der beiden Unterkieferäste vorn mehr oder minder ausfiillend, zu den zusammengesetzten Drüsen mit mehren Ausführungsgängen gehörend 3). 3) Glaudulae sulliuguales, seitlich unter der Zunge oder an den Zungenbeinhörnern gelegen 4), zusammengesetzte Drüsen, deren jede gewöhnlich mit einem Ausführungsgange vor oder neben der Zunge in die Mundhöhle mündet. 4) Parotides oder Mundwinkeldrüsen, schr heständig 5 ); zusammengesetzte Drüsen, gewöhnlieh hinter dem Joehhogen, seltener dicht am Mundwinkel gelegen, meistens mit einem längeren oder kürzeren Ausführungsgange im Mundwinkel sich öffnend. 5) Kleine einfache Follikel \%wiseholl der Zunge und der Kehlkopfsgegend 6), 6) Mehr oder minder zahlreiehe, oft sehr dieht stehende Follikel zur Seite und hinter den hinteren Nasenöffnungen, gewöhnlieh zwisehen den hier hefindlichen Epithelialpapillen gelegen, aus mehr oder weniger zahlreichen Oeffnungen ihr Seeret ergiessend. Sie sind in Gemeinsehaft mit viel grösseren, hinter der Oeffnung der Tuba Eustachii, in zwei Reihen neben einander liegenden, dureh weite Ostia sich öffnenden zusammengesetzteren, inwendig zelligen Follikeln,

1) Er kömmt, so weit die bisberigen Untersuehungen reiehen, nur bei 0 tis tarla vor; Nitzsch vermisste ihn bei beiden Geschlechtern von 0 . tetrax. Auch der weibliehen Otis tarla fehlt er stets, wie Me ekel nach Untersuchung von 12 Exemplaren constatirte.

2) Z. B. bei Anas, Anser, Mergns, Ardea, Aquila, Vultur, sie fehlen, wem die Zunge sehr rudimentär ist, z. B. Peleeanus, Ciconia, den Straussen.

3) Z. B. bei Aptenolytes; überhaupt bei Palmipeden, Gallinaceen, Raubvögeln.

4) Z. B. bei Gallinula, Larıs, Cygnus, Ciconia, Mergus, Aquila, Vultur; sehr stark entwiekelt bei den Spechten und Wendelhalsen.

5) Selten vermisst, nauentlich bei Wasservögeln Colymbus, Haliens, aueh bei Sula nach Meckel, ferner bei Ardea umil den Eulen. - Sonst bei Tagraub. vögeln, Singvögeln, Schnepfen, Störchen (klein), den Schwäneu, Euten, Grinsen 1. S. w. eonstant gefunden. Bei Cygnus dieht an Mundwinkel.

6) Z. B. bei Faleo Buteo naeh Tiedemann; bei Aquila albicilla, Vultur papa. 
welche besonders hei den Ramhvögeln entwickelt sind, neuerlich als 'Tonsillen gedeutet worden $\overline{7}$ ).

[Ueber die verschiedenen Schnahel- und Zungenhildungen s. Ahbildungen hei Owell, in Todd's Cyclop. Vol. 1. - Ueber deri feilleren Bau der Speiclieldrïsen vgl. E. H. Weber, in Meckel's Archiv 1S27. Bd. 2. S. 286. Hnd Mïller, Gland. secern. p. 5s. Tab. VI. fig. 7. - Ueber das Vorkommen dieser Drüsen bei den einzehen Gattungen Meckel, Vergl. Anat. Bd. 4. S. 404 fl. - Ueber die T'onsillen s. Rapp, in Miiller's Archiv 1843. S. 19. Mit Abb.]

\section{Vom Tractus intestinulis.}

\$. 140 .

Die Speiseröhre liegt gewöhnlich iiber oder hinter der Luftröhre, doch meistens etwas nach der rechten Seitẹ hinüber. Ihre Länge entspricht in der Regel derjenigen des Halses 1). Ihre Weite bictet Verschiedenheiten dar, ist aber im Allgemeinen am bedeutendsten bei den eigentlichen Raubvögeln und bei den von Fisehen lebenden Sumpi - Ind Schwimmvögeln. Ihre Muskelhaut, welche, gleich der des ganzen Tractus iutestinalis, durch äussere Quer-und innere Lüngen-Fascikel gebildet wird, ist zwar immer betrïichtlich, doch besonders stark bei den Raubvögeln entwickelt. Ihre Primitivbiundel besitzen keine Querstreifen. - Ihre Schleimhaut bildet gewöhnlich Längsfalten, welehe selten durch feine Querfalten verbunden werden. Bci vielen Vögeln zeigt sich im Verlaufe der Speiseröhre keine Erweiterung ${ }^{2}$ ). Bei anderen Vögeln

7) Von Rapp l.c. Schon Meckel kannte die ersteren, rechnete sie zil den Schleimdriisen und sonderte sie von den Speicheldrüsen (Arch. 1832. S. 275.). Stark ausgebildet sind sie bei Anas, Anser; schwächer bei Larus, Cygnus; wemn die Epithelialpapillen fehlen, sind doch gewöhnlich diese Drüschen vorhanden, wie bei Gallinula, Ciconia. - Rapl) macht, mit Recht, darauf aufmerksam, dass streng genommen nur die inneren beiden Reihen den Tonsillen der Säugthiere vergleichbar sind. Ich finde diese letzteren bei weitem nicht so beständig, als die ersten; ausserordentlich stark sind sie bei Vultur papa. - Beide Arten dieser Follikel sind sehr schön abgebildet von Rapip I. c. Tab. II. fig. 1. u. 2.

1) Das merkwïrdigste Verhablten des Oesophagus ist von L'Herminier bei Opistlıcomus cristatus beobachtet worden. Die Speiseröhre bildet eine zu eineu sehr weiten Sacke ausgedebnte Schlinge, rrelche untel ler Haut vor den Brustmuskeln liegt und den grössten Theil der Brust eimnimnt. Auf diesen Sack folgt ein erweiterter Abschnitt, der, ähnlich dem menschlichen Colou, aussen durch Bänder eingeschnürt, inwendig mit Längsfalten verselıen ist. Dieser führt in den Drüsenmagen. Der grössere vordere Abschnitt des Oesophagns ist mit Längsfalten und parallelen Drüsenreihen besetzt. Die Falten nehmen nach dem Sacke hin zı und sind in ihm sehr sturk. Die Höhle des Sackes ist dırch eine bogenförnige Scheidewand in zwei mit einander communicirende Hälften unvollkommen getheilt. S. Ann. des sc. nat. T. VIII. 1837.

2) Sie fehlt den meisten Passerinen - indessen mit einzelnen Ausnahmen, wohin z. B. Fringilla, Emberiza u. a. gehören -, den meisten Picariae - mit Ausnahme der Papageien und der Trochili -, den Nachtraubrögeln, bei Struthio, 
kömmt eine Erweiterung der Speiseröhre vor, welche unter dem Namen "Kropf" hekannt ist. Dieser Kropf 3) kann ein sehr v(rscliedenartiges Verhalten zeigen. Bei den Raubrögeln stellt er eine seitliche, allmäliclı zu Stande kommende, vor der Furcula gelegene Erweiterung der Speiseröhre dar. Bei vielen anderen Vögeln, z. B. den Ilülınern, nimmt er die Grestalt rines ovalen oder kugelförmigen Sackes an, welcher gewöhnlich auf der die beiden Schenkel der Furcula verbindenden Fascia ruhet. Seine Innenwand ist gewöhnlich drüsenreich. Bei einigen Vögeln bietet er besondere Eigenthümlichkeiten dar. So ist er bei den Tauben doppelt und bestelit aus zwei seitlichen, ovalen Säcken. Die Winde dieser Säcke verdicken sich zur Britezeit und erhalten dann stärker als sonst entwickelte Falten und Drisen, welehe letzteren eine milchige, aschgraue Flüssigkeit secerniren, dic den Jungen in der ersten Lchenszeit zur Nahrung dient. Auffallend ist es ferner, dass nur bei der männlichen Trappe ein in der Mitte des Halses gelegener Kropf angetroffen wird 4). - Ist ein wirklicher Kropf vorhanden, so zeigt sich der unterhalb desselben gelegene Abschnitt der Speiseröhre gewöhnlich etwas verengt, um allmählich in den Vormagen sich zll erweitern, welcher letztere bei den kropflosen Vögeln jedoch oft kaum eine Erwciterung bildet.

Der Magen der Vögel zerfällt nämlich sehr beständig in zwei Abtheilungen 5), von welchen die erste, durch grösseren Gefässieichthum und durch den Besitz zahlreicher, den Magensaft absondernder Driisen ausgezeichnete, unter dem Namen des Vormagens oder Drüsenmagens bekannt ist ${ }^{6}$ ). Das Verhalten dieses Drisenmagens bietet mancherlei Verschiedenheiten dar. Seine vordere Grenze ist bisweilen kaum durch eine Veränderung im Durchmesser des Munddarmes bezeichnet 7); bei den meisten Vögeln zeigt er sich jedoch mehr oder minder deutlich nach aussen vorspringend, bisweilen sehr weit und

Rhea anericana und bei Apteryx, bei den meisten Sumpfrögelu - mit Ausnahme ron Phoenicopterus - , bei den meisten Sclfrinunvögeln, indessen gleichfalls mit eiuzelnen Ausuahuen, wohin namentlich Mormon gebört. Unbestimute, nieht sehärfer abgegrenzte Erweiterungen der Speiseröhre finden sich indessen auch sonst noeh z. B. bei Cieonia, bei Halieus.

3) Er kömmt den Tagraubvögeln, einigen Passerinen, Jen Psittacinen und Trochili, den Tauben, Hühneru, Trappen, Casuaren, so wie einigen Sumpf - und Sehwillmmvögeln zu.

4) Nur bei Otis tarda und hier uie beim Weibchen angetroffen.

5) Bei der Gattung Euphone fehit nach Lund (De genere Euphones ete. Hafniac 1829. 8.) der zweite Magen oder ist völlig redlueirt; s. d. Abl. l. c. und copirt bei Carus mul 0 tto, Erlïuterungstafeln Heft 4 . Tal). VI.

6) Proventriculus; Ventriculus succenturialus; Bullus glandulosus; Echinus; Infundibuluon. - Er ist bei Alcedo nur sehr schwach angedeutet.

7) Z. B, bei Ardea, Rallus. 
grösser als der eigentliche Magen ${ }^{8}$ ). Die Drŭschen ${ }^{9}$ ), welche an seiner Innenfläche münden, sind häufig einfache, am Ende blind geschlossene Einstülpungen; in anderen Fällen münden mehre und oft sehr kurze Blindsäckchen in die Axe eines gemeinsamen Ausführungsganges. Stellung und Vertheilung dieser Drüschen über der Innenwand des Vormagens, der bei starker Entwickelung derselben oft beträchtlich dicke Wandungen besitzt ${ }^{10}$ ), bieten bei den verschiedenen Familien und Gattungen oft charakteristische Eigenthümlichkeiten dar. Ihre Deffnungen sind bald über die ganze Innenwand des Vormagens ziemlich gleichmässig verbreitet ${ }^{11}$ ), bald gürtelförmig ${ }^{12}$ ) gestellt, bald kreisförmig gruppirt, bald in zwei oder selbst in vier ovale oder runde Haufen gesondert ${ }^{13}$ ). Gewöhnlich geht dieser Drisenmagen unmittelbar über in den zweiten Magen, der unter der Benennung des Muskelmagens bekannt ist; im untcren Abschnitte desselben werden aber oft die Drüsen spärlich oder verschwinden, und so unterscheidet man bisweilen noch einen kleinen drüsenlosen Abschnitt 14) oder selbst eine kropfartige Erweiterung 15) zwischen dem Vormagen und Muskelmagen.

Dieser zweite Magensack; der sogenannte Musk elmagen, ist immer durch seine ticfe Lage ausgezeichnet. In seinen oberen, der Leber zugewendeten Rand muinden sehr dicht neben einander der Drüsenmagen und mehr nach rechts der Anfang des Duodenum, so dass er selbst sackförmig oder als dickwandige, unten blind geschlossene, meist längliche Höhle sich abwärts erstreckt. Sowol an der Rücken - als an der Bauchfläche dieses zweiten Magens findet sich sehr beständig eine mehr oder minder beträchtliche, oft scheibenförmigc Sehne, von welcher die muskulösen Theile auf - und abwärts ausstrahlen. Im Uebrigen bietet er, je nach Verschiedenheit der Nahrungsmittel, auf welche die Vögel angewiesen sind, bedeutende Verschiedenheiten dar, welche besonders die Stärke seiner.Muskulatur und seiner Sehnen, so wie die Dicke seiner inneren Epithelialschicltt betreffen. Oft, und namentlich bei den

8) Viel grösser z. B. bei Thalassidroma und besonders bei Procellaria.

9) Abbildungen derselben hat $\mathrm{Hom}_{\mathrm{e}}$, Lect. on comp. anat. Vol. 2. Tab. LVI. gegeben; copirt bei Müller, Gland. struct. Tab. 1. fig. 8. und bei Wagner, Icon. physiolog. Einfach sind sie bei den meisten fleischfressenden Vögeln; zusammengesetzter z. B. bei Hühnern, Enten, Gänsen und Störchen und bei den Struthionen.

10) Z. B. bei Upupa, Caprimulgus, Tetrao, Columba, Phuenicopterus, Haematopus, Ciconia, besonders bei Pelecanus.

11) Z. B. bei Anas, Colyınbus, Ardea, Rallus.

12) Z. B. bei Columba, Larus.

13) Zwei solcher Juga komıten z. B. vor bei Halieus, Numenius, Charadrius; vier bei Falco nisus. S. d. Abb. bei Home l. c.

14) Z. B. bei vielen Papageien, Singrögeln u. a.

15) Letrtere ist von L'Herminier bei Palanedea cornuta beobachtet rvor. den. l. c. 
Raubvögeln, aber auch bei vielen anderen, namentlich bei Carnivoren, erscheint er als weiterer ausdehnbarer Sack mit schwacher Muskelhaut, welche von sehr flaclien Sehnen ausgeht ${ }^{16}$ ). Bei anderen, und namentlich bei den körnerfressenden Vögeln, besitzt er, bei enormer Stärke seiner Muskulatur ${ }^{1} \tilde{7}$ ), eine ausserordentliche Dicke seiner Wände und eine äusserst geringe Capacität. Jede seiner beiden Seiten wird von einem dicken $\boldsymbol{M}$. lateralis umfasst; zwischen ihnen liegen oben an seinem Eingange und unten an seinem blinden Ende die minder starken M. M. intermedii; sämmtliche Muskeln werden in der Mitte der Bauch - wie der Rückenfläche durch die schon erwähnte, hier sehr starke Sehne verbunden. Das überall dicke Epithelium zeigt sich entsprechend den Seitenrändern, wo die M. M. laterales am stärksten sind, am meisten verdickt. So zeigen sich hier inwendig zwei Wülste, welche, bei der beträchtlichen Enge der Höhle, wie Mühlsteine auf einander wirken. - Eigenthümlich sind Wärzchen auf der inneren Magenfläche bei den Papageien und kleine harte Tuberkeln, mit denen dieser zweite Magen bei einigen Sturmvögeln ${ }^{18}$ ) inwendig besetzt ist. - Vor der Uebergangsstelle des Muskelmagens in den Pförtner verdünnen sich dessen Wandungen häufig etwas und bilden so eine eigene kleine Portio mylorica. Bei einigen Raub-, Sumpf- und Schwimmvögeln bildet sich dieser Theil zu einer auch schon äusserlich erkennbaren Nebenhöhle, einem Magenanhang oder Nebenmagen aus ${ }^{19}$ ).

Was den an seinem Gekröse befestigten Darmcanal anbetrifft, so ist seine Länge verhältnissmässig minder beträchtlich, als bei den Säugthieren ${ }^{20}$ ); obgleich sehr verschieden, ist sie doch im Ganzen bei den von Vegetabilien lebenden Vögeln bedeutender, als bei den Carnivoren. Der Darm zerfällt in einen Dünndarm und Dickdarm, welcher letztere

16) Dünnhäutig ist der Magen bei den Tag - und Nachtraubvögeln; wenig stärker bei vielen Picariae: Cuculus, Caprinulgus, Alcedo, Rhamphastos, bei einigen Sumpfögeln: Ardea, Ciconia; schwach muskulös auch bei Haematopus, Charadrius, Recurvirostra, Totanus, Halieus, Aptenodytes; auch bei einigen Singvö. geln: Corvus, Sylvia, Regulus.

17) Sehr stark bei allen Hühuern, Tauben, Schwänen, Enten, Gänsen: Crex, Gallinula; ibnen nähern sich schon viele Singrögel.

18) Procellaria glacialis, Puffinus, nicht bei Thalassidroına.

19) Schwach angedeutet ist diese Nebenhöhle schon bei einigen Falken, bei Gallinula und vielen anderen; deutlicher bei Ciconia alba; scharf abgesetat durch enge Oeffnung bei Colymbus, Halieus, Pelecanus, Vultur papa, an meisten bei Ardea. Bei den exotischen Störchen (C. Argala und Marabou) ebenfalls vorhandel. Vgl. uber diesen Nebenmagen die monographische Arbeit von Le uckart, Zoologische Bruchst. 2. Heft. Stutig. 1841. 4. S. 64. Mit Abb.

20) Ain längsten in Verlüiltniss zum Körper $=15: 1$ fand ihn Meckel bei Aptenodytes, zugleich aber eng und init sehr kurzen Blinddärmen; bei den Raubvögeln, beim Toukan, bei Mormon kaum doppelt so lang als der Körper; noch kürzer bei Rallus; bei Grus und Ciconia etwa 8-9 mal so lang als der Rumpf; bei Ardea noch etwas länger. 
- mit seltenen Ausnahmen - durch grosse Kürze ausgezeichnet ist und, gleichwie bei den Fischen und den meisten Reptilien, nur den Mastdarme der Säugethiere entspricht. Am Anfange des Duodenum findet sich oft, \%. B. beim Strauss, bei Ardea. cine blasenartige Erweiterung. - Der Verlauf des Diinndarmes ist in sofern cigenthiimlich, als sein dem Duodenum entsprechender Abschnitt durch einen absteigenden nnd aufsteigenden Schenkel immer eine Inelı oder minder lange Schlingc 21) bildet, welche das Pancreas einschliesst. Bei schr vielen Vögeln erhält sich, bald regelmässig, bald als individuelle, aber häufige Eigcnthumlichkeit an der ursprüinglichen Insertionsstelle des Dottersackes in den Diinndarm perennirend ein Divertikel 22), nur bei einigen Struthionen, statt seiner, bisweilen ein init entarteter Dottersubstanz gefiillter Sack ${ }^{23}$ ). - Die Schleimhaut des Diinndarnes bildet oft zickzackförmige, parallele Längsfalten 24\}, welche, mitunter durch Querfältchen verbunden, жur Unschliessung von Maschen beitragen; nicht selten erhehen sich ron den Lïngsfalten zottcnartige Vorragungen; oft aber erscheinen atueh, bei Abrescnheit von Falten, wirkliche Lotten 25 ).

Dic Grenze von Diinn- und Dickdaru wird äusscrïch gcwöhnlich bezcichnet durch etwas beträchtlichere Weite des letzteren, besonder's aber durch die in ihn einıuindenden Blinddärıne; inwendig dureh cine schwache, kreisförnige Vorragung, selten durch einc eigentliche Klappe. Das Vorkommen zweier seitlichen, durch Bauchfellfalten befestigten Blinddï rınc ist Regel bei den Vögcln; sclten ist nur cin cinziger vorhanden ${ }^{20}$ ),

21) Ueber einen Fuss lang bein Storch; drei- bis viermal kürzer beim Flamingo.

22) Nicht bei den Raubrögeln und Singvögeln; fast constant bei Gallinula, Rallus, Nunenius, Crex, Limosa, bei den Schwänen, Enten, Gänsen, beim Kornoran, beim Kukuk; unbeständig aber häufig bei vielen Suupfrögeln: Ciconia, Grus, Ardea, Ihis, Phoenicopterus. Vgl. Wagner, Münch. Denkschrift 183\%. S. 286.

23) Von Carus beim jungen, von mir beim ausgewachsenen nenbolländ. Casuar, von 0 wen einmal bei Apteryx beobachtet. An dem verschlossenen Ein. gange in den Darm und anch an dem Umfange des mit schwärzlicher käsiger Masse gefüllten Sackes sind Ueberreste der Dottergefässe erkennbar. Abbild. Carus, Erläuterungstafeln. 4. Tab. VI.

24) Z. B. bei den meisten Schnepfen, Recurvirostra, Haematopus, Tringa, Totanus, Corvus, Cypselus. Bei Grus Zotten von den Zickzackfalten ausgehend. Aehnlich bei Lanius.

25) Z. B. bei den Falken, Geieru, mehren Papageien, Spechten, Störchen, Hühnern, Casuar, nach Rudolphi; auch bei Limosa; bei der Waldschnepfe, der Taube, T'etrao, Upupa u. a.

20) Beständig bei den Reihern. Ich fand in zwei Exemplaren des Kormorans nur einen; eben so als indiriduelle $A$ bweichung bei Colynbus cristatus. Auf bisweilen vorkommende Asymmetrie der Blinddärme hat Wagner aufmerksam gemacht; er fand bisweilen bald den rechten, bald den linken länger. 
oder sie fehlen ganz 2 ). Ihre Ausdehnung bietet die grössten Verschiedenheiten dar 28); sir sind an betriiehtliclısten bei den von Vegetibilien lebenden Vögelı und bei den Omnivoren; in kürzesten in der Regel bei den Carnivoren; hier bisweilen auf ganz kleine Papillen reducirt. Oft sind sie gegen ihr blindes Ende hin keulenförmig erweitert und an ihrer Insertionsstelle in den Darm eng. Inwendig besitzen sie gewöhnlich Lüngsfalten, die durch schiefe Querfalten mit einander verbunden, Masclien oder Zellen bilden; seltener erstrecken sich die Zotten ${ }^{29}$ ) in ihre Höhle linein. Bein Strausse sind sie ausgezeichnet durch den Besitz einer inneren Spiralklappe. Der gewöhnlich kurze, selten lange ${ }^{30}$ ) Dickdarm besitzt anfangs häufig dichtstehende Zotten, weiter abwärts - oder in seiner ganzen Länge - Quer - und Längsfalten. Er inserirt sich mit einer klappenartigen Kreisfalte in die Kloake.

[Abbildungen des Darmcanales der Vögel s. besonders bei Everard Home, Lectures on comp. anatomy. Vol. 2. Tab. XLIV. - LVI. und Tab. CIV.-CXII. uInd bei Carus und 0 tto, Erläuterungstafeln. Heft. 4. Tab. VI.]

\section{Vou den drüsigen Gebilden.}

S. 141.

Die incist beträchtliche, bald dunkeler, bald etwas heller braunroth gefärbte, aus zwei Hauptlappen gebildete Leber liegt etwas vor der Mitte der Bauchhöhle, so, dass ihre convexe Oberflïche der Bauchwand, ihre concave, mehr oder minder unebene Oberfläche aber den Eingeweiden zugewendet ist. Sie erhält durch eine Duplicatur des Bauchfelles, welche von der Mittellinie des Sternum in den Zwischenraum ihrer Lappen tritt, ein Ligamentum suspensorium. Der Bauchfellüberzug ist fuir jeden Leberlappen doppelt, so dass er, ähnlich wie das Pericardium zum Herzen sich rerhaltend, einmal eine losere Umhiillung und dinn, durch Umsclilagung, pinen unmittelbaren Ueberzug jedes Lappens bildet. - Die beiden Hauptlappen, zu welchen bisweilen noch ein dritter, kleinerer, an der Ilinterseite zwischen beiden gelegener

27) Sie fehlen an häufigsten den Picariae, z. B. Psittacus, Rhamphastos, Corythaix, Yunx, Alcedo, Upupa, Cypselıs; oft auch den Spechten, obschon ich sie bier, gleich 0 wen, ausnehmend klein, wie Papillen gefimden babe. Aehnlich sehe ich sie bei Alaula, der man sie gleichfalls abgesprochen hat. Ich vermisse jede Spur bei Vultur papa.

28) Sehr klein bei den Raptores, nanentlich den Tagraubvögeln, den meisten Singvögehn; einigen Schwimmvögeln (Podiceps, Halieus, Sula, Pelecanus); bei Cuculus, den Enlen, den Tauben; verbiiltnissuässig kurz bei den meisten Sumpf. vögeln (aun längsten bei Phoenicopterus); sehr lang bei den meisten Gallinaceen, enoru bei Otis (3 Fuss lang), beim afrikan. Strauss (nicht aber bei den übrigen Struthionen); lang bei Enten, Gänsen, Schwänen. - Beim Strauss inseriren sich die beiden 13 linddärme vereint.

29) Z. B. beim Huhne nach Rudolphi.

30) Beim afrikan. Strauss. 
Lobulus Spigelii $\left.{ }^{1}\right)$ hinzukömnnt, werden durch einen gewöhnlich dünnen Isthmus mit einander verbunden. Oft sind beide von fast gleicher Grösse ${ }^{2}$ ); noch häufiger übertrifft der rechte den linken an Länge, Umfing und Masse ${ }^{3}$ ); sehr selten findet das umgekehrte Verhalten Statt $)$. Nicht selten besitzt der eine oder der andere Lappen noch secundäre Einschnitte 5 ).

Selten fchlt die Gallenblase 6); dann besitzt die Leber gewöhn lich zwei Ausführungsgänge, welche getrennt von einander und bis. weilen weit von einander entfernt in das Duodenum münden ${ }^{7}$ ), seltener, wie beim Strausse, nur cinen einzigen. - Gewöhnlich liegt die Gallenblase unter der concaven Flïche des rechten Leherlappens in einer scichten Aushöhlung desselben, seltener zum Theil oder ganz frei 8). Sie ist mehr oder minder unfünglich, häufig rundlich oder länglich-rund, seltener darmförmig verlängert 9). Bei ihrer Anwesenheit sind folgende Gallengänge vorhanden: 1) ein aus beiden Leberlappen, also zweischenkelig entspringender, bald einfach werdender Ductus hepaticus, der sich bisweilen, gleich nachdem er aus der Leber getreten, schlauchförmig erweitert und immer direct in den Darm führt; 2) ein einfacher oder doppelter (Apteryx), in ersteren, als Regel zu betrachtenden, Falle, aus dem rechten Leberlappen in die Gallenblase übergehender Ductus hepatico-cysticus; und 3) ein aus der Gallenblase in den Darm fuihrender Ductus cysticus. Nur bei Buceros ist ein gemeinschaftlicher Ductus choledochus angetroffon $10 \%$. Die beiden zum Darme führenden Gallengänge münden gewöhnlich in geringer Entfernung von einander ${ }^{11}$ ), nicht dicht hinter dem Pförtner, sondern

1) Z. B. beim Schwan, der Gans, dem Cormoran, der Taube.

2) Bei den meisten Raubrögeln; beim Storch.

3) Sehr wenig bei den Möven, bei Colyubus, mehr bei den Enten, hei Ar. dea, den meisten Singrögeln.

4) Bci Charadrius nach Nitzsch; bei Rhea americana; Aquila albicilla.

5) Beim Hulsn, beim Strauss der linke.

6) Bei Rhamphastos (doch nicht bei Buceros), bei den meisten (nicht allen) apageien, den Cuculidae, Columbae und unter den Straussen bei St. Camelıs und Rhea anericana. Selten fehlt sie ausnahusweise und blos individuel, wie z. B. hei Ardea Virgo von Perrault, bei Apteryx von 0 we n beobachtet ward.

7) Bei den 'Tauben z. B. mündet der eine weitere und kurze in den Anfang des Duodenum, dicht hinter dem Pylorus, während der zweite lange ınit deı Ductus pancrealici in das Ende des Duodenum sich einsenkt.

8) Beim Adler, Cormoran, mehr noch beim indischen Casuar.

9) Gross bei den Raubvögeln; klein bei Tétrao, Otis; länglich rund beinı Storch; sebr lang und darmförnig bei den Spechten.

10) 0 we $n$ in d. Transact. of the zool. soc. of London. Vol. I. p. 118. Tab. 18. fig. 1. Der linke Ductus hepaticus inserirt sich abgesondert, weit entfernt vou 1). choledochus.

11) Eine Ausnahıe macht Aptenodytes, wo die Mündungen beider weit von einander entfernt liegen. 
in das Ende der Duodenalsehlinge. Sie treten schief durch die Wände des Darmes und münden auf Papillen. Sie sind selır dickhäutig und eontractil.

\section{§. 142.}

Das gewölınlieh sehr beträeltliche, weisse Panereas der Vögel liegt selır beständig zwisehen dem ab - und aufsteigenden Sehenkel des Duodenum, also in der sogenannten Duodenalschlinge, welcher es häufig an Länge gleieh kömmt ${ }^{1}$ ), ohne dass dies jedoeh beständig der Fall wäre 2). Bisweilen erstreekt sieh ein Fortsatz des Panereas bis zur Milz ${ }^{3}$ ). Es zeiehnet sich gewöhnlieh aus durch seine gestreekte Gestalt und besteht in der Regel 4) aus zwei längliehen Lappen, welehe bald sehr sehwaeh init einander verbunden sind, bald selbst in zwei völlig von einander getrennte Drüsen zerfallen ${ }^{5}$ ), die dann gewöhnlieh der Länge nach neben einander liegen. Nur selır selten sind drei Lappen des Pancreas beobaehtet worden \%). Die Anzahl der langen Ausführungsgänge beträgt in der Regel zwei 7 ), seltener drei ${ }^{8}$ ); sind drei Ausführungsgänge vorhanden, so inserirt sich der dritte gewöbnlieh ${ }^{9}$ ) in einiger Entfernung von den andern und zwar gewöhnlich in den Winkel der Duodenalsehlinge, während die beiden anderen alternirend mit den Gallengängen und neben ihnen in das Duodenum eintreten.

Die Milz, von dunkelrother Farbe, von verschiedenartiger Form 10/,

1) Bei den ureisten Schwimmvögeln, namentlich den Dermorhynchi Nitz; ferner bei Ibis, Oedienemus, Otis, Tetrao, Cuculns, Caprimulgus u. A.

2) Viel kürzer als die Duodenalschlinge z. B. bei Ciconia, Grus, Rallus, Ardea.

3) Columba, Buceros n. A.

4) Ein einfacher schunaler Lappen findet sich bei Ciconia; zwei in der Mitte verbundene Lappen bei 0 tis; zwei hinten vereinigte Lappen bei Arlea, Anas, Anser.

5) Z. B. Colymbus, Grus, Oedienemus, Columba, Picus, Sitta, Certhia, Upupa, Caprimnlgus.

6) 7. B. bei Oriolus.

7) Naclı Meckel besitat der Strauss nur einen, der in bedeutender Entfernung vom Gallengange sich einsenkt. 0 wen fand bei Apteryx zwei; zwei Ausführungsgäıge finden sich bei len mcisten Schwimmvögeln, bei Ciconia, Arlea, Grus, Phoenicopterus, Rallus, lbis.

8) Beobaclitet beim Hnlne, der Taube, ausnalunsweise bei inehren Schwimmvögeh, namentlich Enten, bei Oedicnemus, Otis, Corvus, Oriolus.

9) Z. B. bei der Taube, der Trappe, bei Corvus.

10) Sie ist oft länglich rund und von gestreckter Form, wie bei fast allen Singrögelı, den Krälıen, den Spechten, den Tauben; sie ist gleichfalls etwas länglich, aber plattgelrückt bei den meisten straussartigen Vögeln, rund hei den Raubvögreln, den Hühnern, deu Trappen; breit, flach, scheibenförmig beiu Kormoran, sehr lïnglich bei Larus und Lestris; nach Wagner sehr gross, gegen die Mitte henkelartig ungeknickt und wurstförmig bei Crex, Rallus, Gallinula. Fine Nebenmilz wurde von Meckel und mir beim indischen Casuar beobachtet. Auch beim Strauss kömmt ein Zerfallen der Milz in uehre Lobi vor. 
liegt in der Nähe der Lober zur Seite des Vormagens. Sic ist bei den Vögeln fast immer einfach. Ihr Unfang ist fast nie beträichtlich.

\section{Sechster Abschnitt.

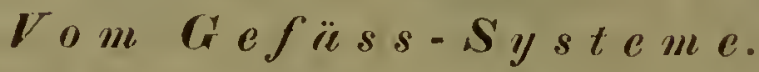

\section{Vom Herzen.}

§. 143.

Die Vögel zeichnen sich, gleich den Säugthieren, durch den Mangel jeder Communication zwischen den beiden Herzhïlften und zwischen den grösseren, verschiedene Blutarten führenden Gefässstämmen aus.

Ihr in der Mittellinie des Körpers, sciner Längsaxe parallel, gelegenes Herz ist noch nicht in einer abgesonderten Brusthöhle enthalten, bleibt von den ganz nach hinten gedrängten Lungen völlig unbedeckt und erstreckt sich mit seiner Spitze zwischen die Leberlappen. Es ist eingeschlossen von einem diunnen, aber derben Herzbeutel, dessen äussere Oberfläche häufig an den unngebenden Luftzellen befestigt ist. - Die Gestalt des Herzens ist immer kegelförmig, bald mehr verlängert, bald küirzer und weiter. - Es bestcht aus zwei Vorböfen und zwei Kammern. Die Auriculae der Vorhöfe ragen nicht frei vor, sondern erscheinen durch die innere Lamelle des Pericardium straff niedergezogen. Der rechte Vorhof ist weiter, als der linke und hat eine stärkere Auricula, als dieser; clie Auricula besitzt zahlreiche, starke, grossentheils kammförmige Muskelleisten, welche durch ziemlich tiefe Zwischenräume geschieden werden. In den rechten Vorhof münden die drei, das Blut zum Herzen zuriickführenden Venenstämme; in seinen vorderen und oberen Theil tritt dic rechte obere Hohlader; in seinen unteren Theil senkt sich die, kurz zuvor die Kranzvene des Herzens aufnehmende, linke obere IIohlader und oberhalls dieser, getrennt von ihr durch eine betrïchtliche klappenartige Vorragung, findet sich die Insertionsstelle der unteren Hohlader. An den Mündungen der Venen sind schwach muskulöse Klappen vorhanden, ausgehend zum Theil von queren oder sclırägen Mruskelleisten, welche ilırerseits wieder mit mehr senkrecht stchenden $\boldsymbol{M}$. $\boldsymbol{M}$. pectimati zusammenhangen. Contraction dieser letzlgenannten Muskeln befördert den Uebertritt des venösen Blutes in den rechten Ventrikel. Das fötale Foramen ovale ist durch eine dünne durchscheinende, dabei aber derbe Scheidewand vollständig verschlossen. Das Orificium atrio-ventriculare bildet einen schiefen Schlitz. - Die IIöhle des rechten Ventrikels, welcher ungleich dünwwandiger, als der linke ist und nicht bis zur Herzspitze reicht, zeigt sich sehr wenig weiter, als die linke Kammerhöhle. Dic Scheide- 
wand dieser letzteren lilklet einen stark gewölbten Vorsprung in die IIöhle des rechten Ventrikels. Das Orificium atrio-ventriculare kann durch eine eigenthiunliche, starke, sehr muskulöse Klappe verschlossen werden, welche gewölınlich fast dieselbe Dicke, wie die VentricularWandungen besitzt ${ }^{1}$ ). Diese Klappe stellt gewissermaassen eine frei nach innen vorspringende Einkrempung des dem Atrium zugewendeten Randes der rechten oder äusseren Wand des Ventrikels dar. Sie erstreckt sich von dem vorderen Ende des Septum ventriculorum, also ron dem obersten Theile der linken oder inneren Wand der rechten Kamıner schräg und bogenförınig abwärts und hinterwärts zu dem Winkel, welcher durch den unteren und hinteren Theil der äusseren Ventricularwand mit dem Septum gebildet wird. Der innere freie Rand dieser Klappe ist dem convex vorragenden Septum zugewendet und muss während der Systole der Ventrikel so kräftig an dasselbe gedrückt werden, dass die Kammerhöhle von der Vorkammer vollständig abgeschlossen und so jeder Rückfluss des Blutes in letztere verhindert wird. Im Uebrigen ist der rechte Ventrikel ausgezeichnet durch Glätte und Ebenheit seiner Wandungen, welche vollständig genannt werden könnte, gingen nicht vom Septum an den Vereinigungswinkeln mit den äusseren Kammerwänden zahlreiche kurze Fleischbündel zu diesen letzteren über. Die aus dem rechten Ventrikel hervorgehende Lungenarterie besitzt an ihrem Ursprunge drei, den Ruicktritt des Blutes hindernde, halbmondförmige Klappen. - In die Höhle des linken Vorhofes, welcher zahlreiche und complicirte Muskelbiindel besitzt, münden hinten zwei Lungenvenen mit gemeinschaftlicher Oeffnung. Ein derber muskulöser klappenartiger Vorsprung, dessen freier Rand der Höhle zugewendet ist, scheint bestimmt das Blut der Kammer zuzuleiten. - Der linke Ventrikel stellt eine längliche, kegelförmige Höhle dar, deren Wandungen die der rechten Kammer etwa um das dreifache an Dicke übertreffen. Die innere Oberfläche des Septum ist glatt, während von den iibrigen Innenwandungen mohr oder minder seichte Längsbalken und zum Theil auch complicirtere Vorsprünge sich erheben. Von zwei seichten Vorragungen, die unterhalb des Orificium atrio-ventriculare liegen, gehen gewöhnlich zahlreiche, kurze, dicke Sehnen aus, welche zu zwei oder drei häutigen, den Valvulae mitrales entsprechenden, am Eingange des Ventrikels gelegenen Klappen sich begeben. Am Ursprunge der Aorta finden sich drei halbmondförmige klappen.

1) Diese Klappe bietet rücksiehtlieb ihrer Stärke interessante Verschiedenheiten bei den einzelnen Gruppen der Vögel dar. Am stärksten ist sie bei den Schwimmvögeln, an schwïehsten bei den straussartigen Vögeln nnd unter diesen wieder bei Apteryx, wo sie, nach 0 wen's Mittheilungen, nicht nur überliaupt diinne, sondern stellenweise sogar fast membranös ist und wo ausserdem von ihrem freien Rande einige kurze Chordae tendineae zur Wand des Ventrikels treten. Zool. Transart. Vol. 2. Tab. 32. fig. 3. g. 
[Abildungen des Vogelherzens s. in Carus und Otto, Erläuterungstafeln, Heft VI., in Wagner's Ieones, in Todd's Cyelopaedia 1i. a. a. 0. - Ueber einzelne Versehiedenheiten in Bane vergl. die ausführlieheren Darstellungen von Cuvier, Meekel und Owen.]

\section{If. Von den Arterien.}

\section{§. 144.}

Die Aorta, von welcher sogleich die beiden Artt. coronariac cordlis abgehen, theilt sich, nur cinen sehr kurzen Stamm bildend, sehr bald nach ihrem Ursprunge in einen rechlen und einen linken $\Lambda$ st. Von dem rechten $\Lambda$ ortenaste sondert sich sogleich ein Stamm, der entweder der Art. asonyma dextra, oder blos der. Art. sulu:lavia elextra entspricht, je nachdem er eine Art. carotis commanis abgibt, oder nicht; nach scinem Abgehen steigt die Fortsetzung des rechten Aortenastes in einem Bogen iiber dem rechten Bronchus als Aorta desceudens an der recliten Seite der Wirbelsäule und vor derselben abwärts. - Der linke Aortenast ist gewöhnlich cine Art. anonyma; selı1 selten blos eine Art. sulclavia siuistra. - Es kommen nämlich bri den Vögeln bedeutende Verschiedenheiten riicksichtlich des Verhaltens der Garotiden vor. Bald entspringt aus jerler Art. amonyma eine Art. curotis communis, was als häufigste Bedingung bezeichnet werken kann 1), bald findet sich nur ein unpaarer Carotidenstamm (Ar\% carotis primaria), der dann gewöhnlich aus der linken $\boldsymbol{A} r$. anvuyma ${ }^{2}$ ) und nur schr selten aus der rechten seinen Ursprung nimm( ${ }^{3}$ ). Ist blos cine Art. carotis primaria vorhanden, so theilt sich diese in ziemlich geringer Entfernung vom Kopfe in eine linke und cine rechte Art. carotis commumis. Charakteristisch ist dic Lage dieser Arterien, mögen sie panrig oder unpanr scin, indem sie in der Regel dicht an der Vorderfäche der Ifalswirbel, in dem nie in der ganzen Länge geschlossenen Canale unterer oder vorderer Wirbclfort-

1) Bei allen Tag - und Naehtraubvögeln, bei vielen Picariac, bei allen Tauben und IIiihuern, bei den Struthionen mit Einschluss von Apteryx, aber mit Ausnahue von Rhea amerieana, bei den Grallae mit Ausnahme von Phoenieopterus und bei den Sehwinunvögeln mit Ausuahme von Pelecanus und Colyunbus.

2) Nur eine linke $C$. communis primarin findet siclı bei allen Singrögeln (Passerinae Nitzseh) und vielen Picariac, namentlicli unter den Macrochires bei Cypselus und T'rochilus; unter den Todidae bei Merops; unter den Lipoglossae bei Upupa; unter den Picinae bei Picus, Yunx, Bueco, Rlıamphastos; unter den Psittaeinae bei Psittaeus galeritus; unter den Amphibolae bei Colius. - Ferner bei vielen Arten von Colyumbus, bei Pelecanus und Rhea anerieani. - Diesen Ver. zeichnisse kann ieh nocl die neuholl. Gattungen: Barita und Podargus hinzufijgen.

3) Bei Phoenieoprerus. - Interessant ist der von Nitzsch bemerkte Unstand, dass bei Ardea stellaris die beilen getrennt entspringenden Carotiden zu einer einfachen versehmelzen, was bei nahe verwandten Arten nicht vorköumut und vielleieht bei dieser selbst, nielit einual durcliuns eonstant ist. 


\section{Sechster Abschnitt. Vom Gefüss-Systeme.}

siitze aufsteigen. Selten erleidet dies Gesetz dadurch eine Ausnahme, dass eine der beiden Carotiden oberflichlich und seitlich an Ilalse verliaft 4). Das Verlalten der Carotiden während ihres Verlaufes ant IIalse zeigt noch andere Eigenthiumliehkeiten. Aus jeder entspringen zahlıeiche Arterien für die Haut des Halses, dic Luftröhre, die Speiseröhre und kleinere für die Halsmuskeln. Ausser diesen nimmt aus jeder ihren Ursprung eine Art. vertebralis, welehe schr oft erst nach Abyabe von Arte. vesophagea descendens, tramsversa colli und transversa scapulae in den Canal der Halsrippen tritt, um zuletzt oben in die Art. occipilulis einzuminden ${ }^{5}$ ). Bei Anwesenheit eines einzigen Carotidenstammes nimnt die Art. vertebralis der ihm entgegengesetzten Seite aus der Art. sulclavia ihren Ursprung. Interessant ist, dass die Art. vertebralis bisweilen ${ }^{6}$ ) als gemeinsamer Stamm der meisten Arte. intercostales (also als Art. intercostalis communis) in Canale der Rippenansätze abwärts sich forsetzt, indem so, den Veuae vertebrales analoge, Arterienstamme entstehen. - Gewöhnlich theilt sich jede Art. carotis communis in eine Art. c. facialis und cerebralis; seltener zerfällt sie in letztere und zugleich in Aeste der Carotis fucialis \%). - Die Art. subclavia theilt sich nach Abgabe kleinerer Zwweige in die für die Brustmuskeln bestimnte starke Art. Thoracica exterua und die $\boldsymbol{A} \boldsymbol{r}$. axillaris, welche letztere Schulter- und Oberarmzweige abgibt, als Art. brachialis sich fortsetzt und später in eine Art. radialis und uluaris zerfältt. - Aus der Aorta elescendens entspringen, ausser einer grösseren oder geringeren Zahl von Art. intercostales und lumbales, die starke Art. coeliaca; hinter dieser die Art. mesesterica superior; darauf Artt, renales anteriores, aus welchen gewölnnlich Zweige für die keimbereitenden Gesehlechtstheile abgehen; dann die beiden Art. crurales, deren jede eine Art. eprigastrica abgibt und zuletzt die beiden häufig sehr starken -Awt. ischiadicae, zwischen welchen der Stamm, als Art. sacra media sieh fortsetzt. - Aus der Art. ischiadica entspringen gewöhnlich nittlere Nierenarterien, worauf sie durch dic Incisura ischiadica tritt, um neben dem $\boldsymbol{N}$. ischiadicus zur Kniekehle zu verlaufen und die Zweige für die Unterextremität abzugeben. - Aus der Art. sacra media neh-

4) Dic rechte Carotis steigt, nach Nitzseh und Barkow, an der Vorderfläche der Halswirbel auf, während die linke, weit von ihr entfernt, unter der Haut zur Seite des Halses verläuft bei vielen Papageien: Ps. maeanama, oehrocephalus, erithacus, leueocephalus, eanicularis, aurieapillus.

5) Sie bildet also nicht die Arteria basilaris, welche vielnehr aus der Vereinigung zweier Aeste der Carotides ceielrales entsteht und, nach Abgabe seitlicher Arleriae cerelielli inferiores, in die A.t. spinalis anterior sich fortsetzt.

(j) Bei Anas boschas nach Bauer; bei Cieonia nigra nach Barkow.

7) Bei der Gaus ron Tiedemann, bei Corvus piea, Ardea cinerea, Faleo buteo ron Bauer und Barkow beobachtet. - Die Arterien des Dirmkanales bilden Bogen. 
men in der Regel Artt. renales posteriores ihren Ursprung. Immer gibt sie die Art. mesenterice inferior und zwei seitliche, als Artt. pulendae interuae sich fortsetzende, im Ganzen untergeordnete Artt. hypogastricae ab, um als Art. coccygea zu enden. - Wundernetzbildungen kommen an den Arterien der Vögel häufig vor. Ziemlieh bestïndig ist namentlich ein durch den äusseren Ast der $A$. carotis interna gebildetes Rete mirabile ophlhalwicmm ${ }^{8}$ ), aus welehem Artt. palpelrales, lacrymales und die Art. ophthalmica hervorgehen; fernel das Rete mirabile pectinis ${ }^{9}$ ); dann cin gewöhnlich amphicentrisches Rete mirabile tibiale ${ }^{10}$ ). - Von besonderem Interesse ist enlieh das von Barkow entdeckte Brutorgan, wesentlich gebildet durch die reichsten arteriellen und venösen Gefässnetze an den zur Britezeit von Federn entblössten, eines Panniculus adiposus entbehrenden Brutstellen 11).

[ Man vgl. über die Arterien besonders: F. Bauer, Disquisit. circ. nonnull. avium systema arteriosuu. Berol. 1825. 4. Mit Abb. - Nitzsch, Obserrat. de avium art. carotide commun. Hal. 1829. 4. - J. F. Meckel, System der vergl. Anat. Thl. כ̌. und in s. Archiv für Anat. und Phys. 1826. Bd. 1. S. 20. u. 12 \%. und B. 4. (1829.) S. 221 ff. - Barkow, in Meckel's Archiv. 182? u. 1830. Il ahn, Commentat. de arter. Anatis. Hannov. 1830. - Abbildungen theils in den Schriften von Bauer und Barkow, theils in Carus und 0 tto, Erläuterungstafeln. Hft. 6. Tab. VI. - Interessante Bemerkungen über die abweichende Dicke der Arterienhäute, namentlich der mittleren, in den rerschiedenen Regionen des Körpers finden sich bei Barkow, Nov. Act. Acad. Caes. Leop. Carol. Vol. XX. P. II. 1. 701 sqq. - Bemerkenswerth ist, dass bei der Gans, wie Tiede mann zuerst angegeben, die Art. mesenterica superior da, wo sie die Rami intestinales abschickt, eine Erweiterung bei gleichzeitiger Verdickung der Wände bildet. Innerhalb dieser Erweiterung finden sich zahlreiche Klappen, welche, zum Theil unter einaniler verbunden, der Innenfläche ein netzförmiges Ansehen geben. S. daüuber Barkow l. c. p. 705.]

\section{Von den Venen.}

\section{§. 145.}

Die Venen der Vögel besitzen verhältnissmässig dickere Wandungen, als die der kaltblütigen Wirbelthiere, wie sic auch häıfiger und regelmässiger durch Anwesenheit von Klappen sich auszeichnen.

Die sämmtlichen Venen sammeln sich in zwei oberere oder vordere

8) Bei Anas, Phasianus, Columba, Falco, Fulica 1. s. w. Auch andere Wundernetze kommen vor, z. B. ein Rete micabile maxillare bei Ciconia, bei Anser.

9) Es scheint ganz constant zu sein, liegt gewöhnlich an der äusseren Seite des Sehnerven und tritt durch den Schlitz der Sclerotica in den Kamm des Auges.

10) Z. B. bei Podiceps, Anser, Fulica; sehr schwach beim Huhne; angedeutet bei Ardea.

11) Abbild. von Podiceps suberistatus, wo Barkow es an stärksten antraf. Barkow l. c. 
und in eine untere oder hintere Hohlader, welche in den rechten Vorhof des IIerzens sich öffnen. Die Vena corounria cordis tritt nicht, wie bei den meisten Sïugthieren, isolint in das Ilerz, sondern mündet in die V. cavn supperior sinistrn.

Die Hauptyenenstïmme sind folgende:

1. Die beiden $\boldsymbol{V}, \boldsymbol{V}$, jugul $\mathbf{\text { r }}$ es. Jede derselben entsteht eigentlich aus einer $\boldsymbol{V}$. facialis und steht mit den venösen Gefiissen des Gehirnes nur in sehr schwacher Verbindung. Die beiden Jugularvenen steigen aun Ualse selır oberflïichlich neben der Luftrölıre und den $\boldsymbol{N}$. N. vagi gelegen, deminach weit entfernt von den Carotiden, abwärts. Schon in der Nälı des Kopfes stehen die beiden Jugularvenen gewöhnlich durch eine Queranastomose mit einander in Verbindung, welche das Blut aus der linken in die rechte Vene ableitet. Daher rïhrt denn die gewöhnlich betrachtlichere Weite des rechten Stammes ${ }^{1}$ ), der sogar asymmetrisch allein vorhanden sein kann 2). Die Jugularvenen führen ausser dem venösen Blute des Kopfes, das Blut der $\boldsymbol{V}$. $\boldsymbol{V}$. linguales, thyreölene, oesophlingene zum Herzen zurück ${ }^{3}$ ).

2. Die Venne vertelurales anteriores und posteriores; jene vom Kopfe absteigend, diese zur Halsgegend aufsteigend. Diese Venen liegen bei den Vögeln iiber den Rippenköpfchen, die vordere demnach im Canale der Ialswirbel. Jede vordere Vertebralvene nimmt vorzugsweise das Blut aus den Gehirne 4) auf; in beide Vertebralvenen ergiessen sich ausserden die Venen des Rückenmarkes, so wie die $\boldsymbol{V}$. V. intertransversales und intercostales. Jede hintere Vertebralvene verbindet sich mit der gleichseitigen vorderen und geht mit ihr vereinigt vor der $\boldsymbol{V}$. subclavia in die $\boldsymbol{V}$. jugularis ihrer Seite über.

3. Durch die Verbindung der tlas Blut der Vorderextremitäten zurückfiihrenden Vena sulclavia jeder Seite mit einer $\boldsymbol{V}$. jugularis entstehen dann die beiden oberen oder vorderen llohlvenenstämme.

4. Die Entstehungsweise der hinteren oder unteren Ifohlvene, der auch. das Pfortadersystem der Leber untergeordnet ist, ist folgende: durch das Zusammentreten der Venen des Schwanzes, des

1) Das Ueberwiegen der Weite des rechten Stammes ist oft sehr bedeutend und wird mit Recht von allen Beobachtern hervorgehoben. Es ist bei Vögeln aller Ordungen beobachtet worden; nnter den Schwimurvögeln bei Anser, Anas, Colymbus, Halicus, unter den Sumpfrögeln bei Arica, Grus, Phoenicopterus, unter den Struussen bei Casuarius indicus, ferner bei den Hübnern, Tauben, den Papageien, Schwalbeu, Sperlingen, Würgern, Raben, so wie entlich auch bei Falco und Strix.

2) Von Barkow und Ritlike beobachtet. Der letztere Forscher fand nur eine Jugularvene bei Piens major, P. Martius und P. medius.

3) S. die nähere Beschreibung dieser Zuveige bei Macartney.

4) Dic Sinus der Hirnhïute sind ebenfalls von Macartney genmer be. schrieben. 
hinteren Theiles der Bcckengegend und der Clonke, so wie auch der Venae olturatoriae entstcht ein unpaarer Venenstamm, welcher in einen mittleren, die Wurzel des Leberpfortadersystemes bildenden Ast und in zwei seitliche Caudalvenen sich spaltet ${ }^{5}$.. Jede dieser seitlichen Caudalvenen tritt durch den hinteren Theil der Niere ilırer Seite, nimmt, an Weite gewinnend, sowol Venen aus der Nierensubstanz, als auch Venae lumbales auf und vereinigt sich dann ausserhalb der Niere mit der Vena ischiadica ${ }^{6}$ ) ihrer Seite zur Vena lyphogastrica. Jede Vena hypogastrica wird durch die Verbindung mit der Vena cruralis i) ihrer Seite zur Vena iliaca commenis. In jeden dieser Venenstämme treten bisweilen noch ein Paar Nierenvenen, so wie auch Venen der keimbereitenden Geschlechtstheile ein. Durch die Verbindung der beiden Venae iliacae communes entsteht dann die einfache Vena cava inferior, ein verhältnissmässig sehr kurzer Stamm, welcher rechterseits von der viel engeren Aorta zum rechten Leherlappen aufsteigt, in ihn eintritt und die rechte, so wie darauf auch die linke Lebervene ${ }^{8}$ ! aufnimmt. Gleich darauf senkt sich noch eine Vena abdominalis anterior in sie ein. Diese letztere Vene beginnt vor der Cloake, verläuft zwvischen dem Pcritoneum und den Bauchmuskeln vorwärts, nimmt aus ihnen Zweige auf und tritt die durch Incisura hepatis in die untere Hohlvene. Bei den tauchenden Vögeln ist die untere Hohlvene durch bedeutende Weite, namentlich während ihres Verlaufes durch die Leber ausgezeichnet.

Die Wurzel des Leberpfortadersystemes wird gebildet durch die schon oben erwähnte unpaare mittlerc Fortsetzung der Vena caudalis, welche bald zum gemeinsamen Pfortaderstamme 9) wird, bald den zum rechten Leberlappen tretenden Hauptstamin der Pfortader ${ }^{10}$ )

5) S. d. Abbild. dieses Circulus venosus renalis bei 0 t to l. c.

6) Diese Vena ischiadica ist in Vergleich zur $\boldsymbol{V}$. cruralis ein unbedeutender Ast, der durch das Foramen ischindicum in die Beckenhöhle tritt und aus Venen der Rückseite der Hinterextremität entstelit.

7) Die Venae crurales s. femorales sind sehr beträchtliche Stämme, welche in einiger Entfernung von den entsprechenden Arterien liegen und das meiste Blut aus den Hinterextremitäten aufnehinen. - Nach den Beobachtungen von Nitzsch tritt die $\boldsymbol{V}$. couralis bei allen Passerinen, bei einigen Spechten, beim Storch, so wie auch bei Upupa, Corvus durch die Nierensubstanz hindurch. Weil in die Vena cruralis häufig, z. B. bei den Hïhnern und Tauben, eine aus mehren Lumbarvenen und Nierenvenen gebildete, den vorderen Theil der Nierensubstanz durchsetzende Vena ilen-lumbalis eintritt, wurde Jacobs on verleitet, in diesem letztgenannten Gefässe eine Vena renalis advehens zu sehen - ein Irrthmm, den zuerst Nicolai nachgewiesen hat.

8) Die Lebervenen treten bisweilen, wie z. B. bein Hulne, in mehren einzelnen Aesten in die untere Hohlvene.

9) Z. B. bei Falco milvus nach Nicolai.

10) Beim Huhne, bei der Gans u. A. Der rechte Pfortaderast ist gewölnn. lich der stärkste; in den linken Leberlappen treten, wie Macartney und 
bildet, der dann allmälich verstïrkt wird, indem das Pfortadersysten seine zufuhrenden Yenen aus dem Darmcanale, dem Magen, dem Pancreas, der Milz erhält.

[Man verg]. über das Venensystem der Vügel die schon früher citirten $\mathbf{A b}$. handlungen von Rathke und Nicolai, so wie die Beschreibung der Venen des Hulnes ron Macartney in Owen's Aufsatze: Aves in Todd's Cyclopaedia. Eine Abbildung der Venen des Schwanes hat 0 tto gegelen in Carus und 0 tto, Erläıterungstafeln. Heft 6. Tab. VI. Fig. 1. - Das Veneusystem des Aptery $x$ australis bictet nach 0 we n nichts Eigenthünliches dar.]

\section{Von den Lungengefässen.}

§. 146 .

Die Lungenarteric theilt sich beinahe unmittelbar nach ihrem Ursprunge in zwei Aeste, von denen jede Lunge einen erhält. Aus jeder Lunge kömmt eine aus zwei Aesten gebildete Lungenvene. Beide Lungenvenen vereinigen sich vor ihrem Eintritt in den linken Vorhof zu einem Stamme.

\section{Von den Chylus- und Lymphgefässen.}

\section{§. 147.}

Die Chylus- und Lymphgefässe der Vögel besitzen diunne Wandungen und innere Klappen. Sic kommen in fast allen Gegenden des Körpers vor und bilden häufig ansehnliche Geflechte. Lymphgefäss knäuel (Ganglia lymphatica) sind bisher fast nur an der unteren Irälfte des Halses und am Eingange der Brusthöhle aufgefunden worden 1). - Die grösseren Lymphgefässstämme verlaufen in der Regel neben Arterien- oder Venenstämmen. Die Lyinphgefässe der Hinterextremitäten und der hinteren Hälfte der Eingeweidehöhle vereinigen sich in einen etwas erweiterten, vor der Aorta liegenden Stamm. Dieser theilt sich gabelförmig in zwei Ductus thoracici, in welche lymphatiselıe Gefisse der Lungen, der Vorderextremitäten, so wie die vom Kopfe und vom IIalse absteigenden Stämme einmünden. Jeder Ductus thoracicus ergiesst sich in die obere Hohlader seiner Seite, unterhalb der Einmiindungsstelle der Venae jugulares. Eine zweite, anseheinend sehr beständige Verbindungsstelle von lymphatischen Gefässen mit Venen findet sieh an der Grenze des Beckens und der Schwanzwirbel, zur Seite oder unterhalb des M. coccygeus superior s. spinalis caulae. Mehr oder minder zahlreiche Lymphgefässe der Schwanzgegend treten, nachdem sie in einen oder in mehre Stämme

Wagner schon beinerkten, kleinere Venen vom Magen und vom Duodenum ge. wöhnlich einzelı ein.

1) Beim Storch inlessen sahe ich in Mesenterium eine weisse Drüse, wel. che, allon Auscheine nach, eine Mesenterialdrüse war. 
sich vereinigt, bald in eine blos häutige, blasen - oder sackförmige, oft sehr geräumige Erweiterung, bald in cin muskulöses (obsehon vielleicht nie rhythmiseh) contractiles Lymphherz \%usammen. Aus diesem geht ein gewöhnlich enger Venenstamm hervor, weleher, init anderen Venen der Schwanzgegend später verbınden, in den die Niere durehsetzenden seitlichen Schwanzvenenstanm einınündet. Lymphherzen sind bisher nur beim Strausse und Casuar, so wie bei einigen Sumpf - und Schwimmvögeln angetroffen worden. Ihre aus quergestreiften Primitivbündeln besteliende Muskelsehieht ist bald sehr diek, wie bei den Struthionen, bald sehwäeher, wie bei den Stürehen und Möven, bald nur spurweise zu erkennen, wie bei dein Sehwan, der Gans und vielen anderen Wasservögeln. So findet sich ein allmälicher Uebergang von einem stark muskulösen Herzen zu einer häutigen Blase, wie sie bei Tag - und Nachtraubvögeln, Krähen u. s. w. angetroffen wird. Die eigentliehen Lymphherzen liegen frei im Fettgewebe (wie beim Casuar, beim Storeh und Larus marinus) oder halb unter dem oberen Sehwanzmuskel (wie bei Anser, Cygnus) und sind nur beim Strausse dureh sehnige Verlängerungen an benachbarte Knochen befestigt. In ihrer Höhle besitzen sie wirkliche Trabeculae carneae oder werden durch brüekenartige Sehnen, welche von einer Wand zur anderen gehen, durchsetzt. Stets besitzen sie Klappen, sowol an der Mündung der einführenden Lymphgefässstämme, als aueh an deın Ostium der Vene; jene verhindern den Rüektritt der Lymphe aus dem Herzen, diese den in dasselbe. - Die bäutigen Blasen, welehe gewölunlieh ganz von dem oberen Steissbeinmuskel bedeckt werden, sind inwendig auch gewöhnlich mit Klappen und brüekenartigen Fäden versehen.

[Die Iymphgefässe der Vögel sind von Monro und Hews on zuerst be. schrieben worden. - S. F o hmann, Anatom. Unters. über die Verbindung der Saugadern mit den Venen. Heidelberg 1821. - Ueber den Verlauf der Lyimphgefässe A. Lauth, in Annal. des sc. natur. 1824. T. 3. p. 381. Mit zahlreichen Abbildungen. Tab. 2i-25. (von der Gans). - B. P anizza, Osservazioni antropo-zootonico-fisiologiche. Pavia 1830. Fol. Tal. IX. u. X. (Tab. IX. Fig. 3. das Lymphberz der Gans, von P. als Bläschen beschrieben. p. 63.). Vergl. auch Panizza's Richerehe s. il S. l. d. Rettili. p. 39. - Ueber die Lymphherzen siehe meinen Aufsatz in Müller's Archiv 1843, dem ausführliehere Mittheilungen folgen werden. Nach meinen bisherigen Erfahrungen scheint die Muskelschicht der Lymphherzen bei jungen Thieren stärker entwiekelt, als bei älteren Individuen.] 


\section{Siebenter Aluschnitt. Von d. Respirations- u. Stimm-Organen. 315}

\section{Siebenter Abschnitt. \\ Von den Respirutions - und Stimm-Orgrenen.}

\section{§. 148.}

Dic Athmungs - und Stimmorganc der Vögcl sind durch mchre Umstände vor denen der iibrigen Wirbelthierc verschieden. Sie bestehen 1) aus dem oberen Kehlkopfe, der für die Stimmbildung unwesentlich ist; 2) aus der Luftröhre; 3) aus dem, selten fehlenden, sogenannten unteren Kchlkopfe (Larynx bronchialis), d. h. den gewöhnlich an dcr Theilungsstelle der Luftröhre, sehr selten erst weiter unterhalb derselben, nur an den Bronchien befindlichen, die Stimmbildung wesentlich vcrmittclnden Apparaten; 4) aus den beiden Bronchien; 5̃) aus den Lungen; und 6) aus den mit den Bronchialröhren der Lungen durch Oeffnungen in dirccter Communication stehenden pncumatischen Säcken orler Luftzellen der Rumpfhöhle, welche ihrerseits wieder mit eincm grossen Theile der pneumatischen Knochen communiciren und der Luft den Eintritt in letzterc gestatten.

\section{Vom oberen Kehlkopfe.}

\section{§. 149.}

Den Eingang in den oberen Kehlkopf der Vögel bildet cine hinter dor Zungenwurzel gelegene Längsspalte, in deren hinterer Umgebung häufig verschiedenartig gestaltetc, riickwärts gerichtetc Epithelialpapillen vorkommen 1). Meistens geht dic Schleimhaut des Bodens der Ifundhöhle ohne Bildung von Falten oder Erhabenheiten, welche einem Kehldeckel verglichen werden könnten, in die Höhlc des Kehlkopfes über. Selten erscheint, die Function einer Epiglottis versehend, vor dem Kchlkopfseingangc cine grösserc stumpfe Papille oder eine quere Falte, unter wolcher bisweilen noch ein mit gekerbten Rändern versehener, zur Verschliessung des Aditus laryngis bestimmtcr Vorsprung liegt. Nur bei wenigen Vögeln besitzt dicser Vorsprung eine knorpelige Grundlage in einer wirklichen Cartilago epriglattica.

Die feste Grundlage des oberen Kehlkopfes besteht boi jungen Thieren in mehren Knorpeln, welche, mit scltenen Ausnahmen, bei vorschreitendem Alter mehr oder minder vollständlig ossificiren. Der Schildknorpel besteht aus cincm vorderen, höheren Hauptstücke, das jederscits in einen hinteren, viel niedrigeren Abschnitt sich umljiegt. Er ruhet mit scinem unteren Rande auf dem ersten Luftröhren-

1) Sie fehlen aber häufig, z. B. den Straussen, ılem Pelican, Kiornıoran u. A. S. Näheres bei Meckel, System der vergl. Ahat. Thl. 6. S. 467. 
ringe. Seine hinteren Abschnitto bilden den grössten Theil der hinteren Kehlkopfswand, ohne jedoch in der hinteren Mittellinie vollstïndig sich zu vereinigen. In der Regel erscheinen sie bei älteren Vögeln als zwei, gewöhnlich vierseitige, von dem vorderen Hauptsticke getrennte, an seinen iusseren Rändern anliegende Theile 2). Ihre Trennung hangt mit der Ossification der urspriinglich knorpeligen und ununterbrochenen Grundlage zusammen, welche selten ganz ausbleibt, wie bei den Straussen. Es bilden sich nämlich drei Ossificationspuncte: einer im mittleren Theile des Ilauptstückes und zwei an den äussersten Enden der hinteren Unbiegungen; bei der von diesen entgegengesetzten Puncten aus fortschreitenden Ossification werden später häufig die beiden verbindenden Knorpelbrücken resorbirt, wodurch denn eine Trennung in drei Stücke zu Stande kömmt. - Mit Ausnahme der Papageien zeigen sich an dem Schildknorpel der Vögel durch eine oder mehre Querspalten oder durch abwechselnd schwächere und stärkere ringförmige Ossificationen unverkennbare Spuren seiner Entsteliung aus einzelnen Knorpelbogen. -- An seincm oberen Rande trägt der Schildknorpel bisweilen einen meist knorpeligen, selten ossificirten Processus epiglotlicus ${ }^{3}$ ). Nur bei einigen Schwimm- und Sumpfrögcln ist selbst cine durch Naht getrennte Cartilago epiglottica vorhanden 4). - Yon der inneren Fläche des vorderen Hauptstiickes erhebt sich sehr häufig cin in die Kehlkopfshöhle hineinragender, in verschiedener Stärke entwickelter Längsvorsprung 5 )

Die Lücke zwischen den inneren Rändern der beiden linteren $\Lambda \mathrm{b}$ schnitte des Schildknorpels wird, wenigstens in ihrem oberen Theile, ausgefüllt durch eine schmale, unpaare Cartilago cricoüdea, welche jene oberwärts etwas uiberragt. Dieses meistens ossificirtc Stück besitzt an seinem oberen Randc jederseits eine Gelenkfläche für eine der Cartilagines arytaenoüdeae. Es sind dies zwei schmale, längliche, dreiseitige, in der Regel ossificirte Knorpel, welche vom Ring-

2) Die Trennung wurde von Henle vermisst z. B. bei den Straussen, wo der Sehillknorpel knorpelig bleibt, bei den Papageien, wo er ossificirt; bein Sehwan, Peliean u. A.

3) Beim Storeh, Reiher blattförmig, breit und ganz ossifieirt. Bei Hülnnern, Enten, Möwen weich und diinn. Henle S. 60.

4) Bei Cygnus verknöehert; lang, zungenförmig, weich bei Sterna Rallus. Bei Larus marinus knorpelig. Bei Seolopax Gallinula von Nitzseb entleckt. Meckel, Archiv. 1820. S. 616.

5) Z. B. Anas, Cygnus olor, Larus, Cieonia, Grus, Cueulus, Fringilla; sehr unbedeutend bei Meleagris. Feblend den Strutbionen, vielen Hülınern, allen Raubvögeln 11. A. Vergl. Meckel, l. c. S. 458 fr. und Henle, S. 60, wo sehr vollständige Verzeichnisse ïber Anwesenheit und Mangel gegeben sind. Abgeb. bei H umb ol dt, Recueil d'Observat. Pl. 1. u. 2. 


\section{Siebenter Abschnitt. Von d. Respirations- u. Stimm-Organen. 317}

knorpel aus, längs des Allitus laryngis, den sie begrenzen, bis in die Gegend des oberen Randes der vorderen Schildknorpelplatten sich erstrecken. - Stimmbänder fehlen durclıgängig. - Longitudinalfalten treten bisweilen zwischen den Spitzen der Cartilagines arytaenoüleae hindurch in die Kehlkopfshöhle oder an den inneren longitudinalen Vorsprung.

Bei allen Vögeln kommen drei Paar Kehlkopfmuskeln vor. Als Aufheber des Kehlkopfes und der Luftröhre wirkt ein M. liyotrachen lis. Es entspringt jederseits vom Zungenbeinkörper und erstreckt sich mit seiner äusseren Portion über die Vorderfläche des Kehlkopfes zur Luftröhre; seine innere Portion inserirt sich an den unteren Rand des Schildknorpels ( $\boldsymbol{M}$. hyothyreoüleus) und von diesem entspringen wieder Fasern, die zur Trachea absteigen (M. thyreutrachealis) und mit denen der äusseren Portion verschmelzen. - Als Erweilerer des Kehlkopfeinganges wirkt der $\boldsymbol{M}$. thyreo-arytaenoüdeus posticus entspringend vom unteren Rande des Seitenstiuckes des Schildknorpels, zur oberen Spitze der Cartilago arytacmuildea sich erstreckend. - Als Compressor ist der M. thyreo-arytacnvïllers lateralis zu betrachten. Er entsteht vom oberen Rande der Cartilago arytaenoüden. Seine Fasern verlaufen zum hinteren inneren Winkel dieses Knorpels und hinter der Cart. cricoüdea eommuniciren die Bündel der beiden seitlichen Muskeln mit einander.

[Vgl. als Hauptwerk J. Henle, Vergleichend-anatomische Besehrcibung des Kchlkopfes. Leipzig 1839. 3.; Abbildungen Tab. V. Fig. 32-34.]

\section{Von der Luftröhre.}

§. 150.

Die Luftrölıre der Vögel ist, bei der Länge des IIalses und bei ihrer gewöhnlich 1) erst tief abwärts im Anfange der Brusthöhle erfolgenden Theilung in die beiden Bronchien, ausgezeiclinet durch ihre Länge, welche bisweilen durch Windungen oder Krïmmungen, welehe dies Gebilde macht, noch beträchtlich zunimmt. Ihre in grosser Zahl vorhandenen 2 ), bis auf den tiefsten, dem unteren Kehlkopfe angehörigen Abschnitt, meit discreten, Ringe sind sämmtlich, orler wenigstens zum grössten Theile, vollständig geschlossen, denn nur selten bleiben einige der vordersten, dem oberen Kehlkopfe zunächst gelegenen, hinten

1) Eine Ausnahme macht, nach Meckel, die Gattung Trochilus, wo die Theilung der Luftröhre schon ungefihr in der Mitte des Halses statthat.

2) Die Zahl der Luftröhrenringe schwankt bedeutend. An geringsten ist sie bei einigen Singrögeln $(30-40)$, z. B. bei Ianius; die IIülıner, bei denen sie niclit gewunden ist, haben 100-130; der Storch etwa 140; Ardea cincrea etwa $\mathbf{2 0 0}$; der Flamingo und Kranicl gegen 350. 
unvollständig ${ }^{3}$ ). Nur der neuhollänrlische Casuar 4) steht insofern isolirt da, als melıre seiner mittleren Luftröhrenringe vorn gespalten sind, wodurch eine Oeffnung entsteht, mittelst weleher die Cavität der Traehea mil eineın weiten, geschlossenen, elastisch-mrnıbranösen Sack communicirt. Die 'Textur' der Luftröhrenringe zeigt Verschiedenheiten; bald sind sie weich und knorpelig ${ }^{5}$ ), bald sämmtlich oder grossenthcils ossificirt; bisweilen kommen in dieser Beziehung in den verschiedenen Gegenden der Luftröhre Versehiedenheiten vor. Die häutigen Zwischenräume zwischen je zwei Ringen sind im Ganzen, und besonders im unteren Abschnitte der Luftröhre, unbetrichtlich; nicht selten decken selbst die Ringe einander im ungespannten Zustande der Luftröhre, was am häufigsten an den Seiten möglich wird, da sie hier breiter zu sein pflegen, als vorn und hinten. Häufig alterniren die auf einander folgenden Ringe riicksiehtlich der seitlichen Verbreitung in der Weise, dass der cine links und der folgende rechterseits breiter wird ${ }^{6}$ ). - In Ganzen ist der Luftröhrencanal weit ${ }^{7}$ ) und oft cylindriseh ${ }^{8}$ ), aber oft aueh binten flacher als vorn oder auch von vorn nach hinten deprimirt 9). Ausserdem ist die Trachea keinesweges immer durchgängig von gleicher Weite. Sehr oft ist sie namentlich oben am weitesten ${ }^{10}$ ) und verliert plötzlicher oder mehr allmälich an Durchınesser, um in ihrem ferneren

3) Bei Haenatopus, Oedicnemus, beim indischen und neuholländischen Casuar der erste, bei Vultur, Otis, Mormon, Aptenodytes die beiden ersten; beim zweizehigen Strauss die drei ersten; bein Adler die sieben ersten; bei Grus, Fulica, Picus viridis und Yunx eine grössere Zahl.

4) Näher beschrieben von Fremery, De Casuar. nov. Hollanil. Traject. 1819. 8., von Linox und Wedemeyer in Meckel's Archiv. 1832. - Gespalten finde iclı 6 der weichen breiten Knorpelringe, vom 61sten Ringe all. Innerhalb des Sackes liegen ausser den genanuten 6 , noch 6 obere und 6 untere, also in Ganzen 18 Ringe. Der Sack wird innen ausgekleilet vou der durch die Spalte über die Aussenfläche der geninnten Ringe sich fortsetzende Schleimhaut der Luftrölıre. Auswendig überzogen wird er durch die von den vorderen Luftzellen der Brusthöhle über die Trachea sich fortsetzende äussere Haut jener Zellen, die aber selbst geschlossen sind und nicht nit ilım communiciren.

5) Z. B. bei den Tagraubvögeln, den T'auben, Störchen, Trappen, bei Caprimnlgus, Cypselus, Upupa, Alcedo, Merops, Ampelis, den Hühnern, Struthionen; ossificirt bei vieleı Singvögeln (Lanius, Corvus, Turdus, Sturnus, Fringilla), bei den Spechten; bei manchen Sumpfögeln (Ardea, Grus, Phoenicopterus); bei vielen Schrvimınvögeln (Pelecanus, den Sturmvögelı, Colymbus, Anas, Anser, Cygnus, Mergus, Sula. - 6) Z. B. beim Storch, Schwan, Papagei.

7) Weit namentlich bei der Schnepfenfamilie: Scolopax, Totanus u. A.; verhältmissınässig eng beiın Flamingo.

8) Cylindrisch bei den meisten Singrögeln, vielen Hühnern u. s. w.

9) Deprimirt bei den Tagraubvögeln, Papageien, Störchen, Stranss, neuholl. Casuar, Platalea u. A.; beim Singschwan obeı deprinirt, unten cylindrisch.

10) So bei Corrus, Picus, Cuculus, Phasianus, Numenius, Grus, Strix aluco u. A. Sie vreengt sich stärker gegen den unteren Kehlkopf hin bei Puffinus. 


\section{Sicbenter Abschnitt. Von d. Respirations- u. Stimm-Organen. 319}

Verlaufe gleichmässig eylindrisch zu bleiben; oder sie erweitert sich erst gegen ihre Mitte hin ${ }^{11}$ ), bald allmälich, bald plötzlich und geht gegen ilir unteres Ende hin in eine bedeutendere Verengerung uiber. Nur sehr selten ist die Luftröhre durch eine Scheidewand, in welche die Trachealringe sich fortsetzen, in zwei Seitenhälften gespalten 12). - Dic schon erwiihnten Windungen und Krümmungen der Luftröhre kommen nur bei einigen Palıripeden, Sumpfvögeln und Xühnern vor und zeigen sich, wenngleich keinesweges ausschliesslich, doch vorzugsweise entwickelt bei männlichen Thieren. Sie finden sich am unteren Theile der Luftröhre und liegen bald ausserhalb der Brusthöhle unmittelbar unter der Haut ${ }^{13}$ ), bald eingeschlossen in Knochen, namentlich im Brustbeine 14) und sehr selten in der Furcula 15), bald endlich liegen sie in der Brusthöhle selbst 16). - Bei den meisten Vögeln erscheint der Bau der Luftröhre unten an ihrer Theilungsstelle in die beiden Bronchien, behufs der hier statthabenden Stimmbildung, eigen. thümlich modificirt. Bei den stimmlosen Vögeln werden indessen solche

11) So bei vielen männlichen Enten; cinfach ist die Erweiterung z. B. bei A. Ieucocephala, stärker bei A. fusca und clangula, Mergus serrator; zwei Erweiterungen sind schwach vorhanden bei A. crecca und tadorna; stärker bei Nergus merganser. Die Luftröhrenringe sind oft längs der Erweiterung breiter und härter als sonst. Den Gegensatz bildet die tiefer liegende Erveiterung bei A. glacialis, welche vorn fast häutig ist. - Ausser den Enten besitzt anch Palanedea bispinosa eine solche Erweiterung; abgebildet bei Humboldt, l. c. Tab. II. Fig. 4.

12) Zuerst beobachtet beim Pinguin von G. Jaeger (Meckel's Archiv. Bd. VI. 1832. S. 48.); später von Meekel bei Procellaria. Die Scheidewand nimmt bei Aptenodytes fast die ganze Länge der Luftröhre ein; bei Procellaria nur die untere Hälfte; angerleutet fand M eckel diese Bildung auch bei der männl. Anas clangula.

13) So namontlich bei Tetrao urogallus; bei einigen Crax (Alector u. pauxi); bei einigen Penelope (narail, cristata, abunni); einigen Phasianus (parraca u. garrulıs) und bei Anas semipahmata nach Latham.

14) So bildet bei Cygnus musicus in. et fem. die Luftrölıre innerhalb der Crista sterni eine einfache $W$ indung. Aehnlich verhält es sich bei Cygnus Bewickii (vgl. Wi gumann's Archiv. 1838. Tab. VIII. u. IX.). Cygnus olor besitzt keine Spur von dieser Eigenthïmlichkeit. Dagegen macht nach Yarrell die Luftröhre beim selhwarzen neulıolländischen Schwan (Cygnus plutonius) zwischen den beiden Schenkeln der Furcula eine Biegung, welche nicht in das Brust. bein eindringt. - Bei Grus cinereus, so wie bei mehren ausländlischen Kranichen, liegt die Luftröhrenwindung gleichfalls in Kiele des zelligen Brustbeines. Hier aber kommen rücksichtlich ilıres Verhaltens sehr dentliche sexuelle Verschiedenheiten vor. Auch Ardea virgo gehört lierher. S. Yarrell, I. c. Tab. IX.

15) So bei Nimida cristata nach Yarrell, wo der untere Theil der Furcula blasenartig angeschwollen ist.

16) Bei Platalea leucorodia. S. die Ablild. bei Yarrell, Linn. Transact. Vol. XVI. 1829. 
besondere Einrichtungen an dieser Stelle gänzlich vermisst 18); bei anderen aueh dann, wenn blos Bronchialkehlköpfe vorhanden sind, wie bei Steatornis.

Die beiden Bronchi sind im Verhïlnisse zur Luftröhre immer kurz, seltener mässig lang und selbst gelogen 18), häufiger erweitert 19). Selten hesitzen sie vollstïndig gesehlossene Ringe ${ }^{20}$ ). Meistentheils bestelsen ihre soliden Grundlagen nur in knöchernen oder knorpeligen Bogen, welehe an ihrer eonvexen Aussenseite liegen und ihre flache Innenseite ist in der Regel blos häutig. Vor ihrem Eintritte in die Lungen zerfallen sie niemals in Aeste.

Immer befestigen sich an die Luftröhre Muskeln, welche sie nicderziehen und verkuirzen; bald ist nur ein Paar, bald sind zwei Paare vorhanden. Die beständigsten sind die M. M. sternutracheales ${ }^{21}$ ), welehe vom Brustbeine aus an sie herantreten und zu ihren Seiten hoeh aufwärts sich erstreeken. Weniger beständig sind die $\boldsymbol{M}$. $\boldsymbol{M}$. furculo-tracheales ${ }^{22}$ ) oder ypsilotracheales, welehe von den Aesten der Fureula aus an die Luftröhre sich begeben. Andere Muskeln, welche blos einzelnen Ordnungen oder Familien eigenthüınlich und ausschliesslich auf die Stimmbildung von Einfluss sind, sollen später erwähnt werden.

[Man vgl., ausser den Handbüchern von Cuvier und Meckel, besonders die von Abbildungen begleiteten Ablandlungen von Latham (Linnean Transact. T. IV. 1798.) und von Yarrell (Linnean Transaet. T. XV. 1827.). - Einige Abbild. bei Hu in boldt, Recueil l'Obs. de zool. et d'Anat. comp. Tab. 1. u. 2. und bei Wagner, Ic:0n. zoot. Tab. XII.]

17) Z. B. bei den straussartigen Vögeln, auch bei Apteryx, nach 0 wen, bei Vultur papa, bei den Störchen.

18) Lang bei den Störchen. Bein männlichen schwarzen Storch macht jeler Bronchus eine Sförınige Biegung; bein Weibchen kaum eine Spur davon; eben so wenig bein männlichen weissen Storch.

19) Sehr weit z. B. beim Pelican; anfangs erweitert bei Nunida meleagris. Bei einigen Enten, z. B. bei A. clangula, ist, bei Anwesenheit einer stärkeren linken Pauke am unteren Kehlkopfe, der linke Bronchus ansehnlich weiter, als der rechte.

20) Z. B. bei Ciconia; bei Steatornis nach Müller, unter Anwesenheit zweier Bron;hialkeblköpfe. Mit Ausnahue der ersten vollständig bei einigen Anas, Anser, Cygnus; die häutige Liicke ist sehr schmal bei einigen Enten, bein Cormoran, bei Colyumbus.

21) Eine nnerkwürdige Eigenthümlichkeit besitzen diese Muskeln bei den Tauben, insofern, als sie beide an die rechte Seite der Trachea sich ansetzen.

22) Sie fehlen den Raubrögeln, Tauben, Straussen, der Schnepfenfanilie, den Fulicarien, Störchen, Kranichen, Flamingo, den meisten Schwimuivögeln: Anas, Anser, Carbo, Larus, Peleeanus u. s. w. 


\section{Voin unteren Kehlikopfe.}

\section{§. 151 .}

Bei den meisten Vögeln - d. h. bei denen, welche nicht stimmlos sind, wie die Struthionen, the Störche, einige Geier 1) - findet sich ein unterer Kehlkopf, d. h. ein Apparat von membranösen Theilen, wolche durch die Art ihrer Befestigung an den zunächst gelegenen, eigenthümlich modificirten festen Theilen geeignet sind, in Schwingungen versetzt zu werden oder die Luftsäule in Schwingungen zu versetzen. Ein versehiedentlich entwickelter Muskelapparat bewirkt Verengerung oder Erweiterung der Stimmritzen. Diese die Stimmbildung vermittelnden Einrichtungen kommen sehr selten blos an den beiden Bronchien vor, so dass die Luftröhre ron ihrer Bildung ganz ausgeschlossen ist, wie bei den Gattungen Steatornis und Crotophaga. IIier sind blos zwei Bronchialkehlköpfe (Larynges Uroncliales) vorhanden 2 ). - Ehen so selten beschränken sich diese schwingenden Apparate blos auf den unteren Theil der Luftröhre, wie dies neuerlich rüicksichtlich der Gattungen Thannophilus, Myiothera und Opetiorhynchus beobachtet ist (Laryux trachealis) ${ }^{3}$ ). - Meistens finden sie sich

1) Allen Struthionen, init Einschluss von Apteryx, fehlt der, den Stimmapparat bildende untere Kehlkopf; doch sind bei ihnen die Bronchien nicht von soliden Ringen umgrenzt, sondern inwendig häutig geschlossen. Bei deı Störclien, die au der Theilungsstelle der Luftröhre eine Erweiterung der letzteren lesitzen, sind die Bronchialringe vollständig. Unter den Geiern fehlt der untere liehlkopf der Gattung Sarcoramphus s. Cathartes. Gleich Cuvier und Rudol. phi, vermisse ich ihn durchaus bei S. papa; Rudolphi bemerkt seinen Mangel auch bei S. aura und Yarrell bei S. gryphus. - Wagner will ihn bei Vultur cinereus, fulvus, so wie hei Gypaëtus gefundeu haben. Bei deın Mangel einer eigentlichen Paulie besitzen die genannten Arten angeblich eine Memlrana tymmaniformis interna und $\boldsymbol{M}$. M. Ironcho-tracheales. S. Wagner, Icon. zootom. Tab. XII. Fig. XXX. U. XXXI. und dessen Lelırbuch der Zootomie. Leipzig 18/3. 8. S. 130.

2) Vergl. über Steatornis Müller in seinem Archiv. 1842. S. 7 ff. Tab. I. Zwischen dem Ende der Luftröhre und den Bronchialkehlköpfen liegen links 16, rechts 11 vollständige Bronchialringe. Es ist ein Paar Broncho-Tracheal-Muskeln vorhanden. Aehnlich verhält sich, nach Müller (Stimmorgan der Passerinen. S. 11.), Crotophaga maior. - Sehr verschieden von Steatornis zeigt sich Podargus. Die letzten Ringe der Luftröhre sind hinten unvollständig geschlossen; es ist ein schwacher Steg vorhanden. Der erste Bronchialring jeder Seite ist vollständig; die übrigen sind innen läutig geschlossen. Eine Memlrana tympaniformis externa fehlt. Es findet sich ein Paar tief an den Bronchien sich inserirender Broncho-Tracheal - Muskeln.

3) Siehe Müller (Stimmorgan ler Passerinen. S. 6.). Die festen, breiten Ringe der Luftröhre bören noch vor der Theilung plötzlich auf und es folgt ein dünnhäutiges, eben so langes, als breites Stück der Luftröhre, welches von vorn nach hinten abgeplattet ist und mit einem Luftröhrenringe schliesst, an den sich die Bronchien anschliessen. Der läutige Theil der Luftröhre enthält $5-7$ 
violmelu an der Theilungsstelle der Luftröhre in die beiden Bronchien und an Anfange der letzteren. WVo dies der Fall istoplialt der untere Kolilkopf den Namen: Larynx bromcho-traclecalis. _ .

Wo rin Broncho-Tracheal-Kehlkopf rorkonmt, zoigt der unmitlelbar vor der. Theilungsstelle gelegene unterste Abschnilt der Luftröhre eigenthimuliche, mehr oder weniger ausgeprägte Modificationen sciner l3ililung. Die let\%len Luftröhrenıinge rouicken näılich häufig dicliter all cinander 1 ), oder werden dureh eine Lïngsleiste unter rinander verbunden ${ }^{5}$ ), oder verwachsen, in grösserer oder geringerer Zihl, ganz oder theilweise, mit einander "). Mit dieson, die einzelnen Ringe betreffenden Abweichungen sind gewöhnlich Veräinderungen in der Form und in den Dimensionen des untersten, vor der Theilungsstelle in die beiden Bronchien gelegenen Luftröhrenaloschniltes verbunden. Bald erscheint er erweitert und von vorn nach hinton etwis deprimirt "); häufiger verengt, seitlich zusnmmengedriickt, vorn und hinten vorspringend und in dieser Dimension am liangsten 8). Der so modificirte unlerste Abschnitt der Luftröhre erhialt den Namen der 'Tro mumel.

- Der Bau dieser Trommel erscheint eigenthiimlich alogeänder' bei den Männchen vieler Enten und Tauchel und bei einigen exotischen Vögeln anderer Ordnungen. Iier kommen Erweiterungen 9) an ihr vor, loald

äusserst zarte Ringe. Sie sind an den Seiten, wo sie unterbrochen sind, durch ein Längsband festgehalten, also schwingende Halbringe der Luftröhre nit schwingender Zwischen. Membran, welche sie verbindet. Der häutige Theil der Luftröhre wird bei Myiothera und Thamnophilus durch einen Muskel auf jeder Seite verkïrzt, velcher vom Ende des festen Theiles der Inftröhre zum letzten Luftröhrenringe über der Theilung geht. - Zusammengesetzter sind diese Verhältnisse bei Opetiorlyuchus.

4) Z. B. beim Haushuhme, bei den Allern, Falken, dem Pelikan, bei Rallus 11. A.

כ) So bei den meisten Hiilnem und Tauben. Bei letzteren werden die letzten beiden Trachealringe durch eine Längsleiste mit einander verbunden; bei Tetrao verbindet diese leiste 5-6 Ringe, mehre anch bei Phasianus colchicus. Bei Meleagris Gallopavo findet sich diese Verbindungsart der beiden letzten Ringe: nur vorn.

6) Eine vollständige Verwachsung kommt z. B. vor bei der Gans, den Pinguinen, den Möven, vielen Singvögeln : fast rollständig ist sie bei Phoenicopterus.

7) So bei vielen einbeimischen Vögreln, z. B. den Mören.

8) Sehr auffallend z. B. beim Haushuhne.

9) Dergleichen Erweitermugen waren bisher mur bei allen Arten der Gattung Mergus und bei vielen Enten hekannt. Yarrell (Amals ad magazin of nat. Vol. IX. p. 147.) traf sie auch bei Anser gambensis au. Tschudi (Mïller's Archiv. 1843. S. 473.) beschreilt eine solche auch bei Cephalopterus ornatus mind Miller (1. c. S. 3.) gedenkt ihrer bei Gymnocephalıs, beide Gattungen ans Nit»sch"s Familie der Ampelinie. - Was die Enten anbetrift, so ist die Panke anch bei den Mänuchen nicht constant. Sie wirl vermisst bei Anas fusca, A. nigra, A. lencocephala. Dagegen habeu A. mollissima, A. boschas, A. crecci, A. acuta, A. sponsa แ. A. 11. linkerseits eine knöcherne blasige Erweiterung. Bei A. querquedula 
in Gestalt knücherner unregelmiissiger Blasen, bald als Nebenhöhlen, welehe durch Membranen, die in knöchernen Rahııen ausgespannt sind, geschlossen werden. Sie sind bei den Tisuehern und Enten asymmetrisch, meist unpaiı und links gelegen, oder linkerseits vorzüglieh entwickell, sehr selten reehterseits stärker ausgebildet und werden gewöhnlich als Pauken oder Labyrinthe bezeiehnet. - Selten ist die Trommel auclı ohne solehe aecessorisehe Labyrinthe asyminetriseh 10).

Der in die Bronehien fiihrende Ausgang aus der Trommel ist bald blos dureh den Vereinigungswinkel der die beiden Bronehien einwärts begrenzenden IIäute, bald dureh einen ilın von vorn nach hinten durehsctzender, meist knöehernen Steg, an welehen jene membranösen Theile sieh befestigen, getheilt. Unter den Vögeln, die keinen Steg be sitzen 11), sind besonders die Papageien von Interesse. Bei ihnen liegt unter jedem der beiden unteren Seitenränder der Trommel ein halbmondförmiger, abwärts eoneaver Knoehenbogen und am Anfange eines jeden Bronchus ein ähnlieher aufwärts eoneaver Bogen. Die oberen Bogen bilden mit dem unteren Rande der Trommel eine Art falsehes Gelenk und bewegen sieh, gleieh Ventilen, ein- und auswärts. Zwisehen beiden Bogen ist eine Membran (die sogenannte äussere Paukenhaut, Membrana tympaniformis cxterna,) so ansgespannt, dass sie, in der Mitte zwisehen beiden, kein Continuum bildenden, Bogen, naeh innen in einem Winkel oder einer Falte vorspringt. Die.Falten der beiden entgegengesetzten Seiten begrenzen die einfaehe Stiminritze. An der Innenfläehe des Randes jeder Falte findet sieh noch ein häutiger Streifen, weleher dureh die Luft zuerst in Sehwingung rersetzt wird. Jederseits finden sieh drei eigenthümliehe Muskeln. Zwei derselben: ein längerer und ein kiirzerer (M. M. broncho-tra-

und clangula ist der ganze Kehlkopf blasig erweitert, links aun stärksten. Eine dopjelte knöcherne Pauke unter Anwesenheit einer Erweiterung an der rechten Seite findet sich bei A. talorna. Bei A. ferina, fuligula, rufina, marila, glacialis u. A. ist die linkerseits gelegene eckige Pauke nicht knöchern, sondern zun Theil durch häutige, zwischen bogenförmigen Leisten ausgespannte Theile ge. schlossen, wodurch diese Enten sich denn eng an die Mergus-Arten, bei denen dieser Bau der Pauken au entwickeltsten vorkonmt, anschliessen. - Auch bei Weibchen einiger Enten und der Taucher ist der untere Kehlkopf etwas asymuetrisch.

10) Theils gehören hieher die Weibchen mehrer Enten und Taucher, theils auch, naclı den Angaben von Nitzsch, einige Schmepfen (Scolopax major und gallinago); die Asymmetrie mangelt jedoch bei Sc. rusticola nnd gallinula.

11) Ausser den Paprageien gehören dahin von cinheimischen Vögeln z, B. Scolnpax (wenigstens Sc. rusticola), Halicus carbo, Mormon, Pelecanus u. A. Bei der Waldschnepfe erhebt sich inwendig an der Vordewvand der Trontuel eiue längliche Hautfalte. Die Distanz zwischen dem unteren Rande der Trommel und dom erstru Bronchialhalbringe ist unbedeutend. Eine eigentliche Memfrana. lymprenifmmis cxlerna ist kitun vorhnuden. Der Broncho-Tracheal-Muskel befestigt siclı blos an unteren Eifle der 'Troumel. 
cheales), dic von der Luftröhre zu jedem Bronchus treten, ziehen die Bronchien aufwirts und verengern dadurch die Stimmritze. Der dritte und kiirzeste erstreckt sich von der Trommel zum oberen halbmondförmigen Knorpel, zieht diesen auswärts und 'iweitert dis Stimmritze.

Der Steg (Riegel, Bügcl), welcher den Ausgang der Trommel bei den meisten Vögeln theilt, ist gewöhnlich kuöchern; selten ist er nur knorpelig, dahei gerade und ganz schmal, wie z. B. hei den Tauben; meistens bildet er nur der Trommelhöhle zu nach oben cine schinale comprimirte Leiste, wird unten breiter, macht vorn sowol als hinten einen einfachen oder doppelten, abwärts gerichteten Vorsprung und besitzt zwischen diesen Vorsprüngen einen unterwärts concaven Ausschnitl. Längs jedem Rande dieses Ausschnittes ist der obere Theil der hiiutigen Innenwand jedes Bronehus, wie in einem Bogen oder Rahmen, ausgespannt. Bald unterhalb dieses ausgespannten Theiles sind dic häutigen Innenwäncle beider Bronchien durch schwache, oder starke straffe, elastische Fasern, dic an ihren beiden Ausgangspunkten oft starke Polster bilcken, unter cinander verbunden 12). Der in deın Bogen ausgespannte Theil der häutigen Innenwand der Bronchien erhält den Namen der inneren Paukenhaut (Membrane tympreniformis interua). - Unter ihr bleibt der Bronchus innen bald bäutig, bald besitzt er vollstündige Ringe, wic z. B. beim Singschwan. Häufig ent. spricht ihr cine äussere Paukenhaut (Membrana tympaniformis exterua), deren Umfang ${ }^{13}$ ) verschieden und deren Lage unbéständig ist. Sie kann als häutiges Fenster zwisehen den beiden letzten Trachealringen liegen, die weit von einander entfernt, nur durch eine vordere und hintere Längsleiste unter cinander verbunden werden, wię z. B. bei den Tauben; oder sie liegt zxwischen dem unteren. Rande der Trommel und dem ersten Bronchialringe, wie bei den Gänsen, oder zwischen dem ersten und zweiten Bronchialringe, wic bei den Möven, oder zwischen tieferen Bronchialringen, wie bei den Eulen. Sobald dic Luftröhre niedergezogen wird, kann sic dann, vermöge ihrer Be-

12) R. W agner (T.ehrl). der vergl. Anat. Leipzig 1834. 8. S. 245̆ u. 246.) gedenkt dieser Polster, als runder, knorpeliger, oder aus Fasermasse gebildeter Scheilsen, welche zuweilen selbst ziemlich dieke Kissen oder Peloten darstellen, bei Anas acúta, crecea, Mergus Merganser und besonders bei Fulica. Ich finde sie selır stark auch beim Kuhnlahn (Meleagris gallopavo); immer aber zwisehen diesen Polstern die, beide Bronchi verbindeulen Brüeken, welehe aueh sonst sehr allgemein, obwol in verschielenem Grade ausgebildet, vorkommen. Die Faseru, ans dencn die Polster bestehen, gehören deu elastischen Gewebe an, zeichnen sich durch ihre Breite aus $\left(0,002-0,003^{\prime \prime \prime}\right)$, geben Aeste ab und sind der zweiten, von Henle untersehiedenen Varietät des elastisclien Gewebes zuzuzählen. ( $S$. Heule, Allg. Anat. Leipzig 1841. 8. S. 400.). Sie sind bei den Enten von vielem Fett umhüllt, beim Kulmbahne olıne Fett.

13) Schr gross z. B. bei Tauben, Hühnern, beim Flaningo, bei Platalea, Grus, Rallus, Larus, Lestris, Cygnus u. A. 


\section{Siebenter Abschnitt. Von d. Respirations- u. Stimm-Organen. 325}

festigungsweise, eine nach innen vorspringende Falte bilden, wïhrend ausserdem ihr oberster Theil in dem soliden Ralunen ausgespannt bleibt. Eine ausgebilklete äussẹre Paukenmembran fehlt häufig lif) und dessenungenchtet kann der, zwei bewegliche Bronchialhalloringe vereinigende, schmalere, membranüse Theil bei Annäherung dieser Ringe, als ausseres Labium jeder Stimmritze faltig nach,innen vorspringen. - Gewöhnlich ist der Steg mil der Trommel fest verbunden oder verwachsen; doch ist dies Verhalten nicht beständig. Beisn Haushuhne z. B. ist der, den Steg einschliessende Ring nur ganz lose mit der seitlich comprimirten Tromucl verbunden. - Nicht selten liegen auf der iusseren Paukenhaut polsterartige Anhäufungen von elastischem Gewche 15). Dieso: können auch bei Nangel einer eigentlichen äusseren Paukenhaut die ersten Bronchialhalbringe und deren häutige Interstitien auswendig bedecken 16). - Einige Eigenthümlichkeiten besitzl der untere Kehlkopf - auch abgesehen von seinen Muskeln - bei den einheimischen und einigen exotischen Sing vögeln. Der zweite und dritte Bronchialhalbring sind bei ihnen sehr beweglich. Von dem, die solide Trommel unten durchsetzenden knöchernen Stege erhebt sich eine - schon bei anderen Vögeln, z. B. beim Huhne, schwach angedeutete - Falte (Membrana semilunaris), welche cine Fortsetzung der auch den Steg inwendig überziehenden inneren Paukenhaut ist. Mit dem vorderen inneren Ende des zweiten knöchernen Bronchialhalbringes und mit dem vorderen und unteren Ende des Steges ist ein kleiner viereckiger Knorpel etwas bewrglich verbunden. Elastisches Gewebe, welches längs der Innenfläche der ersten Bronchialhalbringe und, ganz besonders des dritten, wulstig angehäuft ist, bildet als Stimmband die iussere Lefze (ler Glottis ${ }^{17}$ ); in viel geringerer Menge an der Innenfläche der Membr. tympanifurmis intersa vorkommend und hier noch durch ein sehr kleines, in der genannten Membran frei liegendes Knorpelchen unteıstiitzt, bildet es auch cine Art von innerem Lalium glottidis ${ }^{18}$ ). Ein bald zu elwälnnender

14) \%. B. bei den Selınepfen, bei Aquila albieilla u. A.

15) Z. B. bei Otis tetrax nach Angabe ron Nitzscl.

16) Z. B. bei einigen Raubvögchn; so finde ich sic bei Aquila albicilla. Bei den männlichen Auer- und Birkhühnern kommt eine ähnliche Masse im äusseren Umfange des unteren Kehlkopfes vor, die den Weibehen fehlt.

17) Diese elastisehen Fasern weichen wesentlich ab vou denen, welche in die Zusammensetzung der Polster der Memlorana tympaniformis interna eingehen. Sie sind sehr schmal: $0,0006-0,0009$ "' in Durchmesser haltend, geben wenige $A$ cste $a b$ und gleichen durehaus den in den unteren Stimmbändern der Säugethicre vorkommenden. Sie gehören also, gleieh diesen, Henle's erster Varietït des elastischen Gewelses an (s. Hen\}e I. e. S. 400.).

18) Ueber den Bau des Kehlkopfes der ausländischen Singvög»l vergl. Mül. Ier's cilirte Abhandlung. Es kommen, rïrksichtlich seiner, viel beträchtlichere Versclicdenheiten vor, als man bisher geahnet liatte. 
zusammengesetzter Muskelapparat vorändert die Stellung der beweglichen Bronchiallablbringe und die der Stimmbinder.

Der Muskelapparat, mit welehem der untere Kehlkopf. der Vügel versehen ist, zeigt sehr versehiedene Grade der Aisbildung. Mit Ausnahme der die Luftröhre niederzichenden $\boldsymbol{M}$. $\boldsymbol{M}$. ypsilotracheales und sternotrachereles, bei deren Wirkung die Membranen des unteren Kehlkopfes erschlafft werden müssen, besitzen einige Vögel gar keine eige nthü umlichen Muskeln 19). - Andere haben noch ein Paar M. M. Lronchotracheales ${ }^{20}$ ), dic von der Luftröhre bald nur zur Trommel, bald zur äusseren Paukenhaut, bald endlich zu höher oder tiefer gelegenen Bronchialhalbringen sich erstrecken können. - Der untere Kellkopf der einheimischen Singvögel, besitzt, statt dieses cinen Paares, sogar fünf oder selbst sechs eigene Muskelpare 21). Vielen exotischen Singvögeln komnen ganz abweichende Einrichtungen ihres Muskelapparates zu ${ }^{22}$ ). - Senker der Luftröhre sind endlich die $\boldsymbol{M}$. M. sternotracheales und ypsilotracheales.

19) Sie fehlen den Gallinaceen, Enten, Gänsen, Schwänen, Pelieanen; aber auch Vögeh anderur Familien. So z. B. vermisste sic Nitzseh bei Lpupa, bei Hatematopus u. $\boldsymbol{A}$.

20) Sie sind vorhanden bei den meisten Tagraubvögchln (mit Ausuahne der Gattmug Sareoramphus), bei den Nachtraubvögeln (welchen Meckel, iu Widerspruche mit Cuvier und Nitzsch, mit Unrecht sie abspricht), sehr schwach bei vielen Pieariae (Piens, Alcedo, Cuculus, Cypselus, Caprimulgus, Podargus), den Tauben, der Sclinepfenfamilic, den Gattungen Rallus, Ardea, Grus, Phoenicopterus, den Möven (Larıs, Lestris), vielen Wasservögeln: Colymbus, Mormon, Aptenodytes, Puffinus, Thalassidroma, Halieus. - Sie befestigen sich bei den Tauben an die Membrana tympaniformis externa.

21) Dieser sogenannte Singmuskelapparat ist besonders dureh Cuvier und Savart untersucht worden. Cuvier gilut allgemein fün Musticlpaare an; Savart fand 5 bei den Drosseln und Lerchen, 6 bei den Raben, Würgern und Stanren. Die beständigsten sind folgende: ein vorderer und ein hinterer langer Heber (Levatores longi, anterior und posterior), der eine vorn, der andere aussen und mehr nach hinten von den vorletaten unverschmolzenen Ringen der Trachea entspringend, an den beiden Enden des selır beweglichen zweiteı Bronehialhalbringes sich befestigend, diesen, so wie den mit ihn unter zwei Winkeln zusammenstossenden dritten Bronchialhalbring hebend; ein kurzer hinterer Heber (M. levator posterior (revis), an das hintere Ende des zweiten Bronchiallalbringes sich inserirend; zwei $\boldsymbol{M}$. M. obliqui (anterior und posterior) treten von der Trommel schräg und divergirend zu dem zweiten Bronchialbogen, den sie lieben uml rotiren; jener setzt sich, von aussen nach inners schief absteigend, an das innere und vordere Ende dieses Bogens; dieser befestigt sich in der Nähe des hinteren Endes an den zweiten Bogen. Sic wirken rotirend anf den zweiten und namentlich auf den dritten Bugen.

22) Siehe darüber Mïller in der angeführten Abhandlung, in welcher auch numentlich sehr wichtige systematische Consequenzen aus den neuen anatonischen Beobachtungen gezogen sinl. J)er grösste Theil der annerikanischen Passerinen besitzt z. B. nicht den vorhin geschilderten znsanunengesetzten Mnskelapparat und cine anf dic Anrresenheit des letzteren gestütate Eintheilung der Passerinen, wie Nitzsch sie vornahm, ersclseint munä̈rlich. 
[ Man vergl. ïber das Stimmorgan der Vügel besonders: Cirier, Vorlesmgen über vergl. Anatonic, übers. von J. F. Me ekel. Bd. IV. S. 312 fr. Noch ausfiblurlicher mul von Abbildungen begleitet, ist ein Aufsatz von Cnvier in Millin, Noel und Warens, Magasin eneyclopédique. T. II. No. 7. p. 330. nud ïbersetet in Reil's Arcliv für Physiologie. Thl. 5. S. 67. 'Tah. 1. 1. 2. - Einige bildlielıe Darstellungen gab Humboldt, Recneil d'observ. de zoolog. et l'Anat. comp. Tab. 1-3. - Desgleichen Yarrell in len Transactions of the Linnean society. Vol. XII. - Ueber den Stimmaplparat der einheimisehen Singvögel s. besonders Savart in Froriel's Notizen. (1827.) No. 331 u. 332. - Eine sehr klare Darstellung des Stimurorganes ler Papageien, besser als die von $\mathrm{Hum}$. boldt und Cuvier gelieferten, findet sich bei Mïller, Ueber die Compensation fer pliysisehen Kiräfe am mensehliehen Stimmorgane. Berlin 1839. 8. Tab. 2. Fig. 13-15. - Vergl. auch Wagner, Ieones zootomicae. Tab. XIT. - Ueber das Physiologische s. Cuvier, Savart und Müller l. e., so wie anch Müller's Plysiologie. Bd. 2. S. 225 ff. - Ueber die Labyrinthe der Enten und Taucher ist auch Meckel's, sonst für die Geschichte des unteren Kiehlkopfes weniger reiche, Darstellung in dem Systeme der vergl. Anat. BI. VI. S. 321 fi. nachzısehen. - Endlich ist so eben eine wichtige Abhandlung von Miiller publicirt: Ueber die bisher unbekannten typiselıen Verseliedenheiten der Stimmorgane der Passerinen. Berlin 1845. 8.]

\section{Von den Lungen und Luftsiicken.}

\$. 152.

Charakteristisch ist es fïr die Respirationsorgane der Vögel, dass die Gavität der Bronchi nicht blos mit den zahlreichen eigentlich respiratorischen Lungenröhrehen und Lungenzellen, sondern auch, mittelst weiterer an der Lungenoberfaiche mündender Oeffnungen, mit membranösen lufthaltigen Säcken communicirt. Die mit jedem der beiden Bronchi in IJöhlenverbindung stelıenden Theile zerfallen also 1) in die eigentliche Lungensubstanz, an deren Zellen das respiratorische Gefissnctz sich ausbreitet und 2) in woite, hohle, Luft führende Anhiinge, welche cines respiratorischen Gefiisssystemes ermangeln und mit pneumatischen Knochen des Rumpfes und der Extremitäten in Iöhlenverbindung stehen. Die innere Oberfläche der Lungen sowol als der Luftsäcke ist durch den Besitz cines Flimnerepithelium ausgezeichnet.

Wis nun die Lage und Befestigungsweise der Lungen anbetrifft, so hangen sie nicht frei in einer geschlossenen Brusthöhle, wie bei den Sïugllieren, sind auch nicht in eigenen Brustfellsïcken eingeschlossen, sondern liegen als flache, spongiöse Massen von sehr hellrother Farbe ausserhalb der Bauchfellhöhle, an der Rückenwand des Rmmpfes, scitwiirts von der Wirbelsäule, eingesenkt in die dureb sie ausgefiillten Zwischenräune der Rippen und hier durch Zallgewebe fest angeheftet. Ihre Substanz zeigt den spatia intereostaliu, in welche sie cingesenkt sind, entsprechende hintere Oucrvorragungen. 
So erstrecken sie sich in der gemeinschaflichen Eingeweidehöhle etwa rom zweiten Rückenwirbel bis zum Vorderrande der Nieren hinterwärts. Zwisehen ihrer Bauchllaiche und dem Brustbeine bleibt auf diese Weise ein weiter Zwischenraum. An ihrer Bauchseite ist die ebene Lungenoberfläclıe von einer Fortsetzung der der ganzen Bauehhöhle gemeinsamen serösen Mcmbran, welehe an dieser Stelle den Namen Pleura erhält, auswendig überzogen. Ueber die Bauchflïche der Lungen schlïgt sich unter der Pleura, von ihr bedeckt, die dureh muskulöse Fascikel 1) an mehren Rippen (an der Grenze ihrer Sternoeostalknochen) befestigte Zwerehfells-Aponeurose, in der Art, dass sie quer über die Lungen wegtritt. An dem Ende der Lungen ist sie durch einige straffe sehnige Bänder an die Wirbelsäule befestigt. Ihre Continuität ist unterbrochen durch dic Oeffnungen, mittelst weleher die Cavität der Bronehien an der Lungenoberfläche mit den Luftsäcken communicirt; in Umkreise dieser Oeffnungen setzt auch die Pleura iber die Luftsiicke sich fort.

Der Bronchus ${ }^{2}$ ) und die respiratorischenGefässstämme ${ }^{3}$ ) senken sich in ihre Lunge etwa in dem vorderen Drittheile oder in die Mitte ihrer Länge. Jede Lunge besitzt eine unmittclbare dünnhäutige und durchsichtige äussere Umhüllung, welche mit dem eintretenden Bronchus in Verbindung steht. Sobald der Bronchus in die Lunge getreten ist, erweitert er sich und erstreekt sich dann, an Durchmesser allmälich - doch im Ganzen nicht bedeutend - verlierend, tief im Parenchym seiner Lunge, doch dem Innenrande derselben genähert, ziemlich gerade hinterwärts, zu ihrem unteren oder hinteren Rande, an welchem er, mit einem weiten, bisweilen durch Knorpel unterstutzten Orificium, nach aussen in den Bauchluftsack (Cella abdominalis) mündet. - Die Cavität des Bronchus ist alsbald naeh seinenı Eintritte in die Lunge von 4 bis 5 weiten, dicht hinter einander liegenden, durch Knorpelbogen von einander gesonderten und vor dem Zusaminen. fallen gesehuifzten Oeffnungen der Bronchialröhren erster Ordnung durchbroehen. Diese Oeffnungen sind dem Innenrande der Lunge zugekehrt. - Weiter hinterwärts finden sieh - ausser zahlreiehen kleineren Oeff-

1) Der inuskulöse Theil des Zwerchfelles besitzt auch bei den Vügeln mit Querstreifen versehene Primitivbündel.

2) Cuvier, Tiedemann, Meckel, Retzius, Lereboullet haben im Unkreise des Bronchus naeh seinem Eintritte in die Lmngensubstanz bei grösseren Vügeln transverselle Muskelfaserı wahıgenommen. Quergestreift sind sie nielıt.

3) Die Verzweigung der Lungenarterie besitzt Eigenthümlielıkeiten, welche denen der Vertheilung des Bronchus entsprechen. Sie zerfällt in zwei beträchtliche Stämme, von denen der eine den Bronehus begleitet, während der andere für den vorleren Theil der Lunge bestinnnt ist und sich wieler in zwei Aeste spaltet. Diese Arterien vertheilen sich nicht baunförmig in alluälich kleinere Zweige; vieluehr entspringen sowol aus dem Stamme, als ans den Aesten sehr zalılreiclıe, ganz feine Zweige, welche fiir die Röhrchen, welche vom Bronchus ausgelien, bestimmt sint. 
nungen für engere Bronchialröhren - etwa 5 bis 10 grössere und weitere, welehe gleichfalls ron vorn naeh hinten gerade auf cinander folgen und dureh dickere Septa von einander getrennt werden. Sie liegen so, dass von ihnen ausgehende gerade Canäle an der hinteren Oberliiehe der Lunge münden müssen. Alle diese grossen Oeffnungen des Bronchus fülıren in weitere Canäle erster Ordnung, welehe zu den Lungenoberflïchen streben, wohin die vorderen sogleieh, die hinteren, nachdem sie die Substanz der Lunge durchsetzt haben, gelangen. An die Lungenoberfläehe getreten, verzweigen sie sieh in Canäle zweiter und dritter Ordnung. Sämmtliche, an die Lungenoberfläche gelangte Canäle haben das Gemeinsame, dass sie auswendig nur von der zarten, äusseren Tunica propria der Lungen bekleidet, und von cinander durch schwäehere oder stärkere Längsvorragungen des Lungenparenehyms getrennt werden. An ihrer, dem Lungenparenehyine zugewendeten Seite, so wie aueh während ihres ganżen Verlaufes durch die Lungensubstanz selbst, erscheinen sie siebförmig durehlöehert. Diese Löeher sind die Anfänge und Enden von feinen, pfeifenartig gestellten Röhren, welehe dureh die Lungensubstanz sieh erstreeken, überall mit einander eommunieirend. Die ganze Innenwand dieser Röhrehen ist mil polygonalen Zellen besetzt, welehe wieder Zellen zweiter und dritter Ordnung einsehliessen. Wegen der überall vorkommenden Communication dieser feineren Bronehialröhren mit einander kann die ganze Lunge von jedem Punkte aus aufgeblasen werden.

Die dureh die feinen, an der Oberfläehe der Lungen gelegenen Oeffnungen der Bronehialstammes und der prïmären Bronehialröhren mit der Cavität des Bronehi unmittelbar communieirenden Luftsäeke oder Luftzellen 4); deren innere auskleidende Haut eine unmittelbare Fortsetzung der Bronehialsehleimhaut ist, erhalten eine äussere Bekleidung vom Bauchfelle. Sie bieten in Ganzen eine schr constante Anordnung dar. Der crste Sack (Interelavieularsaek) erstreckt sich vom vorderen Theile jeder Lunge vorwärts in den Zwisehenraum beider Sehenkel der Fureula und ist besonders ausgedehnt bei den Gattungen Sula und Pelecanus ${ }^{5}$, wo sieh mit ihm zusammenhangende Siieke unter der Haut der ganzen Körperoberfläehe fortsetzen. Oft steht er mit tiefen Cerviealsïcken. in Verbindung. Bei einigen Vögeln breiten

4) Je nachlem sie Eingeweide einschliessen, oder nicht, theilt Curier sie in leere und in Eingeweide-Zellen. - Dass aber die sogenannten Leberzellen keine Luft enthalten, ist durch Nitzsch nachgewiesen und IIennecke (de functionibus oinentorum. Gotting. 1836. 4.) hat auch gezeigt, dass die grosse Darmzelle den Luftsïcken fremd ist.

5) Schon ron Méry, später von 0 wen, Wagner u. A. ist hierauf auf. merksam gemacht worden. Bei Chama chavaria (Opistholophus Vieill.) dringt, nach Cuvier (Règu. anim. 1. p. 537.), die Luft gleichfalls unter die Haut, selbst unter die der Beine. 
sich vom Vorderrande der Furcula kommende Muskelfasern, bei Sula und Pclecanus IIautmuskeln, fächerförnrig über die Aussenwand dieses Sackes und seiner Fortsetzungen aus, - Durch zwci am vorderen Theile der Lungen befindliche Oeffnungen tritt die Luft in den vorderen Brustsack (Cella thoracice anterior), welehe den unteren Kiehlkopf, die Bronehi und die grossen Gefissstïimme einschliesst, zalılreiche hiutige innere Septa an dirse versehiedenen theile sendet und vorn in tief gelegene Luftzellen des Ilalses sich fortsetzt. - Von derr vorderen Brustsacke bedeckt sind die Seitensäcke des Thorax, welche in Cellae axillares und subscapulares übergehen und dadureh naunentlich auch mit dem meist pneumatisehen Oberarmbein connnuniciren. Auch mit einer hinter dem Ilerzen und den Bronehi gelegenen Cellula cordis posterior stehen sic in Perbindung. - Die betrichtlichsten unter den Luftsäcken sind die Bauchsäeke (Ceillae abdomiuales), am unteren oder hintereh Ende der Lungen beginnend, wo die Enden jedes Bronehus frei durch die schon erwähnte Oeffnung in sie iibergehen. Sie stehen in Ilöhlenverbindung mil kleineren Beckenzellen, mit intermuiskularen Gluteal- und Femoralzclten, und yestatten dureh Oeffnungen der Luft Eintritt in das knöcherne Beckengeriiste, so wie in die Sehenkelknochen. - Den geringsten Grad der Entwiekelung dieser Luftsäcke besilzt Apteryx ${ }^{6}$ ), indem sic hier nicht in die Bauchhöhle sich erstrecken.

[Man rergl, über die Respirationsorgane der Vögel folgende Schriften: John Hunter (iiber die Luftzellen) in den Philos. Transact. 1724. T. LXIV. p. 205. Albers, Beiträge zur Anat. und Physiol. der Thiere. Bremen 1802. S. 107. L. Fuld, de organis, quibus aves spiritus ducunt. Virceb. 1816. S. - Colas im Journal complément. du dict. de Med. 1825. T. 23. - Retzius (ïber den feineren Bau der Lungen) in Froriep's Notizen. 1832. No. 749. - Lereboullet, Anatomie comparée de l'appareil resp. dans les anim. vertébr. Strasb. 1838. 4. p. 48 sqq. - Cuvier, Leçons d'Anatom. comı. p. G. L. Duvernoy. T. VII. Paris 1840. 8. p. 110 sqq. (Sehr sorgfiltige Darstellung.) - Kohlransch, de avium saccorum ä̈riorum utilitate. Gött. 1832. $-\mathrm{Ed}$. We e er im Amtl. Bericht der Naturforscherversamml. in Braunscluweig. Braunschw. 1841.]

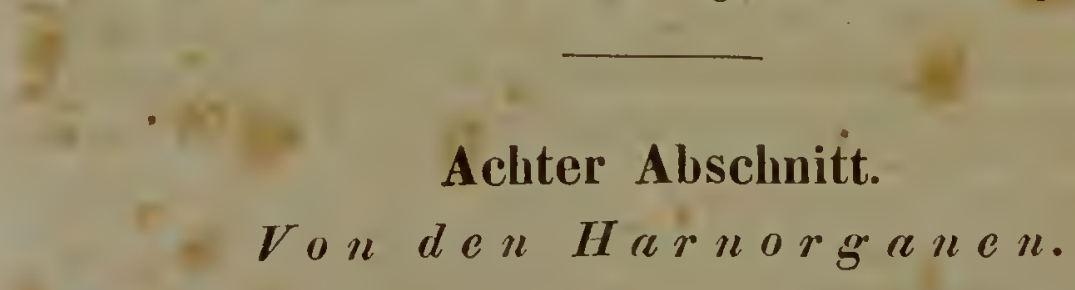

ร. 153.

Die Nieren der Vögel liegen, wie bei allen Virbelthieren, ausserhalb der Peritonealhöhle, sind fast immer ganz synmetrisch, beginnen gewöhnlich unmittelbar hinter den Lungen und erstrecken sich lïngs

6) Nach 0wen 1. c. 1. 278. Tab. LI. F. 4. 5: 
der Beckengegend, eingesenkt in dic flühlıngen des Kreuzbeines, bis zum Ende des lectum. Sie sind von dunkler schwarzrother Farbe und bedeutend weicher, als bei den Sïugthieren. Ihr Unfang ist verschie(len; mehr noch ihre Gesialt; sie sind bald in ihren vorderen 1), bald in ihrem hinteren Theile am breitesten $\left.{ }^{2}\right)$. Die beiden Nieren sind gewölınlich von einander getrennt; in diesen Falle liegen ihre Innenr:inder balk entfernter von einander, bald sind sie sich näher geriickt ${ }^{3}$ ). Dirse Annïherung kann zu vollstiindiger Verschmelzung führen. Die Beriilı'ung und Verschmelzung findel dann an häufigsten im hintersten Abschnitte, selten durch eine mittlere Commissur, bisweilen auch in der ganzen Länge der Nieren Statt $\left.{ }^{4}\right)$. Selten bildet jede Niere eine ungelappte Nasse 5); meist zerfillt sie in grüssere, durch Quereinschnitte getrenute Lappen, deren Zahl Verschiedenheiten darbietet; am häufišsten $\left.{ }^{6}\right)$ sind ihrer drei vorhanden, von denen der mittlere am kleinsten ist; wihrend in diesem Falle bald der vordere, bald der hintere Lappen am unffänglichsten sein kann; seltener bat die Niere nur zwei Lippen r) oder zerfiillt selbst in eine viel grössere Anzahl von Läppchen, die vorzüglich an der hinteren Flïche deutlich erkennlaar sind 8). Der contractile Ifarnleiter verläuft etwa längs der Mitle der Vorderfliche seiner Niere, in deren Substanz er streckenweise eingebettet liegt und tritt spaiter hinter den Mastdarm, um in die Cavilas urogenitalis, einwärts von den Oeffnungen der Geschlechtstheile, sich einzusenken. Eine IIarnblase fehlt den Vögeln 9). - Der feinere Bau der Nieren bietet einige Eigenthümlichkeiten dar. Bei genauerer Untersuchung erscheinen die Nieren oberfäichlich hirnarlig gewunden und zerfallen so in

1) Z. B. bei Ardea, Picus, besonders Rallus.

2) Z. B. bei den Tiuben, bei Sterna.

3) Sic nähern sich z. B. bedeutend bei allen Passerinen, bei Alcedo, Sterna u. A.

4) Dic Versehnelzung des Hintertheiles kommt häufig vor bei Singrögchn, z. B. bei Lanins; constant, vielleicht mit cinzelnen individnelien Ausnabmen, bei der Gattung Ardea, bei Psophia crepitans, bei Puffinus und besonders bei Colynbus, wo man sie, wie Nitzsch sehr richtig bencrkt, gewöhnlich in ihrer ganzeı länge versehmolzen findet. Bei Platalea sah Wa gnel die Mittellappen beider Nicren hufeisenfürmig durch eine breite Substanzbrüche verbunden.

5) So bei Sitta nach Nitzsch, der auch darauf aufnerksam unacht, dass bei den meisten Singvögeln die Lappenbildung undeutlich ist.

6) Z. B. bei den Enten, wo der hinterste Laplen überviegt, bei den Möven, Liormoraner, Rallus, Ciconia, Grus, den Hühnern, Tauben, Spechten, Raub. vögelı ı. s. w. - T) Z. B. beinı Enıcu.

8) Aun grössten ist die Zahl dieser Läppehen an der Hinterfläche der Nieren wol bei Fulica und bei Rallus. Beiun Pelikan zerfallen die drei Hanptlappen der Nieren durch sehwache binsehnitte in kleinere Lappen.

1) Wayer (Nene Unters. a. d. Gebiete der Anatomic u. Phys. Bom 1842. 4. S. 28.) beschreibt jeduch beim Hühnchen ein Rudiment der Harnblase, als ein dümmläntiges, vor dem Mlıstdarm liegendes Säckclıcn, das sich während der Dauer des crsten Lebensjahres crkemeu lasse. 
eine grosse Zahl von Läppehen $\left.{ }^{10}\right)$. Jedes Läppchen besitzt an seine: Oberfläche ein, dureh anseheinend blind und geschlossen endende Seitenzweige gefiedert erscheinendes Ifarncanïilehen ${ }^{11}$ ); diese Canälchen verbinden sieh gabelförmig zu Stämmehen zweiter Ordnung 12), welche eonvergirend und in Bissehel oder Pyranirden gesammelt in die viel weiteren Zweige des Harnleiters sieh einsenken 13). - Die Malpighi'schen Gefässknäuel sind vorhanden.

\section{Neunter Abschnitt. Von den besonderen Absonderungrs-Orgrenen und den
Blutgefïssdrïsen.}

§. 154 .

Die eigenthümliehen Absonderungsorgane der Vögel sind die bei Besehreibung des Ilautorganes bereits alggehandelte Burzeldriise und die sogenannte Bursa Fabriciu, von der bei Sehilderung der Cloake die Rede sein wird.

$\mathrm{Zu}$ den eines Ausführungsganges ermangelnden sogenannten Blutgefässdrii sen gehören zuerst Gebilde, welehe -man der Schilddrü se vergliehen hat. Es sind dies kleine rundliehe oder längliehe, sehr gefässrciehe Körper, welehe seitlieh von der Luftröhre, bald iiber dem unteren Kehlkopfe gelegen, ziemlieh dicht an den Carotiden oder an der Carotis und Art. vertebralis zu haften pflegen. Sie kommen anscheinend durehaus beständig vor ${ }^{1}$ ). Vicl weniger beständig sind zwei ähnliche, tiefer abwärts neben jedem Bronchus liegende, gleiehfalls gefässirciehe Körperehen, welehe für Aequivalente der Thymus gehalten werden können ${ }^{2}$ ).

Niemals fehlen die Nebennieren ${ }^{3}$ ). Von versehiedener, anseliei-

10) S. Mïller, Gland. sec. Tab. XIII. Fig. 8.

11) Mïller l. c. Fig. 7. 9. 10. - Jedoch bleibt es immer selır zweifelhaft und selbst unwahrscheinlieh, dass diese verhältnissmässig weiter, durch bedeu. tende Parenchymmassen getrennten Seitenzweige wirklich dic letzten Enden der Harneanälchen sind.

12) Müller l. e. Fig. 11. - 13) Müller l. c. Fig. 11.

1) Ich habe sie bei Vögeln aller 0rdnungen gefunden und niemals vermisst; unter den Struthionen namentlich bein neuholläudischen und indischen Casuar, so wie bein zweizchigen Strausse angetroffen. Verhältnissmässig sehr gross sele iclı sie beim Flamingo; constant in zwei Körper zerfallen : einen oberen grösseren und einen unten kleineren finde ich sie bei Corvus glandarins.

2) Ich finde sie beim Kormoran und bei Alca; 0 wen silh sie bei Suli.

3) Meckel untersehied in den Nebennieren des Casuars eine Rinden- und Mirksubstauz, was nach $\mathrm{Nagel}$ 's Untersuchungen sonst nicht - vorzukommen scheint. S. Nagel inl Müller's Archiv. 1836. S. 376. 
nend unbestïndiger Form, von okergelber, graugelber oder goldgeller Farbe, nie von bedeutendem Umfange, einer Höhle ermangelnd, liegen sie einwailts rom vorderen Ende der Nieren, of dieht an der unteren Hohlvene, leim Miinnchen mit den Itoden, bei weibliehen Thieren init deın linken Eierstocke in Berührung kommend. Sehr selten und gewiss nur als individuelle Ausnahme findet man die beiden Nebennieren zu ciner Masse versehmolzen 4 ).

\section{Zehnter Abschnitt. \\ $V$ on den Geschlechts-Organen.}

\section{Von den weiblichen Geschlechtstheilen.}

§. 155 .

Fast alle Vögel sind - im Gegensatze zu den iibrigen Wirbelthieren - ausgezeichnet dureh den Besitz eines einzigen Eierstoekes und eines einzigen Eileiters, welche linkerseits liegen. Nachdeın nämlich ursprünglieh die Anlagen zu paarigen weiblichen Geschlechtstheilen aufgetreten sind, verschwinden im Laufe der Entwickelung die der rechten Seite gewöhnlich frühzeitig oder werden abortiv. Sehr häufig jedoch persistiren in der unmittelbaren Nähe der Cloake - oft mit deutlicher Mtindung in dieselbe - Ueberbleibsel des rechten Eileiters 1 ).

4) So fand sie Nitzsch einnal bei Endytes septentrionalis und ich einmal beim männlichen Falco palumbarius.

1) R. Wa gne $r$ hat in den Abhandl. der Miinchener Acad. der Wissenschaften Bd. 2. 1837. S. 278. eine monographische Abhandlung über die Persistenz der weiblichen Geschlechtstheile der rechten Seite geliefert, jedoch, was den rechten Eileiter anbetrifft, ohne Berücksichtigung der früheren vorliegenden Beobachtnngen und ohne eigene Erfahrungen. So nur lässt es sich erklïren, wie er zu der unrichtigen Behauptung köınmt, dass der rechte Eileiter seltener sich erhalte, als der rechte Eierstock. Barkow hatte lingst (Meckel's Archiv. 1829 u. 1830.) gelegentliche Mlittheilungen gemacht über das Vorkommen eines rudimentären rechten Eileiters. So von Fulica atra (Archiv 1829. S. 3ذ1 ; abgebildet Tab. IX. Fig. 16. Barkow untersuchte drei Weibehen und fand bei zweien derselben, die erwachsen waren, das Rudiment des rechten Eileiters), von der Taube (l. c. S. 448), von Strix brachyotos (1. c. S. 449), von der Hausente (1. c. S. 449). Hierzu kömmt Baer's Autoritït, der nach scinen zahlreichen Erfahrungen versichert, dass, beim erwachsenen Haushuhne, die Ueberbleibsel des rechten Eileiters in Gestalt einer Hydatide meist nocl zu erkennen seien (C. E. v. Baer, Ueber Entwickelungsgeschichte der Thiere. Bi. 2. Königsberg 1837. 4. S. 151.). Deu Barkow'schen Beobachtungen kann ich entsprechende hinzufigen, welehe den Schwan (Cygnus musicus), die Gans, Alca, Ciconia alba, Gallinula und Aquila albicilla betreffen. - Der rechte Eierstock persistirt in der Regel zienlich ausgebildet bei den Gattungen Astor und Buteo; viel unbeständiger bei den übrigen 
Seltener erhält sich der rechte Eierstock perennirend, doch immer kleiner als der linke oder ganz rudimentiir. Am lï̈infigsten tritt dieser Fall ein bei einigen Tagraubvögeln; seltener hei Vögeln aus anderen Fanilien und dann nur als individuelle Eigenthiimlichkeit, als Bildungshemmung.

Der linke Eierstock liegt an der oberen oder rorderen Wand der linken Niere und hesteht in einem Paar häutiger Platten, in deren Filten die Eier sieh entwickeln. Die letzteren besitzen anfangs die Gestalt kleiner Bläschen und gehen, indem sie sich ungleiehmiissig vergrössern, der Oherfläche des Eierstockes ein ungleichförmiges, hügeliges Ansehen. Bei noch bedeutenderer Vergrösserung der Dotterkugeln treten sie an die Oberflïche des Eierstockes hervor und ziehen dessen ïussere Haul mil sich, so dass sie mit dem Eierstocke nur noch durch einen Stiel zusammenhangen. Dadurch erhält denn der Eierstoek ein trauhenförmiges Ansehen.

Der linke Eileiter steigt, mehr oder minder stark gewunden, an der Vorderseite der linken Niere zur Cloake abwarts. Befestigt ist er an einen gekrösartigen, durch den Besitz von nicht quergestreiften Muskelfilsern ausgezeichneten Iesometriım. Seine Lünge ist ziemlich heträehtlich; seine Weile und Dicke sind, je nach dem Stande der Geschleehtstlätigkeit, verschieden. Inwendig ist er mit Schleimhaut ausgekleidet, welcher ein Flimnerepithelium zukömmt, und erheilt dureh das Auseinanderweichen der queren Bündel des Mesometrium cine Muskelsehielst, indem nur sein letzler Absehnilt eigene Längsmuskelfasern besitzt. Sein Ostium abdomiuale bestelit in einem schiefen Längsschlitz. Dieser fiihrt in einen diinnwandigen weiten Trichter (Infundilulum). Allmälich sich verengend und, von Trichter dureh einen diinnen Querstreifen geschieden, erlıält scin längster Absehnitt, welcher inwendig Liingsfilten besitzt, den Namen des Eileiters (Ourductus). Die folgende kurze, weilere, stark muskulöse Abtheilnng, deren Schleimhant meistens eigenthümliehe kolbige grosse Zotten oder hlattrörnige Falten hesitzt und in welcher die zur Kalksehale erstarrende, weisse milchige Flüssigkeit secernirt wird, ist unter dem Namen des Eihalters (Uterus) bekannt; während endlich der nicht selten scharf albgesetzte, bald kurze, bald gewundene, meist engere Endabschnitt die Benennung Scheide (Vagina) führt 2). Sic mündct in die Cloake auswärts vom linken

Tagraubrögeln; noch seltener bei den Nachtraubrögeln. Auch bei Papageien und bei ler Krähe (C. corone) hat Wagner ilın ausnahmsweise, als individuelle Eigenthümlichkeit angetroffen; eben so ich bei zwei Tauben. Vergl. über die Tagraubvögel die früheren Mitheilungen von Emmert in Reil's Archiv. Bil. X. S. 383. Der rechte Eierstock ron Falco buteo ist abgeb. in Carus und 0tto, Erläuterungstafelı. Hft. V. Tab. VII. Fig. 1.

2) Abbildungen bei $\mathrm{C}$ arus und 0 tto, Erriuterungstafeln. Hft. V. Tab. VII.

Fig. 1. 7. 8. 9. - Barkow hat, nachdem Geoffroy u. A. ihm darin vorange- 


\section{Zehnter Abschinitt. Von den Geschlechts-Organen.}

IIaruleiter. Die ciuzolnen Abtheilungen des gesammten Eileiters sind am deutlichsten bei solchen Individuen zı unterscheiden, die iun ZıIstande geschlechtlicher Aufregung oder Thitigkeit sich befinden ${ }^{3}$ ). Eino Clitoris 4) ist nur bei deojenigen Vögeln gefunden, deren Mïnnchen durch den Besitz eines Penis ausgezeichnet sind. - Aeussere Britorgane 5) sind bei denjenigen Vögeln, welche selbst brïten, die um die Briilezeit foderlos werdenden, dünnen Hautdecken des Bauches, unter welchen die Gulaisse dann häufig einen hohen Grad von Ausdehnung und Entwickelung zeigen. - Zu Nährorganen fïr die Jungen wroden bri den Tauben die nach Ablauf der Briitezeit eine milchige Flisssigkkrit secernirenden kröpfe $\left.{ }^{6}\right)$.

[Vergl. Spangenberg, Disquisitiones eirca part. genital. avium. Gott. 1813. 4. - Ueber den Bau des Vogeleies s. Purkinje, Symbolae ad ovi avium historian ante incubationeh. Lips. 1830. 4. mit Bemerkungen über den Bau des Mesometrium p. 10. und C. E. v. Baer, Ueber Entwickelungsgeschiehte d. Thiere. B3. 2. Königsherg 183\%. 4.]

\section{Von den inännlichen Geschlechtstheilen.}

\section{\$. 156.}

Die stots paarigen IIoden der Vögcl liegen in der Bauchhöhle oberhalb dir Nieren, neloen den Nobennieren und bestehen aus feinen geschlängelten Samengefässen, welche durch Bindrgewebe zusanmengallalten werden. Unkleidet sind sie durch eine zalte Turica propria. Der linke Horle ist schr häufig umfänglicher, als der rechte, welcher nicht selten auch etwas höher liegt. Umfang, Forur und Färbung der

gangen, in Meckel's Archiv. 1830. S. 40. den Versuch gemacht, die weiblichen ausführenden Geschlechtstheile der Vögøl denen der Säugethiere zn parallelisiren. Er vergleicht das Infundibulum der Tuba; den Oviduet dem Gebärmutterhorn; sicht in dem Uterus die Gebärnntter und vergleiclit die Vagina derjenigen der Säugthiore.

3) Linige auffallende Beobachtungen über das Verschlossensein des in die Cloake fülırenden Ostium des liuken Eileiters wurden von mir im Laufe dieses Winters gemacht. lch fand es geschlossen bei einigen knten, Tauchern (Mergus) und Alca; begierig einen noch grösseren Vogel zu untersuchen, erhielt ich im März einen weiblichen Singschwan (Cygnus uıusicus). Das Ostium des linken Eileiters war völlig verschlossen, das des rudimentären recliten offen. Früheren Beobachtuugen nachforschend finde ich sie bei Barkow (Meckel's Archiv. 1829. S. 35\%.) über das Verhalten des linken Eileiters bei einer jungen Fuliea atra und - minter bestinunt - bei Arrlea cinerea (I. c. S. 375.). Sollte dies hlos eine Eigenthümlichkeit junger Weibchen sein? Oder findet bei den nicht in beständiger Geschlechtsthätigkeit begrifenen Vögeln blos periodisch eine Dehiscenz des Eileiters Statt?

4) Alb. «. Clitoris der Struthionen bei Mïller, Ueber zwei versch. Typen im Baı ı. mäınl. Geschlechtsth. Tab. 1. Fig. 3. 4.

5) Alh. bei Barkow in Meckel's Archiv. 1829. Tab. VIII. Fig. 1.

b) S. Unuter's Works. Palmer's Elition. Vol, IV. p. 122. Tab. XXXIX. 
IIoden verhalten sich, je nachlem sie wïhrend oder ausser der Begattungszeit untersucht werden, äisserst versehieden. In letzterem Falle findet man sie sehr winzig und zusammengeschrumpft; um die Zeit der Begattung seliwellen sie dagegen sehr an und sind stets von weisser Farbe. Die Vosa efferentia bilden, inden sie wenig gekrümmt zum Saamenleiter übergeben, eine dünne, platte, abwärts zugespitzte Anschwellung (Rudiment des Nehenhodens), welehe der Tumica propria des. IIodens fest aufliegt und in das Vas deferens übergeht 1). -

Die beiden Saamenleiter - gleich den Hoden von Bauchfellfalten gehalten und bekleidet, gleichfalls ausser der Begattungszeit enger, als während derselben - verlaufen als geschlängelte Cannile uiber den Nieren zur Cloake, in welche sie, nachdem sie lüufig blïschenartig sich erweitert ${ }^{2}$ ), sich einsenken. Meistens mïndlen sie auf kleinen kegelförmigen oder etwas längeren zugespitzten Papillen, neben denen ein mehr oder minder stark entwickelter röthlicher Kör per, der bei näherer Untersuchung als ein Gefässconvolut sich zu erkennen gibt ${ }^{3}$ ), angetroffen wird. Diese Papillen sind auch bei Anwesenheit eines Penis vorhanden $)$. - Ein eigentlicher Penis mangelt den meisten Vögeln völlig ${ }^{5}$ ). Bei anderen findet sich ein ivarzenförmiger oder zungenförmiger Vorsprung ohne deullicho Rinne oder mit einer solehen an der Vorderwand der Cloake 6\% - Ausgebildeter ist

1) Nüller hat die älteren Angaben über den Nebenhoden der Vögel und ein angeblich vorhandenes Vas aherrans berichtigt, indem er nachwies, dass dies, bei jungen Vögeln vorkommende, Ueberreste der Primordialnieren sind. Vergl. dessen Bildungsgeschichte der Genitalien. Düsseld. 1830. 4. S. $39 \mathrm{ff}$.

2) Solche bläschenartige Erweiterungen werden z. B. bei den Hühnern und den Passerinen angetroffen. Berthold, Beiträge zur Anatom. Zoot. und Phys. Gött. 1831. 8. S. 229. Táb. IX. Fig. 9-11. beobachtete bei Sturnus, Lanius und Turdus kure vor dem Eintritt des Saamenleiters in die Cloake einen platten, rundlichen, etwas gewundenen Körper von weisslicher Farbe, entstehend dadurch, dass die letzten Windungen des Saamenleiters durch Zeligewebe mit einander verbunden werden.

3) Tanneuberg 1. e. p. 20. bezeichnet diesen röthlichen Körper als Pro. stata; Bark ow sicht ihn, init Ge offroy, als Analogen des Corpus cavermosum an (Meckel's Archiv. 1830. S. 38.), nachdem er gefunden, dass er ein Wundernetz darstellt, dessen arteriel'er Theil durch Arterine mudendae internae (Huhn, Gans, Ente) oder durch die $\boldsymbol{d r} t \boldsymbol{t}$. epigastricae (Podiceps) gebildet wird. Aueh gegen diese Deutung erhebt Müller (Ueber zwei verschiedene Typen in deın Baı der ereetilen männliehen Geschlechtsorgane bei den straussartigen Vögeln. Berlin 183S. 4. S. 23.) mit Recht Berlenken.

4) S. d. Abb. v. Strauss in C arus und Otto, Erläuterungstafelı. Hft. 5. Tab. VII. Fig. 3. Es dürfen diese Papillen daher nieht als doppelte Rutben angesehen werden.

5) Den meisten Raubvögeln, den meisten Passerinen, den Picariae Nitzsel ohne bekannte Ausnabme, den Tauben, vielen Hühnern, vielen Sumpf- und Sehwiminvögeln.

6) \%. B. als eine Warze bei einigen grösseren Raubrögeln; stärker entwickelt bei 0 tis, Ardea, Ciconia, Phoenieopterus, Platalea. 
der Penis bei den meisten Struthionen 7 ), mehren Palmipeden und hïhnerartigen Vögehn. An der vorderen Wand der Cloake haftet ein gek riimmter, von Schleimhaut überzogener Körper, der eine etwas gedrehete Rinne zum Abflusse des Saamens besitzt. Seine Grundlage bilden zwei fibröse Körper und die Rinne wird dureh cavernöses Gewebe umkleidet. Das Ende dieser Ruthe setzt sich fort in einen eingestiilpten, sclilauchförnigen, zuletzt blinden Theil, welcher auch eine Fortsetzung der Rinne enthält und zur IJälfte ausgestülpt werden kann. Ein rlastisches Band zieht diesen Schlauch, nachdem er ausgestiilpt worden ist, wieder ein. Die Ruthe besitzt zwei Muskelpaare; durch das eine wird sic vorgezogen und gehoben; durch das andere zurück. gezogen. - Beim afrikanischen Strausse ${ }^{8}$ ) endlich liegt die Basis der gleichfalls an der Vorderwand der Cloake befestigten, coniseh zugespitzten, abwärts gekrümmten Ruthe in einer taschenförmigen Vertiefung, aus welcher sie durch Muskeln vorgezogen und in die sie durch andere Muskeln zurïckgezogen wird. Auch sie besitzt zwei fibröse solide Körper, über denen dic init cavernösem Gewebe ausgekleidete Rinne liegt; aber ihr mangelt cin ausstiilpbarer Theil. Es findet sich jedoch unter den die Rinne stützenden fibrösen Körpern ein dritter, aus elastischem Gewebe gebildeter, im Innern cavernöser Körper, welcher die Krüminung der Ruthe bewirkt.

[Vergl. Tannenberg, Ablandlung ïber die männl. Zeugungstheile d. Vögel. Gött. 1840. 4. Mit Abb. - G e offroy, Philosophie anatomique. T. 2. Tab. 17. Barkow in Meckel's Archiv. 1830. - Müller in d. phys. Abb. d. Berl. Acal. l. Wissensch. Berlin 1838. - Abb. bei Carus und 0 tto, Erlïuterungstafeln. Hft. V. 'Tab. VII.]

\section{Von der Cloake.}

\section{§. 157.}

Sie besteht in einer mit starken kreisförmigen Muskelfasern versehenen, auswendig theilweise vom Bauchfelle überzogenen Erweiterung. Vorne senkt sich in sie der Mastdarm mit einem kreisförmigen, faltigen oder klappenartigen Vorsprunge, der auf diese Weise häufig cine gesonderte erste Abtheilung, das Vestibulum cloacae, bildet. Von der Mastdarü̈ffnung durch einen mehr oder ninder beträchtlichen Zwi-

7) Bei Rhea anericana; beim indischen und neuholländischen Casıar; bei Crypturus; bei vielen Palıniperleu: Enten, Gänsen, Tauchern, Schwänen; bei Penelope und Crax (s. Müller mol Tschudi in Mïller's Archiv. 1843. S. 472.). - Ueber den Bau der Ruthe von Apteryx australis, die 0 wen 1. c. p. 281. el. wähnt, und von Alecto, welcher Lesson (Ornithol. Paris 1831. p. 433.) gerlenkt, sind noch keine genaueren Untersuchungen vorhanden. - Abbild. liei G e of froy I. c.; bei Hom e, Lectures on compar. anat. T. IV. Tab. 134.; bei Müller I. c.
Tab. 1-3

8) Abb. bei Müller l. c. Tab. 1. Fig. 1. 
schenraum getrennt, der lïufig auch durch eine untere Querfalte 1), oder eine breitcre kreisförmige Klappe sehärfer abgesondert wird, senken sieh die Mündungen der Gesehleehtstheile und Harṇleiter in die Cantilas urethro-sexualis (s. Cannlis urogenitalis) der Cloake. Die beiden Saamenlciter öffnen sich meist auf Papillen; zwisehen und hinter ihnen, oder einwärts vom linken Eileiter, miinden neben einancler die beiden Harnleiter. Sobald Penis oder Clitoris vorhanclen sind, liegen sic an der Vorderwand der Cloake. Hinter den Oeffnungen der Llarnleiter, mchr dem Ausgange zu, findet sich in dem sogenannten Vestibulum der Cloakc eine mehr oder minder stark vorspringende Falte oder Klappe 2), welche die häufig beträchtliehe, ringförmige Oeffnung der Bursa Faluricii etwas verdeekt, unter deren Mündung gleiehfalls nicht selten noch ein Wulst vorkönmmt. - An den Seiten des Ostium externum der Cloake sieht man bisweilen starke, mit mehren bogenförmig gcstellten Oeffnungen mündende absondernde Follikel 3). Bei cinigen Vögeln, denen die chen erwähnten Folliculi aunles fehlen, erstreckt sich von dem Ostium der Bursa Falricii aus ein erbabener Wulst gerade zum After, der durch sehr zahlreiche aggregirte Follikel gebildet wird 4 .

Die Bursa Falricii ist ein anscheinend allen Vögeln zukommender, linglieher oder rundlieher, an Ende bisweilen in einen langen Zipfel ausgezogener, vorzugsweise bei jüngeren Individuen entwicketter, bald perennirender, bald in höherem Alter abortiv werdender oder ganz verschwindender Beutel, welcher tief im Beeken, hinter oder über der Cloake, vor dem Ende des Kreuzbeines zwischen den ITarnleitern, bisweilen von Fett und Zellgewebe bedeckt, liegt. Seine innere Schleimhautfläche ist nicht selten stark gefaltet und, namentlieh bei jüngeren Vögeln, mit den Mündungen zahlreicher absondernder Follikel besetzt.

[Vergl. Barkow in J. F. Meekel's Archiv. 1829. S. 443. - Abbildungen bei Geoffroy St. Hilaire, Philosophic anatomique. T. II. Tab. XVII., bei Barkow I. c., bei Müller, Bau der Geseblechtstheile. T'ab. 2. u. 3. (Bursa Fabricii der Struthionen), bei 0 wen in Todd's Cyelop. und bei Carus u. 0 tto, Erläuterungstafeln. Hft. 5. Tab. VII. - Ueber die Bursa Falricii vergl. H us eht ke, de Bursae Fabrieii origine. Jen. 1838. 4. und Berthold in Nov. Aet. Aead. Cates. Leop. Carol. Vol. XIV. p. 903.

1) 7. B. bei Colymbus, Fuliea, Aquila.

2) Z. B. bei Fuliea; sehr stark beim Sehwan.

3) Von nir bei Cygnus musicus und bei Vultur papa beobachtet.

4) So fand ieh die Follikel bei Mcleagris gallopavo mas. 


\section{Viertes Buch.}

\section{D i e s ä u eth i e re.}

L i t e r a t u r.

J. C. D. von Schreber, Die Säugethiere, in Abbildungen nach der Natur uit Beschreibungeu. 1r и. 2r Thl. Erlangen 1775. 4.; 3r u. Ar Thl. Erlang. 1768. Die folgenden Theile sind bearbeitet von Job. Andreas Wagner. כr Thl. Bd. 1. Erlang. 1836.; 5̃r Thl. Bd. 2. Erlang. 1837.; 6r Thl. Erlang. 1835. Dazu komınen drei gleichfalls von $\mathbf{A}$. W a gn er bearbeitete Supplementbände. Erlang. 1840-1845. In diesem noch nicht vollendeten, durch A. W a gner erst zul eigentlicher Bedentung erhobenen Werke sind die anatomischen Verhältnisse sorgfältig berücksichtigt.

Gırlt, Vergleichende Anatomie der Hanssäugethiere. Berlin 1834. 2 Bde. 8. und daran sich schliessend: Gurlt, Anatomische Abbildungen der Haussäugethiere. Berlin 1843. Fol.

Sehr reichhaltig sind die anatomischen Untersuchungen von Daubenton in Buffon's histoire naturelle:

Vorzüglich wiclitige monographische Werke sind folgende:

C. J. T em m in ck, Monogr. de Mammalogie. T. 1. 2. Paris et Leyden 1827-1841.

J. F. Meck el, Ornithorhynchi paradoxi decriptio anatonica. Lips. 1826. Fol. c. Fig.

R. Owen, Monotrentata in Todd's Cyclopaedia of Anatomy and Physiology. Part. XXII. n. XXIII. p. 366 sqq.

R. Owen, Marsupialia in Todd's Cyclopaedia. Part. XXI. u. XXII. p. 2õ sqq.

P. S. Pallas, Novae Species Quadrupedum e Glirium ordine cum illustrationibus variis compluriun ex hoc ordine animalium. Erlangae 1778. 4. c. F. Enthält zahlreiche anatomisclie Bemerkungen nebst Abbildungen von Skeleten, Schedeln, Eingeweiden.

W. vou Rapp, Anatomische Untersuchungen über die Edentaten. Tübingen 1843. 4.

J. Hunter, Observations on the structnre and oeconomy of the Wliales. Philos. Transact. 1787. Vol. LXXVII. (Mit Aumerkungen von 0 we n abgelluckt in I unter's Works. Palmer's Edition. Vol: IV. p. 331 sqq. Mit Abbild. Uebers. von J. G. Schneider. Berlin 1795. 8.)

P. Ca inper, Observations sur la structure intérienre et le squelette de plusieurs especes de Cétacés. Paris 1820. 4. u. Fol. Mit Abb.

W. Rapp, Die Cetaceen zoologisch-anatomisch dirgestellt. Mit Abb. Stuttg. u. Tübing. 1837. 8.

P. Camper, Description anatomique d'un Elephant mâle. Paris 1802. Fol. Mit Abl.. 
G. Fischer, Anatomie der Maki. Frankf. a. M. 1804. 4.

W. Vrolik, Recherches d'anatomie comparée sur le Chimpanse. Amsterd. 1841. Fol. Mit Abb.

Die osteologischen Hauptwerke sind:

Pauder und d'Alton, Vergleichende Osteologie. Ponn 1821-1831. In 12 ein. zelnen Abtheilungen.

Cuvier, Recherches sur les ossemeus fossiles. T. I-X. Paris 1834. Mit Abb. in 4 .

Ducrotay de Blainville, Ostéographie ou description iconographique conn. parée du squelette et du système dentaire des cinq classes d’animaux vertéhrés récents et fossiles. Paris. Fol. (Noch nicht vollendet.)

\section{Erster Abschnitt.}

\section{Vom Knochengerüste.}

\section{Von der Wirbelsiulule und den Rippen.}

\section{§. 158.}

Dic Wirbel der Säugethicre zcrfallen sehr allgemein in Hals-, Riicken-, Lenden-, Kreuzbein - und Schwanzwirbel; nur bei den Cetaceen, welche kein mit der Wirbelsäule verbundenes Becken besitzen, fällt die Abtheilung der Kreuzbeinwirbel wẹg, falls man ihnen nicht einen einzigen dieser Wirbel vindiciren will.

Die Wirbelkörper l) articuliren in der Regel nicht durch erhabene und vertiefte Gelenkflächen 2) mit einander, sondern sind durch zwischenliegende Knorpelbandscheiben verbunden. Diese werden bisweilen oberflächlich von diinnen Knochenscheiben bedeckt, die mit den Körperflächen der Wirbel durch Harmonie vereinigt sind. Die oberen Bogenschenkel verschmelzen immer mit den Wirbelkörpern; bisweilen, wie bei den Phoken, aber erst sehr spät ${ }^{3}$ ).

Der IIalstheil der Wirbelsäule, mag er lang gestreckt sein, wie bei der Giraffe, oder ganz reducirt, wio bei den ächten Cctaceen, wird fast beständig aus sieben Wirbeln gebildet; sehr selten steigt ihre $\Lambda \mathrm{n}$ zahl auf acht ${ }^{4}$ ) oder neun ${ }^{5}$ ), oder sinkt auf sechs $\left.{ }^{6}\right)$. Die grösste Frei-

1) Bei den Monotremen sind die Flächen der Wirbelkörper leicht ausgehöhlt; die sie verbindenden Faserband щuassen schliessen eine durch Synovialhaut ausgekleidete, mit Flüssigkeit erfüllte Höhle eill. Vergl. Owen in Todd's Cycl. Art. Monotremata. p. 375. mit Abb.

2) Wie dies indessen bei Einhufern und Wiederkäueru der Fall ist.

3) Achnlich die oberen Bogenschenkel des Atlas bei Echidna, nach 0wen.

4) Bei Bradypus torquatus.

5) Bei Bradypus tridactylus; nach $R$ app auch bei $B$. cuculliger.

6) Bei Manatus australis finden sich gewölnlich sechs; Leuckart fand an einem Exemplare sieben. Die letztere Zahl gibt auclı Blainville an. 
beweglichkeit dieser Wirbel wird bei Einlufern und Wiederkiuer'n beobachtet, wo ihre Körper vorn stark gewölbt, hinten ausgehöhlt zu sein pflegen \%), wïhrend ihre Beweglichkeit durch Verwachsung mehrer oder der meisten Ifalswirbel bei vielen iichten Cetaceen ${ }^{8}$ ), bei einigen Edentaten 9) und Nagern 10) ganz aufgelıoben, oder wenigstens selır besehränkt erscheint. - Allgemein zeichnen sich der erste und zwoile Halswirbel durch bedeutende Grösse, eigenthümliche Gestalt Innd abweiehendes Verhalten ihrer Fortsälze vor den übrigen aus. In1mer besitzt der Atlas zwei Gelenkvertiefungen für die beiden Processus condyloüdei des Hinterhauptsbeines. Bei den ächten Cetaceen könunt ihı, in Vergleich zu den übrigen Halswirbeln, ein enormer Umfang zu; ihrem Epistropheus mangelt auch der, bei den übrigen Süugethieren beständig vorkommende Zahnfortsatz ${ }^{11}$ ). - Bei mehren Beutelthieren bleibt der Körper des Atlas perennirend knorpelig 12); bei anderen erhält er sich immer als ein vom oberen Bogen getrenntes Knochenstück.

Der Brusttheil der Wirbelsäule ist von sehr verschiedener Länge und bietet rücksichtlich der Anzahl der ihn zusammensetzenden Wirbel sehr bedeutende Schwankungen dar. Am häufigsten finden sich $12-$ 13 Riuckenwirbel; diese Zahl kann sinken auf 10 und steigen auf 23 13).

Die Länge der Lendengegend, so wie die Zalıl der sie bildenden Wirbel, sind gleichfalls beträchtlichen Verschiedenheiten unterworfen. Die Anzahl der Lendenwirbel schwankt zwischen 2 und 9; meist sind 5 bis 7 vorhanden. In der Regel sind sie unter allen Wirbeln die grössten ${ }^{14}$ ). Bisweilen wird, wie dies nannentlich bei den Einhufern

7) Dabei aber finden sich keine Synovialkapseln, wie sie bei den Reptilien angetroffen werden, sondern concentrische Lagen der Ligamenta intervorte. uralin.

8) Solche Verwachsungen erstrecken sich oft über die meisten Halswirbel; so sind bei Delphinus phoraena die 6 ersten und bei Hyperondon alle unter einander verwachsen. Bei D. Ingirostris, Tursio, delphis die beilen ersten; bei D. globicejs die 5 ersten. Die Verwachsung fehit bei D. albiciuns, bei Platanista gangetica u. A. - 9) Nauientlich bei Dasypus und Chlanydophorus.

10) Namentlich bei einigen Dipus, z. B. D. sagitta.

II) Derselbe findet sich dagegen bei den fälschlich sogenannten herbivoren Cetaceen (Sirenia).

12) Bei Phascolirctos und Phascolomys. Bei Petaurus, Hypsiprymuus und Macropus wird die knorjelige Grundlage des hörpers allmälich knöchern; doch findet sich hier längs der Mitte des Körpers in. len trockenrn Skeleten gewöhn. lich cine Fissur; getrennt bleibt der kleine Körper vom sturken oberen Bogen 7. B. bei Perancles. S. Owen l.c. p. 277. Fig. 98. 99. - Pander u. d'A I ton, Bentelthiere. Tab. 3. u. 7. Fig. \%.

13) Nur 10 Riickenwirbel besitzt, nach Cuvier, Dasypus niger; 23, nach Cuvier selbst 24, besitzt Cholnepus didactylus; 18 bis 20 kommon bei den meisten Einlunferu und Pachydermen vor.

14) In geringstro '/ahl kommen sis vor hei einigen Edentaten, namentlich bei Myruecophaga didactyla. Neun hesitzt Stenops grarilis. 
und Paehydermen vorkömint, ihre Verbindung durch das Zusammentreten von Querfortsätzen noch inniger 15 ).

Das Kreuzbein entsteht gewöhnlieh durch Verschmelzung von melıren Wirbeln; am häufigsten von drei bis vier, selten nur von zwei Wirbeln; die Anzahl der mit den Beckenknochen verbundenen Wirbel kann aber bis auf 9 steigen ${ }^{16}$ ). Sehr selten bleiben, wie dies beim Schnabelthiere vorkömmt, die einzelnen Kreuzbeinwirbel von einander getrennt; bisweilen erstreckt sich die Verschmelzung auf mehre Wirbel, welehe nicht sämmtlich 'mit den Beckenknochen sich verbinden ${ }^{17}$ ). Riieksichtlich seiner Dimensionen und seiner Riehtung zeigt das Kreuzbein mancherlei Verschiedenheiten ${ }^{18}$ ).

Die Sehwanzgegend bietet in Bezug auf ihre Länge, die Anzahl der sie bildenden Wirbel und die Gestalt der letzteren die grössten Verschiedenheiten dar; die beträchtlichste Anzahl derselben (46) besitzt Manis macrura; die geringste (4-5) erseheint beim Menschen und einigen höheren Affen. Die einzelnen Schwanzwirbel nehmen von rorne naeh hinten allmälich an Entwickelung und an Aelınlichkeit mit den übrigen Wirbeln ab. Nur in die vordersten oder vorderen verlängert sich die Höhle des Rückenmarkscanales, während die hintersten undurchbohrt zu sein pllegen. Bei den meisten langgeschi wänzten Säugethieren zeichnen sich die mittleren und hinteren Sehwanzwirbel dureh ihre beträehtliche Länge aus.

[Tabellen über die Zahlenverhältnisse der einzelnen Abtheilungen der Wirbelsïule gibt Cuvier, Leçons d'Anat. comp. T. I. p. 17\% und A. Wagner in Sehreber's Säugethierwerk. Ueber die Bänder der Wirbelsäule sowvol, als der übrigen Knoehen muss, in Betreff ihrer Anordnung bei den Haussäugethieren, auf Gu rl t, Lehrbuch der vergl. A natour. der Haussäugetliere. Thl. 1. S. 180. verwiesen werden.]

15) An der Wurzel des Querfortsatzes des letzten oder der letzteren Lenden. wirbel finden sieh überknorpelte Flïchen, dureh welehe sie anfangs beweglich mit einander und nit dem ersten Kíreuzbeinvirbel verbunden werden, während sie in vorgeriiektem Lebensalter oft mit einander verwaehsell. So bei allen Einbufern und rielen Paehydernren, z. B. Tapirus, Rhinoceros, Hippopotamus.

16) Dies geschielrt aber nur in denjenigen Fillen, wo das Kreuzbein nicht blos mit den Hüftbeinen, sondern auch nrit den Sitzbeinen sich verbindet, was nur in den Ordnungen der Chiropteren und Edentaten vorkömmt (vergl. \$. 163.). Unter dieser Bedingung sind die Querfortsätze der letzten Kreuzbeinwirbel selır lang. - Naeh Orven besitzt Perameles nur einen einzigen Kreuzbeinvirbel.

17) Z. B. beim Wombat anf die drei ersten Sehwanzwirbel, welche ganz nahe an die Sitzheine init ibren Querfortsätzen herantreten; bei anderen, z. $\mathbf{B}$. bei Phalangista Cookii auf den letzten Lendenwirbel u. s. w.

18) Durch seine Breite ausgezeiehnet ist es besonders bei den Affen der alten Welt und bei den Faulthieren; breit auch beim Woubat. - Bei allen Säugeflieren, mit Ausnahme der hröheren Affen und des Mensehen, ist es gerade. 


\section{§. 159.}

Was die Wirbelfortsätze anbetrifft, so ist uber dieselben im Wesentlieben Folgendes hervor\%uheben:

1. Die oberen Dornfortsäze l) sind in den verschiedenen Gegenden der Wirbelsäule verschiedentlich entwickelt; in der Inalsgegend in der Rogel schwach; namentlich fehlen sie hiel einigen langhalsigen Säugetlieren, z. B. den Camelen, der Girafle, bei denen sie die Freibeweglichkeit des Halses beschränken wïrden, eigentlich ganz; oder sind nur schwach entwickelt, wic bei den Pferden und vielen Wiederkäuern. Eben so fehlen sie hier den Cetaceen, den Phoken, den meisten Insectivoren und den Chiropteren, bei denen sic zum Theil nur an zweiten und am siebenten Halswirbel hervortreten. Entwickelter sind sie in der Halsgegend bei den Quadrumanen, den Ferae, Nagern, und stark namentlich bei einigen Edentaten und Beutelthieren. Au stiirksten sind gewöhnlich die Dornfortsätze des zweiten unel des' sicbenten llalswirbels entwickelt. Namentlich erscheint der Dornfortsatz des Ljpistropheus, wclcher so häufig dem Nackenbande zur Befestigung dient, hei den meisten Säugethiercn als cine senkrechte hohe Knochenplatte, welche bald vorn den Atlas, bald auch hintere Wirbelbogen iiberragt. Der Dornfortsatz des siebenten Halswirbels steht gewöhnlich am meisten gerade oder selbst etwas rückwärts, gleich den Dornen der Rückenwirbel, während die vor ihm befindlichen etwas vorwärts gerichtet zu sein pflegen. - Die Dornfortsätze der Rückenwirbel sind bei den mesisten Sängethieren - obschon mit manchen Ausnahmen - an höchsten; vorzugsweise lıoch, wenn der Kopf sehe schwer oder der Hals sehr lang ist, wie bei Pachydermen und Wiederkiuern, wo sie den sehr entwickelten Nackenbande 2$)$ starke Stiitzpunkte gew ahren. Bei den

1) Sie entstehen lïufig, namentlich bei Wiederkäuern, P'ferden, Schweinen, als besondere Verknöcherungen; bisweilen finden sich an der Spitze derselben bei ansgewachsenen Thieren noch kleine Ossiticationen, wie ich sie z. B. bei Macropus Bennetti an den Lendenwirbeln tinde. - Verschieden davon ist rine Bildung, welche Theile (Mïller's Archiv. 1839. S. 136.) bei der Ratte beob. achtete. An der angeschwollenen Spitze des Dornfortsatzes vou zweiten Riicken. wirbel hindet sich ein kleines horizontales linöclıelchen, dis durch Sehnen an den oberen Bogen des siebenten Halswirbels und des ersten Rückenwirbels befestigt ist.

2) Das elastische Ligamentum nuchae ist sclıwaclı bei den liatzen, stärker bei den Hunden, wo es rom ersten Rückenwirbel zum Dornfortsatze des Ejpistro. phenss sich erstreckt. Weiter linterwärts von den Rïckenwirbelı entstelit es schon bei den Schweinen. Am entwickeltsten ist es bei den Wiederkänern und Einlufern. Bei letzteren beginnt es an letaten I,endenwirbel; älnliclı bei deu rinheimischen Wiederküuern; bei der Giraffo selbst von den Schwamzwirbeh. Es lestelat bei diesen langlailsigen Thieren in der Regel aus zwroi Scitenhälften;

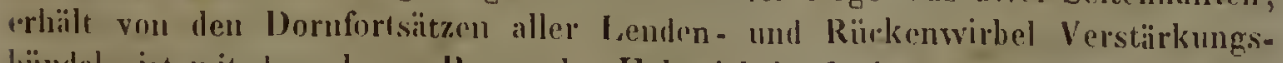
luindel, ist mit den olseren Bogen der Halswirbel oft (namentlich beim Pforde) durrlı cinen breiten lä̈utigen Theril rorbunden nud inserite sich gewölunlich au 
Chiropteren und Maulwürfen fehlen sie oder sind dureh kleine Ilöcker repräsentirt. Die Dornfortsätze der Lendenwirbel stehen, gleieh denen der letzten Rïckenwirbel, gewöhnlich gerade oder sind vorwärts geneigt; letzteres meist um so mehr, je länger und stärker der Schwanz ist. Sie sind bei den äehten Cetaecen die höehsten. In der Kreuzbeingegend fehlen sic selten ganz, sind häulig sehr kurz, wic bei den Affen, verlingern sich aber bedeutend bei den meisten Nagern und Edentaten; häufig bilden sie dureh Verwaehsung einen zusammenliangenden Kamm. Meistens finden sie sieh noeh an den ersten Selıwanzwirbeln; bei den Cetaeeen versehwinden sie erst in den letzten.

2. Die Querfortsätze entstehen bei den Säugethieren bald vom Körper, bald vom obẹren Bogen der Wirbel; namentlich findet sich erstere Entstehungsweise sehr oft an den Lendenwirbeln; letztere immer an den Rüeken - und IIalswirbeln. Die beträehtliehen, meist etwas vorwärts gerichtetén Querfortsätze der Halswirbel besitzen gewöhnlich doppelte Wurzeln, von denen die cine, vom Wirbelkörper stammende, ein Rippenrudiment ist. Diese doppelten Wurzeln umselıliessen dic Canäle zunn Durehtritt der Arteria vertelralis ${ }^{3}$ ). Die Querfortsätze des Atlas bilden ıneist horizontale Platten oder breite flügelartige Fortsätze, wie bei den Ferae. Kürzer sind gewöhnlieh - jedoeh niẻi bei den Monotremen - die des Epistropheus. Bei der zuletzt genannten Ordnung deeken sieh die breiten, rüekwärts gekehrten Querfortsätze der meisten Halswirbel dachziegelartig. Bei den meisten Säugethicren verbreitert sieh der untere Theil des Querfortsatzes der Halswirbel zu einer etwas abwärts gebogenen Platte. Auf diese Weise entsteht an dếr vorderen oder unteren Wirbelfläehe eine breite Rinne zur Aufnahıne der $\boldsymbol{M}$. $\boldsymbol{M}$. longi colli und Recti anteriores. - An den Rüekenwirbeln werden die gerade auswärts gerichteten Querfortsätze bedeutend kürzer. Bei den Cetaecen nehmen sie von vorn nach hinten an Länge zu; bei den Monotremen fehlen sic sowol an den Rüeken-als an den Lendenwirbeln. - An den Lendenwirbeln f) sind sie sclırigg hinterwärts bald quer, bald abwärts geriehtet und oft sehr beträchtlieh, namentlich bei den Cetaceen, Eintufern, Paehydermen und Wiederkäuern. In der Kreuzbeingegend sind sic。 selten ziemlieh lang, wie bei einigen Eden-

Dornfortsatze des Epistrophens, un von hier aus zur Crista des Hinterhauptsbeines zn treten, ohne dass Bündel mit dem beweglichen Atlas zusammenhangen. Ab). von Haussäugeth. bei Gurlt Tab. 1-4.

3) S. über dic Halsrippen \$. 160. Die Conales vertebrules fehten bei den Camelen und der Giraffe, so wie bei den ächten Cetaceen in allen Halswirbelı; manchen Säıgethieren fehlen sie im siebenten Halswirbel; viele besitzen sie in allen.

4) Die Ruerlortsätze der Lendenwirbel zeigen sich bei der Gattung Lejus, in griugerem Grade auch bei Dasyprocta u. A. an ihrem freien Ende in vordere Spitzen ausgezogen. Dies sind bei jungen Thieren distincte Ossificationen, die erst später mit dem Ruerfortsatze verwachsen. 
taten, den Wombat u. A. - In der Schwanzgegend sind sie bei kurzgesclıwänzten Säugethieren gewöhnlich kurz; beträehtlich an den vorderen Schwanzwirbeln bei manchen Nagern (Ratte, Eichhörnchen) und Edentaten, überhaupt stark entwickelt bei den Monotremen, dem Biber, Manis und anderen Edentaten. Bei den Cetaceen, an deren letzten Sehwanzwirbeln sie abortiv werden, sind sie an der Wurzel durehbohrt von einem zum Durchtritte der Rückenäste der Art. sacra media bestimmten Canale, der weiter hinterwärts selbst seillich durch den Wirbelkörper tritl.

3. Die Gelenkfortsätze bicten hinsichtlich ihrer Anordnung manche Verschiedenheiten dar. Bei den Cetaccen kommen nur etwa an den vorderen zwei Drittheilen der Rüekenwirbel die, wic gewöhnlich, liorizontal gestellten, flachen Gclenkfortsätze functionel ausgebildet vor. An den lctzten Rückenwirbeln und an den Lendenwirbeln gehen die hinteren Gelenkfortsätze verloren und es bleiben statt der vorderen nur Muskelfortsätzc (Processus accessorii) 5 ) übrig. Diese kommen schon an den ersten Ruickenwirbeln als Theile der Querfortsätze vor, rücken an den hinteren an die oberen Bogenschenkel und noch weiter hinterwärts an die oberen Dornen. - Bei den übrigen Säugethieren verändern die an den meisten Rückenwirbeln horizontalen Gelenkfortsätze an den letzlen Rückenwirbeln und an den Lendenwirlseln ihre Stellung, treten von den Querfortsätzen ab und zuglcich inchr aufwärts zu den Wurzeln der oberen Bogenschenkel; die Gelenkflächen erhalten von da an, statt der horizontalen, eine mehr verticale Richtung. Von den Gelenkfortsätzen aus verlängern sich, bei den mcisten Säugethicren, naclı vorn oder auch nach hinten gerichtet, mehr oder minder deutliche, zu Muskelansätzen bestimmte Höckcr, Processus accessorii anteriores und posteriores 6 ). Sie sind immer an stärksten und oft selir stark an den Gelenkfortsätzen der Lendenwirbel und der letzten Rückenwirlel, meist weniger an den vorderen Rückenwirbeln, wo sie an dic Querfortsätze übergehen, aber bisweilen noch sehr deutlich ausgeprigt und selbstständig sich erhalten. Durch die Anordnung ihrer Gclenkfortsätze und ilhrer Processus accessorii bckommen die hintersten Rückenwirbel bei den meisten Säugethicren also manche Uebereinstimunung mit den Lendenwirbeln \%). Am eigenthümlielısten

5) S. z. B. die Abbildungen bei Pander und d'Alton, Skelete der Cetaceen. Tab. 1. 2. u. 6. An einer mehr oder minder grossen Zahl von hinteren Riicken - und vorderen Lendenwirbeln verlängern sich diese Muskelfortsätze von hinten nach vorn ïber die nächst vorileren Schenkel der oberen Wirbelbogen.

(i) Die Processus accessurii anteriores sind sebr allgemein vorhanden, z. B. bei deu Einlufern, vielen Wiederkäuern, Pachydermen, Nagern, Affen u. A.; die linteren kommen z. B. z.ugleich vor bei den meisten Affen, vielen Ferae, Bentel. thieren, Nagern и. A. Die vorleren sind oft sehr verlängert, wie z. B. bei Echidna, J،ejus unul besonders bei vielen Eilentaten.

7) Vergl, die Bemerkungen ron Theile in Müller's Archiv. 1839. S. $109 \mathrm{fr}$. 
ist die Einriehtung der Gelenkfortsätze an den Lendenwirbeln und den letzten Rückenwirbeln einiger Edentaten ${ }^{8}$ ). Sie besitzen nicht nur die an der Basis der oberen Bogen gelegenen Gelenkflächen, sondern noeh ausserdem tiefere oder äussere, an der Basis der Querfortsätze befindliche, welehe wieder doppelt sind. Die Processus accessorii, in welehe die oberen oder inneren Gelenkfortsätze sieh auszichen, sind bei ihnen von so ausserordentlieher Länge, dass sie zum Theil den beträchtlichen Dornfortsätzen gleichkommen.

4. Leisten, dornartige Fortsätze und wirkliehe längere untere Dornen gehen bei Säugethieren häufig vom Körper einzelner Wirbel abwärts. Leisten finden sich z. B. an den Körpern der meisten Halswirbel bei den Wiederkäuern, den Einhufern, manchen Ferac; sie dienen dem Musc. lougus colli zur Befestigung; sie kommen vor an mehren Lendenwirbeln von Oryeteropus; naeh hinten geriehtet an mehren Rückenwirbeln der Monotremen, an den Sehwanzwirbeln von Ornithorhynehus. Untere Dornen von beträchtlicher Länge eharakterisiren die drei ersten Lendenwirbel der. Haasen.

5. Untere Bogensehenkel, V förmig gestaltet, also meistens verlunden, selten (und dann nur wenige derselben) aus zwei getrennt bleibenden Sehenkeln bestehend, sehr selten auch an der Basis dureh eine Querleiste vereinigt, kommen bei allen Säugethicren mit langem Sehwanze vor; ausnahmsweise, wie bei Hystrix, aueh bei kurzgesehwänzten. Sie gehen immer von der Verbindungsstelle zweier Wirbelkörper aus.

\section{§. 160 .}

Rippen oder Rippen-Rudimente können an Wirbeln jeder Ordnung bei den Säugethieren vorkommen. Was zunächst die Halswirbel anbetrifft, so erseheint beim Fötus des Mensehen 1) die vordere Wurzel ihrer Querfortsätze, welehe, dem Wirbelkörper verbunden, das Forame» vertebrale vervollständigt, häufig als getrenntes Knochenstiuck und darf als Aequivalent einer II alsrippe gelten. Gewöhnlich erhält sie sieh lange getrennt an siebenten Halswirbel. - Sehr lange getrennt bleiben die Cervicalrippen aller Halswirbel, mit Ausnahme des Atlas, beị den Monotremen 2); besonders ist dies bei Eehidna der Fall, während beinı

8) So bei Myrmecophaga, Dasypus, Oryeteropus. Vergl. z. B. die Abb. von Dasypus bei Pander und d'Alton, Skelete der zalınlosen Thiere. Tab. VII.

1) Die Halswirbel der Säugethiere sind in Bezug auf ihre 0steogenese noclı wenig untersueht; am sorgfiltigsten sind die Beobachtungen ïber den Meuschen. Siobe iı dieser Hinsieht, ansser einzelıen älteren Sehriftstellern, besonders J. F. Meekel in seinem deutsch. Areh. f. Physiol. Bo. 1. S. 594 ff. Mit Abb. 'Tab. VI., Mïller in seiner vergl. Anat. der Myximoïlen. Tlít. 1. S. 236. nud Theile iu Miiller's Archiv. 1839. S. 104.

2) Vergl. Owen, Monotremati. p. 375. Anch bei einen erwachsenen P'era. meles fand 0 wen eine distincte Halsriple an Epistrophens. 
Selnnabelthiere, wo die übrigen Cervicalrippen verwachsen, nur die des Epistropheus, welche sehr gross ist, perennirend gesondert bleibt. Endlich finden sich bei den dreizehigen Faulthieren Rippenrudimente, welehe als diserete Knoehenstiucke von den Spitzen der Querfortsätze ihres achten und neunten Ifalswirbels ausgehen ${ }^{3}$ ).

Dic Rippen der Brustgegend zerfallen, je nachdem sie mit dem Brustbeine articuliren, oder nicht, in walire und falsche. Ihre Verbindung mit dein Brustbeine geselicht selten durch wirkliche Sternocostalknochen, meistens durch Knorpel 4). Sehr selten wird der Knorpel melirer Rippen aus zwei Stücken zusammengesetzt und dadurch eine selıon bei dell Grocodilen eingetretene Anordnung wiederholt 5 ). Die Verbindungsweise der Rippen mit den Rückenwirbeln bietet Versehiedenheiten dar. In der Kegel articulirt jede Rippe durch ihr Capitulum mit einer von je zwei Wirbelkörpern gebildeten Gelenkfläche und dureh ihr Tubereulum mit dem vom oberen Bogen des hinteren dieser Wirbel ausgehenden Querfortsatze 6). Bei den Monotremen hat nur die erstgenannte Verbindungsart Statt, indem das sehr schwache Tubereulum, das den meisten Rippen zukömmt, nicht mit einem Querfortsatze articulirt. Bei vielen Säugethieren articuliren einige der hinteren Rippen nur mit zwei Wirbelkörpern oder einem einzigen. Seltener - und zwar namentlich bei den ächten Cetaceen - haften sämnntliche $\left.{ }^{7}\right)$, oder, gewöhnlich, die hinteren Rippen nur an den Querfortsätzen der Wirbel. Bei einigen Cetaceen bleiben auch ein bis zwvei der allerletzten Rippenpaare durch einen weiten Abstand ganz von den Wirbeln und ihren Fortsätzen getrennt, ein Verhalten, das bei anderen Säugethieren nur ausnahmsweise beobachtet ist 8 ). - Die Verbindung

3) S. darïber Meckel, vergl. Anat. Thl. 2. Abth. 2. S. 294.; Rapp, Edelltaten. S. 17. und den Aufsatz von 'Th. Bell in den Transactions of the zool. soc. of London. Fol. I. 1. 113. Mit Abb. Tab. XVII. Bell sucht, mit Unrecht, den beiden letzten Halswirbelı der Faulthiere den Clarakter von Rückentvirbeln zu vindiciren.

4) Bei den Cetaceen findet mam schon von der Geburt an, anstatt ler Rippenknorpel, wirkliche Knochen, welche selır beweglich unter starken Winkeln mit den eigentlichen Rippen verbunden sind. Frülızeitig tritt auch bei den mei. sten Eilentaten die Verknöcherung ein.

5) Dies könınt z. B. bei Ornithorhynchus an den fünf letzten, bei Manis von der siebenten bis eilften Riple vor; die beiden Stücke stossen hier unter einem nach vorn spitzen Winkel zusammen. - Bei Ornithorhyuchus verknöchern die Sternocostalstiicke.

6) Theile hat die Beobachtung genacht, dass bei der Ratte das Tuberculum der ersten Rippe in einer Gelenkhöhle ruhet, zu deren Bildung der Querfortsatz. des siebenten Halswirbels und des ersten Kückenwirbels gleichmässig beitragen.

т) $\%$. B. bei Balaena longimani.

8) Von $\mathrm{Meck}$ el ausnahusweise beim Esel gefunden; von $\mathbf{R}$ ap als constante Bildung bei Delphinus delphis und plocaena beobarlıtet; ich findr diese losen Rippen (jeclerseits zwei) niclıt nur ganz lestäudig bei D. phocaena (in 17 Exemplaren), sondern aucl bei D). dubius, veruisse sie alber bei 3 frisch untersurhten Nowwals. 
der Rippenknorpel und Sternocostalknochen mit dem Brustbeine geschieht gewöhnlich so, dass erstere in dem Zwischenraume zweier Brustbeinstücke sich befcstigen. - Die Knorpel oder Sternocostalknochen der Ineisten vorderen falschen Rippen legen sich meistens an die gleichnamigen Stücke der hinteren wahren Ripjen; die hintersten falschen Rippen werden dagegen nur durch die Muskeln mit ilnen und dem Brustbeine verbunden. Einige Eigenthümlichkeiten in dein Verhalten der Rippenknorpel zu einander und zum Brustbeine werden bei den Monotremen und bei mehren Edentaten angetroffen 9 ). - Das Zahlenverhältniss der wahren Rippen zu den falschen ${ }^{10}$ ) gestaltet sich bei den einzclnen Ordnungen und Gattungen sehr verschieden. Bald sind die wahren Rippen den falschen an Anzahl gleich; bald sind jene, bald diese - und zwar oft sehr bedeutend - iberwiegend.

Dic Dimensionen der mehr oder minder stark gewölbten Rippen zeigen beträchtliche Verschiedenheiten; bald sind die Rippen rundlich, bald platt; bisweilen verbreitern sie sich bedeutend ${ }^{11}$ ), wie bei mehren Edentaten und ganz besonders bei Myrmecophaga didactyla, wo sie dachziegelförmig einander dccken, wodurch denn die Zwischenrippenräume ganz verschwinden. Iläufig, obschon nicht beständig, ist die erste Rippc die breitestc 12). - Die längsten Rippen besitzen verbältnissmässig die Chiropteren. Unter den einzelnen Rippen ist die erste sehr beständig am kürzesten.

Nicht selten köımmt an dem Querfortsatze des ersten Lendenwirbels ein überzähliges Rippcnrudiment vor ${ }^{13}$ ), und auch an den übrigen Lendenwirbeln ist, wenigstens bcim Schweine im Fötalzustande, in deutlich abgesonderten Knochenkernen an den Querfortsätzen dersclben die Anwesenheit primitiver, später freilich mit den Querfortsätzen diescr. Wirbel verschmelzender Rippenrudimente nachgewiesen ${ }^{14}$ ). Auch an den Querfortsätzen der Kreuzbeinwirbel

9) Bei den Monotremen z. B. bilden die Knorpel der hinteren Rippen Jange und breite Platteu, die einander dachziegelförmig decken.

10) Am meisten überwiegen die falsehen Rippen die wahren bei den Cetaceen. Bei vielen Walen kömut auf 11 falsehe Rippen nur eine wabre; bei vielen Delphinen auf 13 bis 15 nur 4 bis 5 ; bei den lierbivoren Cetaceen auf 16 bis 18 nur 3 bis 4 ; die $\mathbf{Z}$ ahl der wahren Rippen ist dagegen bedeutend ïberwiegend z. B. bei Phoea (10-11 wahre, 5 falsehe), bei Myrmecopliaga (bei tanrandua z B. 18 wahre, 8 falsehe) u. s. w.

11) Breit aueh z. B. bei Galacopithecus, Leinur u. A.

12) Dies ist z. B. der Fall bei allen Beutelthieren; bei Dasypus; hei Chrysoehloris; len Fledermäusen; bei anderen ist sie die schmalste; so z. B. bei vielen Wiederkäuern, Quadrumanen, Galaeopithecus u. A.

13) \%. B. beim Bären, bei Lemur Mongoz und anderen Säugethieren, bald an einer, balıl an heiden Seiten von mir gefunden.

14) S. Müller, Vergl. Anit. der Myxinö̈llelı. Thl. 1. S. 238 . und 'Tlıeilo iı Müller's Archiv. 1839. S. 106. 
und einiger Seluwanzwirbel sind bei jungen Gürtelthieren abgesonderte, rippenartige Knoehenstủeke beobachtet worden ${ }^{15}$ ).

\section{Vom Brustbeine.}

\section{S. 161.}

Das Brustbein der Säugethicre besteht in der Regel aus einer cinfaehen Reilie hinter einander liegender Knoehen von versehiedener Zalıl, die meist unversehmolzen bleiben und deren Zahl gewöhnlieh genau mit der der Interstitic intercostalia übereinkömmt. Zwiselıen ilhnen liegen bisweilen kleine Sesambeinchen ${ }^{1}$ ). Seltener ist die Reilhe dieser Knoehen nieht ursprünglieh einfach, sondern es entstehen wenigstens einige derselben aus paarigen Elementen ${ }^{2}$ ). Meistens ist das Brustbein der Säugethiere lang und sehmal 3), seltener breit, wie bei den Cetaeeen, deir Orang-Utang, dem Chimpanze und dem Mensehen; bei der erstgenannten Ordnung zugleich am kürzesten. Selır häufig ist es vorn breiter, als hinten; selten hat die entgegengesetzte Bedingung Statt; bisweilen behält es aueh iberall ungefähr die gleiehe Breite. - Viele Säugethiere besitzen ein vor die Insertion des Sehlüsselbeines hinaus sieh erstreckendes Manubrium, das dureh das vorderste Brustbeinstuiek gebildet wird. Bei den Phoken und Monotremen kömmt vor diesem ersten Knoehenstiuek noeh ein assessoriseher Episternalknoehen vor; er ist bei den Robben stielförmig und hat bei den Monotremen die Form eines $\mathrm{T}$; bei dieser letzteren Ordnung legen sieh die Claviculae an seinen vorderen Querast und verwaehsen selbst init ihm. Seitliehe paarige Knorpelstiucke sind bei den Cetaeeen an dem knöchernen Brustbeine beständig hefestigt. - Einige grabende und fliegende Säugethiere (namentlieh die Maulwiirfe, Gürtelthiere, Fledermäuse) besitzen an ihrem Brustbeine eine mehr oder minder stark vorspringende Leiste. - Ein scheibenförıniger Processus ensiformis kömmt vielen Säugethicren zu. - Manehe besondere Eigenthümlichkeiten des Brustbeines zeigen die Cetaeeen, mehre Edentaten, Maulwürfe und Fledermäuse 4).

15) Hierauf hat Müller (Myxinoïden. I. S. 240.) aufmerksan gemacht. Er fand auch die rippenartigen Knochenstücke an den vier ersten Schwanzwirbeln dieses Thieres. Theile fand sie auch zwischen dem ersten Kreuzbeinwirbel und lem Hüftbeine eines Schrveinefötus.

1) Bei den Monotremen aus 4 bis 5 , bei den meisten Beutelthieren aus 6 Stïcken; bei den meisten Einluufern, Pachydermen, Wiederkäuern liesteht es ur. sprünglich auch 6 bis 7 Knochen, die linge getrennt bleiben; bei vielen Ferae aus 8 verschmelzenden Ḱnochen; die grösste Zahl von Brustbeinstücken: 13 findet sich bei Choloepus dilartylus.

2) So bei mehren äcliten Cetaceen, z. B. den Delphinen; auclı bei den Schweinen.

3) Alı stärksten zusammengedrückt bei einigen Pachydermen u. d. Einlufern.

4) Es muss in dieser Bezichung auf die früher citirten Abbildungen verwiesen werden. 


\section{Vom Schulter - und Beckengeriiste.}

§. 162.

- Das knöcherne Schultergerüst der Säugethiere Leigt hinsichtlich der Anzahl und Verbindungen der in seine Bildung eingehenden Knocleen und seiner dadurch gegebenen beschränkteren oder unbeschränkteren Freibeweglichkeit beträchtliche Verschiedenheiten. Entweder ist 1) das Schulterblatt sowol durch das, anfangs cinen eigenen Knochen darstellende, später mit ilın verwachsene Os coracoü̊leum, als auch durch die Clavicula mit dem Brustbeine verbunden, wie bei den Monotremen 1); oder 2) das ursprünglich als eigene Ossification entstandene os coracoïdeum ist auf einen mehr oder ninder beträchtlichen Fortsatz (Processus coracoülleus) des Schulterblattes, mit dem es auf das innigste verwachsen erscheint, reducirt, wie bei den übrigen Säugethieren. Dieser Fortsatz tritt dicht über der Gelenkgrube des Schulterblattes vom unteren Ende seines vorderen Randes nach innen, hat aber jede Verbindung mit dem Brustbeine aufgegeben. - Die Säugethicre besitzen bald eine Clavicula, bald ermangeln 2) sic einer solchen, in welchem letzteren Falle dann das Schulterblatt selbst die grösste Freibeweglichkeit erhält. - Wenn eine Clavicula vorhanden ist, verbindet sie bald die Scapula, in deren Acromion sie durch eine Gelenkkapsel eingefïgt ist, mit dem Brustbeine; bald ist sie rudimentär ${ }^{3}$ ) und hat ihre Be-

1) S. die Abbildungen bei Meckel, Ornithorhynch. 'Tab. IV. Fig. 1., der auch p. $12 \mathrm{sqq}$. cine rollständige Uebersicht der verschiedenen Deutungen, welche die Theile des Schultergerüstes der Monotremen erfahren haben, gegeben hat. Cuvier, Recherches. Tab. 214. u. 215. - Pander und d'Alton, Skel. d. zabnlosen Thicre. Bonn 1825. Tab. 1-4. - 0 we en, Monotr. p. 376. - Der Schulterknochen älterer Thiere ist entstanden durch die Verschmelzung zweier Knochen: der eigentlichen Scamula und des $O s$ coracoüdeum. An der Stelle, wo beide zusamınenstossen, findet sich die Gelenkfläche für den Humerıs. Die eigentliche Scapula ist scbmal, länglich, der der Vögel ähnlich; die Spina bildet scbeinbar den vordern Rand, springt aber als Acromion vor. Dieses bildet das Gelenk für die Clavicula, welche, wie bei den ineisten Sauriern, auf dem Queraste des Tförmigen vorderen Brustbeinstückes ruhet und mit der der entgegengesetzten Seite fast zusammenstösst. An ihrem Vordereude sind die Ossa coracöidea noch verbunden mit accessorischen Knochen (Epicnracö̈dea), welche die Seitenlücke zwischen dem verticalen und horizontalen Aste des T förmigen vorderen Brustbeinstiickes ausfüllen.

2) Die Claviculae fehlen den Sirenen, allen Cetaceen, Wiederkäuern, Finlufern, Pachydermen, unter den Edentaten bei Manis, Myrmecophaga jubata und tamandua, unter den Beutelthieren bei Perameles, unter den Raubthieren z. B. bei Phoca, Ursus, Nasua, Procyon, Cercoleptes.

3) Völlig entwickelt ist die Clavicula als Verbindungstheil bei den Beutelthieren, Orycteropus, Cblamydophorus, bei viclen Nagern (Cricetus, Sciurus, Mus, Arctonys, Castor u. A.), bei vielen Insectivoren, Erinaceus, Talpa, Chrysochloris, Sorex, den Chiropteren mit Einschluss der Galäopitheken, den Quadruinanen. - Bei mebren Edentaten schon wird sie unvollkommener; bei den Faul. 
deutung als Yerbindungsknochen zwischen Scapula und Sternumı aufgegeben. - Das Schulterblatt, gewöhnlich ein länglich dreieckiger oder viereckiger kwochen, dessen oberer Rand oft (wie bei den Einhufern und Wiederkäuern) eine breite Knorpelplatte trïgt, besitzt an der Vereinigung seines vorderen und hinteren Randes eine scielte Gelenkgrube für den Oberarm; dicht über dieser tritt der Processus coracoüdeus nach innen ${ }^{4}$ ). Die Aussenfläehe des Schulterblattes ist allgeinein durch eine Lïngsleiste: die Gräthe, Spina, in eine vordere und eine hintere Grube getheilt ${ }^{5}$ ). Die hintere Grube zerfällt bisweilen durcls eine zweite, der Spina parallele, Leiste in zwei unvollkommen getheilte Hälften 6). Die Spina endet häufig in der Gegend der Gelenkfä̀che mit einem Vorsprunge: der Grätheneeke (Acromion), deren Anwesenheit und Stärke im Ganzen mit der Ausbildung des Schlüsselbeines correspondirt. - Einige Eigenthümlichkeiten seiner Bildung zeigt das Schulterblatt - ausser bei den Monotremen - aueh bei den Faulthieren und bei einigen grabenden oder fliegenden Säugethieren z), besonders bei Talpa, Chrysochloris, den Chiropteren und Galäopitheken. Bei den letztgenannten Säugethieren ist auch das Schlüsselbein mannich fach und eigenthümlich gestaltet.

\section{§. 163.}

Alle S:iingethiere, mit Ausnabme der Sirenen und Cetaceen, besitzen ein ausgebildetes Becken. Bei der letztgenannten Ordnung ist es im höchsten Grade rudimentïr. Es wird bei den Delphinen, dem Narwal und den Walen 1) nur durch zwoi kleine, längliche Knochen repräsentirt, die

thicren erreicht sie den Processus coracoüdens; bei den Faulthieren, den Gürtelthieren und Myrmecophaga didactyla steht sie mit dem Brustbeine durch Ligament in Verbindung. Unvollkommen ist sie auch bei vielen Nagern, z. B. Cavia, Lepus. Bei Hystrix ist sie nur mit den Brustbeine, nicht mit der Scapula verbunden. Bei den meisten Raubthieren wird sie sehr rudimentär; bei Felis nimumt sie nur die Hälfte des Zwischenraumes zwischen Scapula und Brustbein ein; so nimmt sie aur Umfang ab bei Meles, Lutra, Mustela, Hyaena, Canis.

4) Es ist sebr entwickelt bei Galaeopitbecus und den Chiropteren überhaupt. - Bei Myrnecophaga jubata und tamandua entsteht durch eine Knochenbrücke, die vom Haken zum vordern Rande der Scapula geht, ein Loch.

5) Bemerkungen über die Grube der Monotremen bei 0 wen p. 376; der vordere Rand ist hier die wirkliche Spina; der eigentliche Vorderrand liegt vorwärts.

6y Bei Dasypus, Myrmecophaga. Abb. bei Pander und d'Alton, Skel. der zahnlosen Thiere. Tab. $5-7$.

i) Abbildungen von Talpa und Chrysochloris bei Pander und d'Alton, die Skelete der Chiropteren und Insectivoren. Bonn 1831. Tab. IV. V. - Abbild. von Chiropteren ebendaselhst Tab. VI. VII., so wie auch bei T emininck, Mo. nographies de Mammalogie.

1) Abgeb. bei Rudolphi, Ueber Balaena longinana in d. Abhandl. d. phys. Klisse d. Acar. d. Wissensch. zu Berlin. Aus d. J. 1829. Berlin 1832. S. 139. Tah. I. und Tab. 4. Ganz ähndich gestaltet sind die Beckenknochen bei den Delphinen und bein Narwal. Die Abbildung, welche Albers, Icones Tab. 1. gegeben, ist gewiss nicht naturgennäss. 
weder unter einander, noch init der Wirbelsäule verbunden sind. Diese Knochen entsprechen den Sitzbeinen. - Bei dem Dügong scheint jederseits noch ein Knochen, ein Sehaambein, hinzuzukummen 2). - Das Becken der übrigen Säugethiere entsteht wesentlieh aus den II üftbeinen, Sitzbeinen und Schaambeinen, welche meistens früh zeitig verschmelzen und nur bei den Monotremen während der grössten Zeit des Lebens distinct bleiben ${ }^{3}$ ). Bei den Monotremen und Beutelthieren kommen zu den genannten Knochen noch dic Beutelk nochen (Ossa marsupialia) hinzu. - Mit dem Becken des Menschen verglichen, erseheint das der Säugethiere verhältnissmässig eng; an engsten bei den Maulwürfen. Im Gegensatze zu den Säugethieren sind bein Menschen die IIüftbeine am breitesten, am niedrigsten und am wenigsten senkrecht. - Gewöhnlich verbinclet sich nur das Hüftbein mit dem Kreuzbein; meist geschieht diese Verbindung durch Fdserbandmasse, seltener durch Anehylose 4); bei einigen Edentaten 5 ) ist auch der Sitzbeinhöcker, Vogel-ähnlich, mit dem Kreuzbeine verwaehsen, wodurch der Sitzbein-Ausschnitt in ein Loch verwandelt wird; dieselbe Ver. wachsung der Sitzbeine mit dem Kreuzbeine kehrt bei vielen Chiropteren ${ }^{6}$ ) wieder, bei clenen ausserdem, ähnlich wie bei Rheit americana, die Sitzbeinhöcker unter einander sich vereinigen. Annäherungen zu diesen Bildungen kommen bei einigen Nagern und beim Wombat vor. - Die Verbindung zwischen den beiden Seitenhälften des Beekens geschieht meistens nur durch die beiden Schaambeine, seltener auch zugleich durch die Sitzbeine, wodurch eine beträehtliche Verlängerung der Fuge zu Stande kömmt ${ }^{7}$ ). - Bei einzelnen Säugethieren bleiben aber die Schaambeine etwas von einander entfernt oder werden nur durch laxe Bandmasse beweglich und verschiebbar unter einander verbunden 8). Auf der anderen Scite fehlt es auch nicht an Beispielen von vollständiger Verschmelzung derselben $9 \%$ - Das Hüftbeinloch ist

2) S. darüber die Zusammenstelłungen von Meckel 1. c. S. 423. und Blainville, Ostéographie (Lamantias). p. 63.

3) Vergl. 0we n, Monotremata. p. 378. Fig. 177.

4) Bei ulinchen Chiropteren, Elentaten u. A.

5) Bei den Gürtelthieren, den Faulthieren, so wie bei Myrmecoplıaga jubata und tamandua. S, die Abb. bei Cuvier, Recherches. Tab. 205. 208. 210. u. 211. und bei Pander und d'Alton, das Riesenfaulthier. Tab. VI., die Skelete d. zahnlosen Thiere. Tab. V. u. Tab. VI. e. Tab. VII.

6) Z. B. bei Pteropus, Pbyllostoma u. A. S. Abb. bei Pander und d'Alton, Skelete der Chiropteren und Insectivoren. Tab. VI. u. VII., Temminck, Monographies de Maum. Vol. I. Tab. XVI.

7) So namentlich bei den Beutelthieren, den meisten Nagern, den Wiederkïuern, Einhufern, Pachydermen.

8) Namentlich bei vielen Fledermäusen, Insectivoren (Talja, Sorex u. A.) und einigen Nagern (z. B. Cavia).

9) Bei Wiederkäuern, Einhuferu, Pachydermen u. A. 
immer einfach; sehr selten unvollkommen in zwei Theile abgeschnürt 10). - Die sonst allgemein geschlossene Pfanne bleibt nur bei Echidna nach der Beckenhöhle zu offen. - Bei jungen Säugethieren findet man am inneren Rande der Pfanne häufig noch eine distincte Ossification 11). Die Eminentia ileu-pectinea an der Verbindungsstelle von Irüft- und Schaambein ist bei einigen Säugethicren schr stark 12). - Die Beutelknochen ${ }^{13}$ ) bleiben beweglich mit den vorderen Schaambeinästen verbunden und weehseln in Betreff ihrer Länge und Stärke, sind aber bei beiden Geschlechtern glcichmässig entwickelt.

[S. ausfiuhrlichere Angaben bei Cuvier, Leçons Vol. 2. und bei Meckel, Systein Thl. 2. Abth. 2. S. 421 ff.]

\section{Von den Knochen der Extremitäten.}

§. 164 .

Mit Ausnahme der Sirenen und Cetaceen, denen die Hinterextremitäten mangeln, besitzen alle Säugethiere Vorder - und Hinterextremitäten, deren einzelne Abtheilungen einander entsprechen. Bei der Verschiedenartigkeit des Gebrauches, den die Säugethiere zu ihren mannichfachen Bewegungen (Schwimmen, Graben, Fliegen, Springen, Gehen, Greifen) von ihren Extremitäten machen, sind dieselben zwar höchst mannichfach gebildet, ohne dass jedoch die Einheit des, ihrer Anordnung zum Grunde liegenden, Planes im mindesten gestört erschiene; dasselbe System von Theilen kehrt immer, dem besonderen $Z$ wecke gemäss, welchem es einem Thiere dienen soll, entsprechend gebildet, wieder.

Der Humerus ist bei allen schwimmenden Säugethieren, und unter diesen besonders bei den Sirenen und Cetaceen, durch seine Kürze ausgezeichnet; kurz ist er auch bei den Pachydermen, den Wiederkäuern und besonders bei den Einhufern, bei welchen letzteren Thieren dafür die Mittelhand sehr verlängert ist. Durch beträchtliche Breite und starke Entwickelung seiner Muskelfortsätze ausgezeichnet ist er bei den gra-

10) So hach Meckel bei Otaria ursina.

11) Z. B. bei Raubthieren, Nagern, Beutelthieren. Ge offroy St. Hilaire hat in derselben selir unpassend einen translocirten Beutelknochen sehen wollen. Sein Vorkommen bei Beutelthieren, bei gleichzeitig vorhandenen Beutelknochen deckt den Irrthum hinreichend auf. Auch in der Symphysis ischio-pubica findet sich bei Beutelthieren bisweilen eine distincte Ossification. S. Ovven, Marsu. pialia. p. 284.

12) Jhre Spitze stellt bei jungen Thieren bisweilen eine eigene Ossification dar. Sie ist sehr stark bei vielen Beutelthieren, einigen Nagern und Chiropteren.

13) 0 wen und Laurent sehen sie als Verknöcherungen der Sehne des $\boldsymbol{M}$. aldominis obliquus externus an. Sie haben ihre Analoga in ähnlichen Kunchen der Salanander, des Strausses u. s. w. - Verkümmert sind sie, nach 0wen (Proceedings of the zool. soc. of London. 1843. p. 148.), bei Thylacinus Harrisii, wo sie durch längliche Faserknorpel ersetzt werden; sebr klein und dünn bei Myrınecobius. 
benden Thieren: den Gïrtelthicren, Ameiscnfressern, dem Schnabelthicre, und zcigt unter diesen wieder bei Talpa und Chrysochloris die auffallendsten Bildungsverhältnisse. Sonst ist er meist länglich, schlınk, cylindrisch, wenig oder schwach gebogen, mit mïssig entwickelten Fortsätzen; sehr lang und schlank ist cr bee den klelternden Faulthicren, bei Stenops, Ilylobates, so wie auch bei Galacopithecus und den Chiropteren. - Am unteren Ende des Ilumerus kommen oft cine oder zwei Ocffnungen vor; dic eine dersclben, das sogenannte Furamero supracandyloüdeumn 1), durchbohrt den Comblylus internus und dicnt gewöhnlich zum Durchtritte der Arteria ulnaris, oft auch der cntsprechenden Vene und des Nervus medianus. Die zweitc Ocffnung verbindet die vordere und hinterc Grube, dic an unteren Endstiucke des Humerus sich finden. Einc Patella brachialis 2) kömunt blos viclen Chiropteren zu. - Dic Vorderarmgegend ist bei den Chiropteren, den Galïopitheken und unter den Nagern bei Pteronys und Meriones durch ihre Länge ausgezeichnet. Sie bestcht immer aus zwci Knochen, dem Radius und der Ulna, welche letzlerc zwar gewöhnlich länger ist, als der Radius, indem sic ihn durch ihr Olccranon uiberragt, oft alser auch rudimentär wird, wie dies bei den Einhufern, den. Wiederkäuern und vor Allen bei den Chiropteren der Fall isı. Bei der letztgenannten Ordnung liegt dic Ulna als cin schr dünner, griffclförmiger, unten allmälich mit dem Radius verwachsender Knochen gewöhnlich hinter diesem und scheint einzelnen Arten sogar ganz zu fchlen. Bei den Einhufern verlängert sich das Olecranon gleichfalls in eincn dünnen Stiel, der, am äusscren und hintercn Theile des Radius gclegen, mit dicsem, ohne scin Ende zu erreichen, verschmilzt. Länger ist die Ulna bei den Wiederkäuern, wo sie als dünner Knochen bis zum Ende des Radius hinabreicht. Unter den Cetaceen sind beide Knochen beim Caschelol, unter den Pachydermen bei Hippopotamus und Dicotyles theilwcise oder ganz verwachsen. Bci den schwimmenden Säugethieren,

1) Eine Aufzählung der Säugethiere, bei denen es vorkömut, s. bei A. G. 0 tto, de rarioribus quibusdam sceleti hunani cun animalium sceleto analogiis. Vratisl. 1839. 4. p. 25. Unter den Quadrumanen gehören dahin Cebus, Callithrix, Nycticebus, Stenops, Tarsius, Galago; ferner besitzen ihn Galaeopithecus, viele Insectivoren (Sorex, Talpa u. A.), viele Ferae (Mustela, Lutra, Felis. Phoca u. A.), viele Beutelthiere, Nager, Edentaten und die Monotremen. Ueber die verschiedenen Gefässe und Nerven, welche bei verschicdenen Thieren durch diesen Canal treten, s. 0 t to l. c. p. 26. Vergl. auch \$. 198.

2) Von Meckel zuerst bei Vespertilio Vaupyrus beobachtet (System d. vgl. Anat. Thl. 2. Abth. 2. S. 375. Durch Isid. Ge offroy (Férussac, Bullet. des sc. Mars 1827. und Diction. d'hist. nat. Vol. XIV. p. G96.), R. Wa gner (Heusinger's Zeitsehr. f. organ. Physik. I. S. 593.), Temminck (Monogr. d. Manแ1. 11. 1. 52.) bei vielen andern Chiropteren beobachtet. Niumentlich bei Pteropus, Cephalotes, Rhinolophus und Vespertilio, bei welcher letzteren Gattung sic in der Sehne des M. triceps verborgen liegt. 
namentlich den Cetaceen, den Phoken, dem Wallrosse, sind beide Knochen kurz, platt, breit. Eigenthümliche Modificationen bieten, bei aufgehobener Höglichkeit der Axenbewegung beider Knochen, dieselben dar bei mehren grabenden Thieren, namentlich bei den Maulwürfen. Die freieste Beweglichkeit erlangen sie bei einigen Ferae, besonders aber bei den Beutelthieren, den Quadrumanen und dem Menschen. Die Handwurzel ist immer der kleinste Theil der Iland und besteht aus mehren, kleinen, in zwei Reihen auf einander folgenden Knochen, deren Zahl zwischen 5 und 11 schwankt; gewöhnlich sind die Knochen der ersten Ordnung grösser, als die der zweiten. Die grösste Anzahl der Knochen findet sich in der zweiten Reihe bei den Maulwürfen, deren zum Graben bestimmte Hand dadurch an Breite gervinnt. - Die Mittelhandgegend bietet in Bezug auf ihre Länge und auf die Anzahl der sic zusammensetzenden Knochen beträchtliche Verschiedenheiten dar. Sie ist ain kürzesten bei denjenigen Thieren, deren Hand blos zum Greifen und Graben dient; sehr lang bei den Chiropteren und bei den Einhufern und Wiederkäuern. Bei den der letztgenannten Ordnnng angehörigen Thieren körnmt die grösste Reduction der Mittelhandknochen vor. Es ist ein Hauptknochen vorhanden, der aus zwei ursprünglichen, aber frühzeitig verwachsenen Knochen entstanden ist. Jederseits finden sich zwei meistens sehr rudimentäre, nur bei der Gattung Moschus ausgebildetere Nebenknochen oder Griffel, so dass also die Anlagen zu vier Mittelhandknochen vorhanden sind. Entwikkelter, als bei den meisten Wiederkäuern sind die Griffelbeine neben einem einzigen IIauptmittelhandknochen (dem von den Thierärzten sogenannten Schienbeine) bei den Einhufern. - Während bei den meisten Säugethieren fünf Mittelhandknochen vorhanden sind, erscheint ihre Zahl reducirt bei einigen Edentaten und Pachydermen. - Nicht minder gross sind dic Verschiedenheiten, welche die Fingerknochen in Bezung auf Zahl und Gestalt darbieten. Die gewöhnliche Zahl der Finger beträgt fünf, wie bei den ächten Cetaceen, den Elephanten, den Monotremen, den Beutelthicren, den Nagern, den Ferae, den Insectivoren, den Chiropteren und Quadrumanen. Gewöhnlieh sind hier die vier äusseren Finger aus drei Gliedern gebildet, während der Daumen nur zwei besitzt. Eine Vermehrung der Glieder der mittleren Finger wird bei den ächten Cetaceen angetroffen; während dagegen der Daumen bei Thieren verschiedener Ordnung oft nur cin einziges Glied besitzt. Selten ist der Daumen der längste Finger, wie ber den Phoken und bei Trichecus, oder doch länger als der zweite Finger, wic bei den Chiropteren. Die der letztgenannten Ordnung angehörigen Thiere zeichnen sich durch Lünge, Zartheit und Streckung ihrer Finger aus, welche die Flughaut zwischen sich nehmen. - Die Anzahl der Finger vermindert sich in wehren Ordnungen. So schwankt sie bei den Edentaten zwischen 4 und 2; die meisten Pachydermen - mit Ausnahine der Ele- 
phanten - besitzen 4 bis 3 Finger; die mcisten Wiederkäuer - mit Ausnalıne der Camecle - haben, ausser zwei kurzen Hauptfingern, zwei verschiedentlich entwickelte Nebenfinger; die Einhufer endlieh sind dureh den Besitz eines einzigen, aus drei Ǵliedern (dem Fesselbcinc, dem Kronenbeine und dem Hufbeine) gebildcten Fingers ausgezeichnet. Sehr allgemein kommen Sesambeine, zwisehen den Mittelhandknochen und den Fingerknochen, so wie zwischen den Phalangen der Finger vor. - Bei vielen Nagel- oder Krallentragenden Säugethieren ist das Nagelglied der Finger eigenthümlich gebildet; meist ist cs vorwärts gebogen, seitlich zusammengedrückt, nach vorn mehr oder uninder scharf zugespitzt, oben uud unten mit scharfem Rande versehen. Bei: mehren Edentaten und besonders bei den meisten Ferae besitzt es an seiner Basis jederseits eine aufwärts gebogene vorspringende Plattc, zwischen weleher und dem Körper des Nagelgliedes cine Lüeke bleibt, in die das hintere Ende des Nagels tritt. Am meisten entwiekelt ist diese Nagclscheide unter den Ferac bei den Katzen, unter den Edentaten bei den Faulthieren und vor Allen bei Myrmeeoplaga jubata. Bei den Katzen bietet auch die hinterc Gelenkfläche Eigenthüinliclıkeiten dar, welche zur Aufwärtsziehung des Nagelgliedes erforderlich sind. Aufwärts geriehtet und zurückgezogen wird das Nagelglicd hier übrigens nur durch eigenthümliehe, aus elastisehem Gewebe gebildete Bänder. Bei den Faulthieren kommen ähnliche Einrichtungen vor, dureh welehe die Nagelglieder aber nicht aufwärts, sondern abwärts gekrümmt werden. .

\section{§. 165 .}

Das Oberschenkelbein ist bei den sehwimmenden Robben und Walrossen, bei den Einhufern, den Wiederkäuern und Monotremen durch seine Kürze ausgezeiehnet und wird unter den Nagern besonders bei Dipus und Mleriones, unter den Beutelthieren bei Maeropus, dann auch allgemein bei den Insectivoren und Chiropteren von den Knoehen des Untersehenkels an Länge übertroffen. Bei den übrigen Ordnungen hat es cntweder gleiche Länge mit dem. Unterschenkel, oder ist wenig länger als dieser. - Die Knieseheibe ist breil bei den Pachydermen und Einhufern; sehr stark bei den Monotremen, klein bei den Ferae und fehlt vielleicht nur einigen Beutelthieren $\left.{ }^{1}\right)$. - Von den beiden Knochen der Untersehcnkelgegend ist die Tibia immer stärker, als die Fibula. Letztere ist häufig abortiv; so bei den Einlufern, wo die allein entwickelte obere Hälfte des Knochens zugespitzt bis zur

1) Den Chiropteren, welchen man sie häufig abgesprochen lat, kömmt sie, namentlich nach den Beobachtungen von Andr. Wagner (Schreber's Säugethiere. Ir Supplemertband. S. 333 u. 334), sehr allgemein und anscleinend ohne Ausnahme z1. Unter den Beutelthieren wurde sie von 0 wen (Marsupialia p. 284) bei Petaurus, Phascolomys und Phascolarctos, so wie bei Myrmecobius vermisst. 
Mitte der Tibia reicht; noch mehr bei den Wiederkïuern, wo nul das untere Endstück entwickelt ist, das neben dem unteren Ende der Tibia liegt und mit dem Astragalus artieulirt. Auch bei den meisten Chiropteren ist nur das untere Endstiuck oder die untere Mälfte der Fibula vorhanden, welche oben zugespitzt endet. Unter den Pachydermen fehlt bei Hippopotamus das obere Endstück der Fibula. Partielle Verwachsungen der Fibula mit der Tibia kommen häufig vor; selten oben wic bei Orycteropus; meist in der unteren Ilälfte, wie bei vielen Nagern (z. B. Lepus, Dipus, Pedetes, Bathyergus, Pteromys, Cricetus, den Maiusen, Castor u. A.) und Insectivoren (Erinaeeus, Talpa, Chrysochloris, Sorex), so wie bei Tarsius unter den Quadrumanen. Bei den übrigen Säugethieren sind beide Knochen getrennt und liegen mehr oder minder dicht an einander. Bei vielen Beutelthieren findet sieh am oberen Ende der Fibula cine dem Olecranon der Ulna vergleichbare distincte Ossifiention 2); auch sind bei mehren Gattungen ${ }^{3}$ ) dieser Ordnung Tibia und Fibula in der Veise mit einander verbunden, dass dem Fusse eine rotirende Bewegung, :ihnlich der Pronation und Supination der Hand möglich wird. Sie besitzen meist zugleich einen gegenüberstellbaren Daumen und sind daher auch Pedimana genannt worden 4 ). - Die Fusswurzelgegend ist meistens kurz; nur bei Tarsius und Otolienus, unter ausserordentlicher Entwickelung des Fersenbeines und Kahnbeines, ungewöhnlich verlängert. Die Zahl der Fusswurzelknochen schwankt zwischen $\mathbf{4}$ und $\mathbf{9}$; ja bei den dreizehigen Fuulthieren verwachsen die beiden Keilbeine frühzeitig mit einander und mit den Yittelfussknochen, so dass im erwachsenen Thiere nur der Astragalus und Calcaneus vorhanden sind. Bei mehren Chiropteren ist das Fersenbein in einen dem Unterschenkel an Länge beinahe gleichkommenden Fortsatz ausgezogen, der im inneren Rande der Flughaut liegt. - Die Länge der Mittelfussgegend wechselt sehr; sie ist am beträchtlichsten bei den Einhufern, den Wiederkäuern, der Nagergattung, Dipus und unter den Pachydermen bei den Schweinen und Tapiren. Bei den meisten aufgeführten Thieren - mit Ausnahme der zuletztgenannten Paehydermen ist zugleieh die Zahl der Mittelfussknochen reducirt. So findet sich bei den Wiederkäıern nur einziger Mittelfussknochen; neben ihm kommen bei den Einhufern an scinem oberen Ende zwei Nebenknochen oder Griffelbeine vor; bei Dipus geht der einfache Mittelfussknochen am unteren Ende in drei Rollen aus und zeigt sich so aus drei versehmolzenen Knochen zusammengesetzt. Bei den Schweinen finden sich, ausser zwei IIauptknochen, zwei Nebenknochen. Unter den übrigen Säuge-

2) Z. B. bei Didelpliis (ursina, Philander), Dasyurus, Petaurus, Plaalangista.

3) Namentlich bei Phascolarctos, Phascolomys, Plialangista, Petaurus, Didelphis, Dasyurus.

4) Eiı soleher kömmt auch der den Nagern zugezähiten Gittung Chiromys zu. 
thieren besitzen wenige nur vier, die meisten fünf Mittelfussknochen. Bei den Faulthieren sind der äusserste und innerste der fünf Mittelfussknochen verkiurzt; sie verwachsen früh init den Fusswurzelknochen; auch die drei mittelsten Mittelfussknochen verwachsen an ihrem hinteren Ende unter einander. Bei mehren Beutelthieren, namentlich den hiipfenden Gattungen: Macropus und Hypsiprymnus, die nur vier Zehen besitzen, sind die beiden inneren Mitlelfussknochen sehr dünn, während die beiden äusseren durch ihre Stärke sich auszeichnen. - Die Zehenknochen kommen ruicksichtlich ihrer Gestalt nnd Anzahl in der Regel mit den Fingerknochen überein; so sind sie bei den Einhufern, Wiederkäuern und Pachyderınen meistens nur etwas grösser, als diese. - Unter den Edentaten haben die dreizehigen Faulthiere drei, der Unau vier, die iibrigen fünf Zehen. - Die Nager besitzen wenigstens drei, gewöhnlich vier vollkommene äussere Zehen. - Bei mehren Beutelthieren sind die beiden inneren Zehen sehr klein und diinn, während die äusseren, und unter diesen besonders die zweite, durch ihre Stärke sich auszeichnen. - Bei vielen Ferae und auch einigen Affen (Ateles) ist der Daumen verkümmert oder fehlt ganz.

\section{Vom Schedel.}

\section{§. 166.}

Dén Schedel der Säugethiere charakterisirt die mittelst zweier Gelenkhöcker Statt habende Verbindung seines Hinterhauptes mit dem Atlas, so wie die am Schedel selbst geschehende, nicht inehr durch das Quadratbein vermittelte Einlenkung des Unterkiefers. Die Gesichtsknochen sind - etwa mit Ausnahne des, in diesem Falle ganz rudimentären, Zwischenkiefers 1) - sowol unter einander, als mil den Knochen des eigentlichen Schedeltheiles unbeweglich verbunden. Selten erbalten sich Luicken zwischen ihnen. Auch sonst findet eine feste Verbindung der Kopfknochen unter einander Statt, eine Regel, welche indessen in dem blos durch fibröses Gewebe vermittelten Zusammenhange des Gehörtheiles des Schläfenbeines bei den Sirenen ınd Cetaceen eine Ausnahme erleidet. - Die Tendenz zu so vollständiger und frïhzeitiger Verwachsung der Schedelknochęn, wie sie bei den Vögeln angetrolfen wird, ist nur den Honotremen eigen, obgleich auch bei Thieren anderer Ordnungen die Nähte allmälich und bisweilen selhst spurlos verschwinden. - Bei den höheren Ordnungen der Säugethiere wird der Schedeltheil des knöchernen Kopfes inmer mehr überwiegend über

1) Eine so lose Verbindung des rudimentären Zwischenkiefers kömmt z. B. vor bei einigen Chiropteren und Edentaten, so wie auch beim Schnabelthier. Selten erhalten sich Lücken zwischen cinzelnen Gesichtsknochen; so bleibt bei vielen Wiederkäuern an stïrksten, z. B. den Hirschen, eine Lücke zwischen Stimbein, Thränenbein, Nasenbein und Oberkieferbein. 
den Antlitztheil. Doch lässt der ïussere Unfang des Schedeltheiles nicht immer auf entsprechenden Unfang der inneren, zur Umschliessung des Hirnes dienenden Ilöhle schliessen, indem die Ausdehnung der Diploc-Zellen und Hohlen, ganz besonders der mit dem Geruchsorgane in IIöhlenverbindung stehenden, oft schr beträchtlich ist 2). - Schr deutlich erscheint die Zusammensetzung des Säugethicrschedels aus drei Wirbelelementen, deren vorderstes das Os sphenoüdeum anterius ausmacht. - Viele Sïugetliere besitzen innerhalb der Schedelhöhle ein knöchernes Teutorium cerelelli; nur beim Schnabelthier findet sich eine knöcherne Sichel 3 ). - Schr bedeutend sind häufig die Altersverschiedenheiten des Schedels derselben Species 4), bedingt theils durch die verschicedenartige Ausbildung des Gebisses zu verschiedenen Lebenszeiten, theils durch die nur allmälich fortschreitende Entwickelung von Leisten und Fortsätzen, welche den Muskeln, besonders denjenigen des Unterkiefers und Ilinterhauptes, Ansatzpunkte gewähren. Wie unter den Fischen die Schollen, so sind unter den Säugethieren die meisten ächten Cetaceen durch Asymmetrie der Schedelbildung ausgezeichnet ${ }^{5}$ ). Vorzugsweise bei Thieren dieser Ordnung sind auch einzelne Kopfknochen oft schuppenartig über einander geschoben; auch erhalten sich bei ihnen, gleich wic bei manchen Phoken und wenigen Nagern, oft lange Zeit, oder perennirend, einzelne Lücken in den Schedelknochen.

2) Dies gilt namentlich z. B. vom Elephanten, von den Wiedcrkänern, von den Faulthieren u. A.

3) Das knöcherne Tentorimn cerelselli ist am meisten entwickelt bei dell Ferae, mit Ausnahme der Insectivoren; es kömmt auch vor bei den Einhufern, den Caureelen, den ächten Cetaceen, einigen Edentaten, Bentelthieren und Nagern. Es ist gewöhnlich ein Theil des Sclucitelbcines und wird balıl von ihı allein, bald in Verbindung mit dem Os interparietale orler mit deu Hinterhauptsbeine oder dem Keilbcine gebildet. Die knöcherne Sichel ist ausgebildet bei Ornithorhynchus; angedleutet bei Echidna und bei den Delphinen.

4) Dicse Altersverschiedenheiten treten an meisten hervor bei den Ferae, bei den Affen u. A. Instructiv ist in dieser Bezichung z. B. die Vergleichung junger und alter Schedel des Orang. Utang, in Temminck's und Owcn's Abbildungen. S. Temminck, Monographics de Mammalogie. T. 2. Tab. XLV. и. XLVI. und 0 wen in den Transactions of the zoolog. society of Lond. Vol. I. Tab. $48-58$.

5) Namentlieh bei den Gattungen Delphinus, Munodon, Physeter, Hypernodon. Vergl. die Abb. bei Cuvier, Recherches. Tab. 222. 223. 225. und bei Pander und d'Alton, Cetaceen. S. Näheres darüber bei J. F. Meckel, Anatomischphysiol. Beobachtungen. Halle 1822. S. 259. - System der vergl. Anat. Thl. 2. Abth. 2. S. 586. - Leuckart, Zoologisclie Brnclistücke. Hft. 2. Stuttg. 1841. 4. S. 49. In der Regel ist das linke Nasenloch weitcr, als das rechte. Die Asymmetrie erstreckt sich sonst besonders anf Zwischenkieferbein und Oberkieferbein. Die der rechten Seite angehörigen Knochen sind länger und entwickelter, als die der linken Seite. 
[Ueber den Schedel der Säugethiere handeln aul ausfülırlichsten Cuvier, Leçons d'Anat. comp. 2me Edit. Paris 1837. 8. 'T. 2. p. 158 sqq. und Meckel, System der vergl. Anatomie. Thl. 2. Abth. 2. S. 473 ff. Zablreiclıe Abbildungen s. auch in $S_{p}$ ix, Cephalogenesis. Monach 1815. Fol.; neu herausgegeben von Erdl (Tafeln zur vergl. Anato inie des Schedels. München 1842.). Vergl. auclı 0. Köstlin, Bau des knöchernen Kopfes. Stuttg. 1844. 8. S. 14 ff. - In Betreff der Abbildungen muss auch auf die Kupferwerke von Pander und d'Alton, Cuvier, Blainville und auf die zahlreichen monographischen Arbeiten ver. wiesen werden.]

\section{§. 167 .}

Trotz der grossen Mannichfaltigkeit der Formen, welche der Säugethierschedel darbietet, zeigt die Anzahl der einzelnen, in seine Zusammensetzung ursprünglich eingehenden Knochen eine wesentliche Uebereinstimmung. Die Hinterhauptsgegend wird durch die vier, bei den übrigen Wirbelthierklassen beständig vorkommenden Ossa occipitalia $\left.{ }^{1}\right)$ gebildet, welche aber meistens, obschon mit vielen Aus-

1) Die Verschiedenheittn, welche das Hinterhauptsbein bei den Säugethieren darbietet, betreffen vorzüglich die Ausdehnung und die Wölbung oder Steilheit der Schuppen, die Gestalt des Basilartheiles, die grössere oder geringere Entwickelung der Procesus jugulares s. paramastö̈dei, die Stellung und Beschaffenheit der Gelenkfortsätze, so wie endlich Stellung, For'n und Unfang des Foramen magnumn. - Die Schuppe ist an grössten und zugleich an stärksten gevölbt beim Menschen; sehr gross bei den Delphinen, bein Elephanten; sehr entwickelt auch bei Phoca und Trichecus; bei vielen Säugethieren wirl sie steil und zerfällt dann oft in zwei Abschnitte: einen oberen kleineren, zur Bildung der Schedeldecke beitragenden und einen unteren, grïsseren, der die Hinterwand bildet. So nainentlich bei den Wiederkäuern, den Einhufern, wehren Pachylermen, den meisten Edentaten; oft beschränkt sie sich, steil und gerade werdend, ausschliesslich auf Billung der hinteren Schedelwand, wie bei den meisten Pachydermen, Nagern, Beutelthieren. Die Schuppe wird oft, z. B. bei den Cetaceen, mehren Paclıydermen, einigen Ferae (den Hunden), durch das mit ihr verwachsene $O_{s}$ interparietale vergrössert. - Der Basilartheil ist breit und dünn bei den Plı. ken; noch breiter und zugleich in zwei beträchtliche Seitenflïgel ausgezogen bei den Delphinen; eigenthümlich vertieft beim Biber. - Die Processus jugulares s. paramastöidei, die Griffelfortsätze der Thierärzte, von den Occipitalia lateralia ausgehend, mit Unrecht liäıfig als Processus mastö̈dei bezeichnet (vergl. Duvernoy bei Cuvier, Leçons d'Anat. comp. T. IV. P. 1. p. 483. und Hall. in ann, Vergl. Osteologie des Schläfenbeines. Hannov.. 1837. 4. S. 7.), sind vorzüglich stark entwickelt bei den Schveinen, beim Känguruh, bei Phascolarctos, bei Hydrochoerus; weniger bei den Einbufern, Tapiren, Hippopotanns, den Wielerkäuern, den meisten Nagern, dem Wombat und den ineisten Ferae, unter denen sie den Amphibiensäugethieren fehlen. - Die Gelenkhöcker sind am meisten nach unten gerückt beim Menschen; gross, flach, breit bei den Delphinen; aus zwei unter einem Winkel in einander übergehenden Flächen gebildet bei den meisten Wiederkänern; bei einigen derselben (z. B. den Cameelen, den Antilopen) dicht an einander gerückt; bei den Monotremen gross und sehr genähert; fast quer steheud bei den Chiropteren. - Das Foramen magnum, gewöhnlich um. schlossen von allen Stiicken des Hinterhauptsbeines, seltener mit Ausschlıss der 
nahmen, bald unter einander verwachsen. Fortsätze des Hinterhauptsbeines, welche beim Menschen sehr schwach entwickelt sind, bei vielen Säugethicren aber ausserordentlich stark hervortreten, sind die Processus jugulnres. - Das Keilbein 2) besteht - wic beim Menschen fruhzeitig - aus zwei an einander sich schliessenden Körpertheilen: dem Os sphenoüdeum anterius und posterius, welche häufig perennirend sich getrennt erhalten. Dem hinteren Keilbeinkörper gehören die Alae tempornles und dic absteigenden Fortsätze an, dem vorderen die, nicht selten beträchtlicheren Alae orlitales. - Die Schläfengegend ${ }^{3}$ )

Schuppe, wie bei den Sirenen, vielen Wiederkäıern, Nagern und Beutelthieren, oder mit Ausschluss des Körpers, wie bei einigen Cetaceen, ist durch seinen Umfang besonders ausgezeichnet bei den Chiropteren und den Delphinen; am meisten an die untere Schedelfläche gerückt und horizontal gestellt ist sie beim Menschen, von dem die Affen in dieser Hinsicht nur allmälich sich entfernen; senkreclit schon bei den Halbaffen und den übrigen Säugethieren; nach hinten geneigt bei vielen Nagern, einigen Insectivorell, den Chiropteren. - Die vier Elemente des Hinter. hauptsbeines haben nicht bei allen Säugethieren gleich starke Neigung zur Verschmelzung unter einander, sondern bleiben, z. B. bei vielen Beutelthieren, bei Manatus u. A., lange und perennirend getrennt.

2) Das vordere und hintere Keilbein bleiben bei den Säugethieren in der Regel sehr lange oder imner nur durch Synchondrose verbunden und unverwachseu, während ihre Verschmelzung beim Menschen frühzeitig Statt hat. Das letztere gilt auch von den Sirenen. Schnell erfolgt sehr allgemein die Verwachsung des hinteren Keilheinkörpers mit dem Basilartheile des Hinterhauptsbeines. Häufig z. B. bei den Cetaceen, Wiederkäuern, Einhufern, Paehydermell, ist das vordere Keilbein grösser als das hintere, welches jenes dagegen bei den Nagern, den Eilentaten, delı Ferae überwiegt. Bei fast allen Beutel. thieren, mehren Insectivoren (z. B. Erinaceus), den Halbaffen u. A. tragen die Fliigel des hinteren Keilbeines zur Unrschliessung der Trommelhölle bei. Siehe Näheres bei Owen, Marsupialia. p. 271. - Das vordere Keilbein dient immer zum Durchtritte der Sehnerven. Oft sind die Foramina optica nur durch eine schmale Scheidewand von einander getrennt, wie z. B. hei Cebus, Callithrix, Pteropus; bisweilen fliessen sie selbst zusammen, z. B. bei Lepus, Pedetes.

3) Ueber das Schläfenbein s. d. a. Schrift von Hallmann. S. 3. Vergl. auch §. 1S5. - Dass der Processus styliformis des Menschen und mancher Säugethiere, z. B. der Orangs, einiger Pachydermen u. A., nicht eigentlich dem Schläfenbeine, sondern dem vorleren Zungenbeinhorne angehört, hat Hall in an 1. c. S. 10 aus einander gesetzt. S. \$. 168. Die einzelnen Elemente des Schläfenbeines bleiben hïufig unverschmolzen, mit Ausnahme der Pars mustö̈dea, die bei den ächten Cetaceen (vielleicht mit seltenen Ausnahmen, wohin nach $\mathrm{Cu}$ vier, Leçons. II. 1) 374. Delphinus uicropterus gehört) und bei den Monotremen fehlt, sonst aber sehr allgemein frühzeitig mit deın Felsenbeine versehmilzt. Dass dies aueh von wehren Pachylermen (Schwein, Elephant, Hyrax) gilt, bei denen Hall mann die sehr kleine Pars mastö̈ea geläugnet hatte, haben 0 tto (De rarioribus quibusdam sceleti hmmani cum animalium sceleto analogiis. Vratislav. 1839. 4. 1. 14.) und Köstlin (Bau des knöchernen Kopfes. S. 150.) bereits gezeigt. Bei den Sirenen, bei der Mebrzahl der Beutelthiere, len Monotremen, den Insectivoren, bei Lemur u. A. erhalten sich die Ossa tympanica als getrennte Knochenstücke; bei fast alleu Säugethieren gilt dies von der 
wird in der Regel urspringlieh dureh vier Knoehen gebildet: 1) der getrennt bleibenden Schuppe mit ihrem Jochfortsatze, weleher der Unter. kiefer eingelenkt ist; 2) dem Os tympanicum, das ebenfalls oft perennirend als getrennter Knoehen sieh erhïlt; 3) dein Os mastoüdeum, das nieht zu den beständig anwesenden Theilen gehört und wenn es, wie gewöhnlieh, vorhanden ist, mit dem Felsenbeine frühzeitig verwächst; 4) dem Os petrosum. - Die oberen Sehlussstücke 4) der Schedel-

Squama temporalis. Der permanenten Trennung des Gehörtheiles oder des Os tympanicum und Os petrosum vom übrigen Schedel bei den Cetaceen geschah schon früher Erwälınung. - Der Processus mastö̈deus ist von sehr ver. schiedener Stärke; sehr entwvickelt bei den meisten Affen, bei Trichecus; ziemlich stark bei Ursus, Meles, Phascolonys, vielen Nagern. - Selten besitzt die Par's mastoïdea Zellen, wie bei Pedetes, Dipus Sagitta, einigen Beutelthieren. - Ueber das Paukenbein und die Bulla ossea vergl. §. 185̃. - Die Syuama temporalis besitzt bei keinem Säugethiere gleiche Ausdehnung, wie beim MIen. schen, dem die Affen zunächst stehen; bei den Einhufern, Pachyderınen, dem Känguruh, den Chiropteren, besonders aber bei den Wiederkäuern und Cetaceen, trägt sie nur sehr wenig zur Begrenzung der Schedelhöble bei. Bei vielen Säugethieren (schon bein Climpanze, mehren andern Affen, den meisten Nagem u. A.) stösst sie vorn an das Stirnbein. An der Wurzel des Jochfortsatzes findet sich die Gelenkfläche für den Unterkiefer. Diese bietet, je nach der verschiedenartigen Bewregungsweise des Unterkiefers bei den Ferae, den Nagern, den Wiederkäuern u. s. w. grosse Verschiedenheiten ibrer Anordnung dar. Zur Begrenzung derselben tragen bei den Pachydermen, Nagern und Beutelthieren auch noch das Jochbein oder bei letzteren selbst die Ala temporalis des Keilbeines bei. Duvernoy (Cuvier, Leçons d'Anat. comp. Vol. IV. P. 1. p. 98.) fand bei $\mathrm{Hy}$. drochoerus (Cabiai) den Gelenktheil von der Sypama temporalis getrennt. Der Jochfortsatz selbst ist enorm bei Manatus, stark beim Dügong und bei den meisten ächten Cetaceen. Bei vielen derselben erreicht der Jochfortsatz des Schläfenbeines beinahe ganz den des Stirnbeines und so entstehen zwei Jochbogen, von denen der eine durch diese Fortsätze, der andere durch die dünnen Jochlbeine gebildet wird.

4) Häufig verwachsen die beiden Scheitelbeine in der Mittellinie sehr früh mit einander; so bei den Sirenen, bei den Wiederkäuern, Einhufern, den meisten Pachydermen, den Monotremen, mehren Edentaten, vielen Ferae, einigen Beutelthierell u. s. w. An die Stelle der Sutura sagittalis entwickelt sich oft, wie z. B. bei vielen Ferae, bei Didelphis, Arctomys u. A. eine beträchtliche Crista sagittalis. Bei den Delphinen sind die Seitentheile der Scheitelbeine hreit, aber ganz auf die Schläfengegend beschränkt; ihr zwischen Stirnbein und Hinterhauptsschuppe gelegener Theil erscheint nur als schunaler Streifen und beide Scheitelbeine erreichen einander, ähnlich, wie bei vielen Fischen, in der Mittellinie nicht. Auf diese Weise kominen Stirnbein und Hinterhauptsschuppe in Berührung. Bei jungen Thieren liegt das Os interparietale dazwischen. Den ächten Cetaceen nähern sich Bos und Ovis, wo die Scheitelbeine in der Mittcl. linie sehr verschnälert sind. In Gegensatze dazu sind bei den meisten Nagern und bei vielen Beutelthieren die Seitentheile der Scheitelbeine sehr zurïckgetreten. Seitwärts vergrössern sich die Scheitelbeine bei den Ferae und Quadrumanen.Ueber das Os interparietale handeh, ausser $\mathrm{Cuvier}$ und $\mathrm{Mcckel}$, G. Fischer, de osse epactali s. Goethiano. Moscov. 1811. Fol., Leuckart in seinen zoolog. 
höhle sind nindestens die beiden Sclieitelbeine und die beiden Stirnbeine; bei vielen Sïugethieren aber findet sieh zwisehen deul oberen Rande der Hinterhauptssehuppe und den beiden Scheitelbeinen ein eigener Knochen: das Zwisehenscheitelbein: Os isoterpurietale. Er verschmilzt entrveder ziemlich frühzeitig bald mit der Ilinterhauptsschuppe, bald mit den Scheitelbeinen, oder bleibt fast während der ganzen Lebensdauer ein selbstständiger Knochen. Kleine aecessorische Knoehen der Fontanellen werden bei manehen Säugethieren melir oder minder beständig beołaehtet. - Das Siebbein ${ }^{5}$ )

Bruchstücken. Hft. 2. Stuttg. 1841. 4. und 0tto 1. c. p. 4. Es ist mehr oder minder beträchtlich bei Sängethieren aller Ordnungen angetroffen; namentlich bei allen Cetaceen, Wiederkäuern (auch bei Auchenia), bei mehren Pachydermen, einigen Edentaten (vielleicht nur ausnahmsweise; Rapp sah es nie; ich finde es bei Dasypus novemcinctus, Myrmecophaga didactyla, Choloepus didactylus; Meckel sah es beim Ä̈, wo ich es vermisse), den Nagern, den meisten Beutelthieren, den Ferae (aber nicht bei Phoca und Trichecus), einigen Chiropteren und Quadrmuanen (constant z. B. beiın Chimpanze). Beim Hunde entsteht es aus einem einfachen Kern; bei anderen Säugethieren (Nager, Wiederkäuer, Pferd) aus zwei Seitenhälften. Häufig, z. B. bei den Nagern, den Wiederkäıern, verschmilzt es zunäcbst mit den Scheitelbeinen; bei anderen, z. B. den Delphinen, einigen Pachydermen, den Hunden u. A. unit der Hinterhauptsschuppe. Bistveilen liegen kleinere Fontanellknochen vor ihu (Pferd, Woubat, Didelphis, Biber, Katzen, Hunde). Kleine Ossificationen kommen auch in den übrigen Fontanellen bisweilen vor, z. B. in der vorderen (Cebus, Ateles, Erinaceus). S. darüber Leuckart l. c. S. 51. - Das Stirubein verliert vou Menschen abrvärts sehr bald seinen verticalen Theil ganz und wird auf seinen horizontalen Theil reducirt. Es wird bei den Delphinen fast ganz rom 0 berkiefer bedeckt, während es bei den Walen über einen grossen Theil des Oberkiefers sich erstreckt. Bei denjenigen Wiederkäuern, welche Hörner tragen, läuft es am hinteren Ende seiner oberen Fläche in einen längeren, gewölınlich (mit Ausnahue von Antilope) hohlen, mit den Stimhühlen communicirenden Zapfen aus; bei denjenigen, welche ihr Geweih abwerfen, ist der Fortsatz gewölnnlich kurz, platt, solide. Bei der Giraffe erhält er siclı lange als distincte Epiphyse; er entsteht hier als ein beweglich mit dem.Pericranium verbundener Knorpel (s. Owen, Transact. of the zool. soc. of London. Vol. III. p. 26. Tab. II. Fig. 4.). Bei den zweigehörnten Rhinoceros-Arten trägt das Stimbein auf einer rauhen Erhabenheit das hintere Horn. Nur bei einigen Säugethieren (Monotremen, Rhinoceros, Elephas, Insectivoren, Chiropteren, Quadrumanen) verwachsen die beidell Stirnbeine frühzeitig unter einander.

5) Das Siebbein ermangelt, mit Ausnahme der Affen und einiger Gürtelthiere, sehr beständig der Lamina papyracen und trägt daher meist nicht zùr Begrenzung der Augenhöhle bei. An eigenthümlichsten verhält es sich bei den Delphinen und dem Narval, wo seine sngenannte Lamina crilıros nicht durch. lächert ist; zugleich fehlen hier die oberen Muscheln und die Siebbeinzellen. Durchbrechung der Lamina cribrosa und Muscheln fiulen sich dagegen bei den Walen (s. die nälıere Beschreibung bei Köstlin S. 90). Vorhanden sind sie auch bei Manatus und Halicore. Ornithorlynchus besitzt, statt zahlreicher Siebbeiulöcher, die bei Echilna vorkolmmen, zwei grössere. 
birtet in seinem Verhalten bei einigen Gattungen bedeutende Eigenthümlichkeiten dar.

Zu diesen eigentlichen Schedelknochen kommen die dem $\Lambda$ ntlitz und den Kiefern angehörigen. Es sind dies : 1) die sehr verschiedentlich entwickelten Nasenbeine ${ }^{6}$ ) 2) die Muschelbeine 7 ); 3) der einfache Voiner ${ }^{8}$ ); 4) die, selten fehlenden, Thränenbeine 9); 5) die Jochbeine ${ }^{10}$ ),

6) Die Nasenbeine sind zwar gewöhnlieh paarig, verwaehsen jedoeh, na. mentlich bei den Affen der alten Welt, bei einigen Inseetivoren, und bein Rhinoeeros früh zu einem Knoehen. Gewöhnlich bilden sie eine mehr oder minder ausgedehnte Bedaehung der Nasenhöhle; aher bei den äehten Cetaecen, besonders bei den Delphinen und deın Narwal, überragen sie die Nasenhöhle nieht, sondern liegen nach hinten gerüekt, als unbedeutende aber ziemlich dieke Knoehen vorn auf den Stimbeinen. Aehnlich verkümmern sie bei einigen Phoken, z. B. bei Phoca leonina. Bei einigen Säugethieren, namentlich z. B. bei den Faulthieren, beiın Hasen u. A. gehen von der inneren Oberfläche der Nasenbeine musehelförmige Verlïngerungen aus.

7) Ueber die unteren Muscheln vergl. §. 183. Die Muschelbeine der Delphine sind repräsentirt dureh zwei kleine, hinter den Zwisehenkieferbeinen ain Vorderrande der Nasenöffnung gelegene rundliche Knöehelehen.

8) Er weehselt sehr in Länge und Höhe. Sehr gross bei den ächten Cetaeeen; bei Delphinus phocaena tritt er vor dem vorderen Kieilbeine, unter dem Siebbein sehr wenig an die innere Schedelhöhle; hinten verlängert er bei den Delphinen die Mitte des knöehernen Gaumens ein wenig.

9) Das Thränenbein fehlt den Delphinen, den Phoken, deın Walross, und, falls es nieht etwa früh mit deın Oberkiefer versehmelzen sollte, bei Manis. Es ist klein und undurehbohrt bei den Walen, den pflanzenfressenden Cetaceen, den Elephanten. Bei den Affen und dem Menseben ist es klein und tritt ganz in die Augenhöhle zurüek; sein Antlitztheil ist unbeträehtlich bei den Ferae, den Nagern, den Beutelthieren, den Faulthieren. Bei den Einhufern, den Wiederkäuern, den meistell Paehydermen, so wie unter den Edentaten bei Myrnecophaga, Dasypus, Oryeteropus, ist, neben dein Angenhöhlentheile, auch der Antlitztheil sehr entwiekelt, der unter einem Winkel in jenen übergeht. Bei den Hirschen, den Antilopen, den Sehaafen ist der Antlitztheil zur Aufnahme von Hautdrüsen sehr vertieft.

10) Das Jochbein zeigt hinsichtlieh seiner Ausbildung beträchtliche Verschiedenheiten. Bei wenigen Säugethieren (Eehinops, Centetes, Sorex und Manis [wo Köstlin 1. e. S. 108. aber ein Rudiment gefunden zu haben seheint]), fehlt es; wahrscheinlich auch bei den Monotremen ( 5 . 0 we n, Monotremata. p. 370. 373.). Bei inchren Edentaten (Myrnecophaga, Faulthiere) erreicht das rom Oberkieferbeine und Thränenbeine ausgehende Jochbein hinten den Joehfortsatz des Schlä. fenbeines nicht und ist nur dureh Ligament mit ihm verbunden. Sonst erstreckt es sieh vom Oberkieferbeine allein, oder von diesein und deın Thränenbeine aus, zum Joehfortsatze der Schläfenschuppe; beim Menschen, den Affen, bei Galaeopitheeus, den Einhufern, den Wiederkäuern und bei Hippopotanus verbindet es sich durch einen aufsteigenden Stimfortsatz unit dem Jochfortsatze des Stimbeines. Bei einigen Ferae (Felis, Herpestes) ist der aufsteigende Fortsatz sehr entwickelt, erreicht jedoeh das Stirnbein nieht. Bei Delphinus und Monodon rerlängert sich der viel diekere (von Meckel deın Thränenbeine vergliehene) Körper stielförmig vom Oberkiefer und Stirnbein aus zmm Joehfortsatze des Schläfenbeines hin. Bei Trieheeus köınmt bisweilen noeh ein accessorischer, deın Jochbeille aufsitzen. der kleiner Ḱnochen vol. 
welche bisweilen abortiv sind und bei einigen Thieren völlig vermisst werden; 6) die Oberkieferbeine ${ }^{11}$ ); 7) die Zwischenkiefer ${ }^{12}$ );

11) Das Oberkieferbein besteht aus den beträchtlichen Antlitztheile und dem horizontalen Gaumentlieile. Bei den ächten Cetaceen ist es durch seinen Umfang ausgezeichnet, bedectit namentlich bei den Delphincn, deın Narwal u. A. mit dem breiteren hinteren Absclınitte seines Antlitztheiles das Stimbein fast ganz, wälrend es bei den Walfischen von dem letzteren Knochen grossentheils bedeckt wird. Bei Hyperoodón (s. Cuvier, Recherches. Tab. 225. Fig. 20.) verleihet es durch einen steilen Kamın, weliheı es bildet, dem Schedel eine sehr eigenthüın. liche Forn. Bei den meisten ächten Cetaceen (iın höchsten Grade bei Platanista) verlängern sich die beiden 0 herkieferbeine inehr oder uninder schnabelförulig nach vorn und nehmen die Zwischenkieferbeine fast ganz oder grösstentheils zwischen sich. Sehr lang sind sie auch bei einigen Edentaten, namentlich Dasypus und besonders Myrmecophaga. - Eine Eigenthümlichkeit des Hasen ist es, dass der Antlitztheil des 0 berkieferbeines aus einem von zahlreichen Lücken durchbrochenell Knochengewebe besteht. - Das Unteraugenhöhlenloch ist nicht immer ein. facl, sondern oft inehrfach vorhanden. Bei vielen Nagern hat das, die Basis des Jochfortsatzes durchbohrende und dieselbe in zwei Schenkel spaltende Unteraugenhöhlenloch eiıen enormen Unfang. So besonders bei Dipus, Hystrix, Coelogenys, Cavia, Dasyprocta u. A. Diese Vergrösserung der genannten Oeffnung hangt mit einer eigenthüulichen Anordnung des MIusculus masseter zusaumen, der aus zwei Portionen besteht, von denen die kleinere (der M. mnndilualomaxillaris, Cuvier, Leçons. Vol. 4. P. 1. p. 67.) vom Antlitztheile des Oberkiefers entspriugt und durch jenes Loch zum oberen Rande des Unterkiefers tritt, wo sie sich inserirt. Vergl. \$. 178. Bei manchen Nagern (Dipus, Coelogenys) wird das eigentliche Foramen infraorlitale von dem Muskelloche durch ein knöchernes Septum geschieden. Enorm ist das Foramen auch bei Manatus.

12) Die Zwischenkieferbeine bieten rücksichtlich ihrer Grösse und Gestalt beträchtliche Verschiedenheiten dar. Bei den meisten Säugethieren besitzen sie, mehr oder minder entwickelte Nasen- und Gaumenfortsäıze. Ganz rudimentär sind sie bei viclen Chiropteren und einigen Edentaten. Bei Vespertilio bleiben die beiden Zwischenkieferbeine durch eine weite Lücke von einander getrennt. Knorpelig bleiben sic bei Taphozous und Megaderma. Oft sind sie bei Thieren dieser beiden Ordnungen nicht durch Naht, sondern nur durch Banduasse mit dein vorderen Theile des Oberkiefers verbunden; so unter den Chiropteren bei Nycteris, Rhinolophus und besonders - zugleich beweglich - bei Hypoderma; unter den Edentaten bei Bradypus und Myruecophaga. Schwach entwickelt sind sie auch bei Manis; ausgebildeter bei Dasypus und Orycteropus. Der Alveolartheil der Zwischenkieferbeine trägt entweder die Schneidezähne oder ist zahnlos; letzteres hei den ineisten ächten Cetaceen (die Delphine besitzen jelloch anch ein Paar Scbneidezähne), fast allen Wiederkäıern (mit Ausnahme von Camelus und Aucheuia), den Monotremen, fast allen Edentaten (mit Ausnahue von Dasypus sexcinctus), wenigen Pachydermen unl Chiropteren. Dessenungeachtet sind sie bei den Wiederkäuern u. A. sehr entwickelt. Aın unfänglichsten sind sie bein Dügong. In Ganzen selten sind die Intermaxillarknochen zwischen den Oberkieferbeinen eingekeilt; grösstentheils z. B. bei den Delphinen; Schildkröten-ähnlich bei Trichecus. - Nur bei Echidna treten die Nasenäste der Zwischenkieferbeine in der Mittellinie vor den Nasenbeinen zusammen und schliessen die Nasenöffnung ein. - Die Foramina incisiva s. palatina anteriora liegen bald ganz im Zwischenkiefer, wie bei vielen Nagern, bald werden sie hinten von den 0berkieferbeinen begrenzt. Sie sind bald einfach, bald doppelt; oft, wie namentlich bei den 
8) die Gaumenbeine ${ }^{13}$ ); 9) die Ossa pterygö̈lea ${ }^{14}$ ), welche gewöhnlich an die absteigenden Fortsätze des hinteren Keilbeines sich anlegen und selten den knöchernen Gaumen seitlich verlängern. Sie verwachsen selten, und, wenn die Verwachs!ng erfolgt, erst spät. 10) Der Unterkiefer ${ }^{15}$ ). - Accessorische Knochen, welche nur ein-

Sirenen und Wiederkäuern sehr gross, bisweilen zu Canälen verlängert, wic beim Elephanten. - Vergl. Leuekart, Untersuchungen ïber das Zwisebenkicferbein des Menschen. Stuttg. 1840. 4. S. $67 \mathrm{ff}$.

13) Dic Gaumenbeine sint in ihrelı Gaumentheile bei den Beutelthieren ganz allgeulein von 0 effnungen durchbrochen. Diese sind zahlreich und klein bei Ma. cropus gigantels, Hypsipryınus, Didelphis 0possum u. A.; grösser bei anderen Arten von Macropus; sie werden bei den meisten Gattungen, z. B. bei Phascolomys, Dasyurus, Thylacinus, Phaseogale u. A. zu beträchtlichen Lücken und Spalten und erreichen ihren grössten Unfang bei Peranreles und Acrobates. S. die Abb. bei Temininck, Monogr. d. Mammalog. Vol. 1-7.; bei 0 wen, Marsupialia. p. 270. Fig. 94. und p. 274. Fig. 96. Andere Abb. bei Pander und d'dl. ton, Skelete der Beutelthiere. Bonn 1828. - Bei den Nagern sind die Ḱnochen schmal; breit bei den Delphinen; verlängert bei Myrinecophaga, Dasypus.

14) Dic Ossa pterygoidea entsprecheu den Alae pterygoidere internae des Menschen, welche auch beim menschlichen Fötus getrennte Knoclienstücke sind. Sic erhalten sich bei Säugethieren jeglicher Ordnung perennirend getrennt oder verwachsen erst schr spät. Bei der Gattung Myrmecopbaga (wenigstens bei jubata und tamandua), bei einigen Gürtelthieren, bei Echilna und hei mehren ächten Cetaceen tragen die Flügelbeine zur Verlängerung des knöchernen Gaunens bei. Bei den Ameisenfressern legen sich dic Innenränder beider Flügelbeine an einander. Bei den Delphinen verbreitert jedes der sehr grossen Flïgelbeine erst die Schedelbasis und tritt dann, in zwei, eine Höhle einschliessende Blätter gespalten, vorwärts und abwärts, um den knöcherıen Gaumen seitwärts und hinten zu vervollständigen.

15) Der Unterkiefer der Säugethiere articulirt dureh inmer berveglich eine einfache, conrexe, aber verschicdenartig gestaltete Gelenkfläche mit der Schuppe des Schlafbeines und entsteht immer nur aus z ive iS eit enhälf ten. Diese letzteren bleiben entwedel perennireud mnverwachsen oder verschmelzen bald mit einander. Ersteres ist der Fall bei den meisten ächten Cetaceen, bei den Sirenen (mit Einschluss von Manatus, wie ich an mehren Exemplaren sehe), bei den Wiellerkäuern (uit Einsehluss von Moschus und Tragulus, indessen mit Ausnahme von Camelus und Auchenia), bei den Monotremell, den Beutelthieren, bei den Eslentaten (mit Ausnahme der Faulthiere), bei den Nigern, den Ferae (Init Ausnahme von Trichecus), den Halbaffen; frïhe Verschuelzung hat Statt, ausser bei den sehon nambaft gemachten Gattungen, auch bei den Einhufern, den Pachydermen, den Chiropteren, den Affen und dem Menschen. - Die Strecke, in welcher die beiden Unterkieferhälften einander unmittelbar berïliren oder selbst mit einaniler verwachsen, verlängert sich bei Manatus und bei einigen ächten Cetaceen bedeutend; so bei Hyperoodon in fast $\frac{1}{3}$ ihrer Länge; bei den Delphinorlynchi, bei Physeter; besonders aber bei Platanista gangetica. - Bei den Delphinen, dem Narwal, dem Caschelot besteht jede Unterkicferhälfte hinten aus cinem einfachen äusseren Knochenblatte; weiter vorn tritt ein inneres Knochen. blatt hinzu; zvisehen beiden bleibt cine weite, mit Fett ausgefülte Höhle, die erst vorn verscliwindet. Bei mehren Walfisclien ist der.Unterkiefer auswärts gebogen und erstreekt sich seitwärts weit über den Oberkiefer hinaus (s. z, B. 
zelnen Gattungen zukommen, sind: das Os praesasale 16) der Faulthicre; das Os praemaxillnre ${ }^{17}$ ) des Schnabelthieres; der Rüsselknochen 18) der Schweine, Maulwürfe u. A.

\section{Vom Zungenbeinc.}

\section{§. 168.}

Das Zungenbein der Säugcthiere besteht aus dem Körper und den sogenannten Hörnern, deren gewöhnlich zwei Paar vorhanden sind. Die vorderen oder kleinen Hörner sind an der Prrs petrosa des Sclliafenbeines suspendirt 1), während die hinteren Itörner durch die Ligamenta hyo-thyreoielea lateralia mit den oberen Hörnern des Schildknorpels verbunden zu sein pflegen. Die Verschiedenheiten, welche das Zungenbein bei den Säugethieren darbietet, betreffen vorzüglich die Form seines Körpers, die Verbindungsweise seiner vorderen Hörner mit dem Scliedel und das Verhalten seiner hinteren Hörner. Die Gestalt

die Abb. bei Cuvier, Recherches. Tab. 226.). - Nirgend ist der Unterkiefer verhältnissuässig so schwach entwickelt, als bei Echidna, wo seine beiden, nur durch Band schwach verbundene Hälften zwei dünne Kicle darstellen und der Processus coronoüdeus blos angedeutet ist. Ain nächsten stehen der Echidna in dieser Beziehung viele Edentaten, besonders Myruecophaga und Manis. Bei vielen Säugethieren, namentlich bei den Nagern, den Faulthieren, den Beutelthieren besitzt der Unterkiefer einen melır oder minder starken Winkelfortsatz; derselbe ist besonders beträchtlich bei den Nagern, wo er nach hinten gebogen ist; bei allen Beutelthieren ist er einwärts gebogen. - Bei deu Nagern findet sich an der inneren Fläche des Unterkiefers ein starker Vorsprung, der vom vorderen Ende bis gegen die hinteren Backzäbne reicbt. - Die Säugethiere besitzen allgemein einen deutlichen, of nur schwach angerleuteten, meist (Einhufer, Wiederkäuer, Beutelthiere etc.) stark entwickelten Kronenfortsatz. - Immer treten durch eine Oeffunug, die in ver hinteren Gegend der Innenfläche jedes Astes sich befindet, Gefässe und Nerven ein, welche durch Deffnungen, die vorn an der Aussenfläche vorkommen, vieder austreten. - Nur der Mlensch besitzt, durch den vorn vorspringenden unteren Rand des Unterkiefers, ein vorspringendes Kinn.

16) Es liegt unmittelbar vor den Nasenbeinen als unpaares Knöchelchen bei allen Faulthieren. Rapj fand ein ähnlicbes Knöchelchen bei Dasyjus. Abgebildet bei Ra p 1', Elentaten. Tab. 3. Fig. 2. 3. b.

17) Abb. bei Mecke1, Ornithorhynchus. Tab. IV. Fig. 1. b. - Cuvier, Recherches. Tab. 21 s.

18) Abb. rom Rïsselknochen des Maulwurfes bei Pander und d'Alton, Skelete der Cliropteren und lisectivoren. Tab. IV. - 0 wen hat auch bei einem Beutelthiere, Perameles lagotis, zwei kleine Verknöcherungen im Nasenknorpel angetroffen.

1) Nach Hallmann (Vergleichende Osteologie des Sclulaifenbeines. S. 11.) soll bein Delphin das Zungenhein an die Pars lateralis Ossis occipitis sich inseriren. Ich finde jedoch sowol bei Delphinus phocaena als bei Monodon die gewöhnliclie Anheftungsweise und zwar nicht allein beim Fötus, sondern auch bei erwachsenen Thicren; bei Heransmahne des locker dem Schedlel verbundenen Geliörtheiles des Schläfenbeines bleibt das Zungenbein an letzterem haften. 
des Körpers wechselt sehr ${ }^{2}$ ); gewölbt, ausgchöhlt, oder mit einem einwärts gerichteten Fortsatze versehen erseheint er bei den Affen, welche einen Luftsack ihres Kehlkopfes besitzen ${ }^{3}$ ); am auffallendsten ist seine Bildung bei Mycetes 4), wo er cine länglich runde, mit weiter Oeffnung versehene Blase darstellt, welche zul Aufnahme eines merkwürdigen Resonanzapparates: des unpaaren mit der Kehlkopfshölle in Verbindung stehenden Zungenbeinsackes dient. Oft ist er bogenförmig, oft prismatisch; bisweilen, wie bei den Einhufern, vorn stielförmig verlängert ${ }^{5}$ ). Die Ossa entoglossa anderer Wirbelthiere sind bei den Säugethieren oft durch einen meist vorn vom Zungenbeinkörper ausgehenden fibro-cartilaginösen Streifen (die sogenannte Lytta) angedeutet 6). Die vorderen Hörner erscheinen in der Regel als eigene, dem Körper durch Synchondrose verbundene Knochenstiicke von versehiedener Länge; sehr sclten, wie z. B. bei Mycetes, werden sie vermisst. Sie sind beständig an der Pars petrosa des Schläfenbeines suspendirt. Beim Menschen, den Orangs und einigen Pachydermen haften sie an den Griffelfortsätzen (Processus' stylliformes) des Schlïfenbeines. Dies sind aber dem Schedel urspriinglich fremde Theile, welehe nur durch Verwachsung des verknöcherten obersten Abschnittes des ZungenbeinSuspensoriums mit dem Schedel an den letzteren gelangen 7 ). Bei den übrigen Säugethieren bleibt diese Verwachsung sehr allgemein aus. Das urspriinglich knorpelige Suspensorium wird selten ganz ligamentös, wie bei Hycetes, enthält vielmehr gewöhnlich eine, je nach der Verschiedenheit der Familien und Gattungen verschicdene, Anzahl von discreten, unter einander und mit dem Schedel durch Band verbundenen Ossificationen 8). - Die hinteren IIörner fehlen selten ganz, wie bei cinigen Nagern, Edentaten und Cetaceen, und bestehen meistens aus einfachen, mit dem Körper durch Synchondrose verbundenen Stücken. Selten sind

2) Abbildungen desselben s. bei Blainville, Ostéographie und bei Gurlt; einzelne auch bei Cuvier, Recherches sur les ossen. foss. z. B. von uehren Cetaceen Tab. 226.; andere bei Geoffroy St. Hilaire, Philos. anatomique. Tab. IV.

3) S. die nähere Besehreibung bei Brandt, Observationes anatomieae de manualiun quorundain rocis instrumento. Berol. 1816. 4. Stark gewölbt namentlich bei Ateles, Cebus; der untere, nach innen ausgehöhlte Fortsatz beson. ders bei Cereopithecus Mona, aethiops, Papio Maimon u. A.

4) S. die Abbildung dieses Zungenbeines bei B randt 1. c. Tab. 1. Fig. 1. u. 2. und bei Müller, Ueber die Compensation der pbysischen Kräfte am mensehliehen Stimmorgan. Berl. 1839. Tab. 3. Fig. 2oั.

5) S. Abb. bei Ge offroy 1. e. Fig. 33.; angedeutet ist dieser Stiel bei den ineisten Wiederkäuern, s. ebendas. Fig. 34.

6) Vergl. §. 188.

7) Vergl. Hallın ann, Vergl. Osteol. des Sehläfenbeines. S. 10.

8) Zahl und Ausdehnung derselben selıwanken sehr. S. Näheres darüber bei Cuvier l. e. Meist finden sich zwei bis drei, von denen der dem Schedel zunächst liegende als $O_{s}$ stylö̈deum bezeichnet wird. 
sie mil den körper verschmolzen. Noch seltener sind die unteren Iförner eigene, vam Körper al)gelösete Stiicke, wie bei den Honotremen 9) unil bei Manatus.

[ Him virgl. über das Zungenlein besonders Cuvier, Leçoos d'amat. comp. T. 1V. P. 1. Paris 183ว̆. P. 464 sqq. - Geoffroy St. Hilaire, Philosophie anatomique. T. 1. 1. 141. und denselben in den Nouv. Amuales d. Mnsée d’list. nat. p. 321.]

\section{Zweiter Abschnitt.}

\section{V'm!n den üusseren Hruntbedeckinngen und den drïsiggen "In der IIrntoberffiëche mïndenden Ciebilden.}

\section{§. 169.}

Die aus verschlungenen Zellgewebsfasern gebildete $\mathrm{Cu}$ tis der Säugethiere haftet ineistens innig an den unterliegenden Gebilden, namentlich an dem Fette und den selır entwickelten Hautmuskeln. Bei den Cetaceen findet sich unter ihr eine dicke Speckschicht. - Sehr selten kinn sie, an ganzen Rumpfe, den sie in diesem Falle nur lose und sackförmig unhüllt, durch von der Mundhöhle ausgehende Oeffnungen aufgeblasen werden - eine Eigenthümlichkeit, welche bisher nur bei der Chiropteren-Gattung Nycteris ${ }^{1}$ ) angetruffen worden ist. - Nur bei den Giirtelthieren hat - bei grosser Diinne der unterliegenden Cutis - die: Entwickelung eines wirklich $k n \ddot{b} c h e r n e n$, mit den charakteristischen Knochenkörperchen versehenen IIautskeletes Statt. Die Knochenschilder, welche einen grossen Theil des Rumpfes dieser Thiere bedecken, gehören also nicht den Hornbillungen an, sundern werden von lornartiger Epidermis iiberzogen.

Die grösste Mannichfaltigkeit bieten die verschjedenartigen Epidermialgebilde, so wir die rerwandten Nagel-, Horn-, Ifaar- und Stachellildungen dar. - Die gewöhnlich nicht sehr dicke Epidermis, erscheint bisweilen schivielenartig verdickt; bald an dem grössten Theile der Körperoberfläche, wic bei einigen Pachydermen, namentlich den Elephanten und khinoceros, bald nur stellenweise, wie an den Gesisssschwiclen der altweltlichen Affen, an den Brust - und Gliederschwielen der Camele, an ten Sohlenballen vieler Säugethiere. - In anderen Fällen bildet sie dachziegelfürmig sich deckende Schuppen 2). - Die

9) Bei den Monotremen verbinden sich die hinteren Hömer unter cinander und stelien in so enger Bezielıung zum Schildknorpel, dass Meckel Theile des Zum. genbeines als dem Scliillknorpel angehörig beschrichen hat. S. Cuvier 1. c. 1. 476.

1) S. Geoffroy St. Hilaire in den Ann. d. Mus. d'hist. mat. T. XX. p. 11 .

2) Z. B. bei Manis; ferner an Schwanze mehner Nager (Biber, Ratte), Insertivoren, Beutelthiere u. $\Lambda$. 
gervöhnlichste Bekleidung der Hautoberfläche bilden die II a r e ${ }^{3}$ ), deren nur wenige Säugethiere gänzlich ermangeln und die bei anderen durch Stacheln vertreten werden, oder mit letzteren zugleich vorkommen. Die Bildung der Ilaare geschieht vom Grunde der Cutis aus, in welcher sie init ihrem Balge stecken, durcì eine gefässreiche Pulpa, die in die Höhle des Iaarknopfes eindringt und bei stärkeren Haaren oft weit aufwürts sieh erstreekt. Dicke und Stärke der Haare sind sehr verschieden und die letzteren führen, zum Theil je nach ihrer verschiedenen Dieke, zum Theil aber auch je nach ihrem Vorkommen an bestimmten Stellen des Körpers, verschiedene Benennungen. Durch Dicke, Derbheit und Steifigkeit ausgezeichnet sind die z.1 'Tastapparaten entwickelten Spürhaare, deren Pulpa Faden vom $\boldsymbol{N}$. Irigemimus erhält und deren muskulöser Bewegungsapparat unter Einfluss von Zweigen des $\boldsymbol{N}$. frecialis steht. - Form und äussere Umrisse der ffarie sind mannichfach. Die äussere Oberfläche ist eben oder uneben. Diese Unebenheit riihrt oft her von üusseren Wiilsten, ästigen, knotigen oder dornartigen Fortsätzen, welche entweder einseitig oder beiderseits bervortreten. Die Ilaare bestehen aus Rinden- und Marksubstanz, von der die erstere häufig noch wenigstens in der Wurzelhälfte oder am Sehafte einen Epithelialubberzug besitzt. Die genannten beiden Bestandtheile des Ilaares können in den verschiedenartigsten Verhältnissen zu einander stehen; häufig bildet das dunkele Mark Querstreifen und Ringe. - Die Staeheln sind von den IIaaren nieht wesentlich versehieden, und bestehen aus denselben Substanzen. Bei Ilystrix treten von der Spitze der Pulpa aus viele parallele Gefässe in dic Marksubstanz hinein. -

3) Ueber die mannichfachen Haarbildungen der Säugethiere vergl. Heusinger, System der Histologie. S. $164 \mathrm{ff}$ - B. Eble, die Lehre von den Haaren. Wien 1831. 8. Thl. 1. S. 63. - Gurlt in Mïller's Archir. IS36. S. 272. Erdl, Vergleichende Darstellung des inneren Batues der Haare, in den Abhaudl. d. math. phys. Classe d. Baierśch. Acad. d. Wissensch. zu München. 184 J. Bd. 3. Abth. 2. S. 415. Sämmtlich mit Abb. - S. auch Henle, Allg. Anat. S. $292 \mathrm{ff}$. - Ueber die Stacheln vergl. noch Boeklı, de spinis hystricmm. Berol. 1834. 4. und Erdl in dem zweiten Supplementbande zu Schreber's Sängethieren. S. 14. - Interessant ist es, dass auch bei denjenigen ächten Cetaceen, die im späteren Leben keine Spur von Haarbildung zeigen, wenigstens im Fötalzustande einige Barthaare an der 0 berlippe (wie bei Inia perennirend) angetroffen werlen; so z. B. bei Delphinus phocaena; bei deın Fötus eines exotischen Delphines, den ich besitze, finde ich sie viel zalılreicher. Beim Narwal habe ich sie vermisst. Ansfïhrlichere Mittheilungen über das Vorkommen von Haaren am Schnabel der Cetaceen, besonders der Wale, gibt, wie ich nachtrïglich bemerke, Eschricht in seinen Undersögelser over Hvaldyrene. Anden Afhandling. Kjöbenharn 1844. p. 48. mit Abbildung ihrer Stellung. Tab. UII. Fig. C. - Sehr eigenthïmlich sind, nach Erdl's Beobachtung, die Haare ron Bralypus, in so ferne über ilıer ganzen Aussentläche Längserhabenheiten sich bilden, wvelche ihnen ein cannelirtes Ansehen geben. S. Erdl l. c. Tab. III. Fig. 89. 
Die Nïgel und Krallen 4) der Siiugethiere zeigen einen blätterigen Bau und werden von einer gefisssreichen Matrix aus gehildet. - Verschieden von den Niigeln zeigt sich der Ban der Hufe 5 ). Ihre Bildung lat gleichfalls von einer gefässreichen Matrix (der sogenannten Fleischkrone) aus, Statt. Verschieden gestaltete (zottenartige, fadenförmige, blatterige) gefässhaltige Fortsätze dieser Matrix dringen in hohle hornartige, unter einander durch ein mit Zellen versehenes Horngewebe verbundene Röhren und zwischen IIornblättchen, aus denen die Substanz der Itufe besteht, ein. Hornartig verdickte Epiderınis (Saumband) verbindet die Aussenfläche des IIufes nit der Oberhaut. - Innig verwandt den Hufen sind, in Bildungsweise und Bau, die Klauen 6). Eben so entstehen die IIörner ${ }^{7}$ ) der Wiederkäuer von einer, die hohlen Zapfen der Stirnbeine überziehenden Matrix aus, welche aber, statt der zottenartigen und blätterigen Fortsätze, nur unregelmässige kleine Wuilste bildet. Die Substanz der Hörner besteht aus wellenförmigen, einander einschliessenden Streifen, welche zu Bändern, die von breiteren Streifen durchsetzt werden, vereinigt sind.

\section{§. 170 .}

An den verschiedensten Gegenden der Körperoberfläche iniinden bei einzelnen Gattungen und Familien der Säugethiere die Ausführungsgïnge eigenthümlicher drüsiger Gebilde, welche meist ein schmieriges Secret absondern, das nicht selten auch einen specifischen Geruch besitzt. Bei einigen liegen solche Absonderungsorgane am Kopfe. Dahin gebören z. B. die an der Basis der Hörner mehrer Antilopen ausmiindenden, unter der Kopfhaut liegenden Drüsen, welche zur Brunstzeit anschwellen 1); die Occipitaldrüsen der Camele 2); die bei den Gattungen Cervus, Antilope und Ovis unterhalb der Orbitac in Vertiefungen der Thränenbeine liegenden Schmeerdrüsen (Folliculi und Sacci (ncrymales ${ }^{3}$ )); die bei einigen Fledermäusen beobachteten, iiher dem Alveolalrande des Oherkiefers, zwischen Nase und Auge gelegenen, cine fettige Masse absondernden Gesichtsdrüsen 4); kleinere in der Backengegend beim Murmelthiere und bei Myrmecophaga didactyla

4) S. Gurlt in Müller's Archiv. 1836. S. 263 u. 266. - Hesse, de ungularum, harbae Balaenae, dentium Ornithorhynchi penit. structura. Berol. 1839. 8. Henle, Allg. Anat. S. 270.

5) Vergl. Gurlt a, a. 0. S. 267. Tab. XII. Fig. 5. 6.

6) Vergl. Grurlt a. a. 0. S. 270 .

7) S. Gurlt a. a. 0. S. 270. Tab. XII. Fig. 7.

1) S. darüber Géné in d. Mémoires de l'académie d. scienc. de Turin. 1834.

2) Mayer (Analekten zur vergl. Anatomie. Hft. 2.) fand vier solcher Drüsen ain Hinterhaupte des Dromedars.

3) Vergl. über ihr Vorkommen bei den Antilopen die Proceedings of the zool. society of London. 1830. p. $35 \mathrm{sqq}$.

4) Beschrieben und abgebildet von Tiedemann in Meckel's deutschem Archiv f. Phys. Thl. 2. S. 112. Tab. 2. Fig. 9. 10. 
vorkommende Drüsen "); die Simus maxillures ciniger Antilopen; die in der Nïhe des äusseren Ohres z. B. bei der Gemse, bri Lemmus norwegicus 6) u. A. vorhandene Driise; die zwischen Ohr und Auge ausinündende Schläfendrüse des Elephanten T); cine Ansammlung von Schmeerdrüsen unter der IIaut des Unterkiefers bei Mosehus javanicus 8). - Bei anderen Sïugethieren finden sich dergleiclen Drüsen unter der Ilaut des Rumpfes. Dahin gehören: die am Ilalse und am Anfange der Brust liegende Drise bei der Gattung Pedimanus Temm. 9); die seillich vom Rumpfe in den IIypochondrien liegenden Drüsen, welehe z. B. (ler Gattung Sorex 10) zukommen; die bei Dieotyles in der Kreuzbeingegend vorhandene Drise $\left.{ }^{11}\right)$. - Bei einigen Säugethieren kommen dergleichen Absonderungsapparate am Schwanze vor; dahin gehörig sind die mit zahlreiehen Orificia zwisehen den Sehuppen der Sehwanzwourzel mündenden Follikel der Myogale mosehata 12) und des Macroscelides Rozeti ${ }^{13}$ ), deren Secret einen Mosehusgeruch besitzt; ferner die Folliculi sebacei unter der Haut des Schwanzes beim IIrsche 14). - Oefter kommen absondernde Driisen in der Inguinalgegend vor, wie z. B. bei manchen Nagern, \%. B. bei der Gattung Lepus 15), wo diese zusammengesetzten Follikel seitlich vor der Yorhaut miinden. Hierher gehört auch der in der Nähe der Yorhaut ausmündende, zwisehen der Ruthe und dem Nabel gelegene Moschusbentel von Moschus moschiferus ${ }^{16}$ \}, der aber nur dem männlichen

5) Vergl. T'iedemann in Meckel's deutschem Archir. Thl, 4. S. 221.

6) Ueber die Drüse bei Lemmus s. Rathke, Beiträge zur vergl. Anat. und Physiol. Danzig 1842. S. 3.

7) S. Peter Camper, léscript. d’un Élephant måle. 1. 44.

8) S. Rapp in Wicgmann-Erichson's Archiv fïr Naturgeschichte. Bd. IX. S. ริ0.

9) S. Temminck, Monographies de Manmalngie. Vol. 2. p. 3วั0.

10) Vergl. Geoffroy St. Hilaire in den Mém. Ulı Musée d'list. nat. T. I. p. 299. Diesc Drüsen sind, uach späteren Beobachtnngen von Nathusius, bei erwachsenen Männchen rorzugsweise entwickelt. Sic kommen auch bei Nagern, z. B. bei Hypulacus amplribius ror.

11) Nälıer beschrieben von Seiffert, Spicil gia adenologica. Berol. 1823. 4. 1. 10. und ron Müller, Gland. sccern. p. 41. Tab. 11. Fig. 2.

12) S. über ihren Ban, ausser den früheren Mittheilungen ron Pallas (Act. Academ. Petropolit. 1781. P. 2. 1) 320.), B rand t (in den Nov. Act. Acad. Caes. Leop. Carol. T. XVIII. P. 1. 1. 241. Tab. X.), der eine rortreffliche Beschreibung ihres feineren Baues geliefert liat.

13) Entileckt vou Andreas Wagner. S. Schreber's Säugeth. Zweiter Supplementbd. S. 85 .

14) Von Rapp beobachtet. (S. Mïller's Archiv. 1830. S. 366.) Ausserdem fand Rapp beim Hirsche ein drüsenähnliches, zum Theil gelipptes Organ unter der Hant, welches die acht letzten Schwanzwirbel umgibt.

15) S. Mïller, Gland. secern. p. 43.

10) S. Näleres bei Pallas, Spicilegia zool. fascic. XIIr. p. 39. Mit Abb. $0 \mathrm{ken}$, Isis. 1820. Bil. XIX. Hft. 8. S. 849. Nit Abb. - Brandt und Ratze- 
Geschlechte eigenthümlich ist. Er besteht in einer einfachen, durch Hautmuskellagen zusammendrücklaren, beutelförmigen, kleine Grüibchen enthaltenden Hauteinsackung. Achnliche Säicke, welclıe eine stinkente Materie absondern, sind bei cinigen Antilopen beobachtet worden. Hïufig münden pararige, ans zelligen Schliauchen bestehende, im Allgemeinen den Tysonschen Drüsen entsperchende absondernde Apparate in die Vorhaut des Penis und der Clitoris. Sie erscheinen sehr entwickelt bei virlen Nagern ${ }^{1}$ ) und sind am umfänglichsten beim Biber; wo in ilınen das bekannte Castoreun alugesondert wird. Diese Biber geilsäcke 18) miinden mit einer gemeinsamen Oeffnung in die Vorhaut und liegen unterhalb des Schàmbogens. Sie stellen birnförnigr Sacke dar und zeigen eine init zahlreichen verstreucten Griibchen versehene, derbc, gerunzclte Innenfïchc. - Sehr vicle, Süugethiere besitzen absondernde Gebilde in der Perineal- und Aftergegend 19 ). Sie sind naunntlich bei den Monotremen, Beutethieren, Niggern, Edentaten, den Insectivoren und den eigentlichen Ferae sehr allgemein vorlanden und häufig schr entwickelt. Bei der Gattung Vivcrra 20) komunen After - und Perinealdrüsen zugleich vor. Erstere bestehen in Säkken, welche seitlich voin After muinden. In jeden dieser Säcke öffnen sich zahlreiche absondernde Follikel. Die Perinealdrüsen der Viverren, deren Secret das bekannte Zibeth ist, liegen zwischen After und Geschlechtstheil'n. Eine hier befindliche Spalte führt in eine Einsackung, in welche jederscits cin weiter Schlauch einmündet. Bcide: der gemeinschaftliche Sack und die beiden Schläuche sind inwendig brlıart und zahlrciche zusanmengesetzte Follikel münden an der Innenwand der letzleren. Die äusseren Bedeckungen der Schläinche bestehen in Schnenhaiuten, die mil Muskelausl)reitıngen belegt und durch diese zı comprimiren sind. - Einzig in der Classe der Säugethiere steht die in

burg, Darstellung und Besclureibung ler Thiere, din in der Arzneimittellehnce in Betracht kommen. Bd. 1. S. 45. 'Tab. VIII. Copirt bei Miiller, Glani. secern. Tab. II. Fig. 9. - Pallas lat bei Antilope gutturosa einen älunlichen Sack ('ntJeckt (Spicil. zool. XII. p. 58.) und auch hei Antilope Sä̈ga (1. c. 1. 43.) einen schrvächer entwickelten. - Bei Moschus javanicus findet sich keine Spur des Bentels. - Die meisten Antilopen besitzen ïbrigens parige Inguinalırüsen.

17) S. Miiller, Gland. seccrn. 13. 42. Tab. HI. Fig. 10. u. 16. (Hanster und Ratte).

18) S. besonders Brandt und Ratzeburg I. c. Thl. 1. S. 20 u. 135. Abb. Tal,. IV. n. IV. a. Sie siml nirhe nit den, din Biber gleichfalls pigenen Afterdriisen oder sogenanuten Oelsäcken zu rerwerliseln.

19) S. Müllor, Glanl. secern. [1. 41. Abb, dieser Drüsen ron mehren Rauls. llieren ibicl. Talb. II. Figr. 3-7. Alb. der Afterlrïsen des Bibers bei B randt Inul Ratzehulg I. c. Tab. IV. II. IV. a.; copirt loci Miiller I. c. Tah. II. Fig. o).

20) S. busomlers Brandt mul Ratzoburg I. C. p. S. uml die Abl. Tab. II Ah. der Follikel bei Miiller l. c. Tilb. I.l. Fig. 
einen an jeder Fusswurzel befindlichen, gespaltenen liornartigen Sporn ausmündende Cruraldirüse der männliehen Monotremen ${ }^{21}$ ) da, deren Seeret man - hauptsächlich wegen einer gewissen Analogie des Sporns mit den durehbohrten oder geschlitzten Giftzühnen vieler Ophidier lange Zeit, aber anseheinend ganz irrthümlich, für giftig gehalten hat. Die Drüse selbst, in ihrem Baue der Harder'sehen Drüse verwandt, liegt bei Ornithorhynehus in der Oberschenkelgegend, bei Eehidna aber, wo sie viel kleiner ist, in der Regio poplitea, bedcekt von der äusseren Haut. Ein bei Ornithorhynchus längerer, bei Eehidna kürzerer, dickwandiger und weiter Ductus excretorius verläuft an der Hinterseite der Extremität abwärts, erweitert sich an der Basis des Sporns blasenartig und setzt sieh verengt in die Spalte desselben fort. - Viele Wiederkäuer endliel besitzen Hu f- und Klauendrüsen ${ }^{22}$ ) in Gestalt saekförmiger, längerer oder kürzerer, inwendig behaarter Einstülpungen der Cutis, welehe zwischen den oberen Phalangen der beiden Zehen liegen. Der absondernde Apparat dieser Säeke besteht in kleinen, dieht stehenden, unter ihrer inneren Oberfläehe gelegenen Follikeln.

Ueber das Vorkommen und das Verhalten der in die Haarbäilge mündenden Talgdrüsen bei den Säugethieren liegen nur wenige Untersuchungen vor. Bei den Haussíugethieren sind gewöhnlich zwei Talgdrüsen mit einem Haarbalge verbunden; seltener kömmt nur eine

21) S. über diesen Apparat bein Schnabelthiere Meckel, Ornithorhynchus. p. 54 sqq. Abb. des Sporns Tab. Il.; der Drüse, ihres Ausführungsganges und ihres Verhältnisses zum Sporn Tab. VI.; isolirte Darstellungen dieser Theile Tab. VIII. Fig. 8-13. - Die neueren Untersuchungen über diesen Apparat sind in ihren Resultaten zusaminengestellt bei 0 wen, Monotrem. p. 405 sqq. Ueber den feineren Bau der Drïse s. Müller, Gland. secern. p. 43. Abb. Tab. II. Fig. 10. Bei jungen Thieren beiderlei Geschlechtes fand $\mathbf{0}$ wen einen kleinen Sporn in einer Grube der äusseren Hautbedeckungen liegend. S. die Abb. 1. c. p. 401. Fig. 197. und noch besser in 0 wen's ausführlicher Abhandlung in den Trans. actions of the zool. society of London. Vol. I. Tab. XXXII. Fig. 5. Bei vorschreitendem Alter des Weibchens nimut zwar die Grube an Umfang und Tiefe zı, aber der Sporn blcibt rudimentär oder schwindet. Versuche euglischer und französisclıer Naturforscher, mit beiden Gattıngen angestellt, lassen schliessen, dass die Männchen sich ihres Sporns nicht als Waffe bedienen. Wahrscheinlich steht er zu dem Geschlechtstriebe in Beziehung und dient, wie auch 0 wen verinutliet, als Reizorgan vor oder während der Begattung.

22) S. darüber Mülle r, Gland. secern. 1). 43. mit Angabe der älteren Beobachtungen. F. Klein, de sinu cutaneo ungularum ovis et capreae. Berol. 1830. 8. c. tab. aen. Sie sind beobachtet beim Lama, bei den Schaafen, Ziegeu und hein Hirschgeschlechte; scheinen jedoch einigen Hirschen, namentlich Cervus Elaphus zu fehlen. Géné leugnet sie bei der Ziege, wo Klein und Gurlt sie gefundeu (s. Mém. de l'Acad. de Turin 1834.). Brandt hat sie bei Auchenia sowol an den Hinter., als auch an den Vorderfüssen beobachtet, während er sie bein Drone!lar vewnisste. 
vor: - Auch die Schweissdrüsen sind bisher nur bei den Haussäıgethieren untersucht worden ${ }^{23}$ ).

\section{Dritter Abschnitt. \\ Von dem Muskelsysteme.}

§. 171.

Der allgemeine Plan, welcher der Anordnung des Muskelsyslemes der Säugethiere zum Grunde liegt, ist derselbe, den wir beim Menschen realisirt finden. Die mannichfaclien Abänderungen, welche die Einriehtung der Muskulatur bei den verschiedenen Gruppen der Säugethiere erleidet, entsprechen auf das genaueste den Eigenthümlichkeiten ihrer Skeletbildung und hangen, gleielı dieser letzteren, mit ihrer Lebensweise und namentlieh mil den physikalisehen Bedingungen, welche durch die Art ihrer Locomotivitiit gesetzt sind, innig zusammen.

[ Ueber die Muskeln der Säugethiere vergl. Cnvier, Leçons. Vol. 1. p. 266. und Vol. 4. P. 1.; Meckel's System der vergl. Anat. Thl. 3. S. 392 fr. und Thıl. 4.; Carns, Erlänterungstafeln. Hft. 1. Tab. V. VI. VII. VIII. (Abbildungen, betreffend die Affen, Igel, Fledermaus, Sechınd und Maulwurf.) - Wiehtige monographisclie Arbeiten sind folgende: Dic Monotremen behandeln Meckel, Ornithorliynehus. p. 22 sqq. Ind $0 \mathrm{w}$ en, Monotr. p. 379; die Beutelthicre, ausser Morgan und Vrolik (s. \$. 174.), Owen, Marsupialia. p. 28 Ra p), Cetaceen 1) $79 \mathrm{ff}$; die Haussäugethiere Gurlt in s. vergl. Anat. Tlıl. 1. S. 217 ff. und seinen Abbildnngen; iiber Phoca siehe, ausser Rosentlıal (bei Carus 1. c. p. 35.), Duvernoy, Mém. du Mus. d'hist. natur. T. IX. - Ueber die Affen s. die sehätzbare Ablinndlung von E. Burlach im Neunten Rerichte von der anit. Anstalt zu Königsberg. Königsb. 1838. 8. und V rolik, Chimpanzé, 1. 25 sqq. mit zahıreichen vergleichenden Bemerkungen über vlie Extremitätenunnskeln anderer Säugetliere.]

\section{§. 172.}

Das System der Ifautmuskeln ist bei alten Säıgethieren mongleich stïrker entwickelt, als beim Menschen. Bei den meisten ist der ganze Rumpe eingehiullt von einem auch über den Hals und einen Theil des hopfes und des Gesichtes sich erstreckenden, von den unterliegenden Rumpfmuskeln direh Zell- oder Fettgewebe mehr oder minder gesonderten Ilautmuskel, der oft längs der Rückenkante und längs dos

23) S. Gurlt iı Mïller's Arehiv. Jahrg. I\$3ว. S. 399. 'Tab. IX. Iı. X. Beim P'ferde, Sehaafe und Scliweine und in den Sollenballen des Hundes sind die Schweissdrüsen durch ihre vielfachen Windungen denen des Menschen ïlunlicl. Den Selıweissdrüsen des Rindes (Tab. IX. Fig. 6.) und denen der beliatiten Körperstellen des Hundes (Tab. X. Fig. 2.) fehlen die Wimlungen. Diene Srluweiss. drüsen der Honde sind sehr kleine, lange Bälge; die ilıror Sohleuballen simd dargegen selı betrïchtlich ('Tab. X. Fig. 1.). 
Bauches aponeurotisch wird. Meistens, und selbst noch bei den Affen, inseriren siclı seine vorn zusaumenstralılenden Faseikel sehnig an den IIumerus. Nirgend erreicht das System der IIautumskeln eino solche Ausbildung, wie bei denjenigen Säugethieren, welche das Vermögeıl besitzen, sich zusammenzukugeln. Dahin gelıoron z. B. die Gürtelthiere, Echidna und die, riieksichtlielı ibrer Mıskulatur an genatuesten untelsuchten, Igel (Erinaceus).

[Ueber die Hintmuskeln in Al]gemeinen s. Cuvier, Leçons T. 3. Paris 1845. p. $395 \mathrm{sqq}$. - Ueber die des Sclnibelthieres Mecke1, Ornithorh. 1. 22. Abb. Tab. V. VI. - Abb. der Hautmuskeln der Katze und des Hundes Gurlt, Auat. Abb. 'Tab. 21.; des Schweines und Schalafes Tab. 31.; des Rindes Tab. 48.; des Pferdes Tab. 41. - Bei den Cetaceen ist der Hautunuskel selır ansgebildet. Er umhïllt Hals, Brtust, Bauch und Rücken, geht aber hinter dem After in eine, die Schwanzmuskeln überziehende Aponeurose ïber. Er erstreckt sich nit seiner unteren IJ̈lfte bis zur Spitze des Unterhiefers: an der Rückenseite des Kopfes bis znr Querleiste des Hinterhauptes. Einzelne Bündel erstrecken sich zur Schlïfengegend; andere unschlingen den äusseren Gcliörgang. Von den unter ihm liegenden Muskeln ist er durch eine diimne Lage ron Speck geschieden. Der Rumpftheil wird durch eine Rücken -, eine Banch - und eine jedel Seite zukommende Aponeurose in vier Portionen geschieden. Starke Fascikel rom Bauchund Bristheile und andere vom Rückentheile treten an den Humerus. Jene ziehen die Brustflosse abwärts und zuı Theil hinterwärts, diese heben sie mol zichen sie rorwïrts. - Ueber die Hautmuskeln des Igels siche, ausser Cnvier, Himly, Ueber das Zusammenkugeln des Igels. Braunschweig 1801. 4. - Wet. ter, Erinacei europaei anatome. Gotting. 1818. 8. - Seubert, Syınbolae ad Erinacei europaei anatomen. Bonn. 1841. 4. Mit Abb. Tab. 1. - Carus in seinen Erläuterungstafeh. Hfr. I. Tab. VI. Die Hautunuskelnasse des Igels zerfällt in die sogenannte Kappe (Cucullus), welche die Rückseite des Halses und des Rumpfes bedeckt, in die Bauchmasse, welche den Bauch, die Seiten des Rumpfes und den obersten Theil der Extremitäten bekleidet und in die sogenannten Niederzicher (Depressores cuculli), deren vordere und hintere vorhanden sind. Ueber die Hautınskeln der Affen (Inuns, Cercopithecus, Cynocephalıs), die, ganz nach dem Typus der übrigen Säugethiere, eine Hülle un den Rmmpf bilden, s. Burdach 1. c. S. 5. Nach Vrolik p. 25. sollen der Chimpanze und der OrangUtang nur den Platysma myoides besitzen, ler anch bei andern Affen von deu Rmmpf-IIautmuskel getrennt ist. Indessen habe ich bei jungen Exemplaren beider Affen einen schwichen Rumpf-Haumuskel wahrgenoınmen.]

\section{§. 173.}

Die Muskulatur der Wirbelsäule entspriclıt in ihrer allgemeinen Anordnung derjenigen des Mensehen. Bei der. Melurzahl der Säugethiere, welche, gleich dom Mensehen, einen ausgebildeten Halstheil der Wirbolsäule besitzen, weicht gleichfalls die Anordnung der die Riickscite der Halsgegend eiunchmenden Ifuskeln ron der der eigentlich sogenannten Riickenmuskeln ab, obgleich jene als Wirderholungen dieser letzteren sich zu erkennen goben. Bei den Sirenen und Cetaceen aber, wo die Ialsgegend aborliv wirl, lreten solche Modifieationen in der Anordnung der 
die Riickseite des IIalses sinnehmenden Muskeln weniger hervor und die in engerem Wortsinne sogenannten Rückenumskeln verlaingern sich unınittelbar und ununterbrochen bis zur Ilinterhauptsgegend. - Die bei den Säugethieren an der Riuckseite des Selıwanzes liegenden Muskeln sind inodificirte Fortsetzungen der eigentlichen Riickenmuskeln und dic: an der Vorderfäche des Schwanzes gelegenen Muskeln sind Aquivalente der die Riickscite einnehmenden. Den strengsten Beweis fïr die Richtigkeit dieser Ansicht liefern die ächten Cetaceen, wo dic Schwanzgegend ausserordentlich ausgebildet ist, und wo zugleich die vollkommenste Uebereinstimmung zwischen den grösstentheils zum Riicken und Kopfe sich. fortsetzenden Muskeln der Rückscite des Schrvanzes und den bis in die Brusthöhle rerlängerten Muskeln seiner Vorderfläche herrscht. Dic Muskeln der Vorderseite des Halses zeigen nirgend wesentliche Verschicdenheiten von dem bekannten Plane ihrer Anordnung beim Henschen. - Das System der Rippenheber ist verschiedentlich ausgebildet. - Dasselbe gilt von den Interprocessualmuskeln mit Einschluss der $\boldsymbol{M}$. M. intercostales.

[Eine oft wiedlerholte sorgfältige Untersuchumg der Nuskulatur der Cetaceen hat mir, in Betreff der für die Morphologie so wichtigen Muskeln des Stammes, in Wesentlichen folgende, anderswo ausführlicher mitzutheilende, Resultate geliefert: 1) Es finden siclı zwei Hauptmuskeln, die, voın Ende des Schwanzes beginnend, längs der Rückenfläche bis zum Hinterhanpte sich erstrecken. Diese sind 1) der $\boldsymbol{M}$. transversarius superior und 2) der M. longissimus dorsi cum sacrolumbali. - Der Schwangegend eigenthümlich ist ein an äussersten Ende des Schwanzes selnig beginnender, in der Gegend des achten Lendenwirbels ganz in den $\boldsymbol{M}$. sacrolumbalis übergehender $\boldsymbol{M}$. caudulis superior. Auf den Brustund Halstheil der Wirbelsäule beschränkt sind: der $\boldsymbol{M}$. spinalis, der zum Hinterliaupte sich fortsetzende $\boldsymbol{M}$. semisninalis, der $\boldsymbol{M}$. multifidus und die $\boldsymbol{M}$. M. rotutores. - Den Bereich des am meisten nach aussen gelegenen M. transversurius superior, der auch bei Manatus ganz ähnlich sich verhält, bilden die Ruerfortsätz: der Wirbel, insbesondere deren äusseren freien Enden, und die Rippen. Vom änssersteı Ende des Schwanzes beginnend, die Ruerfortsätze der Schwanz- und Lendenwirbel cirinehmend, erstreckt er sich längs des Thorax ïber die Rippen. An dem Rippen. theile des Muskels kann man eine innere, auf dem Winkel der Rippen rubende, den Rippentheil des Sacrolumbalis sanmartig begrenzende dickere, schmale Portion und eine äussere, flache, die Ripjen überzichende Portion (M. costalis Rapp) unterscheilen. Dieser äussere Rippentheil endet an der ersten Rippe. Die innere dickere Portion des Muskcls nimmt schon in der Gegend der dritten Rippe an Masse zu, geht mehr auswärts, erreicht den oberen Bogen des Atlas nnd den Seitentheil des Hinterhauptsbeines. - Der $\boldsymbol{M}$. Longissimus dorsi entspringt mit starker Sehne am Schwanze, liegt in dem grössten Theile seines Verlaufes neben den Processius spinosi der Wirbel, rückt rom zehnten Rückenwirbel an mehr answäits mul befestigt sich zuletzt fleischig an dic Schuppe des Hinterhanptsheines. Der M. sacrolumbalis fängt in dor Gegend des aclitzelıten Lenden-Schwanzwirbols

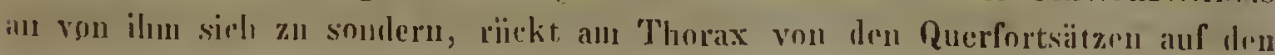
lertebralthesl der Ripurn, erreicht den Bngen des Atlas mol condet mil-2wei 
Sehnen an Schedel, deren eine an den Seitentheil des Hinterhauptsbeines, die andere an der Basis des Jochfortsatzes des Schläfenbeines sich befestigt. - Wie nuı an deu Schwanzwirbeln der Cetacecn das untere Segment genan $\mathrm{dcm}$ oberen cntspricht, so herischt auch rücksichtlich Jer Anordıung der Muskehn die voll. kommenste Uebereinstimuung zwischen Rücken- und Bauchseite. 1) Dem $\boldsymbol{M}$. ¿ransversarius superior entspricht ein $M$. Lansversarius inferior, der nur vorn keine Portio costulis bcsitzt. 2) Die weiter einwärts gelegene Muskel. masse ist freilicl gewöhnlich als $\boldsymbol{N}$. psoas betrachtet worden. In der That besteht sie ans mehren Muskeln: dcu M. coudalis inferior, dem M. Longissimus inferim und deın $\boldsymbol{M}$. sacrolumhalis inferior. Vollständig zu sondern sind sie nur linten. Sie verschınelzen näınlich alhıälich zu einer einzigen, sehr dicken Muskelmasse, welche von hinten nach vorn imuer inebr an Unfang gewinnt, in der Gegend der letzten Rippe sich verbreitert, an Dicke verliert und endlich sehr verflacht in die Brusthöhle hineinreicht. Die dem Longissimus angehörige Portion liegt an den Wirbelkörpern und Querfortsätzen; der den Sacrolumbalis reprïsentirende Theil wird sehr flach und überzieht die Innenfläche des Vertebral. theiles der bis 5 hintersten Rippen. - So ist zugleich der Beweis geliefert, dass die Bauchunskeln der höheren Wirhelthiere ein System billen, das dem. jenigen der eigentlichen Rückenmuskeln, so wie des $\boldsymbol{M}$. lateralis der niederen Wirbelthiere, durchaus fremd ist. Hieraus ergibt sich auch, wie wenig statthaft es ist, Sternum und Rippen oder Sternocostalknochen bei den höheren Wirbelthieren als Repräsentanten der unteren Bogenschenkel der Wirbel zu betrachten, wie dies z. B. von 0 we n geschieht (Monotrem. p. 375. Anm.). - Eine genau durchgeführte vergleichende Anatomie der Muskeln des Stanmes der Wirbelsäule bei den Säugethieren gehört noch zu den Desideraten; sie setzt eine strenge Beachtung des Verhaltens der einzelnen Wirbelfortsätze für ihren inorphologischen Theil, für ihren physiologischen Theil aber eine rein physikalisch-mechanische Auffassungsweise voraus. - Ueber die Muskulatur der Schwanzgegend s. Cuvier, Leçons T. 1.; Meckel, Systen 3. 430. Gurlt l. c. S. 283. Ueber die M. M. rotatores dorsi s. Theile in Müller's Archiv. 1839. S. 102 ff.]

\section{§. 174.}

Die Bauchmuskeln der Säugethiere zeigen einzelne interessante Eigenthümlichkeiten. - Sie besehränken sieh oft nicht blos auf die Bauchgegend, sondern nehmen bei manchen Säugethieren mehr oder minder die ganze Vorderfläche des Rumpfes ein. Dies gilt sowol von den äusseren schiefen Bauchmuskeln, als auch namentlich von den geraden und vom queren Bauchmuskel, welcher letztere mit dem $\boldsymbol{M}$. triangularis sterni oft völlig zusammenfällt. Auch die unteren Befestigungen der Bauchmuskeln bieten, namentlich bei den mit ganz rudimentärem Becken versehenen Cetaceen, abweichende Verhältnisse dar. - Die Inscriptiones teudiueae verhalten sich verschieden und fehlen bisweilen ganz, wie bei den Cetaceen. - Bei viclen Säugethieren, vorzuglich bei den Monotremen und Beutelthieren, ist der $\boldsymbol{M}$. pyramilalis besonders entwickelt, während er den meisten anderen fehlt. - Bei denjenigen Thieren, deren Iloden in der Unterleibshöhle bleiben, fehlt der Leistenring. - Bei den Beutelthieren, welche in 
Leistenringe einen beweglichen Knochen besitzen, tritt durch jenen bei beiden Geschlechteru ein mit dem M. transversus abdominis zusammenhangender Muskel, der dem Cremaster verglichen werden kann. Er verlikuft iiber den Beutelknochen und breitet sich beim Männchen über der Scheidenhaut des Ilodens, beim Weibchen an der Hinterwand des Beutels ubbr der Brustdriise aus.

Alle Säugethiere besitzen ein zu eineu vollständigen Septun zwischen Brust- und Bauchhöhlc ausgebildetes Zwerchfell. Bei einigen derselben ist das Centrum tendisenm desselben sehr schwach entwickelt. Eigenthümlich ist den Gattungen Camelus und Auchenia eine neben dem Foramen quadrilaterum im hinteren Theile der Mittelsehne gelegene Ossification, während bei Erinaceus zwei Ossificationen am Aortenschlitze vorkommen. Bemerkenswerth ist es ferner, dass bei den Ploken die untere Jlohlvene durch einen ringförmigen, muskulösen Fortsatz des Zwerchfelles, nach ihrem Eintritte in die Brusthöhle, scheidenartig unschlossen wird.

[Ueber die Bauchınuskeln der Beutelthiere vergl. besouders Morgan in d. Linnean Transactions. 1833. Vol. XVI. - V rolik in van der Hoeven's Tijdschrift. 1837. - Owen, Marsupialia. p. 287. Fig. 112. - Der beträclitliche M. pyramidalis entspringt bei den Beutelthieren und Monotrenen von der ganzen Inneuseite der Bentelknochen. Er erstreckt sich vorn beinalıe zum Sternum. Ueber den Pyramidalis des Schnabelthieres s. Meckel, Ornith. p. 25. - Er kommut nach Meckel sonst vor bei Erinaceus, einigen Quadrumanen und dem Menschen. Beim Chimpanze ward er von Traill und Vrolik vernisst. - Der äussere schiefe Bauchmuskel erstreckt sich bei den Delphinen und, nach Meckel, aucli l,ei den Monotremen über alle Rippen. Seine hintersten Bündel erreichen bei jenen das Beckenrudiment nicht. Bei den Beutelthieren befestigt sich seine innere Sehne an Belttelkochen, über den sie weggeht. - Die M. M. recli erstrecken sich über den Costaltheil der Rippenknorpel odler zugleich über den Aussenrand des Brustbeines bei den Cetaceen, den Monotremeı, einigen Beutel. thieren (z. B. Dasyurus, Didelphis), den Ferae und vielen Andern. S. Meckel I. e. p. 450. Beim Delphin trennen sich die beiden $\boldsymbol{M}$. recti zuletzt und jeder geht dünn unł spitz über das Beckenrudinent seiner Seite weg, un an den Processus transversus des nẹnzelnten Lendenwirbels und an die Fascia der übrigen Muskeln sich anzuheften. - Der M. transversus fältt mit deın Triun. gularis sterni zusamnen, z. B. beim Delphin, wo er vorn über die erste Ripje linausreicht, indeun er den zwischen ihr und ihrem Sternocostalknochen entstelienden 13ogen ausfültt. Der hinterste selnige Theil ist zwischen den beiden Beckenknochen ausgespannt. - Das Centrum tendineum des Zwerchfelles fehlt z. B. bei Deiphimus, ist kaum vorhanden bei Talpa u. A. - Ueber die Zwerchfellsknoclien s. Meckel 1. c. S. 45̃9., wo die frïhıre Literatur angegeben ist. Brandt hat neuerlich die des Lama beschrieben. Ueber die des Igels siehe Meckel in seinem Archiv. 1829. Bd. 4. S. 233. - Ueber die muskulöse Scheidle, die die IJuhtvene der Robben bekleidet, siehe die sehr genane nnd treue Darstellung vou N. J. Weber in Müller's Archiv. 1840. S. 235\%. Burow (M̈̈l. ler's Arrhiv. 1838.) hat eine ganz murichtige Beschreibmig gegreben; dir von 
Weber kamn ich dagegen vollkomnen bestätigen, habe mich auch von der Existenz quergestreifter Primitivbündel in der Venenscheide überzengt. Dagegen fehlt dieser King Ilem Delphin durchaus.]

\section{\$. 175 .}

Die Anordnung der Muskeln des Sulultergerüstes zeigt sich, entsprechend den osteologisehen. Versehiedenheiten desselben, verschieden. Bei den meisten Säugethieren zerfällt der M. sternocleidomasiöilens 1) des Mensehen in zwei getrennte Portionen, von denen die eine au Brustbeine, die andere an Sehlüsselbeine sieh inserirt. Wenn das Schliisselbein fellit, oder nur sehr unvollkommen ausgebildet ist, findet sich statt der M. M. cleidomastoüdens, cucullaris und delıöilens gewöhnlich ein gemeinsamer Muskel; bei anderen Säugethieren, z. B. den Delphinen, wird dagegen der $\boldsymbol{M}$. cleidomastö̈leus rlureh einen rom Ilinterhaupte zum Oberarm gehenden M. humero-mastoüleuis, der vom M. deltoüleus getrennt bleibt, vertreten. - Beim Hangel des Sehlüsselbeins fehlt entweder der M. subclavius oder wird, wie bei den Delplinen, dureh einen vom Knorpel der ersten Rippe zun Humerus sieh begebenden Muskel ersetzt. Aueh die übrigen Muskeln des Schultergerüstes: der Levator, die Rhomboïdei, die Scrrati, namentlieh der Serratus minor, zeigen einzelne, dureh die besonderen meehanisehen Bedingungen nothwendig erforderlieh gewordene Abweichungen von der bekannten Einriehtung beim Mensehen.

[Es finden sich auch für diesen Theil der Myologie in den Angaben der Anatomen, welche dasselbe Thier untersuchten, manche nicht unbedeutende Widersprüche, wie z. B. bei der Vergleichung der Arbeiten von Duvernoy, Rosenthal und Meckel über Ploca sich ergibt.]

\section{\$. 176 .}

Sehr bedeutend sind die Modifieationen, welche die Anordnung der Muskeln der Vorderextremitäten, je naeh den physikalisch - mechanisehen Erfordernissen der versehiedenartigen Weisen der Ortsbewegung erfährt. Bei den Cetaceen, wo die Vorderextremitäten als Ruder verwendet wer den, befestigen sieh an den Humerus die gewöhnliehen vom Sehulterblatte, dem Brustbeine, der binteren Fläche der Rippen kommenden Muskeln und mit ihnen die starken Fascikel des Ilautmuskels und des M. Inumero-mestö̈deus; aber der Vorderarm und die tiefer liegenden Knoclıen sind von Muskeln entblösst. Bei den Hufthieren erschleinen,

1) Bei einigen langhalsigen Süıgethieren, wie heim Pferle, beim Camele und namentlich der Giraffe, erhält sich der Ausatzpmnkt des Sternomastoïdeus ann Schedel nicht mehr, inden dieser Muskel oben an den Unterkieferwinkel sich befestigt, den er hernbzicht. Bei den Wielerkäneln befestigt sich eine seiner Portinnen am Oberkieferheine, wïlrend die andere mit dem $\boldsymbol{M}$. rectus capilis renticus maim versejunilıt. 
unter starker Ausliblung der Schulter- und Oberarmunuskeln, die des Vorderarmes dureh Mangel der Pronatoren und Supinatoren 1) vereinfacht und namentlich dic der IIand verkümmert. - Bei den fliegenden Chiropteren kehrt die die Yögel charakterisirende, und auch bei grabenden Säıgethieren, z. B. bri Talpa, vorhandene, brdeutende Entwickehung des in mehre Portionen zerfallenen $\boldsymbol{M}$. pectoralis maior wieder; es findet sich ein vom Oberarm ausgehender Spanner der Flughaut; alle Muskeln sind dureh ihre langen Selinen ausgezcichnet. - Bei der Mehr\%alnl der Sïngethierc wird die IIand, bei stärkerer Entwickelıng der Streckselınen der Finger, fussähnlich kräftiger gehoben als beim Menschen. - Bei allen Säıgethieren, mit Einschluss der Affen, ist die Bewegung der einzelnen Finger eingeschränkter, als beim Henschen.

[ Ueber die Muskeln der Vorderextremitäten vergl., besonders in Betreff der Unterschiede zwischen Mensch und Affen, Bưrdach und Vrolik. Ersterer vermisste den M. Alexm lorevis digiti minimi und den M. extensor pollicis Irevis gänzlich. Den $M$. Alexor pollicis lrevis fand er mit dem $M$. alductor pollicis verschmolzen; der M. fiexor pollicis longus zeigte sich als Theil des M. Alexor digitorun communis mofundus; der M. extensor digiti quinti gibt anch eine Selule an len vierten Finger; der M. extensor pollicis longus und der M. extensor indicis sind mit einander verschmolzen und gehen eine dritte Seline an den Mittelfinger ( $s$. Burdach S. 102.). - Melır näliert sich schow der Bewegungsapplarat der Hand beim Orang-Utang und besonders beim Chimpanze der menschlichen Billung. - Ueber die Muskulatur ron Talpa s. noch Ljunggren, de extremitate anteriore Talpae. I.minl. 1819. 4.]

\section{ร. $17 \%$.}

Unter den Muskeln des Beckens kömmt der Mr. quadratus lumliorum allen Säugethieren, mit Ausnahme der Cetaceen und Sirenen, zı. Diese besitzen dagegen cinen M. ischio-coccygeus. Die iibrigen Säugethice haben cinen M. ileo-coccygens und pubo-coccygeus.

Dic Abweiclungen, welche die Muskeln der Hinterextremitätun von der dem Menschen cigenthiimlichs'n A nordnung zeigen, sind nicht uinder betriichtlich, als dic der Muskcln ihrer Vorderextremitäten. Sie betreffen sowol die Zahl, als die Stärke und die Insertionsstellen der einzelnen Muskeln. Was zuyörderst die Gesässmuskeln anbelangt, so sind sie bei allen Sïngethieren schwiicher entwickelt, als beim Menschen; am stïksten aber noch bei solchen Thieren, dic auf den Hinterfüssen sich aufrecht halten, wie z. B. beim Känguruh, beim Bären, beim Fanlthierc, schwach digegen bei allen Affen. Unter den Gesïssmuuskeln ist meistens (namentlich bei den Einhufern, den Wiederkä̈uern, den meisten Raubthieren) der mittlere am beträchtlichsten; der drittc, der bisweilen den

1) Es.s fehlen ihnen nannentlich der M. supinator longus und brevis, der M. pronator teres mud gundiatus; noch grösser ist die Anzalıl der iluen man. gelndeu Zehenumiskeln. 
ersten an Umfang noch übertrifft, ist nicht selten durch zwei Muskcln repräsentirt. - J)ie Auswïrtsroller des Oberschenkelbeines kommen Incistens säinmtlich bei Sängethieren verschiedener Ordnungen vor. Die beiden Schenkelbenger: der Psoas magusus und Iliacus internus, zeigen sich fast immer so eng mit einander verbunden, dass sie mit Recht als ein gemeinsamer Muskel betraehtet werden können. Sie befestigen sich mittelst einer gemeinschaftliehen Sehne an den kleinen Rollhügel. Bei einigen springenden Säugethieren, wie z. B. beim Haasen, beim Känguruh, ist der M. psoas minor schr stark entwickelt und befestigt sich an den horizontalen Ast des Schaambeines. - Dic Anzieher des Oberschenkels sind bei den Säugcthicren in der Regel stark ausgebildet; aber die Zahl der Köpfe des eigentlichen $M$. adductor femoris ist nicht überall gleich, indem sie bald sich vermindert, wie bei den Fledermäusen, mehren Paehydermen und Wiederkäuern, balủ steigt, wie bei einigen Affen und Nagern. - Unter den an die Knochen des Unterschenkels sich befestigenden Muskeln liegt der M. sarturius in der Regel viel gerader, als beim Menschen. Die merkwürdigste Abweichung von seiner gewöhnlichen Insertion zeigt er bci den Faulthieren, wo er breit von der Aponeurose des äussern schiefen Bauchmuskels entsteht und in zwei Hauptbündel zerfällt, von welchen das eine an die innere Flächc des Oberschenkelbeines, das andere an die Innenfläche des Schienbeines sich befestigt. So untcrstützt er die Bauchmuskeln und hebt aueh den Oberschenkel bei Zusammenziehung derselben. Bei den ıneisten Ferae zerfällt er gleichfalls in zwei Portionen, von denen die eine am Kniegelenk und die andere, mit dem $\boldsymbol{M}$. gracilis verbunden, an der Innenseite der 'Tibia sich befestigt. Der $\boldsymbol{M}$. gracilis, besonders stark bei den Einhufern entwickelt, tritt bald nur hoch oben an das Schienbein, wie bei den Quadrumanen, bald erstreckt er sich tief abwärts, wic besonders bei den Faulthieren, den Phoken u. A. Die eigentlichen Beuger des Unterschenkels befestigen sich meistens viel tiefer abwärts an den Knoehen desselben, als beim Menschen, wodurch jener beständig in stärkerer Beugung erhalten und seine vollständige Strekkung verhindert wird. Während die Schienbeinbeuger gewöhnlich vom oberen Rande des Sitzbeincs ihren Ursprung nehmen, erhalten bei den Einhufern beide von dem Seitentheile des Kreuzbeines und von den vorderen Schwanzwirbeln obere Köpfe; bei anderen Säugethieren, wie z. B. bei den Wiederkäuern, den Pachydermen, einigen Nagern, tritt ein so entspringender oberer Kopf blos zum M. semimembranosns, der gewöhnlich stärker ist, als der $\boldsymbol{M}$. scmicenulinosns. Bisweilen sind auch die beiden Schienbeinbeuger mit einander verwachsen, wie z. B. beim Künguruh, bei den Faulthicren u. A. Der Wadenbeinbeuger ( $\boldsymbol{M}$. Uiceps femoris) zcrfiilt bci mehren Säugethieren in zwei Muskeln; der kleinere entspringt vom Sitzbeinhöcker und befestigt sich an mittleren äusseren Theilc des Schenkelbeines, während der grössere, der an der 
ausseren Seite des Unterschenkels sich inserirt foder aponeurotisch werdend, di Unterschenkelnuskeln umfasst, wie z. B. heim Känguruh), voun Sitzbeinhöeker, und oft auch von der Seite des Kreuzbeines entspringt, wie dies namentlich bei den Einhufern, den Wiederkäuern, dem Känguruh u, A. der Fall ist. Uebrigens bietet er in Betreff seiner Anordnung bei den einzelnen Gattungen der Säugethiere grosse Verschiedenheiten dar. Bei den Einhufern und Schweinen kömmt noch ein accessorischer Abeluctor cruris Grevis hinzu. - Der M. popliteus ist - mit Ausnahme der Fledermäuse, denen er fehlt, - bei den meisten Süugethieren sehr stark entwickelt. Die Streckmuskeln des Unterschenkels zeigen minder grosse Verschiedenheiten als die Beuger. - Der Musc. tensor fascine lutae wird nur ausnahmsweise vermisst. - Bei den meisten Beutelthieren sind Tibia und Fibula so mit einander verbunden, dass sie einer rotirenden Bewegung, ähnlich der Pronation und Supination der Vorderarmknochen, fähig sind. Zur Vollziehung derselben ist auch die Muskulatur eigenthümlich modifieirt. Nach anssen gewendet wird der Fuss durch einen dem Prosator quadratus des Vorderarmes analogen Yuskel, dessen Fasern am Ligameutum interosseum schräg von der Fibula zur Tibia absteigen. Sein Antagonist ist der nur von der Fibula entspringende $\boldsymbol{M}$. plantaris, dessen Sehne schief einwärts, hinter dem Mallealus iutermus, in die Fascia plantaris übergeht und der bein Strecken des Fusses zugleich die Tibia einwïrts drehet. - Unter den Muskeln, welehe den Fussrieken und die Fussz.ehen der Yorderseite des Unterschenkels nähern, wird der M. exteusor hallucis lougus der Mensehen bei den Einhufern und Wiederkäuern vermisst. - Der lange Zehenstrecker nimmt bei den Säugethieren seiven Ursprung öfter von der Vorderfläche des äusseren Oberschenkelknorrens, als vom Unterschenkel. Iräufig ist er mit dem kurzen Zehenstreeker mehr oder minder innig verbunden. Bei vielen Nigern komInen noch accessorisehe, für einzelne Zehen bestimmte Streeker hinzu. - Was diejenigen Muskeln anbetrifft, welche die Fusssohle und die Zehen nach hinten wenden, so ist zuerst über den dreiköpfigen Wadenmuskel zu bemerken, dass eine eigentliche Wade, wie er sie beim Menschen bildet, den Säugethicren fehlt. Die $\boldsymbol{M}$. M. gastrocnemii wechseln rücksichtlich ihres Ursprunges, indem sie bald höher aufwärts vom Oberschenkelbeine, bald ungekehrt von diesem und zugleich vom Wadenbeine entspringen. Der $\boldsymbol{M}$. soleus fehlt selten ganz, aber häufig trägt er nicht zur Bildung der Achillesselne bei, sondern inserirt sieh mit einer gesonderten Sehne, die bisweilen, z, B. bei den Wiederkäuern, den Schweinen, dem Ilunde, für die Zehen sich spaltet und zugleich den M. flexur Urevis digitorum darstellt. Der M. tibialis posticus fehlt oft oder endet in der Sehne des M. flexur digitorum longius; erhilt er sich gesondert, so befestigt er sich bald an die hintere Fläche des vittelfusses, bald an die innere Seite und untere Flache der Fusswurzel. 
1)er M. flexor digitormm longus zeigt bedeutende Verschicdenheiten sciner Anordnung; nannentlich tritt or häufig in Verbinclung mit dem M. plantaris, der gewöhnlich stärker ist, als beim Mensehen, und ist aueh oft init dem $\boldsymbol{M}$. flexor pollicis lougres veisehmolzen. Yon den beiden $\boldsymbol{M}$. M. peronei fehlt der kurze bei ren Einhufern, ist aber sonst in der Regel rorhanden; der lange bietet rücksiehtlich seines Ursprunges Yerschiedenheiten dar, inclem er namentlich oft ganz oder theilweise vom äusseren Olıerschenkelknorren entsteht, wie z. B. bei mehren Ferae, bei den Wiederkäuern ॥. A. - Die kurzen gemeinschaftlichen Zehenstreeker und Zehenbeuger sind häufig innig mit den langen gleichnamigen Muskeln verhunden. Dic Zahl ihrer Schnen wechselt sehr. - Die Anzicher, Abzieher und Beuger der einzelnen Zehen sind sehr versehiedentlieh entwickelt, namentlieh bei den Einhufern und Wiederkäuern theils verkiinmert, theils fehlend; sonst oft stärker und manniehfaltiger ausgebildet als beim Menselien. Aueh die M. M. iurerossei sind bei den Einhufern und Wiederkäuern meist sehnig.

[Näheres über die Muskeln der Hinterextremitäten bei Meckel, Burdach, Vrolik, Gurlt; über die der Beutelthiere vergl. 0 wen, Marsupialia. p. 290. Mit Abb. Fig. 113.]

\section{§. 178.}

Dic cigentlichen Gesichtsmuskeln $\left.{ }^{1}\right)$ sind bei den Siugethieren in sehr versehiedenem Grade entwiekelt. Bein Schnabelthiere mangeln sie ganz. Bei den Delplinen finclet sich ausser dem starken Ringmuskel der Nase und den Muskeln der Augenlider, nur cine mit Fott durehzogene, auf dem Oberkieferbeine licgende schwache Muskelausbreitung. Stärker entwiekelt sind sie bei den meisten übrigen Säugrthieren. In Unkreise des Mundes findet sieh gewöhnlich cin M. orluicularis oris. Die Hebung der Oberlippe und des Nasenfligels wird meistens durch einen Musc. levator labii superiuris alaeque nasi hewirkt. IIäufig findet sich noeh ein eigener Levator labii superioris, der aber eben so oft noch nit den vorigen Muskel verschmolzen ist. Sein Antagonist ist cin $\boldsymbol{M}$. incisiuns labii superioris. Von den $\boldsymbol{M}$. $\boldsymbol{M}$. zy/gomatici ist del kleinere bei den Siugethieren be stiindig vermisst worden, wihrend der grosse seltener, wie z. B. bei den Edentaten, fehlt. Die zur Bewegung der Unterlippe bestimmten Iluskeln sind gewöhnlich gar nicht oder nur schwach gesonderte Fascikel vom Iralstheile des Hautmuskels (M. sulucutaneus colli), in denen man mebr oder minder deutlich Aequivalente des Depressor angul; oris und des Depressor labii inferioris des Menschen erkennt. Der M. risorius Santurini ist nur ein Theil vom Ilantmuskel des Gesichtes.

1) S. über dieselben nähere Angaben bei Meckel, System der ver⿳⺈. Auat. Thl. 4.; in Betreff der Haussäugethiere vergl. Gurlt Thl. I. S. 240.; iiber die Gesichtsmuskeh der Affen s. Burdach 1. c. S. 11. 
- Der M. Uuccinator ist bei den Delphinen sehr schwach cntwickelt, stiirker dagegen bei den übrigen Süugethieren, namentlich bei den mit Backentaschen versehenen. Bedeckt von ilum liegt bei vielen Süugcthicren noch cin rom Processus coronoüleus d's Unterkiefers entspringender, zum Alscolarrande beider Kiefer absteigender, auch in den Lippenwinkel uibergehender $\boldsymbol{M}$. malaris. Bei der geringen Sonderung der einzelnen Gesichtsmuskeln und bei der sehr allgemein, und selbst noeh bei den Affen, Statt habenden Ausbreitung des Ilautmuskels über das Gesicht, fehlt den Säugethieren das Vermögen zu dem charakteristischen Mienenspiel des Menschen.

Die Kaumuskeln der Säugethiere bieten nur geringe Abweichungen von denen des Menschen dar. Allgemein und oft sehr beträchtlich entwickelt zeigen sich die M. M. masseter, temporalis, pterygö̈lleus externus und internus. Der M. masseter zerfällt bei vielen Nagern in zwci Iälften, von welchen die grösșere den gewöhnlichen Verlauf hat, während die kleinere, tiefere vorn vom Oberkiefer und Jochbogen durch das sehr grosse Foramen infraorlitale zum oberen Rande des Unterkicfers tritt 2). Mehr Versehiedenhciten bietet die $\Lambda$ nordnung des M. Nigastricus dar. Er fehlt als gesonderter IIuskel den Dclphinen, so wie aueh mehren Edentaten ${ }^{3}$ ). Bei den meisten Säugcthiercn besitzt er nur einen Baueh. - Zur Senkung des Unterkiefers tragen bisweilen noeh andere Muskeln bei; so bei den Einhufern die M. stylomaxillares; bei ihnen, den Camelen, Lamas 11. A. die M. M. sternomaxillares; beim Schnabelthiere eine an den Unterkiefer tretende Portion des M. omohyoüdeus.

Unter den $Z$ ungenbeinmuskeln sind bei den Säugethieren die M. M. mylohyoülleus, geniohyoülleus, stylohyoülens und sternohyoüdeus beständig vorhanden. Der letztgenannte Muskel ist oft, z. B. bei Manatus, bei mehren Wiederkäuern, mit dem M. sternothyreoïdeus verschmolzen 4); bei einigen Edentaten verlängert cr sich als $\boldsymbol{M}$. sternoglossus zur Zunge 5 ). Unbeständig ist der M. omohyoüdeus, der z. B.

2) S. §. 167. Anın. 11 .

3) Vergl. über die letzteren M e ekel, System der vergl. Anat. Bd. 4. S. 605. Er wird dureh einen voun Brustbeine zum Kinn sich erstreckenden diinnen Muskel ersetzt.

4) Auf eine interessante Eigenthümlichkeit des gemeinschaftlichen $\boldsymbol{M}$. sternohyoüders und thyreoüdeus bei der Giraffe hat $0 \mathrm{rven}$ (Transact, of the zool. soc. of Lond. Vol. 2. 1. 232.) aufinerksam gemaeht. Er entspringt fleisehig vom Brustbeine und rerwandelt sieh dann in eine runde Sehne. Diese theilt sich später in zwei Portionen, welche bald muskulös, dann wieder sehnig und zuletzt wieder muskulös rerden, un sich an Schildknorpel und Zungenbein zu befestigen.

э) Eigenthïmlich und in morphologiseher Beziehung instructiv ist dies Verhalten bei Myruecophaga und Manis. Der M. sternohyoüdeus entspringt lier vou hinteren Ende des Brustbeines, an dessen Innenfläehe er aufsteigt, übelspringt dann das Zungenhein und begibt sich in die Zunge, ist dennaeh mit dem 
bei den Cetaceen, Sirenen, Pachydermen, Edentaten und Ferae fehlt, bei den Einhufern seine Insertion am Schulterblatte aufgibt und an der Aussenfläche der ersten Rippen entspringt, bei den Wiederküuern vom dritten Halswirbel entsteht u. s. w. Die kleineren Zungenbeinmuskeln bieten manche kleine Verschiedenheiten hinsichtlich ihrer Zahl und Anordnung dar 6$)$.

\section{Vierter Abschnitt.}

\section{Vom Nervensysteme und von den Sinnesorgrnen.}

\section{Von den Centralorganen des Nervensystemes.}

§. 179.

Das aus den gewöhnlichen vier Strängen bestehende Rückenmark der Säugethiere erstreckt sich in dem Canale der oberen Wirbelbogen meistens weit hinterwärts, bald in der Lumbargegend, bald in der Kreuzbeingegend sehr verdïnnt, oft fadenförmig, endend. Ausnahmen von dieser Regel bilden wenige Säugethiere, wie namentlich Fledermäuse, Erinaceus und Echidna, bei denen es, durch seine Dicke und Kürze ausgezeichnet, in der Mitte der ejgentlichen kückengegend endet 1). - Indem die Ursprungsstellen der hinteren Spinalnerven beständig viel weiter vorwärts, als ihre Austrittsstellen aus den Faramina ivotervertebralia liegen, entsteht auch immer eine Cauda equiua, welche natuirlich bei den vorhin namhaft gemachten, durch bedeutende Kürze des Rückenmarkes ausgezeichneten Thieren an stärksten ist. Entsprechend den Ursprungsstellen der für die Extremitäten bestimmten Nerven finden sich im Verlaufe des Rückenmarkes zwei Anschwellungen, welche selbst bei den durch beträchtliche Kürze und Dicke desselben ausgezeichneten Gattungen unverkennbar sind. Bei den mit auffallend stark entwickelten Hinterextremitäten versehenen Säugethieren, wie z. B. beim Känguruh 2), ist die hintere Anschwellung besonders stark. Sie fehlt sogar nicht bei den der Hinterextremitäten er-

M. hyoglossus versehmolzen und wird zu einem M. sternoglossus. S. Cuvier, Vorlesungen. Bd. 3. S. 281.

6) Vergl. in Betreff der Haussäugethiere Gurlt Thl. 1. S. 259. und sonst die ausführliehe Darstellung bei $\mathrm{Cuvier}$, Leçons. T. IV. P. 1. p. 483 sqq.

1) Vergl. Meekel in s. deutsehen Arehiv für Physiol. Bd. 1. S. 354. Abgebildet ist das Rüekenmark des Igels bei Swan (Illustrations) Tab. XXVIL. Fig. 3. Ueber das der Eehidna vergl, 0we n, Monotremata. p. 385. Fig. 185. Diese Eigenthümliehkeit des Rüekenmarkes der Eehilna ist um so auffallender, als das des verwandten Ornithorbynehus in den Canal der Kreuzwirbel sieh erstreekt und nur eine sehr sehwaehe Cauda equina besitzt.

2) Abb. 0 wen, Marsupialia. p. 296. Fig. 119. 
mangelnden Cetaccen. - Bei cinigen Nagern ist die den Nerven der Vorderextremitaiten entsprechende Anschwellung nur schwach von der Medulla oblongata gesondert. - Eine dem Sims rhomboüdalis der Vögel entsprechende Spalte fohlt immcr. - Dic hintere Furchc oder Spalte ist deutlich und bisweilen tief. - Spuren des Mediancanales erhalten sich niclit selten perennirend. - Auf Querdurchschnitten crscheinen dic grauen IIörner.

\section{§. 180.}

Das die Schedelhöhle vollständig ausfüllende Gehirn aller Säugcthiere besitzl - in Gegcnsatze zu dem der Vögel — folgende bestïndige Eigenthiimlichkeiten: 1) die bei den Vögeln blos durch einige Qucrfascrn angedeutete Brücke crscheint ungleich stärkcr entwickelt; 2) hiermit steht in Zusammenhang die beträchtlichere Ausbildung der Seitenlappen des Cerebellum; 3) der den Vögeln noch fehlende Fornix bildet eine Längencommissur für die Ammonshörner und die Sehhügel und verbindel die beiden Ammonshörner unter einander; 4) die Corpora quaulrigemina sind solide, ermangeln jeder Höhle und zerfallen in vier mehr oder minder scharf gesonderte Abtheilungen.

Andere Unterschiede treten erst allmälich in den Reihen der höheren Säugethiere hervor, charakterisiren also keinesweges beständig das Grehirn aller Säugethiere, als solcher. Zu denjenigen Gebilden, welche bei niedriger organisirten Gruppen - Monotremen und Beutelthicren noch vermisst werden, gehört die grosse Commissur der Hemisphären oder das Corpus callosum, nelsst dem Septum pellucidum und seinem Ventrikel 1). Die oft die Vierhügel noch nicht bedeckenden Jlemisphären des grossen Gehirnes gewinnen erst allmälich an Umfang und Masse, und namentlich erscheinen ihre hinteren Lappen erst bei den Affen und dem Menschen. Ehen so allmálich erscheinen ihre Windungen, deren Vorkommen nicht einmal für alle der gleichen Ordnung angehörigen Thiere charakleristisch ist. Die meistens zu einer einfachen Masse versehmolzenen Corpora candicantia theilen sich erst bei den höchsten Säugethiercn deutlich in paarige Körper.

Gebilde, welche dem Gehirne vieler Säugcthierc zukommen, dem des Menschen aber völlig oder in gleichem Grade der Ausbildung fehlen, sind: 1) dio Corpora trapezoüdea; am verlängerten Marke hinter der Brücke gelegene Erhabenheiten, von welchen namentlich Fascikel des sechsten und siebenten Hirnnerven ausgehen; 2) die, mit

1) Auf diesen interessanten Umstand hat znerst aufmerksam gemacht 0 wen in einein wichtigen Aufsatze in den Philosophical Transactions 1837. P. 1. p. 87., in welchem namentlich anch das Hirn des Wounbat nit den des Bibers verglichen wird. Ausfübrlich behandelt $\mathbf{O}$ wen denselben Gegenstand in seinem Artikel: Marsupialia bei Todd p. 293 sqq. und Monotremata ibid. p. 382. Mit Abb. 
Ausnahme der Cetaceen, $\Lambda$ ffen und Phoken, vorn an den Hemisphären befindliehen hohlen $\Lambda$ nsehwellungen der Geruehsnerven (Processus memmillures); 3) dic an ihre Anwesenheit geknüpften, an der Basis der Mittellappen des grossen Gehirnes befindlichen seitlichen Erhabcnhciten (Processus natiformes s. pyriformes).

[Man vergl. über das Gehirı der Sängethiere, ausser den Schriften rou Carus, Treviranus (Vermischte Schriften anatomischen und physiologischen Inlaalts. 3r Bd. S. 4 fr.), Serres, Desmoulins, und den Abbililungen, welche $\mathrm{Sw}$ an in seinen Illustrations of the nerrous system Tab. XXIX. gegeben, aucl noch Gall et Spurzheim, Recherches sur le système nerreux en géneral et sur celui du cerreau en particulier. Paris 1809. 4.; Rolando, Saggio sulla vera struttura del cervello dell' uomo e degli animali. Sassari 1809. - Rolando, Recherches anatomiques sur la moülle allongée. Torino 1822. - Rolando, Della struttıra degli emisferi cerebrali. Torino 1830. 4. - Zahlleiche Ábbildungen und Beschreibungen von S̈̈ugethiergehirnen gibt 'Tiedemann, Icones cerebri simiarum et quornndam maumalium rariorum. Heidelb. 1821. Fol. - Andere Abbild. finden sich bei Volkmann, Anatomia Animalium. Hft. 2. und bei Wagner, Icones zootomic. Tab. VIII. und Icones physiologic. Tab. XXIV-XXVI. - Dann auch bei Leuret, Anatomie comparée du système nerveux. Paris 1839. Mit Atlas in Fol. - Was die monographlischen Arbeiten anbetrifft, so siehe über das Gehirn der Monotremen und Bentelthiere besonders die schon oben citirten Arbeiten von 0 wen; ïber das Geliru des Delphins Tiedemann in seiner Zeitschrift für Physiologie. Bd. 2. S. 251. Tab. XII. und die zum Theile in Widerspruch zu Tiedemann's Angaben stehende Abhandlung von Stannius in den Denkschriften des Hauburg. Natnrw. Vereines. Hamb. 1845.; über das Gehirn von Hyperoodon vergl. besonders Eschricht, Undersögelser over Hvaldyrene. Fierle Afhandl. Kjöbenh. 1845. 4. p. 38. Mit einer schönen Abb. Tab. VIII.; über das Gehirn der Giraffe s. $\mathbf{O}$ wen in den 'Trausact. of the zool. soc. of London. Vol. 2. Nit Abb. Tab. 43. 44,; über das des Lama B randt in den Mém. de l'acad. imper. de St. Petersbourg. T. 4. 1841. Mit Abb.; ïber das der Katzen 0 wen in den Transact. of the zool. soc. Vol. I. p. 133. Tab. XX.; über das des Chimpanze s. Vrolik, Recherches s. 1. Climpanze. p. 39. Tab. VI.; über das des Orang-Utang s. Tied emann in seiner Zeitschrift für Plyssiologie. Bul. 2. S. 17. Tab. IV. und dessen Schrift: Das Him des Negers mit dem des Europäers und Orang-Utangs rerglichen. Heidells. 1837. 4., so wie auch Sand if ort, Verhandel. over de naturlijke Geschiedenis d. Nederlandsche Besittingen. Leiden 1S39. Fol.]

\section{\$. 181.}

Das verlängerte Mark der Säugethiere ist in Verhältniss zum Gehirne beträchtlieher, als dies beim Menschen der Fall ist. Dic Corpora olivaria bilden keine so deutliche Hervorragungen, als beim Menschen, oder treten gar nicht hervor und enthalten aueh nicht immer einen zackigen Körper, welcher aber bei Delphinen und höheren $\Lambda$ ffen wahrgenommen ist. - Die Kreuzung der oft starken Pyramiden ist gewöhnlich erkennbar. - Die Corpora trapezö̈lea hinter der Brücke sind allgemein vollianden, sowol da; wo dic Brücke schr schwach ist, 
wie bei den Monotremen 1), als bei starker Entwickelung derselben, wie sie bei den Delphinen Statt finclet.

Das kleine Gehirn besitzt neben seinem, oft seitwiirts gebogenen oder gekriummen, Nittelstiicke (dem Wurm) immer anch Seitenlappen. Bei den niedrigsten Säugethicren, den Monotremen, bleilst jenes noch so sehr vorlerrschend, dass die Seitenlappen nur als unbeträchtliche Anhänge erscheinen; wenig slïrker entwickelt sind die letzteren bei den Chiropteren, Beutelthieren, Nagern und Edentaten; erst bei den Raubthicren, Einhufern, Wiederkiiuern tritt das Mittelstiick des Cerebellun gegen die Seitenlappen mehr zuriick, was noch mehr der Full ist bei den Phoken, Delphinen und den höheren Affen. Doch erreichen auch bei diesen Gruppen die beträchtlichen, in viele, denen des Henschengehirnes entsprechende Lappen zerfallenden Seitenlappen nicht ein so bedeutendes Uebergewicht tiber den Wurm, wie beim Menschen. Auch ist bei allen Säugethieren die Anzahl der Querfalten des Cerebellum stets geringer, als beim Menschen. - Die Anhänge der Seitenlappen des Cerebellum oder die Flocken liegen, auch noch bei vielen Säugethicren sehr ausgebildet, in eigenthümlichen Vertiefungen der Felsenbeine, oberhalb des inneren Meatus auditorins.

Entsprechend der geringen Entwickehung der Hemisphären des Cerebelhum ist auch die Briicke bei den Honotremen und Beutelthieren am schwächsten ausgebildet, während auch sie wiederum bei den Robben, Delphinen und den höheren Affen die beträchtlichste Breite gewinnt.

Bei schwächerer Ausbildung der Bricke und geringerer Ausdehnung der Hemisphären des grossen Gehirnes erscheinen die Hirnschenkel vor der Brücke gewöhnlich länger, als beim Henschen, was besonders bei den Monotremen und Beutelthieren, aber auch bei den höher stehenden Wiederkäuern und Ferae und selbst noch beim Delphin — obschon hier in geringerem Grade - hervortritt.

Dic - oft noch hinter und nicht unter den llemisphären liegenden - Vierhïgel stellen weniger, als bei den niederen Wirbelthieren, vorherrschende Hirngebilde dar. Sie ermangeln immer jeder Spur von IIöhlung und zerfallen durch einen schwächer oder stärker entwickelten Querspalt in vier Massen. Sehr schwach ist diese Trennung noch bei Ornithorhynchus, wo selbst die Lingsfurche so wenig deutlich ist, dass die rorderen Vierhïgelmassen oder die Testes fast eine cinzige Erhabenheit zu bilden scheinen. Der Unterschied in dem Umfange der Testes unrl Nates ist bald gering; bald sind erstere, bald letztere melir oder minder ïberwiegend 2 ).

1) Abb. derselben bei den Monotremen bei 0 wen 1. c.; den Delphinen wurden sie mit Unrecht ron 'Tiedemann algesprochen; ich habe sie bei Delphimus phocaena immer angetroffen. S. d. oben citirte Abhandl. Tab. II. Fig. 2.

2) Die vorderen Hügel sind überwiegend bei dem Pferde, len Nagern, den 
Neben den Vierhügeln gelegen, treten bei den Säugetlieren noeh die Corpora geniculata externa auf.

Die Ifemisphären des grossen Gehirns stehen auf versehiedenen Entwickelungsstufen. Sie sind am wenigsten ausgedelınt bei den Monotremen, den Beutelthieren, den Nagern, Edentaten, Chiropteren und Inseetivoren, wo die Vierhügel noeh zum Theil frei liegen; ausgedelnter sind sie bei den Wiederkäuern, Einhufern und Raubthieren; noeh melır bei den Robben und Delphinen, wie denn endlieh bei den höheren Affen ein grosser Theil des Cerebellum von ihnen bedeekt wird. Während das grosse Gehirn sonst immer eine mehr oder weniger lïngliehe Form besitzt, überwiegt bei den Robben, den Delphinen und den Walen der grösste Querdurchmesser den Längendurchmesser.

Die Theilung jeder IIemisphäre in zwei hinter einander liegende Lappen erseheint, sehwaeh angedeutet, sehon bei einigen Beutelthieren, ist aber bei den höher stehenden Ordnungen, besonders den Paehydermen, Wiederkäuern, Einhufern, so wie bei den Ferde, den Robben und Delphinen sehr deutlieh ausgesproehen. Diese beiden Lappen entsprechen dem vorderen und dem mittleren des menschlichen Gehirnes, dessen hinterer Lappen erst bei den Affen - obgleich rüeksiehtlich seines Umfanges verschiedentlich, immer aber schwach entwiekell - auftritt.

Glatt und windungslos erscheinen die Hemisphären beim Selınabelthiere, bei den Fleiseh - und Insekten - fressenden Beutelthieren, bei einigen Edentaten; die ersten Andeutungen von Windungen zeigen sich bei Eehidna, bei den herbivoren Beutelthieren, den meisten Nagern, Insektenfressern, Fledermäusen, Faulthieren; ausgebildeter finden sie sieh bei allen höheren Ordnungen der Säugethiere. Sie sind bei den meisten Affen sehwäeher, als z. B. bei den Delphinen und Walen, wo sie stark entwiekelt und zugleieh unsymmetrisch erseleinen. Ueberhaupt sind die hinteren Hemisphärenlappen der Affen entweder sehwaeh mit Windungen versehen oder ganz windungslos; anseheinend sind die Windungen der vorderen Hemisphärenlappen bei den Affen regelmässiger und zugleieh symmetrischer, als beim Menschen ${ }^{3}$ ).

Aueh der verticale Durehmesser der Hemisphären zeigt beträehtliehe Yerschiedenheiten und bemerkenswerth erseheint es, dass selbst bei sonst verhältnissmässig hoher Organisation des Gehirnes, wie sie bei den Phoken und Delphinen angetrolfen wird, noch ein eigentliehes Centrum semiovale Vieusseni vermisst wird.

Wiederkäuern, den Maulwürfen, den Spitzmäusen, den Fledermäusen, die hinteren bei den Delphinen, den Ferae. Bei den Beutelthieren sind die vorderen Hügel mehr in der Längendimension, die binteren mehr in der Querdimension entwickelt.

3) Auf den verschiedenartigen Verlauf der Windungen haben besonders Ma lacarne, Treviranus uni Leuret ihre Aufmerksankeit gewendet; auch Owen hat sie (Zool. Transact. Vol. 1. p. 133.), namentlich bei den Katzen, genauer verfolgt. 
Die Seitenventrikel sind verhältnissmässig weit, besitzen aber - mit Ausnahur der meisten Affen, denen cin mehr oder weniger deutlich entwickeltes hinteres Itorn und der Phoken, denen es spurweise zukörmmt - nur ein rorderes und unteres Hlorn. Das Vorderhorn ist meistens weit, besonders bei schwacher Ausbildung der Marksubstanz der Hemisphären.

Die gestreiften Körper sind verschiedentlich entwickelt; besonders gross bei den Chiropteren, Nagern und Edeutaten. Das immer vorhandene A m mo nshorn ist bei den meisten Säugethieren verbältnissmässig grösser, als beim Irenschen; bei den niedriger stehenden Ordnungen erscheint es gerade und ermangelt, vielleieht beständig, der Zacken. Auch der beständig vorkommende Fornix ist bei vielen Säugethieren, im Vergleiche zum Umfange der Seitenventrikel beträchtlicher, als beim Ifensehen, namentlich bei den niedrigeren Ordnungen breit. - Die Vogelklaue fehlt den Säugethieren anscheinend immer.

Zwisehen dem Corpus striatum und dem Thalamus opticus erscheint die Taenia. Die Thalami optici selbst zeigen hinsichtlich ihres Unfanges mannichfache Abweiehungen.

Besonders wichtig sind die Versehiedenheiten, welche die Entwiekelung des Commissur ensystemes der beiden Hemisphären des grossen Gehirnes betreffen. Die beim Menschen und den höheren Säugethieren beträchtlichste dieser Commissuren: das Corpus callosum, dessen Anwesenheit lange Zeit als charakteristisch für das Gehirn aller Säugethiere angesehen ward, fchlt - nach den Mittheilungen von Owen noch den Ilonotremen und Beutelthieren, die auf diese Weise eng an die Vögel sich anschliessen. Mit dem Corpus callosum mangelt ihnen auch das $\boldsymbol{S}_{e p t u m}$ pellucidum. Bei den übrigen Säugethieren finden sieh diese Gebilde, obwol in verschiedenem Grade entwiekelt. Sehwaeh entwiekelt sind sie bei den Nagern, Edentaten, Chiropteren und Insectivoren. Das Corpus callosum gewinnt an Länge bei bedeutenderer Längenausclehnung der Hemisphären. - Die Commissura anterior seheint im Allgemeinen um so beträchtlicer zu sein, je mehr das Corpus callosum zurücktritt; so fand Owen sie namentlieh sehr stark bei den Monotremen und Beutelthieren. - Die Commissura mollis und posle. rior sind immer vorhanden.

Die Corpora candicantia erscheinen bei der Mehrzahl der Säugethiere zu einem einzigen mittleren Gebilde versehmolzen, dessen Theilung aber sehon bei einigen Raubthieren, z. B. den IIunden und Katzen, schwach beginnt, bei den Delphinen deutlicher wird und bei den höchsten Affen vollstiindig ist.

Dic IIypophysis ist bei den meisten Süugethieren noch verhältnissmässig umfänglicher, als beim Mensehen. - Die vorn mit den Thalami optici, hinten mit den Vierhiigeln in Verbindlung stehende 
Zirbel ist sehr gefäss'eich, scheint aber selten, und auch dann vielleicht nur ausnahmswoise, Ilirnsand \%u enthalten.

An den mittleren Lappen der Basis des grossen Gehirnes ragen bei der Mehrzahl der Säugethiere - indessen mit Ausnahme der Delphine, Robben und Affen - zwei graue seitliehe Erhabenheiten hervor (dic sogenannten Protulerautine natiformes s. Jyriformes), dercn Ausdehnung zu dem Uinfange der Processus mommillues der Geruchsnerven in directem Verhältnisse steht. Sie sind holle Verlängerungen der Seitenventrikel, in welche die Ammonshörner sich hinabsenken und von denen die Geruchsnerven grossentheils (wenigstens mit ihrer äusseren Wurzel) ausgehen. Als uninittelbare vordere Verlängerungen des Gehirnes erscheinen bei den meisten Säıgethieren - mit Ausnahme der iichten Getacecn, der Phoken und Affen - die hohlen Ricehnerven, welche mehr oder minder beträehtliehe keulen- oder knollenförmige, auf der Siebplatte liegende, häufig, wie bei Nagern und Inscetivoren, dureh eine Einschnürung in zwei Abtheilungen zerfallende Ansehwellungen (dio sogenannten Corpora mammillaria) bilden, aus denen dann die lileinen, das Sieb durehbohrenden Fädchen hervorgehen. Die IIöhlen der Geruchskolben eommuniciren mit den Seitenventrikeln. Die Kolben selbst sind gewöhnlieh vorn von den Vordertheilen der IIemisphären grösstentheils bedeckt; bei sehwacher Ausbildung der letzteren liegen sie ganz frei und unbedeckt vor ihnen, wie bei den Beutclthieren, Nagern, Chiropteren u. A. ${ }^{4}$ ).

Die Umhiillungen des Rückenmarkes und Gehirnes sind bei den Säugethieren wesentlich die nämliehen, wic heim Mensehen. Der Processus fulciformis der harten IIirnhaut, welcher nur beim Schnabelthiere und, obwol äusserst schwach angedeutet, auch bei Delphinen, eine knöeherne Grundlage besitzt, ist bei den Säugethieren im Allgemeinen und ganz besonders bei den tiefer stehenden Ordnungen der selben kürzer und schmäler, als beim Mensehen. Dis ansehnliche Tentorium cerebelli wird häufig durch eine knöeherne Grundlage (Tentorism ossenm) unterstütat ${ }^{5}$ ). Die Falx cercbelli fehlt durehaus oder

A) Die wesentlichsten Eigenthümliehkeiten des menselıliehen Gehirnes, aueh im Gegensatze zu deujenigen der lı̈ehsten Affen, sind: Stärkstes Ueberwiegen der Masse des Gehirnes über das verlängerte Mark, das Rüekenmark und das gesanmte peripherische Nervensystem; beträchtliehster Umfang des grossen Gelimes; mit der Hölıe der Stirn in Beziehung stehende Entwiekelung des Vordertheiles seiner Hemisphären; bedeutendste Entwickelung der hintersten Hemisphärenlappen und des hinteren Fornes der Seitenventrikel, bei Anwesenheit der Vogelklaue; asymmetrisehe Ausbildung der tiefen Windungen an der Oberfäehe der Hemisphären; Ausdelınung der Hemisphären über das kleine Gehirn; stärkste Entwickelung der Hemisphären des kleinen Gehirnes; grösster Umfang und tärkste Verzweigung des Arlior vilae; grösster Umfang der Mandeln.

5) Vergl. \$. 166. Anm. 3. 
ist nur schwaeh angedeutet. Das Ligamentum denticulatum der Dura mater spinalis wird anscheinend nie vermisst. Zwiselien den Blätern der harten Ilirnhaut liegen die venösen Sinus $\left.{ }^{6}\right)$. Arachnö̈lea und Pia mater seheinen keine wesentlichen Eigenthümlichkeiten darzubieten. Die Plexus chorioülei medii und laterales sind bestiindig rorhanden und besitzen, wenigstens bei Embryonen, ein FlimmerEpithelium.

\section{Voin peripherischen Nervensysteme.}

§. 182.

Das peripherische Nervensystem der Säugethiere bietet, so weit die bisherigen Untersuehungen es dargelegt haben, nur leichte und unbedeutende Abwciehungen von den bekannten Bildungen des Mensehen dar. - Dic Spinalnerven entspringen mit vorderen und hinteren Wurzeln. Der den Säugethieren eigenthümliehe $\boldsymbol{N}$. phrenicus wird immer gebildet dureh die vorderen Aeste mehrer Cervicalnerven. Der Plexws brachialis entsteht gewöhnlich dureh dic vier letzten Cerviealnerven und den ersten Dorsalnerven. Bei vielen Säugethieren tritt der $\boldsymbol{N}$. medianus durch das Foramen supracosulyloïleum Inumeri ${ }^{1}$. - Die Bildung eines Lumbargeflechtes für den $\boldsymbol{N}$. ischiadicus ist beständig. Bei den der Ilinterextremitäten ermangelnden Delphinen geht aus dem Lumbarplexus ein Nervenstamm hervor, dessen Zweige für die Muskeln des Beckenrudimentes und für die äusseren Gesehlechtstheile und ihre Muskeln, so wie für die Aftergegend bestimmt sind 2). - Bei Anwesenheit cines längeren Schwanzes verbinden sich die Rami amteriores der Rami sacrales gefleehtartig unter einander. - Gleich den Spinalnerven zeigen aueh die Hirnnerven eine sehr beständige, der des menschlichen Körpers entsprechende Anordnung. Unter den Sinnesnerven ist der $\boldsymbol{N}$. olfactorius der abweiehendste, sowol dureh seinen gänzliehen Hangel bei cinigen Delphinen ${ }^{3}$ ), als dureh seine beträehtlichen Corpora mammillaria bei den meisten übrigen Säugethieren, mit Ausnabme der höheren Affen, der Phoken und einiger Cetaeeen 4), bei welehen er ihnlieh, wic boim

6) S. über ihre Vertheilung bei den Haussäugethieren Gurlt, Vergl. Anat. Thl. 2. S. 358 .

1) Vielleicht bei den meisten oder bei allen Thieren, die dies Foramen be. sitzen. S. \$. 164.

2) Als Nerv dasselbe, was die Art. hypogastrica der Delphine, als Gefäss.

3) S. die Schiriften von Rapp (Cetaceen S. 106.) und von mir. Ich muss nach wielerholten Untersuchungen ihre Abwesenheit bei Delphinus phocaena behaupten.

4) 0 w en beschreibt den $N$. olfactorius von Balaena mysticetus als solide, rund, mehr als $\frac{1}{2}$ Zoll diek, allüälich zu einem Bulbus anschwellend, von welchem aus die Zweige durch die Lamina cribrosa des Siebbeines treten. Siehe 
Menschen, gebildet ist. - Der $\boldsymbol{N}$. opticus ist bei wenigen blödsichtigen Säugethieren sehr rudimentiii, fehlt jedoch nie gänzlich. Das Chiasma der beiden Sehnerven entspricht in seiner Bildung demjenigen des Menschen. - Der $\boldsymbol{N}$. acusticus ist bisweilen sehr stark. - Unter den Augeninuskelnerven ist es der $\boldsymbol{N}$. abducens, welcher bei den mit einem $M$. retractor bulbi $s$. choanö̈les versehenen Säugethieren auch in diesen Muskel sich vertheilt. Die Bildung des Ciliarganglion erfolgt, gleich wie bei den übrigen Wirbelthieren; über die Beständigkeit einzelner walırgenommener Abweichungen bleibt zu entscheiden übrig ${ }^{5}$ ). Bei einigen Säugethieren sind Verbindungen von Augenmuskelnerven ${ }^{6}$ ) mit Fäden des Ramus primus Nervi trigemini wahrgenommen. Nur bei Säugethieren mit sehr winzigen Augen, z. B. beim Maulwurf, wurden die Augenmuskelnerven bisher vergebens gesucht. - Der immer mit zwei Portionen entspringende $N$. $t \cdot \boldsymbol{i}$ ge eminus ist oft ausnehmend stark. Unter den Zweigen des Nerven ist der Rasnus infraorbitalis bei viclen Säugethieren ") sehr beträchtlich; seine Zweige verbreiten sich beim Ornithorhynchus unter der Haut des Schnabels; bei den durch Rüsselbildung ausgezeichneten Säugethieren an den häutigen Theilen des Rüssels; bei denen, wo die Barthaare als Tastorgane dienen, an den Bälgen dieser letzteren. Haut und Barthaare des Unterkiefers erhalten ihre $Z$ weige vom $\boldsymbol{R}$. alveolaris inferior. - Eigenthümlich ist den Säugethieren ein vom dritten Aste des $N$. trigeminus stammender $\boldsymbol{R}$. lingualis. Der Ramus unccinatorius erhält bei Wiederkäuern Elemente der Portio maior ${ }^{8}$ ). - Interessante Entwickelungsverschiedenheiten bietet der $\boldsymbol{N}$. facialis dar. Es sind die Muskeln des Mundes und der Nasenlöcher, welche er - ausser dern $\boldsymbol{M}$. mylolyyö̈leus, den Hautmuskeln des Halses und den Muskeln des inneren und äusseren Ohres - beherrscht. Bei den Delphinen vertheilt er sich besonders, wenn gleich keinesweges ausschliesslich, in die Muskelmassen des sogenannten Spritzloches. Bei den mit Rüsseln versehenen Säugethieren werden die oft ausserordentlich entwickelten Muskeln des

Hunter's Works edid. Palmer. Vol. IV. p. 377. Anm. a. Er gedenkt auch des $\boldsymbol{N}$. olfactorius von Balaenoptera p. 378. Eschricht bildet ibn ab am Hirne von Hyperoodon.

5) M u ck (de gangl. ophthalınico. p. 21. 22.) vermisste es bei einigen Nagern: Sciurus, Arctomys marmota. Dass er es beim Pferde init. Unrecht geleugnet, ist seitdem nachgewiesen. S. über dasselbe auch Swan 1. c. p. 158.

b) So des $\boldsymbol{N}$. trochlearis beim Schaafe, des $N$. abducens beim Kalbe nach Swan p. 164.

7) Abb. desselben ron Cystophora, Phoca, Dicotyles s. b. Rapp 1. c.; zahlreiche andere $\mathbf{A b b}$. der Aeste des Trigeminus bei Swan Tab. XXX.-XXXIII.; ron Ornithorhynchus bei Meckel Tab. V. VI.; voun Elephanten bei P. Cauper Tab. X. Enorm entwickelt finde ich ihn auch bei Manatus.

8) Vergl. Hagenbach im Berichte über die Verliandlungen d. naturf. Gesellschaft in Basel. Basel 18/4. 8. S. 97. 


\section{Vierter Abschnitt. Vom Nervensysteme u. v. d. Sinnesorganen. 395}

Ruissels von ilun mit Zweigen versorgt 9). Die kleinen Ilautmuskeln, welche die Bewegungen der Barthare bei vielen Säugcthieren vermitteln, erlualten Fiiden vom $\boldsymbol{N}$. facialis. Beim Menschen, wo die Muskeln der Nasenfligel und der Lippen inannichfach ausgebildet sind und wo von iliren Bewegungen der Gesichtsausdruck so wesentlich ablangt, wird der $\boldsymbol{N}$. facialis zum physiognomischen Nerven des Gcsichtes. Die Chorda tympaui scheint nie zu fehlen 10). - Der $\boldsymbol{N}$. glossop/laryngeus zeigt bisweilen rücksichtlich seiner Wurzeln einige Eigenthümlichkeiten $\left.{ }^{11}\right)$. - Der $\boldsymbol{N}$. vagus hat anscheinend immer zwei Ganglien 12). Als letztes Analogon des Systemes der Seitennerven niederer Wirbelthiere ist sein in die Paukenhöhlc tretender und an den $\boldsymbol{N}$. facialis sich legender $\boldsymbol{R}$. auricularis zu betrachten ${ }^{13}$ ). Dic übrigen Hauptästc des $\boldsymbol{N}$. vag'us entsprechen denen des Menschen. Am Halse verläuft der Stamın des Nerven bei vielen Säugethieren eng verbunden init dem oberflächlichen Halstheile des $\boldsymbol{N}$. sympathicns 14 ), während er bei anderen völlig getrennt ist von dem letzteren 15$)$. Der $\boldsymbol{N}$. accessorius kömmt allen Säugethieren zu; seine hintersten Wurzeln reichen his zu den Wurzeln des dritten, füften, sechsten oder siebenten Halsnerven. Seine Verbindungen mit dem Vagus innerhalb des Foramen lacerum sind mchr oder minder innig. Sein Ramus externus ist gewöhnlich für die $\boldsymbol{M}$. M. sternomastö̈deus und cucullaris, bei den Delphinen auch für den $\boldsymbol{M}$. occipito-humeralis bestimmt. - Der $\boldsymbol{N}$. lyppoglossus mehrer Säugethiere ist durch.sden Besitz eincr hinteren gangliösen Wurzel ausgezeichnet 16). - Die bislier bekannt gewordenen Abweichungen des sympatlischen $\mathrm{Ner}$ vensysteines von seinem Baue beim Menschen sind nicht erheblich.

9) Ueber das Schwein rergl. Swan; über den Elephanten s. P. Camper, Descript. p. 45. Tab. X. Fig. 3. 5. Stark entwickelt ist er auch bei Manatus.

10) Sic bildet bei einigen Wiederkäuern, namentlich bei der Ziege (und beim Schaaf) ein deutliches Ganglion. S. Swan p. 163.

11) Mayer fand beim Ochsen zwei Wurzelfäden, welche innerhalb der Dura mater in zwei Ganglien anschwellen.

12) Ueber seine Ganglien vergl. bes. die Schrift von Bendz.

13) Bemerkungen darüber bei $A$. Hannover libr. cit.

14) Eng verbunden bei Säugethieren aus allen Ordnungen. Wic Eininert (Reil's Archiv Bd. XI. S. 117.) gefunden, beim Hund, Wolf, Fuchs, Marder, Iltis, Katze, Ziege, Rind, Scliaaf, Pferd, Esel, Schwein, Murmelthier; nach E. H. Weler 1. c. p. 14. bei Cercopithecus; nach Bischoff anch bei der Ratte; naclı Barkow beim Ziesel. - Gurlt leugnet mit Recht die enge Verbindung beim Schwein; sie findet sich nicht bei Hystrix, Lepus, bei Mus sylvaticus (nach Bischoff), bei Talpa, bei den Delphinen und den Affen.

15) Eine sehr abweichende Eitstehung des $\boldsymbol{R}$. recurvens $N$. vagi beobachtete 0 wen bei der Giraffe. Er entsteht durch die Vereinigung mehrer, voin Stamme des Vagus, während seines Verlaufes an Halse, abtretender Zweige.

16) Bein Rinde, Schwein, Hund von M a yer beobachtet, 1. c. Tab. 54. 55. 
[Ueher das gesammte periplierische Nervensysten der Säugethiere s. detailliıte Angaben und Abbildungen von Swan in seinen oft citirten Illustrations. - Eiızelne Bemerkungen und Abbildungen bei Rapp, die Verrichtungen des fünften Nervenpaares. Leipzig 1832. 4. - Barkow, Disquisitiones neurologicae. Vratislav. 1836. 4. (über die Hautnerven tles Igels und den $N$. symmathicus). Ueber den $N$. accessorius s. die Schrift von Bischoff und H. C. B. Bendz, Tractatus de comnexu inter Nervum vagun et accessoriun Willisii. Havniae $\mathbf{1 8 3 6 .}$ 4. c. fig. p. 23 sqq. - Ueber die Ursprünge der letzten Hirnnerven M ay er in Nov. Act. Acad. Caes. Leop. Nat. Cur. Vol. XVI. p. 2. p. 740 sqq. - Ueber den N. sympathicus: die citirten Schriften von E. H. Weber und Swan l. c. Ueber den Kopftheil des sympathischen Nervensystemes beim Kalbe s. Arnold in Tiedemann und Treviranus Zeitschrift Bil. 2. S. $125 \mathrm{fr}$. - H. Bendz, Anatomisk Undersögrelse af den J a c obsonske Anastomose og Ganglion A rnoldi. (Aus den Scliriften der dän Acarl. der Wissensch.) Tjjöbenhavn 1835. 4. - Ueber den Halstheil des Sympathicus Mayer in Froriep's Notizen. No. 7รã. - Ueber inehre Hirnnerven vergl. die Bemerkungen von A. Hannover, de cartilaginibus, musculis, nervis Auris externae atque de nexu nervi vagi et nervi facialis. Harn. 1839. 4. - Ueber den Ciliarknoten s. die Schrift von Muck. - Ueber die peripherischen Nerven der Cetaceen: V. B ruls, Disquisitiones de nervis cetaceorum cerebralibus. Tubing. 1836. 8.; Stannins, Erster Bericht von dem zoot. phys. Institute der Universität Rostock. Rostock 1840. 4. S. 6 11. ff. und Stannius in Müller's Archiv 1842. S. 378. - Ueber die peripherischen Nerven der Haussäugethiere vergl. E. F. Gırlt, Handbuch der vergl. Anat. der Haussäugethiere. Bd. 2. S. $378 \mathrm{ff}$.]

\section{Von den Geruchsorganen.}

\section{§. 183.}

Die Geruchsorgane der meisten Säugethiere zeigen eine grosse Uebereinstimmung in ihrer Anordnung, welche nur bei den ächten Cetaceen $\left.{ }^{1}\right)$ wesentlich modificirt erscheint. Die bei allen Säugethieren

1) A In häıfigsten und genauesten untersuchlıt ist die Nasenhöhle von Delphinus phocaenit. Die Nasenbildung anderer ächter Cetaceen scheint wesentliche Verschiedenheiten darzubieten, wie schon aus der ganz abweichenden Beschaffenbeit des Siebbeines und aus der anscheinend keinem Zweifel unterliegenden Anwesenheit der Geruchsnerven bei den Walen hervorgeht. Dass ich von den Vorhandensein diesel letzteren bei $D$. phocaena mich nicht habe überzeugen könmen, wurde schon früher bemerkt. Oft habe ich an ganz frischen Gehirnen Fädchen gesehen, ganz so, wie sie als Gerucbsnerven, nanentlich durch Baer, beschrieben sind; aber die mikroskopische Untersuchnng liess keine Nerven in ihnen erkennen. - Die Nasenhöhle der Cetaceen liegt nicht horizontal über der Mundhöhle, sondern erstreckt sich fast vertikal von oben in die Rachenhöhle hinab; somit erscheint der äıssere Eingang in dieselbe weiter nach hinten gerückt. Die älussere Nasenöffnung ist bei den Walen vollkommen getheilt; bei den Delphinen unpaar. Hier besitzt sie eine wulstige vordere und lintere Lippe, welche durch Wirkung eines, aus mehren Schichten bestehenden, von der ganzen Oberfläclie des Schedels entspringenden Muskels ans einander gezogen werden können. Diesé Lippen unschliessen ten Eingang in einen, von derbein, fibrösell, in seiner feineren Textur noch nicht hinlänglich untersuchtem, Gewebe gebilleten, inwendig 
paarigen, bisweilen, wie z. B. bei den Monotremen und mehren Edentaten, sehr verliingerten Nasenhöhlen besitzen vordere und hintere Oeffnungen. Die zu ihrer Umschliessung beitragenden Knochen sind gewöhnlich: die Oberkiefer- und Zwischenkieferbeine, die Gaumenbeine, die Niscntheile der Stirnlucine, die Nasenbeine, die Thränenbeine, das Sichbein und das Keilbein nebst den Ossa pterygnädea, so wie auch die Muschelbeine und der Vomer. Die Scheidung der beiden Nasenhöllen gesehicht durch den Vomer und durch hinzutretende knorpelige Theile (Cartilağo septi narium). - Die äusseren Nasenöffnungen werden gewöhnlich dureh Knorpel unterstiitzt, welche bald selbstständige Theile sind, wie z. B. bei den Einhufern und Wiederkäuern 2), bald dureh Auswärtsrollung des knorpeligen Septum narium entstehen, wie bei Janatus und vielen Ferae, und bisweilen röhrig verlängert erscheinen, wie bei einigen Plantigraden Ferae ${ }^{3}$ ) und Insectivoren. Die Erweiterung der äusseren Nasenöffnungen geschieht bei den meisten Säugethieren theils durch einen, der Nase aussehliesslich angehörigen, verschicdent. lieh entwickelten Muskelapparat 4), theils auch durch Muskeln, welche

von Schleimhaut ausgekleideten, noch ausserhalb odler oberhalb des knöchernen Kopfes gelegenen weiten einfachen Canal. Mit dieseın communiciren zwei gleichfalls durch Fascikel jenes Muskels zu erweiternile Säcke, die sogenannten Spritzsäcke, deren schwarz tingirte Innenfläche parallele längliche Erhabenheiten und Vertiefungen besitzt. In der Tiefe des einfachen Canales zeigen sich Avei durch eine enge Spalte getrenute Klappen. Zwischen jeder dieser Klappen und dem knöchernen Kopfe finden sich noch zwei Paar Nebensäcke. - Unterhalb derselben zerfüllt die Nasenhöhle, von Knochen unschlossen, durch die vom Vomer gebildete Scheidewand in zwei Hälften und mündet in den Rachen. Die Verschiedenheiten, welche dieser hier nicht ausführlicher zu beschreibende Apparat bei anderen Cetaceen darbietet, sind noch fast unbekannt. Die Aussagen iiber das Ausspritzen des Wassers durch die Cetaceen sind von Baer (Isis 1826 . S. 323. u. 1828. S. 927.) in Zweifel grezogen, während Eaber (Isis 1827. S. 858.) und Sandifort, Bijdragen tot de ontleedk. Kennis der Valvisschen. Austerl. 1831. 4. p. 31.) sich (lurch Autopsie von diesem Ausstossen des Wassers ïberzeugt haben. Mir bleibt immer Scolesby's Angabe (An account of the arctic regions. Vol.1. p. $456 \mathrm{sqq}$.) am wahrscheinlichsten, wonach die Cetaceen nur den mit Schleiu gemischten, feuchten - von der Oberfläche der Athmungswerkzeuge ausgehauchten - Dunst beim Ausathmen ansstossen, der nur dann von Wasser begleitet wird, wenn das Ausathmen unter Wasser geschieht. - Abbildungen der Nasenhöhle des Braunfisches geben: P. Camper, Cétacés 'Tab. XLVIII. Fig. 1.; Baer, Isis 1826. Tab. V. und Sandifort, Op. citat. Tab. V.

2) S. ihre nähere Beschreibung bei Gurlt, Lehrbuch 'Thl. 1. S. 168.

3) S. Näheres bei Cuvier, Vorlesungen Thl. 2. S. 642 .

4) Selten fehlt jeder Muskelapparat, wie beim Schnabelthiere; über dic Mus. keln der einheimischen Säugethiere s. Gurlt Thl. 1. S. 238.; über die anderer Säugethiere s. Cuvier, Vorlesungen Thl. 2. S. 641.; über die der hölıeren Affen mangeln noch fast alle Angaben. Bei den meisten Affen scheint nur der gemeinsame Nasen - und Lippenleber vorhanden zu sein. Ueber die Nasenmuskeln von Phoca s. Rosentlal in den Nov. Act. Acal. Leop. T. Xll. P. 2. Tab. LVI. 
zugleich dic Lippen bewcgen. Diesc Muskeln stehen unter Einfluss des Nervus facialis. Schon bci einigen Plantigraden Ferae, z. B. bei Ursus, Nasua u. A. liegen die äusseren Nasenöffnungen am vorderen Ende der vcrlängerten und sehr beweglichen Schnauze. Diese erscheint bei den Maulwürfen, den Schweinen und Tapiren zu einem Rüssel ${ }^{5}$ ) verlängert, der beim Elephanten, wo er ausserordentliel entwickelt ist, ein sehr wichtiges Tast- und Ergreifungsorgan darstellt und zugleich die sehr verlängerten Eingänge in die Nasenhöhlen enthält. - Anders ist die Organisation der äussercn Nase beim Klappmützen-Seehunde, wo sie als cine grosse, häutig-muskulöse Blase erscheint $\left.{ }^{6}\right)$. - Die Nasenhöhlen der meisten Säugethiere communicircn mit Nebcnhöhlen. Diese sind - abgesehen von den Siebbeinzellen - die Sinus froutales ${ }^{7}$ ), maxillares ${ }^{8}$ ) und sphenoüdules ${ }^{9}$ ), welche bei den verschiedenen Familien und Gattungen von sehr verschiedener Weite sind. - Die Flächenvergrösserung der inneren Nase geschieht durch die Muscheln. Von diesen sind die beiden oberen, deren Stellung von der den Muscheln des Menschen zukommenden manniehfach abweieht, Theile des Siebbeines oder selbst nur vergrösscrte Zellen dessclben, während die untere als selbstständiger Knochen erseheint. Selten gehen aueh von anderen Knochen, z. B. den Nasenbeinen, muschelförmige Bildungen aus. Riucksichtlieh der Bildungsverhältnisse der unteren Muschel finden bei den Säugethieren wichtige Unterschiede Statt. Bei vielen und namentlic) Phei Planzenfressern 10) ist der Bau der Muschel wenig zusammen-

5) Ueber die Bildung des Rüssels der Säugethiere, namentlich des Elephanten, handelt am ausführlichsten Cuvier l. c. S. 642 u. 645. Von früheren Ab. handlungen vergl. noch besonders Perrault, Mém. p. servir à l'list. nat. d. anim. p. ร̌ร̌. und Camper, Decript. d'un Eleph. p. 45 .

6) S. Näheres über den Klappunïtzen-Seehund bei Rap $\mu$ in Meckel's Arcliv 1829. S. 236. Mit Abb. Tab. VII.

7) Die Stirnhöhlen sind aın beträchtlichsten bei den Elephanten, wo sie, auch Jurch die Scheitelbeine und Schlafbeine sich erstreckend und in zahlreiche, mit einander communicirende Zellen zerfallend, bis zu den Gelenkfortsätzen des Hinterhauptsbeines reichen. Aelınlich ausgedehnt sind sie bei den Schweinen und Faulthiereı. Bei den meisten gehörnten Wiederkäuern sind sie gross und comınuniciren gewöhnlich - doch nicht immer, wie z. B. nicht bei den Antilopen, - mit den Höhlen der die Hörner tragenden Zapfen. Ausgedehnt sind sie auch bei den Einhufern und einigen Beutelthieren. Weniger ist dies der Fall bei den meisten Ferae; noch kleiner sind sie bei den Quadrumanen. Einigen derselben, so wie auch vielen Nagern und Edentaten (Myrmecophaga, Manis) fehlen sie.

8) Sehr beträchtlich bei den Einhufern (wo sie doppelt sind), den Wiederkäuern und den meisten Beutelthieren; von mässigem Unfange bei den Quadrumanen; bei den Ferae, den meisten Nagern und Edentaten fast ganz verschwindentl.

9) Wiederum am umfänglichsten beim Elephanten; bei den übrigen Säugethieren unbeträchtlicher, als bein Menschen; zun Theil auch ganz felılent.

10) Einfach ist der Bau der unteren Muschel bei den Affen der alten Welt; wenig zusammengesetzter bei den Affen der neuen Welt; die oben kurz beschrie. 
gesetzt. Selir oft spaltet sich der frcic Theil der an ihrer Bcfestigungsstelle einfachen Muschel in eine oberc und einc untere Lamclle, wolche nach entgegengesetzten Riclutungen: dic cine nach oben, die andere nach unten sich umrollen. Bei anderen Siugcthieren und besonders bei Fleischfressern 11) zeigt dagegen der genannte Knochen viel complicirtere Bildungen. Der am Oberkieferbeinc befestigtc Stamm desselben theilt siclı in mehre Hauptäste, deren jcder durch fortgesetzte Theilungen in eine sehr grosse Zahl von Zweigen mchrer Ordnungen zcrfällt. Die ganzc Vertheilungsweise hat, namentlich bei den Scehunden und Fischottern, wo die geschilderte Bildung der unteren Muschel am meisten entwickelt ist, unverkennbare Aehnlichkeit mit der der Blätter am Arbor vilae des kleinen Gehirnes. - Durch diese Muscheln zerfällt bei den meisten Säugethieren jede Nascnhöhle in drei Gänge. - Eigenthümlich sind den Nasenhöllen vielcr Säugethiere die Stenson'schen Gäinge 12) und die Jacobson'schen Organe ${ }^{13}$ ). Erstere bestehen in Canälen, welche eine knorpelige, von Schleimhaut überzogene Grundlage besitzen und, durch die Foramina incisiva sich fortsetzend, mit oft ziemlich weiten Oeffnungen, welche auf Erhabenheiten hinter dem Alveolarrande des Zwischenkiefers sich finden, an der Gaumenoberläche muinden. Die Jacobs on'schen Organe sind lange und enge, am Boden der Nisenhöhlen und zur Seite ihrer Scheidewand gelegene, von Knorpel umschlossene, inwendig von drüsenreicher Schleimhaut übcrzogene

bene Bildung findet sich bei den meisten Wiederkäuern und vielen Pachydo $\mathrm{A}$; bei ersteren sind die Blätter der Muscheln gewöhnlich noch von zahlreichen 0effnungen durchbrochen. Den Muscheln der Wiederkäuer ähnlich sind die der meisten Elentaten, mit Ausnahme der durch abweichende Bildung ansgezeichneten Faultbiere; wenig entfernen sich davon die mebrer Nager (Hystrix, Arctomys n. A.), wälırend andlere zusammengesetztere Bildungen zeigen. Sehr einfach sind auch die Muscheln vieler Beutelthiere, z. B. des Känguruhs, des Wombat, Koala u. s. w. Von dem complicirten Baue anderer Ferae entfernen sich auch Einige, z. 13. Viverra. Vergl. Cuvier I. c. p. 625 .

11) Der zusammengesetzteste Bau der unteren Muscheln wird angetroffen unter den Beutelthieren z. B. bei Dasyurus und Phalangista, unter den Nagern bui Lepus, Sciurus, Castor, Mus, so wie bei den meisten Ferae: Felis, Canis, Mustela, Meles, besonders aber bei Lutra und Phoca."Abb. vergl. b. Harwood l. c. Tab. VIII. u. $\mathbf{I X}$.

12) Vergl. N. Stenonis, de musculis et glandulis observationum specimen. Anstel. 1664. 12. p. 37. - S. über die Stenson'schen Camäle des Menschen Huschke in der neuen Ausgabe von Soemmering. Thl. 5. S. 610 .

13) S. Cuvier's Rapport darüber in den Annales du Muséuu d'hist. nat. Vol. XVIII. 1811. p. 412. Vergl. ferner J. A. Re iffsteck, D. sist. disquisitiones anatomicas de structura organi olfactus mammalium nonnullorum. Tubing. 1823. 4. p. 27. (Mit Abb. vom Schaafe) und Rosentlal in Tiedemann und Treviranus Zeitschrift für Plyysiologie. Bd. 2. S. 289. Tab. XIV. (Schaaf). Das Jacobson'sche Organ ist bei Säugethieren verschiedener Orilnungen angetroffen; besonders entwickelt bei Nagern, Pferden, Wiederkäuern und bei Manatus; spurweise bei den Ferae. - Deu Pferle fehlen die Stens on'schen Camäle. 
Röhren, in welchen Zweige des $\boldsymbol{N}$. olfuctorins sich vertheilen und der R. nasopalatinus $\boldsymbol{N}$. trigemini unter Abgahe von Verzweigungen verläuft. Jede dieser Röhren öffnet sich gewöhnlich in den Stenson'schen Gang ihrer Seite und communicirt durch diesen init der Mundhöhle. Die, die ganze Nasenhöhle auskleidende Srhieimhaut besitzt innmer ein Flimmer-Epithelium. - Bei den meisten Sïugethieren kömmt eine conglomerirte Nasendriise vor. Sie liegt an der äusseren Wand der Nasenlröble oder in dem Sinus maxillaris. Ihr aus dem Zusammentreten kleiner Zweige gebildeter Ausführungsgang öffnet sich am vorderen Theile der unteren Muschel 14 ).

[Man vergl. über das Geruchsorgan der Säugethiere, ausser den Schriften ron Scarpa nud Harw o od, besonders Cuvier's Vorlesungen über vergl. Anat. übers. von Meckel. Bd. 2. S. 614 ff. - Ueber das Geruchsorgan von Delphinus phocaena handelt sehr ausfülurlich $\nabla$. B a er in der Isis 1826. S. 811 fr. Mit Abb. Tab. IV. 11. V.]

\section{Von den Gesichtsorganen.}

\section{§. 184.}

Die Augen der Säugethiere besitzen fast durchgängig einen im Verhältnisse zum Körper und namentlich zum Kopf und zum Gehirne - viel weniger beträchtlichen Umfang, als die der Vögel; in dieser Bezichung erscheinen die Augen einiger Halbaffen 1) aın grössten; rudimentör- ind sie dagegen bei den in der Erde lebenden Maulwürfen 2) und be hax typhlus. - Bei der Mehrzahl der Süugethiere öffnen sich die knöchernen Augenhöhlen ${ }^{3}$ ), deren knöcherner Boden immer unvollkommener wird und allmälich ganz verloren geht, in die Schläfen- oder Jochgruben; bei manchen tritt auswärts eine Scheidung beider Höhlen hervor, indem der hintere Augenhöhlenfortsatz des Stirnbeines mit dem

14) Stenson hat sie zuerst beim Schaafe beobachtet (De muscnlis et glandulis. Aust. 1664. 1. 38.). J a cobson (Nouveau Bulletin des scienc. par la soc. philow. de Paris. T. 3. $6^{\mathrm{me}}$ ann. p. 267. und Ḧ̈ller, Gland. secern.) fand sie bei Haluaturus, vielen Nagern, Wiederkänern, Pachydermen, Ferae, Chiropteren und Affen. Beim Pferde und Menschen sind nur einzelne Acini übrig. Bein Rinde hat er sie vermisst. Ich finde sie bei Manatus.

1) Stenops, Tarsius, Galago; selır gross auch bei einigen Affen, z. B. bei Nyctipithecus.

2) Besonders bei Talpa coeca, Chrysochloris; etwas entwickelter schon bei der Gattung Sorex und bei Talpa europaea. Siehe über das Auge des letzteren Treviranus in der Zeitsclırift für Physiol. Bd. II. S. 176. Tab. 7. Fig. 7. u. 8. - Anch das Auge von Talpa coeca soll nach Is. Geoffroy cine selı feine Angenlidspalte besitzen, die von Savi gelengnet war. - Ueber das Ange von Spalax s. Olivier (Bulletin de la soc. philounath. T. 2. N. 38. 1. 105\%). Er fand darin ille Theile des Säugethierauges.

3) Bei Ornithorhynchus wird nach Meckel (Ornithorl. p. 39.) die Angenhöhle oben und vorn durch einen bewegliclıen Knorpel und durclı fibröse Substant vervollständigt. 
des Jochbeines oder unit dem Jochfortsatze des Schlifenbeines durch rin fibröses l3and oder wirklich unmiltelbar sich rerbindet 4 ); nur bei den eigentlichen Affen erscheint die Augenhöhle, wie beim Henschen, durch eine Knochenwind von der Schliffengrube abgesehlossen. Bei dénjenigen Sïugethieren, welchen diese Knochenwand fehtt, wird die Trennung ron der Schliafengrube meistens durch eine fibröse, auch elistisches Gewebe reichlich enthaltende, Menubran bewirkt, welche vom Umfange des Forumen opticum ausgeht ${ }^{5}$ ); bei anderen, wie beim Bären, ward, statt dieser Membran, cin Muskel (M. orlitalis) angetroffen. - Bei der Hebrzahl der Säugethiere sind die Augen nach aussen gerichtet und divergiren daher so, dass ihre Axen sich nicht in einem Punkte des Gegenstandes vereinigen; bei den Affen und Menschen treten sie vorwïrts. Die grösste Annïherung beider Bulbi, welche hier durch ein diirmes, biswcilen nicht einmal vollständig ossificirtes Septum geschieden werden, findet sich bei einigen Halbaffen und Affen 6) - Den meisten Säugethieren kömmt, ausser dem oberen und unteren Augenlide, noch die Nickhaut T) zu; gewöhnlich nzerden alle drei Augenlider durch Kinorpel gestiutzt. Meistens liegr pen der Coujunctiva palpebramm und dem Tarsus, als längli nache Follikel die Mcibom'schen Drüsen, welche aber oft, wic z. B. bei den Cetaceen, fehlen. Augenwimper sind noch selten vorhanden. - Dic Anordnung der Muskeln der beiden oberen Augenlider bietet einzelne Verschiedenheiten dar ${ }^{8}$ ). Gewöhnlich findet sich ausser dem M. orticularis pal-

4) Eine Verbindıng des knöchernen Orbitalfortsatzes des Jochheines mit dem gleichen Fortsatze des Stirnbeines und ein dadurch gebildeter vollständiger Augeuhöhlenring olıne Abschliessung gegen die Schläfengrube findet sich bei den Halb. affen; ferner unter den Chiropteren bei Pteropus und Euballonura, unter den Insectiroren bei Cladobates, unter den Ferae bei einigen Herpestes und einigen Arten von Felis (z. B. bei F. javanensis), bei allen Wiederkäuern; unter den Pachydermen bei Hippopntaıns, bei den Einhufern. - Bei anderen Sängethieren, wo jene Fortsätze sich nicht erreichen, geschieht die Vervollständigung des Ringes durch ein fibröses Band; so bei Felis, Canis, Hyrax u. A.

5) Näher beschrieben von Bendz in Miiller's Arehiv 1841. S. $196 \mathrm{ff}$. Er fand das eingeschohene elastische Gewebe an deutlichsten beim Pferde; dïnner beim Rinde, Schaafe und Schweine, dann anch beim Hunde. Rudolphi, Phys. 2r Bd. 1. Abth. S. 159. hatte diese elastischen Fasern für Muskelfasern erklärt. In Eisbären fand Rudolphi den $\boldsymbol{M}$. orluitalis am stärksten; beim gewölnnlichen Bären schon schwächer. Meckel erwähnt dieses Muskcls auch beim Schnabclthiere. - 6) Besonders bci Cebus, Callithrix, Tarsius. - Auch bei den Phoken ist die Scheidewand der Augenhöhlen sehr schunal.

б) Als Ueberrest derselben erhält sich bei den Affen und beim Menschen die Plicre semilunaris, welche anch hier bisweilen cinen kleinen Kinorpel enthält. Die Nickhaut fehlt den ächten Cetaceen, findet sich aber bcim Dügong und Alanatus sehr entwickelt.

8) S. die Beschreihung derselben von Phoca bei Rosenthal, Nov.Act. Acad. Caes. I.eop. T. XII. P. 2. p. 689. 
pelurarum ein $\boldsymbol{M}$. levator palpelrac superioris. Aber diese Anordnung ist nicht bestandig. Bei den Delphinen zeigt sich z. B. innerhalb der Augenhöhle ein hohler, trichterförmiger Muskel, der in Umkreise des Foramen opticum entspringt und in den Augenlidern sich ausbreitct. Durch Schlitzc dicses Muskels treten die schiefen Augenmuskeln zum Bulbus, während er die gcraden völlig einschliesst. Ausser ihm findet sieh nur ein schwacher $\boldsymbol{M}$. orlicularis palpelrarum, der volzugsweise fuir das untere Augenlid bestimmt ist. Diese's besitzt hier und bei andercn Säugethieren, z. B. den Wiederkäuern, Pachydermen, Einhufern, noch einen herabziehenden Muskel in dem M. malaris $\boldsymbol{c} \boldsymbol{x}$ ternus. - Die Nickhaut der Säugethicre kann fast nie über das ganze Auge vorgezogen werden; meistens scheinen eigene Muskeln derselben zu fehlen; bei einigen Thieren sind sie jedoch naehgewiesen ${ }^{9}$ ). An ihrer Innenseite mündct der Ausführungsgang der, bei ihrer Anwesenheit, anseheinend niemals fehlenden, am Innenwinkel der Orbita gelegenen, nieht selten aus zwei Portionen bestehenden und beträchtlichen Harder'schen Drüse 10) _ - Nur selten bleibt die Snaltung der Augenlider aus, wie denn bei Spalax typhlus dic mit IIaaren besetzte Haut uber das rudimen, aro Auge weggeht; unter ihr findet sich hier, ähnlieh wie bei mehren Reptilien, eine kleine, von der Bindehaut gebildete Capsel 11). - Dass der Thränenapparat je einem Säugethiere spurlos fehle, darf bezweifelt werden 12); unter den ächten Cetaceen, denen man dic Thränendrủse lange Zeit ganz abgesproehen hatte, besitzen die Delphine eine ringförmige, grösstentheils innerhalb des trichterförmigen $\boldsymbol{M}$. prlpelralis gelegene Thränendrise, welche nur in der Gegend des inneren Augenwinkels aus diesem Trichter sieh hervor-

9) Von Perrault und Camper (Elephant p. 45.) beim Elephanten. S. die Abb. Tab. X. Fig. 6.; von Cuvier bein Rhinoceros; von Albers (Beiträge zur Anat. und Phys. Hft. 1. S. 7.) beim Seehunde; von Rudolphi bei der Hyäne und sehwächer bein Hunde (S. C. G. E. Reimann, Spieilegium observ. anat. de Hyaena. Berol. 1811. 4. 1. 21.); von R os enthal bei mehren Säugethieren. Vergl. A. Blumentha \}, Diss. de externis oeulorum tegumentis. Berol. 1812. 4. - Bendz l. e. S. 199. leugnet neuerdings wieder jeden Muskelapparat der Niek. haut bei den Haussäugethieren und erklärt das Vortreten der Nieklıaut auf ganz meehanisehe Weise.

10) Zweilappig ist sie z. B. bei ilen einheimisehen Nagern: der Ratte, deur Masen. (Abgeb. bei Müller, Gland. seeern. Tab. V. Fig. 7. p. 51.) Sie ist, mit Ausnahıne der Quadrumanen, der Chiropteren und der Cetaceen, bei Säugethieren jeder Ordnung angetroffen worlen.

11) So nach Carus (Zootom. S. 408.) und Müller.

12) Die Thränendrüse wurde von Cainper (Elepbant p. 45.) beim Elepharten, nebst den Thränenpunkten, dem 'Thräneneanal u. s. w. vermisst; Periault hatte sie gefunilen. Nach Blainville l. e. p. 394, hat sie die Grösse einer Erbse. Auch er vermisste Thränenpunkte und Thräneneanal. - Sie kömmt nach Rosen. thal bei Phoca vor, obsehon klein; die Ableitungsorgane fehlen. 


\section{Vierter Alschnitt. Vom Nervensysteme u. v. d. Simesorganen. 403}

drängt 13). Bei den übrigen Säugethieren belıauptet sie ihre Lage am oberen und äusseren Theile der Augenhöhle. Rüeksiehtlieh der Thräinenpunkte und des Thrïneneanales kommen manehe kleine Versehiedenheiten ror. - Bei den meisten Säugethieren ist die Anzahl der den Bulbus bewegenden Muskeln beträehtlicher, als beim Menschen, indem zu den vier geraden und zwei sehiefen Muskeln ${ }^{14}$ ) noeh der von den geraden Augenmuskeln umschlossene, übrigens versehiedentlieh ausgebildete, of in vier Porlionen zerfallene, vom Umkreise des Sehnervenloehes zum Bulbus tretende M. suspensorins s. retractor oculi s. choanoz̈des hinzukömmt 15).

Die Form des Bulbus ${ }^{16}$ ) ist häufig fast kugelig; bei einigen, wie z. B. bei den Cetaceen, ist er vorn mehr abgeplattet; bei andern vorwiirts stark gewölbt, wie beim Maulwurf. Der Querdurehmesser iibertrifft am bedeutendsten die Längenaxe beim Walfiseh, weniger bei den Phoken, dem Pferde, den Wiederkäuern, Nagern, Beutelthieren, während bei den Fledermäusen, den Affen und dem Mensehen die Längenaxe beträehtlieher ist ${ }^{17}$ ). Die einzelnen Theile des Augapfels sind im Wesentliehen ähnlieh, wie beim Mensehen and ficationen sind in abweiehender Lebensweise begründet, erklären sich daher aus dem Medium, in welehem die Thiere leben, ans ihrer Regsamkeit zur hellen Tages - oder Dämmerungszeit, aus der ihnen zu Erlangung ihrer Nahrung erforderliehen Nah-oder Fernsichtigkeit u. s. w. - Allgemein fehlt den Säugethieren der den Vögeln und vielen Repti lien zukommende Knochenring der Selerotiea, so wie aueh der Kamm. - Bei den im Wasser lebenden Säugethieren, namentlich den Cetaceen, den Phoken nähert sieh die Linse der Kugelform, während sie bei den in der Luft lebenden Thieren flaeher wird; dagegen ist bei diesen die Hornhaut eonvexer und die Menge der wässerigen Feuehtigkeit grösser, während jene dureh flachere Cornea und Abnahme des Humor aqueus sieh auszeiehnen. - Die Selerotiea zeigt bei vielen Säugethieren und namentlieh bei den im Wasser lebenden, Verschiedenheiten ihrer

13) Zucrst beschrieben von Rapp in den naturw. Abhandlungen einer Gesellschaft in Würtemberg. Thl. 1. 1826. S. 25\%.; Cetaceen S. 93 . Ich fand sie eben so beim Narwal.

14) Die Rolle für den Mr. olliguus superior fchlt bei den ächten Cetaceen. Rudolphi beobachtete eine Spaltung der Sehnen beider schiefen Augenuuskeln beim Tiger; von den beilen Schnen, in dic jeder Mnskel sich spaltet, umfassen dic des oberen diejenige des Rectus superior und dic des unteren die Sehne des Rectus inferior. Bcim Löwen zeigt dic Sehne des Olliguus superior dasselbe Verhalten. Rudlol liti vermisste diese Einrichtung bei anderen Raubthieren, auch bei der Hauskatze (Phys. S. 169.).

10) Abb. rour Sechunde bei Roscuthal, Nor. Act. Acad. Cacs. Lcop. Vol. XII. P. 2. Tal. I.VII.

16) S. die sehönen Abb. bei Soc inmerring, de sect. horizont. Tab. If.

17) Vergl. die Messungen bei Soemuerriug p. 79. 
Dieke in ihren verschiedenen Gegenden ${ }^{18}$ ); rom Strahlenlarinde aus nimmt ihre Dicke, z. B. bei Phoea, sowol naeh vorne zur Cornea hin, als auch nach hinten zum Sehnerven hin betrïchtlielı zu; beim Walfische hat nur die letztere Verdiekung Statt. Das gleiche gilt bei den Phoken und Cetaceen von der Choriö̈lea. Bei viglen Siugethieren erschcinen regelunilssig an bestimmten Gegenden dés Auges Stellen ron grïn-, blau- oder nctalliseh-glänzendem Aussehen, wie z. B. bej den Wiederkäuern, den meisten Ferae, den Delphinen und Roblon. Sic bilden das sogenannte Tajetum 19$)$. Diese Stellen finden sielı gevölınlieh um den Eintritt des Sehnerven herum, besonders aber oberhalb und auswärts ron ihm, bei Delphinen und Robben über den granzen Grund des Auges verbreitet. Bei den Wiederkäuern fehlen hier die Pigmentkörnchen der Chorioïdea oder werden sparsam und es elseheint, statt der sonst den Pigmentkörnchen zur Grundlage dienenden Schieht ron Bindegewelse, eine sehnige, gefïsslose Membran (das eigentliche Tapetum). Bei den Carnivoren findet sich hinter dem abweichend gebildeten, zelligen Tapetym hiufig noch eine eigenthuimliche, kalkartige, kreideweisse Masse. Hic Pupille ist bald rund, wie bei den Quadrumanen, den meisten Niagern u. $\Lambda$., oder vertikal verlängert, wie bei den Katzen und vielen anderen Raubthieren, oder horizontal, wie bei den Einhufern, Wiederkäuern u. $\Lambda$. Bei den Einhufern, den meisten

18) Ueber ihre Dimensionen beim Walfisch und Narwal s. Albers in den Abhandl. der phys. med. Soc. zu Erlangen. Bı. 1. S. 40̃9. Mit Abb. und Socmmerring 1. c. j. 43.; ähnlich bei den Delphinen; ïber Phoca s. Esclıricht in Müller's Archiv 1838. - Carus bemerkte Achnliches beim Schwein (vergl. Zootom. S. 407.).

19) S. über das Tapetmn besonders: Hassenstein, de luce ex quorundam animalium oculis prodcunte atque de tapeto lucido. Jenae 1830. 4. - Er fand hinter deın Tapetum der Katzen und Carnivoren überhaupt eine kreideweisse Masse, gebildet durch Kügelchen aus phosphorsaurer Talkerde und Kalkerile rou

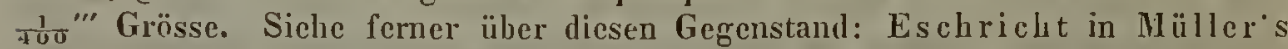
Archir 183S. S. 575. Er beschreibt das Tapetum, namentlich das der Wiederkäuer, als eigene Membran, die bei den zuerst genannten Thieren milchweiss, beim Rinde flechsenartig, bei allen aber gefässlos ist und nur Löcher zum Durchgange von Gefüssen besitzt. Ausserdem macht er auf die schon den älteren Ana. tomen bekannte Hovius'sche Membran oder Chorioeapillarhaut mit sternförmiger Gefässbildung, welehe die innere Seite des Tapetuın ïberzieht, aufmerksan. Abb. der Choriocapillarmeubran des Rindes Tab. XVI. Fig. 1. - Bei den meisten Quadrumanen, mit Ausnahıre von Nyetipithecus, den Monotremen, Nagern und den meisten Edentaten (uit Ausnahme von Orycteropus) ist bislıer kein Tapetum angetroffen worden. - Nachträglich erwähne ich der eben erschienenen wichtigen Untersuchungen von Brü cke (Müller's Archiv 1845. S. 387.) ïber diesen Gegenstand. Er fand das von Eschricht beschriebene Tapelum filrosum bei den Wicderkäucrn, Einhufern, dem Elephanten, den Cetaceen und einigen Beutelthieren (Thylacinus, Dasyurus). Bei den Ferac und Robben enteckte er aber ein Tapelum cellulosum. Es besteht aus unregehnässigen, sechseckigen, glatten, gelblichen Zellen mit wasserhellen Kenen. 
Wiederküuern, dem Narwal finden sieh pignentreiche Floeken, welche, besonders rom oberen Rande der Pupille herab, schleierartig vorhangeu ${ }^{20}$ ). - Der gelbe Fleek der Netzhaut ist, ansser beim Menschen, nur noch bei Affen angetroffen worden. - Der Sehnerv ist nur bei cinigen blüdsichtigen Säugethieren, z. B. den Maulwürfen, ein äusserst feines Fädchen 21), sonst gewöhnlich sehr stark. Die blitterige Bildung, welche dem Schnerven-Chiasma des Vogelanges zukömnt, ist bei keineu Säugethier gefunden worden. Die Primitivfasem beider Sehnewen kreuzen sich im Chiasma nur zum Theil; theihweise laufen sie an iltrer urspriinglichen Seite fort 22). Die Eintrittsweise des Sehnerven ${ }^{23}$ ) in die Selerotiea bietet einige Verschiedeńheiten dar; bei den meisten Säugethieren erscheint der Sehnerv unmittelbar ror scinem Eintritte in die runde Oeffnung der Selerotica (ihre sogenannte Sicbplatte) etwas eingeschniurt; bei anderen gexinnt die Oeffnung etwas an Breite; bri Aretomys aber breitet sieh der Nerv hufeisenförmig und unvollkommen in zwei Ilauptfaseikel zerfallend, aus, um durch eine lange, schmale, horizontale Spalte cinzutreten. Eine solche Spaltung trfolgt bei Lepus erst nach dem Durehtritte des indessen verbreiterten Nerven dureh die Sclerotica, wo denn seine Fasern in seillichen Büscheln ausstrahlen. Die Eintrittsstelle liegt meist unterhall der Axe des Bulbus, selten über ihr, oder seitlich und zwar bald einwïrts, bald auswärts von ihr.

[Man rergl. über das Auge der Säugethiere, ausser den schon früher angefiihrten Schriften von Cuvier, D. W. Soenumerring, Blainville, Treviranns, IInek, zalleceche Angaben bei Rudolphi, Physiol. 2r Bd. 1. Abth. S. İ̀ ff. Ueber den feineren Bau der einzelnen Gewebstheile muss auf die bekaunten Darstellungen der menschlichen Anatomie und Gewelslehre von E. H. Weber, Kranse, Iluschke unl Henle verwiesen werden, da es ausserhalb des Planes dieser Schrift lag, näher darauf einzugehen.]

\section{Von den Gehörorganen.}

§. 185 .

Sämmtliche Theile des Gehörorganes bieten in den Reihen der Säıgethicre mehr oder minder bedeutende Versehiedenheiten dar. -

20) Abb. bei Kieser, de anamorphosi cculi. Gotting. 1804. 4. Tab. 1. (Ziege Cancl) und bei Soemuerring Tab. 2. vom Pferde.

21) Vergl. Carus, Versuch einer Darstellumg des Nerrensystemes. S. 241 und Treviranus, Vermischte Schriften. Bd. 3. S. 137.

22) Abb. bei Mïller, Plıysiol. des Gesichtssinnes. Tab. 2. Fig. 1. u. 5.

23) S. über diesen Gegenstand besonders Barkow, Disquisitiones neurolo. gicae. Vratislav. 1830. 4. p: 10 sqq., der anch Fig. 3- 5. Abbi'duugen über das Verhalten des Sehnerren bei Aretomys citillus gegeben hat Vergl. über Aretn. mys anch Perrault und Soemuerring l. c. 1. 2\%. - Ueber Lepus siehe Zinu in den Comment, soc. scient. Goetting. 1754. T. 3. 1. 191. Tab. Vill. Fig. 3. und Foutaua, Viperngift Thl. 2. Tiab. 3. Fig. 12. 
Das äussere Ohr fehlt den meisten im Wasser lebenden, so wie einigen in der Erde wühlenden Thieren $\left.{ }^{1}\right)$. Bei manchen tauchenden Thieren finden sich, sowol bei Anwesenheit, als bei Mangel eines äusseren Ohres, klappenartige Bildungen, welche die Schliessung des äusseren Gehörganges bewirken und das Eindringen von Wasser in denselben verhüten ${ }^{2}$ ). Beim Vorhantensein von äisseren Ohren sind diesclben in verschiedenem Grade ausgebildet: klein und unbedeutend sind sie z. B. bei Otaria, bei den Faulthieren; ungeheuer z. B. bei Plecotus und anderen Chiropteren ${ }^{3}$ ). Meistens sind sie viel beweglicher, als beim Menschen, und demgemäss ist ihr Muskelapparat gewöhnlieh ungleich stäker und mannichfaltiger entwickelt, als bei letzterem s). Statt des einen Ohrknorpels, welcher dem Menschen zukömmt, besitzen viele Säugethiere drei ${ }^{5}$ ). Die Säugethiere ohne äusseres Ohr ermangeln gewöhnlich 6) auch eines knöchernen äusseien Gehör-

1) Es fellt den Cetaceen, den Sirenen, deu Monotremen, den Robben (mit Ausnahme der Gattung Otaria), dem Walrosse, den Gattuugen Chlamydophorus, Manis, Talpa, Scalops.

2) S. z. B. bei Ornithorhynchus; auch bei Sorex, wo die Schliessung vorzüglich durch den ausgebildeten Antitragus geschieht. Vergl. Ge off roy in den Mémoires du Musée d’hist. nat. de Paris 1815. T. 1. p. 299. Tab. XV.

3) Die mannichfacben Verschiedenheiten, welche die Bildung des äusseren Ohres darbietet, können hier nicht genau geschildert werden. In Betreff der Fledermäuse ist besonders auf die zahlreichen Abbildungen von Temminck in seinen Monographies de Marnmalogie zu verweisen.

4) Ueber die Muskeln des äusseren Ohres vergl. Gurlt in seiner vergl. Anatomie der Haussäugethiere. Thl. 1. S. $249 \mathrm{ff}$. und die noch speciellere Schil. derung rou A. Hannover, de cartilaginibus, musculis, nervis auris externae. Havniae 1839. 4. Der Verf. beschreibt 18 Muskeln des äusseren Ohres beim Pferde; 20 beim Hasen; 28 bei der Katze. Der Muskelapparat steht vorzugsweise unter Einfluss des Nervus facialis; ausserdem crhält das äussere Ohr einen Ramus auricularis cervicalis rom dritten Cervicalnerven, den $\boldsymbol{N}$. occipilalis minor vom zweiten und dritten Cervicalnerven, einen $R$. muricularis rom $N$. trigeminus und einen vom $N$. vagus, der an den $N$. facialis sich anlegt.

5) Es sind dies: 1) die Muschel (Concha); 2) der Schild (Cartilago scutiformis) und 3) der Kürass oder Ring (Cartilago annularis). Vergl. Gurlt's vergl. Anatomic der Haussängethiere. Thl. 1. S. 165. und die angeführte Schrift ron Hannover. Bei Cavia Cobaya hat Leuckart (Tiedemann's Zeitschrift Bd. 5. Heft 2.) eine doppelte Ossification in Knorpel des äusseren Ohres entdeckt. Miram fand sie auch beim Biber.

6) Chlamylophorus, obschon eines äusseren Ohres ermangelnd, besitzt einen knöchernen äusseren Gehörgang. - Bei Talpa wiṛd der fibrös-häutige, kurze, äussere Gehörgang durch einen, mehre Windungen machenden, Spiralknorpel umgeben, wie Hannover gezeigt hat; bei Echirlna wird er, luftröhrenartig, durch eine Reilhe unvollständiger, mittelst eines schnalen Längsstreifens verbundener Knorpelringe unterstützt; sehr lang, eng, gekrümut, grösstentheils fibrös. häutig, aber stellenweise durch einzelne, discrete, unregelmässig gestaltete Finor. pelplatten unterstützt, ist er bei den Delphinen. 
ganges und ihr meist fibrös-häutiger, durch einzelne Knorpel unterstuitzter äusserer Gehörgang ist bisweilen, wie namentlich bei den Cetaceen, sehr lang und gekrümmt. Der knöcherne äussere Gehörgang mangelt aber auch vielen anderen Säugethieren oder ist nur schwach angedeutet 7 ). - Die Paukenhöhle 8) zeigt mannichfache Bildungen. Bei der Mehrzahl der Säugethiere weiter, als beim Menschen und den ihm rerwandten altweltlichen $\Lambda$ ffen, zeigt sie sich oft zu einer beträchtlichen Iröhle ausgedehnt. Diese bildet dann eine Erhabenheit an der Schedelbasis oder erscheint blasenartig hervorgetrieben, in welchem Falle sie den Namen der Bulla ossea erhält. Gebildet wird sie meistens durch das $O_{s}$ tympanicum ${ }^{9}$ ) in Gemeinschaft mit dem knöchernen äusseren Gehörgange; bisweilen wird sie aber auch durch andere Knochen mit umschlossen. Während die beiden Paukenkapseln gewöhnlich durch das $0 s$ occipitale basilare von einander getrennt werden, stossen sie selten, wie z. B. beim Maulwurfe, unmittelbar an einander. Das Innere der Paukenkapsel: ihre Höhle ist bald einfach, bald zellig, bali durch Scheidewände in Fächer abgetheilt, bald communicirt sie mit Nebenhöhlen. - Die Tuba Eustucliii, ausgehend vom

7) Vergl. die ausführlichen Mittheilungen von $\mathrm{Hagen}$ ba ch in seiner Schrift: die Paukenhöhle der Säugethiere. Leipzig 1835. 4. Der knöcherne äussere Gehörgang fehlt den Affen der neuen Welt, dem Igel u. A.; er fehlt ferner den ineisten Edentaten (mit Ausnahme von Chlanydophorus) oller ist sehr kurz. Sehr unvollkommen ist er auch bei den meisten Ferae und Glires; viel ausgebildeter erscheint er bei den Affen der alten Welt, den Wiederkäuern, Pachydermen und Einhufern; unter den Ferae bei Lutra und Meles; unter den Nagern bei Castor und Lepus.

8) Genan geschildert von $\mathrm{Hagenbach}$ in d. a. Sch. Die Bulla findet sich noch unter den Quadrumanen bei Hapale und Leurur; ausgebildet ist sie bei den Chiropteren, den meisten Elentaten, den Beutelthieren und besondlers bei den Ferae und Glires; sehr gross bei Phoca; unter deu Nagern am grössten bei Dipus und Pedetes. - Hohl ist sie z. B. bei der Ziege, dem Schaaf, bei Cervus, Hystrix, Lepus, Mus, Cavia; mit Zellen gefüllt bein Kalb, Schwein, Iltis, Wiesel, Maulwurf; in Fächer getheilt bei der Katze, dem Marder, Lutra, Sciurus. Sio communicirt mit Nebenhöhlen bei den meisten Edentaten (Myrmecophaga, Manis, Orycteropus, Bradypus) und vielen Nagern (Pedetes, Hydrochoerus, Hystrix, Cavia, Arctomys, Sciurus, Hypudaens), so wie anch bei einigen anderen Säuge. thieren, z. B. dem Elephanten, dem Maulwurfe. - Bei den Cetaceen und Sirenen werden das Os tympanicum und petrosum mit dem übrigen Schedel nur durch fibröses Gewebe verbunden. Die Trommelhöhle hangt bei den Delphinen mit merk würdigen grossen Sinus zusammen. S. darüber Rapp's Cetaceen S. 99.

9) Dieser Knochen stellt anfangs immer einen zur Einfassung des Tromınel. felles bestimnten Ring dar; während er bei den meisten Säugethieren später den Meatus auditorius osseus und die Paukenhöhle umschliesst, behält er bei den Monotremen und den Beutelthieren perennirend blos seine nrspriingliche Function, oder billet, wie bei letzteren, nur noch den Anfang des knöchernen Geliörganges. Dagegen entsteht die Paukenhöhle bei den genannten Fanilien, wie auch bei manchen andern Säugethieren, z. B. bei Erinaceus, Sorex, Lemur, durch das $O_{s}$ petrosum und die Ala temporalis Ossis sphenoidei. 
Os rympreicum oder ron benaehbarten Knoehen, besitzt allgemein eine knorpelige Grundage. In der Regel fiihrt sie aus der Patukenhöhle in den Raehen; bei den Delphinen dagegen beschreibt sie cimen Bogen, erhebt sich und mündet, von einem Wulste umgeben, in den Nasencanal. Bei den Einhufern verbreitert sieh die knorpelige Grundlage der Tuba in der Raehenhöhle und stcht mit dem sogenannten Luftsacke: einem von Schleimhaut ausgekleideten häutigen Saeke, der unter dem Occipilale basilare liegt, in Verbindung. - Das in Irinsieht auf Form und Richtung variirende, aussen meist eoneave, seltener fliche oder, wie beim Walfische, selbst eonvexe Paukenfell ist in der Rinne eines dem Os tympanicrm angelı̈rigen hervorspringenden knöehermen Rahmens eingefügt. - Die Gehörknöehelehen 10) bieten in Betreff ihrer

10) Eiue genaucre Beschreibung der mannichfaltigen Formen der Gehör. knöchelchen liegt ausserhalb der Grenzen dieses Lehrbuches. Ich rerweise rücksichtlich ler einheimischen Säugethiere auf Dietrich's Aufsatz in Niüller's Archiv 1841. p. 55. und sonst anf folgende Abbildnngen: Hinsichtlich der Monotremeu auf Meckel, 0rnithorh. Tab. IV. Fig. ว̌. und 0 wen, Monotren. p. 369. Fig. 169. 170.; in Betreff der Beutelthiere auf $0 \mathrm{wen}$, Mlarsupialia p. 200. Fig. 120. 121.; rücksichtlich der Cetaceen auf Pallas, Zoographia rosso-asiatica. T. 1. Fig. 8. und auf $\mathrm{Home}$, Lectures Vol. IV. Tab. 101. - Andere Abbildungen s. bei IIagenbach l. c.; bei Buchanan, Plyssiological Illustrations of the organ of hearing. London 1828.; bei Breschet, Recherches anat. et physiol. sur l'organe de l'onie. Paris 1836. 4. und bei Wa grner, Icones zoot. Tab. VIII. - Der Steigbügel ist bisweilen undurchbohrt und stäbchenförmig; so bei den Monotremen. Anch bei ilen Beutelthieren besitzt er noch grosse Aehnlichkeit mit der Colnmella der Vögel und Reptilien; undurchbrochen ist er z. B. bei Pe. rameles; bei Halmaturus und Didelphis besitzt er einen langen Stiel und zwei kurze Schenkel. Bei Bradypns ist der Zwischenraum seiner Schenkel solide; bei den Delphinen und Sirenen bleibt zwischen seinen sehr dicken Schenkeln nur eine sehr feine 0effuung, die bei älteren Thieren und bei einzelnen Arten selbst ganz verschwindet. Ein Beispiel ron weitem Zwischenraume zwischen den Schenkeln des Stapes liefert Erinacens. - Bei vielen Säugethieren tritt zwischen die Schenkel des Stapes ein bald hohler, bald solider Kinochen hindurch. Carlisle (Philosoph. Transact. 1805. p. 204.) hat diesen Pessulus entdeckt. 0 tto (Nov. Act. Acad. Cars. Leop. Carol. Vol. XIII. P. 1. p. 24 sqq.) hat angegeben, lass bei den Chiropteren, Erinaceus, Sorex, Talpa, Hypudaeus, Myoxus, Cricetus, Dipns, Arctonys, Sciurus u. A. die Carotides internae, welche die Hirncarotiden abgeben, durch diesen Pessnlus hindurchtreten. Hyrtl dagegen (Mediz. Jahrbiicher des Oesterr States. 1843. Bu. 33. S. 270.) salı niemals die Carotis interna, sondern den vereinten Stanun der Artt. maxillares superior mind ophthalmica durchtreten; bei Vospertilio die Art. meningea medin; bei Myoxus glis eine accossorische Arteric der harten Hitnhaut. Er fand den Pessulus solide bei Cavia, Bathyergus, Otomys; hohl bei Arvicola, Scinrus, Spermophilus citillus, Tilpa; er vermisste ilın bei Dasyprocta, Cricetus, Mus. - Vergl. ïber diesen Gegenstand auch Rudolphi, Grundr. d. Physiol. Bd. 2. Abth. 1. S. 132. - Bei manchen Säugethieren findet man die Basis des Stapes uit deu Rande des Foramen ovale rerwachsen; namentlich kömmt dies ror bei Einlufern, Wiederkïuern und Cetaceen. - Rudolphil. c. hat bei Chrysochloris zwischen Ham. 
Form, Grösse, Verbindung und sethst ilırer Zalrl mannichfache Verschiedenlieiten dar. Zu den drei bekannten Gehörknöchelehen des Mrenschen kommen bisweilen noch accessorische kinochen oder Sesambeinchen hinzu. Ilure Bewegungen "I) gescluehen durch den Musc. stupedlius und den M. tensor tymprani s. mallei interums. - Dis vom Stapes rerschlossene Foramen ovale verhält sich, gleich dem Foramen rotumlum, in Grösse und Gestalt verschieden. - Das innere Oh.12) zeigt bei den einzelnen Ordnungen und Gattungen mannichfache und interessante Eigenthümliclkeiten. Am geringsten sind die Abweichungen, welche in dem Vestibulum und seinen beiden Säckehen hervortreten. Inmer sind drei halbcirkelförmige Canäle oder Bogengiinge vorhanden. Sie münden bald mit fünf, bald mit vier Oeffnungen in das Vestibulum. Ihre Grösse und Weite wechseln sehr; am kleinsten sind sie bei den ächten Cetaceen, denen dagegen die grösste Schnecke

wer und Ambos noch einen kleinen keulenförmigen Knochen angetroffen. Hyrt entleckte ihn anch bei Condylura cristata. - Ein Ossiculum lenticulare Sylvii höannt lü̈ıfig vor und scheint zu dem Aunbos in Bezichung zu stehen. - Ein Sestumbeinchen in $\boldsymbol{M}$. stapedius wird beim Rimle und Pferde angetroffen. Vergl. Berthold in Mïller's Archiv 1838. S. 46. und Hyrtl l. c. S. 270. - Der Haumer dient bei den Monotremen, in Verbindung mit dem Os tympanicum, dem Paukenfelle zur Stütze. Bei den meisten einheimischen Säugethieren, besonders dentliclı bei den Wiederküuern, kömmt, wenigstens im Fötalzustande, eiı Anlaung des Processus spinosus des Hammers vor, der später mit der vorderen und äusseren Fläche des Paukenknochens verschunilzt. Hagenbaclı (1lïller's Archiv 1841. S. 46.) hat ihn entdeckt und Ossiculum accessorium mallei genannt. - Der Mecliel'sche Knorpel erstreckt sich beim Fötus del Säugethierc längs der Innenseite des Unterkiefers und erhält sich bisweilen (z. B. bei Pboca) lange.

11) Vergl. Hagenbach, Disquisitiones anatom. circa uusc. aur. intern. Basil. 1833.

12) Ueber das innere Ohr ver Säugethiere rergl., ausser den allgemeinen Schriften von Comparetti, Polıl, Blainville, Buchanan, Breschet mul den cinzclıen monographiselien Arbeiten, noch A. Meckel in J. F. Meckel's Archiv 1827. S. 356. Tab. V. und ganz besonilers dic schon citirten vorläıfigen Mitrheilungen ron Hyrtl, denen eine ausfülırliche Schrift ïber das Gehörorgan der Säugetliere bald folgen soll. Hyrtl's Präparate erregen Bewunderung. Hy'tl fand die Ampullen verlıältnissmïssig kleiı beim Menschen, den Affen, den Wiederkäucm, Einhufern, Pachydermen; gross bei den Fleischfressem, Nagern und Cliropteren. Die Aupulle am unteren Schenkel des linteren Canales ist gewölunlich am grössten. In Verhältniss zu den engen Bogengüngeu habeu Dasyprocta uni Coelogenys die grö̈ssten Ampullen. - Die Schnecke hat $1_{2}^{1}$ Winlungen bei Erinaceus; 2 bei Ploca, bei ler Geinse; fist $2 \frac{1}{2}$ beim Reh, Llirsch, Schiaf, Lama, Camel, Pferl, Elephanten und den meisten Edentaten, während die Aften und Fledermïuse, wie der Mensel sich verhalten; 3 Winlungen bei den meisten Ferae (nit Ausualıme der Bären); mehr als 3 , fast 4 Windungen bei Sus, Dicotyles, Hystrix, Sciurus, Pterouys und Phalangista; 4 Wiulmugen bei Cavia und Dasyprocta; 5 bei Coelogenys Paca. Bei Dasypus octocinctus ist die zwrite Winlung der Sclunceke grösser, als die erste. Vergl. Iyrtl l. c. 
zukömmt. Thiere mit grosser Bulla ossea besitzen häufig kleine hall)cirkelförmige Canäle. Das relative Grösscnverhältniss der einzelnen Canäle bietet Versehiedenheiten dar. Mit Ausnahme der Faulthiere, denen die Ampulle am äussercn Bogengange fehıt, besitzen alle Säugethierc an jedcm Bogengange eine Ampulle. Die Ampullen sind in der Rcgel um so wciter, je enger die halbcirkelförmigen Canäle sind. Die von den knöehernen Theilen eingeschlossenen häutigen Bogengänge entsprechen den crsteren genau; in jeder $\Lambda$ mpulle findet sich zur Ausbreitung des Gehörnerven ein qucrer wulstiger Vorsprung, der ein unvollkommenes Septum bildet. - Dic bedeutendsten Versehiedenheiten bietet die Schnccke dar. Bei den Monotremen ist sie Vogel-ähnlieh und beschreibt kaum einen Bogen; bei den Cctaceen bildet die sehr grosse Schnecke nur $1 \frac{1}{2}$ Windungen, welehe beinahe in einer Ebene bleibcn; die grösstc Zahl der Windungen (5) erscheint bei Coelogenys Paca. Besitzt die Schnecke mehr als drei Windungen, so wird sie conisch aufgethürmt und ragt zapfenförmig in die Paukcnhöhlc hinein ${ }^{13}$ ). - Die Aquaeductus cochleae und vestibuli sind anscheinend constant vorhanden.

\section{Fünfter Abschnitt. Von den Verdaungs -Organen.}

\section{Voin Gebisse.}

§. 186.

Rücksichtlich des Gebisses walten die grössten Verschiedenheiten bei den Säugethieren ob. Einige ermangeln zu jeder Lebenszeit der Zähne. Dies ist der Fall bei den Gattungen Echidna, Myrmecophaga, Manis; ein hartes, hornartig verdicktes Epithelium am Unterkieferrande ersetzt bei einigen dieser Thiere die Zälnne. - Bei den eigentlichen Walfischen kommen, statt der Zähne die aus Hornsubstanz gebildeten Barten vor; im Fötalzustande jedoch besitzen sie in beiden Kiefern kleine, abortive, Zähne in grosser Zahl 1). Auch Ornitho-

13) Auffallend ist es, dass, nach Fick (Müller's Archiv 1844. S. 431.), beim Elephanten ein ächtes Schneckenfenster zur Paukenhöble hin fehlt.

1) Sie wurden beim Fötus des grönländischen Walfisches (Balaena mysticetus) von Geoffroy St. Hilaire entleckt. S. Annal. d. Musée d'hist. nat. T. X. 1807. 1. 364. Ge offroy beobachtete sie nur reihenweise im Canalis alveolar is des Oberkiefers. Ausführlichere Mittheilungen über diese transitorischen Zähne der Wale gibt so eben Eschricht, Undersögelser over Hvaldyrene. Tredie Afhandling. Kjöbenhavn 18 35 . p. 25 sqq. Auch die Fötus anderer Wale besitzen in beiden Kiefen verborgene Zähne. Eschricht fand bei Balaena longimana im Oberkiefer etwa 102, im Unterkiefer 84; bei seinem Vaaghelival 
rhynchus 2) liat nur IIornziiline, die aus hohlen IIornfasern bestehen und mil breiter Fläche auf dem Zahnfleisehe sitzen. Dic Barten der Walfische ${ }^{3}$ ) liegen in zwei seitlichen muldenförmigen Vertiefungen der Gaumenflache des Oberkieferbeines, die durch einen stark vorspringenden Knochenkamm geschieden werden. An Gaumenbeine und am Vorderende des Kicfers eonvergiren die Barten bcider Seiten. Sie bestchen aus grösseren und kleineren, parallel stehenden, ungleich vierseitigen, gekrümmten Hornplatten, mit scharfen Rändern, deren Concavitït vorwärts geriehtet ist. An ihrer Basis werden sämmtliche Platten durch ('in sie vercinigendes IIornband kranzartig umfasst. Jede Barte ruhet auf eincr gefässreichen Haut, deren Falten als Matrix in cinc Höhle der Hornplatten eindringen und franzenartig zwischen der röhrigen Marksubstanz sich fortsetzen. Jede Iornplatte selbst besteht nämlich aus einer blätterigen, nagclartigen Rindensubstanz und einer von ihr eingesehlossenen röhrigen Marksubstanz, welche letztere an der Basis der Platten fehlt, so dass hier die Rindensubstanz die zur Aufnabme der Keimhaut bestimmte IIöhle einschliesst. An dem unteren freien Ende der Platten ragen die Markröhren borstenartig aus der Rindensubstanz hervor. - Den Barten der ïchten Walfische am nächsten verwandt, aber schon durch den Besitz von Kalkerde wesentlich verschicden, sind

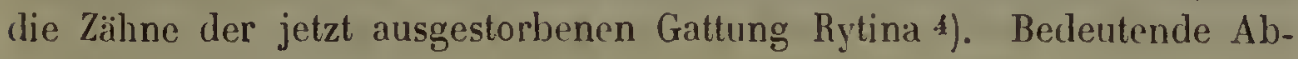
wcichungen von dem gewöhnlichen Baue zeigen auch die Zähne bei Orycteropus ${ }^{5}$ ), welche jedoch hinsichtlich ihrer chemischen Zusammen-

im Oberkiefer 88, in Unterkiefer 80. Es sind wirkliche Zähne, welche in Zahısïckchen eingeschlossen sind; in Betreff ihrer Form besitzen sie Aehnlichkeit mit den Zähnen der Delphine. Eschricht lat sie auch mikroskopisch untersucht. S. d. Abb. I. c. Tab. IV. - Beim Fötus des Narwal kommen zwei, gewöhnlich lose in den weichen Bedeckungen der Kiefer sitzende abortive Schneidezähne vor, wie Mulder gezeigt liat. Ich habe sie bei zwei Fötus gefunden; in zwei Schedeln von erwachsenen Narwals salı ich je einen dieser Zähne bleibend. Eigenthümlicl ist es dem im Oberkieferbeine haftenden Stosszahne des Narwal, dass er stets von rechts nach links gerichtete Windungen zeigt. Sehr selten erhalten sich zwei solcher Stosszälıne perennirend, wie sie in der Jugend immer vorhanden sind. Ich sah sie beide ausgebildet an Schedeln in Hanburg und Wien.

2) Vergl. Meckel, Ornithorhynchus p. 43. und Hesse, de ungularum, Barbae Balaenae, dentiun Ornithorhynchi structura. Berol. 1839. 8. p. 21. Tab. I. Fig. 2. u. 3. und Tab. III. Fig. 1. 2. 5.

3) Ueber die Barten von Balaena rostrata vergl. Rosenthal in d. Abhandl. der physikal. Klasse der Acad. der Wissenschaften zu Berlin. A. d. Jahre 1829. Berlin 1832. S. 127 ff. Mit Abb. Tab. 1-3. - Vergl. auch Ra vin (Ann. des sc. natur. Série zool. 1836. T. 5. p 266.); so wie Hesse 1. c. p. 9. nit d. Abb.

4) S. Brandt in den Mémoires de l'académie de Petersbourg. 1834.; ausge. zogen in Müller's Archiv 1834. S. 48.

5) Vergl. Cuvier, Leçons T. IV. P. 1. p. 205. - Owen, Odontography PI. 78. - Rapp's Edentaten S. 52. und die Abb. eines Querdurchsclinittes Tab. VI. Fig. 3. - Diese Zähne bestehen aus parallelen, meist sechsseitigen Röhren 
setzung den gewöhnlichen Zülınen näher stehen. - Die Zähne der iibrigen Säugethiere bestehen in der Regel aus melıren Schiehten rersehiedener Substanzen; unter ihnen erscheint am regelmaissigsten das Zahn - oder Elfenbein; sehr läufig auch die eigentiche Knochensubstanz, als deren Modificationen das Caement und rie Ossificationen der Pulpa zu betrachten sind. Zu diesen, in Bau und chemischer Zusammensetzung, durchaus mit den Knochen iubereinstimmenden oder ilnen wenigstens nahe verwandten Bestandtheilen kömmt noch sehr allgemein der Zahnsehmelz hinzu, welcher bisweilen durch ein eigenthümliches Pigment ausgezeichnet ist $\left.{ }^{6}\right)$. Diese versehiedenen, in die Zusammensetzung der Säugethierzïhne eingehenden Substanzen sind nicht inumer zugleieh vorhanden; ist dies letztere aber der Fall, so bleibt sieh das wechselseitige Lagenverhältniss derselben nicht immer gleich. Eine Classification der Zähne, gestützt auf die Zahl und die Verschiedenartigkeiten der in ihre Zusammensetzung eingehenden Substanzen, setzt noch viele und wiederholte mikroskopiseh-chemische Untersuehungen der Säugethierzähne voraus. Guvier hat eine sehr allgemein angenommene Eintheilung der Säugethierzähne versucht, deren Princip das Verhalten der harten Zahnsubstanzen zur Pulpa-Höhle alıgegeben hat. Hiernaeh heissen einfaeh (Dentes simplices) diejenigen, mit einer oder mehren Wurzeln versehenen Zähne, deren Höhle von einer einfachen, durch Elfenbein gebildeten Wand umschlossen wird; gewöhnlich wird zugleich das Elfenbein an der Krone von einer zusammenhangenden Schmelzschicht überzogen, während die eigentliche Knochensubstanz den Wurzeltheil des Zahnes umkleidet. Dahin gehören z. B. die Zähne des Menschen, der Quadrumanen, Ferae u.s. w. Zus ammengesetzt wird ein Zahn dadurch, dass seine, aus mehren Schichten bestehenden Wandungen ron mehren Stellen aus in seine Pulpahöhle hineindringen; daher sieht man an der Kronenoberfläehe eines solchen Zahnes versehiedene Substanzen alterniren. Je nachdem ein zusammengesetzter Zahn mit einer einfachen Wurzel versehen ist, wie an den Baekenzähnen der Wiederkïuer, oder dagegen aueh seine Wurzel den zusammengesetzten Bau der Krone theilt, wie an den Backenzähnen der

oder Säulen, so dass der Querdurchschnitt wie der eines Schilfstengels aussicht. In der Axe jeder Säule verläuft nümlich ein Canal, der gegen die Kauflïche liu mit Knochenerde ausgefüllt ist. Dic unmittelbar den Canal umgebende Wand ist durchsichtig; dinn folgt eine dickere, aus undurchsichtigen, filzartig mit einander verbundenen Fasern bestehende Schicht. Nach Lassaigne enthalten diese Zäbne wenig mehr, als $\frac{1}{4}$ organischer Substanz; übrigens phosphorsaure und kohlensaure lialkerde.

6) So bei vielen Nagern, z. B. dem Aguti, dem Bilıer, an den Sclmeilezïhnen. S. dariiber Mayer, Metamorphose der Monaden. S. 24. Nach Mayer ist das pignent in die Oberfliche des Schnelzes gebunden, ohne eine besondere Lage \%u bilden. 
Elephanten, heisst er entweder schmelzfaltig (D. compliculus) orler bliitterig (D. Iamellosus). - Nicht alle Säugethierziihne besitzen wirklicle Wurzeln in dem Sinne, wie sie bei den Ziilınen des Menschen und der meisten Sïugethiere rorkommen. Iliufigg (wie z. B. bei vielen Nigem: Lepus, Cavia, IIypudaeus u. A.) nähern sich nämlich die Wandungen der Pulpa-Ilöhle unten nirgend, so dass letztere an der Basis cinen grösseren Durchmesser besitzt, als aufwïrts. - Bei den meisten Sïngethieren hal ein Zahnwechsel Statt; häufig werden aber die Jugendzühne nach ihrem frühzeitig erfolgenden Ausfallen gar nicht durch bleibende Zähne erselzt ${ }^{7}$ ). - Zahntragende Knochen sind bei den Sïugethieren nur Zwischenkiefer, Oberkiefer und Unterkiefer, jedoch bei vielen nicht alle genannten Knochen zugleich. Niemals sind die Gaumenknochen mil Zähnen besetzt. - Riicksichtlich ihrer Anordnung zerfallen die Zähne in Schneidezähne, Eckzähne oder Backenzähne, die jedoch gleichfalls sehr hïufig nicht sämmtlich rorhanden sind. - Dic Zahl der bleibenden Zähne schwankt ausserordentlich; in keiner Ordnung sind die Zahlenschwankingen bedeutender, als in der der Celaceen. - Nicht minder wechselnd sind Form und Grösse der Zähne. Die Erläuterung dieser Verhältnisse gehört der descriptiven Zoologie an.

[Die Literatur der Odontologie ist schr reichhaltig. Man vergl. besonders G. Cuvier, Leçons d'Anat. compar. ed. Duvernoy. T. IV. 1. I. Auch Cuvier's Vorles. übers. von Meckel (unit vielen Zusïtzen des Herausgebers). Thl. 3. Ferner Curvier, Recherches sur les ossem. fossiles. T. 1-7. - In Bezng auf die Stellıng der Zälıne ist, ausser den zoologischen Werken, besonders zu vergleichen: Fr. Cuvier, Des dents des mammifères, considérćes coume caractères zoologiques. Paris 1825. 8. Mit Abb. - Ducrotay de B lainville, Osténgraphie (mit besonderer Berïcksichtignng der Zähne). - S. ferner L. F. E. Rousseau, Anatomie comparée du systeme dentaire chez l'homme et les principaux animaux. A rec 30 \%l. Paris 1827. 8. - Die mikroskopische Zusammensetzung erläutern: 0 we u (in seiner noch nicht vollendeten Odontography); Retzius (in Müller's Archiv 1837. 1. 498.); Erdl (Untersuchungen über den Bau der Zähne bei deıı Wirbelthieren, insbesondere den Nagern, in den Abhandl. d. mathemat. physikal. Classe der Baierschen Acad. der Wissenschaften zu München. Bd. 3. A btl.. 2. S. 485 ff.); Nasmyth (in den Melico-chirurgical Transactions. Vol. XXII. †. 312.). - Kritische Zusammenstellungen der älteren Beobachtungen bei Heusinger (System der Histologie. S. 199.); der älteren und neueren mit eigenen Lintersuchungen über den Baı der menschlichen Zähne bei Henle (Allg. Anat. S. 849 f.); Historisches auch bei Erdl 1. c. - Genauere Angaben liegen ausserhalb der Grenzen dieser Schrift.]

Ђ) Bei manchen Säugethieren, z. B. den Elephanten, den Sirenen (Manatus, Halicore), werden die hinteren Bakenzähne alluälich vorgeschoben mind treten an die Stelle der vorleren abgenntzten und ausfillenden. 


\section{Von der Mund - und Rachenhöhle und den in sie mündenden Drüsen.}

\section{§. 187.}

Weiche Lippcn ${ }^{1}$ ), deren Bewegungen unter Einfluss cines Muskelapparates stehen, der bis zum Mensehen hinauf an Ausbildung und Manniehfaltigkeit zunimmt, finden sieh bei den meisten Säugcthieren, mit Ausnahme der Monotremen und der ächten Cetaecen. Eigenthüinlich sind fast allen Säugethieren die Baeken und ihr Muskel, der $\boldsymbol{M}$. unccinatorius. Vielen von Früelten lebenden Affen der alten Welt 2), so wie vielen Nagern ${ }^{3}$ ), wenigen Beutelthieren und dem Schnabelthier, vielleieht aueh einigen Chiropteren 4), kommen beutel(örmige Einsaekungen der Mundhöhle, sogcnannte innere Baekcntaschen, zu, deren Ausdehnung und Verengerung dureh starkc Ausbreitungen des IIautmuskels bewirkt wird. Einige Nager besitzen äussere, nicht mit der Mundhöble communieirende Backentasehcn 5 ). - Die Mundhöblc ist bald glatt, bald mit Warzen ${ }^{6}$ ), oder selbst mit Staeheln, Ilaaren, Borsten, wenigstcns stellenwcise 7), besetzt. Häufig zeigt der Gaumcn Querfurchen, zwisehen welehen bisweilen noeh Papillen liegen. - Das Gaumensegel bietet bei den meisten Säugethieren nichts Eigenthümliehes dar; zeigt aber bei cinigen Nagern, den Elephanten und den

1) Abbildungen der Mundhöhle s. bei Carus und 0 tto, Erläuterungstafeh IIft. 4. Tab. VIII.

2) Sie finden sich bei den amcrikanischen Affen nicht. Die sackförmige Backentasche beginnt an der Commissur der Lippen und crstreckt sich hinterwärts und abwärts.

3) Namentlich T'anias, Spernophilus, Arctomys, Cricetus, Cricetomys. Abb. von Arctomys Marmota bei Carus und 0 tto, Erläıterungstafeln Hft. 4. Tab. VII. Fig. 3. 0 wen entdeckte Backentaschen bei Phascolarctos und bei Perameles lagotis.

4) Meckel fand sie bei Vespertilio inurinus, wo allerdings eine Spur daron vorkömut. Anderen Fledermäusen scheinen sie zu fehlen und $\mathrm{Cuvier}$ und Te mminck leugnen sie gänzlich. Abb. der Backentaschen von Ornithorhynchus bei Meckel (Ornithorh. Tab. V. F.).

5) Bei Coelogenys schwach; besonders aber bei Ascomys. Ein Schlitz, der ron der Nasenspitze sich zum Unterkiefer herabzieht, führt bei Ascomys in eine weite, inwendig mit feinen Haaren besetzte Tasche, welche bis gegen die Schulter herabreicht.

6) Z. B. bci den Wielerkäuern, wo die Warzen kegelförmig sind. Die grösseren derselben sind an der Spitze hornig oder selbst faserig.

7) Z. B. bei Echidna ist der Gaumen mit mehren Querreihen kurzer, harter, scharfer, rückwärts gerichteter Stacheln besetzt, die die fehlenden Zähne ersetzen. Borsten an der innerı Flächc der Backenhaut kommen ror bei Loncheres, Caria, Castor, Bathyergus, Cricetomys; Warzen bei Myrmecophaga, Manis; ähnlich allch beim Dügong und Manati; bekannt sind die Haare an der inneren Backe der Haasen. Abb. der Mundhöhle mehrcr Säugethiere bei Carus und Utto, Erläuterungstafcln Hft, 4. 'Tab. VII. Fig. 1. 1. 2. 
Cetaceen einige, von der Einrichtung ihrer Nase und dem Hineinragen ilıes Kehlkopfes in die hintere Nasenöffnung abhängige Modificationen seiner Bildung ${ }^{8}$. Eine Uvula 9) fehlt den moisten Säugethieren, mit Ausnahme der Affen. - Der Schlundkopf hat einen stark entwickelten Muskelapparat.

Die drüigen Organe der Mund-und Rachenhöhle bestehen in Schleimdriisen und Speicheldrüsen. Zu ersteren gehören: 1) die längs der Unterlippe häufig vorkommenden Folliculi labiales 10); 2) die verschiedenen Backendrisen II): Folliculi buccales, molares und die Glandula zygomatica einiger Säugethiere; 3) Folliculi palatini 12); 4) die Tonsillen ${ }^{13}$ ). Sie sind nicht immer sämmtlich vorbanden und zeigen, wo sie vorkommen, verschiedene Grade der Entwickelung.

8) So steigt beim Elcphanten, nach $\mathrm{Cu}$ ier, das Gaumensegel tiefer abwärts als die Spitze der Epiglottis und legt sich dicht an dieselbe. Ueber den weichen Gaumen der Cetaceen vergl. Rapp, Cetaceen S. 132. Sehr gut werden seine Verhältnisse versinnlicht durch die im Ganzen gelungenen $\mathrm{Abb}$. vom Delphin bei Carus und 0 tto, Erläuterungstafeln Hft. 4. Tab. VII. Fig. 4. - Ueber das Gaumensegel von Hydrochoerus Capybara, das, mit den Schlundwänden und der Wurzel der Zungc verwachsen, nur eine sehr kleine 0 effnung zum Durchtritt der Speisen lässt, s. Morgan, Linnean Transact. XVI. p. 465 .

9) Ein schr klcines Zäpfchen besitzen auch die Caulcle und Giraffen. Verschieden von dem Zäpfchen ist aber die, vor dcin Velum palatinum liegende, gefässreiche, drïsige Schlundblase des Dromedars, welche beim erwachsenen Männchen zur vollen Entwickelung gelangt und zur Brunstzeit beträchtlich anschwillt. S. die Beobachtungen älterer und neuerer Naturforscher hierüber zusanmcngestellt bei A. Wagner in s. Ausgabe von Schreber's Säugethieren Bd. 5. Abth. 2. S. 1725 ff. Vergl. besonders Grundler, Diss. de Camelo dromedario observata quaedam anatomica. Tubing. 1817. 8.

10) Z. B. bci den meistcn Affen der alten Welt, den Beutelthiercn.

11) Die Glandulae buccales erstrecken sich gewölnnlich längs der Zahn. höhlenränder der Kiefer und münden mit zahlrcichen Ausführungsgängen in glcicher Höhe mit den Kronen der Backenzähnc. Sie sind besonders cntwickelt bei den Wiederkäuern, den Einhufern und Pachydermen. Rapp beobachtete eine ähnliche Drüse bci Myrmecophaga tamandua, dcren Ausführungsgänge zwischen den an der Innenfläche der Wangen befindlichen Warzen münden. S. Edentaten S. 53. - Bei den Ferae liegt, statt der oberen Backendrüse, eine rundliche Drüse (Glandula zygomatica s. orbitalis) hinter dem Jocbbogen in der Augenhöhle, welche, ausser einem grösseren, mehre kleine Ausführungsgänge (Ductus Nuckiani) besitzt. - 12) Z. B. bei Myrmecophaga, nach Rapp.

13) S. über die Tonsillen der Säugethiere besonders W. $\nabla . R$ app in Mül. ler's Archiv 1839. S. $189 \mathrm{ff}$. Mit Abb. Sie sind verschiedentlich entwickelt: häufig bilden sie eincn einfachen Sack, der mit einfacher Oeffnung mündet, wie bei Affen, Felis, Orycteropus, Hyrax; oder erscheinen als dicke horizontale Blätter nit sehr kleincn Oeffnungen, wie bei Ursus, Hyaena; oder bilden eine ein. fache längliche Hervorragung, wie bei Procyon, Mustela, Herpestes, einigen Chiroptcren, Talpa, Erinaccus; odcr sie bestehen aus vielcn verästelten kurzen Canälcn, die mit zerstreuten Orificia sich öffıeı, wie bei Einhufern, Wiederkäuern, Schweinen, Trichccus, Cystophora, den Cetaleen und Sirenen. Vermisst wurden sie bci Hystrix und bei der Ratte. 
Durehaus beständig sind nur die Tonsillen. Die Speieheldriisen sind am wenigsten entwickelt bei den im Wasser lelonden Carnivoren; den äehten Cetaceen fehlen sie ganz, während sie bei den Sirenen (Ialieore und Manatus) stark entwiekelt sind; bei den Robluen sind sie sehwach. Ihre-stärkste Ausbildung erlangen sie dagegen bei den meisten Edentaten, bei Eehidna und dem Biber. Ueberhaupt sind sie bei den Ilerbivoren und Omnivoren viel bedeutender entwickelt, als bei den Carnivoren. Gewöhnlieh finden sich die drei Parr Speieheldrïsen des Mensehen; selten fehlt ein Paar 14). Bald ist die Puro. lis ${ }^{15}$ ), bald die Glaudula sulmexillaris an grössten, letzlere oft ausserordentlieh ausgedehnt und bei einigen lidentaten ${ }^{16}$ ), so wie bei Eehidna dureh eigenthümliehe Verhältnisse ihres Ausfiihrungsganges ausgezeichnet. Die Glandula sublingualis besitzt immer zahlreiche Ausführungsgänge ${ }^{1 \tau}$ ).

\section{Von der Zunge.}

§. 188 .

Die Verschiedenheiten, welehe dic Zunge der Sïugethiere darbietet, betreffen besonders ihre Gestalt, den Grad ihrer Bewegliehkeit, ihre Texturverhältnisse, dic Besehaffenheit ihrer Papillen, so wie endlieh die $\mathrm{Ab}$ - oder Anwesenheit von sogenannten Unterzungen. - Die Geslalt der Zunge wechselt mannichfaeh. Sie ist breit, platt, flach, an ihren Seitenrïndern zum Theil gefranzt und zugleich nieht vorstreekbar bei den äehten Cetaceen 1); viel sehmaler und zugleieh vorstreekbar

14) Dic Parotis bei Echidna, während sie bei Phoca ganz rudimentär ist; öfter fehlt ansclicinend die Glandula sublingualis, z. B. bei Phoca, bei den meisten Bentelthieren nach 0 wen u. A. Die Sirenen besitzen nur zwei grosse Parotiden.

15) Sic ist enorm entwickelt bei Castor, Hahmaturus, Hypsiprymnus; sie ist grösser, als die Unterkicferdrüse bei den meisten Affen; bei Erinaceus u. A. Die Glandula submaxilluris überwiegt an Unfang bei allen Edentaten (unter denen nur die Faulthicre schwach entrickelte Speicheldrüsen besitzen), bei Echillna, bei den meisten Ferac, den Chiropteren, den Makis u. A.

16) Bei Dasypus sammeln sich, wie Rapp gezeigt hat, 5-6 Ausfülırungs. günge der Sıbmaxillardrüse in einc dickwandige, muskulöse Blase, aus deren vorderem Ende ein an der Symphyse des Unterkicfers mïndenter Ductus excretorius hervorgeht. Eine schwächere blasenartige Erweitermng kömut auch bei Myrmecophaga vor. Abb. von Dasypus Rapp, Edentaten Tab. VII.

17) Bei Echidna tritt, nach 0 wen, ein weitcr Ausfiihrungsgang aus der grossen Drüse ab, der zwischen den Aesten des Unterkicfers sich erweitert, dann 8 bis 10 gewundene Acste abgibt, welche, vielfach getheilt, mit zahlicichen Oeffnungen in die Mundhöhle münden.

1) Abb. von Delphinus phocacna bei Carus und 0 tto, Erläuterungstafeln IIft. 4. 'Tab. VII. Fig. 4. Achnlich verhält sie sich bei anderen Delphinen unt beim Narwal. Sehr wenig berweglich ist aluch die Kunge des Dïgong. Abb. bei Hone, Lectures Vol. 4. Tab. XXIV. Fig. 2. Ganz angewachsen finde ich sic bei Nlanatus. 
bei den meisten Pachydermen, den Wiederkäuern und Einhufern; flach und of viel freier heweglich, als beim Menschen, bei Thieren der ineisten ibbrigen Ordnungen; bei mehren Chiropteren, besonders aber mehren Edentaten 2) und bei Echidna ist sie dagegen schmal, lang, of sehr weit rorstreckbar, bisweilen, wie bei Myrmecophaga, rundlich, wurmförmig. Bei den meisten Wiederkäuern ist sie in ihrem hinteren Abschnitte dicker, löher und breiter, als im vorderen; bei vielen Nagern ${ }^{3}$ ) besitzt sie in ihrem hinteren Theile cine oft ziemlich beträchtliche, verschiedentlich gestaltete und bekleidete Erhabenheit; diese kehrt noch eigenthümlicher beim Schnabelthiere 4 ) wieder, wo sie nicht nur uiber den vorderen Theil der Zunge frei vorragt, sondern vorn auch zwei rorwärts gerichtete Hornspitzen besitzt. Bei Dasypus peba 5) kommen ähnliche Gebilde, zangenartig gestaltel, aber unmittelbar unter der Zungenspitze, vor. Bei einigen Chiropteren, vielen Affen der neuen Welt und mehren Halbaffen findet sich dagegen, vom Anfange des freien Theiles der Zunge ausgehend, unterhalb derselben nach rorn, aber nicht bis zu ihrer Spitze sich erstreckend, eine einfache oder selbst doppelte Yorragung, die sogenannte Unterzunge $\left.{ }^{6}\right)$. - Die meisten Ferae besitzen in der Nittellinie der unteren Zungenfläche einen langen, anscheinend fibrösen, bisweilen einen Knorpel enthaltenden, Strang, der vorn bis zur Zungenspitze reicht. Er ist bekannt unter dem Namen des Wurmes $(\boldsymbol{L} y \boldsymbol{t t a} \boldsymbol{a}) \boldsymbol{\%}$. - Die Bekleidung der Zunge wechselt sehr. Selten trägt sie, wie bei Hystrix ${ }^{8}$ ), knochenharte Schuppen auf ihrem vorderen Theile; oft ist sie, besonders in ihren vorderen Abschnitten, mit verschiedenartig gestellten, aber meist hinterwärts gerichteten, bisweilen hornartig verdickten Epithelial-Borsten oder Stacheln besetzt 9).

2) Abb. von Myrmecophaga und Manis bei Carus und 0 tto l.c. Fig. 5. u. 6.; ron Myruecophaga tamandua bei Rapp, Edentaten Tab. VI. Fig. 4. Rapp fand bei den Ameisenfressern an der Zungenspitze eine halbkugelförnige, glatte, vielleicht zum Tasten dienende Verdickung. - Abb. der Zunge von Echidna bei Holl e, Lectures on compar. anat. Vol. II. Tab. LVII. - Unter den Chiropteren besonders vorstrectibar bei Glossophaga und Macroglossus.

3) Z. B. beim Haasen, beim Meerschweinchen u. A.

4) Abb. hei Meckel, Ornithorhynchus Tab. VII. Fig. 9.

5) S. Mayer, Neue Untersuchungen a. d. Gebiete der Anatom. u. Physiol. Bomi 1842. S. 32 .

6) Abb. bei Carus und 0 tto 1. c. Fig. 10-14. 0tto fand diese Unterzunge doppelt bei Stenops gracilis. Meckel beobachtete sie unter den Chiro. pteren bei Noctilio. 0 tto sah sie bei Mycetes, Ateles, Cebus, Callithrix, Hapale, Midas; ferner bei Lemur und Stenops.

7) Andeutungen lavon finden sich auch bei anderen Säugethieren, deutlich z. B. bei Dasyurus, bei einigen Einhufern und Wiederkäuern, bein Menschen. Abb. bei Carus und 0 tto l. c. Fig. 15. von Ursus. Meckel liat diese Lytta zuerst als eine Spur voin Os entoglossum anderer Wirbelthiere gedeutet.

8) Abh. bei Carus und 0 tto l. c. Fig. 9.

9) So bei den Monotremen, vielen Ferae (z. B. Felis, Hyaena, Viverra); 
Bei Anderen ist sie dagegen glatt oder mit kurzen, weichen Papillen versehen ${ }^{10}$ ), die sonst auch bisweilen zwischen den Epithelialstacheln vorkommen. Die Papillae vallatae an der Basis der Zunge scheinen sehr selten zu fehlen; ihre Zahl wechselt sehr; seiten findet sich nur eine, wie beim Känguruh, oder es sind ihrer nur zwei vorhanden, wie bei einigen Edentaten; finden sich, wie gewöhnlich, mehre, so sind sie meist V förmig gestellt. - Die Bewegungen der Zunge geschehen durch einen verschiedentlich angeordneten Muskelapparat. Zu den beständigsten Muskeln gehören die M. M. genioglossus, hyoglossus 11) und styloglossus. Der M. Myjoglossus ist bisweilen, wie z. B. beim Schnabelthiere, einigen $\Lambda$ ffen u. A., ein M. thyreo-liyoglossus. Bei den Einhufern und Wiederkäuern kömmt noch ein M. myloglossus vor, der den vordern Theil der Zunge an den Gaumen drückt.

[Ra]p (Verrichtungen des fünften Nervenpaares S. 8.) hat auf das Vorkounnen parallel laufender Spatten aun hinteren Theile des Zungeurandes bei vielen Affen, beim Tapir, bei Hyrax, manchen Nagern aufuerksam gemacht. Später sind sie von Mayer (Nene Untersuch. a. d. Gebiete d. Anat. u. Plyysiol. Bonn 1842. S. 25.) näher untersucht worken. Ueber ihr Verhalten bein Menschen s. auch Huschke in s. Ausgabe von Soemmerring's Lehre v. d. Eingew. u. Sinnesorganen. Leipzig 1844. S. 590. - Genaue Beschreibung der sehr beweglichen Zunge ler Giraffe von 0 we n, Transact. of the zoolog. soc. of London. Vol. 2. Tab. XLI.]

\section{Vom Tractus intestiualis.}

§. 189.

Die Anordnung des Verdauungsschlauches der Säugethiere ist mannichfach modificirt. Seine Verschiedenheiten erstrecken sich nicht nur auf die Dimensionen und die Texturverhäitnisse, sondern betreffen auch ganz vorziiglich die Bildung des Magens und des Blinddarmes. Bedingt sind die verschiedenen Anordnungsweisen des Verdauungsschlauches der Säugethiere durch ihre Ernährungsweise. In der Regel ist die Bildung des ganzen Tractus intestimalis um so einfacher, je ausschliesslicher die Thiere auf rein animalische Nahrung und namentlich auf Fleisch angewiesen sind, - Unter den Carnivoren besitzen nur die von Fischen und Mollusken lebenden ächten Cetaceen eine zusammengesetzte Magenbildung bei ziemlich bedeutender Länge des Darmes; aber dabei ermangeln sie der Speicheldrüsen, besitzen keine Zähne

sebr fein bei Myrinecophaga, Manis. - Abb. von Felis s. bei Carus und 0 t to 1. c. Fig. 7. u. 8. - Bei Echilna ist sie hinten mit zahnartigen Schüppchen besetzt.

10) Bei den Affen, Chiropteren, Beutelthieren, einigen Elentaten (Dasypus), vielen Ferae (z. B. den Hunden, Bären u. A.).

11) Dieser Muskel ist bei einigen Elentaten: Manis, Myruecophaga, Dasypus, mit dem $\boldsymbol{M}$. stermolyyoüdeus zu einem $\boldsymbol{M}$. sternoglossus verschmolzen. S. §. 178. 
oder nur solche, die zur Zerkleinerung der Speisen nicht geeignet sind, und ermangeln zum Theil eines Blinddarmes und cines eigentlichen Dickdarmes. - Bei den von Vegetabilien lebenden Säugcthieren und besonders bei den ächten Herbivoren, werden nicht nur dic betrïchtlichsten Dimensionen des Verdauungsschlauches angetroffen, sondern es finden sich bei ihnen auch die zusammengesetztesten Verhältnisse des Magens und Blinddarmes. - Dic von gemischter Nahrung lebenden Säugethiere stehen rijcksichtlich der Ausdelınung ihres Vcrdauungsschlauches in der Mitte zwischen den Carnivoren und Frugivorcn. Zwischen dem Magen und dem Blinddarme stellt sich oft cin gewisses antagonistisches Verhältniss heraus 1); namentlich besitzen Pflanzenfressende Säugethiere mit relativ einfacherer Construction des Magens oft einen enormen Blinddarm, während dieser letztere nicht selten da weniger entwickelt ist, wo der Magen einen sehr zusammengesctzten Bau zeigt.

[ Ueher den Verdauungs-Apparat der Säugethiere sind folgende Schriften zu vergleichen: Die zahlreichen anatomischen Bemerkungen ron $\mathrm{Daubenton}$ in Buffon's Naturgeschichte; II om e's Lectures on comparat. anatomy (mit trefflichen Abb.). - Neergard, Vergleichende Anat. und Physiol. der Verdauungs. werkzeuge der Säıgethiere und Vögel. Mit Abb. Berlin 1806. - Cuvier, Leçons d'Anat. comp. 'T. IV. P. 2. Paris 1835. - Meckel's System der vergl. Anat. Bd. 4. - Rapp, Observationes de situ tubi intestinalis Mammalium. T'ubing. 1820. - Sehr gute Abbild. in Carus und 0 tto, Erläuterungstafeln Heft 4. Immer berücksichtigt sind die anatomischen Verhältnisse des Verdauungsapparates der Säugethiere von Andreas Wagner in seiner Ausgabe des Schreber'schen Säugethierwerkes; hier finden sich namentlich über die einzelnen Gattungen dio erforderlichen literarischen Nachweisungen.]

\section{\$. 190 .}

Die Speiscröhre behält in ihrem Verlaufe zum Magen einen ungefähr gleichmässigen Durchmesser. Sie ist in Allgemeinen weiter und ausdchnbarer bei den Carnivoren, als bei den Herbivoren. Ihre Länge ist, schr verschieden 1). Gewöhnlich senkt sie sich dicht unterhalb 2) ihres Durchtrittes durch das Foramen oesophageum des Zwerchfelles in den Magen; nicht selten aber verläuft sie, vor ihrem Eintritte in

1) Mangel eines Blinddarmes bei zusanmengesetzten Bildungsverliältnissen des Magens z. B. bei den ächten Cetaceen, den Faulthieren; Kleinheit des Blinddarmes bei bedeutender Ausdehnung des Magens z. B. bei Halmaturus, Hypsiprymnus, Dicotyles; bedeutender Umfang des Blindlarmes bei einfachem Magen z. B. bei Phalangista unter den Beutelthieren, bei vielen Nagern, bein Pferde.

1) Zuın grossen Theile natürlich von der Länge des IIalses ablängig; bei den Wielerkäuern daher lang und zugleich eng; bei den Cetaceen kurz und weit.

2) Z. B. bei den Cetaceen, Wiellerkäuern, Einhufern, Pachydermen, Edentaten, inanchen Nagern, z. B. dew Biber, vielen Insectivoren, den Ferae, den Quadrumaneu, bei Phalangista unter den Beutelthieren. 
den letzteren, noch eino mehr oder minder beträchtliche Strecke weil innerhalb der Bauchböhle abwärts ${ }^{3}$ ). Während ihres Verlaufes durch die Brusthöhle ist sie gewöhnlich innig, seltener, wie z. B. bei den meisten Beutelthieren, lose durch das Brustfell an die Körper der Riickenwirbel geheftet. Ihre starke Muskelliaut besteht bald aus äusseren Längen - und inneren Querbündeln, bald besitzt sie in ihrer ganzen Ausdehnung, oder in dem grösseren Theile derselben, zwei in entgegengesetzter Richtung verlaufende Spirdfaserlagen 4). Die Primitivbündel ihrer Muskeln sind meist, bis zum Magen, quergestreift 5 \%. Die Innenfläclıe der Speiserölıre, an welcher zahlreiche, einfache Follikel münden, ist gewöhnlich glatt, oder besitzt feine Wärzchen, oder zcigt schwache Längsfalten. Beim Katzengeschlechte und bci Didelphis kommen im unteren Theile derselben zahlreiche, dicht stehende Querfaltcn vor; beim Biber dagegen finden sich, gleichfalls in der Nähe der Cardia, kreisförmig gestellte, nach hinten gerichtete, den Rücktritt der Speisen aus dem Magen verhindernde, stachelförmige Vorragungen; denselben Zweck erfüllen bei den Pferden klappenartige Bildungen.

Der Magen, immer durch beträchtlichere Weite vor der Speiscröhre ausgezeichnet, bietet in seinen Bildungsverhältnissen die grössten Verschiedenheiten dar. Die beiden Extreme seiner Bildung sind sein Erscheinen als einfache längliche Erweiterung mit sehr schwacher Andeutung eines Blindsackes und sein Zerfallen in vier, durch Einschnürungen und Texturverhältnisse gesonderte Abtheilungen bei den meisten eigentlichen Wiederkäuern. - Einen einfachen Magen besitzen die Monotremen, die meisten Beutelthicre, einige Nager, die meisten Edentaten, einige Pachydermen, die Einhufer, die Insectivoren, die eigentlichen Ferac, mit Einschluss der Phoken, viele Chiropteren und die meisten Quadrumanen. - Dicser einfache Magen stellt selten einen länglichen, fast gerade absteigenden, erst in der Nähe des Pförtners umgebogenen Schlauch mit sehr schwacher Andeutung eines linken Blindsackes dar, wie bei vielen Phoken ${ }^{6}$ ) und beim Walrosse. Er ist in der Regel mehr quergestellt, meist zugleich rundlicher und bildet linkerseits von der Insertion der Speiseröhre einen Blindsack. Dieser ist nur schwach

3) Z. B. bei Didelphis und Macropus unter den Beutelthieren, bei den meisten Nagern, z. B. Cricetus, Mus, Loncleres, Myoxus, A rctomys, Sciurus, weniger beträchtlich bei Cavia und Lepus; bei vielen Chiropteren, bei Talpa u. A.

4) Bei Wiederkäuern, Einbufern, einigen Pachydermen, vielen Ferae. Vergl. Cuvier, Leçons T. 4. P. 2. 1) 16.

5) Vergl. die Untersuchungen von Gulliver in seiner Uebersetzung ron Gerber's allg. Anat. (ausgezogen von Valentin, Repertorium 1843. S. 198.).

6) Abb. des Magens von Trichecus bei Carus und 0 tto, Erläntcrungstafeln Hft. 4. Tab. VIII. Fig. 1.; ron meliren Phoken bei Thienemann, Natuihist. Bemerkungen, gesammelt auf einer Reise im Norden von Europa. Leipzig 1824. Tab. VIII., XU. u. s. w. 
entwickelt bei den Ifyänen ') und Katzen ${ }^{8}$ ), erscheint dagegen mehr oder minder beträchtlich bei den Monotremen, den ineisten Beutclthieren, manchen Nagern und Edentaten 9 ), cinigen Pachydermen, unter den Ferac bei den Plantigraden und besonders den Insectivoren, so wie unter den Quadrumanen vorziiglich bei Lemur ${ }^{10}$ ), IIapale u. A. Je weitcr, bei zunehmender Ausdehnung des Blindsackes, die Cardia nach rechts rückt, un so näher licgt sie gewöhnlich dem Pylorus. - Abweichend von dieser gewöhnlichen Bildung und complicirt wird der Magen besonders bei Thieren, die von Vegetabilien leben, auf mehrfache Weise. Schon beim Elephanten 11) und Rhinoceros zeichnet cr sich, bei Anwesenheit eines beträchtlichen Blindsackes, durch bedeutende Länge aus; ähnliches stellt bei Galaeopithecus ${ }^{12}$ ) sich heraus. Dadurch gewinnt der Magen einen mchr darmähnlichen Gharakter. Dieser ist, bei Ausbildung einer Windung, sehr scharf ausgeprägt bei Pteropus ${ }^{13}$ ) unter den Chiropteren, wo zuglcich links ein enormer, in der Mitte eingeschnurrter, blinddarmartiger Blindsack rorhanden ist. Dem Colon des Menschen ähnlich erscheint der aus drei Abtheilungen bestehende darmähnliche Magen bei einigen Quadrumanen (Semnopithecus 14) und Colobus) und mehr noch, wegen beträchtlicherer Länge, bei Halmaturus ${ }^{15}$ ) (Macropus) und Hypsiprymnus unter den Beutelthieren. Es sind äussere, kürzere, bandartige Lüingsstreifen yorhanden, welche Einschnürungen der längeren Magenhöhle und die Entstehung inehr oder minder zahlreicher Taschen bewirken. Dabei findet sich ein, meist einfacher, seltener, wie bei einigen Arten von Macropus, doppelter

7) Abb. bei Carus und Otto 1. c. Fig. 2.

8) Abb. vom Luchs, $H_{0}$ unc, Lectures on comparat. Anat. Vol. 2. Tab. XI.; rom Leopard Tab. CXIII.

9) Abb. von Manis bei Carus und 0 tto l. c. Fig. 6. u. 7.; bei einigen Ederntaten, Myrmecophaga didactyla und Dasypus peba (Abb. bei Rapp, Edentaten Tab. VIII. Fig. 1.), ist die kleine Curvatur convex.

10) Abb. von Lemur bei Carus und 0 tto Tab. VIII. Fig. 3.

11) Abb. bei $H_{0} m \mathrm{e}$, Lectures Vol. II. Tab. XVIII. In dem beträchtlichsten Blindsack finden sich starke Querfalten; vom Rbinoceros s. eine Abb. bei Home Vol. IV. Tab. XXVIII.

12) S. Cuvier, Leçous Vol. 4. P. 2. p. 31.

13) Abb. bei Home, Lect. Vol. 11. Tab. XX. Fig. 1.

14) Abb. des Magens von Semnopithecus bei Carus und 0 tto l. c. Tab. V'lll. Fig. 9. S. auch 0 t to in Nov. Act. Acar. Caes. Carol. Leop. T. XII. P. Il. p. 105. Tab. XLVI. u. XLVII. - Boie in 0ken's Isis 182s. Hft. 10. S. 1027. 0 wen in Transactions of the zool. society of London. Vol. 1. p. 65. Tab. VIII. u. IX. - Ueber Colobus siehe 0 wen in den Proceedings of the zool. society. 1841. p. 84 .

15) Abb. bei Hounc, Lect. on compar. Anat. Vol. II. Tab. 19.; genauc Be. schreibung bei 0 wen in Todd's Cyclopaedia 1. c. 1).301. Die Abb. von 110 ule ist copirt bei 0 wen 1. c. Eine Originalabb. s. bei Carus und 0 tto Tab. VIII. Fig. 10. 
Blindsack. - Eine Theilung des Magens in zwei Säcke kömmt oft zu Stunde 16). Schon bei vielen Nagern geht dessen Purtio cardiack durch einen verengten Abschnitt in die wieder weitere Portio pyloricu über. An sie schliessen sich andere, bei welchen durch eine Einschuürung - bei gleichzeitig vorhandenen Abweichungen in den inncren Tcxturverlaältnissen - eine schärfere Theilung in einen Cardiaund Prörtner-Sack zu Wege gebracht wird. Bei einigen Säugcthieren koinmen neben oder an diesen beiden Säcken noch eigenthümliche Anhänge oder Ausstiilpungen vor; ihrer sind z. B. drei vorhanden am Cardiasacke von Dicolyles 17); bei Manatus und Halicore 18) treten zwei blinddarmartige Ausstullpungen in die Verengerung, welche den Cardiasack voin Pförtiersack scheidet und der Blindsack der linken Magenhälfte geht gleichfalls noch in eine blindc Verengerung über. Bei vielen Nagcrn hat der Pförtnersack zwei bis drei untergeordnete beutelförmige Aussackungen ${ }^{19}$ ). - Zu den zusammengesetzen Magenbildungen gehören die der ächten Cetaceen ${ }^{20}$ ). Der linke Blindsack hat sich z. B. bei Mlonodon und Delphinus zu eincr beträchtlichen Höhle

16) Diese Theilung beginnt z. B. unter den Nagern schon bein Hlaasen und Kaninchen; sie wird deutlicher bei Hystrix, Cricetus u. A. Sie erscheint sehr rollständig z. B. bei der Pachylermen-Gattung Hyrax, wo eine innere Falte die beiden Abtheilungen des Magens scheidet, welche sehr diverse Texturrerbältuisse zeigen. Ueber Hyrax siehe, ausser den älteren Angaben von Cuvier: Kaula, Monographia Hyracis. Tubing. 1830. und 0 wen in den Proceedings of the zool. soc. of Lond. Vol. 2. (1832.) p. 202.

17) Abb. bei Carus und 0 tto Tab. VIII. Fig. 11. S. auch Rapp in Mek. kel's Arch. f. Anat. u. Physiol. 1830. S. 363.

18) Abb, ron Manatus bei Hoine, Lectures Vol. IV. Tab. XXVI.; voin Dïgong ibid. Tab. XXV. und von Rïppel im Museum Senkenbergianum Vol. 1. Tab. VI. Fig. 2. Copie der Ho me'schen Abbild. von Manatıs bei Carus und Otto l. c. Tab. VIII. Fig. 12. Rüppel beschreibt den Pförtnersack des Magens als Erweiterung des Duodenum.

19) S. d. sorgfältige Beschreibung, welche Retzius in Müller's Arch. 1841 . S. 403. geliefert hat voun Magen der Wasserratte, der Feldmans und des Lemming. Abb. Tab. XIV. Diese Thiere besitzen eine deutliche Schlundrinne.

20) Abb. des Magens von Delphinus phocaena s. bei Carus und 0 tto l. c. Tab. VIII. Fig. 14. und bei Rapp, Cetaceen Tab. VI. Meiner Ansicht nach besclıränkt sich die Zahl der Magenabtlıeilungen bei den äcliten Cetaceen wesentlich auf drei, ron denen die erstere oft nur eine Erweiterung der Speiseröhre darstellt, während die dritte cịne darmförmige Gestalt besitzt. Dieser bietet rücksichtlich der ZahI von Unterabtheilungen, in die er zerfält, grosse Ver. schiedenleiten lar, und wenn man jene Unterabtheilungen als eigene Magess. höllen ansielıt, kann unan, wie dies namentlich in Betreff des Hyperoodon geschehen ist, eine sehr grosse Zahl von Mägen bei einigen ächten Cetaceen unter. scheiden. - Der fünfte Magen der Delphine, von dein viele Schriftsteller reden, ist nur der erweiterte Anfang des Duodenuın. Uebrigens kommen, wie dic Untersuchungen ron Hunter, Bennett, Vrolik, Eschricht u. A. gezeigt haben, rïcksichulicl des speciellen Verhaltens dor einzelnen Magenhöhlen wannichfacho rerscliedenheiten bei den Cetaceen ror. 
entwickelt, welche neben der Insertion der Speiseröhre mittelst einer weiten Oeffnung init einer zweiten Höhle communicirt; diese steht durch ein sehr enges Orificium mit der darmförmigen Purlio pylorica in Verbindung, welehe hier wieder in zwei (bei anderen Gattungen oft in mehre) gesonderte Höhlen zerfällt. - In anderer Weise zusammengesetzt ist der Magen bei den Faulthieren ${ }^{21}$ ), wodureh eine Annäherung an seine Bildung bei der Ordnung der Wiederkäuer ${ }^{22)}$ zu Stande kömmt. Bei diesen letzteren bildet der Magen drei, gewöhnlich vicr Höhlen, in welehen letzteren Falle dic drei ersten weitere Entwickelungen der Portio cardiaca sind. Die erste, immer durch ilıre Weite ausgezciehnete, links gelegene, wieder in Nebenhöhlen zerfallende Höhle fülıt den Namen des Pansen (Rumen, Iugluvies); die zweite ist der Nietzmagen oder die Haube (Reticulum, Ollulu), welche unter der Speiseröhre von links nach rechts sich erstreekt; die beiden letzten, reehterseits gelegenen Höhlen sind der Blättermagen oder Löser (Umasus, Psulterium) und der Labmagen oder Käsemagen ( $\boldsymbol{A}$ bomasus). Die Spciseröhre steht nicht nur mit dem Pansen, sondern auch mit dem Netzmagen und dem Blättermagen in Verbindung. Von ihrer Insertionsstelle in den Pansen aus erstrecken sich nämlieh zrvei lippenartige, eine Rinne (die sogenannte Schlund-oder Speiseröhrenrinne) einschliessende, contractile Vorragungen längs der Innenseite des Netzmagens zur Miindung des Blïttermagens. Das frische Futter tritt zuerst in den Pansen und von diesem aus in den, durch eine weite Oeffnung mit ihm communicirenden Netzmagen; aus letzterem gelangt es dinn wieder dureh dic Speiseröhre in die Mundhöhle, um wiedergekäuet zu werden. Das wiedergekäuete Futter tritt aber aus der Speiseröhrc durch die, mittelst Annälıerung ihrer Labia, zu einer Röhre unge-

21) Abb. von Bradypus speculiger bei Carus und 0tto l. c. Tab. VIII. Fig. 13.; genaue Beschreibung der inneren Textur bei Rapp, Edentaten S. 57. Es sind drei Magenböhlen vorlanden. Auelı hier kömut eine Sehlundrinne vor.

22) Abb. voun Schaaf bei Carus und 0 tto Tab. IX. Fig. 16.; rom Laina ibid. Fig. XVII. - Durch eine Reduetion der Magenhöhlen auf drei zeiehnen siel unter den Wiederkäuern besonders Camelus, Auehenia und, wie Rapp (WiegIII a In-Erichson's Archiv 1843. S. 43.) und Leuekart (Müller's Arehiv 1843. S. 24. Tab. 2.) neuerlieh gezeigt haben, aueh Mosehus ('Tragulus) jaranicus aus. S. d. Abl. bei Rapp l. e. Tab. 2. - Die Bildungsverhältnisse des Epitheliun in den ersten drei Mägen der Wiederkäuer zeigen übrigens grosse Verschiedenheiten; namentlieh gilt dies ron den Papillen des Pansen und den Zellen des Netzmagens, welehe z. B. bei den Camelen und Lama's so beträehtlieh sind. - Ueber den Magenbau der einheimisehen Wiederkäuer rerweise ich auf Gurlt, Lebrbuch Thl. 2. S. 34., so wie auf Berthold, Beiträge zmr Anat., Zootoll.. n. Plıysiol. Gött. 1831. S. 186. - Die Eigensehaft des Wiederkïuens beschränkt sich aber mieht auf die Orlnung der Ruminantia, sondern kommt auteh andern Säugethieren, wie z. B. einigen Beutelthieren (Känguruh), den Faulthieren und einigen Nagern, bei denen gleichfalls eine Schlundriune angetroffen wirl, zu. Vergl. Anmerk. 19. 
wandelte Speiseröhrenrinnc unmittelbar in den Blättermagen und von diesem aus in den Labınagen.

Ausser diesen Yerschiedenheiten in der Anordnung des Magens kommen noch wesentlich dicjenigen in Betracht, welche seine in nere Textur betreffen. Die Höhle des äusserlich einfachen Magens ist nicht immer überall und gleichnässig von einer weichen, schlïpfrigen, mit Cylinder-Epithclium versèhenen Schleimhaut ausgekleidet; läufig ist die Innenwand des Blindsackes mit einer dicken Schicht PflasterEpithclium, wie es der Speiseröhre zukömmt, bekleidet 23). So ist eine innere Theilung ausgesprochen, ohne dass sie zugleich äusserlich hervortritt. Bei den mit getheilter Nagenhöhle versehenen Säugethieren, z. B. vielen Nagern, ist der ganze Cardiasack von solchem dickerenı Epithelium überzogen; bei Delphinus und Monodon der erste Magensack (der bei Monodon zugleich durch kolben - oder fingerförmige Vorragungen sich auszeichnet); bei den Wiederkäuern ist das Epithelium am dicksten in Pansen, ändert abcr erst in dem, dem einfachen Magen anderer Säugethiere entsprechenden, Labmagen wesentlich seinen Charakter. - Bei einigen anderen Säugethieren tritt dagegen ein Anschluss an die Bildung des Vogelmagens dadurch ein, dass die Epithelialschicht in dem, oft zugleich stärker muskulösen, Pförtnertheile sich verdickt; so z. B. bei Echidna 24), wo in der Nähe des Pförtners atuch zahlreiche scharfe, hornige Papillen vorkonmen, bei den Faulthieren, wo die letzte Magenabtheilung ein dickes hornartiges Epithelium besitzt; so wie auch beim Kängurul. - Sehr grosse Verschiedenheiten bieten Entwickelung und Anordnung der drüsigen Apparate der Magenhöhle dar. In denjenigen Abschnitten des Magens, die von dickeren Lagen Pflaster-Epithelium bekleidet sind, finden sich gewöhnlich nur die einfachen Follikel, welche auch in der Speiseröhre vorkommen. Die übrigen, mit schlüpferiger, von einem Cylinder-Epithelium ausgekleidcter, Sclıleimbaut verschenen Abschnitte des Magens sind dagegen in der Regel durch Anwesenheit äusserst zahlreicher, dicht neben einander stehender, meist traubig endender absondernder Drüschen ausgezeichnet 25$)$. Bei vielcn Säugcthicren kommen dagegen eigenthümliche Anordnungen des drüsigen Apparates der Magenhöhle vor. Bcim Siebenschläfer sind die beträchtlichen Magendrüsen, ïhnlich, wie bei den Vögeln, auf eine $\Lambda \mathrm{rt}$ von Vormagen concentrirt ${ }^{26}$ ); bci Phascolomys, Phascolarctos und

23) Z. B. bei den Einhufern (s. d. Abb. von Ho in e, Lectures II. Tab. XVI.), bei manchen Nagern u. $A$.

24) Abb. bei Ed. Home, Lectures Vol. II. Tab. XLIII.

25) S. Näberes bei Bisch off in Müller's Archiv 1838. Tab. XIV. u. XV. Vergl. auch die treffliche Sclirift von $W$ a s m a n $n$, De digestione nonnulla. Berol. 1838. 8. Mit Abb., wo die Magendriischen des Schweines speciel besclırieben sind.

26) S. die $A$ bb. bei Home Vol. II. Tab, XIII. Fig. 3. 4. 
Castor ${ }^{2}$ ) liegen auffallend starke absondernde Drisenmassen unterhalb der Cardia an der kleinen Curvatur des Magens und münden nit zahlreiehen Orificia in seine IIöhle; eine ähnliehe starke Drüse findet sieh bei Minis an der grossen Curvatur des Magens ${ }^{28}$ ); bei vielen Nagern kömmt ein scharf begrenzter, durch drüsigen Bau ausgezeiehneter Saek an der grossen Curvatur des Magens vor ${ }^{29}$ ); bein Känguruh erstreeken sieh drei Reihen von rundliehen Drüsenhaufen durch die zweite Hälfte des darmiihnlichen Magens ${ }^{30}$ ). - Auch die Sirenen besitzen eine starke Magendrüse.

An der Uebergangsstelle des Magens in den Darmcanal findet sieh beständig eine Pförtnerklappe, die den Eingang in den Darm oft beträchtlich verengt.

\section{§. 191.}

Der Darmcanal der Sïugethiere sondert sich meistens in einen Dünn - und Dickdarm, deren Grenze dann gewöhnlich durch den verschiedentlich entwickelten Blinddarm bezeichnet wird. Wo aber der letztere fehlt 1), mangelt aueh gewöhnlich jeder bestimmte Unterschied zwischen den genannten beiden Abtheilungen des Darmcanales, dessen letzter Absehnitt dann höchstens durch abweiehende Texturverhältnisse oder etwas grössere Weite sieh anszeichnet. - Die übrigen Verschiedenheiten, welche der Darmcanal der Säugethiere darbietet, betreffen besonders seine Dimensionen, den Umfang seiner einzelnen Abtheilungen, so wie das Verhalten sciner Schleimhaut und ihrer AbsonderungsApparate; endlich auch die Ausmiindungsweise des Afters. - Der Dünndarm hat eine sehr verschiedene Lünge 2 ); in der Regel ist sie

27) Abb. vou Wombat bei Home l. c. Vol. II. Tab. XIV.; vom Biber ebendas. T'ab. XIII.

28) Beschrieben und abgebildet von 0 tto in den Erlüıterungstafeln Hft. 4. S. 19. Tab. VIII.

29) So bei der Wasserratte, der Feldmaus, dem Lemming; vergl. die Abb. von Retzius in Miller's Archiv 1841. Tab. XIV.

30) Abgeb. bei Home, Lectures Vol. II. Tab. XIX.

1) S. weiter unten. Bei manchen ächten Cetaceen, z. B. den Delphinen, ist es unüöglich, die Grenzc zwischen Dünn- und Dickdarm zu bezeichnen; auch der Narwal besitzt zwar weder Blinddarm, noch Valvula coli, aber der Endabschnitt seines Darmcanales erweitert sich ziemlich plötzlich und eruangelt zugleich aller Zotten und Falten. Eiı ähnliches Verbalten kömmt auch bei anderen Säugethieren vor.

2) Zahlreiche Messungen des Darmcanales s. zusammengestellt bei Curier, Leçons Vol. IV. P. 2. 1. $182 \mathrm{~s} \eta q$ ๆ; in Betreff der Hanssäugethiere vergl. die Ta. belle bei Gurlt, Vergl. Anatomie der Haussängethiere 'Tlı. 2. S. 47. - A kürzesten ist der Darmcanal bei vielen carnivoren Chiroptcren, den Insectivoren und anderen Ferae; au längsten dagegen bei den Sirenen und den Wielderkäuern. - Das Verlıältniss der Läıge des Darıncanalcs zu derjenigen des Körpers bietet, je nach dem verschiedencn Lebensaltcr, iu Ganzen nicht umbeträchtliche Sehwankungen dar. Neben den Messungen muss aber in Betracht gezogen werden, ob die Innenfläche des Darmes etwa durch Schleimlautfalten oder andcre Mittel eine bedeutcnde Vergrösserung crfährt, oder nicht. 
bei den herbivoren Säugethieren beträehtlicher, als bei den Carnivoren; indessen zeichnen auch einige Carnivoren, z. B. die Phoken, durch bedeutende Länge ihres Diinndarms sieh aus 3 ). Seine Flächenvergrösserung kann auf verschiedene Weise zu Stande kominen; bisweilen dureh Längsfalten seiner Schleimhaut 4); bei anderen durch mehr oder minder dicht stehende Querfalten ${ }^{5}$ ), welche bei einzelnen Gattungen der ächten Cetaceen, durch kiirzere Längsfalten verbunden, Zellen bilden, die wiederum kleinere Zellen einschliessen.

Das Duodenum beginnt nicht selten mit einer mehr oder minder beträehtlichen Erweiterung ${ }^{6}$. - - Sehr allgemein ist die Innenfläche des Dünndarms mit dichtstehenden, aber hinsiehtlich ihrer Ausdelnnung und Form etwas variirenden Zotten ${ }^{7}$ ) besetzt, die nur selten fehlen und dann durch netzbildende Falten ${ }^{8}$ ) oder lappige Verlängerungen der Sehleimhaut $\left.{ }^{9}\right)$ vertreten werden. - Was die drüsigen Gebilde 10) anbetrifft, so zeigt namentlich das Duodenum einen grossen Reichthum derselben; die hier vorkommenden Brunn'schen Drüsen sind bisweilen dicht an einander gedrängt ${ }^{11}$ ). Die Peyer'schen Driisen kommen anscheinend

3) Bei den Phoken, deren Dickdarm allgemein sehr kurz ist und etwa $\frac{1}{40}$ der ganzen Darmlänge beträgt, ist der Darm oft über 20 mal länger, als der Körper; auch bei den ächten Cetaceen besitzt er eine bedeutende Länge; so ist er z. B. bei Delphinus phocaena fast 11 mal länger, als aler Körper.

4) Nanentlich bei vielen, wenngleich nicht allen, ächten Cetaceen; z. B. bei den Delphinen und dem Narwal.

5) Quere oder fast schiefe Falten finden sich z. B. im ganzen Dünndarın von Ornithorhynchus. - Die durch scbief gestellte Querfalten und kürzere verhindendo Längsfalten bewerkstelligte Zellenbildung in Dünndarın des bottle-nose Whale (Hyperoodon) bat schon Hunter beschrieben. Eschricht entdeckte diesen Balı auch bei Balaena boops Fabr. S. die Abb. in seinen Undersögelser over Hualdyrene. Fierde Afh. Kjöbenh. 1845. Tab. VI.

6) Z. B. bei den Cetaceen, beim Lama, Dromedar, bei Phascolarctos, bei vielen Nagern (Coelogenys, Capromys, Dasyprocta u. A.).

7) Vergl. über die Darmzotten $\mathrm{Rudol} p \mathrm{hi}$ in seinen anatomisch-physiol. $\mathrm{Ab}$ handlungen S. 39 ff. und Physiologie Bd. 2. Abth. 3. S. 207.; ferner A. Meckel in Meckel's deutsch. Archiv für Physiol. Bd. 5. S. 163. Taf. 3. A. und dessen Observationes circa superficiem animalium internam. Bern 1822. 8. Zotten fehlen bei Talpa und Chrysochloris; nach Rudolphi bei Ornithorhynchus, nach 0 tto beim Elephanten, nach $R$ app bei Myrmecophaga tamandua und jubata, so wie bei Dasypus peba. Was die Cetaceen anbetrifft, denen man sie bisweilen abge. sprochen hat, so liabe ich sie bei Delphinus und Monodon beobachtet.

8) Wie bei Talpa. Abb. bei Rudolphi, Abandl. Tab. 5. Fig. 1.

9) Wie beim Elephanten. Abb. bei Carus und Otto, Erläıterungstafeln Hft. 4. Tab. IX. Fig. XVIII.

10) Vergl. über diese besonders auch $\mathrm{B}$ o $\mathrm{ehm}$, de glandularum intestinalium structura penitiori. Berol. 1835. 4. Ueber das eigenthümliche Verhalten der Dünndarmdrüsen bei Hyrax vergl. Owen, Proceedings of the zool. soc. Vol. 2. p. 203.

11) Gürtelförmig gruppirt sind sie z. B. bei den meisten Beutelthieren; s. d. Abb. vom Kängurul bei Carus ind 0 t to Hft. 4. Tab. VIlI. Fig. 10. 
beständig vor. - Gewöhnlich, doch keinesweges beständig, geschielıt die Abgrenzung des Duinndarmes vom Dickdarme durch eine Valvula coli 12). - Kein Theil des Darmcanales bietet eine grössere Verschiedenartigkeit seiner Verbältnisse dar, als der Blinddarm. Häufig fehlt er ganz und zwar ist dies meistentheils bei Fleisch- und Insectenfressern, selten bei IIerbivoren der Fall. $\mathrm{Er}_{\mathrm{r}}$ mangelt namentlich mehren ächten Cetaceen 13), den Fleischfressenden Beutelthieren 14), unter den Edentaten den Faulthieren und den meisten Guirtelthieren, unter den Nagern den Myoxina, unter den Raubthieren den Insectivoren, mit Ausnahine der Gattungen Cladobates und Macroscelides, ferner den Familien der Ursina und Mustelina, so wie endlich allen eigentlichen Chiropteren. Bei denjenigen Säugethieren, die einen Blinddarm besitzen, zeigt sich letzterer auf sehr verschiedenen Stufen der Ausbildung. So ist er klein und einfach bei den Ferae ${ }^{15}$ ), den Walfischen, den Monotremen, den Insectenfressenden Beutelthieren. Bei einigen Planzenfressenden Beutelthieren 16), beim Pekari u. A., fällt eine geringe Entwickelung des Blinddarmes mit sehr complicirten Bildungsverhältnissen des Magens zusammen. Bei den Quadrumanen ist er allgemein umfänglicher, als beim Menschen, obschion bei den einzelnen Gattungen und Arten verschiedentlich entwickelt ${ }^{17}$ ). Bei den Wiederkäuern ist er einfach und verluältnissmässig weniger weit und gross, als bei den Einhufern und den meisten Pachydermen (mit Ausnahme von Dicotyles, Sus u. A., wo er klein ist). Durch seinen Umfang ausgezeichnet ist er vorzüglich bei einigen Fríchte-fressenden Beutelthieren 18) und bei sehr vielen Nagern 19); er uibertrifft hier nicht nur den Dickdarın, sondern meist auch den Magen an Weite und ist bisweilen mehrmals länger, als der Körper. Sehr häufig ist er durch bandförmige Längsmuskelstreifen, die kürzer

12) Sie felrlt z. B. den ächten Cetaceen, den meisten Edentaten u. A.

13) Namentlich Physeter macroceplialus nach Bennett, ferner bei Hyperoodon, Delphinus und Monodon; Hunter (Works Tom. IV.p. 360.) traf ihn an bei Balaena mysticetus und rostrata. Durernoy (bei Cuvier T. IV. 2. p. 209.) bei Platanista gangetica. Auch Eschricht bestätigt seine Existenz bei den Walen.

14) Den Gattungen Thylacinus, Dasyurus, Phascogale.

15) Abb. ron Phoca bei $\mathrm{C}$ a rus und 0 to Tab. IX. Fig. XIX. Sehr unbeträchtlich bei Viverra, Rhyzacna u. A.

16) Besonders Hypsipryınmus; länger schon bei Halmatnrus; sehr kurz auch beim Wombat; aber zugleich selır eigenthümlich. Abb. d. Coecum der Beutel. thiere bei 0 wen, Marsupialia p. 302.

17) Sehr unfänglich bei Mycetes fuscus, s. Carus und 0 tto T'ab. IX. Fig. 20. Vergl. auch Meckel, System Thl. 4. S. 729.

18) Bei Phalangısta zweimal so lang, als der Körper; noch länger bei Phascolarctos.

19) Vurzüglich lang und weit bei den Gattrngen Lepus, Lagonys, Hystrix, einigen Georhyclus und Lemmus, so wie auch bei Coelogenys. Man vergl. dio Tabelle bei Curier 1. c. p. 190. Zahlreiche Abb. bei Pallas, Nov. spec. quadr. e Glir. ord. Tab. IV. IX. XVII. XXV. 
als er selbst sind und deren sich meistens drei bis vier finden, in zalll reiche Beutel oder Taschen zerfallen. So namentlich bei den Einhufern, vielen Pachydermen und Nagern, dem Känguruh u. A. Einige Säugethiere sind durch eigenthümliche blinde, bei eirigen Nagern drüsige, Anhänge oder Aussackungen ihres Blinddarınes ausgezeichnet 20); manche Affen und Halbaffen (z. B. Nycticebus), der Wombat u. A. besitzen einen eigentlichen Processus vermicularis. Sehr selten kehrt, als Vogel-Aehnliclikeit, ein doppelter Blinddarm 21) wieder; oder es finden sich gar zwei hinter einander liegende Blinddärme 22 ). Gleich deın Unfange und der Form des Blinddarmes, zeigt auch seine Schleimhaut ein verschiedenartiges Verhalten; bisweilen bildet sie Querfalten, wie bei Mycetes, bei Arctomys u. A.; bei manchen Nagern, z. B. bei Lepus, findet sich eine innere Spiralklappe. In der Regel ist die Schleimhaut schr driisenreich; selten besitzt sie Zotten, wie z. B. hei Lagumys; eben so selten bildet sie Zellen, wie bei den Sirenen.

Was nun den Dickdarm anbetrifft, so wechseln dessen Dimensionen bedeutend; oft ist er, wie bei den meisten Vögeln, durch grosse Kürze ausgezeichnet ${ }^{23}$ ); gewöhnlich ist er kürzer, als der Dünndarm; selten, aber nur bei IIerbivoren, übertrifft er den letzteren beträchtlich an Länge 25). Oft ist er wenig weiter, als der Dünndarm, oft übertrifft er ihn beträclıtlich an Weite. Nur bei herbivoren und omnivoren Säugethieren entstehen durch Längenmuskelbündel, welche kürzer sind, als der Darmschlauch, Taschen im Grimmdarme. Die Texturverhältnisse der Schleimhaut der dicken Därme sind meist einfacher, als im Duinndarme. Zotten kommen nur sehr ausnahınsweise vor; gewöhnlich ist die Schleimhaut glatt, seltener besitzt sie netzförmige Maschen. Der

20) Dahin gehört unter den Sirenen Manatus (Abbildungen bei Home, Lectures Vol. IV. Tab. XXVII. (Man vergl. damit die Abb. des einfachen Blind. darmes rom Dügong ibid. Tab. XXIV. Fig. 3.). Copie bei Carus und 0 tto Hft. 4. Tab. VII. Fig. XXI. - Andere blinde Anhänge finden sich am Coecum mancher Nager, z. B. bei den Gattungen Lepus und Lagomys. Abb. ron letz. teren bei Pallas, Glires Tab. IV., copirt bei Carus und otto Tab. VIII. Fig. 23. 24.

21) So bei wenigen Elentaten, namentlich bei Dasypus sexcinctus und bei Myrmecophaga didactyla, wo die Bildung wirklich Vogelähnlich ist. Vergl. die Abb. bei Carus und 0 tto Hft. 4. Tab. VIII. Fig. XXII. - Sebr rerschieden davon verhält sich Phascolomys, wo eine Aussackung des Dickdarmes eine Art von zweitem Coecum bildet, wo aber alle Symmetrie mangelt.

22) Dahin gehört Hyrax. Ein einfaches Coecum liegt an der Grenze von Dünn - und Dickdarm; im Verlaufe des letzteren kommen noch zwei symmetriscl gestellte Coeca vor. S. Pillas, Spicilegia zoologica. Fasc. 2. Tal. III.; copirt bei Carus und 0 t to 'Tab. VIIL. Fig. 25. Vergl. auch 0 wen, Proceedings of the zool. soc. Vol. 2. p. 204.

23) Besonders bei den Plioken, Viverra, Rbyzaena, mehren Edentaten; vergl. die 'Tabelle bei Cuvier, Leçons d'Anat. comp. Vol. IV. P. 2. p. 224.

24) Fast noch einmal so lang, als ter Dünndarm, ist er beim Dügong. 
Reichthum an Follikeln ist oft ziemlich bedeutend. - Ruicksichtlich der Afterdrüsen ist auf $\$$. 170. zu verweisen. - Der After mündet bei den Monotremen in den gemeinsamen Vorhof der Cloake; bei den Beutelthieren fallen die Muindungen des Afters und der Geschlechtstheile zusammen; ersterer hat einen eigenen Sphincter und einen mil letztern gemeinschaftlichen sphincter cloacae. Bei den übrigen Ordnungen sind die After - und Geschlechtsöffnungen getrennt, liegen abcr, namentlicl bei vielen Nagern und Edentaten, sehr dicht neben einander.

[Man vergl. nähere Angaben ïber den Darmcanal der Säugethiere bei Cuvier, Leçons T. IV. P. 2. p. 226 sqq. und Meckel, System Thl. 4.; über die einzelnen Ordnungen s. die monographischen Werke. Viele Abbild. liefert, ausser den citirten, Ho me, Lectures Vol. II. Tab. CXIII._CXXXIII.]

\section{§. 192.}

Die Befestigung des Tractus intestinalis geschieht durch das Bauchfell. An die Rückenfläche der Bauchböhle werden seine einzelnen Theile geheftet durch Peritonealduplicaturen, welche, die Gefässe einschliessend, je naeh den einzelnen Theilen des Darmcanales, zu welchen sie treten, im Allgemeinen die Benennungen: Mesolluolenum ${ }^{1}$ ), Mesenterium, Mesocolon und Mesorectum erhalten. Ihre Anordnung bietet aber, je nach den verschiedenen Verhïltnissen des Darncanales, manche Verschiedenheiten dar. So fällt z. B. bei den ächten Cetaccen der Grund zur Unterscheidung der genannten einzclnen Theile des sehr einfach gebildeten Mesenterium weg, während dagegen bei anderen Säugethicren, die einen beträchtlichen Blinddarm besitzen, auch dieser durch eine eigene, vom Mesocolon ausgehende Peritonealduplicatur befestigt zu werden pflegt. - Die Netze (Omemta) sind beständig, obschon verschiedentlich entwickelt, vorhanden. Das kleine Netz (Omentum gustrolicpaticum) findet sich immer zwischen der kleinen Curvatur des Magens und der Fossa transversa der Leber und erscheint bald als einfaches Band, bald sackförmig ausgedehnt und fetthaltig. Das grosse Netz (Omentum gastrocolicum), gleichfalls beständig vorhanden, bietet beträchtliche Verschiedenheiten dar. Am einfachsten, und ohne Fett, erscheint es bei den Cetaceen; seine höchste Entwickelung erlangt es bei den Wiederkäuern als Hiille um die Magen, bei den Ferae als Iüllle um die Gedïrme. Je einfacher der Magen ist, um so weniger wird er vom grossen Netz umgeben. - Das Omentum colicum und die Appendices cpiploicae werden bei denjenigen Säugethieren, bei welchen dic dicken Därme gar nicht oder nur wenig von den diinnen sich unterscheiden, wie dies z. B. bei den Celaceen, den Ferne u. s. w. der Fall ist, vermisst; sie finden sich aber am Colon der Herbivoren. - Eigenthümlich endlich sind vielen Nagern (z. B. den Ratten) die, die Därme beiderseits deckenden, biswcilcn bis zum Magen

1) Vergl. darüber Robert l. c. p. 36 . 
aufsteigenden, von den Peritonealduplicaturen der Geschlechtstheile ausgehenden Omeruta Lumbaria ${ }^{2}$ ).

[Ueber das Bauchfell der Säugethiere siche, ausser Cuvier's Leçons, die zahlreichen monographischen Schilderungen der Eingewcille und ihrer Befestigung. Dann vergl. noch: A. G. Stosch, Diss. de onentis mammaliun. Berol. 1807. 8.; besonders aber die reichbaltige Abhandlung ron Hennecke, De functionibus omentorem in corpore humano. Goett. 1836. 4.; so wie auch Robert, De ligamentis ventriculi et liberis Peritonaei plicis. Marburg. 1837. 4.]

\section{Von der Leber.}

§. 193.

Die bei allen Säugethieren unterhalb des Zwerchfelles in der Bauch höhle gelegene, mit ihrer convexen Oberfläche den Bauchwandungen, mit der concaven den Eingeweiden zugewendete, durch das Ligamentnm suspensorium befestigte Leber zeigt manche Verschiedenheiten riicksichtlich ihres Umfanges, ihrer Form und der geringeren oder grösseren Anzahl von Lappen, in die sie zerfällt. Am kleinsten scheint sie verhältnissmässig bei Bradypus zu sein ${ }^{1}$ ); klein ist sie auch bei den Wiederkäuern und Cetaceen und unter den Beutelthieren beim Känguruh 2). Bei den meisten Wiederkäuern, Pachydermen, Einhufern, ïchten Cetaceen, Faulthieren und den höheren Affen zerfällt die Leber gewöhnlich mehr oder minder deutlich in zwei Hauptlappen. Drei bis vier Lappen besitzen schon einige Hacacus und Cynocephalus, die meisten Affen der neuen Welt, viele Chiroptcren und einige Edentaten; vier Lappen die Monotremen; zahlreichere Lappen lassen sich unterscheiden bei den meisten Insectivoren, Raubthieren, Nagern, Beutelthieren; gewöhnlich sind indessen hier drei Hauptlappen vorhanden, von denen der mittlere oder die seitlichen, oder beide durch Einschnitte wieder in untergeordnetere Lappen zerfallen. Einzelne Beispiele vom Zerfallen der Leber in sehr zahlreiche Läppchen kommen in den Ordnungen der Nager ${ }^{3}$ ) und Beutelthiere ${ }^{\text {f) }}$ vor.

Eine Gallenblase besitzen die meisten, aber bei weitem nicht alle Säugethiere; sie fehlt namentlich den ächten Cetaceen, den Ein-

2) Vergl. Hennecke l. c. p. 23. und die entsprechende Abb. Tab. II-IV.

1) Rayp (Edentaten S. 62.) bestimmte ihr Gewicht bei einem erwachsenen dreizehigen Faulthier, das die Grösse einer Katze hatte, auf 270 Gran.

2) In Ganzen erscheint also, wie auch Cuvier und Duvernoy hervorheben, ihr Umfang verhältnissuässig gering bei den Säugethicren mit zusanmengesetzter Magenbildung; doch bedarf es, un diesen Satz als gültig anzuerkennen, noch sorgfaltigerer Gewichtsbestimunngen, als wir sie bis jetzt besitzen.

3) Bei Capromys Fournieri nach Cuvier und Duvernoy 1. c. p. 454 .; be. stätigt von 0 wen.

4) Bein Koala zerfällt, nach 0 wen, Marsupialia p. 305. Fig. 130., die untere Fläche durch Einschnitte in 30 bis 40 Läppchen. In geringerem Grade findet dasselbe Statt bei Dasyurus ursinus. 
hufern, den meisten Pachydermen - mit Ausnahme der Schweine -, mehren Wiederkäuern (Cervus, Auchenia, Camelus und in der Regel auch Camelopardalis), vielen - indessen bei weitem nicht allen Nagern (Mus, Cricetus, Echimys, Eretizon, Synetheres u. A. ${ }^{5}$ ) und unter den Edentaten bei Bradypus tridactylus. - Sie findet sich bei den lebenden Sirenen ${ }^{6}$ ), den Monotremen, Beutelthieren, bei allen Raubthieren, mit Einschluss der Robben und Insectivoren, allen Chiropteren, Halbaffen und Affen. Die Anwesenheit zweier Gallenblasen ist als individuelle Eigenthümlichkeit bei Camelopardalis ") und, vielleicht als normale Bildung, bei Orycteropus ${ }^{8}$ ) beobachtet. Den Uebergang zu dieser Duplicität bilden Abtheilungen, in welche die einfache Blase durch Septa, z. B. beim Löwen, zerfällt. Die Gallenblase, in Umfang und Form mannichfach verschieden ${ }^{9}$ ), liegt in einer mehr oder minder tiefen Grube der concaven Leberoberfläche und selten nur kömmt ihr Grund an der Convexität der Leber zu Tage 10).

Die Leber- und Gallengänge bieten mancherlei Verschiedenheiten dar. Die gewöhnlichste Bildung ist die, wo zwei Hauptleberïste zu einem Ductus hepaticus sich verbinden, der unter mehr oder minder spitzem Winkel, einerseits den Ductus cysticus abgibt und von hier aus andererseits als Ductus choledochus sich fortsetzt. Bisweilen senken sich dann noch untergeordnete Ductus hepatico-cystici in die Gallenblase ${ }^{11}$ ), oder solche treten in den Ductus cysticus 12), oder erst mehr gegen das Ende des Ductus choledochus ${ }^{13}$ ) in diesen ein.

5) S. Cuvier 1. c. p. 549. Meckel S. 643. und einzelne Angaben bei Pallas, Glires.

6) Steller vermisste sie bei Rytina; bei Manatus und Halicore wurde sie von Home, Rapp, Rüppel, 0 wen gefunden.

7) Unter drei Giraffen, die 0 we n untersuchte, waren zwei, denen die Gallenblase fehlte; bei der dritten war sie doppelt vorhanden: bei der äusseren Besich. tigung einfach erscheinend, obschon an Fundus zweilappig, in dler That aber durch ein Septuın in zwei gleich grosse Hälften getheilt; jede communicirte init den Ende des einfachen Ductus cysticus. Transact. of the zool. soc. of London. Vol. 2. p. 228.

S) Jaeger und Rapp fanden bei Orycteropus capensis an der unteren Fläche des mittleren Leberlappens zwei längliche Gallenblasen, welclıe, durch den Peritoneal-Ueberzug oberflächlich vereinigt, einfach erschienen. Jedle dieser Gallen. blasen setzte sich in einen schlangenförunigen Blasengang fort; beicle Gänge vereinigten sich endlich und unuittelbar nach der'Vereinigung mündeten drei Ductus hepatici ein. Rapp's Ellentaten S. 61.

9) Sie ist rund bei Fledermäusen, den meisten Insectiroren, meist birnförmig, wie bein Menschen, oft cylindrisch, 2 . B. bei vielen Raubthieren: Mustela, Lutra, Viverra, bisweilen gewunden: Felis, Leo, Nasua u. A.

10) Z. B. bei Didelphis.

11) Z. B. beim Rinde. Rudolphi fand hier 8 bis 10 (Physiologio Bd. 2. Abth. 2. S. 153.). - 12) Z. B. beim Schaaf, beim Hunde.

13) Z. B. bei einigen Phoken ( $\mathrm{Ph}$, litorea). 
Es kann aber die Vercinigung zweier oder mehrer Duclus hepatici zu einem gemeinsamen Stamm ausbleiben, und sie können successive in den Ductus cysticus sich einsenken ${ }^{14}$ ). Endlich können, wie beim Diigong, z.wei Ductus lepatici in den Blascnhals treten, während ein einfacher Blasengang erweitert in das Duodenum mündet. - Bei Abwesenheit einer Gallenblase vereinigen sich die Leberäste gewöhnlich zu einem Ductus hepatico-eutericus. Das Ende des, bald etwas höher, bald etwas tiefer in das Duodenum sich einsenkenden, Ductus hepatico-entericus oder des $\boldsymbol{D}$. choledlochus bietet manche Verschiedenheiten dar. Bald nimmt es den Ausfiihrungsgang der Bauchspeicheldrüse auf 15), bald mündet dieser von dem Gallengange getrennt. Bei einigen Säuge. thieren, und zwar sowol bei Anwesenheit, als bei Abwesenheit ciner Gallenblase, bildet er vor seiner Einmündung in das Duodenum, indem er dessen Wandungen durchdringt, eine mehr oder minder blasenförmige Erweiterung, welche meistens inwendig spirale Klappen besitzt 16). Bisweilen verdicken sich die Wände des Ductus choledochus gegen dessen Ende hin und sind mit Schleimfollikeln besetzt, die in seine Ilöhle münden ${ }^{17}$ ).

[Ansfïhrlichere Angaben iiber das Verhalten der Leber und ihrer Alsführungsgänge bei den versehiedenen Säugethieren s. bei Meckel, System der vergl. Anat. Bd. 4. und bei Cuvier, Leçons d'Anat. comp. T. 4. P. 2. Paris 1835. Abb. der Leber einiger Nager gibt Pallas, Nov. sp. glirium. Tab. IV. XVII. XXV. Abb. von Phoca Roscnthal, Nov. Act. Acad. Leop. XV. 2. Tab. LXXV. Fig. 2.]

\section{Vom Pancreas und der Milz.}

§. 194.

Das Pancreas der Säugethiere zeigt cinzclne, wenig erhebliche Gestaltungsverschiedenheiten. Gewöhnlich vercinigen sich die von scinen cinzelnen Lappen kommenden Ausfiihrungscanäle zu einem gemeinsamen pankreatischen Gange (Ductus paucreaticus s. Wirsungiauus). Dieser mündet bald in den Ductus choledochus oder in dessen End-

14) Z. B. bei Tarsius, nach Cuvicr, Galaeopithecus, Echidna, Ornithorhynchus u. $A$.

15) Z. B. bci viclen Affen, bci Ornithorhynchns, bei den meisten Beutelthieren, vielen Raubthieren, vielen Wiellerkäıern, z. B. beim Schaaf, Hirsch, dem Lama, bei den incisten Pachyderınen, mit Ausnahme der Schweinc, bei den meisten Cctaceen.

16) Einc solehe Ampullc, dic gewöbnlich auch den Succus pancrenticus entbält, finclet sich z. B. bei viclen Raubthieren, z. B. Canis, Procyon, stärker bei Intra, Felis, Phoca, Trichecus nach $\mathrm{Hom}_{0}$ e, Delphinus delphis (nicht bci phocaena); besonders stark und aus mehren Höhlcu zusammengesctzt endlich bcim Elephanten, nach P. Calupcr, Déscription d'un Elephant. Tab. VII. p. 39.

17) Namcntlich bei inchren Beutelthiercn: Känguruh, Didelphis, Phalangista. 
erweiterung ${ }^{1}$ ), bald tritt er isolirt in den Darm, in welchem letzteren Falle er bisweilen, gleich dem Ductus choledochus, eine blasige Endcrweiterung bildet 2 ). Wenn, wie dies verhïiltnissmässig selten der Fall ist 3), zwei pancreatische Gänge vorkommen, so treten sie entweder heide getrennt in den Darm, oder der cine mindet in den Ductus choledochus, während der andere seine besondere Insertion im Duodenum hat 4).

Die Milz ${ }^{5}$, immer mehr oder minder eng an den Magen, bei den mit mehren Magenhöhlen versehenen Säugethieren gewöhnlich - und vielleicht nur mit Ausnahme von Bradypus ${ }^{6}$ ) — an die erste derselben geheftet, bietet bei einzelnen Familien charakteristische Formverschiedenheiten dar $\%$. Waihrend sie bei den meisten Säugethieren einfach ist und Nebenmilzen nur ausnahmsweise vorkommen, zeigen sich die letzteren in verschiedener Anzahl regelmässig bei Delphinus und Monodon 8).

1) Vergl. \$. 193. Anmerk. 15. Näheres s. bei 'Tiedemann in Meckel's deutsch. Archiv Thl. 4. S. 404.

2) Wenigstens als individuelle Eigenthünlichkeit, z. B. bei Katzen, vorkommend.

3) 7. B. bei den Einhufern, dem Elephanten, dem Biber, dem Hundegeschlechte.

4) So wenigstens oft bei den IUnden.

5) Ueber die weissen Malpighi'schen Körperchen in der Milz vom Rirıd, Schaaf, Schwein, welche als Auswüchse einer eigenthümlichen weissen Scheide der kleinen Artcrien sich zu erkennon geben, s. Müller in seinem Archiv 1834. S. 80. Tab. 1. Schwager-Bardeleben identificirt diese Körperchen mit den weissen Körperchen der Milz anderer Säugethiere.

6) Hier liegt sie tiefer am sogenanuten dritten Magen.

7) Dahin gehört z. B. ihr Bestehen aus zwei Lappen bei den Monotremen; ihre fast T förmige Gicstalt bei den Beutelthieren; ihre runde kugelige Forın bei den Cetaceen u. s. w.

8) Bei allen Delphinen auch von mir, gleichwie von den früheren Beobachtern, gefunden. Da Mleckel (System Thl. 4. S. 532.) über die Anwesenheit von Nebenmilzen beim Narwal in ' Zweifel geblieben, mag hier bemerkt werden, dass ich in drei von mir untersuchten Exemplaren jedesmal 3-4 Nebenmilzen angetroffen habe. So eben scbe ich bei einem frischen Delphinus phocaena neben der grossen kugelrunden Milz, 17 kleinere Nebenmilzen. $-0 \mathrm{~b}$ sie bei den Walfischen vorkommen, bleibt zweifelhaft. Eschrich thut derselben keine Erwähnung. 


\section{Sechster Abschnitt. \\ $V$ om Gefüss-Systeme.}

\section{Vom Herzen.}

\section{§. 195 .}

Uas meist gerade, selten, wie beim Menschen, mit der Spitze nach links gelegene 1) IJerz der Sïugethiere wird rom IIerzlocutel umschlossen, dessen untere Fläche nur bei den höheren Affen und den Cetaccen ${ }^{2}$ ), wie beim Menschen durch Zellgewebe an dem Zwerchifelle innig befestigt ist. Es besteht wesentlich aus zwei getrennten Vorkammern und zwvei getrennten Kammern. Perennirend erhält im Normalzustande bei kcinem Säugethiere das eirunde Loch sich offen ${ }^{3}$ ), olowol es bei den tauchenden Gattungen allerdings verhältnissmässig später sich zu schliessen scheint, als bei den uibrigen. Die äussere Gestalt des Ilerzens bietet, je nach Verschiedenheit der Ordnungen, manche Eigenthümlichkeiten dar. Am auffallendsten ist die äusserliche Spaltung ${ }^{4}$ ) der beiden IIerzkammern bei der Gruppe der Sirenen. Breit und plattgedrückt erscheint es bei allen Cetaceen; in geringerem Grade auch bei einigen anderen Siuugethieren ${ }^{5}$ ); häufig ist es rundlicher $\left.{ }^{6}\right)$, als beim Menschen und anderen rücksichtlich der IIerzform ihm nahe stehenden Thicren 7 . - Das Verhalten der Klappen

1) Bei Simia satyrus und troglorlytes, weniger bei den übrigen Affen; mehr bein Maulvurf.

2) Wenigstens bei den Delphinen und dem Narwal.

3) Auch nicht bei den Phoken und Delphinen, wie Meckel, Rosenthal, Rapp, Burow richtig angeben und wie ich es nach zablreichen Untersuchulgen bestätigen kanu. - Bemerkenswerth ist es, dass, den Untersuchungen ron Owe n zufolge, bei den Beutelthieren keine Spur einer Fossa ovalis oder eines Anmulas ovalis angetroffen wird. Bei dem noch im Uterus verweilenden Embryo des Känguruh findet allerdiugs noch eine Communication zwischen den beilen Vorliöfen durch eine schräge Fissur Statt; aber später verschwindet jedes Ueberbleibsel dieser Communication spurlos. S. I. Physiol. Catalngue of the Musemn of the Royal Coll. of surgeons. Vol. II. p. 52. und 0 we 1 , Marsupialia p. 306.

4) An stärksten ist sie beim Dïgong. S. Abb. bei Home, Lectures on colup. anat. Vol. IV. Tab. L.; bei Rapp, Cetaceen Tal. VIII.; bei Carus und 0 tto, Erlïuterungstafeln Tab. VII. Fig. 3. Achnlich bei Manatus nacli Daubenton und Cuvier und bei Rytina nach Steller; bei den ächten Cetaceen funden sich höchstens ganz sclıvache Andeutuugen Hieser Spaltung.

5) Z. B. Lei Phoca (Abl. bei Roseuthal, Nov. Act. Acad. Leop). Carol. Vol. XV. P. 2. Tab. LXXV. Fig. 1.), Brarlypus, Mauis, Elephas.

6) So bei den meisten Fleischfressern, Nagern, Beutelthieren.

7) Viederkäuer, Schweine, Einlufer, Makis, Affen. 
zeigt bei einigen Siugethieren Eigenthiimlichkeiten 8). - Bemerkenswerth ist es, dass bri vielen Wiederkäuern und einigen Pachydermen 9) an der Grenzo zwisehen der Seheidewand der IIerzkammern und der Vorkimmern, bei vorgerückterem Alter, einfache oder doppelte Ver. knöcherungen (IIr \% \%knoehen) entstehen.

\section{Vou den Arterien.}

\section{§. 196.}

Der bei allen Sïugethieren einfaehe Stamm der Aorta tritt in einem Bogen naeh links, un als absteigende Aorta sieh fortzusetzen. Zuerst gibt sie gewöhnlich zwei Kranzarterien des Herzens (sehr selten 1) nur eine) ab. Die Zahl und Bedeutung der aus dem Aortenbogen entspringenden Aeste bistel beträehtliehe Versehiedenheiten dar, die um so mehr die Aufmerksamkeil auf sieh ziehen, als die bei den Säugethieren beständigen Anordnungen beim Mensehen ausnahmsweise rorkommen können. Die wichtigsten dieser Versehiedenheiten, welehe aber bei derselben Art bisweilen variiren, sind folgende:

1. Die kurze einfaehe Aorta theilt sieh sogleieh in einen vorderen Stamm (Aorta superior s. auterior) und in einen linteren (Aorta

8) Statt der Valvula tricuspidalis findet sich, Vogelähnlich, eine theilweise muskulöse Klappe der rechten Herzkammer bei Ornithorhynchus (Abb. bei Mekkel, Ornithorh. Tab. VI. Fig. 2.). Man kann, nach 0 wen, an ihr zwei fleischige und zwei läutige Portionen unterscheiden. Häntig ist die Klappe bei Echidna. S. Owen, Nonotrem. bei Todd p. 390. - Ueber das Tuberculum Loweri und die Eustaclı' sche Klappe hat Rudolphi (Physiol. Thl. 2. Abth. 2. S. 332.) sehr ausgedehnte Untersuchungen mitgetheilt. Er fand grosse Verschiedenheiten: 1) Ein grosses oder kleines Tuberculum Lonveri (Vorspring, der die obere Hohlvene von der unteren an der Eintrittsstelle in den rechten Vorhof scheirlet) ohne Enstachi'sche Klappe bei den Gattungen Felis, Canis, Ursus, Phoca, Gulo, Mustela, Procyon, Talpa, Halmaturus und bei den meisten Wiederkäuern, dem Pferd und Schwein. 2) Kein-Tuberculın; aber zwei halbmonılförmige Klappen ler unteren Hohlvene: Didelphis, Dasypus, Hystrix, Cavia, Lepus, Sciurus maximus (liier mit Spur des Tuberculum). 3) Keine Enstachi'sche Klappe, aber unter der Fossa ovalis ein Querband und vorspringende Fleischfasern bei Myrmecophaga und Bradypus. 4) Eine Eustachi'sche Klappe und ein schwaches Tuberculın: ausser dem Menschen, viele Affen, Lemur, Lutra (Echilnil). 5) Beide, die Klappe und das Tuberculum, fehlend: Ornithorhynchus, De-lphinus. Vergl. hiernit die Angaben von Meckel, System Bi. 3. S. 203.

9) Diese Herzknochen, welche bei jungen Thieren knorpelig sind, wurden beolachtet bei Ovis, Bos, Cervus, Camelus, Camelopardalis ( 0 we n, Transact. of the z.ool. soc. Vol. 2. p. 229.), Antilope, Sus. - Anch bei den Einhufern kömmit in der Scheidewand der Vorkanmer vor der Mündung der unteren Holılvene ein bei alten Thieren nicht selten verknöchemder Herzknorpel vor. - Abbild. bei Carus und Otto, Erläntermugstafeln Hft. 6. Tab. VIII. Fig. 1.

1) Nach Camper (Kl. Schriften, herausgegeb. von $\mathrm{Herbell,} \mathrm{Tbl.} \mathrm{1.} \mathrm{S.} \mathrm{7..)}$ entstelit sic beim Elephanten einfach, theilt sich aber bald in zwei Zwyeige. 
prosterior. 2). Der schwäichere vordere Stamm gibt die linke Subclavia und sodann aus seiner Fortsetzung den gemeinschaftlichen Stamm beider Carotiden (Carotis communis primaria) oder diese beiden sogleich getrennten Gefässe und die A. subclavia dextra ab.

2. Es nelimen aus dem Aortenbogen zwri Stämme: 1) cin Truncus annnymus, dessen Aeste die beiden Gárotiden und die A. sulclavin dextre sind, und 2) die A. subclavin simistra ihren Ursprung ${ }^{3}$ ).

3. Aus dem Aortenbogen entspringen zwei Trunci anomymi ${ }^{4}$ ).

4. Der Aortenlogen gibt drei Stämme ab: einen Truncus anomymus alexter, die Carotis communis sinistra und dic A. subclaria sivistre 5 ).

5. Die beiden Garotiden entstehen als gemeinschaftlicher Stamin (Curotis communis primaria) zwischen den beiden Arteriae sulclaviae aus dem Aortenbogen ${ }^{6}$ ).

6. Neben den genannten Ilauptstämmen können noch untergeordne tere Arterien direct aus der Aorta ihren Ursprung nehmen 7).

Bei einigen tauchenden Säugethieren kommen Erweiterungen des Bogens der Aorta vor $\left.{ }^{8}\right)$.

2) Bei den Einlufern, den meisten Wiederkäuern und einigen Pachylermen, z. B. dem Rhinoceros mach Cuvier. - Nach Owen's Bemerknng ist die Crrotis commnnis primarin bei der Giraffe vorzüglich lang (Proceedings of the zool. soc. of London. Part. VI. 1838. p. 11. - Bei den Einhufern entspringe aus der Aorta superior auch die strt. vertelralis dextra.

3) Bei den meisten Beutelthieren, nach den Untersinchungen ron Cuvier, Meckel und Owen; bei vielen Nagern (z. B. Castor, Myoxus, Arctomys, Hydrochoerus, Cavia, Dasyprocta, Hystrix, Lepus); bei meliren Edentaten (namentlich Myrmecophaga jubata und tamandua, Orycteropus nach $\mathrm{R}$ app, bei Manis); bei den meisten Ferae (Ursus, Mele's, Lutra, Canis, Felis, Mustela); ferner bei Sorex nach 0 tt 0 ; bei Halicore nach Ho ue (Lect. on comp. anat. Vol. 4. Tab. L.); beim Lama; bei den Schweinen. Bei den letztgenannten Gattungen entsteht aber aus der A. anonyma zunächst eine kurze $d$. carotis communis primaria.

4) Bei den Chiropteren und bei Talpa nacll 0 tto; bei Delph. phocaena. (Abweichend verliait sich schon $D$, orca.)

5) Bei den Monotremen nach Cuvier, Meckel, Owen; nnter den Beutelthieren beim Koala und Wombat nach 0 wen; unter den Edentaten bei Bradypus, Dasypus und Myrmecophaga didactyla; unter den Nagern bei allen Mäusen, so wie auch bei Cricetus nach Barkow, bei Dipus und Meriones nach 0 tto; unter den Insectivoren bei Erinaceus; ferner bei den Ploken, den meisten Affen, namentlich auch bei dem Orang-Utang nach Sandifort und dem Chimpanze nach Vrolik (welche beiden Beobachtungen mit den meinigen übereinstimmen); so wie endlich beim Menschen. - Ebenso finde ich das Verhalten bei Manatus australis. - 6) Bein Elephanten. S. Cuvier, Leçons Vol. 6. p. 112.

7) Z. B. bei Delphinus phocaena eine Art. thoracica interna sinistra; die rechte $A$. Lhoracica interna entspringt aus der $A$. anomyma dextra. Aelnlich sclıeint sich zu verlıalten der Dügong, s. IIome Vol. IV. Tab. L.

8) Angeblich soll dies bei allen tanchenden Säugethieren der Fall sein. D 11 . vernoy macht ihre Anwesenheit namhaft bei Castor, Lutra, Plioca, Delphinus, Monodon. Was die beiden letateren Gattungen, so wie die Seelunde anbetrifft, 
[Man vergl. über die Vertlreilungsweise der arteriellen Gefässe bei den Säugethieren, ausser Cuvier's Leçons d'Anatomie comp. T. (o. Paris 1839. p. 107 sqq. mnd Neckel's System der vergl. Anat. 'Tlıl. 5. S. 298 fr, folgende Specialschriften: J. C. L. Bark ow, Disquisitiones circil originem et ılecursum Arteriarum Mammalium. C. tab. ten. IV. Lips. 1829. 4.; B ark ow (iiber Lutra) in Meckel's Areliv 1829. S. 30.; Barkow, Ueber die Kopfarterien d. Schaafes, in Nor. Act. Acall. Caes. Leop. Carol. Vol. XIIl. P. 1. 1. 397.; B a rkow, Disquisitiones nomnullae angiologicae. Vratislav. 1830. 4.; Barkow, Disquisitiones recentiores de arteriis mammalium et avimm, in Nov. Act. Acad. Caes. Jecop. Carol. Vol. IX. P. II. 1. 609. - Die Kopfarterien vieler Süugethiere berücksiclitigt A. W. 0 tto in Nov. Act. Acal. Caes. Leop. Carol. Vol. XIII. P. 1. p. 24. Ueber die Arterien der Haussäugethiere s. Gurlt, Handb. der vergl. Anat. der Haussïngethiere Bı. 2. S. 194. - Ueber die Arterien von Phoca s. Burow in Müller's Archiv 1838. S. 25̃3. - Ueber die des Delphins s., ausser Rapp's Cetaceen S. 158 ff., die abweichende Darstellung von Stannius in Müller's Archiv 1841. S. 379. - Ueber die der Monotremen s. Meckel und 0 wen; über die der Bentelthiere 0 wen l. c.; über die iler Elentaten s. Rapp I. c. S. 66. Ueber die Wundernetzbildungen der Arterien vergl. besonders: Carlisle in den Pliilos. Transactions 1800. 1. 98. Tab. 1. u. 2. - Vrolik, Disquisitio anatomico-physiologica de peculiari arteriarum extremitatum in nonnullis animalibus dispositione. Anstelod. 1826. 4. c. f. - R app in Meckel's Archiv 1826. S. 1. Mit Ab. Tab. 1. u. 2. (Kalb und Hirsclı). - K. E. v. Baer, Ueber die Geflechte, in welche sich einige grössere Schlngadern der Säugethicre früh auflösen, in Mémoires présentés à l'Académie des scienc. de St. Petersbourg. T. II. 1835. 4. - G. Breschet, Histoire anatom. et physiol. d'un organe de nature vasculaire dec. dans les Cétacés. Paris 1834. 4. Mit Abb. - Rückisichtlich des Details muss auf diese Schriften verwiesen werlen.]

\section{ร. 197.}

Verästelung und Yerlauf vieler Arterienstämme bioten bei den Säugethieren interessante Eigenthümliehkeiten dar, von denen nur einige hier hervorgehoben werden mögen:

1. Die Arferia carotis communis ist im Allgemeinen um so lïnger, je länger der IIals ist. Bei den Delphinen, wo der Ials die grösste Kürze besitzt, fehlt ein grmeinschaftlicher Stamm beider Carotiden ganz, so dass die innere Carotis sowol, als die äussere unmittelbar aus den Arct. anorbymae entstehen 1).

2. Bei Anwesenheit ciner Carotis communis theilt sich diese nur selten in zwei Inauptäste, welche wirklich als Aequivalente der Curotis

so habe ich eine starke Erweiterming des Aortenbogens nur bei jungen Thieren angetroffen. Burow gibt für Phoca an, dass eine Erweiterung beim ervachsenen T'hiere als gewölnnliche Bildung niclit vorhanden sei. Bark ow erwälnnt keiner Erweiterung des Aortenbogens bei Istra.

1) Ich kann diese schon früher von mir gemachte Bemerkung, in Folge wiederholter Untersuchungen bestiitigen und muss dalier der Angabe von Rapp (Cetaceen S. 1j9.), wonach die $A$. cacotis cetelvalis ans der A. maxillaris interna entspringen soll, willersprechen. 
facialis und cerebralis des Mensehen zu betrachten wären; der zweite IIauptast heisst daher, wo er überhaupt vorhanden, besser Carotis interna $\left.{ }^{2}\right)$. -

Die dem Ilirne Blut zufuihrenden Arterice carotides cerelrales, im engeren Sinne des WVortes, treten entweder als einfache Aeste in die Schedelhöhle ${ }^{3}$ ), oder sie treten als Stämme dureh Wundernetze, in welche Zweige derselben sieh aufgelöset haben, hindurch 4), oder sie entstehen aus Wundernetzen, welehe durch ihie Wurzeln gebildet sind 5). - Verlaufen die Carotides cerelrales als cinfache Aeste uhne Wundernetzbildung, so können sie sehr verschiedene Ursprungsstellen haben. Entweder sind sie Jauptäste oder Nebenaiste der Carotides communes ${ }^{6}$ ), oder sie sind Aeste der Caratides internae, welche die Carotidles cereluales erst naeh Entsendung anderer bedeutender Aeste abgeben '); oder sie erscheinen als Aeste der Artt. maxillares interuce ${ }^{8}$ ), oder endlich selbst als Aeste der aus letzteren entstandenen Artt. oplithalmicae ${ }^{9}$ ). - Die bipolaren Wundernetze, aus welchen die Crratides cerelrales hervorgehen, können dureh die Auflösung versehiedenartiger Gefässe entstanden sein. Bei der Katze entstehen die Arterien, welche das WVundernetz bilden, aus welchem die Carotidcs cerelurales hervorgehen, aus einem anderen grösseren Wundernetze, in welehes die Endzweige der Artt. carotides communes sich aufgelöset haben 10); beim Schwein lösen sieh die Artt. curotides interuae in Wundernetze auf, dic den Hirnearotiden den Ursprung geben; beim

2) S. hierïlser die treffenden Bemerkungen von Barkow, Disquis. p. 80 .

3) So, ausser dem Mensehen, bei den bisher untersuehten Affen, Chiropteren, Inseetivoren, Nagern, Beutelthieren, Einhufern und einzelnen - obsehon nicht allen - Ferae (z. B. Ursus, Lutra, Canis, Mustela).

4) Bei Delphinus phoeaena.

5) Bei den Wiederkäuern, den Schweinen, und unter den Ferae bei den Katzen.

6) So, ansser dem Mensehen, bei den bisher untersuchten Affen; mebr Nebenast der Caratis communis ist sie bei Canis, wo die Carotis cerebralis aueh einen Zweig aus einem schwaehen Wundernetze aufnimult. Abb. bei Barkow, Disquisitiones T'ab. III. Fig. 1.

7) Z. B. bei den Chirnpteren, Inseetivoren, den meisten Nagern (z. B. Myoxus, Mus, Hypulaens u. A.) nach 0 tto, bei einigen Carnivoren, z. B. bei Lntra, nach Barkow, wo die Corotis interna, ein Nebenast der Carotis communis, vor der Hirnarterie erst eine drt. occipitalis algibt.

8) Bei Hystrix cristata naeh Otto.

9) Bei Cavia Cobaya nach Barkow; ebenso bei Dasyproeta aguti.

10) Abgebildet ist das Kete mirabile caroticum der Katze bei Barkow, Disquis. circ. orig. Tab. III. Fig. 2. - Das Wundernetz, aus welehem die Wrurzeln des Carotidenwumdernetzes hervorgehen, liegt an Condylus des Uiterkiefers. Aus ihul entstehen nicht nur die genannten Gefisse, sondern naeh Bark ow l.e. p. 9. aueh noch R. R. temporales, pterygoüdei, musculares oculi, buccinatorii unt ferner die strt. ciliaris, ma.villaris interna, ellmö̈dalis, meningea anterior und kleinere Zweige. 
Sehaal sind drei Aeste der Art. maxillaris interna die Wurzehn jedes Rete mirabile earotierm; beim Rinde 11) werden die Wundernetze vorzüglieh gebildet dureh Aeste der Artt. maxillares intermae, die durch die Foramina optiea und ovalia, so wie durch die Fissarne orbitales in dic Schedehöhle treten. Hier lösen sieh aber anch Zweige der Artt. vertebrales und occipitules in Greflechte auf, die mil jenen Wundernetzen communiciren. - Das Rete mirabile caroticum der Delphine 12) mit durehtretendem Stamme der Arterie wird hauptsïehlich aus Zweigen der $\mathcal{A}$. ecerotis interna gebildet, steht jedoch mit den ausserhalb der Schedelhöhle liegenden Gefleehten, welche besonder's dureh Zweige der Crrotis externa und der Art. cervico-oceipitulis formirt werden, in enger Verbindung. - Immer findet durch transverselle Briieken eine Communication der Wundernetze beider Seiten Statt. - Die dem Ilirne Blut aus den Carotiden zufiihrenden Gefïsse treten, wie sehon aus diesen Thatsachen hervorgeht, auf sehr verschiedenen Wegen ${ }^{13}$ ) in die Sehedelhöhle ${ }^{14}$ ).

3. Ausser den Carotides ecrebrales führen gewöhnirch die durch dic Wirbeleanïle tretenden Artt. vertebrales dem Gehirne Blut zu. Wie beim Mensehen, vereinigen sich auch bei vielen Säugethieren die Fortsetzungen der Stämme beider Artt. vertebrules, die bis dahin nur kleine Remi museulares und spiuales alggegeben haben 15), zur Bildung der Art. basiluris; bei anderen ist es nur ein starker Ast der, übrigens mit der $A$. occipitalis sieh verbindenden, $A$. vertebralis, welcher die $A$. basilaris bildet 16$)$. Sehr gering wird der Antheil, den bei den Wiederküuern die besonders für den Casalis spinalis,

11) S. dic Abb. bei Rapp 1. c. Tab. I. Fig 1. (Schaaf); Fig. 2. (Rind); Tab. II. (Hirsch). - Carus und 0 tto, Erlänterungstafeln Hft. 6. Tab. VIII. Fig. 2. (Kalb).

12) Abb. bei Stannius l. c. Tab. XIV. Fig. 1.

13) Durch die Canales corolici beim Mensclien, den Affen; bei U1sus, 1111 stela, Meles, Lepus, Castor; durch die Foramina jugularie bcim Pferd, Schwein; durch die Foramina lacera auterioce bei Hystrix, nach 0 to; durch die Fo. ramina optica bei Casia, nach Barkow; durch die Forauina ovalia und Fissucae orbitales superioues beim Schaaf; durch die meisten der genannten Oeffuungen zugleich beim Rinde.

14) Den Durchtritt der Caiotides internae durch den Pessulus des Steig. bügels beobachtete 0 tto bei den Chiropteren, bei Erinacens, Sorex, Talpa, Hypmlacus, Georhychus, Myoxus, Mus, Cricetns, Dipus, Meriones, Arctomys, Scimus. S. 0 tt 0 l. c. Vergl. dagegen \$. 185. Anm. 10.

15) Z. B. bei Cercopithecus, Erinaceus, Mus, Lepus, Felis u. A.

16) Z. B. bei Mustela, Canis I. A, nach Barknw. Nicht selten bilden die A.lt. vertelicules durch Verschuelanng mud abermalige Tremumg vor ihrer Vercinigung zur A. Lasilaris schon einen Gefïsszirkel. Achuliche Gefïsszirkel entstehen in Verlaufe der Arte. spimeles muteriores, welche als Fortsetzmimgen der A. Lasilaris erscheinen, immer aber durch Intervertebraläste der Iell. derle. beales und spaiter der intercoslales und lumliales verstïlkt werden. 
aber aneh für die Nackennuskeln bestimmten Artt.vertelrales an der Bildung der $A$. Lasilar is haben ${ }^{17}$ ). Noeh weniger sind sie dabei betheiligt bei den Einhufern und Sehweinen, wo die Art. basilaris durch die Vereinigung beider Artt. occipitales (im Foramen magnum) entsteht ${ }^{18}$ ), bis endlich bei den Delphinen die $A$. vertebralis, bei Verkïmmerung der Ilalsgegend, als eigener Ast fellt. Hier ist sie nämlieh mit der $A$. occipitalis und $\operatorname{der} \boldsymbol{A}$. cervicalis alscendens in einem gemeinsamen Stamme enthalten (A. cervico-occipilalis), welehe dureh zahlreiehe unipolare Wundernetze, in welche ihre Zweige sieh auflösen, mit den Artı. spinales communieirt.

4. Der stets vorhandene Circulus Willisii entsteht daher entweder theils dureh die Carotides cerebrales, theils durch Spaltung der zur $A$. Lasilaris zusammengetretenen Artt. vertebrales; oder dureh die Curotides cerebrales und durch Trennung der zur Basilaris vereinigten Oecipitales, oder er wird fast nur durch die Caratides cerebrales, oder einzig dureh diese gebildet. Während beim Menschen und vielen Säugethieren die Carotides cerebrales vorn dureh einen Ramus communicass sich verbinden, treten sie bei einigen der letzteren in einen kürzeren oder längeren gemeinsamen Stamrn der beiden Artt. corporis callosi zusammen ${ }^{19}$ ).

\section{§. 198.}

Die Arleria sulclavia ${ }^{1}$ ) setzt sieh, naehdem sie sehwäehere oder stärkere Aeste abgegeben, als Ait. axillaris und spiter als $A$. Urachialis fort. Bei den Sirenen, Cetaeeen und Phoken 2) zerfällt die $A$. Urachialis, entweder naeh vorausgegangener Bifurcation oder ohne dieselbe, in zahlreiche, büschelförmig neben einander liegende, Zweige. Bei mehren Edentaten, so wie bei Stenops und Tarsius, kommen an den Armarterien gleichfalls starke und merkwürdige Wundernetzbildungen vor ${ }^{3}$ ). Bei Bradypus und Stenops tritt der Stamm der $\boldsymbol{A}$. Urachialis

17) S. darüber Rapp l. c. und Barkow, Disquis. p. 85 .

18) Vergl. Gurlt 1. c. und Barkow, Nov. Act. T. XX. P. 1. p. 610.

19) Bei Cercopithecus sabaeus, beim Pferde; beim Haasen nach Barkow.

1) Zu den beständigsten Aesten der Ait. subcluvia gehören die Ait. mammaria interna, Art. verteliralis, Art. cervicalis adscendens, welche letzteren Arterien jedoch auch zu einem gemeinsamen Stamm verschmelzen können, wie z. B. bei den Delphinen. - Bei Erinacens theilt sich die Art. subclavia nach Abgabe der genannten gewöhnlichen Aeste in zwei gleich starke Stämme: die Axillaris und eine Art. musculo-crtaner, welche mit einer gleichnamigen Arterie aus der Iliuca Bogen bildet. Abb. bei Barkow, Disquis. Tab. 1. Fig. 1. Ueher die einzelnen Verschiedenheiten muss auf die monographischen Werke verwiesen werdell.

2) S. hierüber die citirten Abliandlungen ron Baer, Burow, Rapp und Stannius.

3) Vergl. die Abhandlungen von Carlisle, Vrolik, Rapp. Nach AllIII ann (Froriep's Notizen 1843. BI. XXVII. S. 330.) sollen diese Wundernetze auch bei Dasypus sexcinctus vorkommen. 
dureh die ilnn umgebenden zahlreichen, gestreekten Arterienreiser hindureh; bei Myrmecophaga didaetyla und Tarsius zerfällt der Arterienstamm selbst in Reiser; bei Myrmecophaga jubata und tamandua beschränken sieh die Wundernet\%e fast ganz auf den Vorderarm. Ein schwaches Wundernetz findet sieh bei den Sehweinen an einem, die Vorderarmarterien verbindenden Aste 4 ). - Bei einigen Säugethieren gibt der Stamm der Armarterie nur untergeordnete Aeste ab ${ }^{5}$ ); bei andern theilt er sich gabelförmig. - Die Theilung der Art. Urachialis in die beiden Vorderarmarterien kann an versehiedenen Stellen Statt finden; sie erfolgt entweder sehon hoeh oben am Humerus ${ }^{6}$ ), oder etwa in der Mitte desselben 7 ), oder an der Grenze von Oberarm und Vorderarm ${ }^{8}$ ), oder selbst erst in der Mitte des Vorderarmes 9). - Bisweilen tritt die Art. Urachialis 10 ), öfter die $A$. ulnaris ${ }^{11}$ ) dureh ein Foramen supracondyloüdeum humeri.

§. 199.

Die Aorla thorncica mehrer Säugethiere zeigt die Eigenthümliehkeit, dass sie die einzelnen Intereostalarterien nieht unmittelbar abgibt. Bei Mustela 1) entspringt aus ihr an Ende der Brusthöhle ein in zwei aufsteigende Vertebralarterien sieh spaltender Ast, aus welehem die vorderen Intereostalarterien hervorgehen. Bei den Delphinen sind es zwei absteigende Artt.thorrcicae internae s. intercostales supremae ${ }^{2}$ ), von denen die reehte aus der $A r t$. cnosyma dextra, die linke aus dem Arcus Aorlac entstelit, welche die fünf vordersten Intereostalarterien al)geben. Bei ihnen kommen aus der Aortu thoracica aueh noeh einige unpaare aufsteigende Aeste, die mit den $\Lambda$ rteriengefleehten der Brusthöhle und des Wirbeleanales durch ilhre Zweige communieiren. Durch die eben erwähnten ungeheuren, aus geschlängelten Gefüssen bestehen-

4) Abgeb. bei Barkow, Nov. Aet. T. XX. P. 1. Tab. XXVII. Fig. 2.

5) Z. B. bei Tricheeus nach Cuvier, bei Mustela, Cricetus, Seiurus nachl Barkow.

6) Z. B. bei Delphinus phocaena, bei Cercopithecus sabaeus nach Barkow; ferner bei Cebus und Callithrix; endlieh aueh bei Lagothrix IIumboldtii nach Tsehudi, wo beide Gefisse vielfaeh mit einander anastomosiren und so den Uebergang bilden zu der fiir Stenops und Tarsius charakteristischen Anorduung.

7) Z. B. bei Didelphis, Halmaturus I. A. nach Cuvier.

8) Wie beim Mensehen z. B. aueh bei Felis u. A.

9) Bei Mus decumanus, Cavia cobaya nach Barkow.

10) Mustela nach Barkow.

11) Bei selır vielen Säugethieren, z. B, den Beutelthieren, vielen Nagern, Affen 11. s. w. Vergl. §. 164. und s. die Abhdl. von Tiedemann in Meckel's deutseh. Archiv für Pliys. Bd. 4. S. 545. Mit Abb. Tab. V. Fig. 1. 2.

1) Abb, bei Barkow, Nov. Aet. XX. P. 1. Tab. XXIX. Fig. 9. 11. 10.

2) Rapp ınd ieh hatten sie früher Artt. thoracicae posteriores genanut; diese Gefässe sind Aequivalente der Artt. mammariae internae an der Hinterseite des Thorax. 
den Wundernetze der Brusthöhle $\left.{ }^{3}\right)$ - welehe mit den innerhalb des Crunalis spinatis befindliehen, so wie mit denjenigen Wundernetzen, in welche die Zweige der Artt. cervico-occipifales am Nacken und Ilinterhaupte und einzelne Aeste der Carotiden an der Schedelbasis sich aullösen, communieiren - treten die Stimme der Intercostalarterien hindureh.

Dic Aeste der Aorta abdominalis entsprechen zwar im Ganzen denen des Menselien, bieten jedoch einzelne Eigenthümlichkeiten dar:

1. Dic Arteria coelince und mesenterica superior bilden bisweilen einen gemeinsamen Stamm 4), oder entstehen als einfueher Stamm, der sich bald theilt 5), oder verbinden sich gleich nach ilhrem getrennten Ursprunge dureh eine starke Anastomose 6). - Die bei vielen Säugethieren unbetrichtliche $A \cdot t$. mesenterica inferior fehlt den Monotremen und Beutelthieren gänzlieh 7). - Einzelne Zweige dieser Eingeweidearterien bilden bei einigen Säugethieren Wundernetze ${ }^{8}$ ).

2. Bei den meisten Säugethieren entstehen aus dem Stamme der Aorta grössere, für die sehiefen und queren Bauehmuskeln, für den Psoas oder für die unteren Muskeln des Stammes bestimmte Aeste ${ }^{9}$ ).

3. Häufig entstehen Artt. uretericae, spermaticae oder aterinae aus dem Stamme der Aorta.

4. Die aus dem hinteren Theile der Unterleibs-Aorta paarig entspringenden sogenannten Arteriae iliacre communes sind selten vollständige Aequivalente der gleiclınamigen Gefässe des mensehlielıen Körpers. Bei den Cetaceen entsprechen sie an meisten den Artt. Iıppogastricae; doeh sind sie mehr als diese, indem sie auch die sonst aus den Artt. crurales entspringenden Art. epigastricue abgeben. Bei den meisten übrigen Säugethieren sind sie mehr den Artt. crurales analog, indem nicht von ihnen, sondern von der Fortsetzung des Stammes der Aorta die Artt. hypognstricae entstehen, oder wenigstens Aeste abgegeben werden, welehe im menschlichen Körper aus den Artt. hypogastricas hervorgehen. So entspringen bei den Monotremen

3) Abb. bei Breschet l. c. Diese Wundernetze in der Brusthöhle, welche von Hunter, Breschet und mir näher beschrieben sind, kommen allen ächten Cetaceen anscheinend zu. Ganz ähnlich angeorduet finde ich sie bei Manatus; dagegen vermisste sie 0 wen beim Dügong. S. Proceedings of the zool. society of London. 1838. p. 35. - 4) Bei Cavia cobaya nach Barkow.

5) Bei Talpa, Vespertilio murinus nach Kamerer.

6) Von unir neuerlich bei Delphiuus phocaena beobachtet.

7) Nach Owen. Abb. in Todd's Cyclop. Art. Marsipialia 1. 209. Fig. 134.

8) Z. B. die At.t. coronaria ventriculi sinistra beim Schweine am Magen s. Ba rkow, Nor. Act. XX. Tab. XXVIIl. Fig. 4.; die Artt. mesentericue des Schweines nach Barkow l. c. p. 616.

9) Bei den Raubthieren (Canis, Felis, Mustela, Lutra etc.), den Nagern, Schweinen u. A. ron Barkow nachgewviesen; bei den Phoken und Cetaceen von B urow und inir; bei letzteren führen sie das Blut den Venengeflechten der Lendengegend zu. 
und den Beutelthieren die ditt. ischiadicae, bei vielen anderen Süugrthicren die Artt. sacrae laterales unterlialb der Artt. iliacae communes parig aus der Fortsetzung der Aorta 10\%. - Bei einigen, mit starken Mautunuskeln und sehr entwickeltem Iautsysteme versehenen Sïugethieren entstehen aus den Aru. crurales starke aufsteigende Aru. musculo-cutuneue, welche mit ähnlichen, aus den Arle. axillares hervorgegangenen, absteigenden Gefässen anastomosiren und Bogen bilden 11). - Die Spaltung der Arl. cruralis kann hülıer oder tiefer erfolgen, als beim Irenschen 12 ). - An den Hinterextremititen der Phoken, mehrer Edentaten ${ }^{13}$ ) und einiger Halbaffen ${ }^{14}$ ) kehren die an den Vorderextremitäten schon bemerkten Wundernetzbildungen, obschon gewöhnlich sehwäeher ausgebildet, als an diesen, wieder.

Die Fortsetzung der Unterleibs-Aorta bildet gewöhnlieh die Art. sacra media. Sic ist bei den langgeschwänzten Säugethieren oft sehr stark und verläuft innerhalb des Canales der unteren Bogenschenkel; sehr oft bildet sie Wundernetze 15) oder tritt als einfaeher Stamm dureh Wundernetze $\left.{ }^{16}\right\}$, in welehe ihre Zweige zerfallen, hindureh. Bei vielen anderen Säugethieren, namentlich den kurzgesehwänzten, sind die $\boldsymbol{A} \boldsymbol{t} \boldsymbol{t}$. ilincae, in Vergleieh zur $\mathcal{A}$. sacra media, so stark, dass letztere nur als ganz unbedeutender Zweig erseheint und ihren Charakter, eine unmiltellare Fortsetzung der Aorta für den Schwanz zu bilden, mehr oder minder verliert ${ }^{17}$ ), wie sie denn auch bisweilen fast ganz wegfältt.

\section{Von den Venen.}

\section{§. 200.}

Das Körpervenensystem der Säugethiere ist zwar im Allgemeinen demjenigen des Menschen sehr entspreehend angeordnet, bietet aber bei einzelnen Ordnungen und Gattungen manehe bemerkenswerthe Eigenthïmlielkkeiten dar ${ }^{1}$.

10) S. hierüber die Sehriften von Barkorv.

11) Z. B. bei Erinaceus. Abb. bei Barkow, Disquis. Tab. 1. Fig. 1.

12) S. Barkow l. c. p. 99.

13) S. die Abb. bei Vrolik; den venösen Theil des Extremitätenwundernetzes bildet ab: 0 tt o, Erläuterungstafeln Hft. 6. 'Tab. VIII. Fig. 4.

14) Abb. von Stenops graeilis bei Rapp, Eilentaten Tab. IX. Fig. 2.; Bradypus cueulliger ibid. Fig. 1.

15) Stenops, Bradypus, Myrnecophaga. Abb. bei Rapp (Stenops) Tal. IX. Fig. 2. - 16) Delphinus phoeaena.

17) Z. B. Erinaceus, Iepus, den meisten Wiederkäuern, z. B. den Lama, und besonders bei den Eimhufern. - Bei Manatus australis theilt sieh der Stamn der Aorta in zwei Arlt. hypogrestricae, olme als sacia media sich fortzusetzen. Zweige der Artt. hypogrestricue lösen sieh sogleieh in enorme Wundernetze auf, die in den Canal der unteren Wirbelbogensehenkel treten.

1) Klapplen scheinen dem Venensystenre der Säugethiere nie zu fehlen. Baer (Nov. Act. Acar. Caes. Leop. Carol. Vol. XVII. P. 1. 1835. p. 400.) hebt den Klappenuangel als auffallendste Eigenthümlichkeit des Venensystens bei den 
Was das System der oberen oder vorderen Hohlvenen anbetrifft, so erhalten sich bald zwei obere Ilohlvenen, bald entsteht durch Uebergang der linken in die rechte ein einfacher in den rechten Herz vorhof miindender Stamm. - Zwei obere Hohlvenen, bei deren Anwesenheit die Kranzvene des Herzens in die linke Hohlvene sieh einzusenken pflegt, sind vorhanden bei den Monotremen, den Beutelthieren, bei den meisten Nagern ${ }^{2}$ ), unter den Pachyderınen beim Elephanten, unter den Insectivoren bei Erinaceus und Sorex und bei einigen Fledermäusen. Angedeutet ist die Vereinigung der beiden oberen llohlvenen zu einem einfachen Stamme schon bei einigen der genannten Thiere durch eine Queranastomose, welche einen Theil des Blutes aus dem linken Iohlvenenstamme in den rechten überführt ${ }^{3}$ ). Ein einfacher oberer Hohlvenenstamm kömmt zu Stande bei den Edentaten; inehren Pachydermen, den ächten Cetaceen, den Einhufern, Wiederkïuern, den Ferae, den Makis, den Affen, so wie auch bei einzelnen Gattúngen der Nager und Insectivoren 4). - Die dem oberen Hohladersysteme angehörigen Veuae jugulares zeigen gleichfalls ein verschiedenartiges Verhalten ${ }^{5}$. Dic Venae jugulares iuternae sind oft so untergeordnet, dass sie kaum als eigene Stämme betraehtet werder können, wïhrend die, beim Menschen zuriiektretenden, äusseren Jugularvenen nicht nur beträchtlich weit erscheinen, sondern auch das Blut aus dem Gehirne zurückfiuhren. Bei manchen Säugethieren werden die inneren Jugularvenen etwas st:arker und bedeutender, indem aus dem Foramen jugulare kommende Aeste ihnen cinen Theil des venösen

Delphinen hervor; aher mit Unrecht; ich habe, unter anderen, in den unter der Haut liegenden, oft beträchtlichen Venenstämmen immer Klappen angetroffeu.

2) Ausnahmen bilden z. B. Cavia, Dasyprocta.

3) Z. B. bei Lepus. - 4) Z. B. bei Talpa.

5) Vergl. hierüber nähere Angaben bei Rathke (Dritter Bericht über das naturwissenschaftliche Seminar bei der Universität zu Königsberg. Königsb. 1838. 4.). Ganz untergeordnet und kaum als eigene Stämıne zu betrachten sind die inneren Jugularvenen z. B. bei Lepus, Seiurus, Arctomys, bein Pferde, bei den Wiederkäuern. Bei der Ratte fand Rathke dic $V$. jugularis interna dïn und untergeordnet, ohne Blut aus der Schelelhühle aufzunehmen. Aehnlich verhalten sich Mus, Myoxus, Castor. Sie gewinnt etwas an Weite und nimut einen Zweig aus dem Foramen jugulave auf bei Erinaceus, den meisten Ferae (Canis, Felis, Mustela, Meles, Ursus), bis sie endlich bei den Affen und beim Mensehen alles Blut aus der Sebedelhöhle abführt. Die Weite der äusseren Jugularvene und das Zurücktreten der inneren hangt mit einer anderen Eigenthümlichkeit zusammen, auf die besonders 0 tto (Nov. Act. Acall. Leop. Carol. Vol. XIII. P. 1. p. 24 sqq.) aufunerksan gẹmacht hat. Die Blutleiter der Sehedelhöhle mïnilen näunlich bei den Säugethieren mit ganz untergeordneter $\boldsymbol{V}$. jugalaris interna nicht aus durch das Foramen jugulare, sondern dureh einen Canalis temporalis, der zwischen dein Felsenbeine und der Schlafbeiuschuppe oder in letzterer sich findet. Erst wo das Foramen jugulare zum eigentlichen Abzugscunale des venösen Blutes der Schedelhöhle wirl, erlangt die $\boldsymbol{V}$.jugularis interna die Bedeutung, welche ihr beim Menschen zukömmt. 
Blutes der Schedilhöhle zuleiten. Bei anderen gewinnen sie noch melır an Stärke, bis sie endlich beim Affen und Menschen alles Blut aus der Schedelhöhle zurïckfiihren.

Dic vorderen Vertcbralvenen liegen als Venae vertebrales prefundae gewöhnlich in deın Canale der Querfortsätze der IIalswirbel und senken sich bald in die $\boldsymbol{V} . \boldsymbol{V}$. axillares, bald in die $\boldsymbol{V}$. vertebrales posteriores.

Die hinteren Vertebralvencn, bei den Säugethieren unter den Namen des Systemes der Vena azygos bekannt, liegen, mit cinigen Ausnahmen, zu welchen namentlich die Sirenen und Cetaceen gehören, bei (denen, statt ihrer, im Canalis spinalis gelegene Venen vorkommen 6 ), innerbalb der Bauchhöhle. Bisweilen sind die beiden seitlichen Venenstämme von gleicher Stärke ₹). Dann mündet jeder bisweilen in den vorderen Hohladerstamm seiner Seite; selten der eine direct in die rechte Vorkammer des Herzens, der andere aber in die einfache vordere Hohlvene ${ }^{8}$ ). IIäufig aber überwiegt der linke Stamm den rechten und dann senkt sich dieser früher oder später in jenen, wodurch ein wirklich unpaarer Stamm ( $\boldsymbol{V}$. azygos) entsteht, der bald in den linken vorderen Hohlvenenstamm, bald in die gemeinsame vordere Hohlvene einmündet ${ }^{9}$ ).

Die Entstehungsweise des Stammes der unteren oder hintercn Hohlvene bietet gewöhnlich keine bedeutenden Abweichungen von den bekannten, dem Menschen eigenthümlichen Bedingungen dar 10). An den meisten Stellen, wo die Arterien Wundernetze bilden, lösen auch die Venen in Wundernetze sich auf. - Bei den tauchenden Säugethicren ist das Körpervenensystem durch seine beträchtliche Capacität ausgezeichnet ${ }^{11}$ ); es kommen bei ihnen häufig starke Venengeflechte

6) Vergl. über diese Eigenthümlichkeit Baer l. c. (Anm. 1.) S. 408. Statt des Systemes der subvertebralen $\boldsymbol{V}$. $a z y g o s$ anderer Säugethiere finden sieh, nach Baer, zwei unter dem Rüekenmarke liegende Blutleiter, die zuletzt zu einem weiten Canale verbunden, in die hintere Hohlvene sieh ergiessen. Ieh sah rech. terseits zwisehen den Köpfehen der dritten und vierten, sowie der dritten und zweiten Rippe zwei weite, sieh zll einem kurzen Stanme vereinigende Venenstämule hervortreten und den letztgenannten Stamm in die dureh Vereinigung der $\boldsymbol{V}$. jugulares und axillaris entstandene rechte $W$ urzel der oberen Hohlvene eintreten. Aueh bei Manatus vermisste ich das System der hintern Vertebralvenen in der Bauchhöhle.

7) Bei deu Monotremen, den Beutelthieren, einigen Nagern, z. B. der Ratte, nach Rathke; aueh beim Maulwurf.

8) So nach Rathke bei Chiropteren und Talpa.

9) S. nähere Angaben bei Rathke l.c.

10) An abweichendsten ist ihre Entstehungsweise bei Manatus und den Delphinen. Hier erseheint der Stamm der unteren Hohlvene noeh zwisehen den beiden Nieren in zwei dieht an einander gedrängte Stämme getheilt, welche mehr als Aequivalente der Venae iliacae sind. In den reehten Stamm sah ich, gleich $\mathrm{Ba}$ er, die starke untere Sehwanzvene übergehen. S. Baer 1. e. S. 404. Táb. XXIX.

11) S. darüber Näheres bei Baer und bei Burow in Mïller's Archiv 1838. S. 253. (Phoca). 
in der Unterleibshöhle vor, denen nieht beständig arterielle verbunden sind 12); ihr unterer IIohlvonenstamm bildet oft eine sackfürnige Erweiterung ${ }^{13}$ ). Bei Phoea wird die untere Ifohlvene von einer ringförmigen muskulösen Fortsetzung des Zwerchfelles naeh ihrem Durchtritte dureh dasselbe eine kurze Streeke weit auswendig umkleidet und kann so - anseheinend willkührlich - zusammengedriiekt werden 14). - Rïeksichtlieh der Bildung des Leberpfortadersystomes sind durch die bisherigen Untersuehungen keine erhebliehen $\Lambda$ bweiehungen von seiner Zusammensetzung beim Mensehen näehgewiesen ${ }^{15}$ ). Bei einigen Säugethieren sind Klappen im Bereiehe des Pfortadersystemes angetroffen worden 10 ).

\section{Von den Lungengefïssen.}

\section{§. 201.}

Die beständig einfache Artcria pulmonalis theilt sieh in zwei Aeste, deren einer für jede Lunge bestimmt ist. Bei vielen tauehenden Säugethieren 1) wird eine beträchtliche Ausdehnung der Lungenarterie an ihrem Ursprunge angetroffen.

Die Lungenvenen bieten in Betreff ihrer Zahl einige Verschiedenheiten dar. Gewöhnlich finden sieh jederseits zwei Stämme, seltener kommen an beiden oder an einer Seite mehre Stamme vor. Meistens treten die Stämme beider Seiten getrennt in den linken Vorhof des

12) So bei Phoca; bei Delphinus. Vergl. die Abb. bei Baer und bei Burow Tab. VII.

13) Besonders stark bei den Phoken, den Delphinen; nach Meckel auch bei Lutra, Castor, Ornithorhynchus; bei Nyogale moschata findet sich nach $\mathrm{Pal}$ las (Act. Petropolit. 1781. p. 332.) sogar eine doppelte Erweiterung.

14) Burow l. c. hat eine ganz verfehlte Darstellıng dieses Verhältnisses gegeben, wie M. J. Weber (Mïller's Archiv 1840. S. 236.) gezeigt hat. Ich habe in 6 Exemplaren von Phoken Weber's Darstellung geprüft und kann ilıre Rielıtigkeit vollkommen bestätigen. Der breite Muskelring, welcher, vom Zwerehfell ausgelıend, flen unteren Hoblvenenstamm auswendig ringförmig umgibt, ent. lıält quergestreifte Primitivbündcl. Beim Delphin, wo allerdings die Hohlvene gleichfalls durch den muskulösen Theil des Zwerchfelles hindurehtritt, fehlt aber dieser Ring gänzlich, wic ich schon früher (Erster Bericht v. zoot. phys. Institut zn Rostock. Rost. 1841. S. 22.) gegen Weber bemerkt habe.

15) Dass die Pfortader bei den Cetaceen weniger algeschlossen sei, als bei den übrigen Säugethieren, wird. lurch Baer 1. c. S. 401. behauptet; wie es mir scheint, aber mit Unrecht. Verbindungen mit den Venen der Beeken- und Schwanzgegend finden Statt, aber nicht betrïichtlicher, als anderswo. S. über das Pfortadersystem Hoenlein, Descriptio anatonnica systematis venae portarum in homine et quibusdam brutis. Francof. 1808.

16) Beim Pferde und Rinde. S. Weigel (E. H. Weber), De strato musculoso tunieae venarmm. Lips. 1823.

1) Namentlich bei Delphinen, Seehunden, Fischottern und Bibern wahrgenommen. 
Iferzens; selten vereinigen sie sich ror ihrem Eintritte in den letzteren z.11 (نueun einfachen Staume 2).

[Niheres Detail über das Verhalten der Lungengefisse siche bei Meckel, System der vergl. Anat. Thl. 5. S. 330 ก.]

\section{Vom lymphatischen Gefiiss -Systeme.}

\section{§. 202.}

Das lympliatische Gefiisssystem der Süugethiere ist durch melıe Bedingungen vor demjenigen der übrigen Wilbclthicre ausgezeichnel. Seine Stämmc erscheinen mehr gefäss- oder canalförmig; die Klappen ihrer Innenwiinde, welche den Zutritt ihres Inlıaltes nach dem Ductus thoracicus hin fördern, dessen Rücktritt aber hemmen miissen, sind ausgebildeter und zahlreicher 1). Die sogenannten lymphatischen Drüsen, wolche wesentlich aus netzförmigen Anastomosen der Chylus- und Lymphgefässe bestehen, werden unglcich zahlreicher und erscheinen an sehr verschiedenen Stellen des Körpers, namentlich im Mesenterium, an den Bronchien, in der Oberschenkelbeuge, in der Achselgegend, am IIalse u. s. w. Bei vielen carnivoren Siungethiercn, aber nicht blos bei solchen, welche durch bedcutende Kürze des Darmcanales ausgezeichnet sind 2 ), sondern namentlich auch bei einigen, die einen längeren Darm besitzen, z. B. bei Phoca, Delphinus, Ifonodon, erscheinen die Mesentcrialdrüsen haufenweise zu sammengedrängt und bilden das sogenannte Pancreas Asellii, in welches alle Chylusgefässc des Darmes übergehen. Aus dieser Masse treten bald zahlreiche Vasa lympliatica efferentin hervor ${ }^{3}$ ), bald, wie bei Phoca, nur cin einziger (Ductus Rosenthaliaums) 4). - In der Regel findet sich unterhalb des Zwerchfelles eine erweiterte $C$ ister $u$ a chyli. Aus ihr geht ein doppelter 5 ) oder cinfacher Ductus thara-

2) Vou Meckel beim Hamster, von 0 wen beim Dïgong beobachtet.

I) Sehr dickwandig und dabei verhältnissmässig weit fand ich den Ductus thoracicus und die in ihn mündenden Chylusgefässe des Mesenterinu bei den Delphinen; übrigens keinerlei Abweichung von der gewölmlichen Anorinung.

2) Ich hebe dies hervor, weil Breśchet (Le système lymphatique, considéré sous les rapports anatomique, physiologique et pathologique. Paris 1836. 8. p. 194.) das Vorkunmen des Pancreas Asellii irrthüınlich nur bei de n Säuge. thieren statuirt, die durch Kürze des Darmeanales sich auszeichmen.

3) So nach Rudolphi (Pliysiol. Bd. 2. Abth. 2. S. 246.) beim Hunde nnd bei den Delphinen, für welche letztere ich $R$ udolphi's Angabe völlig bestätigen kaun.

4) Von Rosenthal entleckt (Froriep's Notizen 1822. Bd. 23. S. 5. und Nor. Act. A carl. Caes. Lepp. Carol. T. XV. P. 2. p. 235. Abb. Tab. LXXVI. u. LXXVII.); bestätigt von Rudolphi (Physiol. 2. 2. 242.). Rosenthal's Abb. copirt bei Carus und 0 tto, Erläuterungstafeln.

כ) Doppelt ist der Stamm z. B. bei dem Pferde nach Gurlt; bei Phoca nach Rosenthal; bei Macropus Parryi nach Hodgkin, s. Owen, Marsupialia p. 305. Hier verläuft der eine rechts, der andere links an den Wirbelkörpern. Der reclite verbindet sich in der Gegend des siebenten Brustwirbels mit dem linken; vor der 
cicus hervor; ist er anfangs doppelt, so geht der rechte Stamm später in den linken über und dieser senkt sich in die Vereinigungsstelle der linken Veuae subclavia und jugularis; selten treten Zweige in die Vena azygos $\left.{ }^{6}\right)$. Kleinere lymphatische Gefässe münden auch in die eben genannten Venen der rechten Seite. Sn weit die bisherigen Erfahrungen reichen, steht das lymphatische Gefässsystem bei den Sïugethieren demnach nur in Conmunication mit dem Systeme der vorderen oder oberen Hohlvenen 7 ).

[Ueber die Lymphgefässe der Haussäugethiere s. Gurlt, Handbuch d. vergl. Anat. d. Haussäugethiere. Thl. 2. S. 338 ff.]

\section{Siebenter Abschnitt.}

\section{Von den Stimm- und Atthmungs - Organen.}

\section{Voin Kehlkopfe.}

§. 203.

Die, verhältnissmässig selten verknöchernden, Knorpel, welche die solide Grundlage des Säugethier-Kehlkopfes bilden, stimmen gewöhnlich in ihrer Zahl und in den wesentlichsten morphologischen Bedingungen ihrer Anordnung mit denen des menschlichen Kehlkopfes überein; indessen treten nicht selten kleinere, eigenthümliche, accessorische Knorpel zu den gewöhnlich vorhandenen hinzu. Der Schildknorpel, rücksichtlich seiner Wölbung, seiner Ausschnitte, seines Vorspringens in eine mittlere Leiste u.s. w. manche Verschiedenheiten darbietend 1),

Einmündung in dic Vena sulbclavia findet noch eine Theilung und Wiedervcreinigung unter Bildung eines Geflechtes Statt.

6) Dies wurde von Panizza (Osservazioni antropo-zootomico-fisiologiche. Pavia 1830. Fol. - ein Wcrk, das zahlreiche einzelne Mittheilungen über die Lymphgefässe der Säugethicre enthält - p. 56.) beim Schweinc gefunden.

7) Ueber die Annahmen vielfacher Communicationen mit den Venen verweise ich auf die literarischen Notizen bei Rudolphi l. c. S. 247.

1) Beim Diigong bcsteht, nach 0 wen (Proceedings of the zool. socicty of London. Part. VI. 1838. p. 37.) der Schildknorpcl aus zwci, nur durch fibröses Gcwebe und Zell - und Fettgcwebc verbundenen Seitcnhälften. Bei Manatus ver. misse ich diese vollständige Trennung beider Seitenhälftcn. - Eine gute Uebersicht über die vcrschiedencn Formen dcs Kehlkopfcs bei den meisten Säugcthieren gewähren dic Abbildungen von Wolff l. c. und von Brandt l. c.; indesscu finden sich hier keinc bildlichen Darstellungen des abwcichend geformten Laryux der Cetaceen. Rücksichtlich des Kchlkopfes der Delphine, mit dem der des Narwals nach meinen Untcrsuchungen wesentlich übereinstimnt, kann auf die Abbildung bci Albers (Icones ad anat. comparat. Tab. V.), in Bctreff derjenigen dcr Walfische aber auf Sandifort l. c. verwiesen werden. Bei den Delphinen und dem Narwal bildet die Epiglottis, nit den bciden Giessbcckenknorpclu bis zur Spitze verbunden, eine lange, pyramidale Rölre, welche in die hinterc Nasen. 
bildet allgemein nur die Vorder- und Seitenflächen des Stimmorganes. Err verbindet sich mit dem Ringknorpel durch dic Spitzen seines unteren Randes, welche, meistens stielfürmig verlängert, als untere Ilörner bezeichnet werden \%). Bei den meisten Säugethicren bildet er obere IIörner zur Verbindung mit dem Zungenbeine ${ }^{3}$ ). Andeutungen einer Theilung des Scliildknorpels in mehre Luftröhrenringe sind bei den Säugethieren nicht angetroffen worden. Häufig kommen indessen zwei melır oder minder beträchtliche, seitliche Oeffnungen, znm Durchgange von Gefässen bestimmt, vor ${ }^{4}$ ). - Dic Cartilago epiglottica ist fast immer voun Schildknorpel getrennt; nur bei einigen ächten Cetaceen (Delphinus, Monodon) erscheint sie noch continuirlich mit ihm verbunden, fehlt dagegen bei den Sirenen als eigener Knorpel, indem sic nur aus fibrösem Gewebe besteht ${ }^{5}$ ). Unter allen Säugethieren besitzt sie bei den Delphinen die beträchtlichste Länge. - Der Ringknorpel, fast immer hinten höher als vorn, ist meist vorne geschlossen; diesc vordere Schliessung bleibt aber bei den ächten Cetaceen, bei denen auch dic ersten, oder sogar sümmtliche Luftröhrenringe vorne geöffnet sind, aus ${ }^{6}$ ); auch bei einigen Ferae erhält sich eine vordere Lücke in dem Ringknorpel. Schr bemerkenswerth erscheint es, dass bei einigen ächten Cetaceen die Riickseite des Ringknorpels ohne alle bestimmto Grenze in die mit ihm und unter einander hinten verschmolzenen Luftröhrenringe ubergeht \%). - Die Giessbeckenknorpel sitzen auf dem oberen Rande der Ringknorpelplatte und sind in der Regel von dreicckiger Gestalt. Ihre vorderen Ränder entfernen sich von den Seitenrändern des Schildknorpels und zwischen ihnen ist jederseits als Schleimbautfalte das Ligramentum ary-epiglotticum ausgespannt, in

öfnung hineinragt. Diese bis zur Spitze reichende Verbindung der genannten Knorpel und damit aueh die Röhrenbildung fehlt, sowol bei Balaena, als bei den Sirenen.

2) Diese unteren Hörner fehlen fast ganz beim Luchs (s. Wolf $\mathrm{f}$ Tab. II. Fig. 10.); bei Ornithorhynehus (s. Meckel, Ornithorh. Tab. VIT. Fig. 19.), sind dagegen sebr beträchtlich bei Anderen, z. B. bei den Cetaceen (s. die Abb. bei Sandifort Tab. 1-3.).

3) Sie sind bei einigen Wiederkäıern (Cervus) und mehren Katzen sehr entwiekelt, treten dagegen bei Didelphis ganz zurück und verselwwinden beim Seliwein und bei den äehten Cetaceen. Wolff sahe beim Löwen die oberen Hörner als eigene Knorpel.

4) Z. B. bei vielen Cetaceen, bei Felis, Phoea u. $\Lambda$.

5) So, naeh 0 wen, beim Dügong, und, naeh meinen Untersuehungen, bei Manatus. - Bei Lutra vulgaris kömmt ein Processus epiglotticus des Schildknorpels ausser einer eigenen Epiglottis vor. S. Wolff Tab. I1. Fig. 13. 14.

6) Er ist rorn weit geöfnet bei Balaena (s. Sand ifort Tab. 1-3.), bei Delphinus, Monodon; ferner aueh ganz oder fast offen bei Mustelia (s. Wolff Tab. III. Fig. 21.), bei Ursus (Wolff Tab. III. Fig. 16.), bei Lutra (Tab. IJ. Fig. 14.).

7) So bei Balaena rostrata nach Sandifort. S. die Abb. Tab. 1. u. 2. 
welehem bei einigen Siugethieren ein eigentlümlicher Knorpel, dis: Cartilago cune iformis s. Wrisbergiaua sich entwiekelt 8). Die obere Spitze der Giessbeckenknorpel lïuft bei den Wiederkïuern, Einhufern und Sehweinen in einen hakenförmigen Fortsatz aus. Statt desselben kömmt bei den meisten Süugethirren ein eigenthümlieher Knorpel (Curtilago Santoriuiuna) 9) vor. Andere kleine aecessorisehe Knorpel sind die bisweilen vorkommenden Cartilugines sesamö̈leae und C. interarticulures 10). Erstere linden sieh bisweilen doppelt, bisweilen aber auch dureh Verschnelzung einfaeh auf dem hinteren und inneren Rande der Giessbeckenknorpel. Letztere kommen bei einigen Säugethieren zwisehen den Gelenkfläehen der Giessbeekenknorpel und dem oberen Rande des Sehildknorpels vor.

Stimmbänder fehlen den ichten Cetaeeen, sind ther, mit Ausnahme dieser Ordnung, wahrscheinlich allgemein vorhanden. Bei den Sirenen kommen nur, und zwar sowol beim Diigong, als bei Manatus, clastisehe Ligameuta vocalia inferiora vor. Diese allein sind aueh den meisten Wiederkïuern ${ }^{11}$ ) eigenthümlich, während bei den meisten uibrigen Säugethieren noeh gewöhnlich sehwïehere obere Stimmbänder hinzukommen. Zwisehen unteren und oberen Stimmbändern liegen dann die Morgagni'schen Ventrikel. - Viele Säugethiere versehiedener Ordnungen sind dureh den Besitz von Luftsäeken, welehe mit der Kchlkopfshöhle communieiren, ausgezeiehnet. Bei einigen Walen tritt ein soleher Luftsaek unter dem Sehildknorpel, zwvisehen ihm und dem vorn geöffneten Ringknorpel, hervor 12). Eine ähnliche Lage zwischen Schild - und Ringknorpel besitzt er bei Yustela furo und Hapale rosalia. Bei einigen Wiederkäuern ${ }^{13}$ ) und den mei-

8) Ein sehr vollständiges Verzeiehniss derjenigen Säugethiere, bei welehen diese Knorpel vorkoumen, liefert Brandt l. e. p. 30. Sie liegen frei im Liga. mentum aryepiglotticum bei Ursus, Canis, Phoea, Myrmeeophaga; sie verwaclı. sen mit den Giessbeekenknorpeln bei Didelphis, mit diesen und den Santorini schen Knorpeln bei Sus, Bradypus, Mustela, Nasua; mit den Santorini'schen Knurpelı bei den neuwelclichen Affen.

9) S. Wolff 1. e. p. 43. und Brandt 1. c. p. 30. Nota 1. - Bein Fötus ron Monodon besteht jeder Giessbeekenknorpel aus zwrei Stücken: eineu Basilarstïck und einer etwa eben so grossen Spitze. Bei erwachsenen Delphinen finde ich keine Spur soleher 'Trennung.

10) S. über diese Knorpel Brandt l. e. p. 32., der sehr ausfülurliche Verzeiehnisse der Thiere gibt, bei welchen er sie beobaelitet hat.

11) So wenigstens bei Cervus, Ovis, Capra, Bos. - Auehenia und Camelus besitzen obere Stimmbänder. Die letzteren fehlen dagegen, naeh mehren Angaben, dem Elephanten. - Bei Hippopotamus sollen die Stimmbänder gänzlich felılen.

12) Bei Balaena rostrata und mysticetus. S. Abb. bei Sandifort I. e. Tab. 1. 2.

13) Z. B. bei Antilope doreas und Corinna, beim Rennthier (s. Campel, Naturgesch. des Orang - Utang, des Nashorns und des Rennthiers, übersetzt von Herbell. Düsseld. 1791. 4. Tab. VIII. Fig, 7.) 
sten Mfen 14) findet sieh die Austrittsstelle des meist einfachen, seltener doppelten Luftsackes zwiselien dem Schildknorpel und dem Zungenbeine. Am incrkwij rdigsten ist die Bildung dieser Luftsäicke bei den Briillaffen (Mycetes) 15 ). Hier sind die Morgagni'schen Ventrikel vorn zu drei selı weiten Säcken ausgedehnt, von welchen der mittelste, zwischen Kehldeckel und Schildknorpel austretend, in den blasenförmig ausggehöhlten Körper des Zungenbeines eintritt und dessen Höhle auskleidet. Aisserdem finden sich, zwischen Kehldeckel und Schildknorpel hervortretend, zwei eigenthiimliche liangliche, in den Schlund inindende Säcke. - Einige ächte Cetaceen sind ausgezeichnet durch den Besitz einer unterlıalb des Sehildknorpels, zwischen den beiden vorn unvercinigten Bogen des Ringknorpels gelegenen Kehlkopfsdriise, deren Ausfülırungsgänge in die Iöhle des Kchlkopfes münden 16).

Zur Bewegung rles ganzen Kehlkopfes sind dic ihn herabzichenden M. M. steruothyreoülei und die ihn aufwärts ziehenden $\boldsymbol{M}$. M. hyothyrevïdei bestimmt. Bci den Delphinen kommen noch eigenthümliche M. M. occipito-thyreoüdei hinzu 17). - Die klcineren Kehlkopfsmuskeln entsprechen, selbst bei sehr eigenthümlichen Gestaltungsverhältnissen des Larynx, ihrer Zahl und Befestigungsweise nach, gewöhnlich denjenigen des Menschen ${ }^{18}$ ).

14) Beim Orang-Utang und Chimpanze, Hylobates syndactylus (nicht bei agilis), bei Semnopithecus nasicus und lcucopryunus, Cercopithecus aethiops, fuliginosus, ruber, sabaeıs, Inuus sinicus, ecaudatus, cynomolgus, nemcstrinus, Cymocephlalus Sphinx, porcarius, Mormon angetroffen.

15) Vergl. besond crs die genaue Beschreibung von Brandt l. c. p. 16. und die Abb. Fig. 1-5. Andere Abb. s. bei Müller, Ueber die Compensation der physischen Kíräfte an menschlichen Stimmorgan. Berlin 1839. 8. Tab. III. Fig. 25-27. Abb. auch bci Huuboldt und Bon pland, Recueil d'observat. Tab. IV. Fig. 1-3. - Müller erläutcrt in der genannten Schrift auch die Kehlkopfsbildung des Ateles arachnoïles, bei dem die Kehlkopfshöhle über den unteren Stimumbändern zu einer gekrïmuten, anfangs aufwärts, dann rückwärts steigenden Röhre vcrlängert ist. S. 50. Tab. III. Fig. 23. u. 24. Vergl. damit B randt l. c. 1. 14.

16) Zuerst bescluriclen von $R$ app in den Würtemberger naturviss. Abhandl. Bdl. 1. und: Cetaceen S. 147. Bei Delphinus phocaena erstreckt sich eine starke unpaare Längsfalte der Schlemhant der Kehlkopfshöhle von der Innenfläche des Kiehldeckels abwärts. Sic spaltet sich in der Gegend des Schildknorpels in zahlreiche Falten, die unter einander netz-oder maschenförmig sich verbinden. Dio so gebildeten Maschen enthalten die weiten 0effnungen, in welche die zahlreichen Ausfiihrungsgänge der aggregirten Follikel, welche jene Driise bildcn, ausuünden. Ganz älınlich verhält es sich beim Narwal, nur dass die Maschen noch zahl. reicher sind.

17) Das Vorkommen dieses von der Seite des Hinterhauptsbeines zum Seitenrande des Schildknorpels und an die Basis der Epiglottis gelıendeu Muskels hangt wol mit dem Hineinragen des Tíehlkopfes in die hintere Nasenöfnnung zusammen und der genaunte, den Kehlkopf hebende, Muskel dürfte vielleicht allen äclıten Cetaceen zukommen.

18) S. Näleres liei Henle S. 69. Einige Abreichungen fand Escliricht bei Hylobates (Miiller's Archiv 183\%. p. 218. Tab. 2.), Bei Mamatus australis 
[Man vergl. über den Kehlkopf der Säugethicre, nusser Cuvier's Leçons, besonders: L. Wolff, De organo vocis mammalium e. tab. IV. Berol. 1812. 4. - J. F. Brandt, Observationes anatomicac de manmalium quorundan prac. sertim quadrumanorum vocis instrumento. Berol. 1826. 4. - Henle, Vergl. anat. Besch. des Kelılkopfes S. 66. - Meckel, System der vergl. Anat. Thl. 6. S. 498. - Ueber den Kehlkopf der Cetaceen siehe ausserdeur: G. Sandifort, Bijdragen tot de ontledkundige Kennis der Walvisschen. Austerd. 183I. M. Mit Abb.; Esehricht, Undersögelser over IIvaldyrene. Tredie Aflandl. Kjöbeuharn 1S 5.5. 1. 18. Mit Abb.; Rapp, Cetaceen S. 146.; und über die Sirenen: 0 wen, Procedings of the zool. soc. of Lond. Part. VI. 183S. und Stannius, Beitrïge zur Kenntniss der Amerikanischen Manati's. Rostock 1845. 4. Tab. II.]

\section{Von der Luftröhre, den Bronchien und Lungen.}

\section{§. 204.}

Die Länge der bald cylindrischen, bald von oben abwäris etwas ver engten L u f $\mathrm{r}$ öh re ist im Allgemeinen von der Länge des Halses abhänğg. Wo sie, wie bei den Sirenen und Cetaceen, durch sehr bedeutende Kürze ausgezeichnet ist, pllegt sie zugleich sehr weit zu sein 1). Die einzigen Beispiele vom Yorkommen einer ge wun denen Luftröhre liefern die dreizehigen Faulthiere ${ }^{2}$ ). Partielle Erweiterungen dieses Gebildes scheinen nur als individuelle Eigenthimlichkeiten vorzukommen ${ }^{3}$ ). Gewöhnlich theilt sich-die Luftröhre in zwei Bronchi, zu welchen jedoch bei vielen Cetaceen, einigen Pachydermen und bei den Wiederkäuern noch ein dritter, für die rechte Lunge bestimmter, hinzukömmt, der vor der eigentlichen Bifurcation abgeht ${ }^{4}$ ). Meistens sind diese unter mehr oder minder spitzem Winkel abtretenden Bronchi kurz ${ }^{5}$ ), was besonders von dem, gewöhnlich zugleich weiteren, rechten Luftröhrenaste gilt. Beide Bronchi theilen sich yor und bei ihrem Eintritte in die Lungen in mehre Zweige.

finde ich rorn zwischen den beiden Seitenplatten des Schildknorpels noch einen M. tingreoüdeus transversus.

1) Bei den Cetaceen ist sie wenig länger, als weit. Weit auch bei den meisten anderen tauchenden Säugethieren, z. B. Ornithorhynchns, Phoca u. A.

2) Bradypus tridactylus, torquatus, cuculliger. Abb. bei Wolff, de organo vocis mamnalinm Tab. III. Fig. 20. und Daubenton bei Buffon T. 13. p.64. Tab. VII. Fig. 3. - Eine andere Eigenthümlichkeit bietet nach 0 tto (bei Mekkel S. 405.) die Gattung Pedetes (Helamys) dar, indem die Luftröhre durch eine Scheidewand in zwei Seitenhälften getheilt ist.

3) Von Meckel bei Hystrix einige Male wahrgenommen. System 6. 403.

4) Der dritte Bronehus ist constant bei den Delphinen (ich fand ihn bei D. phocaena, delphis, dubius, orea) und beim Narwal; S andifort fand ihn bei Balaena rostrata, vermisste ilm aber bei B. mysticetus; unter den Paelydermen köımmt er vor beim Sclrwein und Pecari; bei den Wielerkïnern ist er anscheinend beständig, da er auch bei Auchenia, Canclus und Moschus vorkömmut. Bei den Einhufern finden sich nur zwei Bronchi. Ebenso nur zwei bei den Sirenen.

5) In Verhältniss zur kurzen Luftröhre aber lang bei allen Cetaecen und Sirenen. 


\section{Siebenter Abschnitt. Von den Stimm- u. Athmungs-Organen. 453}

Die solide Grundlage der Luftröhre und der Bronchien bilden Kin o rpe l, welehe nur selten ossificiren. Ihre Anzalıl ist am geringsten bei den Cetaceen und Sirenen, selı beträchtlich bei den linghalsigen Wicderkäuern und den Faulthieren. Bei der Mehrzalhl der Säugethiere stellen die Trachealknorpel keine vollstiandigen Ringe dar ${ }^{6}$ ), sondern werden hinten durch einen melr oder minder weiten, von Membranen und Muskelfasern geschlossenen Zwiselicnraum von einander getrennt. Bei cinigen Säugethieren sind dic hinteren freien Enden der Luftröhrenknorpel einer Seite so über dic der anderen Seite geschoben, dass sie letztere decken ${ }^{7}$. Eigenthümlich ist das Verhalten der Trachealknorpel bei den Cetaceen und Sirenen. Die Knorpel der Luftröhre sowol, als die der Bronchicn sind nicht regchmässig bogenförmig oder kreisförmig angeordnet, sondern theils spiralförmig, theils gabelförmig getheilt, theils unvollständig, oder selbst stellenweise in grösserer Zahl unter einander verschmolzen. Bei Baluena sind sämmtliche Luftröhrenknorpel vorn weit geöffnet und die Luftröhre ist hier nur durch Hembranen geschlossen ${ }^{8}$ ). Bei Delphinus und Monodon ist diese Trennung nur auf den oder die ersten Trachealknorpel besehränkt. Selten kommen bei anderen Säugethieren Spaltungen an der Vorderfläche des ersten Luftröhrenringes vor ${ }^{9}$ ).

Die Bronchien zeigen in Betreff ihrer Knorpel gewöhnlich dasselbe Verhalten, wie die Luftröhre; sind dicselben in letzterer hinten unvollständig und nieht gesehlossen, so bleiben sie es auch in den Bronchieno der werden hier selbst durch noch weiterc Abstände von einander getrennt. Die Bronehialknorpel anderer Säıgethiere digegen sind eben so wenig, wie die der Luftröhre, discret ${ }^{10}$ ), wie dies namentlieh von den Cetaceen und Sirenen gilt. Nach dern Eintritte der Bronchien in die Lungen behalten dieselhen oft nur in ihren grösseren Aesten die solide knorpelige Grundlage; bei anderen Säugethieren werden die Knorpel aber sehr bald, selbst in den grösscren Bronehialverzweigungen, unkenntlich 11), während dagegen Beispiele vorkommen, wo vollständig

6) Vollstïndige Ringe kommen ror z. B. bei einigen Bentelthieren, namentlich Phalangista fuliginosa, bein Biber, bein Aguti, bei Galaeopithecus nach Curier, bei der Gattung Lemur u. A.

7) Z. B. bei Hyaena (s. Abb. bei Reimann, Spicil. obs. de Hyaena. Berol. 1811. 4. Fig. 2. und bei Wolff Tab. II. Fig. 4.); ähnlich beim Schwein, zum Theil anch bei Phoca, wo aber die ersten Ringe vollständig sind ( $s$. Wolff Tab. 2. Fig. 8.). - 8) S. die Abb. bei Sandifort, Bijlragen Tab. 1. 11. 3.

9) Z. B. bein Pecari, bein Löwen, wenigstens in einzelnen Fäillen, unl bei Aniern. Henle l. c. S. 68. sah beim Löwen den ersten Trachealring vorn ge. schlossen, dann folgten vier offene, zwischen denen ein Längsknorpelstreif ver. lief. Ich rermisste diese Eigenthïnlichkeit.

10) Vollständig bleiben sie z. B. anch bei den Makis. Eigenthümlich ist die von Daubent on (bei Buffon XIII. 1. 207. T. 29.) beschriebene, von Meckel bestätigte, Erweiterung der Bronchien bei Lenur Macaco.

11) Sie schwinden sogleich bei Mycetes, bei den Makis, den Chiropteren, einigen Beutelthieren u. $\boldsymbol{A}$. 
geschlossene Knorpel sellst in schr kleinen Bronehialverzweigungen sich erhalten und wo in noeh engeren Canitlen wenigstens deutliehe Spuren derselben vorkommen. Es sind die tauehenden Säugethiere, bei denen die Bronehien diese Eigenthümliehkeit zeigen, die wieder nirgend sehïrfer ausgepriigt erseheint, als hoi den Cetaecen 12). - Die Interstitien der Traeheal - und Bronehialknorpel werden, der von flinunernder Sehleimhaut ausgekleideten IIöhle zunäehst, von elastisehen, in Längsfaseikeln angeordneten Fasern, weiter auswärls von queren ungestreiften Huskelbündeln ausgefüllt. Beide Arten von Fasern erstreeken sieh zugleieh theilweise oder ganz über die Knorpel. In den der Knorpel ermangelnden feinsten Bronehialverzweigungen kommen Längsinuskelfasern vor.

Die stets paarigen Lungen der Süugethiere hangen immer frei, von Pleurasäcken umsehlossen, in der dureh ein vollständiges Diaphragma von der Bauhhhöhle abgeschiedenen Brusthöhle. Die Dieke des PleuraUeberzuges bietet bedeutende Versehiedenheiten dar; sie ist auffallend stark bei den Cetaeeen, wo die die Lungen umkleidende, grossentheils aus elastisehen Fasern zusammengesetzte Pleura aus zwei leicht trennbaren Lagen besteht, zwisehen welehen Blutgefässe und Nerven verlaufen ${ }^{13}$ ). - Die Längenausdehnung der Lungen ist am bedeutendsten bei den Cetaceen und den Sirenen, wo sie längs der Rüekwand der verlängerten Brusthöhle, jedoeh olıne feste Anheftung an dieselbe, sielı hinterwärts crstreeken. Während bei vielen Säugethieren ${ }^{14}$ ) die Lungen niebt in einzelne Lappen zerfallen, kömmt bei den meisten die Lappenbildung vor. Die Zahl der Lungenlappen ist aber sehr verschieden 15) und oft grösser, als beim Mensehen. Im Allgemeinen sind die Lappen der reehten Lunge zalılreieher, als die der linken, welehe sogar nieht selten ungetheilt bleibt. - Die Lungen der

12) S. die vortreffliehe Abb. bei Albers, Icones ad illustrandam anatomen comparatam Fas. 2. Lips. 1822. Fol. Tab. V. Fig. 3. Unbedingt darf behauptet werden, dass die Knorpel nach Eintritt der Bronchien in die Lungen an Consistenz gewinnen. Barclay sah hei einem alten Delphin die Knorpel innerhalb der Lungen ossificirt. Aelnnliehe Beobaehtungen maehte $\mathrm{Meekel}$ an dem gleichfalls tauehenden Ornithorhynehus (System Thl, 6. S. 396.).

13) Stürker als beim Mensehen ist die Pleura auch bei einigen anderen Siingethieren, z. B. beim Elephanten, Panther, Bären. Vergl. Bazin (Annales franç. et étrangères d'auat. et de physiolog. Paris 1836. p. 28.). Nirgend ist sie so stark als bei den Cetaceen. R a p p (Cetaeeen S. 151.) beselireibt an den Lungen von D. phoeaena ein lïıgs ihres Vorderrandes gelegenes eigenthümliches Organ. Es ist dies nur eine Anhäufung von Fett zwisehen den beiden hier ans einander weichenden Blättern der Pleura mulmonalis. Das Fett ist von Gefässen durchzogen, dic auch ïber die ganze Lunge zwisehen jenen Pleuralamellen sich ausbreiteı.

14) Dahin gehören alle Cetaceen, die Sirenen, mehre Pacbydermen (Elephaut, Rhinoceros, Hyrax), die Einhufer, das Laun, die Faulthiere, einige Chiropteren.

15) Eine tabellarisehe Uebersieht der Zahl der Lungenlappen hat Durernoy gegehen: Cuvier, Leçons T. VII. p. 156. 
Situgethiere sinel durch baunförmige Verastelung iluer Bronchien und dureh Terninalblischen der letzleren eharakterisirt lij). Die Sirenen zeichnen dureh betraichtlichen Unfang ihrer' Lungenblaischen sich ans 1i).

[Vergl. Cuvier, Lecons el. Duvernoy 'Tome 7. Paris 1840. - Meekel, Systeu der vergl. Aluat. Bl. (j. - Le re boullet, Anatomie comprée de l'ajprareil respiratoire. Strasb. 1838. 4. - Abb. der Luftrülıren vieler Sängethiere bei W'olff, De organo vocis manmalimm. Berol. 1812. 4.; Abb. derjenigen des Mimatus bei Stannius, 1. c. 1. 452. 'Tab. 11.]

\section{Achter Abschnitt. \\ Von den Blutgefüssdrüsen.}

§. 205 .

Dic Schilddriise (Glandula thyrevïlea) 1), allen Siugrtbieren ohne Ausnahme zukommend, aber immer verhältnissmässig kleincr, als locim Menschen, liegt gewöhnlich am Kehlkopfe, von dem aus sie of abwïrts zur Luftröhre sich erstreckt; seltener bedeckt sie, mit Ausschluss des Kehlkopfes, nur einen Theil der Luftröhre. Bei viclen Sïugethieren besteht sie aus zwei völlig getrennte'n, zur Seite der Luftrühre odler des Kohlkopfes liegenden Körpern ${ }^{2}$ ); bei anderen sind zwei sulcher Kürper nur durch einen schmalen Streifen verbunden ${ }^{3}$ ); selten ist ilure Ver-

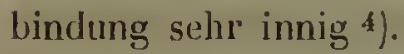

Die Thymus ${ }^{5}$ ), unter den Säugethioren violleicht nur bri den Beutelthieren abortiv oder fehlend, liegt im vorderen Cavum mediastini, die Basis des Ilerzens und der grossen Gefaissstimme bedeckend. Ihre oberen Hörner erstrecken sich meistens nur wenig aus der Brusthühle

16) Vielleicht besitzen die Cetaceen noch einige Eigenthümliclikeiten der inneren Anordnung; Hunter hat gezeigt, dass durch Einblasen in einen Ast der Luftrölıre nieht blos der Theil der Lunge, in welchen er sich verzweigt, sondern die ganze Lunge mit Luft gefüllt wirol.

17) Diese Eigenthümlichkeit wird von allen Anatomen, die diese Thiere untersucht haben, nauentlich neuerdings wieler vou 0 ve en hervorgeholien. Barkow fand bei den einlıeimischen Winterschläfern die Lungenbläsclıen verlıältnissıüissig weit.

1) S. C. A. F. 13 орр (Praes. Rap p), Ueber die Schilddrüse. Tüljing. 1840. 8.

2) So bei den Monotremen, den meisten Beutelthieren, meliren Edentaten, einigen Nagern (Hystrix, Mus), bei Auchenia nnl einigen Antilopen, bei Ploca, Lutra, Talpa, einigen Chiropteren, dem Orang-Utang u.. A.

3) Bei den meisten Nagern, einigen Ferae (Katzen, Hunden, Ursus, Herpestes) und ilen ureisten Affen.

4) Bei den Cetaceen und einigen Affen.

5) Vergl. über dieses Gebilde F. C. II ingsted, Thymi in lomine ac per seriem animaliun descriptio anatonico-pleysiologicio. Fascic. 1. Havniat: 1831. 8 . Ansserdem $\mathrm{Heckel}$ in den Zusïtzen zu Cuvier's Vorlesungen iiber vergl. Anat. Thıl. 4. S. 705. und in seinen Abhemilunge'n. 
heraus, sind jedoch bei einigen Säugethieren zcitweise weiter aus gedehnt, indeın sie vorn bis über die Schilddrüsc weggehen. Immer scheint ihr Umfang bei neugeborenen Thieren am beträchtlichsten zu sein. Indessen behält sic bei. einigen Säugethieren - z. B. Phoca, Delphinus - lange, und anscheinend während der ganzen Lebensdauer, cinen nicht unbedeutenden Umfang. Die Annahıne, wonach sie bei den Winterschlafenden Säugethieren während deren Lethargic an Masse beträchtlich zunehmen soll, erscheint nach neueren Untersuchungen unwahrscheinlich; aus dicsen ergibt sich vielmehr, dass mchre Beobachter, von denen jenc Behauptung ausging, nicht sowol die Thymus, als einen ihr fremden Apparat von anscheinend lymphatischen Gefässknäucln gesehen haben ${ }^{6}$ ).

Die Nebenniercn $\left.{ }^{7}\right)$ kommen allen Säugethieren ohne Ausnahme zu. Sie liegen bald einwärts von den Nieren an ihrem ołseren Dritttheile, bald uiber dem oberen oder vorderen Nierenrandc. Sie scheinen immer aus Rinden- und Harksubstanz zu bestehen. Ihr Umfang ist sehr verschicden ${ }^{8}$ ) und ihre Gestalt bietet mancherlei klcine Abweichungen dar. Bei mehren Säugethieren sind sie im Fötuszustande und kurz nach der Geburt bedeutend kleiner, als während der späteren Lebenszeit ${ }^{9}$ ).

[S. über diese Gebilde besonders die Arbeit von J. F. Meckel in seinen Abhandlungen aus der mensehl. und vergl. Anat. und Physiol. Halle j806. 8. S. 1. lhren feineren Bau behandelt: Schwager-Bardeleben, Observationes unicro. scopicae de glandularum duetu excretorio carentimm struetura. Berol. 1841.]

\section{Neunter Abschnitt.

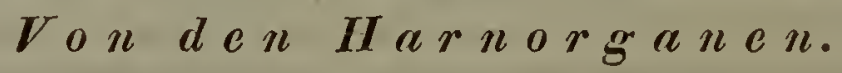

§. 206.

Die Nieren der Säugcthiere, in ihrer Lagc ${ }^{1}$ ) keine bedeutende

6) S. Jacobson in Meckel's deutschem Arehiv Bd. 3. S. 151. und damit übereinstimmend $\mathrm{H}$ augsted l. e.

7) Vergl. die Abhandlung von Nagel in Müller's Archiv 1836. S. 36r. Mit Abb. Tab. XV.

8) Verhältnissmässig aın grössten sind sie bei einigen Nagern, namentlich bei Cavia Cobaya und Coelogenys Paca; sehr klein bei den ächten Cetaceen, namentlich Delphinus und Monodon.

9) Namentlich bei Cavia und Auchenia von Meekel bemerkt; so auch von mir bei den Cetaceen (Delphinus, Monodon) gefunden.

1) Häufig liegt die rechte Niere mehr oder minder bedeutend höher, als die linke; so z. 13. bei den Monotremen, vielen Beutelthieren, den meisten Nagern, den Einhufern, Wiederkäıcru (z. B. dem Kalbe, dem Lama), den Delphinen, manchen Ferae u. A. 
Eigenthümlichkeiten, in ihrer Gesammtform 2) manche klcine Abweiehungen von derjenigen darbietend, welche diesen Gebilden bein Nenschen zukömmt, besitzen bald ebcne, gleichmüssigc Oberflïchen, bald crsclieinen sie höckerig (Renes tulercutati), bald endlich bestehen sie aus zalllircichen, gesonderten, unter einander blos durch die Zweige des Harnleitcrs zusanmonhhangenden Läppchen (Reuculi) und erhalten dann ein trauben - oder beerenförmiges Anschen, wic es am meisten bei den Robben und besonders den Delphinen und anderen iieliten Cetaceen auffällt ${ }^{3}$ ). Wenn sic in ausgcwachsencn Süugcthieren höekerig bleiben, zeigen sie also im Wcsentlichen dasjenige Verhalten perennirend, das für andere Säugethiere, z. B. für den Mcnschen, blos transitorisch ist. - Immer gibt sich in den Nieren der Säugethicre der Gegensatz von Corticalsubstanz und Medullarsubstanz zu erkennen. Wo die einzelnen Rcnculi getrennt sich erlalten, schlägt sich die Corticalsubstanz haubenförmig um die Medullarsubstanz cincs jeden herum. Wird aber die Niere durch Verwaehsung der Reneuli zu einer zusammenhangenden Masse, so zieht die Corticalsubstanz in Lagen von verschiedener Dieke von der Nierenoberfläehe bis zu der Basis oder der Warze jedes ursprünglichen Reneulus sich hin. - Sobald dic Nieren aus einzelnen Renculi bestehen, ist jcder der letzteren mit einer cigenen Papille versehen. Wenn aber durch Versehmelzung der Renculi die Nieren compact werden, fliessen häufig ihre Papillen zusammen. Die Zahlenverhältnissc der letzteren unterliegen demnach sehr beträchtlichen Schwankungen 4). - Rücksichtlich ihres feincren Baues schlicssen

2) Mehr rundlich z. B. bei den Katzen, noch mehr bei Dasypus; verlängert beim Schwein und einigen Nagern u. s. $\mathbf{~}$.

3) Gleichmässig ist ilıre Oberfläche z. B. bei den Monotremen, den Beutelthieren, den Edentaten, den Nagern; vielen Wiederkäuern (Lama, Giraffe, Schaaf, Hirsch u. A.), mehren Pachydermen; unter den Sirenen beiun Dügong (nach Rapp und 0 wen); vielen Ferae (Hund), den Insectivoren, Chiropteren und Quadrumanen; liöckerige Nieren besitzen die Gattungen Hyaena, Viverra, Felis, das Rind, der Elephant (Abb. bei Camper Tab. IX. Fig. 2. 3.), das Rhinoceros; mehr getrenut bleiben die Lappen bei Ursus, Lutra, besonders aber bei Phoca und bei den ächten Cetaceen. Die Zahl der Läppchen scheint bei Phoca je nach der Artverschiedenlieit, und selbst bei den Individuen, zu schwanken. Albers zählte 69-76; Cuvier 120-140. - Bei Delphinus delphis fand Rapp wehr als 200 Renculi; daunit stimuen meine Zählungen bei $\mathrm{D}$. phocaena und bei Monodon. - Abb. der Nieren ron Cetaceen s. bei Rapp, Cetaceen Tab. ViI.; Carus und 0 tto, Erläuterungstafelu Heft 5. Tab. IX. Fig. 1.; von Waleu bei Eschricht, Undersïgelser over Hvaldyrene. Tredie Afhandling. Kjöbenhavn 1835. 4. p. 10. u. 13.

4) Eine cinzige Papille busitzen z. B. die Bentelthiere, Edentaten, Nager, manche Wiederkïuer (Lama), die Hunde, Katzen, Marder, einige Affen u. A. Drei gibt Cuvie $r$ an für den Elephanten; für Echidna; 5 fïr den Igel u.s. w.; 0 wen fand 11 beim Dügong. Ihre Zahl wächst mit der der getrenut bleibenden Renculi. 
sich die Nieren der Säugethiere an die des Menschen an 5). - Die Eintrittsstelle der grossen Gefïssstämme, so wie deren Vertheilung an der Oberfläche der Nierensubstanz zeigt bisweilen charakteristische Eigenthïmlichkeiten $\left.{ }^{6}\right)$. Die Malpighi'schen Gefässknaäuel sind immer vorhanden. - Die muskulösen Harnleiter, welche am Innenrande ihrer Niere herabtreten, münden gewöhnlich - obschon nicht immer - in den Ifals der bestindig vorhandenen II a $n$ blase, die hinsichtlich ihrer Ausdehnung, ihrer Form und namentlich der Dicke ihrer Muskelschiclıt nanche Verschiedenheiten darbietet 7 ). Während bei Ifyrax und einigen Nagern ${ }^{8}$ ) die IIarnleiter höher aufwärts in die Rückenwand der IIarnblase sich inseriren, münden sie bei den Monotremen unterhalb des Blasenhalses in den Canalis urogenitalis $\left.{ }^{9}\right)$.

Bei einigen Säugethieren werden Canäle angetroffen, die vielleichı perennirende Ueberreste der Ausführungsgiinge der Primurdialnieren oder Wolff'schen Körper sein möchten. Es sind dies die sogenannten Gartner'schen Canäle 10) oder Scheidengänge. Jeder dieser dünnhïutigen Canäle erstreckt sich, vom breiten Mutterbande aus, längs dem Cervix uteri und dann zwischen der Schleinhaut und Muskellaut der Scheide abwärts, um seitwärts von der IIarnröhrenmündung sich zu öffnen.

5) Vergl. Müller, Gland. seeern. p. 94 sqq. Tab. XIV. - Husehke, Isis 1828.

6) Bei den ächten Cetaceen z. B. treten die grossen Gefässstämme hoch oben in die Niere ein. - Charakteristiseh ist ferner die baumförmige Gefäss. vertheilung an der Nierenoberfläche einiger Ferae (Felis, Hyaena u. A.).

7) S. darüber Cuvier, Leçons Vol. 7. p. 591 sqq. - Wälırend sonst der Urachus rom Blasengrunde ausgeht, wurzelt er, naeh $R$ udolphi, Abhandl. der Aead. der Wissenseh. zu Berlin. 1828. S. 41., bei Myrneeophaga und dem Faulthiere in der Nähe des Blasenhalses. S. 'Tab. IV. Fig. 2.

8) Namentlich bei den Gattungen Lepus und Lagostomus, z. B. den Kaninclien, über die Nitte der Harnblase hinauf; ähnlieh naeh Pallas (Glires) bei L. alpinus (p. 57.), L. ogotona (p. 67.); bei Lepus pusillus sollen sie gar in deu Fundus der Blase münden (p. 43. Abb. Tab. IV. Fig. 9.).

9) Abb. bei Meckel, Ornithorh. Tab. VIII. Fig. 1-3.; 0 wen, Monotreu. Fig. 190. 191.

10) Bei Wiederküuern, Einhufern, Schweinen. S. darüber L. Jacobson, Die $0 \mathrm{ken}$ 'sehen Körper oder die Primordialnieren. Kíopenb. 1830. 4. S. $17 \mathrm{ff}$. Rathke in Meckel's Arehiv 1832. S. 380. Gurlt, Vergl. Anat. Thl. 2. S. 115. 


\section{Zehnter Abschnitt.}

\section{Vou den Geschlechtstheilen.}

\section{Vou den weiblichen Geschlechtstheilen.}

§. 207.

Die Eierstöcke odcr Ovarien sind bei allen Säugethicren pararig und in der Regel auch symmetrisch; nur die Monotremen schliessen sich durch Asymmetrie derselben eng an dic Vögel; ihr rechtes Ovarium ist nämlich klein und fast verkiimmert, während das linke völlig entwickelt ist 1 ). - Die Grundlage der Ovaricn bildet ein gefässrciches, ziemlich dichtes, aus Zellgewebsbündeln bestehendes Keimlager (Stroma), in welchem die Graaf'schen Follikel eingebettet sind. Die einzelnen, in demselben Eierstocke enthaltenen Follikel besitzen einen sehr ungleichen Umfang; die grössten und entwickeltsten liegen am oberflächlichsten und ragen an der Aussenfläche des Eierstockes mehr oder minder vor, wodurch dieser böckerig wird; scltener erhält, bci geringerer Menge des Stroma und stärkerem Vorragen der Follikel, der Eierstock selbst ein traubenförmiges Aussehen ${ }^{2}$ ).

Den cigentlichen Ueberzug der in ihrer Gcsammtform manche Verschiedenheiten darbietenden ${ }^{3}$ ) Eierstöcke bildet die feste, weisse, fibröse Tunica albuginea, mit der der äusserc, von dem breiten Mutterbande ausgehende, Pcritonealibberzug eng verbunden ist. Bei vielen Säugethieren steht der Eierstock in einer innigeren Verbindung mit dem Eileiter, als dies beim Menschen der Fall ist. Bei Einigen liegt er in dem erweiterten Orificium ouricum seiner Tuba 4). Bei Anderen wird der Eierstock von einer, durch eine Bauchfollsduplicatur gebildeten, nach der Bauchhöhle hin bald unvollkommen ${ }^{5}$ ), bald vollkommen geschlos-

1) S. d. Abb. bei 0 we n, Monotremata p. 393. Fig. 191. Vergl. auch 0 wen in den Pliilosoph. Transactions 1832.

2) Z. B. beim Schnabelthiere, bei viclen Nagern und unter den Beutelthicren besonders bei Phascolonys. S. d. Abb. des letzteren bei 0 wen, Marsupialia p. 313. Fig. 137.

3) Bei den ächten Cetaceen sind sie eiförınig; länglich rund bei den Ein. hufern; mehr platt bei den Wiederkäuern; bei einigen Nagerı und deu Maul. wurfe zerfallen sie durch cine Einsclinürung in zwei IIälften, worlurch eiue gewisse Aehmlichkeit des Eierstockes mit Hoden und Nebenhoden zu Wege gebracht wird. Vergl. die Abb. bei Treviranus, Bcobachtungen aus der Zootomie und Physiologic. Brellen 1839. 4. Tab. XIX. Fig. 113.

4) Z. B. beim Kängurul. S. l. Abb. h. Ovve n, Marsupialia 1. 314. Fig. 138.; ähnlich ist das Verhalten bei cinigen Nagerı.

5) Unvollkommen ist die Scluliessung der Peritonealtasche z. B. bei den Chiropteren, bei vielen Ferae, wie bei Canis, Felis; bei den Monotremen; voll- 
senen scrüsen Tasche oder Capsel umgeben, welche der Seheidenhaut des Hodens entspricht und in welche die Tuba mündet. Bei einigen Raubthieren ${ }^{6}$ ) erstrecken sich die Tuben kreisförmig um die Peritonealcapsel des Eierstockes herum und münden dann erst in dieselbe ein. Beim Wombat umschlicsst dieselbe die mit sehr zahlreichen Fimbrien, Falten, Wärzchen beselzten und zugleich sehr erweiterten Orificiu oarica der Tuben 7 ).

Jeder von einer doppelten Hülle umschlossene Graaf'sche Follikel enthält eine ciweissartige Flüssigkeit, worin Körnchen suspendirt sind. Diese stellen an der Innenwand des Follikels, wo sie dicht an einander gedrängt liegen, einc körnige Haut (Membrana granulosa) dar. Eingebettet in einer von dieser Membrana granulosa gcbildeten, verdickten, ringförmigen Scheibe (Discus proligerus) liegl an der Wand des Graaf'schen Follikels das kugelrunde, immer sehr kleine Ovulum. Es wird zunächst umhüllt von einer durchsichtigen, verhältnissmässig dicken Membran, der Zona pelluciela. Auf sie folgt die glcichfalls durchsichtige Dotterhaut, welche die zähe, dickfluissige, körnige Dottermasse umschliẹst. An der Wand der Dotterhaut liegt in der Höhle des Orulum das Keimbläschen mit seinem Keimfleck.

\section{§. 208.}

Die Bildungsverhältnisse der Theilc, welche die Ovula aus den Ovarien aufnehmen, sie Behufs ihrer Entwickelung beherbergen und später ausführen: also im Allgemeincn der Eileiter, des Fruchthälters und der Seheide, zeigen die grösste Mannichfaltigkeil. Bei den Monotremen, den Beutelthieren, den meisten Nagern und einigen Edentaten sind zwei Eileiter (Fallopi'sche Röhren) und zwci als deren Fortsetzungen erscheinende, getrennt in den Canalis urogenitalis oder in die Scheide ausmündende Fruchthälter (Uteri) vorhanden.

Bei den Monotremen 1) bildet das Orificium oaricum jedes Eileiters eine weite Tasche, welche, der Fimbrien crmangelnd, in dis Peritonealtaschc seines Eierstockes sich öffnet. Jeder der beiden Eileiter, von denen der rechte, dem abortiven Ovarium entspreehende, durch grössere Kürze vor dem linken, ausgcbildeten sich auszeichnct, vcrliuft, als mässig enger Canal, schwach gekrümmt, abwärts und bildet bald eine längliche, durch etwas beträchtlichere Dicke der Muskelhaut und Sehleimhaut, so wie durch abweichende Texturvcrhältnisse der letzteren charakterisirte Erweiterung (Uterus), welche, etwas verengt, init eincr

ständig ist sie z. B. bei Phoca, Lutra, Mustela. Viverra, Rhyzaena, Ursus u. A. Vergl. über diesen Gegenstand: Treviranus in Tiedemann's und Treviranus's Zeitschrift für Physiologie Bd. 1. 1825. S. 180.

6) So bei Viverra, Khyzaena, Lutra, Mustela putorius. Vergl. E. H. W eber in Meckel's Archiv für Anat. u. Physiol. 1826. S. 105. Mit Abb. Tab. Jll.

7) S. die Abb. bei 0 we n, Marsupialia p. 313. Fig. 137.

1) S. die Abb. bei 0 wen, Munotremata p. 393. Fig. 191. 
vorragenden Papille (Os uteri, s. Os tincre) in den Caurlis urogenilalis iiber oder vor dem IIarnleiter seiner Seite ausmündet. Zwwisehen den Miindungsstellen der beiden IIarnleiter öffnet sieh die IIarnblase. Der Canalis urogenilalis selbst geht mit einer verengten Oeffnung iiber in den gemeinsamen Yorhof (Vestibulum) der Cloake, in welehen auch das Rectum mündet.

Den Beutelthieren hat man lange einen Cterus anfractuosus vindicirt, bis sorgfältige Untersuchungen der neuesten Zeit 2) zu einer richtigeren Deutung ihrer Sexualorgane geführt haben. Jeder der beiden Eileiter beginnt mit einem beträehtlich weiten Orificium oaricum, das meist sehr zahlreiehe Fimbrien, Falten und Papillen trägt und bildet hierauf einen engen, gewundenen Canal, der später zu einem dickhäutigeren, von Falten-bildender Sehleimhaut ausgekleideten Uterus sich erweitert. Jeder dieser beiden Uteri muindet mit einer Vorragung (Os uteri) in die Höhle einer der beiden Vaginae. - Diese Vaginae zeigen aber in der Ordnung der Beutelthiere sehr eigenthuimliehe Bildungsverhältnisse. Bei den meisten, dieser Ordnung angehörigen, Thieren bilden nämlich die beiden Vaginac einen äusserlieh gemeinsehaftlichen, inwendig jedoch durch ein Septum vollständig oder unvollständig in zwei Seitenhälften getheilten Saek, der gerade zum Canalis urogenitalis absteigt, mit ihm jedoch an seinem Ende in keiner offenen Communieation steht, sondern blind endet. Yon dem oberen oder vorderen Theile, also dem Anfange dieses Seheiden-Blindsaekes geht jederseits ein Seheidencanal aus, der henkelartig seitwärts von ihm liegend, zuerst aufwärts und dann abwärts sieh erstreckt, um endlieh seitlich in den Caualis urogenitalis cinzumünden. Nur sehr selten bleibt die Bildung eines mittleren Scheiden-Blindsackes aus, wie dies z. B. bei Didelphis dorsigera der Fall ist ${ }^{3}$ ). Jede der beiden Vaginae bildet hier, zwcimal auf - und absteigend, Windungen, bis sie, dieht neben einander, in den Camalis urogenitalis muinden. Die äussere Apertur des letzteren fällt mehr oder minder vollständig mit derjenigen des Afters zusammen, wodureh wieder eine Cloakenbildung zu Stande kömmt.

Bei den meisten Nagern ${ }^{4}$ ) und bei Orycteropus ${ }^{5}$ ) unter den Edentaten führt jeder der beiden, am Orificium oaricum gewöhnlieh, doch

2) Besonders von 0 wen und Vrolik. S. die Abhandlung des Ersteren in den Philosophical Transactions 1843. und dessen Artikel Marsupialia bei Todd, Cyclopaedia p. 314 s 1 . mit den entsprechenden Abbildungen p. 138 u. 139; so wie endlich Vrolik in van der Hoeven's Tijlschrift 1837. Die Richtigkeit dieser Deutung wird in Zweifel gezogen von Miiller, Archiv 1835. p. 43.

3) S. die Abb. bei 0 wen l. e. Achnlich verhält sich, nach 0 we n, Hypsipryunnus Whitei.

4) Dahin gehören z. B. die Gattungen Lepus, Sciurus, Aretomys, Spalax, Bathyergus, Echimys, Hydrochoerus u. A.

5) Naeh Rapp und Jaeger. Vergl. Rapp's Edentaten S. 64. 
nicht bestïndig, mit Fimbrien besetzten, oft stark gewundenen Eileiter in einen langen darmförmigen Uterus. An ihrem Ende liegen beide Fruchthälter dicht neben einander und inünden mit zwei getrennten Ostia in dic durch ihre Länge ausgezeichnete Scheide. Schaam- und Afteröffnung münden hier noch so dicht neljen einander, dass sie fast zusammenfallen.

Bei anderen Gattungen der Nager ${ }^{6}$ ) bleibt der bei weitem grösste Theil des Uterus zwar getheilt, aber es erscheint durch Vereinigung der beiden Fruchthälter an ihrem äussersten Ende schon ein sehr kleiner, einfach ausmündender Gebärmulterkörper.

Der Körper des Uterus gewinnt an Umfang bei den ubbrigen Ordnungen. Bei den meisten derselben, namentlich bei den Raubthieren ") und Insectivoren, so wie bei allen Cetaceen, den Pachydermen, Einhufern und Wiederkäuern bleibt die ursprüngliche Duplicitait des Fruchthalters scharf ausgeprägt. Der einfache Körper des Uterus besitzł nämlich noch zwei von seinem Grunde ausgehende, in der Regel lange IIörner, in welche die Eileiter meist ziemlich scharf abgegrenzt, seltener ohne deutliche Grenze, übergehen. Diese IIörner erhalten sich, obschon ron geringerer Ausdehnung, noch bei den meisteh Chiropteren ${ }^{8}$ ) und unter den Quadrumanen bei den IIalbaffen.

Bei Mangel der Hörner erscheint der Fruchtbälter endlich einfach bei den meisten Edentaten, den eigentlichen Affen ${ }^{9}$ ) und dem Menschen. Aber bei einigen Edentaten ${ }^{10}$ ) wird die ursprüngliche Duplicität des Fruchthälters durch eine Verdoppelung seiner Ausmündung, also durch einen doppelten Muttermund angedeutet. - Von dem menschlichen Fruchthälter unterscheidet sich auch der der zuletzt namhaft gemachten Säugethiere durch seine gestrecktere Form und durch beträchtlichere Diinne seiner Wandungen. Am einfachsten, am rundlichsten, am dickwandigsten ist der menschliche Uterus.

Die Scheide (Vagina) ist bei den meisten Säugethieren von ziemlich betrïchtlicher Länge. Sie ist bald runzelig, wie z. B. bei den Delphinen, bald glatt und drüsenreich, wie z. B. bei den Wiederkäuern.

6) Z. B. bei Mus, Cavia, Coclogenys, Dasyprocta u. A. Abb. des Uterus ron Mus decumanus s. bei Carus und 0 tto Tab. VIII. Fig. 8., wo jedoch dic Anwesenheit eines einfachen Gebärmutterkörpers nicht angegeben ist.

7) Abb. der weiblichen Geschlechtstheile von Phoca siche in den Nor. Act. Acad. Caes. Lcop. Carol. Vol. XV. P. II. Tab. LXXVII. Fig. 5. - Von Felis Leo bei Carus und 0 tto l. c. Tab. VIII. Fig. 7.; von Cercoleptes ibid. Tab. VIII. Fig. 6.

8) Vergl, über diese Emmert in Meckel's Archiv f. Physiol. Bd. 4. S. 4.

9) Abb. von Mycetes s. bei Carus und 0 t to Tab. VIII. Fig. 8.

10) So bei Bradypus trilactylus und cuculliger (vergl. Baer in Meckel's deutsch. Archiv Bd. 8. S. 366.) und bei Mlyrmecophaga. Baer (in Mïller's Archiv 1836. S. 384.) fand dies Verhalten bei M. didactyla, Rapl (Edentaten S. 74.) bei allen drei Arten von Myrmecophaga. 
Von der oft verlingerten Vulva (Canalis arethro-sexurtis) wird sic hiiufig durch rine kreisförınige Einschnirung, oder, vor der ersten Bogattung, durch rine wirkliche Scheidenklappe (Iymen), die nur vine enge, bald cinfaclie, bald durch ein sclimales Septum verdoppelte Oeffnung ïbrig liisst, unvollkommen alogegrenzt. Die Schaam miindet - mit den schon namhaft gemachten Ausnahmen - durch ein schmaIeres oder breiteres Perinaeum getrennt rom After und wird ron kaum erhobenen Riindern, oder von einfachen Wuilsten, welche den grossen Schammlippen des Monschen entsprechen, begrenzt.

§. 209.

Die Befestigung der Eileiter und Fruchthailter geschieht bei allen Säugethieren durch Bauchfellfalten, welche denjenigen des menschlichen Körpers entspreehen. Die breiten Mutterbänder umschliessen immer zugleieh die Eileiter. Zwischen ihren Platten erscheinen, namentlich zur Zeit der Schwangerschaft, deutlich entwickelte, aber der Querslirifon crmangelnde Muskelfasern 1). Auch die sogenannten runden Mutterbänder, welche deutlich muskulös sind, erstreeken sieh bestïndig in die Gegend des Bauchringes. Ausser ihnen kommen häufig noch Ligamenta teretia auteriora vor, welche, gleichfalls deutlich muskulös, von den Enden der Hörner des Uterus ausgehen und, rom Bauehfelle bedeckt, aufwärts sich erstrecken. Sie verlieren sich bald im Bauchfelle, hald heften sic sieh an die Rippen, bald crreiehen sic das Zwerchfell 2). - Sowol die Tuben, als die Fruchthälter besitzen mehre Schich ten von Muskelfasern und inwendig einen Schleimhautiberzug, dem ein Flimmerepithelium zukömmt. Die Schwingungen der Cilien haben die Riehtung von innen nach aussen. IIäufig, und vielleicht bestiindig, kommen der Sehleimhaut des Uterus absondernde Follikel zu. Unter ihnen haben die Glaudulae utriculares ${ }^{3}$ ), wegen ihrer Beziehungen

1) S. darüber Pappenheim in Mïller's Archiv 1840. S. 346. Mit Abb. Tab. IX. I. X.

2) Sie wurden von Stenson beim Igel entdeckt, später von Rudolphi bei der Hyäne und dem Bären gefunden ml von Nitzsch bei Ferae und Nagern sehr allgemein angetroffen. S. Nitzsch in Meckel's deutsch. Archiv f. Physiol. Bd. 2. S. $590 \mathrm{ff}$.

3) Auf diese, schon Malpighi und Baer bekannten, Drïsen hat besonders E. H. Weber in seiner vierten Ausgabe von Hildebrandt's Handhuch der Anat. des Menschen. Braunschw. 1832. Bil. 4. S. 505. aufinerksam gemacht und hat sie namentlich von der Kuh, dem Rehe und dem Kaninchen beschrieben. Sie sind anch unter Jen Cetaceen bei den Delphinen, unter den Pachydermen bei den Schweinen, unter den Raubthieren bei Hunden und Katzen, so wie auch endlich von E. H. Weber und Sharpey beim Menschen beobachtet worden. In die Deffnung einer jelen solchen Drüse, welche wälırend der Träichtigkeit eine be. deutende Entwickelung erfährt, senkt sich, wie als Beobachtnngen ron Weber, Reid, Sharpey, Reichert, von mir und Anderen hervorgeht, eine Zotte des Chorion hinein. - Eine genane Beschreibung dieser Glandulae utriculnres ans dem Uterus der Kuls gibt A. Burckhardt in seinen Observationes amatomicae 
zur Erniihrung des Fötus, am meisten die Aufrnerksankeit der Physiologen gefesselt. - Die gleichfalls oft driisenreiche Schleinhaut der Vagina ist, gleich der der Schaam, nur von Pflaster-Epithelium bekleidet.

\section{§. 210.}

Dic immer vorhandene, oft mit eincm eigenen $\boldsymbol{M}$ husc. erector versehene Clitoris, zeigt eine grosse Mannichfaltigkeit der Bildungen. Sie

de uteri vaccini fabrica. Basil. 1824. 4. p. 13. mit einer vortreflichen Abb. Tab. I. - Rücksichtlich der Bildungsverhältnisse der Placenta herrschen unter den Säıgethieren die grössten Verschiedenheiten. Man vergl, über diesen Gegenstand insbesondere: C. E. v. Baer, Untersucliungen über die Gefässverbindung zwischen Nutter und Frucht in den Säugethieren. Leipzig 1828. Fol. Baer, Ueber Entwickelungsgeschichte der Thiere. Thl. 2. Königsberg 1837. 4. S. 201 ff. Eschricht, De organis, quae respirationi et nutritioni foctus mammalium inserrimnt. Hafniae 1837. 4. und Müller's Handbuch der Physiologie des Menschen. Thl. 2. Coblenz 1840. S. 725 ff. -- Durch die Untersuchungen von 0 w en (s. Proceedings of the zool. society of London 1833.; Philosoph. Transact. 1834. und Narsupialia (bei Todd) p. 323 sqq.) über die Beutelthiere ist es erwiesen, dass bei ihnen kein Mutterkuchen sich bildet. 0 wen fand beim Kï̈nguruh kein gefässreiches, mit Zotten versehenes Cborion; das letztere war vieluehr glatt, anffallend dünn und zeigte, selbst bei mikroskopischer Untersuclung, keine Spur von Gefässen. Das Nabelbläschen fand el beträchtlich und durch die Vasa omphalo-mesaraica sehr gefässreich. Die Allantois, an welcher die Vasa umliticalia sich ausbreiten, bleibt klein, hangt frei rom Nabel herab und geht nirgend, weder selbst, noch durch ihre Gefässe, eine Verbindung mit dem Chorion ein. 0 wen stelit es als wahrscheinlich hin, dass bei den Monotremen das gleiclie Verhalten Statt findet. Bei allen übrigen Säugethieren kömmt dagegen die Bildung einer Placenta zu Stande. 0 wen theilt also die Säugethiere in Implacentalia und Placentalia. Die wesentlichsten Verschiedenheiten, welche der Mutterkuchen bei dieser letzteren Gruppe darbietet, sind folgende: 1) Die ganze Oberfläche des Cliorion ist gleichuässig mit gefässreichen Zotten besetzt (Placenta diffusa). Eine solche besitzen die Cetaceen, die Pachyderinen, die Einhufer, und unter den Wiederkäuern die Cantele und Lama's. 2) Die gefässreichen Zotten rücken an einzelnen Stellen dicht zusammen und bilden die sogenamnten Cotyledones (Placentae colyliformes). Diese Cotyledonen werden meist durch grössere zottenlose und gefảssarule Zwischenräume von einander getrennt, wie bei deı meisten Wiederkäuerı (mit Einschluss der Gattungen Alces nach $R$ athke in Meckel's Archiv 1832. S. 389. und Camelopardalis nach 0 we $n$ in den Transact. of the zool. society of London Vol. 3. Tab. II. Fig. 1-3.). Seltener sind die Cotyledonen dicht an einander gedrängt, während der grösste Theil des Chorion gefässlos ist. (S. die Abb. der Placenta ron Bradypus tridactylus bei Carus, Erläuterungstafeln $\mathrm{Hft} .3$. Tab. IX. Fig. XV.) 3) Die gefässreichen Zotten erscheinen dicht zusammengedrängt zu zwei Nassen oder zu einer einzigen (Placenta discreta). Hierher gehören die Ferae, welche (nit Einschluss von Phoca, Lutra) eine gürtelförnige Placenta besitzen, die Nager mit zwei oder einer rundlichen Placenta, die eine rundliche Placenta besitzenden Insectivoren, die mit eiförmiger Placenta versehenen Chiropteren und die Quadruınanen. (Abb. der einfachen Placenta von Hapale und Mycetes s. bei Rudolphi in den Abhandl. der phys. Classe der Acad. der Wissensch. zu Berlin. 1828. Tab. 2. u. 3.) 
enthält gewölnnlich zwei seitliche Corpora crvernosn, so wie atueh oft ein molir oder minder rudimentïres Corpus cavernosum urethrae. Mristens hesitzt sie eine deutliche Eichel und eine Vorhant (Proeputium clitorillis), in welche oft drisige Gebilde münden. Bei vielen, doch anscheinend lange nicht bei allen, Säugethieren, deren Penis einen Knochen besitzt, kömınt aueh der Clitoris ein kleinerer Knochen oder Knorpel zu. In der Regel wird sie von der Ilarnrölıre nicht durchbohıt; nur bei den Maki's und Lori's ist dies, den bisherigen Beobachtungen zufolge, der Fall. Häufig aber loesitzt sie an ihrer unteren Fläche eine tiefe Furche, in weleher der Harn abfliesst. Bei den Monotremen ist die an der Grenze des Canalis urogenitalis und der Cloake gelegene Clitoris in der Mitte ihres Endes eingekerbt und entsprieht dadurch in ihrer Form einigermaassen derjenigen des Penis. Bei den Beutelthieren liegt sie in der Nähe der Mündung des Caunlis urogenilalis; bei denjenigen Gattungen, welche eine cinfache männliche Ruthe besitzen, ist sie einfach; bei denen mit gespaltener Cluns penis gleiehfalls gespalten. Bei den Affen, besonders den amerikanischen, zeichnet sich die Clitoris durch ihre Grösse aus; namentlich ist dies bei der Gattung Ateles der Fall, wo sie aber rieht erectil ist, indem im Inneren der Corpora cavernosa blos Fett angetroffen ward 1 ). §. 211.

Die a eeessorischen Drüsen sind beim weiblichen Gesehleehte spärlicher, als beim männlichen. Die den Cowper'schen Druisen entspreehenden parrigen Duvernoy'sehen Drisen liegen bei den Wiederkäuern jederseits am Seheideneingange und münden jede mit einem ziemlich weiten Ausführungsgange an der Innenfläche der Scheide. Entsprechende Driisen, die aber mehre Ausführungsgänge besitzen, sind bei einigen Edentaten angetroffen worden.

\section{\$. 212.}

Milehdrusen (Mrmmae) kommen allen Säugethieren ohne Ausnahme zu; deutlich entwickelt und zur anatomischen Untersuchung geeignet sind sie aber gewöhnlich nur um die Zeit des Werfens und der Lactation. Die wesentlichsten Verschiedenheiten, welehe sie darbieten, betreffen ihre Lage, die Ab-oder Anwesenheit von Warzen, die Zall der letzteren, die Anzahl der Gänge, von welchen sie durchbohrt werden, so wie endlich den feineren Bau der Drüsen selbst. Bei den Quadrumanen, den Chiropteren, den Faulthieren, den Sirenen, den Elephanten liegen und muinden sie am Thorax; bei vielen anderen Säugethieren theils am 'Thorax, theils in der Bauchgegend; bei anderen nur an Bauehe, oder hier und in der Sehaamgegend, welehe letztere Stelle

1) S. die Abb. bei $F u g g e r$, de singulari clitoridis in simiis generis Atelis magnitudine. Berol. 1835. A. C. Tab. Vergl. über diesen Gegenstand auch die Bemerkungen von Le u ckart in seinen Zoologischen Bruchstücken Hft. 2. S. 3 - ff. 
sie bei manchen ausschliesslich einnehmen 1). Bei vielen Sängethieren können sie durch den sie bedeckenden Hautınuskel comprimirt werden 2). - Die Zitzen fehlen nur den Monotremen, wo die zalılreichen Ausführungsgiinge auf einer kaum iiber die Oberfläche der umgebenden Ilaut sich crhobenden Areola münden ${ }^{3}$. Dic Zahl der Zitzen bei den iibrigen Säugethieren unterliegt sehr grossen Verschiedenheiten; cs sind wenigstens zwei, höchstens 13 vorhanden 4). Bei den ächten Cetaccen liegt jede der beiden Warzen in einer länglichen Verticfung neben der Schaamspalte. Bei den Bcutelthieren liegen sie, oft kreisförmig gestellt, im Beutel. Dieser selbst ist durch einc Duplicatur der :iussercn Hant, deren Falten von Hautmuskcln unterstützt werden, gebildet; er ist inwendig fast glatt und vermöge des Secretes zahlreicher . Follikel schluipfrig ${ }^{5}$ ). In kciner anderen Säugethierordnung kommen verhiiltnissmässig so lange Warzen vor, als unter den Beutelthicren, wo sie zugleich am Ende kolbig zu sein pflegen. Jede Brustwarze 6) wird bei den ächten Cetaccen, den Wiederkäuern und den Schweinen von einem einzigen Ausführungsgange durchbohrt, zwei finden sich in jeder Warze der Einhufer, fünf bis sechs bei cinigen Nagern und Raubthieren; noch grösser ist dic Zahl bei den Sirenen, den Elephanten, den Beutelthieren, den Hunden und Affen. - Rücksichtlich des Baues der Brustdrüsen sind bei den Sängethieren verschiedene Typen beob.

1) S. in Betreff der Lage der Brustwarzen die Tabelle bei Cuvier l. c. S. $551 \mathrm{ff}$, die allerdings einiger Modificationen bedarf.

2) So namentlich bei den Cetaceen, bei den Monotremen und bei den Beutelthieren, bei welcher letztern Ordnung der sie comprinirende Muskel dem Cremaster der inännlichen Thicre analog sich verhält.

3) Vergl. Meckel, Ornithorh. p. 54. 0 wen in den Philosoph. T'ransact. 1832. p. 537. Tab. XVII. Fig. 2. u. 3. 0 wen, Monotremata p. 404. Fig. 200. 0 wen hat jeden Zweifel darüber, dass die Milclıgänge hier münden, beseitigt. Bennett (bei 0 wen p. 405. und in den Transactions of the zoological society of Loudon Vol. 1. p. 254.) sah Milch hervortreten. - Interessant ist es, dass, wie Morgan (Transact. of the Linnean society Vol. XVI. p. 455.) und 0 wen gezeigt liaben, beim jungen Kängurul die Brustwarzen eingezogen und Statt derselben nur kleine Oeffnungen vorhanden siud.

4) Auch über die Zahlenverhältnisse der Warzen s. Cuvier's Tabelle I. c. S. 551., deren Angaben indessen nicht immer genau sind. Zwei Warzen besitzen die meisten Quadrumanen, die Chiropteren, die Faulthiere, die Einbufer, urehre Pachydermen, die Sirenen; Schaaf und Ziege haben hinter ihren beiden vollkommenen Zitzen noch zwei kleine. Allch Galaeopithecus hat nicht 2, sondern 4. Die grösste Anzahl von Warzen besitzen Thiere aus den Ordnungen der Insectivoren, Nager und Beutelthiere. S. über die der Edentaten Rapp 1. c. S. 76.; ïber die der Bentelthiere 0 wen, Marsupialia p. 327.

5) Ueben den Bau des Beutels rergl. Cuvier 1. c. S. 550. und 0 wen, Marsupialia p. 327. Abb. s. bei Carus und 0 tto, Erläuterungstafeln Ilft. V. Tab. VIII. Fig. 3. 4.

6) Vergl. lierüber besonders R I dolphi l. c. Bei den Bentelthieren finden sich nach 0 wen $6-10$ Oefinungen in jeder Warze. 
achtet worden. Sie bestehen entweder aus blinden Rühren, welche inwendig wieder einen zelligen Bau zeigen, wie bei den Monotremen ${ }^{\top}$ ), oder aus baumförmig verzweigten Blinddïrmen, wie bei den ächten Cetaceen ${ }^{8}$ ), oder erscheinen gelappt und bestehen aus verzweigten, am Ende in Bläschen iibergehenden Canälen, wie bei den iibrigen Sïugethieren 9). Bei denjenigen Säugethieren, deren Brustwarze von einem einzigen Ausführungsgange durchbohrt wird, wie bei den ächten Cetaceen, den Wiederkäuern und Schweinen, öffnen sich alle grösseren Milchgänge in cine gemeinsame, oft sehr weite Höhle (Simus mammae); bei den Einhufern in zwei getrennte Sinus; bei den übrigen Säugethieren bilden sich blos mehr oder minder zahlreiche Stämme.

[S. über die Brustdrüsen: Cuvier, Vorlesungen über vergl. Anat, ïbers. $\nabla$. Meckel. Thl. 4. S. 549. - Mïller, De glandular secern. structur. p. $48 \mathrm{sq \%}$. Gurlt, Vergl. Anatomie der Haussäugethicre Thl. 2. S. 123. - Rudolphi, Bemerkungen über den Bau der Brüste in den Albandll. der physik. Classe der Acad. der Wissensel. zu Berlin. A. d. Jahre 1831. S. 337. Mit Abb. Tab. 1. 11. 2.]

\section{Von den männlichen Geschlechtstheilen.}

\section{§. 213.}

Die hinsichtlich ihrer Gestalt etwas variirenden, meist ovalen, aber auch bisweilen sehr länglichen ${ }^{\text {) }}$ oder mehr rundlichen 2) Hoden besitzen eine sie umhüllende Tunica albuginea und liegen in einer Bauchfellstasche (der Tunica vaginalis propria). Ruicksichtlich ihrer Lage bieten sie beträchtliche Verschiedenheiten dar. Bei vielen Säugethieren liegen sie perennirend innerhalb der Bauchhöhle, vor den Nieren oder unterhalb derselben. Dies ist der Fall bei den Monotremen ${ }^{3}$ ), vielen Edentaten 4), allen Cetaceen $\left.{ }^{5}\right)$, den Sirenen und manchen Pachydermen ${ }^{6}$ ). Bei anderen liegen sie in der Leistengegend unter der Haut ${ }^{7}$ ), jedoch

7) S. die Abb. bei Meckel, Ornithorh. Tab. VIII. Fig. 5.; bei Müller Tab. IV. Fig. 9. und besonders bei 0 we n, Philosopb. Transact. 1832. und Monotremata p. 404.

8) S. Baer in Meckel's Arehiv 1827. S. 569.; Rapp ebendas. 1830. S. 35 S ff. Abb. bei Mïller Tab. XVII. Fig. 1. 2.

9) Abb. bei Mülle r, Gland. secern. 'Tab. IV. Fig. 2.

1) Z. B. bei den Delphinen.

2) Z. B. bein Kängurul; nach $\mathrm{Cuvier}$ auch beim Elephauten, bei einigen Raubthieren (Procyon, Meles) u. s. w.

3) $\Lambda$ bb. bei M eckel, Ornithorh. Tab. VIII. Fig. 2.

4) Namentlich bei Brarlypus, Myrunecophaga, Dasypus.

5) Alb. voun Delphin s. bei Carus und 0 tto Hft. 5. Tab. IX. Fig. 1.

6) Z. B. beim Elephanten (s. Ca nper, Deseription 1. 35. Abl. Talb. IV. Fig. 1.); beiu Rlinoceros, bei Hyrax.

7) Z. B. bei vielen Nagern (Castor, Myopotamus u. A.); unter den Wiederkäuern beim Launa und Caunel; bei einigen Pachydermen; manchen Ferae (Vi. verra, Lutra, Plioca II. A.). 
nicht in einem herabhangenden Hodensacke, der dagegen vielen Säuge(hieren zukömmt ${ }^{8}$ ) und bald cin Scptum besitzt, bald cincs solchen ermangelt. Bei den mcisten Säugethieren bleibt der Scheidencinal bestiindig offen, womit es denn zusammenhangt, dass ihre IIoden, an deren Scheidenhaut der Musculus cremuster sich ausbreitet, zur Brunstzeit gewölınlich in die Bauchhöhle schlïpfen und darum bei der gleichen Species zu verschicdenen Zeiten in verschiedenen Lagenverhällnissen angetroffen werden $9 \%$ - Die absondernden Theile der Hoden: die Saamencanälchen, bietcn rücksichtlich ihrer Wcite und ihrer Anordnung kleine Verschiedenheitcn dar, welche im Ganzen noch wenig genau erforscht sind. - Der Nebenhode licgt meist dicht am Iloden, selten frcier neben ihm. Die contractilen Ductus deferentes sind bei denjenigen Säugethieren, dercn Hoden perennirend in der Bauchhöhle bleiben, immer sehr stark gewunden. Oft verdicken sich ihre Wändc gegen das Endc ihres Verlaufes, erweitern sich auch bisweilen zugleich 10 ). Bei wenigen Säugethieren findet sich cin hinter der IIarnblase liegender, verschieden gestalteter, in die Urethra fiihrender Schlauch (Utriculus prostaticus), welcher einem rudimentären Uterus um so mehr verglichen werden' kann 11), als bisweilen wirklich die beiden Saamenleiter in seine Iröhle münden.

\section{§. 214.}

Die Ruthe der Säugethiere bietct die mannichfachsten Verschicdenheiten dar. Zuvörderst wechselt ihre Lage. Bei cinigen Familien, na-

8) Z. B. bei den Beutelthieren, dem Haasen, den Wiederkänern, dem Pferile n. A.

9) Dies ist namentlich der Fall bei den Beutelthieren, Nagern, Chiropteren, Insectivoren, den Phoken $11 . A$.

10) Z. B. bei vielen Nagern (Biber, Haase, Hamster, Meerschweinchen); beim Pferde, bei mehren Wiederkänern.

11) Auf dieses Gebilde haben in neuester Zeit besonders E. H. Weber (Amtlicher Bericht von der Versammlung der Naturforscher zu Braunscliweig. Braunschw. 1842. S. 64.) und Huschke (in der neuen Ausgabe von Soemmerring, Vom Baue des menschl. Körpers Bd. 5. Leipzig 1844. S. 409 ) die Aufmerksamkeit der Anatomen gelenkt. Weber hat es vom männlichen Biber, Huschke vom Haasen beschrieben. Schon bei älteren Schriftstellern findet man deutliche Spuren ilurer Kenntniss dieses Theiles. Pallas z. B. (Glires p. 67.) gibt an, dass bei Lepus (Lagomys) Ogotona die beiden Ductus deferenles in eine Rölıre znsammenmünden und bildet dies Verhalten ab Tab. IV. Eine selır sorgfältige Beschreibung des zweihörnigen Utriculns des männlichen Bibers haben Brandt und Ratzeburg (Medicin. Zool. Thl. 1. S. 137.) gegeben. Sie lieferten zugleich eine Abb. Tab. IV. a. Nach Huschke's Angabe (l. c. S. 411.) münden beim Haasen die Saamenleiter $1^{\prime \prime}$ ron einander entfernt und $1 \frac{1}{2}-2^{\prime \prime \prime}$ über dem $0 s$ utriculinum neben einander mit ziemlich grossen Oeffnnngen auf einer Papille in die Vorderwand ein, so dass, wenn man Luft in einen Sammenleiter bläset, diese nicht nur aus dem $O s$ utriculi hervordringt, sondern auch den Utriculus selbst und den entgegengesetzten Saamenleiter füllt. 
mentlieh bei den Monotremen $\left.{ }^{1}\right)$ und Beutelthieren 2) liegt sie in der Cloake und wird von dem Schliessmuskel derselben ungeben; bei vielen Nagern ${ }^{3}$ ) liegt und öfnet sie sich unmittelbar vor dem After; bei den meisten Ordnungen, namentlich den Cetaceen, Sirenen, Pachyderınen, Einlufern, Wiederkaituern, den Ferae und Inseetivoren erstreekt sie sich von der Schalambeinfuge an unter der Mittellinic des Unterleibes, oft gekrümut oder gewunden vorwärts, und öffnet sich hinter dem Nabel; bei andern endlich (den Chiropteren und den Quadrumanen) verkiuft sie lïngs der Schaambeinfuge und hangt frei herab, wie bein Menschen. Sie wird von einer Fortsetzung der äusseren Haut: der Vorhaut (Praeputium), die bald behaart, bald glatt ist, meist scheidenartig, umhiillt. Bei viclen Sätgethieren 4) wird die Vorhaut durch eigene, vom Bauchhautmuskel ausgehende, Muskeln zurückgezogen; ausserden sind zwei Muskeln bestimmt; sie nach vorn zu ziehen. Verschiedene drüsige Gebilde (den Tyśon'sehen Drüsen entsprechend) münden in diese Scheide 5). - Gestalt und Länge der Ruthe zeigen beträchtliche Abweichungen und namentlich bietet die Eichel die mannichfachsten Bildungen dar. Bei Ornithorbynehus ist der Penis kurz und besteht zur IIälfte aus der gespaltenen und mit zahlreichen, kurzen und harten, an Ende aber mit vier längeren und weicheren Stacheln besetzten Eichel 6); bei Eehidna theilt sich die Eichel in vier warzenartige, nit kleinen Papillen besetzte Fortsätze. - Unter den Beutelthieren ') besitzen einige, welehe nur ein einziges Junges zur Welt bringen, wohin namentlich z. B. Maeropus, Halmaturus, Hypsiprymnus gehören, eine einfache Eichel; bei anderen, wic bei Dasyurus und Phaseolarctos, eudet die Eichel zweilappig; bei Phascolomys hat sie an Ende vier unvollkomınene Lappen; bei den meisten Beutelthieren, welche zahIreiche Junge gebären, namentlich bei den Gattungen Didelphis, Perameles, Phalangista, Petaurus, ist die Eichel völlig in zwei Hälften gespalten. Bei mehren Beutelthieren ist sie mit feinen, riickwärts gerichteten Papillen, nur bei Phascolomys dagegen mit bornartigen Stacheln besetzt. - Einfach sind Penis und Eichel bei allen uibrigen Ordnungen

1) Abgeb. bei Meckel, Ornithorh. Tab. VIII. Fig. 2.

2) Abgeb. bei Carus und Otto T'ab. IX. Fig. 6.

3) Z. B. bei Lejus, Dipus, Mus, Castor.

4) Diese Wuskeln kommen, verschiellentich entwickelt, z. B. vor bei Wiederkäuern, Pachydermen, den meisten Ferae. S. Näheres bei Cuvier, Vorlesungen Thl. 4. S. 463. und bei Gurlt Thl 2. S. 104.

5) Vergl. §. 170.

6) Abb. bei Meckel, Ornithorh. Tab. VIIl. Fig. 2.; bei Home, Lectures Vol. IV. Tab. CXXXI. und von Echidna ibil. Tab. CXXXIV.

6) Abb. von Hypsiprymus, Phascolarctos und Phascolomys bei Owen, Marsupialia p. 311. Fig. 135.; von Ditelphis ibid. 1). 312. Fig. 136.; so wie anch bei Carus und 0 tto Tab. IX. Fig. 6. und Treviranus, Beitrïge Tab. XIV. und $\mathrm{XV}$. 
der Sïugethiere; aber ihre Gestalt und Bckleidung wechseln ausserordentlich. Bei den Nagern wird die Forn der Eichel gewölnnlich durch die des hicr vorhandenen Ruthenknochens bestimmt, dessen einfaches oder gespaltenes Ende vorn bisweilen zahnartig vorspringt. Die iussere Bekleidung besteht oft in Scluppen, Warzen, Ifaren, zu denen nicht ganz selten noch hornartige Bewaffnungen in Gestalt von Haken oder Sägen, oder kleinc knorpelige Anhänge hinzukommen ${ }^{8}$ ). - Aı̣ch bei den Ferae wird die Gestalt der Eichel im Allgemeinen durch die des Ruthenknoclicns bestimmt. Bei der Gattung Felis ist die Haut der Eichel mit rückwärts gerichteten Stacheln besctzt. - Den Cetacecn 9), Sirenen, Pachydermen, Einhufern und den meisten Wiederkäuern, deren Ruthe lang, bald cylindrisch, bald zugespitzt zu sein pflegt und dercn Eichel selten, wic beim Lama, cigenthümliche, knorpelig-sehnige Fortsälze besitzt, mangeln gewöhnlich die sonst so häufig vorkommenden hornartigen Bewaffnungen der Eichel. - Bei mehren Affen, bcsonders amerikanischen, dcren Ruthe durch ihre Grösse ausgezeichnet ist, nimmt die schcibenartig verbreiterte Eichel einc eigenthümliche Pilzartige Form an $\left.{ }^{10}\right)$. - Das Verhalten der Harnröhre (Uretlira) zum Penis zeigt bei den Monotremen und Beutelthieren einige Eigcnthümlichkeiten. Bei ersteren 11) senken sich die beiden Vasa deferentia und die beiden Harnleitcr in den Anfang des Canalis urogenitalis, welcher durch das Becken sich erstreckt und im Vestibulum der Cloake vor dem Rectum muindet. Die eigentliche Urethra oder der Canal des Penis beginnt mit einer kleinen Oeffnung an seiner Wurzel in der Nähe des Ausganges des Canalis urogenitalis und kann durch die gemeinsame Wirkung des Sphincter cloacae und eincs von der Schwanzwurzel entspringenden $\boldsymbol{M}$. retractor penis dem letzteren genähert werden. Die Urethra verläuft einfach bis zur Mittc der Eichel, um sich dann in zwei Canäle zu spalten, die bald darauf abermals sich theilen, und an der Spitze der Papillen und Warzen mit vicr Oeffnungen ausmünden. - Bei den Beutelthieren 12) treten die Saamenleiter in den Anfang der durch ilıre Länge und Weite ausgezeichneten, gleich nach ilırem Austritte aus der Blase erweiterten Urethra, die durch die

8) Abb. der Eiehel von Dipus und Pteromys bei Carus und Otto Tab. IX. Fig. 3. u. 4.; von einigen Lepus bei Pallas, Nov. spee. Quadrup. e glir. ordin. Tab. IV. B.; von Arctomys und vom Ziesel ibid. 'Tab. IX. Fig. 5. 8. u. 9.; vom Hamster und Biber ibid. 'Tab. XVII. Fig. 1. 2.

9) Abb. bei Carus und 0 tto l. e. Tab. IX. Fig. 1. - Abb. der Eiclel des Lama bei Brandt, Mémoires de l'aead. de Petersbourg. Vol. IV. 1841.

10) So besonders bei der Gatumg Callithrix. - Abb. der Eichel von Stenops tardigradus bei Carus und 0 tto 'T'ab. IX. Fig. VIll.

11) S. besonders Meekel, Ornithorh. 1\% 49 sqq. und D uvernoy, Mémoir. de la soe. d'hist. nat. de Strasbourg. Vol. I.

12) Abb. bei 0 wen, Marsupialia p. 311. Fig. 135.; Treviranus, Beitrïge Tab. XIV. XV. 
Ruthe sieh fortsetzt und, je nach der Besehaffenheit der Eiehel, vorn bald einfach, bald doppelt miindet. - Bei den meisten ${ }^{13}$ ) iibrigen Säugethieren setzt sich die einfnehe, die Samenleiter aufnehmende, IIarnröhre durelı den Penis fort und mündet bald an der Spitze der Eichel, bald vor dem Ende derselben. - Die Corpora cavernosa pe uis sind, mit Ausnahme der Monotremen und der Beutelthiere, mit ihren beiden Wurzeln an den Sitzbeinen befestigt, was aueh bei den Sirenen und Cetaceen, wo diese Knoclıen unter allen Beckenknochen allein vorhanden sind, der Fall ist. Bald sind die beiden Zellkörper 14) dureh ein mittleres Septum vollständig von einander getrennt, bald verschwindet dasselbe friill, oder fehlt. Dureh beträehtliche Dieke seiner fibrösen Hülle ist der Zellkörper der Cetaeeen ausgezeiehnet. Je grösser der Ruthenknochen ist, um so kleiner pflegen bei den mit jenem überhaupt versehenen Säugethieren die Zellkörper zu sein. - Das Corpus ca veruosum urethrae beginnt bei allen Beutelthieren und einigen anderen Säugethieren ${ }^{15}$ ) paarig, so dass ein doppelter Bullus urethrae entsteht; die beiden Körper vereinigen sieh bald, um die Harnröhre zu umgeben; beim Känguruh versehmelzen die beiden Wurzeln des cavernösen Körpers der Harnröhre sehr bald mit denen des Penis, um einen einfaehen eylindrisehen Körper zu bilden, durch dessen Axe die Urethra veriäuft, während bei den iibrigen Siiugethieren der Zellkörper der Harnröhre unter dem der Ruthe gelegen ist. Bei den mit gespaltener Eiehel versehenen Beutelthieren theilt sieh der Zullkörper der Harnröhre für die beiden Iälften derselben. - Viele Säugethiere besitzen in ihrer Ruthe einen eigenen Knoehen, den Ruthenknoehen ( $\boldsymbol{s}$ peris), dessen Grösse und Gestalt manniehfaehe Verseliedenheiten zeigt. Er ist unter den Cetaeeen nur bei Walfischen angetroffen worden ${ }^{16}$ ) und kömmt ferner den Nagern, fast allen Ferae (mit Einschluss der Phoken), den Chiropteren und Quadrumanen zu ${ }^{1 \bar{T}}$ ); beim Menschen

13) Eine Ausnahme bildet, nach R app (Edentaten S. 74.), das Faulthier, indem die Harnröhre an der Wurzel der unten der Länge nach gespaltenen Ruthe sich öffnet.

14) Cuvier fand das Septmu z. B. beim Hunde, beim Rhinoceros, bei einigen Affen; unvollständig bei den Maki's; er vermisste es beim Bären, beinı Dachs, den Wiederkïuern, Einhufern, Cetaceen u.s.w. Es findet sich bei den Sirenen. Bei Dasypus pela sah $\mathrm{R}$ ap 1 6-7 fibröse Längsscheidewände.

15) Z. B. bei der Wisserratte, nach Cuvier.

16) Rapp (Cetaceen S. 172.), der, mit Cuvicr, ganz richtig den Delphinen Ien Penisknochen abspricht, leugnet ihn auch bei den Walen, denen $\mathrm{Cuvier}$ ilı zuschreibt. Bei welchen Balinen er mangelt und welelien er zukoumen soll, finde ich nirgend angegeben. Auch unsere Sammlung hesitzt einen, angeblich •inem Walfische angchörigen Penisknochen, der voru keulenförmig verlickt ist.

17) Abb. der Ruthenknochen mehrer Ferae und Affen bei Carus mil Otto Tab. IX. Fig. 10-13.; von cinigen Nageru Pallas, Glires Tab. XVll, rom Lemuning, wo er vorı in drei Spritzen ausläuft, Pallas ibid, Tab. XXYll. Fig. 17. 
ist bisweilen cin prismatischer Knorpel (Cartilago glaudis) im Mittelpunktc der Eichel angetroffen worden 18). Bei vielen der genannten Säugethiere erstreckt sich der Rutlıenknochen durch den grössten Theil des Penis, bei anderen beschrainkt er sich auf einen kleinen Theil desselben und namentlich auf die Eichel, deren Spitze er oft bildet und der er grossentheils ihre mannichfachen Formen verleihen hilft. - Die Muskcln der Ruthe sind bei den Säugethieren zum Theil zishlreicher, als beim Menschen. Der M. bulbo-caveruosus, welcher selır beständig vorkömmt, zerfällt bei den Beutelthieren und cinigen Nagern, welche einen doppelten Bulbus methroe besitzen, in zwei Seitenmuskeln; diese Duplicität wiederholt sich jedoch auch bei cinigen andern Säugethiercn mit cinfachem Bulbus. - Die M. M. ischio-cavernosi zeigen nicht unbeträchtliche Grösscnverschiedenheiten und bieten bei den Beutelthieren einige Eigenthümlichkeiten dar. - Ausser ihnen findet sich häufig noch ein, meist paariger, gewöhnlich vom Schaambogen entspringender $\boldsymbol{M}$. Levator penis ${ }^{19}$ ), der längs dem Rücken der Ruthe verläuft. Endlich kömmt biswcilcn ein paariger, vom Kreuzbcine entspringender $\boldsymbol{M}$. retractor penis vor ${ }^{20}$ ).

[Ueber die männliehen Gesehleehtstheile der Säugethiere vergl. besonders Cuvier in s. Vorlesungen Thl. 4. der Me ekel'schen Uebersetzung. S. $397 \mathrm{ff}$; über die der Monotremen s. Meckel, Ornithorh. p. 49. Tab. VIII. und 0 wen, Monotremata p. 392.; über die der Beutehthiere 0 wen, Marsıpialia p. 310 sqq.; Treviranus, Beobaeht. aus d. Zoot. U. Physiol. S. 109. (Dilelphis virginiana); über die der Haussäugethiere Gurlt, Vergl Anat. Thl 2. S. 90.; über die der Cetaeeen vergl. Rapp, Cetaceen S. 169.; zahlreiche Abbildıngen gibt Otto in Carus und 0 tto, Erläuterungstafeln Hft. V. Tab. 1X. Gelıngene bildliehe Darstellungen der männliehen Geschleehtstheile des Igels gibt Senbert, Symbolae ad Erinacei europaei anatomen. Bonn 1841. 4. Tab. 11.]

\section{§. 215.}

Beständig kommen bei den Säugethicren accessorische absondernde Gebilde vor, welche theils in Verbindung mit den Ductus deferentes, theils später in die Marnrölıre rinmünden. Die ersteren sind als Saamenblasen (Vesiculae semiuales) zu bezeichnen, während dic übrigen der Prostata und den Cowper'schen Drüsen entsprechen. - Was zucrst die Saamenblasen 1) anbetrifft, welche, wenigstens

18) S. darüber Mayer in Froriep's Notizen 1834. No. 883.

19) Z. B. bei den Pavianen, vielen Nagern (Lepus, Cavia), dem Elephanten, den Beutelthieren nit gespaltener Eichel.

20) Z. B. unter den Beutelthicren beim Känguruh; bei den Sirenen u. A.

1) Man sehe über diese Gebilde besonders C. J. Lampferhoff, De vesieularum seminalium, quas voeant, natura atque usı. Berulini 1835. 8. - Aus Funter's (Works, Palmer's Edition Vol. 1. 1. 20.) und Lampferh off's Untersuchungen ergibt sieh, dass die Saanenblasen der Säugethiere als absondernde Gebilde anzuschen sind. Namentlich sind die mikroskopischen Beobachtungen des letzteren Autors, der fast nie Spernatozoïlen in ihnen antraf, ron Interesse. 
bei der Mehrzahl der Säugethiere, als eigenthümliclıe Secretionsorgane und nicht als Receptocula seminis anzusehen sind, so kommen sie vor hei den Sirenen, den meisten Pachydermen, den Einhufern, den Edentaten, den Nagern, den Insectivoren Ferae, den Chiropteren und Quadrumanen, fehlen dagegen den Monotremen, den Beutelthicren, den ächten Cetaceen und den eigentlichen Ferae (mit Ausschluss der Inseetivoren). Was die Wiederkäucr und cinige Pachydermen anbetrifft a), so hat man ihnen die Saamenblasen bald abgesprochen, bald zugeschrieben, je naclıdem man die beträchtlichen paarigen, ınit einfachen Ausführungsgängen versehenen, mit den Ductus deferentes in die IIarnröhre müindenden, hohlen, gewundenen Blasen von drüsigem Baue für Prostatae hielt, oder nicht. Ihrer Lage und Insertionsstelle nach entsprechen sie mehr den Saamenblasen, als den Vorsteherdrüsen. Rücksichtlich ihres Baues und Umfanges bieten die Saamenblasen grosse Verschiedenheiten dar ${ }^{3}$ ). - Der Prostata analoge drüsige Gebilde scheinen den Monotremen zu fehlen; auch die Wiederkäuer besitzen, ausser den schon erwähnten drüsigen Saamenblasen, keine besondere Vorsteherdrüsen. Bei den Beutelthieren finden sich zahlreiehe Mündungen von Follikeln, welche in der Nähe des Blasenhalses eine dicke Schicht bilden, an der Innenwand des Beckentheiles der langen Urethra. Bei den meisten Säugethieren bilden die, gewöhnlich mit zahlreichen Ostia in die Harnröhre mündenden, Schläuche der Prostata eine einfache Masse, welche, von der Gegend der Einmündungsstelle der Harnleiter aus, im Umkreise der Harnröhre liegt. So bei den Cetaccen, wo sie durch ihren Umfang sich auszeichnet, bei den Einhufern, bei den Edentaten, den mcisten Ferae, den Chiropteren und Quadrumanen. Beim Elephanten, bei den meisten Nigern und einigen Inscctivoren sind zwei oder selbst drei Paar solcher Drüsen von sehr verschiedenartigem Baue vorhanden 4).

2) Gurlt vindicirt ihnen den Namen falscher Saamenblasen (Vergl. Anat. der Haussäugethiere Thl. 2. S. 200.). Cuvier bezeichnet sie, anscheinend besonders deshalb, weil sie hier deutlich als Secretionsorgane sich zu erkennen gebell, als Prostatae und Meckel stimmt ihm bei (Vorles. Bd. 4. S. 440.).

3) Ausnehmend gross sind sie bei den Insectivoren Ferae, z. B. bei Talpa und Erinaceus, wo sie aus gewundenen und verzweigten Blindlärunchen besteben; sehr entwickelt auch bei vielen Nagern, wo sie unverzweigte, aber sebr gewun. dene und lange Blindsäcke darstellen, wie z. B. bei Mus, Cavia, Sciurus; bei anderen, wie beim Kaninchen, bestehen sie in einer einfachen weiten Blase; bei anderen Säugethieren, z. B. Wiellerkäuern, Schweinen u. s. w., sind sie inwendig zellig.

4) Oft bestehen sie aus verzweigten Blinddärmchen, wie beim Maulwurf, wo sie am blinden Ende bald wenig, bald mehr erweitert sind und dadurch keulenförmig oder traubig werden. (S. die Abb. bei Mïller, Gland. secern. Tab. III. Fig 3-5.); bei Erinaceus aus sehr langen, vielfach gewundeuen Röh. ren. (Abb. bei Treviranus, Beobachtungen aus der Zoot. und Physiol. Hft. 1. Tah. XVIII. Fig. 109.) - Zwei Paar solcher Drïsen sind z. B. vorhanden beim Hanster, beim Aguti, beim Meerschweinchen; drei Paar z. R. bei der Ratte. 
- Die Cowper'schen Drüsen, welche nielıt ganz so allgemein vorkommen, wie die Prostata, zeigen in Betreff ihrer Anzahl, ihres Baues ${ }^{5}$ ) und ihres Umfanges nicht geringere Versehiedenheiten. Sie werden vermisst bei den Cetaeeen, bei vielen Ferae (namentlieh bei Phoca, Canis und den meisten Plantigraden), so wie bei einzelnen Gattungen anderer Ordnungen. Beträichtlich, und mit einem langen und weiten Ausfuilırungsgange versehen, sind sie bei den Monotremen ${ }^{6}$ ); in dreifaeher Zahl jederseits vorhanden, und in den Bulbus der Harnröhre mündend, bei den meisten Beutelthieren ${ }^{7}$ ); einfach paarig bei den iibrigen Ordnungen, zugleich aber verhältnissmässig viel umfänglicher, als beim Mensehen. - Der Vorhautdrüsen ist schon fruher (\$. 170.) Erwähnung geschehen.

[Man vergl. über diese Absonderungsapparate besonders Cuvier in seinen Vorlesungen über vergl. Anat. ïbers. v. J. F. Meckel Thl. 4. S. 430 fr. Ihren feineren Bau erläutert Müll er, Gland. secern. p. 46 sqq. Tab. III.]

5) S. darüber Müller l. c. p. 47. mit den entsprechenden Abb. Tab. III.

6) Abb. bei Meckel, Ornithorh. Tab. VIII. Fig. 2. u. 3.

7) Abb. bei 0 wen, Marsupialia p. 311. Fig. 135. unl bei Treviranus 1.c. Tab. XIV. Fig. 97. 98. und Tab. XV. Fig. 99. 100 


\section{Berichtigungen und Zusätze.}

Das Jahr 1845 hat mehre umfänglichc und an wichtigen Ergebnissen reiche Arleeiten über dic Anatomie der Fische gebracht. Ausser der, während des Druckes dieses Lehrbuches erschienenen ausführlichen Selırift von Müller über Branchiostoma (s. S. 3. Anm.), welche auch durch zahlreiche Abbildungen die Anatomie dieses merkwürdigen Thieres zur Ansehauung bringt, sind besonders folgende Sehriften und Abhandlungen nambaft zu machen:

J. Müller, Ueber den Bau und die Grenzen der Ganoïden und uiber das natürliche System der Fische in Erichson's Archiv für Naturgeschichte 1845. S. 91 ff.

J. Müller, Untersuchungen über dic Eingeweide der Fische. Schluss der vergleichenden Anatomic der Myxinoïden. Berlin 1845. 4. Mit 5 Kupfertafeln.

W. Peter's, Ueber einen dem Lepidosiren annectens verwandten Fisch von Quellimanc in Muiller's Archiv 1845. S. 1. Mit Abbildungen. Tab. $1-3$.

J. Ilyrtl, Lepidosiren paradoxa. Monographic. Prag 1845. 4. Mit 5 Kupfertafeln.

S. 17. Ueber den Sehedel von Lepidosiren vergl. Peters a. a. O. Tab. 2. u. 3.

S. 21. Jacobson's Untersuchungen über den Primordialschedel finden sich mitgetheilt in den Förhandlingar vid de skandinaviske Naturforskarnes tredje Möte i Stoekholın d. 13-19. Juli 1842. und ausgezogen von Hannover in Müller's Archiv 1844. S. 36. Ich bitte S. 21. Anm. Zeile 17 in den Satz: "Ist es einmal - Grundlage" cinzuschalten: "und nicht auf Kosten eines coexistirenden Sehedelknorpels".

S. 28. Das einzige Beispicl von Duplicität des Vomer bei den Fisehen liefert, wic Agassiz bemerkl, Lepidosteus. 
S. 45̃. Die Extremitäten von Lepidosiren annectens aff. sind, nach Peter's, nicht so cinfach, wie man bisher glaubte. Der bekannte, von der Ilaut überzogenc, lange gegliederte Strahl ist mit knorpeligen Neloenflossenstrahlen besetzt, welche wieder einen feineren Flossenbart tragen. Nebenstrahlen und Flossenbart sind von der äusseren Haut überzogen. S. d. Abb. 1. c. Tab. 1. u. 2. S. 6.

S. 48. Ueber die Schuppen von Lepidosiren vergl. If y $\mathrm{rtl}$ a, a, O.

S. 49. Die Schleimsäcke der Myxinoïden sind, nach M üllcr, Eingeweide der Fische S. 11, von besonderen muskulösen Iäuten uıngeben. Sic entlialten eine grosse Anzahl ovaler Körper, welche aus einem in unzähligen Windungen aufgerollten klebrigen Faden bestehen. Abgeb. 1. c. Tab. II. Fig. 9.

Bei den Plagiostomen finden sich ausser den grösseren knorpeligen Röhren des Seitencanales, welche, ihrem Verlaufe nach kurz beschrieben sind, kleinere, dünnhäutigere Röhrchen, die in grosser Menge büschelweise neben einander licgend, am Kopfe, besonders im Umkreise der Augen, der Nase, und an der Schnauze vorkommen. Sie münden durch zahlreiche Oeffnungen nach aussen und enthalten eine klebrige Feuchtigkejt. Viele derselben bestehen ursprünglich aus runden Bläschen, welche in Röhren übergehen. Jedes dieser Bläschen cnthält nach Savi (s. Ma tte u c ci, Traité des phénomènes electro-physiologiques. Paris 1844. p. 329. Tab. III.) drei zweilappige Kernc, welche durch Gefässe und eintretende Nerven an der Innenwand des Bläschens befestigt sind.

S. 51. Ucber die Muskulatur von Lepidosiren handelt ausfiuhrlich Iyrtl 1. c. S. 13.

Das in \$. 22. geschildcrte Verhalten der Seitenmuskeln erscheint - wie ich nachtriglich bemerke - wesentlich modificirt bei denjenigen Fischen, welche keine entwickelte untere Wirbelbogenschenkel und keine letzteren anhangende oder sie vertretende Rippen in der Rumpfgegend bcsitzen, wie dies S. 12 von mehren Knochenfischen, z. B. einigen Plectognathen, angeführt ward. Bei diesen Fischen wird die Bauchhälfte des Seitenmuskels in der Rumpfgegend abortiv. Sie verlängert sich nur eine Strecke weit an der Vorderfläche der mit ganz rudimentären untcren Wirbelbogenschenkeln versehenen Rückenwirbeln, schliesst also nicht die Bauchhöhlc. Geschieht nun die Umschliessung der letzteren nicht blos durch Ilautmuskelstreifen, wie bei Diodon, finden sich vielinehr an ihrer unteren oder vorderen Schlusslinie stärkere Muskeln, wie bei Ostracion, so cntsprechen diese letzteren nicht den unteren Seitenınuskeln, sondern gehören einem andern Systeme von Muskeln an. - Auch die zickzackförmigen Querstreifen fehlen den eigentlichen Seitenmuskcln mehrer Plectognathen.

S. 57. Ueber das Gehirn von Chimaera siehe Berichtigungen der Valentin'schen Angaben in R. Wagner's Lehrbuch der Zootomie. 
2te $\Lambda$ unf. S. 239. und bei Mïller, Archiv 1843. Jahresberieht S. CCLIII. Valentin's Lappen des dritten Ventrikels ist das Cerebellum; sein Cerebellum sind Lappen der Medulla ollongata. Das Hirn der Chimären stimmt in Wesentliehen mit dem der Plagiostomen überein. - Vortreffliehe Abbildungen des flirnes und der Nervenursprünge von Torpedo gibt Savi in Matteucci, Traité des phénemènes electro-physiologiques des animaux. Paris 1844. 8. Tab. 2. u. 3.

Aelınlich dem Gehirne des Störes ist, nach Müller, das des PoIypterus, der mit Lepidosteus und den Stören und Spatularien Miille r's Familic der Ganoïden bildet. - Verwandt ist aueh die Hirnbildung von Lepidosiren. S. d. Abb. von Peters 1. e. Tab. 3. Fig. 6. u. 7.

S. 61. §. 26. Bei Lepidosiren sind, nach Hyrtl S. 49, die Urspringe der Spinalnerven nieht zweiwurzelig, sondern einwurzelig.

S. 64. Ueber die Hirnnerven von Torpedo s. Savi a. a. O. S. 301. unter besonderer Berüieksiehtigung des $\boldsymbol{N}$. trigeminus und vagus. Savi hat sehr eigenthümliehe Organe beim Zitterroehen entdeckt, welehe in enger Bezichung zu Zweigen des vorderen Wurzeltheiles des $\boldsymbol{N}$. trigeminus stehen und vom Entdecker als Appareil folliculaire nerveux bezeiehnet werden (1. e. p. 322. Abb. Tab. III. Fig. 10-14.). Es sind dies Reihen von geschtossenen Zellen oder Follikeln, welehe auf aponeurotisehen Bändern ruhend, längs dem Vorderrande des Maules, der Nasenlöeher, im Umkreise und oberhalb der Aponeurosen der eleetrisehen Organe vorzugsweise an der Bauehseite, in geringerer Anzahl aueh an der Riiekenseite vorkommen. Jeder Follikel hält etwa eine Linic im Durehmesser und besitzt zwei Membranen, welche an der Stelle, wo der Nervenfaden in ihn eintritt, dieht an einander liegen, an der entgegengesetzten Seite aber von einander abstehen. Er enthält eine gallertartige Masse und ausserdem einen grauen Kern, ähnlieh der grauen Substanz der Gehirnhemisphären. In diesen grauen Kern verästelt sieh der eintretende Nerv; aber nieht vollständig, indem ein freier Faden aus dem Follikel wieder austritt, um in den nächsten Follikel wieder einzutreten, mit dessen Nerven er sich verbindet.

Bei Lepidosiren sind, ausser den höheren Sinnesnerven, nur zwei Hirnnerven, entsprechend dem $\boldsymbol{N}$. trigeminus und vagus, von Peters und Hyrtl beobachtet. S. Hyrtl l. e. S. 44. und die Abb. von Peters I. c. Tab. IIl. Fig. 6. u. 7. - Jeder der beiden letztgenannten Nerven bildet ein Ganglion. Die Ganglien beider stehen dureh eine Anastomose in Verbindung. In die Augenmuskeln sind noch keine Zweige des $\boldsymbol{N}$. trigeminus verfolgt. Vom ersten Aste des $\boldsymbol{N}$. trigeminus tritt, nach $\mathrm{Hyrtl}$, ein Verbindungszweig zur $\Lambda$ nsehwellung des $\boldsymbol{N}$. olfactorius. Ein $\boldsymbol{R} \boldsymbol{a}$ mus lateralis $\boldsymbol{N}$. trigemini fehlt (wie bei den Stören, Plagiostomen und wenigen Familien der Knochenfische; den meisten der letzteren körnmt er naeh neueren Untersuehungen von mir zu). - Der $\boldsymbol{N}$. trigeminus enthält die bekannten Elemente des N. facialis; der $\boldsymbol{N}$. vagus 
dio des $\boldsymbol{N}$. glossopharyngens und wahrscheinlich die des $\boldsymbol{N}$. hypoglossus in einem merkwürdigen $\Lambda$ ste, der in den geraden Bauchmuskel eintritt, in welchem er bis zum Ende der Bauclihölle verfolgt ward. Der Ramus visceralis 8. pueumogastricus des Vagus enthält, nach IIyrtl, die Elemente des felılenden $\boldsymbol{N}$. sympathicus. Die Intercostalnerven stehen mit den Gefleehten jenes $\boldsymbol{R}$. visceralis durch sehr feine Fädchen in Verbindung. Der $\boldsymbol{R}$. lateralis $\boldsymbol{N}$. vagi verläuft tief unter den Seitenmuskeln an der Chorda dorsalis.

S. 65. Ein Chiasma der Sehnerven, wie der Stör, besitzt, nach Miiller, auch Polypterus, so wie, den Abbildungen von Peters zufolge, auch Lepidosiren.

S. 75. Peters fand aueh bei Lepidosiren aus dem Gambia hintere, den Gaumen durchbohrende Nasenlöcher. - Sorgfältige Beschreilung der Nase von Lepidosiren paradoxa bei IIyrtl S. $\mathbf{5 0 .}$

Bei Polyplerus entdeckte Müller (Erichs. Archiv) ein Labyrintl von 5 häutigen Nasengängen, parallel um eine Axe gestellt. Jeder einzelne Gang enthält die kiemenartige Faltenbildung, welche bei anderen Fischen nur einfach vorhanden ist.

Bei einer neuen Gattung Arothron, welche Müller von Tetrodon geschieden, vermisste Müller die äussere Nasenöffnung. Die Geruchsnerven treten in solide Tentakeln ohne Oeffnung.

S. 76. §. 30. Bei Lepidosiren wurden sowol von Peters, als auch von IIyrtl vier gerade Augenmuskeln angetroffen; die schiefen fehlen; jene liegen in einem fibrös-häutigen, am Schedel befestigten Trichter.

S. 77. Ueber das von St. delle Chiaje entdeckte Tapetum einiger Fische handelt Brüeke in Müller's Archiv 1845. S. 402. Es kömmt vor bei Stören, vielen Haien und Rochen, so wie auch bei einigen Pereoïden, Scomberoïden und Theutiern. Bei Hexanchus griseus besteht das Tapetum aus unregelmässigen, sehr grossen Zellen, in welchen die den Silberglanz verursachenden, in Wasser, Alkohol und Aether unlösliehen Krystalle abgelagert sind. Abramis Brama besitzt ein Pseudotapet, indem das sonst dunkele Pigment auf der Choriocapillarmembran hier weisslich ist.

S. 78. Müller hat die Nickhautmuskeln bei den mit einer Nickhaut versehenen Haien entdeckt, beschrieben und abgebildet. Eingew. d. Fische S. 13. Tab. V. Fig. 1-3.

S. 80. §. 31. Ueber das Gehörorgan von Lepidosiren s. Hyrtl l. c. S. 51. - Flimmerbewegung im Innern des die halbcirkelförmigen Canïle repräsentirenden ringförmigen Rohres von Petromyzon wurde beobachtet von Eeker (Mïller's $\Lambda$ rchiv 1844. S. 520.).

S. 83. §. 32. Ueber die Verbindung der Schwimmblase mit dem Gehörorgane bei den Characinen s. Näheres bei Müller, Eingew. der Fische S. 46. 
S. 85. Bei Malapterurus electricus fand Peters (Müller's Archiv 1845. S. 375. Tab. XIll. Fig. 8-11.) nur ein einziges über den ganzen Körper sich ausdehnendes eleetrisehes Organ.

S. 90. Ueber den Tractus intestinalis der Myxinoïden, Plagiostomen und Ganoüden handelt ausführlich Mäller, Eingeweide der Fische S. 3. und S. 14 ff. Ueber den Magen der Silurus s. Retzius im IIannover'schen Jahresberiehte (Miiller's Arehiv 1844. S. 8.).

Bei der Gattung Enchelioplis (Ophidini) Müll. liegt der After weit nach vorne, sogleich hinter den Kicmen. Abb. b. Miiller l. c. Tab. V. Fig. 4. 5.

S. 94. Die bei den Myxinoïden jederseits an der Cardia gelegenen Drïsen werden von Müller als Nebennieren gedeutet. - Bei Lepidosiren hat Peters die Milz aufgefunden.

S. 99. 100. Die wiehtigen Mittheilungen Müller's über das Verhalten des Bulbus arteriosus bei den versehiedenen grossen Abtheilungen der Fische haben den Verf. bewogen, den ursprünglichen $A b$ druek dieses Blattes zu eassiren und cinen Carton einzulegen.

S. 101. Ueber das Yerhalten der Kiemengefüsse bei Lepidosiren s. die angeführten Schriften von Peters und Hyrtl nebst den Abbildungen.

S. 102. Schr sorgfältige Besehreibung der Körperarterien von Le pidosiren bei II yrtl S. 37 .

S. 105. Das hier erwähnte Caudalherz des Aales ist abgebildet von scinem Entdecker Marshall Hall in dessen Sehrift: A eritieal and experimental essay on the eireulation of the blood, espeeially as observed in the minute and capillary vessels of the Batrachia and of fishes. London 1831. 8. (p. 170.) Tab. X.

S. 106. Beschreilung des Venensystemes von Lepidosiren bei Ifyrtl 1. e. S. 39., unter abweiehender Deutung der grossen Stämme.

Besehreibung des Pfortaderherzens der Myxinoïden bei Müller, Eingew. d. Fisehe S. 4.

S. 107. Von der Existenz eines Nierenpfortadersystemes bei den Fisehen haben mieh neuere Untersuehungen siehır überzeugt. Zur Untersuehung eignen sieh am besten solehe Fisehe, deren Nieren freier liegen, z. B. Cyelopterus, Diodon. Die zuführenden Gefässe treten in ein längs dem Aussenrande der Nieren zur Eintrittsstelle der Caudalvene absteigendes Gefäss. Sie kommen aus den Rumpfwandungen, bei Diodon selbst vom Diaphragma und den Vorderextremitäten.

S. 112. Besehreibung der Muskelsehieht an den Kiemensäeken der Myxinoïden bei Müller, Eingew. d. Fisehe S. 112.

S. 115. Bei Lepidosiren anneetens beobachtete Peters (Müller's Archiv 1845. S. 3.) eonstant in jedem Alter drei äussere Kiemenfäden. 
Zu ihnen gehen Arterien von den inneren Kiemenarterien und es treten Venen von ihnen zu den inneren Kiemenvenen zurüek. Es finden sieh also hier äussere Kiemen, innere Kiemen und Lungen zugleieh.

Besehreibung der Lungen von Lepidosiren bei Peters 1. c. und besonders bei Hyrtl l. e. S. 29. Abb. Tab. II!. Fig. 1. u. 2. Die innere Oberfläehe jeder Lunge ist vorn ähnlieh wie bei den Sehlangen, hinten wie bei den ungesehwänzten Batraehiern gebildet. Die Lungenarterien sind, naeh If yrtl (von dessen Darstellung übrigens Peters abweieht), Fortsetzungen des dritten Aortenbogens jeder Seite; sie versorgen noeh andere Weiehgebilde und geben namentlieh Intereostalarterien ab. Die Lungenvenen treten, zu einem Stamme verbunden, in die linke Vorkammer des Jerzens.

S. 116. Nähere Beschreibung und Abbildung der merkwürdigen Nieren der Myxinoïden bei Müller, über d. Eingew. d. Fisehe S. 10. und S. 57. Abb. Tab. I. Fig. 2-7.

Flimmerbewegung innerhalb der Harneanïlehen der Nieren wurde beobaehtet bei Roehen von Simon und von Mïller. S. Müller's Archiv 1845 . S. 520 .

S. 118. §. 50. Bei den Myxinoïden liegt hinter den Kiemen, zu beiden Seiten der Cardia, eine eigenthümliehe traubige Drüse, bestehend aus Büscheln sehr kleiner länglieher Lobuli, welehe an Blutgefässen hangen. Diese Organe hält Müller (Eingew. der Fische S. 8. Abb. Tab. I. Fig. 8.) für Nebennieren. Ist diese Deutung riehtig, so sind die von mir bei Knoehenfischen entdeekten und als Nebennieren besehriebenen Körperchen wol anders zu deuten, da ihr Bau völlig abweicht.

S. 119. Neunter Absehnitt. -

Die der Thymus der Fische vergleiehbaren Gebilde wurden S. 88. Anm. 2. nur gelegentlich erwähnt. Ich maehte hier auf ihre Existenz bei den Stören aufmerksam. Analoge Gebilde scheinen allen Fisehen zuzukommen. Ieh sehe z. B. bei Gadus, Salmo, Cyelopterus u. A. an der untern Fläehe der Kiemenbogen-Copulae, in der Umgebung der vom Bulbus arteriosus ausgehenden Kiemenarterienstämme kleine traubige Bliisehen, ähnlich denen, die das Herz des Störes umkleiden. Sie erhalten ihre Gefässe beim Dorsch aus Arteriae epigastricae (ventralen Verlängerungen der Kiemenvenen). Sie sollen bald ausführlieher beschrieben werden.

S. 119. §. 51. Sehr reiehhaltige Beobaehtungen über die Sehrwimmblase der Fisehe s. bei Müller, Eingew. d. Fisehe S. 46 ff. mit Abb. Tab. 3. u. 4 .

S. 120. Anm. 5. Nach Müller (Erielıson's Arehiv 1845. S. 120.) sind die Trabeculae carneae nieht Ursache der zelligen Bildung der Schwimmblase bei Lepidosteus, wie Valentin behauptet. 
S. 124. Anui. 2. Die Angabe iiber das Vorkonmen unpaarer Ovarien bei Petromyzon muss als irrthiumlich zurüekgenommen werden.

Ann. 8. Miiller findet unter den Malacopterygii apodes bei den Symbranchii (Symbranchus und Monopterus) und bei den Gymnotini (Gymnotus, Carapus, Sternarchus) nicht die Bildung der Muraenoïdei, sondern schlauchartige Eierstöcke. Solehe besitzt auch Cobitis. (Siehe Miiller in Erielison's Archiv 1845. S. 133.)

Für S. 125 u. 126 ist wegen wesentlicher Irrthümer in der früheren Darstellung ein Carton eingelegt und die neuere betreffende Literatur berïcksichtigt.

S. 127. Der Zusammenhang des Hodens mit dem Nebenhoden durch Vasa efferentia bei Plagiostomen ist abgebildet bei Müller, Eingew. d. Fische Tab. 2. Fig. 15. u. 16.

S. 143. Nach Schlegel (Bcricht über die Versamml. der Naturforseher in Mainz S. 215.) sind bei einigen Arten der Gattung Dibamus nur die Männehen mit Fussstummeln versehen.

S. 188. §. 82. Ueber die $N . N$. glossopharyngeus, vagus, acces. sorius Willisii und hypoglossus der Reptilien s. Bendz in: Det kongelige Danske Videnskabernes Selskabs naturvidenskabelige og mathematiske Afhandlinger. Copenhag. 1843. Vol. X. p. 113. Ausgezogen von Hannover in Müller's Archiv 1844. S. 10.

S. 273. Ueber die Schultermuskeln der Vögel s. Bemerkungen von A. Retzius, durch IIannover im Auszuge mitgetheilt, in Müller's Archiv 1844. S. 15 .

S. 314. Von Lymphherzen und auch von lymphatischen Sinus ist es mir noch immer nicht gelungen, eine Spur bei Hühnern anzutreffen. Ieh untersuchte, ausser sämnitlichen hühnerartigen Hausvögeln, neuerlich auch Crax rubrirostris Neuw. vergebens darauf.

S. 335. Anm. 3. Auch im Laufe des gegenwïrtigen Winters (18451846) wurden einige Beobachtungen von Verschlossensein des linken Eileiters bei Vögeln gemaeht. Sie betreffen: Anas nigra und Emberiza miliaris. Doch kömmt diese Verschliessung nicht beständig, selbst bei nahe verwandten Vögeln und bei Vögeln derselben $\Lambda$ rt, vor. Ich fand den Eileiter offen bei Anas nigra und glacialis.

S. 340. Literatur:

L. Reichenbach, Anatomia Mammalium. Pars 1. Cetacea et Pachydermata tabulis arncis LXV illıstrata. Lips. 1840̃. (Compilation.) 
S. 363. Anm. 4. Paarige Ossa interparietalia finden sieh aueh bei Phoca vitulina.

S. 405. Indessen ist auch die ausführliehe Sehrift von Ifyrtl über das Gehörorgan der Säugethiere ersehienen. Sie führt den Titel: Vergleichend-anatomisehe Untersuehungen über das innere Gehörorgan des Mensehen und der Säugethicre. Mit 9 Kupfertafeln. Prag 1845. Fol. 


\section{Vom Herzen.}

§. 40.

Bei allen Fisclien - mit Ausnahme von Branchiostoma - liegt das II erz ${ }^{1}$ ), sammt dem Bullus arteriosus, in einem bald mit der Bauchhöhle communicirenden ${ }^{2}$ ), bald von ilır abgeschlossenen ${ }^{3}$ ) Herzbeutel, welcher zugleich einen unmiltelbaren Ueberzug des Herzens bildet. Der Herzbeutel besitzt bei Petromyzon eine knorpelige Decke, welche mit den Kiemendeckknorpeln zusammenhangt. Bei vielen Fischen steht er mit der Oberfläche der Herzkammer durch anscheinend tendinöse Fäden in Verbindung, welche jedoch, wenigstens bisweilen, nicht solche, sondern Blutgefässe sind 4 ).

Die Bildung des Gefässsystemes bei Branchiostoma 5) zeigt, wegen herzartiger Contractilität seiner grösseren Stämme, auffallende Aehnlichbeit mit derjenigen der Anneliden. Der dem Herzen der übrigen Fische entsprechende Abschnitt dieses Gefässsystemes besteht in einer, das Kiemerarterienherz repräsentirenden, gleichförmig dicken, ziemlich langen contractilen Röhre, die, unter dem Kiementhorax gelegen, am Ende der Speiserölıre mit dem gleichfalls röhrenförmigen, contractilen Hohlvenenherzen zusammenhangt. Von der das Kiemenarterienherz reprä-

1831). Auch bei Monopterus liegt, nach Müller, jederseits an dem keine Spur von Kieme besitzenden vierten Kiemenbogen, ein von der Kiemenarterie direct zur Aorta verlanfender Aortenbogen. - Bei Lepidosiren setzen sich Inehre Aeste der Kiemenarterien direct in Körperarterien und in die Aorta fort. - Bei Bran. chiostoma geht, naclı Retzius und Müller, jederseits von dem Mittelherzen ein herzartiger, contractiler Aortenbogen ab, der direct in die Aorta führt. Bei den Myxinoïden hat Müller aus dem vordersten Kiemenarterienaste hervorgehende obliterirte Ductus arteriosi angetroffen, woraus sich ergibt, dass eine analoge Bildung bei den Myxinoïllen wenigstens temporär vorkömmt. S. M üI . ler, Vergleiclıende Anatomie dles Gefässsystemes der Myxinoïden. Berlin 1841 . S. 27 u. 19.

1) Vergl. Tiedemann, Anatomie des Fischherzens. Landshut 1809. 4.; Meckel, System Thl. 5. und J. Müller in Erichson's Archiv 1845. S. 138. stomen.

2) Bei den Myxinoïlen, Amnocoetes, Accipenser, Chimaera, den Plagio.

3) Bei Petromyzon und bei den eigentlichen Knochenfischen.

4) Solche Fäilen kommen z. B. constant vor bei Petromyzon, Accipenser, Lepidosiren, Muraena, Cobitis, Anarrhichas. Beim Stör sind es zum Theil Ar. terien, welche aus der Arteria mammaria interna an die die Herzoberfläche umkleidenden drüsenähnlichen Lymphräuıne treten. Siehe über diese §. 45. Anm. 3. Auch bei anderen Fischen sind es Arteriae thymicae aus der A. mam. maria interna. S. über die Thyınus S. 480 .

5) Vergl. die Abb. bei Müller, Ueber den Bau und die Lebenserscheinun. gen des Branchiostoma lubricum. Berlin 1844. 4 . 
sentirenden Röhre gehen seitlich sehr zahlreiche contractile Bullilli an den Ursprüngen der Kiemenarterien ab.

Das II rz der ibrigen Fische besteht aus einer gewöhnlich dickwandigen, sehr muskulösen $\mathrm{K}$ am mer und einer weiten, mit diinneren Wandungen versehenen Vorkammer, welche die Kammer gewöhnlich an den Seiten stark iiberragt. Sowol die Kammer als die Vorkammer besitzt in der Regel eine einfache IIöhle. Nur bei Lepidosiren ${ }^{6}$ ) ist die Vorkammer durch eine unvollkommene Scheidewand in zwei Hälften getheilt, welche jedoch mit einem gemeinsamen, einfachen, klappenlosen Ostium in den noch unvollkommener getheilten Ventrikel münden. - An der Eintrittsstelle des Körpervenensinus in die Vorkammer fehlın gewölınlich klappen und nur bei den Myxinoïden kömmt hier eine häutige Doppelklappe 7) vor. - Am Ostiumu arteriosum der Vor kammer sind sehr regelmässig halbınondförmige Klappen vorhanden ${ }^{8}$ ). Die Ka inmer, in Form und Umfang beträclitliclıe Verschiedenheiten darbietend, geht vorn iber in den sogenannten $B$ ulbus arteriosus 9 ). Dieser ist bei den Cyclostomen und bei den eigentlichen Knochenfischen nur der bald unverdickte, bald in seinen Wänden sehr verdickte Anfang des gemeinsamen Kiemenarterienstammes; bei den genannten Fischen finden sich zwischen ihm und der arteriősen Mündung der Kammer zwei einfache halbmondförmige Klappen $\mathbf{1 0}$ ). Bei den Ganoïden, den Chimären, den Plagiostomen und bei Lepidosiren ist er dagegen eine wahre Verlängerung der Kammer und, als solche, mit Muskelbündeln belegt, welche vorn, scharf abgeschnitten, aufhören ${ }^{11}$ ). Bei diesen Fischen fehlen an dem Abgange des Bulbus aus der Kammer die Klappen; dagegen ist die Innenwand des Bulbus mit Klappen besetzt; namentlich finden sich bei Lepidosiren ${ }^{12}$ ) im Inneren des lier gekriimmten Bulbus zwei spirale, longitudinale Falten; bei den Ganoïden, Chimären und Plagiostomen dagegen zwei bis fünf Querreiben von dicht neben einander stehenden halbmondförmigen Klappen 13). -

6) Vergl. Peters in Müller's Archiv 1845. S. 3. und Hyrtl's Lepidosiren laradoxa S. 34. Abb. Tab. 1. Fig. 4.

7) Nach Angabe von Müller.

8) Indessen fehlen sie, naeh übereinstimmenden Angaben, bei Lepidosiren.

9) S. über die fundamentalen Unterschiede, welehe der Bulbus arteriosus bei den Fischen darbietet, Müller in Erichson's Arehir 1845. S. 138. M üller vereinigt in dieser wichtigen Abhandlung die Sturionen und Spatularien mit Polypterus und Lepidosteus zur Gruppe der Ganoïlen.

10) S. die Tabelle bei Mïller l. e. S. 101.

I1) S. die Abb. bei Tiedemann 1. e. Tab. 1. u. 2.

12) Vergl. Peters a. a. 0. S. 4. und Hyrtl S. 36.

13) In jeder Querreihe stehen bei den Plagiostomen drei, seltener vier Kilappen. S. die näheren Angaben von Mïller in seinelu Arehiv für Physiol. 1842, S. 477. und in Eriehson's Arehiv für Naturgesehichte 1845. l. c., wo er die Existenz der Klappen bei Lepidosteus naehweiset, nachdem er früher sehon 
den blattartigen Vorsprïngen gebildeten Eier fallen in die Bauchhöhle und werden aus ihr dureh einen einfaehen, hinter dem After gelegenen Porus genitalis ausgefülırt.

3. Es finden sich trichterförmige Eileiter mit weiten Ostia abdominatia. Die Eier fallen aus den plattenförnigen Ovarien zuerst in die an ihrer Aussenseite mit Flimmer-Epithelium ausgekleidete Bauelhoühle und gelangen aus dieser in jene Eileiter. Diese letzteren münden beim Stör in die llarnleiter ${ }^{9}$ ); bei Polypterus aber, wo sie liinger selbststïndig bleiben, mit den letzteren in den hinter dem After gelegenen Porus urngenitalis.

4. Bis dicht an den vorderen 'Theil der Ovarien vorwärts verlängert sind die mit weiten Ostia abndominalia versehenen Eileiter bei Lepidosiren $10 \%$. Jeder bildet, nach stark gewundenem Verlaufe in der Nähe seines hinteren Endles einen bedeutend erweiterten Uterus. Beide Eileiter nuinden verbunden am hinteren Umfange der Cloakenöffnung der Harnhlase.

5. Am eigenthümliehsten verhalten sich die Eileiter bei den Ghimären und Plagiostomen 11). Sie sind immer paarig, mag der Eierstock selbst unpaar sein, wie bei den Scyllien und den mit Nickhaut verselıenen Haien, oder paarig, wie bei anderen Haien, den Rochen und Chimiiren. Immer bilden die beiden Tuben ïber der Leber ein gemeinschaftliches, mittleres Orificium abelominale. Jede Tuba zerfällt in mehre Abtheilungen. Die crste engere ist durch eine, Längsfalten bildende Schleimbaut ausgekleidet. An ihrem Ende finden sieh die bei den einzelnen Gattungen der Plagiostomen sehr versehiedentlich entwickelten Eileiterdrüsen ${ }^{12}$ ), welehe in ihre Höhlen münden. Die

allen ächten Salınonen, wo die Bauchhöhle seitwärts flimmert. - Hierher gchören auch, nach Müller, dic Myxinö̈leu mit unpaarem, rechterseits gelegenem Ovarium und die mit paarigen Eierstöcken versehenen Petroulyzonten, bei denen erst auı Encle der Bauchhöhle ganz kurze Canäle sich finden, die in den Porus abdominalis münden.

9) Abbild. der Geschlechtstheile des Störs bei Brandt und Ratzeburg, Mediz. Zoologie Thl. 2. Tab. IV. - Das zur Seite der Ovarien die Bauchhöhle des Störs auskleidende Flimmer-Epithelium setzt sich, nach meinen Beobachtıngen, fort in die trichterförnigen Eileiter; die Bewegungen der Cilien orfolgen so, dass Substanzen, z. B. aufgestreutes Kiohlenpulver, aus der Bauchböble dem Harıleiter zugeführt werden. Im Harnleiter selbst hört alle Flimmerbewegung anf. Mïller sah mehrmals Verscbliessung der Eileiter an ihrem Ende; ich sah sie noch kürzlich offen. - Ueber Pulypterus s. Müller in Erichson's Archiv 1845. S. 109.

10) Vergl. Hyrtl's Lepidosiren paradoxa. Prag 18Æ5. 4. S. 41. und die Abb. Tab. V. Hyrtl sah anch in Verlaufe des Eileiters eine der Eileiterlrüse der Plagiostomen vergleichbare absondernile Driise.

11) Vergl. darïber die reichhaltigen Beobachtıngen von Müller in seinen Uutersuchungen über die Eingeweide der Fische. Berlin 1845. A. S. $19 \mathrm{ff}$.

12) Sie sind, nach Müller, an grössten bei den Eierlegenden Gattungen: 
Eileiter gehen nun bald sogleich, bald mittelst eines zwischenliegenden Abschnittes über in die beträchtlich erweiterten Uteri, deren innerer Schleimhautüberzug sehr verschiedenartig sich verhält. Die beiden Uteri münden mittelst einer Art Scheide hinter dem Afterdarme in die Cloake. - Bei den mil Nickhaut versehenen Haien findet sich in Bauchfellfalten noch ein paariges, aus Körnchen gebildetes, accessorisches Organ ohne Ausführungsgang ${ }^{13}$ ).

[Ueber den Geschlechts-Apparat der Myxinoïden und Plagiostomen vergl. besonders Mülle r, Untersuchungen über die Eingeweide der Fische. Berlin 1845. 4. Von besonderen Interesse ist auch - vorzüglich in Betreff der hier nicht zu erläuternden Placenta - Bildungen - Müller's Schrift: Ueber den glatten Hai des Aristoteles in d. Abhandl. d. Berl. Acad. d. Wissensch. Berlin 1842. Ueber die Plagiostomen s. noch Treviranus in seiner und Tiedemann's Zeitschr. für Physiol. Thl. 3. - Ueber die Knochenfische vergl. Rathke in dessen Beiträgen z. Geschichte d. Thierwelt Thl. 3. S. 117 ff. und in Meckel's deutsch. Archiv f. Physiol. Thl. 6. S. 589.]

\section{§. 53.}

Die Hoden der Fische sind gewöhnlich paarig, selten unpaar, wic z. B. bei den Myxinoïden. Rücksichtlich ihres inneren Baues und der Ausfülırungsart ihres lnhaltes zeigen sie folgende wesentliche Verschiedenheiten:

1. Die Hoden mehrer Fische sind, ihrem äusseren Verhalten nach, von den Eierstöcken derselben Thiere nicht zu unterscheiden. Sic besitzen einen körnigen Bau. Zugleich fehlen eigene Saamenleiter und der Saame wird frei in die Bauchhöhle ergossen, aus welcher ein hinter dem After gelegener Porus abulominalis ihn ausführt. Hierher gehören die Cyclostomen und unter den Malacopterygii apodes die Muraenoïdei M(üll. 1). - Bei den männlichen Stören dagegen, deren Hodenbau noch nicht aufgeklärt ist ${ }^{2}$ ), findet sich, ganz wie bei den weiblichen, jederseits ein in die Bauchhöhle mündender Trichter, der in den Harnleiter seiner Seite fülırt.

den Scyllia, den Raja, Platyrhina und den Chimären. Eine eigene Form dieser Drüsen entdeckte Müller bei den Haien mit Nickhaut. Sie bilden zwei schnek. kenartig gekrüımıte hohle Schläuche, welche sich gegenüberliegen. Die Wände sind drüsig. Als drüsige Elemente erscheinen Rölırchen.

13) S. die Abb. dieses, seiner Bedeutung nach, räthselhaften Organes bei Müller l. c. Tab. 2. Fig. 13.

1) S. darüber Mïller in Erichs on's Archiv 1845. S. 133. und, was die Cyclostomen anbetrifft, dessen Schrift: Ueber d. Eingew. d. Fische S. A.

2) Rathke vindicirte den Stören, gleich den Cyclostomen, den Aalen (und einigen sicher nicht hierher gehörigen Knochenfischen), einen körnigen Bau. Müller fand bei Accipenser dagegen sehr verwirrte reiserförmige Saamencanälchen; zugleich öfter eine Verschliessung des Trichters, wie beim weiblichen Stör. Ich fand den Trichter kürzlich offen, vermisste aber die Flimmerbewegung darin. 




$$
\text { • }
$$



